PNNL-17992

WTP-RPT-166, Rev 0

Prepared for the U.S. Department of Energy under Contract DE-AC05-76RL01830

\title{
Characterization, Leaching, and Filtration Testing for Bismuth Phosphate Sludge (Group 1) and Bismuth Phosphate Saltcake (Group 2) Actual Waste Sample Composites
}

$\begin{array}{llll}\text { GJ Lumetta } & \text { MK Edwards } & \text { ED Jenson } & \text { RW Shimskey } \\ \text { EC Buck } & \text { SK Fiskum } & \text { AE Kozelisky } & \text { SI Sinkov } \\ \text { RC Daniel } & \text { RT Hallen } & \text { PJ MacFarlan } & \text { LA Snow } \\ \text { K Draper } & \text { LK Jagoda } & \text { RA Peterson } & \end{array}$

February 2009

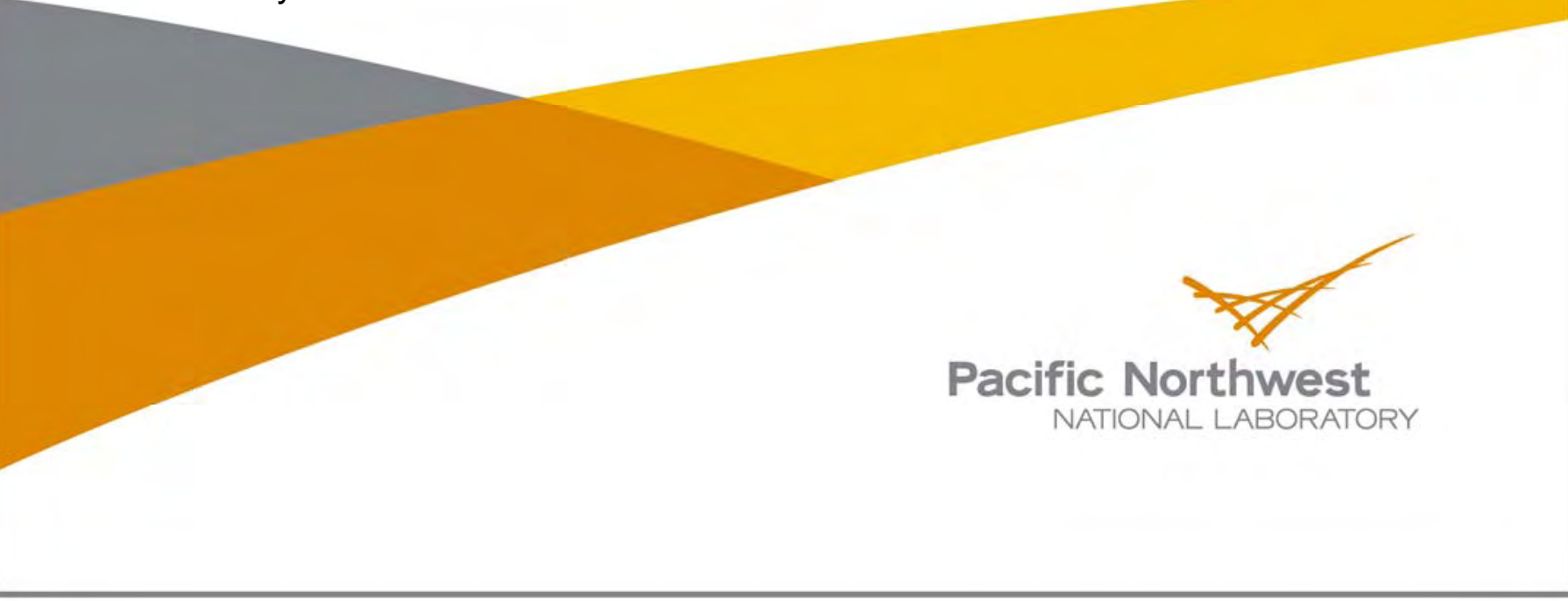




\section{DISCLAIMER}

This report was prepared as an account of work sponsored by an agency of the United States Government. Neither the United States Government nor any agency thereof, nor Battelle Memorial Institute, nor any of their employees, makes any warranty, express or implied, or assumes any legal liability or responsibility for the accuracy, completeness, or usefulness of any information, apparatus, product, or process disclosed, or represents that its use would not infringe privately owned rights. Reference herein to any specific commercial product, process, or service by trade name, trademark, manufacturer, or otherwise does not necessarily constitute or imply its endorsement, recommendation, or favoring by the United States Government or any agency thereof, or Battelle Memorial Institute. The views and opinions of authors expressed herein do not necessarily state or reflect those of the United States Government or any agency thereof.

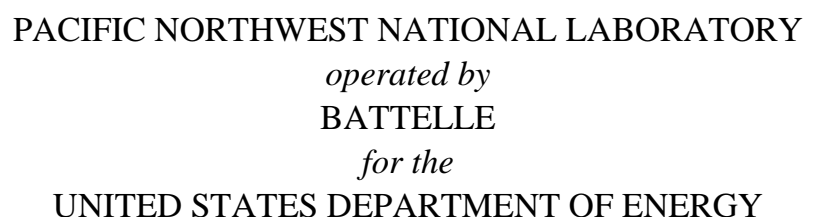
under Contract DE-AC05-76RL01830

Printed in the United States of America

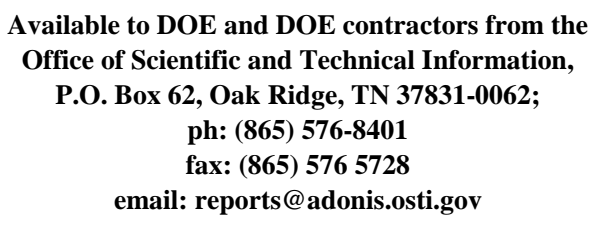

Available to the public from the National Technical Information Service, U.S. Department of Commerce, 5285 Port Royal Rd., Springfield, VA 22161 ph: (800) 553-6847 fax: (703) 605-6900

email: orders@nits.fedworld.gov online ordering: http://www.ntis.gov/ordering.htm 


\section{Characterization, Leaching, and Filtration Testing for Bismuth Phosphate Sludge (Group 1) and Bismuth Phosphate Saltcake (Group 2) Actual Waste Sample Composites}

$\begin{array}{llll}\text { GJ Lumetta } & \text { MK Edwards } & \text { ED Jenson } & \text { RW Shimskey } \\ \text { EC Buck } & \text { SK Fiskum } & \text { AE Kozelisky } & \text { SI Sinkov } \\ \text { RC Daniel } & \text { RT Hallen } & \text { PJ MacFarlan } & \text { LA Snow } \\ \text { K Draper } & \text { LK Jagoda } & \text { RA Peterson } & \end{array}$

February 2009

Test Specification: 24590-PTF-TSP-RT-06-003, Rev. 1

Work Authorization: 019

Test Plan: TP-RPP-WTP-467, Rev. 1 and TP-RPP-WTP-456, Rev. 0

Test Exceptions: None

R\&T Focus Area: Pretreatment

Service Requisition Number: 24590-QL-SRA-W000-00107, Rev 0

Pacific Northwest National Laboratory

Richland, Washington 99352 


\section{COMPLETENESS OF TESTING}

This report describes the results of work and testing specified by Test Specification 24590-PTF-TSP-RT-06-003, Rev. 1 and Test Plans TP-RPP-WTP-467, Rev. 1 7/31/07 and TP-RPP-WTP-456, Rev. 0 11/29/06. The work and any associated testing followed the quality assurance requirements outlined in the Test Specification/Plan. The descriptions provided in this test report are an accurate account of both the conduct of the work and the data collected. Test plan results are reported. Also reported are any unusual or anomalous occurrences that are different from expected results. The test results and this report have been reviewed and verified.

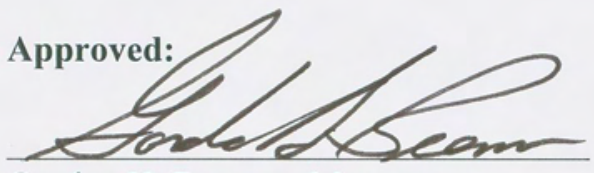

Gordon H. Beeman, Manager WTP R\&T Support Project

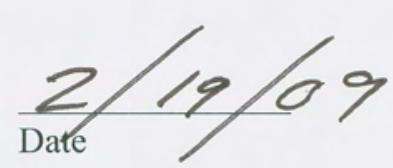

iii 


\section{Contents}

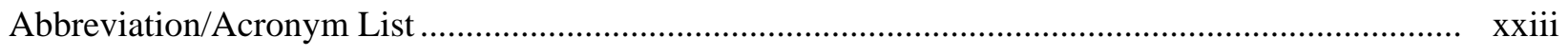

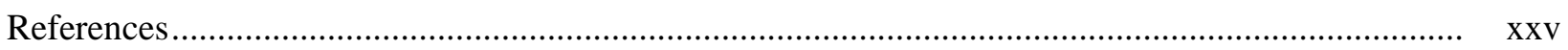

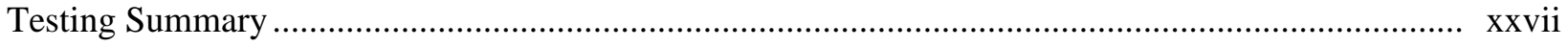

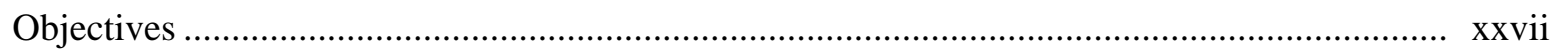

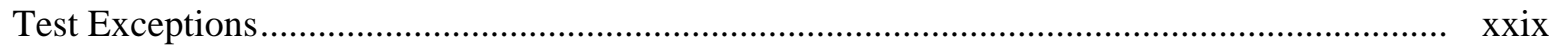

Results and Performance Against Success Criteria ............................................................. xxix

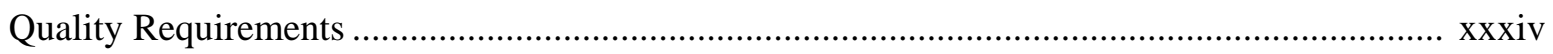

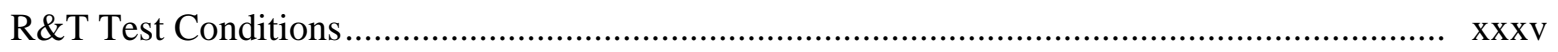

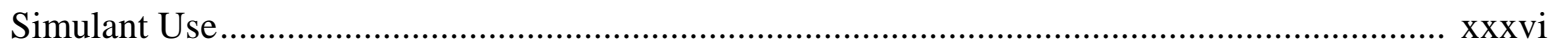

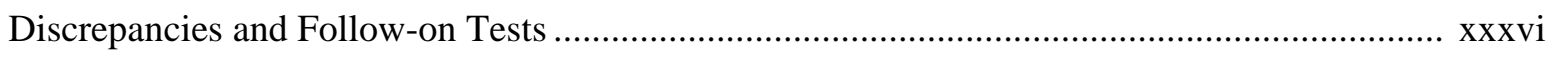

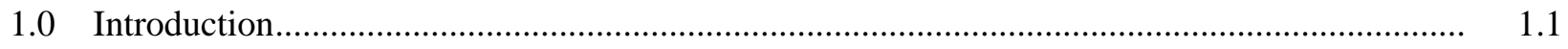

1.1 Tank Waste Pretreatment Operations at the WTP ...................................................... 1.1

1.2 Issues Identified by the External Flowsheet Review Team ............................................ 1.2

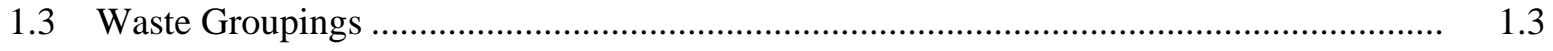

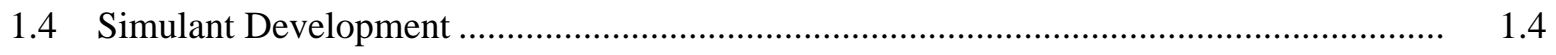

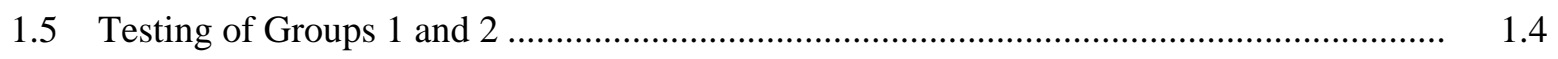

2.0 Test Sample Selection, Compositing, and Homogenization................................................ 2.1

1.1 Group 1-Bismuth Phosphate Sludge Sample Selection .............................................. 2.1

2.1 Group 2-Bismuth Phosphate Saltcake Sample Selection ................................................ 2.4

2.2 Group 1 Sample Homogenization and Sub-sampling.................................................... 2.8

2.3 Group 2 Sample Homogenization and Sub-sampling................................................. 2.17

3.0 Group 1 Characterization and Leaching .......................................................................... 3.1

3.1 Group 1 Characterization Experimental ............................................................... 3.1

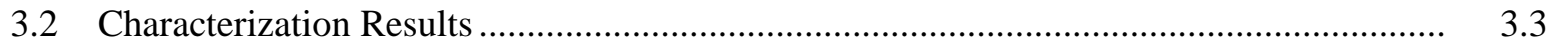

3.2.1 Physical Properties of the Composite Slurry …................................................. 3.3

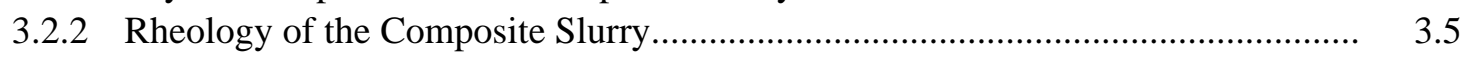

3.2.3 Chemical and Radiochemical Composition...................................................... 3.11

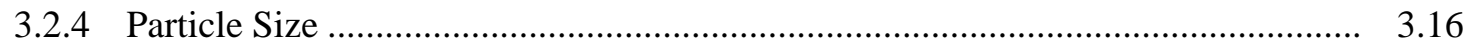

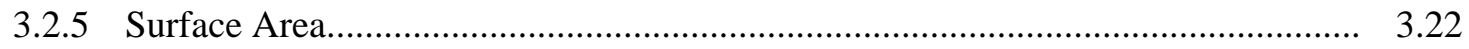

3.2.6 Crystal Form and Habit.................................................................................... 3.22

3.3 Group 1 Batch Parametric Leaching: Experimental ...................................................... 3.35

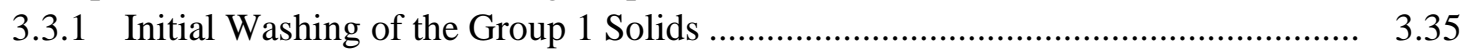

3.3.2 Division of the Washed Group 1 Solids................................................................ 3.36

3.3.3 Caustic Leaching of the Washed Group 1 Solids ............................................... 3.36

3.3.4 Washing of Caustic-Leached Group 1 Solids for Analysis .................................. 3.38

3.4 Group 1 Bi-Phosphate Sludge Waste Parametric Caustic-Leaching Test Results............. 3.39 
3.4.1 Time, Temperature, and Hydroxide Effects on Phosphorus Dissolution from the Group 1 Solids

3.4.2 Time, Temperature, and Hydroxide Effects on Aluminum Dissolution from the Group 1 Solids

3.4.3 Time, Temperature, and Hydroxide Effects on Chromium Dissolution from the Group 1 Solids

3.4.4 Anion, Silicon, and Iron Leaching Behavior ..................................................... 3.55

3.4.5 Assessment of Final Leaching Conditions ......................................................... 3.56

3.4.6 Comparison of Initial and Caustic-Leached and Washed Solids Properties.......... 3.66

4.0 Group 2 Characterization of Bismuth Phosphate Saltcake ...................................................

4.1 Group 2 Characterization Experimental …............................................................. 4.1

4.2 Group 2 Characterization Results .............................................................................. 4.2

4.2.1 Physical Properties of the Composite Slurry ......................................................... 4.2

4.2.2 Rheology of the Composite Slurry ................................................................... 4.5

4.2.3 Chemical and Radiochemical Composition....................................................... 4.9

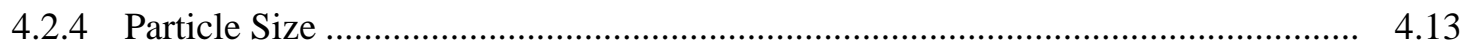

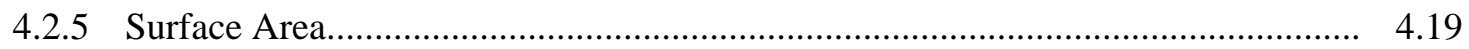

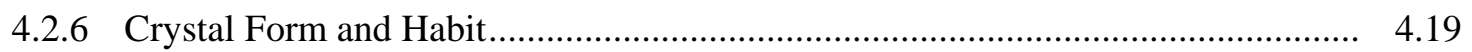

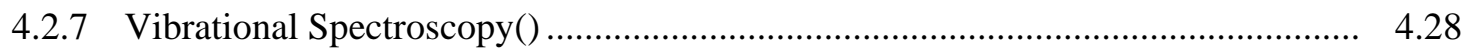

4.3 Group 2 Batch Parametric Leaching: Experimental ....................................................... 4.30

4.3.1 Initial Washing of the Group 2 Solids ............................................................. 4.30

4.3.2 Division of the Washed Group 2 Solids............................................................. 4.30

4.3.3 Caustic Leaching of the Washed Group 2 Solids ............................................... 4.30

4.3.4 Washing of Caustic-Leached Group 2 Solids for Analysis .................................. 4.31

4.4 Group 2 Bi-Phosphate Saltcake Waste Parametric Caustic Leaching Test Results ........... 4.32

4.4.1 Time, Temperature, and Hydroxide Effects on Aluminum Dissolution from the

Group 2 Solids ...................................................................................... 4.32

4.4.2 Time, Temperature, and Hydroxide Effects on Chromium Dissolution ................. 4.34

4.4.3 Time, Temperature, and Hydroxide Effects on Phosphorus Dissolution................ 4.36

4.4.4 Anion, Silicon, and Iron Leach Behavior .......................................................... 4.38

4.4.5 Assessment of Final Leach Conditions .............................................................. 4.38

4.4.6 Comparison of Initial and Caustic Leached and Washed Solids Properties .......... 4.39

5.0 Group 1/2 CUF Filtration and Leach Testing and Results..................................................... 5.1

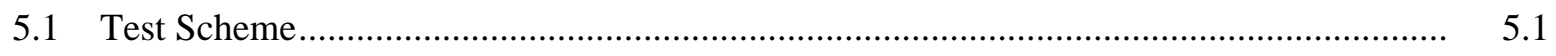

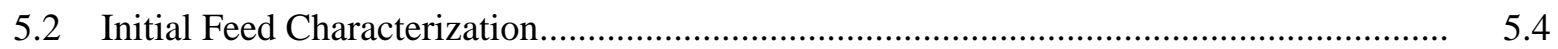

5.3 Filter Flux Testing and Dewatering of Waste Slurry ..................................................... 5.11

5.3.1 Initial Clean Water Flux Testing....................................................................... 5.12

5.3.2 Low-Solids Filter Matrix Testing (10 wt\%) ...................................................... 5.13

5.3.3 Dewatering of Low-Solids Waste Slurry ........................................................ 5.19

5.3.4 High-Solids Filter Matrix Testing................................................................ 5.22

5.4 High-Solids Slurry Characterization........................................................................ 5.27

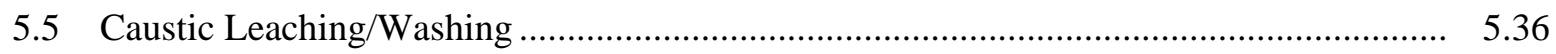

5.5.1 Batch Caustic Leaching Results................................................................... 5.38 
5.5.2 Caustic Leaching Dewatering ...................................................................... 5.43

5.5.3 Characterization of Dewatered Leached Slurry .............................................. 5.46

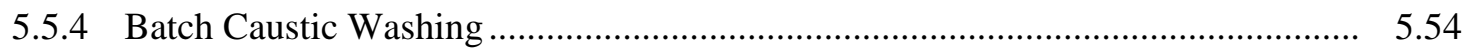

5.5.5 Characterization of the Washed Caustic-Leached Slurry .................................... 5.66

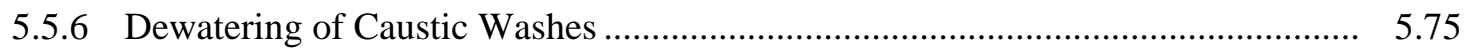

5.6 Oxidative Leaching/Washing ............................................................................. 5.77

5.6.1 Batch Oxidative Leaching Results and Characterization.................................... 5.78

5.6.2 Batch Oxidative Washing Results................................................................. 5.83

5.6.3 Dewatering Oxidative Washes Results ........................................................... 5.91

5.7 Final Dewater and Filter Flux Test Matrix ................................................................. 5.93

5.8 Characterization of the Washed Oxidative Slurry ….................................................. 5.100

5.9 Summary and Lessons Learned from the Group 1/2 CUF Run....................................... 5.116

6.0 Group 1/2 Post-CUF Batch Parametric Oxidative Leaching ................................................. 6.1

6.1 Group 1/2 Post-CUF Batch Parametric Leaching: Experimental ...................................... 6.1

6.1.1 Preparation for Oxidative Leaching Tests ............................................................. 6.1

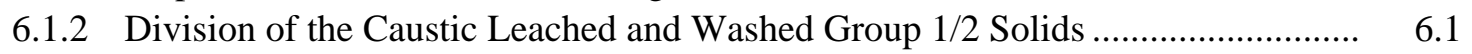

6.1.3 Oxidative Leaching of the Caustic Leached Group 1/2 Solids .............................. 6.1

6.1.4 Washing of Oxidative-Leached Group 1/2 Solids for Analysis............................. 6.3

6.2 Group 1/2 Bi-Phosphate Sludge/Saltcake Waste Parametric Oxidative Leaching Test

Results ........................................................................................................... 6.4

6.2.1 Chromium Behavior During Oxidative Leaching of the Caustic-Leached Group 1/2 Solids ........................................................................................... 6.5

6.2.2 Aluminum Behavior During Oxidative Leaching of the Caustic-Leached Group $1 / 2$ Solids .......................................................................................... 6.7

6.2.3 Phosphorus Behavior During Oxidative Leaching of the Caustic-Leached Group $1 / 2$ Solids ......................................................................................... 6.8

6.2.4 Behavior of Plutonium and Other Safety-Related Components During Oxidative Leaching of the Caustic-Leached Group 1/2 Solids .......................................... 6.10

6.2.5 Assessment of Final Leach Conditions .............................................................. 6.11

6.2.6 Composition of Group 1/2 Caustic and Oxidatively Leached and Washed Solids

Appendix A: Analytical Methods

Appendix B: Physical Properties Determination and Rheology Methods ....................................... B.1

Appendix C: Crystal Form and Habit ...................................................................................... C.1

Appendix D: Quality Assurance and Quality Control …............................................................... D.1

Appendix E: Duplicate Sample Differential Particle Size Plots for the Initial Group 1 Sample .......... E.1

Appendix F: Detailed Cumulative PSD for the Initial Group 1 Sample ............................................ F.1

Appendix G: Group 1 Analytical Results from Parametric Leaching ........................................... G.1

Appendix H: Duplicate Sample Differential Particle Size Plots for the Initial Group 2 Sample.......... H.1

Appendix I: Detailed Cumulative PSD for the Initial Group 2 Sample........................................... I.1

Appendix J: Group 2 Analytical Results from Parametric Leaching............................................... J.1 
WTP-RPT-166, Rev 0

Appendix K: CUF Filtration/Leaching Experimental Methods and Analyses ................................. K.1

Appendix L: Group 1/2 Analytical Results from Parametric Leaching ........................................... L.1

Appendix M: Group 1/2 CUF Analytical Results......................................................................... M.1 


\section{Figures}

Figure No.

Caption

Page No.

1.1. Schematic Representation of the Key Processes to be Performed in the WTP.

2.1. Estimated Tank Waste Composition of Selected Analytes for 1C and 2C Sludge Wastes in the Hanford Tank Farm (BBI Source).

2.2. Selection Decision Process $1 \mathrm{C}$ and 2C Sludge Samples

2.3. Estimated Tank Waste Composition of Selected Analytes for Bismuth Phosphate (BY and T) Saltcake Wastes in the Hanford Tank Farm (BBI Source)..

2.4. Selection Decision Process for the Bismuth Phosphate Saltcake Samples

2.5. Homogenization Vessel Used to Prepare and Sub-Sample the Group 1 Composite Slurry

2.6. Photographs of a High Yield Stress Clay Simulant in the Homogenization Vessel Used for Group 1.

2.7. Photographs of the Mixing of a Min-u-sil ${ }^{\circledR}$ Simulant that Settles Rapidly in the Homogenization Vessel Used for Group 1 and the Vessel After Draining of the Material

2.8. Photographs of Three Different Sub-Samples Taken from the Homogenization Vessel During Non-Radioactive Testing with a Min-u-sil® Simulant.....

2.9. Representative Photographs of As-Received Group 1 Waste Samples.

2.10. Contribution of the Individual Tanks to the Composition of the Group 1 Composite Sample ... 2.15

2.11. Group 1 Confirmation of Successful Material Composite Based on Density and Settled Solids.

2.12. Corrosion Seen in Non-Radioactive Homogenization Tank After Saltcake Simulant Testing... 2.19

2.13. Representative Photographs of the Group 2 Bismuth Phosphate Saltcake Samples .................. 2.21

2.14. Example of Group 2 Waste Transfer into the Homogenizer ...................................................... 2.22

2.15. Homogenizer Tank after Dispensing Composite Group 2 Sample ........................................... 2.26

3.1. Group 1 Characterization Process Flowchart .................................................................... 3.2

3.2. Wash Sequence of Group 1 Sludge Supporting Initial Characterization ................................. 3.3

3.3. Centrifuged Solids for Chemical Characterization Sample of Group 1 .................................... 3.3

3.4. Group 1 Settling Curves: a) Volume Percent Settled Solids vs Time and b) Settled Solids Height vs Time.

3.5. Flow Curve (shear stress versus shear rate) for the Group 1 Initial Characterization Slurry Sample TI508-G1-AR-RH1 at $25^{\circ} \mathrm{C}, 40^{\circ} \mathrm{C}$, and $60^{\circ} \mathrm{C}$.

3.6. Model Fits of Flow Curve Data for Group 1 Initial Characterization Slurry Sample TI508-G1-AR-RH1 at $40^{\circ} \mathrm{C}$

3.7. Selected Analyte Phase Distribution for Group 1

3.8. Pre-Sonication Volume Distribution Result for the Primary Group 1 Initial Characterization Sample as a Function of Pump Speed 
3.9. Volume Distribution Result for the Primary Group 1 Initial Characterization Sample as a Function of Sonication (75\% power) .

3.10. Post-Sonication Volume Distribution Result for the Primary Group 1 Initial Characterization Sample as a Function of Pump Speed

3.11. Comparison of Primary and Duplicate Sample Differential Volume PSD at 3,000 RPM Before Sonication for the Group 1 Solids

3.12. Comparison of Primary and Duplicate Sample Differential Volume PSD at 3,000 RPM After Sonication for the Group 1 Solids

3.13. Raw X-ray Diffraction Pattern of Washed Group 1 Solids.

3.14. XRD Pattern of Washed Group 1 Solids, Background-Subtracted with Stick-Peak Identification: a) Probable Phases Present and b) Possible Phases Present ..

3.15. SEM Images of Group 1 Initial Characterization Solids

3.16. Additional SEM Images of Group 1 Initial Characterization Solids.

3.17. SEM-EDS Image 1 .

3.18. SEM-EDS Image 2 .

3.20. EDS Elemental Map of Group 1 Solids (1)

3.21. EDS Elemental Map of Group 1 Solids (2)

3.23. STEM-EDS Image of Nano-Agglomerates

3.24. Aluminum Heating Block and Shaker Table Used in Parametric Leaching Tests......

3.25. Washing, Subdivision, and Analysis Scheme for the Group 1 Caustic Leached Solids .

3.26. Phosphorus Concentration and Percent Removed Versus Time at $40^{\circ} \mathrm{C}$ for Leaching of the Group 1 Washed Solids in 1 and $3 \mathrm{M} \mathrm{NaOH}$

3.27. Color Change Observed in Group 1 Solids upon Addition of $\mathrm{NaOH}$ : (a) Initial Solids;

(b) Solids After Addition of $\mathrm{NaOH}$

3.28. Phosphorus Concentration and Percent Removed Versus Time at $60^{\circ} \mathrm{C}$ for Leaching of the Group 1 Washed Solids in 1 and $3 \mathrm{M} \mathrm{NaOH}$

3.29. Phosphorus Concentration and Percent Removed Versus Time at $80^{\circ} \mathrm{C}$ for Leaching of the Group 1 Washed Solids in 1 and $3 \mathrm{M} \mathrm{NaOH}$

3.30. Phosphorus Concentration and Percent Removed Versus Time at a) $1 \mathrm{M} \mathrm{NaOH}, 40,60$, and $80^{\circ} \mathrm{C}$ and b) $3 \mathrm{M} \mathrm{NaOH}, 40,60$, and $80^{\circ} \mathrm{C}$ for Leaching of the Group 1 Washed Solids.

3.31. Visual Comparison of the Washed Group 1 Solids (right) with Iron(III) Phosphate Prepared by Mixing $\mathrm{Fe}\left(\mathrm{NO}_{3}\right)_{3}$ Solution with $\mathrm{Na}_{3} \mathrm{PO}_{4}$ Solution (left).

3.32. SEM-EDS Elemental Mapping for Iron(III) Phosphate Prepared by Mixing Fe( $\left(\mathrm{NO}_{3}\right)_{3}$ Solution with $\mathrm{Na}_{3} \mathrm{PO}_{4}$ Solution 
3.33. FTIR Spectrum (taken on diamond ATR plate) of a) the Washed Group 1 solids, b) the Iron(III) Phosphate Prepared by Mixing $\mathrm{Fe}\left(\mathrm{NO}_{3}\right)_{3}$ Solution with $\mathrm{Na}_{3} \mathrm{PO}_{4}$ Solution,

c) Commercially Procured $\mathrm{Fe}\left(\mathrm{PO}_{4}\right) \cdot \mathrm{xH}_{2} \mathrm{O}$, and d) $\mathrm{BiPO}_{4}$

3.34. Aluminum Concentration and Percent Removed Versus Time at $40^{\circ} \mathrm{C}$ for Leaching of the Group 1 Washed Solids in 1 and $3 \mathrm{M} \mathrm{NaOH}$

3.35. Aluminum Concentration and Percent Removed Versus Time at $60^{\circ} \mathrm{C}$ for Leaching of the Group 1 Washed Solids in 1 and $3 \mathrm{M} \mathrm{NaOH}$

3.36. Aluminum Concentration and Percent Removed Versus Time at $80^{\circ} \mathrm{C}$ for Leaching of the Group 1 Washed Solids in 1 and $3 \mathrm{M} \mathrm{NaOH}$

3.37. Aluminum Concentration and Percent Removed Versus Time at a) $1 \mathrm{M} \mathrm{NaOH}, 40,60$, and $80^{\circ} \mathrm{C}$, and b) $3 \mathrm{M} \mathrm{NaOH}, 40,60$, and $80^{\circ} \mathrm{C}$, for Leaching of the Group 1 Washed Solids.

3.38. Chromium Concentration and Percent Removed Versus Time at $40^{\circ} \mathrm{C}$ for Leaching of the Group 1 Washed Solids in 1 and $3 \mathrm{M} \mathrm{NaOH}$

3.39. Chromium Concentration and Percent Removed Versus Time at $60^{\circ} \mathrm{C}$ for Leaching of the Group 1 Washed Solids in 1 and $3 \mathrm{M} \mathrm{NaOH}$.

3.40. Chromium Concentration and Percent Removed Versus Time at $80^{\circ} \mathrm{C}$ for Leaching of the Group 1 Washed Solids in 1 and $3 \mathrm{M} \mathrm{NaOH}$.

3.41. Chromium Concentration and Percent Removed Versus Time at a) $1 \mathrm{M} \mathrm{NaOH}, 40,60$, and $80^{\circ} \mathrm{C}$, and b) $3 \mathrm{M} \mathrm{NaOH}, 40,60$, and $80^{\circ} \mathrm{C}$, for Leaching of the Group 1 Washed Solids

3.42. Group 1 Bi-Phosphate Sludge Reduction in Solid Mass with Water Washing and Caustic Leaching.

3.43. Pre-Sonication Volume Distribution Result for the Caustic-Leached and Washed Group 1 Solids (sample 555-G1-CL-PSD) as a Function of Pump Speed.

3.44. Volume Distribution Result for the Caustic-Leached and Washed Group 1 Solids Before, During, and After Sonication at 3000 RPM.

3.45. Post-Sonication Volume Distribution Result for the Caustic-Leached and Washed Group 1 Solids as a Function of Pump Speed .

3.46. Influence of Caustic-Leaching and Washing on Group $1\left(\mathrm{BiPO}_{4}\right.$ sludge) Waste Solids PSD....

3.47. XRD Pattern of Caustic-Leached Group $1 \mathrm{Bi}$-Phosphate Sludge with Rutile $\left(\mathrm{TiO}_{2}\right)$ Internal Standard (a) Raw Data and (b) Background-Subtracted with Stick-Peak Identification

3.48. SEM Images of Group 1 Bi-Phosphate Sludge Caustic-Leached and Washed Solids (a) $10 \mathrm{kV}, 1000 \times$; (b) $20 \mathrm{kV}, 2500 \times$; (c) $5 \mathrm{kV}, 1000 \times$; (d) Elemental Map of Area 5 in (b)......

3.49. STEM-HAADF Images of Group 1 Bi-Phosphate Sludge Caustic-Leached and Washed Solids (a) Low Magnification; (b) Medium Magnification (inverted contrast)

3.50. High Resolution TEM Images of Group 1 Bi-Phosphate Sludge Caustic-Leached and Washed Solids (a) Amorphous Solids; (b) Magnification Shows Lattice Fringes.

3.51. EDS Analysis of Group 1 Bi-Phosphate Sludge Caustic-Leached and Washed Solids (a) Fe and $\mathrm{Bi}$; (b) Aluminum Oxide.

4.1. Wash Sequence of Group 2 Saltcake Supporting Initial Characterization 
4.2. Chemical Characterization Sample of Group 2 Centrifuged Solids........................................ 4.2

4.3. Group 2 Samples Vol\% Settled Solids after 24-h ....................................................................

4.4. Group 2 Settling Data: a) Volume \% Settled Solids Versus Time and b) Settled Solids Height Versus Time

4.5. Flow Curve (shear stress versus shear rate) for the Group 2 Initial Characterization Slurry Sample TI517-G2-AR-RH at 25, 40 , and $60^{\circ} \mathrm{C}$

4.6. Model Fits of Flow Curve Data for Group 2 Initial Characterization Slurry Sample TI517-G2-AR-RH at $40^{\circ} \mathrm{C}$

4.7. Selected Analyte Phase Distribution for Group 2

4.8. Pre-Sonication Volume Distribution Result for the Primary Group 2 Initial Characterization Sample as a Function of Pump Speed.

4.9. Volume Distribution Result for the Primary Group 2 Initial Characterization Sample as a Function of Sonication (75\% power) .

4.10. Post-Sonication Volume Distribution Result for the Primary Group 2 Initial Characterization Sample as a Function of Pump Speed

4.11. Comparison of Primary and Duplicate Sample Differential Volume PSD at 3000 RPM Before Sonication for the Group 2 Solids

4.12. Comparison of Primary and Duplicate Sample Differential Volume PSD at 3000 RPM After Sonication for the Group 2 Solids

4.13. XRD Pattern of Washed Group 2 Solids, Background-Subtracted

4.14. SEM Images of Group 2 Initial Characterization Solids.

4.15. SEM-EDS Image Group 2 Initial Characterization Solids.

4.16. EDS Elemental Map of Group 2 Solids

4.17. TEM Image of the Washed Group 2 Solids Indicating a Gibbsite Particle (upper left) and an Iron Oxide Particle (lower half) .

4.18. TEM Image of the Washed Group 2 Solids Indicating a Large Iron Oxide Particle (upper left) and an Agglomeration of Mixed Phases (lower right)

4.19. TEM Image of an Agglomeration of Mixed Phases in the Washed Group 2 Solids.....

4.20. TEM Image of the Washed Group 2 Solids Indicating a Sodium Phosphate Phase, Presumably Dorfmanite

4.21. TEM Image of the Washed Group 2 Solids Indicating Aluminosilicate and Uranium-Rich Phases

4.22. Measured and Calculated FTIR Spectrum of the Washed Group 2 Solids

4.23. Washing, Subdivision, and Analysis Scheme for the Group 2 Caustic Leached Solids .

4.24. Aluminum Concentration Versus Time at $80^{\circ} \mathrm{C}$ Leach Temperature in 1 , 3 , and $5 \mathrm{M} \mathrm{NaOH}$ Solutions for Group 2, Bi-Phosphate Saltcake....

4.25. Aluminum Concentration and Percent Dissolved in $3 \mathrm{M} \mathrm{NaOH}$ for Group 2, Bi-Phosphate Saltcake 
4.26. Chromium Concentration Versus Time at $80^{\circ} \mathrm{C}$ Leach Temperature in 1 , 3 , and $5 \mathrm{M} \mathrm{NaOH}$ Solutions for Group 2, Bi-Phosphate Saltcake.

4.27. Chromium Concentration and Percent Dissolved in $3 \mathrm{M} \mathrm{NaOH}$ for Group 2, Bi-Phosphate Saltcake

4.28. Phosphorus Concentration Versus Time at $80^{\circ} \mathrm{C}$ Leach Temperature in 1 , 3, and $5 \mathrm{M} \mathrm{NaOH}$ Solutions for Group 2, Bi-Phosphate Saltcake

4.29. Phosphorus Concentration and Percent Dissolved in $3 \mathrm{M} \mathrm{NaOH}$ for Group 2, Bi-Phosphate Saltcake

4.30. Group 2 Bi-Phosphate Saltcake Reduction in Solid Mass with Water Washing and Caustic Leaching.

4.31. FTIR Spectra of the Group 2 Solids Before and After Leaching in $3 \mathrm{M} \mathrm{NaOH}$ at $80^{\circ} \mathrm{C}$ for $24 \mathrm{~h}$

4.32. Volume Distribution Result for the Caustic-Leached and Washed Group 2 Solids (sample 549-G2-CL-PSD) as a Function of Pump Speed (initial measurement) ..

4.33. Volume Distribution Result for the Caustic-Leached and Washed Group 2 Solids (sample 549-G2-CL-PSD) as a Function of Pump Speed (replicate measurement)

4.34. Comparison of Initial and Replicate PSD Measurements for the Caustic-Leached and Washed Group 2 Solids.

4.35. Influence of Caustic-Leaching and Washing on Group 2 Waste Solids PSD

4.36. XRD Pattern of Caustic Leached Group 2 Bi-Phosphate Saltcake with Rutile $\left(\mathrm{TiO}_{2}\right)$ Internal Standard (a) Raw Data and (b) Background-Subtracted with Stick-Peak Identification

4.37. SEM Images of Group 2 Bi-Phosphate Saltcake Caustic Leached and Washed Solids (a) $5 \mathrm{kV}, 1000 \times$; (b) $20 \mathrm{kV}, 2000 \times$; (c) $5 \mathrm{kV}, 1000 \times$; (d) $5 \mathrm{kV}, 500 \times$

4.38. SEM Image of Group 2 Bi-Phosphate Saltcake Caustic Leached and Washed Solids with EDS Spectra (a) SEM Image; (b) EDS Spectra of Spot 3; (c) EDS Spectra of Spot 6;

(d) EDS Spectra of Spot 8 .

4.39. SEM Image of Group 2 Bi-Phosphate Saltcake Caustic Leached and Washed Solids with EDS Spectra (a) SEM Image; (b) EDS Spectra of Spot 2; (c) EDS Spectra of Spot 3; (d) EDS Spectra of Spot 5.

4.40. SEM-EDS Image of Caustic Leached Group 2 Bi-Phosphate Saltcake with Al, Fe, Si, Ca, $\mathrm{U}, \mathrm{P}$, and Na Maps

4.41. TEM Image of Caustic Leached Group 2 Bi-Phosphate Saltcake 4.56

4.42. Cumulative Distribution Plot of Caustic Leached Group 2 Bi-Phosphate Saltcake and a Mathematical Fit to the Data

4.43. STEM-HAADF Image with EDS Analysis.

4.44. TEM Image with EDS Analysis Showing Uranium and Iron Rich Particles.

4.45. Energy Filtered TEM Images: (a) EFTEM Image Showing Particles Rich in U, Fe, and Mn; (b) EELS Elemental Mapping of (a); (c) EFTEM Image Showing Particles Rich in U and Fe; (d) EELS Elemental Mapping of (c) 
5.1. Group 1/2 Test Flowchart ........................................................................................

5.2. Flow Diagram of the Initial Feed Composite and Sampling ................................................ 5.4

5.3. PSDs for the Individual Group 1 and 2 Composites and the Mixed Group 1/2 Composite (low solids slurry) After Sonication ................................................................................. 5.9

5.4. Low Solids Matrix Slurry PSD at Varying Pump Speeds Before Sonication .......................... 5.9

5.5. Low Solids Matrix Slurry PSD with Sonication ................................................................

5.6. Flow Curve for the Group 1/2 CUF Low-Solids Slurry Sample at 25, 40, and $60^{\circ} \mathrm{C} \ldots \ldots \ldots \ldots \ldots . . . . . .11$

5.7. Initial CWF After Nitric Acid Cleaning from Group 6/5 Test ............................................... 5.12

5.8. Flow Diagram of the Low-Solids Matrix Testing ............................................................... 5.13

5.9. Filter Flux Data from Dilute Group 1/2 Matrix Test, 10 wt\% UDS ...................................... 5.16

5.10. Group 1/2 Filter Test Matrix for Lows-Solids ..................................................................... 5.17

5.11. Group 1/2 Flux vs. TMP for Low-Solids ................................................................

5.12. Group 1/2 Flux vs. AV for Low-Solids ....................................................................... 5.17

5.13. Group 1/2 Flux vs. Relative Time for Low-Solids............................................................ 5.17

5.14. Linear Model of Filter Flux of Group 1/2 Slurry at Low-Solids Concentration ........................ 5.18

5.15. Exponential Model of Filter Flux of Group 1/2 Slurry at Low-Solids Concentration ............... 5.18

5.16. Flow Diagram of the Dewatering of the Low-Solids Slurry ................................................. 5.19

5.17. Filter Flux During Dewatering of Group 1/2 Blended Waste from $10 \mathrm{wt} \%$ to $20 \mathrm{wt} \%$ UDS..... 5.21

5.18. Flow Diagram of the High-Solids Matrix Testing ............................................................... 5.22

5.19. Filter Flux Data for Group 1/2 High-Solids Matrix, 20 wt\% UDS ........................................ 5.24

5.20. Group 1/2 Filter Test Matrix for High-Solids .................................................................... 5.25

5.21. Group 1/2 Flux vs. TMP for High-Solids......................................................................... 5.25

5.22. Group 1/2 Flux vs. AV for High-Solids ............................................................................ 5.25

5.23. Group 1/2 Flux vs. Relative Time for High-Solids .......................................................... 5.25

5.24. Linear Model of Filter Flux of Group 1/2 Slurry at High-Solids Concentration ...................... 5.26

5.25. Exponential Model of Filter Flux of Group 1/2 Slurry at High-Solids Concentration............... 5.26

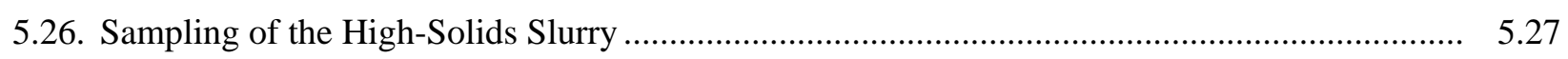

5.27. High-Solids Slurry Matrix PSD at Varying Pump Speeds .................................................... 5.32

5.28. High-Solids Slurry Matrix PSD with Sonication at a Pump Speed of 3000 RPM................... 5.32

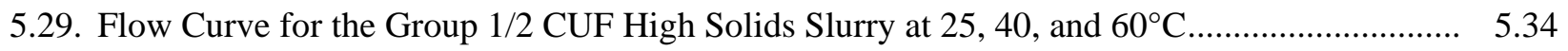

5.30. A Comparison of Feed Material (Group 1 and Group 2) and CUF 1/2 (high and low

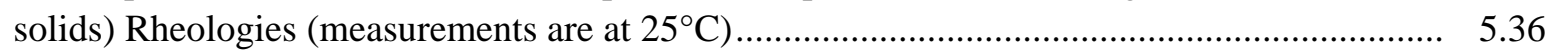

5.31. Flow Diagram for Batch Caustic Leaching ......................................................................... 5.37

5.32. Group 1/2 Batch Leach Sampling/Evaporation Loss and Water Additions ............................. 5.38

5.33. Concentration of Al, Cr, P, and K During Caustic Leach of Group 1/2 Slurry........................ 5.41 
5.34. Temperature Profile/Aluminum Leach Factors During Caustic Leaching............................... 5.42

5.35. Flow Diagram for Caustic-Leach Dewatering Operations .................................................... 5.43

5.36. Permeate Flux During Leach Dewatering Step .................................................................... 5.45

5.37. Sampling Losses for the Dewatered Leached Group 1/2 Slurry ........................................... 5.46

5.38. Caustic-Leached, Dewatered Slurry PSD as a Function of Pump Speed ................................ 5.51

5.39. Caustic-Leached, Dewatered Slurry PSD as a Function of Sonication at 3000 RPM............... 5.51

5.40. Flow Curve for the Group 1/2 CUF Caustic-Leached and Dewatered Slurry at 25, 40, and $60^{\circ} \mathrm{C}$.

5.41. Flow Diagram for Batch Caustic Washing..................................................................... 5.55

5.42. Normalized Aluminum Inventory in Group 1/2 Slurry through Caustic Leach and Washing.... 5.64

5.43. Normalized Phosphorus Inventory in Group 1/2 Slurry through Caustic Leach and Washing.....

5.44. Sampling of the Washed Leached Slurry ........................................................................ 5.66

5.45. Caustic-Leached, Washed Slurry PSD as a Function of Pump Speed .................................... 5.69

5.46. Caustic-Leached, Washed Slurry PSD as a Function of Sonication at 3000 RPM .................. 5.69

5.47. Flow Curve for the Group 1/2 CUF Caustic-Leached, Dewatered, and Washed Slurry at 25,40 , and $60^{\circ} \mathrm{C}$.

5.48. A Comparison of Group 1/2 CUF Slurries Showing the Effect of Caustic Leaching/Washing on Rheology at $25^{\circ} \mathrm{C}$.

5.49. Flux Data from Dewatering Caustic Rinses at Standard Conditions (TMP $=40 \pm 5$ psid, $\mathrm{AV}=13 \pm 1 \mathrm{ft} / \mathrm{s})$

5.50. Process Flow for Batch Oxidative Leaching and Washing ....

5.51. Process Flow for Oxidative Leach 5.78

5.52. Moles of Chromium and Manganese in the Slurry Before and After Oxidative Leaching. 5.79

5.53. Oxidative Leached, Dewatered PSD as a Function of Pump Speed 5.82

5.54. Oxidative Leached, Dewatered Slurry PSD as a Function of Sonication at 3000 RPM 5.82

5.55. Process Flow for Washing after Oxidative Leaching. 5.83

5.56. Normalized Chromium Inventory in Group 1/2 Slurry through Oxidative Leach and Washing..

5.57. Chromium, Phosphorus, and Aluminum Behavior in the Group 1/2 CUF Slurry 5.90

5.58. Flux Data from Dewatering Oxidative Washes. 5.92

5.59. Flow Diagram for the Final Filter Flux Test Matrix 5.93

5.60. Final Filter Flux Testing of Washed Leached Group 1/2 Solids, 7-wt\% UDS 5.95

5.61. Group 1/2 Filter Test Matrix for Leached-Solids 5.96

5.62. Group $1 / 2$ Flux vs. TMP for Leached-Solids 5.96 
5.64. Group 1/2 Flux vs. Relative Time for Leached-Solids......................................................... 5.96

5.65. Linear Model of Filter Flux for Leached Group 1/2 Slurry ................................................... 5.97

5.66. Exponential Model of Filter Flux for Leached Group 1/2 Slurry .......................................... 5.97

5.67. CWF Tests Before and After 2-M Nitric Cleaning ............................................................... 5.99

5.68. CWF Testing Before and After Cleaning with 0.5-M Oxalic Acid......................................... 5.99

5.69. Sampling of the Leached Matrix Test Slurry …..................................................................... 5.100

5.70. Radionuclides/Total Solids in CUF 1/2 Slurry, Adjusted for Sampling .................................. 5.104

5.71. Sodium, Free Hydroxide, Al, and P Molarities During CUF Run .......................................... 5.105

5.72. Inventory of Selected Anions in the Liquid Phase of the CUF 1/2 Slurry During Test ............. 5.106

5.73. XRD Scan of CUF 1/2 Final Leached and Washed Solids ..................................................... 5.107

5.74. SEM Image of Leached/Washed CUF $1 / 2$ Solids ................................................................... 5.108

5.75. SEM and EDS of Leached Washed CUF 1/2 Solids .............................................................. 5.109

5.76. TEM Image of Leached Washed CUF Solids ......................................................................... 5.110

5.77. Oxidative Leached, Washed Slurry PSD as a Function of Pump Speed.................................. 5.111

5.78. Oxidative Leached, Washed Slurry PSD as a Function of Sonication at 3000 RPM................. 5.112

5.79. Flow Curve for the Group 1/2 CUF Oxidative Leached and Washed Slurry at 25, 40, and $60^{\circ} \mathrm{C}$

5.80. A Comparison of Group 1/2 CUF Slurries Showing the Effect of Oxidative-Leaching and Post-Oxidative-Leach Solids Washing on Rheology at $25^{\circ} \mathrm{C}$

5.81. Comparison of Slurry Composition Before and After Leaching and Washing......................... 5.122

6.1. Washing, Subdivision, and Analysis Scheme for the Group 1/2 Oxidatively Leached Solids ... $\quad 6.4$

6.2. Chromium Concentration Versus Time at $45^{\circ} \mathrm{C}$ with $\mathrm{Mn} / \mathrm{Cr}$ Mole Ratios of 0.59, 0.79, 0.98, and 1.19 in $0.25 \mathrm{M} \mathrm{NaOH}$, and at a Mn/Cr Mole Ratio of 0.98 in $1.25 \mathrm{M} \mathrm{NaOH}$ for Group 1/2 Bi-Phosphate Sludge/Saltcake (During Oxidative Leaching)

6.3. Amount of Chromium Removed as a Function of $\mathrm{Mn} / \mathrm{Cr}$ Mole Ratio and Time for Group 1/2 Bi-Phosphate Sludge/Saltcake (During Oxidative Leaching)....

6.4. Total Chromium and Cr(VI) Concentrations Versus Time for Group 1/2 Bi-Phosphate Sludge/Saltcake (during oxidative leaching).

6.5. Aluminum Concentration Versus Time at $45^{\circ} \mathrm{C}$ Leach Temperature at $\mathrm{Mn} / \mathrm{Cr}$ Mole Ratios of $0.59,0.79,0.98$, and 1.19 in $0.25 \mathrm{M} \mathrm{NaOH}$, and at a $\mathrm{Mn} / \mathrm{Cr}$ Mole Ratio of 0.98 in $1.25 \mathrm{M}$ $\mathrm{NaOH}$ for Group 1/2 Bi-Phosphate Sludge/Saltcake (During Oxidative Leaching)...

6.6. Phosphorus Concentration Versus Time at $45^{\circ} \mathrm{C}$ Leach Temperature at $\mathrm{Mn} / \mathrm{Cr}$ Mole Ratios of $0.59,0.79,0.98$, and 1.19 in $0.25 \mathrm{M} \mathrm{NaOH}$, and at a Mn/Cr Mole Ratio of 0.98 in $1.25 \mathrm{M}$ $\mathrm{NaOH}$ for Group 1/2 Bi-Phosphate Sludge/Saltcake (during oxidative leaching)

6.7. Effect of Free-Hydroxide Concentration on Pu Mobilization During Oxidative Leaching for Group 1/2 Bi-Phosphate Sludge/Saltcake

6.8. Group 1/2 Bi-Phosphate Sludge/Saltcake Reduction in Solid Mass with Oxidative Leaching .. 
6.9. Pre-Sonication Volume Distribution Result for Sample 584-G1/2-OL-PSD as a Function of Pump Speed

6.10. Volume Distribution Result for Sample 584-G1/2-OL-PSD Before, During, and After Sonication at 3000 RPM

6.11. Post-Sonication Volume Distribution Result for Sample 584-G1/2-OL-PSD Sample as a Function of Pump Speed ..

6.12. Influence of Caustic and Oxidative Leaching and Washing on Group 1/2 Mixed Waste Solids PSD

6.13. Comparison of Caustic- and Oxidatively-Leached and Washed Group 1/2 Mixed Waste Solids PSD from Parametric and CUF Testing....

6.14. XRD Pattern of Oxidatively Leached Group 1/2 Bi-Phosphate Sludge/Saltcake with Rutile $\left(\mathrm{TiO}_{2}\right)$ Internal Standard (a) Raw Data and (b) Background-Subtracted with Stick-Peak Identification

6.15. SEM images of Group 1/2 Bi-Phosphate Sludge/Saltcake Oxidatively Leached and Washed Solids (a) $20 \mathrm{kV}, 2500 \times$; (b) $5 \mathrm{kV}, 1000 \times$; (c) $5 \mathrm{kV}, 500 \times$; (d) $5 \mathrm{kV}, 250 \times$.

6.16. SEM Image of Group 1/2 Bi-Phosphate Sludge/Saltcake Oxidatively Leached and Washed Solids with EDS Spectra (a) SEM Image; (b) EDS Spectra of Spot 1; (c) EDS Spectra of Spot 5

6.17. SEM Image of Group 1/2 Bi-Phosphate Sludge/Saltcake Oxidatively Leached and Washed Solids with EDS Spectra (a) SEM Image; (b) EDS Spectra of Spot 1; (c) EDS Spectra of Spot 4

6.18. SEM Image of Group 1/2 Bi-Phosphate Sludge/Saltcake Oxidatively Leached and Washed Solids with EDS Spectra (a) SEM Image; (b) EDS Spectra of Spot 3; (c) EDS Spectra of Spot 7

6.19. SEM-EDS Image of Oxidatively Leached Group 1/2 Bi-Phosphate Sludge/Saltcake with Fe, $\mathrm{Si}, \mathrm{Bi}, \mathrm{Ca}, \mathrm{Mn}, \mathrm{U}$, and Na Maps.

6.20. TEM Images of Oxidatively-Leached Group 1/2 Bi-Phosphate Sludge/Saltcake

6.21. TEM Images with EDS Analysis: (a) STEM-HAADF Image; (b) TEM Image Showing Cancrinite Particle and Bi-Fe Phases; (c) EDS Spectrum of Bi-Fe Phase; (d) EDS Spectrum of a Bi-Fe Particle that is Under the Cancrinite Particle

6.22. Particle High in Iron (a) TEM Image; (b) EDS Analysis Showing High Iron Content as Well as Very Little Bismuth

6.23. TEM Analysis of Cancrinite Phase: (a) SAED Image; (b) EDS Spectrum

6.24. (a) TEM Image; (b) EDS Analysis Showing Uranium Phase, Iron Bismuth Phase, and Cancrinite

6.25. TEM image of a Nickel Particle: (a) TEM Image; (b) Close-up of Area in the Dotted Square in (a); (c) EDS Spectrum Taken of the Area 1 Shown in (a) 


\section{Tables}

Table No.

Caption

Page No.

S.1. Test Objectives xxviii

S.2. Results and Performance Against Success Criteria …......................................................... xxx

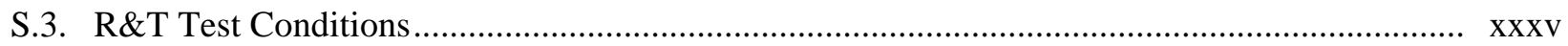

1.1. Projected Distribution of Water-Insoluble Components in the Tank Waste Groupings ............. 1.4

2.1. Selection of Bismuth Phosphate Sludge Tanks .................................................................... 2.4

2.2. Group 1 Targeted Samples and Masses from 222S Archive................................................. 2.5

2.3. Selection of Group 2 Bismuth Phosphate Saltcake Tanks ................................................... 2.9

2.4. Group 2 Targeted Samples and Masses from 222S Archive................................................ 2.10

2.5. Bi Phosphate Sludge Samples (Group 1) ............................................................................. 2.14

2.6. Group 1 Sub-Sample Mass Density and Settling Data............................................................ 2.16

2.7. Group 2 Bismuth Phosphate Saltcake Sample Masses......................................................... 2.23

2.8. Mass of DI Water Used in Compositing/Homogenization of Group 2 Bismuth Phosphate

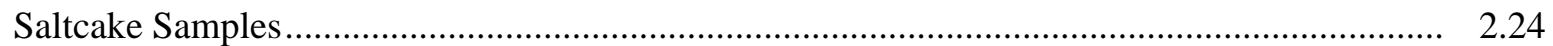

2.9. Tare Weight, Sample Gross Mass, Slurry Volumes, and Settled Solids Volumes for Group 2 Bismuth Phosphate Saltcake Homogenized Samples.............................................................. 2.26

3.1. Group 1 Characterization Samples ...................................................................................... 3.1

3.2. Physical Properties of Homogenized Group 1 Sludge ........................................................... 3.5

3.3. Results of Fitting Analysis for Rheology Sample TI508-G1-AR-RH1 ….............................. 3.9

3.4. Apparent Viscosity of Sample TI508-G1-AR-RH1 ............................................................... 3.11

3.5. Radionuclide Characterization of the Group 1 Sludge ......................................................... 3.12

3.6. Chemical Characterization of the Group 1 Test Material ....................................................... 3.13

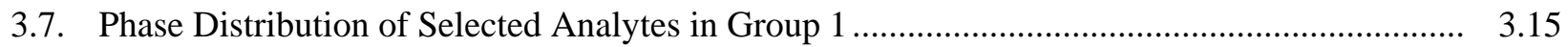

3.8. Particle-Size Analysis Percentile Results of the Primary Group 1 Initial Characterization Sample, TI483-G1-S-WL-PSD-1

3.9. Particle Size Analysis Percentile Results of the Duplicate Group 1 Initial Characterization Sample, TI483-G1-S-WL-PSD-2

3.10. Absolute Relative Percent Difference Between Primary and Duplicate Group 1 Initial Characterization Samples

3.11. Possible Phase Identification of Group 1 Water-Insoluble Solids ........................................... 3.25

3.12. Group 1 Caustic Leaching Conditions .............................................................................. 3.36

3.13. Group 1 Bi-Phosphate Sludge Leaching Final Aqueous Phase Conditions ............................. 3.56

3.14. Group 1 Solids Wash Solution Composition and Density ....................................................... 3.57 
3.15. Group 1 Bi-Phosphate Sludge Leached Solids Composition and Leach Factors (Dry Mass Basis)

3.16. Group 1 Bi-Phosphate Sludge Leach Factors.

3.17. Particle-Size Analysis Percentile Results for the Caustic-Leached and Washed Group 1 Solids (sample 555-G1-CL-PSD).

3.18. Cumulative Undersize Percentiles Showing the Influence of Caustic-Leaching and Washing on the PSD of Group 1 Solids at Measurement Condition 7-3000 RPM, Post-Sonication .......

3.19. Wt \% of Various Elements by SEM and ICP-OES .

4.1. Group 2 Characterization Samples

4.2. Physical Properties of Homogenized Group 2 Saltcake.

4.3. Results of Fitting Analysis for Rheology Sample TI517-G2-AR-RH

4.4. Apparent Viscosity of Sample TI517-G2-AR-RH

4.5. Radionuclide Characterization of the Group 2 Saltcake

4.6. Chemical Characterization of the Group 2 Test Material

4.7. Phase Distribution of Selected Analytes in Group 2

4.8. Particle Size Analysis Percentile Results of the Primary Group 2 Initial Characterization Sample, TI517-G2-S-WL-PSD-1

4.9. Particle Size Analysis Percentile Results of the Duplicate Group 2 Initial Characterization Sample, TI517-G1-S-WL-PSD-2

4.10. Absolute Relative Percent Difference Between Primary and Duplicate Group 1 Initial Characterization Samples....

4.11. Group 2 Caustic Leaching Conditions

4.12. Group 2 Bismuth Phosphate Saltcake Leaching Final Aqueous Phase Conditions

4.13. Solids Wash Solution Composition and Density

4.14. Group 2 Bi-Phosphate Saltcake Leached Solids Composition and Leach Factors (Dry Mass Basis)

4.15. Comparison of Fe-Normalized Compositions of the Initial Group 2 Characterization Sample and the Washed Group 2 Sample Used for Parametric Leaching for Selected Components ......

4.16. Group 2 Bi-Phosphate Slurry Leach Factors

4.17. Initial Particle-Size Analysis Percentile Results for the Caustic-Leached and Washed Group 2 Solids (sample 549-G2-CL-PSD)

4.18. Replicate Particle-Size Analysis Percentile Results for the Caustic-Leached and Washed Group 2 Solids (sample 549-G2-CL-PSD)

4.19. Relative Percent Difference Between the Initial and Replicate PSD Percentile Results for Sample 549-G2-CL-PSD.

4.20. Cumulative Undersize Percentiles Showing the Influence of Caustic-Leaching and Washing on the PSD of Group 2 Solids at Measurement Condition 1: 3000 RPM, Before Sonication .... 
4.21. Normalized Weight Percents for Various Analytes Found by EDS of SEM Images for

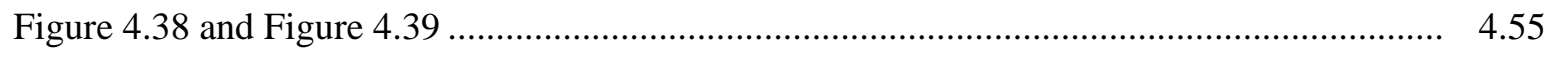

5.1. Low-Solids Slurry Physical-Properties Measurements ........................................................ 5.5

5.2. Group $1 / 2$ Low-Solids Slurry Total Inventory and Composition........................................... 5.6

5.3. Group 1/2 Low-Solids Supernate Opportunistic Composition ............................................. 5.7

5.4. Results of Fitting Analysis for Rheology of the Low-Solids Slurry .......................................

5.5. Comparison of Initial CWF Between Group 1/2 and Group 6/5 Wastes .................................. 5.13

5.6. Average Operating Conditions and Filter Flux for the Low-Solids Matrix Test ...................... 5.15

5.7. Mass Balance Overview for Initial Slurry Dewatering to High-Solids Condition.................... 5.20

5.8. Average Operating Conditions and Filter Flux for the High-Solids Matrix Test...................... 5.23

5.9. Physical Property Measurements of the High-Solids Slurry .................................................. 5.28

5.10. Group 1/2 High-Solids Slurry Inventory and Composition ................................................ 5.29

5.11. Group 1/2 High-Solids Slurry Composition Based on ICP-OES/Radionuclide

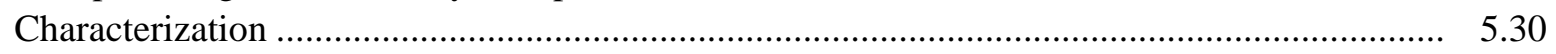

5.12. Results of Fitting Analysis for the High-Solids Slurry ....................................................

5.13. Apparent Viscosity of the High-Solids Slurry ................................................................. 5.35

5.14. Effect of Waste Stream Mixing and Dewatering on Group 1/2 CUF Rheology (at $25^{\circ} \mathrm{C}$ ) ......... 5.36

5.15. Concentration of Major Analyte Components of Filtered Caustic Leach Samples, Corrected for Sample Evaporation................................................................................................ 5.40

5.16. Prediction of Average Flux of Leach Dewatering Step from Initial Dewatering Flux Based on Viscosity Differences According to the Darcy Equation ..................................................... 5.44

5.17. Physical Property Measurements of the Dewatered Caustic Leached Slurry ........................... 5.47

5.18. Group 1/2 Caustic leached, Dewatered Slurry Inventory and Composition ............................ 5.48

5.19. Group 1/2 Dewatered Leached Slurry Composition and Calculated Solids Leach Factors........ 5.49

5.20. Results of Fitting Analysis for the Group 1/2 CUF Caustic-Leached and Dewatered Slurry ..... 5.53

5.21. Apparent Viscosity of the Group 1/2 CUF Caustic-Leached and Dewatered Slurry ................. 5.54

5.22. Group 1/2 Caustic leached Slurry Inventory and Composition after the First Wash ................. 5.56

5.23. Group $1 / 2$ Caustic Leached Slurry Inventory and Composition after the Second Wash ........... 5.57

5.24. Group 1/2 Caustic Leached Slurry Inventory and Composition after the Third Wash .............. 5.58

5.25. Group 1/2 Caustic leached Slurry Inventory and Composition after the Fourth Wash.............. 5.59

5.26. Group 1/2 Caustic leached Slurry Inventory and Composition after the Fifth Wash................. 5.60

5.27. Caustic Wash Solutions Radionuclide and Opportunistic Compositions................................ 5.61

5.28. Physical-Property Measurements of the Group 1/2 Caustic-Leached and Washed Slurry ......... 5.66

5.29. Group 1/2 Washed Leach Slurry Composition and Caustic Leach Factor Calculations Based on ICP-OES/Radiochemical Characterization 
5.30. Results of Fitting Analysis for Group 1/2 CUF Caustic-Leached, Dewatered, and Washed Slurry.

5.31. Apparent Viscosity of Group 1/2 CUF Caustic-Leached, Dewatered, and Washed Slurry ........ 5.72

5.32. Effect of Caustic Leaching/Washing on Group 1/2 CUF Slurry Rheology .............................. 5.73

5.33. Average Flux of Caustic Washes ....................................................................................... 5.75

5.34. Physical Property Measurements of the Group 1/2 Oxidative Leached Slurry ......................... 5.79

5.35. Group 1/2 Oxidative Leached Slurry Composition and Leach Factor Calculations Based on ICP-OES/Radiochemical Characterization

5.36. Slurry composition after the first wash of the Group 1/2 Oxidative leached Slurry (Including Permeate Hold-up)

5.37. Slurry Composition After the Second Wash of the Group 1/2 Oxidative Leached Slurry (Including Permeate Hold-up).

5.38. Slurry Inventory and Composition After the Third Wash of the Group 1/2 Oxidative Leached Slurry (including permeate hold-up).....

5.39. Oxidative Wash Solutions Radionuclide and Opportunistic Compositions.

5.40. Average Operating Conditions and Filter Flux for the High-Solids Matrix Test......

5.41. Physical Property Measurements of the CUF $1 / 2$ Washed Oxidative Leached Slurry

5.42. CUF $1 / 2$ Caustic and Oxidative Leached Material (final slurry including permeate hold-up) ... 5.101

5.43. Group 1/2 Washed Oxidative and Caustic Leach Slurry Composition and Overall Leach Factor Calculations Based on ICP-OES/Radiochemical Characterization.

5.44. Results of Fitting Analysis for the Group 1/2 CUF Oxidative Leached and Washed Slurry

5.45. Effect of Oxidative-Leaching and Washing on Group $1 / 2$ CUF Slurry Rheology (at $25^{\circ} \mathrm{C}$ )

5.46. Group 1/2 CUF Filtration, PSD, and Rheology Test Result Summary ....

5.47. Summary of Overall Solid Leach Factors and Removal from Slurry ..... 5.122

6.1. Oxidative Leaching Conditions for Group 1/2 Caustic-Leached Solids .

6.2. Group 1/2 Bi-Phosphate Sludge/Saltcake Oxidative Leaching Final Aqueous Phase Conditions

6.3. Solids Wash Solution Composition.

6.4. Leached Solids Composition and Leach Factors of Group 1/2 Bi-Phosphate Sludge/Saltcake (Water-Insoluble Solids).

6.5. Group 1/2 Bi-Phosphate Sludge/Saltcake Leach Factors

6.6. Particle Size Analysis Percentile Results for Sample 584-G1/2-OL-PSD

6.7. Cumulative Undersize Percentiles Showing the Influence of Caustic and Oxidative Leaching and Washing on the PSD of Group 1/2 Mixed Waste Solids at Measurement Condition 73000 RPM, post-sonication

6.8. Normalized Weight Percents for Various Analytes Found by EDS of SEM Images for Figures 6.6, 6.17, and 6.18 
WTP-RPT-166, Rev 0

\section{Table No.}

Caption

Page No.

6.9. Electron Diffraction Analysis Data for Group 1/2 Bi-Phosphate Sludge/Saltcake Oxidatively Leached Solids . 


\section{Abbreviation/Acronym List}

\begin{tabular}{|c|c|}
\hline AEA & alpha energy analysis \\
\hline ASO & Analytical Support Organization \\
\hline ASR & Analytical Service Request \\
\hline ATL & Advanced Technologies and Laboratories, International Inc. \\
\hline AV & Axial Velocity \\
\hline BBI & Best Basis Inventory \\
\hline BET & (Brunauer, Emmett, and Teller) surface area analysis technique \\
\hline BNI & Bechtel National, Incorporated \\
\hline BS & blank spike \\
\hline CCD & charge coupled device \\
\hline CCN & corporate correspondence number (BNI) \\
\hline CUF & cell unit filter \\
\hline CWP & PUREX cladding waste \\
\hline CWR & REDOX cladding waste \\
\hline DACS & data acquisition collection system \\
\hline DI & deionized \\
\hline DOE & U.S. Department of Energy \\
\hline ED & electron diffraction \\
\hline EDS & energy-dispersive spectroscopy \\
\hline EELS & electron energy-loss spectroscopy \\
\hline EFRT & external flowsheet review team \\
\hline EQL & estimated quantitation limit \\
\hline FTIR & Fourier transform infrared \\
\hline GEA & gamma energy analysis \\
\hline GIF & Gatan Imaging Filter \\
\hline HAADF & High Angle Annular Dark-Field Detector \\
\hline HDPE & high-density polypropylene \\
\hline HLRF & High-Level Radiochemistry Facility \\
\hline HLW & high-level waste \\
\hline HP & hot persulfate \\
\hline IC & ion chromatography \\
\hline ICDD & International Centre for Diffraction Data \\
\hline ICP-OES & inductively coupled plasma-optical emission spectroscopy \\
\hline ICSD & Inorganic Crystal Structure Database \\
\hline $\mathrm{KOH}$ & potassium hydroxide \\
\hline KPA & kinetic phosphorescence analysis \\
\hline LAW & low activity waste \\
\hline LCS & laboratory control sample \\
\hline LEPS & Low-Energy Photon Spectroscopy \\
\hline MDL & minimum detection limit \\
\hline MRQ & minimum reportable quantity \\
\hline MS & matrix spike \\
\hline M\&TE & measuring and test equipment \\
\hline
\end{tabular}


NIST

OES

ORP

PB

PNNL

PSD

PTF

PUREX

QA

QAM

QAPjP

QARD

QC

REDOX

RIR

RPD

RPL

RPP

RSD

R\&T

TBP

TGA

TIC

TMP

TOC

TRU

SBMS

SEM

STEM

TEM

TP

TWINS

UDS

UFP

WCS

WTP

XRD
National Institute of Standards and Technology

optical emission spectroscopy

Office of River Protection

preparation blank

Pacific Northwest National Laboratory

particle-size distribution

Pretreatment Facility

plutonium-uranium extraction

quality assurance

Quality Assurance Manual

quality assurance project plan

Quality Assurance Requirements and Descriptions

quality control

reduction oxidation

relative intensity ratio

relative percent difference

Radiochemical Processing Laboratory

River Protection Project

relative standard deviation

research and technology

tributyl phosphate

thermogravimetric analysis

total inorganic carbon

transmembrane pressure

total organic carbon

transuranics

Standards Based Management System

scanning electron microscopy

scanning transmission electron microscopy

transmission electron microscopy

test plan

Tank-Waste Information Network System

undissolved solids

ultrafiltration process

wet centrifuged solids

Hanford Tank Waste Treatment and Immobilization Plant

X-ray diffraction 
WTP-RPT-166, Rev 0

\section{References}

Barnes HA, and NQ Dzuy. 2001. "Rotating Vane Rheometry - A Review.” Journal of Non-Newtonian Fluid Mechanics 98(1):1-14.

Cleveland JM. 1970. The Chemistry of Plutonium. Gordon and Breach Science Publishers, New York.

CRC. 1978. CRC Handbook of Chemistry and Physics, $59^{\text {th }}$ Edition, CRC Press, West Palm Beach, Florida.

de Barry Barnett E, and CL Wilson. 1953. Inorganic Chemistry: A Text-Book for Advanced Students, Longmans Green and Co, London.

Fiskum SK, EC Buck, RC Daniel, K Draper, MK Edwards, TL Hubler, LK Jagoda, ED Jenson, GJ Lumetta, BK McNamara, RA Peterson, SI Sinkov, and LA Snow. 2008. Characterization and Leach Testing for REDOX Sludge and S-Saltcake Actual Waste Sample Composites. PNNL-17368 (WTP-RPT157), Pacific Northwest National Laboratory, Richland, Washington.

Li H, J Addai-Mensah, JC Thomas, and AR Gerson. 2005. “The Influence of Al(III) Supersaturation and $\mathrm{NaOH}$ Concentration on the Rate of Crystallization of $\mathrm{Al}(\mathrm{OH})_{3}$ Precursor Particles From Sodium Aluminate Solutions.” J. Colloid and Interface Science 286:511-519.

Li J, CA Prestidge, and J Addai-Mensah. 2000. "Viscosity, Density, and Refractive Index of Aqueous Sodium and Potassium Aluminate Solutions.” J. Chem. Eng. Data 45:665-671.

Liu Q, H Xu, and A Navrostsky. 2005. "Nitrate cancrinite: Synthesis, characterization, and determination of enthalpy of formation.” Microporous and Mesoporous Materials 87:146-152.

Lumetta GJ. 2008. Mechanism of Phosphorus Removal from Hanford Tank Sludge by Caustic Leaching. PNNL-17257, Pacific Northwest National Laboratory, Richland, Washington.

Lumetta GJ, LP Darnell, PA Garza, LR Greenwood, BM Oliver, DE Rinehart, DR Sanders, CZ Soderquist, T Trang-Le, MW Urie, JJ Wagner. 2002. Caustic Leaching of Hanford Tank T-110 Sludge. PNNL-13956, Pacific Northwest National Laboratory, Richland, Washington.

Lumetta GJ, KJ Carson, LP Darnell, LR Greenwood, FV Hoopes, RL Sell, SI Sinkov, CZ Soderquist, MW Urie, JJ Wagner. 2001. Caustic Leaching of Hanford Tank S-110 Sludge, PNNL-13702, Pacific Northwest National Laboratory, Richland, Washington.

Lumetta GJ and BM Rapko. 1999. "Removal of Chromium from Hanford Tank Sludges." Sep. Sci. Technol. 34:1495-1506.

Lumetta GJ, BM Rapko, J Liu, DJ Temer, and RD Hunt. 1998. Washing and Caustic Leaching of Hanford Tank Sludges: Results of FY 1998 Studies. PNNL-12026, Pacific Northwest National Laboratory, Richland, Washington.

Malvern Instruments Ltd. 1997. Sample Dispersion and Refractive Index Guide. MAN 0079, Version 3.1, Worcestershire, England. 
Rapko BM, GJ Lumetta, JD Vienna, and SK Fiskum. 2005. Oxidative Alkaline Leaching of SX-101 and SY-102 and Its Impact on Immobilized High Level Waste. PNWD-3600 (WTP-RPT-137), BattellePacific Northwest Division, Richland, Washington. (WTP Doc. No. 24590-101-TSA-W000-0004-16800002 Rev 00A.)

Rapko BM, JGH Geeting, SI Sinkov, and JD Vienna. 2004. Oxidative-Alkaline Leaching of Washed 241-SY-102 and 241-SX-101 Tank Sludges. PNWD-3512 (WTP-RPT-117), Battelle-Pacific Northwest Division, Richland, Washington. (WTP Doc. No. 24590-101-TSA-W000-0004-99-00012 Rev 00A.)

Rapko BM, and JD Vienna. 2002. Selective Leaching of Chromium from Hanford Tank Sludge 241-U108. PNNL-14019, Pacific Northwest National Laboratory, Richland, Washington.

Rapko BM, JD Vienna, SI Sinkov, J Kim, and AJ Cisar. 2002. Alkaline Leaching of Key, NonRadioactive Components from Simulants and Hanford Tank Sludge 241-S-110: Results of FY 01 Studies. PNNL-14018, Pacific Northwest National Laboratory, Richland, Washington.

Rapko BM. 1998. Oxidative Alkaline Dissolution of Chromium from Hanford Tank Sludges: Results of FY 98 Studies. PNNL-11908, Pacific Northwest National Laboratory, Richland, Washington.

Rector DR, and BC Bunker. 1995. Effect of Colloidal Aggregation on the Sedimentation and Rheological Properties of Tank Waste. PNL-10761, Pacific Northwest Laboratory, Richland, Washington.

Templeton DH, HW Ruben, and A Zalkin. 1990. "Entropy and Crystal Structure of Hydrates of Disodium Hydrogen Phosphate.” J. Phys. Chem. 94:7830-7834.

Wefers K, and C Misra. 1987. Oxides and Hydroxides of Aluminum. Alcoa Technical Paper No. 19 Revised, Alcoa Laboratories, Alcoa Center, Pittsburg, Pennsylvania.

Wellman DM, JG Catlano, JP Icenhower, and AP Gamerdinger. 2005. "Synthesis and Characterization of Sodium meta-Autunite, $\mathrm{Na}\left[\mathrm{UO}_{2} \mathrm{PO}_{4}\right] \cdot 3 \mathrm{H}_{2} \mathrm{O}$.” Radiochim. Acta, 93:393-399.

Zhukhlistov AP, and BB Zvyagin. 1977. "Determination of Crystal-Structures of Chapmanite and Bismuthoferrite by High-Voltage Neutron-Diffraction Method.” Soviet Physics Crystallography 22:419423. 


\section{Testing Summary}

A testing program evaluating actual tank waste was developed in response to Task 4 from the M-12 External Flowsheet Review Team (EFRT) issue response plan. ${ }^{(a)}$ The test program was subdivided into logical increments. The bulk water-insoluble solid wastes that are anticipated to be delivered to the Hanford Tank Waste Treatment and Immobilization Plant (WTP) were identified according to type such that the actual waste testing could be targeted to the relevant categories. Eight broad waste groupings were defined. Samples available from the 222S archive were identified and obtained for testing. The actual waste-testing program included homogenizing the samples by group, characterizing the solids and aqueous phases, and performing parametric leaching tests.

Two of the eight defined groups — bismuth phosphate sludge (Group 1) and bismuth phosphate saltcake (Group 2) -are the subjects of this report. The Group 1 waste was anticipated to be high in phosphorus and was implicitly assumed to be present as $\mathrm{BiPO}_{4}$ (however, results presented here indicate that the phosphate in Group 1 is actually present as amorphous iron(III) phosphate). The Group 2 waste was also anticipated to be high in phosphorus, but because of the relatively low bismuth content and higher aluminum content, it was anticipated that the Group 2 waste would contain a mixture of gibbsite, sodium phosphate, and aluminum phosphate. Thus, the focus of the Group 1 testing was on determining the behavior of $\mathrm{P}$ removal during caustic leaching, and the focus of the Group 2 testing was on the removal of both $\mathrm{P}$ and $\mathrm{Al}$. This report discusses the waste-type definition, archived sample conditions, homogenization activities, characterization (physical, chemical, radioisotope, and crystal habit), and caustic leaching behavior as functions of time, temperature, and hydroxide concentration. Testing was conducted according to TP-RPP-WTP-467. ${ }^{(\mathrm{b})}$

\section{Objectives}

The test objectives are summarized in Table S.1 along with a discussion of how the objectives were met. Several objectives (in gray shading lighter than header shading) did not specifically apply to the scope provided in this report; they will be reported in companion reports as indicated in the controlling test plan.

(a) SM Barnes, and R Voke. 2006. "Issue Response Plan for Implementation of External Flowsheet Review Team (EFRT) Recommendations - M12: Undemonstrated Leaching Process.” 24590-WTP-PL-ENG-06-0024 Rev. 0.

(b) SK Fiskum. 2007. Characterization and Small Scale Testing of Hanford Wastes to Support the Development and Demonstration of Leaching and Ultrafiltration Pretreatment Processes. TP-RPP-WTP-467, Rev. 0, 2/2/07 and Rev. 1, 7/31/07. 
Table S.1. Test Objectives

\begin{tabular}{|c|c|c|}
\hline Test Objective & $\begin{array}{c}\text { Objective } \\
\text { Met? (Y/N) }\end{array}$ & Discussion \\
\hline $\begin{array}{l}\text { 1) Determine the physical and chemical } \\
\text { characteristics (summarized in } \\
\text { Section } 6.2 .2 \text { of the test plan) } \\
\text { relevant to leaching and } \\
\text { ultrafiltration behaviors of actual } \\
\text { waste samples required for the } \\
\text { validation of simulants. }\end{array}$ & $\mathrm{Y}$ & $\begin{array}{l}\text { The following characterizations were conducted on } \\
\text { the washed solids for Group } 1 \text { and Group 2: } \\
\text { - } \text { solids chemical composition } \\
\text { - } \text { mineral composition } \\
\text { - particle-size distribution } \\
\text { - crystal habit and morphology } \\
\text { - slurry density } \\
\text { - slurry rheology, flow curve, and shear strength } \\
\text { - } \text { settling rate, fraction of settled solids, fraction of } \\
\text { centrifuged solids. } \\
\text { The results are summarized in Sections } 3 \text { and } 4 \text {. }\end{array}$ \\
\hline $\begin{array}{l}\text { 2) Determine the dissolution rate of } \\
\text { aluminum in the actual waste } \\
\text { samples, present predominantly as } \\
\text { gibbsite, as a function of } \\
\text { temperature, free hydroxide } \\
\text { concentration, and over a range of } \\
\text { sodium concentrations of interest to } \\
\text { the caustic leaching process. }\end{array}$ & $\mathrm{Y}$ & $\begin{array}{l}\text { A significant portion of the } \mathrm{Al} \text { in the Group } 2 \text { waste } \\
\text { was present in the form of gibbsite. The behavior of } \\
\text { this component during caustic leaching could be } \\
\text { reasonably discerned because most of the remaining } \\
\mathrm{Al} \text { was present as aluminosilicate materials (which are } \\
\text { not leachable). } \\
\text { These results are discussed in Section } 4.4 \text {. }\end{array}$ \\
\hline $\begin{array}{l}\text { 3) Determine the dissolution rate of } \\
\text { aluminum in the actual waste } \\
\text { samples, present predominantly as } \\
\text { boehmite, as a function of } \\
\text { temperature, free hydroxide } \\
\text { concentration, and over a range of } \\
\text { sodium concentrations of interest to } \\
\text { the caustic leaching process. }\end{array}$ & NA & $\begin{array}{l}\text { Neither Group } 1 \text { nor Group } 2 \text { was expected to contain } \\
\text { significant quantities of boehmite and indeed this was } \\
\text { found to be the case. Aluminum was only a minor } \\
\text { component of the Group } 1 \text { solids constituting only } \sim 3 \\
\text { wt\% of the washed Group } 1 \text { solids (Table } 3.6 \text { ). XRD } \\
\text { and microscopy analyses revealed no boehmite in the } \\
\text { Group } 1 \text { solids (Section } 3.2 .6 \text { ). The washed Group } 2 \\
\text { solids contained } ~ 12 \mathrm{wt} \% \mathrm{Al} \text { (Table } 4.6 \text { ), but XRD } \\
\text { and microscopy analyses indicated the Al to be } \\
\text { primarily in the forms of gibbsite and aluminosilicate } \\
\text { (Section 4.2.6). }\end{array}$ \\
\hline $\begin{array}{l}\text { Determine the dissolution rate of } \\
\text { chromium and the extent of } \\
\text { dissolution of plutonium and other } \\
\text { safety-related constituents ( } \mathrm{U}, \mathrm{Fe} \text {, } \\
\mathrm{Mn}, \mathrm{Ni} \text {, and } \mathrm{Zn} \text { ) in the actual waste } \\
\text { samples as functions of temperature } \\
\text { and over a range of } \mathrm{NaOH} \\
\text { concentrations of interest for } \\
\text { oxidative leaching. (The } \mathrm{NaMnO}_{4} \\
\text { dosage will be predetermined for the } \\
\text { oxidation of the chromium in the } \\
\text { waste solids.) }\end{array}$ & NA & $\begin{array}{l}\text { Oxidative leaching was not an objective of the Group } \\
1 \text { and Group } 2 \text { testing because neither of these was } \\
\text { anticipated to be a high-Cr waste. } \\
\text { Parametric oxidative leaching tests were performed on } \\
\text { the Group } 1 / 2 \text { composite solids that had been caustic- } \\
\text { leached in the CUF apparatus. The parameters } \\
\text { examined included } \mathrm{NaOH} \text { concentration }(0.25 \text { and } \\
1.25 \mathrm{M}) \text {, and the } \mathrm{Mn} / \mathrm{Cr} \text { molar ratio }(0.75,1.0,1.25 \text {, } \\
\text { and } 1.5) \text {. Temperature was not a parameter examined } \\
\text { in these experiments; all oxidative leaching } \\
\text { measurements were made at } 45^{\circ} \mathrm{C} \text {. } \\
\text { These results are discussed in Section } 6 \text {. }\end{array}$ \\
\hline $\begin{array}{l}\text { 5) Determine the dissolution/reaction } \\
\text { rate of phosphates in the actual waste } \\
\text { samples as a function of temperature }\end{array}$ & $\mathrm{Y}$ & $\begin{array}{l}\text { Both Group } 1 \text { and Group } 2 \text { contained significant } \\
\text { amounts of P. The P behavior for the Group } 1 \text { and } \\
\text { Group } 2 \text { composites during caustic leaching was }\end{array}$ \\
\hline
\end{tabular}


Table S.1 (Contd)

\begin{tabular}{|c|c|c|}
\hline Test Objective & $\begin{array}{c}\text { Objective } \\
\text { Met? (Y/N) }\end{array}$ & Discussion \\
\hline $\begin{array}{l}\text { and over a range of } \mathrm{NaOH} \\
\text { concentrations of interest for the } \\
\text { caustic leaching process as well as } \\
\text { the extent of dissolution during post- } \\
\text { leaching wash. }\end{array}$ & & $\begin{array}{l}\text { characterized as a function of time, temperature, and } \\
\text { free hydroxide concentration. However, for Group 2, } \\
\text { the P behavior was only tracked opportunistically } \\
\text { (without full quality assurance [QA] review of the } \\
\text { analytical data). } \\
\text { The P results can be found in Sections } 3 \text { (Group 1), } 4 \\
\text { (Group 2), and } 6 \text { (Group 1/2). }\end{array}$ \\
\hline $\begin{array}{l}\text { 6) Determine ultrafiltration flux before } \\
\text { and after caustic and oxidative } \\
\text { leaching over the operating range of } \\
\text { solids concentrations during the } \\
\text { leaching processes at } 25^{\circ} \mathrm{C} \text { when } \\
\text { sufficient actual waste sample is } \\
\text { available for testing of the filtration } \\
\text { behavior. }\end{array}$ & $\mathrm{Y}$ & $\begin{array}{l}\text { Ultrafiltration (CUF) testing was performed on a } \\
\text { blended composite of the Group } 1 \text { and Group } 2 \text { solids. } \\
\text { The CUF testing was performed before leaching using } \\
\text { slurries with both low- and high-solids contents. } \\
\text { Further CUF testing was performed after caustic } \\
\text { leaching, and after oxidative leaching. During these } \\
\text { tests, the ultrafiltration flux was determined as a } \\
\text { function of transmembrane pressure and axial } \\
\text { velocity. The CUF tests were conducted at ambient } \\
\text { temperature. } \\
\text { All the CUF testing results are discussed in Section } 5 .\end{array}$ \\
\hline $\begin{array}{l}\text { 7) Scanning electron microscopy } \\
\text { (SEM), transmission electron } \\
\text { microscopy (TEM), energy } \\
\text { dispersive spectroscopy (EDS), and } \\
\text { X-ray diffraction (XRD) will be used } \\
\text { to determine the primary mineral } \\
\text { forms present for Al, Cr, and P and } \\
\text { provide information to enable the } \\
\text { correlation of these mineral forms to } \\
\text { dissolution behavior. }\end{array}$ & $\mathrm{Y}$ & $\begin{array}{l}\text { SEM, TEM, EDS, and XRD were performed on the } \\
\text { washed Group } 1 \text { and Group } 2 \text { solids both before and } \\
\text { after caustic leaching. In addition, preliminary } \\
\text { application of vibrational spectroscopy [Fourier- } \\
\text { transform infrared (FTIR) and Raman spectroscopies] } \\
\text { to the characterization of tank sludge solids was } \\
\text { performed for these two waste samples. } \\
\text { The solids characterization results are distributed } \\
\text { throughout the report, at the specific relevant sections. }\end{array}$ \\
\hline
\end{tabular}

\section{Test Exceptions}

No test exceptions applied to this work.

\section{Results and Performance Against Success Criteria}

The test plan delineated several success criteria, which are listed in Table S.2. Selected criteria were relevant to the test scope included in this report; the other criteria that are outside of the reported scope are shaded. 
Table S.2. Results and Performance Against Success Criteria

\begin{tabular}{|c|c|c|}
\hline \multicolumn{2}{|r|}{ List Success Criteria } & \multirow{2}{*}{$\begin{array}{l}\text { Explain How the Tests Did or Did Not } \\
\text { Meet the Success Criteria } \\
\text { Letter report number RPP-WTP-07-705 (GJ Lumetta } \\
\text { and RT Hallen, WTP-RPT-151, Review of Caustic } \\
\text { Leaching Testing With Hanford Tank Waste Sludges) } \\
\text { which addressed this success criterion, was delivered to } \\
\text { BNI-WTP on 1/24/2007. }\end{array}$} \\
\hline & $\begin{array}{l}\text { A summary (letter report format) of the available } \\
\text { information (including published literature) is } \\
\text { provided on the characteristics (both known } \\
\text { characteristics and those needed to be determined) } \\
\text { relevant to leaching and filtration behaviors of the } \\
\text { tank farm waste groupings identified for testing. }\end{array}$ & \\
\hline & $\begin{array}{l}\text { The physical and chemical characteristics for each } \\
\text { of the actual waste-sample composites selected for } \\
\text { testing are provided (including a format in } \\
\text { conformance with the presentation protocols } \\
\text { [24590-WTP-GPG-RTD-001]). The relevant } \\
\text { physical and chemical characteristics are } \\
\text { elaborated in Test Conditions, Section 6.0, of the } \\
\text { test plan. }\end{array}$ & $\begin{array}{l}\text { All physical and chemical characterization testing as } \\
\text { defined in the test plan was completed. This included } \\
\text { extensive physical and chemical characterization of the } \\
\text { homogenized slurry materials and extensive chemical } \\
\text { characterization of selected leach solids. The analytical } \\
\text { results for each test group are reported in the appropriate } \\
\text { report sections. }\end{array}$ \\
\hline & $\begin{array}{l}\text { The dissolution rate and the extent of dissolution of } \\
\text { aluminum present predominantly as gibbsite in } \\
\text { actual waste solids are determined as a function of } \\
\text { temperature, free-hydroxide, and sodium } \\
\text { concentrations. The associated uncertainties in test } \\
\text { results are provided. }\end{array}$ & $\begin{array}{l}\text { Dissolution of the gibbsite fraction of the Group } 2 \\
\text { washed solids was evaluated by measuring the } \mathrm{Al} \text { in the } \\
\text { leaching solution as a function of time }(1,2,4,8 \text {, and } \\
24 \mathrm{~h} \text { ). The effects of free hydroxide concentration and } \\
\text { temperature were assessed. Testing was conducted at } \\
\text { three free hydroxide concentrations }(1,3 \text {, and } 5 \mathrm{M}) \text { and } \\
\text { at three temperatures }\left(60,80 \text {, and } 100^{\circ} \mathrm{C}\right) \text {. One test } \\
\left.\text { condition ( } 3 \mathrm{M} \text { free hydroxide at } 80^{\circ} \mathrm{C}\right) \text { was conducted } \\
\text { in triplicate to assess overall test precision. } \\
\text { The dissolution of the (presumed) gibbsite fraction of } \\
\text { the Group } 2 \text { solids was rapid, with steady state reached } \\
\text { in } 4 \text { to } 8 \text { h under all conditions examined. The steady- } \\
\text { state Al concentrations in these experiments represented } \\
60 \text { to } 70 \% \text { Al dissolution, suggesting that } 30 \text { to } 40 \% \text { of } \\
\text { the Al in the Group } 2 \text { solids was present as an } \\
\text { aluminosilicate (nitrate cancrinite, as identified by XRD } \\
\text { and FTIR). Detailed results are presented in Section } 4.0 \text {. } \\
\text { The Group } 1 \text { solids did not have any significant fraction } \\
\text { of gibbsite present, so this success criterion is not } \\
\text { applicable to the Group } 1 \text { test. }\end{array}$ \\
\hline & $\begin{array}{l}\text { The dissolution rate and the extent of dissolution of } \\
\text { aluminum present predominantly as boehmite in } \\
\text { actual waste solids are determined as a function of } \\
\text { temperature, free-hydroxide, and sodium } \\
\text { concentrations. The associated uncertainties in test } \\
\text { results are provided. }\end{array}$ & $\begin{array}{l}\text { Not applicable. Neither Group } 1 \text { nor Group } 2 \text { samples } \\
\text { had significant amounts of boehmite. }\end{array}$ \\
\hline & $\begin{array}{l}\text { The dissolution rate and the extent of dissolution of } \\
\text { chromium in the actual waste solids are determined } \\
\text { as a function of temperature and over a range of }\end{array}$ & $\begin{array}{l}\text { For the Group } 1 / 2 \text { caustic-leached solids, } \mathrm{Cr} \text { reaction } \\
\text { with the } \mathrm{MnO}_{4}^{-} \text {was rapid, with near-steady state } \mathrm{Cr} \\
\text { concentration reached within } 1 \mathrm{~h} \text { of leaching. The }\end{array}$ \\
\hline
\end{tabular}


Table S.2 (Contd)

\begin{tabular}{|c|c|}
\hline List Success Criteria & $\begin{array}{l}\text { Explain How the Tests Did or Did Not } \\
\text { Meet the Success Criteria }\end{array}$ \\
\hline $\begin{array}{l}\mathrm{NaOH} \text { concentrations of interest to oxidative } \\
\text { leaching. The } \mathrm{NaMnO}_{4} \text { dosage will be } \\
\text { predetermined for the oxidation of the chromium in } \\
\text { the waste solids. The associated uncertainties in } \\
\text { the test results are provided. }\end{array}$ & 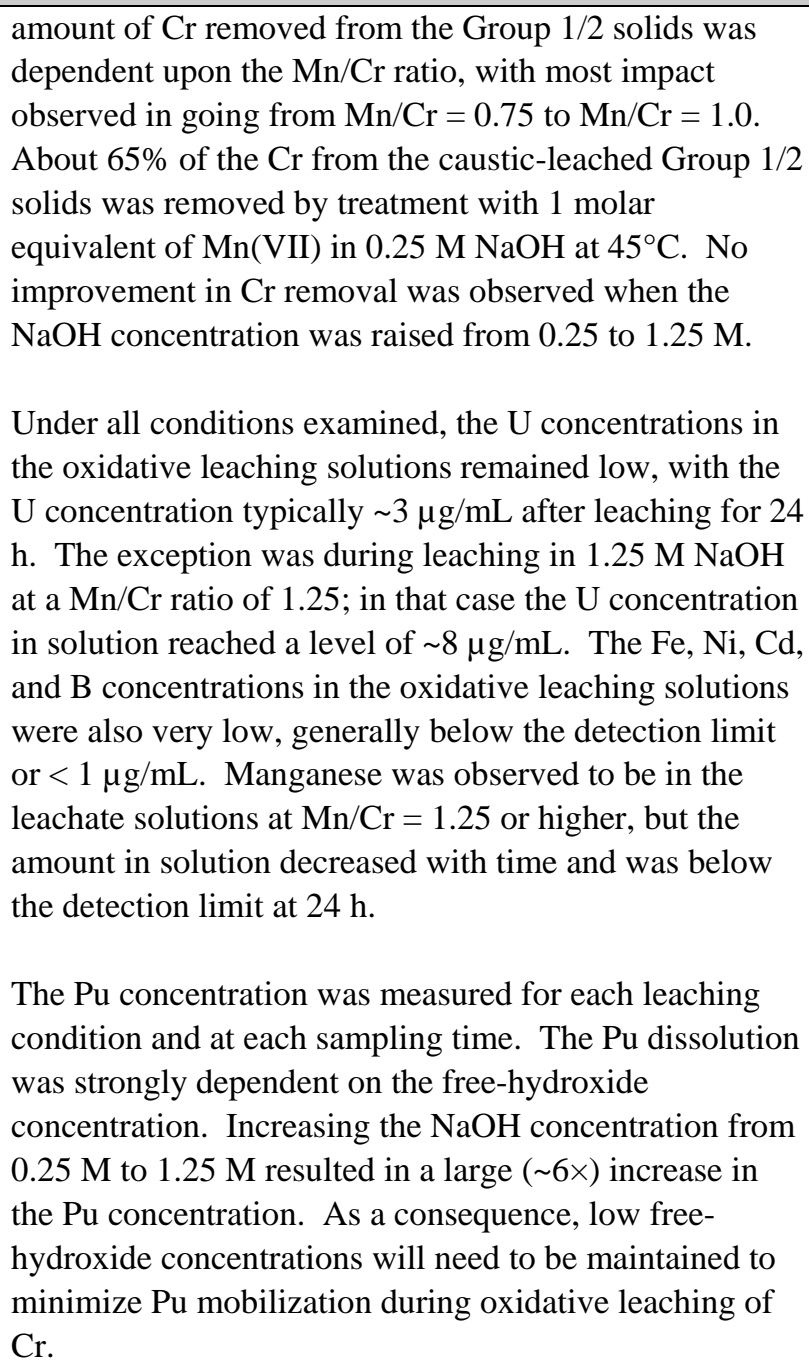 \\
\hline $\begin{array}{l}\text { 6) The dissolution rate and the extent of dissolution of } \\
\text { phosphates in the actual waste solids are } \\
\text { determined as a function of temperature and } \mathrm{NaOH} \\
\text { concentration along with the uncertainty in these } \\
\text { estimates. }\end{array}$ & $\begin{array}{l}\text { Phosphorus removal from the Group } 1 \text { washed solids } \\
\text { was evaluated by measuring the P in the leaching } \\
\text { solution as a function of time }(1,2,4,8 \text {, and } 24 \mathrm{~h}) \text {. The } \\
\text { effects of free hydroxide concentration and temperature } \\
\text { were assessed. Testing was conducted at two free- } \\
\text { hydroxide concentrations }(1 \text { and } 3 \mathrm{M}) \text { and at three } \\
\text { temperatures }\left(40,60 \text {, and } 80^{\circ} \mathrm{C}\right) \text {. One test condition } \\
\left.\text { ( } 3 \mathrm{M} \text { free hydroxide at } 40^{\circ} \mathrm{C}\right) \text { was conducted in triplicate } \\
\text { to assess overall test precision. } \\
\text { The P removal from the Group } 1 \text { solids was rapid, with } \\
\text { steady state reached within } 4 \mathrm{~h} \text { under all conditions } \\
\text { examined. Near quantitative P removal was achieved } \\
\text { for nearly all conditions examined. Detailed results are } \\
\text { presented in Section } 3.0 \text {. } \\
\text { Phosphorus removal from the Group } 2 \text { solids was } \\
\text { opportunistically evaluated as a function of time (1, 2, 4, }\end{array}$ \\
\hline
\end{tabular}


Table S.2 (Contd)

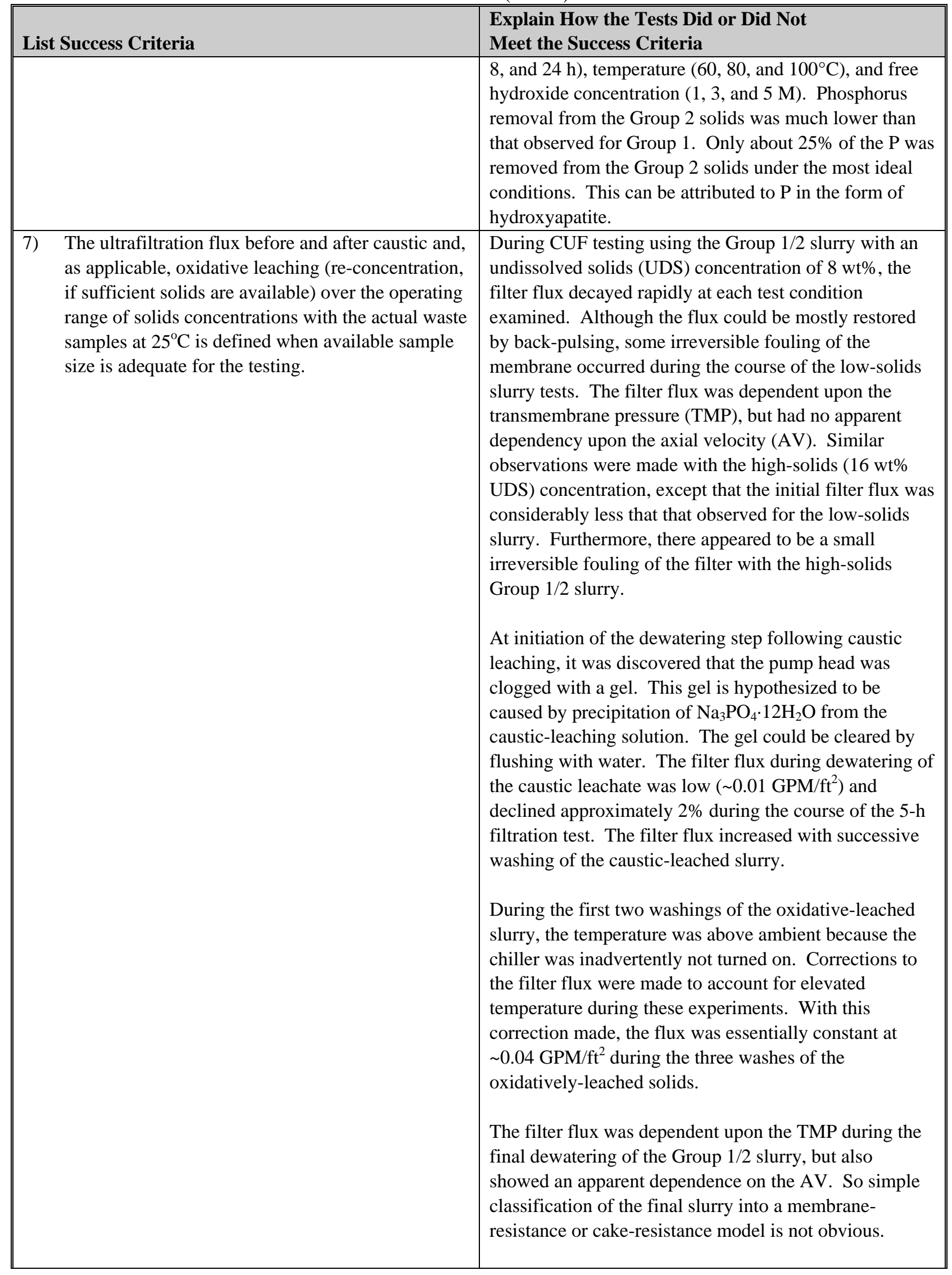


Table S.2 (Contd)

\begin{tabular}{|c|c|}
\hline List Success Criteria & $\begin{array}{l}\text { Explain How the Tests Did or Did Not } \\
\text { Meet the Success Criteria }\end{array}$ \\
\hline & $\begin{array}{l}\text { Comparison of the initial clean water flux measurements } \\
\text { suggests an irreversible fouling of the membrane } \\
\text { following the leaching and filtration tests. Iron present } \\
\text { in the waste was suspected because it was believed not } \\
\text { to be impacted by the leaching operations or by the } 2 \mathrm{M} \\
\text { nitric acid cleaning. Cleaning the filter with } 0.5 \mathrm{M} \\
\text { oxalic acid before the next test significantly improved } \\
\text { the flux. This supports the theory of iron present in the } \\
\text { slurry solid fouling the filter because oxalic acid is very } \\
\text { effective in dissolving iron into solution. }\end{array}$ \\
\hline $\begin{array}{l}\text { 8) Determination of the primary mineral forms } \\
\text { present for } \mathrm{Al}, \mathrm{Cr} \text {, and } \mathrm{P} \text {, and a qualitative } \\
\text { correlation of the dissolution behavior of these } \\
\text { waste elements to the mineral forms identified. }\end{array}$ & 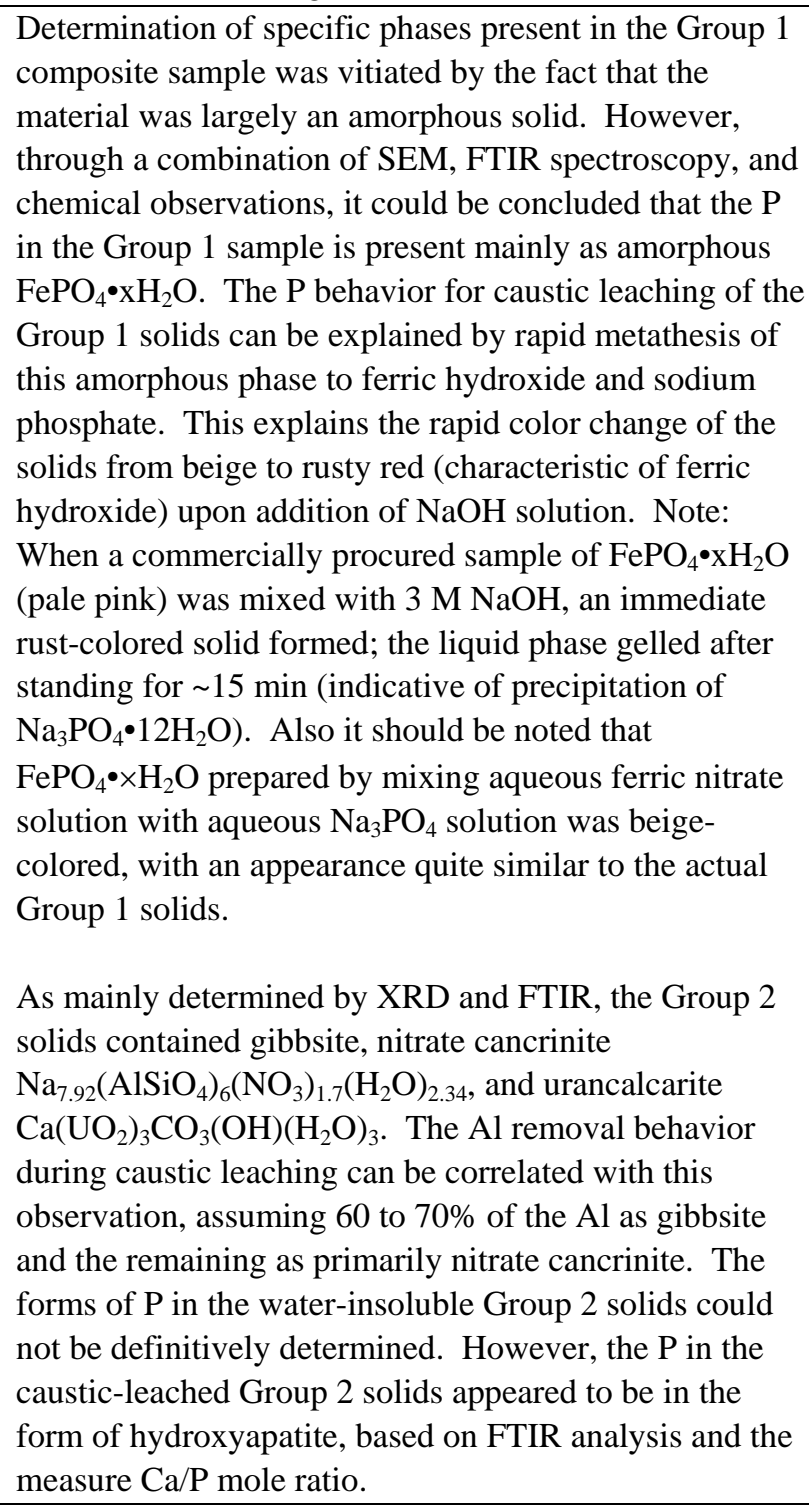 \\
\hline
\end{tabular}




\section{Quality Requirements}

Pacific Northwest National Laboratory (PNNL) is operated for the U.S. Department of Energy (DOE) by Battelle under Contract DE-AC05-76RL01830. PNNL implements a Quality Assurance Program that is based upon the requirements as defined in DOE Order 414.1C, "Quality Assurance,” and 10 CFR 830, “Energy/Nuclear Safety Management,” Subpart A—“Quality Assurance Requirements.” PNNL has chosen to implement the requirements of DOE Order 414.1C and 10 CFR 830, Subpart A by integrating them into the laboratory's management systems and daily operating processes. The procedures necessary to implement the requirements are documented through the laboratory's Standards-Based Management System (SBMS).

PNNL implemented the RPP-WTP quality requirements by performing work in accordance with the River Protection Project - Waste Treatment Plant Support Program (RPP-WTP) Quality Assurance Plan (RPPWTP-QA-001, QAP). Work was performed to the quality requirements of NQA-1-1989 Part I, "Basic and Supplementary Requirements,” NQA-2a-1990, Part 2.7, and DOE/RW-0333P, Rev 13, Quality Assurance Requirements and Descriptions (QARD). These quality requirements were implemented through the River Protection Project - Waste Treatment Plant Support Program (RPP-WTP) Quality Assurance Manual (RPP-WTP-QA-003, QAM). The analytical requirements were implemented through RPP-WTP's Statement of Work (RPP-WTP-QA-005) with the Radiochemical Processing Laboratory (RPL) Analytical Service Operations (ASO).

A matrix that cross-references the NQA-1, NQA-2a, and QARD requirements with the procedures for RPP-WTP work was provided in the test plan TP-RPP-WTP-467. It included justification for those requirements not implemented.

Experiments that were not method-specific were performed in accordance with RPP-WTP's procedures QA-RPP-WTP-1101 “Scientific Investigations” and QA-RPP-WTP-1201 “Calibration and Control of Measuring and Testing Equipment" so that sufficient data were taken with properly calibrated measuring and test equipment (M\&TE) to obtain quality results.

RPP-WTP addressed internal verification and validation activities by conducting an Independent Technical Review of the final data report in accordance with RPP-WTP's procedure QA-RPP-WTP-604. This review verified that the reported results were traceable, that inferences and conclusions were soundly based, and the reported work satisfied the Test Plan objectives. This review procedure is part of PNNL's RPP-WTP Quality Assurance Manual. 


\section{R\&T Test Conditions}

The R\&T test conditions, as defined in the Test Specification, ${ }^{(a)}$ are summarized in Table S.3.

Table S.3. R\&T Test Conditions

\begin{tabular}{|c|c|}
\hline List R\&T Test Conditions & Were Test Conditions Followed? \\
\hline $\begin{array}{l}\text { 1) Selection of actual wastes for testing: the waste } \\
\text { samples selected for testing will be from the } \\
\text { groupings identified in the resolution of Issue M4. }\end{array}$ & $\begin{array}{l}\text { Yes. Two of the eight waste groupings identified in } \\
\text { resolution to Issue M4 were tested: Group } 1 \\
\text { (bismuth phosphate sludge) and Group } 2 \text { (bismuth } \\
\text { phosphate saltcake). }\end{array}$ \\
\hline $\begin{array}{l}\text { 2) Physical and chemical characterization properties } \\
\text { shall be stated and carried out according to the } \\
\text { Guideline document } 24590-W T P-G P G-R T D-001 \text {. }\end{array}$ & $\begin{array}{l}\text { Yes. Physical characterizations, including specific } \\
\text { gravity (density), settling rate, rheology, volume- } \\
\text { percent settled solids, and volume-percent } \\
\text { centrifuged solids, were determined for both test } \\
\text { groups according to the requirements document. } \\
\text { Chemical characterization was conducted on the } \\
\text { supernatant (water used to dissolve and slurry the } \\
\text { solids into a workable homogenized composite) on } \\
\text { the solids rinsed with three contacts of } 1: 1 \text { volume } \\
\text { ratios of } 0.01 \mathrm{M} \mathrm{NaOH} \text { and on the rinse solution } \\
\text { composite. }\end{array}$ \\
\hline $\begin{array}{l}\text { 3) Actual determinations of waste leach kinetics } \\
\text { will be carried out in well-mixed conditions. A test } \\
\text { matrix will be forwarded to the research and } \\
\text { technology (R\&T) M12 Issue manager for } \\
\text { concurrence before testing. Residual leached and } \\
\text { washed solids will be characterized. }\end{array}$ & $\begin{array}{l}\text { Yes. Test matrices for both the Group } 1 \text { and } \\
\text { Group } 2 \text { waste samples were forwarded to, and } \\
\text { approved by, the R\&T M12 Issue Manager. Actual } \\
\text { test conditions are given in Sections } 3.0 \text { and } 4.0 \text { and } \\
\text { were compliant with the test matrices. }\end{array}$ \\
\hline 4) Testing for filtration behavior will be performed. & $\begin{array}{l}\text { Yes. Cross-flow filtration testing was performed on } \\
\text { a mixture of solids from Groups } 1 \text { and } 2 \text {. CUF } \\
\text { testing matrices were applied to a low-solids slurry, } \\
\text { a high-solids slurry, post-caustic leaching, and post- } \\
\text { oxidative leaching. Rheology and particle size } \\
\text { distribution measurements were made before and } \\
\text { after the various process steps. }\end{array}$ \\
\hline
\end{tabular}

(a) PS Sundar. Nov. 2006. Characterization and Small Scale Testing of Hanford Wastes to Support the Development and Demonstration of Leaching and Ultrafiltration Pretreatment Processes. 24590-PTF-TSPRT-06-003, Rev. 1. 
WTP-RPT-166, Rev 0

\section{Simulant Use}

The testing used actual Hanford tank wastes; simulant usage does not apply.

\section{Discrepancies and Follow-on Tests}

None. 
WTP-RPT-166, Rev. 0

\subsection{Introduction}

This report is one in a series that defines the characterization, parametric leaching, and filtration testing of actual Hanford tank wastes in support of the Hanford Tank Waste Treatment and Immobilization Plant (WTP) pretreatment process development and demonstration. The tests reported here were conducted according to test plan TP-RPP-WTP-467, ${ }^{\text {a) }}$ which was written in response to Test Specification 24590PTF-TSP-RT-06-003 Rev. 1. ${ }^{(b)}$

\subsection{Tank Waste Pretreatment Operations at the WTP}

Figure 1.1 provides a schematic illustration of the primary functions to be performed in the WTP. Initially, the low-activity waste (LAW) liquid stream will be removed from the high-level waste (HLW) solids phase by ultrafiltration in the Pretreatment Facility (PTF). The concentrated HLW solids will be pretreated with caustic and, in some cases, oxidative leaching processes to dissolve and remove components (specifically, aluminum, chromium, phosphates, and sulfates) that would otherwise limit HLW loading in the immobilized waste glass. The current plant design calls for the pretreatment leaching processes to be carried out in the ultrafiltration feed vessels. The function of caustic leaching is to solubilize the aluminum, phosphorus, and sulfur in the HLW solids, thereby removing these components from the HLW vitrification feed. The function of oxidative leaching is to oxidize the chromium [from $\mathrm{Cr}(\mathrm{III})$ to $\mathrm{Cr}(\mathrm{VI})]$ with a sodium permanganate $\left(\mathrm{NaMnO}_{4}\right)$ solution, so that the $\mathrm{Cr}$ can be routed to the LAW stream. The HLW solids will be re-concentrated after each leaching and washing operation in the ultrafilter.

The current design of the PTF was based on aluminum dissolution results from earlier small, bench-scale, caustic leaching tests that were provided to Bechtel National, Incorporated (BNI) by the U.S. Department of Energy's (DOE's) Office of River Protection (ORP). Only a limited number of small bench-scale oxidative leaching tests using two selected actual waste tank samples (SX-101 and SY-102) with the preferred oxidant $\mathrm{NaMnO}_{4}$ were carried out to estimate the oxidant dosage and the efficacy of the oxidative leaching process (Rapko et al. 2004; Rapko et al. 2005), but a number of previous studies demonstrated the technical feasibility of the oxidative leaching process (Rapko 1998; Lumetta and Rapko 1999; Rapko and Vienna 2002; Rapko et al. 2002). The testing with actual radioactive wastes has been generally limited to small-scale testing (typically 1 to $10 \mathrm{~g}$ ) because of limited sample availability and personnel safety associated with sample handling.

(a) SK Fiskum, TP-RPP-WTP-467, Rev. 0, 2/2/07 and Rev. 1 7/31/07, Characterization and Small Scale Testing of Hanford Wastes to Support the Development and Demonstration of Leaching and Ultrafiltration Pretreatment Processes.

(b) PS Sundar. 2006. 24590-PTF-TSP-RT-06-003 Rev. 1, Characterization and Small Scale Testing of Hanford Wastes to Support the Development and Demonstration of Leaching and Ultrafiltration Pretreatment Processes. 


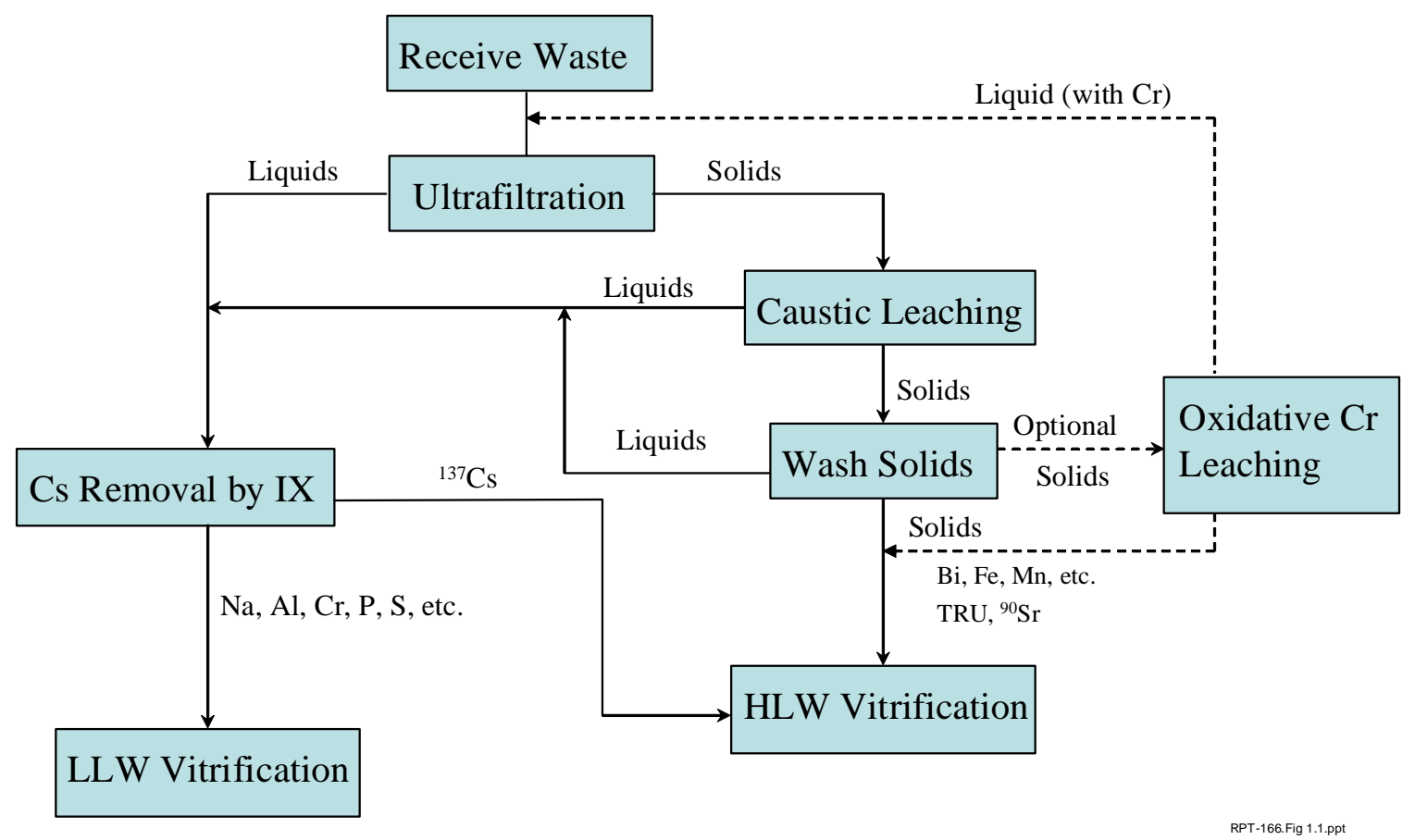

Figure 1.1. Schematic Representation of the Key Processes to be Performed in the WTP (Note: This is for illustrative purposes only, it is not meant to be a comprehensive view of the functions performed within the WTP)

\subsection{Issues Identified by the External Flowsheet Review Team}

A team of foremost experts from industry, national laboratories, and universities (referred to as the External Flowsheet Review Team or EFRT) was assembled by BNI in October of 2005 to conduct an indepth review of the process flowsheet supporting the design of the WTP. The EFRT identified several issues from the critical review of the process flowsheet, ${ }^{(\mathrm{a}, \mathrm{b})}$ including

- Issue M4: The WTP has not demonstrated that its design is sufficiently flexible to reliably process all of the Hanford tank farm wastes at the design throughputs.

- Issue M12: Neither the caustic leaching nor the oxidative leaching process has been demonstrated at greater than bench scale. The small-scale experiments are capable of defining the leaching chemistry. However, they are limited in their capability to predict the effectiveness of these processes without a scale-up demonstration.

- Issue M13: For wastes requiring leaching, a combination of inadequate filter flux and area will likely limit throughput to the HLW or LAW vitrification facilities.

(a) WTP Doc. No. 24590-WTP-PL-ENG-06-0008, Rev 0, "Hanford Waste Treatment and Immobilization Plant (WTP) Project Response Plan for Resolution of Issues Identified by the Comprehensive Review of the WTP Flowsheet and Throughput.” L Lucas, March 2006.

(b) WTP Project Doc. No. CCN 132846 "Comprehensive Review of the Hanford Waste Treatment Plant Flowsheet and Throughput - Assessment Conducted by an Independent Team of External Experts.” March 2006, chartered by the Hanford Waste Treatment and Immobilization Plant Project at the Direction of the U.S. Department of Energy, Office of Environmental Management, Washington DC. 
The work scope defined in the TP-RPP-WTP-467 represented the initial actual waste-testing part of Task 4 from the M-12 EFRT issue response plan. ${ }^{(a)}$ The actual tank waste testing was based on responses developed to resolve EFRT Issue M4. In this case, a family of waste groupings representing the behavior of $\sim 75 \%$ of the tank-farm inventory was developed to assist in designing subsequent tests that will assess the adequacy of the overall flowsheet design in treating the tank-farm wastes. These waste groupings were the basis for selecting actual wastes for the current scope of testing.

The results from the actual waste testing reported herein also support the resolution of following related EFRT issues:

- Issue M1: Piping that transports slurries will plug unless it is properly designed to minimize this risk. This design approach has not been followed consistently, which will lead to frequent shutdowns due to line plugging.

- Issue M2: Large, dense particles will accelerate erosive wear in mixing vessels. The effects of such particles on vessel life must be re-evaluated.

- Issue M3: Issues were identified related to mixing-system designs that will result in insufficient mixing and/or extended mixing times. These issues include a design basis that discounts the effects of large particles and of rapidly settling Newtonian slurries. There is also insufficient testing of the selected designs.

- Issue M6: Many of the process operating limits have not been defined. Further testing is required to define process limits for WTP unit operations. Without this more complete understanding of each process, it will be difficult or impossible to define a practical operating range for each unit operation.

\subsection{Waste Groupings}

The available information regarding tank history and tank waste characterization was analyzed. This analysis revealed eight groupings of waste tanks that represent $~ 75 \%$ of the inventory of those components that are most significant with respect to leaching in the WTP; i.e., Al, Cr, phosphate, and sulfate (Fiskum et al. 2008). Table 1.1 summarizes the eight waste groups along with the estimated water-insoluble fractions (with respect to the entire tank farm inventory) of selected components contained in each one. To support the actual waste testing, samples were obtained from the archives at the Hanford 222S Laboratory. Composites of these archived samples were made to obtain the most representative samples of each group as practical. The details of the sample selection for Groups 1 and 2 are provided in Section 2.0.

(a) SM Barnes, and R Voke, September 2006, 24590-WTP-PL-ENG-06-0024 Rev. 0, "Issue Response Plan for Implementation of External Flowsheet Review Team (EFRT) Recommendations - M12: Undemonstrated Leaching Process." 
Table 1.1. Projected Distribution of Water-Insoluble Components in the Tank Waste Groupings (Fiskum et al. 2008)

\begin{tabular}{|c|c|c|c|c|c|c|c|c|}
\hline Group ID & Type & $\begin{array}{c}\text { Al } \\
(\%)\end{array}$ & $\begin{array}{l}\mathrm{Cr} \\
(\%)\end{array}$ & $\begin{array}{c}F \\
(\%)\end{array}$ & $\begin{array}{c}\mathrm{Fe} \\
(\%)\end{array}$ & $\begin{array}{c}\text { Oxalate } \\
(\%)\end{array}$ & $\begin{array}{c}\text { Phosphate } \\
(\%)\end{array}$ & $\begin{array}{c}\text { Sulfate } \\
(\%)\end{array}$ \\
\hline 1 & Bi Phosphate sludge & 4 & 4 & 22 & 22 & 0.5 & 36 & 7 \\
\hline 2 & $\begin{array}{l}\text { Bi Phosphate saltcake } \\
(\mathrm{BY}, \mathrm{T})\end{array}$ & 13 & 18 & 24 & 8 & 37 & 23 & 42 \\
\hline 3 & $\begin{array}{l}\text { CWP, PUREX Cladding } \\
\text { Waste sludge }\end{array}$ & 17 & 1 & 1.3 & 5 & 1 & 2 & 0.4 \\
\hline 4 & $\begin{array}{l}\text { CWR, REDOX Cladding } \\
\text { Waste sludge }\end{array}$ & 10 & 1 & $<0.1$ & 1 & 0.4 & 0.1 & $<0.1$ \\
\hline 5 & REDOX sludge & 29 & 6 & 0.1 & 4 & 3 & 1 & 0.4 \\
\hline 6 & S - Saltcake (S) & 8 & 46 & 0.6 & 4 & 27 & 4 & 14 \\
\hline 7 & TBP Waste sludge & 1 & 0.4 & 0.5 & 7 & 0.1 & 17 & 3 \\
\hline 8 & FeCN Waste sludge & 1 & 1 & 0.4 & 7 & 1 & 6 & 1 \\
\hline & Balance & 17 & 24 & 51 & 41 & 30 & 10 & 32 \\
\hline \multicolumn{9}{|c|}{$\begin{array}{l}\text { Note: The component values were rounde } \\
\text { CWP = PUREX cladding waste } \\
\text { CWR = REDOX cladding waste } \\
\text { FeCN = ferrocyanide } \\
\text { PUREX = plutonium uranium extraction } \\
\text { REDOX = reduction oxidation } \\
\text { TBP = tributyl phosphate }\end{array}$} \\
\hline
\end{tabular}

\subsection{Simulant Development}

BNI plans to carry out process development and scale-up testing to demonstrate the design effectiveness of both the caustic- and the oxidative-leaching processes over the entire applicable range of Hanford tank farm wastes. ${ }^{\text {(a) }}$ Scale-up testing will require substantial volumes of feed. Therefore, the development of simulants that mimic the chemical, leaching, and ultrafiltration behaviors over the range observed for actual waste groups is necessary to the process development and demonstration. The characterization and leaching performance data obtained from the actual waste testing will serve as benchmarks for defining the simulant characteristics and behaviors for revising the parameters used in process models for evaluating WTP process performance using the appropriate process models.

\subsection{Testing of Groups 1 and 2}

The characterization and parametric leaching of two of the eight defined groups, bismuth phosphate sludge (Group 1) and bismuth phosphate saltcake (Group 2), are the subject of this report. In the case of the bismuth phosphate sludge, the phosphate behavior is of particular interest, as this is the major component targeted to be removed by caustic leaching (Table 1.1). Phosphate is also of interest for the

(a) WTP Doc. No. 24590-WTP-PL-ENG-06-0008, Rev 0, "Hanford Waste Treatment and Immobilization Plant (WTP) Project Response Plan for Resolution of Issues Identified by the Comprehensive Review of the WTP Flowsheet and Throughput.” L Lucas, March 2006. 
bismuth phosphate saltcake, but the behaviors of aluminum, chromium, and sulfate are also expected of significance (Table 1.1).

The waste-type definition, sample identification, archived sample conditions, and homogenization activities are discussed in this report. The caustic leaching experiments and results are described for the Group 1 and Group 2 solids. The physical, chemical, radioisotope, and crystal morphology characterization in the waste before and after leach processing are also discussed. Crossflow ultrafiltration tests using a blend of the Group 1 and Group 2 solids are described and the results presented.

The results from these tests will refine the knowledge base of the tank waste chemical and mineralogical characteristics. Parametric leach testing will provide the leaching kinetics of gibbsite, phosphorus, and chromium and support follow-on leach and filtration testing. 
WTP-RPT-166, Rev. 0

\subsection{Test Sample Selection, Compositing, and Homogenization}

This section describes the rationale for selecting bismuth phosphate sludge (Group 1) and saltcake (Group 2) test materials from the Hanford tank waste sample archive located in the 222S building of the Hanford Site. Retrieval of new sample materials from the tanks was deemed to be prohibitively expensive and time intensive and therefore was not considered. Also described is the homogenization and sub-sampling of Group 1 and Group 2 composite samples.

\subsection{Group 1-Bismuth Phosphate Sludge Sample Selection}

Bismuth phosphate first and second cycle (1C and 2C, respectively) tank waste sludge samples with high bismuth content were targeted to construct the Group 1 composite. The $1 \mathrm{C}$ and $2 \mathrm{C}$ wastes originated from neutralization of acidic process solutions from the bismuth phosphate process used to separate plutonium from irradiated fuel in the 1940s and 1950s (Cleveland 1970, pp. 500-503). The Tank-Waste Information Network System (TWINS) database ${ }^{(a)}$ was queried to identify the tanks containing $>95 \% 1 C$ and/or 2C waste type. These tank wastes were queried in the Best Basis Inventory (BBI) ${ }^{(a)}$ for the major inorganic components (phosphate, $\mathrm{Bi}, \mathrm{Al}, \mathrm{Fe}, \mathrm{Cr}, \mathrm{Si}$, and $\mathrm{U}$ ) in the solid and sludge phases. Figure 2.1 shows the relative mass distributions of these analytes; mass fraction variation between these components in the tank wastes was relatively minor. (Note that major elemental and anionic contributions from $\mathrm{Na}$, nitrate, nitrite, and oxalate are excluded from the data in Figure 2.1.)

The decision process flowchart for selecting tank waste samples from the sample archive is summarized in Figure 2.2. The 222S archive sample inventory ${ }^{(\mathrm{b})}$ was searched for sludge samples from the tanks identified as containing first (1C) and second (2C) cycle bismuth phosphate waste (Figure 2.2). The samples were then cross-referenced to the TWINS database to determine if analytical data from the specific samples were available; samples identified as containing $>10 \mathrm{mg} \mathrm{Bi}$ per g sludge (reported on a wet mass basis) were carried forward in the selection process. It was assumed that samples high in Bi were also high in phosphate. Of these samples, those with $<5 \mathrm{~g}$ material were omitted. The final list of samples was submitted to $\mathrm{CH}_{2} \mathrm{MHill}_{\text {personnel }}{ }^{(\mathrm{c})}$ for a two-step evaluation process: 1 ) the samples were confirmed to represent the bismuth phosphate sludge waste stream based on the tank strata, core segment, and corresponding characterization results, and 2) the samples were not held for other activities and could be released from the archive.

Table 2.1 summarizes the tank sources evaluated and shows whether the tank met or failed the selection criteria. Samples highlighted in bold in the table were those determined to meet all of the selection criteria.

(a) The TWINS database and the BBI are DOE-owned resources.

(b) Personal communication of the inventory database, file "Vials May18," provided from P Brackenbury, Bechtel, June 2006.

(c) David Place and Bruce Higley, Process Engineers, Process Analysis Organization, CH2MHill. 


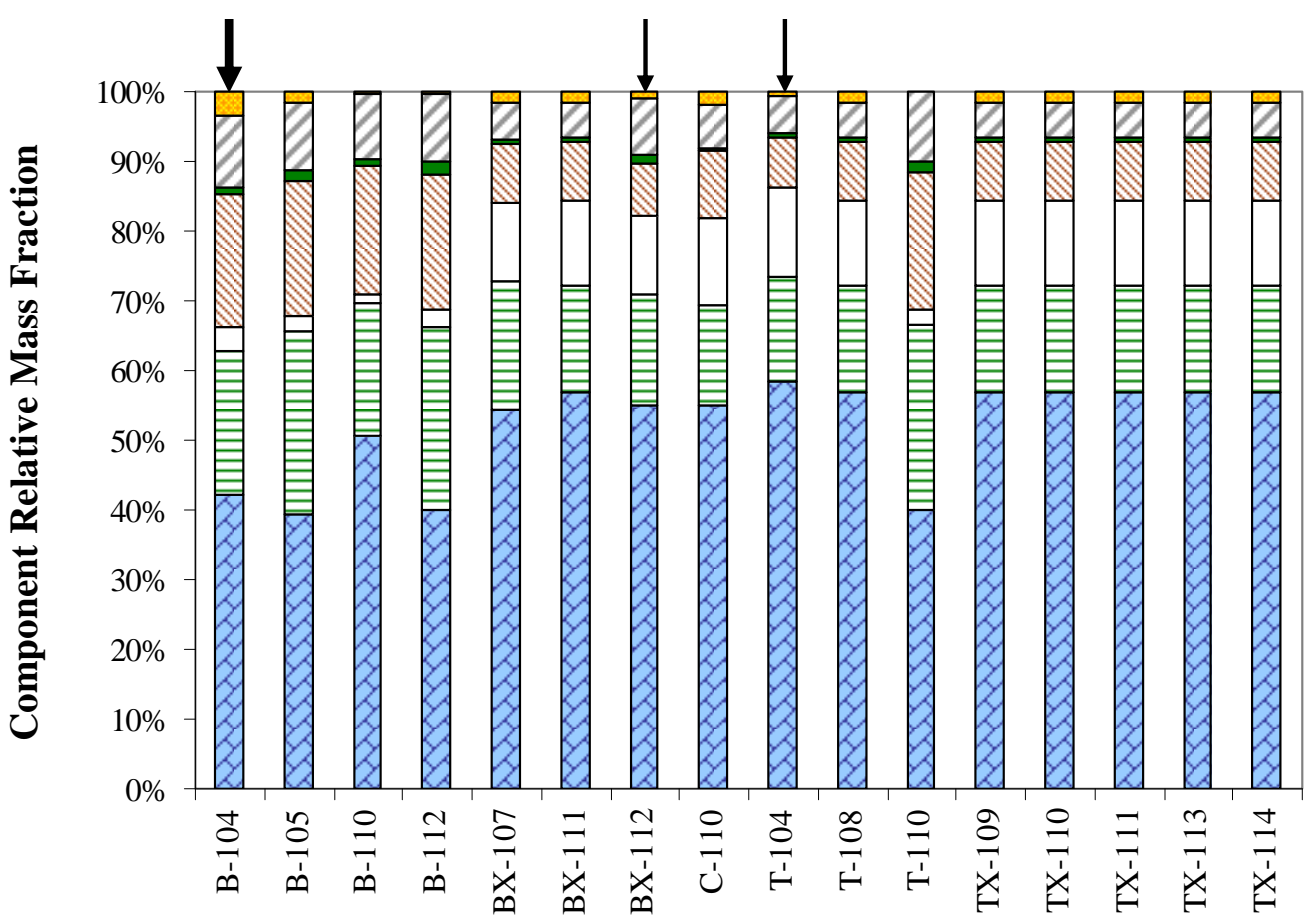

Tank Identification

$\square \mathrm{PO} 4 \quad \boxminus \mathrm{Bi} \quad \square \mathrm{Al} \quad \square \mathrm{Fe} \quad \square \mathrm{Cr} \quad \square \mathrm{Si} \quad \square \mathrm{U}$

Figure 2.1. Estimated Tank Waste Composition of Selected Analytes for 1C and 2C Sludge Wastes in the Hanford Tank Farm (BBI Source). Note: arrows point to the tanks actually used to prepare the Group 1 composite; B-104 dominated the composite mass (see text).

Table 2.2 summarizes the individual samples (sample date, tank ID, sample core, and segment) from the archive that met the selection criteria. These samples had been in storage at 222-S for 12 to 15 years. The long storage time could potentially cause the sample characteristics to be altered relative to the asretrieved sample condition through aging and drying. But, as stated previously, obtaining fresh core samples from the Hanford waste tanks was outside the scope of the project budget and schedule. Also shown in Table 2.2 are the anticipated bismuth concentrations (wet sample basis) and the mass assumed available based on the archive inventory in $~ 2002$. A total of $2.28 \mathrm{~kg}$ of bismuth phosphate sludge was assumed to be available and sufficient for the complete testing scope.

The Group 1 sample set was heavily represented by one tank, B-104. The potential impact of the Group 1 composite representation primarily by B-104 was evaluated. As seen in Figure 2.1, gross deviations in the elemental compositions within this suite of tank wastes were relatively minor, so it was concluded that B-104 would be reasonably representative of the group. 
WTP-RPT-166, Rev. 0

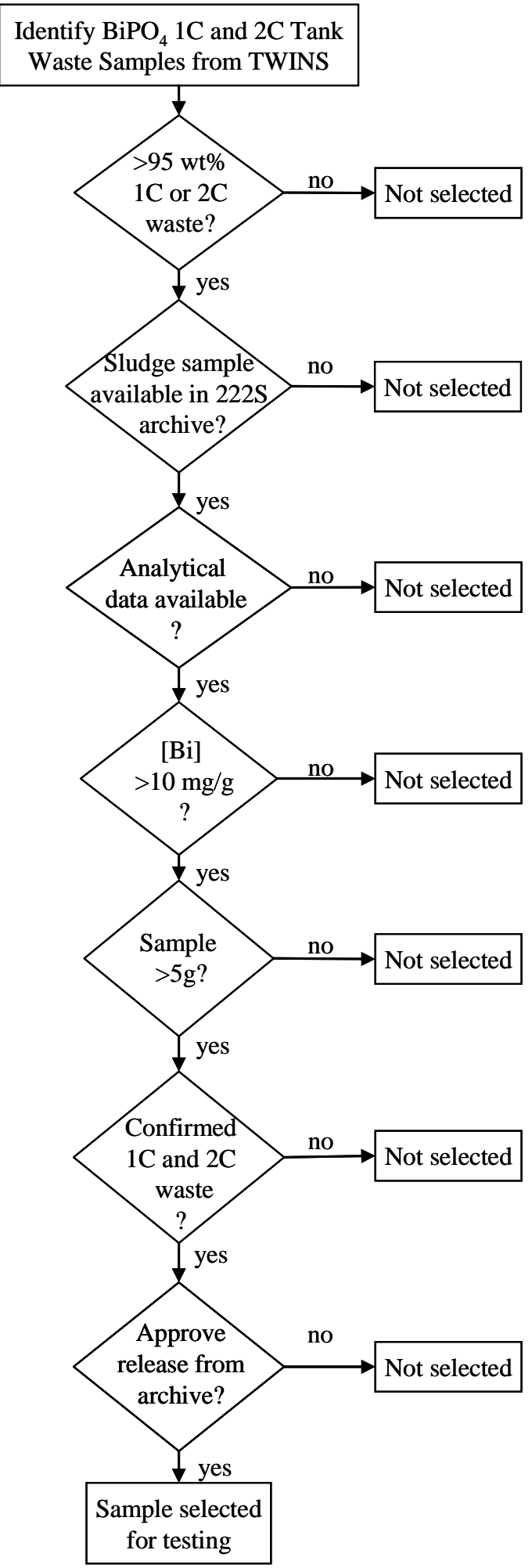

Figure 2.2. Selection Decision Process 1C and 2C Sludge Samples 
Table 2.1. Selection of Bismuth Phosphate Sludge Tanks

\begin{tabular}{|c|c|c|c|c|c|c|}
\hline \multirow[b]{2}{*}{$\begin{array}{c}\text { Tank } \\
\text { 241-B-104 }\end{array}$} & \multirow[b]{2}{*}{$\begin{array}{l}1 \mathrm{1C} \text { or } 2 \mathrm{C} \\
\text { Sludge, } \mathrm{kL} \\
\quad 1170\end{array}$} & \multirow[b]{2}{*}{$\begin{array}{l}\text { Total } \\
\text { Sludge, } \mathbf{k L} \\
1170\end{array}$} & \multirow[b]{2}{*}{$\begin{array}{l}\text { Fraction } \\
1 \mathrm{C} \text { or } 2 \mathrm{C} \\
\text { Sludge } \\
\quad 1\end{array}$} & \multicolumn{3}{|c|}{ 222S Archive } \\
\hline & & & & $\begin{array}{c}\text { Available } \\
\text { Samples }\end{array}$ & $\begin{array}{l}\text { Identified as } \\
\text { Sludge }\end{array}$ & $\begin{array}{c}\text { Analytical } \\
\text { Results }\end{array}$ \\
\hline 241-B-105 & 106 & 106 & 1 & no & & \\
\hline 241-B-110 & 914 & 925 & 0.99 & no & & \\
\hline 241-B-112 & 56 & 56 & 1 & no & & \\
\hline 241-BX-107 & 1313 & 1313 & 1 & no & & \\
\hline 241-BX-111 & 121 & 121 & 1 & no & & \\
\hline 241-BX-112 & 617 & 617 & 1 & & & \\
\hline 241-C-108 & 27.3 & 27.3 & 1 & & & $\mathrm{no}^{(\mathrm{b})}$ \\
\hline 241-C-110 & 670 & 670 & 1 & no & & \\
\hline 241-T-104 & 1199 & 1199 & 1 & & & \\
\hline 241-T-108 & 20 & 20 & 1 & no & & \\
\hline 241-T-110 & 1360 & 1397 & 0.97 & & & $\mathrm{no}^{(\mathrm{b})}$ \\
\hline 241-TX-109 & 1375 & 1375 & 1 & no & & \\
\hline 241-TX-110 & 140 & 140 & 1 & no & & \\
\hline 241-TX-111 & 163 & 163 & 1 & no & & \\
\hline 241-TX-113 & 351 & 351 & 1 & & $\mathrm{no}^{(\mathrm{a})}$ & \\
\hline 241-TX-114 & 15 & 15 & 1 & no & & \\
\hline \multicolumn{7}{|c|}{$\begin{array}{l}\text { (a) The available TX-113 samples in the 222S inventory were identified as saltcake in the TWINS } \\
\text { database. } \\
\text { (b) Bismuth analytical data were not available from TWINS. }\end{array}$} \\
\hline
\end{tabular}

\subsection{Group 2-Bismuth Phosphate Saltcake Sample Selection}

In the Best-Basis Inventory (BBI), saltcake is generally divided into six main groupings as a function of waste source: A, B, BY,R, S, and T (in general, these designations refer to the tank farm at the Hanford Site from which these saltcake wastes originate). Saltcake tank wastes high in phosphate and chromium concentrations were targeted for testing. The TWINS database was queried to identify the tanks containing $100 \% \mathrm{BY}$ and T saltcake waste types, which were derived from evaporation of neutralized solutions from the bismuth phosphate process and were expected to have high phosphate and chromium content based on a previous evalutation (Fiskum et al. 2008). These tank wastes were queried in the BBI for major inorganic components (phosphate, $\mathrm{Bi}, \mathrm{Al}, \mathrm{Fe}, \mathrm{Cr}, \mathrm{Si}$, and $\mathrm{U}$ ) in the saltcake phase. Figure 2.3 shows the relative mass distributions of these analytes. (Note that major elemental and anionic contributions from $\mathrm{Na}$, nitrate, nitrite, and oxalate are excluded from the data in Figure 2.3.) The disparate fractionation of all components is evident.

The decision process flowchart for selecting tank waste samples is summarized in Figure 2.4. The 222S archive sample inventory was searched for samples from the identified tanks; those defined as a saltcake matrix were retained for consideration. These samples were then cross-referenced to the TWINS database to determine if analytical data from the specific samples were available; samples containing $>20 \mathrm{mg} \mathrm{PO}_{4}{ }^{3-} / \mathrm{g}$ saltcake were carried forward. Of these samples, those with $>20 \mathrm{~g}$ material as identified in the $222 \mathrm{~S}$ archive inventory were selected. The final list of samples was submitted to CH2MHill 
personnel for a two-step evaluation process: 1) the samples were confirmed to represent the BY or T saltcake waste based on strata from tank and corresponding characterization results, and 2) the samples were not held for other activities and could be released from the archive.

Table 2.2. Group 1 Targeted Samples and Masses from 222S Archive

\begin{tabular}{|c|c|c|c|c|c|c|}
\hline $\begin{array}{c}\text { Tank Sampling } \\
\text { Date }^{(a)}\end{array}$ & Jar \# & Tank & Core & Segment & $\begin{array}{l}\text { Estimated } \\
\mathrm{Bi}, \mathrm{mg} / \mathrm{g}^{(\mathbf{b})}\end{array}$ & $\begin{array}{l}\text { Net Sample } \\
\text { Weight (g) }{ }^{(\mathrm{c})}\end{array}$ \\
\hline $8 / 20 / 1992$ & 13518 & T-104 & 45 & Comp & 18 & 62.41 \\
\hline \multirow{14}{*}{ 6/1/1995 } & 7197 & B-104 & 88 & 1 & 13 & 54.8 \\
\hline & 7190 & B-104 & 88 & 2 & 16 & 62.1 \\
\hline & 8427 & B-104 & 88 & 2 & 16 & 46.15 \\
\hline & 8428 & B-104 & 88 & 2 & 16 & 49.48 \\
\hline & 7200 & B-104 & 88 & 3 & 14 & 62.4 \\
\hline & 8421 & B-104 & 88 & 3 & 14 & 64.04 \\
\hline & 8423 & B-104 & 88 & 4 & 12 & 60.89 \\
\hline & 7206 & B-104 & 88 & 4 & 12 & 57.19 \\
\hline & 7205 & B-104 & 88 & 4 & 12 & 58.67 \\
\hline & 7207 & B-104 & 88 & 5 & 12 & 56.98 \\
\hline & 7208 & B-104 & 88 & 5 & 12 & 57.4 \\
\hline & 8425 & B-104 & 88 & 5 & 12 & 60.16 \\
\hline & 10113 & B-104 & 88 & 5 & 12 & 101.66 \\
\hline & 7373 & B-104 & 88 & Comp & 10 & 78 \\
\hline \multirow{14}{*}{ 6/9/1995 } & 11843 & B-104 & 89 & 1 & 11 & 172.1 \\
\hline & 7228 & B-104 & 89 & 5 & 12 & 59.99 \\
\hline & 7227 & B-104 & 89 & 5 & 12 & 60.92 \\
\hline & 13164 & B-104 & 89 & 5 & 12 & 77.52 \\
\hline & 17523 & B-104 & 89 & 5 & 12 & 94 \\
\hline & 7231 & B-104 & 89 & 6 & 11 & 58.48 \\
\hline & 7229 & B-104 & 89 & 6 & 11 & 59.77 \\
\hline & 8419 & B-104 & 89 & 6 & 11 & 60.13 \\
\hline & 8418 & B-104 & 89 & 6 & 11 & 62.11 \\
\hline & 7232 & B-104 & 89 & 7 & 11 & 60.44 \\
\hline & 7233 & B-104 & 89 & 7 & 11 & 60.68 \\
\hline & 9018 & B-104 & 89 & 7 & 11 & 79.46 \\
\hline & 9028 & B-104 & 89 & 7 & 11 & 81.34 \\
\hline & 13442 & B-104 & 89 & Comp & 11 & 81.82 \\
\hline \multirow{3}{*}{ 11/30/1995 } & 9151 & BX-112 & 118 & 1 & 17 & 60.28 \\
\hline & 9152 & BX-112 & 118 & 1 & 17 & 66.52 \\
\hline & & & & & Sum & 2128 \\
\hline \multicolumn{7}{|c|}{$\begin{array}{l}\text { (a) Sample date is defined in TWINS database. } \\
\text { (b) Wet mass basis, as defined in TWINS database. } \\
\text { The anticipated mass was determined based on the sample mass inventory in database } \\
\text { "Vials May } 18 \text { " provided by P Brackenbury. }\end{array}$} \\
\hline
\end{tabular}




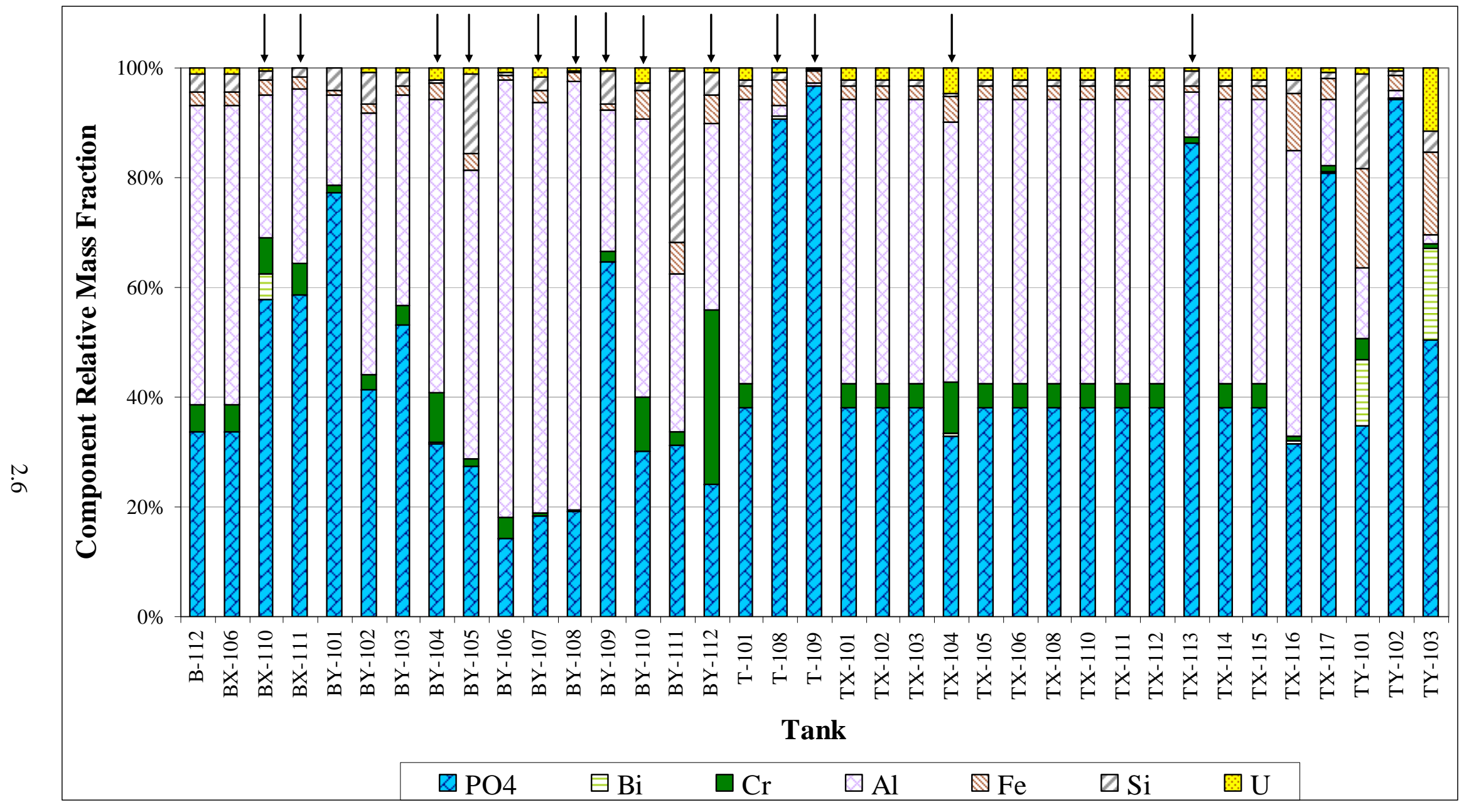

Figure 2.3. Estimated Tank Waste Composition of Selected Analytes for Bismuth Phosphate (BY and T) Saltcake Wastes in the Hanford Tank Farm (BBI Source). Note: arrows point to tank wastes actually used to prepare the Group 2 composite. 
WTP-RPT-166, Rev. 0

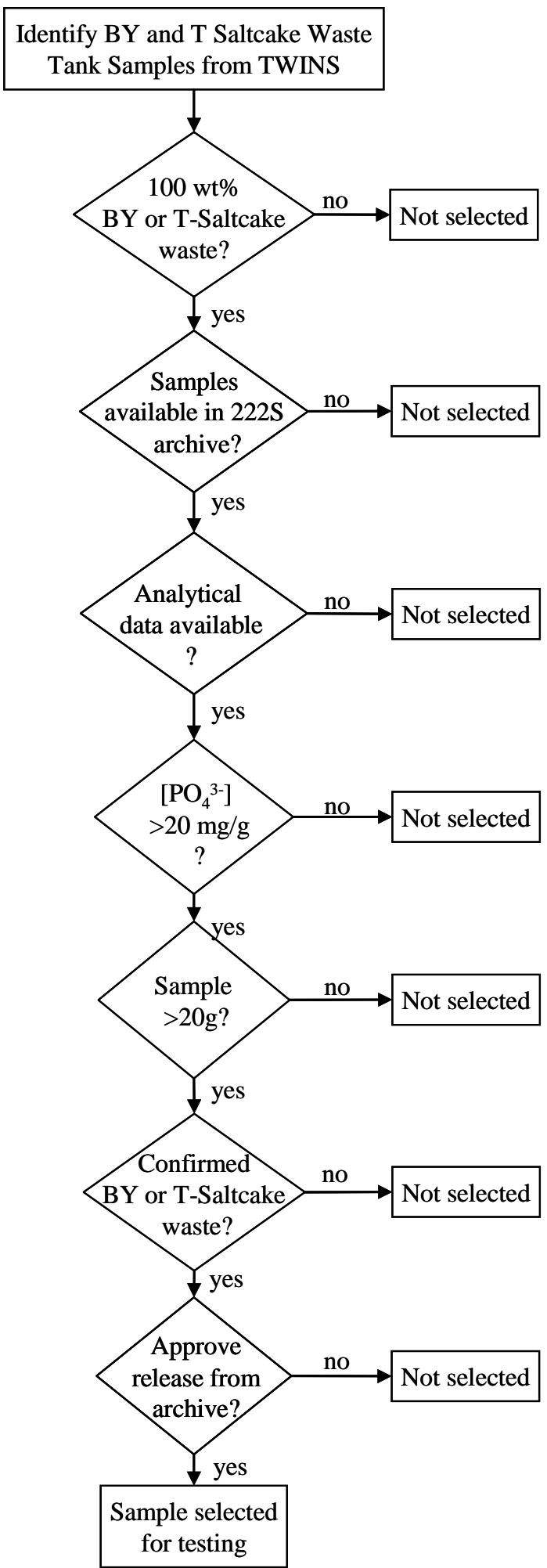

Figure 2.4. Selection Decision Process for the Bismuth Phosphate Saltcake Samples 
WTP-RPT-166, Rev. 0

Table 2.3 summarizes the evaluated BY and T saltcake tank sources and shows whether the tank met or failed the selection criteria. Samples highlighted in bold in the table were those determined to meet all of the selection criteria.

Table 2.4 summarizes the specific samples selected from the 222S archive that met the selection criteria. These samples had been in storage at 222-S for $\sim 8$ to 12 years. Again, the aging and probable desiccation processes could result in changes to the waste mineralogical forms, but these were deemed to be the best samples available given the project budget and schedule.

The BBI-predicted BY and T saltcake compositions varied widely (refer to Figure 2.3). The source tanks used to generate the Group 2 composite, shown with arrows in Figure 2.3, were chosen to provide a reasonable approximation of the overall waste type, based on the constrained set of archive samples that were available.

\subsection{Group 1 Sample Homogenization and Sub-Sampling}

The homogenization vessel and mixing system used to homogenize the Group 1 bismuth phosphate sludge sample was designed and fabricated for use at the Pacific Northwest National Laboratory (PNNL) in the High-Level Radiochemistry Facility (HLRF). This stainless steel equipment was specifically designed to composite tank wastes and divide them into homogeneous sub-samples. The homogenization vessel was designed to hold and effectively mix a variable volume of 1 to $5 \mathrm{~L}$ of waste. A set of removable baffles was designed and added to enhance mixing. Industry experience shows that the best mixing is achieved when a tank height to diameter ratio is 1:1. For a fixed volume batch tank, this is easy to achieve. For a variable volume tank, this presents a challenge usually solved by making the tank conical. Height restrictions and volume requirements made it unfeasible to make the entire homogenization vessel conical, so to optimize mixing, a compromise tank design was devised. The bottom of the tank with a volume capacity of $\sim 1.5$ to $2.0 \mathrm{~L}$ was conical. At low volumes, the mixing assistance from the baffles was less than at larger volumes. Therefore, the need to rigorously maintain the 1:1 ratio was achieved in this section of the tank. When the volumes are above $2 \mathrm{~L}$, the baffles combined with a down-sweeping mixer blade were shown to be sufficient to maintain a good mixing profile in the non-conical portion of the tank. The bottom of the conical section slopes toward the side to facilitate good subdivision of the samples.

Figure 2.5 shows photographs of the homogenization vessel along with a schematic representation of its design. The Group 1 sample material was loaded into the vessel through a Tyler sieve mounted to the top of the vessel (see right side of Figure 2.5). This was done so that no chunks of material greater than 3.2 $\mathrm{mm}$ in diameter were included in the composite, which was necessary for forming a uniform composite and protecting the crossflow ultra filtration (CUF) equipment during later testing. This vessel was used to composite several groups of tank samples. Extensive cleaning was done between each group with water, $0.01 \mathrm{M} \mathrm{NaOH}$, and $0.01 \mathrm{M} \mathrm{HNO}_{3}$.

Before the actual tank waste samples were homogenized, non-radioactive testing of this system with various simulants was performed to establish the best operating conditions and procedures and to verify the uniformity of the sub-samples obtained with this tank. Simulants with high yield stress values (Figure 2.6) and simulants with the capability to settle rapidly (Figure 2.7) were tested to verify that good mixing could be maintained and uniform sub-samples removed. Operating conditions and guidelines that 
resulted in a composite with homogeneous sub-samples of the most challenging simulants were then incorporated into the test instructions for the actual waste testing.

Table 2.3. Selection of Group 2 Bismuth Phosphate Saltcake Tanks

\begin{tabular}{|c|c|c|c|c|c|c|}
\hline \multirow[b]{2}{*}{ Tank ID } & \multirow[b]{2}{*}{$\begin{array}{c}\text { BY Saltcake, } \\
\text { kL }\end{array}$} & \multirow[b]{2}{*}{$\begin{array}{c}\text { Total, } \\
\text { kL }\end{array}$} & \multirow[b]{2}{*}{$\begin{array}{c}\text { Fraction of } \\
\text { BY }\end{array}$} & \multicolumn{3}{|c|}{ 222S Archive } \\
\hline & & & & $\begin{array}{l}\text { Available } \\
\text { Samples }\end{array}$ & $\begin{array}{l}\text { Samples >20 } \\
\mathrm{mg} \mathrm{PO}_{4}{ }^{3-} / \mathrm{g} \\
\end{array}$ & $\begin{array}{l}\text { Samples } \\
>20 \text { g? }\end{array}$ \\
\hline B-112 & 49 & 49 & 1.0 & no & & \\
\hline BX-106 & 80 & 80 & 1.0 & no & & \\
\hline BX-110 & 433 & 433 & 1.0 & & & \\
\hline BX-111 & 538 & 538 & 1.0 & & & \\
\hline BY-101 & 1208 & 1208 & 1.0 & & & no \\
\hline BY-102 & 897 & 897 & 1.0 & & & \\
\hline BY-103 & 1316 & 1316 & 1.0 & no & & \\
\hline BY-104 & 1208 & 1208 & 1.0 & & & \\
\hline BY-105 & 1481 & 1481 & 1.0 & & & \\
\hline BY-106 & 1365 & 1365 & 1.0 & & no & \\
\hline BY-107 & 835 & 835 & 1.0 & & & \\
\hline BY-108 & 587 & 587 & 1.0 & & & \\
\hline BY-109 & 851 & 851 & 1.0 & & & \\
\hline BY-110 & 1123 & 1123 & 1.0 & & & \\
\hline BY-111 & 1378 & 1378 & 1.0 & & no & \\
\hline BY-112 & 996 & 996 & 1.0 & & & \\
\hline \multirow[b]{2}{*}{ Tank ID } & \multirow[b]{2}{*}{ T Saltcake, $\mathbf{k L}$} & \multirow[b]{2}{*}{ Total, kL } & \multirow[b]{2}{*}{$\begin{array}{c}\text { Fraction of } \\
T\end{array}$} & \multicolumn{3}{|c|}{ 222S Archive } \\
\hline & & & & $\begin{array}{l}\text { Available } \\
\text { Samples }\end{array}$ & $\begin{array}{l}\text { Samples >20 } \\
\mathrm{mg} \mathrm{PO}_{4}{ }^{3-} / \mathrm{g}\end{array}$ & $\begin{array}{l}\text { Samples } \\
>20 \mathrm{~g} \text { ? }\end{array}$ \\
\hline $\mathrm{T}-101$ & 179 & 179 & 1.0 & no & & \\
\hline T-108 & 30 & 30 & 1.0 & & & \\
\hline T-109 & 197 & 197 & 1.0 & & & \\
\hline TX-101 & 49 & 49 & 1.0 & no & & \\
\hline TX-102 & 692 & 692 & 1.0 & no & & \\
\hline TX-103 & 454 & 454 & 1.0 & no & & \\
\hline TX-104 & 93 & 93 & 1.0 & & & \\
\hline TX-105 & 2044 & 2044 & 1.0 & no & & \\
\hline TX-106 & 1147 & 1147 & 1.0 & no & & \\
\hline TX-108 & 415 & 415 & 1.0 & no & & \\
\hline TX-110 & 1580 & 1580 & 1.0 & no & & \\
\hline TX-111 & 1194 & 1194 & 1.0 & no & & \\
\hline TX-112 & 2290 & 2290 & 1.0 & no & & \\
\hline TX-113 & 2045 & 2045 & 1.0 & & & \\
\hline TX-114 & 1923 & 1923 & 1.0 & no & & \\
\hline TX-115 & 1960 & 1960 & 1.0 & no & & \\
\hline TX-116 & 1903 & 1903 & 1.0 & no & & \\
\hline TX-117 & 1659 & 1659 & 1.0 & no & & \\
\hline TY-101 & 159 & 159 & 1.0 & no & & \\
\hline TY-102 & 199 & 199 & 1.0 & no & & \\
\hline TY-103 & 150 & 150 & 1.0 & no & & \\
\hline
\end{tabular}


Table 2.4. Group 2 Targeted Samples and Masses from 222S Archive

\begin{tabular}{|c|c|c|c|c|c|c|}
\hline $\begin{array}{c}\text { Tank Sample } \\
\text { Date }^{(\mathrm{a})}\end{array}$ & Jar \# & Tank & Core & Segment & $\begin{array}{c}\text { Estimated } \\
\mathrm{PO}_{4}{ }^{3-}, \mathrm{mg} / \mathbf{g}^{(\mathbf{b})} \\
\end{array}$ & $\begin{array}{l}\text { Net Sample } \\
\text { Weight (g) } \\
\end{array}$ \\
\hline \multirow{7}{*}{ 5/19/1997 } & 19298 & BX-110 & 197 & 1 & 45 & 54.5 \\
\hline & 12694 & BX-110 & 197 & 1 & 45 & 87.77 \\
\hline & 12744 & BX-110 & 197 & 2 & 38 & 55.12 \\
\hline & 13021 & BX-111 & 200 & 1 & 51 & 67.5 \\
\hline & 12647 & BX-111 & 200 & 2 & 42 & 78.5 \\
\hline & 13022 & BX-111 & 200 & $2 \mathrm{~A}$ & 27 & 92.77 \\
\hline & 13031 & BX-111 & 202 & 1 & 45 & 59.1 \\
\hline \multirow{3}{*}{ 10/31/1995 } & 8410 & BY-104 & 116 & 2 & 25 & 20.2 \\
\hline & 8757 & BY-104 & 116 & 3 & 35 & 29 \\
\hline & 8758 & BY-104 & 116 & 3 & 35 & 69.9 \\
\hline 8/30/1995 & 8643 & BY-105 & 108 & 2AR & 27 & 79.87 \\
\hline \multirow{3}{*}{ 6/12/1996 } & 18632 & BY-107 & 151 & 4 & 25 & 38.7 \\
\hline & 10544 & BY-107 & 151 & 4 & 25 & 51.5 \\
\hline & 10545 & BY-107 & 151 & 4 & 25 & 109.3 \\
\hline $7 / 25 / 1996$ & 10848 & BY-107 & 161 & 1 & 30 & 30.9 \\
\hline \multirow{11}{*}{ 8/16/1995 } & 15622 & BY-108 & 104 & 1 & 75 & 48.8 \\
\hline & 16950 & BY-108 & 104 & 2 & 32 & 27.2 \\
\hline & 15570 & BY-108 & 104 & 2 & 32 & 29.5 \\
\hline & 7686 & BY-108 & 104 & 2 & 32 & 49.57 \\
\hline & 7679 & BY-108 & 104 & 2 & 32 & 60.22 \\
\hline & 7689 & BY-108 & 104 & 3 & 67 & 24.5 \\
\hline & 7687 & BY-108 & 104 & 3 & 67 & 58.79 \\
\hline & 13525 & BY-108 & 104 & 4 & 32 & 27.78 \\
\hline & 7690 & BY-108 & 104 & 4 & 32 & 33 \\
\hline & 7691 & BY-108 & 104 & 4 & 32 & 67.3 \\
\hline & 7692 & BY-108 & 104 & 4 & 32 & 67.3 \\
\hline \multirow{3}{*}{ 6/6/1997 } & 13040 & BY-109 & 203 & 3 & 36 & 69.9 \\
\hline & 13039 & BY-109 & 203 & 3 & 36 & 72.3 \\
\hline & 19086 & BY-109 & 203 & 3 & 36 & 95.9 \\
\hline 9/25/1995 & 8375 & BY-110 & 96 & 1 & 65 & 49.89 \\
\hline $8 / 15 / 1995$ & 13472 & BY-110 & 103 & 1 & 57 & 33.5 \\
\hline $8 / 22 / 1995$ & 7655 & BY-110 & 106 & 1 & 25 & 39.5 \\
\hline 9/13/1995 & 7972 & BY-110 & 109 & 1 & 30 & 41.47 \\
\hline $10 / 2 / 1996$ & 11799 & BY-112 & 174 & 1 & 38 & 29.3 \\
\hline $10 / 3 / 1996$ & 11793 & BY-112 & 177 & 1 & 106 & 20.3 \\
\hline 7/19/1995 & 7428 & $\mathrm{~T}-108$ & Riser 5 & Auger-35 & 25 & 27.32 \\
\hline $8 / 21 / 1995$ & 7467 & T-109 & Riser 2 & Auger-41 & 270 & 34.7 \\
\hline $2 / 18 / 1998$ & 13856 & TX-104 & 230 & 1 & 35 & 100.9 \\
\hline $2 / 18 / 1998$ & 14021 & TX-104 & 231 & $2 \mathrm{~A}$ & 25 & 26.75 \\
\hline $10 / 22 / 1998$ & 19272 & TX-113 & 253 & 5 & 40 & 23.3 \\
\hline $4 / 15 / 1999$ & 18801 & TX-113 & 258 & 5 & 29 & 143.5 \\
\hline \multicolumn{6}{|c|}{ Sum } & 2227 \\
\hline \multicolumn{7}{|c|}{$\begin{array}{l}\text { (a) Sample date is defined in TWINS database. } \\
\text { (b) Wet mass basis, as defined in TWINS database. } \\
\text { (c) The anticipated mass was determined based on the sample mass inventory in database "Vials } \\
\text { May 18” provided by P Brackenbury. }\end{array}$} \\
\hline
\end{tabular}


Clay simulants were prepared with high Bingham yield stresses and cohesive properties that would make them sticky. These consisted primarily of kaolin and bentonite clay mixtures. These simulants mixed well and delivered uniform samples while the homogenization vessel was tested (Figure 2.6, left and center). However, they did leave a thick film of material coating the tank, mixer, and baffle surfaces (Figure 2.6, right). In compositing the actual tank waste samples, solids materials with these characteristics would need to be recovered for CUF testing with extra rinses of de-ionized (DI) water after completing homogenization and sub-sampling of the bulk material.
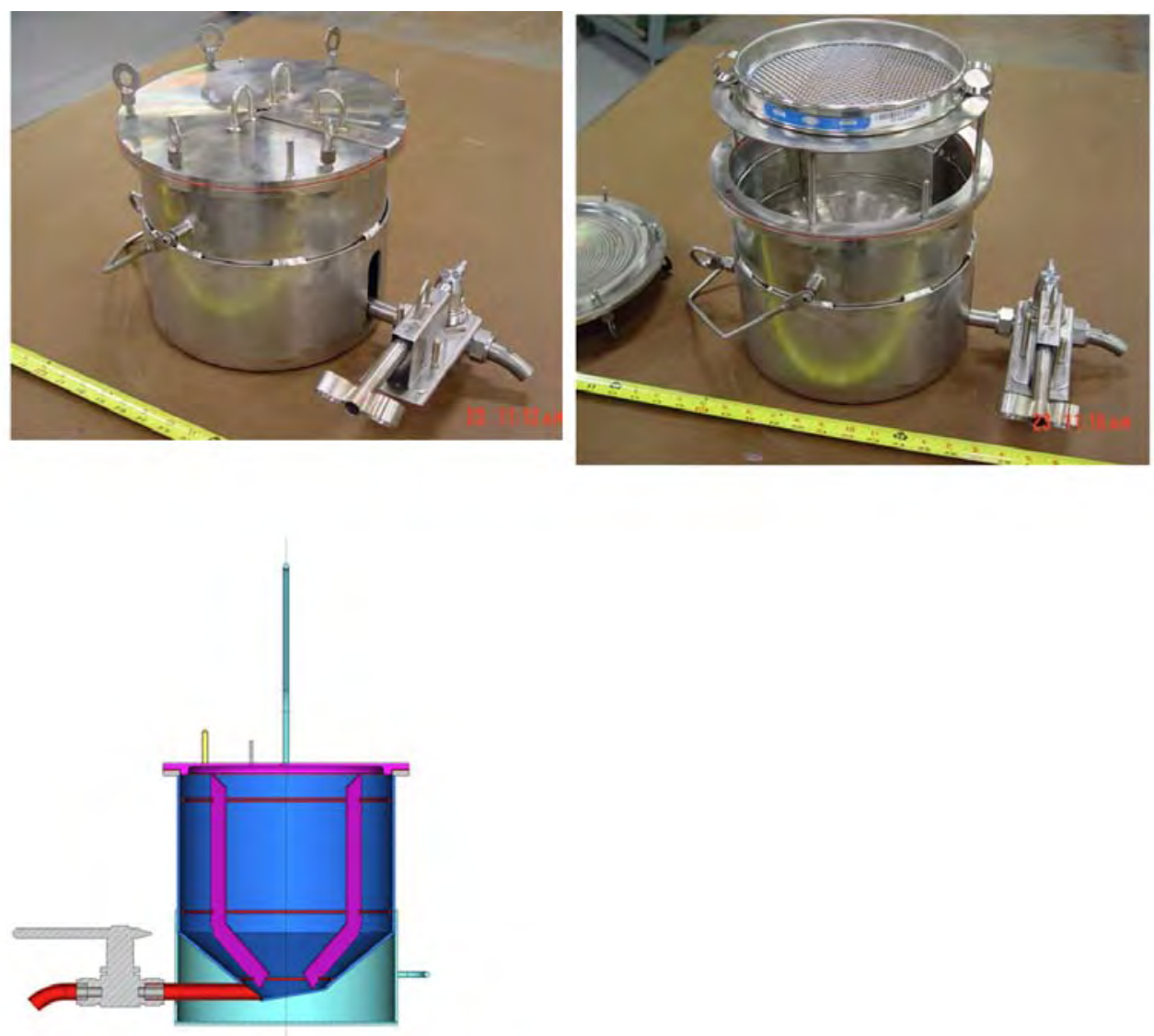

Figure 2.5. Homogenization Vessel Used to Prepare and Sub-Sample the Group 1 Composite Slurry
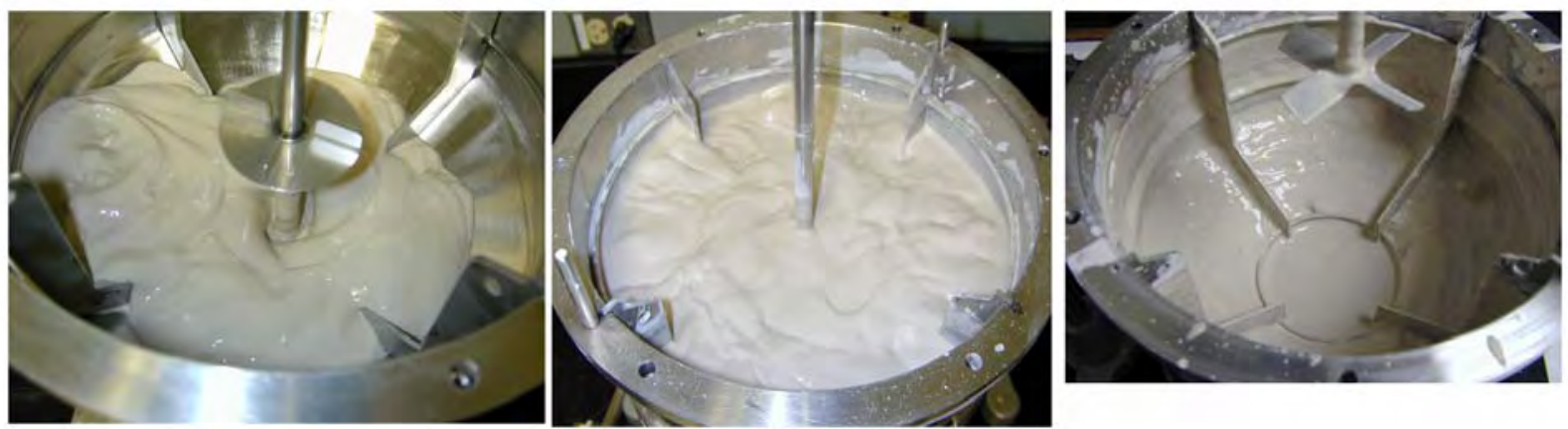

Figure 2.6. Photographs of a High Yield Stress Clay Simulant in the Homogenization Vessel Used for Group 1 
Min- $u$-sil ${ }^{\circledR}$-based simulants were used to test variable mixing speeds and propeller placement because of their tendency to settle swiftly when mixing is not sufficient. Figure 2.7 shows that these simulant types could usually be cleanly and completely recovered from the tanks. However, the sub-samples were often non-uniform with the Min-u-sil ${ }^{\circledR}$ simulants. Figure 2.8 shows an example of non-uniform settling results for sub-samples taken when the mixer speed was too low. Based on these results, a hold point was inserted into the compositing test instructions such that after 3 days of settling, the settled solids of all the composite samples would be compared and statistically analyzed to verify that good homogenization of the composite had been achieved and maintained during the sub-sampling process.

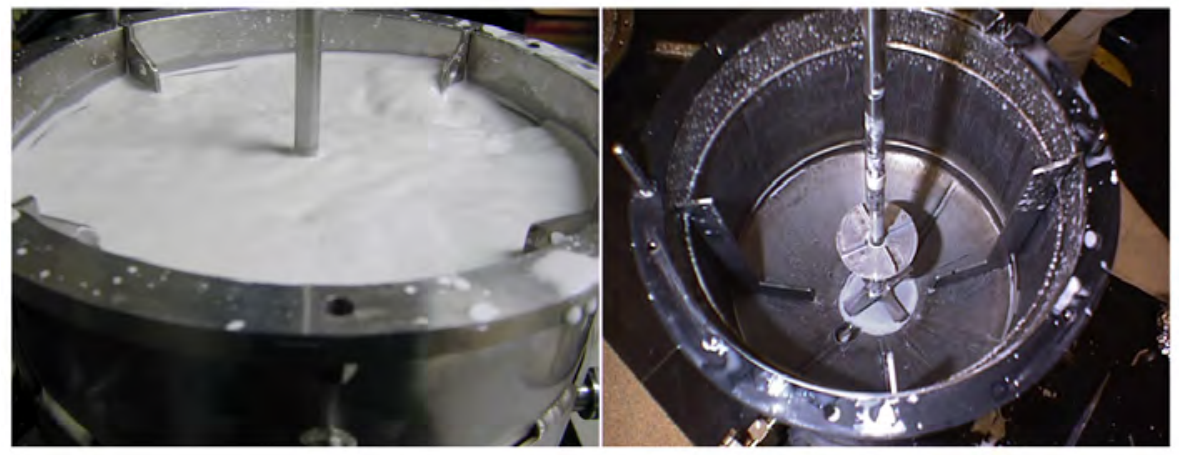

Figure 2.7. Photographs of the Mixing of a Min-u-sil ${ }^{\circledR}$ Simulant that Settles Rapidly in the Homogenization Vessel Used for Group 1 (left) and the Vessel After Draining of the Material (right)
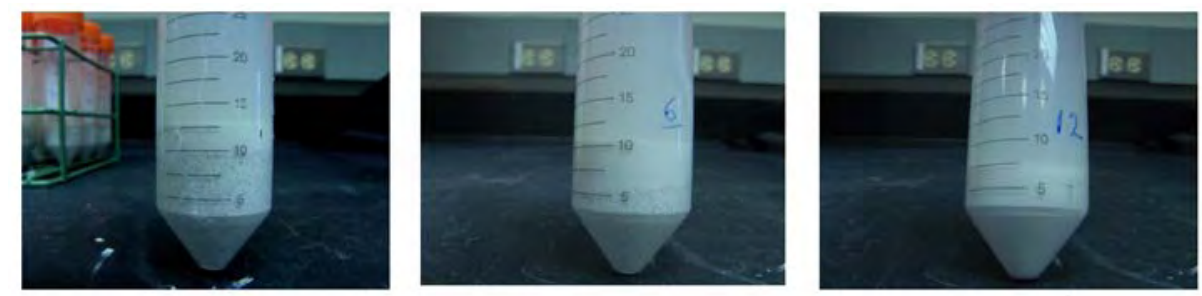

Figure 2.8. Photographs of Three Different Sub-Samples Taken from the Homogenization Vessel During Non-Radioactive Testing with a Min-u-sil ${ }^{\circledR}$ Simulant. Note the different degrees of settling, which indicates in-homogeneity in the slurry.

The 31 Group 1 bismuth phosphate sludge samples were shipped from the Hanford 222-S laboratory to PNNL. Masses for these archived samples were provided by Advanced Technologies and Laboratories International (ATL) in the shipping letter report. Many of the samples had dried out during the time spent in archived storage. Photographs, as received weights, and detailed sample descriptions were all recorded in TI-RPP-WTP-508. There were crystallized deposits on the outsides of many of the jars. Efforts were made to get this material into the composite, provided it was immediately around the threads of the jar. However, if the crystals were further down on the jar and were potentially contaminated with unknown materials, they were left intact, and the loss accounted for in the mass balance done after sample transfer from the jar was completed. The samples' appearance and color ranged from white dry crystals, to grey pastes, to brownish yellow sludge. The supernate liquid was yellow on the samples that still had standing liquid. Figure 2.9 shows some representative photographs of the as-received samples. 
The Group 1 sample material fell into the following general categories:

a. Dry powdery sample-added directly to the homogenizer though the screen.

b. Dry solid sample-added water to soak sample so it could be broken up and removed from the jar for addition to the homogenizer.

c. Semi-solid—sample was added to homogenizer without soaking sample with water first.

d. Clearly visible supernate liquid in jar.
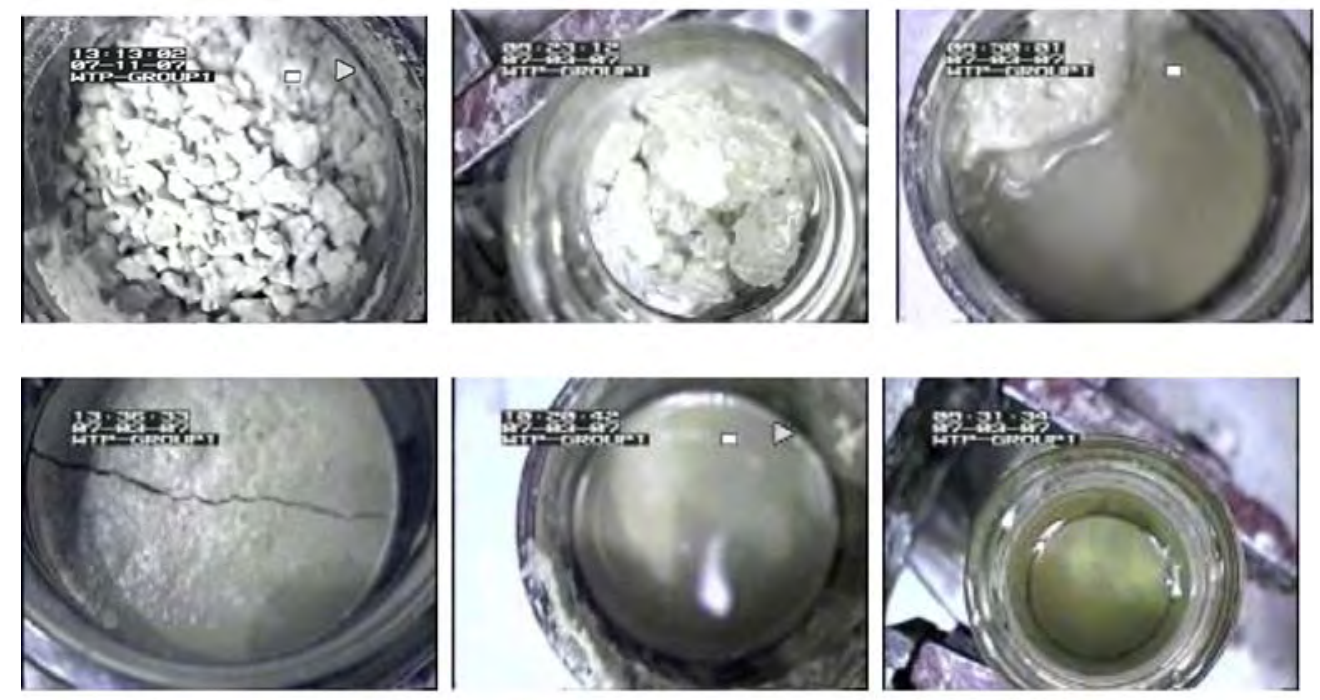

Figure 2.9. Representative Photographs of As-Received Group 1 Waste Samples

Table 2.5 lists the individual samples added to the composite sample, along with gross mass (expected and found), the mass of the empty container, and the net mass of waste transferred to the homogenizer. Samples that appeared to be fine solids were added first and easily passed through the sieve. If foreign material such as pieces of broken caps were present, those were picked out with stainless steel tweezers and weighed when possible (there were very few instances of this for these samples). In some cases, the thin Teflon ${ }^{\circledR}$ liner pieces often disintegrated in the tweezers, so no weights could be obtained for these. For wet samples, the solids were removed from the sample jar by a process of scraping and rinsing with DI water using a squirt bottle. In this fashion, nearly all residues were removed from the sample jars. These samples were originally placed in secondary containment and removed from their smaller jars into larger jars to minimize evaporative losses that sitting in the larger tank might have allowed over the several days required to empty the smaller jars. Three of the larger transfer jars were used for Group 1; the contents of all of these were transferred into the homogenizer on the morning the final mixing was done.

Solids and semi-solids were forced through the sieve using DI water, rubber spatulas, and a stainless steel mashing tool that also was used in breaking up some chunks of solid materials so they could pass though the sieve. To the maximum extent possible, all sample materials were placed into the homogenizer; there was very little loss of actual sample due to splattering or spillage. Water was used conservatively during the entire process of removing the samples from the jars so as to have enough water to remove all sample residues and come close to the desired total solution added to reach the desired $\mathrm{Na}$ concentration. 
Table 2.5. Bi Phosphate Sludge Samples (Group 1)

\begin{tabular}{|c|c|c|c|c|c|c|}
\hline $\begin{array}{l}\text { Hanford } \\
\text { Tank ID }\end{array}$ & 222-S ID & $\begin{array}{c}\text { 222S } \\
\text { Expected } \\
\text { Gross } \\
\text { Mass (g) }\end{array}$ & $\begin{array}{l}\text { PNNL } \\
\text { As-found } \\
\text { Gross } \\
\text { Mass (g) }\end{array}$ & $\begin{array}{c}\text { PNNL } \\
\text { Jar and } \\
\text { Lid Condition }\end{array}$ & $\begin{array}{c}\text { PNNL } \\
\text { Empty } \\
\text { Container } \\
\text { Mass (g) }\end{array}$ & $\begin{array}{c}\text { PNNL } \\
\text { Mass } \\
\text { Transferred } \\
\text { (g) }\end{array}$ \\
\hline B-104 & 7190 & 86.8 & 86.83 & Good & 27.69 & 59.14 \\
\hline B-104 & 7197 & 80 & 75.76 & Good & 30.26 & 45.50 \\
\hline B-104 & 7200 & 87.6 & 87.95 & Good & 29.34 & 58.61 \\
\hline B-104 & 7205 & 83.5 & 84.00 & Good & 27.61 & 56.39 \\
\hline B-104 & 7206 & 82.4 & 83.89 & Good & 27.82 & 56.07 \\
\hline B-104 & 7207 & 82.3 & 82.46 & Good & 28.07 & 54.39 \\
\hline B-104 & 7208 & 82.8 & 83.15 & Good & 29.91 & 53.24 \\
\hline B-104 & 7227 & 86.3 & 83.95 & Good & 27.27 & 56.68 \\
\hline B-104 & 7228 & 85.4 & 82.16 & Good & 27.59 & 54.57 \\
\hline B-104 & 7229 & 85.1 & 85.65 & Good & 28.02 & 57.63 \\
\hline B-104 & 7231 & 83.7 & 82.65 & Good & 27.68 & 54.97 \\
\hline B-104 & 7232 & 85.7 & 83.84 & Good & 28.89 & 54.95 \\
\hline B-104 & 7233 & 86.2 & 86.40 & Good & 28.53 & 57.87 \\
\hline B-104 & 7373 & 202.2 & 199.32 & Good & 128.3 & 71.02 \\
\hline B-104 & 8418 & 87.8 & 86.32 & Good & 28.92 & 57.40 \\
\hline B-104 & 8419 & 85.8 & 86.33 & Good & 28.73 & 57.60 \\
\hline B-104 & 8421 & 89.7 & 87.93 & Good & 27.96 & 59.97 \\
\hline B-104 & 8423 & 86.7 & 87.25 & Good & 29.32 & 57.93 \\
\hline B-104 & 8425 & 85.8 & 86.42 & Good & 29.53 & 56.89 \\
\hline B-104 & 8427 & 71.6 & 71.53 & Good & 28.49 & 43.04 \\
\hline B-104 & 8428 & 75.4 & 70.86 & Good & 28.84 & 42.02 \\
\hline B-104 & 9018 & 165.3 & 166.01 & Good & 95.12 & 70.89 \\
\hline B-104 & 9028 & 167.2 & 168.1 & Good & 95.49 & 72.61 \\
\hline BX-112 & 9151 & 151.8 & 151.96 & Good & 98.22 & 53.74 \\
\hline BX-112 & 9152 & 157.7 & 119.74 & Good & 93.35 & 26.39 \\
\hline B-104 & 10113 & 189.6 & 190.58 & Good & 95.59 & 94.99 \\
\hline B-104 & 11843 & 292.4 & 225.18 & Lid Loose Sample loss & 93.55 & 131.63 \\
\hline B-104 & 13164 & 163.4 & 166.13 & Good & 94.11 & 72.02 \\
\hline B-104 & 13442 & 166.5 & 163.11 & Good & 92.54 & 70.57 \\
\hline $\mathrm{T}-104$ & 13518 & 151.0 & 146.94 & Good & 95.20 & 51.74 \\
\hline B-104 & 17523 & 176.4 & 169.86 & Good & 90.41 & 79.45 \\
\hline
\end{tabular}

After all of the recoverable sample materials were transferred to the homogenizer tank, the sample jars were allowed to dry, and they were then reweighed. These values were used to calculate sample recovery and actual amount of sample added to the homogenizer (Table 2.5). A few jars had significant differences between the expected gross mass and the as-found gross mass. These larger differences are probably due to loss of water from the sample over time during storage at $222 \mathrm{~S}$ and/or sample loss in 
shipping. The jar lids tend to become brittle in the radiological environment over time, so some of these likely cracked, and the water evaporated. Some tare masses were based on vials with blue lids; lids had been replaced with green lids for shipping. The mass difference associated with the change in lids was $\sim 4.6 \mathrm{~g}$ and this was taken into account for the samples this applied to. New lids were placed on the jars before shipping. One of the B-104 samples (11843) had a loose lid during shipping. This was noted by moisture in the double containment bag when unloading the cask after shipping. Weight of sample lost due to this leak was 67.22 grams.

There was an $11.2 \%$ mass loss from the expected mass, archive records, and the received mass. A total of $94.7 \%$ of the received mass was recovered from the sample jars and put into the composite. The received mass was calculated by subtracting the $222 \mathrm{~S}$ supplied tare weights for the sample jars from the total mass measured in HLRF before transferring the sample materials. The recovered mass was determined by subtracting the mass of the jars after being emptied of sample from the total mass obtained beforehand. Approximately $5.3 \%$ of the material could not be removed from the jars. The final tank composite based on the mass balance was primarily made of B-104 tank waste as can be seen in Figure 2.10.

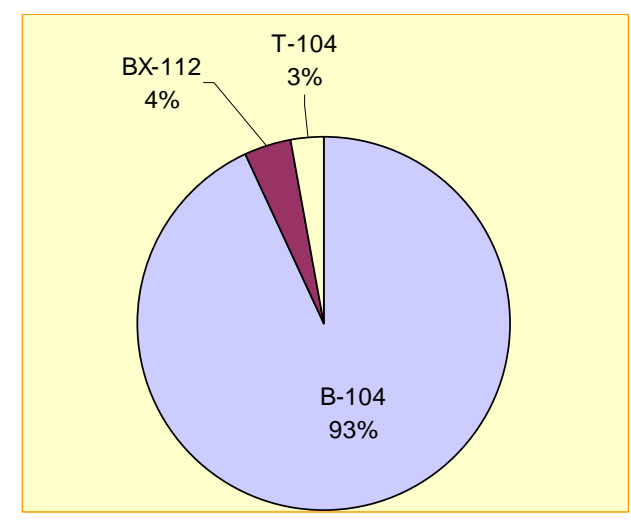

Figure 2.10. Contribution of the Individual Tanks to the Composition of the Group 1 Composite Sample

After all samples had been added to the homogenizer tank, and all equipment (spatula, sieve, mashing tool) had been rinsed free of sample, the sieve screen was removed. A total of $742.97 \mathrm{~g}$ of DI water was added during the compositing process. A mechanical stirrer with stainless steel impeller was lowered into the tank, the fitted lid was placed on the tank, and the material was mixed thoroughly. The temperature in the hot cell was $35^{\circ} \mathrm{C}$ at the start of mixing. The goal of this step was to homogenize the sample using as little force as possible. The stirrer speed was slowly increased until the solids were mobilized. The positions and arrangements for the height of the mixer relative to the support rod and impeller were predetermined during the preliminary non-radioactive testing, and the proper alignments marked onto the impeller and support rod correctly aligned. While operating the vessel agitator, material was extracted from the collection port at the bottom of the tank and returned through the top of the vessel to so that all the material was mixed well.

The test plan defined a minimum required mixing time of 1 hour. The total mixing time for the Group 1 composite slurry was 1 hour and 40 minutes before sub-sampling began. Sub-sampling took 40 minutes, and the mixer continued to mix during this time. The consistency of the Group 1 composite was about that of a light milkshake and remained that way throughout all the subsamples. The sub-samples were 
removed in a specific order to pre-determined target volumes. Pre-weighed and labeled jars and centrifuge tubes were staged in collection vessels in the order provided in Table 2.6.

At the start of sub-sampling, while operating the vessel agitator, one sub-sample of sufficient size (minimum of $100 \mathrm{~mL}$ ) was extracted through the sample valve into TI508-G1-AR-J1 to clear material from the lowest portion of the vessel. This was then added back to the mixing vessel before sub-sampling began. Approximately 10 to $20 \mathrm{~mL}$ of composite was lost from the spigot because surface tension kept the sample in the nozzle initially but cleared after the jar was filled. The S-1 test tube over-filled, losing $\sim 10 \mathrm{~mL}$, and also several of the test tubes missed the target volume. The excess was decanted as quickly as possible to AR-J6. A video was taken of the homogenized samples showing the settled solids after 3 days settling time.

Table 2.6. Group 1 Sub-Sample Mass Density and Settling Data

\begin{tabular}{|l|c|c|c|c|c|c||}
\hline $\begin{array}{l}\text { Sample ID in Order of } \\
\text { Collection }\end{array}$ & $\begin{array}{c}\text { Target } \\
\text { Collection } \\
\text { Volume }\end{array}$ & $\begin{array}{c}\text { Total } \\
\text { Net Wt, }\end{array}$ & $\begin{array}{c}\text { Settled } \\
\text { Slurry } \\
\text { Volume, } \\
\text { mL }\end{array}$ & $\begin{array}{c}\text { Solids } \\
\text { Volume, } \\
\text { mL }\end{array}$ & $\begin{array}{c}\text { Gross } \\
\text { Slurry } \\
\text { Density }\end{array}$ & $\begin{array}{c}\text { Vol \% } \\
\text { Settled } \\
\text { Solids }\end{array}$ \\
\hline TI508-G1-AR-J1 & $300-400 \mathrm{~mL}$ & 331.199 & 280 & 170 & 1.18 & $60.7 \%$ \\
\hline TI508-G1-AR-S1 & $10-15 \mathrm{~mL}$ & 9.745 & 8.3 & 5.2 & 1.17 & $62.7 \%$ \\
\hline TI508-G1-AR-C1 & $25 \mathrm{~mL}$ & 29.162 & 22.5 & 14.5 & 1.30 & $64.4 \%$ \\
\hline TI508-G1-AR-J2 & $300-400 \mathrm{~mL}$ & 325.810 & 275 & 170 & 1.18 & $61.8 \%$ \\
\hline TI508-G1-AR-RH1 & $50 \mathrm{~mL}$ & 113.315 & 85 & 50 & 1.33 & $58.8 \%$ \\
\hline TI508-G1-AR-C2 & $25 \mathrm{~mL}$ & 48.513 & 37.5 & 22 & 1.29 & $58.7 \%$ \\
\hline TI508-G1-AR-S3 & $50 \mathrm{~mL}$ & 19.785 & 16.5 & 9.6 & 1.20 & $58.2 \%$ \\
\hline TI508-G1-AR-P1 & $150 \mathrm{~mL}$ & 180.760 & 145 & 75 & 1.25 & $51.7 \%$ \\
\hline TI508-G1-AR-J3 & $300-400 \mathrm{~mL}$ & 343.648 & 285 & 175 & 1.21 & $61.4 \%$ \\
\hline TI508-G1-AR-J4 & $300-400 \mathrm{~mL}$ & 339.914 & 280 & 165 & 1.21 & $58.9 \%$ \\
\hline TI508-G1-AR-S2 & $10-15 \mathrm{~mL}$ & 15.818 & 13 & 7.5 & 1.22 & $57.7 \%$ \\
\hline TI508-G1-AR-C3 & $25 \mathrm{~mL}$ & 36.071 & 28.5 & 16.5 & 1.27 & $57.9 \%$ \\
\hline TI508-G1-AR-J5 & $300-400 \mathrm{~mL}$ & 354.478 & 295 & 170 & 1.20 & $57.6 \%$ \\
\hline TI508-G1-AR-J7 & $300-400 \mathrm{~mL}$ & 315.525 & 255 & 155 & 1.24 & $60.8 \%$ \\
\hline TI508-G1-AR-J6 & $300-400 \mathrm{~mL}$ & 168.138 & 135 & 75 & 1.25 & $55.6 \%$ \\
\hline
\end{tabular}

For compositing to be considered successful, the sample density and settled solids data standard deviation had to be less than $\pm 5 \%$, and there had to be no statistically significant trend in settled solids and density variation due to subsample removal order. Figure 2.11 shows that the Group 1 composting and subsampling successfully met these criteria.

Following is a summary of Group 1 sample homogenization and sub-sampling:

- The total mass of Group 1 bismuth phosphate sludge samples homogenized together was $1889 \mathrm{~g}$.

- The total mixing time after all Group 1 bismuth phosphate sludge samples had been added to the homogenizer tank, including a sufficient volume of water to bring the total volume to about $2.3 \mathrm{~L}$, was $1 \mathrm{hr}$ and 40 minutes at $35^{\circ} \mathrm{C}$, after which the material was sub-sampled. 
- The total mass of water used in this test was $968 \mathrm{~g}$ based on the difference between the starting amount stored in the DI water containers and the amount remaining at the end of the test. The actual amount of water that actually was mixed in the tank was somewhat less because of the loss of water by spillage and evaporation.

- The total gross mass of the entire homogenized sample collected was $2632 \mathrm{~g}$ with a total slurry volume of $2161 \mathrm{~mL}$. The volume of insoluble solids (gravity-settled) as described above was determined to be $849 \mathrm{~mL}$.

The total gross mass of the entire homogenized Group 1 bismuth phosphate saltcake sample collected was $1889 \mathrm{~g}$ sample $+968 \mathrm{~g}$ water $=2857 \mathrm{~g}$. The difference between that total mass and that actually collected in the final sample jars is $2857-2632 \mathrm{~g}=225 \mathrm{~g}$ ( $8 \%$ loss). The difference is likely due to evaporative losses of water, followed by loss of water through spilling during manipulations using the squirt bottle and dispensing water from the water-storage bottles. About 30 to $40 \mathrm{~mL}$ of sample was lost during problems dispensing the sample from the homogenizer tank.

\subsection{Group 2 Sample Homogenization and Sub-Sampling}

The Group 2 composite was prepared at the Hanford 222S laboratory using equipment that had previously been installed in the hot cell facility. This equipment was somewhat different than that used for Group 1 homogenization. It had a conical bottom, but its outlet valve was straight down, and the baffles were not removable. Modifications to the vessel were proposed and tested with a non-radioactive duplicate system out of the cell.

Before homogenizing the actual tank waste sample in the 222-S hot cell facility, non-radioactive testing and preparation of equipment was carried out at PNNL. A homogenizer that was an exact replica of the one to be used in the hot cell was obtained from ATL staff to design and fit the new components. The new components specifically fitted for the tank were a new stainless steel valve and spout at the base of the tank for dispensing of samples, a stainless steel lid with manipulator rings to prevent contamination and evaporation of water from the samples, a device to hold a stainless steel rod for placement of a stainless steel impeller/electrical stirring device, a stainless steel funnel and special lid with a slit and slit hole cover for use during the actual homogenization/mixing process, and a mounting for a video camera to record pictures of the samples and the process. 
WTP-RPT-166, Rev. 0

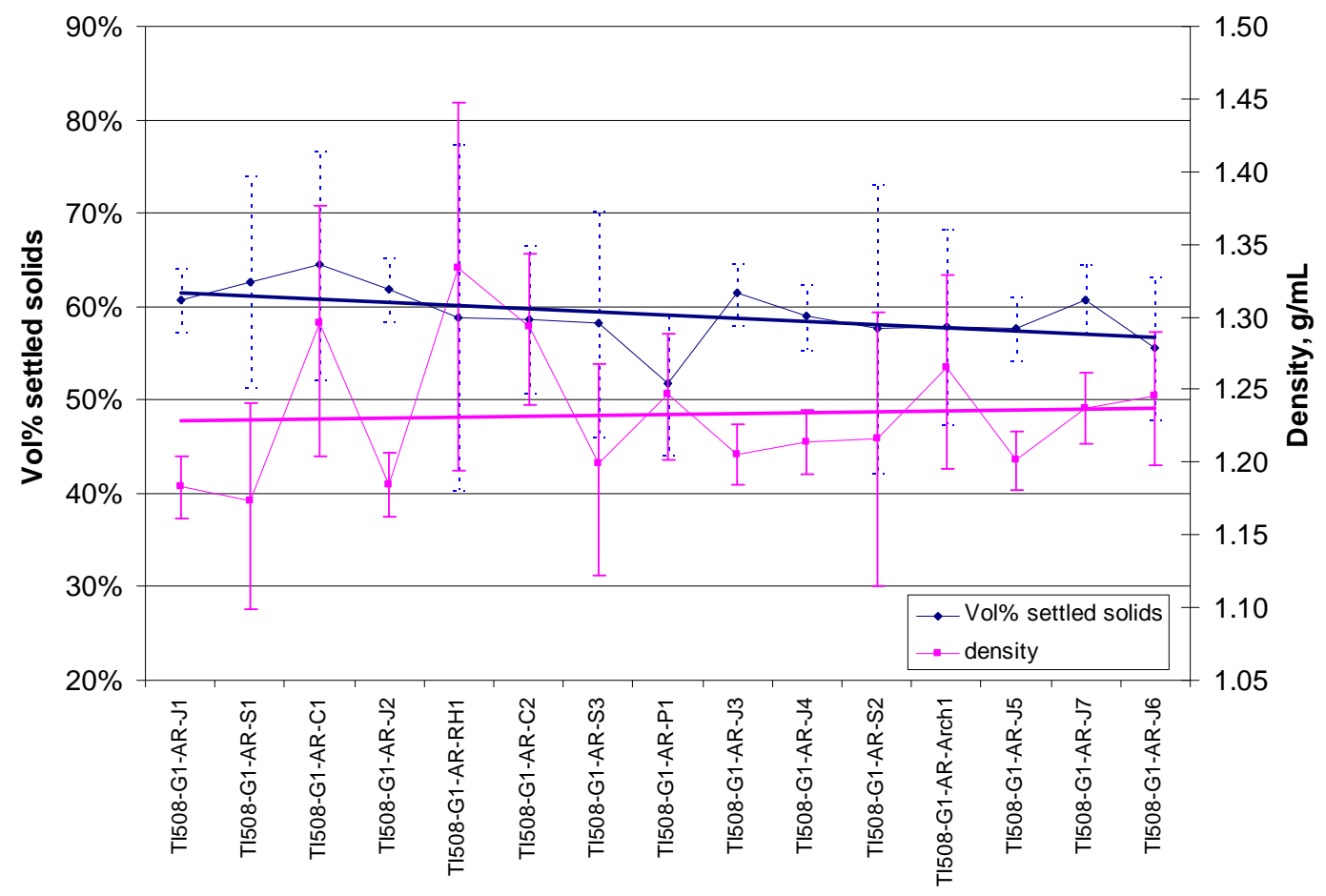

Figure 2.11. Group 1 Confirmation of Successful Material Composite Based on Density and Settled Solids

Additional equipment that was fabricated and/or supplied for this test was a heavy stainless steel "mashing" tool to help force sample through the stainless steel sieve (all samples went through a sieve so that no rocks or other foreign objects that were larger than $3.2 \mathrm{~mm}$ were a part of the final homogenized samples). Stainless steel manipulator rings were fabricated onto the stainless steel sieve, stainless steel spatulas, and a stainless steel "probe" to work loose the solids that settled to the bottom of the tank after homogenization so that the final samples could be dispensed. A few additional items were supplied in the form of plastic trays for secondary containment to recover any samples that may have been spilled during the test and stainless steel tweezers with manipulator rings for removing foreign matter.

Non-radioactive testing with a saltcake stimulant solution on the "cold test" tank at PNNL resulted in some areas of corrosion (Figure 2.12). After consulting other experts about corrosion and the potential causes, it was decided to proceed with the test as conceived, but to minimize the homogenizer tank residence time for the saltcake samples as much as reasonably possible to minimize the opportunity for corrosion. No corrosion was observed in the in hot cell homogenization tank before or after compositing the actual Group 2 samples.

The actual homogenizer tank that was used for the test in the 222S hotcell 11A5 was the one that appeared to be the cleanest of the three tanks in that hot cell. This tank was fitted with the new stainless steel ball valve/spout. To verify that the tank was clean and would not result in cross-contamination, it was cleaned with the following order of rinse solutions: $\mathrm{NaOH}$, DI water, $\mathrm{HNO}_{3}$, and finally with copious amounts of DI water according to Test Procedure TPR-RPP-WTP-489. The order of the cleaning procedure was to first release the water that had been sitting in the tank since the last homogenization procedure for Group 6 S-Saltcake was completed. A liter of $0.1 \mathrm{M} \mathrm{NaOH}$ was poured into the tank and down the sides of the wall, then the mixing apparatus was attached to the support rod, and the stainless 
steel impeller was immersed in the solution. Some additional DI water was added to fill the level up to a sufficient level to immerse all the stirring vanes. After stirring for about 30 minutes, this solution was released through the bottom valve, and the entire apparatus was rinsed with copious amounts of DI water. Three liters of $0.1 \mathrm{M} \mathrm{HNO}_{3}$ were then added to the tank, and the apparatus was stirred for about 30 minutes. The acid solution was released through the bottom valve, and the entire apparatus was rinsed with copious amounts of DI water, including the lids and ancillary parts of the homogenizer. The entire apparatus was well rinsed and then dried before beginning work with the Group 2 tank waste samples. There was no noticeable residue in the tank, on the impeller, or the ancillary lids.
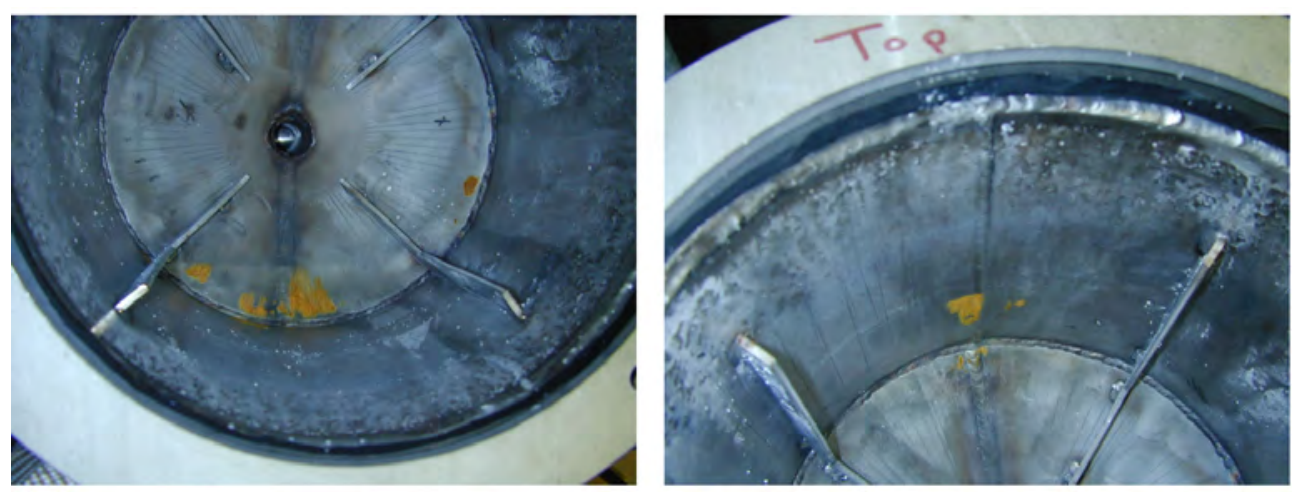

Figure 2.12. Corrosion Seen in Non-Radioactive Homogenization Tank After Saltcake Simulant Testing

During the sample homogenization, the temperature in hot cell 11A5, where the work was carried out, varied from 26.9 to $27.7^{\circ} \mathrm{C}$. All original sample jars were weighed and the masses recorded (Table 2.7), and lids were removed to inspect the contents inside. Water was added to some of the samples, and the lids were replaced (to minimize evaporation) so that the samples could soak and the solids could be broken up and added to the homogenizer. A triage of the samples was performed, and the general procedure was to first add all samples that appeared to be fine-grain dry solids since those should travel easily through the sieve without the need to add water to transfer the contents.

The sample jars fell into the following general categories:

a. Semi-solid - sample was added to homogenizer without soaking sample with water first. 222-S sample jars 19298, 12694, 13021, 8643, 18632, 10544, 10545, 10848, 16950, 15570, 7686, 7689, 13040, and 8375.

b. Dry solid sample-added water to soak sample so it could be broken up and removed from the jar for addition to the homogenizer. 222-S sample jars 12744, 12647, 8410, 13039, and 14021.

c. Dry solid sample - no water added for sample soaking. Was fairly easy to remove from container and place in homogenizer. In the case of 222-S sample Jar 13472, there was a single hard chunk of solid that was returned to the container for soaking to break it up after the majority of this sample was added to the tank as a dry solid. 222-S sample jars 13031, 8757, 8758, 15622, 13525, 7690, 13472, 7655, 7972, 11799, 11793, 7428, 7467, 19272, and 18801.

d. Clearly visible supernate liquid in jar. 222-S sample jars 13022, 7679, 7687, 7691, 7692, 19086, and 13856.

The sample jars that had caps that broke or chipped during operations to remove the samples from the jars included 12744, 10545, 10848, 7689, 7691, 13040, 13856, and 18801. The mass of water added to the samples were as follows: 12744 (10.932 g), 13021 (10.711 g), 12647 (13.457), 8410 (16.141 g), 13039 
(14.428 g), 13472 (12.224 g), and 14021 (11.294) g. Roughly half the samples had the appearance of a dark gray-brown solid, either dry or moist, while the other half had a whitish or tan (light) colorationmost of the latter samples tended to be fine dry samples and had perhaps been homogenized previously. Two jars, 19298 and 12694, appeared to be a blackish-green color and were sticky semisolids (19298 did have some specks of light material in it). Figure 2.13 presents some representative photographs of the Group 2 samples.

All samples were added to the top of the homogenizer, which was fitted with a stainless steel sieve that would not allow passage of particles of a size greater than $3.2 \mathrm{~mm}$. Samples that appeared to be fine solids were added first and easily passed through the sieve. No water was added to the tank for those samples in order to minimize the chance for corrosion of the tank during the entire homogenization operation. Sample jars were placed inside a plastic tray for secondary containment, the lids were removed, and using a stainless steel spatula (wood handle, blade size $3 / 4$ inch wide by 5 inches long), the contents were thoroughly mixed to a consistency such that most of the contents could be poured or scraped out onto the sieve with the spatula for semi-solids. If foreign material such as pieces of broken caps were present, those were picked out with stainless steel tweezers; there were only a few instances of this for these samples.

The remaining residues were then removed from the sample jar by a process of scraping and rinsing with DI water (using a squirt bottle). In this fashion, nearly all residues were removed from the sample jars. Solids (or semi-solids) were forced through the sieve with the stainless steel mashing tool, which was very effective in breaking up some chunks of solid materials that otherwise would not have easily gone through the sieve. Figure 2.14 provides a typical illustration of semi-solid material on the sieve. To the maximum extent possible, all sample materials were placed into the homogenizer; there was very little loss of actual sample due to splattering or spillage for this group of samples. During the entire process of transferring the samples from the jars to the homogenizer, the use of water was conservative so as to have enough water to remove all sample residues and come close to the desired total solution volume for the homogenized material of $3 \mathrm{~L}$.

After transferring all sample materials to the homogenizer tank, the sample jars were allowed to dry and were reweighed (Table 2.7, Final Gross Mass). These values were used to calculate the amount of sample added to the homogenizer (Table 2.7, Sample Mass Transferred to Homogenizer). The total mass of Group 2 tank waste sample added to the homogenizer was 1,966.1 g. 


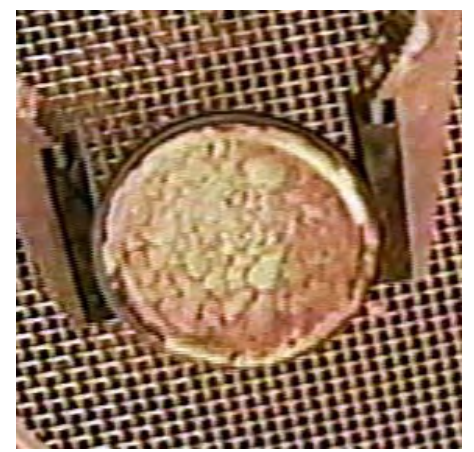

222-S Sample Jar 12647

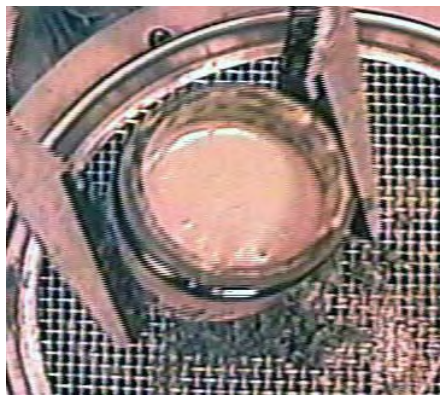

222-S Sample Jar 13021

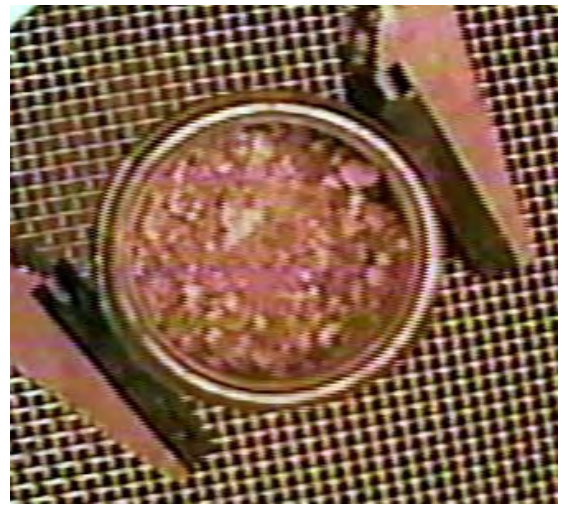

222-S Sample Jar 11799

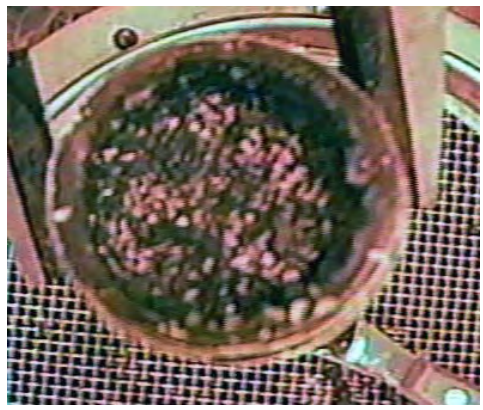

222-S Sample Jar 12694

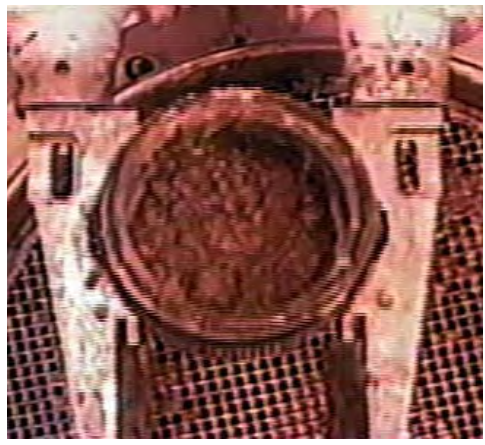

222-S Sample Jar 15570

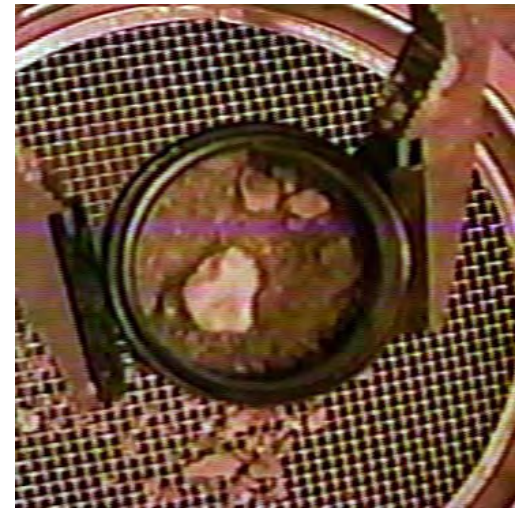

222-S Sample Jar 11793

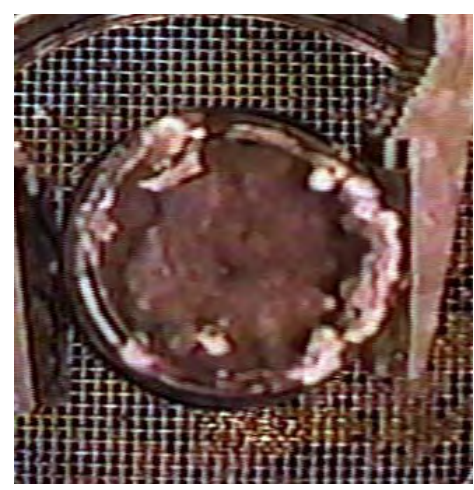

222-S Sample Jar 10545

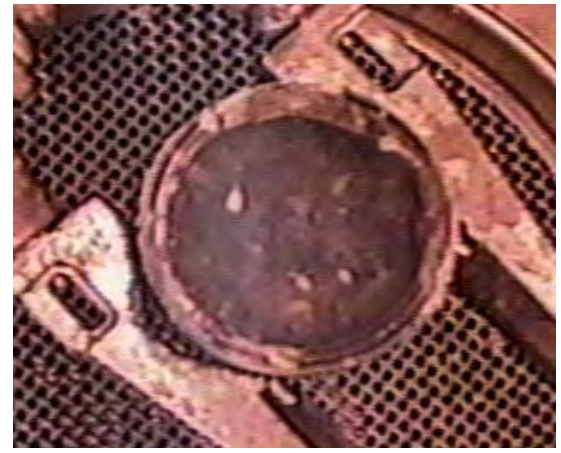

222-S Sample Jar 13022

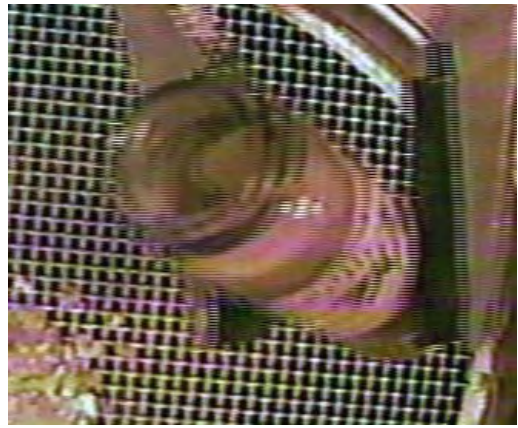

222-S Sample Jar 7428

Figure 2.13. Representative Photographs of the Group 2 Bismuth Phosphate Saltcake Samples 
WTP-RPT-166, Rev. 0

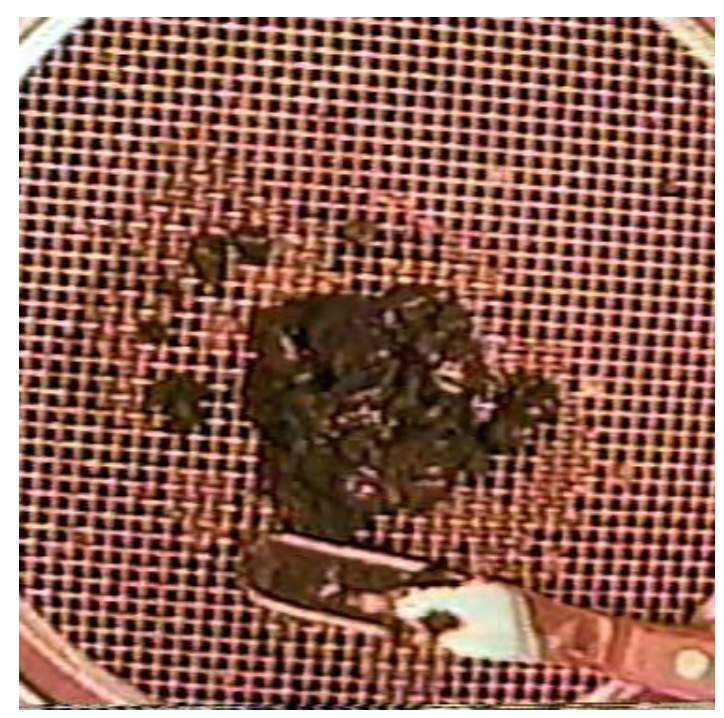

Figure 2.14. Example of Group 2 Waste Transfer into the Homogenizer

The following jars had fairly significant differences between the Expected Gross Mass and the As-Found Gross Mass (greater than 20 g): 12694 (31.47 g), 12744 (28.93 g), 13021 (21.9 g), 12647 (28.1 g), 13031 (21.7 g), and 13856 (21.3 g). These larger differences are probably due to loss of water from the sample over time during storage and/or a change in the cap at sometime during storage sample.

During the course of adding samples to the homogenizer, it was noticed that a small leak had developed where the valve at the bottom of the homogenizer connects to the tank. The leak probably occurred as a result of a poor seal due to decomposing Teflon ${ }^{\circledR}$ tape used on the thread. A small finger of bright yellow solid was noticed forming at this juncture. The solid was recovered and placed back in the tank. Also, it was possible to recover (minus evaporated water) the leaked liquid because a clean tray had been placed under the bottom of the tank. The valve-to-tank connection was tightened several times, but eventually there was inevitably a small leak that occurred within a few days. All solid material was recovered, and the losses here consisted primarily of water loss due to evaporation. This situation had to be managed because there was a delay of several days in the homogenization operation when some of the bands on the manipulator broke and required repair.

After all samples had been added to the homogenizer tank, and all equipment (spatula, sieve, mashing tool) had been rinsed free of sample, the sieve screen was removed and sufficient DI water was added to the tank to bring the volume to approximately $3 \mathrm{~L}$. An electrical stirrer with stainless steel impeller was lowered into the tank, and the solution was mixed thoroughly. A special lid, which had a slot cut out radially so as to fit the stirring apparatus, was placed on the tank. Another small lid with a manipulator ring covered up the open space left by the slot to prevent cross contamination of the sample and to minimize evaporation and/or splattering losses during mixing. These pieces were made from stainless steel. 
Table 2.7. Group 2 Bismuth Phosphate Saltcake Sample Masses

\begin{tabular}{|c|c|c|c|c|c|c|}
\hline $\begin{array}{l}\text { Hanford } \\
\text { Tank ID }\end{array}$ & $\begin{array}{c}\text { 222-S Jar } \\
\#\end{array}$ & $\begin{array}{l}\text { Expected Gross } \\
\text { Mass (g) }\end{array}$ & $\begin{array}{c}\text { As-Found } \\
\text { Gross Mass } \\
\text { (g) }\end{array}$ & $\begin{array}{l}\text { Final Gross } \\
\text { Mass (g) }\end{array}$ & $\begin{array}{c}\text { Sample Mass } \\
\text { Transfer'd to } \\
\text { Homogenizer } \\
\text { (g) }\end{array}$ & $\begin{array}{c}\text { Mass Loss } \\
\text { Between } \\
\text { Expected and } \\
\text { As-Found (g) }\end{array}$ \\
\hline BX-110 & 19298 & 138.2 & 137.879 & 83.397 & 54.482 & 0.3 \\
\hline BX-110 & 12694 & 175.17 & 143.697 & 86.146 & 57.551 & 31.47 \\
\hline $\mathrm{BX}-110$ & 12744 & 141.22 & 112.292 & 86.522 & 25.770 & 28.93 \\
\hline BX-111 & 13021 & 154.9 & 133.013 & 87.765 & 45.248 & 21.9 \\
\hline BX-111 & 12647 & 164.6 & 136.534 & 84.553 & 51.981 & 28.1 \\
\hline BX-111 & 13022 & 179.87 & 178.638 & 88.085 & 90.553 & 1.23 \\
\hline BX-111 & 13031 & 146.9 & 125.229 & 87.891 & 37.338 & 21.7 \\
\hline BY-104 & 8410 & 105.4 & 103.325 & 84.884 & 18.441 & 2.1 \\
\hline BY-104 & 8757 & 113.8 & 113.535 & 85.418 & 28.117 & 0.3 \\
\hline BY-104 & 8758 & 155.2 & 154.129 & 85.582 & 68.547 & 1.1 \\
\hline BY-105 & 8643 & 165.35 & 164.453 & 86.677 & 77.776 & 0.90 \\
\hline BY-107 & 18632 & 122.5 & 122.799 & 91.189 & 31.610 & -0.3 \\
\hline BY-107 & 10544 & 139.9 & 139.774 & 94.285 & 45.489 & 0.1 \\
\hline BY-107 & 10545 & 197.9 & 183.202 & 87.835 & 95.367 & 14.7 \\
\hline BY-107 & 10848 & 118.9 & 117.576 & 88.820 & 28.756 & 1.3 \\
\hline BY-108 & 15622 & 132.2 & 131.784 & 83.433 & 48.351 & 0.4 \\
\hline BY-108 & 16950 & 112.3 & 111.943 & 84.706 & 27.237 & 0.4 \\
\hline BY-108 & 15570 & 113.2 & 112.903 & 84.094 & 28.809 & 0.3 \\
\hline BY-108 & 7686 & 75.27 & 74.982 & 25.719 & 49.263 & 0.29 \\
\hline BY-108 & 7679 & 85.92 & 85.636 & 25.693 & 59.943 & 0.28 \\
\hline BY-108 & 7689 & 50 & 49.134 & 25.469 & 23.665 & 1 \\
\hline BY-108 & 7687 & 84.48 & 83.684 & 26.772 & 56.912 & 0.80 \\
\hline BY-108 & 13525 & 115.78 & 114.519 & 88.096 & 26.423 & 1.26 \\
\hline BY-108 & 7690 & 58.6 & 54.219 & 25.424 & 28.795 & 4.4 \\
\hline BY-108 & 7691 & 92.9 & 92.355 & 25.334 & 67.021 & 0.5 \\
\hline BY-108 & 7692 & 93.1 & 92.983 & 25.626 & 67.357 & 0.1 \\
\hline BY-109 & 13040 & 156.7 & 150.817 & 89.017 & 61.800 & 5.9 \\
\hline BY-109 & 13039 & 159.6 & 145.048 & 87.807 & 57.241 & 14.6 \\
\hline BY-109 & 19086 & 180 & 179.670 & 84.324 & 95.346 & $<<1$ \\
\hline BY-110 & 8375 & 135.49 & 135.027 & 85.798 & 49.229 & 0.46 \\
\hline BY-110 & 13472 & 117 & 117.101 & 83.969 & 33.132 & $<1$ \\
\hline BY-110 & 7655 & 65.3 & 65.206 & 26.030 & 39.176 & 0.1 \\
\hline BY-110 & 7972 & 66.97 & 64.305 & 26.144 & 38.161 & 2.66 \\
\hline BY-112 & 11799 & 117.7 & 116.636 & 88.449 & 28.187 & 1.1 \\
\hline BY-112 & 11793 & 106.5 & 104.385 & 86.254 & 18.131 & 2.1 \\
\hline T-108 & 7428 & 52.6 & 44.722 & 25.358 & 19.364 & 7.9 \\
\hline T-109 & 7467 & 59.6 & 59.886 & 25.714 & 34.172 & $\begin{array}{l}-0.3 \\
\end{array}$ \\
\hline TX-104 & 13856 & 184.2 & 162.858 & 85.000 & 77.858 & 21.3 \\
\hline TX-104 & 14021 & 112.1 & 111.722 & 85.784 & 25.938 & 0.378 \\
\hline TX-113 & 19272 & 106.6 & 88.522 & 83.359 & 5.163 & 18.1 \\
\hline TX-113 & 18801 & 267.6 & 266.574 & 124.176 & 142.398 & 1.0 \\
\hline
\end{tabular}


The positions and arrangements for the height of the mixer relative to the support rod and impeller were predetermined using the cold testing tank (done at PNNL), and the proper alignments were marked onto the impeller and support rod using a marking pen. The impeller itself was composed of three separate blade units. The bottom unit was situated as close as reasonably possible to the bottom of the funnel/cone shaped tank to maximize stirring/mixing of the solids. There was another blade unit situated roughly in the center of the slurry (based on a volume of $3 \mathrm{~L}$ ) while the final mixing blade was situated just below the highest level of the liquid (again based on a volume of $3 \mathrm{~L}$ ).

The temperature of the hot cell during the mixing period was $27.1^{\circ} \mathrm{C}$, and the total mixing time was 1 hour and 56 minutes. After the solution had been mixed for about 50 minutes, mixing was briefly stopped, and the valve at the bottom of the tank was opened to collect some of the sample into a jar. The purpose of this procedure was to make sure that the solids in the bottom neck of the homogenizer tank were actually being thoroughly mixed to obtain a homogeneous solution. About $100 \mathrm{~mL}$ of solid and liquids were collected and recycled into the top of the tank. A small amount of additional DI water was used to rinse out this jar back into the vessel. The valve was firmly closed, and mixing was restarted. Upon completion of the mixing time, the mixing apparatus was first clamped above the slurry in the tank, and the impeller blades were washed carefully with DI water to recover as much sample as possible. Then the mixing apparatus was completely removed from the support rod, and the solid tank lid was placed on the tank to allow the solids to settle in the tank.

The amount of water used in compositing and homogenizing the Group 2 sample is listed in Table 2.8. Water usage was determined by tracking the masses of the stock water bottles used during the course of the compositing and homogenization work. The total mass of water used as determined in this manner was $2973.6 \mathrm{~g}$. The actual amount was undoubtedly somewhat less due to minor losses of water through spillage and evaporation.

Table 2.8. Mass of DI Water Used in Compositing/Homogenization of Group 2 Bismuth Phosphate Saltcake Samples

\begin{tabular}{|l|c|c|c|c|c|}
\hline Water Container & $\begin{array}{c}\text { Tare of Container } \\
\text { (g) }\end{array}$ & $\begin{array}{c}\text { Tare and Wt } \\
\text { of Water (g) }\end{array}$ & $\begin{array}{c}\text { Mass of } \\
\text { Water } \mathbf{( g )}\end{array}$ & $\begin{array}{c}\text { Mass of } \\
\text { Residual Water } \\
\mathbf{( g )}\end{array}$ & $\begin{array}{c}\text { Total Mass } \\
\text { of Water } \\
\text { Used (g) }\end{array}$ \\
\hline Bottle 1 & 103.80 & 1056.11 & 952.31 & 0.41 & 951.90 \\
\hline Bottle 2 & 103.64 & 1052.49 & 948.85 & 0.93 & 947.92 \\
\hline Bottle 3 & 104.31 & 1065.50 & 961.19 & 6.77 & 954.42 \\
\hline Bottle 4 & 104.6 & 1047.1 & 942.5 & 767.8 & 174.7 \\
\hline Squirt Bottle & 39.19 & 39.19 & 0 & 55.34 & -55.34 \\
\hline
\end{tabular}

For the Group 2 sample, the goal was to separate the settled solids after homogenization, rather than to collect a uniform composite. Thus, the entire lot of material was allowed to settle for about 91 hours (over the weekend).

Upon removing the lid covering the tank, it did appear that the mixture consisted of insoluble material in the bottom of the homogenizer tank with a clear supernatant as the fixed baffles of the tank interior could be seen clearly towards the bottom of the tank. There was also a very minor dark ring of material noted at the top of the liquid level, and the material appeared to be a dark bluish black color. Some very minor pieces of material were also floating on the top of the solution. 
The intended procedure was to dispense the samples into the collection jars such that essentially all of the insoluble materials would be collected in the first three jars (volume to be about $600 \mathrm{~mL}$ total). As it turned out, this was not possible as the solids were quite fine and easily re-suspended. The procedure used to dispense the samples was to place a collection jar directly under the spout with the top lip of the jar close to the bottom of the spout so as to minimize any spattering/loss of sample. The operation was conducted with a secondary containment tray in place in case there was any sample spilled. The capacity of the collection jars was $250 \mathrm{~mL}$, and the jars were marked with volume calibrations on the side and included matching bar codes on the lids and jars along with regular markings to clearly identify each cap and jar unit.

Dispensing of the sample into the first jar proved difficult. The solids that had settled to the bottom of the homogenizer tank plugged the ball valve so that there was very little flow of material initially, which had been considered a possibility. In anticipation of this possibility, a stainless steel probe was fabricated for this specific issue. The probe was used to prod the solids at the bottom of the tank to get flow of the material started. This proved to be successful.

It proved to be critically important to use a clean tray to serve as secondary containment. When trying to get the solids collected in the bottom neck of the homogenizer to loosen up so the material could flow freely out of the tank, the stainless steel probe became stuck in the valve, forcing it to stay open and thus overfilling the collection jar. About five jars worth of solution was spilled into the secondary containment tray before the probe was removed and the valve closed. However, all but about $20 \mathrm{~mL}$ of the homogenized sample solution was recovered from the containment tray, and the tray had been clean, so the integrity of the samples was not compromised. It was decided to let the rest of the sample in the tank settle for another day since the solids in the solution in the tank had become resuspended; during this course of action, the stainless steel spatula was also dropped into the tank with the remaining solution. Part of the wood handle on this spatula was submerged below the liquid level in the tank, but it was decided to leave this as it was in the tank rather than risk any further potential for contamination.

The remaining slurry of solids was moved out of the tank easily. Even though the probe, essentially a stainless steel rod of small diameter, was used primarily in a downward probing manner to minimize stirring and mixing of the solids, it become clear that the insoluble materials did become re-suspended into the solution. All the jars had some insoluble solids collected in them by the time the tank had been emptied, although the amounts of the solids did decrease steadily.

Data on the homogenized sample collection vessels are given in Table 2.9. Viewing the tank after all sample had been dispensed showed that essentially the entire sample had been dispensed to the sample jars, and there was a clear view through the opened ball valve to the floor of the hot cell; there was nothing entrained in the valve area (Figure 2.15). There was also no evidence of tank corrosion. 
Table 2.9. Tare Weight, Sample Gross Mass, Slurry Volumes, and Settled Solids Volumes for Group 2 Bismuth Phosphate Saltcake Homogenized Samples

\begin{tabular}{|l|c|c|c|c|c||}
\hline \multicolumn{1}{|c|}{ Jar ID } & Tare (g) & Gross Mass (g) & $\begin{array}{c}\text { Net Sample } \\
\text { Mass (g) }\end{array}$ & $\begin{array}{c}\text { Total Slurry } \\
\text { Volume, } \mathbf{~ L L}\end{array}$ & $\begin{array}{c}\text { Settled Solids } \\
\text { Volume, } \mathbf{~ m L}\end{array}$ \\
\hline TI487-G2-AR-J1 & 255.750 & 519.514 & 263.76 & 197 & 72 \\
\hline TI487-G2-AR-J2 & 253.220 & 494.993 & 241.77 & 200 & 40 \\
\hline TI487-G2-AR-J3 & 250.788 & 510.648 & 259.86 & 215 & 42 \\
\hline TI487-G2-AR-J4 & 254.067 & 513.114 & 259.05 & 208 & 35 \\
\hline TI487-G2-AR-J5 & 251.586 & 519.300 & 267.71 & 210 & 70 \\
\hline TI487-G2-AR-J6 & 251.830 & 489.416 & 237.59 & 187 & 53 \\
\hline TI487-G2-AR-J7 & 251.972 & 489.970 & 238.00 & 185 & 40 \\
\hline TI487-G2-AR-J8 & 252.269 & 497.419 & 245.15 & 190 & 50 \\
\hline TI487-G2-AR-J9 & 251.160 & 498.814 & 247.65 & 204 & 48 \\
\hline TI487-G2-AR-J10 & 249.120 & 496.972 & 247.85 & 200 & 47 \\
\hline TI487-G2-AR-J11 & 250.692 & 492.631 & 241.94 & 195 & 42 \\
\hline TI487-G2-AR-J12 & 249.218 & 494.290 & 245.07 & 200 & 35 \\
\hline TI487-G2-AR-J13 & 251.822 & 501.340 & 249.52 & 200 & 35 \\
\hline TI487-G2-AR-J14 & 249.745 & 488.428 & 238.68 & 200 & 30 \\
\hline TI487-G2-AR-J15 & 248.403 & 488.623 & 240.22 & 200 & 17 \\
\hline TI487-G2-AR-J16 & 249.847 & 499.055 & 249.21 & 200 & 45 \\
\hline TI487-G2-AR-J17 & 252.499 & 508.867 & 256.37 & 205 & 63 \\
\hline TI487-G2-AR-J18 & 252.740 & 464.437 & 211.70 & 175 & 45 \\
\hline TI487-G2-AR-J19 & 250.850 & 336.101 & 85.25 & 70 & 35 \\
\hline TI487-G2-AR-J20 & 249.823 & 265.610 & 15.79 & 15 & 5 \\
\hline
\end{tabular}

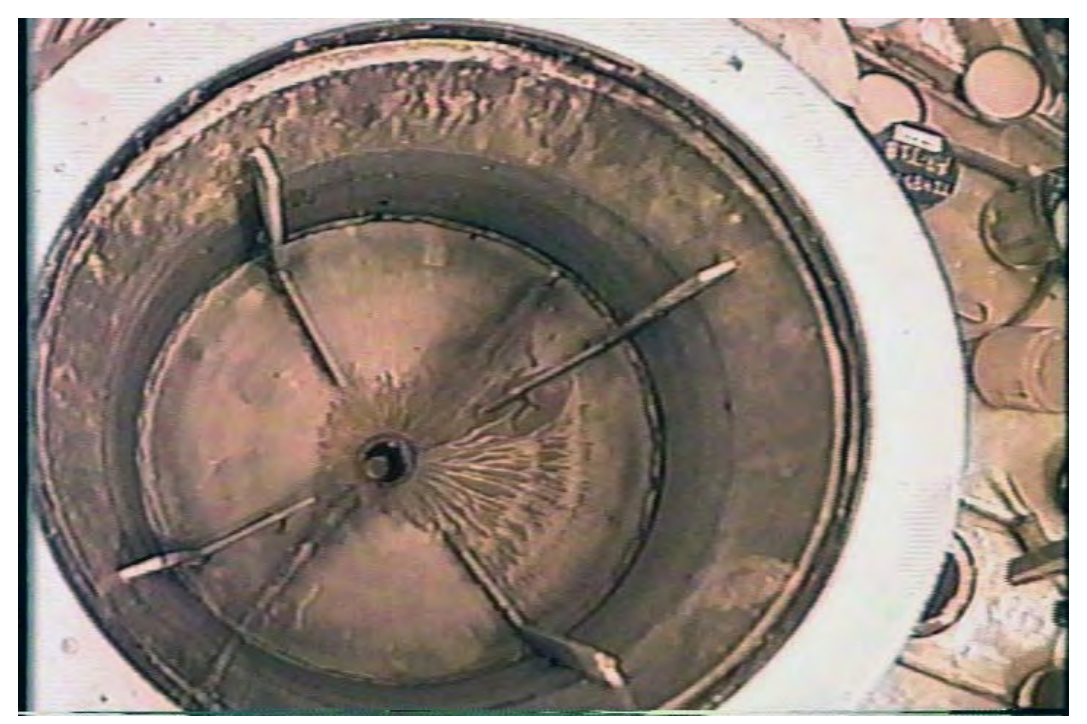

Figure 2.15. Homogenizer Tank after Dispensing Composite Group 2 Sample

Sample jar TI487-G2-AR-J20A was used to collect the minor amount of dark ring material that had collected at the high solution mark in the homogenizer tank. Collection of this material showed that it would not settle after 3 days, and some of the insoluble material that had dried out looked very similar in coloration to the blue jar lids that were used on the sample storage jars in the hot cells in 222S. Because the appearance of several of the Group 2 samples seemed to suggest that they may have been previously 
homogenized using a tissue homogenizer, it seems likely that these are pieces of jar lid that were also finely ground up during a previous homogenizing procedure. This would also explain the tendency of the fine bluish residue to float on top of the sample solution (density of the plastic would be less than the salt solution).

The solids in the jars were allowed to settle for 3 days, and then the volume of solids in each jar was determined using the graduated markings on the jars. The insoluble solids were dark brown while the supernate liquid was bright yellow. Even after settling for 3 days, it could be seen that the interface between the insoluble fraction and the supernate liquid was not rigid, although solids were not resuspended by careful movement of the jars. The solids had a fair amount of the sample liquid entrained in that volume, and a process such as centrifugation would likely be required to get a more accurate assessment of the true volume of the insoluble fraction.

Following is a summary of Group 2 sample homogenization and sub-sampling:

- The total mass of Group 2 bismuth phosphate saltcake samples homogenized together was $1966 \mathrm{~g}$.

- The total mixing time after all Group 2 bismuth phosphate saltcake samples had been added to the homogenizer tank, including a sufficient volume of water to bring the total volume to about $3 \mathrm{~L}$, was 1 hour and 56 minutes at $27.1^{\circ} \mathrm{C}$.

- The total mass of water used in this test was $2974 \mathrm{~g}$ based on the difference between the starting amount stored in the DI water containers and the amount remaining at the end of the test. The actual amount of water that actually was mixed in the tank was somewhat less because of the loss of water by spillage and evaporation.

- The total gross mass of the entire homogenized sample collected was $4542 \mathrm{~g}$ with a total slurry volume of $3656 \mathrm{~mL}$. The volume of insoluble solids (gravity-settled) as described above was determined to be $849 \mathrm{~mL}$.

- Sample overflowed the first collection jar while it was dispensed from the homogenizer tank, but it was recovered from a clean secondary containment tray that had been used in the procedure. All but about $20 \mathrm{~mL}$ of the sample solution was recovered.

- Sample jar TI487-G2-AR-J20A was used to collect the minor amount of dark ring material that had collected at the high solution mark in the homogenizer tank. Because the appearance of several of the Group 2 samples seemed to suggest that they may have been previously homogenized using a tissue homogenizer, it seems likely that these are pieces of jar lid that were also finely ground up during a previous homogenization procedure. This would also explain the tendency of the fine bluish residue to float on top of the sample solution (the density of the plastic would be less than the salt solution).

The total gross mass of the entire homogenized Group 2 bismuth phosphate saltcake sample collected was $1966 \mathrm{~g}$ sample $+2974 \mathrm{~g}$ water $=4940 \mathrm{~g}$. The difference between that total mass and that actually collected in the final sample jars is 4940 - $4542 \mathrm{~g}=398 \mathrm{~g}$ ( $8 \%$ difference). The difference is likely due to evaporative losses of water, followed by loss of water through spilling during manipulations using the squirt bottle and dispensing water from the water-storage bottles. About $20 \mathrm{~mL}$ of sample was lost during problems dispensing sample from the homogenizer tank. 


\subsection{Group 1 Characterization and Leaching}

This section reports on and discusses the characterization activities, analytical results, parametric leach testing, and leaching results for the Group 1 bismuth phosphate sludge slurry composite.

\subsection{Group 1 Characterization Experimental}

Table 3.1 lists the Group 1 characterization samples that were taken during the homogenization and sample splitting activities described in Section 2. Figure 3.1 summarizes the sample processing performed to characterize the Group 1 sample, and Figure 3.2 shows the specific washing scheme for the Group 1 sludge solids.

Table 3.1. Group 1 Characterization Samples

\begin{tabular}{|l|l|c|c||}
\hline Sample ID & Characterization Activity & $\begin{array}{c}\text { Slurry } \\
\text { Volume, mL }\end{array}$ & $\begin{array}{c}\text { Slurry } \\
\text { Mass, }\end{array}$ \\
\hline TI508-G1-AR-S1 & Physical Properties & 8.3 & 9.745 \\
\hline TI508-G1-AR-S2 & Physical Properties & 13.0 & 15.818 \\
\hline TI508-G1-AR-S3 & Physical Properties & 16.5 & 19.785 \\
\hline TI508-G1-AR-C1 & $\begin{array}{l}\text { Chemical characterization } \\
\text { and crystal habit }\end{array}$ & 22.5 & 29.162 \\
\hline TI508-G1-AR-C2 & $\begin{array}{l}\text { Chemical characterization } \\
\text { and crystal habit }\end{array}$ & 37.5 & 48.513 \\
\hline TI508-G1-AR-RH1 & Rheology & 85 & 113.315 \\
\hline
\end{tabular}




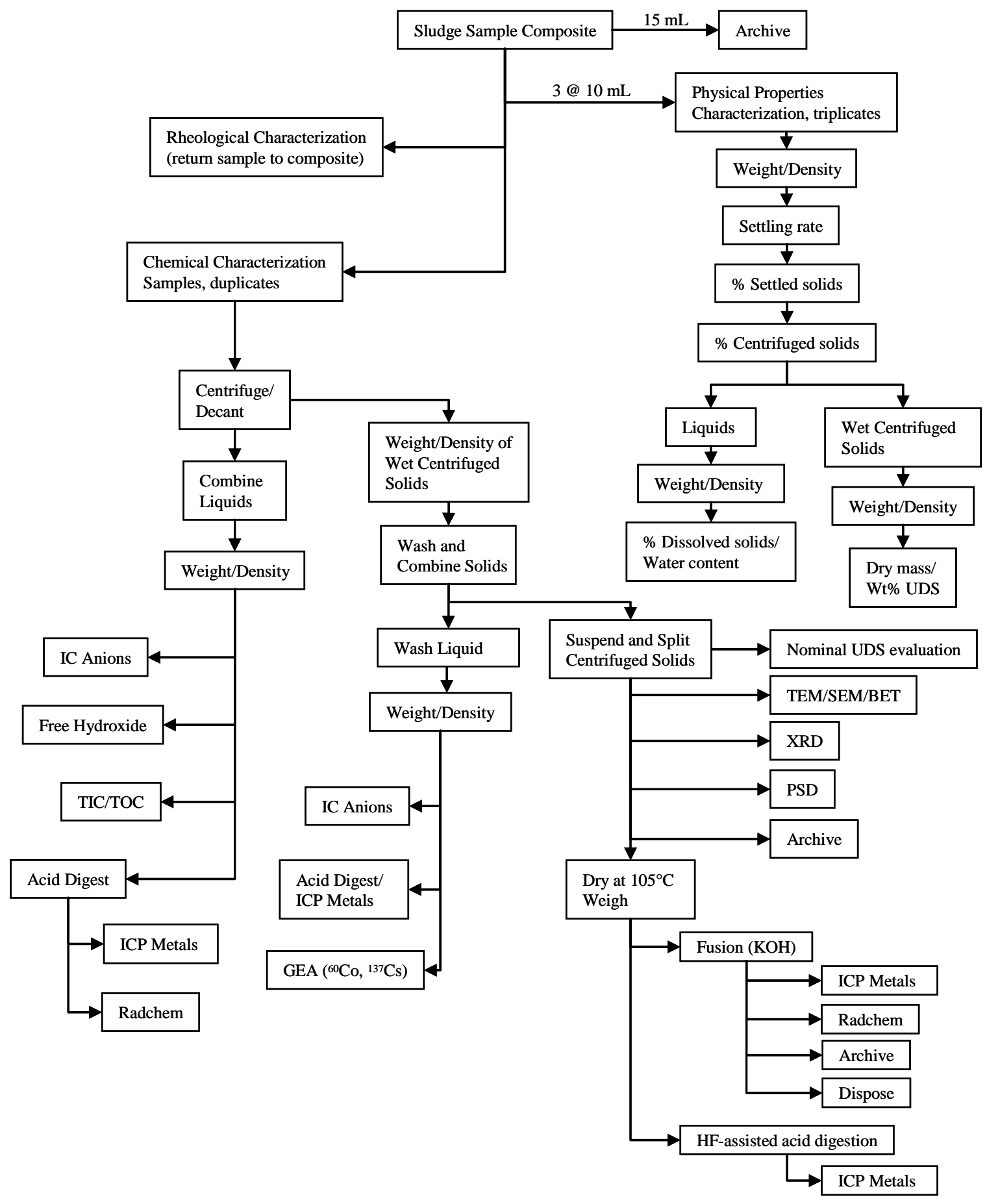

Figure 3.1. Group 1 Characterization Process Flowchart 
WTP-RPT-166, Rev. 0

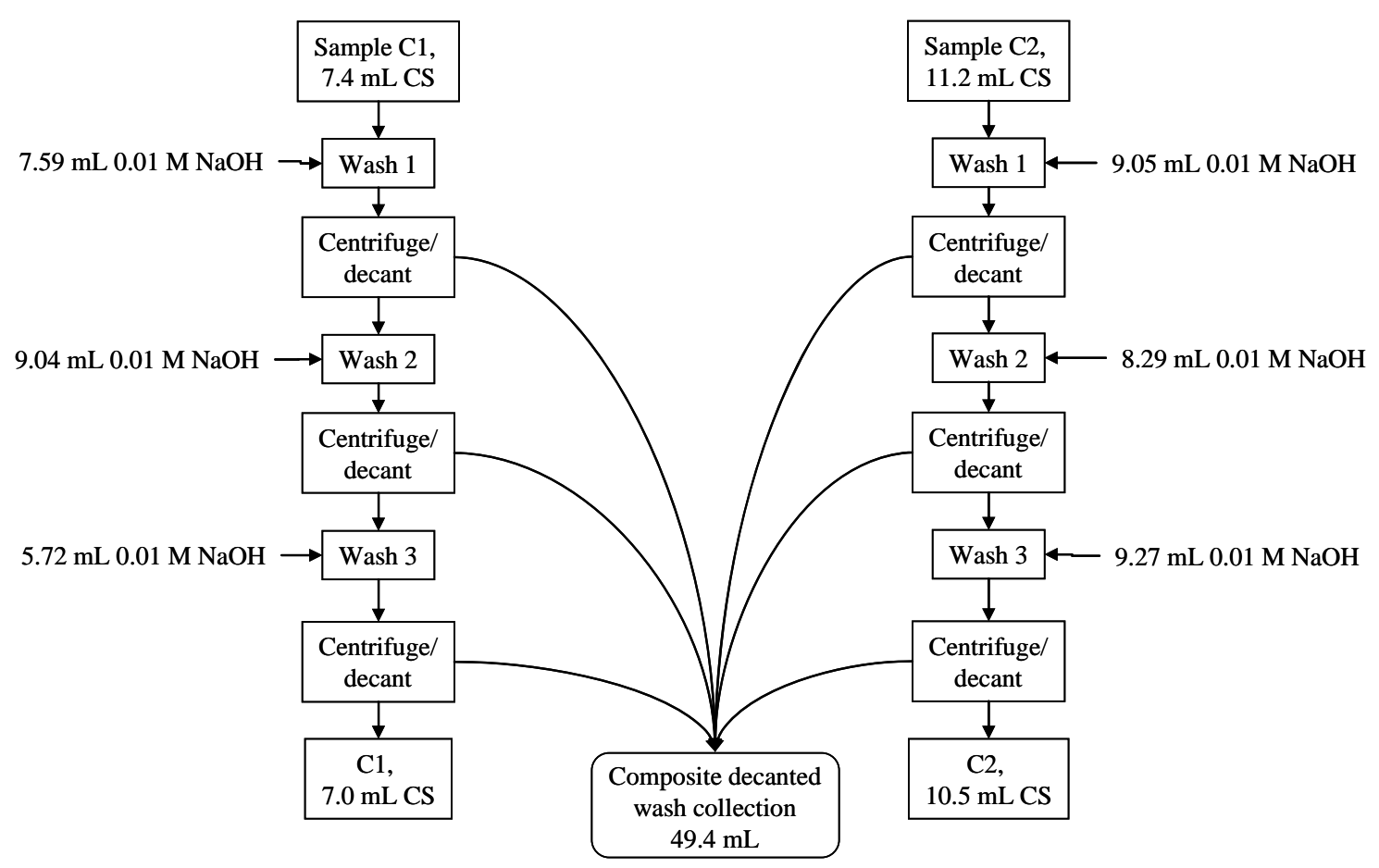

Figure 3.2. Wash Sequence of Group 1 Sludge Supporting Initial Characterization

$$
\text { (CS = centrifuged solids) }
$$

After each successive washing step, the wet centrifuged solids were stratified in three layers (see Figure 3.3). The whitest layer was apparently the densest layer. The middle layer was the darkest color. The top layer appeared light brown or tan.

\subsection{Characterization Results}

\subsubsection{Physical Properties of the Composite Slurry}

Figure 3.4 shows the settling curves for the Group 1 samples in two different manners: the volume percent of the settled solids as a function of time and the solids height as function of time. Precision between the triplicate tests was good. The solids settled rapidly during the first $6 \mathrm{~h}$, but the settling rate slowed beyond that point. The initial settling rate was $\sim 0.6$ $\mathrm{cm} / \mathrm{h}$. The solids appeared to be completely settled after $48 \mathrm{~h}$. The observed settling behavior is consistent with a slurry in which the initial solids loading is below the gel point, i.e., the

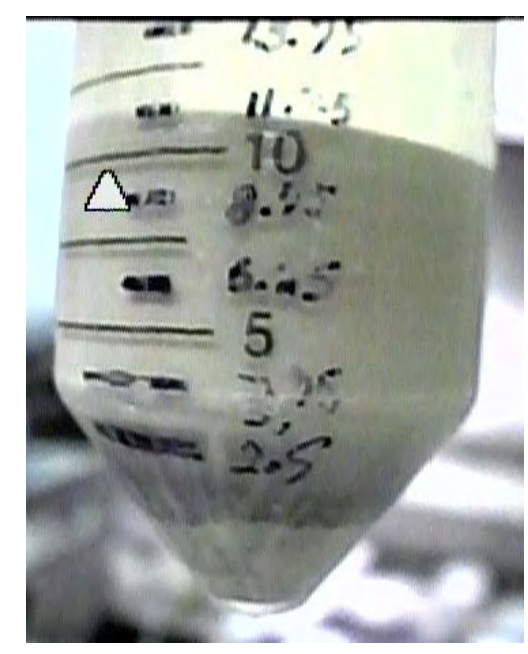

Figure 3.3. Centrifuged Solids for Chemical Characterization Sample of Group 1 point at which agglomerates interconnect to form a network (Rector and Bunker 1995). The change in the slope of the settling curve is approximately at a settled-solids volume of $70 \%$. Based on an initial 
undissolved solids loading of $9 \mathrm{wt} \%$ (Table 3.2), the gel point for this slurry is estimated to be $13 \mathrm{wt} \%$ $(9 \mathrm{wt} \% \div 0.7){ }^{(\mathrm{a})}$
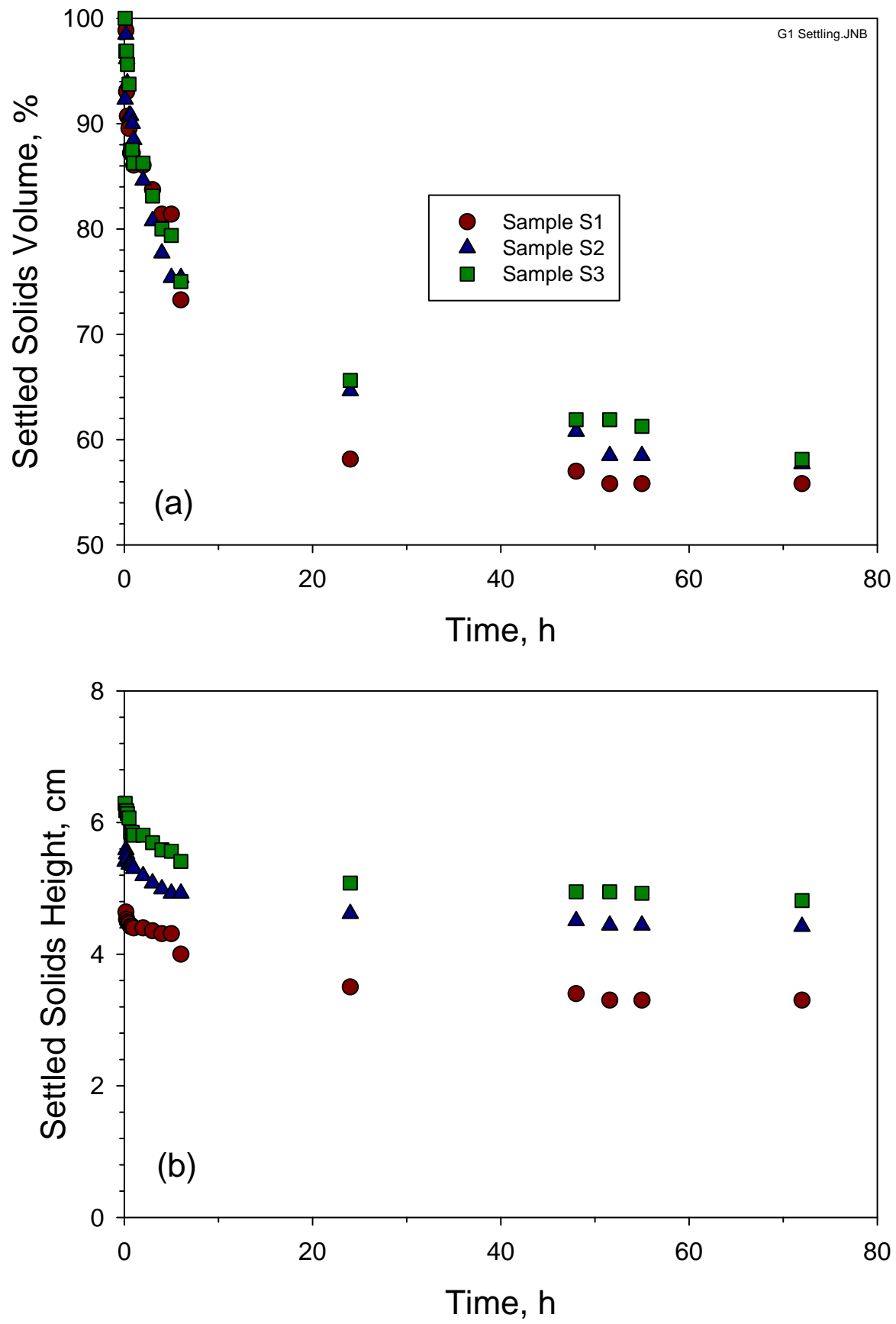

Figure 3.4. Group 1 Settling Curves: a) Volume Percent Settled Solids vs Time and b) Settled Solids Height vs Time

(a) This estimate of the gel point does not take into account the increasing density of the settled-solids layer as settling progresses. 
Table 3.2 presents the physical properties of the Group 1 samples, including the propagated 1- $\sigma$ error, the average values of the triplicate measurements, and the relative standard deviation. Good precision was obtained for the sample set.

Table 3.2. Physical Properties of Homogenized Group 1 Sludge

\begin{tabular}{|c|c|c|c|c|c|c|}
\hline Description & AR-S1 & AR-S2 & AR-S3 & $\begin{array}{l}\text { Nominal } \\
1 \sigma \text { error }\end{array}$ & Avg. & $\begin{array}{c}\text { RSD }^{(a)} \\
(\%) \\
\end{array}$ \\
\hline \multicolumn{7}{|c|}{ Bulk Sample } \\
\hline Density (g/mL) & 1.29 & 1.33 & 1.32 & 0.17 & 1.31 & 1.2 \\
\hline Total Solids (wt\%) & 31.5 & 34.7 & 32.5 & 0.047 & 32.9 & 5.0 \\
\hline Total Undissolved Solids (wt\%) & 7.1 & 11.4 & 8.4 & 0.05 & 9.0 & 25 \\
\hline \multicolumn{7}{|c|}{ Settled Solids } \\
\hline Density $(\mathrm{g} / \mathrm{mL})$ & 1.31 & 1.39 & 1.38 & 0.25 & 1.36 & 3.6 \\
\hline $\begin{array}{l}\text { Vol\% relative to the total sample } \\
\text { volume }\end{array}$ & 57 & 57.7 & 58.1 & 9.0 & 57.4 & 0.97 \\
\hline $\begin{array}{l}\text { Wt\% relative to the total sample } \\
\text { weight }\end{array}$ & 52.5 & 57.9 & 58.9 & 13 & 56.4 & 6.1 \\
\hline Total Undissolved Solids (wt\%) & 10.9 & 17.3 & 12.9 & 2.9 & 13.7 & 24 \\
\hline \multicolumn{7}{|c|}{ Wet Centrifuged Solids } \\
\hline Density $(g / m L)$ & 1.36 & 1.43 & 1.46 & 0.22 & 1.41 & 2.1 \\
\hline $\begin{array}{l}\text { Vol\% relative to the total sample } \\
\text { volume }\end{array}$ & 37.3 & 37.8 & 34.9 & 7.4 & 36.7 & 4.1 \\
\hline $\begin{array}{l}\text { Wt\% relative to the total sample } \\
\text { weight }\end{array}$ & 39.4 & 40.8 & 38.8 & 0.04 & 39.6 & 2.6 \\
\hline Total Undissolved Solids (wt\%) & 18.1 & 26.4 & 20.8 & 7.2 & 21.8 & 19 \\
\hline Total Solids (wt\%) & 39.5 & 46.9 & 42.3 & 0.082 & 42.9 & 8.7 \\
\hline \multicolumn{7}{|c|}{ Supernatant } \\
\hline Density (g/mL) & 1.25 & 1.21 & 1.21 & 0.032 & 1.22 & 0 \\
\hline Total Dissolved Solids (wt\%) & 26.1 & 26.2 & 26.2 & 0.06 & 26.2 & 0.22 \\
\hline Water Content (g/g) & 0.739 & 0.738 & 0.738 & 0.738 & 0.001 & 0.08 \\
\hline
\end{tabular}

\subsubsection{Rheology of the Composite Slurry}

\subsubsection{Shear Strength}

A single measurement of shear strength was made on the settled solids in sample jar TI508-G1-AR-RH1. It was not possible to satisfy the geometric constraints for vane immersion because of the limited volume of settled solids $(<100 \mathrm{~mL})$ in the test sample. As a consequence, the shear strength result is not independent of container geometry and may not even be representative of the actual shear strength of the settled solids. For this reason, no duplicate measurements were taken. The single value reported herein should be taken as a rough estimate of the shear strength of the settled Group 1 solids. 
The settled solids in test jar TI508-G1-AR-RH1 were fully dispersed and allowed to settle undisturbed for $67 \mathrm{~h}$ before performing the shear strength measurement. The shear strength test was performed directly in the 250-mL Qorpak sample jars in which the slurry was provided. The shear strength was tested as follows (the measurements were conducted at the ambient cell temperature of $\sim 24^{\circ} \mathrm{C}$ ):

1. A $16 \times 16 \mathrm{~mm}$ (diameter by height) shear vane tool was installed on the measuring head.

2. The sample jar being tested was opened and positioned on a laboratory jack stand directly beneath the measuring head/vane.

3. The laboratory jack was slowly raised until the top of the vane blades were just below the surface of the settled solids. For this sample, the volume of settled solids was just barely sufficient to fully immerse the vane without contacting the bottom of the container.

4. The vane was slowly rotated at 0.3 revolutions per minute (RPM) for 240 seconds. For the entire duration of rotation, the time, rotational rate, and vane torque were continuously monitored and recorded.

At the completion of testing, the vane was removed from the settled solids, rinsed clean of residual solids with deionzied (DI) water, and allowed to air dry before the next test. The sample jar was closed and set aside.

At the end of the measurement, the software parsed the shear stress versus time data and determined and reported the maximum measured shear stress (i.e., the material's shear strength). The curve of shear stress versus time was visually inspected using the RheoWin software to verify that the appropriate stress maximum was selected.

The single observation at 67 hours of settling time indicated that the shear strength of the settled Group 1 slurry was $15 \mathrm{~Pa}$. Because the geometric constraints required for shear strength testing could not be met given the low settled solids volume, this result is an order-of-magnitude estimate only. The measured 15Pa shear strength is relatively low. For comparison, Group 5 solids attained shear strengths of $72 \mathrm{~Pa}$ after 52 hours of settling (Fiskum et al. 2008). It should be noted that only the transient shear-strength behavior was observed for 2 to 3 days in accordance with the test plan. Again, the limited solids volume for the Group 1 sample prevented examining the shear strength at longer settling periods.

\subsubsection{Flow Curve}

Flow curve testing for both slurry and supernatant samples employed an MV1 cup and rotor (see Appendix B). Each flow curve measurement was accomplished as follows:

1. The MV1 rotor was installed on the measuring head.

2. The temperature jacket was installed and the recirculator turned on and set to $25^{\circ} \mathrm{C}$. The jacket was allowed to achieve temperature equilibrium.

3. The test sample was transferred from its source jar into the MV1 measurement cup. The sample was added to the cup until the fluid level was above the first (i.e., lowest) cup level marker but still below the second level marker. This typically required 40 to $50 \mathrm{~mL}$ of sample. Gross material transfer was accomplished by pouring the sample into the test container until a rough estimate of the required sample volume was obtained. Fine-level adjustments were made by adding and removing material to and from the measuring cup using a plastic transfer pipette. 
4. The measuring cup was installed into the water jacket by slowly raising it on a laboratory jack stand. The cup was raised until the test material was observed to spill over the top of the rotor. Before continuing, excess material was removed from the top of the rotor (to the extent possible) using a plastic transfer pipette. In most cases, there was approximately 1 to $3 \mathrm{~mL}$ of excess material that could not be removed from the upper rotor recess.

5. A moisture barrier was wetted and installed over the opening at the top of the temperature jacket. This barrier is a stainless steel clamshell collar lined with a sponge. It serves to minimize sample evaporation by blocking openings at the top of the water jacket (where the sample is exposed to air) and by humidifying the air space above the sample.

6. The sample was left undisturbed in the measuring system for 5 minutes to allow temperature equilibration.

7. The sample was sheared for 3 minutes to break the sample structure, to attempt to re-suspend any settled slurry particles, and to verify that the rotor was properly centered.

8. The material flow curve data were measured. Rheological analysis was performed over a 15-minute period, split into three 5-minute intervals. Over the first 5 minutes, the shear rate was smoothly increased from zero to $1000 \mathrm{~s}^{-1}$. For the second 5 minutes, the shear rate was held constant at $1000 \mathrm{~s}^{-1}$. For the final 5-minutes, the shear rate was smoothly reduced back to zero. During this time, the resisting torque and rotational rate were continuously monitored and recorded.

9. The flow curve data for $25^{\circ} \mathrm{C}$ were saved using the RheoWin file format and a unique filename identifier. Sample information and the associated RheoWin filename were entered into the laboratory record book (LRB).

10. The cup was raised so that fresh sludge/slurry filled the gap. Excess sludge was pipetted from the top. The moisture guard was removed, re-wetted, and then re-installed.

11. The flow curve measurement at $25^{\circ} \mathrm{C}$ was repeated as per steps 7 through 9 .

12. The temperature set point was set to $40^{\circ} \mathrm{C}$. Once the jacket had reached the temperature set point, the sample was allowed an additional 5 minutes to reach temperature equilibrium. The cup was raised so that fresh sludge/slurry filled the gap. Excess sludge was removed from the top using a pipette. The moisture guard was removed, re-wetted, and then re-installed.

13. The flow curve at $40^{\circ} \mathrm{C}$ was measured as per steps 7 through 9 .

14. The temperature set point was set to $60^{\circ} \mathrm{C}$. Once the jacket had reached the temperature set point, the sample was allowed an additional 5 minutes to reach temperature equilibrium. The cup was raised so that fresh sludge/slurry filled the gap. Excess sludge was removed from the top using a pipette. The moisture guard was removed, re-wetted, and then re-installed.

15. The flow curve at $60^{\circ} \mathrm{C}$ was measured as per steps 7 through 9 .

At the end of testing, the measuring cup was removed from the system. The test material was returned to its original container. The measuring system was disassembled. Any slurry or precipitated salt solids remaining in the cup or rotor were cleaned-off by rinsing with copious amounts of water and by wiping down the instrument with a damp cloth.

Visual inspection of the Group 1 slurry before testing found no observable solids settling during transfer from sample jar to rheometer measurement cup. In addition, when performing Step 7, the rotor torques that were measured while mixing were constant. This indicated that for short periods of time, such as the 
3-minute mixing step or the time required to transfer the sample to the measuring cup ( $\sim 5$ minutes), settling and shear history effects were minimal for the Group 1 slurry sample.

The RheoWin Pro Data Manager software, Version 2.96, was used for post-measurement analysis and review of flow-curve data. For each set of measurement data, the flow curve data were characterized by determining the best-fit parameters for the constitutive equation outlined in Appendix B of this report (i.e., the Newtonian, Power-Law, Bingham-Plastic, and Herschel-Bulkley flow models). This analysis used the least-squares data regression routine native to the RheoWin 2.96 software. Each regression included both up- and down-ramp portions of the flow curve, resulting in an "average" set of model parameters for the total flow curve. In certain cases, model fits were limited to specific shear rate ranges to avoid flow curve anomalies such as Taylor Vortices (at high shear rates) and slip (at low shear rates).

Figure 3.5 shows the results of flow curve testing for the Group 1 initial characterization slurry sample, TI508-G1-AR-RH1. The flow behavior is somewhat difficult to characterize. In some respects, this slurry appears to show slight non-Newtonian behavior. The basis for this conclusion is the small but finite yield stresses $\left(\sim 0.5 \mathrm{~Pa}\right.$ ) and the downward curvature in the 0 to $100 \mathrm{~s}^{-1}$ region observed in the flow curve at each temperature set point studied. On the other hand, the stress versus strain rate response is linear over 100 to $1000 \mathrm{~s}^{-1}$. In addition, the yield stress is at the instrument sensitivity limit of $0.5 \mathrm{~Pa}$ (i.e., the yield stress may not be significantly different than zero) and the low shear curvature may be an artifact of poor sampling. Based on the latter arguments, it may be more appropriate to classify the flow behavior Newtonian. For the purposes of reporting herein, the flow behavior was treated using a Bingham-Plastic model to obtain parametric estimates for yield stress and consistency (or Newtonian viscosity, if the yield point was not significantly different than zero). A Herschel-Bulkley analysis of the flow curve data was also done to determine the degree of shear thinning or thickening.

Table 3.3 summarizes the best-fit rheological parameters for flow curve data for sample TI508-G1-ARRH1. Bingham-Plastic fits consider shear rates from 200 to $1000 \mathrm{~s}^{-1}$ to avoid the strong downward curvature in the flow curve data from 0 to $100 \mathrm{~s}^{-1}$. Herschel-Bulkley fits consider the entire range of shear rate studied. An example of the quality of the data fit that these parameters provide is shown in Figure 3.6, which shows both Bingham-Plastic and Herschel-Bulkley flow curve fits at $40^{\circ} \mathrm{C}$. In terms of capturing the range of magnitude, curvature, slope, and yield, both Herschel-Bulkley and Bingham-Plastic equations provide roughly the same fit. Additionally, the fitting parameters confirm the observations made in the preceding paragraphs. Specifically, they show that, at $9 \mathrm{wt} \%$ UDS (Table 3.2):

- The Bingham-Plastic yield stresses typically range from 0.0 to $0.5 \mathrm{~Pa}$. Given the typically $\pm 0.5 \mathrm{~Pa}$ measurement limit for the M5 system, the measured yield stress is likely not significantly different than zero. Overall, this suggests that Group 1 waste slurries are Newtonian fluids with regards to our measurement capability.

The Herschel-Bulkley flow indices fall between 1.0 and 1.2, indicating that the flow curve curvature is minor and that the stress response to increased shear is linear (i.e., consistent with the Bingham-Plastic model). 


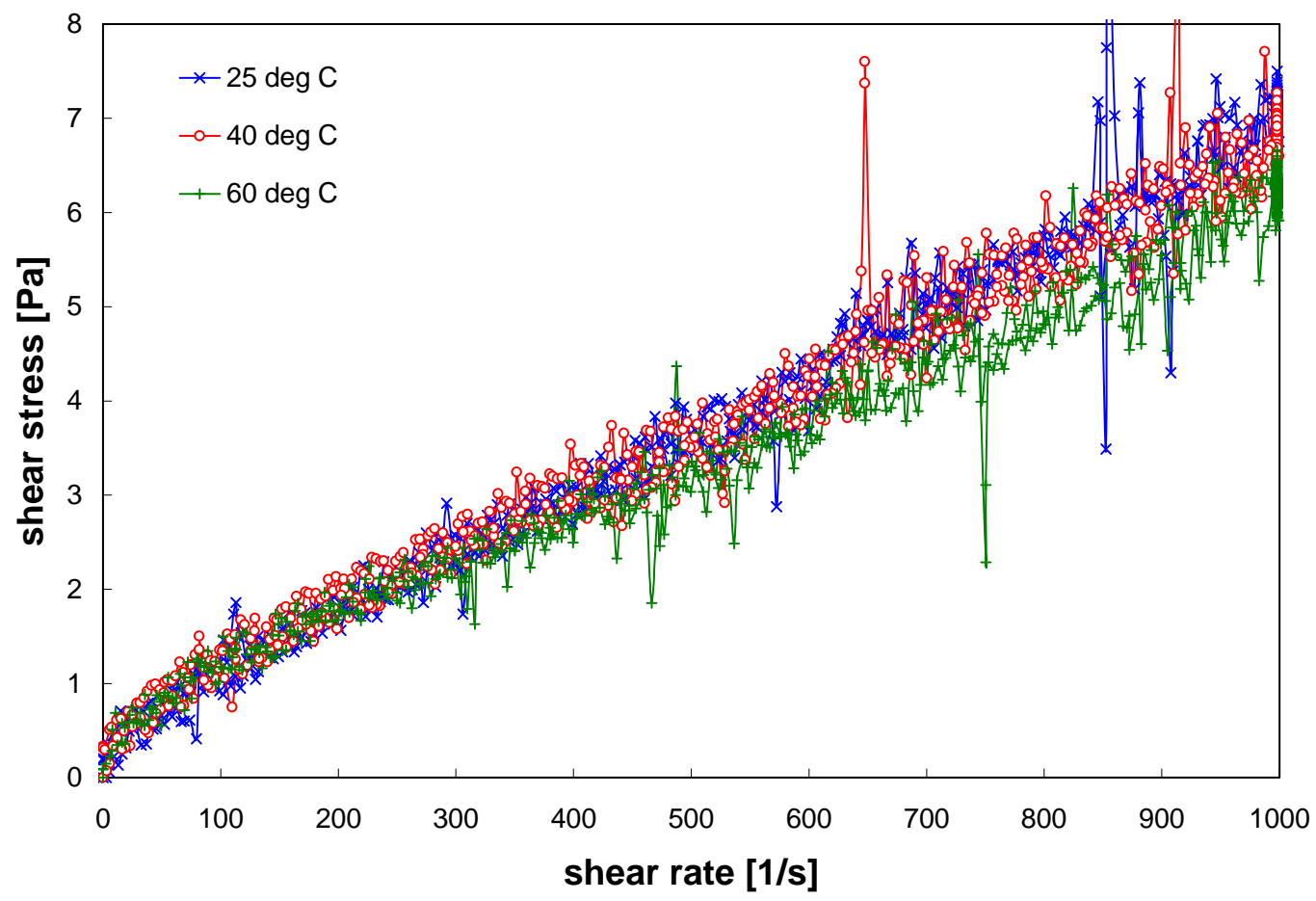

Figure 3.5. Flow Curve (shear stress versus shear rate) for the Group 1 Initial Characterization Slurry Sample TI508-G1-AR-RH1 at $25^{\circ} \mathrm{C}, 40^{\circ} \mathrm{C}$, and $60^{\circ} \mathrm{C}$. Note: the second repeat measurement for $25^{\circ} \mathrm{C}$ is shown here, as it is the closest to the $40^{\circ}$ and $60^{\circ} \mathrm{C}$ measurements in time.

Table 3.3. Results of Fitting Analysis for Rheology Sample TI508-G1-AR-RH1

\begin{tabular}{||c|c|c|c|c|c||}
\hline Model & $\begin{array}{c}\text { Temperature } \\
{\left[{ }^{\circ} \mathbf{C}\right]}\end{array}$ & $\begin{array}{c}\text { Yield } \\
\text { Stress [Pa] }\end{array}$ & $\begin{array}{c}\text { Consistency } \\
{\left[\mathbf{P a} \cdot \mathbf{s}^{\mathbf{n}}\right]}\end{array}$ & $\begin{array}{c}\text { Flow } \\
\text { Index }\end{array}$ & $\mathbf{R}$ \\
\hline $\begin{array}{c}\text { Bingham-Plastic } \\
\left(200-1000 \mathrm{~s}^{-1}\right)\end{array}$ & $25(1$ of 2$)$ & 0.0 & 0.0064 & $\mathrm{n} / \mathrm{a}$ & 0.992 \\
\cline { 2 - 6 } & $25(2$ of 2$)$ & 0.3 & 0.0067 & $\mathrm{n} / \mathrm{a}$ & 0.993 \\
\cline { 2 - 6 } & 40 & 0.5 & 0.0063 & $\mathrm{n} / \mathrm{a}$ & 0.989 \\
\cline { 2 - 6 } & 60 & 0.5 & 0.0056 & $\mathrm{n} / \mathrm{a}$ & 0.991 \\
\hline \multirow{3}{*}{$\begin{array}{c}\text { Herschel-Bulkley } \\
\left(0-1000 \mathrm{~s}^{-1}\right)\end{array}$} & $25(1$ of 2$)$ & 0.4 & 0.0014 & 1.2 & 0.994 \\
\cline { 2 - 7 } & $25(2$ of 2$)$ & 0.5 & 0.0044 & 1.1 & 0.993 \\
\cline { 2 - 7 } & 40 & 0.6 & 0.0056 & 1.0 & 0.989 \\
\cline { 2 - 7 } & 60 & 0.7 & 0.0027 & 1.1 & 0.991 \\
\hline
\end{tabular}

In addition, the fitting results provide qualitative information on the stress response of the fluid and how it changes with temperature:

- The fluid consistency decreases from $6.7 \mathrm{cP}$ to $5.6 \mathrm{cP}$ as the temperature is increased from $25^{\circ}$ to $60^{\circ} \mathrm{C}$. Figure 3.5 confirms this observation, as the slope of the flow curve for the $60^{\circ} \mathrm{C}$ temperature is less than that at $25^{\circ} \mathrm{C}$. This decrease is consistent with a decrease in suspending phase viscosity; however, changes in suspending phase viscosity with temperature are not necessarily the only physical mechanism by which the slurry consistency can be decreased. 
- The apparent Bingham fluid yield stress increases with 0.0 to 0.5 Pa throughout the course of testing. This change may be the result of shearing effects, suspending phase evaporation, temperature increases, or some combination thereof. However, the final estimated yield stress of $0.5 \mathrm{~Pa}$ is still not significant.

Both Bingham yield and consistency of the replicate measurement at $25^{\circ} \mathrm{C}$ are within the $\pm 0.5 \mathrm{~Pa}$ and $\pm 0.5 \mathrm{cP}$ stress and consistency fitting limits for the instrument. In other words, the replicate measurement confirms the primary measurement. This, combined with the absence of flow curve hysteresis (even at $60^{\circ} \mathrm{C}$, where hysteresis is typically observed for slurry samples), indicates that evaporation does not significantly impact the Group 1 rheological properties.

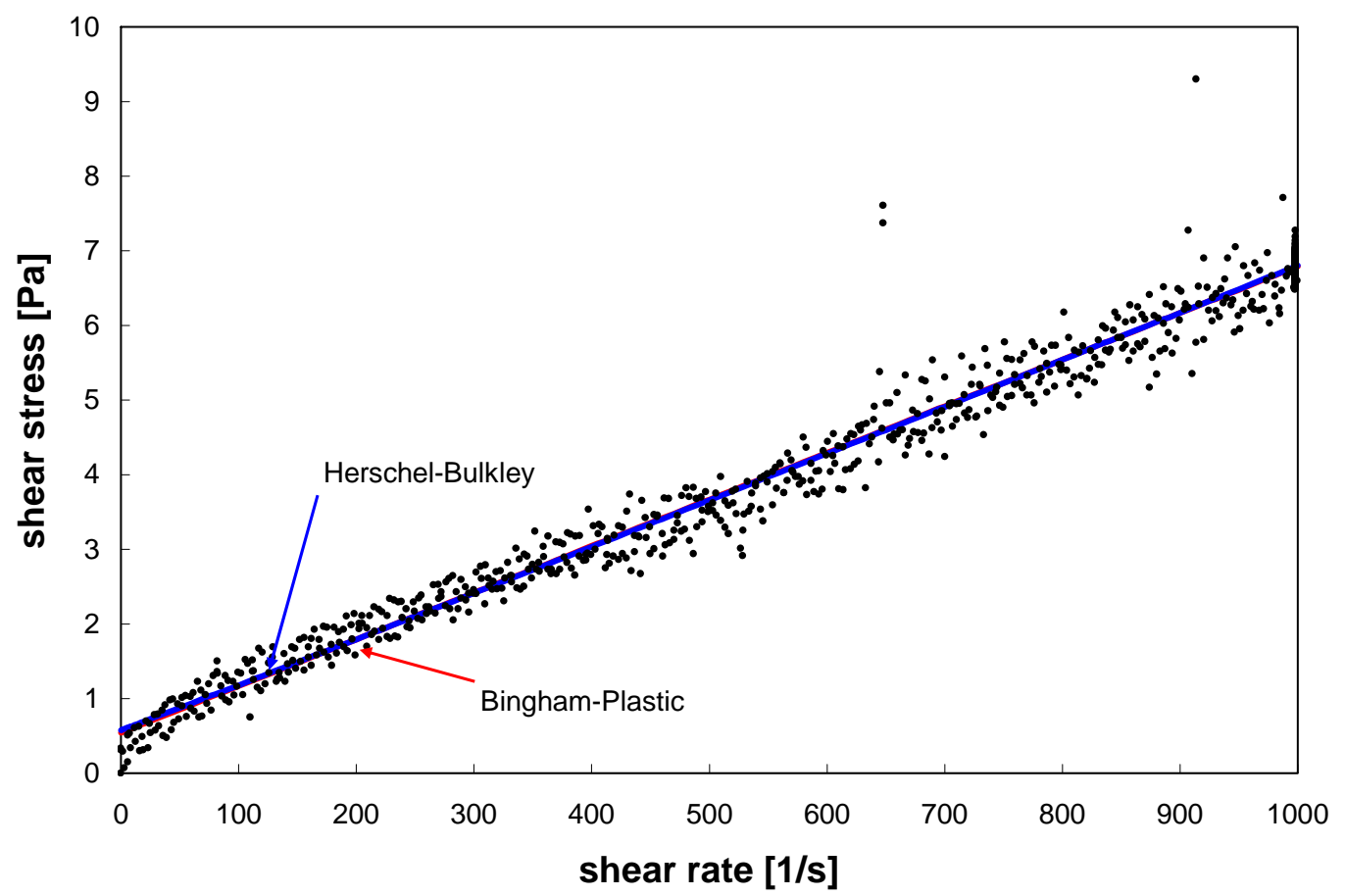

Figure 3.6. Model Fits of Flow Curve Data for Group 1 Initial Characterization Slurry Sample TI508G1-AR-RH1 at $40{ }^{\circ} \mathrm{C}$. Both model fits consider the full shear rate range of 0 to $1000 \mathrm{~s}^{-1}$.

For ease of reference, apparent viscosities at $33 \mathrm{~s}^{-1}, 100 \mathrm{~s}^{-1}, 500 \mathrm{~s}^{-1}$, and $1000 \mathrm{~s}^{-1}$ were derived from each measurement. For each temperature, the $33 \mathrm{~s}^{-1}, 100 \mathrm{~s}^{-1}$, and $500 \mathrm{~s}^{-1}$ reference viscosities were determined from the average of up-ramp and down-ramp flow curve data. The apparent viscosity at $1000 \mathrm{~s}^{-1}$ averages apparent viscosity measurements over the period of constant rotation at $1000 \mathrm{~s}^{-1}$. As a point of comparison, apparent viscosities at $33 \mathrm{~s}^{-1}, 100 \mathrm{~s}^{-1}, 500 \mathrm{~s}^{-1}$, and $1000 \mathrm{~s}^{-1}$ were also calculated using the Bingham-Plastic and Herschel-Bulkley fitting parameters in Table 3.3. The results of these analyses are provided in Table 3.4 and show that apparent viscosities typically range from 6.7 to $26 \mathrm{cP}$ at $33 \mathrm{~s}^{-1}$, 6.5 to $12 \mathrm{cP}$ at $100 \mathrm{~s}^{-1}, 5.5$ to $7.4 \mathrm{cP}$ at $500 \mathrm{~s}^{-1}$, and 6.2 to $7.1 \mathrm{cP}$ at $1000 \mathrm{~s}^{-1}$. 
Table 3.4. Apparent Viscosity of Sample TI508-G1-AR-RH1

\begin{tabular}{|c|c|c|c|c|c|}
\hline \multirow[b]{2}{*}{ Source } & \multirow{2}{*}{$\begin{array}{c}\text { Temperature } \\
{\left[{ }^{\circ} \mathrm{C}\right]} \\
\end{array}$} & \multicolumn{4}{|c|}{ Apparent Viscosity [cP] } \\
\hline & & @ $33 \mathrm{~s}^{-1}$ & @ $100 \mathrm{~s}^{-1}$ & @ $500 \mathrm{~s}^{-1}$ & @ $1000 \mathrm{~s}^{-1}$ \\
\hline \multirow[t]{4}{*}{ Measured } & 25 (1 of 2$)$ & 13 & 8.5 & 5.5 & 6.5 \\
\hline & 25 (2 of 2$)$ & 16 & 11 & 7.2 & 7.1 \\
\hline & 40 & 22 & 12 & 7.1 & 6.8 \\
\hline & 60 & 20 & 11 & 6.4 & 6.2 \\
\hline \multirow[t]{4}{*}{ Bingham-Plastic } & 25 (1 of 2$)$ & 6.7 & 6.5 & 6.4 & 6.4 \\
\hline & 25 (2 of 2$)$ & 17 & 10 & 7.4 & 7.0 \\
\hline & 40 & 23 & 12 & 7.3 & 6.8 \\
\hline & 60 & 21 & 11 & 6.7 & 6.2 \\
\hline \multirow[t]{4}{*}{ Herschel-Bulkley } & 25 (1 of 2$)$ & 16 & 8.1 & 6.1 & 6.5 \\
\hline & 25 (2 of 2$)$ & 20 & 11 & 7.3 & 7.1 \\
\hline & 40 & 23 & 12 & 7.3 & 6.8 \\
\hline & 60 & 26 & 12 & 6.5 & 6.2 \\
\hline
\end{tabular}

In summary, visual inspection of flow curves for Group 1 initial characterization slurry sample, TI508G1-AR-RH1, suggests rheological properties consistent with a Bingham Plastic model; however, the yield stress is sufficiently low that the rheometer used for the current measurements cannot qualitatively distinguish the rheology from that of a Newtonian fluid. Regression analysis of the flow curve data finds Bingham-Plastic yield stresses that range from 0.0 to $0.5 \mathrm{~Pa}$ with an associated uncertainly of $\pm 0.5 \mathrm{~Pa}$, indicating that they are not distinguishable from zero. Bingham-Plastic consistencies for the slurry range from $6.4 \mathrm{cP}$ at $25^{\circ} \mathrm{C}$ to $5.6 \mathrm{cP}$ at $60^{\circ} \mathrm{C}$. Flow curve hysteresis effects were not observed, which indicates that evaporation of the suspending phase does not noticeably increase slurry viscosity over time.

\subsubsection{Chemical and Radiochemical Composition}

The two samples of the Group 1 composite taken for chemical characterization were evaluated for volume-percent centrifuged solids as part of the initial phase separation. In this case, the volume-percent centrifuged solids duplicated well at $31 \mathrm{vol} \%$, but was slightly less than the $37 \%$ centrifuged solids found with the physical-property testing samples. Centrifuging conditions were the same in each case; however, the centrifuge cones were constructed of different materials: polypropylene for the characterization samples and glass for the physical-property test samples.

The supernatant density was determined to be $1.193 \mathrm{~g} / \mathrm{mL}\left(\mathrm{T}=28^{\circ} \mathrm{C}\right)$ based on the average masses of four 1-mL volume deliveries. This compared well with the density determined as part of the physical-property testing procedure (density $=1.2 \mathrm{~g} / \mathrm{mL}$ ). The density of the composite washing solution was $1.063 \mathrm{~g} / \mathrm{mL}$. The volumes of the supernatant liquid and the washing solution were 41.91 and $49.46 \mathrm{~mL}$, respectively, and the mass of the washed solids on a dry weight basis was $6.387 \mathrm{~g}$.

The average radioanalytical results for the supernatant, composited wash solution, and washed solids are provided in Table 3.5 along with the applicable relative percent differences (RPD, measure of precision between duplicates). The gross-beta results showed good agreement with the sum of beta emitters: ${ }^{137} \mathrm{Cs}$ and ${ }^{90} \mathrm{Sr}$ (in secular equilibrium with ${ }^{90} \mathrm{Y}$ ) thus indicating that no other major source of beta-gamma activity was present. The gross-alpha activity in the supernatant liquid was below the method detection limit. The gross-alpha activity measured in the solids agreed with the summation of alpha emitters $\left({ }^{238} \mathrm{Pu}\right.$, 
${ }^{239+240} \mathrm{Pu}$, and $\left.{ }^{241} \mathrm{Am}\right)$. The fusion blank processed with the washed solids contained ${ }^{60} \mathrm{Co}$ and ${ }^{238} \mathrm{Pu}$ contamination. The ${ }^{60} \mathrm{Co}$ contamination in the blank was equivalent to the sample concentration and should be considered an upper bound. The ${ }^{60} \mathrm{Co}$ concentration was 3 times lower than the detection limit defined in the test plan (3.0E-2 $\mu \mathrm{Ci} / \mathrm{g})$. The ${ }^{238} \mathrm{Pu}$ activity concentration in the process blank represented $40 \%$ of the sample activity; because sample contamination could not be ruled out, the reported value is provided for information only and should be considered an upper bound.

Table 3.5. Radionuclide Characterization of the Group 1 Sludge

\begin{tabular}{|c|c|c|c|c|c|c|}
\hline \multirow{3}{*}{$\begin{array}{c}\text { Sample ID> } \\
\text { Analyte } \\
\end{array}$} & \multirow{2}{*}{\multicolumn{2}{|c|}{$\begin{array}{c}\text { Supernatant } \\
\text { 07-01714 } \\
\end{array}$}} & \multirow{2}{*}{\multicolumn{2}{|c|}{$\begin{array}{c}\text { Wash Composite } \\
\text { 07-01715 } \\
\end{array}$}} & \multirow{2}{*}{\multicolumn{2}{|c|}{$\begin{array}{c}\text { Washed Solids } \\
\mathbf{0 7 - 0 1 7 1 6} \\
\end{array}$}} \\
\hline & & & & & & \\
\hline & $\mu \mathrm{Ci} / \mathrm{mL}$ & RPD & $\mu \mathrm{Ci} / \mathbf{m L}$ & RPD $^{(a)}$ & $\mu \mathrm{Ci} / \mathbf{g}^{(\mathbf{b})}$ & RPD \\
\hline${ }^{137} \mathrm{Cs}$ & $3.56 \mathrm{E}+0$ & 1.69 & 8.07E-1 & na & $2.19 \mathrm{E}+1$ & 1.4 \\
\hline${ }^{60} \mathrm{Co}$ & $<6$. E-5 & na & 5.31E-5 & na & $9.59 \mathrm{E}-3^{(\mathrm{c})}$ & 25 \\
\hline${ }^{241} \mathrm{Am}$ & $<3 . \mathrm{E}-3$ & na & $<3 . \mathrm{E}-4$ & na & $5.87 \mathrm{E}-2$ & 24 \\
\hline${ }^{238} \mathrm{Pu}$ & $<1$. E-6 & na & \multirow{7}{*}{\multicolumn{2}{|c|}{ na }} & $1.02 \mathrm{E}-2^{(\mathrm{d})}$ & 44 \\
\hline${ }^{239+240} \mathrm{Pu}$ & $3.90 \mathrm{E}-5$ & 14 & & & 5.64E-1 & 0.71 \\
\hline${ }^{90} \mathrm{Sr}$ & $8.40 \mathrm{E}-4$ & 4.9 & & & $3.95 \mathrm{E}+1$ & 1.0 \\
\hline Gross alpha & $<7 . \mathrm{E}-4$ & na & & & 6.31E-1 & 8.7 \\
\hline Sum of alpha & na & na & & & 6.33E-1 & 0.87 \\
\hline Gross beta & $3.64 \mathrm{E}+0$ & 3.6 & & & $1.07 \mathrm{E}+2$ & 0.94 \\
\hline Sum of beta & $3.56 \mathrm{E}+0$ & 1.7 & & & $1.01 \mathrm{E}+2$ & 1.09 \\
\hline \multicolumn{7}{|l|}{ Opportunistic } \\
\hline${ }^{154} \mathrm{Eu}$ & $<2$.E-4 & na & $<9$. E-6 & na & $<5$.E-3 & na \\
\hline${ }^{155} \mathrm{Eu}$ & $<2 . \mathrm{E}-3$ & na & $<2 . \mathrm{E}-4$ & na & $<2 . \mathrm{E}-2$ & na \\
\hline \multicolumn{7}{|c|}{$\begin{array}{l}\text { ASR 7985; Reference date is July 15, } 2007 \text {. } \\
\text { (a) This sample was not required to be run in duplicate; therefore, an RPD was not calculated. } \\
\text { (b) Analyte concentrations are calculated on a dry-mass basis. } \\
\text { (c) High analyte activity was found in the process blank; the }{ }^{60} \mathrm{Co} \text { in the blank was equal to the sample } \\
\text { concentration. The sample concentration was a factor of three lower than contracted detection limit, and } \\
\text { thus, it is reported for information only and should be considered an upper bound. } \\
\text { (d) High analyte activity was found in the process blank; the }{ }^{238} \mathrm{Pu} \text { in the blank was } 40 \% \text { of the sample } \\
\text { concentration. The sample concentration was a factor of } 10 \text { higher than the contracted detection limit, and } \\
\text { thus is reported for information only and should be considered an upper bound. } \\
\text { Notes: na = not applicable }\end{array}$} \\
\hline
\end{tabular}


The chemical composition of the washed Group 1 solids is provided in Table 3.6. The supernatant liquid consisted primarily of sodium nitrate with minor contributions of other sodium salts (sulfate, phosphate, and nitrite). The free-hydroxide concentration in the supernatant liquid was very low. The anionic and cationic charge balance was evaluated for the supernatant, resulting in a relative $6.0 \%$ difference, well within analytical uncertainties. Agreement between the total $\mathrm{S}$ and $\mathrm{P}$ values (determined by inductively coupled plasma-optical emission spectrometry [ICP-OES]) and $\mathrm{SO}_{4}{ }^{2-}$ and $\mathrm{PO}_{4}{ }^{3-}$ (determined by ion chromatrography [IC]) were well within the analytical uncertainties.

Table 3.6. Chemical Characterization of the Group 1 Test Material

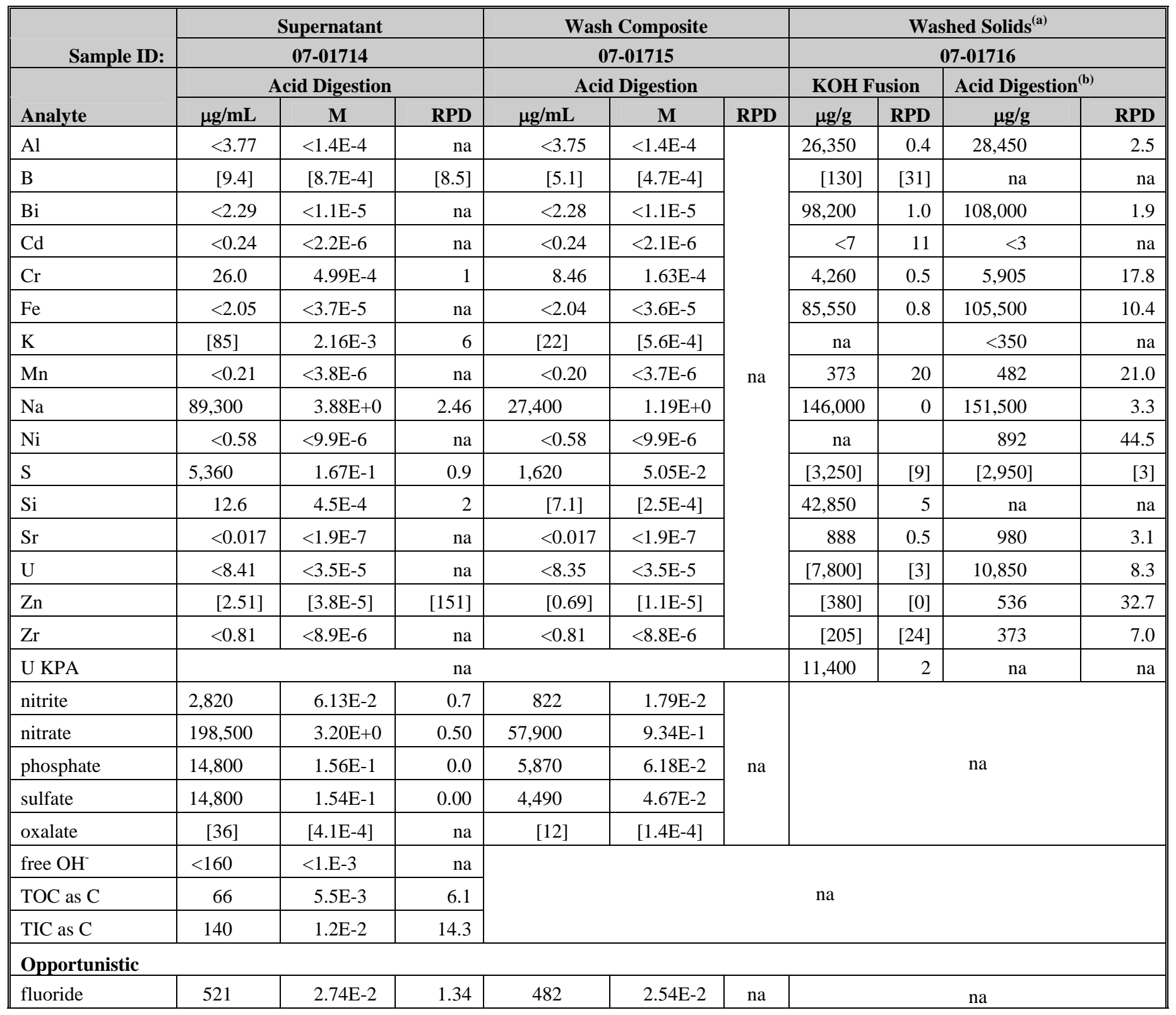


WTP-RPT-166, Rev. 0

Table 3.6 (Contd)

\begin{tabular}{|c|c|c|c|c|c|c|c|c|c|c|}
\hline \multirow{4}{*}{$\begin{array}{c}\text { Sample ID: } \\
\text { Analyte }\end{array}$} & \multirow{3}{*}{\multicolumn{3}{|c|}{$\begin{array}{c}\text { Supernatant } \\
\text { 07-01714 } \\
\text { Acid Digestion }\end{array}$}} & \multirow{2}{*}{\multicolumn{3}{|c|}{$\begin{array}{c}\text { Wash Composite } \\
\text { 07-01715 } \\
\end{array}$}} & \multicolumn{4}{|c|}{ Washed Solids $^{(\mathrm{a})}$} \\
\hline & & & & & & & \multicolumn{4}{|c|}{ 07-01716 } \\
\hline & & & & \multicolumn{3}{|c|}{ Acid Digestion } & \multicolumn{2}{|c|}{ KOH Fusion } & \multicolumn{2}{|c|}{ Acid Digestion $^{(\mathbf{b})}$} \\
\hline & $\mu \mathrm{g} / \mathrm{mL}$ & $\mathbf{M}$ & RPD & $\mu \mathrm{g} / \mathrm{mL}$ & M & RPD & $\mu \mathrm{g} / \mathrm{g}$ & RPD & $\mu \mathrm{g} / \mathrm{g}$ & RPD \\
\hline chloride & 1515 & $4.27 \mathrm{E}-2$ & 0.66 & 445 & $1.26 \mathrm{E}-2$ & \multirow{32}{*}{ na } & & & & \\
\hline $\mathrm{Ag}$ & $<0.42$ & $<3.9 \mathrm{E}-6$ & na & $<0.42$ & $<3.9 \mathrm{E}-6$ & & $<14$ & na & $<5$ & na \\
\hline As & $<7.0$ & $<9.3 \mathrm{E}-5$ & na & $<7.0$ & $<9.3 \mathrm{E}-5$ & & $<230$ & na & $<85$ & na \\
\hline $\mathrm{Ba}$ & $<0.34$ & $<2.5 \mathrm{E}-6$ & na & $<0.34$ & $<2.5 \mathrm{E}-6$ & & [54] & {$[4]$} & 60.7 & 4.0 \\
\hline $\mathrm{Be}$ & $<0.012$ & $<1.3 \mathrm{E}-6$ & na & $<0.012$ & $<1.3 \mathrm{E}-6$ & & $<1$ & na & $<0.2$ & na \\
\hline $\mathrm{Ca}$ & {$[2.6]$} & [6.5E-5] & {$[38]$} & $<2.1$ & $<5.2 \mathrm{E}-5$ & & $<2600$ & na & 1,790 & 7.3 \\
\hline $\mathrm{Ce}$ & $<1.2$ & $<8.6 \mathrm{E}-6$ & na & $<1.2$ & $<8.5 \mathrm{E}-6$ & & $<170$ & na & 175 & [74] \\
\hline Co & {$[0.58]$} & [9.8E-6] & [12] & $<0.39$ & $<6.5 \mathrm{E}-6$ & & $<18$ & na & [18] & [33] \\
\hline $\mathrm{Cu}$ & $<0.49$ & $<7.6 \mathrm{E}-6$ & na & $<0.48$ & $<7.6 \mathrm{E}-6$ & & [59] & [39] & 82.1 & 10.1 \\
\hline Dy & $<0.35$ & $<2.2 \mathrm{E}-6$ & na & $<0.35$ & $<2.2 \mathrm{E}-6$ & & $<44$ & na & $<4$ & na \\
\hline $\mathrm{Eu}$ & $<0.11$ & $<7.2 \mathrm{E}-7$ & na & $<0.11$ & $<7.1 \mathrm{E}-7$ & & $<14$ & na & $<5$ & na \\
\hline $\mathrm{La}$ & $<0.13$ & $<9.6 \mathrm{E}-7$ & na & $<0.13$ & $<9.5 \mathrm{E}-7$ & & $<9$ & na & $<2$ & na \\
\hline $\mathrm{Li}$ & [3.95] & [5.7E-4] & [13] & [2.5] & $3.60 \mathrm{E}-4$ & & $<27$ & na & {$[60]$} & [13] \\
\hline $\mathrm{Mg}$ & {$[0.78]$} & [3.2E-5] & [20] & $<0.70$ & $<2.9 \mathrm{E}-5$ & & [900] & [2] & 942 & 5.1 \\
\hline Mo & [1.55] & [1.6E-5] & [19] & $<0.65$ & $<6.8 \mathrm{E}-6$ & & $<25$ & 11 & {$[15]$} & [21] \\
\hline $\mathrm{Nd}$ & $<1.7$ & $<1.2 \mathrm{E}-5$ & na & $<1.7$ & $<1.2 \mathrm{E}-5$ & & $<260$ & na & [28] & [4] \\
\hline $\mathrm{P}$ & 4,720 & $1.52 \mathrm{E}-1$ & 1.27 & 1,870 & $6.04 \mathrm{E}-2$ & & 81,300 & na & 90,700 & 4.2 \\
\hline $\mathrm{Pb}$ & $<3.7$ & $<1.8 \mathrm{E}-5$ & na & $<3.7$ & $<1.8 \mathrm{E}-5$ & & [285] & [4] & 579 & 0.9 \\
\hline $\mathrm{Pd}$ & $<1.3$ & $<1.2 \mathrm{E}-5$ & na & $<1.3$ & $<1.2 \mathrm{E}-5$ & & $<160$ & na & $<15$ & na \\
\hline $\mathrm{Rh}$ & $<2.5$ & $<2.5 \mathrm{E}-5$ & na & $<2.5$ & $<2.4 \mathrm{E}-5$ & & $<100$ & na & $<31$ & na \\
\hline $\mathrm{Ru}$ & $<0.82$ & $<8.1 \mathrm{E}-6$ & na & $<0.82$ & $<8.1 \mathrm{E}-6$ & & $<44$ & na & $<10$ & na \\
\hline $\mathrm{Sb}$ & $<3.2$ & $<2.6 \mathrm{E}-5$ & na & $<3.1$ & $<2.6 \mathrm{E}-5$ & & $<150$ & na & $<38$ & na \\
\hline Se & $<4.9$ & $<6.2 \mathrm{E}-5$ & na & $<4.9$ & $<6.2 \mathrm{E}-5$ & & $<250$ & na & $<60$ & na \\
\hline Sn & $<2.0$ & $<1.7 \mathrm{E}-5$ & na & $<2.0$ & $<1.7 \mathrm{E}-5$ & & $<230$ & na & {$[26]$} & na \\
\hline Ta & $<1.3$ & $<7.4 \mathrm{E}-6$ & na & $<1.3$ & $<7.3 \mathrm{E}-6$ & & $<50$ & na & $<16$ & na \\
\hline $\mathrm{Te}$ & $<3.2$ & $<2.5 \mathrm{E}-5$ & na & $<3.1$ & $<2.5 \mathrm{E}-5$ & & $<200$ & na & $<39$ & na \\
\hline Th & $<1.2$ & $<5.1 \mathrm{E}-6$ & na & $<1.2$ & $<5.1 \mathrm{E}-6$ & & $<150$ & na & $<14$ & na \\
\hline $\mathrm{Ti}$ & $<0.10$ & $<2.0 \mathrm{E}-6$ & na & $<0.10$ & $<2.0 \mathrm{E}-6$ & & [45] & na & 64.1 & 11.4 \\
\hline $\mathrm{Tl}$ & $<6.1$ & $<3.2 \mathrm{E}-5$ & na & $<6.5$ & $<3.2 \mathrm{E}-5$ & & $<180$ & na & $<79$ & na \\
\hline $\mathrm{V}$ & $<0.32$ & $<6.2 \mathrm{E}-6$ & na & $<0.31$ & $<6.1 \mathrm{E}-6$ & & $<12$ & na & $<4$ & na \\
\hline $\mathrm{W}$ & $<1.5$ & $<8.2 \mathrm{E}-6$ & na & $<1.5$ & $<8.1 \mathrm{E}-6$ & & $<78$ & na & $<18$ & na \\
\hline $\mathrm{Y}$ & $<0.08$ & $<9.6 \mathrm{E}-7$ & na & $<0.08$ & $<9.5 \mathrm{E}-7$ & & $<17$ & na & $<1$ & na \\
\hline
\end{tabular}

(a) Analyte concentrations are calculated on a dry-mass basis.

(b) The solids acid digestion results were "J" flagged or estimated because of uncertainties associated with the dry-mass measurement. ASR 7985.

Analyte uncertainties were typically within $\pm 15 \%(2-\sigma)$; results in brackets indicate that the analyte concentrations were less than the minimum detection limit (MDL) and greater than the estimated quantitation limit (EQL), and uncertainties were $>15 \%$.

Opportunistic analytes are reported for information only; QC requirements did not apply to these analytes. 
Major constituents in the washed solids were sodium, iron, phosphorus, and bismuth. Aluminum, uranium, and chromium provided minor contributions to the mass of the washed solids. Overall good agreement was obtained between the two different sample preparation methods (potassium hydroxide $[\mathrm{KOH}]$ fusion and acid digestion). The $U$ results between kinetic phosphorescence analysis (KPA) of the fusion preparation and the ICP-OES analysis of the acid digestion agreed well.

The fractional distribution of selected analytes between the supernatant, wash, and solids phases is shown in Table 3.7 and Figure 3.7. A large portion of the Na (85\%) and S (as sulfate, 94\%) partitioned to the aqueous phase as a result of the initial contact with water during homogenization and the continued water washing. The $\mathrm{Al}$ and $\mathrm{Cr}$ remained primarily in the solids phase. Phosphorus was split between the aqueous and solids phases.

The total P concentrations in the supernatant and wash solutions determined by ICP-OES were equivalent to the phosphate concentrations determined by IC. Likewise, the total S concentrations were equivalent to the sulfate concentrations. Therefore, the mobilized forms represented the water-soluble sulfate and phosphate salts. The forms of S and $\mathrm{P}$ in the solids were not determined. For most analytes, the concentration in the wash composite was $\sim 30 \%$ of that in the supernatant. However, the phosphate (and total P) concentration in the wash composite was $\sim 40 \%$ of that in the supernatant liquid, indicating that some phosphate was further dissolved as a result of water washing.

The $\mathrm{Cr}, \mathrm{Na}, \mathrm{Al}, \mathrm{P}$, and S water-wash factors (analyte fraction in combined aqueous phases) obtained from the current testing were compared with B-104 water-wash factors obtained from the TWINS database. The experimental wash factors generally agreed with those provided in the TWINS database.

Table 3.7. Phase Distribution of Selected Analytes in Group 1

\begin{tabular}{|c|c|c|c|c|c|}
\hline Analyte & $\begin{array}{c}\text { Supernatant } \\
\% \\
\end{array}$ & $\begin{array}{c}\text { Wash } \\
\text { Solution } \\
\% \\
\end{array}$ & $\begin{array}{c}\text { Solids } \\
\%\end{array}$ & $\begin{array}{c}\text { Water-Wash } \\
\text { Factor } \\
\% \\
\end{array}$ & $\begin{array}{c}\text { TWINS Water- } \\
\text { Wash Factor }^{(\mathbf{a})} \\
\% \\
\end{array}$ \\
\hline $\mathrm{Cr}$ & 3.8 & 1.5 & 94.8 & 5.2 & 3 \\
\hline $\mathrm{Al}$ & $<0.1$ & $<0.1$ & 99.8 & 0.2 & 1.6 \\
\hline $\mathrm{Na}$ & 62.1 & 22.5 & 15.5 & 84.5 & 93 \\
\hline $\mathrm{P}$ & 24.4 & 11.4 & 64.1 & 35.9 & $45^{(\mathrm{b})}$ \\
\hline $\mathrm{S}$ & 69.0 & 24.6 & 6.4 & 93.6 & $92^{(\mathrm{c})}$ \\
\hline $\begin{array}{l}\text { (a) The } \\
\text { (b) Phosf } \\
\text { (c) Sulfa } \\
\end{array}$ & $\begin{array}{l}\text { r-wash factors ar } \\
\text { e water-wash fac } \\
\text { ater-wash factor. }\end{array}$ & resented by & $(2 / 29 / 08$ & of TWINS datab & \\
\hline
\end{tabular}




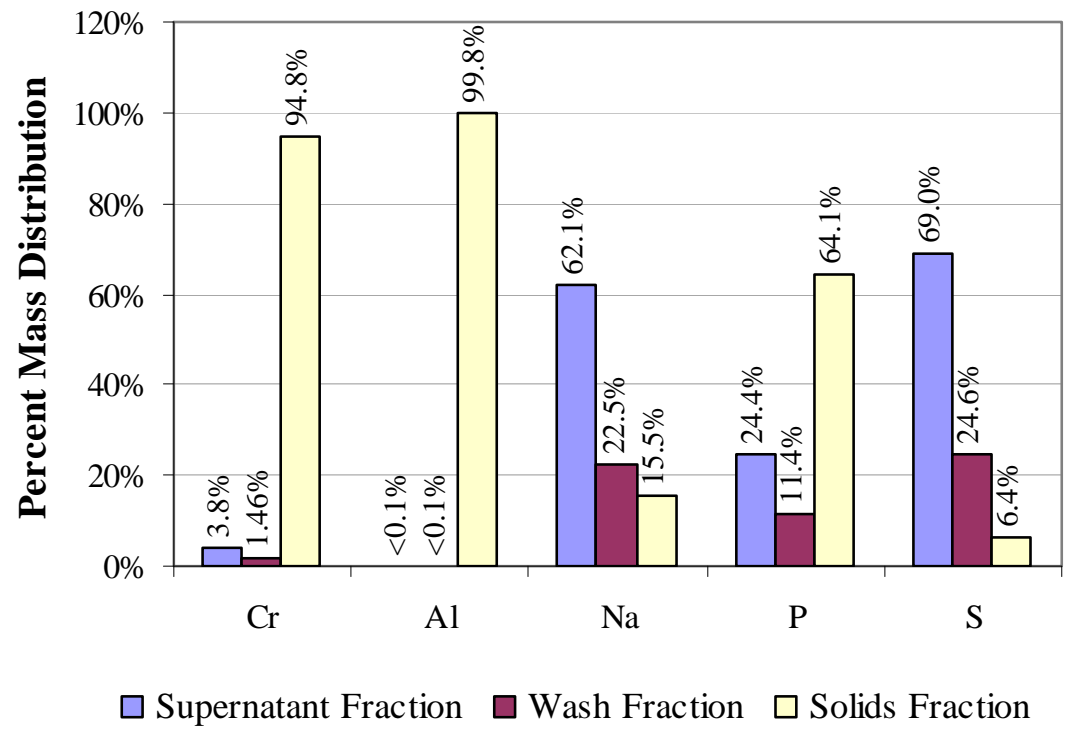

Figure 3.7. Selected Analyte Phase Distribution for Group 1

\subsubsection{Particle Size}

Figure 3.8 through Figure 3.10 and Table 3.8 and Table 3.9 present the results of Group 1 initial characterization particle-size analysis as a function of test conditions. Figure 3.8 through Figure 3.10 show the differential volume population distribution for the primary Group 1 initial characterization sample (see Appendix E for the duplicate sample results) and allow a qualitative examination of the particle-size distribution (PSD) behavior with respect to pump speed and sonication. Table 3.8 is a summary of the measured oversize diameter percentiles (by volume/weight) for the primary, TI483-G1-SWL-PSD-1. Table 3.9 presents the analogous data for the duplicate standard, TI483-G1-S-WL-PSD-2. Both tables present cumulative oversize diameters corresponding to the $10^{\text {th }}, 50^{\text {th }}$, and $90^{\text {th }}$ volume/weight percentiles, hereafter referred to as $d(10), d(50)$, and $d(90)$, respectively. More extensive percentile results are provided in Appendix F. These tables will be used to quantitatively examine reproducibility and changes in particle size.

Figure 3.8 shows the PSD for the primary Group 1 initial characterization sample as a function of pump speed before sonication. The distribution of particles is broad, ranging from 0.3 to $100 \mu \mathrm{m}$ and peaks near $10 \mu \mathrm{m}$. Although a small shoulder is visible near $2 \mu \mathrm{m}$, the distribution is relatively continuous. The size distribution of particles and particle aggregates before sonication is not significantly affected by changes in pump speed. From this, we may conclude that Group 1 solids are stable with respect to transient effects, such as shear-induced agglomeration, and mechanical effects, such as shear break-up of particle aggregates. Because a significant increase in the population of very large particles (10 to $100 \mu \mathrm{m}$ ) does not occur as pump speed is increased, it may be tentatively concluded that most (if not all) Group 1 solids are dispersed by the analyzer pump and sampled in the current set of analyses. 


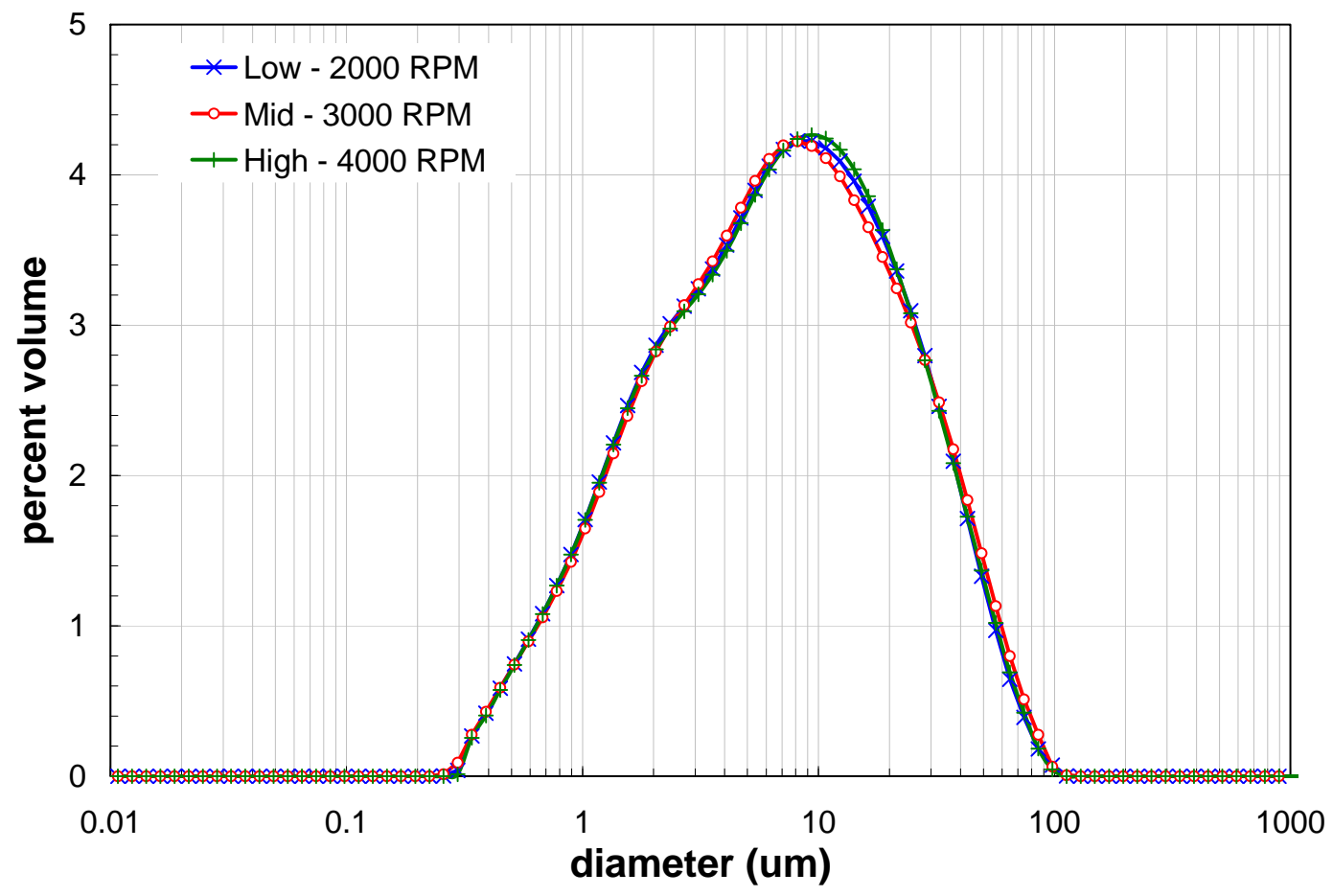

Figure 3.8. Pre-Sonication Volume Distribution Result for the Primary Group 1 Initial Characterization Sample as a Function of Pump Speed

Figure 3.9 shows the PSD for the washed Group 1 solids as a function of sonication. This figure indicates that sonication does not alter the range of the PSD, as it still spans 0.3 to $100 \mu \mathrm{m}$, but does shift the population to smaller diameters. Specifically, sonication decreases the volume of 10 - to $100-\mu \mathrm{m}$ particles while increasing the volume of the "shoulder" (i.e., 0.3 to $4 \mu \mathrm{m}$ ) particles. This change could result from sonic disruption (breakup) of particle aggregates.

Figure 3.10 shows the primary Group 1 initial characterization PSD as a function of pump speed after being sonicated. As with the distribution before sonication, changes in pump speed to not appear to significantly change the distribution. Based on this observation, it can be concluded that the particles are still stable with respect to mechanical (shear-induced) break-up even after sonication. Transient changes in the PSD are also minor. Indeed, the disruption of large particles as a result of sonication is permanent within the time scale of the measurement as the 10 - to $100-\mu \mathrm{m}$ particle population does not recover in any of the post-sonication distributions. 


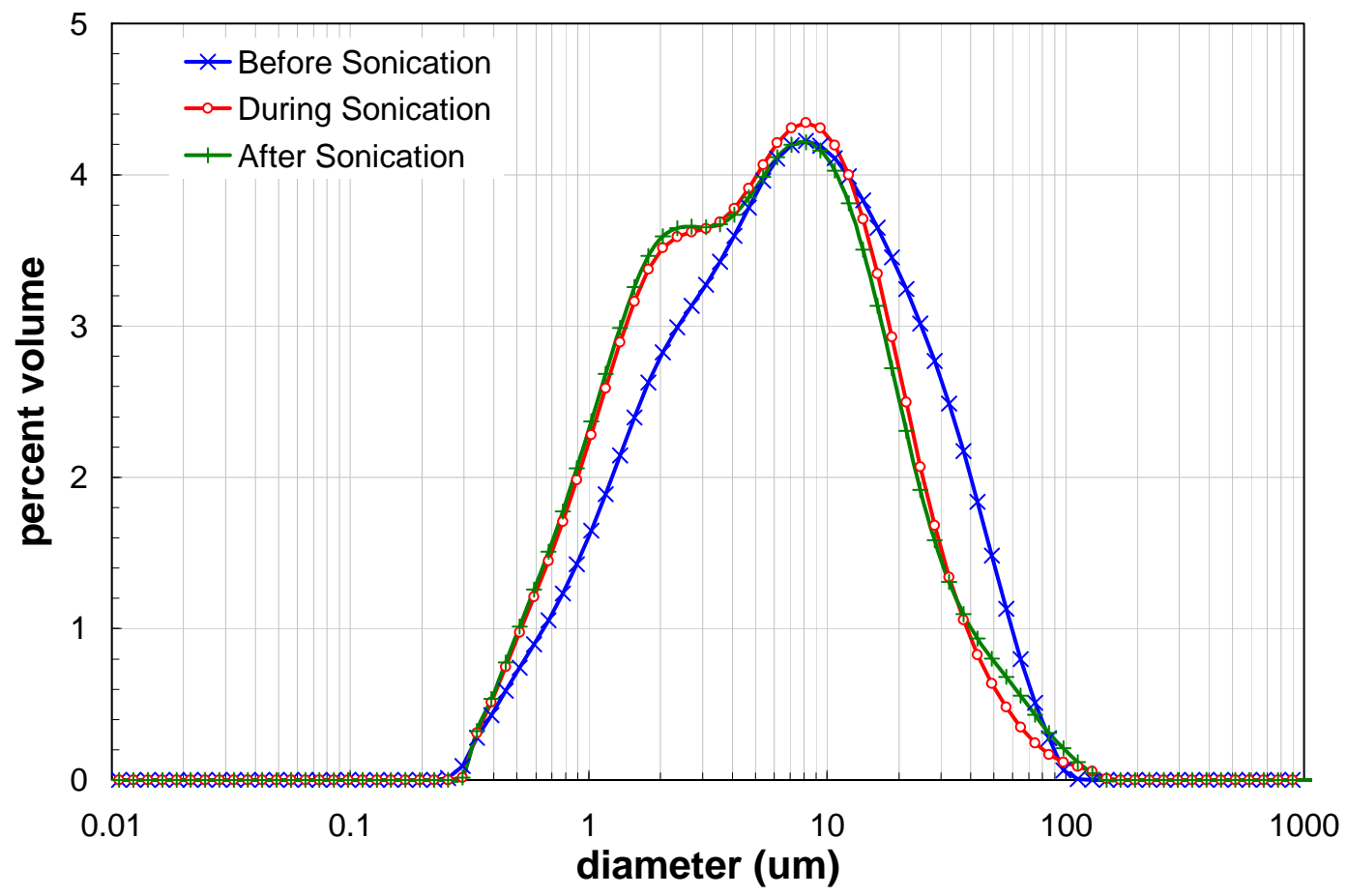

Figure 3.9. Volume Distribution Result for the Primary Group 1 Initial Characterization Sample as a Function of Sonication (75\% power)

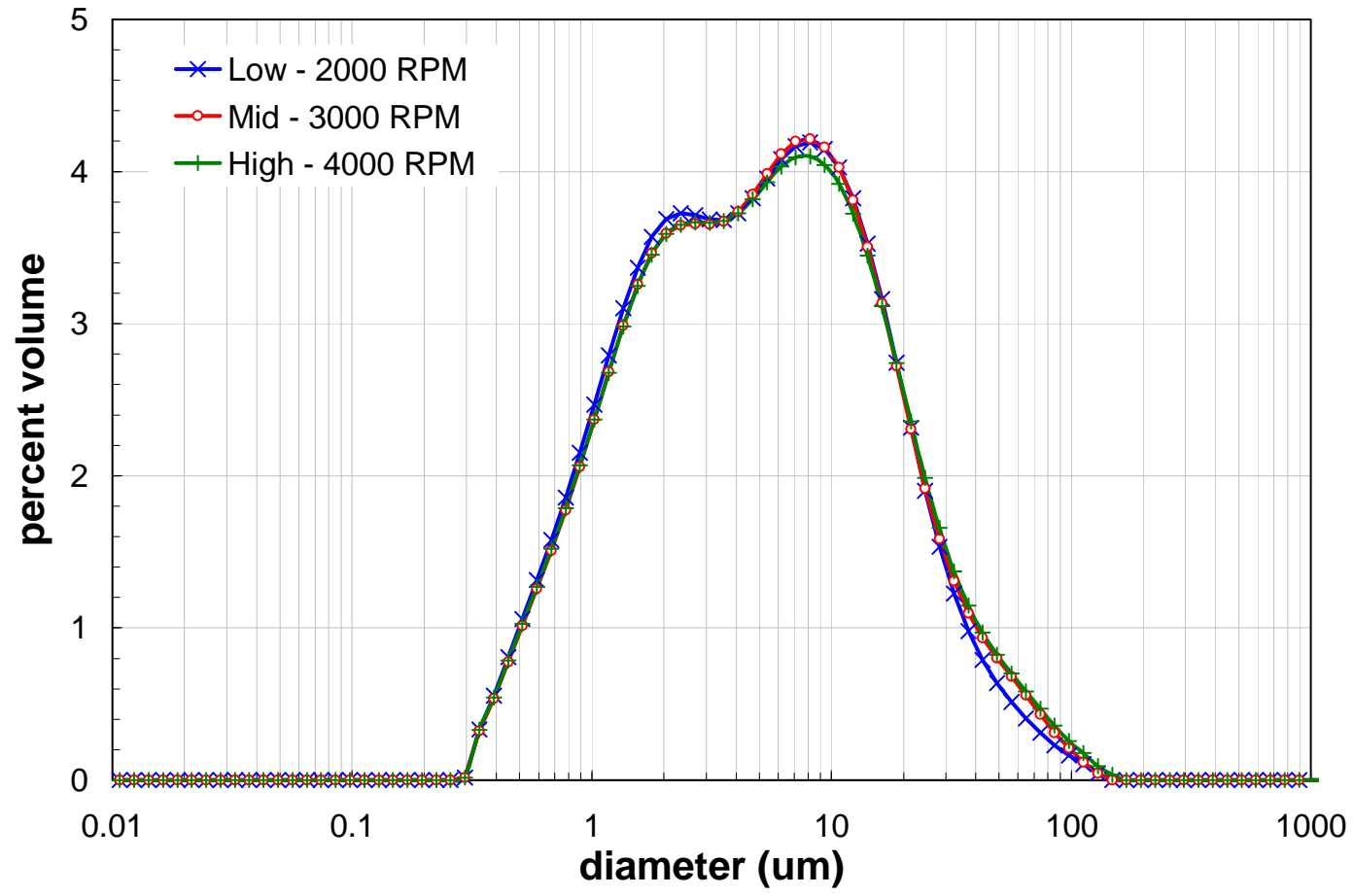

Figure 3.10. Post-Sonication Volume Distribution Result for the Primary Group 1 Initial Characterization Sample as a Function of Pump Speed 
Using the results in Table 3.8 (i.e., those of the primary sample) as a reference, the behavior of Group 1 initial characterization particle size as a function of pump speed and sonication can be quantitatively evaluated. Specifically, the following observations can be made:

- In general, the d(10) falls between 0.97 and $1.2 \mu \mathrm{m}$, the $\mathrm{d}(50)$ between 5.0 and $7.0 \mu \mathrm{m}$, and the $\mathrm{d}(90)$ between 21 and $31 \mu \mathrm{m}$.

- The listed diameter percentiles appear to be relatively insensitive to changes in pump speed, both before and after sonication. Changes in the distribution that occur as flow rate is first decreased from 3,000 to 2,000 RPM and subsequently increased to 4,000 RPM are below the limit of accuracy (10\%) for the measurement.

Sonication of the Group 1 solids dispersion decreases particle size. With reference to the measurements at 3,000 RPM, sonication lowers the mean particle size [i.e., the d(50)] from 6.9 to $5.0 \mu \mathrm{m}$. This represents a decrease of $\sim 27 \%$ in the mean particle size as a result of sonication.

Table 3.8. Particle-Size Analysis Percentile Results of the Primary Group 1 Initial Characterization Sample, TI483-G1-S-WL-PSD-1

\begin{tabular}{||c|c|c|c|c|c||}
\hline $\begin{array}{c}\text { Measurement } \\
\text { Condition }\end{array}$ & Pump Speed & Sonication & $\begin{array}{c}\mathbf{d}(\mathbf{1 0 )} \\
{[\boldsymbol{\mu \mathbf { m } ]}}\end{array}$ & $\begin{array}{c}\mathbf{d}(\mathbf{5 0 )} \\
{[\boldsymbol{\mu \mathbf { m } ]}]}\end{array}$ & $\begin{array}{c}\mathbf{d}(\mathbf{9 0}) \\
{[\boldsymbol{\mu m}]}\end{array}$ \\
\hline 1 & 3000 & pre-sonic & 1.2 & 6.9 & 31 \\
\hline 2 & 2000 & pre-sonic & 1.2 & 6.9 & 30 \\
\hline 3 & 4000 & pre-sonic & 1.2 & 7.0 & 30 \\
\hline 4 & 3000 & $25 \%$ & 1.2 & 6.4 & 26 \\
\hline 5 & 3000 & $50 \%$ & 1.1 & 5.8 & 24 \\
\hline 6 & 3000 & $75 \%$ & 1.0 & 5.2 & 22 \\
\hline 7 & 3000 & post-sonic & 1.0 & 5.0 & 23 \\
\hline 8 & 2000 & post-sonic & 0.97 & 4.8 & 21 \\
\hline 9 & 4000 & post-sonic & 0.99 & 5.0 & 24 \\
\hline
\end{tabular}

Table 3.9. Particle Size Analysis Percentile Results of the Duplicate Group 1 Initial Characterization Sample, TI483-G1-S-WL-PSD-2

\begin{tabular}{||c|c|c|c|c|c||}
\hline $\begin{array}{c}\text { Measurement } \\
\text { Condition }\end{array}$ & Pump Speed & Sonication & $\begin{array}{c}\mathbf{d}(\mathbf{1 0}) \\
{[\boldsymbol{\mu m}]}\end{array}$ & $\begin{array}{c}\mathbf{d}(\mathbf{5 0}) \\
{[\boldsymbol{\mu m}]}\end{array}$ & $\begin{array}{c}\mathbf{d}(\mathbf{9 0}) \\
{[\boldsymbol{\mu m}]}\end{array}$ \\
\hline 1 & 3000 & pre-sonic & 1.1 & 5.7 & 28 \\
\hline 2 & 2000 & pre-sonic & 1.1 & 5.7 & 26 \\
\hline 3 & 4000 & pre-sonic & 1.1 & 6.0 & 29 \\
\hline 4 & 3000 & $25 \%$ & 1.0 & 5.3 & 22 \\
\hline 5 & 3000 & $50 \%$ & 0.99 & 5.0 & 21 \\
\hline 6 & 3000 & $75 \%$ & 0.94 & 4.6 & 19 \\
\hline 7 & 3000 & post-sonic & 0.92 & 4.5 & 21 \\
\hline 8 & 2000 & post-sonic & 0.90 & 4.3 & 20 \\
\hline 9 & 4000 & post-sonic & 0.92 & 4.6 & 24 \\
\hline \hline
\end{tabular}


The behavior of the duplicate sample PSD with respect to pump speed and sonication mirrors and confirms that of the primary sample. However, the PSD of the duplicate sample is consistently lower than that of the primary at equivalent measurement conditions. Table 3.10 shows the absolute relative percent difference between the $\mathrm{d}(10), \mathrm{d}(50)$, and $\mathrm{d}(90)$ values determined for the primary and duplicate Group 1 initial characterization samples. Here, absolute relative percent difference is determined using the following equation:

$$
R P D=\left|\frac{d_{d}(n)-d_{p}(n)}{d_{p}(n)}\right|
$$

where $d_{p}(n)$ and $d_{d}(n)$ are the primary and duplicate cumulative oversize diameters corresponding to the $n^{\text {th }}$ percentile. The listed RPDs indicate that there is a slight difference between samples.

Table 3.10. Absolute Relative Percent Difference Between Primary and Duplicate Group 1 Initial Characterization Samples

\begin{tabular}{||c|c|c|c|c|c||}
\hline \hline \multirow{2}{*}{$\begin{array}{c}\text { Measurement } \\
\text { Condition }\end{array}$} & \multirow{2}{*}{ Pump Speed } & \multirow{2}{*}{ Sonication } & \multicolumn{3}{|c||}{ Absolute RPD } \\
\cline { 4 - 6 } & 3000 & pre-sonic & $12 \%$ & $17 \%$ & $12 \%$ \\
\hline 1 & 2000 & pre-sonic & $12 \%$ & $18 \%$ & $13 \%$ \\
\hline 2 & 4000 & pre-sonic & $10 \%$ & $14 \%$ & $4.1 \%$ \\
\hline 3 & 3000 & $25 \%$ & $11 \%$ & $16 \%$ & $13 \%$ \\
\hline 4 & 3000 & $50 \%$ & $9.4 \%$ & $14 \%$ & $12 \%$ \\
\hline 5 & 3000 & $75 \%$ & $8.4 \%$ & $12 \%$ & $13 \%$ \\
\hline 6 & 3000 & post-sonic & $7.9 \%$ & $10 \%$ & $6.8 \%$ \\
\hline 7 & 2000 & post-sonic & $8.0 \%$ & $11 \%$ & $7.9 \%$ \\
\hline 8 & 4000 & post-sonic & $7.5 \%$ & $8.3 \%$ & $2.3 \%$ \\
\hline 9 & & & & & \\
\hline
\end{tabular}

For particle-size measurements on the Malvern Mastersizer 2000, RPDs of up to $10 \%$ are generally expected given the accuracy of the instrument. The results for Group 1 initial characterization samples show RPDs that range from 2 to 18\%, depending on the measurement condition and percentile examined. Based on the large number of RPDs greater than $10 \%$ in Table 3.10, it is likely that there is a significant size difference in the solids species in the primary and duplicate sample. It should be noted, however, that the largest differences affect only the before- and during-sonication measurement conditions. In contrast, post-sonication RPDs generally fall below $10 \%$, indicating that sonication eliminates any size difference between the samples. As such, it can be postulated that the differences in particle size observed before sonication derive from differences in the state of solid particle aggregation (i.e., apparent particle size) between the primary and duplicate sample rather than an actual difference in the actual size of the solids sampled.

Figure 3.11 and Figure 3.12 show how the differences in the primary and duplicate PSDs described in the preceding paragraphs manifest in the differential volume distributions. The primary and duplicate samples, both before and after sonication (Figure 3.11 and Figure 3.12, respectively), show roughly the same distribution of particles. Specifically, both pre-sonication samples show distributions ranging from 0.3 to $100 \mu \mathrm{m}$ with peak populations between 6 and $10 \mu \mathrm{m}$ and a shoulder over 2 to $3 \mu \mathrm{m}$. Both postsonication distributions show a more strongly bimodal distribution with peaks at $\sim 2$ and $\sim 8 \mu \mathrm{m}$. 


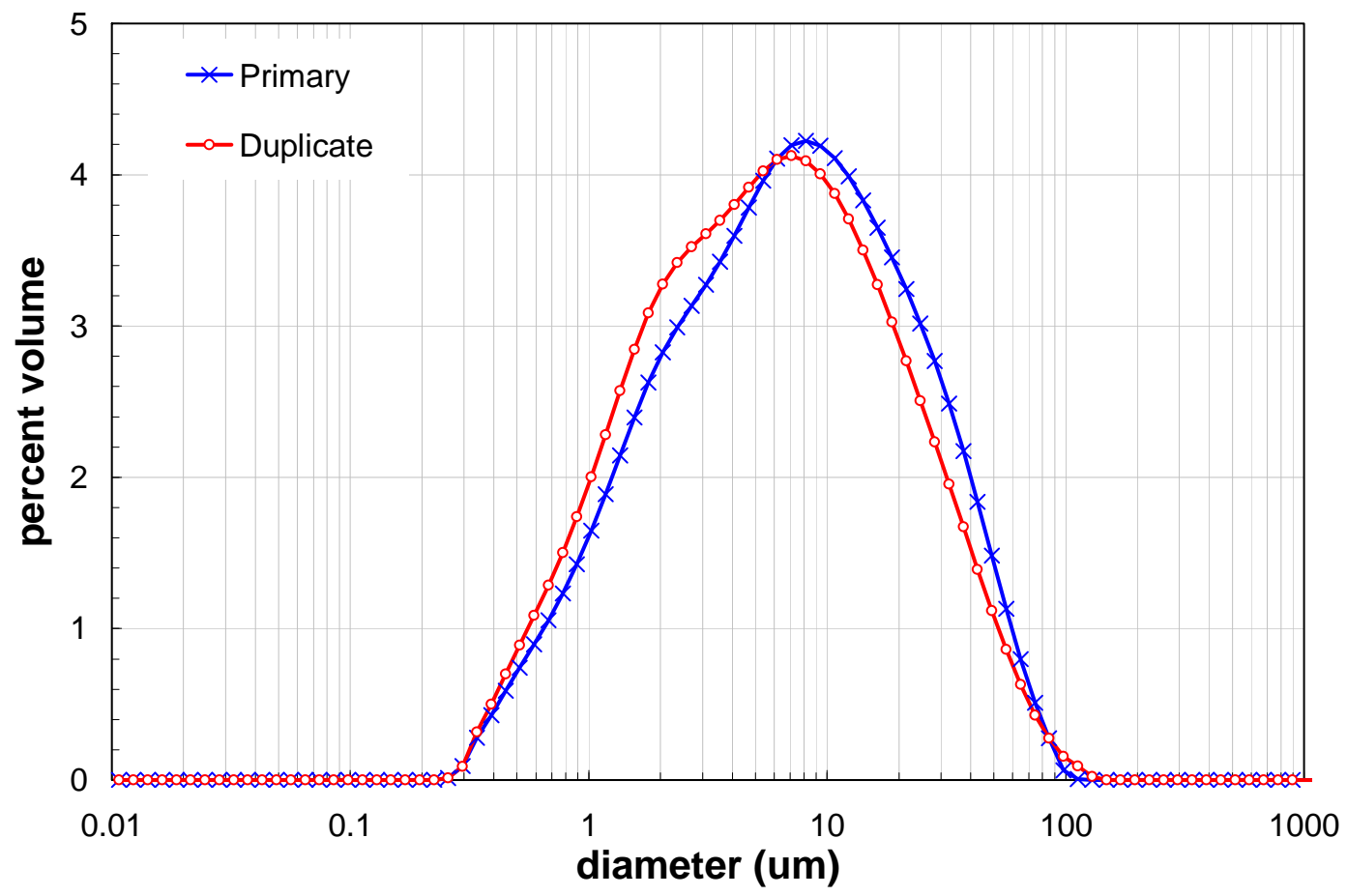

Figure 3.11. Comparison of Primary and Duplicate Sample Differential Volume PSD at 3,000 RPM Before Sonication for the Group 1 Solids

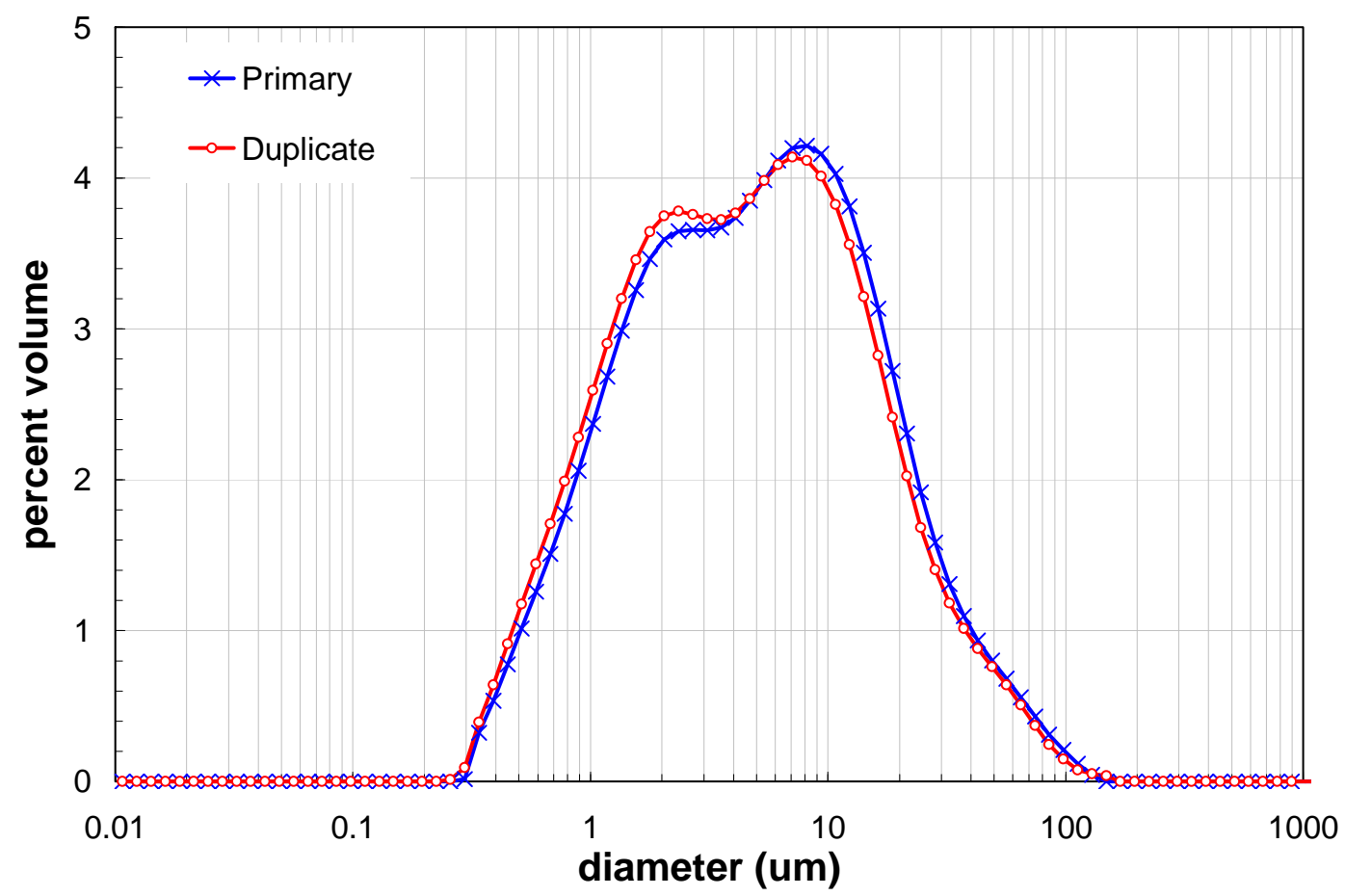

Figure 3.12. Comparison of Primary and Duplicate Sample Differential Volume PSD at 3,000 RPM After Sonication for the Group 1 Solids 
In summary, particle-size analysis of Group 1 bismuth phosphate sludge samples derived from initial characterization efforts indicates a broad distribution of solids particle sizes ranging from $0.3 \mu \mathrm{m}$ to $100 \mu \mathrm{m}$. The initial distribution of solids is nearly uni-modal, with a peak population near $10 \mu \mathrm{m}$ and a small shoulder at $4 \mu \mathrm{m}$. Changes in the pump speed used to disperse the solids during analysis did not significantly change the PSD observed, indicating 1) that the state of particle aggregation for Group 1 solids is stable with respect to shear and 2) that most of the Group 1 solids were adequately dispersed (and as such, well-sampled) by the measurement apparatus. The application of sonic energy to the dispersion significantly reduced the particle size, affecting an $\sim 27 \%$ reduction in the mean diameter of the dispersion. This reduction is likely caused by the break-up of 10 - to $100-\mu \mathrm{m}$ particle aggregates. This break-up appears to be irreversible, as a recovery of the 10 - to $100-\mu \mathrm{m}$ particle population was not observed after dispersion sonication was stopped. After sonication, the distribution is more strongly bimodal with population peaks at 2 and $8 \mu \mathrm{m}$.

\subsubsection{Surface Area}

Samples were analyzed in duplicate for surface area by Brunauer, Emmett, and Teller (BET), each with a nominal $\sim 0.11$-g sample size. The results, 96 and $93 \mathrm{~m}^{2} / \mathrm{g}$, demonstrated excellent precision.

\subsubsection{Crystal Form and Habit}

The X-ray diffraction (XRD) pattern for Group 1 washed solids is provided in Figure 3.13; the background-subtracted XRD pattern with stick-figure phase identification is shown in Figure 3.14. The raised background associated with the raw data diffraction pattern indicated the material had a significant amorphous component. The sample material was difficult to grind (sample grinding is required for powder XRD analysis), indicative of a hard, dense material. The final sample mount showed some granular particles, indicating incomplete pulverization of the sample. For the best results in power XRD, the final sample must have roughly equal numbers of crystallites oriented in every possible direction. The presence of visible grains leads to preferred orientation for that phase, resulting in large variations in peak intensities, and, in extreme cases, may result in some peak intensities being reduced to near zero. However, these specific granular particles should have no significant effect on other phases in the sample.

Identification of the phases present in the washed Group 1 solids sample was difficult because of the large number of peaks and the low intensity of many of them. Identification by XRD is dependent on the pattern of peaks present, not just their location. This includes the spacing of peaks as well as their relative intensities. Many phases identified in Table 3.11 showed one strong peak and then several much-lessintense peaks. These lower intensity peaks are, in many cases, close to the same count rate as the observed background statistical variation. This results in some identifications being based on one peak, or the pattern resulting from very few peaks. Additional indications of whether a phase is present come from the chemistry restrictions. Failure to meet both requirements, pattern and chemistry, eliminates many phases, but meeting these requirements based on a pattern of 1 or 2 peak positions is also questionable. Because of these considerations, the following designations are used in Table 3.11. Phases identified based on a limited pattern are designated as "possible" to emphasize the weakness of the identification. Phases for which identification may be based on a better pattern, but far from ideal, have been labeled "probable.” Phases showing good pattern matching and meeting chemistry requirements have been labeled "excellent” or "good.” 


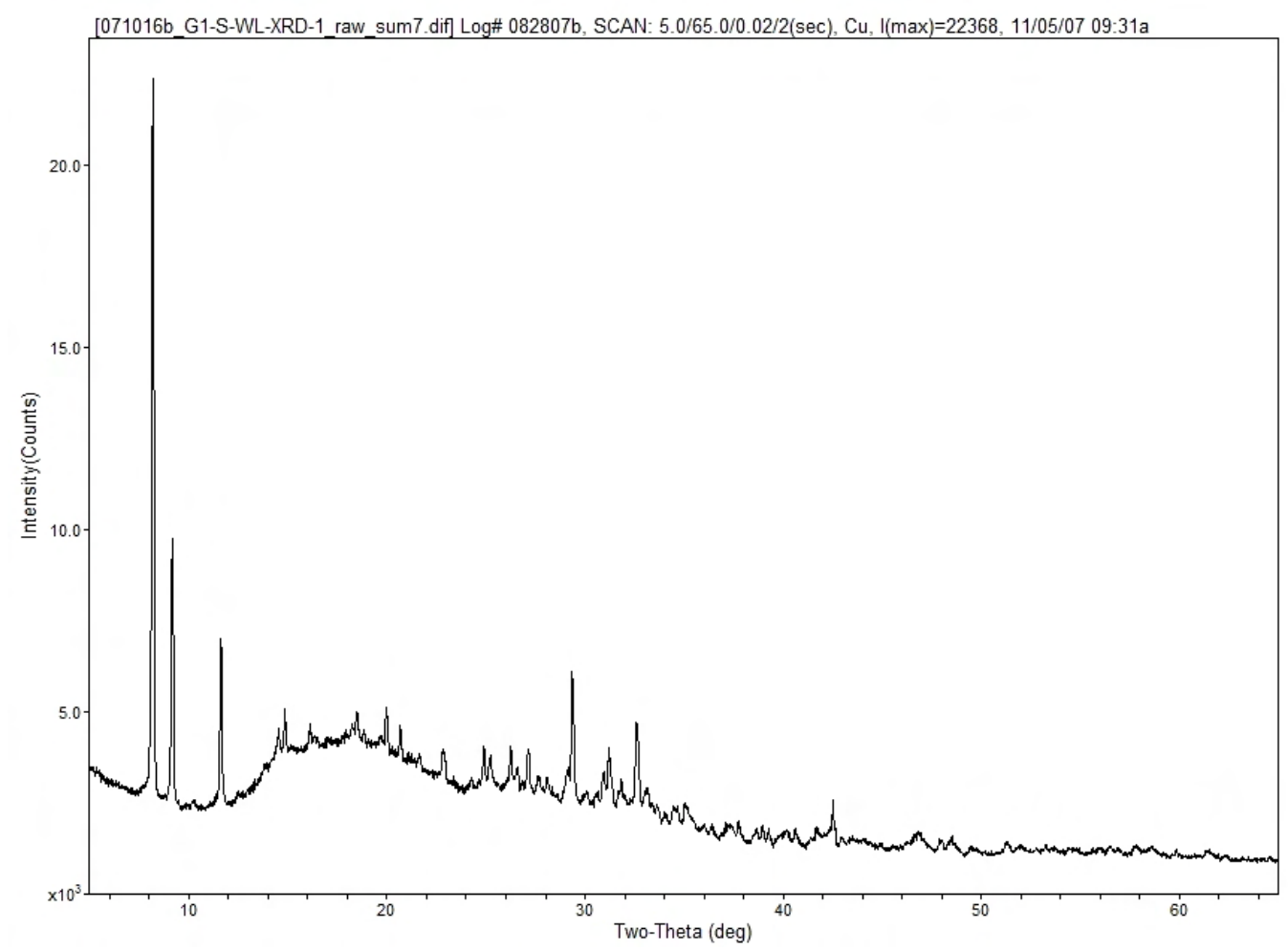

Figure 3.13. Raw X-ray Diffraction Pattern of Washed Group 1 Solids

The strongest peaks present in the sample were in the 8 to $10^{\circ} 2-\theta$ range. The 8.26 and $9.24^{\circ} 2-\theta$ peaks could potentially be due to a form of silicon oxide (crystal density $3.56 \mathrm{~g} / \mathrm{cm}^{3}$, JADE Version 8.0 ), vauxite [ $\left.\mathrm{FeAl}_{2}\left(\mathrm{PO}_{4}\right)_{2} \cdot 6 \mathrm{H}_{2} \mathrm{O}\right]$ (crystal density $2.39 \mathrm{~g} / \mathrm{cm}^{3}$, JADE Version 8.0), beyerite $\left[\mathrm{CaBi}_{2}\left(\mathrm{CO}_{3}\right)_{2} \mathrm{O}_{2}\right]$ (crystal density $6.55 \mathrm{~g} / \mathrm{cm}^{3}$, JADE Version 8.0, calculated value), uranyl hydrogen phosphate acetone $\left[\mathrm{C}_{3} \mathrm{H}_{6} \mathrm{O} \cdot \mathrm{UO}_{2} \mathrm{HPO}_{4}\right]$, or combinations of these phases. Except for beyerite, each of these phases shows the characteristics mentioned above, i.e., one major peak followed by a series of peaks of intensity too low to confirm the identification. That is, these species are considered to possibly be present.

$\mathrm{SiO}_{2}$ (silicon oxide, ICDD card 74-3423), shows a good fit to the $9.24^{\circ} 2-\theta$ line. However, this is a theoretical zeolite structure; the actual phase was not in existence in 2003, the time the paper was published. This phase is not quartz. The only other phase matching this diffraction line and the appropriate chemistry conditions was $\mathrm{C}_{3} \mathrm{H}_{6} \mathrm{O} \cdot \mathrm{UO}_{2} \mathrm{HPO}_{4}$. The phase uranyl hydrogen phosphate acetone $\left(\mathrm{C}_{3} \mathrm{H}_{6} \mathrm{O} \cdot \mathrm{UO}_{2} \mathrm{HPO}_{4}\right.$, ICDD card 37-1501) is a good match to the observed strong peak at $9.24^{\circ} 2-\theta$ if the organic database is searched. Other lines from the card are too low intensity to be observed, so this phase cannot be confirmed. Based on the processing history it is highly unlikely that such an acetone adduct would form in the Hanford tank waste. Indeed, the quality of these card data is listed as "doubtful," but it is the only phase representing material actually in existence giving a good match to this peak. Other potential matches to organic phases were dismissed on the basis of chemistry or overall card pattern. 
WTP-RPT-166, Rev. 0
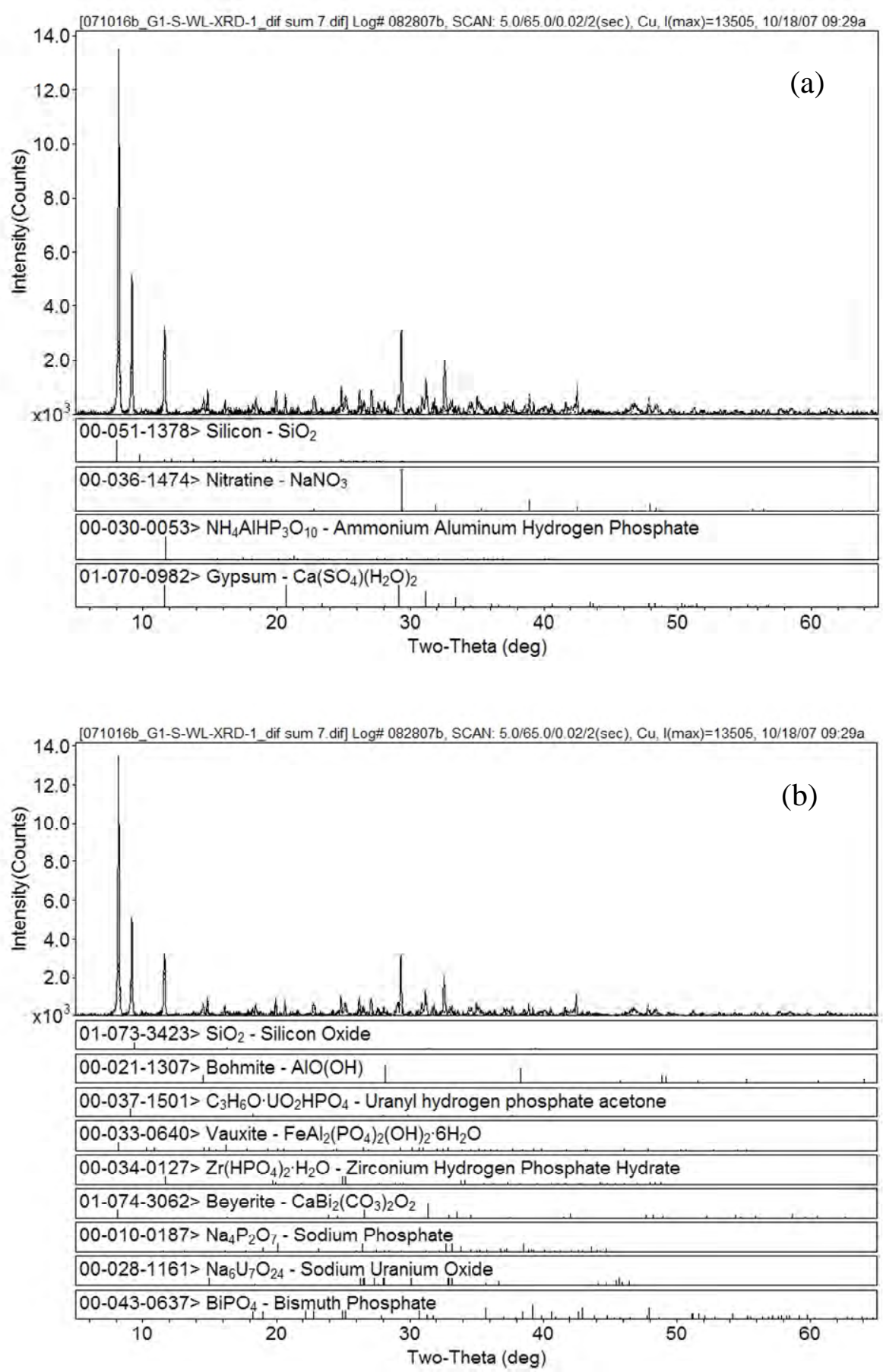

Figure 3.14. XRD Pattern of Washed Group 1 Solids, Background-Subtracted with Stick-Figure Peak Identification: a) Probable Phases Present and b) Possible Phases Present

Calcium sulfate $\left[\mathrm{Ca}\left(\mathrm{SO}_{4}\right)\left(\mathrm{H}_{2} \mathrm{O}\right)_{2}\right]$ was identified in some of the replicate sample preparations. Since these samples were dried over "Drierite," which is calcium sulfate, the source of this phase (sample or "Drierite”) cannot be definitively determined. However, the Fourier transform infrared (FTIR) spectrum taken on a separate sample of the washed Group 1 solids did not display any evidence of calcium sulfate, so the Drierite is the suspected source of this. 
WTP-RPT-166, Rev. 0

Table 3.11. Possible Phase Identification of Group 1 Water-Insoluble Solids

\begin{tabular}{|l|l|c|}
\hline Crystalline Phase & Chemical Structure & Phase Match Description \\
\hline Silicon oxide (ITQ-9) & $\mathrm{SiO}_{2}$ & Possible $^{(\mathrm{a})}$ \\
\hline Nitratine (sodium nitrate) & $\mathrm{NaNO}_{3}$ & Excellent $^{(\mathrm{b})}$ \\
\hline Ammonium aluminum hydrogen phosphate & $\mathrm{NH}_{4} \mathrm{AlHP}_{3} \mathrm{O}_{10}$ & Probable $^{(\mathrm{c})}$ \\
\hline Calcium sulfate & $\mathrm{Ca}\left(\mathrm{SO}_{4}\right)\left(\mathrm{H}_{2} \mathrm{O}\right)_{2}$ & Good $^{(\mathrm{d})}$ \\
\hline Bismuth phosphate & $\mathrm{BiPO}_{4}$ & Probable $^{(\mathrm{e})}$ \\
\hline Silicon oxide & $\mathrm{SiO}_{2}$ & Possible $^{(\mathrm{f})}$ \\
\hline Boehmite & $\mathrm{AlO}(\mathrm{OH})$ & Possible $^{(\mathrm{g})}$ \\
\hline Vauxite & $\mathrm{FeAl}\left(\mathrm{PO}_{4}\right)_{2}(\mathrm{OH})_{2} \cdot 6 \mathrm{H}_{2} \mathrm{O}$ & Possible $^{(\mathrm{h})}$ \\
\hline Zirconium hydrogen phosphate hydrate & $\mathrm{Zr}_{(}\left(\mathrm{HPO}_{4}\right)_{2} \cdot \mathrm{H}_{2} \mathrm{O}$ & Questionable $^{(\mathrm{i})}$ \\
\hline Beyerite & $\mathrm{CaBi}_{2}\left(\mathrm{CO}_{3}\right)_{2} \mathrm{O}_{2}$ & Possible $^{(\mathrm{j})}$ \\
\hline Sodium phosphate & $\mathrm{Na}_{4} \mathrm{P}_{2} \mathrm{O}_{7}$ & Possible $^{(\mathrm{k})}$ \\
\hline Sodium uranium oxide & $\mathrm{Na}_{6} \mathrm{U}_{7} \mathrm{O}_{24}$ & Possible $^{(\mathrm{l})}$ \\
\hline Uranyl hydrogen phosphate acetone & $\mathrm{C}_{3} \mathrm{H}_{6} \mathrm{O} \cdot \mathrm{UO}_{2} \mathrm{HPO}_{4}$ & Questionable $^{(\mathrm{m})}$ \\
\hline
\end{tabular}

(a) $\mathrm{SiO}_{2}$, (ICDD card 51-1378) not confirmed. Intensity of confirming lines is too low. Lattice parameter "a" drifts by $1.6 \%$, "b" and "c" drift by $1 \%$. Delta $2-\theta$ was high, but was the best fit to the observed strong peak at $8.24^{\circ} 2-\theta$. Appears to be a zeolite.

(b) $\mathrm{NaNO}_{3}$, excellent match to card data and associated with supernatant entrainment.

(c) $\mathrm{NH}_{4} \mathrm{AlHP}_{3} \mathrm{O}_{10}$, not confirmed; confirming lines too low intensity to detect.

(d) $\mathrm{Ca}\left(\mathrm{SO}_{4}\right)\left(\mathrm{H}_{2} \mathrm{O}\right)_{2}$, excellent match to card data. However, the presence of gypsum is likely attributable to contamination of the sample during drying over the Drierite desicant.

(e) $\mathrm{BiPO}_{4}$ confirming lines were good matches.

(f) $\mathrm{SiO}_{2}$ (ICDD card 73-3423), one fair confirming line, but low intensity. From study of theoretical structure of zeolites.

(g) $\mathrm{AlO}(\mathrm{OH})$, one good confirming line, others too low intensity.

(h) $\mathrm{FeAl}_{2}\left(\mathrm{PO}_{4}\right)_{2}(\mathrm{OH})_{2} \cdot 6 \mathrm{H}_{2} \mathrm{O}$, fair match to strong $8.24^{\circ} 2-\theta$ peak. Fair match to confirming lines, some missed.

(i) $\mathrm{Zr}\left(\mathrm{HPO}_{4}\right)_{2} \cdot \mathrm{H}_{2} \mathrm{O}$, good match to moderate intensity lines. Although this provides an excellent match to the observed data, it does not fit the chemistry constraints since the Group 1 solids contain little $\mathrm{Zr}$.

(j) $\mathrm{CaBi}_{2}\left(\mathrm{CO}_{3}\right)_{2} \mathrm{O}_{2}$, good match to $8.24^{\circ} 2-\theta$ line. Good match to moderate intensity lines. Misses some lower intensity lines.

(k) $\mathrm{Na}_{4} \mathrm{P}_{2} \mathrm{O}_{7}$, fair match to major peak and stronger confirming lines.

(l) $\mathrm{Na}_{6} \mathrm{U}_{7} \mathrm{O}_{24}$, fair match to major peak. Matches some confirming lines, misses some.

(m) $\mathrm{C}_{3} \mathrm{H}_{6} \mathrm{O} \cdot \mathrm{UO}_{2} \mathrm{HPO}_{4}$, fair match to major peak and one confirming line. Other confirming line intensities (ICDD card 37-1501) too low to be observed in this pattern. Furthermore, this phase is not reasonable based on tank history.

Sodium nitrate (crystal density $2.26 \mathrm{~g} / \mathrm{cm}^{3}$, CRC 1978) was found in the XRD mount and was a constituent of entrained supernatant. The following phases were excluded because no match to the XRD pattern could be defined: gibbsite $\left[\gamma-\mathrm{Al}(\mathrm{OH})_{3}\right]$, sodium phosphate $\left(\mathrm{Na}_{3} \mathrm{PO}_{4}\right)$, quartz $\left(\mathrm{SiO}_{2}\right)$, and sodium oxalate $\left(\mathrm{Na}_{2} \mathrm{C}_{2} \mathrm{O}_{4}\right)$. It is interesting to note that with the possible exception of vauxite, no major ironcontaining phases were identified in the XRD pattern. This would be consistent with the bulk of the iron and phosphate being present in an amorphous form of iron(III) phosphate, which is supported by other evidence (see Section 3.4.1). Furthermore, although bismuth phosphate (crystal density $6.75 \mathrm{~g} / \mathrm{cm}^{3}$, 
JADE Version 8.0) was identified as a possible phase by the XRD analysis, the intensities of the lines for $\mathrm{BiPO}_{4}$ are very weak. So at best, $\mathrm{BiPO}_{4}$ is only a minor constituent of the Group 1 solids (again consistent with the FTIR spectral data presented in Section 3.4.1).

Scanning electron microscopy (SEM), coupled with energy dispersive spectroscopy (EDS), was used to obtain information regarding the particle morphology and elemental distribution within the Group 1 solid phases. Several SEM images of the washed solids are shown in Figure 3.15 and Figure 3.16. Highly variable particle morphologies are apparent in these figures. Spheroids with a primary size of $<1 \mu \mathrm{m}$ appeared to form aggregates that are 1 to $3 \mu \mathrm{m}$ (e.g., see the upper left hand image in Figure 3.17). Needle-like structures were visible in lengths up to $40 \mu \mathrm{m}$ (see the bottom images in Figure 3.17). Rod structures, possibly tetragonal, are shown prominently in Figure 3.16.

The EDS spectra of selected solids phases are shown in Figure 3.17 through Figure 3.19. In virtually all cases, $\mathrm{Na}, \mathrm{Si}, \mathrm{P}, \mathrm{Fe}$, and $\mathrm{Bi}$ were present in significant quantities, as would be expected based on the ICPOES analysis of the bulk material. Aluminum was also evident in most of the EDS spectra. The EDS elemental mapping is particularly useful in interpreting the results of the SEM examination of the washed Group 1 solids. Figure 3.20 shows an example elemental map for the washed Group 1 solids. The most striking feature of this map is the close association of Fe and P; the patterns displayed for these two elements are nearly identical. Sodium (and to some degree, Sr) also appears to track with the Fe and P. The other major components appear to be evenly distributed across the image, suggesting that these are likely present as the individual oxides or hydroxides that are intermingled together. Similar results are seen in other areas within the SEM image (Figure 3.21). Thus, the SEM results suggest that most of the phosphorus in the Group 1 solids is present in the form of an iron phosphate phase. Further evidence for this is presented in Section 3.4.1. The XRD analysis suggested one possible crystalline iron phosphate species-vauxite, $\mathrm{FeAl}_{2}\left(\mathrm{PO}_{4}\right)_{2}(\mathrm{OH})_{2} \cdot 6 \mathrm{H}_{2} \mathrm{O}$. However, the EDS mapping in Figure 3.20 and Figure 3.21 do not support the notion that vauxite is the primary iron phosphate phase because $\mathrm{Al}$ does not map closely with the Fe and P. So the bulk of the iron phosphate material is likely an amorphous material. 

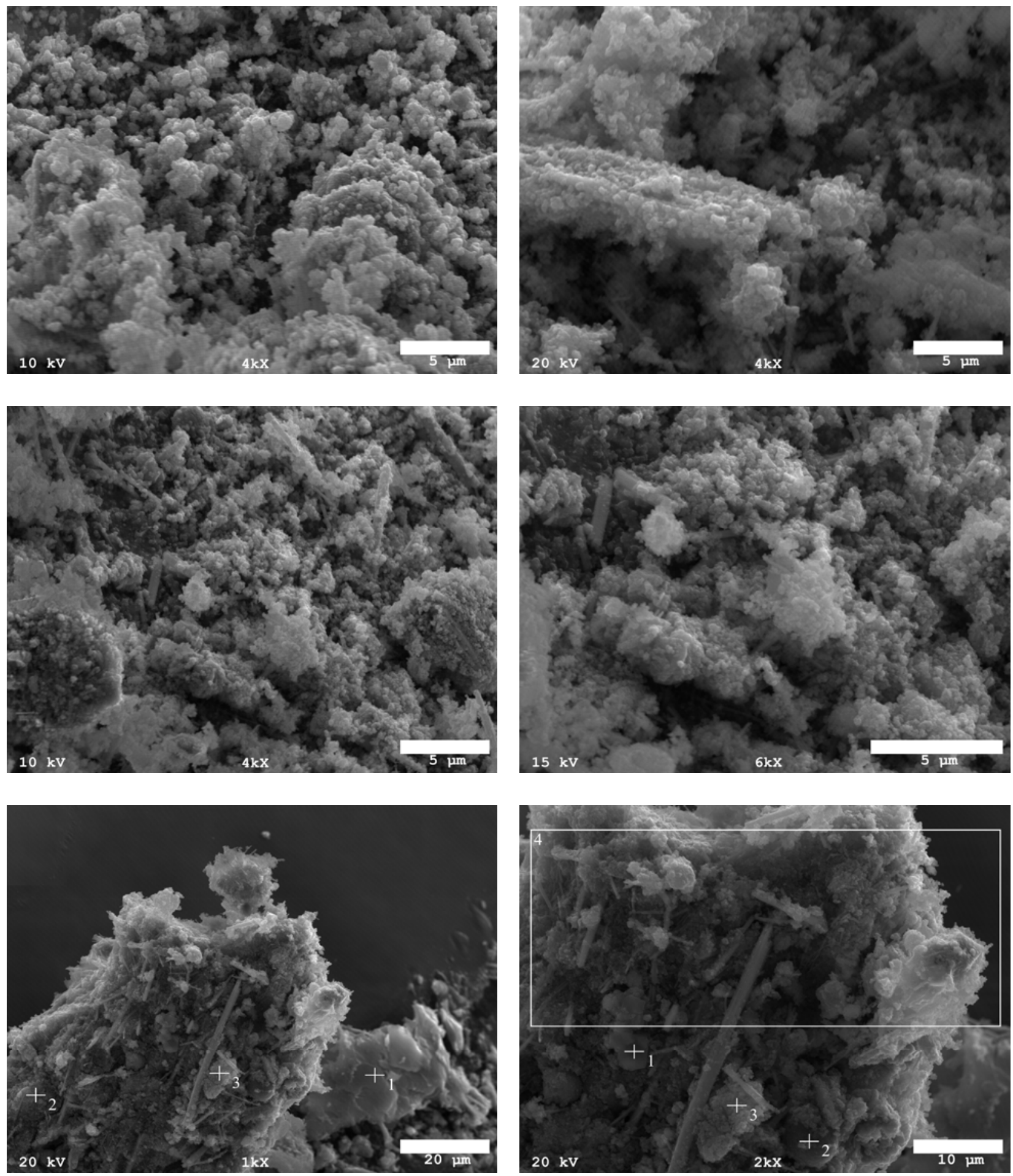

Figure 3.15. SEM Images of Group 1 Initial Characterization Solids 


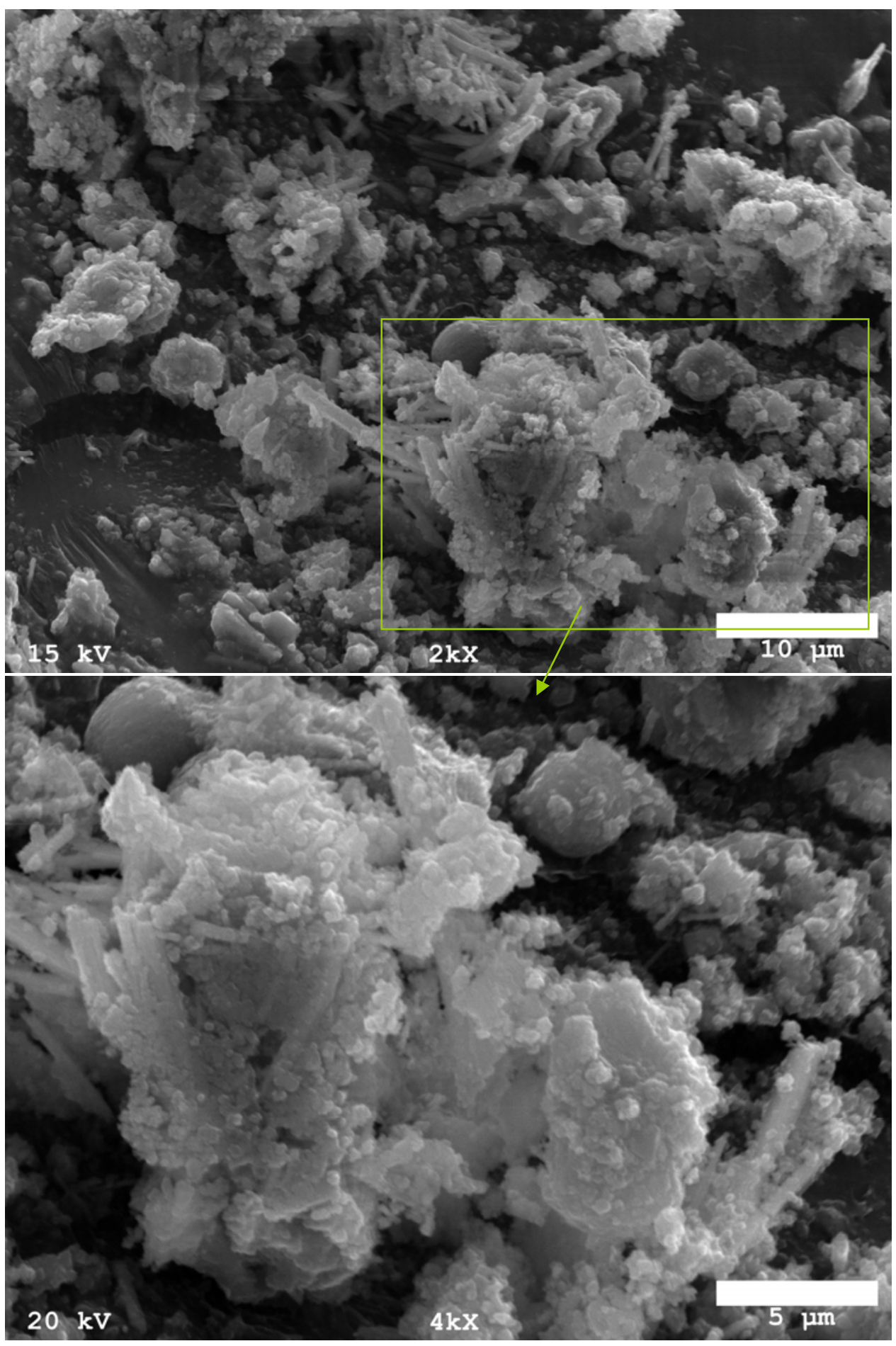

Figure 3.16. Additional SEM Images of Group 1 Initial Characterization Solids 
WTP-RPT-166, Rev. 0

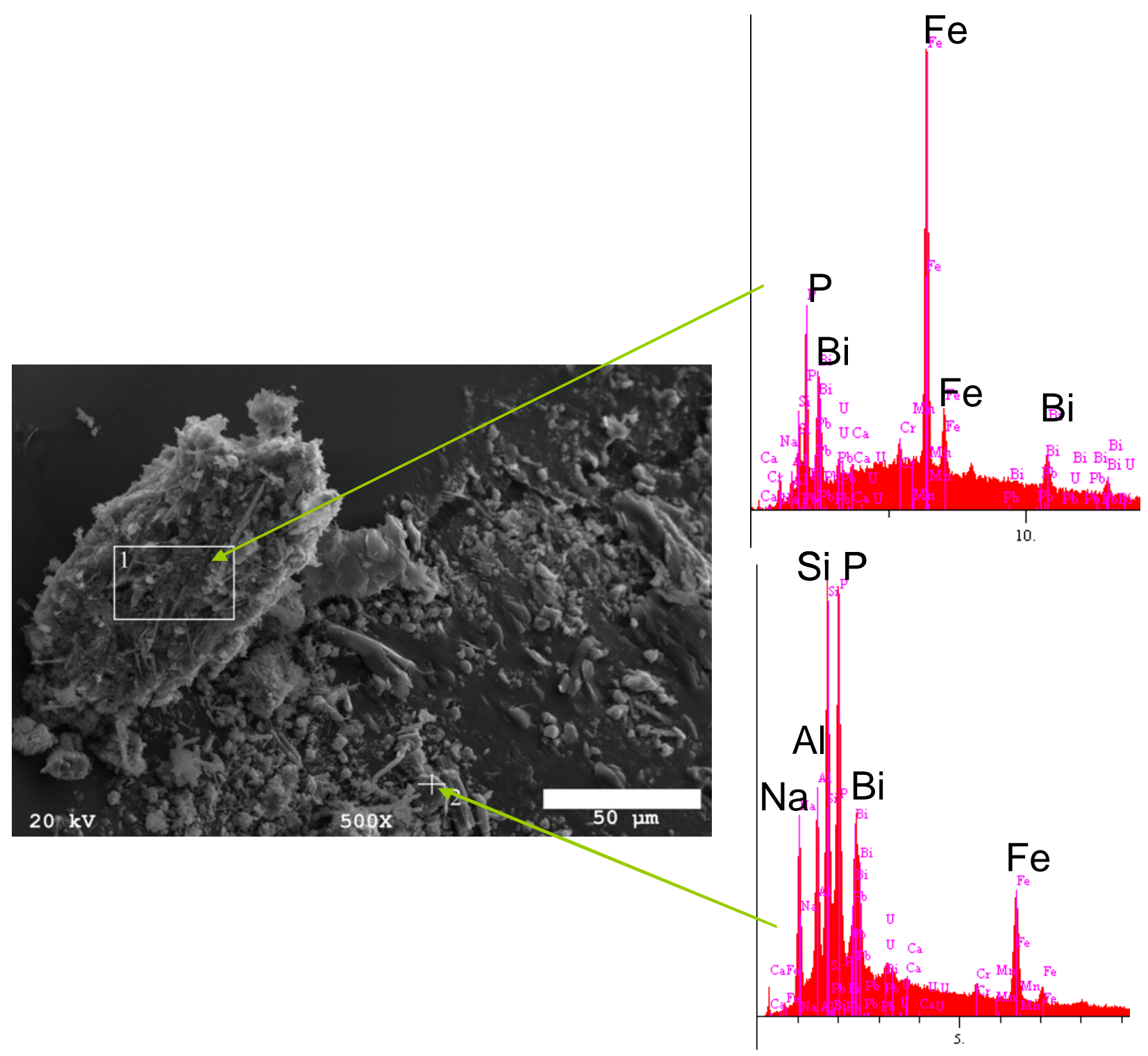

Figure 3.17. SEM-EDS Image 1 
WTP-RPT-166, Rev. 0

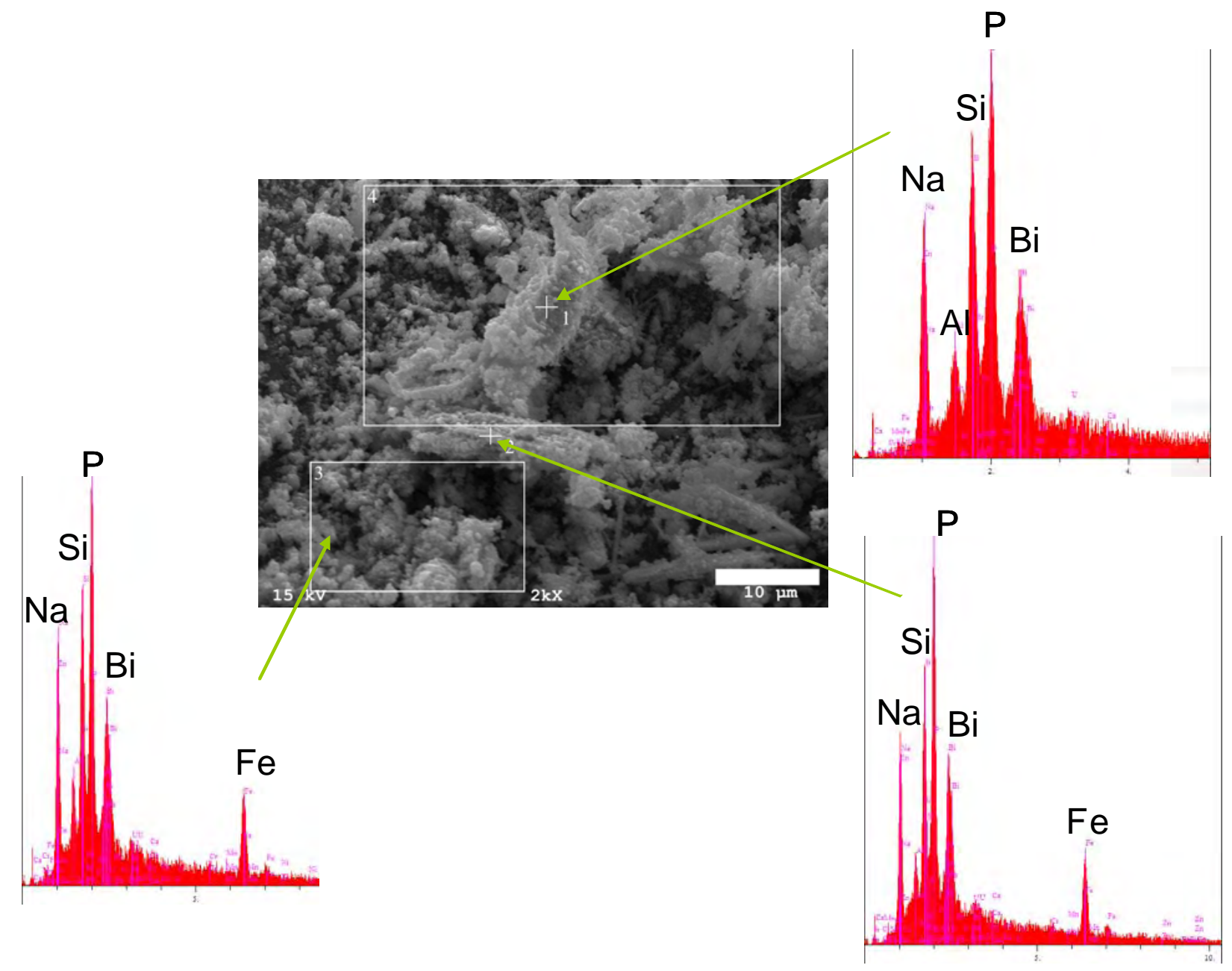

Figure 3.18. SEM-EDS Image 2 
WTP-RPT-166, Rev. 0

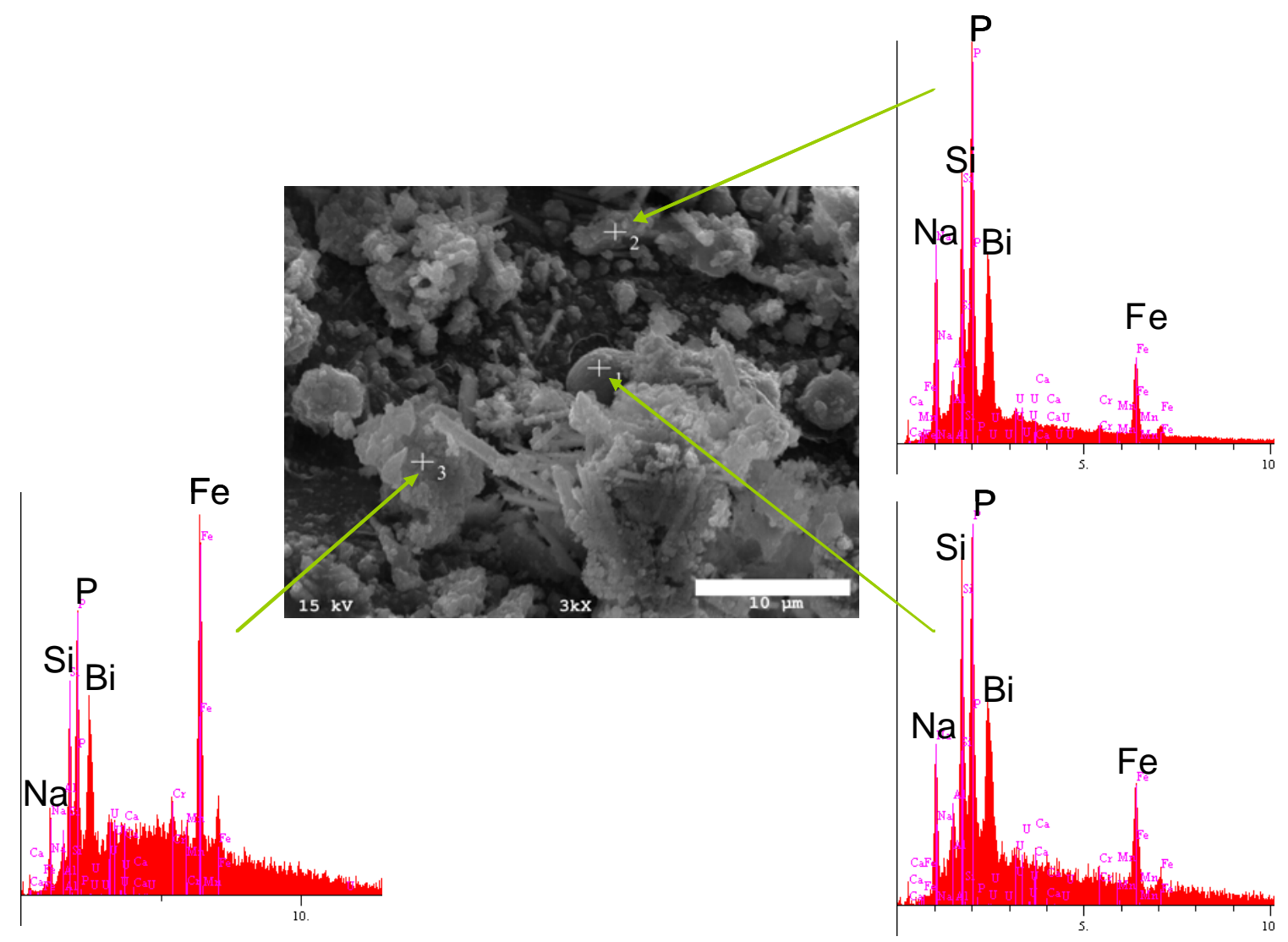

Figure 3.19. SEM-EDS Image 3 

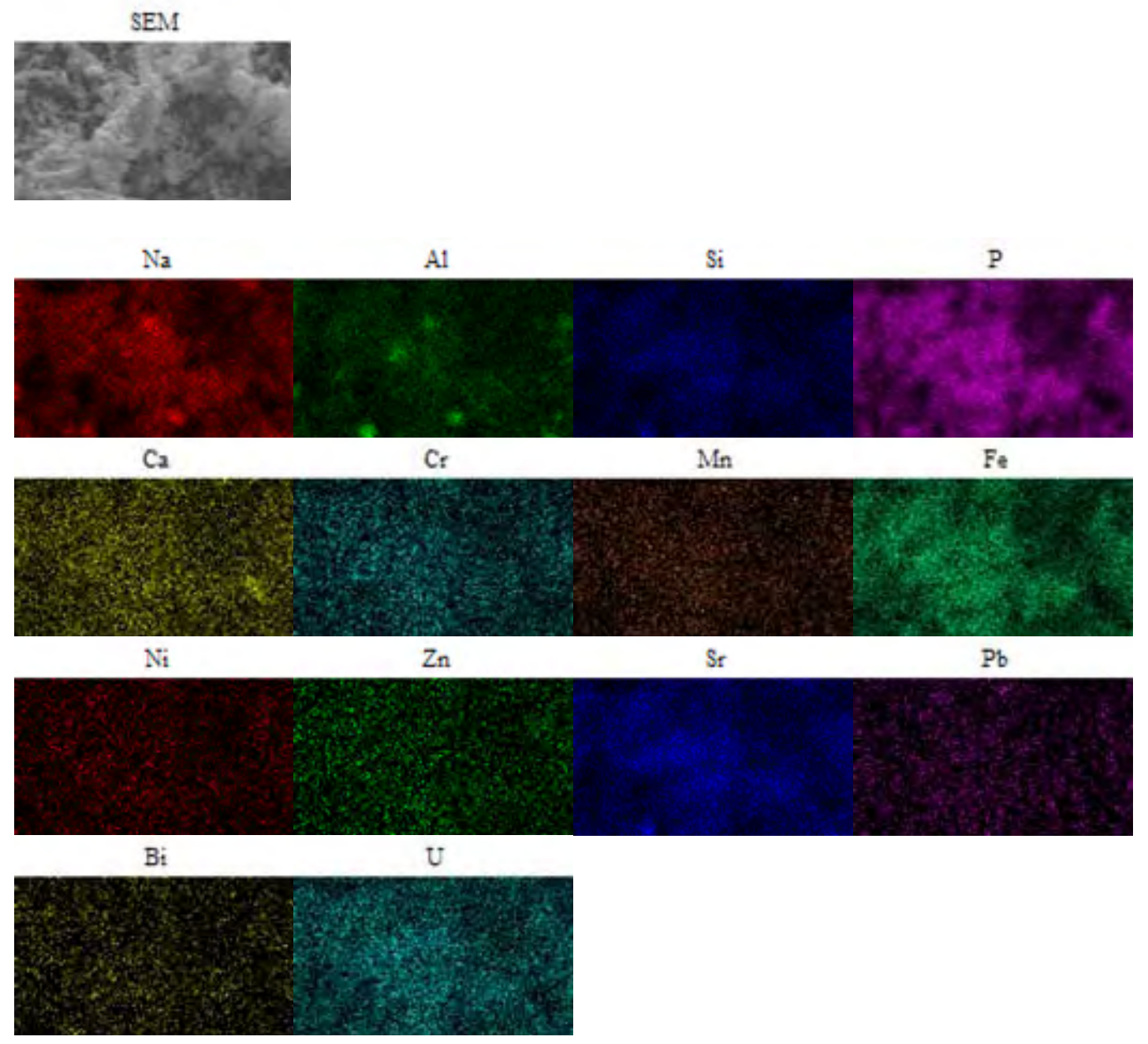

Figure 3.20. EDS Elemental Map of Group 1 Solids (1) 


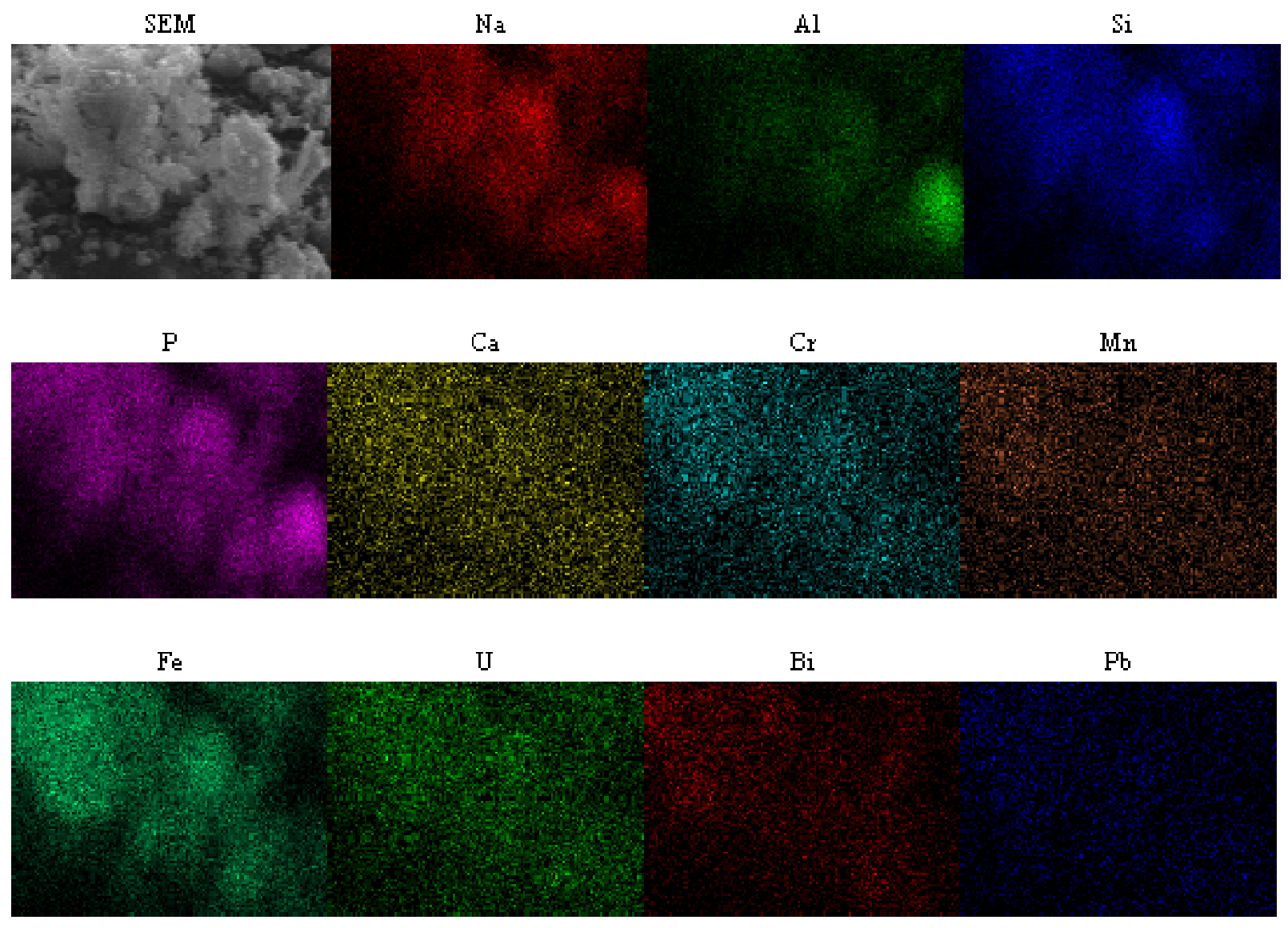

Figure 3.21. EDS Elemental Map of Group 1 Solids (2) 
The TEM micrographs of the solids phase are shown in Figure 3.22, and STEM micrographs with EDS are shown in Figure 3.23. As the particles were too thick to allow viewing of diffraction spots, it was not possible to determine if the particles in this region were crystalline. The material had a relatively high surface area with small particles and was dominated by Bi, Fe, P, and Si phases (as was found by SEMEDS).
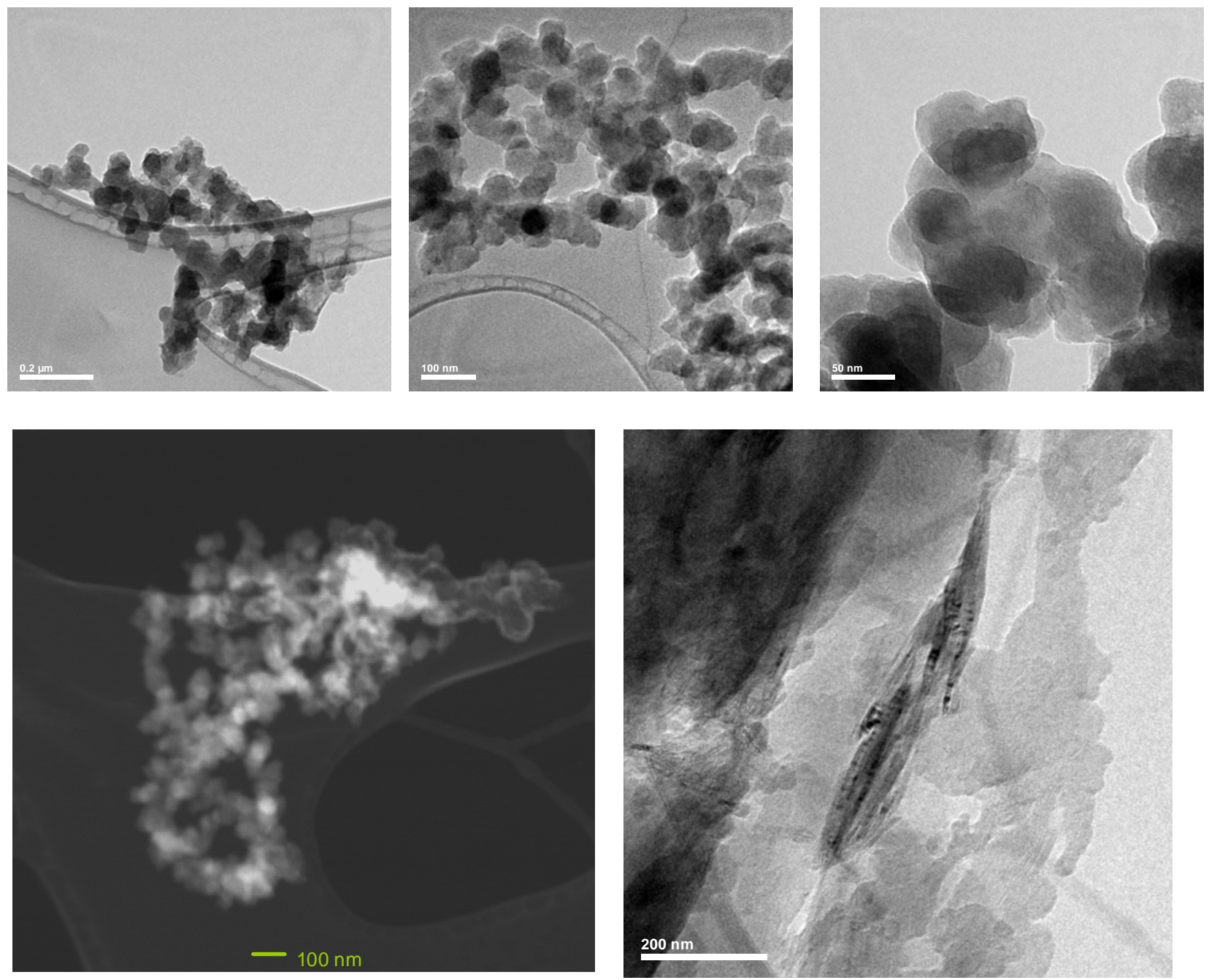

Figure 3.22. TEM Images of Group 1 Washed Solids 

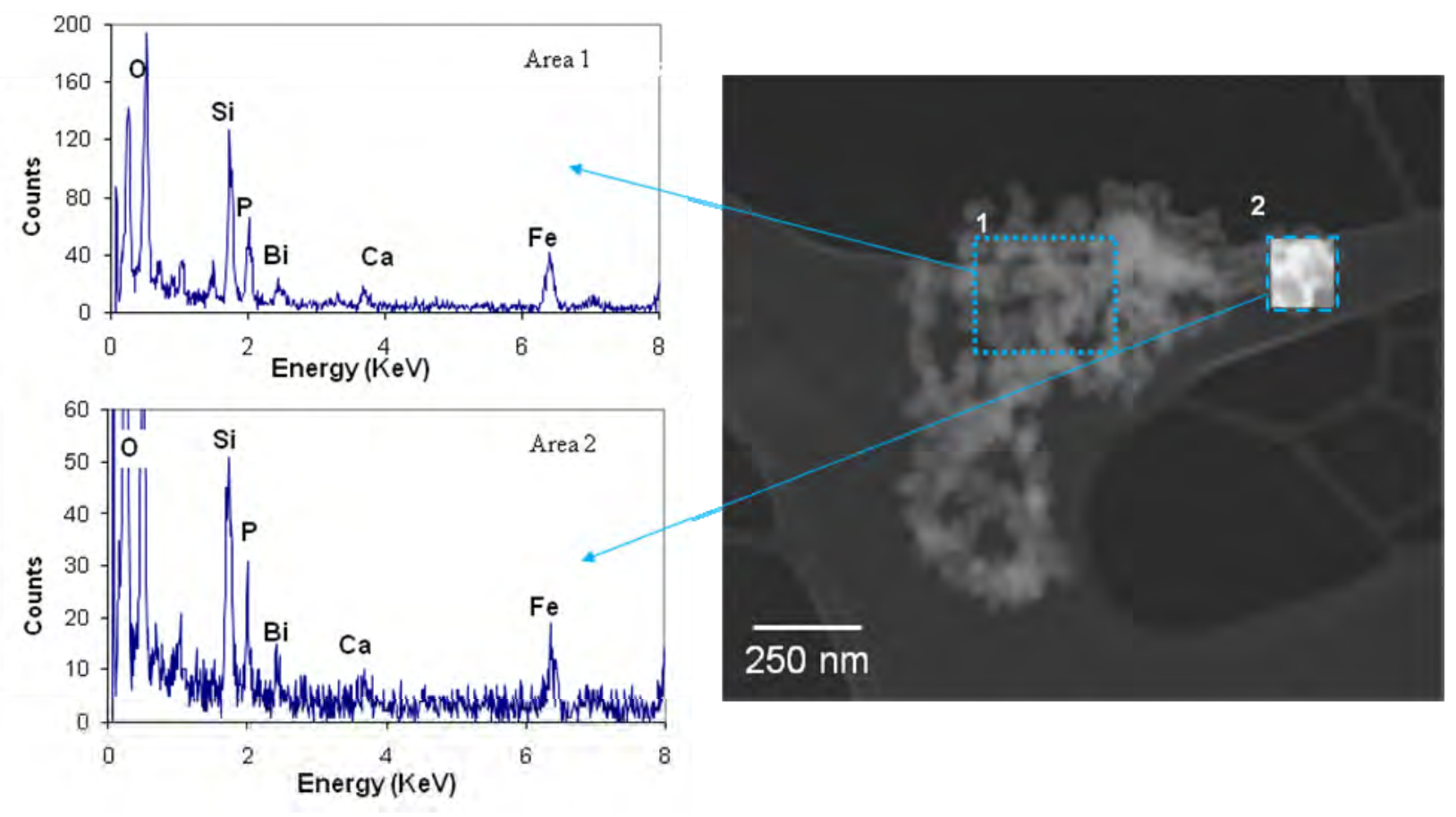

Figure 3.23. STEM-EDS Image of Nano-Agglomerates

\subsection{Group 1 Batch Parametric Leaching: Experimental}

Parametric caustic leaching tests were performed on the Group 1 bismuth phosphate sludge sample to determine the behavior of phosphate and other components during leaching at different conditions. The composite Group 1 sample material was rinsed with $0.01 \mathrm{M} \mathrm{NaOH}$, subdivided, and subjected to a parametric test matrix for caustic leach testing as discussed in the following sections. ${ }^{(a)}$

\subsubsection{Initial Washing of the Group 1 Solids}

The Group 1 composite sample was mixed with an overhead stirrer fitted with a bladed stainless steel impeller. A 122-g aliquot was removed with a large transfer pipet and transferred to a $200-\mathrm{mL}$ centrifuge bottle. At a concentration of $0.082 \mathrm{~g}$ dry water-insoluble solids per gram of slurry, the 122-g slurry contained $\sim 10$ g of water-insoluble solids. The slurry aliquot was centrifuged at 2500 RPM (1200 G) for $15 \mathrm{~min}$, and then the supernatant was removed. The volume of centrifuged solids was estimated to be $\sim 20 \mathrm{~mL}$ based on volume graduations on the sample bottle. Approximately $60 \mathrm{~mL}$ (3× the centrifuged solids volume) of $0.01 \mathrm{M} \mathrm{NaOH}$ was added to wash the solids, and the slurry was mixed for 15 minutes with an overhead mixer. The slurry was centrifuged at $1200 \mathrm{G}$ for $15 \mathrm{~min}$, and then the supernatant was removed. The washing steps were repeated twice for a total of three washes.

(a) Testing was conducted according to TI-RPP-WTP-555, Parametric Caustic Leach Test of Group 1 Hanford BiPhosphate Sludge Waste, L Snow, November, 2007. 


\subsubsection{Division of the Washed Group 1 Solids}

To conduct a successful sample subdivision, the washed centrifuged solids needed to be thinned. DI water ( $60 \mathrm{~mL}$ ) was added to the solids, resulting in a final volume of $\sim 85 \mathrm{~mL}$ (or $10 \mathrm{~g}$ solids in $87 \mathrm{~g}$ of slurry, equivalent to $11.5 \mathrm{wt} \%$ undissolved solids [UDS]).

An overhead mixer equipped with a 3-bladed stainless steel impeller was used to homogenize the thinned slurry. Eight $\sim 9.9$-g slurry samples were transferred to 125 -mL high-density polyethylene (HDPE) bottles with a large disposable polyethylene pipet. Each sample contained $\sim 0.95 \mathrm{~g}$ UDS. The samples were removed from the hot cell for follow-on processing at the fume hood workstation.

One additional sample (G1-WL-Solids) containing approximately $6.5 \mathrm{~g}$ of slurry (equivalent to $0.75 \mathrm{~g}$ dry solids) was transferred to a 60-mL HDPE bottle. A portion of this sample was submitted for a potassium hydroxide $(\mathrm{KOH})$ fusion and the following subsequent analyses: inductively coupled plasma-optical emission spectroscopy (ICP-OES) metals, gamma energy analysis (GEA), Pu, total alpha, total beta, ${ }^{90} \mathrm{Sr}$, and $U$ by KPA. These analyses were performed to establish the starting composition of the washed solids.

\subsubsection{Caustic Leaching of the Washed Group 1 Solids}

The leaching test matrix for each of the eight samples is summarized in Table 3.12. The test matrix evaluated the effects of free-hydroxide concentration (1 to $3 \mathrm{M} \mathrm{NaOH})$ and temperature $\left(40\right.$ to $\left.80^{\circ} \mathrm{C}\right)$ on phosphate leaching kinetics.

Table 3.12. Group 1 Caustic Leaching Conditions

\begin{tabular}{|c|c|c|c|c|c|}
\hline \multirow[b]{2}{*}{ Bottle ID } & \multicolumn{2}{|c|}{ Free OH, M } & \multicolumn{2}{|c|}{ Na, M } & \multirow{2}{*}{$\begin{array}{c}\text { Temperature, } \\
{ }^{\circ} \mathbf{C}^{(\mathbf{b})}\end{array}$} \\
\hline & Target & Measured $^{(a)}$ & Target & Measured $^{(a)}$ & \\
\hline G1-40-1 & 1 & 1.10 & 1 & 1.14 & 40 \\
\hline G1-40-3a & 3 & 3.28 & 3 & 3.26 & 40 \\
\hline G1-40-3b & 3 & 3.23 & 3 & 3.31 & 40 \\
\hline G1-40-3c & 3 & 3.14 & 3 & 3.18 & 40 \\
\hline G1-60-1 & 1 & 1.03 & 1 & 1.17 & 60 \\
\hline G1-60-3 & 3 & 3.20 & 3 & 3.27 & 60 \\
\hline G1-80-1 & 1 & 1.07 & 1 & 1.17 & 80 \\
\hline G1-80-3 & 3 & \begin{tabular}{|l|}
3.23 \\
\end{tabular} & 3 & 3.25 & 80 \\
\hline \multicolumn{6}{|c|}{$\begin{array}{l}\text { (a) The measured analyte concentrations represent the equilibrium concentration } \\
\text { obtained after a } 24 \text {-h contact time. } \\
\text { (b) The temperature uncertainty was } \pm 2.5^{\circ} \mathrm{C} \\
\text { Analytical Service Request (ASR): } 8060\end{array}$} \\
\hline
\end{tabular}

The $\mathrm{NaOH}$ concentration in each leaching mixture was adjusted to support the test matrix. Sodium hydroxide (19 M) was added to each aliquot of the washed solids slurry in the following amounts: $5.3 \mathrm{~mL}$ to yield $1 \mathrm{M} \mathrm{NaOH}$ and $15.8 \mathrm{~mL}$ to yield $3 \mathrm{M} \mathrm{NaOH}$. The leaching mixtures were then diluted to a final volume of $100 \mathrm{~mL}$ (with an estimated uncertainty of $2 \mathrm{~mL}$ ) with DI water. The contact time with the concentrated $\mathrm{NaOH}$ was brief ( $<5 \mathrm{~min}$ ). The sample bottles were weighed after each addition of reagents ( $\mathrm{NaOH}$ and water). Each leaching vessel was closed with a cap equipped with a tube condenser. The 
condenser was used to eliminate pressurization and minimize water loss, while at the same time minimizing the spread of contamination.

The sample slurries were transferred to a temperature-controlled shaker table. The temperature was controlled with an aluminum heating block (J-KEM Scientific, Inc.) equipped with a Type T thermocouple. The heating block was supported on a J-KEM BTS-3500 digital bench-top shaker (Figure 3.24). The shaking speed was digitally controlled to 200 RPM; based on visual inspection, the solids were well suspended in solution. The samples were grouped according to the leaching temperature, and one group was leach-tested at a time. The heating block was pre-heated to the appropriate temperature before leach testing.

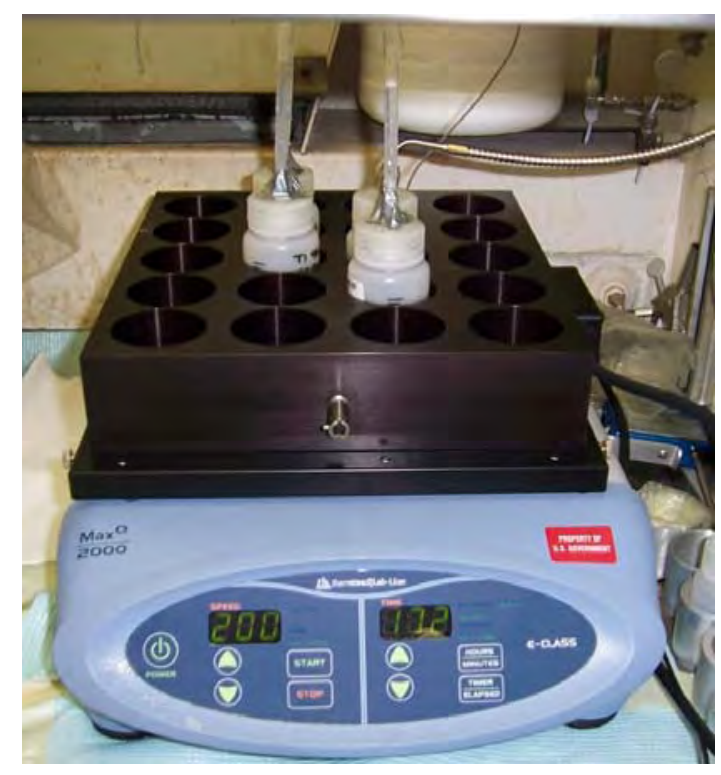

Figure 3.24. Aluminum Heating Block and Shaker Table Used in Parametric Leaching Tests

The leaching mixtures were shaken at temperature for 24 hours, and solution samples were withdrawn at 0 (taken before insertion into heating block), 1, 2, 4, 8, and 24 hours. At each sampling time, the shaker was stopped, and the solids were allowed to settle for $\sim 5$ to $10 \mathrm{~min}$, resulting in sufficient clarification of the aqueous portion to support sampling without removing any solids. Approximately $1.5-\mathrm{mL}$ of the clarified leachate solution was withdrawn with a transfer pipette and filtered through a $0.45-\mu \mathrm{m}$ pore size nylon syringe filter; the syringe filter and the syringe had been pre-heated in an oven to the sample temperature $\left(40,60\right.$, or $\left.80^{\circ} \mathrm{C}\right)$ before filtering in an effort to minimize temperature changes impacting the sample. One $0.5-\mathrm{mL}$ sample of filtered solution was acidified with $15 \mathrm{~mL}$ of $0.3 \mathrm{M} \mathrm{HNO}_{3}$ for analysis by ICP-OES; another 0.5-mL sample of filtered solution was added to $2.5 \mathrm{~mL}$ of $1 \times 10^{-4} \mathrm{M} \mathrm{NaOH}$ for analysis by ion chromatography. The remaining filtered solution was returned to the leaching vessel, and the leaching process was continued. The new liquid level was marked after each sample was taken. Evaporation was minimal during the course of the experiment, but when evaporation was observed, DI water was added to restore the volume to the previously marked liquid level. After 24 hours, additional leachate samples were taken to determine the free-hydroxide ion concentration and gamma-emitting isotopes by GEA. 
After the final samples were taken at temperature, the slurries were removed from the mixing/heating block and cooled to ambient $\left(\sim 22^{\circ} \mathrm{C}\right)$ temperature. The slurries were centrifuged, and half of the leachate was decanted. $^{(a)}$

The equilibrium concentration values for free hydroxide and sodium are shown in Table 3.12 and were based on results from the samples taken at 24 hours.

\subsubsection{Washing of Caustic-Leached Group 1 Solids for Analysis}

The solids from the triplicate samples (G1-40-3a, -3b, -3c, leached at $40^{\circ} \mathrm{C}$ in $3 \mathrm{M} \mathrm{NaOH}$ ) were prepared for characterization as shown in Figure 3.25. One of the solids samples was slurried in $15 \mathrm{~mL}$ of $0.01 \mathrm{M}$ $\mathrm{NaOH}$ and divided between the remaining two solids samples. The leaching bottle was then rinsed with $10 \mathrm{~mL}$ of $0.01 \mathrm{M} \mathrm{NaOH}$, and the wash was split between the remaining two solids samples. The solids were mixed on a shaker table for 15 minutes. The slurry was centrifuged for 5 min and the supernatant removed. Dilute sodium hydroxide solution $(0.01 \mathrm{M} ; 15 \mathrm{~mL})$ was added to the solids, the compacted solids were broken up with disposable pipet, and the slurry was mixed on a shaker table for 15 minutes. The slurry was centrifuged for $5 \mathrm{~min}$ and the supernatant removed. The wash steps were repeated once more for a total of three washes. After the final wash, the solids were slurried in $\sim 2 \mathrm{~mL}$ of DI water and sub-divided for analysis by particle-size distribution (PSD), X-ray diffraction (XRD), transmission electron microscopy (TEM), scanning electron microscopy (SEM), Brunauer, Emmett, and Teller (surface area analysis technique) (BET) surface area, and a $\mathrm{KOH}$ fusion with subsequent analysis for ICP-OES metals, GEA, Pu, total alpha, total beta, ${ }^{90} \mathrm{Sr}$, and U by KPA.

(a) The contact dose rates of the leached solids were too high to safely conduct transfer to volume-graduated centrifuge tubes to assess the volume of centrifuged solids. 
WTP-RPT-166, Rev. 0

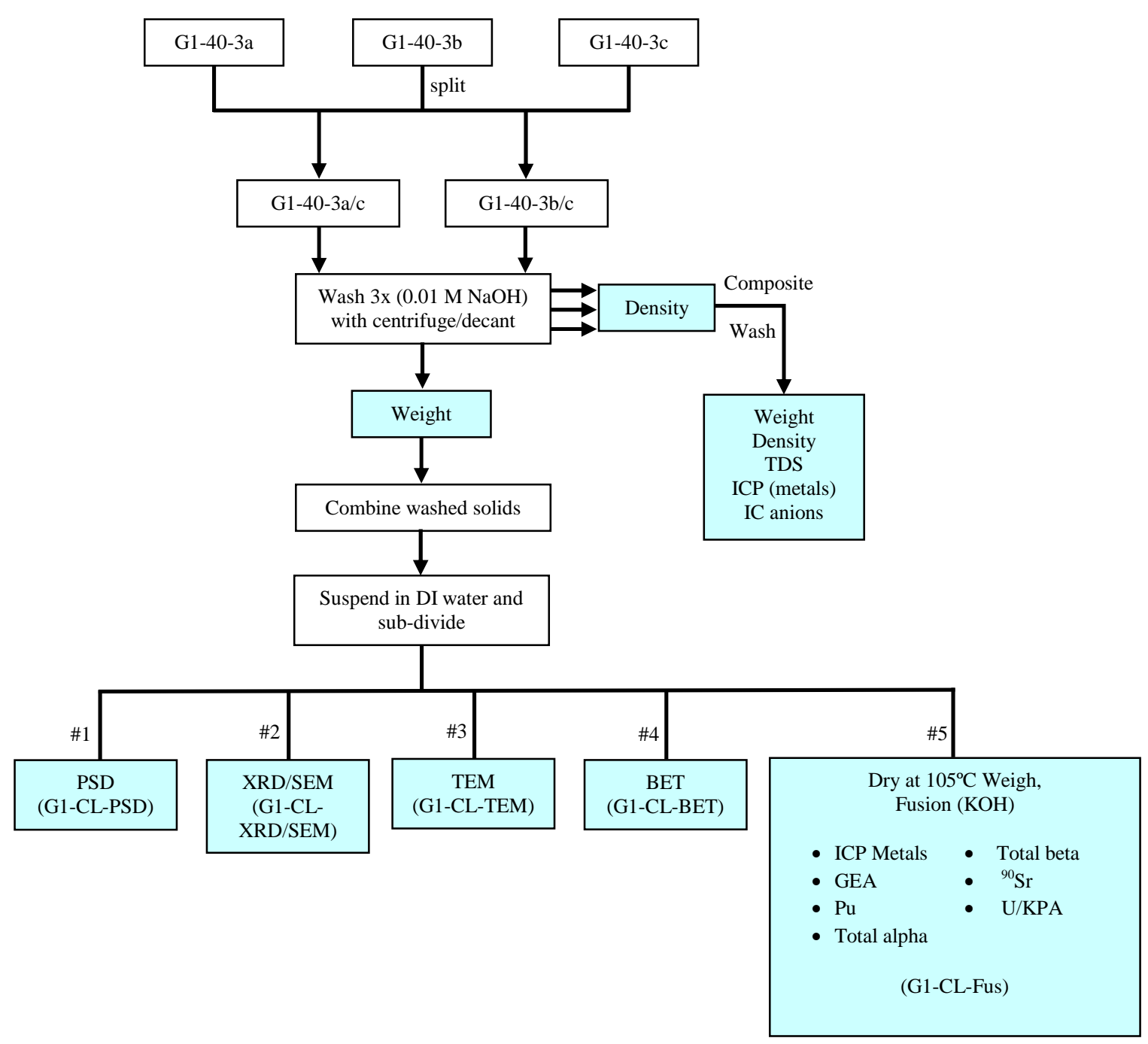

Figure 3.25. Washing, Subdivision, and Analysis Scheme for the Group 1 Caustic Leached Solids

\subsection{Group 1 Bi-Phosphate Sludge Waste Parametric Caustic- Leaching Test Results}

Phosphorus is the most important component in the water-insoluble Group 1 bismuth phosphate sludge solids with respect to caustic leaching. Aluminum is present at a relatively low concentration (2.7 wt\%), so the behavior of this element is less important for this particular waste group. However, the behavior of $\mathrm{Cr}(0.51 \mathrm{wt} \%)$ is of interest because this can become a glass-limiting component if sufficient $\mathrm{P}$ is removed by caustic leaching. The parametric leach testing of this sample was primarily directed at understanding the phosphorus dissolution in the actual tank waste in order to understand and subsequently match the dissolution properties to a simulant material. But the behaviors of $\mathrm{Al}$ and $\mathrm{Cr}$ were also determined. The parametric leaching results and residual solids composition are discussed in the following sub-sections. 


\subsubsection{Time, Temperature, and Hydroxide Effects on Phosphorus Dissolution from the Group 1 Solids}

The P dissolution behavior for the washed Group 1 solids was evaluated as a function of time, temperature, and free-hydroxide concentration. Based on the total P concentration in the solids material ( $0.101 \mathrm{~g} \mathrm{P} / \mathrm{g})$, and the wt\% UDS of the starting slurry (9.62\%), the complete dissolution of P would result in a concentration of $0.96 \mathrm{mg} \mathrm{P} / \mathrm{mL}$ or $0.031 \mathrm{M}$. This expected maximum concentration is about $24 \%$ less than the value of $0.038 \mathrm{M} \mathrm{P}$, which was actually determined in the liquid samples. This difference can be attributed to the experimental uncertainty in the solids analysis and to the uncertainty in determining wt\% UDS. The reported $\mathrm{wt} \%$ of $\mathrm{P}$ dissolved at each sampling point was calculated based on the final concentration in the triplicate solids samples, as discussed in Section 3.4.6.2.

Figure 3.26 summarizes the $\mathrm{P}$ behavior during leaching of the washed Group 1 solids in $1 \mathrm{M}$ and $3 \mathrm{M}$ $\mathrm{NaOH}$ at $40^{\circ} \mathrm{C}$. In $1 \mathrm{M} \mathrm{NaOH}$, there was rapid transfer of $\mathrm{P}$ to the liquid phase. Even before heating was applied (i.e., at $\mathrm{t}=0$ ), $\sim 60 \%$ of the $\mathrm{P}$ was removed from the solid phase. It should be noted that this was accompanied by the visual observation of a dramatic color change from the initial beige color of the solids to rusty-red after adding $\mathrm{NaOH}$ (this was seen for all conditions examined) as shown in Figure 3.27. This result points to a rapid metathesis of an iron(III) phosphate phase to sodium phosphate and ferric hydroxide (vide infra). After $1 \mathrm{~h}$ at $40^{\circ} \mathrm{C}, 97 \%$ of the $\mathrm{P}$ had dissolved, and $99 \%$ had dissolved after $2 \mathrm{~h}$. For the triplicate runs done at $40^{\circ} \mathrm{C}$ and $3 \mathrm{M} \mathrm{NaOH}$, there is considerable scatter in the data. The reason for this scatter is not clear, but it appears to be dominated by lower P concentrations in the 1and 2-h sampling points for Trials b and c (the data for Trial a are more similar to that observed for $1 \mathrm{M}$ $\mathrm{NaOH})$. Regardless, complete $\mathrm{P}$ removal is achieved after $4 \mathrm{~h}$ of leaching in $3 \mathrm{M} \mathrm{NaOH}$ at $40^{\circ} \mathrm{C}$.

Figure 3.28 and Figure 3.29 show the $\mathrm{P}$ behavior for leaching of the Group 1 solids at 60 and $80^{\circ} \mathrm{C}$, respectively. Within the experimental uncertainty, the $\mathrm{P}$ behavior in $1 \mathrm{M} \mathrm{NaOH}$ is essentially the same as that in $3 \mathrm{M} \mathrm{NaOH}$ at $60^{\circ} \mathrm{C}$; the same can be said for the results at $80^{\circ} \mathrm{C}$. Figure 3.30 compares the $\mathrm{P}$ leaching behaviors at the three different temperatures examined at the individual $\mathrm{NaOH}$ concentrations investigated. Generally, the temperature had little influence on the P leaching kinetics. Rapid P removal was observed in all cases, typically with essentially complete removal being achieved after $2 \mathrm{~h}$. Again, the final P concentrations observed were essentially the same, within the experimental uncertainty. 


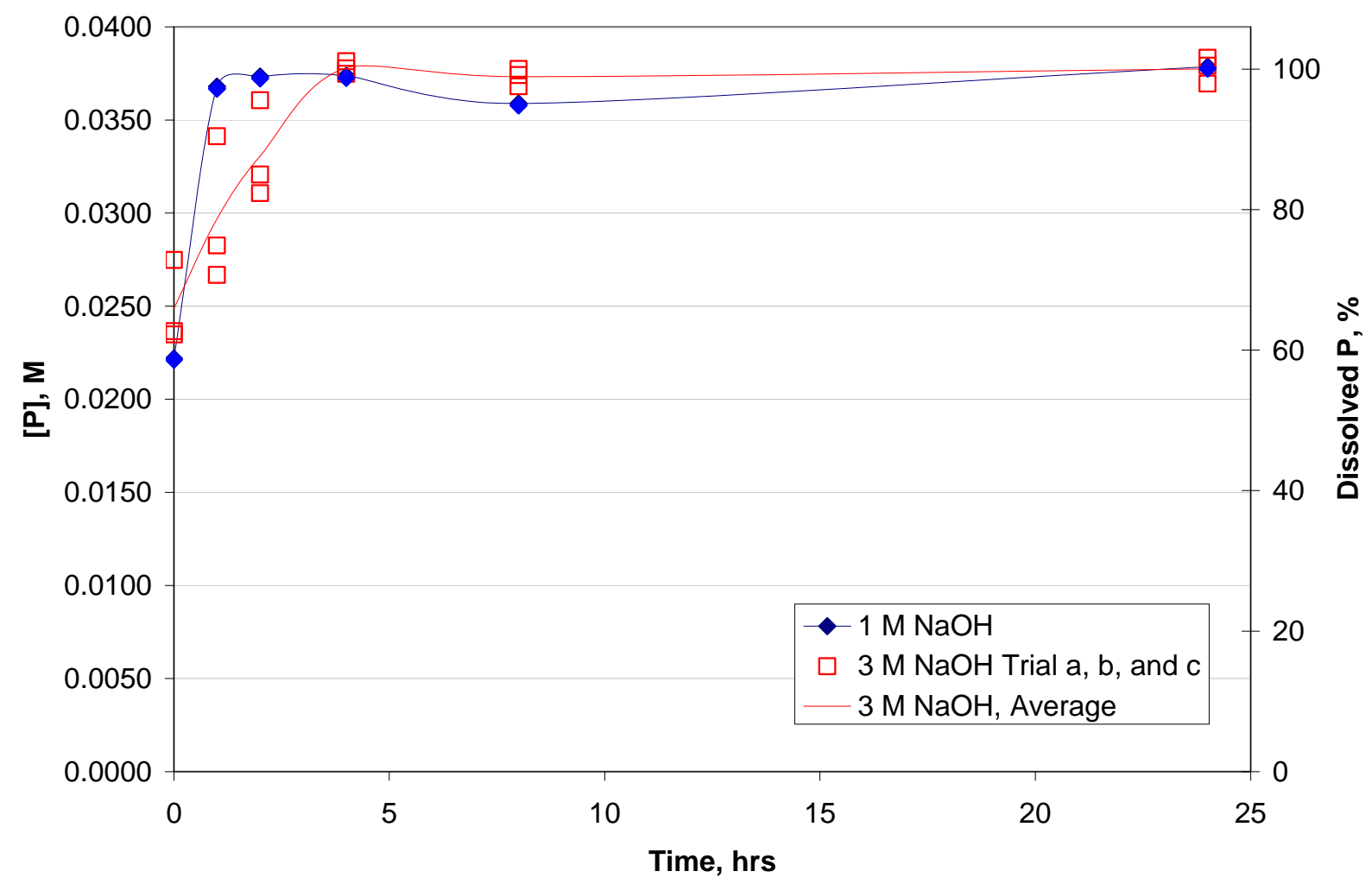

Figure 3.26. Phosphorus Concentration and Percent Removed Versus Time at $40^{\circ} \mathrm{C}$ for Leaching of the Group 1 Washed Solids in 1 and $3 \mathrm{M} \mathrm{NaOH}$

(a)

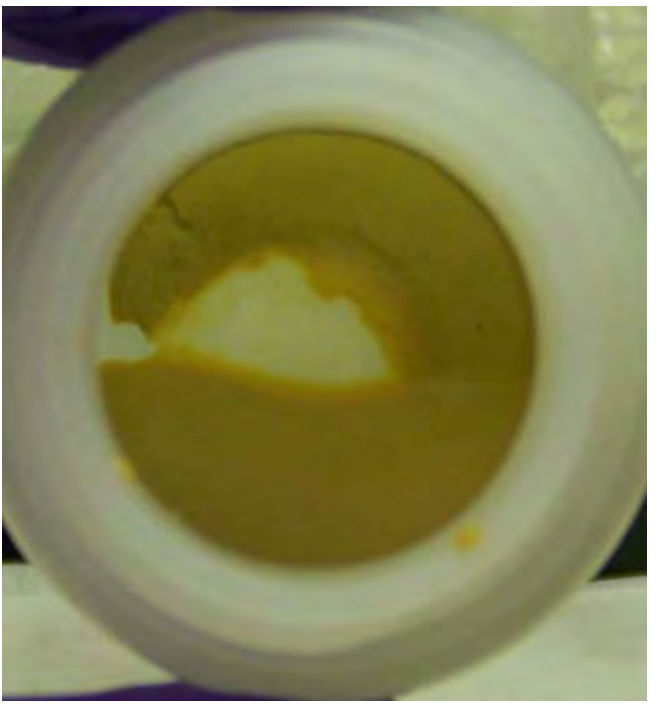

(b)

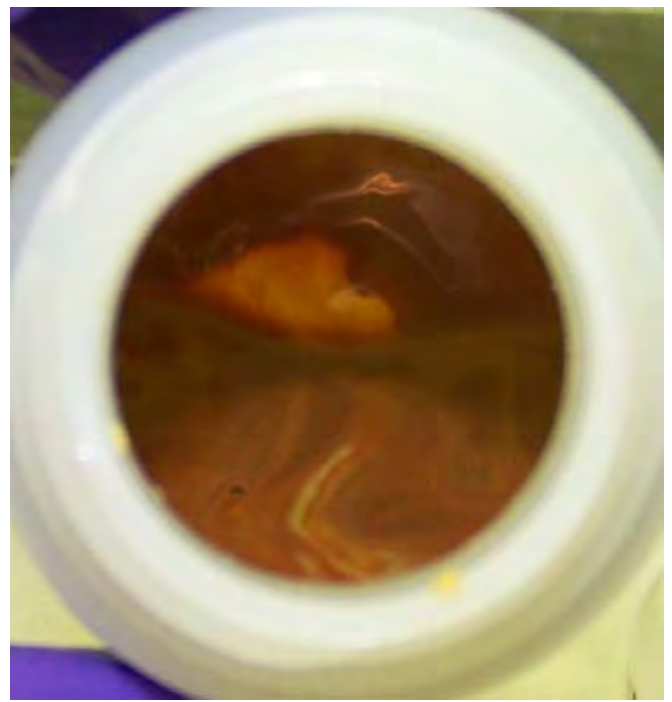

Figure 3.27. Color Change Observed in Group 1 Solids upon Addition of NaOH: (a) Initial Solids; (b) Solids After Addition of $\mathrm{NaOH}$ 
WTP-RPT-166, Rev. 0

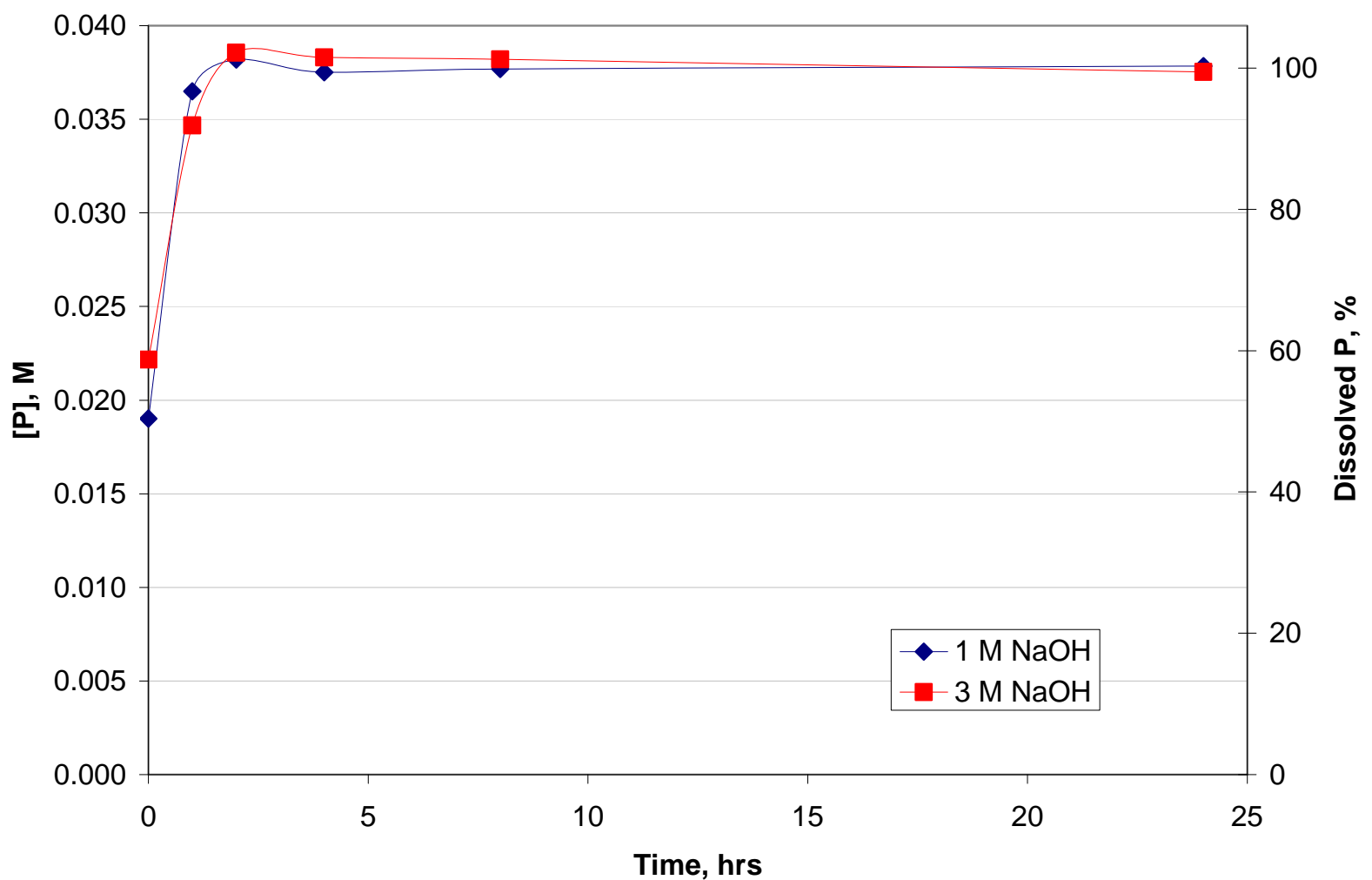

Figure 3.28. Phosphorus Concentration and Percent Removed Versus Time at $60^{\circ} \mathrm{C}$ for Leaching of the Group 1 Washed Solids in 1 and $3 \mathrm{M} \mathrm{NaOH}$ 
WTP-RPT-166, Rev. 0

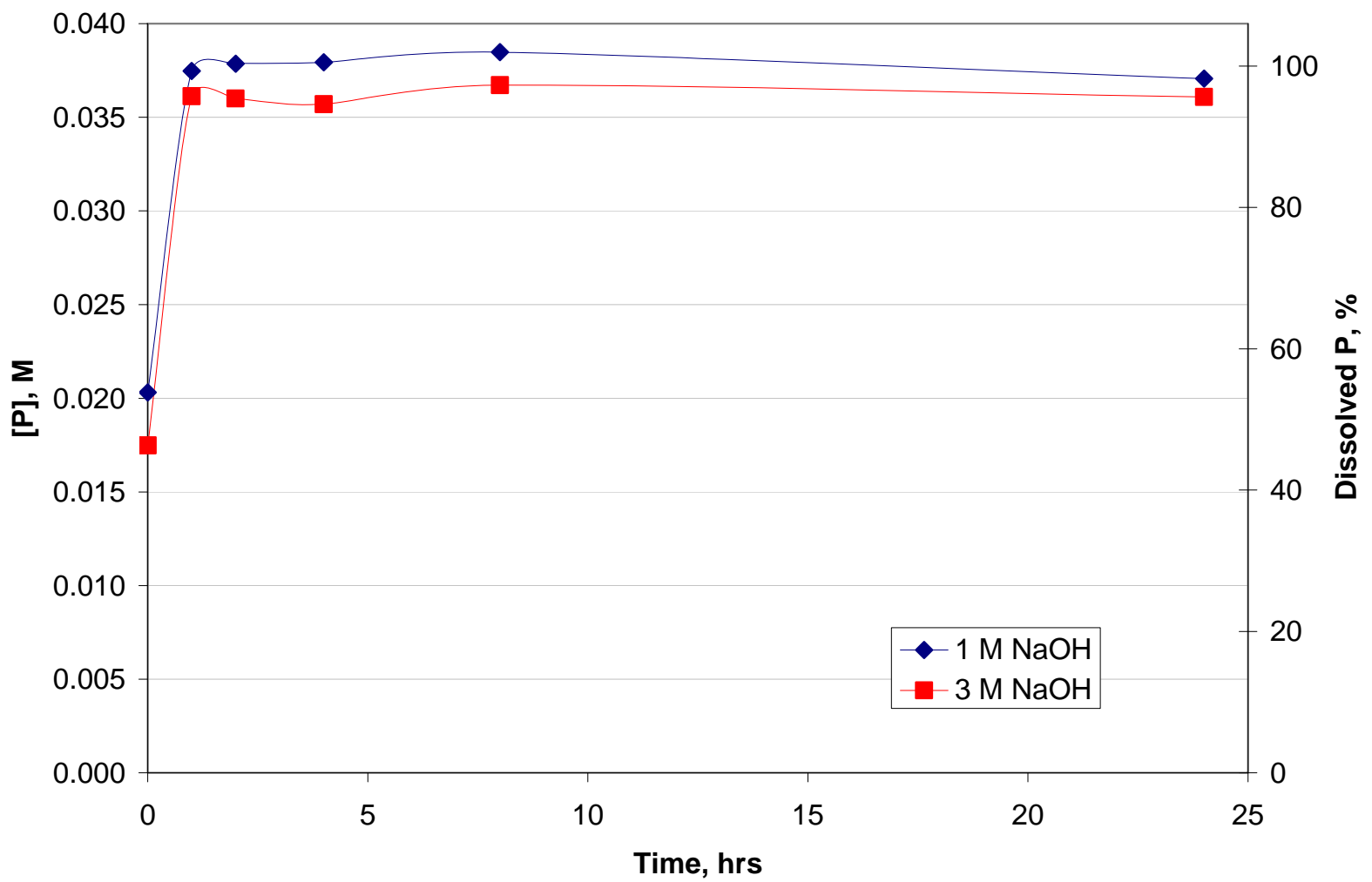

Figure 3.29. Phosphorus Concentration and Percent Removed Versus Time at $80^{\circ} \mathrm{C}$ for Leaching of the Group 1 Washed Solids in 1 and $3 \mathrm{M} \mathrm{NaOH}$ 
WTP-RPT-166, Rev. 0
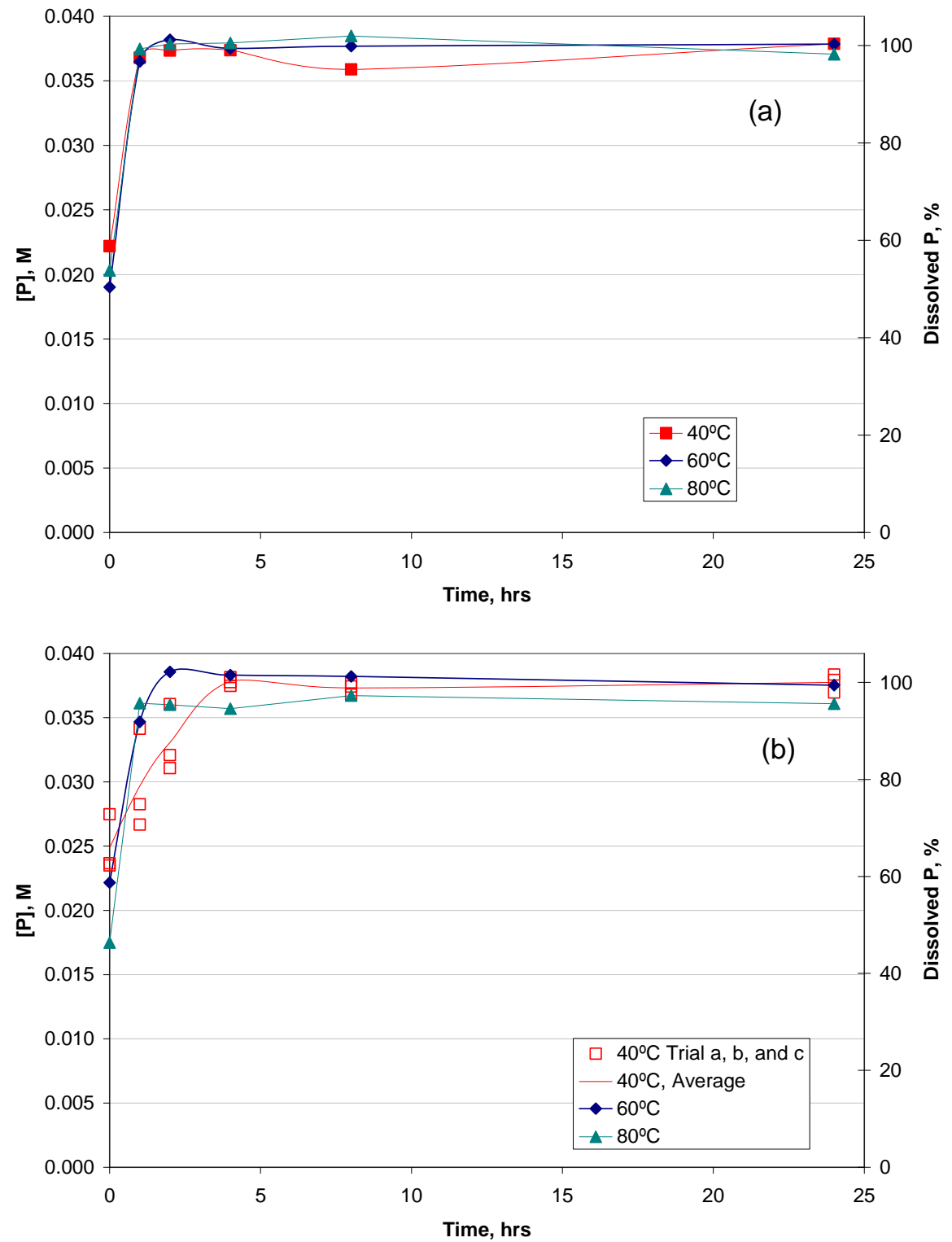

Figure 3.30. Phosphorus Concentration and Percent Removed Versus Time at a) $1 \mathrm{M} \mathrm{NaOH}, 40,60$, and $80^{\circ} \mathrm{C}$ and b) $3 \mathrm{M} \mathrm{NaOH}, 40,60$, and $80^{\circ} \mathrm{C}$ for Leaching of the Group 1 Washed Solids

Based on the observations described above, it was hypothesized that the phosphorus in the washed Group 1 solids was primarily in the form of an iron(III) phosphate phase. To test this hypothesis, the Raman spectrum $^{(a)}$ of a portion of the washed Group 1 solids was recorded and compared to that of commercially procured $\mathrm{FePO}_{4} \cdot \times \mathrm{H}_{2} \mathrm{O}$. The latter material displayed distinct $\mathrm{PO}_{4}{ }^{3-}$ bands at 997 and $1034 \mathrm{~cm}^{-1}$. On the other hand, the Raman spectrum of the Group 1 solids was featureless. A second "FePO $\mathrm{P}_{4}$ " material was prepared in-house by adding ferric nitrate solution to an aqueous solution of $\mathrm{Na}_{3} \mathrm{PO}_{4}$. This resulted in a beige precipitate that was quite different in appearance from the commercially procured $\mathrm{FePO}_{4} \times \mathrm{H}_{2} \mathrm{O}$ (which was a pale pink crystalline solid). On the other hand, this beige precipitate

(a) All Raman and FTIR spectroscopic work discussed here is for indication only. 
was visually very similar to the actual Group 1 tank waste sample (Figure 3.31). Indeed, the SEM-EDS elemental mapping for the beige iron(III) phosphate product (Figure 3.32) was similar to that seen for the Group 1 sample (Figure 3.20 and Figure 3.21), with Na, Fe, and P mapping very closely together. It is unclear whether the $\mathrm{Na}$ is entrained sodium nitrate or phosphate or whether it is actually incorporated into the iron phosphate solid structure.

The Raman spectrum of the beige $\mathrm{FePO}_{4}$ product displayed a weak phosphate band at $1069 \mathrm{~cm}^{-1}$. Because the Group 1 solids did not display any Raman bands, the FTIR spectrum was recorded. Figure 3.33 shows the FTIR spectrum of the washed Group 1 solids along with the spectra of beige iron(III) phosphate product, the commercially procured $\mathrm{FePO}_{4} \cdot \times \mathrm{H}_{2} \mathrm{O}$, and $\mathrm{BiPO}_{4}$. The FTIR spectrum of Group 1 solids is consistent with an iron(III) phosphate species, although there is not a perfect match with the material formed by mixing ferric nitrate solution to an aqueous solution of $\mathrm{Na}_{3} \mathrm{PO}_{4}$. This is not surprising since the product formed by reacting ferric ion with aqueous sodium phosphate can only approximately be considered to be $\mathrm{FePO}_{4} \times \mathrm{H}_{2} \mathrm{O}$ (amorphous), and its composition depends upon the $\mathrm{pH}$ of the solution during precipitation (de Barry Barnett and Wilson 1953, p. 202). The amorphous iron(III) phosphate product prepared in this work was undoubtedly formed under conditions that were different from that for the actual tank waste, so slight differences in their FTIR spectra should be expected. It can be definitively concluded, however, that the phosphate present in "bismuth phosphate" sludge (i.e., Group 1) is not in the form of $\mathrm{BiPO}_{4}$.

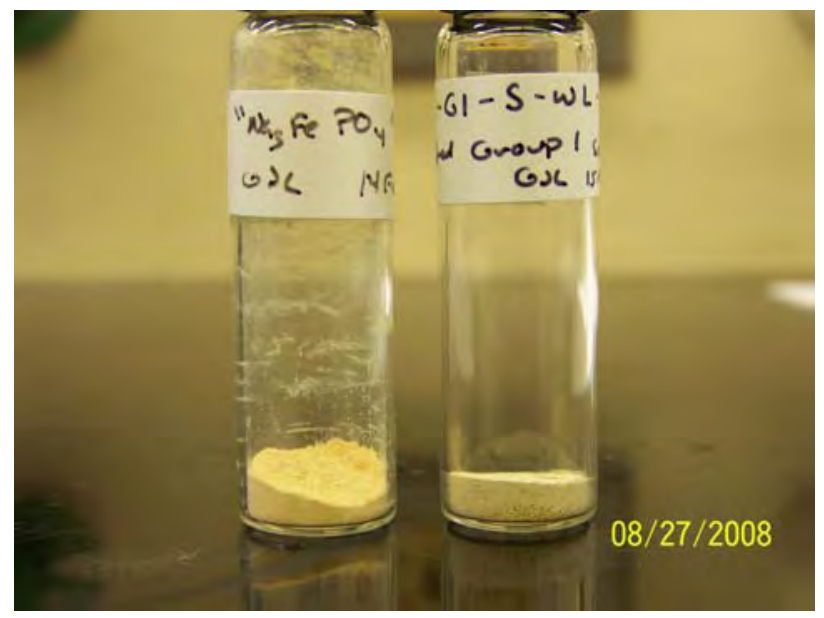

Figure 3.31. Visual Comparison of the Washed Group 1 Solids (right) with Iron(III) Phosphate Prepared by Mixing $\mathrm{Fe}\left(\mathrm{NO}_{3}\right)_{3}$ Solution with $\mathrm{Na}_{3} \mathrm{PO}_{4}$ Solution (left) 


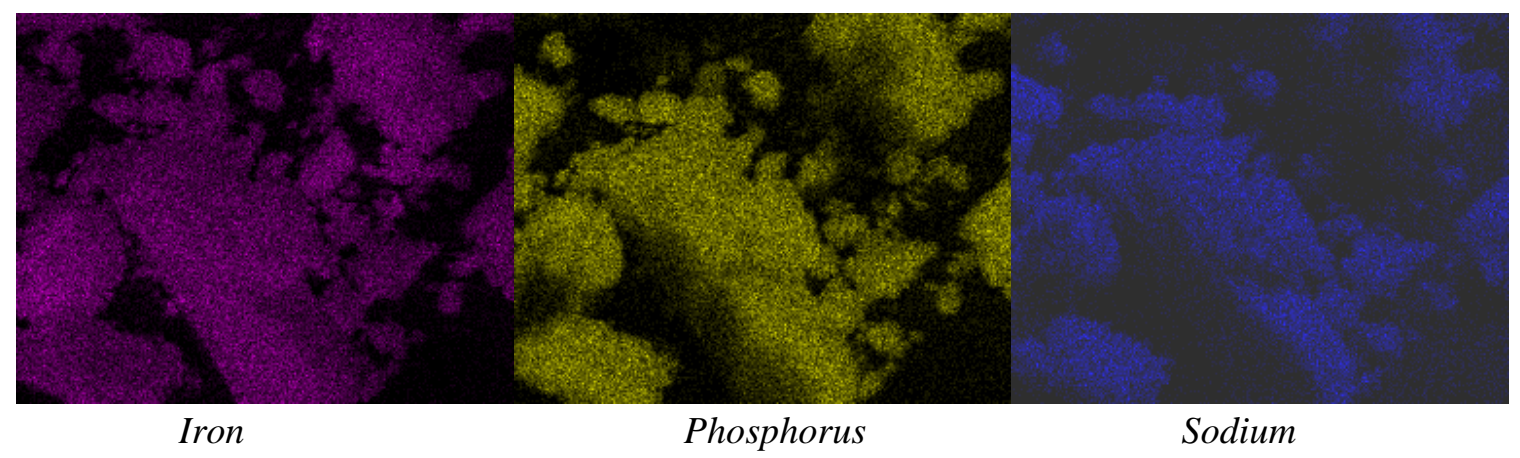

Figure 3.32. SEM-EDS Elemental Mapping for Iron(III) Phosphate Prepared by Mixing $\mathrm{Fe}\left(\mathrm{NO}_{3}\right)_{3}$ Solution with $\mathrm{Na}_{3} \mathrm{PO}_{4}$ Solution

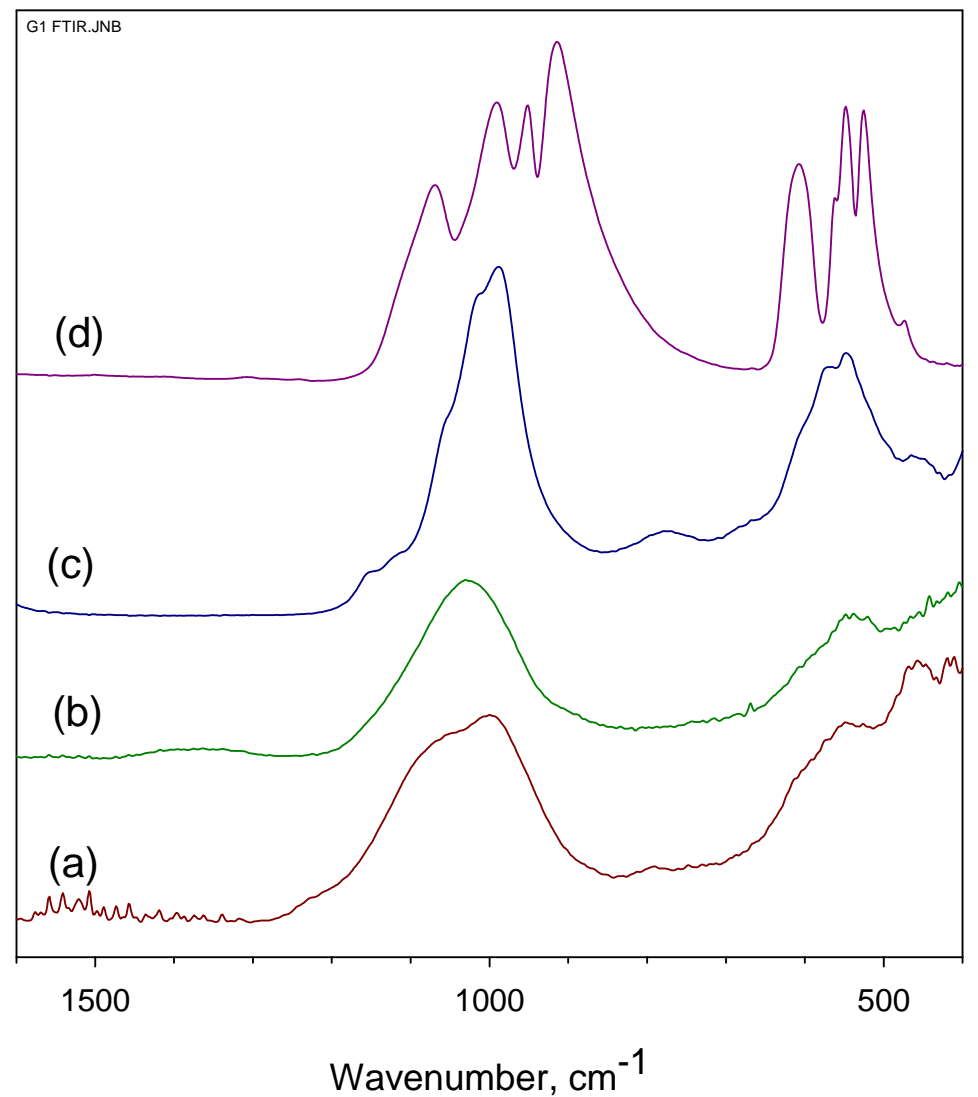

Figure 3.33. FTIR Spectrum (taken on diamond ATR plate) of a) the Washed Group 1 solids, b) the Iron(III) Phosphate Prepared by Mixing $\mathrm{Fe}\left(\mathrm{NO}_{3}\right)_{3}$ Solution with $\mathrm{Na}_{3} \mathrm{PO}_{4}$ Solution, c) Commercially Procured $\mathrm{Fe}\left(\mathrm{PO}_{4}\right) \cdot \mathrm{xH}_{2} \mathrm{O}$, and d) $\mathrm{BiPO}_{4}$ 
Heating of the Group 1 solids in air would not change their elemental form but rather would alter their chemical speciation. Four thermal gravimetric (TG) scans were acquired for washed Group 1 solids. The samples would be best represented by the elemental concentrations in the 2nd column of Table 3.15. In each case, the samples lost between 20 and $24 \mathrm{wt} \%$ of their initial mass. The majority of the mass loss occurred below $200^{\circ} \mathrm{C}$. No other large thermal signature was apparent between 200 and $500^{\circ} \mathrm{C}$ but slow mass loss was observed over this range. Heating the washed Group 1 solids to $830^{\circ} \mathrm{C}$ in quartz pans produced a dark red-brown slag.

Bismuth as $\mathrm{Bi}_{2} \mathrm{O}_{3}$ melts at $824^{\circ} \mathrm{C}$. The phosphate $\left(\mathrm{BiPO}_{4}\right)$ melts at $350^{\circ} \mathrm{C}$ and decomposes at high temperature to $\mathrm{Bi}_{2} \mathrm{O}_{3}$. Melting of $\mathrm{BiPO}_{4}$ was not observed in the TG scans of the four samples. It is also fairly certain that the melting of $\mathrm{Bi}_{2} \mathrm{O}_{3}$ was not observed in the TG analysis of the Group 1 solids, but rather was precluded by vitrification of the sample near $800^{\circ} \mathrm{C}$ in air.

TG scans of the commercially procured $\mathrm{FePO}_{4} \cdot \times \mathrm{H}_{2} \mathrm{O}$ indicated that this material had a dehydration pattern different from that observed in the Group 1 samples. The TG scan of the amorphous iron phosphate obtained by precipitation from $\mathrm{Na}_{3} \mathrm{PO}_{4}$ solution (i.e., the material shown in Figure 3.31) displayed mass loss and dehydration pattern very similar to that seen for the Group 1 samples. This material also formed a glass, with a transition temperature near $660^{\circ} \mathrm{C}$. In the four tank waste samples, the observed glass transition temperatures were consistently higher; between $710^{\circ} \mathrm{C}$ and $794^{\circ} \mathrm{C}$. The redbrown surfaces of the slags were scrapped with a needle and this exposed a shiny-looking material just below the surface. The shiny material appeared to be a bismuth phosphate glass. The presence of the exterior red-brown material indicates that the stoichiometry of the glass that formed partially excluded some iron. The TG analysis was consistent with the conclusion from the FTIR that the phosphate in the Group 1 solids is not in the form of distinct crystalline $\mathrm{FePO}_{4} \cdot \times \mathrm{H}_{2} \mathrm{O}$ or $\mathrm{BiPO}_{4}$, but probably more resembles the amorphous material precipitated from $\mathrm{Na}_{3} \mathrm{PO}_{4}$ solution. The degree of Bi inclusion into this phase is not clear.

\subsubsection{Time, Temperature, and Hydroxide Effects on Aluminum Dissolution from the Group 1 Solids}

The aluminum leaching data at 40,60 , and $80^{\circ} \mathrm{C}$ are plotted in Figure 3.34 through Figure 3.36, respectively. There was some variability in the initial $(\mathrm{t}=0) \mathrm{Al}$ concentrations; this might have been due to variability in the initial sub-sampling or from differences introduced when the $\mathrm{NaOH}$ solution was first added to the sample (e.g., slight differences in the time interval between $\mathrm{NaOH}$ addition and dilution to $100 \mathrm{~mL}$ ). As expected, the amount of $\mathrm{Al}$ removed increased with increasing concentration of $\mathrm{NaOH}$, although effective $\mathrm{Al}$ removal (> 70\%) was achieved in $1 \mathrm{M} \mathrm{NaOH}$ at all temperatures examined. That is, only 5 to $10 \%$ more $\mathrm{Al}$ was removed by going from $1 \mathrm{M}$ to $3 \mathrm{M} \mathrm{NaOH}$. Furthermore, the $\mathrm{Al}$ was removed fairly rapidly, reaching maximum removal for each leaching condition within $2 \mathrm{~h}$. Figure 3.37 compares the $\mathrm{Al}$ leaching behaviors at the three different temperatures examined at the individual $\mathrm{NaOH}$ concentrations investigated. Only a weak temperature dependence was observed, which was most pronounced at $1 \mathrm{M} \mathrm{NaOH}$. These observations indicate that 75 to $85 \%$ of the $\mathrm{Al}$ present in the washed Group 1 solids was present in a form that is readily dissolved in caustic media. Candidate phases that would explain this behavior include gibbsite (or amorphous aluminum hydroxide) and aluminum phosphate (Lumetta 2008). Definitive identification of the specific Al-containing phases was vitiated by the relatively low concentration of $\mathrm{Al}$ in the sample. 
WTP-RPT-166, Rev. 0

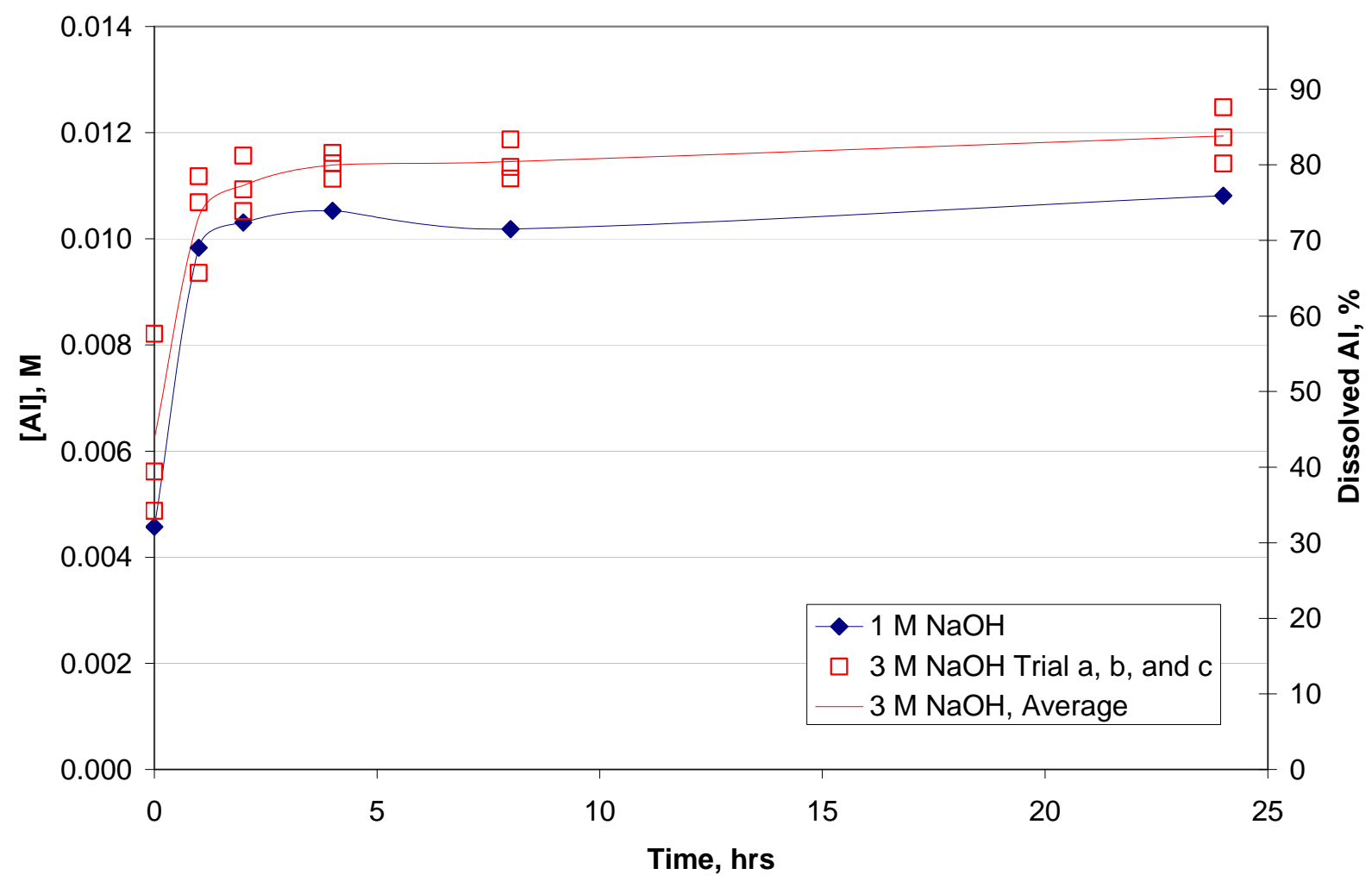

Figure 3.34. Aluminum Concentration and Percent Removed Versus Time at $40^{\circ} \mathrm{C}$ for Leaching of the Group 1 Washed Solids in 1 and $3 \mathrm{M} \mathrm{NaOH}$ 
WTP-RPT-166, Rev. 0

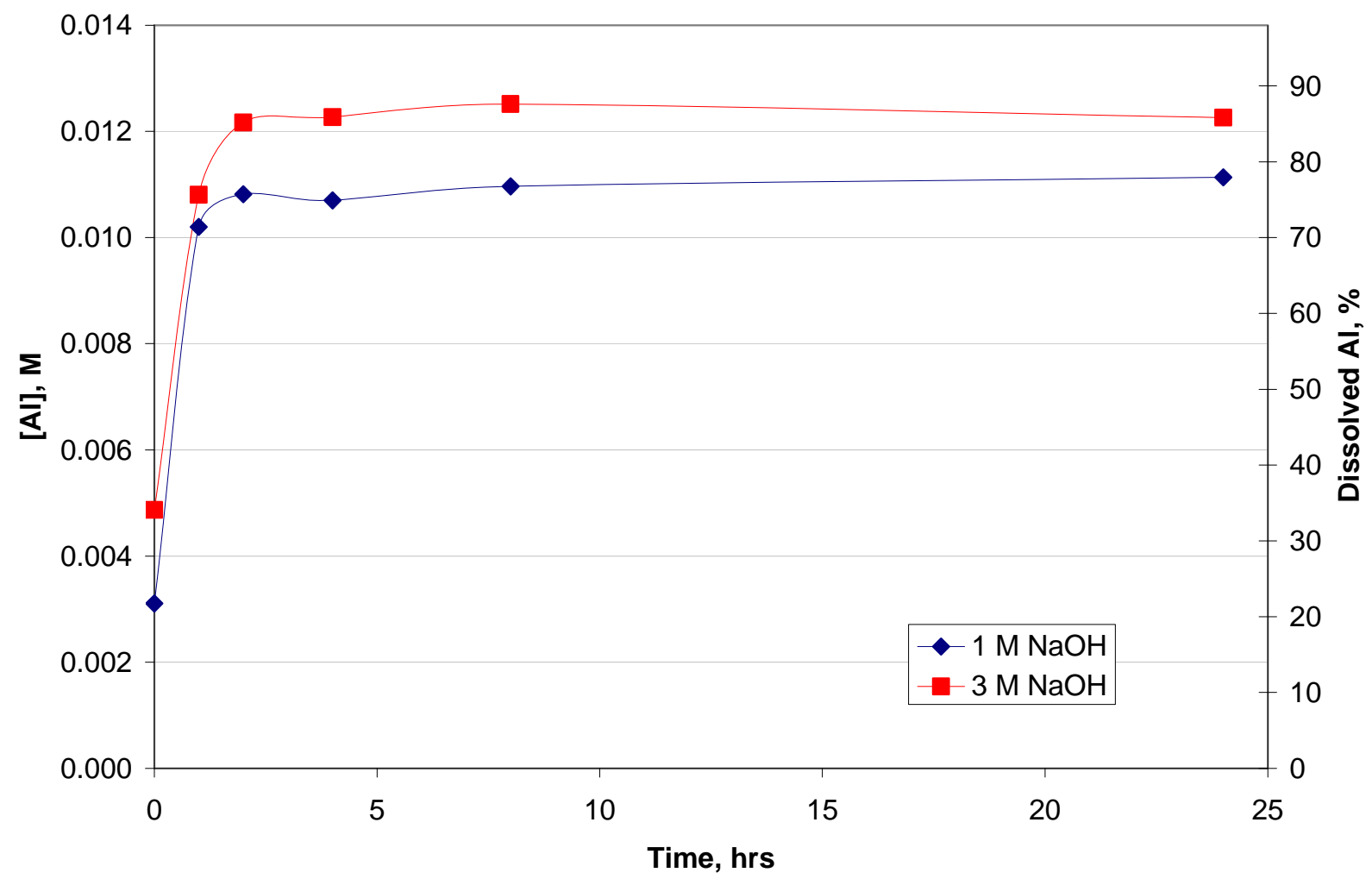

Figure 3.35. Aluminum Concentration and Percent Removed Versus Time at $60^{\circ} \mathrm{C}$ for Leaching of the Group 1 Washed Solids in 1 and $3 \mathrm{M} \mathrm{NaOH}$ 
WTP-RPT-166, Rev. 0

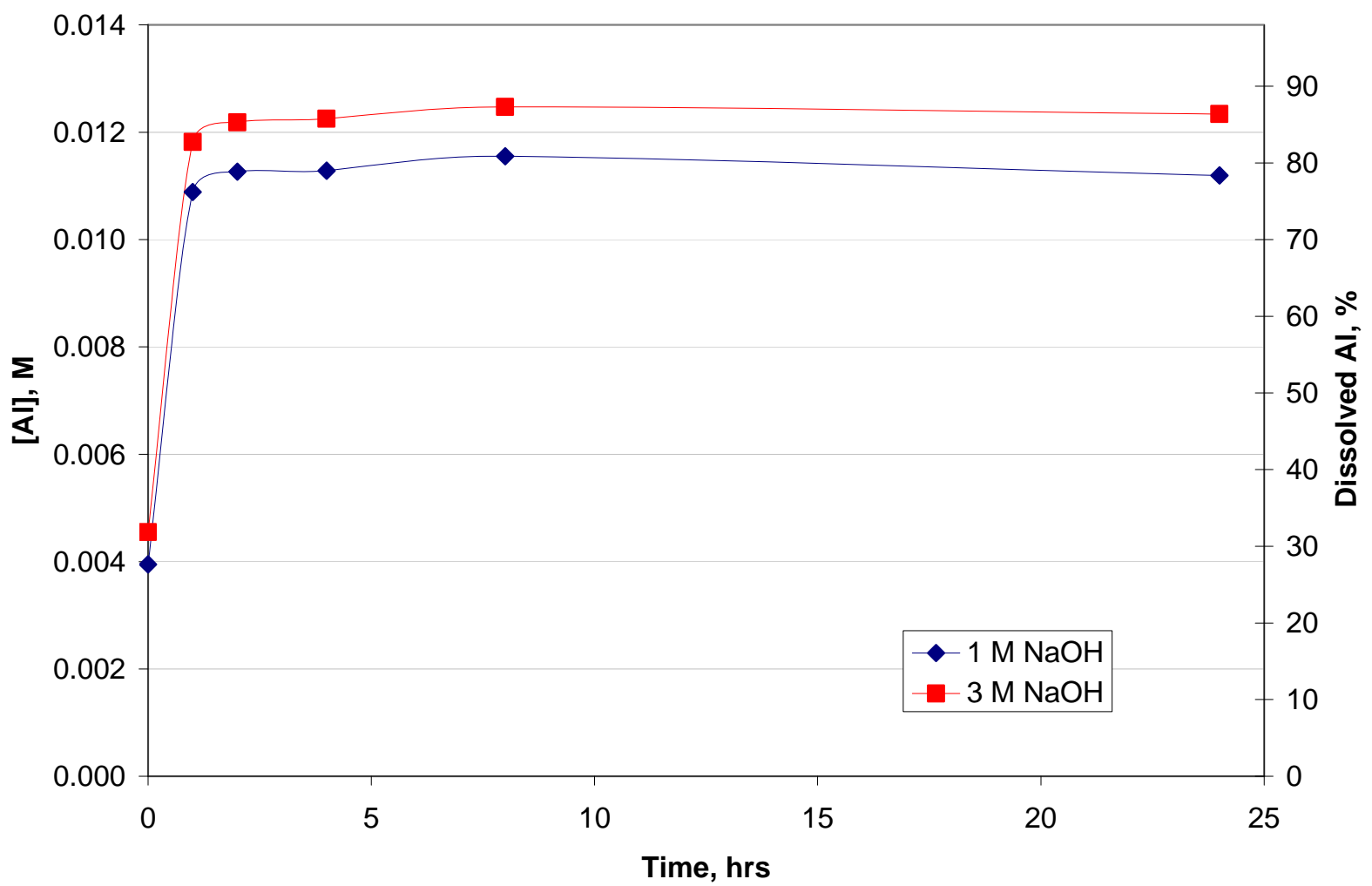

Figure 3.36. Aluminum Concentration and Percent Removed Versus Time at $80^{\circ} \mathrm{C}$ for Leaching of the Group 1 Washed Solids in 1 and $3 \mathrm{M} \mathrm{NaOH}$ 
WTP-RPT-166, Rev. 0
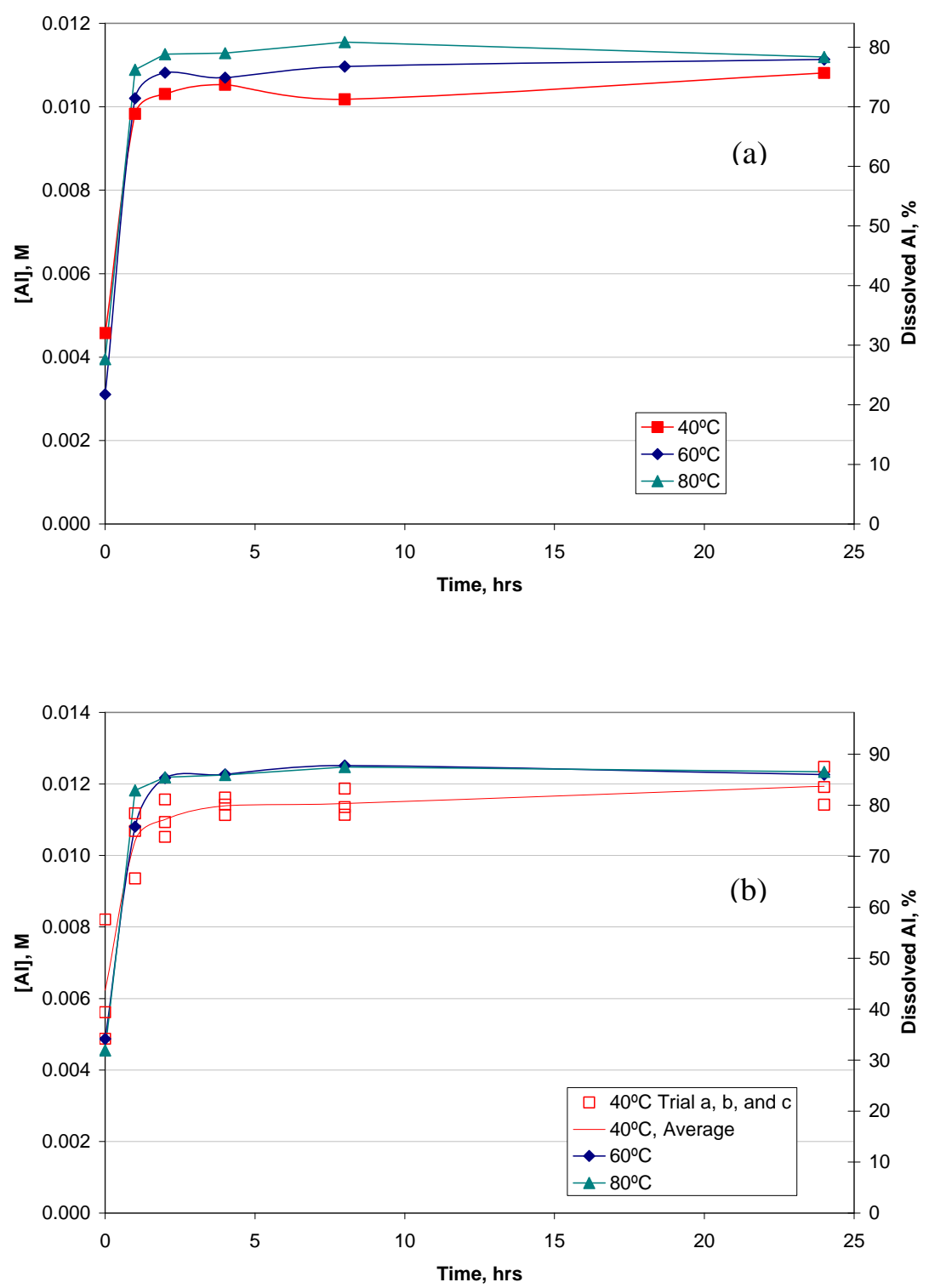

Figure 3.37. Aluminum Concentration and Percent Removed Versus Time at a) $1 \mathrm{M} \mathrm{NaOH}, 40$, 60, and $80^{\circ} \mathrm{C}$, and b) $3 \mathrm{M} \mathrm{NaOH}, 40,60$, and $80^{\circ} \mathrm{C}$, for Leaching of the Group 1 Washed Solids

\subsubsection{Time, Temperature, and Hydroxide Effects on Chromium Dissolution from the Group 1 Solids}

The rate and extent of $\mathrm{Cr}$ removal from the washed Group 1 solids were investigated as a function of time, temperature, and free-hydroxide concentration. Based on the total $\mathrm{Cr}$ concentration in the washed Group 1 solids (5.37 mg/g-free of residual supernatant), the complete dissolution of Cr would result in a concentration of $0.051 \mathrm{mg} \mathrm{Cr} / \mathrm{mL}$ or $0.0010 \mathrm{M}$.

The chromium leaching data at 40,60 , and $80^{\circ} \mathrm{C}$ are plotted in Figure 3.38 through Figure 3.40, respectively. Figure 3.41 compares the $\mathrm{Cr}$ leaching behaviors at the three different temperatures 
examined at the individual $\mathrm{NaOH}$ concentrations investigated. Under all temperature conditions, the amount of $\mathrm{Cr}$ in solution increased with increasing $\mathrm{NaOH}$ concentration. Similarly, at a given $\mathrm{NaOH}$ concentration, the amount of $\mathrm{Cr}$ removed during caustic leaching increased with increasing temperature. However, even under the most rigorous leaching conditions examined ( $3 \mathrm{M} \mathrm{NaOH}$ at $80^{\circ} \mathrm{C}$ ), only $22 \%$ of the $\mathrm{Cr}$ was removed after $24 \mathrm{~h}$ of leaching. These observations are consistent with previous parametric caustic-leaching tests with Hanford tank sludges (Lumetta et al. 1998, 2001, 2002).

At 40 and $60^{\circ} \mathrm{C}$ and $3 \mathrm{M} \mathrm{NaOH}$, the $\mathrm{Cr}$ concentration at $1 \mathrm{~h}$ of leaching appeared to be lower than expected based on the shape of the rest of the curve (Figure 3.38 and Figure 3.39). This might suggest an initial partial reduction of the $\mathrm{Cr}(\mathrm{VI})$ present [leading to precipitation of $\mathrm{Cr}(\mathrm{III})$ ]. Based on the experimental uncertainty, it is not entirely clear that this phenomenon is real, but given the reproducibility of the observation in the triplicate $40^{\circ} \mathrm{C}$ runs and the similar observation at $60^{\circ} \mathrm{C}$, the lower than expected $\mathrm{Cr}$ concentration at $1 \mathrm{~h}$ does appear to be real. A similar observation is not observed at $80^{\circ} \mathrm{C}$. Perhaps with the higher rate of $\mathrm{Cr}(\mathrm{III})$ oxidation at higher temperature, any $\mathrm{Cr}(\mathrm{III})$ initially formed was rapidly oxidized back to $\mathrm{Cr}(\mathrm{VI})$ at $80^{\circ} \mathrm{C}$.

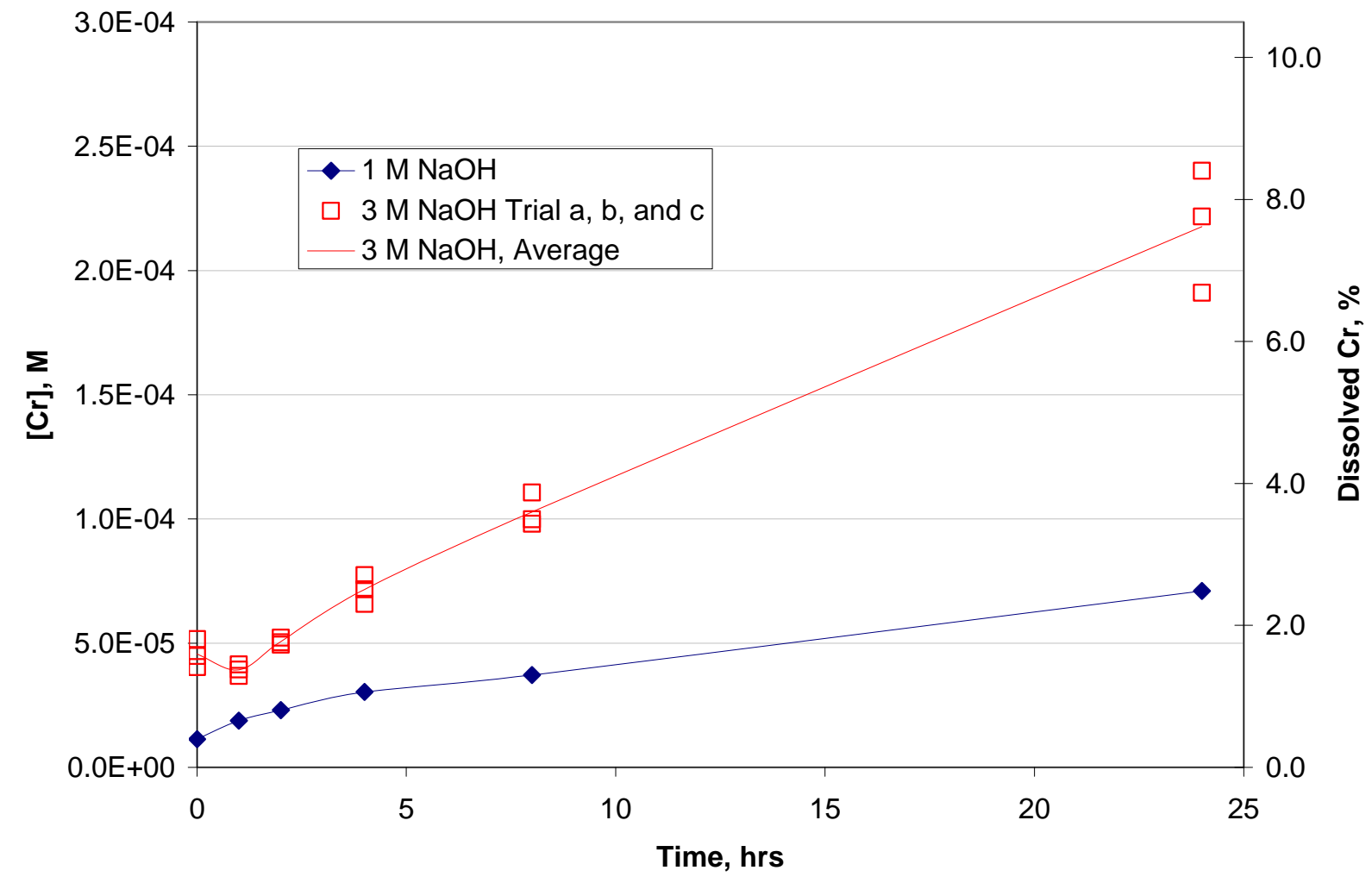

Figure 3.38. Chromium Concentration and Percent Removed Versus Time at $40^{\circ} \mathrm{C}$ for Leaching of the Group 1 Washed Solids in 1 and $3 \mathrm{M} \mathrm{NaOH}$ 
WTP-RPT-166, Rev. 0

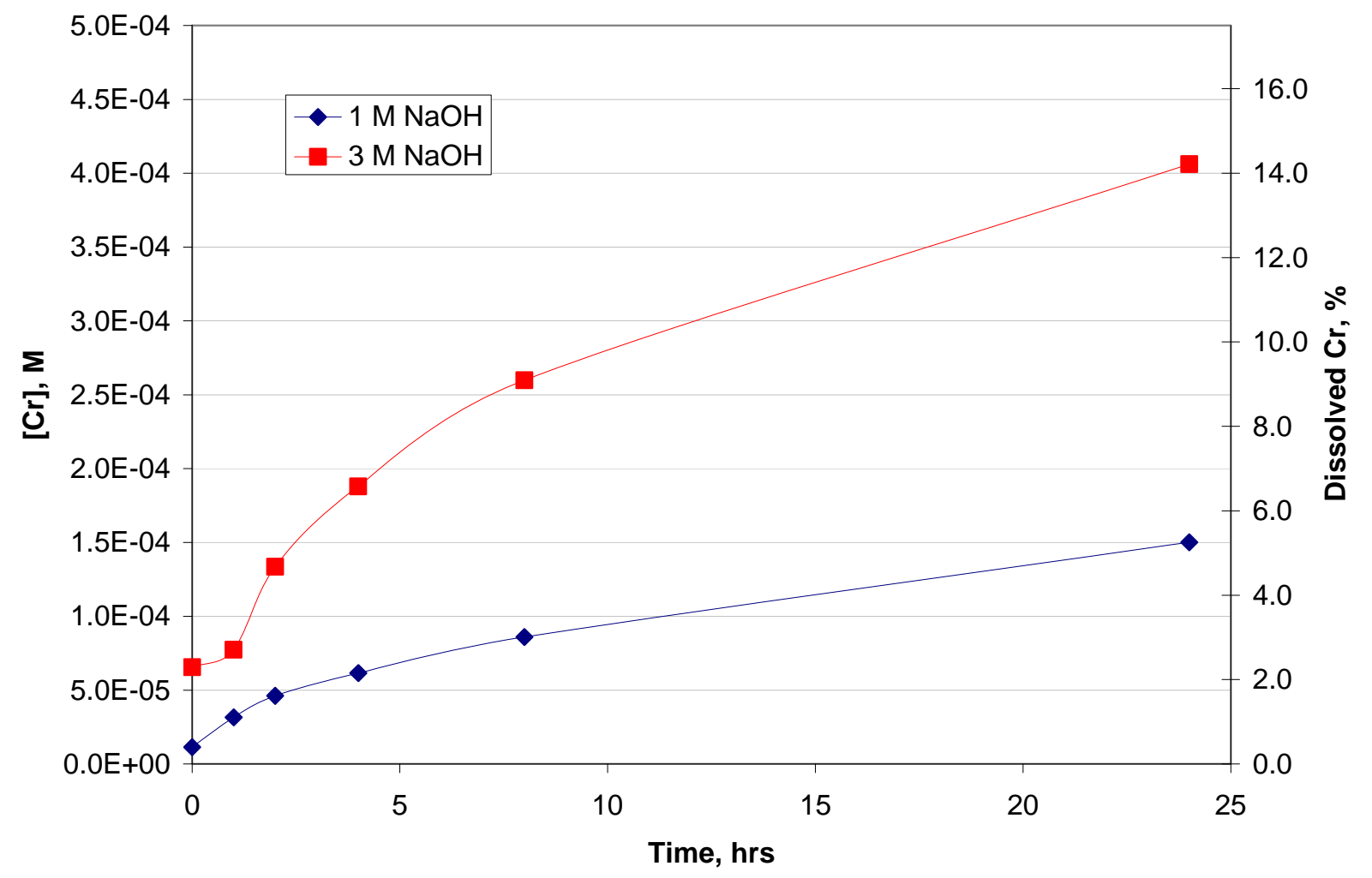

Figure 3.39. Chromium Concentration and Percent Removed Versus Time at $60^{\circ} \mathrm{C}$ for Leaching of the Group 1 Washed Solids in 1 and $3 \mathrm{M} \mathrm{NaOH}$ 
WTP-RPT-166, Rev. 0

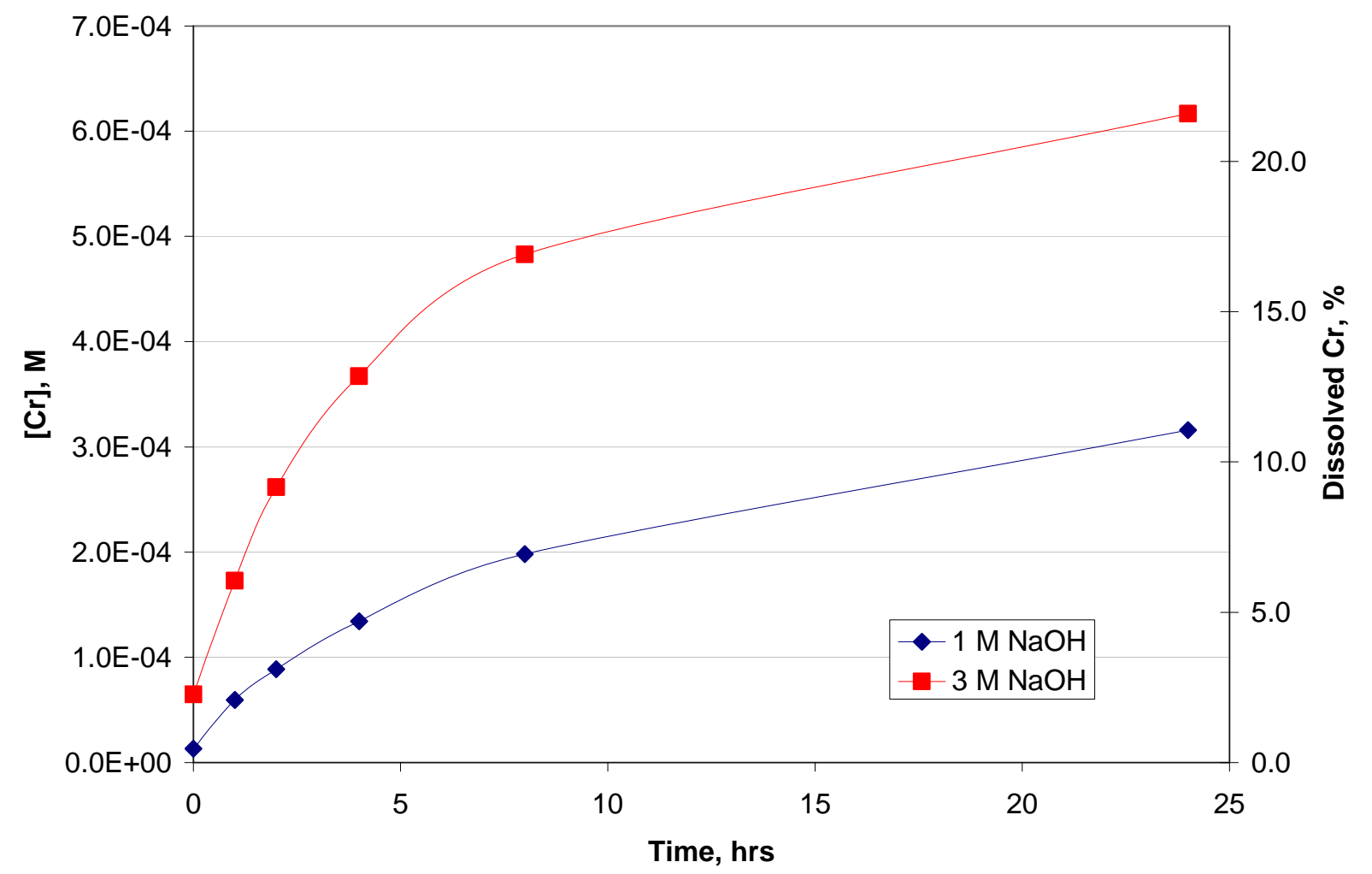

Figure 3.40. Chromium Concentration and Percent Removed Versus Time at $80^{\circ} \mathrm{C}$ for Leaching of the Group 1 Washed Solids in 1 and $3 \mathrm{M} \mathrm{NaOH}$ 
WTP-RPT-166, Rev. 0
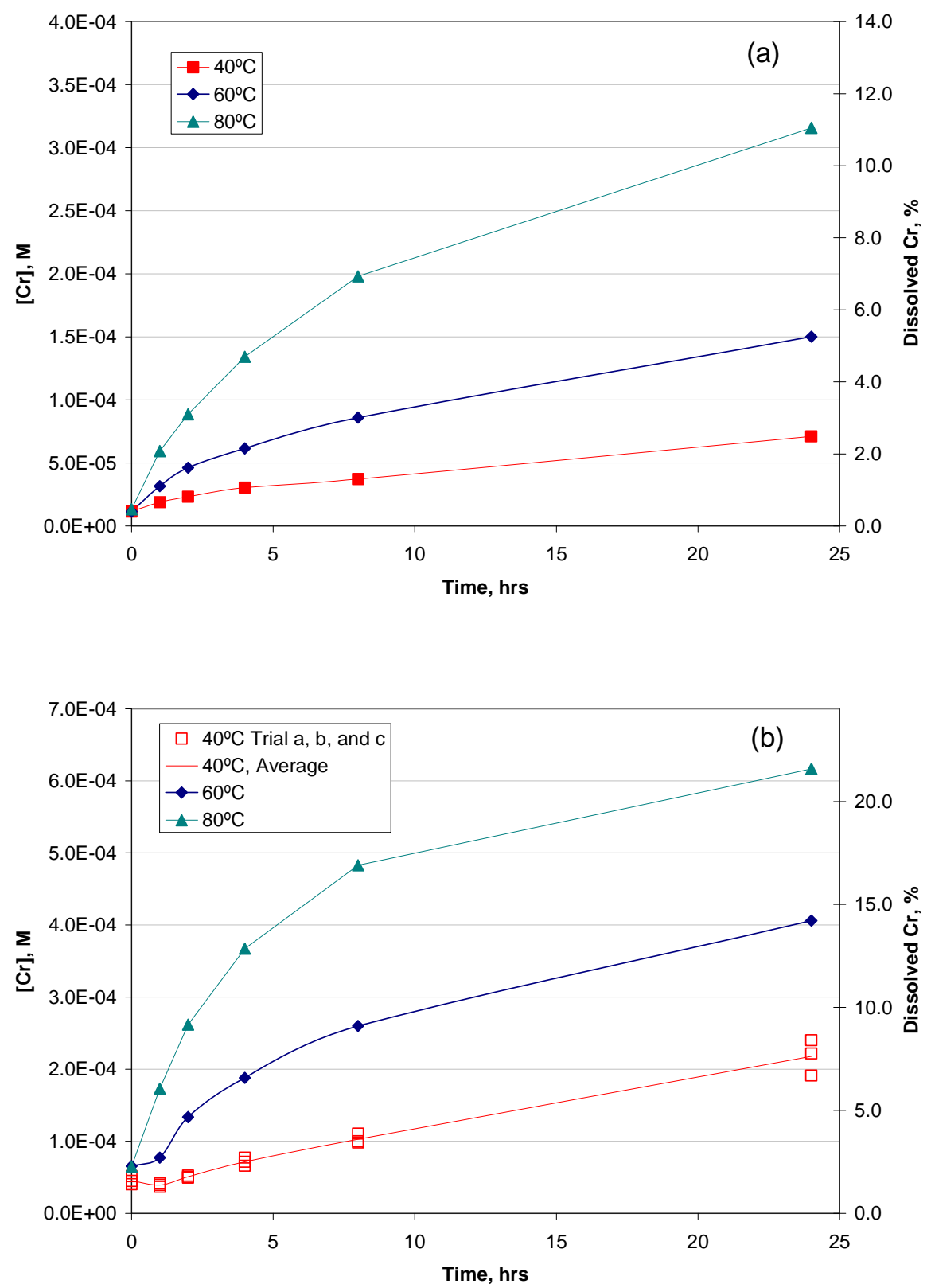

Figure 3.41. Chromium Concentration and Percent Removed Versus Time at a) $1 \mathrm{M} \mathrm{NaOH}$, 40, 60, and $80^{\circ} \mathrm{C}$, and b) $3 \mathrm{M} \mathrm{NaOH}, 40,60$, and $80^{\circ} \mathrm{C}$, for Leaching of the Group 1 Washed Solids

\subsubsection{Anion, Silicon, and Iron Leaching Behavior}

The concentration of Si was measured opportunistically by ICP-OES. The anionic compositions were also assessed at each sampling period. Anion and Si concentrations in the leachate did not significantly change during the leach testing. The results are summarized in Appendix G.

Iron concentrations were also measured opportunistically by ICP-OES. The Fe concentrations in the leachates decreased relative to the first sampling period at $0 \mathrm{hr}\left(4.85 \times 10^{-4} \mathrm{M} \mathrm{Fe}\right)$ to the 24-hr sampling 
period $\left(<2.23 \times 10^{-4} \mathrm{M} \mathrm{Fe}\right)$ for the triplicate samples treated at $40^{\circ} \mathrm{C}$ in $3 \mathrm{M} \mathrm{NaOH}$. Concentrations were lower $\left(\sim 7 \times 10^{-5} \mathrm{M}\right)$ for samples treated in $1 \mathrm{M} \mathrm{NaOH}$.

\subsubsection{Assessment of Final Leaching Conditions}

A summary of the final (24-h) leach solution chemistry and physical parameters is shown in Table 3.13. The final free-hydroxide and sodium concentrations were at the targeted values within the uncertainty of the analytical methods $( \pm 15 \%)$. The calculated percentage of phosphorus and aluminum that was removed at each leaching condition is also shown. Appendix $\mathrm{G}$ provides a compilation of the concentrations of $\mathrm{Al}, \mathrm{Cr}, \mathrm{Fe}, \mathrm{Na}, \mathrm{P}, \mathrm{Si}$, nitrite, nitrate, phosphate, and sulfate in the final leaching solutions. The GEA results for ${ }^{60} \mathrm{Co}$ and ${ }^{241} \mathrm{Am}$ were $<\mathrm{MDL}$; the GEA results are also provided in Appendix G.

Table 3.13. Group 1 Bi-Phosphate Sludge Leaching Final Aqueous Phase Conditions

\begin{tabular}{|c|c|c|c|c|c|c|c|}
\hline Temp., ${ }^{\circ} \mathrm{C}$ & $\begin{array}{c}\text { Density, } \\
\text { g/mL }\end{array}$ & $\begin{array}{c}\text { Free } \mathrm{OH} \text {, } \\
\mathbf{M}\end{array}$ & Na, M & $\mathbf{P}, \mathbf{M}$ & $\begin{array}{c}\text { Wt \% P } \\
\text { Removed }\end{array}$ & $\mathrm{Al}, \mathbf{M}$ & $\begin{array}{l}\text { Wt \% Al } \\
\text { Removed }\end{array}$ \\
\hline 40 & 1.05 & 1.10 & 1.14 & 0.0379 & 100.0 & 0.0108 & 75.9 \\
\hline 40 trial a & 1.14 & 3.28 & 3.26 & 0.0383 & 100.0 & 0.0125 & 87.6 \\
\hline 40 trial $b$ & 1.14 & 3.23 & 3.31 & 0.0379 & 100.0 & 0.0119 & 83.6 \\
\hline 40 trial c & 1.13 & 3.14 & 3.18 & 0.0370 & 97.6 & 0.0114 & 80.1 \\
\hline 60 & 1.05 & 1.03 & 1.17 & 0.0378 & 100.0 & 0.0111 & 78.1 \\
\hline 60 & 1.14 & 3.20 & 3.27 & 0.0375 & 99.2 & 0.0123 & 86.0 \\
\hline 80 & 1.05 & 1.07 & 1.17 & 0.0371 & 97.9 & 0.0112 & 78.5 \\
\hline 80 & 1.14 & 3.23 & 3.25 & 0.0361 & 95.3 & 0.0123 & 86.6 \\
\hline
\end{tabular}

\subsubsection{Comparison of Initial and Caustic-Leached and Washed Solids Properties}

The Group 1 solids that had been caustic leached at $40^{\circ} \mathrm{C}$ in $3 \mathrm{M} \mathrm{NaOH}$ for 24 hrs were combined and washed in preparation for analysis. The wash solution composition and the washed solids chemical, radiochemical, particle size, and crystal habit are discussed.

\subsubsection{Leached Solids Wash Solution}

After the third washing of the caustic-leached Group 1 solids, the wet centrifuged solids mass was $7.644 \mathrm{~g}$. The densities of the three sequential wash solutions were $1.012 \mathrm{~g} / \mathrm{mL}, 1.006 \mathrm{~g} / \mathrm{mL}$, and $1.004 \mathrm{~g} / \mathrm{mL}$, respectively. The composite wash solution (132.7 mL volume) density, ICP metals, and anion composition are shown in Table 3.14. 
WTP-RPT-166, Rev. 0

Table 3.14. Group 1 Solids Wash Solution Composition and Density

\begin{tabular}{||c|c|c|c|c|c||}
\hline Analyte & $\mu \mathbf{g} / \mathbf{m L}$ & Analyte & $\mu \mathrm{g} / \mathbf{m L}$ & Density Measurement & Value \\
\cline { 1 - 3 } $\mathrm{Al}$ & {$[4.73]$} & $\mathrm{Si}$ & 6.32 & Density & $1.009 \mathrm{~g} / \mathrm{mL}$ \\
\cline { 1 - 3 } $\mathrm{Cr}$ & 1.23 & nitrate & 86.6 & & \\
\cline { 1 - 3 } $\mathrm{Na}$ & 1,542 & phosphate & 16.1 & & \\
\cline { 1 - 3 } $\mathrm{P}$ & {$[5.61]$} & sulfate & {$[2.75]$} & & \\
\hline
\end{tabular}

\subsubsection{Chemical and Radiochemical Composition}

The initial composition of washed solids (before caustic leaching) is provided in Table 3.15 along with selected results from the initial characterization study. The solids composition after leaching in $3 \mathrm{M}$ $\mathrm{NaOH}$ at $40^{\circ} \mathrm{C}$ for 24 hours and washing is also shown in Table 3.15. The solids used for the initial characterization had been washed three times, resulting in an estimated $14 \mathrm{wt} \%$ salt entrainment from the supernatant phase. The "before leaching" material had been more extensively washed, i.e., little or no salt entrainment was expected (except for $\mathrm{NaOH}$ from the washing liquid). The composition of the initial characterization sample was generally consistent with that for the "before leaching” material. This can be discerned by normalizing the major component concentrations to the iron content. For example, the Bi/Fe ratio was 1.15 for the initial characterization sample versus 1.12 for the material used for parametric leaching. Similarly, the P/Fe ratio of 0.95 for the initial characterization sample agreed well with the value of 0.93 for the material used for parametric leaching. On the other hand, the $\mathrm{Na} / \mathrm{Fe}$ ratio for the initial characterization sample was 1.71 compared to 1.23 for the parametric leaching sample. This is consistent with the more extensive washing procedure that was performed on the latter sample.

Because the maximum $\mathrm{P}$ concentration projected to be in the caustic leachate solutions (based on the $\mathrm{P}$ in the initial solids) was $24 \%$ less than that found in the final $3 \mathrm{M} \mathrm{NaOH}$ leachate solutions, three methods of determining the percent leached were performed. Method 1 used the concentration of each analyte experimentally determined in the initial solids and the concentration of the analytes determined in the final leachate solutions. Method 2 used the concentration of the analytes in the final leachate solutions and the concentration in the final leached solids. Method 3 used the concentrations in the initial and final solids and the "concentration factor" method.

For the first method, the total amount (on a dry solids basis) of solids that went into each sample was determined based on the measurement of the UDS in the sample slurry and the mass of slurry added to each leaching bottle. The mass of solids in each leaching bottle was multiplied by the concentration of each of the analytes (i.e., $\mathrm{Al}, \mathrm{Cr}$, and $\mathrm{P}$ ) in the initial solids to determine the total mass (in $\mu \mathrm{g}$ ) of $\mathrm{Al}, \mathrm{Cr}$, and $\mathrm{P}$ in each sample. The total mass of $\mathrm{Al}, \mathrm{Cr}$, and $\mathrm{P}$ in the final leachate solutions was calculated by multiplying the concentration of each analyte $(\mu \mathrm{g} / \mathrm{mL})$ determined to be in solution at $24 \mathrm{~h}$ by $100 \mathrm{~mL}$ (the total volume of leaching solution). The leach factor was then taken as the mass of each component in the leachate solution at $24 \mathrm{hrs}\left(\mathrm{W}_{\mathrm{L}}\right)$ divided by the mass of that component in the initial sample $\left(\mathrm{W}_{\mathrm{IS}}\right)$ (Equation 3.2).

$$
L F_{1}=\left(\frac{W_{L}}{W_{I S}}\right)
$$


WTP-RPT-166, Rev. 0

Table 3.15. Group 1 Bi-Phosphate Sludge Leached Solids Composition and Leach Factors (Dry Mass Basis)

\begin{tabular}{|c|c|c|c|c|}
\hline Analyte & $\begin{array}{c}\text { Avg. Initial } \\
\text { Charac. } \\
\mu \mathrm{g} / \mathrm{g} \\
\text { (ASR 7985) }\end{array}$ & $\begin{array}{l}\text { Avg. Before } \\
\text { Leaching, } \\
\mu \mathrm{g} / \mathrm{g} \\
\text { (ASR 8060) }\end{array}$ & $\begin{array}{l}\text { Avg. After } \\
\text { Leaching, } \\
\mu g / g \\
\text { (ASR 8060) }\end{array}$ & $\begin{array}{c}\text { Observed } \\
\text { Leach } \\
\text { Factor }\end{array}$ \\
\hline $\mathrm{Al}$ & 26,350 & 26,400 & {$[11,500]$} & 0.84 \\
\hline B & [130] & [160] & {$[240]$} & 0.44 \\
\hline $\mathrm{Bi}$ & 98,200 & 121,000 & 314,500 & 0.03 \\
\hline $\mathrm{Cd}$ & $<6.6$ & [120] & $<<12.1$ & 0.96 \\
\hline $\mathrm{Cr}$ & 4,260 & 5,370 & 13,300 & 0.08 \\
\hline $\mathrm{Fe}$ & 85,550 & 108,500 & 304,500 & -- \\
\hline $\mathrm{Mn}$ & 373 & 441 & 1,290 & -- \\
\hline $\mathrm{Na}$ & 146,000 & 133,500 & {$[14,000]$} & 0.96 \\
\hline $\mathrm{P}$ & 81,300 & 101,000 & [795] & 1.00 \\
\hline $\mathrm{S}$ & {$[3,250]$} & {$[1,700]$} & [840] & 0.82 \\
\hline $\mathrm{Si}$ & 42,850 & 60,000 & 19,850 & 0.88 \\
\hline $\mathrm{Sr}$ & 888 & 1,215 & 3,160 & 0.03 \\
\hline $\mathrm{U}$ & {$[7,800]$} & 13,300 & 8,580 & 0.76 \\
\hline $\mathrm{Zn}$ & [380] & 522 & 193 & 0.86 \\
\hline $\mathrm{Zr}$ & [205] & 745 & 723 & 0.64 \\
\hline \multirow[t]{2}{*}{ U (KPA) } & 11,400 & 10,400 & 7,900 & 0.72 \\
\hline & $\mu \mathrm{Ci} / \mathrm{g}$ & $\mu \mathrm{Ci} / \mathrm{g}$ & $\mu \mathrm{Ci} / \mathrm{g}$ & \\
\hline${ }^{60} \mathrm{Co}$ & $9.59 \times 10^{-3}$ & $1.18 \times 10^{-3}$ & $7.15 \times 10^{-3}$ & -- \\
\hline${ }^{90} \mathrm{Sr}$ & $3.95 \times 10^{1}$ & $4.45 \times 10^{1}$ & $1.35 \times 10^{2}$ & -- \\
\hline${ }^{137} \mathrm{Cs}$ & $2.19 \times 10^{1}$ & $3.00 \times 10^{1}$ & $1.25 \times 10^{0}$ & 0.98 \\
\hline${ }^{154} \mathrm{Eu}$ & $<5.0 \times 10^{-3}$ & $2.73 \times 10^{-3}$ & $8.51 \times 10^{-3}$ & -- \\
\hline${ }^{155} \mathrm{Eu}$ & $<2.0 \times 10^{-2}$ & $1.65 \times 10^{-2}$ & $1.29 \times 10^{-2}$ & 0.71 \\
\hline${ }^{239+240} \mathrm{Pu}$ & $5.64 \times 10^{-1}$ & $6.88 \times 10^{-1}$ & $1.86 \times 10^{0}$ & -- \\
\hline${ }^{241} \mathrm{Am}$ & $5.87 \times 10^{-2}$ & $6.80 \times 10^{-2}$ & $1.74 \times 10^{-1}$ & 0.05 \\
\hline total alpha & $6.31 \times 10^{-1}$ & $6.78 \times 10^{-1}$ & $1.99 \times 10^{0}$ & -- \\
\hline total beta & $1.07 \times 10^{2}$ & $1.22 \times 10^{2}$ & $2.70 \times 10^{2}$ & 0.17 \\
\hline${ }^{238} \mathrm{Pu}$ & $1.02 \times 10^{-2}$ & $6.79 \times 10^{-3}$ & $1.51 \times 10^{-2}$ & 0.17 \\
\hline \multicolumn{5}{|l|}{ Opportunistic } \\
\hline $\mathrm{Ag}$ & $<14$ & $<6.44$ & $<6.25$ & 0.64 \\
\hline As & $<230$ & $<167.6$ & $<162.6$ & -- \\
\hline $\mathrm{Ba}$ & [54] & 106 & 203 & 0.29 \\
\hline $\mathrm{Be}$ & $<1$ & $<0.21$ & $<0.20$ & 0.63 \\
\hline $\mathrm{Ca}$ & $<2600$ & $<4726$ & {$[5,800]$} & -- \\
\hline $\mathrm{Ce}$ & $<170$ & 452 & [275] & 0.77 \\
\hline Co & $<18$ & [17] & [53] & -- \\
\hline $\mathrm{Cu}$ & [59] & 211 & 193 & 0.66 \\
\hline Dy & $<44$ & $<12.5$ & $<12.1$ & 0.64 \\
\hline $\mathrm{Eu}$ & $<14$ & [4.95] & $<2.54$ & -- \\
\hline $\mathrm{La}$ & $<9$ & [74] & $<11.3$ & 0.94 \\
\hline $\mathrm{Li}$ & $<27$ & [48] & {$[56]$} & 0.56 \\
\hline
\end{tabular}


WTP-RPT-166, Rev. 0

Table 3.15 (Contd)

\begin{tabular}{||c|c|c|c|c||}
\hline Analyte & $\begin{array}{c}\text { Avg. Initial } \\
\text { Charac. } \\
\mathbf{\mu g} / \mathbf{g} \\
\text { (ASR 7874) }\end{array}$ & $\begin{array}{c}\text { Avg. Before } \\
\text { Leaching, } \\
\boldsymbol{\mu g} / \mathbf{g} \\
\text { (ASR 8032) }\end{array}$ & $\begin{array}{c}\text { Avg. After } \\
\text { Leaching, } \\
\boldsymbol{\mu g} / \mathbf{g} \\
\text { (ASR 8032) }\end{array}$ & $\begin{array}{c}\text { Observed } \\
\text { Leach } \\
\text { Factor }\end{array}$ \\
\hline $\mathrm{Mg}$ & {$[900]$} & 1,050 & 2,950 & -- \\
\hline $\mathrm{Mo}$ & $<25$ & $<30.9$ & {$[39]$} & -- \\
\hline $\mathrm{Nd}$ & $<260$ & {$[58]$} & $<26$ & 0.83 \\
\hline $\mathrm{Pb}$ & {$[285]$} & {$[635]$} & {$[1,150]$} & 0.32 \\
\hline $\mathrm{Pd}$ & $<160$ & $<27.5$ & $<26.7$ & -- \\
\hline $\mathrm{Rh}$ & $<100$ & $<55.9$ & $<54.2$ & -- \\
\hline $\mathrm{Ru}$ & $<44$ & {$[40]$} & {$[95]$} & 0.11 \\
\hline $\mathrm{Sb}$ & $<150$ & $<134$ & $<130$ & -- \\
\hline $\mathrm{Se}$ & $<250$ & $<473$ & $<459$ & -- \\
\hline $\mathrm{Sn}$ & $<230$ & $<108$ & $<105$ & -- \\
\hline $\mathrm{Ta}$ & $<50$ & $<85.9$ & $<83.4$ & -- \\
\hline $\mathrm{Te}$ & $<200$ & $<112$ & {$[108]$} & -- \\
\hline $\mathrm{Th}$ & $<150$ & {$[50]$} & {$[69]$} & 0.49 \\
\hline $\mathrm{Ti}$ & {$[45]$} & 59.7 & 199 & -- \\
\hline $\mathrm{Tl}$ & $<180$ & {$[190]$} & $<125$ & 0.75 \\
\hline $\mathrm{V}$ & $<12$ & $<13.8$ & {$[22]$} & -- \\
\hline $\mathrm{W}$ & $<78$ & $<90.3$ & $<87.6$ & -- \\
\hline $\mathrm{Y}$ & $<17$ & {$[3.45]$} & {$[4.75]$} & 0.49 \\
\hline
\end{tabular}

For the second method, the mass of residual solids in each of the three samples treated at $40^{\circ} \mathrm{C}$ in $3 \mathrm{M}$ $\mathrm{NaOH}$ was first determined. These three solids samples were combined, washed, and then slurried in water. A sample of this slurry was dried to determine the wt \% UDS. The total mass of solids was determined from the slurry mass and wt\% UDS. This number was then divided by three to obtain the average mass of dried solids in each of the three samples of leached solids. This mass was then multiplied by the concentration of each of the analytes in the final solids to determine the mass (in $\mu g$ ) of $\mathrm{Al}, \mathrm{Cr}$, and $\mathrm{P}$ in each leached sample. The leach factor was then calculated by dividing the mass of the component in the leachate solution $\left(\mathrm{W}_{\mathrm{L}}\right)$ by the total mass of the analyte in each sample, calculated from the mass of each in the final solids and leachate solution (sum of $\mathrm{W}_{\mathrm{L}}$ and weight in the final samples $\left[\mathrm{W}_{\mathrm{FS}}\right]$ ) as shown in Equation 3.3.

$$
L F_{\text {triplicate_samples }}=\left(\frac{W_{L}}{W_{L}+W_{F S}}\right)
$$

As is done with the "concentration factor" method, the average leach factor from the three samples for each analyte was calculated. The average of the concentration of each analyte in the final leachates from the triplicate runs was divided by the average leach factor of the triplicate samples to obtain an average corrected concentration (CC) that corresponds to the concentration that would be obtained if $100 \%$ of the sample had dissolved. The weight of each analyte in the leachate solutions is divided by the average corrected concentration to determine the leach factors as shown in Equation 3.4. 


$$
L F_{2}=\left(\frac{W_{L}}{C C}\right)
$$

The third method is the same that was previously reported in Fiskum et al. (2008). The analysis of the leachate solutions showed that $\mathrm{Bi}, \mathrm{Cr}, \mathrm{Fe}, \mathrm{Mn}$, and $\mathrm{Sr}$ were not dissolved by caustic leaching. The average ratio of the concentration of these components in the leached solids divided by the concentration in the solids before leaching (referred to as the relative concentration factor or CF) was 2.68. This term was used to determine the specific analyte leach factors according to Equation 3.5:

$$
L F_{3}=1-\left(\frac{C_{L}}{C_{W} \times 2.68}\right)
$$

where $\mathrm{LF}_{3}$ is the caustic-leach factor, $\mathrm{C}_{\mathrm{L}}$ is the analyte concentration in the leached solids, and $\mathrm{C}_{\mathrm{W}}$ is the analyte concentration in the initial washed solids.

Results from all three methods are given in Table 3.16. The results from the first method are higher than those obtained from the second two methods. Reasonably good agreement is seen between methods two and three. This would indicate an error in the initial solids data, either in the wt\% UDS or in the ICPOES data. This error is not seen in the third method of calculating the leach factor because, although this method also uses the initial solids data, the absolute weights of the various analytes are not used, only the concentration, which is normalized with the concentrations in the final solids by using the concentration factor. All values of percent leached plotted in this section and shown in Table 3.13 and Table 3.15 were calculated using method three, the "concentration factor" method.

Figure 3.42 presents the mass fraction for selected components of the Group 1 waste in the initial waterinsoluble solids and in the leached and washed material. As can be seen from the figure, approximately $45 \%$ of the metals mass dissolved within a 24-hr leaching time ( $3 \mathrm{M} \mathrm{NaOH}$ at $40^{\circ} \mathrm{C}$ ).

\begin{tabular}{|c|c|c|c|c|c|c|c|c|c|c|c|}
\hline \multirow[b]{2}{*}{ Temp., ${ }^{\circ} \mathrm{C}$} & \multirow{2}{*}{$\begin{array}{c}\text { Free } \\
{[\mathrm{OH}]} \\
\mathbf{M}\end{array}$} & \multirow{2}{*}{$\begin{array}{c}\mathrm{Na}, \\
\mathrm{M}\end{array}$} & \multicolumn{3}{|c|}{$\begin{array}{c}\text { Fraction Removed } \\
\text { Based on Initial } \\
\text { Solids/Leachate } \\
\text { Solution }\end{array}$} & \multicolumn{3}{|c|}{$\begin{array}{c}\text { Fraction Removed } \\
\text { Based on Final } \\
\text { Solids/Leachate } \\
\text { Solution }\end{array}$} & \multicolumn{3}{|c|}{$\begin{array}{l}\text { Fraction Removed } \\
\text { Based on Initial/ } \\
\text { Final Solids } \\
\text { (“concentration } \\
\text { factor” method) }\end{array}$} \\
\hline & & & Al & $\mathrm{Cr}$ & $\mathbf{P}$ & Al & $\mathrm{Cr}$ & $\mathbf{P}$ & Al & $\mathrm{Cr}$ & $\mathbf{P}$ \\
\hline 40 & 1.10 & 1.14 & 1.16 & 0.07 & 1.22 & 0.81 & 0.07 & 1.00 & 0.76 & 0.02 & 1.00 \\
\hline 40: trial a & 3.28 & 3.26 & 1.34 & 0.24 & 1.24 & 0.90 & 0.22 & 1.00 & 0.88 & 0.08 & 1.01 \\
\hline 40: trial b & 3.23 & 3.31 & 1.30 & 0.23 & 1.24 & 0.89 & 0.21 & 1.00 & 0.84 & 0.08 & 1.00 \\
\hline 40: trial c & 3.14 & 3.18 & 1.22 & 0.19 & 1.18 & 0.89 & 0.18 & 1.00 & 0.80 & 0.07 & 0.98 \\
\hline 60 & 1.03 & 1.17 & 1.21 & 0.15 & 1.23 & 0.83 & 0.14 & 1.00 & 0.78 & 0.05 & 1.00 \\
\hline 60 & 3.20 & 3.27 & 1.33 & 0.42 & 1.22 & 0.92 & 0.38 & 0.99 & 0.86 & 0.14 & 0.99 \\
\hline 80 & 1.07 & 1.17 & 1.21 & 0.32 & 1.20 & 0.84 & 0.30 & 0.98 & 0.79 & 0.07 & 0.98 \\
\hline 80 & 3.23 & 3.25 & 1.34 & 0.63 & 1.17 & 0.92 & 0.58 & 0.95 & 0.87 & 0.17 & 0.95 \\
\hline
\end{tabular}

Table 3.16. Group 1 Bi-Phosphate Sludge Leach Factors 


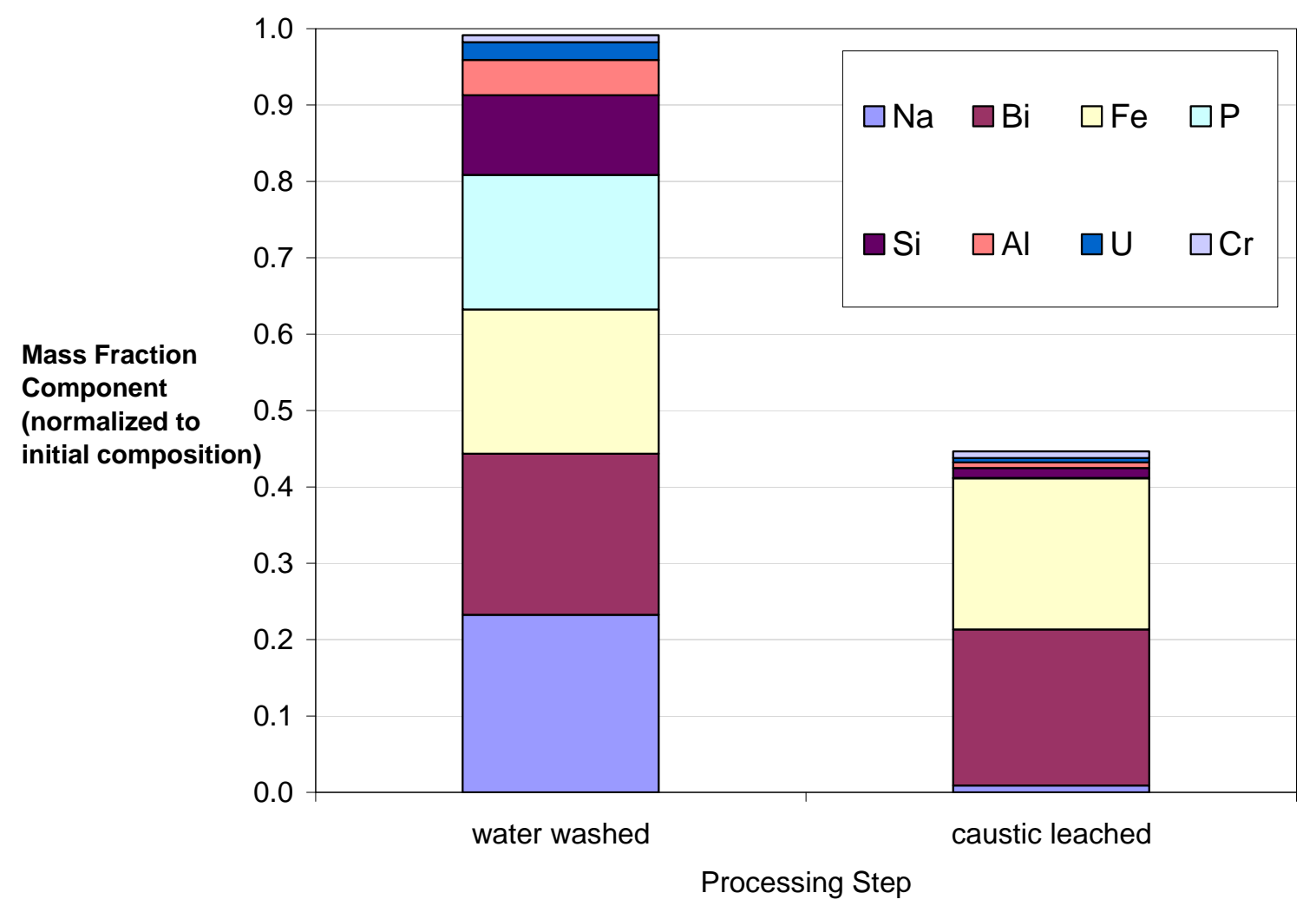

Figure 3.42. Group 1 Bi-Phosphate Sludge Reduction in Solid Mass with Water Washing and Caustic Leaching

\subsubsection{Particle-Size Distribution}

PSD measurements were performed on a sample of the caustic-leached solids (sample ID 555-G1-CLPSD). Table 3.17 shows selected cumulative undersize percentiles for this sample. Here, the $\mathrm{d}(10)$ ranges from 2.2 to $8.3 \mu \mathrm{m}$, the $\mathrm{d}(50)$ ranges from 14 to $42 \mu \mathrm{m}$, and the $\mathrm{d}(90)$ ranges from 76 to $130 \mu \mathrm{m}$. All percentiles, regardless of measurement condition, are significantly $(>10 \%)$ larger than those observed in the Group 1 source material (sample ID TI483-G1-S-WL-PSD). The increase observed in percentiles for the leached material compared to the starting material could be attributed to either dissolution of the smaller particles originally present (with the larger particles being insoluble in caustic) or to the formation of agglomerates in the leached material. A combination of both of these is also possible.

Before sonication, the PSD appears to shift towards smaller particles at high pump speed (4000 RPM). This could indicate possible breakage of weak agglomerates through shearing action; this conclusion is supported by increased obscuration at 4000 RPM (i.e., more particles in the dispersion). Applying sonic energy causes a dramatic decrease in obscuration accompanied by an increase in particle size. Both trends suggest sonication-induced agglomeration. The rapid agglomeration upon sonication appears to be unique to caustic-leached and washed Group 1 solids. The post-sonication PSD behaves in a similar manner to that of the pre-sonic distribution. A high pump speed (4000 RPM) causes significant reductions in $\mathrm{d}(10)$ and $\mathrm{d}(50)$. A low pump speed (2000 RPM) causes increases in both d(50) and d(90). 
Overall, the dispersion appears to be unstable, as evidenced by the decreasing obscuration and increasing values for cumulative percent undersize as the measurement progresses.

Table 3.17. Particle-Size Analysis Percentile Results for the Caustic-Leached and Washed Group 1 Solids (sample 555-G1-CL-PSD). Also reported is the laser obscuration (i.e., the percent laser blocked/scatted by the dispersion) for the measurement.

\begin{tabular}{||c|c|c|c|c|c|c||}
\hline $\begin{array}{c}\text { Measurement } \\
\text { Condition }\end{array}$ & Pump Speed & Sonication & $\begin{array}{c}\text { Obscuration } \\
{[\mathbf{\%}]}\end{array}$ & $\begin{array}{c}\mathbf{d}(\mathbf{1 0}) \\
{[\boldsymbol{\mu m}]}\end{array}$ & $\begin{array}{c}\mathbf{d}(\mathbf{5 0}) \\
{[\boldsymbol{\mu m}]}\end{array}$ & $\begin{array}{c}\mathbf{d}(\mathbf{9 0}) \\
{[\boldsymbol{\mu m}]}\end{array}$ \\
\hline 1 & 3000 & pre-sonic & 9.4 & 2.9 & 25 & 99 \\
\hline 2 & 4000 & pre-sonic & 10.2 & 2.2 & 14 & 76 \\
\hline 3 & 2000 & pre-sonic & 9.2 & 2.2 & 18 & 110 \\
\hline 4 & 3000 & $25 \%$ & 7.2 & 2.2 & 20 & 87 \\
\hline 5 & 3000 & $50 \%$ & 5.1 & 3.0 & 27 & 96 \\
\hline 6 & 3000 & $75 \%$ & 3.9 & 4.5 & 30 & 100 \\
\hline 7 & 3000 & post-sonic & 3.4 & 8.3 & 36 & 100 \\
\hline 8 & 4000 & post-sonic & 4.3 & 3.6 & 31 & 100 \\
\hline 9 & 2000 & post-sonic & 4.2 & 3.1 & 42 & 130 \\
\hline
\end{tabular}

Figure 3.43 shows the PSD in the caustic-leached and washed Group 1 solids before sonication. The distributions are broad, spanning 0.3 to $300 \mu \mathrm{m}$, and multimodal. At $3000 \mathrm{RPM}$, the distribution is dominated by a peak with a maximum population at 30 to $40 \mu \mathrm{m}$. A secondary population of particles spans 0.3 to $8 \mu \mathrm{m}$ and has a peak population over 4 to $5 \mu \mathrm{m}$. Increasing the pump speed decreases the relative contribution of particles in the range of 20 to $200 \mu \mathrm{m}$ and correspondingly increases the relative contribution of particles from 0.3 to $8 \mu \mathrm{m}$. Again, this trend suggests shear breakage of agglomerates. At low pump speeds (2000 RPM), the PSD suggests agglomerate reformation through an increase in the contribution of particles in the range of 80 to $200 \mu \mathrm{m}$. On the other hand, this behavior could also result from decreased suspension of dense particles from 10 to $50 \mu \mathrm{m}$. However, for this behavior to hold, flocculates in the 50- to 200- $\mu$ m range must be very loose (i.e., low-density) and easy to suspend. Considering all of these observations, the state of pre-sonication particle aggregation/flocculation appears to be highly sensitive to changes in pump speed. 
WTP-RPT-166, Rev. 0

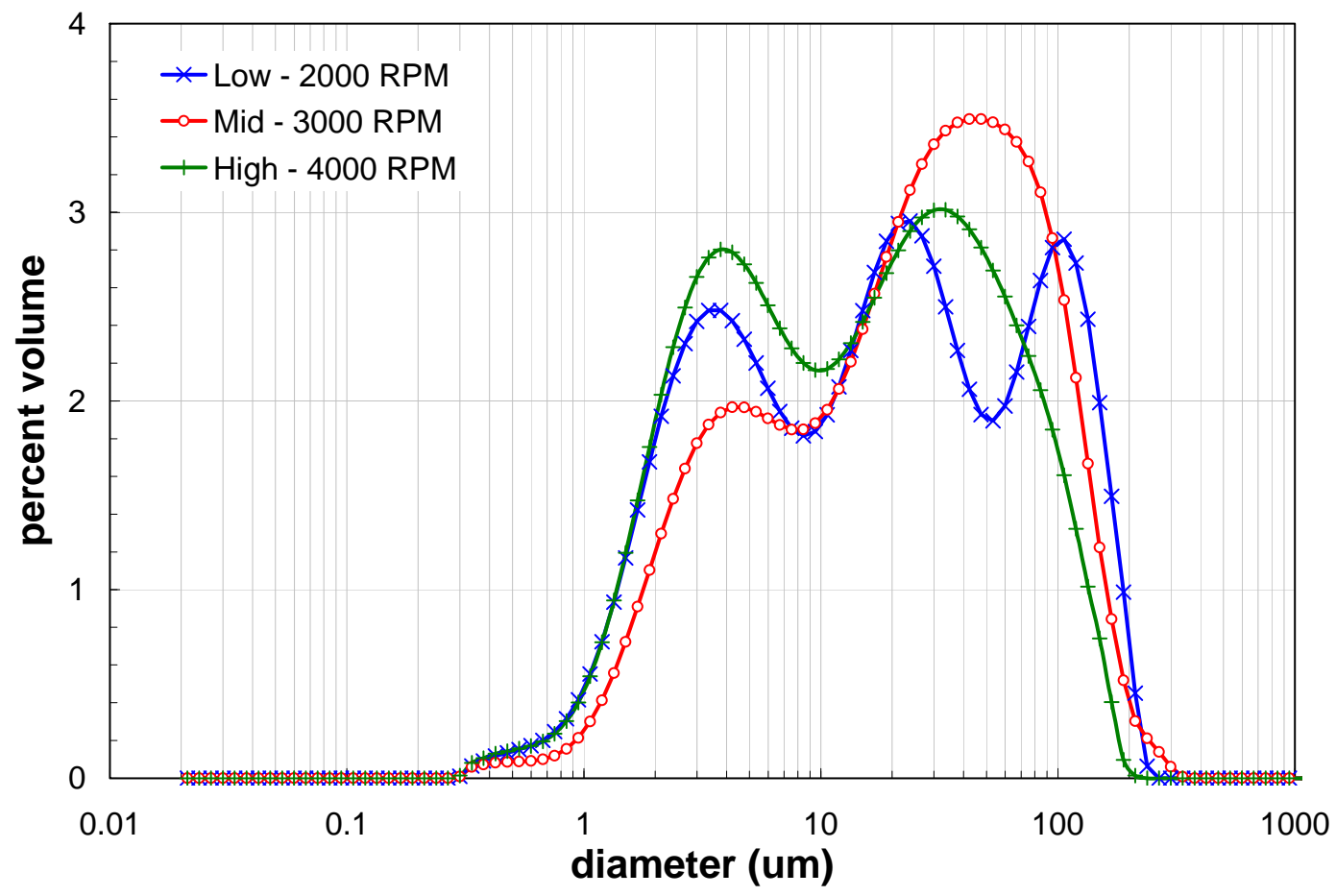

Figure 3.43. Pre-Sonication Volume Distribution Result for the Caustic-Leached and Washed Group 1 Solids (sample 555-G1-CL-PSD) as a Function of Pump Speed

Figure 3.44 shows changes that occur in the distribution of particles as a result of applying sonication. Relative to the PSD at measurement condition 1 (Table 3.17), the "during-sonication" PSD shows increases in the relative volume contribution of submicron and $\sim 10$ - to $50-\mu \mathrm{m}$ particles and a significant decrease in the contribution of 1 - to $10-\mu \mathrm{m}$ particles. Both the increase in the 10- to $50-\mu \mathrm{m}$ particles and the decrease in the 1- to 10- $\mu \mathrm{m}$ particles suggest sonication-induced aggregation. Although the energy applied to particle systems by sonication typically disrupts agglomerates, there are cases where sonication can actually help particle systems overcome the particle-particle repulsion that prevents the formation of strong agglomerations (i.e., coagulation). An alternative explanation for the behavior observed in Figure 3.44 is that sonication eliminates (through dissolution or complete disruption) particles in the 1- to $10-\mu \mathrm{m}$ particle range, effecting apparent increases in the contribution of submicron and 10 - to $200-\mu \mathrm{m}$ size ranges. Given that these solids have been thoroughly washed and allowed to equilibrate in the lowionic-strength suspending phase, it is unlikely that any further dissolution occurred. After turning off the sonicator, there is little overall change in the PSD with the exception of an increased population of 30- to $100-\mu \mathrm{m}$ agglomerates. This suggests that aggregate formation (or dissolution) continues after sonication is removed. 
WTP-RPT-166, Rev. 0

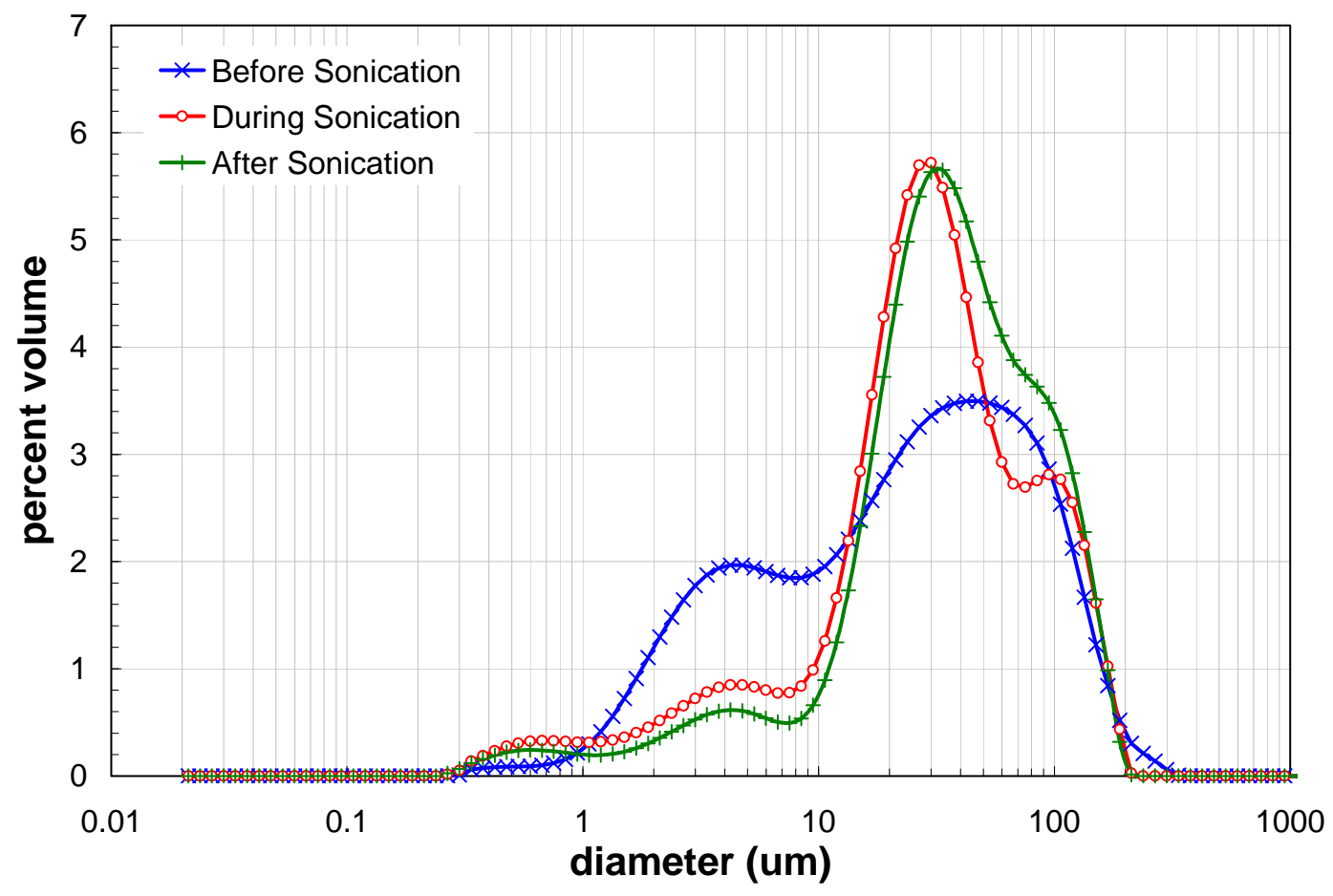

Figure 3.44. Volume Distribution Result for the Caustic-Leached and Washed Group 1 Solids Before, During, and After Sonication at 3000 RPM. Note: the during-sonication condition corresponds to measurement condition 6 (see Table 3.17).

Figure 3.45 shows the post-sonication PSD behavior of the caustic-leached and washed Group 1 solids sample as a function of analyzer pump speed. The trends are similar to those observed in the presonication measurements. Increasing the pump speed (from 3000 to $4000 \mathrm{RPM}$ ) both increases the fraction of middle-sized (1- to $10-\mu \mathrm{m}$ ) particles and decreases the fraction of large (10- to 200- $\mu \mathrm{m}$ ) particles, indicating shear disruption of flocculates. As before, low pump speeds (2000 RPM) show diminished particles in the 10 - to $50-\mu \mathrm{m}$ range, indicating loss of these particles to aggregate formation or poor suspension. 


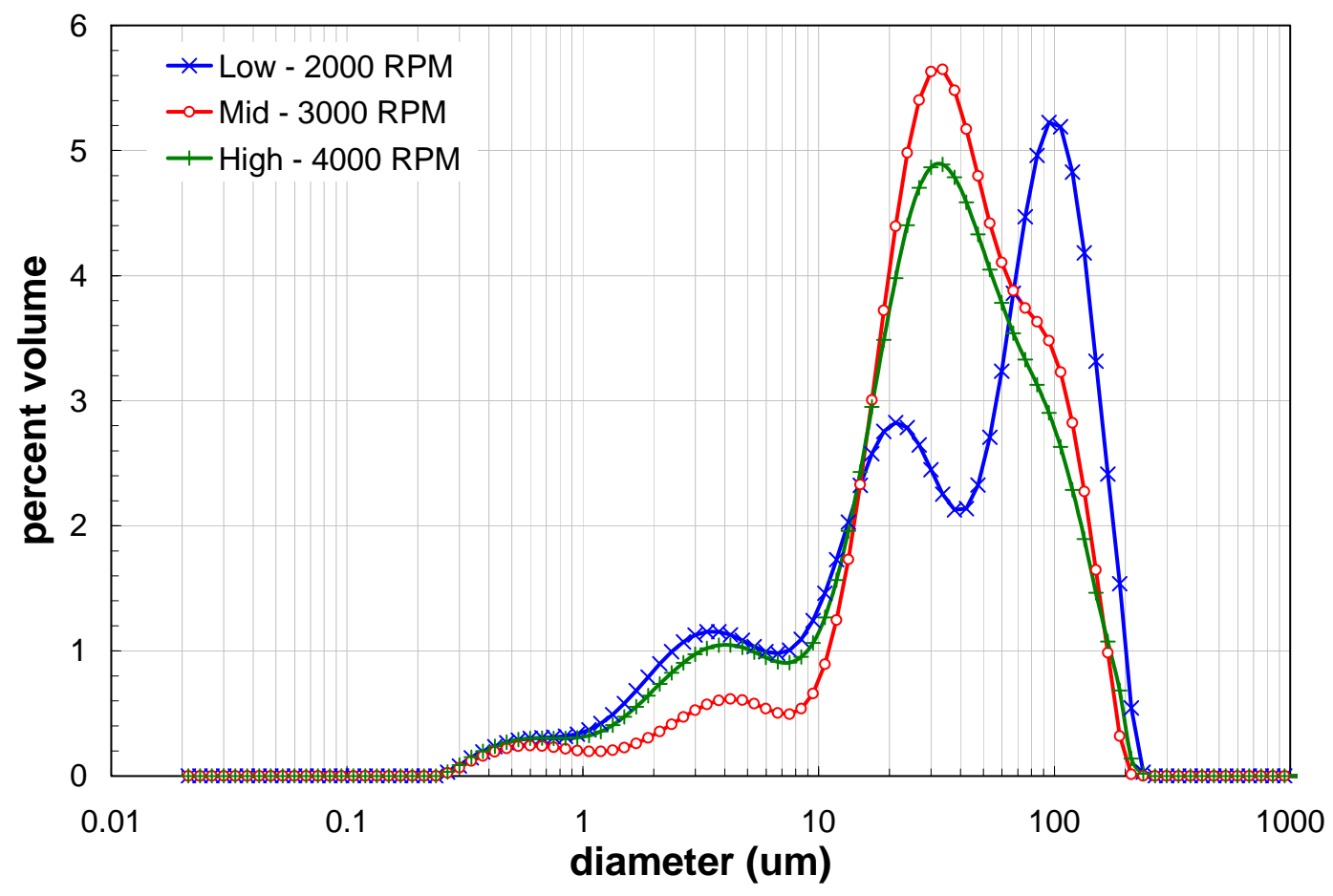

Figure 3.45. Post-Sonication Volume Distribution Result for the Caustic-Leached and Washed Group 1 Solids as a Function of Pump Speed

The influence of caustic-leaching and washing on the Group 1 particles can be evaluated by comparing the PSD for the source material (i.e., that for initial characterization sample TI483-G1-S-WL-PSD) to the caustic-leached and washed Group 1 Parametric PSD sample (555-G1-CL-PSD). The PSD measurement for the primary initial characterization samples is used for this comparison. Table 3.18 and Figure 3.46 indicate the changes that occur to the Group 1 solids PSD as a result of the caustic-leaching and washing operations. The caustic-leached solids show a significant contribution of large ( 10 - to $200-\mu \mathrm{m})$ particles not observed in the source Group 1 solids. It is speculated that this 10- to 200- $\mu \mathrm{m}$ fraction corresponds to particle flocs that form in the caustic-leached solids as a result of changed surface chemistry. The causticleached solids also show a small shoulder population spanning 0.3 to $10 \mu \mathrm{m}$. This lower range distribution shows maxima at 0.6 and $4 \mu \mathrm{m}$. It is possible that this population corresponds to remaining (i.e., those un-reactive to caustic) Group 1 solids as both distributions over this range are roughly bimodal.

Table 3.18. Cumulative Undersize Percentiles Showing the Influence of Caustic-Leaching and Washing on the PSD of Group 1 Solids at Measurement Condition 7-3000 RPM, Post-Sonication (see Table 3.17)

\begin{tabular}{||l|c|c|c||}
\hline \multicolumn{1}{|c|}{ Sample } & $\begin{array}{c}\mathbf{d}(\mathbf{1 0}) \\
{[\boldsymbol{\mu m}]}\end{array}$ & $\begin{array}{c}\mathbf{d}(\mathbf{5 0 )} \\
{[\boldsymbol{\mu m}]}\end{array}$ & $\begin{array}{c}\mathbf{d}(\mathbf{9 0}) \\
{[\mu \mathbf{m}]}\end{array}$ \\
\hline Group 1 Initial Characterization (TI483-G1-S-WL-PSD-1) & 1.0 & 5.0 & 23 \\
\hline Group 1 Caustic-Leached and Washed (555-G1-CL-PSD) & 8.3 & 36 & 100 \\
\hline
\end{tabular}


WTP-RPT-166, Rev. 0

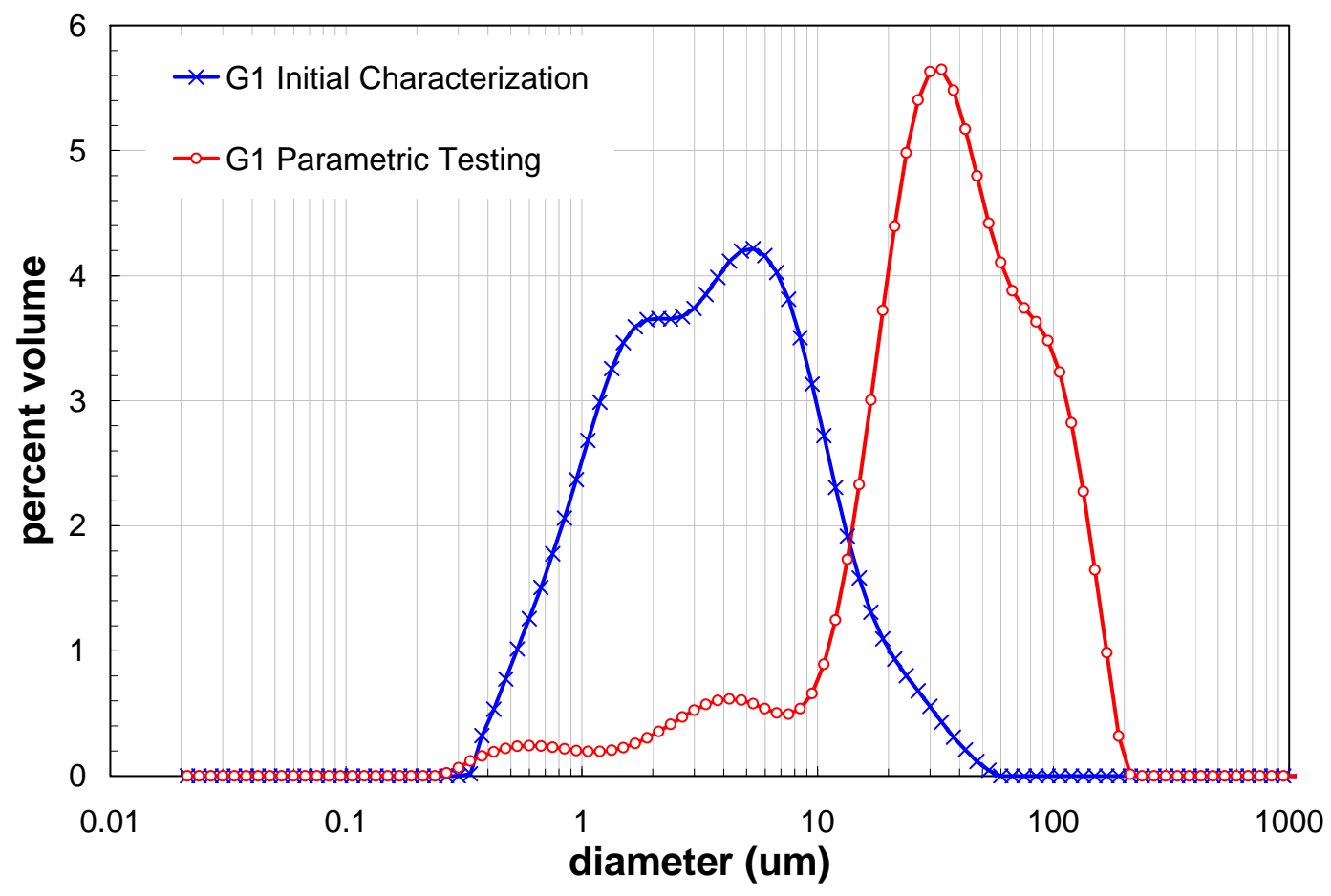

Figure 3.46. Influence of Caustic-Leaching and Washing on Group 1 ( $\mathrm{BiPO}_{4}$ sludge) Waste Solids PSD. All PSDs taken at measurement condition 7-3000 RPM, post-sonication (see Table 3.17)

\subsubsection{Crystal Form and Habit}

The following sections summarize the mineral-phase evaluation of the leached and washed solids.

\subsection{XRD}

The XRD pattern of the leached and washed solids (sample ID 555-G1-CL-XRD) is provided in Figure 3.47a; the background-subtracted XRD pattern with stick-figure phase identification is shown in Figure 3.47b.

Rutile, $\mathrm{TiO}_{2}$, was used as an internal standard for 2-theta calibration. Identification was done on 2-theta calibrated data. This material is predominantly amorphous as indicated by the very broad peak system from about 12 to 37 degrees 2-theta. Another broad peak (centered at 14.60 degrees 2-theta with a FWHM of 1.68 degrees 2-theta) superimposed on that peak is indicative of boehmite (crystal density $3.01 \mathrm{~g} / \mathrm{cm}^{3}$, Wefers and Misra 1987) with a crystallite size on the order of $30 \AA$. One of the minor peaks present matches $\mathrm{AlPO}_{4}$, berlinite (crystal density $2.62 \mathrm{~g} / \mathrm{cm}^{3}$, JADE, Version 8.0), but cannot be confirmed because the peak intensities are less than the background. Furthermore, the presence of $\mathrm{AlPO}_{4}$ in the leached solids is unlikely because this compound has been shown to rapidly dissolve in $\mathrm{NaOH}$ solution (Lumetta 2008). 
WTP-RPT-166, Rev. 0

(a)

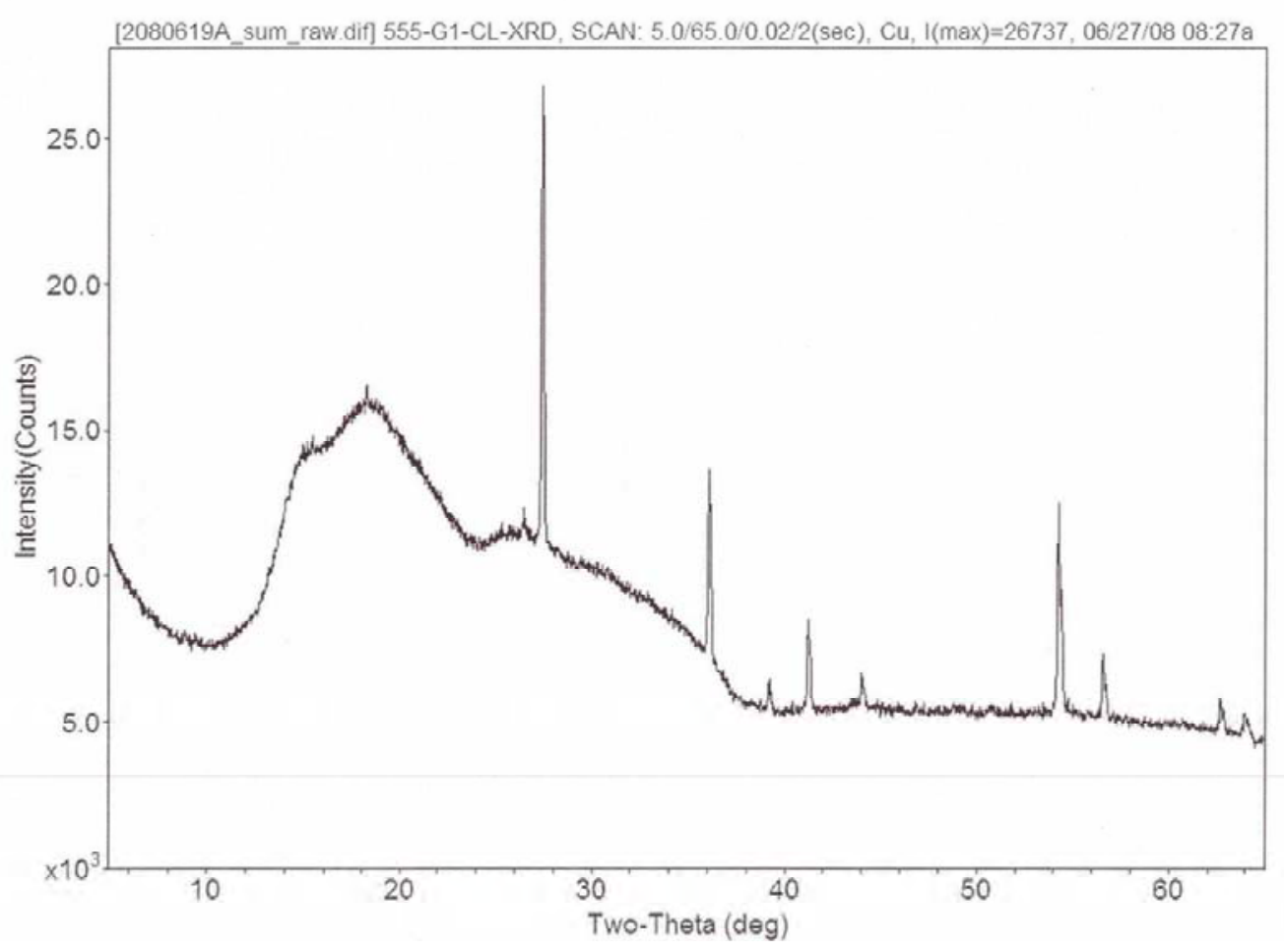

(b)

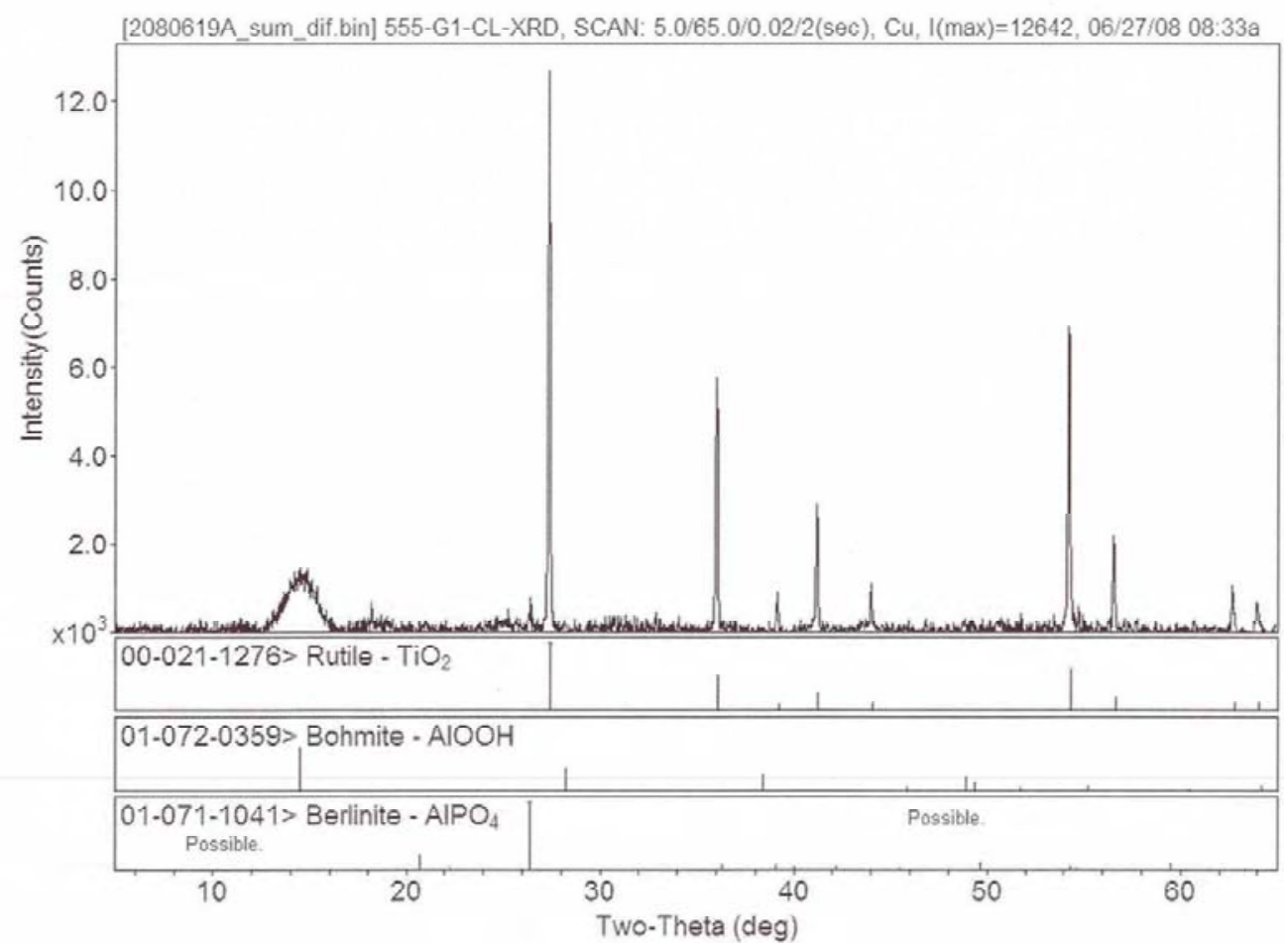

Figure 3.47. XRD Pattern of Caustic-Leached Group $1 \mathrm{Bi}$-Phosphate Sludge with Rutile $\left(\mathrm{TiO}_{2}\right)$ Internal Standard (a) Raw Data and (b) Background-Subtracted with Stick-Figure Peak Identification 


\subsection{SEM and TEM}

Several SEM images are shown in Figure 3.48 as well as an elemental analysis of one area. The particles seen in these images are typically on the order of 5 to $50 \mu \mathrm{m}$. The elemental analysis shows a large amount of oxygen and carbon, which is an artifact of the sample preparation (carbon is sputtered onto the sample to eliminate problems with charging). If this is removed, and the other constituents normalized, the average weight percentages shown in Table 3.19 are obtained, which are in reasonable agreement with the values obtained by ICP-OES. These average values represent the average of thirteen individual particles that were examined. The Group 1 caustic leached solids were very homogeneous throughout the sample.

(a)

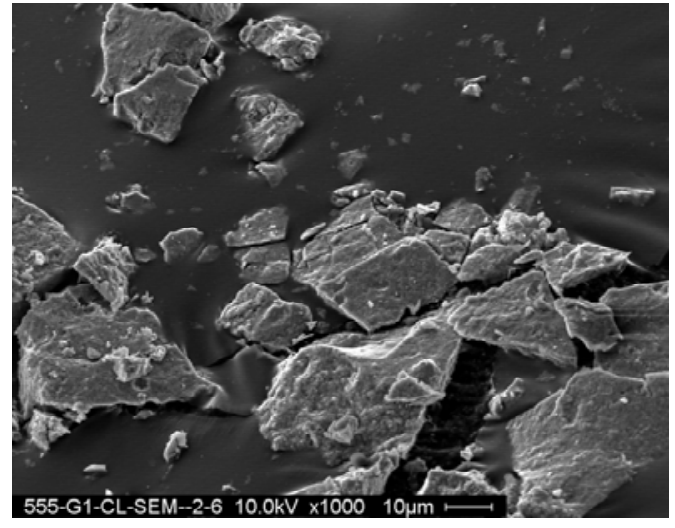

(c)

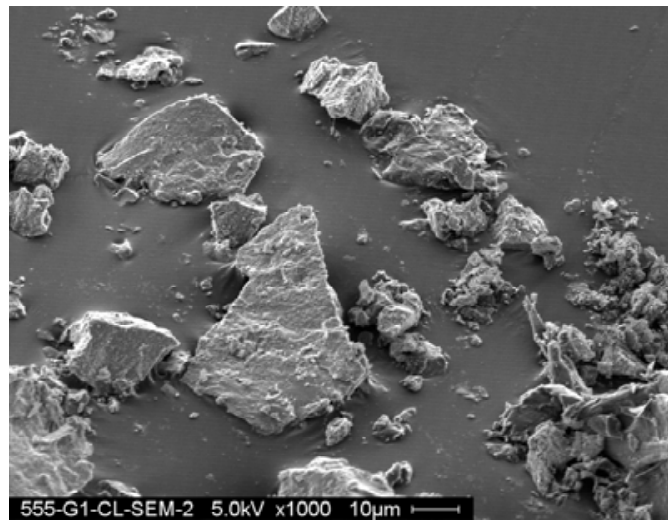

(b)

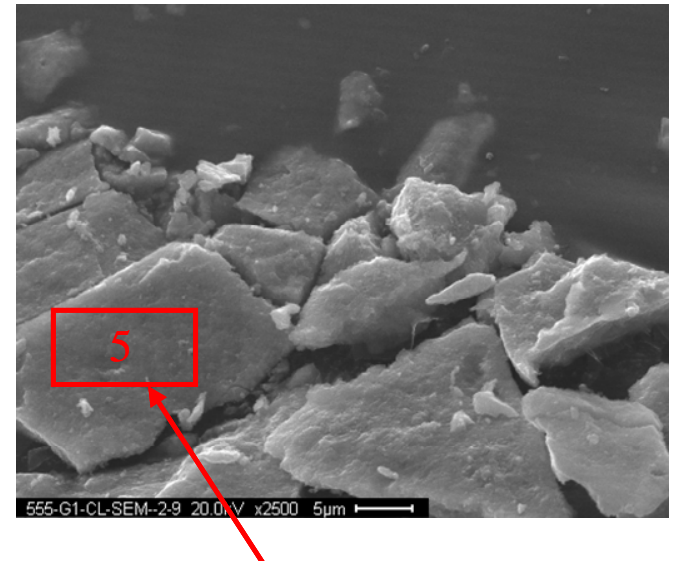

(d)

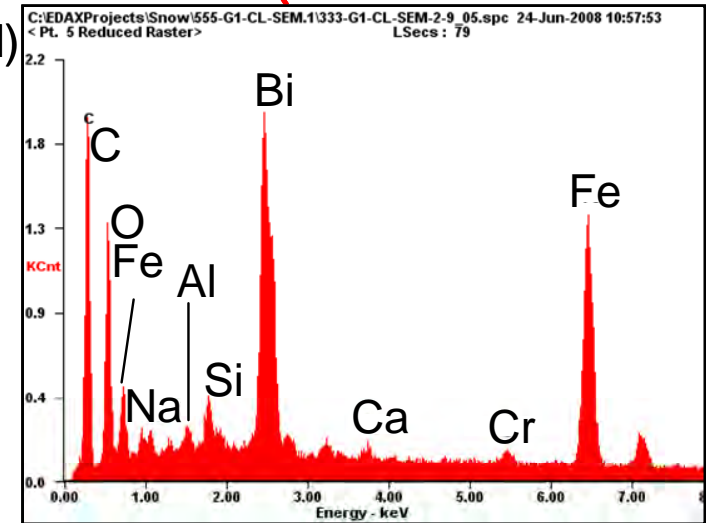

Figure 3.48. SEM Images of Group $1 \mathrm{Bi}$-Phosphate Sludge Caustic-Leached and Washed Solids (a) $10 \mathrm{kV}, 1000 \times$; (b) $20 \mathrm{kV}, 2500 \times$; (c) $5 \mathrm{kV}, 1000 \times$; (d) Elemental Map of Area 5 in (b)

Figure 3.49 shows STEM-HAADF images of particles in the Group 1 caustic-leached sample showing that the sample mostly consists of amorphous agglomerates. Figure 3.50 shows that on the larger scale, all that is seen is an amorphous solid. However, when a small area of this material is highly magnified, lattice fringes are seen, indicating the crystallinity of the agglomerated material. Although lattice fringes were observed, the material did not generate a clear selected area electron diffraction pattern. Because of the small crystallite size, the bulk material would be expected to appear amorphous to X-rays (which, as discussed above, is the case). 
Table 3.19. Wt \% of Various Elements by SEM and ICP-OES

\begin{tabular}{|c|c|c||}
\hline Element & $\begin{array}{c}\text { Avg Wt\% by } \\
\text { SEM }\end{array}$ & Wt\% by ICP-OES \\
\hline $\mathrm{Na}$ & 2.1 & 1.4 \\
\hline $\mathrm{Al}$ & 1.2 & 1.2 \\
\hline $\mathrm{Si}$ & 2.3 & 2.0 \\
\hline $\mathrm{Bi}$ & 48.2 & 31.5 \\
\hline $\mathrm{Ca}$ & 0.9 & 0.6 \\
\hline $\mathrm{Cr}$ & 1.8 & 1.3 \\
\hline $\mathrm{Fe}$ & 43.6 & 30.5 \\
\hline
\end{tabular}

(a)

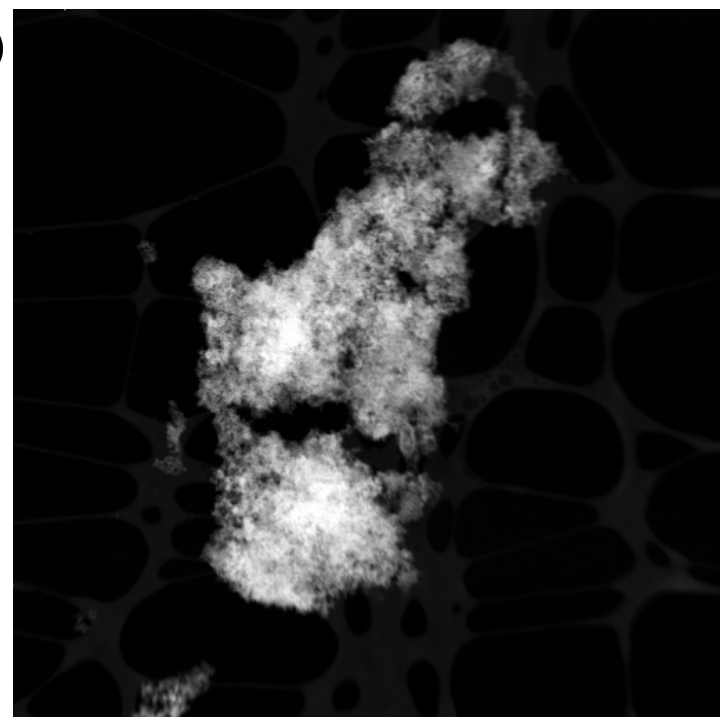

(b)

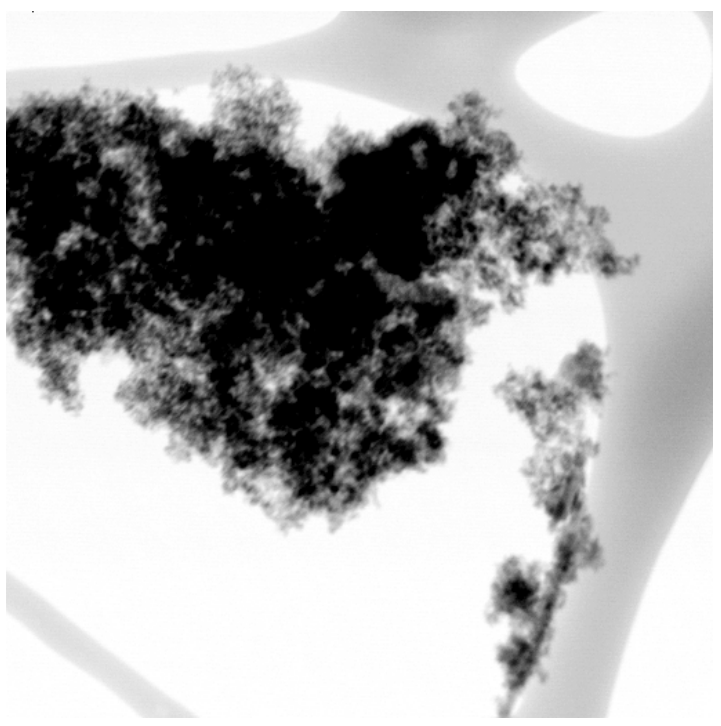

Figure 3.49. STEM-HAADF Images of Group 1 Bi-Phosphate Sludge Caustic-Leached and Washed Solids (a) Low Magnification; (b) Medium Magnification (inverted contrast)

Figure 3.51 shows EDS analysis of two areas of the sample. In several areas, bismuth and iron were seen by EDS. In one area, aluminum was seen. The major phase in the caustic-leached sludge, as indicated by the TEM examination, appears to be a nano-crystalline iron bismuth phase. Only a small amount of an aluminum oxide was detected, which might be boehmite as suggested by the XRD. 
(b)

(a)

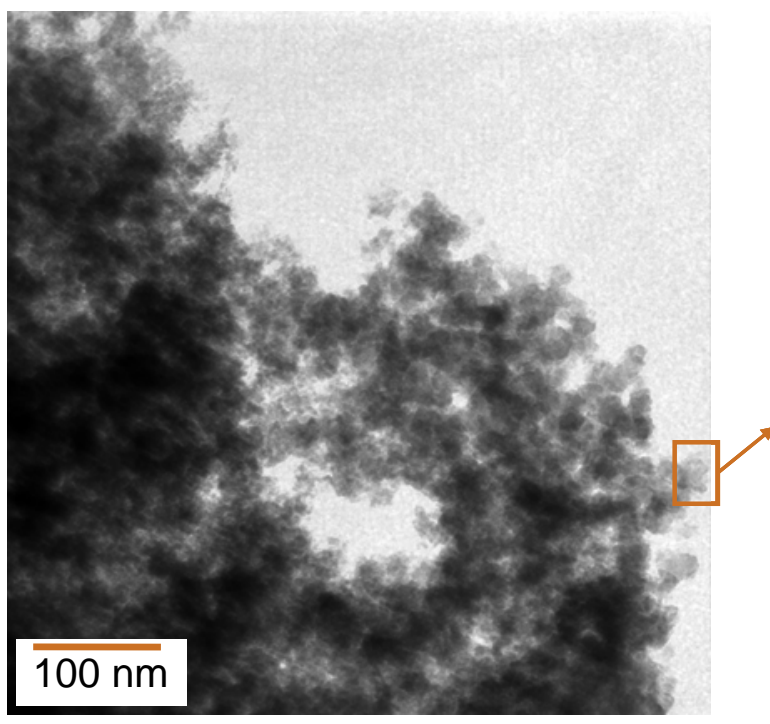

Figure 3.50. High Resolution TEM Images of Group 1 Bi-Phosphate Sludge Caustic-Leached and Washed Solids (a) Amorphous Solids; (b) Magnification Shows Lattice Fringes

(a)

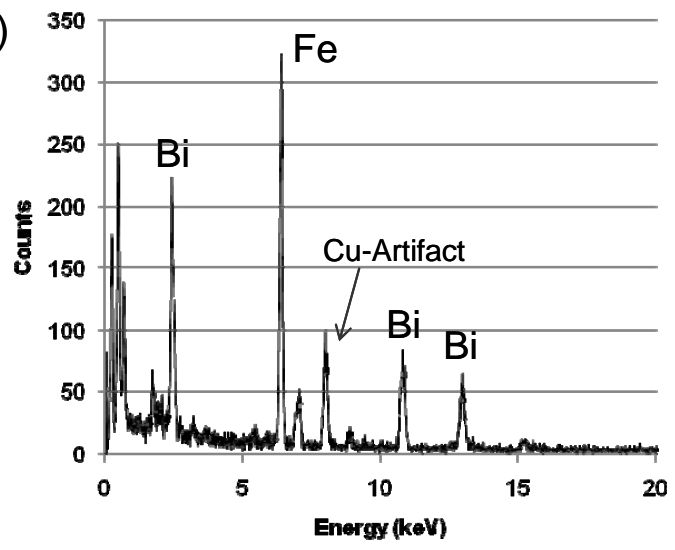

(b)

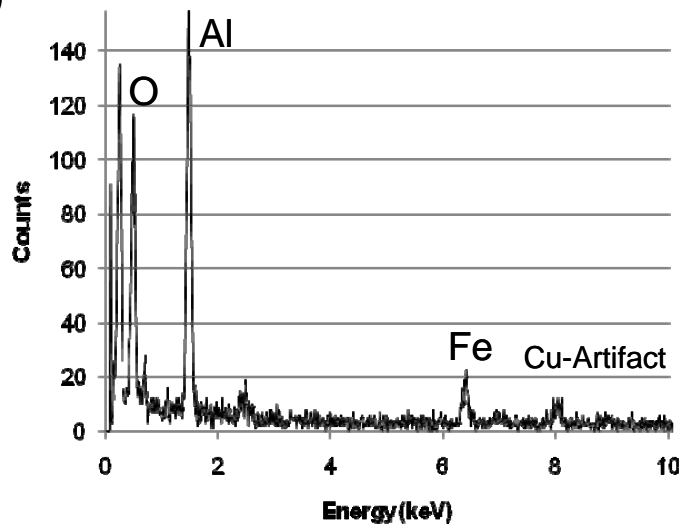

Figure 3.51. EDS Analysis of Group 1 Bi-Phosphate Sludge Caustic-Leached and Washed Solids (a) Fe and $\mathrm{Bi}$; (b) Aluminum Oxide 
WTP-RPT-166, Rev. 0

\subsection{Surface Area by BET}

A BET measurement was conducted on the caustic-leached and washed solids, resulting in a surface area of $265.3 \mathrm{~m}^{2} / \mathrm{g}$. This shows an increase in relative surface area following caustic leaching from the average value of $94.5 \mathrm{~m}^{2} / \mathrm{g}$ found in the initial, washed solids. 


\subsection{Group 2 Characterization of Bismuth Phosphate Saltcake}

This section reports and discusses the analytical results for the bismuth phosphate saltcake (Group 2) slurry composite. The supernatant results represent the equilibrated aqueous phases in contact with the solids; the solids characterization results were obtained after three washes with $0.01 \mathrm{M} \mathrm{NaOH}$.

\subsection{Group 2 Characterization Experimental}

Table 4.1 shows the samples obtained during homogenization and sample splitting. Sample processing supporting the Group 2 characterization activities were identical to those for Group 1 and are summarized in Figure 3.1.

Table 4.1. Group 2 Characterization Samples

\begin{tabular}{||c|l|c|c||}
\hline Sample ID & Characterization Activity & $\begin{array}{c}\text { Slurry } \\
\text { Volume, mL }\end{array}$ & $\begin{array}{c}\text { Slurry } \\
\text { Mass, }\end{array}$ \\
\hline TI517-G2-AR-S1 & Physical Properties & 8.6 & 13.45 \\
\hline TI517-G2-AR-S2 & Physical Properties & 7.5 & 11.78 \\
\hline TI517-G2-AR-S3 & Physical Properties & 8.9 & 13.60 \\
\hline TI517-G2-AR-C1 & $\begin{array}{l}\text { Chemical characterization } \\
\text { and crystal habit }\end{array}$ & 9.2 & 14.24 \\
\hline TI517-G2-AR-C2 & $\begin{array}{l}\text { Chemical characterization } \\
\text { and crystal habit }\end{array}$ & 12 & 17.18 \\
\hline TI517-G2-AR-RH & Rheology & 132 & 195.99 \\
\hline
\end{tabular}

The specific washing scheme applied to the Group 2 saltcake is provided in Figure 4.1. After washing and centrifuging, the solids settled uniformly to the bottom of the cone with no observed stratification into layers (Figure 4.2). 


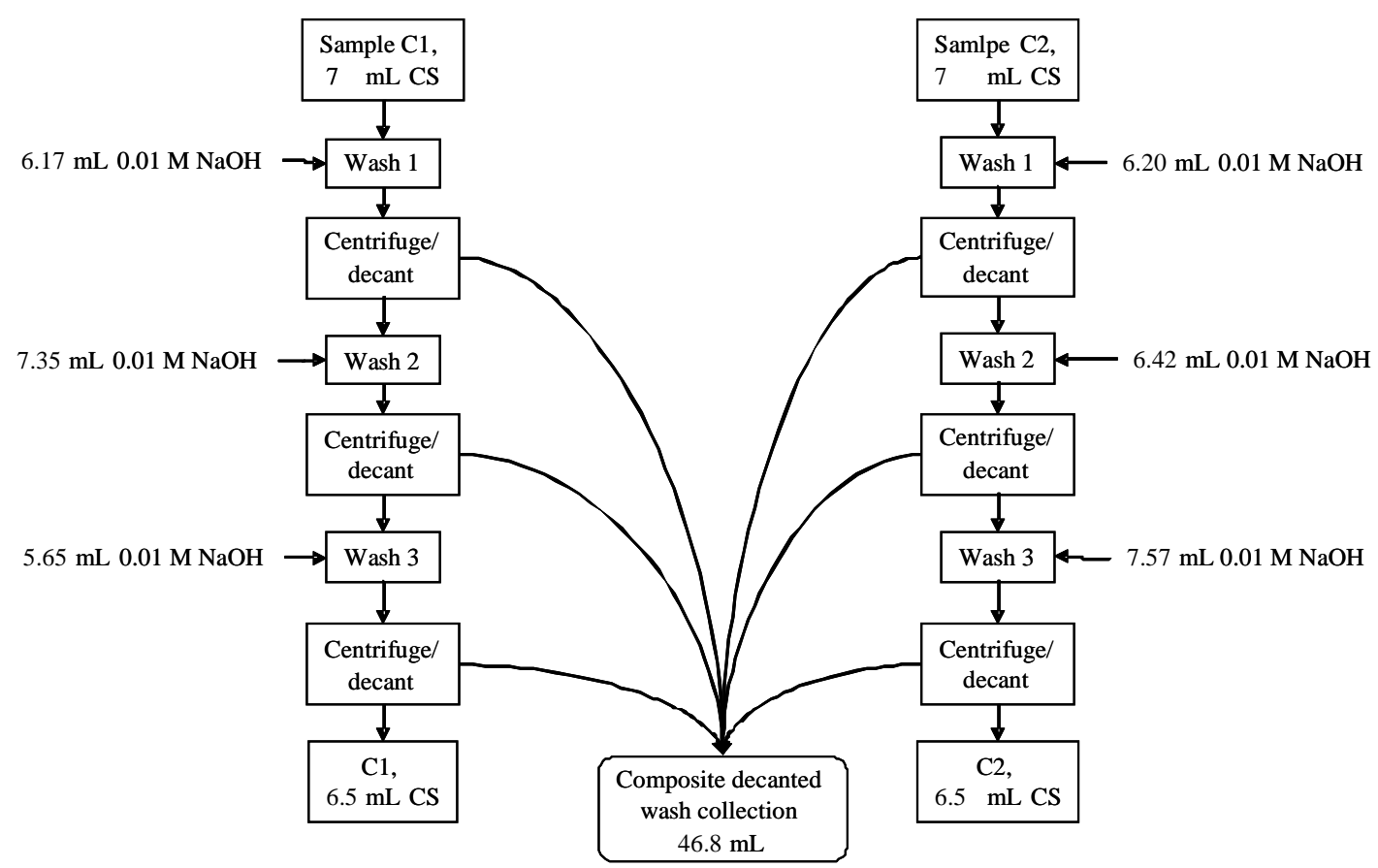

Figure 4.1. Wash Sequence of Group 2 Saltcake Supporting Initial Characterization

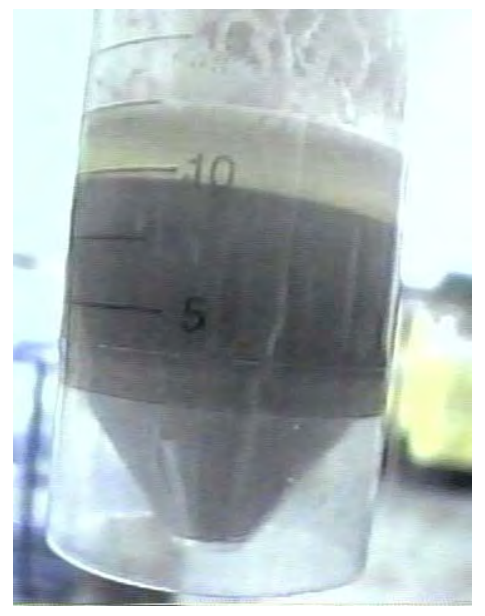

Figure 4.2. Chemical Characterization Sample of Group 2 Centrifuged Solids

\subsection{Group 2 Characterization Results}

\subsubsection{Physical Properties of the Composite Slurry}

The original Group 2 sample slurry was thick and difficult to stir and had a large percentage of solids in relation to supernatant liquid. These factors made it difficult to obtain reproducible representative samples. In the nine samples taken during the Group 2 characterization effort, the volume of settled solids varied from $75 \%$ to $90 \%$ (Figure 4.3 ), indicating considerable variability in the amount of solids 
collected in each sample (error bars represent estimated errors at the time of measurement). For the three samples taken specifically for the settling test, good agreement in the settled-solids volume was observed between S1 (90\%) and S2 (89\%), but these were considerably higher than the value obtained for S3 (79\%). The latter value is more consistent with the original sample, as can be seen from Figure 4.3).

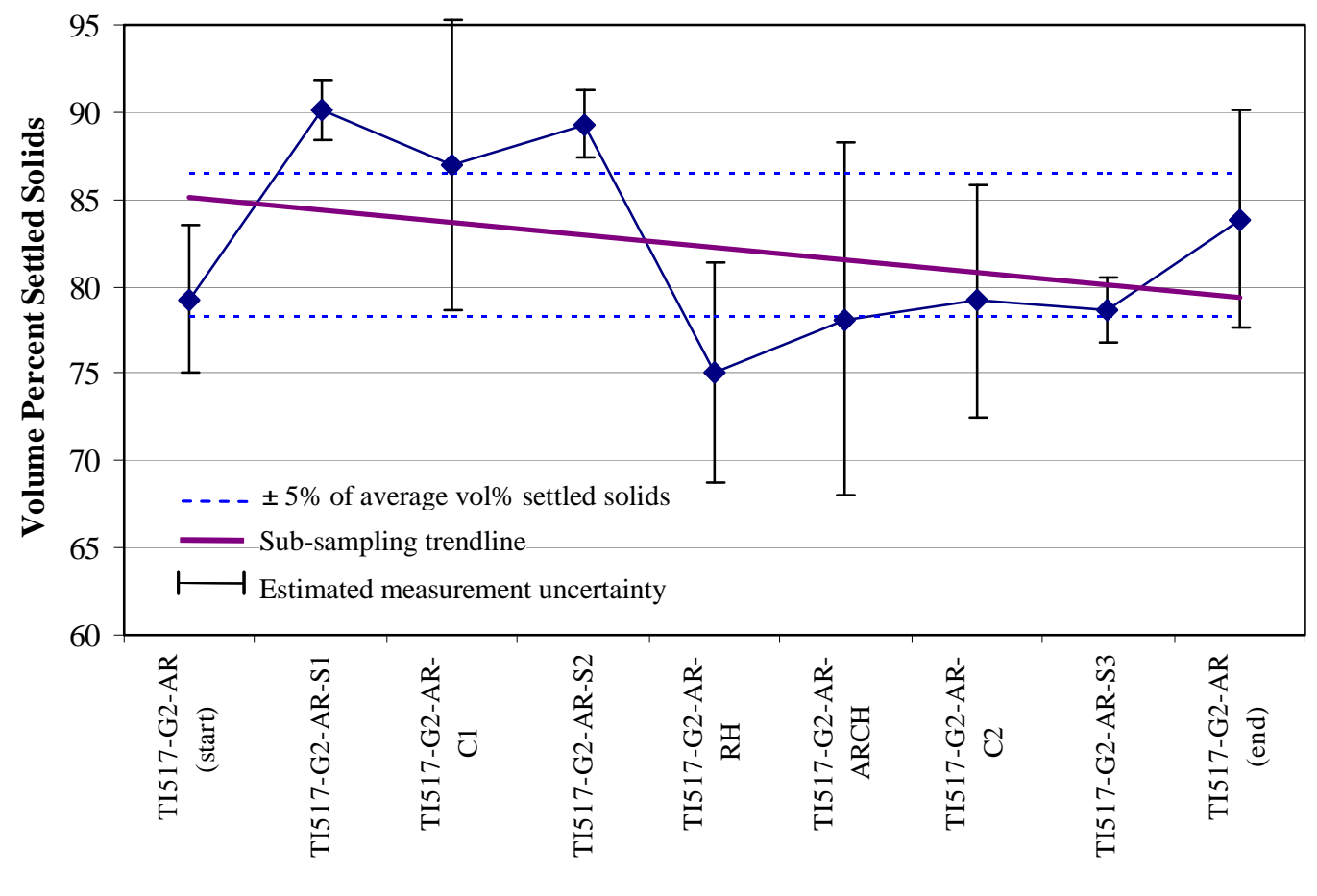

Sample ID

Figure 4.3. Group 2 Samples Vol\% Settled Solids after 24-h

Figure 4.4 shows the settling data for the Group 2 samples in two different manners: the volume percent of the settled solids as a function of time and the solids height as function of time. The settling data indicate gradual settling of solid materials over the first 36 to 48 hours with complete settling by 72 hours. The observed settling behavior is consistent with slurries in which the initial solids loading is near the gel point (Rector and Bunker 1995). Only a short initial period of free settling of the solids would be expected in this regime. Once the gel point is reached, settling slows dramatically. The initial settling rate was $\sim 0.9 \mathrm{~cm} / \mathrm{h}$. 

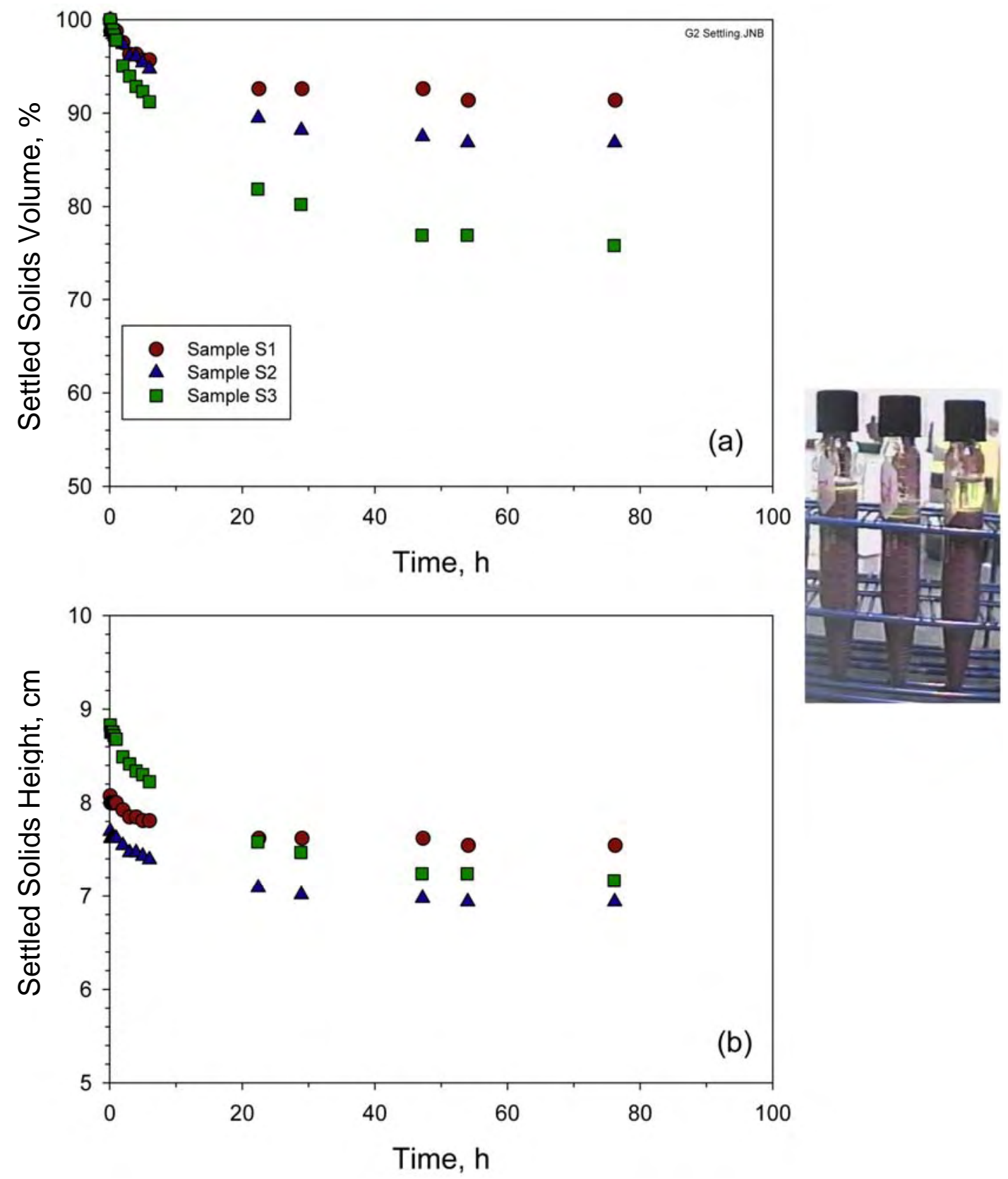

Figure 4.4. Group 2 Settling Data: a) Volume \% Settled Solids Versus Time and b) Settled Solids Height Versus Time. Inset: photograph of the samples used in the settling experiments.

Table 4.2 presents the physical properties of the Group 2 samples, including the propagated 1- $\sigma$ error, the average values of the triplicate measurements, and the relative standard deviation. Again, the variation in measurements can be attributed to the uneven sample distribution. 
Table 4.2. Physical Properties of Homogenized Group 2 Saltcake

\begin{tabular}{|l|c|c|c|c|c|c|c|}
\hline & AR-S1 & AR-S2 & AR-S3 & $\begin{array}{c}\text { Nominal } \\
\text { 16 error }\end{array}$ & Avg. & $\begin{array}{c}\text { RSD } \\
\text { (\%) }\end{array}$ \\
\hline \multicolumn{7}{|c|}{ Bulk Sample } \\
\hline Density (g/mL) & 1.82 & 1.55 & 1.60 & 0.07 & 1.66 & 8.7 \\
\hline Total Solids (wt\%) & $62.9 \%$ & $55.0 \%$ & $51.9 \%$ & $0.05 \%$ & $56.6 \%$ & 10.0 \\
\hline Total Undissolved Solids (wt\%) & $46.2 \%$ & $36.2 \%$ & $29.8 \%$ & $0.1 \%$ & $37.4 \%$ & 22.1 \\
\hline \multicolumn{7}{|c|}{ Settled Solids } \\
\hline Density (g/mL) & 1.73 & 1.60 & 1.60 & 0.07 & 1.64 & 4.6 \\
\hline Vol\% relative to the total sample volume & $92.5 \%$ & $85.7 \%$ & $76.7 \%$ & $6 \%$ & $85.0 \%$ & 9 \\
\hline Wt\% relative to the total sample weight & $94.6 \%$ & $88.7 \%$ & $80.8 \%$ & $5 \%$ & $88.0 \%$ & 8 \\
\hline Total Undissolved Solids (wt\%) & $46.2 \%$ & $40.3 \%$ & $34.9 \%$ & $2 \%$ & $40.5 \%$ & 14 \\
\hline \multicolumn{7}{|c|}{ Wet Centrifuged Solids } \\
\hline Density (g/mL) & 1.83 & 1.72 & 1.74 & 0.09 & 1.76 & 3.3 \\
\hline Vol\% relative to the total sample volume & $81.1 \%$ & $67.1 \%$ & $57.6 \%$ & $5 \%$ & $68.6 \%$ & 17 \\
\hline Wt\% relative to the total sample weight & $85.6 \%$ & $74.8 \%$ & $65.6 \%$ & $0.1 \%$ & $75.3 \%$ & 13 \\
\hline Total Undissolved Solids (wt\%) & $52.9 \%$ & $48.7 \%$ & $44.5 \%$ & $3 \%$ & $48.7 \%$ & 9 \\
\hline Total Solids (wt\%) & $67.7 \%$ & $63.2 \%$ & $62.3 \%$ & $0.1 \%$ & $64.4 \%$ & 4 \\
\hline \multicolumn{7}{|c|}{ Supernatant } \\
\hline Density (g/mL) & 1.211 & 1.213 & 1.245 & 0.106 & 1.223 & 1.6 \\
\hline Total Dissolved Solids (wt\%) & $29.8 \%$ & $28.8 \%$ & $30.9 \%$ & $0.2 \%$ & $29.8 \%$ & 4 \\
\hline Water Content (g/g) & 0.7019 & 0.7116 & 0.6914 & 0.0026 & 0.7016 & 1.4 \\
\hline (a) RSD = relative standard deviation & & & \\
\hline
\end{tabular}

\subsubsection{Rheology of the Composite Slurry}

\subsubsection{Shear Strength}

A single measurement of shear strength was made on settled solids in sample jar TI517-G2-AR-RH. As was the case with the Group 1 solids, the limited volume of settled solids ( $<100 \mathrm{~mL}$ ) made it impossible to satisfy the geometric constraints for vane immersion. As a result, the shear-strength result was not independent of container geometry and may not even be representative of the actual shear strength of the settled solids. For this reason, no duplicate measurements were taken. The single value reported herein should be taken as a rough estimate of settled-solids strength.

The settled solids in test jar TI517-G2-AR-RH had been fully dispersed 67 hours before testing and allowed to settle undisturbed for the entire 67-hour period between dispersion and testing. The shearstrength test was performed directly in the 250-mL Qorpak sample jars in which the slurry was provided. The shear strength of the Group 2 slurry was tested in a manner identical to that for the Group 1 slurry (see Section 3.2.2.1). 
The single observation at 67 hours of settling time indicates a shear strength of $21 \mathrm{~Pa}$. Because the geometric constraints required for shear strength testing could not be met given the current settled solids volume, this results is only an order-of-magnitude estimate. Some caution should be taken when applying it for engineering design. On the other hand, the shear strength attained by Group 2 settled solids over 2 to 3 days of settling is relatively low. For comparison, the shear strength is less than the $30 \mathrm{~Pa}$ design basis for slurry yield stress in the pretreatment facility. It should be noted that only the 2- to 3-day observation of the transient shear strength behavior was made in accordance with the test plan. The limited solids volume available after sampling of the material for the flow curve testing prevented the shear strength from being examined at longer settling periods.

\subsubsection{Flow Curve}

Flow curve testing for both slurry and supernatant samples employed an MV1 cup and rotor. Each flow curve measurement was accomplished according to the procedure outlined in Section 3.2.2.2. Visual inspection of the Group 2 slurry before testing found no observable solids settling during transfer from sample jar to rheometer measurement cup. In addition, when performing step 7 (Section 3.2.2.2), the rotor torques measured while mixing were constant. This indicates that for short periods of time, such as the 3-minute mixing step or the time required to transfer the sample to the measuring cup ( $\sim 5$ minutes), settling and shear history effects were minimal for the Group 2 slurry sample.

Figure 4.5 shows the results of flow curve testing for the Group 2 initial characterization slurry sample, TI517-G2-AR-RH. This slurry showed non-Newtonian behavior at all temperatures studied, with all flow curves showing small but finite yield stresses ( $\sim \mathrm{Pa})$ and linear stress behavior over 0 to $1000 \mathrm{~s}^{-1}$, with exception of the strong downward curvature observed near zero. The latter was almost certainly an artifact created by poor rotational sampling. Flow curve hysteresis was absent in all measurements, including $60^{\circ} \mathrm{C}$ (where hysteresis is typically observed for slurry samples). The latter indicated that evaporation did not significantly impact the rheological properties of the Group 2 slurry sample. Increasing the slurry temperature appeared to cause a decrease in slurry consistency (i.e., the slope of the flow curve data); the decrease in consistency between 25 and $40^{\circ} \mathrm{C}$ was similar in magnitude to that between 40 and $60^{\circ} \mathrm{C}$. The yield stress did not appear to change significantly with temperature. 


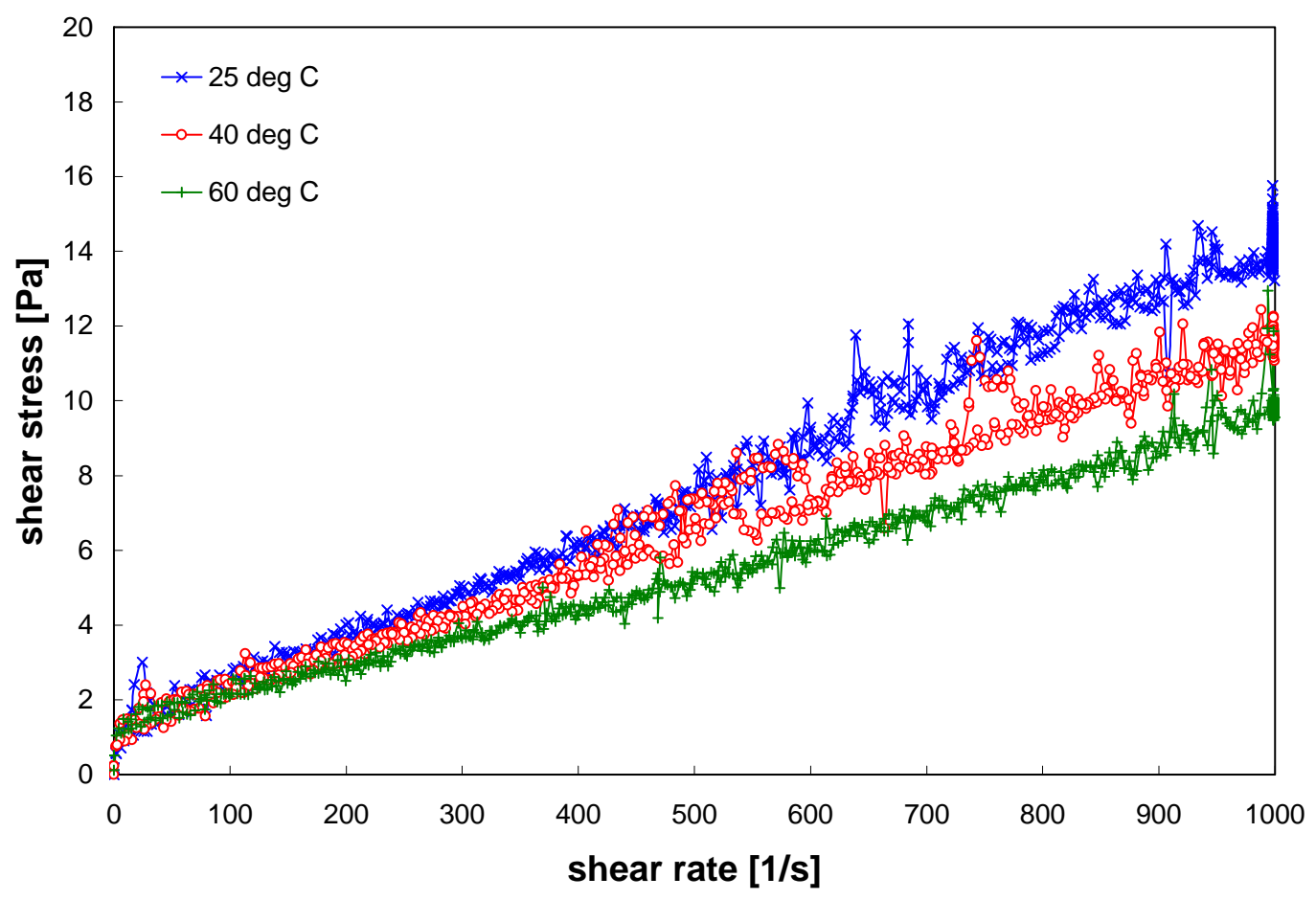

Figure 4.5. Flow Curve (shear stress versus shear rate) for the Group 2 Initial Characterization Slurry Sample TI517-G2-AR-RH at 25,40 , and $60^{\circ} \mathrm{C}$. Note: the second repeat measurement for $25^{\circ} \mathrm{C}$ is shown here, as it is the closest to the 40 and $60^{\circ} \mathrm{C}$ measurements in time.

In previous studies of tank waste rheology, increases in yield stress with increasing slurry temperature have usually been observed. These increases were typically associated with increased solids concentration and were accompanied by flow curve hysteresis. As such, the absence of both increased slurry yield and flow curve hysteresis with increasing temperature are self-consistent. Regarding slurry consistency, the observed decrease at higher temperatures can be attributed to lower suspending phase viscosity (as pure liquid viscosity generally decreases with increasing temperature). Similar behavior has been observed in previous studies of dilute slurries and tank waste supernatants. With this in mind, it should be noted that the rheology of high ionic strength aqueous particle suspensions is complex. Attributing the changes observed to physical phenomena described above is tenuous when based on flow curve data alone as other mechanisms can yield similar bulk rheological behavior.

Table 4.3 summarizes the best-fit rheological parameters for flow curve data for sample TI517-G2-ARRH. Only Bingham-Plastic and Herschel-Bulkley models were evaluated, and both fits employ the entire range of shear rate. ${ }^{(a)}$ An example of the quality of the data fit these parameters provide is shown in Figure 4.6, which shows both Bingham-Plastic and Herschel-Bulkley flow curve fits at $40^{\circ} \mathrm{C}$. In terms of capturing the range of magnitude, curvature, slope, and yield, both Herschel-Bulkley and Bingham-Plastic

(a) This typically includes 0 to $1000 \mathrm{~s}^{-1}$ for both up- and down-ramp measurements and the period of constant rotation at $1000 \mathrm{~s}^{-1}$. However, the fitting analysis for the first measurement at $25^{\circ} \mathrm{C}$ (i.e., measurement 1 of 2) does not consider the period of constant rotation at $1000 \mathrm{~s}^{-1}$, as the rotor appears to have over-spun during this phase of the measurement, causing a significant variation of stress during the constant-rotation period here. 
equations provide roughly the same fit. Additionally, the fitting parameters confirm a number of the observations made in the preceding paragraphs. Specifically, they show that at $37 \mathrm{wt} \%$ UDS (Table 4.2):

- The Bingham-Plastic and Herschel-Bulkely yield stresses typically range from 1.0 to 1.7 Pa. Given the typically \pm 0.5 Pa measurement limit for the M5 system, differences between these yield stresses are minor and in most cases insignificant.

- Bingham-Plastic consistency ranges from 8.6 to $14 \mathrm{cP}$ and decreases monotonically with increasing temperature.

- The Herschel-Bulkely flow indices fall between 0.9 and 1.2, indicating that the flow curve curvature is minor and that, overall, the behavior is consistent with the Bingham-Plastic model.

Regarding measurement repeatability, the two measurements at $25^{\circ} \mathrm{C}$ show similar consistencies $(\sim 13 \mathrm{cP})$ but slightly different yield stresses (1.7 Pa from the primary measurement versus 1.1 Pa for the replicate). As stated in the preceding paragraph, the difference between the regressed yield stresses for primary and replicate measurements is probably not significant given that the difference $(0.6 \mathrm{~Pa})$ is very near the instrument limit of accuracy $(\sim 0.5 \mathrm{~Pa})$.

Table 4.3. Results of Fitting Analysis for Rheology Sample TI517-G2-AR-RH

\begin{tabular}{||c|c|c|c|c|c||}
\hline \multirow{3}{*}{ Model } & $\begin{array}{c}\text { Temperature } \\
{\left[{ }^{\circ} \mathbf{C}\right]}\end{array}$ & $\begin{array}{c}\text { Yield Stress } \\
{[\mathbf{P a}]}\end{array}$ & $\begin{array}{c}\text { Consistency } \\
{\left[\mathbf{P a} \cdot \mathbf{s}^{\mathbf{n}}\right]}\end{array}$ & $\begin{array}{c}\text { Flow } \\
\text { Index }\end{array}$ & $\mathbf{R}$ \\
\hline \multirow{3}{*}{$\begin{array}{c}\text { Bingham-Plastic } \\
\left(0 \text { to } 1000 \mathrm{~s}^{-1}\right)\end{array}$} & $25(1$ of 2$)$ & 1.7 & 0.014 & n/a & 0.976 \\
\cline { 2 - 6 } & $25(2$ of 2$)$ & 1.1 & 0.013 & n/a & 0.996 \\
\cline { 2 - 6 } & 40 & 1.3 & 0.010 & n/a & 0.993 \\
\cline { 2 - 6 } & 60 & 1.1 & 0.0086 & n/a & 0.995 \\
\hline \multirow{3}{*}{$\begin{array}{c}\text { Herschel-Bulkley } \\
\left(0 \text { to } 1000 \text { s }^{-1}\right)\end{array}$} & $25(1$ of 2$)$ & 1.1 & 0.029 & 0.90 & 0.976 \\
\cline { 2 - 6 } & $25(2$ of 2$)$ & 1.1 & 0.013 & 1.01 & 0.996 \\
\cline { 2 - 6 } & 40 & 1.0 & 0.019 & 0.92 & 0.994 \\
\cline { 2 - 6 } & 60 & 1.5 & 0.0028 & 1.2 & 0.996 \\
\hline
\end{tabular}

For ease of reference, apparent viscosities at 33, 100, 500, and $1000 \mathrm{~s}^{-1}$ were derived from each measurement. For each temperature, the 33, 100, and $500 \mathrm{~s}^{-1}$ reference viscosities were determined from the average of up-ramp and down-ramp flow curve data and from the fitting parameters provided in Table 4.3. The apparent viscosity at $1000 \mathrm{~s}^{-1}$ averages apparent viscosity measurements over the period of constant rotation at $1000 \mathrm{~s}^{-1}$. As a point of comparison, apparent viscosities at $33 \mathrm{~s}^{-1}, 100 \mathrm{~s}^{-1}, 500 \mathrm{~s}^{-1}$, and $1000 \mathrm{~s}^{-1}$ were also calculated using the Bingham-Plastic and Herschel-Bulkley fitting parameters in Table 4.3. The results of these analyses are provided in Table 4.4 and show that apparent viscosities typically range from 42 to $67 \mathrm{cP}$ at $33 \mathrm{~s}^{-1}, 20$ to $31 \mathrm{cP}$ at $100 \mathrm{~s}^{-1}, 10$ to $18 \mathrm{cP}$ at $500 \mathrm{~s}^{-1}$, and 10 to $16 \mathrm{cP}$ at $1000 \mathrm{~s}^{-1}$.

In summary, the Group 2 initial characterization slurry sample, TI517-G2-AR-RH, shows rheological properties consistent with a Bingham Plastic model. This slurry exhibits a small but finite yield stress that remains unchanged with temperature and a near-linear flow curve slope over 0 to $1000 \mathrm{~s}^{-1}$ that decreases with increasing temperature, most likely as a result of decreased suspending-phase viscosity. Flow curve hysteresis effects were not observed, which indicates that evaporation of the suspending phase did not noticeably increase slurry viscosity. Based on the Bingham-Plastic fitting parameters, the yield stress of this slurry is approximately $1 \mathrm{~Pa}$; the consistency ranges from $\sim 13 \mathrm{cP}$ at $25^{\circ} \mathrm{C}$ to $8.6 \mathrm{cP}$ at $60^{\circ} \mathrm{C}$. 
Table 4.4. Apparent Viscosity of Sample TI517-G2-AR-RH

\begin{tabular}{|c|c|c|c|c|c|}
\hline \multirow[b]{2}{*}{ Source } & \multirow{2}{*}{$\begin{array}{c}\text { Temperature } \\
{\left[{ }^{\circ} \mathrm{C}\right]}\end{array}$} & \multicolumn{4}{|c|}{ Apparent Viscosity [cP] } \\
\hline & & @ $33 \mathrm{~s}^{-1}$ & @ $100 \mathrm{~s}^{-1}$ & @ $500 \mathrm{~s}^{-1}$ & @ $1000 \mathrm{~s}^{-1}$ \\
\hline \multirow[t]{4}{*}{ Measured } & 25 (1 of 2$)$ & 144 & 31 & 17 & 16 \\
\hline & 25 (2 of 2$)$ & 49 & 25 & 15 & 14 \\
\hline & 40 & 53 & 23 & 14 & 12 \\
\hline & 60 & 50 & 22 & 10 & 10 \\
\hline \multirow[t]{4}{*}{ Bingham-Plastic } & 25 (1 of 2$)$ & 67 & 31 & 17 & 16 \\
\hline & 25 (2 of 2$)$ & 45 & 24 & 15 & 14 \\
\hline & 40 & 51 & 24 & 13 & 12 \\
\hline & 60 & 42 & 20 & 11 & 10 \\
\hline \multirow[t]{4}{*}{ Herschel-Bulkley } & 25 (1 of 2$)$ & 56 & 30 & 18 & 15 \\
\hline & 25 (2 of 2$)$ & 46 & 24 & 15 & 14 \\
\hline & 40 & 44 & 23 & 13 & 12 \\
\hline & 60 & 51 & 21 & 10 & 10 \\
\hline
\end{tabular}

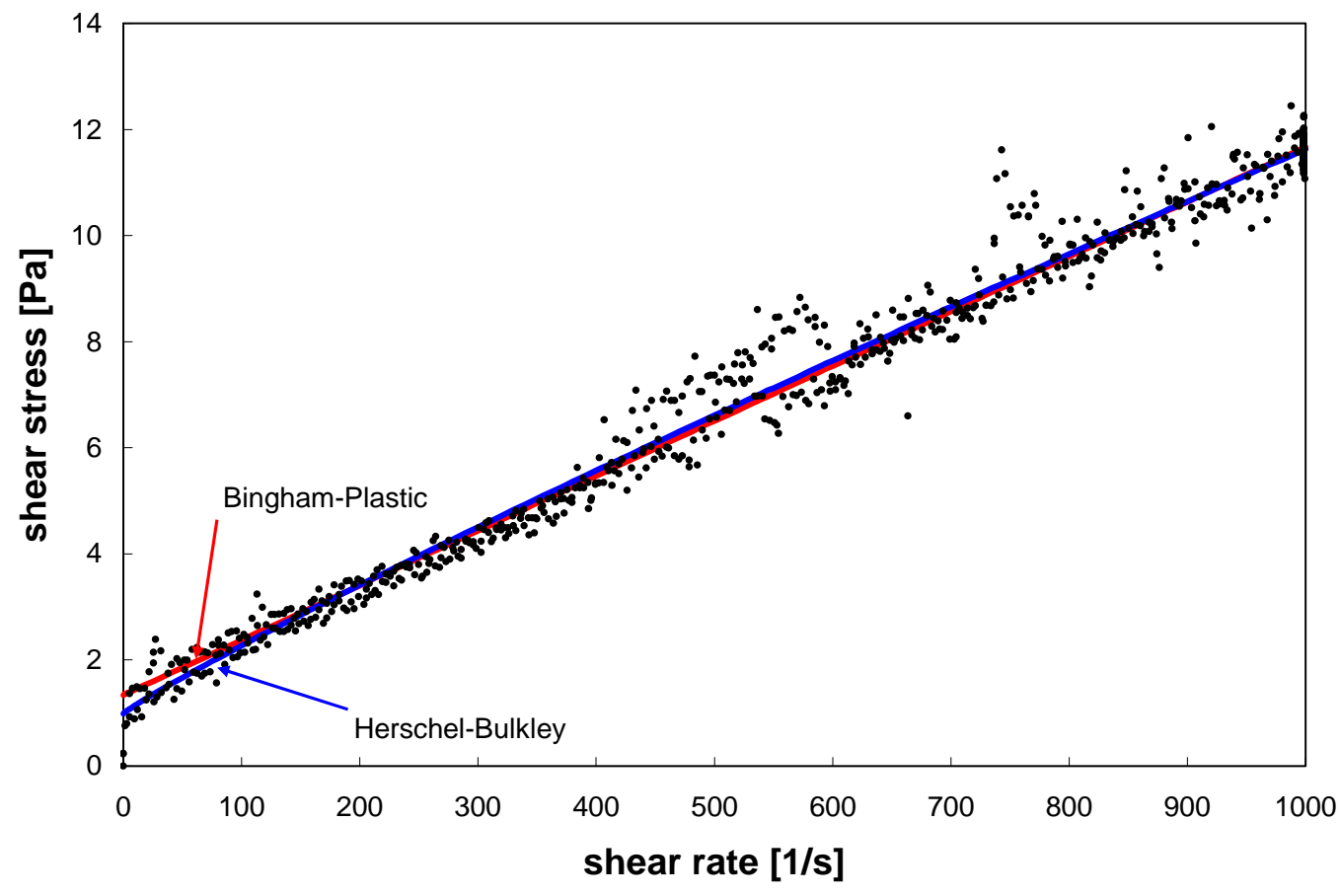

Figure 4.6. Model Fits of Flow Curve Data for Group 2 Initial Characterization Slurry Sample TI517G2-AR-RH at $40^{\circ} \mathrm{C}$. Both model fits consider the full shear rate range of 0 to $1000 \mathrm{~s}^{-1}$.

\subsubsection{Chemical and Radiochemical Composition}

A density determination was done on the supernatant phases of the two samples taken for chemical characterization. The density was determined to be $1.251 \pm 0.002 \mathrm{~g} / \mathrm{mL}\left(\mathrm{T}=28^{\circ} \mathrm{C}\right.$ ) based on the average masses of five 1-mL volume deliveries. This result is comparable to that determined as part of the physical-property testing procedure (density $=1.223 \mathrm{~g} / \mathrm{mL}$ ). The density of the composite washing solution was $1.080 \mathrm{~g} / \mathrm{mL}$. 
The average radioanalytical results for the supernatant, composited wash solution, and washed solids are provided in Table 4.5 along with the applicable RPDs, measure of precision between duplicates). The gross-beta results showed good agreement with the sum of beta emitters: ${ }^{137} \mathrm{Cs}$ and ${ }^{90} \mathrm{Sr}$ (in secular equilibrium with ${ }^{90} \mathrm{Y}$ ) thus indicating that no other major source of beta-gamma activity was present. The gross alpha activity measured in the solids agreed with the summation of alpha emitters $\left({ }^{238} \mathrm{Pu}\right.$, ${ }^{239+240} \mathrm{Pu}$, and $\left.{ }^{241} \mathrm{Am}\right)$.

Table 4.5. Radionuclide Characterization of the Group 2 Saltcake

\begin{tabular}{|c|c|c|c|c|c|c|}
\hline \multirow[b]{2}{*}{ Analyte } & \multicolumn{2}{|c|}{ Supernatant } & \multicolumn{2}{|c|}{ Wash Composite } & \multicolumn{2}{|c|}{ Washed Solids } \\
\hline & $\mu \mathrm{Ci} / \mathrm{mL}$ & RPD & $\mu \mathrm{Ci} / \mathrm{mL}$ & $\mathbf{R P D}^{(\mathbf{a})}$ & $\mu \mathrm{Ci} / \mathrm{g}^{(\mathbf{b})}$ & RPD \\
\hline${ }^{137} \mathrm{Cs}$ & $2.46 \mathrm{E}+1$ & na & $4.36 \mathrm{E}+0$ & na & $9.97 \mathrm{E}+1$ & 11 \\
\hline${ }^{60} \mathrm{Co}$ & $<3 . \mathrm{E}-4$ & na & $<2 . \mathrm{E}-5$ & na & $1.07 \mathrm{E}-2$ & 34 \\
\hline${ }^{241} \mathrm{Am}$ & $<2 . \mathrm{E}-2$ & na & $<1 . \mathrm{E}-3$ & na & $4.21 \mathrm{E}-1$ & 30 \\
\hline${ }^{238} \mathrm{Pu}$ & 4.96E-6 & 6.5 & \multirow{7}{*}{\multicolumn{2}{|c|}{ na }} & $1.44 \mathrm{E}-2$ & 40 \\
\hline${ }^{239+240} \mathrm{Pu}$ & $8.24 \mathrm{E}-5$ & 7.8 & & & $2.67 \mathrm{E}-1$ & 17 \\
\hline${ }^{90} \mathrm{Sr}$ & $3.28 \mathrm{E}-3$ & 7.0 & & & $1.79 \mathrm{E}+2$ & 10 \\
\hline Gross alpha & $<5 . \mathrm{E}-4$ & na & & & $5.05 \mathrm{E}-1$ & 6 \\
\hline Sum of alpha & $8.74 \mathrm{E}-5$ & 7.0 & & & $7.02 \mathrm{E}-1$ & 25 \\
\hline Gross beta & $2.45 \mathrm{E}+1$ & 0.4 & & & $4.63 E+2$ & 10 \\
\hline Sum of beta & $2.46 \mathrm{E}+1$ & na & & & $4.58 \mathrm{E}+2$ & 10 \\
\hline \multicolumn{7}{|l|}{ Opportunistic } \\
\hline${ }^{154} \mathrm{Eu}$ & $<2$.E-3 & na & $<7 . \mathrm{E}-5$ & na & $4.84 \mathrm{E}-2$ & 26 \\
\hline${ }^{155} \mathrm{Eu}$ & $<1 . \mathrm{E}-2$ & na & $<1 . \mathrm{E}-3$ & na & $<0.1$ & na \\
\hline \multicolumn{7}{|c|}{$\begin{array}{l}\text { ASR 7974; Reference date is July 15, } 2007 . \\
\text { (a) This sample was not required to be run in duplicate; therefore, an RPD was not calculated. } \\
\text { (b) Analyte concentrations are calculated on a dry-mass basis. } \\
\text { Notes: na = not applicable }\end{array}$} \\
\hline
\end{tabular}

The chemical composition of the washed Group 2 solids is provided in Table 4.6. The supernatant liquid consisted primarily of sodium nitrate with minor contributions of other sodium salts. The free-hydroxide concentration in the supernatant liquid was $0.295 \mathrm{M}$. The anionic and cationic charge balance was evaluated for the supernatant, resulting in a relative $1.3 \%$ difference, and the total $\mathrm{S}$ and $\mathrm{P}$ values (determined by ICP-OES) and $\mathrm{SO}_{4}{ }^{2-}$ and $\mathrm{PO}_{4}{ }^{3-}$ (determined by IC) were compared, and all were determined to be well within analytical uncertainties.

Major constituents in the washed solids were sodium, aluminum, phosphorus, and silicon, while iron, uranium, calcium, and chromium provided minor contributions. Overall good agreement was obtained between the two different sample preparation methods as well as the uranium results between KPA and the ICP-OES analyses. 
Table 4.6. Chemical Characterization of the Group 2 Test Material

\begin{tabular}{|c|c|c|c|c|c|c|c|c|c|c|}
\hline \multirow[b]{3}{*}{ Analyte } & \multirow{2}{*}{\multicolumn{3}{|c|}{$\begin{array}{c}\text { Supernatant } \\
\text { Acid Digestion }\end{array}$}} & \multirow{2}{*}{\multicolumn{3}{|c|}{$\begin{array}{c}\text { Wash Composite } \\
\text { Acid Digestion }\end{array}$}} & \multicolumn{4}{|c|}{ Washed Solids $^{(\mathbf{a})}$} \\
\hline & & & & & & & \multicolumn{2}{|c|}{ КОН fusion } & \multicolumn{2}{|c|}{ Acid Digestion } \\
\hline & $\mu \mathrm{g} / \mathrm{mL}$ & $\mathbf{M}$ & RPD & $\mu \mathrm{g} / \mathrm{mL}$ & $\mathbf{M}$ & RPD & $\mu \mathrm{g} / \mathrm{g}$ & RPD & $\mu \mathrm{g} / \mathrm{g}$ & RPD \\
\hline $\mathrm{Al}$ & 2,030 & $7.52 \mathrm{E}-2$ & 0.0 & 322 & $1.19 \mathrm{E}-2$ & & 112,500 & 8 & 122,500 & 0.8 \\
\hline $\mathrm{B}$ & 98.6 & $9.12 \mathrm{E}-3$ & 1.0 & 19.8 & $1.83 \mathrm{E}-3$ & & \begin{tabular}{|l|}
{$[105]$} \\
\end{tabular} & [10] & & \\
\hline $\mathrm{Bi}$ & $<2.27$ & $<1 . \mathrm{E}-5$ & & [2.3] & [1.1E-5] & & [895] & [12] & 1,030 & 1.9 \\
\hline $\mathrm{Cd}$ & $<0.24$ & $<2$.E-6 & & $<0.24$ & $<2$. E-6 & & 90.2 & 9 & 106 & 2.8 \\
\hline $\mathrm{Cr}$ & 798 & $1.53 \mathrm{E}-2$ & 0 & 161 & $3.10 \mathrm{E}-3$ & & 7,485 & 9 & 8,285 & 0.6 \\
\hline $\mathrm{Fe}$ & [7.45] & [1.3E-4] & [4] & [2.3] & [4.1E-5] & & 21,150 & 12 & 23,000 & 1.7 \\
\hline $\mathrm{K}$ & 979 & $2.50 \mathrm{E}-2$ & 1 & 186 & $4.76 \mathrm{E}-3$ & & & & {$[240]$} & [33] \\
\hline Mn & $<0.20$ & $<4 . \mathrm{E}-6$ & & $<0.20$ & $<4 . \mathrm{E}-6$ & & 1,034 & 15 & 1,009 & 4.3 \\
\hline $\mathrm{Na}$ & 112,000 & $4.87 \mathrm{E}+0$ & 1.79 & 36,900 & $1.61 \mathrm{E}+0$ & & 177,000 & 10 & 192,000 & 0.0 \\
\hline $\mathrm{Ni}$ & {$[0.72]$} & [1.2E-5] & [35] & {$[0.61]$} & [1.0E-5] & & & & 4,750 & 0.4 \\
\hline $\mathrm{S}$ & 3,845 & $1.20 \mathrm{E}-1$ & 0.3 & 2,480 & $7.74 \mathrm{E}-2$ & & {$[1,450]$} & [7] & {$[1,350]$} & [7] \\
\hline $\mathrm{Si}$ & [8.25] & [2.9E-4] & [10.9] & 11.7 & $4.17 \mathrm{E}-4$ & & 31,650 & 7 & & \\
\hline $\mathrm{Sr}$ & $<0.02$ & $<2 . \mathrm{E}-7$ & & $<0.02$ & $<2 . \mathrm{E}-7$ & & 4,005 & 12 & 4,540 & 0.0 \\
\hline $\mathrm{U}$ & $<8.33$ & $<3 . E-5$ & & $<8.27$ & $<3 . E-5$ & & 14,650 & 6 & 16,250 & 0.6 \\
\hline $\mathrm{Zn}$ & [3.5] & [5.4E-5] & [5.7] & {$[0.85]$} & [1.3E-5] & & [325] & [3] & 399 & 2.0 \\
\hline $\mathrm{Zr}$ & $<0.81$ & $<9 . \mathrm{E}-6$ & & $<0.80$ & $<9 . \mathrm{E}-6$ & & $<59$ & & {$[110]$} & {$[0]$} \\
\hline U KPA & & & & & & & 15,250 & 7 & & \\
\hline nitrite & 11,600 & $2.52 \mathrm{E}-1$ & 3.4 & 2,015 & 4.38E-2 & 9.43 & & & & \\
\hline nitrate & 177,000 & $2.85 \mathrm{E}+0$ & 4.52 & 30,550 & $4.93 \mathrm{E}-1$ & 9.5 & & & & \\
\hline phosphate & 2,805 & $2.95 \mathrm{E}-2$ & 0.4 & 5,965 & $6.28 \mathrm{E}-2$ & 9.9 & & & & \\
\hline sulfate & 11,550 & $1.20 \mathrm{E}-1$ & 4.33 & 8,280 & $8.62 \mathrm{E}-2$ & 9.7 & & & & \\
\hline oxalate & 1,305 & $1.48 \mathrm{E}-2$ & 0.77 & 5,835 & $6.63 \mathrm{E}-2$ & 9.4 & & & & \\
\hline free $\mathrm{OH}$ & & 0.30 & 3.4 & & & & & & & \\
\hline TOC as $\mathrm{C}$ & 765 & 0.064 & 1.3 & & & & & & & \\
\hline TIC as C & 6,500 & 0.542 & 0 & & & & & & & \\
\hline \multicolumn{11}{|c|}{ Opportunistic } \\
\hline fluoride & 4200 & $2.21 \mathrm{E}-1$ & 3.81 & 8480 & 4.39E-1 & 3 & & & & \\
\hline chloride & 776.5 & $2.19 \mathrm{E}-2$ & 1.42 & 126 & $3.72 \mathrm{E}-3$ & 9 & & & & \\
\hline $\mathrm{Ag}$ & {$[0.55]$} & [5.1E-6] & & $<0.42$ & $<3.9 . \mathrm{E}-6$ & & $<17$ & & [8.5] & [11.8] \\
\hline As & $<6.93$ & $<9.3 . \mathrm{E}-5$ & & $<6.88$ & $<9.2 . \mathrm{E}-5$ & & $<269$ & & $<95$ & \\
\hline $\mathrm{Ba}$ & $<0.34$ & $<2.4$.E-6 & & $<0.33$ & $<2.4 . \mathrm{E}-6$ & & [230] & [9] & 257.0 & 0.0 \\
\hline $\mathrm{Be}$ & $<0.01$ & $<1.3 . \mathrm{E}-6$ & & $<0.01$ & $<1.3 . \mathrm{E}-6$ & & $<1.0$ & & {$[0.9]$} & [1.1] \\
\hline $\mathrm{Ca}$ & [5.0] & [1.2E-4] & 8 & [3.6] & [9.0E-5] & & {$[9,200]$} & [7] & 9,795 & 0.3 \\
\hline $\mathrm{Ce}$ & $<1.19$ & $<8.5$.E-6 & & $<1.18$ & $<8.4$.E-6 & & $<202$ & & $<16$ & \\
\hline Co & [0.65] & [1.1E-5] & & $<0.38$ & $<6.5 . \mathrm{E}-6$ & & $<22$ & & [33.5] & [2.99] \\
\hline $\mathrm{Cu}$ & $<0.48$ & $<7.6 . \mathrm{E}-6$ & & $<0.48$ & $<7.5 . \mathrm{E}-6$ & & [155] & [32] & 80.3 & 0.9 \\
\hline Dy & $<0.35$ & $<2.1 . \mathrm{E}-6$ & & {$[0.47]$} & [2.9E-6] & & $<52$ & & $<4.8$ & \\
\hline $\mathrm{Eu}$ & $<0.11$ & $<7.1 . \mathrm{E}-7$ & & $<0.11$ & $<7.1 . \mathrm{E}-7$ & & $<16$ & & $<1.5$ & \\
\hline
\end{tabular}


Table 4.6. Chemical Characterization of the Group 2 Test Material

\begin{tabular}{|c|c|c|c|c|c|c|c|c|c|c|}
\hline \multirow[b]{3}{*}{ Analyte } & \multirow{2}{*}{\multicolumn{3}{|c|}{$\begin{array}{c}\text { Supernatant } \\
\text { Acid Digestion }\end{array}$}} & \multirow{2}{*}{\multicolumn{3}{|c|}{$\begin{array}{c}\text { Wash Composite } \\
\text { Acid Digestion }\end{array}$}} & \multicolumn{4}{|c|}{ Washed Solids $^{(\mathbf{a})}$} \\
\hline & & & & & & & \multicolumn{2}{|c|}{ KOH fusion } & \multicolumn{2}{|c|}{ Acid Digestion } \\
\hline & $\mu \mathrm{g} / \mathrm{mL}$ & M & RPD & $\mu \mathrm{g} / \mathrm{mL}$ & $\mathbf{M}$ & RPD & $\mu \mathrm{g} / \mathrm{g}$ & RPD & $\mu \mathrm{g} / \mathrm{g}$ & RPD \\
\hline $\mathrm{La}$ & $<0.13$ & $<9.5 . \mathrm{E}-7$ & & $<0.13$ & $<9.4 . \mathrm{E}-7$ & & $<11$ & & [18.8] & {$[8.0]$} \\
\hline $\mathrm{Li}$ & $<0.54$ & $<7.8 . \mathrm{E}-5$ & & {$[0.92]$} & [1.3E-4] & & $<32$ & & [48.5] & [10.3] \\
\hline $\mathrm{Mg}$ & $<0.70$ & $<2.9 . \mathrm{E}-5$ & & $<0.69$ & $<2.8 . \mathrm{E}-5$ & & {$[1,100]$} & [18] & 1,255 & 0.8 \\
\hline Mo & 8.01 & 8.35E-5 & 3 & {$[4.6]$} & [4.8E-5] & & $<30$ & & $<9$ & \\
\hline $\mathrm{Nd}$ & $<1.71$ & $<1.2$.E-5 & & $<1.69$ & $<1.2$.E-5 & & $<311$ & & [43.5] & [6.9] \\
\hline$P$ & 859 & $2.77 \mathrm{E}-2$ & 0.23 & 1,800 & $5.81 \mathrm{E}-2$ & & 45,800 & 10 & 49,900 & 0.8 \\
\hline $\mathrm{Pb}$ & $<3.68$ & $<1.8 . \mathrm{E}-5$ & & $<3.65$ & $<1.8 . \mathrm{E}-5$ & & {$[1,010]$} & {$[24]$} & 1,385 & 0.7 \\
\hline $\mathrm{Pd}$ & $<1.25$ & $<1.2$.E-5 & & $<1.24$ & $<1.2$.E-5 & & $<183$ & & $<17$ & \\
\hline $\mathrm{Rh}$ & $<2.51$ & $<2.4 . \mathrm{E}-5$ & & $<2.49$ & $<2.4 . \mathrm{E}-5$ & & $<120$ & & $<35$ & \\
\hline $\mathrm{Ru}$ & $<0.82$ & $<8.1$.E-6 & & $<0.81$ & $<8.0 . \mathrm{E}-6$ & & $<52$ & & $<11$ & \\
\hline $\mathrm{Sb}$ & $<3.12$ & $<2.6 . \mathrm{E}-5$ & & $<3.10$ & $<2.5 . \mathrm{E}-5$ & & $<171$ & & $<43$ & \\
\hline Se & $<4.87$ & $<6.2$.E-5 & & $<4.83$ & $<6.1 . \mathrm{E}-5$ & & $<291$ & & $<67$ & \\
\hline Sn & 22.4 & $1.88 \mathrm{E}-4$ & & [5.9] & [5.0E-5] & & $<272$ & & [80.5] & [16.1] \\
\hline $\mathrm{Ta}$ & $<1.32$ & $<7.3 . \mathrm{E}-6$ & & $<1.31$ & $<7.3 . \mathrm{E}-6$ & & $<59$ & & $<18.2$ & \\
\hline $\mathrm{Te}$ & $<3.14$ & $<2.5 . \mathrm{E}-5$ & & $<3.11$ & $<2.4 . \mathrm{E}-5$ & & $<231$ & & $<43.1$ & \\
\hline Th & $<1.18$ & $<5.1$.E-6 & & [1.2] & [5.2E-6] & & $<180$ & & $<16$ & \\
\hline $\mathrm{Ti}$ & $<0.10$ & $<2.0 . \mathrm{E}-6$ & & {$[0.11]$} & [2.3E-6] & & [135] & [7] & 178 & 11.8 \\
\hline $\mathrm{Tl}$ & $<6.45$ & $<3.2 . \mathrm{E}-5$ & & $<6.41$ & $<3.1 . \mathrm{E}-5$ & & $<209$ & & $<89$ & \\
\hline $\mathrm{V}$ & [0.64] & [1.3E-5] & & [1.5] & [2.9E-5] & & [34] & [12] & 46.1 & 1.7 \\
\hline $\mathrm{W}$ & $<1.49$ & $<$ 8.1.E-6 & 0 & [8.7] & [4.7E-5] & & $<92$ & & $<20$ & \\
\hline $\mathrm{Y}$ & $<0.08$ & $<9.5 . \mathrm{E}-7$ & & $<0.08$ & $<9.4 . \mathrm{E}-7$ & & $<20$ & & [4.1] & [17.3] \\
\hline \multicolumn{11}{|c|}{$\begin{array}{l}\text { Analyte uncertainties were typically within } \pm 15 \%(2-\sigma) \text {; results in brackets indicate that the analyte concentrations were less than } \\
\text { the minimum detection limit (MDL) and greater than the estimated quantitation limit (EQL), and uncertainties were }>15 \% \text {. } \\
\text { Opportunistic analytes are reported for information only; QC requirements did not apply to these analytes. }\end{array}$} \\
\hline
\end{tabular}

The fractional distribution of selected analytes between the supernatant, wash solution, and solids phases is shown in Table 4.7 and Figure 4.7. The bulk of the sodium (86\%) and sulfur (as sulfate, 97\%) partitioned to the aqueous phase as a result of the initial contact with water during homogenization and the continued water washing. The phosphorus (75\%) and aluminum (86\%) remained primarily in the solids phase while the chromium was split between the aqueous (49\%) and solids (51\%) phases.

The total P concentrations in the supernatant and wash solutions determined by ICP-OES were equivalent to the phosphate concentrations determined by IC. Likewise, the total S concentrations were equivalent to the sulfate concentrations. Therefore, the mobilized forms represented the water-soluble sulfate and phosphate salts. For most analytes, the concentration in the wash composite was $\sim 20 \%$ of that in the supernatant. However, the phosphate (and total P) concentration in the wash composite was greater than that in the supernatant liquid, and the sulfur in the wash was $\sim 60 \%$ of that in the supernatant, indicating that phosphate and sulfur were further dissolved as a result of water washing. 
Table 4.7. Phase Distribution of Selected Analytes in Group 2

\begin{tabular}{|c|c|c|c|c||}
\hline Analyte & $\begin{array}{c}\text { Supernatant } \\
\mathbf{\%}\end{array}$ & $\begin{array}{c}\text { Wash Solution } \\
\mathbf{\%}\end{array}$ & $\begin{array}{c}\text { Solids } \\
\mathbf{\%}\end{array}$ & $\begin{array}{c}\text { Water-Wash Factor } \\
\mathbf{\%}\end{array}$ \\
\hline $\mathrm{Cr}$ & 44.9 & 4.8 & 50.4 & 49.6 \\
\hline $\mathrm{Al}$ & 13.1 & 1.1 & 85.8 & 14.2 \\
\hline $\mathrm{Na}$ & 73.6 & 12.7 & 13.6 & 86.4 \\
\hline $\mathrm{P}$ & 11.9 & 13.1 & 74.9 & 25.1 \\
\hline $\mathrm{S}$ & 72.6 & 24.6 & 2.8 & 97.2 \\
\hline
\end{tabular}

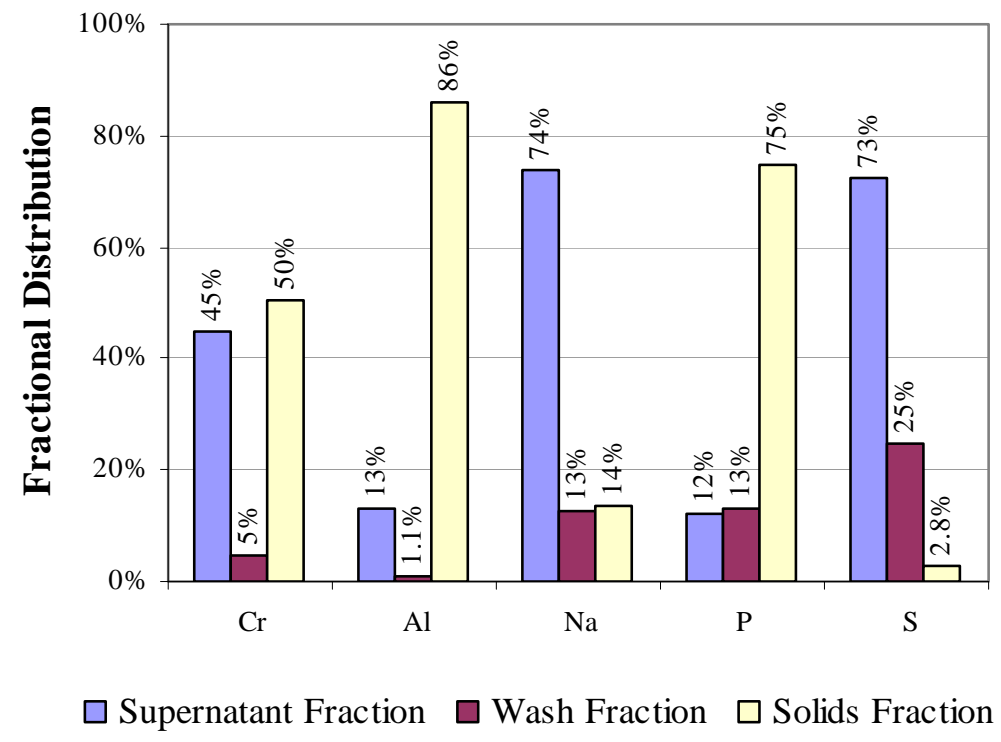

Figure 4.7. Selected Analyte Phase Distribution for Group 2

\subsubsection{Particle Size}

Figure 4.8 and Figure 4.9 present the results of Group 2 initial-characterization particle-size analysis as a function of test condition. Figure 4.8 through Figure 4.10 show the differential volume population distribution for the primary Group 2 initial characterization sample (see Appendix $\mathrm{H}$ for the duplicate sample results) and allow a qualitative examination of the PSD behavior with respect to pump speed and sonication. Table 4.8 is a summary of the measured oversize diameter percentiles (by volume/weight) for the primary, TI517-G2-S-WL-PSD-21. Table 4.9 presents the same results for the duplicate standard, TI517-G2-S-WL-PSD-2. Both tables present cumulative oversize diameters corresponding to the $10^{\text {th }}$, $50^{\text {th }}$, and $90^{\text {th }}$ volume/weight percentiles, hereafter referred to as $\mathrm{d}(10), \mathrm{d}(50)$, and $\mathrm{d}(90)$, respectively. More extensive percentile results are provided in Appendix I. These tables will be used to quantitatively examine reproducibility and changes in particle size.

Figure 4.8 shows the PSD for the primary Group 2 initial characterization sample as a function of pump speed before sonication. The distribution of particles ranges from 0.3 to $20 \mu \mathrm{m}$, and peaks between 3 and $5 \mu \mathrm{m}$, and has a low population peak around $200 \mu \mathrm{m}$ at $4000 \mathrm{RPM}$. With exception of the appearance of the second peak around $200 \mu \mathrm{m}$ at $4000 \mathrm{RPM}$, the distribution is continuous and uni-modal. That is, the 
PSD is a single broad population of particles centered at 3 to $5 \mu \mathrm{m}$. It is possible that the $200-\mu \mathrm{m}$ peak is an artifact of the measurement and analysis; however, the duplicate sample confirms the appearance of a large size population (20 to $200 \mu \mathrm{m}$ ) at high pump speeds. As such, the $200-\mu \mathrm{m}$ peak is likely caused by a relatively large Group 2 particle species that is difficult to suspend and thus that is poorly sampled by the analyzer. Changes in the primary population peak (i.e., that over 0.3 to $20 \mu \mathrm{m}$ ) with respect to changes in flow rate are minor. The 3000 RPM PSD peaks at 2 to $3 \mu \mathrm{m}$, whereas the 2000 and 4000 RPM peak over 3 to $5 \mu \mathrm{m}$. The increase in the population peak diameter as flow rate is increased from 3000 RPM to 4000 RPM is expected, as higher pump speeds are capable of suspending any larger particle and particle aggregates. It is possible that this improved suspension is maintained through the subsequent PSD set-point, thus accounting for the higher population peak diameter of 2000 RPM measurement relative to the initial 3000 RPM measurement.

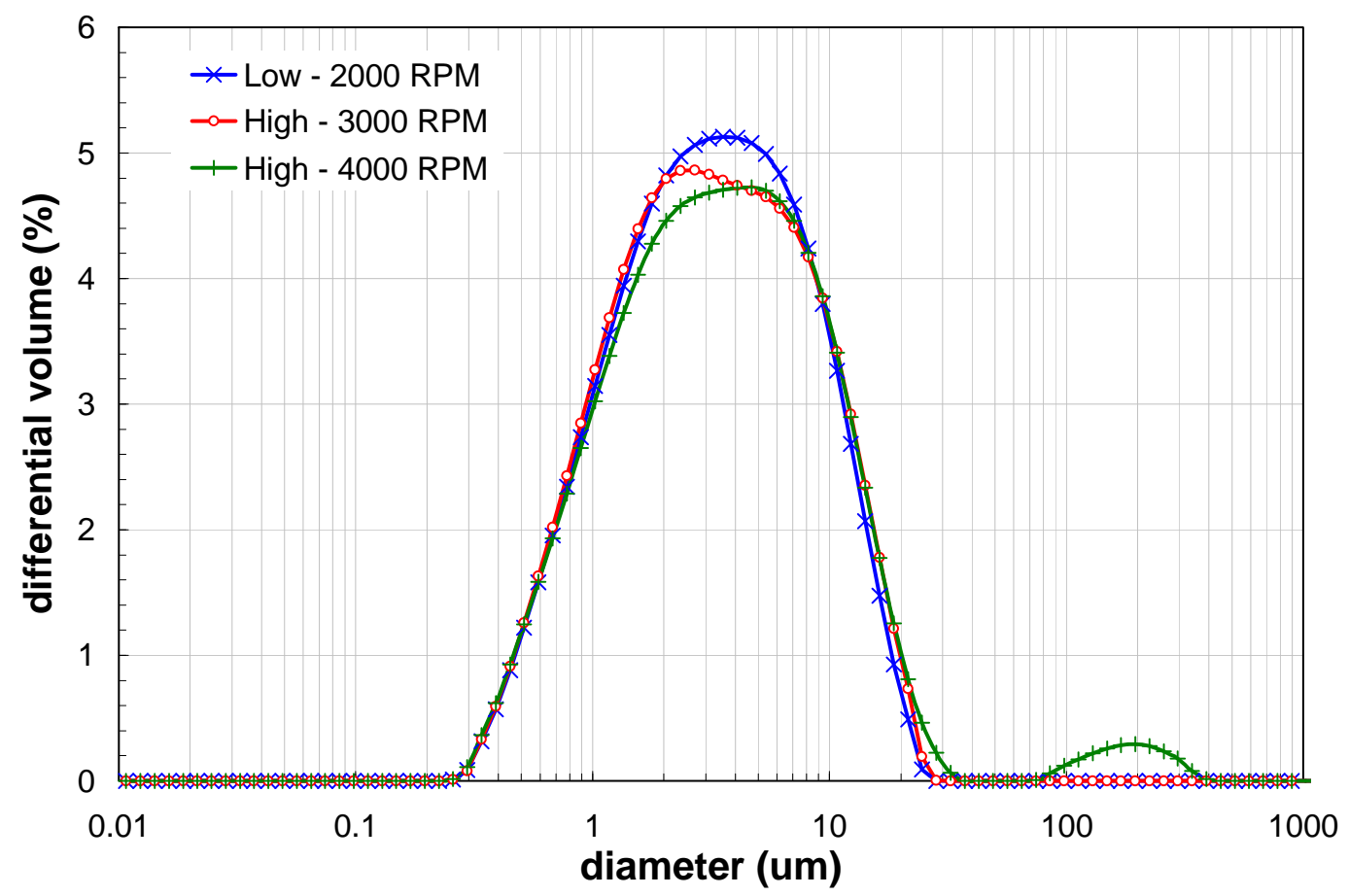

Figure 4.8. Pre-Sonication Volume Distribution Result for the Primary Group 2 Initial Characterization Sample as a Function of Pump Speed

Figure 4.9 shows the PSD as a function of sonication. This figure indicates that sonication shifts the entire particle population to smaller diameters and substantially increases the central (2 to $6 \mu \mathrm{m}$ ) population of particles, probably as a result of particle aggregate disruption. Disruption is evidenced by a slightly decreased fraction of 6 to $20 \mu \mathrm{m}$ and a slightly increased fraction of sub-micrometer particles. The increased population over the 2 to $6 \mu \mathrm{m}$ was observed to occur before the application of sonic energy (see Figure 4.7); however, sonication appears to further enhance the population of 2 to $6 \mu \mathrm{m}$ over that observed at 2000 RPM before sonication. The cause of this observation could be 1) breakdown of the 6to 20- $\mu \mathrm{m}$ into 2- to 6- $\mu \mathrm{m}$ particles and/or 2) increased suspension of particles as a result of input of sonic energy (similar to the improvements caused by increased flow in Figure 4.8). 


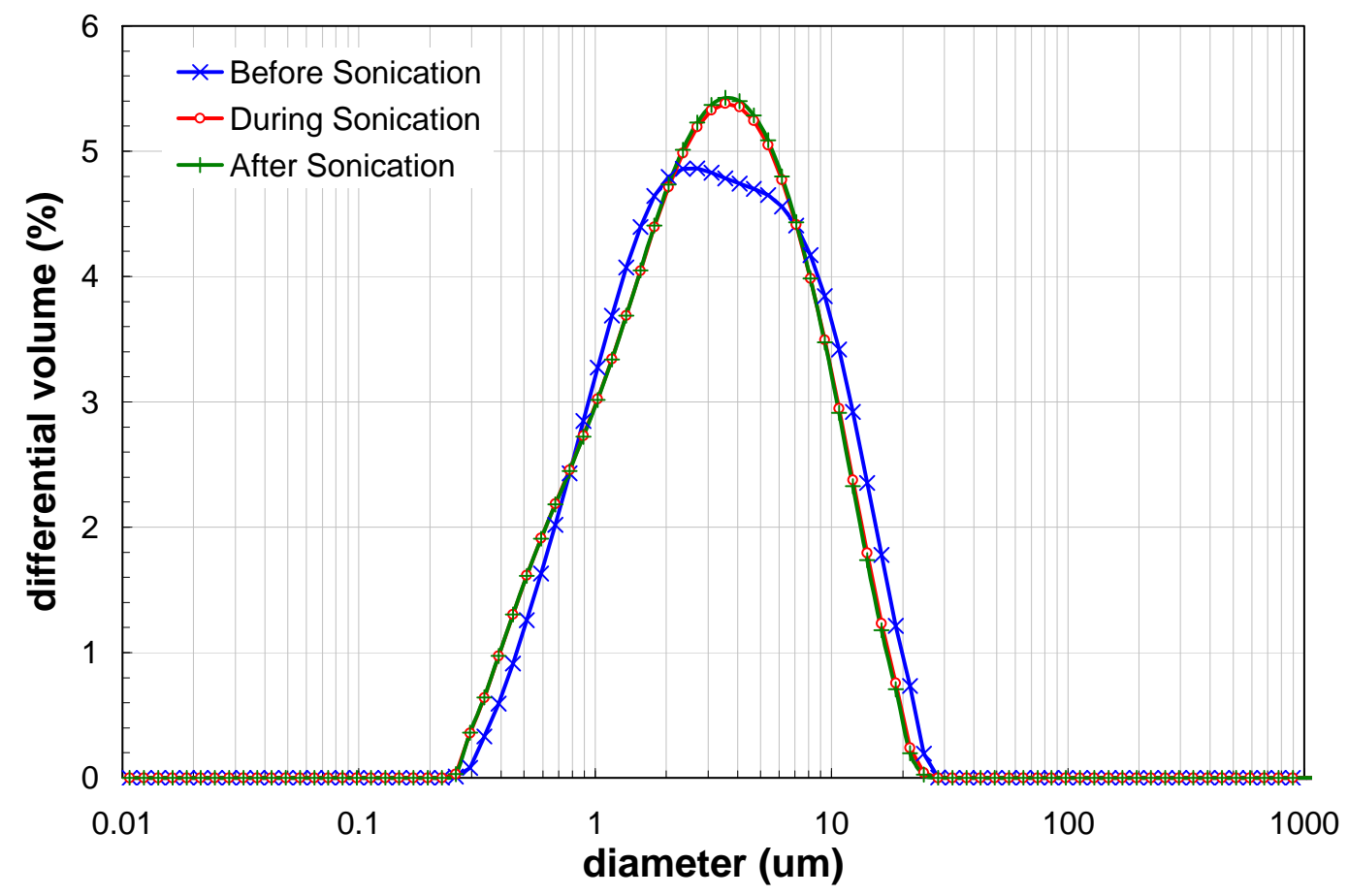

Figure 4.9. Volume Distribution Result for the Primary Group 2 Initial Characterization Sample as a Function of Sonication (75\% power)

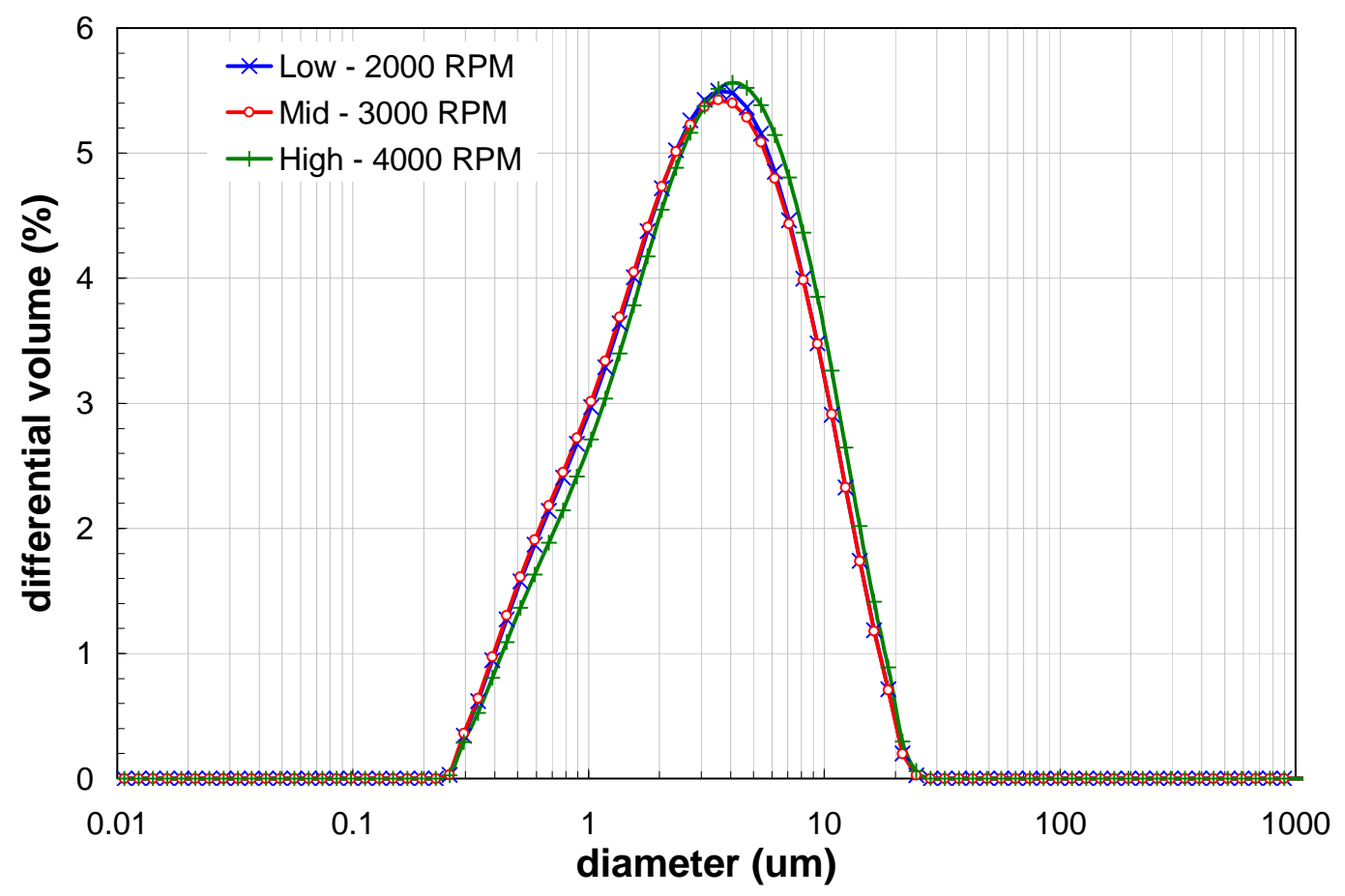

Figure 4.10. Post-Sonication Volume Distribution Result for the Primary Group 2 Initial Characterization Sample as a Function of Pump Speed 
Figure 4.10 shows the primary Group 2 initial characterization PSD as a function of pump speed after the sample dispersion has been sonicated. Here, changes in pump speed do not appear to significantly change the distribution, with the exception of a slight increase in peak population diameter at $4000 \mathrm{RPM}$. This increase is likely a result of a small improvement in large particle suspension as a result of increased mechanical agitation. From the observation of PSD insensitivity to pump speed, we may conclude that sonicated Group 2 solids are stable with respect to transient effects such as shear-induced agglomeration and mechanical effects such as shear break-up of particle aggregates. In addition, the $200-\mu \mathrm{m}$ peak is absent from the 4000 RPM post-sonication PSD. This supports the conclusion that sonication has disrupted particle aggregates and indicates that aggregate recovery does not occur over the duration of PSD measurement ( 15 minutes).

Table 4.8 shows select cumulative oversize percentiles for the primary Group 2 particle dispersion (TI517-G2-S-WL-PSD-1). Using these results as a reference, the behavior of Group 2 initial characterization particle size as a function of pump speed and sonication can be quantitatively evaluated. Specifically, the following observations can be made:

- In general, the $\mathrm{d}(10)$ falls between 0.77 and $0.88 \mu \mathrm{m}$, the $\mathrm{d}(50)$ between 3.1 and $3.5 \mu \mathrm{m}$, and the $\mathrm{d}(90)$ between 9.6 and $13 \mu \mathrm{m}$.

- The listed diameter percentiles appear to be slightly sensitive to changes in pump speed, both before and after sonication. Increases in flow appear to affect increases in the mean diameter [i.e., the $\mathrm{d}(50)$ ]; however, the change is near to the instrument limit of accuracy (10\%). For example, an increase from 3000 to 4000 RPM before sonication increases the mean particle diameter from 3.2 to $3.5 \mu \mathrm{m}$. This is an increase of $9.4 \%$ and, as such, is close but still below the limit of significance.

- Sonication of the Group 2 solids dispersion slightly decreases the particle size, but the change for the mean diameter is well below the instrument's measurement sensitivity. The PSD results at 3000 RPM indicate that sonication lowers the mean particle size from 3.2 to $3.1 \mu \mathrm{m}$. This represents a decrease of $\sim 3 \%$ in the mean particle size and is not significant relative to the measurement accuracy $(10 \%)$.

Table 4.8. Particle Size Analysis Percentile Results of the Primary Group 2 Initial Characterization Sample, TI517-G2-S-WL-PSD-1

\begin{tabular}{||c|c|c|c|c|c||}
\hline $\begin{array}{c}\text { Measurement } \\
\text { Condition }\end{array}$ & Pump Speed & Sonication & $\begin{array}{c}\mathbf{d}(\mathbf{1 0}) \\
{[\mu \mathbf{m}]}\end{array}$ & $\begin{array}{c}\mathbf{d}(\mathbf{5 0}) \\
{[\mu \mathbf{m}]}\end{array}$ & $\begin{array}{c}\mathbf{d}(\mathbf{9 0}) \\
{[\mu \mathbf{m}]}\end{array}$ \\
\hline 1 & 3000 & pre-sonic & 0.86 & 3.2 & 11 \\
\hline 2 & 4000 & pre-sonic & 0.87 & 3.5 & 13 \\
\hline 3 & 2000 & pre-sonic & 0.88 & 3.2 & 10 \\
\hline 4 & 3000 & $25 \%$ & 0.79 & 3.1 & 10 \\
\hline 5 & 3000 & $50 \%$ & 0.77 & 3.1 & 10 \\
\hline 6 & 3000 & $75 \%$ & 0.77 & 3.1 & 9.7 \\
\hline 7 & 3000 & post-sonic & 0.77 & 3.1 & 9.6 \\
\hline 8 & 4000 & post-sonic & 0.84 & 3.4 & 10 \\
\hline 9 & 2000 & post-sonic & 0.78 & 3.1 & 9.6 \\
\hline
\end{tabular}


WTP-RPT-166, Rev. 0

Table 4.9. Particle Size Analysis Percentile Results of the Duplicate Group 2 Initial Characterization Sample, TI517-G1-S-WL-PSD-2

\begin{tabular}{||c|c|c|c|c|c||}
\hline $\begin{array}{c}\text { Measurement } \\
\text { Condition }\end{array}$ & Pump Speed & Sonication & $\begin{array}{c}\mathbf{d}(\mathbf{1 0 )} \\
{[\boldsymbol{\mu} \mathbf{m}]}\end{array}$ & $\begin{array}{c}\mathbf{d}(\mathbf{5 0}) \\
{[\boldsymbol{\mu} \mathbf{m}]}\end{array}$ & $\begin{array}{c}\mathbf{d}(\mathbf{9 0}) \\
{[\boldsymbol{\mu} \mathbf{m}]}\end{array}$ \\
\hline 1 & 3000 & pre-sonic & 0.83 & 3.5 & 14 \\
\hline 2 & 4000 & pre-sonic & 0.84 & 4.0 & 21 \\
\hline 3 & 2000 & pre-sonic & 0.85 & 3.6 & 13 \\
\hline 4 & 3000 & $25 \%$ & 0.86 & 3.6 & 12 \\
\hline 5 & 3000 & $50 \%$ & 0.86 & 3.6 & 12 \\
\hline 6 & 3000 & $75 \%$ & 0.85 & 3.6 & 11 \\
\hline 7 & 3000 & post-sonic & 0.84 & 3.5 & 11 \\
\hline 8 & 4000 & post-sonic & 0.85 & 3.5 & 11 \\
\hline 9 & 2000 & post-sonic & 0.87 & 3.7 & 13 \\
\hline \hline
\end{tabular}

Behavior of the duplicate sample PSD with respect to pump speed and sonication mirrors and confirms that of the primary sample. However, the PSD of the duplicate sample favors consistently larger diameters than that of the primary at equivalent measurement conditions. Table 4.10 shows the absolute relative percent difference between the $d(10), d(50)$, and $d(90)$ values determined for the primary and duplicate Group 2 initial characterization samples, as calculated by Eq. 3.1. The listed RPDs indicate that there is a slight difference between samples.

Table 4.10. Absolute Relative Percent Difference Between Primary and Duplicate Group 1 Initial Characterization Samples

\begin{tabular}{|c|c|c|c|c|c||}
\hline \multirow{2}{*}{$\begin{array}{c}\text { Measurement } \\
\text { Condition }\end{array}$} & \multirow{2}{*}{ Pump Speed } & \multirow{2}{*}{ Sonication } & \multicolumn{3}{|c||}{ Absolute RPD } \\
\cline { 5 - 6 } & Pum(10) & $\mathbf{d ( 5 0 )}$ & $\mathbf{d ( 9 0 )}$ \\
\hline 1 & 3000 & pre-sonic & $4.4 \%$ & $9.8 \%$ & $28 \%$ \\
\hline 2 & 4000 & pre-sonic & $4.3 \%$ & $15 \%$ & $63 \%$ \\
\hline 3 & 2000 & pre-sonic & $3.4 \%$ & $11 \%$ & $24 \%$ \\
\hline 4 & 3000 & $25 \%$ & $9.8 \%$ & $17 \%$ & $20 \%$ \\
\hline 5 & 3000 & $50 \%$ & $11 \%$ & $17 \%$ & $19 \%$ \\
\hline 6 & 3000 & $75 \%$ & $10 \%$ & $16 \%$ & $17 \%$ \\
\hline 7 & 3000 & post-sonic & $9.6 \%$ & $14 \%$ & $15 \%$ \\
\hline 8 & 4000 & post-sonic & $0.6 \%$ & $4.7 \%$ & $10 \%$ \\
\hline 9 & 2000 & post-sonic & $12 \%$ & $20 \%$ & $36 \%$ \\
\hline
\end{tabular}

For particle-size measurements on the Malvern Mastersizer 2000, RPDs of up to $10 \%$ are generally expected, given the accuracy of the instrument. The results for Group 2 initial characterization samples show RPDs that range from 1 to 63\%, depending on the measurement condition and percentile examined. Based on the large number of RPDs greater than 10\% in Table 4.10, it is likely that there is a significant size difference in the solids species in the primary and duplicate sample. The largest RPDs are observed in the before- and during-sonication measurement conditions; however, a significant number of the postsonication RPDs still exceed $10 \%$, indicating that sonication does not completely eliminate the size difference between the samples. The results indicate that duplicate sampling picked up a greater population of large particles, most likely in the form of particle aggregates. While sonication of the dispersions tends to eliminate some of the size disparity between primary and duplicate sample, it still 
remains a significant effect after sonication. The most consistent measurement state after sonication is that at 4000 RPM. Here, the RPDs are at or below the limit of measurement accuracy (10\%). This could suggest that the difference in primary and duplicate PSD is solely a result of particle aggregation and that high shear and sonication can eliminate this difference. However, this conclusion cannot be stated with confidence without additional PSD measurements to confirm it. Overall, there is a significant difference in the size of primary and duplicate Group 2 solids with respect to the limit of instrument accuracy.

Figure 4.11 and Figure 4.12 show how the differences in the primary and duplicate PSDs described in the preceding paragraphs manifest in the differential volume distributions. Figure 4.11 compares the primary and duplicate PSDs at 3000 RPM before sonication. With respect to the pre-sonication comparison, both distributions show the same trends in population with size, namely, a peak population at 2 to $3 \mu \mathrm{m}$ and a broad particle volume plateau over 2 to $6 \mu \mathrm{m}$. The primary difference is that the duplicate sample has a significantly increased population of 10 to $20 \mu \mathrm{m}$. This causes the larger percentiles observed in Table 4.9 (relative to those in Table 4.8) and >10\% RPDs in Table 4.10.

Figure 4.12 compares primary and duplicate distributions after sonication. It shows that the increased particle size observed in the duplicate sample before sonication is maintained after sonication. Overall, the primary and duplicate distributions show the same uni-modal peak centered around 3 to $5 \mu \mathrm{m}$ and spanning 0.3 to $\sim 25 \mu \mathrm{m}$. The main difference is that the duplicate distribution is shifted to larger particle diameters. From a qualitative aspect, the difference between the primary and duplicate distributions after sonication appears less than that before sonication (an observation confirmed by the results in Table 4.10). This supports the earlier assertion that the difference between samples may be in their state of particle aggregation.

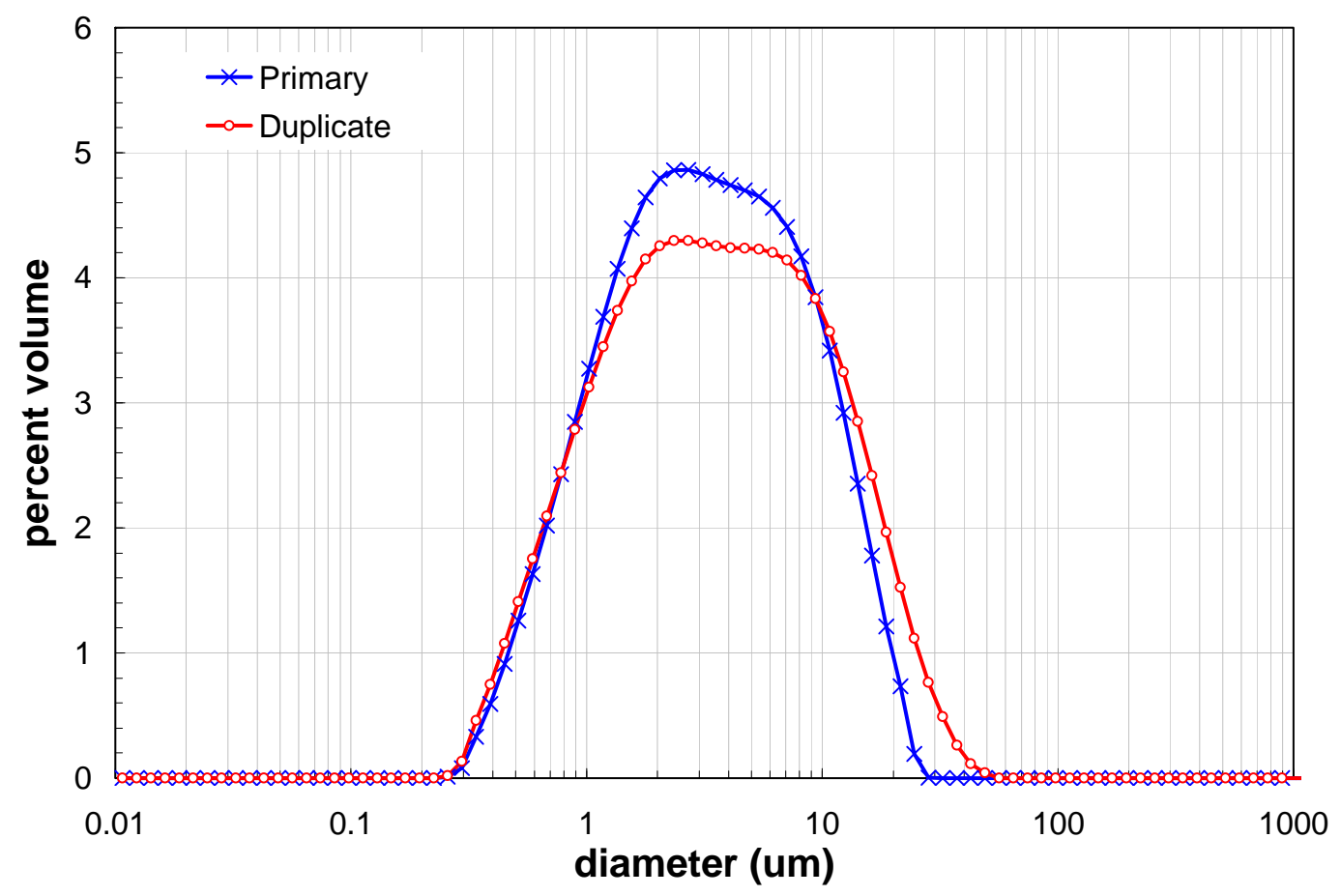

Figure 4.11. Comparison of Primary and Duplicate Sample Differential Volume PSD at 3000 RPM Before Sonication for the Group 2 Solids 


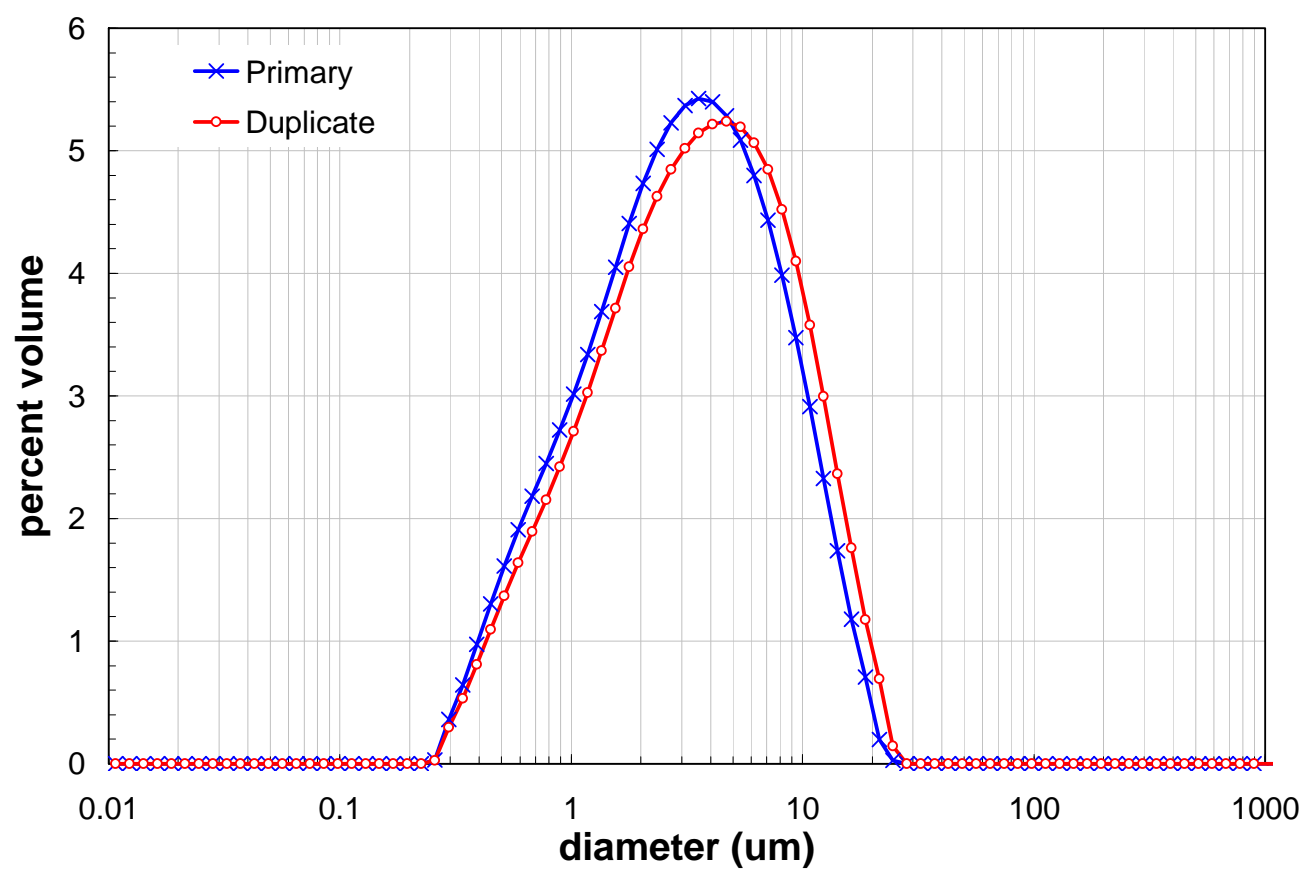

Figure 4.12. Comparison of Primary and Duplicate Sample Differential Volume PSD at 3000 RPM After Sonication for the Group 2 Solids

In summary, particle-size analysis of initial characterization Group 2 (bismuth phosphate saltcake) samples indicates a broad distribution of solids particle sizes ranging from $0.3 \mu \mathrm{m}$ to $\sim 30 \mu \mathrm{m}$ and also suggests the presence of a coarse, difficult-to-suspend fraction of material around $100 \mu \mathrm{m}$ in diameter. The initial distribution of solids is nearly uni-modal, with a peak population that ranges from 2 to $5 \mu \mathrm{m}$, depending on the pump speed used for measurement. Increases in pump speed appear to assist the suspension of large particles as evidenced by the increase in the mean particle diameter and the appearance of a small $\sim 100-\mu \mathrm{m}$ particle population peak as the pump speed was increased from 3000 to 4000 RPM. In-cell sonication of the Group 2 solids dispersion increases the central (2 to $6 \mu \mathrm{m}$ ) population of particles while also causing a slight increase in the population of sub-micrometer particles. Both changes are likely a result of particle aggregate disruption. This disruption is irreversible within the time-frame of analysis, as the PSD does not change measurably with time or pump speed after sonication is stopped.

\subsubsection{Surface Area}

A 57-mg sample was analyzed for surface area by BET with the following result: $46 \mathrm{~m}^{2} / \mathrm{g}$.

\subsubsection{Crystal Form and Habit}

The background-subtracted XRD pattern (rutile used as an internal standard) for Group 2 washed solids is provided in Figure 4.13. The crystalline phases identified were gibbsite $\left[\gamma-\mathrm{Al}(\mathrm{OH})_{3}\right.$, crystal density $2.42 \mathrm{~g} / \mathrm{cm}^{3}$, Wefers and Misra 1987], cancrinite $\left[\mathrm{Na}_{7.92}\left(\mathrm{AlSiO}_{4}\right)_{6}\left(\mathrm{NO}_{3}\right)_{1.7}\left(\mathrm{H}_{2} \mathrm{O}\right)_{2.34}\right.$, crystal density $2.414 \mathrm{~g} / \mathrm{cm}^{3}$, JADE Version 8.0, calculated value], and urancalcarite $\left[\mathrm{Ca}\left(\mathrm{UO}_{2}\right)_{3} \mathrm{CO}_{3}(\mathrm{OH})\left(\mathrm{H}_{2} \mathrm{O}\right)_{3}\right.$, crystal density $4.03 \mathrm{~g} / \mathrm{cm}^{3}$, JADE Version 8.0, calculated value]. Dorfmanite $\left[\mathrm{Na}_{2} \mathrm{HPO}_{4}\left(\mathrm{H}_{2} \mathrm{O}\right)_{2}\right.$, crystal density $2.07 \mathrm{~g} / \mathrm{cm}^{3}$, CRC 1978] was also identified. 
WTP-RPT-166, Rev. 0

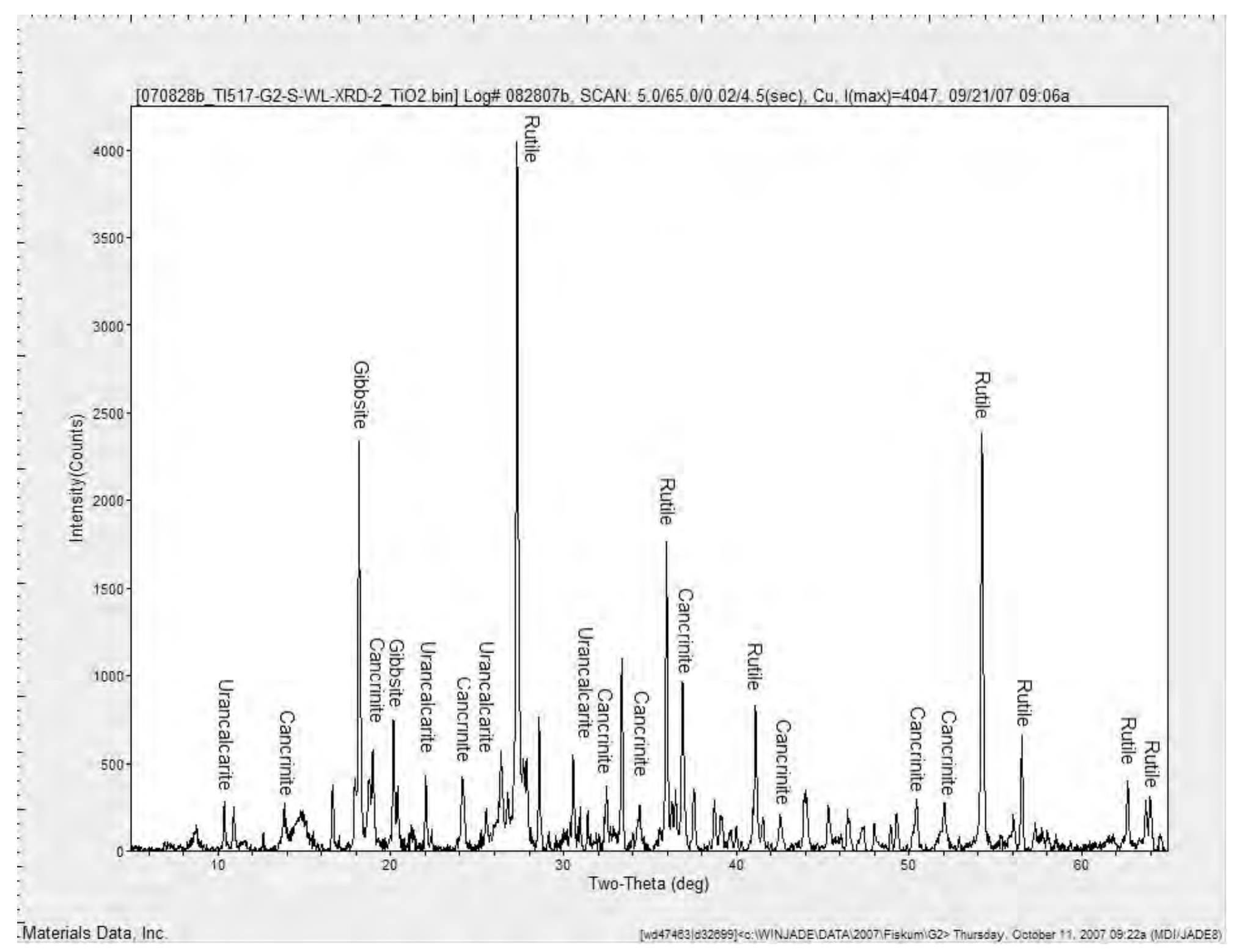

Figure 4.13. XRD Pattern of Washed Group 2 Solids, Background-Subtracted 
SEM, coupled with EDS, was used to obtain information regarding the particle morphology and elemental distribution within the Group 2 solid phases. Several SEM images of the washed solids are shown in Figure 4.14. Small particles appear to be agglomerating together to form a larger mass of solids.
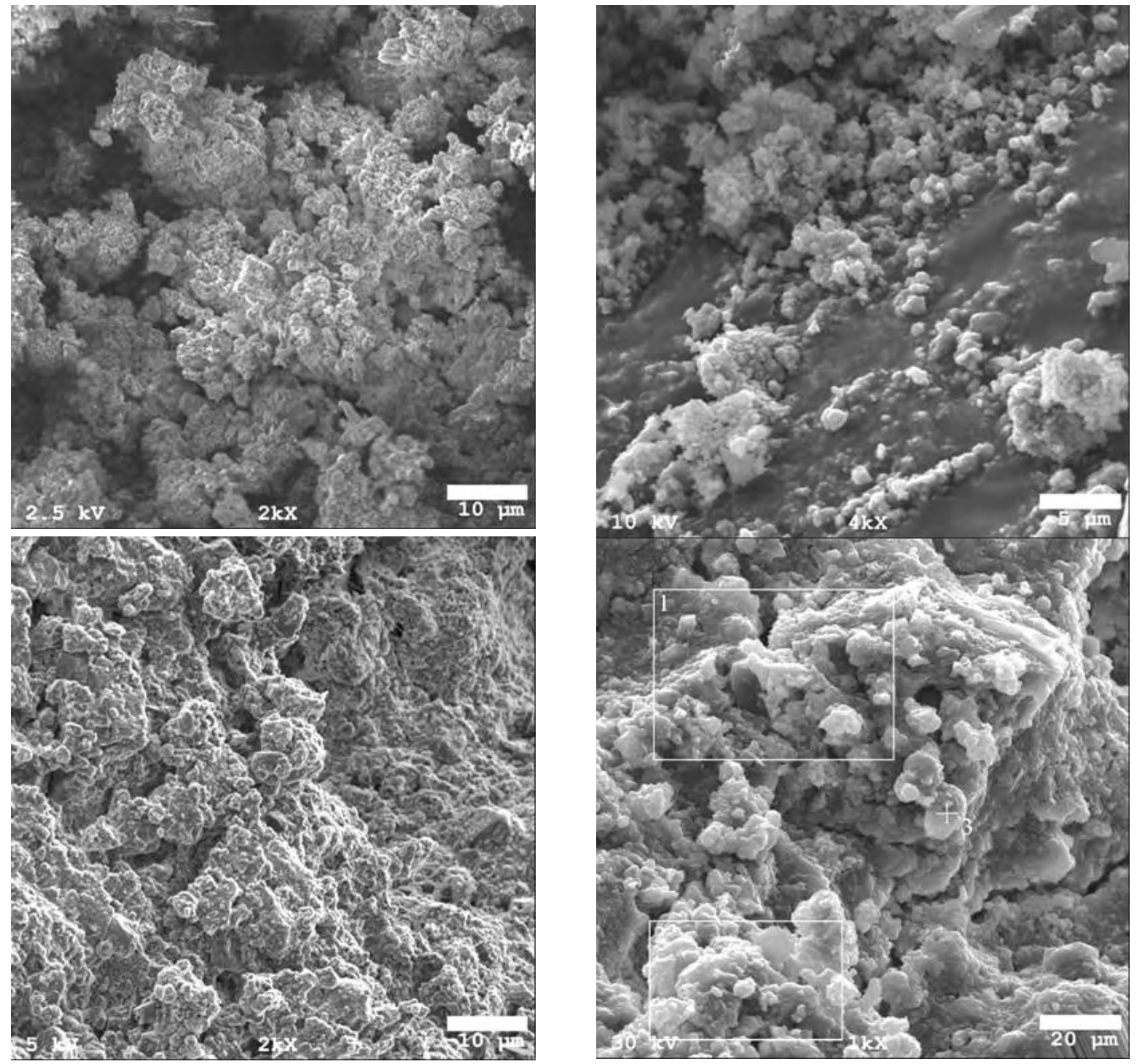

Figure 4.14. SEM Images of Group 2 Initial Characterization Solids

The EDS spectra of selected solids phases are shown in Figure 4.15. The spectrum indicates the presence of elements (Al, Na, Si, P, Cr, Ca, $\mathrm{U}$ and $\mathrm{Fe}$ ) that were identified in significant quantities in the ICP-OES analysis of the bulk material. Figure 4.16 shows an elemental map for the washed Group 2 solids. An item of note on this map is the close association of the $\mathrm{Na}, \mathrm{Al}, \mathrm{Si}$, and P. This is consistent with the XRD result indicating that the washed Group 2 solids contained cancrinite $\left[\mathrm{Na}_{7.92}\left(\mathrm{AlSiO}_{4}\right)_{6}\left(\mathrm{NO}_{3}\right)_{1.7}\left(\mathrm{H}_{2} \mathrm{O}\right)_{2.34}\right]$. The phosphorus could be contributed by entrained dorfmanite $\left[\mathrm{Na}_{2} \mathrm{HPO}_{4}\left(\mathrm{H}_{2} \mathrm{O}\right)_{2}\right]$. The other major components appear to be evenly distributed across the image, suggesting that these are likely present as the individual oxides or hydroxides that are intermingled together. 

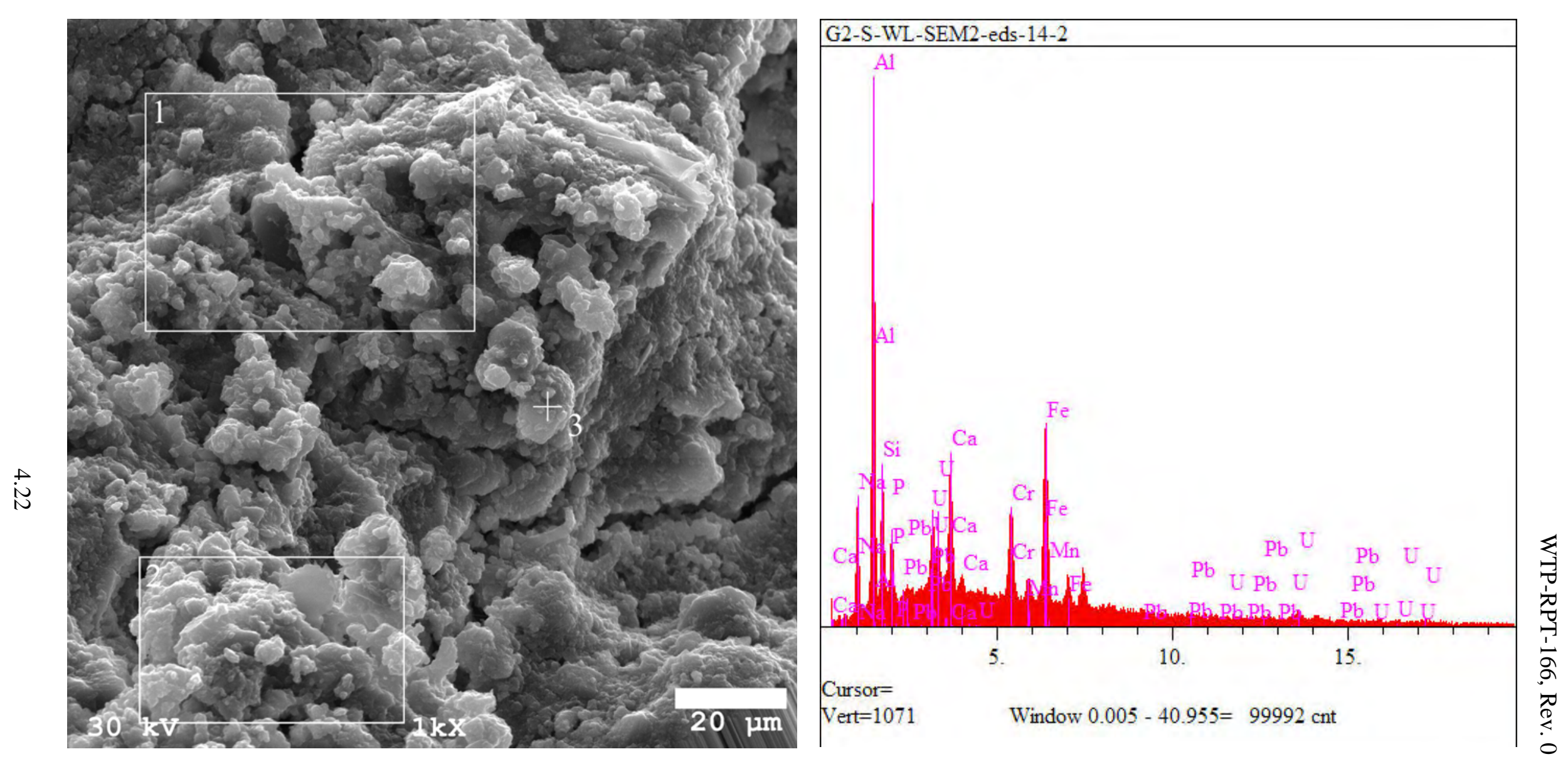

Figure 4.15. SEM-EDS Image Group 2 Initial Characterization Solids 


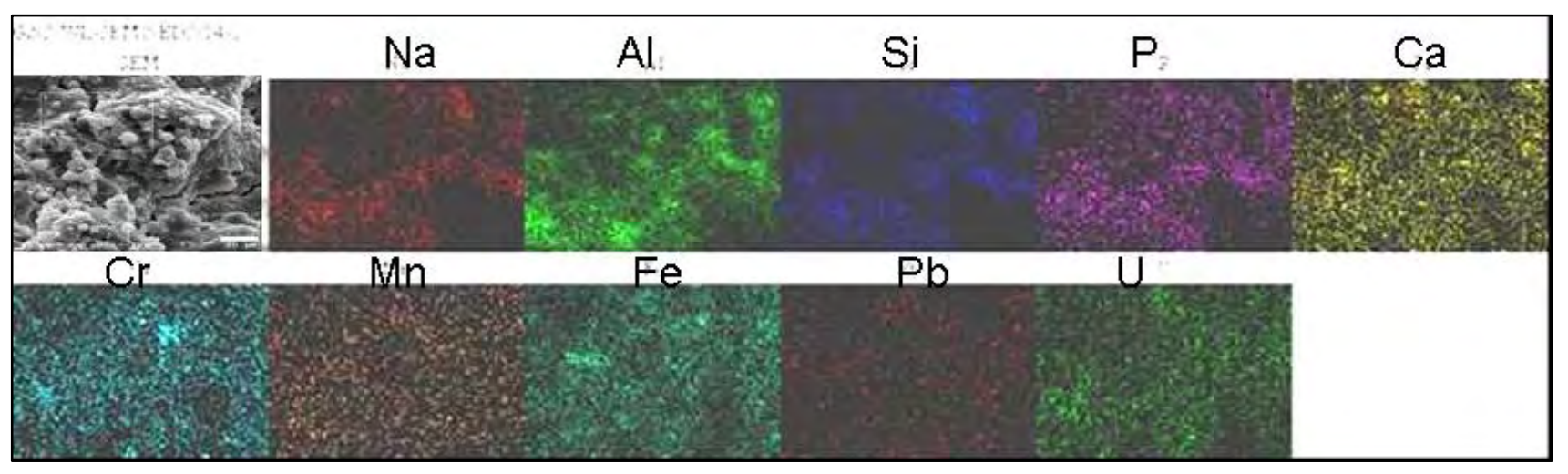

Figure 4.16. EDS Elemental Map of Group 2 Solids

TEM examination of the washed Group 2 solids revealed a number of different types of phases. A particle can be seen in the upper left-hand corner of Figure 4.17 that is a pure aluminum oxide or hydroxide material. Presumably, this particle is gibbsite, based on its shape and the XRD data discussed earlier. This gibbsite particle is on the order of $2 \mu \mathrm{m}$ in size. The material in the lower half of Figure 4.17 is primarily iron oxide, with some associated $\mathrm{Al}, \mathrm{Si}$, and $\mathrm{P}$. Whereas the iron oxide species in Figure 4.17 appears to consist of an agglomerate of submicron primary particles, the iron oxide particle shown in Figure 4.18 appears to be a single particle in excess of $5 \mu \mathrm{m}$ in length. The image at the lower right hand corner of Figure 4.18 shows an agglomeration of submicron particles with a rather broad distribution of elements including $\mathrm{Al}, \mathrm{Ca}, \mathrm{Cr}, \mathrm{Fe}, \mathrm{Si}$, and U. Figure 4.19 shows an expanded view of this agglomerate. The EDS spectra indicate that these agglomerated particles are mainly aluminosilicates, typically with incorporated transition metals, although the larger particle to the upper right in Figure 4.19 is relatively free of transition metals. Point 3 at the lower right hand portion of the figure is rich in Sr and Ca. 
WTP-RPT-166, Rev. 0

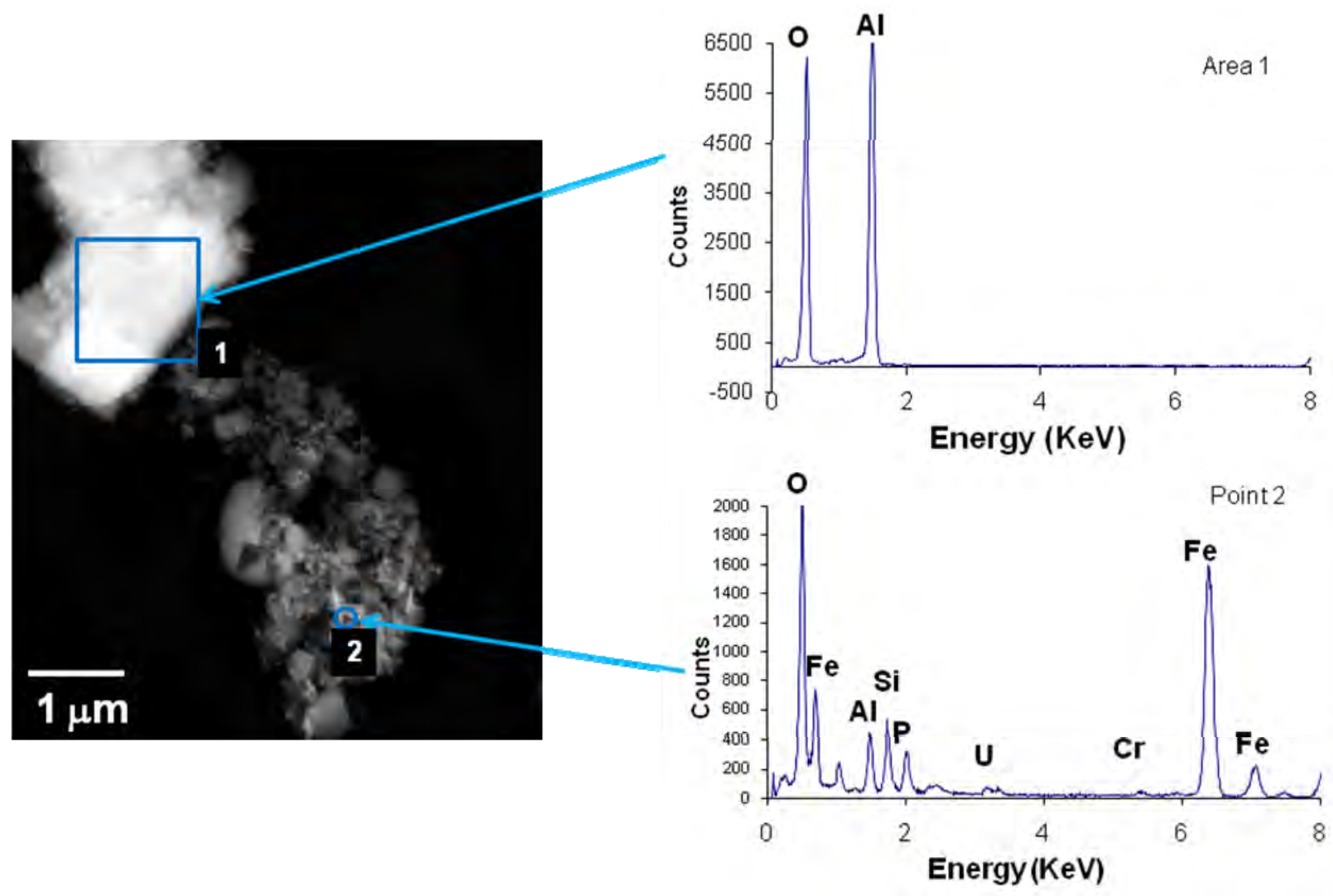

Figure 4.17. TEM Image of the Washed Group 2 Solids Indicating a Gibbsite Particle (upper left) and an Iron Oxide Particle (lower half) 


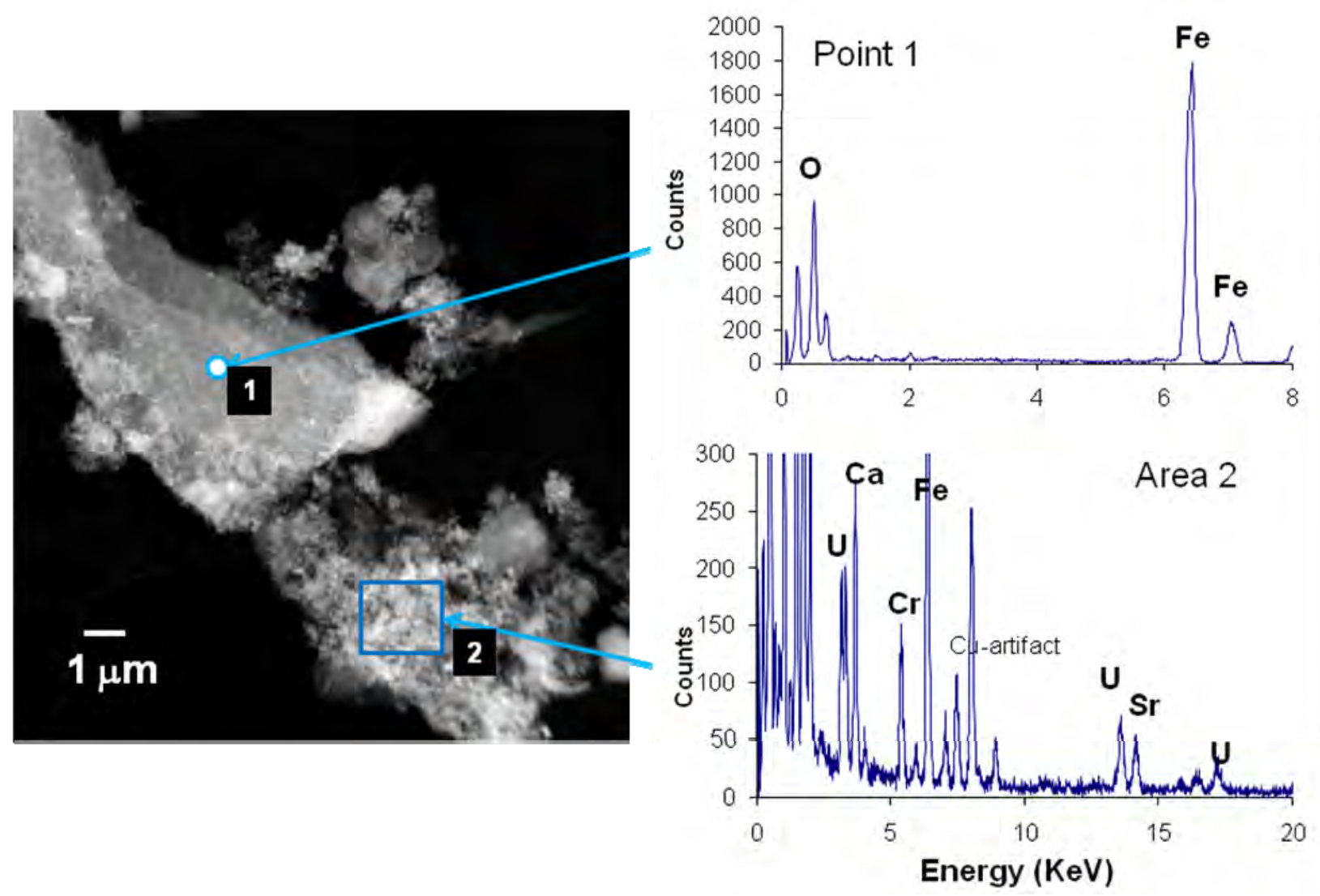

Figure 4.18. TEM Image of the Washed Group 2 Solids Indicating a Large Iron Oxide Particle (upper left) and an Agglomeration of Mixed Phases (lower right) 


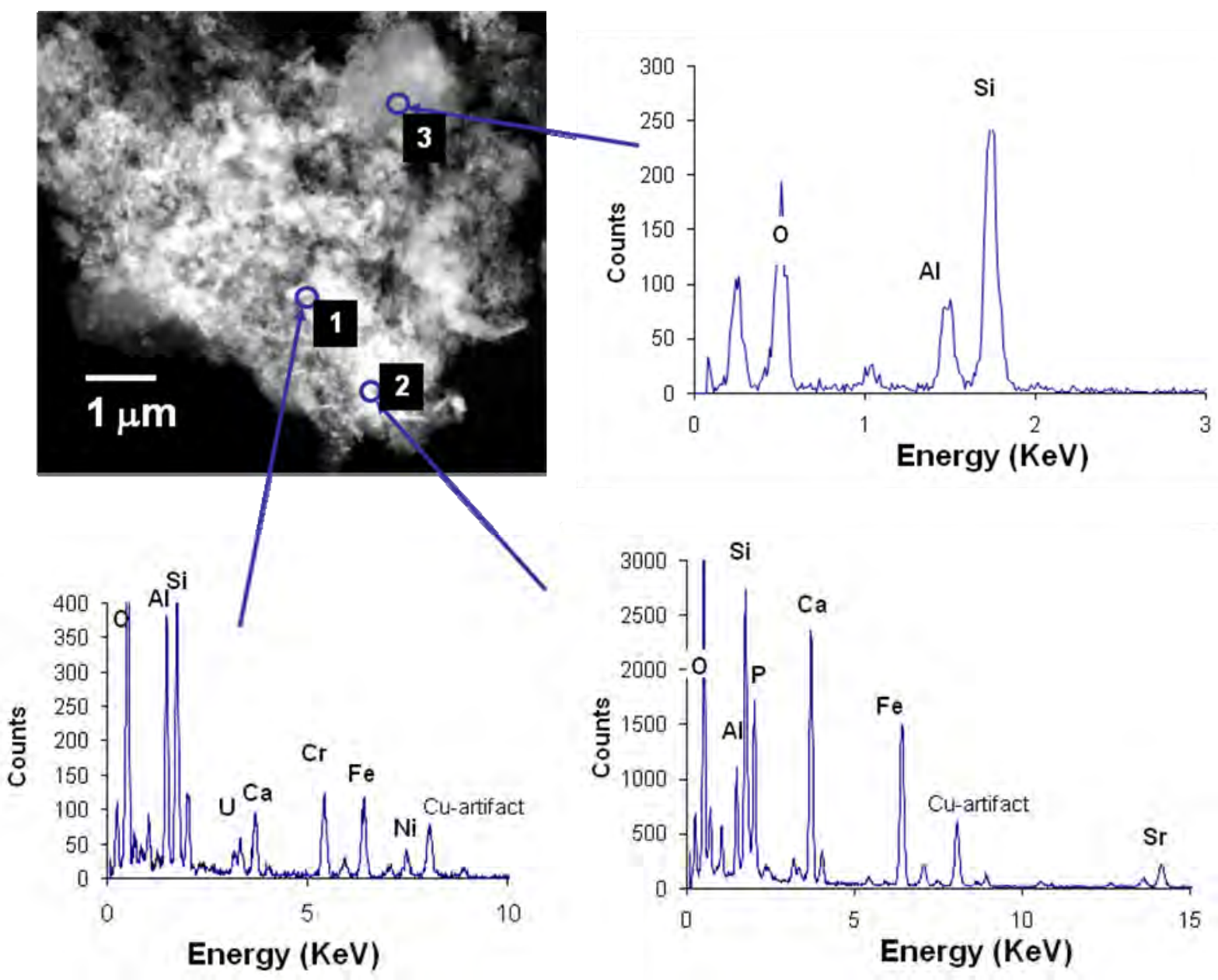

Figure 4.19. TEM Image of an Agglomeration of Mixed Phases in the Washed Group 2 Solids

Figure 4.20 shows a relatively pure phase containing oxygen, sodium, and phosphorus. This would be consistent with the mineral dorfmanite- $\mathrm{Na}_{2} \mathrm{HPO}_{4} \cdot 2 \mathrm{H}_{2} \mathrm{O}$ - which was also identified in the XRD pattern. The bright particle in the lower part of Figure 4.21 is a uranium-rich phase, predominantly a uranium oxide of some sort. The remaining material in Figure 4.21 is an aluminosilicate, probably dominated by cancrinite as was suggested by the XRD analysis. 

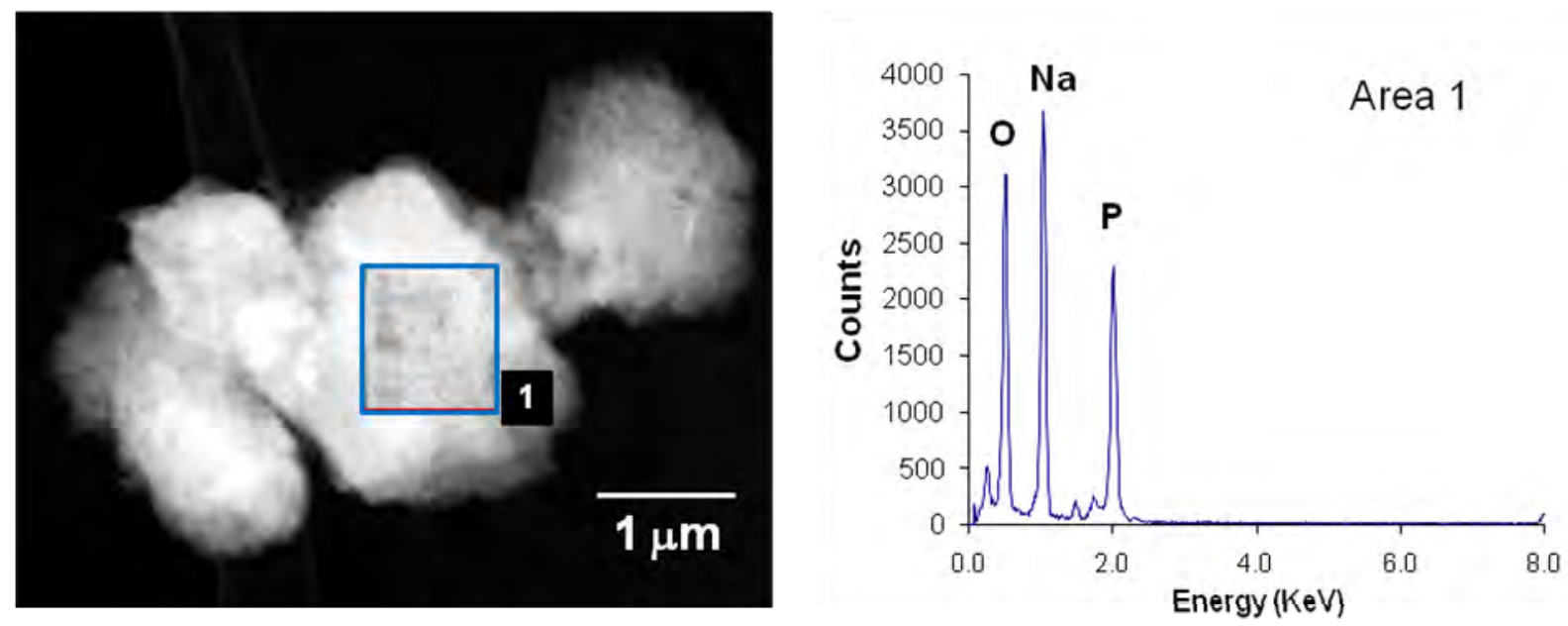

Figure 4.20. TEM Image of the Washed Group 2 Solids Indicating a Sodium Phosphate Phase, Presumably Dorfmanite
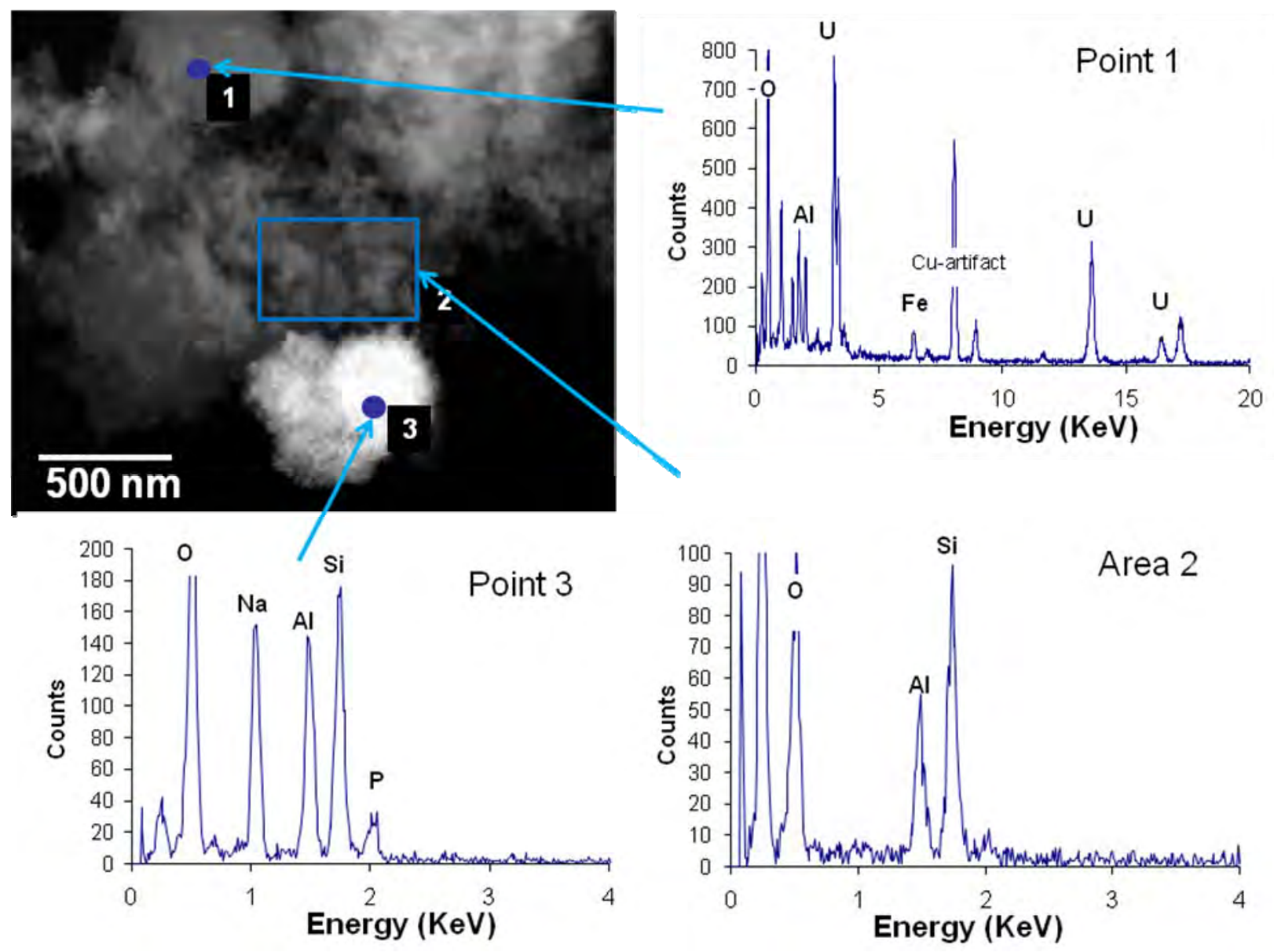

Figure 4.21. TEM Image of the Washed Group 2 Solids Indicating Aluminosilicate and Uranium-Rich Phases 
WTP-RPT-166, Rev. 0

\subsubsection{Vibrational Spectroscopy ${ }^{(a)}$}

In addition to the tools previously applied to characterize Hanford tank sludge solids, we are investigating the use of vibrational spectroscopic tools to further characterize the solids. Vibrational spectroscopy is complementary to the techniques described above and offers an advantage over diffraction techniques in that useful information can be obtained even if the sample is amorphous. The vibrational spectroscopic tools being used include FTIR and Raman spectroscopies. The sample of washed Group 2 solids that was used for the BET measurements (sample ID TI517-G2-S-WL-BET-1) was examined using FTIR spectroscopy, and the sample of Group 2 solids washed for the parametric leaching tests (sample ID TI517-G2-S-WL-B) was examined by Raman spectroscopy. In the case of the FTIR spectral measurement, a small portion of the Group 2 solids was placed directly on an attenuated total reflectance (ATR) cell equipped with a diamond ATR plate, and the spectrum was recorded with a Bruker ALPHA-P spectrometer (Bruker Optics, Billerica, Massachusetts). The Raman spectrum was recorded directly through a 2-Dram glass vial using an InPhotonics Model RS2000-3b-670 Raman spectrometer (Norwood, Massachusetts). The spectrometer was equipped with a fiber optic probe with a 670-nm excitation laser.

To assist in interpreting the vibrational spectra of the tank waste samples, spectra were recorded for a series of inorganic compounds that are likely to be present in the tank waste solids. Ultimately, we intend to create a searchable spectral library with the spectra of the known compounds that can be used to help determine the compounds present in the actual waste. However, for the Group 2 solids, we relied primarily on the above-described results (especially the XRD data) to help guide in interpreting the vibrational spectroscopic data.

The Raman spectrum of the washed Group 2 solids did not prove to be very informative, although there was clear evidence for the presence of gibbsite, based on the very distinctive pattern of four hydroxyl stretching bands at 3364, 3435, 3525, and $3619 \mathrm{~cm}^{-1}$. Figure 4.22 compares the FTIR spectrum of the washed Group 2 solids with a spectrum calculated assuming the presence of selected phases. The calculated spectrum was obtained in the following way. The FTIR spectral data for the compounds assumed to be present were imported into Microsoft Excel ${ }^{\mathrm{TM}}$. The composite spectrum of these species (for $\mathrm{n}$ species present) was taken as:

$$
\mathrm{A}=\sum_{i=1}^{n} \mathrm{~W}_{\mathrm{i}} \mathrm{A}_{\mathrm{i}}
$$

where $\mathrm{A}$ is the composite absorbance at a given wavelength, $\mathrm{A}_{\mathrm{i}}$ is the measured absorbance for species $i$ at that wavelength, and $\mathrm{w}_{\mathrm{i}}$ is the weighting factor for species $i$. The Solver function of Excel ${ }^{\mathrm{TM}}$ was used to minimize the sum of the squares of the residuals between the calculated and measured spectra, with the $\mathrm{W}_{\mathrm{i}}$ values being varied during the minimization process. The following compounds were included in the fitting procedure: gibbsite, nitrate cancrinite, $\mathrm{Na}_{2} \mathrm{HPO}_{4} \cdot 2 \mathrm{H}_{2} \mathrm{O}$, amorphous $\mathrm{FePO}_{4} \bullet \mathrm{xH}_{2} \mathrm{O}$, and $\mathrm{Na}\left[\mathrm{UO}_{2} \mathrm{PO}_{4}\right] \cdot 3 \mathrm{H}_{2} \mathrm{O}$. Gibbsite was obtained from a commercial supplier. The amorphous $\mathrm{FePO}_{4} \bullet \mathrm{xH}_{2} \mathrm{O}$ was prepared as described in Section 3.4.1. Nitrate cancrinite was prepared by a literature method (Liu et al. 2005), and its FTIR spectrum agreed very well with that reported in the literature. Dibasic sodium phosphate, $\mathrm{Na}_{2} \mathrm{HPO}_{4} \cdot 2 \mathrm{H}_{2} \mathrm{O}$, was prepared by slow evaporation of a solution of $\mathrm{Na}_{2} \mathrm{HPO}_{4}$ (dissolved as

(a) The vibrational spectroscopic results presented here are for indication only. 
$\mathrm{Na}_{2} \mathrm{HPO}_{4} \cdot 7 \mathrm{H}_{2} \mathrm{O}$ obtained from Aldrich Chemical Co.) at $59^{\circ} \mathrm{C}$ (Templeton et al. 1990). ${ }^{\text {(a) }}$ This species was included in the spectral fitting because of the evidence for dorfmanite in the XRD analysis. Sodium meta-autunite, $\mathrm{Na}\left[\mathrm{UO}_{2} \mathrm{PO}_{4}\right] \cdot 3 \mathrm{H}_{2} \mathrm{O}$, was previously prepared and characterized at PNNL (Wellman et al. 2005). During the fitting process, the Solver function indicated no significant contribution to the spectrum from $\mathrm{Na}_{2} \mathrm{HPO}_{4} \cdot 2 \mathrm{H}_{2} \mathrm{O}$ (i.e., the weighting factor for this compound was calculated to be zero), which calls into question the assignment of this phase in the XRD. So the calculated spectrum in Figure 4.22 contains contributions from gibbsite, cancrinite, amorphous $\mathrm{FePO}_{4} \cdot \mathrm{xH}_{2} \mathrm{O}$, and $\mathrm{Na}\left[\mathrm{UO}_{2} \mathrm{PO}_{4}\right] \cdot 3 \mathrm{H}_{2} \mathrm{O}$.

As can be seen from Figure 4.22, the calculated spectrum is in reasonable agreement with the measured spectrum, but the presence of gibbsite, cancrinite, amorphous $\mathrm{FePO}_{4} \bullet \mathrm{xH}_{2} \mathrm{O}$, and $\mathrm{Na}\left[\mathrm{UO}_{2} \mathrm{PO}_{4}\right] \cdot 3 \mathrm{H}_{2} \mathrm{O}$ does not represent a complete description of the Group 2 solids. In particular, the band at $991 \mathrm{~cm}^{-1}$ is not well reproduced in the calculated spectrum. This band is likely due to a phosphate species or a silicatecontaining compound. It could also be due to a carbonate species such as urancalcarite, $\mathrm{Ca}\left(\mathrm{UO}_{2}\right)_{3} \mathrm{CO}_{3}(\mathrm{OH})\left(\mathrm{H}_{2} \mathrm{O}\right)_{3}$, which was identified in the XRD analysis of the Group 2 solids. It would be useful to synthesize the latter compound and add this to the vibrational spectral library.

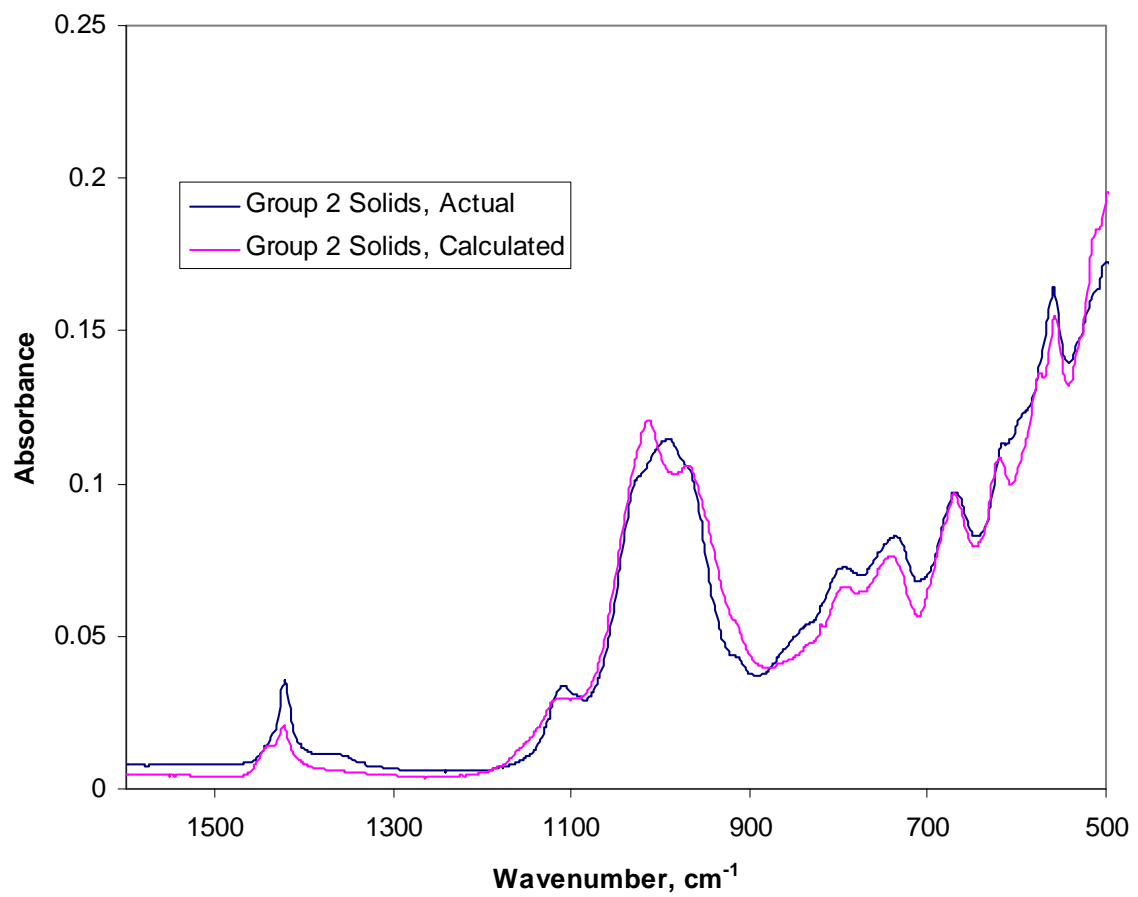

Figure 4.22. Measured and Calculated FTIR Spectrum of the Washed Group 2 Solids

(a) Although the literature indicated the material obtained in this manner should be the dorfmanite phase, $\mathrm{Na}_{2} \mathrm{HPO}_{4} \cdot 2 \mathrm{H}_{2} \mathrm{O}$, XRD analysis (for indication only) suggested the material was actually $87 \%$ anhydrous $\mathrm{Na}_{2} \mathrm{HPO}_{4}$ (nahpoite) and $13 \%$ dorfmanite. 


\subsection{Group 2 Batch Parametric Leaching: Experimental}

This section describes the methods used to conduct the leach testing for the Group 2 bismuth phosphate saltcake composite samples. Testing on the Group 2 solids focused on evaluating gibbsite leaching chemistry in actual tank waste. The composite material was rinsed with $0.01 \mathrm{M} \mathrm{NaOH}$, subdivided, and subjected to a parametric test matrix for caustic leach testing as discussed in the following sections. ${ }^{\text {(a) }}$

\subsubsection{Initial Washing of the Group 2 Solids}

The Group 2 composite solids sample was washed in the same manner as the Group 1 sample (Section 3.3.1). In this case, a 34.5-g aliquot of the homogenized slurry was removed with a large transfer pipet and transferred to a $200-\mathrm{mL}$ centrifuge bottle. At a concentration of $0.29 \mathrm{~g}$ dry water-insoluble solids per gram of slurry, the 34.5-g slurry contained $\sim 10$ g of water-insoluble solids. After centrifuging at $\sim 1200 \mathrm{G}$ for $15 \mathrm{~min}$, the supernatant liquid was removed, and the centrifuged solids volume was determined to be $\sim 15 \mathrm{~mL}$ based on volume graduations on the sample bottle. Approximately $45 \mathrm{~mL}$ (3× the centrifuged solids volume) of $0.01 \mathrm{M} \mathrm{NaOH}$ was added to wash the solids, and the slurry was mixed for 15 min with an overhead mixer. The slurry was centrifuged at $\sim 1200 \mathrm{G}$ for $15 \mathrm{~min}$, and then the supernatant was removed. The washing steps were repeated twice for a total of three washes.

\subsubsection{Division of the Washed Group 2 Solids}

To subdivide the washed Group 2 solids for the leaching tests, $100 \mathrm{~mL}$ of DI water was added to the solids. This resulted in a final volume of $\sim 110 \mathrm{~mL}$ (or $10 \mathrm{~g}$ solids in $112 \mathrm{~g}$ of slurry, equivalent to 8.9 wt\% UDS).

The thinned slurry was homogenized with an overhead mixer equipped with a 3-bladed stainless steel impeller. Seven 14 g slurry samples were transferred to 125-mL HDPE bottles with a large disposable polyethylene pipet. Each sample contained $\sim 1$ g UDS. The samples were removed from the hot cell for follow-on processing at the fume hood workstation.

One additional sample (549-G2-WL-Solids) containing approximately $3.9 \mathrm{~g}$ of slurry (equivalent to 0.34 g dry solids) was transferred to a 60-mL HDPE bottle. A portion of this sample was submitted for a $\mathrm{KOH}$ fusion and the following subsequent analyses: ICP-OES metals, GEA, Pu, total alpha, total beta, ${ }^{90} \mathrm{Sr}$, and $\mathrm{U}$ by KPA. These analyses were performed to establish the starting composition of the washed solids.

\subsubsection{Caustic Leaching of the Washed Group 2 Solids}

The leaching test matrix for the seven samples is summarized in Table 4.11. The test matrix evaluated the effects of free hydroxide concentration (1 to $5 \mathrm{M} \mathrm{NaOH}$ ) and temperature (60 to $100^{\circ} \mathrm{C}$ ) on gibbsite leaching kinetics.

(a) Testing was conducted according to TI-RPP-WTP-549, Parametric Caustic Leach Test of Group 2 Hanford BiPhosphate Saltcake Waste, L Snow, October 2007. 
Table 4.11. Group 2 Caustic Leaching Conditions

\begin{tabular}{|c|c|c|c|c|c|}
\hline \multirow[b]{2}{*}{ Bottle ID } & \multicolumn{2}{|c|}{ Free OH, M } & \multicolumn{2}{|c|}{ Na, M } & \multirow{2}{*}{$\begin{array}{c}\text { Temperature, } \\
{ }^{\circ} \mathbf{C}^{(\mathbf{b})}\end{array}$} \\
\hline & Target & Measured $^{(\mathrm{a})}$ & Target & Measured $^{(\mathrm{a})}$ & \\
\hline G2-60-3 & 3 & 3.04 & 3 & 3.19 & 60 \\
\hline G2-80-1 & 1 & 0.96 & 1 & 1.09 & 80 \\
\hline G2-80-3a & 3 & 2.99 & 3 & 3.16 & 80 \\
\hline G2-80-3b & 3 & 3.05 & 3 & 3.10 & 80 \\
\hline G2-80-3c & 3 & 3.01 & 3 & 3.03 & 80 \\
\hline G2-80-5 & 5 & 5.00 & 5 & 5.00 & 80 \\
\hline G2-100-3 & 3 & 3.09 & 3 & 3.29 & 100 \\
\hline \multicolumn{6}{|c|}{$\begin{array}{l}\text { (a) The measured analyte concentrations represent the equilibrium concentration } \\
\text { obtained after a } 24 \text {-h contact time. } \\
\text { (b) The temperature uncertainty was } \pm 2.5^{\circ} \mathrm{C} \\
\text { Analytical Service Request (ASR): } 8032\end{array}$} \\
\hline
\end{tabular}

The Group 2 leaching tests were conducted in the same manner as the Group 1 leaching tests (see Section 3.3.3). Sodium hydroxide ( $19 \mathrm{M}$ ) was added to each aliquot of washed solids slurry in the following amounts: $5.3 \mathrm{~mL}$ to yield $1 \mathrm{M} \mathrm{NaOH}, 15.8 \mathrm{~mL}$ to yield $3 \mathrm{M} \mathrm{NaOH}$, and $26.3 \mathrm{~mL}$ to yield $5 \mathrm{M} \mathrm{NaOH}$. The leaching mixtures were then diluted to a final volume of $100 \mathrm{~mL}$ (with an estimated uncertainty of 2 $\mathrm{mL}$ ) with DI water. The contact time with the concentrated $\mathrm{NaOH}$ was brief $(<5 \mathrm{~min})$. The remainder of the procedure was identical to that for the Group 1 tests.

The equilibrium concentration values for free hydroxide and sodium are shown in Table 4.11 and were based on results from the samples taken at 24 hours.

\subsubsection{Washing of Caustic-Leached Group 2 Solids for Analysis}

The solids from the triplicate samples (G2-80-3a, -3b, -3c, leached at $80^{\circ} \mathrm{C}$ in $3 \mathrm{M} \mathrm{NaOH}$ ) were prepared for characterization as shown in Figure 4.23. Again, the process followed was essentially the same as that for the leached Group 1 solids (Section 3.3.4). 


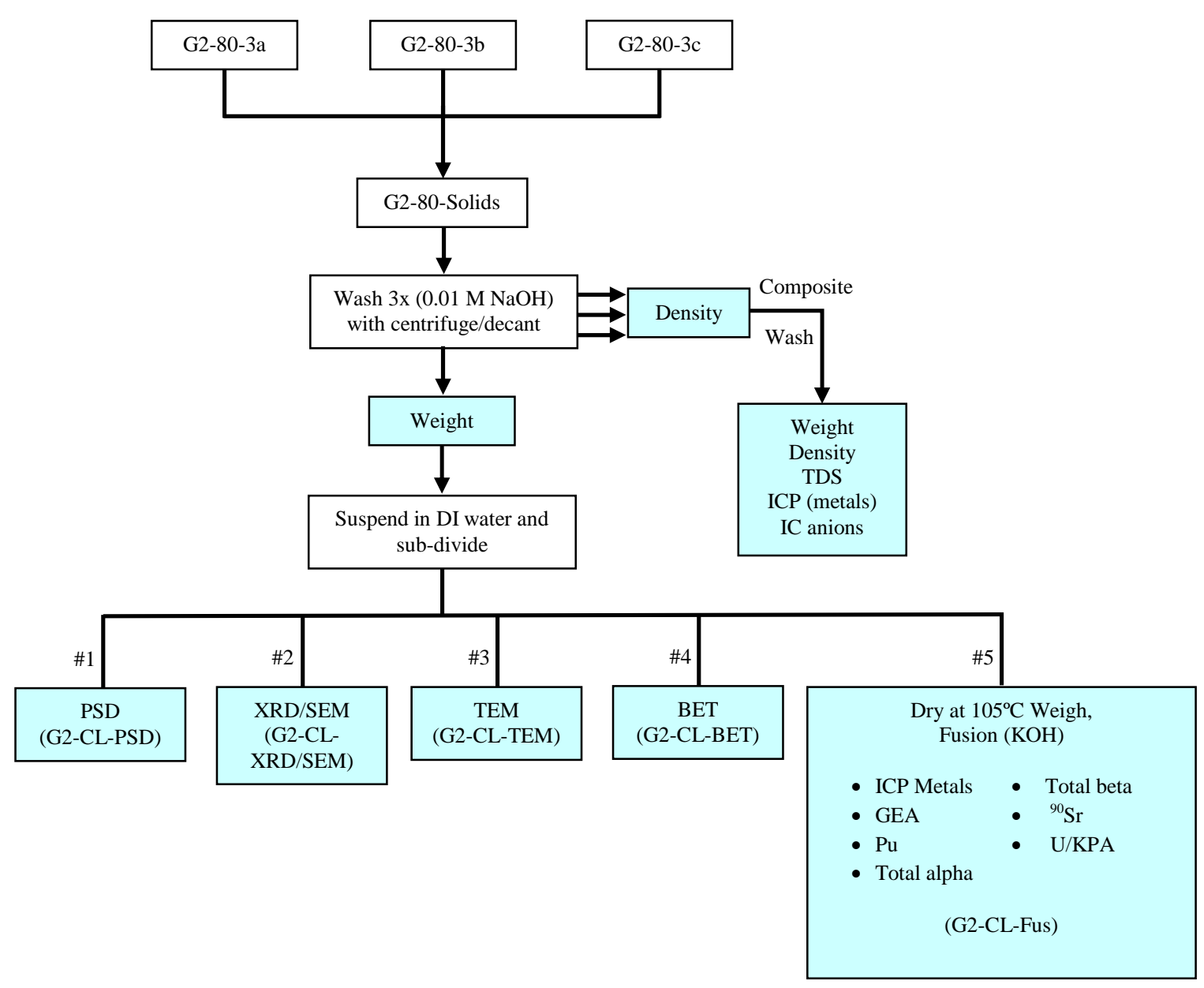

Figure 4.23. Washing, Subdivision, and Analysis Scheme for the Group 2 Caustic Leached Solids

\subsection{Group 2 Bi-Phosphate Saltcake Waste Parametric Caustic Leaching Test Results}

The water-insoluble component of the Group 2 waste sample contained $11.3 \mathrm{wt} \% \mathrm{Al}$ (as gibbsite, cancrinite, and urancalcarite) as well as $4.6 \mathrm{wt} \% \mathrm{P}$. Accordingly, the parametric caustic leach testing of this sample was directed toward understanding the gibbsite and phosphorus dissolution behavior for the actual tank waste to understand and subsequently match the dissolution properties to a stimulant material. The parametric leaching results and residual solids composition are discussed in the following sections.

\subsubsection{Time, Temperature, and Hydroxide Effects on Aluminum Dissolution from the Group 2 Solids}

The aluminum dissolution behavior for the washed Group 2 solids was evaluated as a function of time, temperature, and free-hydroxide concentration. Based on the total Al concentration in the solids material (149.5 $\mathrm{mg} \mathrm{Al} / \mathrm{g}$ ) and the wt\% UDS of the starting slurry (5.76\%), the complete dissolution of Al would result in a concentration of $1.21 \mathrm{mg} \mathrm{Al} / \mathrm{mL}$ or $0.0447 \mathrm{M}$ under the leaching conditions used in these experiments. This expected maximum concentration is about $20 \%$ less than the maximum $\mathrm{Al}$ concentration measured in the leachates $(0.056 \mathrm{M} \mathrm{Al})$. The reason for this discrepancy is not known. In 
this discussion, the reported wt\% of $\mathrm{Al}$ dissolved at each sampling point was calculated based on the final concentration in the triplicate solids samples, as discussed in Section 4.4.6.2.

The $\mathrm{Al}$ leaching data at a constant temperature of $80^{\circ} \mathrm{C}$ and the varying free-hydroxide concentrations are presented in Figure 4.24. The triplicate tests run at 3-M free hydroxide and $80^{\circ} \mathrm{C}$ provide a measure of experimental precision. The observed scatter in the data was within the analytical characterization uncertainty of $\pm 15 \%$.

There was only a slight dependence of Al dissolution on the hydroxide concentration. Dissolution had reached a steady-state in 4 to 8 hours. The rapid dissolution of the $\mathrm{Al}$ is consistent with the fast dissolution of gibbsite under these leaching conditions. The Al dissolution was similar in 3 and $5 \mathrm{M} \mathrm{NaOH}$, and only somewhat slower in $1 \mathrm{M} \mathrm{NaOH}$. However, the dissolution in all concentrations of $\mathrm{NaOH}$ reached a steady-state ( $\sim 60 \%$ dissolved) within $8 \mathrm{~h}$. Approximately $40 \%$ of the Al present in the washed Group 2 solids appears to be in the form of aluminosilicates, which is consistent with the high $\mathrm{Si}$ content found for the residual solids from leaching in $3 \mathrm{M} \mathrm{NaOH}$ at $80^{\circ} \mathrm{C}$. The $\mathrm{Al} / \mathrm{Si}$ molar ratio in $3 \mathrm{M}$ $\mathrm{NaOH} / 80^{\circ} \mathrm{C}$ leached-solids was 1.0 (vide infra) — consistent with a cancranite aluminosilicate phase. The $\mathrm{Al}$ present as aluminosilicate is not readily removed by caustic leaching at $80^{\circ} \mathrm{C}$ and up to $5 \mathrm{M} \mathrm{NaOH}$.

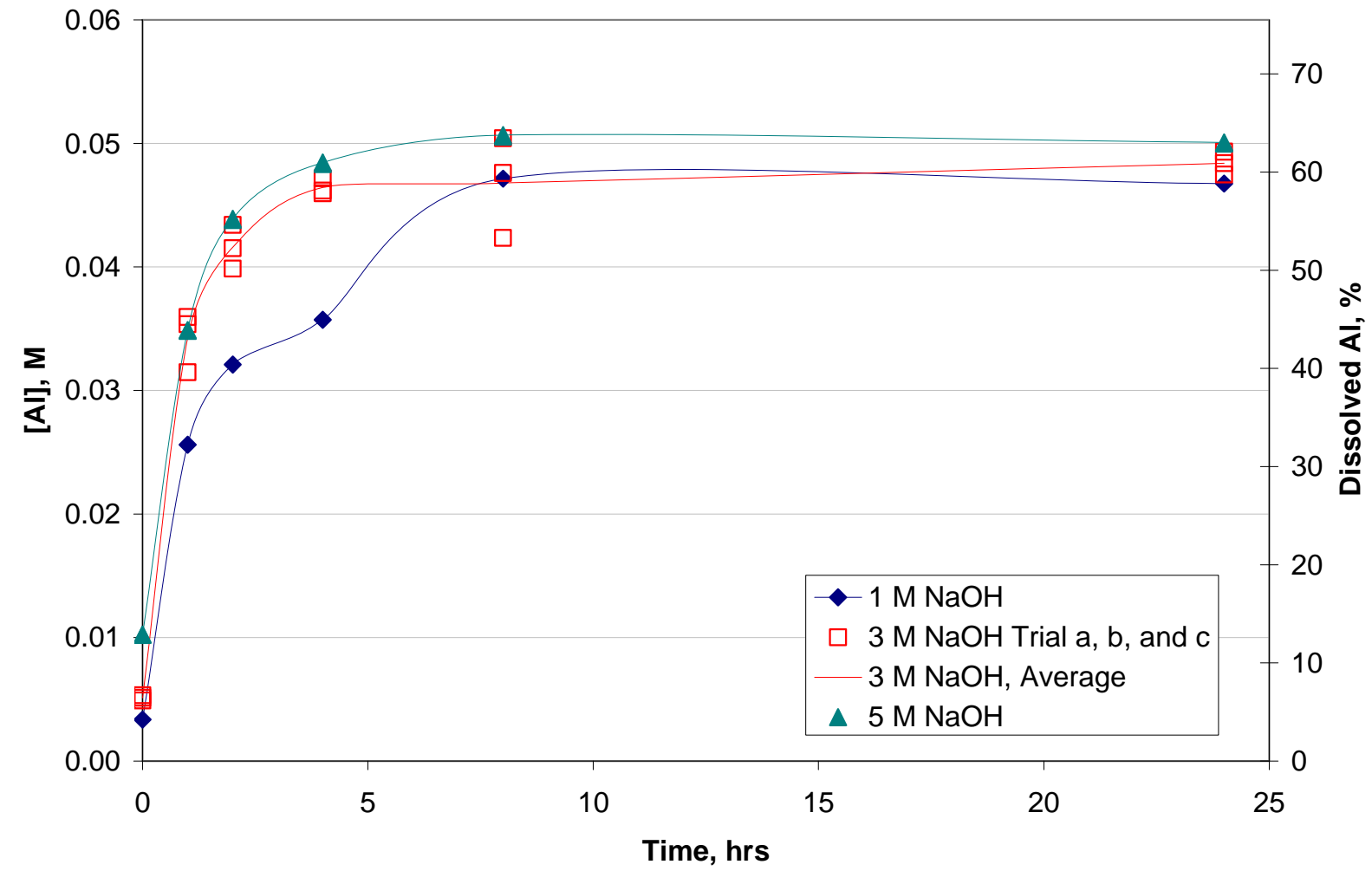

Figure 4.24. Aluminum Concentration Versus Time at $80^{\circ} \mathrm{C}$ Leach Temperature in 1,3 , and $5 \mathrm{M} \mathrm{NaOH}$ Solutions for Group 2, Bi-Phosphate Saltcake

The aluminum leaching data at a constant $\mathrm{NaOH}$ concentration of $3 \mathrm{M}$ at varying temperatures is summarized in Figure 4.25. There was some variability in the initial $(\mathrm{t}=0) \mathrm{Al}$ concentrations; this might have been due to variability in the initial sub-sampling or from differences introduced when the $\mathrm{NaOH}$ 
solution was first added to the sample (e.g., slight differences in the time interval between $\mathrm{NaOH}$ addition and dilution to $100 \mathrm{~mL}$ ). The data indicate a clear dependence of the Al dissolution rate on the temperature. The times to reach a steady-state $\mathrm{Al}$ concentration were 2,4 , and $>8$ (but less than 24 ) $\mathrm{h}$ at 100,80 , and $60^{\circ} \mathrm{C}$, respectively. Dissolution at 60 and $80^{\circ} \mathrm{C}$ reached approximately $60 \%$ dissolved after $24 \mathrm{~h}$, while approximately $70 \%$ of the $\mathrm{Al}$ was dissolved after $24 \mathrm{~h}$ at $100^{\circ} \mathrm{C}$. This suggests that $\sim 10 \%$ of the $\mathrm{Al}$ is in a form not readily removed at $80^{\circ} \mathrm{C}$, but can be dissolved by raising the temperature to $100^{\circ} \mathrm{C}$. The remaining $\sim 30 \%$ of the $\mathrm{Al}$ (presumably aluminosilicate) is resistant to removal by caustic leaching.

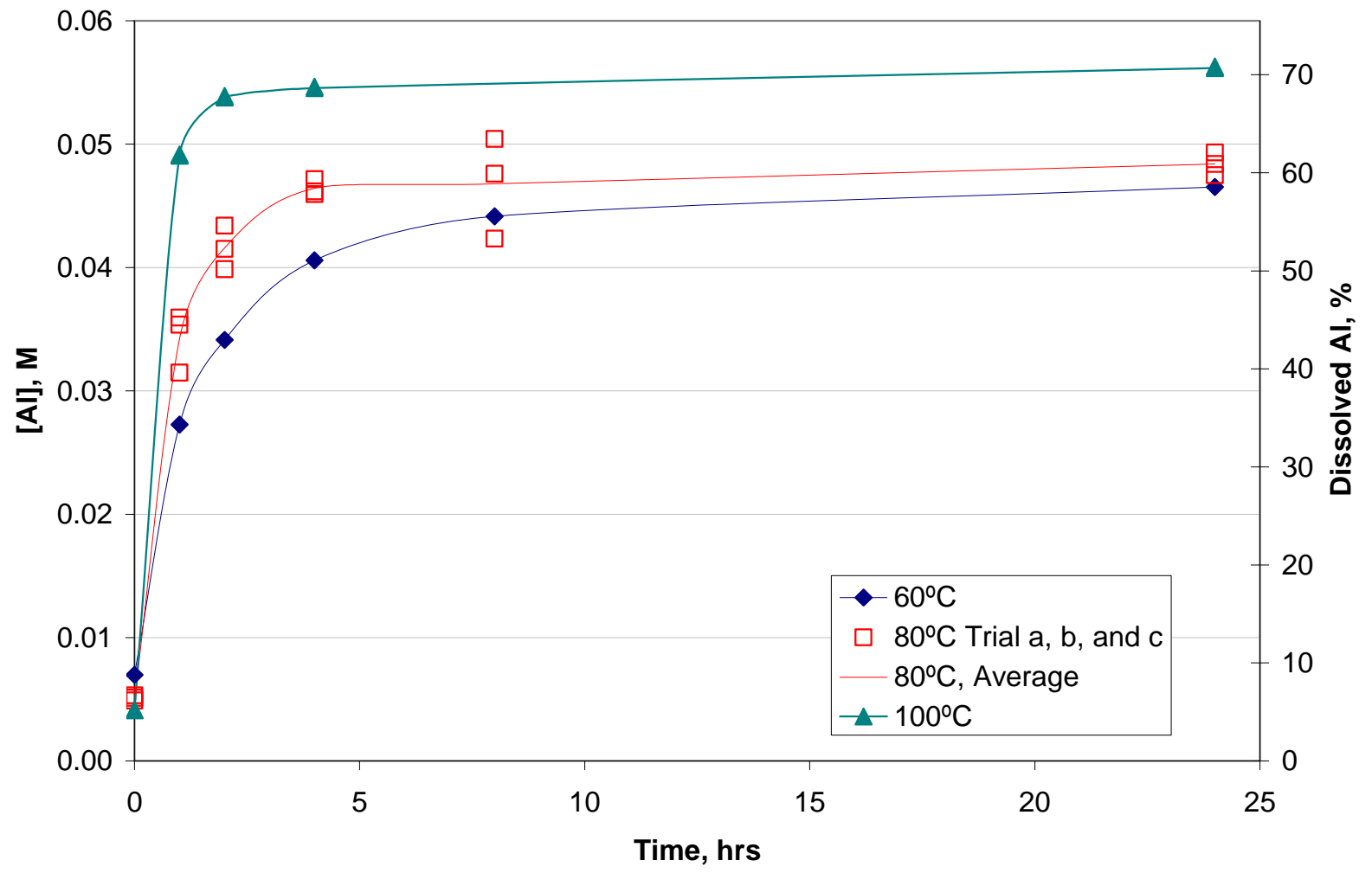

Figure 4.25. Aluminum Concentration and Percent Dissolved in $3 \mathrm{M} \mathrm{NaOH}$ for Group 2, Bi-Phosphate Saltcake. Note: the $8 \mathrm{~h} / 100^{\circ} \mathrm{C}$ data point is suspected to be inaccurate and so was not plotted here.

\subsubsection{Time, Temperature, and Hydroxide Effects on Chromium Dissolution}

The Cr dissolution behavior for the washed Group 2 solids was evaluated as a function of time, temperature, and free hydroxide concentration. The chromium leaching data at a constant temperature of $80^{\circ} \mathrm{C}$ and varying free-hydroxide concentrations is summarized in Figure 4.26. Again, the triplicate runs at $3 \mathrm{M}$ free hydroxide and $80^{\circ} \mathrm{C}$ provided a measure of experimental precision. The scatter in the data was within the analytical uncertainty of $\pm 15 \%$.

There was only a slight dependence of $\mathrm{Cr}$ dissolution on the hydroxide concentration. Unlike with the dissolution of $\mathrm{Al}$, Cr never reached a steady-state for leaching in 3 and $5 \mathrm{M} \mathrm{NaOH}$, rather the $\mathrm{Cr}$ removal gradually increased up to a value of $70 \%$ removed after 24 hours of leaching. This observation is 
consistent with oxidation of $\mathrm{Cr}(\mathrm{III})$ to $\mathrm{Cr}(\mathrm{VI})$ by adventitious oxygen present in the system. In the case of $1 \mathrm{M} \mathrm{NaOH}$, the $\mathrm{Cr}$ removal did appear to stabilize at only $45 \%$ after $8 \mathrm{~h}$ of leaching; continued leaching to $24 \mathrm{~h}$ under these conditions did not remove significantly more $\mathrm{Cr}$.

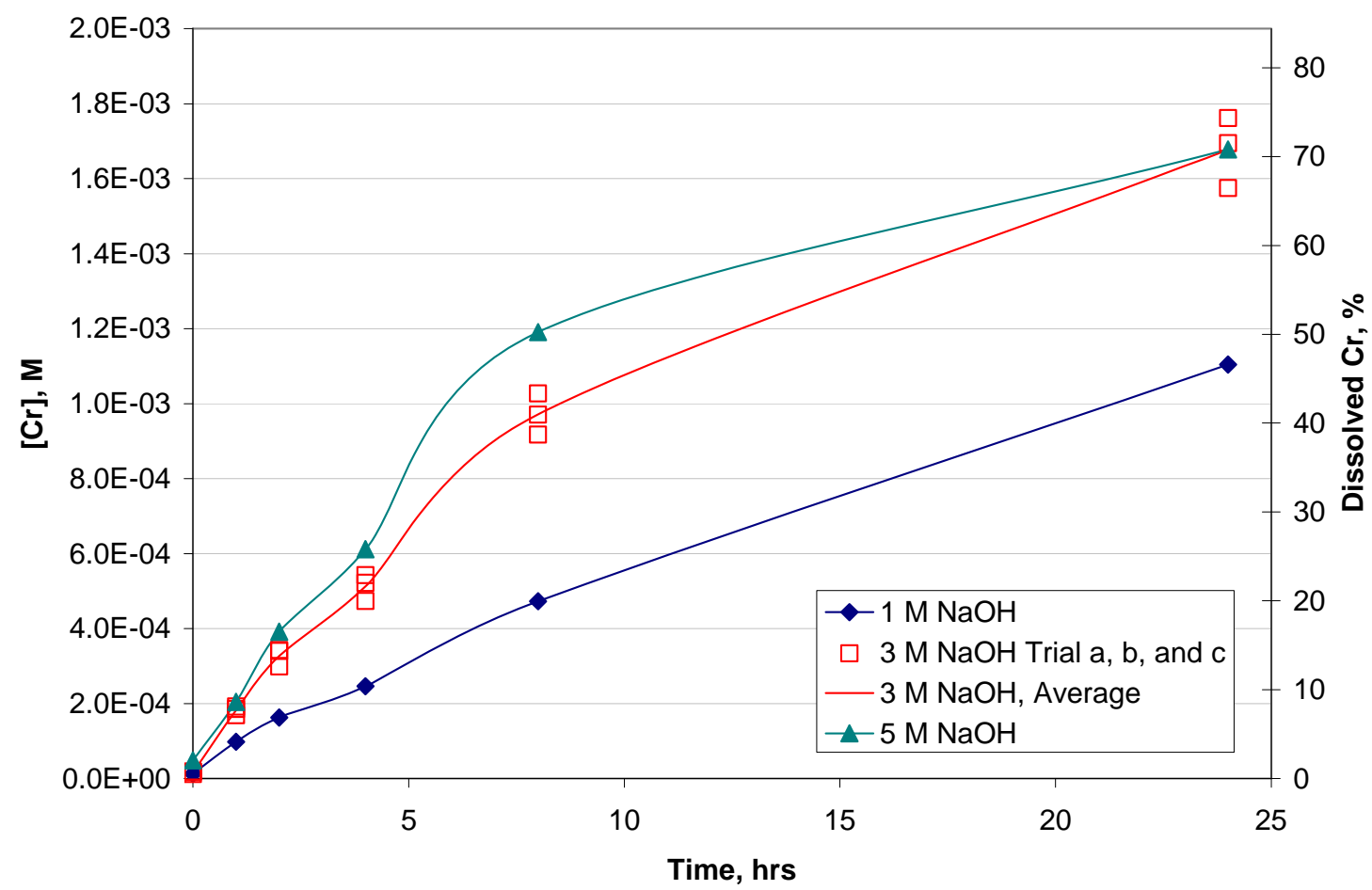

Figure 4.26. Chromium Concentration Versus Time at $80^{\circ} \mathrm{C}$ Leach Temperature in 1 , 3 , and $5 \mathrm{M} \mathrm{NaOH}$ Solutions for Group 2, Bi-Phosphate Saltcake

The chromium leaching data at a constant $\mathrm{NaOH}$ concentration of $3 \mathrm{M}$ at varying temperatures is summarized in Figure 4.27. These data indicate that the $\mathrm{Cr}$ removal is strongly temperature dependent. Under the leaching conditions of $80^{\circ} \mathrm{C}$ in $3 \mathrm{M} \mathrm{NaOH}$, Cr would be the limiting component for the formation of glass waste forms. For $\mathrm{Al}$ to be the limiting component, $85 \%$ of the $\mathrm{Cr}$ needs to be removed from the water-insoluble Group 2 solids under these leaching conditions. Dissolution at $80^{\circ} \mathrm{C}$ reached approximately $70 \%$ dissolved after $24 \mathrm{~h}$, while only $30 \%$ of the $\mathrm{Cr}$ was dissolved after $24 \mathrm{~h}$ at $60^{\circ} \mathrm{C}$. Unfortunately, the $\mathrm{Cr}$ removed at the baseline condition of leaching at $100^{\circ} \mathrm{C}$ for $8 \mathrm{~h}$ could not be confidently evaluated because the measured Cr value $\left(2.3 \times 10^{-3} \mathrm{M}\right)$ is suspected to be inaccurate. This value is suspect because of the low aliquot mass recorded for the sample that was analyzed. If the measured value is correct, it would indicate $\sim 90 \% \mathrm{Cr}$ removal under these conditions. However, if it is assumed that the $\mathrm{Al}$ concentration at $8 \mathrm{~h} / 100^{\circ} \mathrm{C}$ is the same as that at $4 \mathrm{~h}$ (which is reasonable based on Figure 4.25), the "correct" Cr concentration can be estimated to be $1.8 \times 10^{-3} \mathrm{M}^{(\mathrm{a})}$ The latter value corresponds to $\sim 76 \% \mathrm{Cr}$ removed.

(a) The measured $\mathrm{Cr}$ concentration at $8 \mathrm{~h} / 100^{\circ} \mathrm{C}$ was $120 \mu \mathrm{g} / \mathrm{mL}$. Since the $\mathrm{Al}$ concentration at $4 \mathrm{~h}$ was measured to be $1472 \mu \mathrm{g} / \mathrm{mL}$, and that at $8 \mathrm{~h}$ was measured to be $1908 \mu \mathrm{g} / \mathrm{mL}$, the corrected 8-h Cr concentration can be estimated as follows:

Cr corrected $=(120 \mu \mathrm{g} / \mathrm{mL})(1472 / 1908)=92.6 \mu \mathrm{g} / \mathrm{mL}$ or $1.8 \times 10^{-3} \mathrm{M}$ 
Assuming the mechanism of $\mathrm{Cr}$ removal in caustic leaching to be due to oxidation by adventitious oxygen, the rate of air oxidation of the $\mathrm{Cr}$ in the washed Group 2 solids was much faster than that observed for the air oxidation of $\mathrm{Cr}$ in the Group 6 sample (Fiskum et al. 2008), where the sample was $38 \% \mathrm{Cr}$, and the caustic leach factor was only 0.04 . In comparison, the Group 2 sample is only $25 \% \mathrm{Cr}$, and the caustic leach factor is 0.7. Depending on what the sample is blended with during leaching, it could still require oxidative leaching. Either $\mathrm{Al}$ or $\mathrm{Cr}$ will be the limiting component for the formation of glass waste forms.

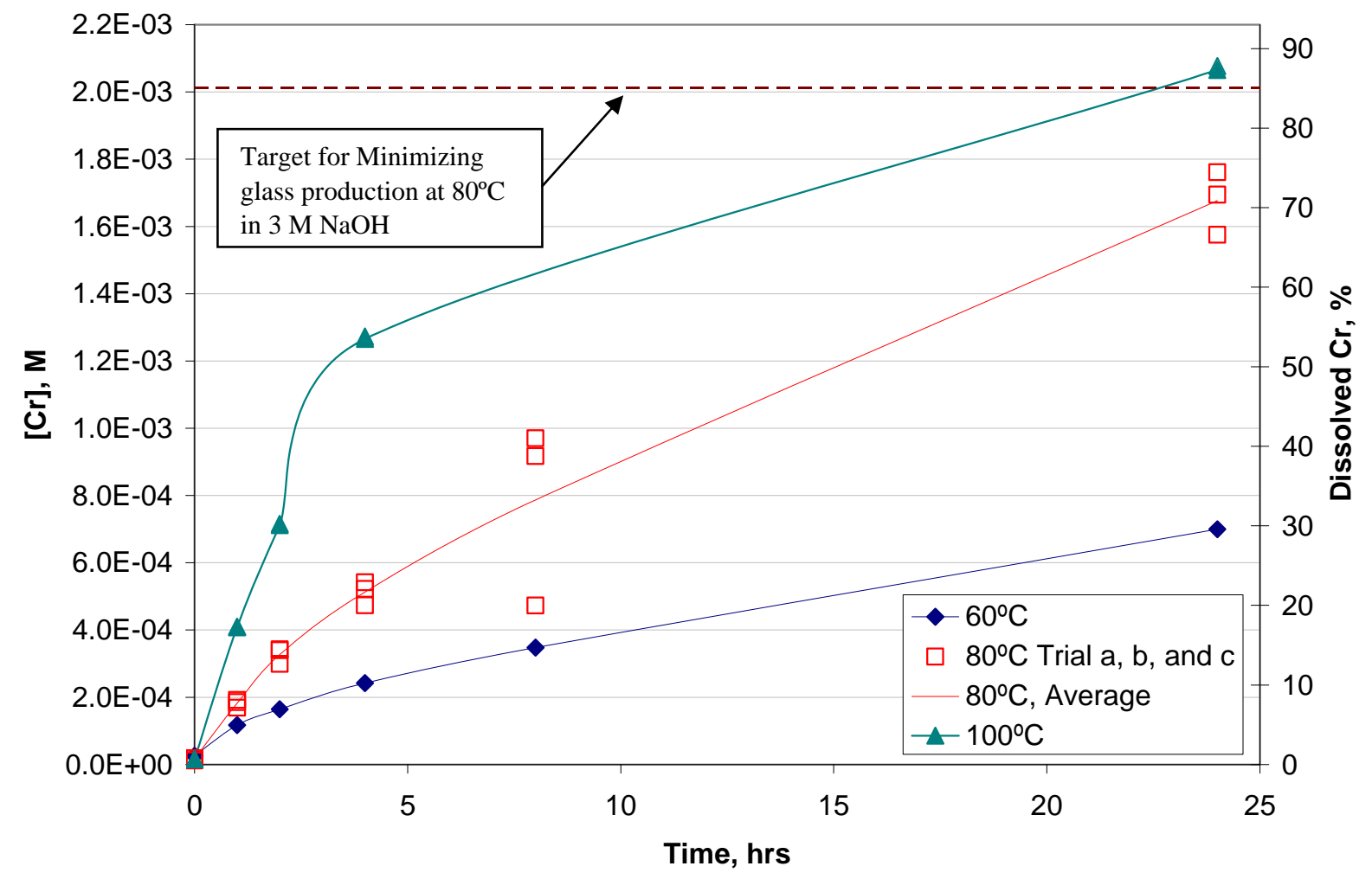

Figure 4.27. Chromium Concentration and Percent Dissolved in $3 \mathrm{M} \mathrm{NaOH}$ for Group 2, Bi-Phosphate Saltcake. Note: the $8 \mathrm{~h} / 100^{\circ} \mathrm{C}$ data point is suspected to be inaccurate and so was not plotted here.

\subsubsection{Time, Temperature, and Hydroxide Effects on Phosphorus Dissolution}

The P dissolution behavior for the washed Group 2 solids was evaluated as a function of time, temperature, and free hydroxide concentration. The P leaching data at a constant temperature of $80^{\circ} \mathrm{C}$ and varying free-hydroxide concentrations is summarized in Figure 4.28. Again, the triplicate runs at $3 \mathrm{M}$ free hydroxide and $80^{\circ} \mathrm{C}$ provided a measure of experimental precision.

There was only a slight dependence of P dissolution on the hydroxide concentration. Unlike with the dissolution of $\mathrm{Al}, \mathrm{P}$ never reached a steady-state during the leaching process. The $\mathrm{P}$ data were rather scattered, above the analytical uncertainty of $\pm 15 \%$ for the triplicate samples. All data showed some 
scatter, with the amount of $\mathrm{P}$ in solution seeming to be nearly the same from the time $=0$ point to the time $=24 \mathrm{~h}$ point .

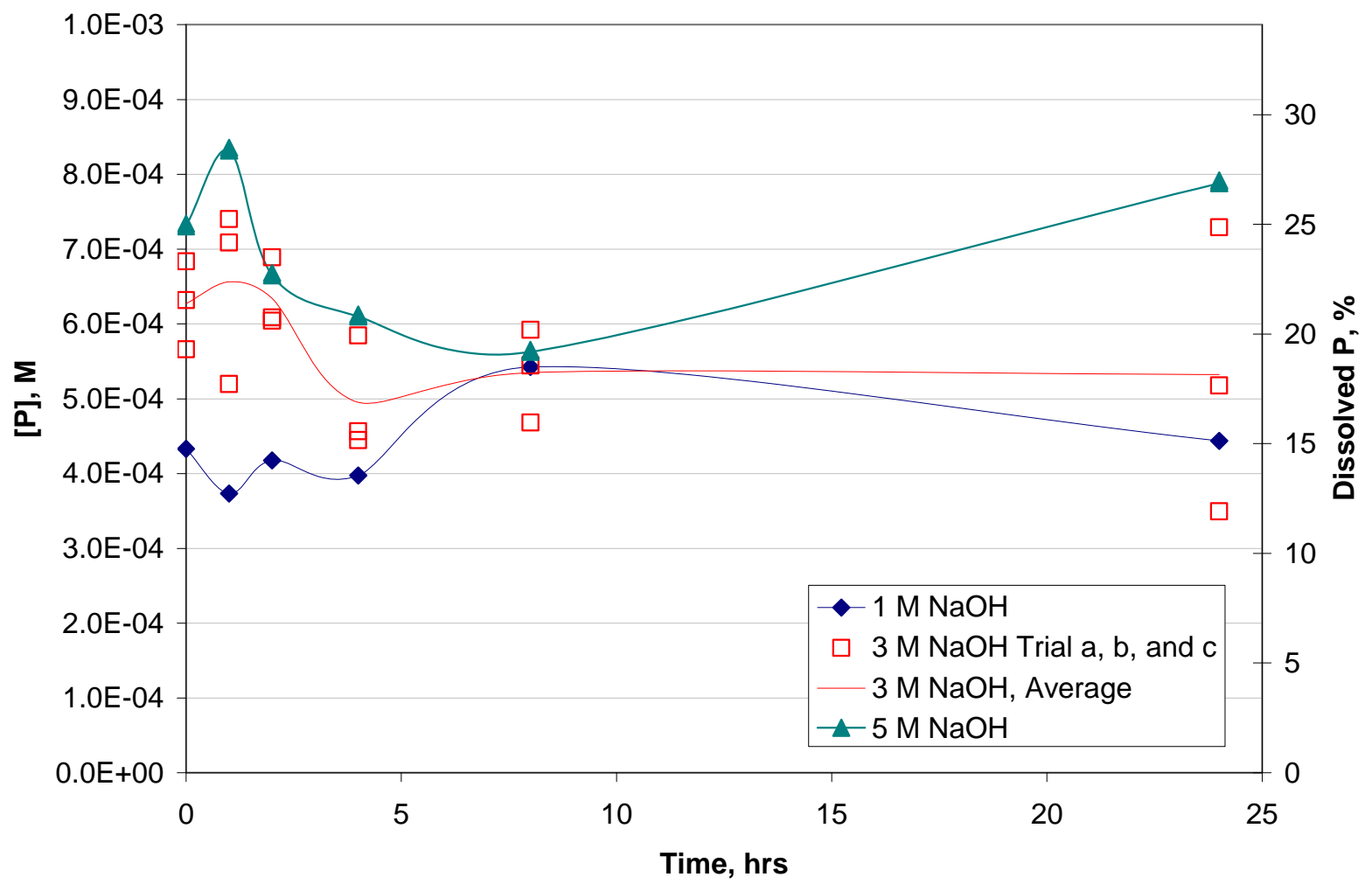

Figure 4.28. Phosphorus Concentration Versus Time at $80^{\circ} \mathrm{C}$ Leach Temperature in 1,3 , and $5 \mathrm{M}$ $\mathrm{NaOH}$ Solutions for Group 2, Bi-Phosphate Saltcake

The $\mathrm{P}$ leaching data at a constant $\mathrm{NaOH}$ concentration of $3 \mathrm{M}$ at varying temperatures is summarized in Figure 4.29. Because of the scatter in the data, it is somewhat difficult to draw any conclusions from these results. The apparent initial drop in the $\mathrm{P}$ concentration, followed by a subsequent rise, is particularly difficult to explain. Comparison of the final $\mathrm{P}$ concentrations at $60^{\circ} \mathrm{C}$ versus $100^{\circ} \mathrm{C}$ does suggest that the $\mathrm{P}$ removal is dependent on temperature. However, the maximum $\mathrm{P}$ removal was $23 \%$; obtained by leaching in $3 \mathrm{M} \mathrm{NaOH}$ at $100^{\circ} \mathrm{C}$. In this respect, the $\mathrm{P}$ behavior in the Group 2 solids is much different than that for the Group 1 solids. That is, the bulk of the P present in the Group 2 solids is resistant to removal by caustic leaching, whereas $\mathrm{P}$ was removed from the Group 1 solids under relatively mild conditions. 


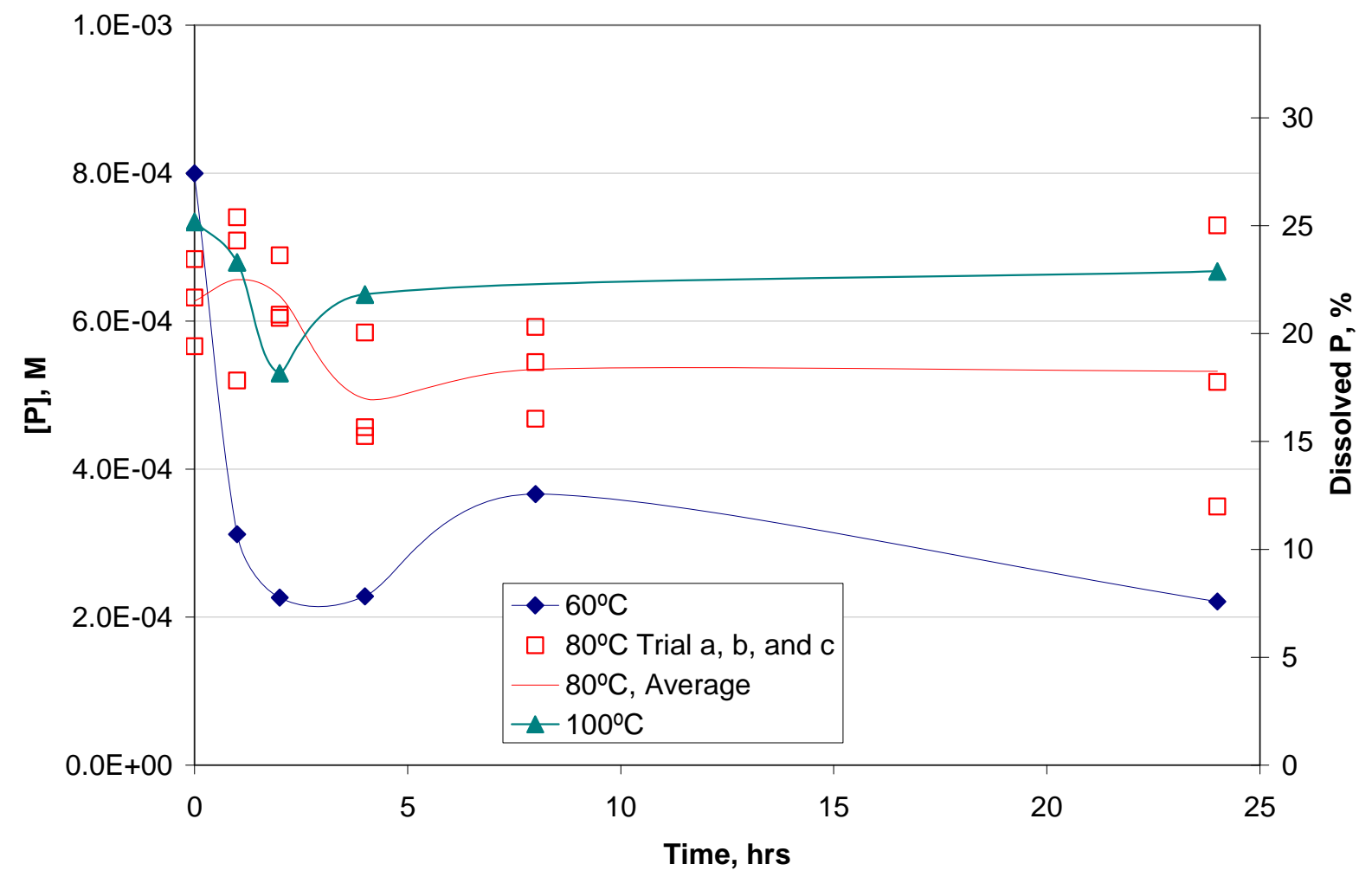

Figure 4.29. Phosphorus Concentration and Percent Dissolved in $3 \mathrm{M} \mathrm{NaOH}$ for Group 2, Bi-Phosphate Saltcake. Note: the $8 \mathrm{~h} / 100^{\circ} \mathrm{C}$ data point is suspected to be inaccurate and so was not plotted here.

\subsubsection{Anion, Silicon, and Iron Leach Behavior}

The concentration of Si was measured opportunistically by ICP-OES. The anionic compositions were also assessed at each sampling period. Anion and Si concentrations in the leachate did not significantly change during the leach testing. The results are summarized in Appendix J.

Iron concentrations were also measured opportunistically by ICP-OES. The Fe concentrations in the leachates were variable. However, they appeared to generally increase relative to the first sampling period at $0 \mathrm{hr}\left(<5 \times 10^{-5} \mathrm{M} \mathrm{Fe}\right)$ to the 24-hr sampling period $\left(\sim 1 \times 10^{-4} \mathrm{M} \mathrm{Fe}\right)$.

\subsubsection{Assessment of Final Leach Conditions}

A summary of the final (24-h) leach-solution chemistry and physical parameters is shown in Table 4.12. The final free-hydroxide and sodium concentrations were at the targeted values within the uncertainty of the analytical methods $( \pm 15 \%)$. The calculated percentage of aluminum that was removed at each leaching condition is also shown. Appendix J summarizes the concentrations of $\mathrm{Al}, \mathrm{Cr}, \mathrm{Fe}, \mathrm{Na}, \mathrm{P}, \mathrm{Si}$, fluoride, nitrite, nitrtate, phosphate, and sulfate in the final leach solutions. The GEA results for ${ }^{60} \mathrm{Co}$ and ${ }^{241}$ Am were $<$ MDL; the GEA results are also provided in Appendix J. 
Table 4.12. Group 2 Bismuth Phosphate Saltcake Leaching Final Aqueous Phase Conditions

\begin{tabular}{|c|c|c|c|c|c|}
\hline Temp., ${ }^{\circ} \mathbf{C}$ & $\begin{array}{c}\text { Density, } \\
\mathbf{g} / \mathbf{m L}\end{array}$ & $\begin{array}{c}\text { Free OH, } \\
\mathbf{M}\end{array}$ & Na, $\mathbf{M}$ & Al, $\mathbf{M}$ & $\begin{array}{c}\text { Wt \% Al } \\
\text { Removed }\end{array}$ \\
\hline 60 & 1.13 & 3.04 & 3.19 & $4.56 \mathrm{E}-02$ & 58 \\
\hline & & & & & \\
\hline 80 & 1.06 & 0.96 & 1.09 & $4.68 \mathrm{E}-02$ & 58 \\
\hline 80 trial a & 1.13 & 2.99 & 3.16 & $4.93 \mathrm{E}-02$ & 61 \\
\hline 80 trial b & 1.13 & 3.05 & 3.10 & $4.75 \mathrm{E}-02$ & 59 \\
\hline 80 trial c & 1.12 & 3.01 & 3.03 & $4.90 \mathrm{E}-02$ & 60 \\
\hline 80 & 1.19 & 5.00 & 5.00 & $5.00 \mathrm{E}-02$ & 62 \\
\hline & & & & & 70 \\
\hline
\end{tabular}

\subsubsection{Comparison of Initial and Caustic Leached and Washed Solids Properties}

The Group 2 solids that had been caustic leached at $80^{\circ} \mathrm{C}$ in $3 \mathrm{M} \mathrm{NaOH}$ for $24 \mathrm{~h}$ were combined and washed in preparation for analysis. The wash solution composition and the washed solids chemical, radiochemical, particle size, and crystal habit are discussed.

\subsubsection{Leached Solids Wash Solution}

The densities of the three sequential wash solutions were 1.019, 1.007, and $1.008 \mathrm{~g} / \mathrm{mL}$, respectively. The composite wash solution (82.16 mL volume) density, ICP metals, and anion composition are shown in Table 4.13.

Table 4.13. Solids Wash Solution Composition and Density

\begin{tabular}{|c|c|c|c|c|c|}
\hline \hline Analyte & $\boldsymbol{\mu} \mathbf{g} / \mathbf{m L}$ & Analyte & $\boldsymbol{\mu} \mathbf{g} / \mathbf{m L}$ & Density Measurement & Value \\
\hline $\mathrm{Al}$ & 103.5 & $\mathrm{Si}$ & 13.6 & Density & $1.004 \mathrm{~g} / \mathrm{mL}$ \\
\hline $\mathrm{Cr}$ & 7.3 & nitrate & 469.7 & & \\
\cline { 1 - 3 } $\mathrm{Na}$ & 5,399 & phosphate & {$[4.5]$} & & \\
\cline { 1 - 3 } $\mathrm{P}$ & {$[2.1]$} & sulfate & {$[0.81]$} & & \\
\hline
\end{tabular}

\subsubsection{Chemical and Radiochemical Composition}

The initial composition of washed solids (before caustic leaching) is provided in Table 4.14 along with selected results from the initial characterization study (i.e., values taken from Table 4.5 and Table 4.6). The solids composition after leaching in $3 \mathrm{M} \mathrm{NaOH}$ at $80^{\circ} \mathrm{C}$ for $24 \mathrm{~h}$ and washing is also shown in Table 4.14. The solids from the initial characterization had been washed three times, resulting in an estimated 26-wt\% salt entrainment from the supernatant phase, but the "before leaching" material had been more extensively washed, i.e., no salt entrainment (except for $\mathrm{NaOH}$ from the washing liquid) was expected. The composition of the material used for the parametric leaching tests was considerably different from that of the initial characterization sample. This can best be seen by comparing the ratios of the masses of the various components to that of iron in the sample (Table 4.15). ${ }^{\text {(a) }}$ The amount of sodium

(a) This comparison assumes that Fe is not soluble in the washing medium. 
Table 4.14. Group 2 Bi-Phosphate Saltcake Leached Solids Composition and Leach Factors (Dry Mass Basis)

\begin{tabular}{|c|c|c|c|c|}
\hline Analyte & $\begin{array}{l}\text { Avg. Initial } \\
\text { Charac. } \\
\mu g / g^{(a)} \\
\text { (ASR 7974) }\end{array}$ & $\begin{array}{l}\text { Avg. Before } \\
\text { Leaching, } \\
\mu \mathrm{g} / \mathrm{g} \\
\text { (ASR 8032) }\end{array}$ & $\begin{array}{c}\text { Avg. After } \\
\text { Leaching, } \\
\mu g / g \\
\text { (ASR 8032) }\end{array}$ & $\begin{array}{c}\text { Observed } \\
\text { Leach } \\
\text { Factor }^{(\mathbf{b})}\end{array}$ \\
\hline $\mathrm{Al}$ & 117,500 & 149,500 & 91,450 & 0.61 \\
\hline $\mathrm{B}$ & [105] & $<161$ & $<186$ & 0.27 \\
\hline $\mathrm{Bi}$ & 1030 & 2,675 & 3,650 & 0.13 \\
\hline $\mathrm{Cd}$ & 98 & 275 & 329 & 0.24 \\
\hline $\mathrm{Cr}$ & 7,885 & 22,850 & 10,300 & 0.71 \\
\hline $\mathrm{Fe}$ & 22,075 & 47,100 & 84,500 & -- \\
\hline Mn & 1,020 & 2,140 & 4,110 & -- \\
\hline $\mathrm{Na}$ & 185,000 & {$[78,500]$} & {$[100,000]$} & -- \\
\hline $\mathrm{S}$ & {$[1,400]$} & {$[1,322]$} & {$[3,250]$} & -- \\
\hline $\mathrm{Si}$ & 31,650 & 42,800 & 92,250 & -- \\
\hline $\mathrm{Sr}$ & 4,270 & 9,110 & 17,450 & -- \\
\hline $\mathrm{U}$ & 15,450 & 46,100 & 59,850 & 0.18 \\
\hline $\mathrm{Zn}$ & 399 & 975 & 1,725 & -- \\
\hline $\mathrm{Zr}$ & [110] & $<107$ & $<124$ & 0.27 \\
\hline \multirow[t]{2}{*}{ U (KPA) } & 15,250 & 47,420 & 58,740 & 0.21 \\
\hline & $\mu \mathrm{Ci} / \mathrm{g}$ & & & \\
\hline${ }^{60} \mathrm{Co}$ & $1.07 \times 10^{-2}$ & $1.44 \times 10^{-2}$ & $2.53 \times 10^{-2}$ & -- \\
\hline${ }^{90} \mathrm{Sr}$ & $1.79 \times 10^{2}$ & $4.95 \times 10^{2}$ & $8.00 \times 10^{2}$ & 0 \\
\hline${ }^{137} \mathrm{Cs}$ & $9.97 \times 10^{1}$ & $1.30 \times 10^{2}$ & $1.93 \times 10^{2}$ & 0.06 \\
\hline${ }^{154} \mathrm{Eu}$ & $4.84 \times 10_{-}^{2}$ & $1.53 \times 10^{-1}$ & $2.38 \times 10^{-1}$ & 0.01 \\
\hline${ }^{155} \mathrm{Eu}$ & $<0.1$ & $5.58 \times 10^{-2}$ & $8.57 \times 10^{-2}$ & 0.03 \\
\hline${ }^{239+240} \mathrm{Pu}$ & $2.67 \times 10^{-1}$ & $3.85 \times 10^{-1}$ & $5.70 \times 10^{-1}$ & 0.06 \\
\hline${ }^{241} \mathrm{Am}$ & $4.21 \times 10^{-1}$ & 1.05 & 1.64 & 0.01 \\
\hline total alpha & $5.05 \times 10^{-1}$ & 1.32 & 1.86 & 0.11 \\
\hline total beta & $4.63 \times 10^{2}$ & $1.84 \mathrm{E}+03$ & $1.84 \times 10^{3}$ & 0.37 \\
\hline${ }^{238} \mathrm{Pu}$ & $1.44 \times 10_{-}^{2}$ & $1.56 \mathrm{E}-02$ & $2.27 \times 10^{-2}$ & 0.08 \\
\hline \multicolumn{5}{|l|}{ Opportunistic } \\
\hline $\mathrm{Ag}$ & [8.5] & $<31$ & $<35$ & 0.27 \\
\hline As & $<269$ & $<493$ & $<570$ & 0.27 \\
\hline $\mathrm{Ba}$ & 257 & 545 & 1,010 & -- \\
\hline $\mathrm{Be}$ & $<1.0$ & $<3$ & $<2$ & 0.49 \\
\hline $\mathrm{Ca}$ & 9,800 & {$[25,000]$} & {$[40,000]$} & 0 \\
\hline $\mathrm{Ce}$ & $<202$ & $<369$ & $<427$ & 0.27 \\
\hline Co & [33] & [105] & [155] & 0.06 \\
\hline $\mathrm{Cu}$ & 80.3 & [310] & {$[1,095]$} & -- \\
\hline Dy & $<52$ & $<<94$ & $<109$ & 0.27 \\
\hline $\mathrm{Eu}$ & $<16$ & $<30$ & $<35$ & 0.27 \\
\hline $\mathrm{La}$ & [19] & [115] & [170] & 0.06 \\
\hline $\mathrm{Li}$ & {$[48]$} & 100 & -- & 1.00 \\
\hline $\mathrm{Mg}$ & 1,255 & 2,450 & 4,690 & -- \\
\hline
\end{tabular}


WTP-RPT-166, Rev. 0

Table 4.14 (Contd)

\begin{tabular}{|c|c|c|c|c|}
\hline Analyte & $\begin{array}{l}\text { Avg. Initial } \\
\text { Charac. } \\
\mu g / g \\
\text { (ASR 7974) }\end{array}$ & $\begin{array}{l}\text { Avg. Before } \\
\text { Leaching, } \\
\mu g / g \\
\text { (ASR 8032) }\end{array}$ & $\begin{array}{l}\text { Avg. After } \\
\text { Leaching, } \\
\mu g / g \\
\text { (ASR 8032) }\end{array}$ & $\begin{array}{l}\text { Observed } \\
\text { Leach } \\
\text { Factor }\end{array}$ \\
\hline Mo & $<30$ & $<54$ & $<63$ & 0.27 \\
\hline $\mathrm{Nd}$ & [43] & $<569$ & $<657$ & 0.27 \\
\hline $\mathrm{P}$ & 47,850 & 14,800 & 19,000 & 0.19 \\
\hline $\mathrm{Pb}$ & 1,385 & 3,280 & 2,925 & 0.43 \\
\hline $\mathrm{Pd}$ & $<183$ & $<335$ & $<388$ & 0.27 \\
\hline $\mathrm{Rh}$ & $<120$ & $<220$ & $<254$ & 0.27 \\
\hline $\mathrm{Ru}$ & $<<52$ & $<94$ & $<109$ & 0.27 \\
\hline $\mathrm{Sb}$ & $<171$ & $<312$ & $<361$ & 0.27 \\
\hline $\mathrm{Se}$ & $<291$ & $<533$ & $<616$ & 0.27 \\
\hline Sn & {$[80]$} & $<498$ & $<576$ & 0.27 \\
\hline Та & $<59$ & $<107$ & $<124$ & 0.27 \\
\hline $\mathrm{Te}$ & $<231$ & $<423$ & $<489$ & 0.27 \\
\hline Th & $<180$ & $<330$ & $<381$ & 0.27 \\
\hline $\mathrm{Ti}$ & 178 & 265 & 640 & -- \\
\hline $\mathrm{Tl}$ & $<209$ & $<383$ & $<443$ & 0.27 \\
\hline $\mathrm{V}$ & 46.1 & $<25$ & $<29$ & 0.27 \\
\hline $\mathrm{W}$ & $<92$ & $<168$ & $<194$ & 0.27 \\
\hline $\mathrm{Y}$ & [4.1] & $<<36$ & $<<42$ & 0.27 \\
\hline \multicolumn{5}{|c|}{$\begin{array}{l}\text { (a) The values listed here are the average of the values obtained by the KOH fusion } \\
\text { and acid digestion methods (see Table } 4.5 \text { and Table } 4.6 \text { ). In those cases, in which } \\
\text { one method yielded high uncertainty, the most reliable value is presented in this } \\
\text { table. } \\
\text { (b) Leach factors calculated by the "concentration factor" method, described in the } \\
\text { text. }\end{array}$} \\
\hline
\end{tabular}

Table 4.15. Comparison of Fe-Normalized Compositions of the Initial Group 2 Characterization Sample and the Washed Group 2 Sample Used for Parametric Leaching for Selected Components

\begin{tabular}{|c|c|c|}
\hline \multirow[b]{2}{*}{ Component } & \multicolumn{2}{|c|}{ g Component/g Fe } \\
\hline & $\begin{array}{c}\text { Initial } \\
\text { Characterization }\end{array}$ & $\begin{array}{c}\text { Before } \\
\text { Leaching }\end{array}$ \\
\hline $\mathrm{Al}$ & 5.3 & 3.2 \\
\hline $\mathrm{Cr}$ & 0.36 & 0.49 \\
\hline $\mathrm{Na}$ & 8.4 & 1.7 \\
\hline $\mathrm{P}^{(\mathrm{a})}$ & 2.2 & 0.3 \\
\hline Si & 1.4 & 0.9 \\
\hline $\mathrm{Sr}$ & 0.19 & 0.19 \\
\hline $\mathrm{U}$ & 0.7 & 1.0 \\
\hline
\end{tabular}


present in the leaching sample was approximately 5 times less than that in the initial characterization sample, confirming the supposition that soluble sodium salts were removed more extensively when washing the solids before leaching. This appears to be the result of washing sodium phosphate from the solids because there is an $\sim 7$-fold decrease in the phosphorus content relative to Fe (caveat: the phosphorus data were determined opportunistically). The Al concentration in the Group 2 solids also decreased $40 \%$ with more extensive washing of the solids (again, relative to $\mathrm{Fe}$ ). The $\mathrm{Cr}$ concentration with respect to the Fe concentration was higher in the more extensively washed leaching sample; however, this might be due to experimental uncertainty.

Because the amount of $\mathrm{Al}$ projected to be in the initial solids was $20 \%$ less than that found in the final leachate solutions, the data from the Group 2 caustic leaching experiments were analyzed by the three methods described in Section 3.4.6.2 for determining the percent of each component removed during leaching. In the case of the Group 2 solids, the leached solids were dominated by $\mathrm{Al}$ (9.1 wt\%), $\mathrm{Cr}$ (1.0 wt\%), Fe (8.4 wt\%), Na (10 wt\%), Si (9.2 wt\%), Sr (1.7 wt\%), and U (6.0 wt\%), and the analysis of the leachate solutions showed that $\mathrm{Bi}, \mathrm{Cd}, \mathrm{Fe}, \mathrm{Mn}, \mathrm{Sr}$, and $\mathrm{U}$ had not dissolved after the initial water washing. The relative concentration factor (CF) of these analytes averaged 2.63 in the final washed solids, based on the concentration ratio after washing to the initial characterization washed sample. This term was used to determine the specific analyte wash factors according to Equation 4.2:

$$
W F=1-\left(\frac{C_{W}}{C_{I} \times 2.63}\right)
$$

where WF is the water wash factor, $\mathrm{C}_{\mathrm{W}}$ is the washed analyte concentration, and $\mathrm{C}_{\mathrm{I}}$ is the initial analyte concentration.

Analysis of the caustic leachate solutions also indicated that the same metals (Bi, Cd, Fe, Mn, Sr, and U) did not dissolve after the caustic leach. The relative concentration factor of these analytes averaged 1.58 in the final leached solids, based on the ratio of the analyte concentrations after leaching to before leaching (after washing). This term was used to determine the specific analyte leach factors according to Equation 4.3

$$
L F_{3}=1-\left(\frac{C_{L}}{C_{W} \times 1.58}\right)
$$

where $\mathrm{LF}_{3}$ is the caustic leach factor, $\mathrm{C}_{\mathrm{L}}$ is the leached analyte concentration, and $\mathrm{C}_{\mathrm{W}}$ is the washed analyte concentration.

Results from all three methods are given in Table 4.16. For Al, the results from all three methods are different, with method one giving the highest values and method three giving the lowest values. For $\mathrm{P}$, all three methods had reasonably good agreement. For Cr, methods two and three gave nearly identical results, with Method 1 giving lower results. All values of percent leached plotted in this section and shown in Table 4.12 and Table 4.14 were calculated using method three, the "concentration factor" method. 
Table 4.16. Group 2 Bi-Phosphate Slurry Leach Factors

\begin{tabular}{|c|c|c|c|c|c|c|c|c|c|c|c|}
\hline \multirow{2}{*}{$\begin{array}{c}\text { Temp., } \\
{ }^{\circ} \mathrm{C}\end{array}$} & \multirow{2}{*}{$\begin{array}{c}\text { Free } \\
\text { [OH], } \\
\text { M }\end{array}$} & \multirow{2}{*}{$\begin{array}{c}\mathrm{Na}, \\
\mathrm{M}\end{array}$} & \multicolumn{3}{|c|}{$\begin{array}{c}\text { Fraction Removed } \\
\text { Based on initial } \\
\text { solids/leachate } \\
\text { solution } \\
\end{array}$} & \multicolumn{3}{|c|}{$\begin{array}{c}\text { Fraction Removed } \\
\text { Based on final } \\
\text { solids/leachate } \\
\text { solution } \\
\end{array}$} & \multicolumn{3}{|c|}{$\begin{array}{c}\text { Fraction Removed } \\
\text { Based on initial/final } \\
\text { solids ("concentration } \\
\text { factor" method) }\end{array}$} \\
\hline & & & Al & $\mathrm{Cr}$ & $\mathbf{P}$ & Al & $\mathrm{Cr}$ & $\mathbf{P}$ & Al & $\mathrm{Cr}$ & $P$ \\
\hline 60 & 3.04 & 3.19 & 1.04 & 0.20 & 0.06 & 0.80 & 0.31 & 0.09 & 0.58 & 0.29 & 0.07 \\
\hline 80 & 0.96 & 1.09 & 1.05 & 0.31 & 0.12 & 0.80 & 0.49 & 0.19 & 0.58 & 0.46 & 0.14 \\
\hline $\begin{array}{r}80 \\
\text { trial a } \\
\end{array}$ & 2.99 & 3.16 & 1.10 & 0.50 & 0.19 & 0.83 & 0.76 & 0.29 & 0.61 & 0.74 & 0.22 \\
\hline $\begin{array}{r}80 \\
\text { trial b } \\
\end{array}$ & 3.05 & 3.10 & 1.07 & 0.48 & 0.09 & 0.83 & 0.75 & 0.17 & 0.59 & 0.71 & 0.11 \\
\hline $\begin{array}{r}80 \\
\text { trial c }\end{array}$ & 3.01 & 2.99 & 1.08 & 0.44 & 0.13 & 0.83 & 0.73 & 0.23 & 0.60 & 0.66 & 0.16 \\
\hline 80 & 5.00 & 5.00 & 1.12 & 0.48 & 0.21 & 0.86 & 0.75 & 0.34 & 0.62 & 0.71 & 0.24 \\
\hline 100 & 3.09 & 3.29 & 1.26 & 0.59 & 0.17 & 0.97 & 0.92 & 0.29 & 0.70 & 0.87 & 0.20 \\
\hline
\end{tabular}

As shown in Figure 4.30, approximately 62\% of the mass dissolved with washing 3 times in $0.01 \mathrm{M}$ $\mathrm{NaOH}$. An additional 9\% of the mass dissolved after leaching for $24 \mathrm{~h}$ in $3 \mathrm{M} \mathrm{NaOH}$ at $80^{\circ} \mathrm{C}$.

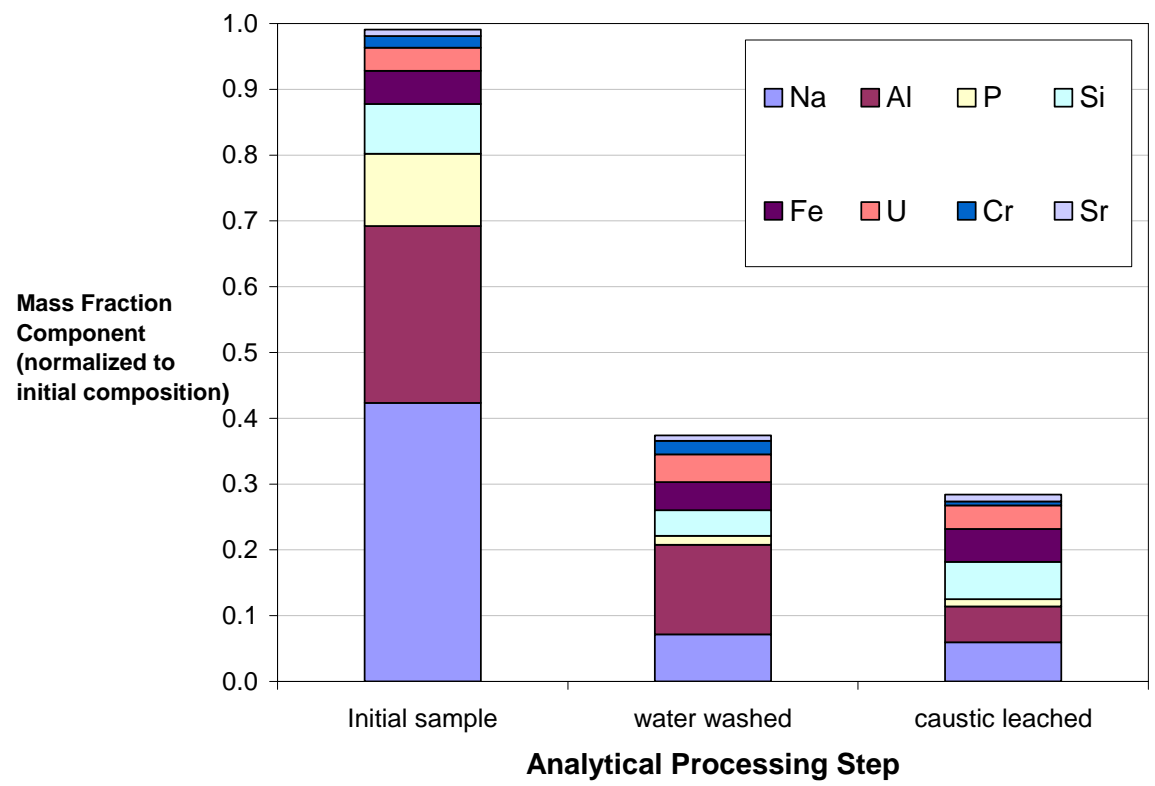

Figure 4.30. Group 2 Bi-Phosphate Saltcake Reduction in Solid Mass with Water Washing and Caustic Leaching

The FTIR spectra of the Group 2 solids before and after caustic leaching ( $3 \mathrm{M} \mathrm{NaOH}, 80^{\circ} \mathrm{C}, 24 \mathrm{~h}$ ) were measured using a diamond ATR sample cell (Figure 4.31). ${ }^{\text {(a) }}$ As discussed in Section 4.2.7, the FTIR spectrum of the washed solids before leaching can mostly be explained by the presence of gibbsite, nitrate cancrinite, amorphous $\mathrm{FePO}_{4} \cdot \mathrm{xH}_{2} \mathrm{O}$, and (perhaps) $\mathrm{Na}\left[\mathrm{UO}_{2} \mathrm{PO}_{4}\right] \cdot 3 \mathrm{H}_{2} \mathrm{O}$. The FTIR spectrum of the

(a) FTIR spectra presented for indication only. 
leached Group 2 solids is distinctly different from that for the solids before leaching. The FTIR spectra clearly show the removal of gibbsite from the solids as evidenced by the disappearance of the characteristic hydroxyl bands in the range 3375 to $3650 \mathrm{~cm}^{-1}$. The elimination of bands due to amorphous (or crystalline) $\mathrm{FePO}_{4} \cdot \times \mathrm{H}_{2} \mathrm{O}$ would also be expected upon caustic leaching because of metathesis to $\mathrm{Fe}(\mathrm{OH})_{3}$ and sodium phosphate. The FTIR spectrum supports this by a large reduction in the relative intensity of the phosphate bands in the range 925 to $1150 \mathrm{~cm}^{-1}$. Beyond that, interpreting the FTIR spectrum of the leached solids is somewhat difficult. One surprising observation is the apparent drastic reduction in the amount of nitrate cancrinite present, which is indicated by the nitrate band at $1422 \mathrm{~cm}^{-1}$ being very weak compared to the other bands observed in the spectrum of the leached solids. Thus, it appears that the nitrate cancrinite is converted to some other aluminosilicate form during the caustic leaching process. The nature of the resulting aluminosilicate species is not obvious from the FTIR spectrum, but the XRD analysis confirms the formation of a nitrate-free cancrinite phase (vide infra). A cancrinite phase is also supported by the Al:Si molar ratio of 1.0.

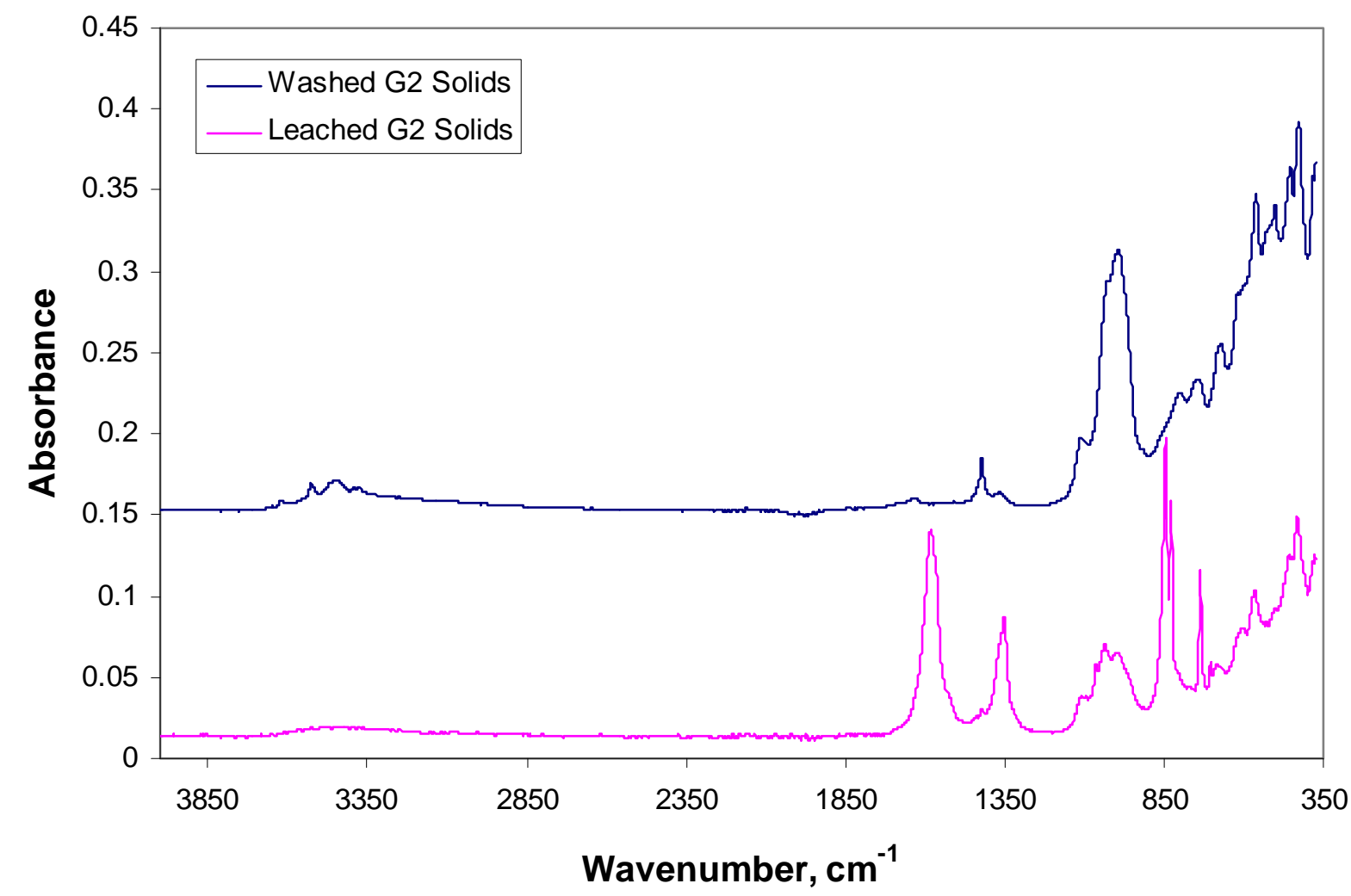

Figure 4.31. FTIR Spectra of the Group 2 Solids Before and After Leaching in $3 \mathrm{M} \mathrm{NaOH}$ at $80^{\circ} \mathrm{C}$ for $24 \mathrm{~h}$

The FTIR examination of the leached Group 2 solids does provide insight into the reason for the low removal of $\mathrm{P}$ for this waste group compared to the Group 1 material. Careful examination of the FTIR spectrum indicates bands at 565, 602, and $1034 \mathrm{~cm}^{-1}$, which can be attributed to hydroxyapatite. The corresponding bands measured for a pure sample of hydroxyapatite were at 564, 601, and $1030 \mathrm{~cm}^{-1}$. Furthermore, an examination of the elemental composition of the leached Group 2 solids (Table 4.14) corroborates this conclusion. The measured $\mathrm{P} / \mathrm{Ca}$ molar ratio was 0.61 , which compares very well with the expected $\mathrm{P} / \mathrm{Ca}$ molar ratio of 0.60 for $\mathrm{Ca}_{5}(\mathrm{OH})\left(\mathrm{PO}_{4}\right)_{3}$. 
Heating of the Group 2 solids would not change their elemental composition but rather would alter their chemical speciation. Thermal gravimetric analysis (TGA) was performed for four Group 2 samples. The solids were washed three times with $0.01 \underline{\mathrm{M}} \mathrm{NaOH}$ and then three times in water; after each washing step the material was centrifuged and the wash liquid decanted. The sample would then be best represented by data in the middle column of Table 4.14 or Figure 4.30, wherein the aluminum and iron contents were about 15 and 5\%, respectively.

Thermogravametric analysis of the washed Group 2 solids before caustic leaching also provides some insight into the leaching behavior for these solids. TGA data were acquired for four Group 2 tank waste samples, while scanning to a temperature of $830^{\circ} \mathrm{C}$. In all cases, the major mass loss component/heat response in the TGA/DTA (DTA = differential thermal analysis) scans, respectively were directly consistent with gibbsite and a small quantity of goethite and magnetite. As determined by the TGA, the Group 2 tank waste solids contained $8.0 \mathrm{wt} \% \mathrm{Al}$ as gibbsite. Because the known $\mathrm{Al}$ content in the Group 2 solids was about $15 \%$ by ICP analysis (Table 4.14 ), the TGA predicts that $~ 53 \%$ (i.e., $8 \div 15$ ) of the Al should be readily removed during caustic leaching of the Group 2 solids. Leaching of the Group 2 tank waste indeed removed $61 \%$ of the aluminum as is indicated in Table 4.14 .

TGA suggests that iron is in equilibrium with at least 3 phases in the Group 2 solids - goethite, magnetite, and ferric hydroxide. A conservative (i.e., maximum) estimate for the mass fraction contributed to the washed Group 2 solids from these three species is $7.6 \mathrm{wt} \%$. This corresponds to $4.2 \mathrm{wt} \% \mathrm{Fe}$, which is in reasonable agreement with the value of $4.7 \mathrm{wt} \%$ measured by ICP-OES (Table 4.14). Iron present as hematite, iron silicate or aluminate phases could account for extra mass (an additional $0.5 \mathrm{wt} \% \mathrm{of} \mathrm{Fe}$ ) present in the solids, but none of these phases would be expected to be leached from the tank-waste under caustic conditions, or identified by the thermal methods used here.

\subsubsection{Particle-Size Distribution}

PSD measurements were performed on the caustic-leached and washed Group 2 solids (sample ID 549G2-CL-PSD). Because the in-cell sonicator on the Hydro $\mu \mathrm{P}$ was not functional at the time of measurement for this sample, only data for measurement conditions 1 to 3 are available (Table 4.17). Two separate measurements, an initial and replicate, were run for this sample to assess reproducibility.

Table 4.17 and Table 4.18 show select cumulative undersize percentiles derived from initial and replicate PSD measurements, respectively, for the caustic-leached and washed Group 2 solids. Reproducibility between the initial and replicate runs was generally reasonable, with the exception of the $d(90)$ values at pump speeds of 2000 and 3000 RPM. Both the initial and the replicate results for cumulative percent undersize show similar trends with respect to pump speed. First, d(10) values appear relatively insensitive to changes in pump speed. The d(50) values at 3000 and 2000 RPM are similar, but show a significant (>10\%) increase at $4000 \mathrm{RPM}$. The $\mathrm{d}(90)$ shows progressive increases with increasing pumping rate, with a dramatic jump as speed is increased from 3000 to 4000 RPM. 
WTP-RPT-166, Rev. 0

Table 4.17. Initial Particle-Size Analysis Percentile Results for the Caustic-Leached and Washed Group 2 Solids (sample 549-G2-CL-PSD)

\begin{tabular}{||c|c|c|c|c|c||}
\hline $\begin{array}{c}\text { Measurement } \\
\text { Condition }\end{array}$ & Pump Speed & Sonication & $\begin{array}{c}\mathbf{d}(\mathbf{1 0}) \\
{[\boldsymbol{\mu m}]}\end{array}$ & $\begin{array}{c}\mathbf{d}(\mathbf{5 0}) \\
{[\boldsymbol{\mu m}]}\end{array}$ & $\begin{array}{c}\mathbf{d}(\mathbf{9 0}) \\
{[\boldsymbol{\mu m}]}\end{array}$ \\
\hline 1 & 3000 & $\mathrm{n} / \mathrm{a}$ & 0.59 & 1.9 & 8.4 \\
\hline 2 & 4000 & $\mathrm{n} / \mathrm{a}$ & 0.61 & 3.5 & 64 \\
\hline 3 & 2000 & $\mathrm{n} / \mathrm{a}$ & 0.62 & 1.8 & 7.0 \\
\hline
\end{tabular}

Table 4.18. Replicate Particle-Size Analysis Percentile Results for the Caustic-Leached and Washed Group 2 Solids (sample 549-G2-CL-PSD)

\begin{tabular}{||c|c|c|c|c|c||}
\hline $\begin{array}{c}\text { Measurement } \\
\text { Condition }\end{array}$ & Pump Speed & Sonication & $\begin{array}{c}\mathbf{d}(\mathbf{1 0}) \\
{[\boldsymbol{\mu m}]}\end{array}$ & $\begin{array}{c}\mathbf{d}(\mathbf{5 0}) \\
{[\mu \mathbf{m}]}\end{array}$ & $\begin{array}{c}\mathbf{d}(\mathbf{9 0}) \\
{[\boldsymbol{\mu m}]}\end{array}$ \\
\hline 1 & 3000 & $\mathrm{n} / \mathrm{a}$ & 0.60 & 2.6 & 30 \\
\hline 2 & 4000 & $\mathrm{n} / \mathrm{a}$ & 0.66 & 4.8 & 70 \\
\hline 3 & 2000 & $\mathrm{n} / \mathrm{a}$ & 0.56 & 2.4 & 16 \\
\hline
\end{tabular}

Figure 4.32 and Figure 4.33 show the initial and replicate PSD measurements, respectively, for the leached Group 2 solids. The PSD observed in the initial measurement spans from $\sim 0.2$ to $20 \mu \mathrm{m}$ (at 3000 RPM) and exhibits a maximum population between 1 and $2 \mu \mathrm{m}$ and a large shoulder population in the range 3 to $20 \mu \mathrm{m}$. The initial measured PSD at 2000 RPM compares well to that at 3000 RPM. A decrease in the relative population contribution of 10 to $20 \mu \mathrm{m}$ indicates that particles in this size range might be difficult-to-suspend. At 4000 RPM, a large secondary peak spanning 20 to $200 \mu \mathrm{m}$ and with a peak population at $60 \mu \mathrm{m}$ is observed. This peak is likely composed of difficult-to-suspend particles. It should be noted that similar 20- to 200- $\mu$ m peaks are observed at 4000 RPM in Group 1/2 mixed waste solids derived from CUF testing (see Section 5.5.3).

The replicate measurement shows a much broader PSD relative to the initial measurement. The relative volume contribution of 20 to $200 \mu \mathrm{m}$ particles is increased at all pump speeds even though it has a similar size distribution to that observed in the initial measurement over 0.2 to $20 \mu \mathrm{m}$. Figure 4.34 compares the initial and replicate PSD measurements for sample 549-G2-CL-PSD at 3000 RPM. As indicated above, the distributions are similar with the exception of the secondary peak spanning 30 to $200 \mu \mathrm{m}$ in the replicate sample. This peak appears to correspond to the same species of particles yielding the secondary 20 - to $200-\mu \mathrm{m}$ peak observed at 4000 RPM during the initial measurement. The contribution for particles in this upper range decreases with decreasing flow (i.e., at 2000 RPM, Figure 4.33), supporting the supposition that the particles making up this peak are difficult to suspend. It is not known why the replicate measurement shows these 20- to 200- $\mu$ m particles at all flows; however, it is possible that the second sampling of the sample vial containing 549-G2-CL-PSD solids yielded an increased volume of large particles relative to the first. 
WTP-RPT-166, Rev. 0

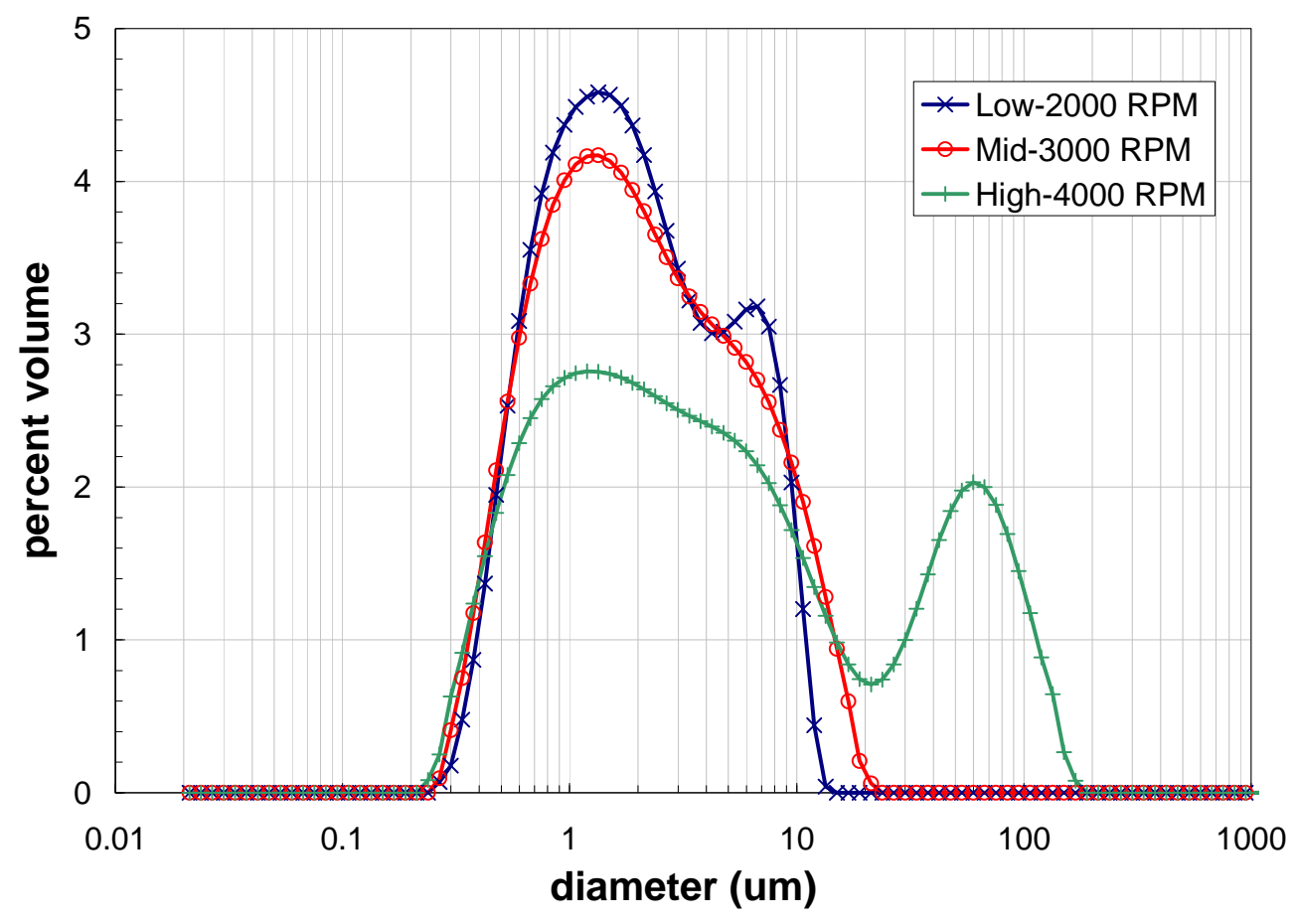

Figure 4.32. Volume Distribution Result for the Caustic-Leached and Washed Group 2 Solids (sample 549-G2-CL-PSD) as a Function of Pump Speed (initial measurement)

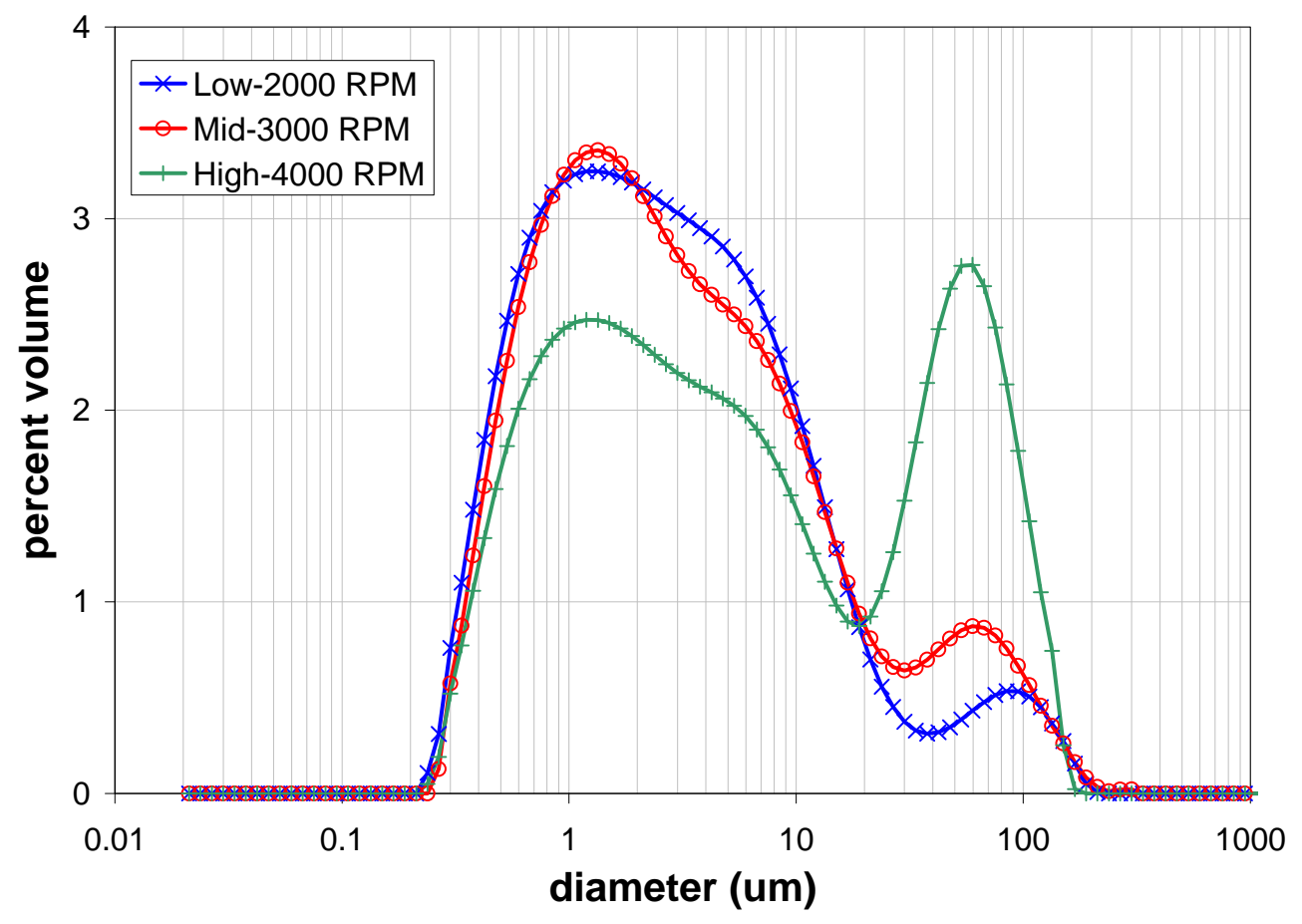

Figure 4.33. Volume Distribution Result for the Caustic-Leached and Washed Group 2 Solids (sample 549-G2-CL-PSD) as a Function of Pump Speed (replicate measurement) 


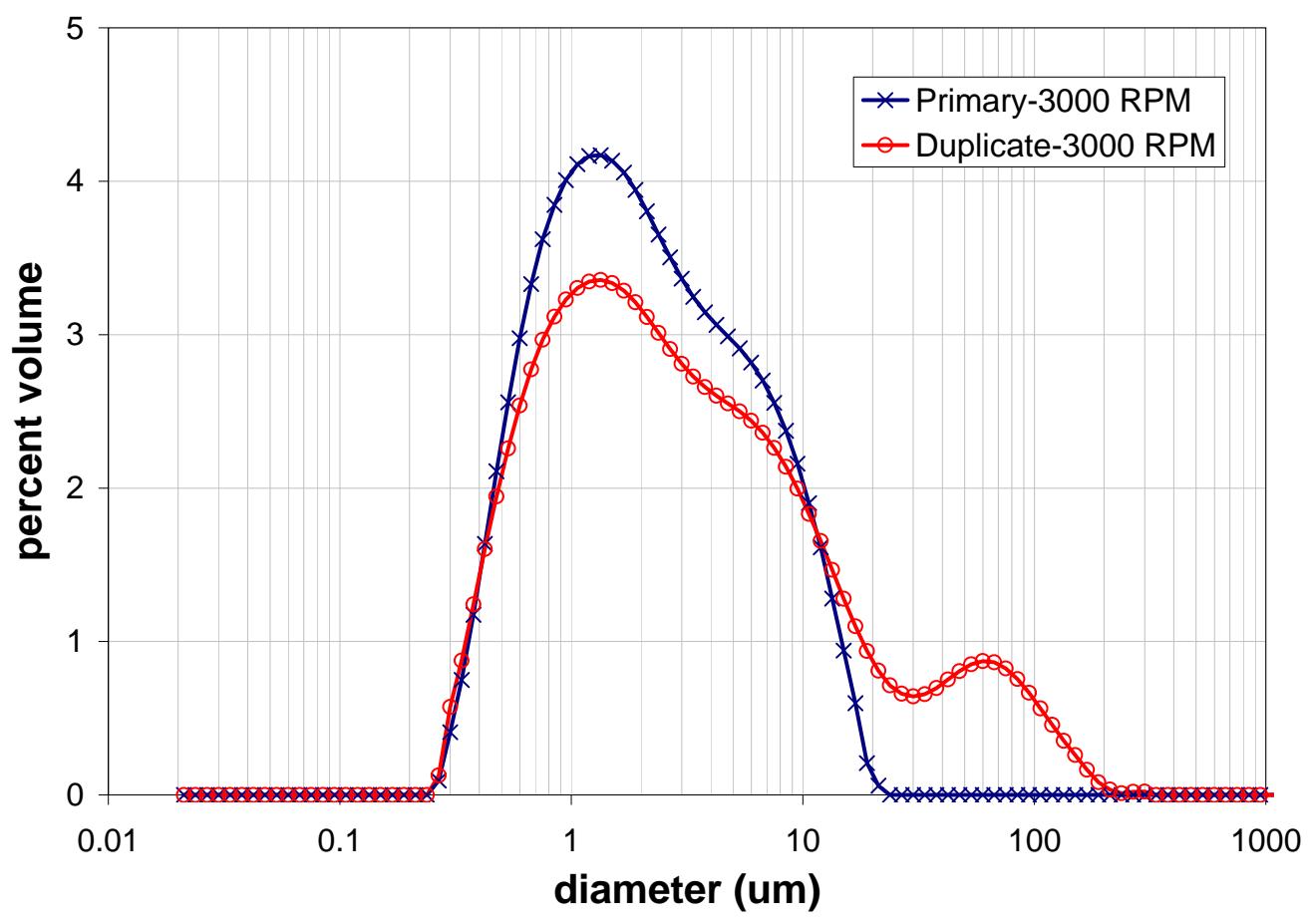

Figure 4.34. Comparison of Initial and Replicate PSD Measurements for the Caustic-Leached and Washed Group 2 Solids

Table 4.19 shows the relative percent difference (RPD) between initial and replicate cumulative undersize percentiles. The $d(10)$ values compare well, typically being within $10 \%$. Both $d(50)$ and $d(90)$ values show significant differences, with RPDs greater than $10 \%$. It should be noted that the large RPDs for $d(50)$ and $d(90)$ result from the significantly higher fraction of 20- to 200- $\mu$ m particles observed in the replicate measurement PSD. This is illustrated by the reasonable ( 10\%) comparison of initial and replicate d(90)s at 4000 RPM, where both samples exhibit a suspension of 20- to 200- $\mu$ m particles. Overall, the initial and replicate RPD calculations indicate a difference in sub-sampling of the material for the PSD measurements.

Table 4.19. Relative Percent Difference Between the Initial and Replicate PSD Percentile Results for Sample 549-G2-CL-PSD

\begin{tabular}{|c|c|c|c|c|}
\hline \multirow[b]{2}{*}{$\begin{array}{l}\text { Measurement } \\
\text { Condition }\end{array}$} & \multirow[b]{2}{*}{ Pump Speed } & \multicolumn{3}{|c|}{ Relative \% Difference } \\
\hline & & $\begin{array}{l}d(10) \\
{[\mu \mathrm{m}]}\end{array}$ & $\begin{array}{l}d(50) \\
{[\mu \mathrm{m}]}\end{array}$ & $\begin{array}{l}\mathrm{d}(90) \\
{[\mu \mathrm{m}]}\end{array}$ \\
\hline 1 & 3000 & 1.3 & 34 & 260 \\
\hline 2 & 4000 & 8.3 & 38 & 11 \\
\hline 3 & 2000 & 10 & 34 & 130 \\
\hline
\end{tabular}

The influence of caustic-leaching and washing of the Group 2 solids can be evaluated by comparing PSDs for the source material (i.e., that for initial characterization sample TI517-G2-S-WL-PSD) to the causticleached and washed Group 2 Parametric PSD sample (549-G2-CL-PSD). The PSD for the primary initial 
characterization sample and initial parametric testing measurement are used for this comparison. Since only pre-sonic PSD measurements are available for sample 549-G2-CL-PSD, comparisons are made at measurement condition 1 (3000 RPM, before sonication). Table 4.20 and Figure 4.35 show the changes that occur to the Group 2 solids PSD as a result of caustic-leaching and washing. Based on Figure 4.35, the caustic-leaching and washing operations appear to reduce the fractional contribution of 2- to 20- $\mu \mathrm{m}$ particles while increasing the fractional contribution of $0.2-$ to $2-\mu \mathrm{m}$ particles. The overall result is a reduction in particle size, likely as a result of either dissolution of material from the surface of particles or breakage of agglomerates. The reported cumulative percent undersize diameters in Table 4.20 confirm a decrease in particle size upon caustic leaching of the Group 2 solids.

Table 4.20. Cumulative Undersize Percentiles Showing the Influence of Caustic-Leaching and Washing on the PSD of Group 2 Solids at Measurement Condition 1: 3000 RPM, Before Sonication

\begin{tabular}{||l|c|c|c||}
\hline \multicolumn{1}{|c|}{ Sample } & $\begin{array}{c}\mathbf{d}(\mathbf{1 0}) \\
{[\boldsymbol{\mu m}]}\end{array}$ & $\begin{array}{c}\mathbf{d}(\mathbf{5 0}) \\
{[\mu \mathbf{m}]}\end{array}$ & $\begin{array}{c}\mathbf{d}(\mathbf{9 0}) \\
{[\mu \mathbf{m}]}\end{array}$ \\
\hline Group 2 Initial Characterization (TI517-G2-S-WL-PSD-1) & 0.86 & 3.2 & 11 \\
\hline Group 2 Caustic-Leached and Washed (549-G2-CL-PSD) & 0.59 & 1.9 & 8.4 \\
\hline
\end{tabular}

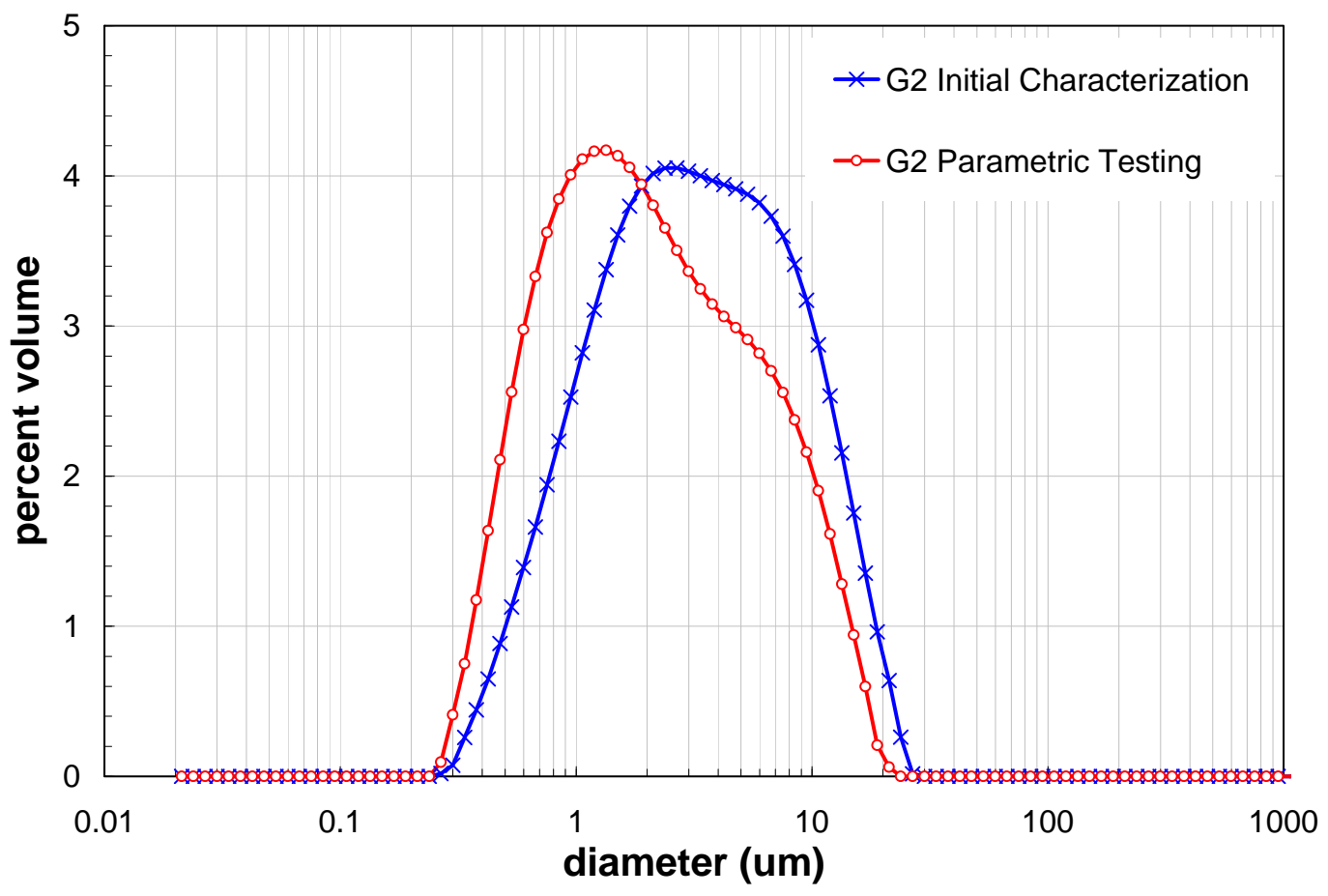

Figure 4.35. Influence of Caustic-Leaching and Washing on Group 2 Waste Solids PSD. All PSDs taken at measurement condition 1: 3000 RPM, before sonication. 
WTP-RPT-166, Rev. 0

\subsubsection{Crystal Form and Habit}

The following sections summarize the mineral-phase evaluation of the leached and washed solids.

\subsubsection{XRD}

The XRD pattern of the leached and washed solids is provided in Figure 4.36a; the background-subtracted $\mathrm{XRD}$ pattern with stick-figure phase identification is shown in Figure 4.36b.

Rutile, $\mathrm{TiO}_{2}$, was used as an internal standard for 2-theta calibration. Identification was done on 2-theta calibrated data. Four crystalline phases were positively identified. These included Cancrinite $\left[\mathrm{Na}_{7.14} \mathrm{Al}_{6} \mathrm{Si}_{7.08} \mathrm{O}_{26.73}\left(\mathrm{H}_{2} \mathrm{O}\right)_{4.87}\right.$, crystal density $2.375 \mathrm{~g} / \mathrm{cm}^{3}$, JADE Version 8.0, calculated value] and clarkeite $\left[\mathrm{Na}\left(\mathrm{UO}_{2}\right) \mathrm{O}(\mathrm{OH})\right.$, crystal density $6.792 \mathrm{~g} / \mathrm{cm}^{3}$, JADE Version 8.0, calculated value], which are both excellent matches to the observed data. Uranium dioxide $\left(\mathrm{UO}_{2}\right.$, crystal density $10.96 \mathrm{~g} / \mathrm{cm}^{3}$, CRC 1978) is a good match to the data; its strongest peak is overlapped by clarkeite, but two isolated confirming peaks in the observed data confirm the identification. Iron hydroxide oxide $\left[\mathrm{Fe}_{1.833}(\mathrm{OH})_{0.5} \mathrm{O}_{2.5}\right.$, crystal density $4.981 \mathrm{~g} / \mathrm{cm}^{3}$, JADE Version 8.0, calculated value] is a fair match; its strongest peak is partially overlapped by clarkeite, and three other peaks occur on the shoulders of other observed peaks.

Amorphous material accounts for a significant amount of the leached Group 2 solids, as indicated by the broad amorphous peak from about 10 to 30 degrees 2-theta in the raw data displayed in Figure 4.36a. This amorphous material cannot be characterized by XRD. 
(a)

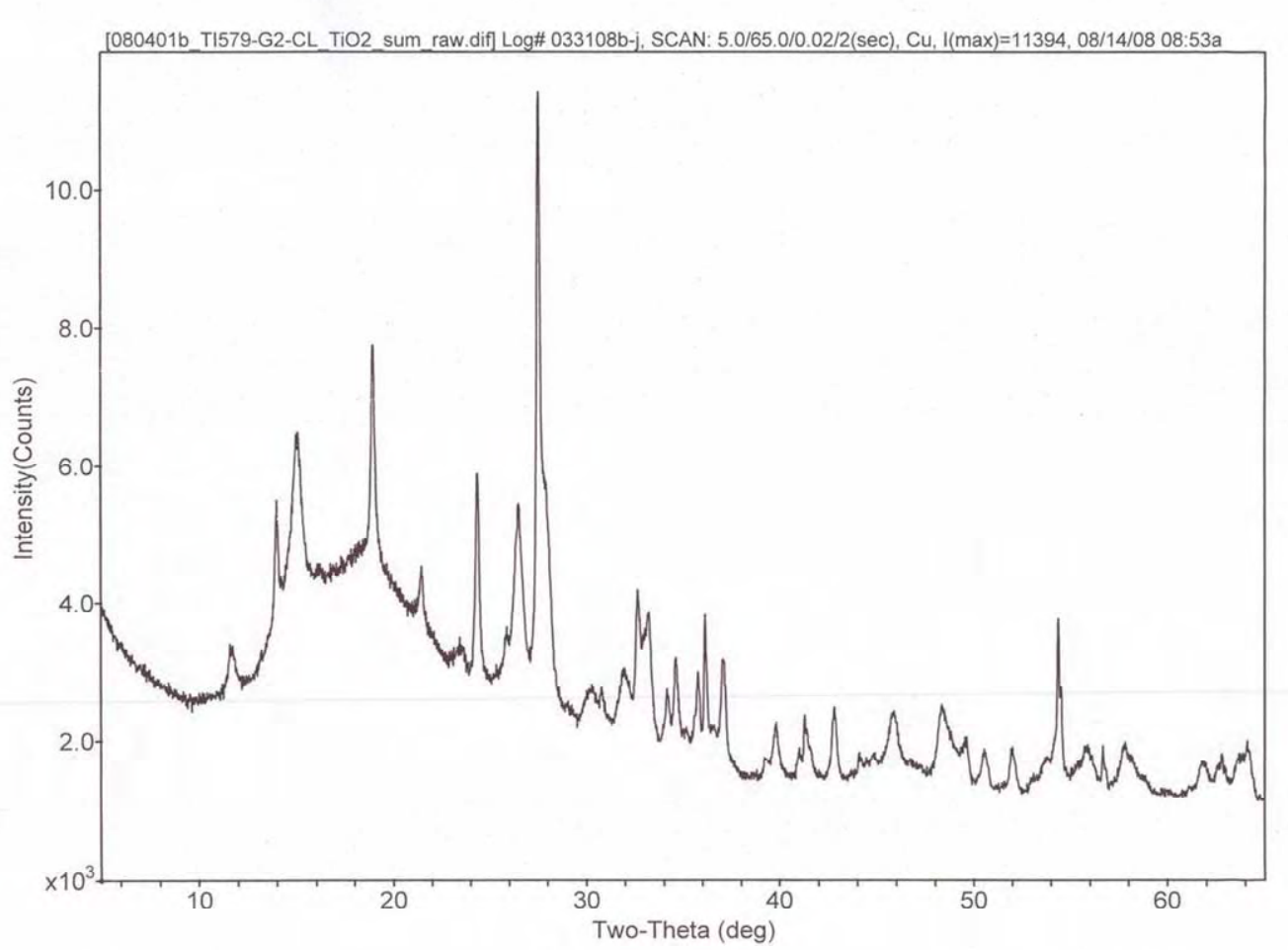

(b)
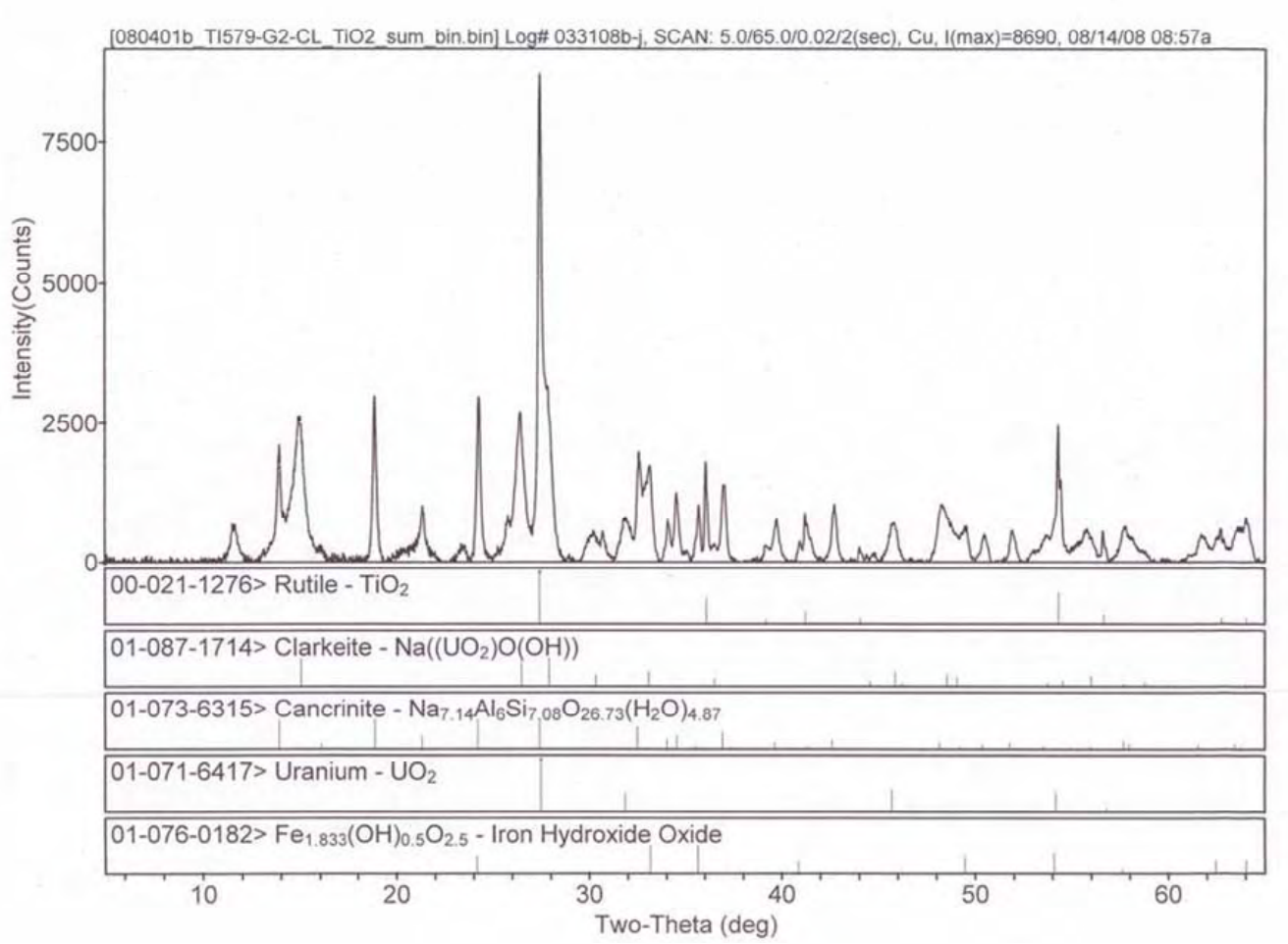

Figure 4.36. XRD Pattern of Caustic Leached Group 2 Bi-Phosphate Saltcake with Rutile $\left(\mathrm{TiO}_{2}\right)$ Internal Standard (a) Raw Data and (b) Background-Subtracted with Stick-Figure Peak Identification 


\subsection{SEM and TEM}

Several SEM images are shown in Figure 4.37. The particles seen in these images are typically on the order of 5 to $60 \mu \mathrm{m}$, which is consistent with the PSD data reported above.

(a)

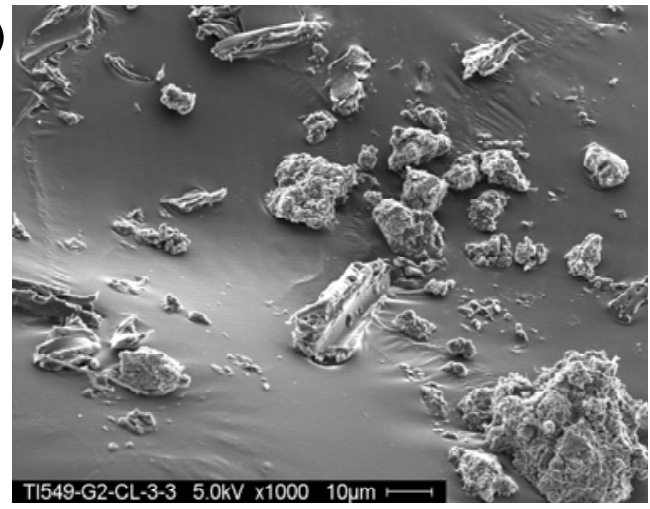

(c)

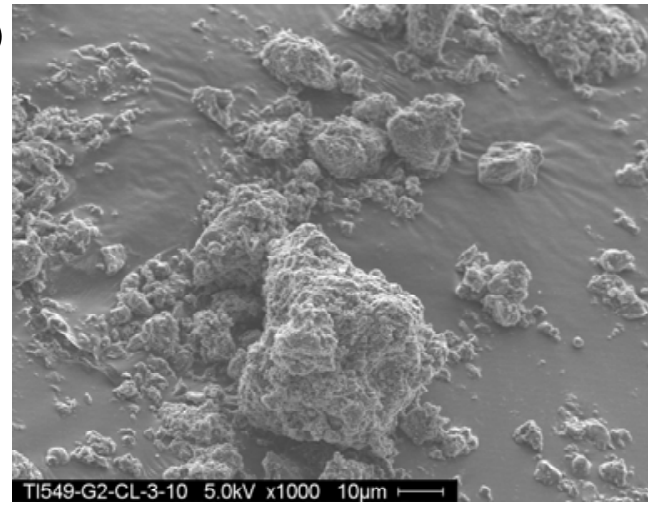

(b)

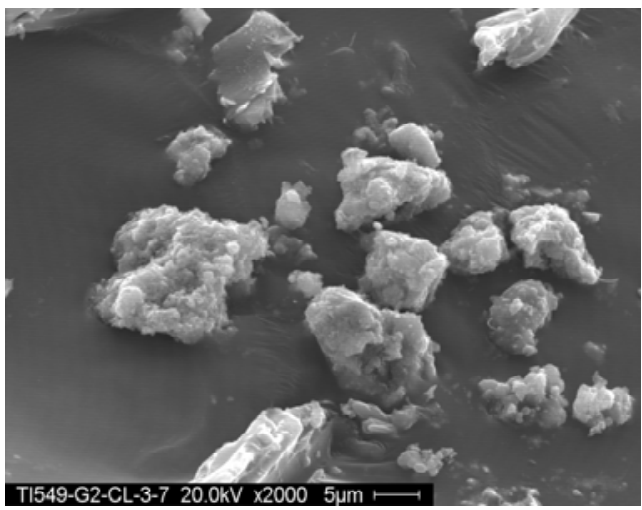

(d)

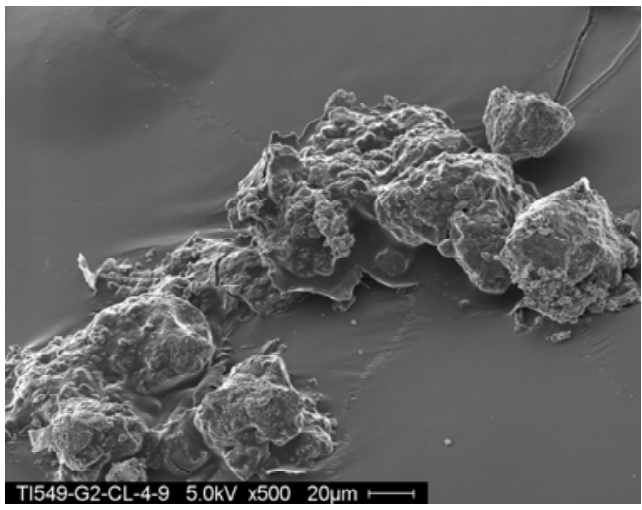

Figure 4.37. SEM Images of Group 2 Bi-Phosphate Saltcake Caustic Leached and Washed Solids (a) $5 \mathrm{kV}, 1000 \times$; (b) $20 \mathrm{kV}, 2000 \times$; (c) $5 \mathrm{kV}, 1000 \times$; (d) $5 \mathrm{kV}, 500 \times$

Figure 4.38 and Figure 4.39 each show an SEM image along with EDS spectra of three different particles for each. The elemental analysis shows a large amount of oxygen and carbon, which is an artifact of the sample preparation (carbon is sputtered onto the sample to eliminate problems with charging). If this is removed, and the other constituents are normalized, the weight percentages shown in Table 4.21 for each analysis are obtained. It is interesting to note that there is a great deal of variability between particles. Whereas for the Group 1 leached sample, most of the particles had the same chemical makeup, the Group 2 leached solids consisted of particles with distinct compositions. The particle at spot 6 in Figure 4.38 and the particle at spot 3 in Figure 4.39 each consist of only $\mathrm{Na}, \mathrm{Al}$, and $\mathrm{Si}$, which is consistent with the identification of cancrinite in the XRD analysis.

The remaining four particles that were examined by EDS and shown in these two figures were composed of several different elements. Two have very similar compositions to one another. The particle at spot 3 in Figure 4.38 and the particle at spot 2 in Figure 4.39 both have high concentrations of $\mathrm{U}(23.4 \%)$ and $\mathrm{Fe}$ (23.0\%), along with about half as much $\mathrm{Na}(12.2 \%), \mathrm{Al}(9.5 \%)$, and $\mathrm{Ca}(12.1 \%)$. Weight percents shown in parentheses are the averages of the two particles. The last two particles have high concentrations of $\mathrm{Na}, \mathrm{Al}, \mathrm{Si}$ (16 to $28 \%$ ) as well as lower concentrations of $\mathrm{U}$ and $\mathrm{Fe}$ (7 to $14 \%$ ). 
(a)

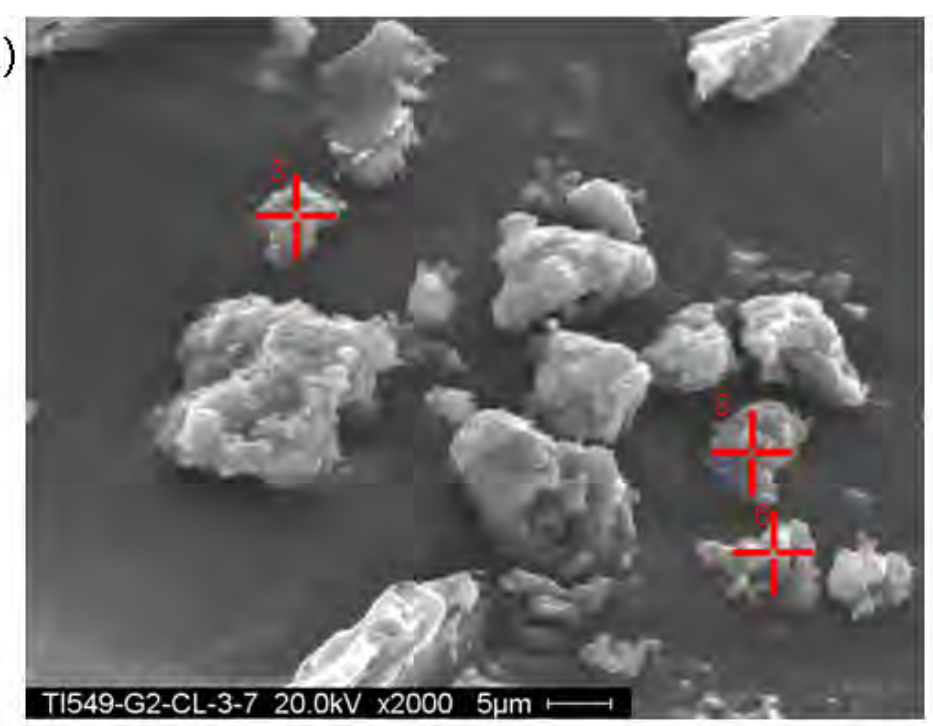

范

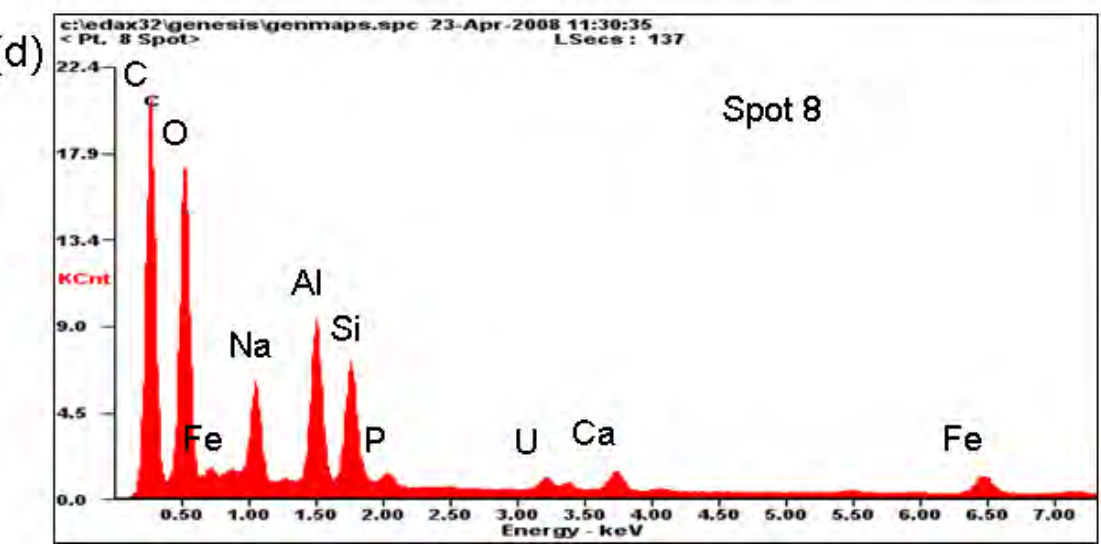

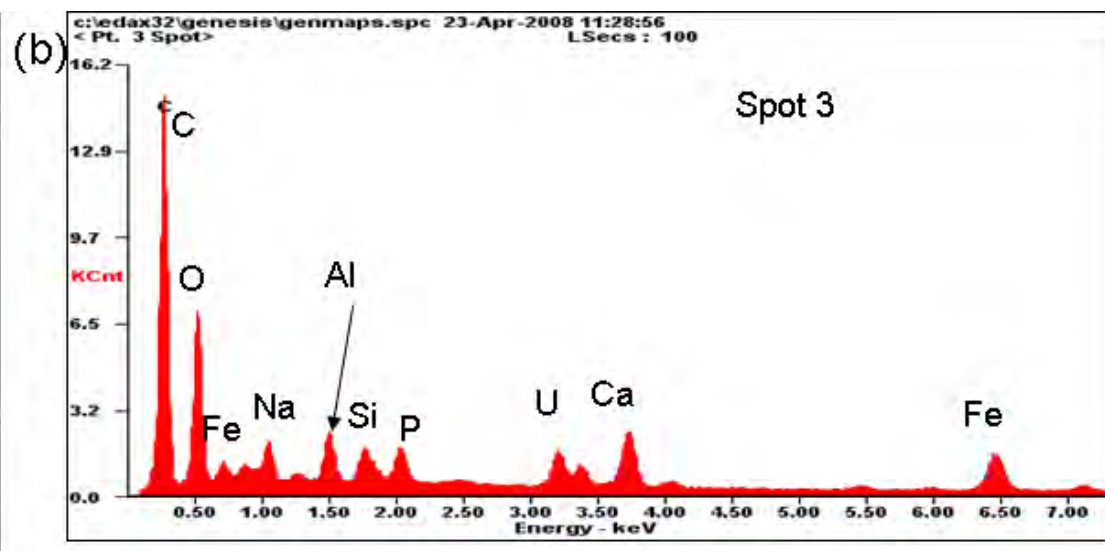

(c)

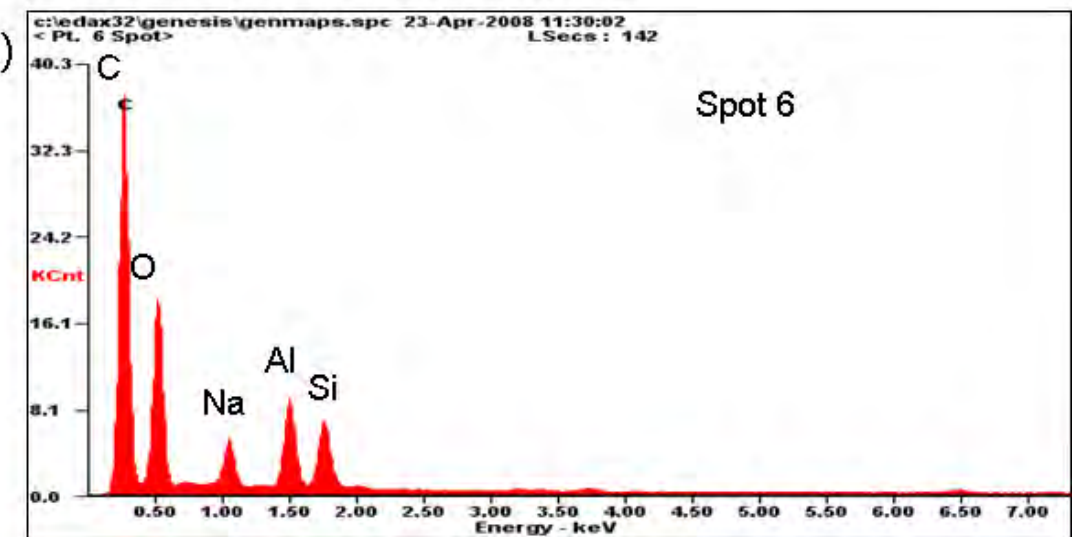

Figure 4.38. SEM Image of Group 2 Bi-Phosphate Saltcake Caustic Leached and Washed Solids with EDS Spectra (a) SEM Image; (b) EDS Spectra of Spot 3; (c) EDS Spectra of Spot 6; (d) EDS Spectra of Spot 8 
(a)

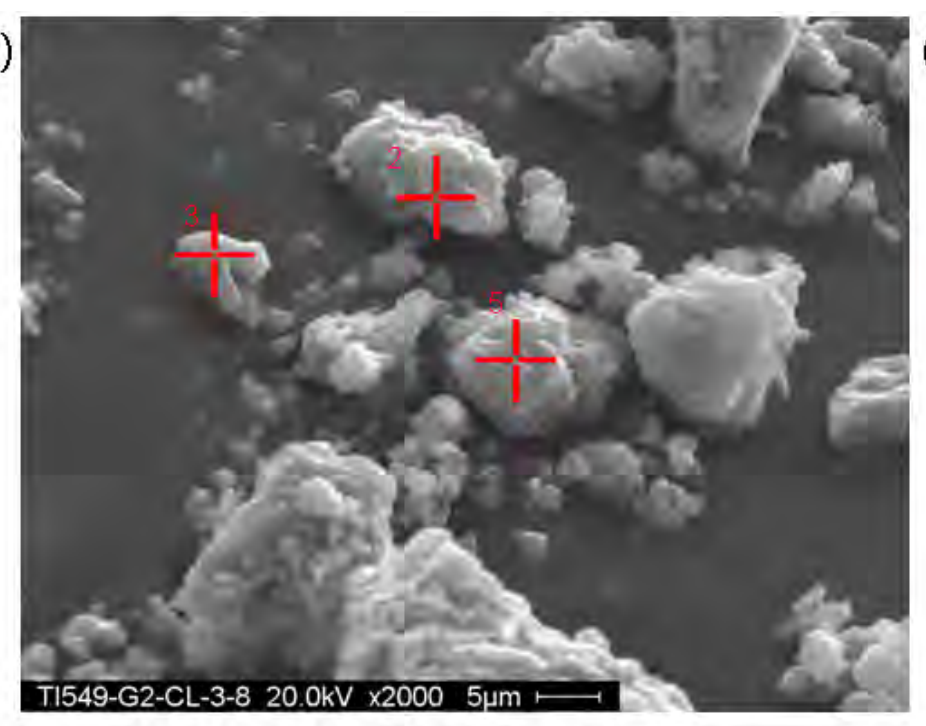

¿̊

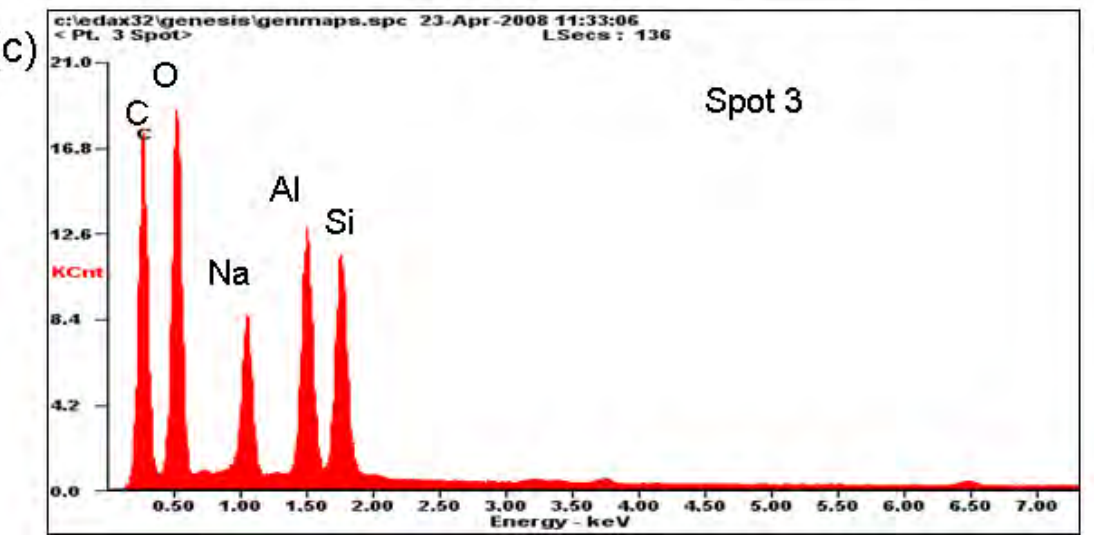

(b)

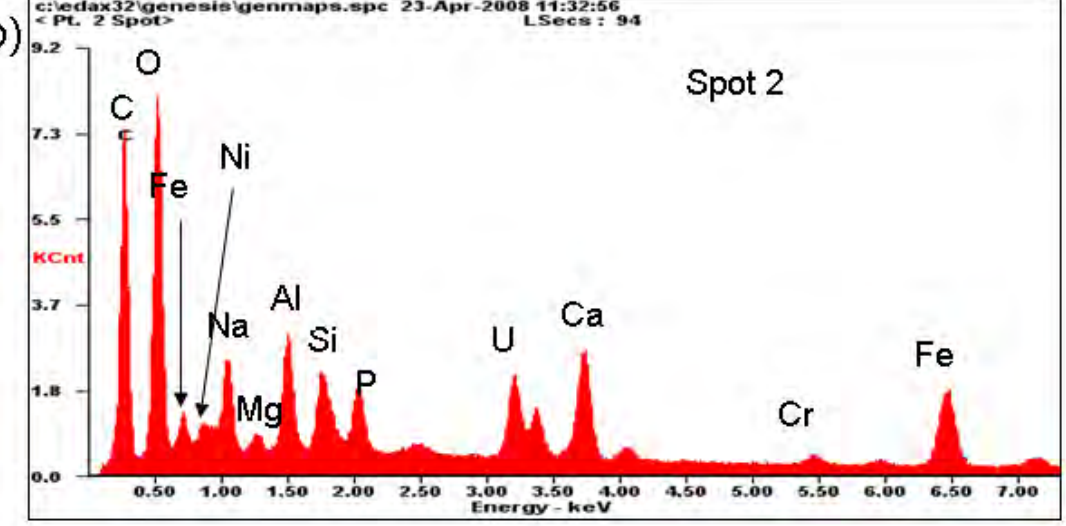

Figure 4.39. SEM Image of Group 2 Bi-Phosphate Saltcake Caustic Leached and Washed Solids with EDS Spectra (a) SEM Image; (b) EDS Spectra of Spot 2; (c) EDS Spectra of Spot 3; (d) EDS Spectra of Spot 5

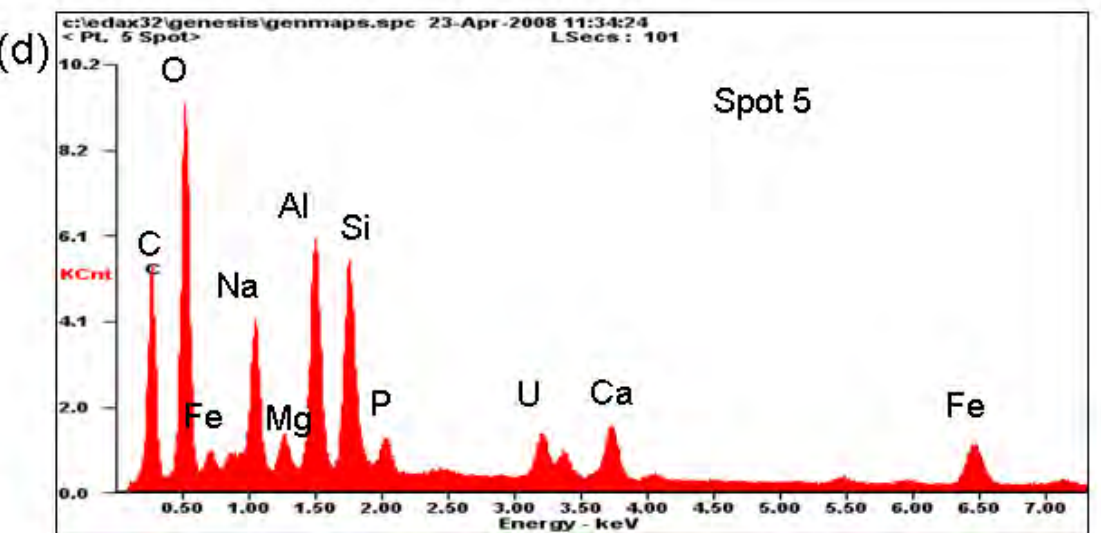


Table 4.21. Normalized Weight Percents for Various Analytes Found by EDS of SEM Images for Figure 4.38 and Figure 4.39

\begin{tabular}{|c|c|c|c|c|c|c|}
\hline & \multicolumn{7}{|c|}{ Normalized Weight Percent } \\
\cline { 2 - 7 } Element & $\begin{array}{c}\text { Fig 4.38 } \\
\text { Spot 3 }\end{array}$ & $\begin{array}{c}\text { Fig 4.38 } \\
\text { Spot 6 }\end{array}$ & $\begin{array}{c}\text { Fig 4.38 } \\
\text { Spot 8 }\end{array}$ & $\begin{array}{c}\text { Fig 4.39 } \\
\text { Spot 2 }\end{array}$ & $\begin{array}{c}\text { Fig 4.39 } \\
\text { Spot 3 }\end{array}$ & $\begin{array}{c}\text { Fig 4.39 } \\
\text { Spot 5 }\end{array}$ \\
\hline $\mathrm{Na}$ & 10.8 & 32.1 & 26.9 & 13.5 & 33.7 & 20.3 \\
\hline $\mathrm{Mg}$ & 0 & 0 & 0 & 1.7 & 0 & 3.5 \\
\hline $\mathrm{Al}$ & 9.0 & 38.4 & 27.6 & 10.0 & 34.5 & 20.8 \\
\hline $\mathrm{Si}$ & 5.1 & 29.5 & 20.3 & 5.8 & 31.8 & 16.5 \\
\hline $\mathrm{P}$ & 6.3 & 0 & 1.7 & 5.1 & 0 & 2.6 \\
\hline $\mathrm{U}$ & 23.6 & 0 & 7.3 & 23.2 & 0 & 13.6 \\
\hline $\mathrm{Ca}$ & 13.1 & 0 & 4.5 & 11.0 & 0 & 5.8 \\
\hline $\mathrm{Cr}$ & 0 & 0 & 0 & 1.9 & 0 & 0 \\
\hline $\mathrm{Fe}$ & 24.6 & 0 & 11.8 & 21.3 & 0 & 12.2 \\
\hline $\mathrm{Ni}$ & 7.6 & 0 & 0 & 6.4 & 0 & 4.6 \\
\hline
\end{tabular}

Figure 4.40 provides an SEM-EDS map of selected elements in the leached and washed solids. Al, Fe, and $\mathrm{Si}$ are present throughout most of the sample. However, there are several areas where these three elements are more concentrated, confirming the suspicion of the insoluble aluminum being an aluminosilicate. This would suggest that iron is also associated with the aluminosilicate phase. The largest particle containing these three elements can be seen in the upper-right-hand quadrant of the micrograph. It is also easy to see that in the corresponding area in the maps of $\mathrm{Ca}, \mathrm{U}, \mathrm{P}$, and $\mathrm{Na}$, these elements are either not present or present in very small quantities. A correlation can also be seen between calcium and uranium in several spots, where these two appear to be more highly concentrated. Phosphorus and sodium are fairly evenly distributed throughout the area.

SEM

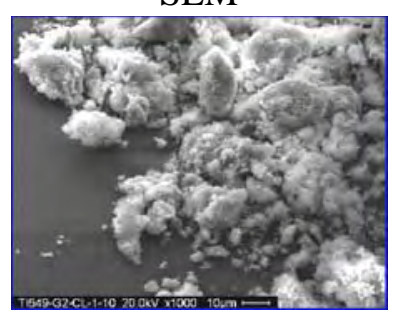

Ca

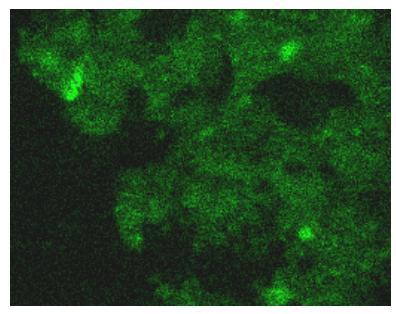

$\mathrm{Al}$

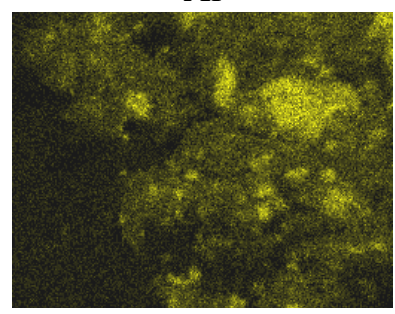

$\mathrm{U}$

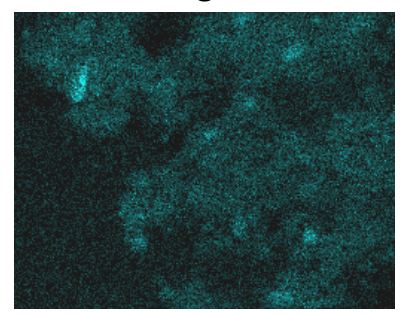

Fe

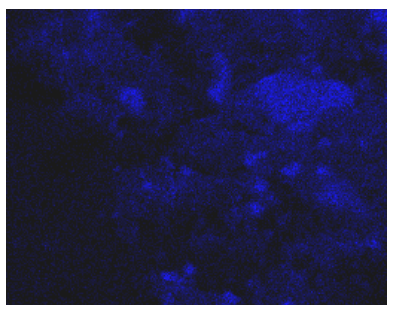

$\mathrm{P}$

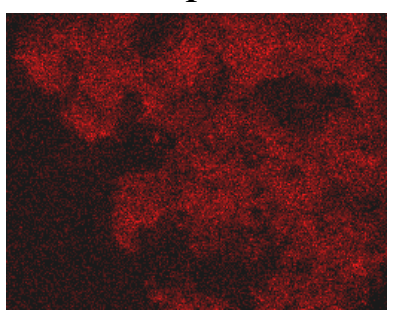

Si

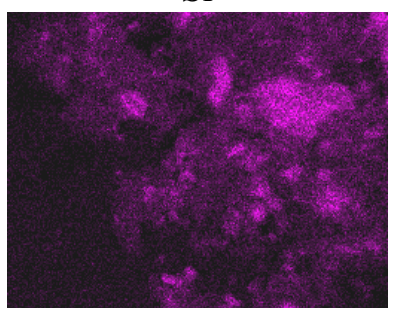

$\mathrm{Na}$

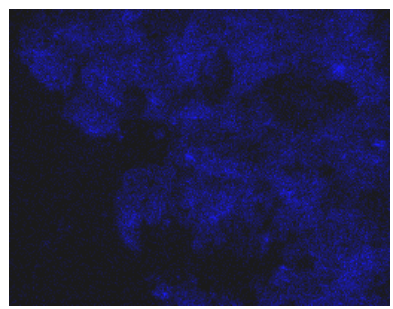

Figure 4.40. SEM-EDS Image of Caustic Leached Group 2 Bi-Phosphate Saltcake with Al, Fe, Si, Ca, $\mathrm{U}, \mathrm{P}$, and Na Maps 
Figure 4.41 shows that the caustic leached solids consist of mixed phase agglomerates with a high surface area. Spherical and elongated particles are seen. The TEM images of the particles were used to estimate the size range of the particles. Using multiple images, measurements were made along the diagonals of the particles. These measurements were then listed and ordered. The data were fit to a $\log _{\mathrm{e}}-$ normal distribution. Figure 4.42 is a cumulative number distribution of agglomerates identified during STEMHAADF imaging that describes the probability of particle sizes from the TEM images. The mathematical fit represents a $\log _{\mathrm{e}}$-normal distribution. The average particle size was $\sim 400 \mathrm{~nm}$.

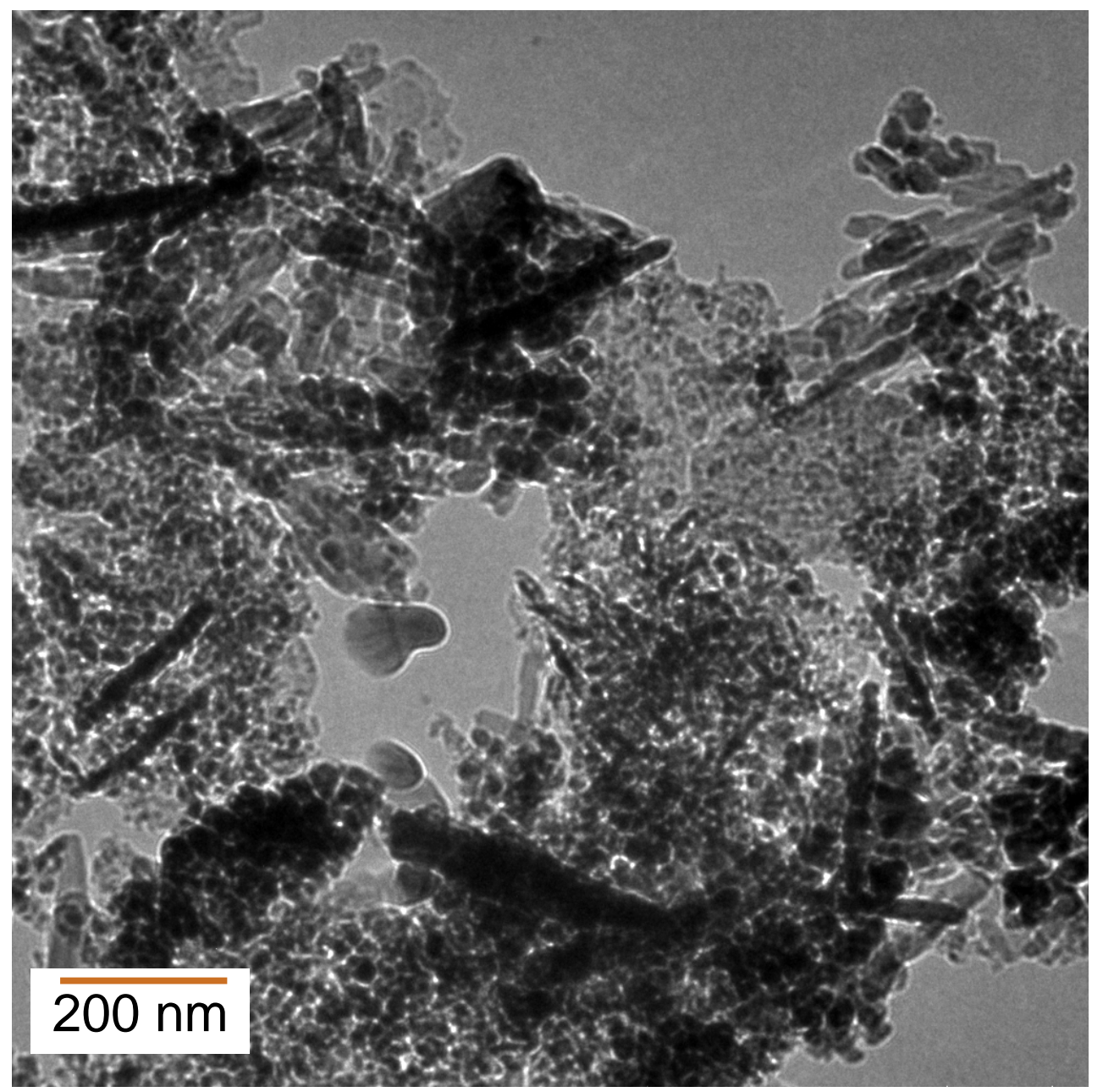

Figure 4.41. TEM Image of Caustic Leached Group 2 Bi-Phosphate Saltcake 


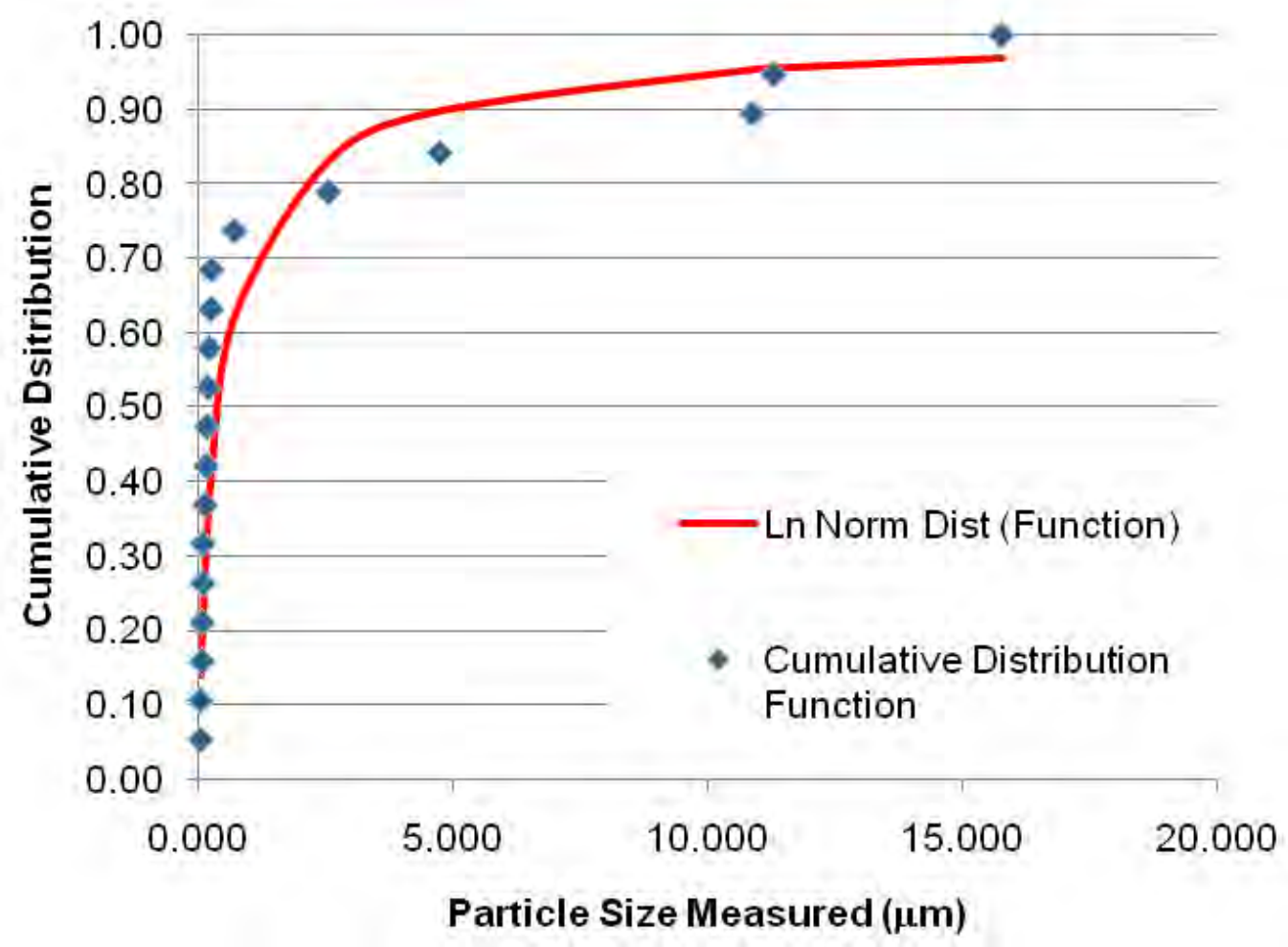

Figure 4.42. Cumulative Distribution Plot of Caustic Leached Group 2 Bi-Phosphate Saltcake and a Mathematical Fit to the Data

Figure 4.43 shows a typical TEM image with EDS analysis of several different regions in the sample. Area 3 is a uranium-rich area, also having several other elements, such as $\mathrm{Mg}, \mathrm{Na}, \mathrm{Si}, \mathrm{Al}, \mathrm{P}, \mathrm{Fe}, \mathrm{Co}$, and Ni. In areas 1 and 2, uranium is not seen, but these other elements are. Point 1 consists of $\mathrm{Si}$, Al, and Fe, which agrees with EDS data from SEM, showing that these three elements are associated in some way. The metals having the highest concentrations (as shown in Table 4.14) in the caustic leached solids are all seen with EDS analysis of the leached solids.

Figure 4.44 and the EDS analysis shows that there are particles in this agglomerate that consist only of iron, other particles that consist of uranium, and there is also an area that has calcium, strontium, and phosphorus. Figure 4.45 shows two different areas of the sample. In Figure 4.45 (a) and (b), an agglomerate that consists of uranium, iron, and manganese is shown. Although there is some overlap of the three elements, it appears that this is mostly three discrete phases. The darker spots in (a) correspond to $\mathrm{Mn}$, which is surrounded in the top particle by iron. The lower half of the image shows an area of Mn surrounded by uranium. There are also solids in the middle and on the lower left of the image that appear to be a pure uranium phase. Figure 4.45(c) shows several needle-shaped crystals of a pure iron phase, surrounded by round areas of a pure uranium species. 

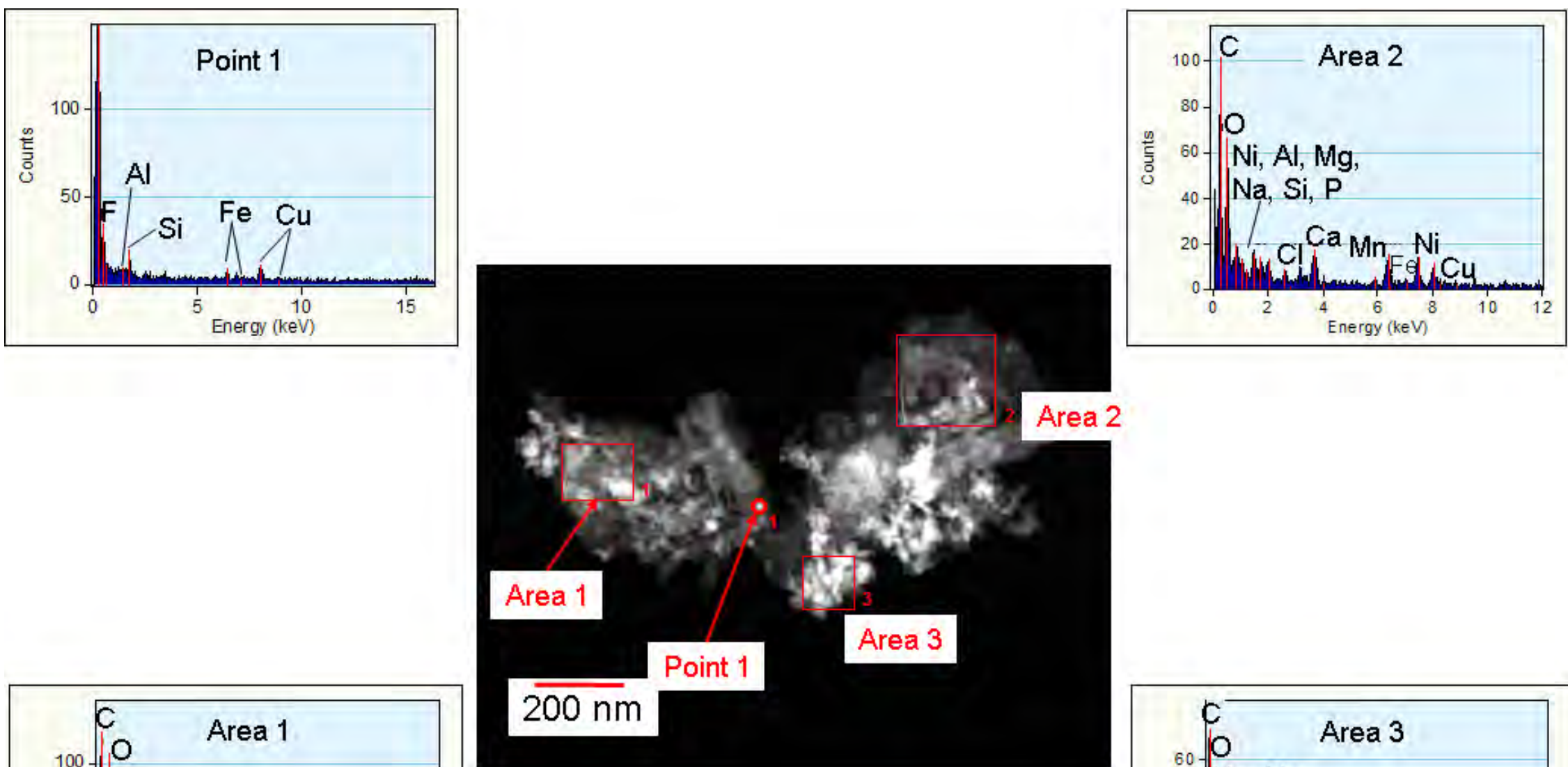

$\underset{\infty}{+}$
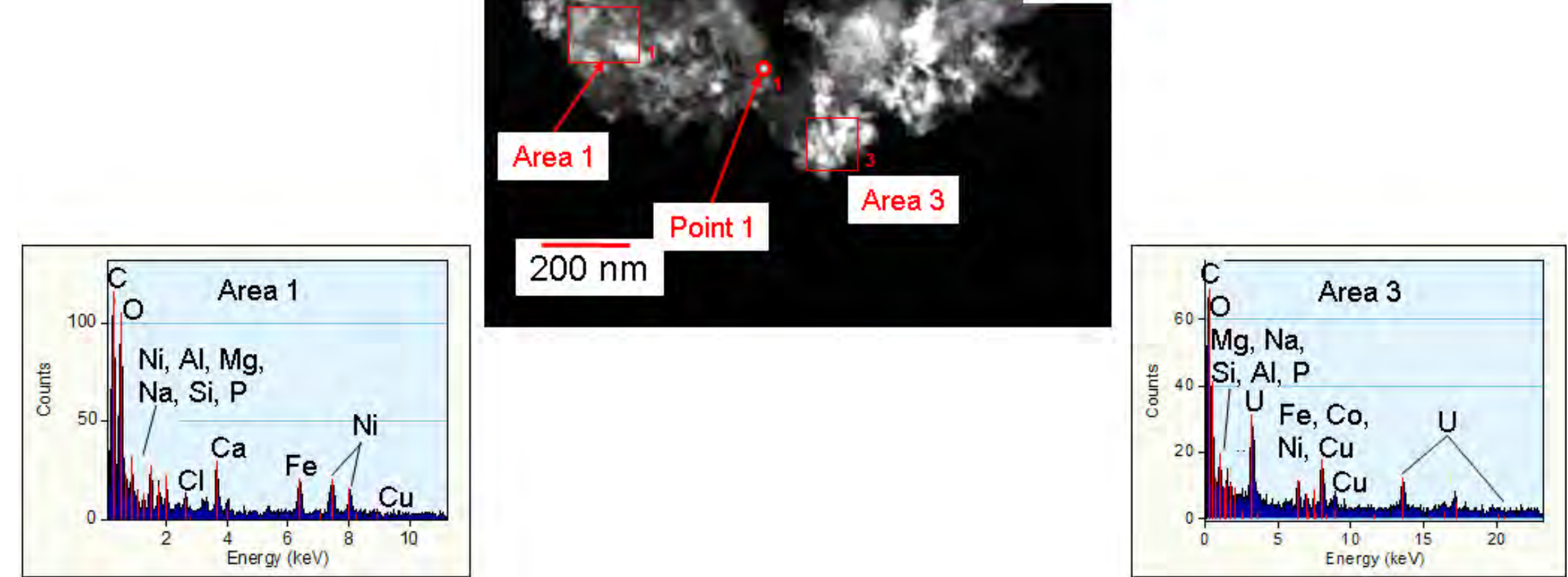

Figure 4.43. STEM-HAADF Image with EDS Analysis 
(a)

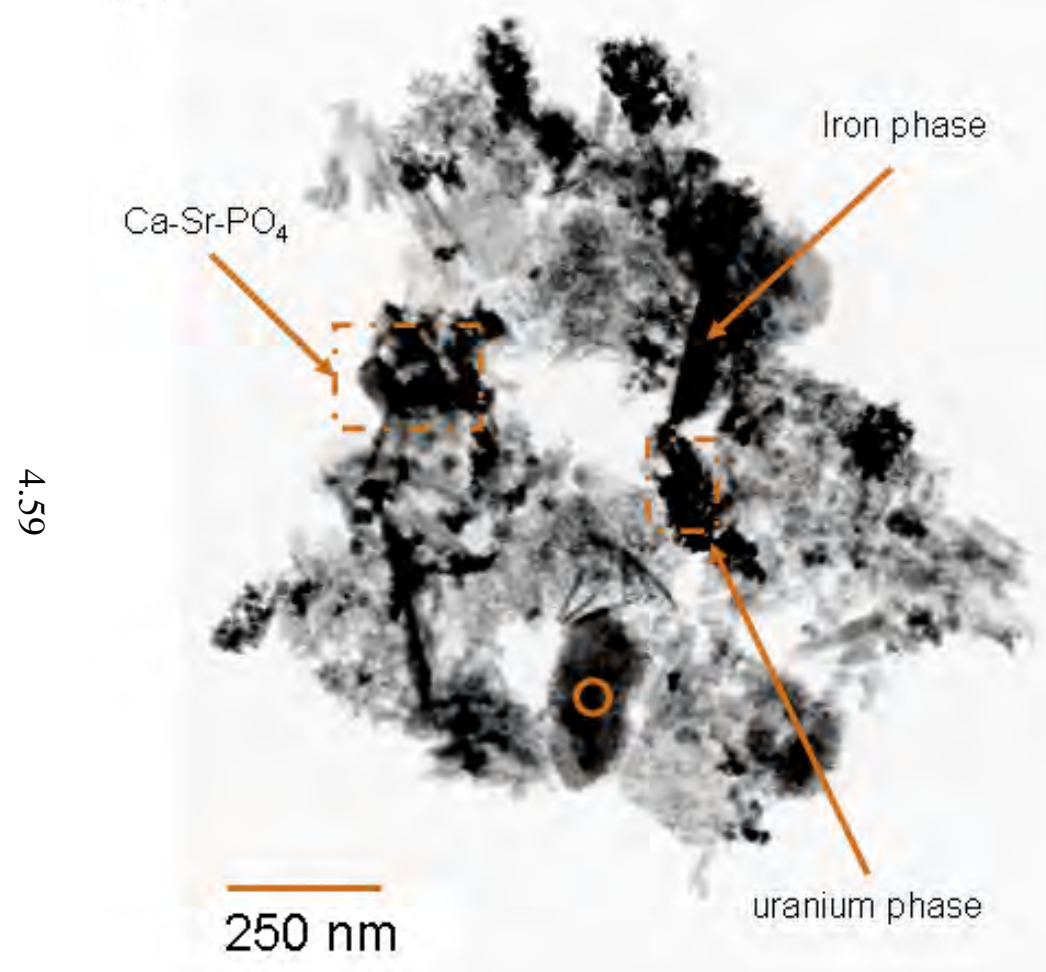

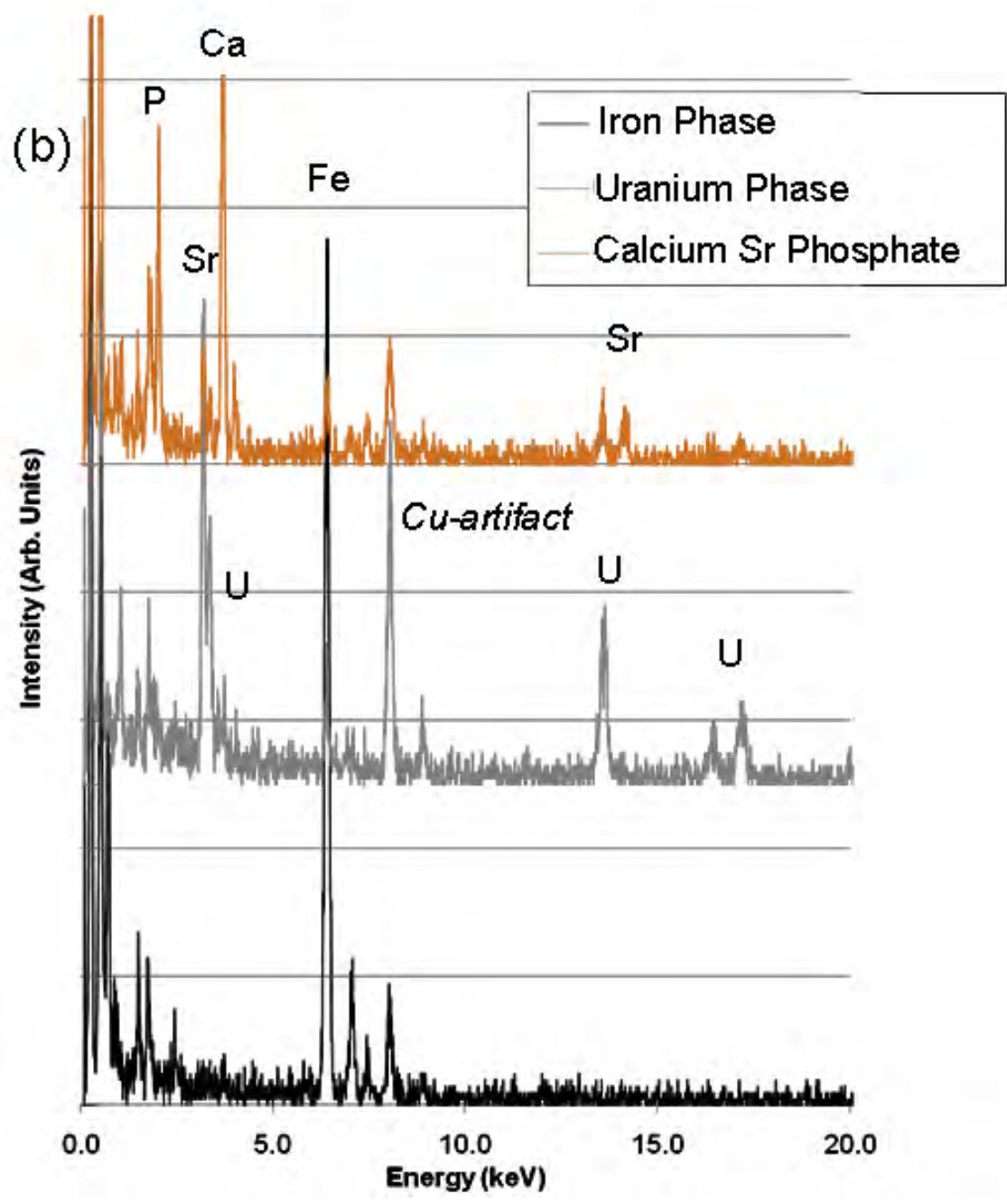

$\sum_{0}$
0
0
0
1
1
2
0
0
0
0
0

Figure 4.44. TEM Image with EDS Analysis Showing Uranium and Iron Rich Particles 
(a)

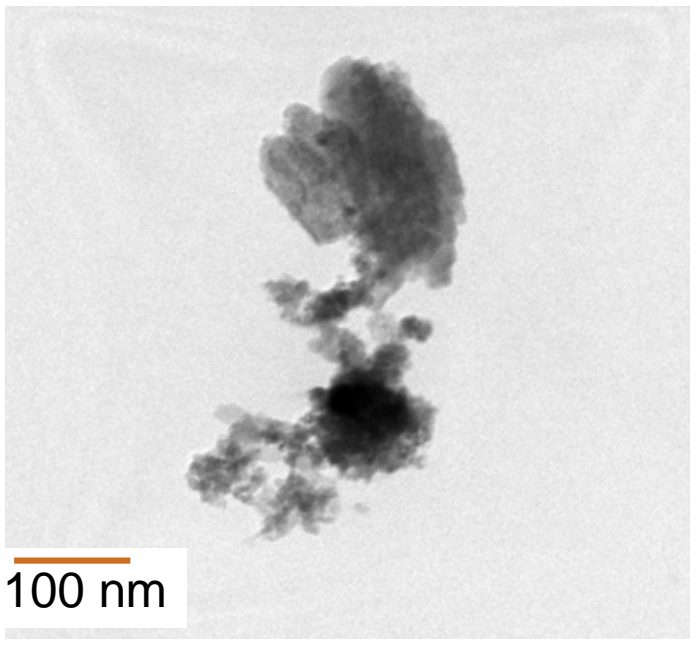

(c)

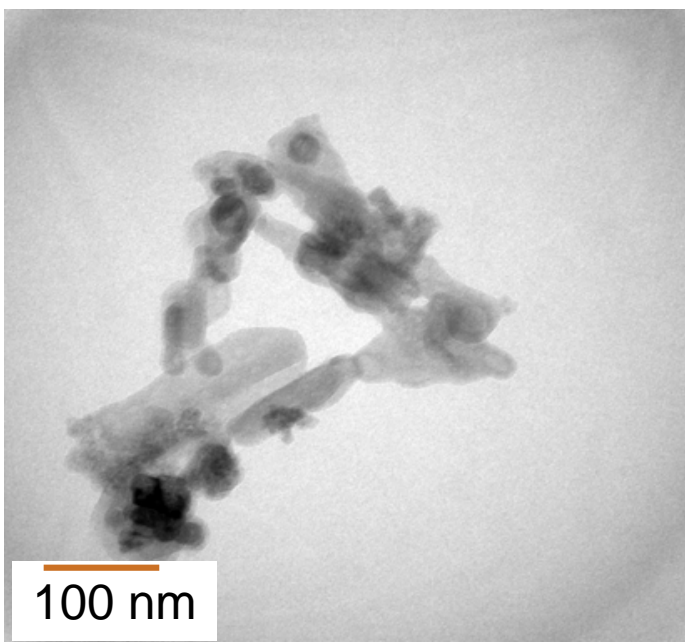

(b)

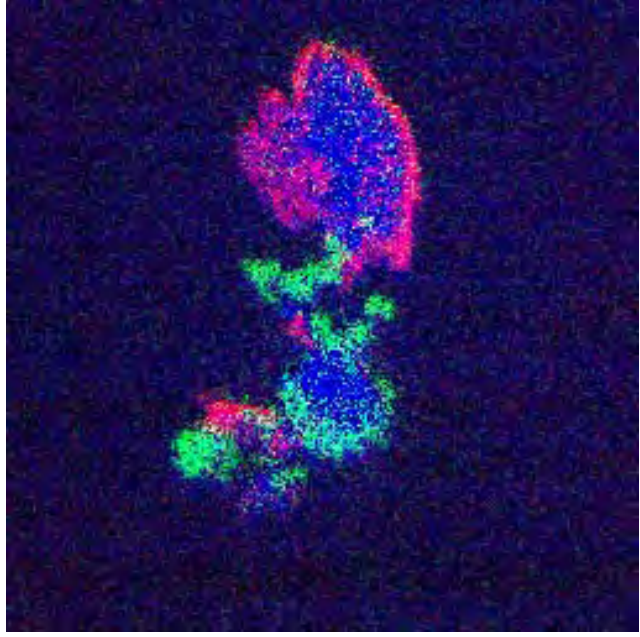

(d)

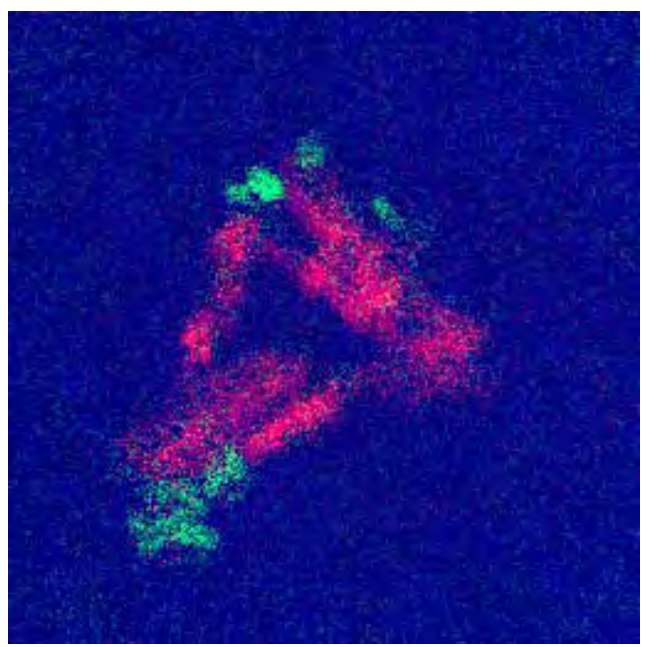

Figure 4.45. Energy Filtered TEM Images: (a) EFTEM Image Showing Particles Rich in U, Fe, and Mn; (b) EELS Elemental Mapping of (a); (c) EFTEM Image Showing Particles Rich in U and Fe; (d) EELS Elemental Mapping of (c). Color coding: $\mathrm{U}$ is green, Fe is red, and Mn is blue.

\subsubsection{Surface Area by BET}

A BET measurement was conducted on the caustic leached and washed solids, resulting in a surface area of $79.7 \mathrm{~m}^{2} / \mathrm{g}$. This shows an increase in relative surface area following caustic leaching from the value of $46.3 \mathrm{~m}^{2} / \mathrm{g}$ found for the initial washed solids. 


\subsection{Group 1/2 CUF Filtration and Leach Testing and Results}

This section describes the filtration/leaching tests ${ }^{(\mathrm{a})}$ performed with a composite blend of the Group 1 bismuth phosphate sludge and the Group 2 bismuth phosphate saltcake (referred to here as the Group 1/2 sample). Descriptions of the experimental methods and analyses performed can be found in Appendix K.

\subsection{Test Scheme}

Figure 5.1 outlines the testing of the blended Group 1/2 sample.

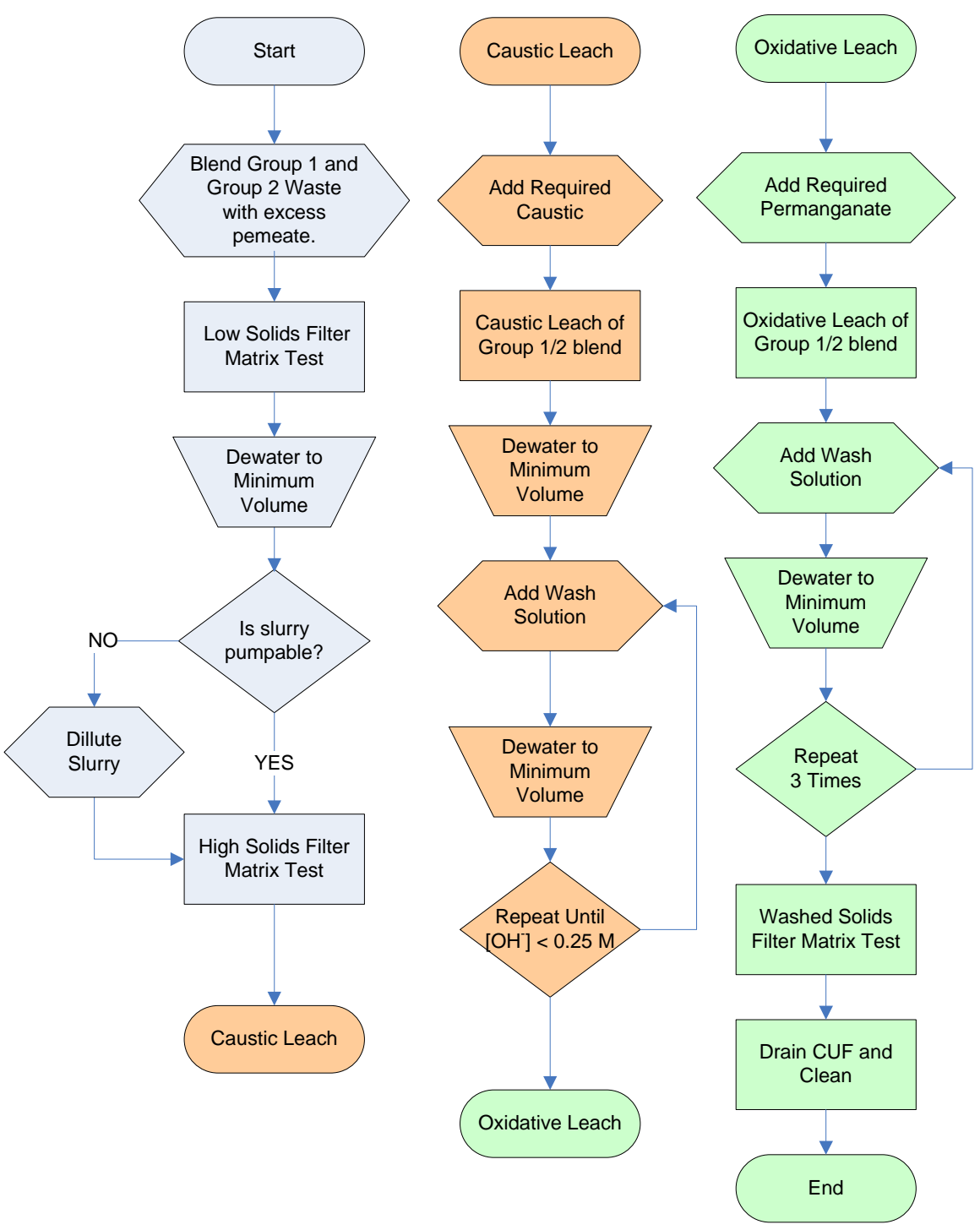

Figure 5.1. Group $1 / 2$ Test Flowchart

(a) Conducted according to TI-RPP-WTP-572, HLW Filtration and Caustic/Oxidative Leaching of Group 1/2 Composite Waste, R Shimskey, January, 2008. 
WTP-RPT-166, Rev. 0

The goals of this test were to:

- Evaluate the filtration of the bismuth phosphate sludge and saltcake wastes blended together

- Evaluate the effectiveness of caustic leaching in removing aluminum, phosphorus, and chromium from the blended waste

- Evaluate the effectiveness of oxidative leaching (using sodium permanganate) in removing chromium from the blended waste

- Evaluate the filtration of the washed leached solids.

The initial slurry introduced to the CUF skid used the inventory of the Group 1 and 2 sludge samples diluted with excess Group 2 permeate to produce a composite slurry with a target UDS concentration of $9 \mathrm{wt} \%$. The combined slurry was to contain 520 grams of UDS and an estimated volume of $4 \mathrm{~L}$. A filter test matrix was performed on the diluted slurry waste as described in Appendix K, and then the material was to be dewatered to a target concentration of $20 \mathrm{wt} \%$ UDS, if possible. To achieve that, the slurry was to be dewatered to a target volume of $2 \mathrm{~L}$. At this point, an abridged test matrix was performed to evaluate the change in the filtration behavior after concentrating the waste slurry.

Next, the waste slurry was removed from the CUF skid to be caustic leached. The slurry reservoir tank functioned as a batch reaction vessel, but first had to be drained and isolated from the skid's piping. Once the tank was isolated, the slurry was returned to the slurry reservoir tank and was blended with a caustic solution for the leaching. The amount of caustic added was based on a prediction ${ }^{(a)}$ of $60 \%$ dissolution of aluminum in the Group 1 solids and 90\% dissolution of aluminum in the Group 2 solids. Sufficient caustic was added to maintain aluminum solubility after cooling to ambient temperature. The amount of caustic added was determined using the gibbsite solubility data using an empirical model developed by C. Misra, as reported by Li et al. (2005). The empirical model used is shown in Equation 5.1 where concentrations of aluminum and sodium hydroxide are in moles/liter, and $\mathrm{T}$ is the absolute temperature of the solution in Kelvin.

$$
\ln ([\mathrm{Al}])=5.71-\frac{2486.70}{T}+\frac{33.71[\mathrm{NaOH}]}{T}+\ln ([\mathrm{NaOH}])
$$

The volume of the addition was established to include the volume of water representing the leaching solution and the volume increase predicted to occur from heating with steam injection in the UFP2 vessel. The leach solution was heated to $100^{\circ} \mathrm{C}$ over a 5.3-h interval and held at $100^{\circ} \mathrm{C}$ for $8 \mathrm{~h}$. The slurry permeate was sampled during the heat ramp and temperature soak to evaluate the aluminum dissolution rate during these two periods. Afterwards, the solution was allowed to cool back to room temperature over a 12-h interval. At this point, the leached slurry solution in the slurry reservoir tank was allowed to enter the piping of the CUF skid, and it was dewatered to the minimum operating volume for the filtration skid.

(a) The dissolution factors were based on data assembled in report WTP-RPT-151 (GJ Lumetta and RT Hallen, Review of Caustic Leaching Testing With Hanford Tank Sludges). Results of parametric studies for the Group 1 and 2 composites were not available at this time. 
Five equal volumes (1.2 L each) of caustic rinse solutions were then added to the leached solids slurry and dewatered each time. The $\mathrm{NaOH}$ concentration of each rinse solution was established to maintain sufficient free hydroxide in solution such that the aluminum concentration was always below saturation. The caustic concentration of each rinse solution was calculated by:

- Estimating the initial $\mathrm{Al}$ concentration of the caustic leachate using the assumptions of the $\mathrm{Al}$ leach factor stated above.

- Assuming perfect mixing, the addition of each rinse solution would decrease the aluminum concentration by $50 \%$.

- The final free hydroxide concentration of the supernate needed to prevent Al precipitation at that concentration was calculated. This was done in the same manner that the targeted free hydroxide concentration was calculated for the caustic leachate solution—using reported $\mathrm{Al} / \mathrm{OH}$ solubility data (Li et al. 2005) to ensure that sufficient hydroxide was present to prevent Al precipitation.

- The additional mass of hydroxide needed to be added to the supernate was then calculated and this amount of hydroxide was added to the rinse solution as $\mathrm{NaOH}$.

As the $\mathrm{Al}$ concentration decreases, the free hydroxide concentration required to maintain solubility decreases as well, allowing more dilute rinse solutions to be used over time. After the fifth rinse, the free hydroxide level of the washed permeate was predicted to be below the $0.25 \mathrm{M}$ level needed to perform oxidative leaching.

Once the slurry was rinsed after caustic leaching, it was removed from the CUF skid for oxidative leaching. As before, the waste solution was returned to the slurry reservoir tank once the tank was isolated from the filtration piping. At this point, a solution of $1 \mathrm{M}$ sodium permanganate was added to the slurry. Sufficient sodium permanganate solution was added to achieve a 1:1 molar ratio of Mn to the predicted quantity of $\mathrm{Cr}$ in the waste solids. After the solution was added to the waste slurry, it was mixed for 6 hours at room temperature. Slurry permeate samples were periodically collected during this time to evaluate the chromium dissolution rate for the blended waste sample. After 6 hours, the oxidative leaching slurry was immediately rinsed with three equal-volume washes of $0.01 \mathrm{M} \mathrm{NaOH}$ solution. After dewatering the last rinse solution, a final test matrix was performed. The combined slurry was further dewatered to a minimum volume to increase the UDS concentration higher than that from the previous test and to obtain additional dewatering data for the leached waste. After dewatering the combined leached slurries from both tests, an abridged filter matrix test was performed on the dewatered slurry to compare how the filtration behavior changed after leaching.

Slurry and permeate samples were periodically collected to track the solid loading in the waste slurry and the chemical components of the slurry to perform mass balance calculations afterwards. This was done to evaluate the effectiveness of the process to separate LAW waste components from the HLW components in the waste sample. Chemical analyses were performed by the ASO, under the QA requirements discussed in Appendix D. All analyses performed by ASO were performed under Analytical Service Request (ASR) 8113; the analytical results are compiled in Appendix M. 


\subsection{Initial Feed Characterization}

Figure 5.2 summarizes the preparation of the initial Group 1/2 feed composite. The low-solids slurry was composed of 2,161 grams of homogenized Group 1 slurry (TI508-G1-AR-J1 through -J7), 158 grams of Group 1 rinse solution (TI508-G1-Rinse), 881 grams of homogenized Group 2 slurry (TI517-G2-AR), 2,011 grams of Group 2 supernatant, and 33.2 grams of solid sodium hydroxide $(98 \% \mathrm{NaOH})$. The mass of UDS present in the composite waste slurry was estimated to be 520 grams, based on the physicalproperty data reported in Table 3.2 for Group 1 and Table 4.2 for Group 2. After the slurry was blended in the slurry reservoir using the overhead mixer, the pump began circulating the slurry through the filter. Filtrate was then allowed to flow through the mass flow meter of CUF permeate piping. Once the measured density of the mass flow meter appeared stable, the back-pulse chamber was filled with permeate. After the back-pulse chamber and permeate piping were filled, an estimated $200 \mathrm{~mL}$ of slurry supernate was removed from the circulating slurry, which is referred to as the system permeate holdup volume.

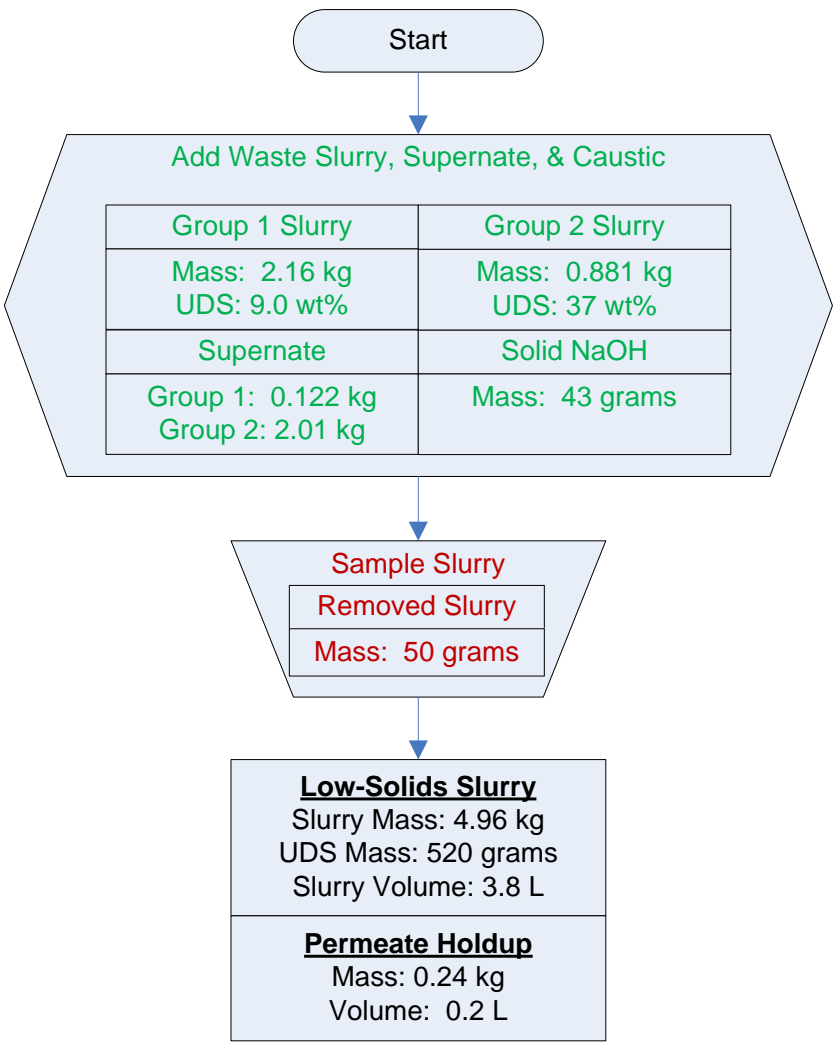

Figure 5.2. Flow Diagram of the Initial Feed Composite and Sampling Note: Mass and volume values in figure are rounded to the nearest significant digit of accuracy.

After the slurry and permeate piping were filled, the circulating slurry was sampled for characterization. Physical-property measurements were performed on two samples collected in 10- to 15-mL glass centrifuge tubes that were allowed to settle for a minimum of 24 hours and then centrifuged for a minimum of 1 hour at $1000 \mathrm{G}$. The average results from the two samples are detailed in Table 5.1. The definition of each term in the table is: 
- Slurry density: The measured density of the sampled circulating slurry using the net weight of the sample and the volume of the sample collected.

- Supernate density: The measured density of the decanted slurry supernate after centrifuging the sample at $1000 \mathrm{G}$ for a minimum of 1 hour.

- Settled Solids: The solid volume fraction of the slurry after gravity settling for a minimum of 24 hours.

- Centrifuged UDS: The weight percent of UDS present in the centrifuged solids fraction of the slurry after decanting the supernatant liquid.

- Total Solids (TS): The TS fraction of the slurry.

- UDS: The UDS fraction of the slurry

- Dissolved Solids (DS): The DS fraction of the supernate. This is not the same as the DS of the slurry, which is equal to the difference between the TS and UDS measurements of the slurry.

Table 5.1. Low-Solids Slurry Physical-Properties Measurements

\begin{tabular}{|r|c||}
\hline Slurry Density (g/mL) & 1.30 \\
\hline Supernate Density (g/mL) & 1.21 \\
\hline Settled Solids (Vol\%) & $58 \%$ \\
\hline Centrifuged UDS (Wt\%) & $25 \%$ \\
\hline Total Solids of the Slurry (Wt\%) & $33 \%$ \\
\hline Dissolved Solids of the Supernate (Wt $\%)$ & $28 \%$ \\
\hline UDS of the Slurry $(\mathbf{W t} \%)$ & $7.2 \%$ \\
\hline
\end{tabular}

The average measured UDS of the sampled slurry (7.2 wt\%) was lower than the expected value of 10 to $11 \mathrm{wt} \%(0.52 \mathrm{~kg} \div 4.96 \mathrm{~kg}=10.5 \mathrm{wt} \%)$. The difference between the two values was likely a result of grabbing a non-homogenous slurry sample from the slurry reservoir pot. After the test was completed, the mixer blade from the overhead mixer was found to have come off the mixing shaft. Erosive wear at the bottom of the blade caused failure of the crimp seal that attached the mixer blade to the shaft collar. Because of this, it cannot be assumed that the slurry was well mixed inside the slurry reservoir when the physical-property samples were collected.

An overall mass balance was performed on the composite slurry through the CUF testing. Using the composition of the Group 1 slurry in Section 3 and Group 2 slurry in Section 4, the initial composition of the blended slurry for the Group 1 and Group 2 slurry was calculated. Using a supernate sample analysis performed on the slurry to confirm that no dissolution of solids occurred during mixing, the composition of the slurry was calculated as shown in Table 5.2. Measurements of opportunistic analytes from the ICP-OES metals analysis of the slurry supernate is reported in

Table 5.3. 
Table 5.2. Group $1 / 2$ Low-Solids Slurry Total Inventory and Composition

\begin{tabular}{|c|c|c|c|c|c|}
\hline & Slurry $^{(a)}$ & \multicolumn{2}{|c|}{ Liquid Fraction $^{(b)}$} & \multicolumn{2}{|c|}{ Solids Fraction $^{(c)}$} \\
\hline Mass (kg) & 5.19 & \multicolumn{2}{|c|}{4.68} & \multicolumn{2}{|c|}{0.52} \\
\hline Wt\% of Slurry & $100 \%$ & \multicolumn{2}{|c|}{$90.0 \%$} & \multicolumn{2}{|c|}{$10.0 \%$} \\
\hline Metal & g & g & $\mu g / m L$ & $\mathbf{g}$ & $\mu g / g$ \\
\hline Al & $5.0 \mathrm{E}+01$ & $3.6 \mathrm{E}+00$ & $9.4 \mathrm{E}+02$ & $4.6 \mathrm{E}+01$ & $8.9 \mathrm{E}+04$ \\
\hline Bi & $2.1 \mathrm{E}+01$ & $<1 . \mathrm{E}-2$ & $<4 . \mathrm{E}+0$ & $2.1 \mathrm{E}+01$ & $4.1 \mathrm{E}+04$ \\
\hline $\mathrm{Cr}$ & $5.6 \mathrm{E}+00$ & $1.8 \mathrm{E}+00$ & $4.8 \mathrm{E}+02$ & $3.8 \mathrm{E}+00$ & $7.2 \mathrm{E}+03$ \\
\hline $\mathbf{F e}$ & $2.8 \mathrm{E}+01$ & $2.0 \mathrm{E}-02$ & $5.3 \mathrm{E}+00$ & $2.8 \mathrm{E}+01$ & $5.4 \mathrm{E}+04$ \\
\hline Mn & 4.2E-01 & 3.5E-04 & $9.0 \mathrm{E}-02$ & 4.2E-01 & $8.1 \mathrm{E}+02$ \\
\hline Na & $5.2 \mathrm{E}+02$ & $3.9 \mathrm{E}+02$ & $1.0 \mathrm{E}+05$ & $1.3 \mathrm{E}+02$ & $2.5 \mathrm{E}+05$ \\
\hline $\mathbf{P}$ & $4.5 \mathrm{E}+01$ & $4.0 \mathrm{E}+00$ & $1.0 \mathrm{E}+03$ & $4.1 \mathrm{E}+01$ & $7.9 \mathrm{E}+04$ \\
\hline $\mathrm{S}$ & $1.9 \mathrm{E}+01$ & $2.0 \mathrm{E}+01$ & $5.3 \mathrm{E}+03$ & $\mathrm{n} / \mathrm{a}^{(\mathrm{d})}$ & $\mathrm{n} / \mathrm{a}^{(\mathrm{d})}$ \\
\hline $\mathrm{Si}$ & $1.9 \mathrm{E}+01$ & 4.1E-02 & $1.1 \mathrm{E}+01$ & $1.9 \mathrm{E}+01$ & $3.6 \mathrm{E}+04$ \\
\hline Sr & $1.7 \mathrm{E}+00$ & 8.8E-04 & 2.3E-01 & $1.7 \mathrm{E}+00$ & $3.2 \mathrm{E}+03$ \\
\hline $\mathbf{U}$ & $7.2 \mathrm{E}+00$ & 4.2E-01 & $1.1 \mathrm{E}+02$ & $6.8 \mathrm{E}+00$ & $1.3 \mathrm{E}+04$ \\
\hline \multirow{2}{*}{$\begin{array}{l}\text { Radiochemical } \\
\text { Isotopes }\end{array}$} & Slurry & \multicolumn{2}{|c|}{ Liquid Fraction } & \multicolumn{2}{|c|}{ Solid Fraction } \\
\hline & $\mathrm{mCi}$ & $\mathrm{mCi}$ & $\mathrm{mCi} / \mathbf{m L}$ & $\mathrm{mCi}$ & $\mathrm{mCi} / \mathrm{g}$ \\
\hline Co-60 & $5.4 \mathrm{E}+00$ & $<2$.E- 1 & $<4 . \mathrm{E}-5$ & $5.4 \mathrm{E}+00$ & $1.0 \mathrm{E}-02$ \\
\hline Cs-137 & $9.5 \mathrm{E}+04$ & $4.7 \mathrm{E}+04$ & $1.2 \mathrm{E}+01$ & $4.9 \mathrm{E}+04$ & $9.4 \mathrm{E}+01$ \\
\hline Eu-154 & $1.6 \mathrm{E}+01$ & $<8 . \mathrm{E}-1$ & $<2$.E-4 & $1.6 \mathrm{E}+01$ & $3.0 \mathrm{E}-02$ \\
\hline Am-241 & $1.5 \mathrm{E}+02$ & $<8 . \mathrm{E}+0$ & $<2$. E-3 & $1.5 \mathrm{E}+02$ & 2.9E-01 \\
\hline Gross Alpha & $2.9 \mathrm{E}+02$ & $2.8 \mathrm{E}+00$ & 7.3E-04 & $2.8 \mathrm{E}+02$ & 5.5E-01 \\
\hline Gross Beta & $2.3 \mathrm{E}+05$ & $4.4 \mathrm{E}+04$ & $1.1 \mathrm{E}+01$ & $1.8 \mathrm{E}+05$ & $3.5 \mathrm{E}+02$ \\
\hline Sr-90 & $6.6 \mathrm{E}+04$ & $3.7 \mathrm{E}+01$ & 9.7E-03 & $6.6 \mathrm{E}+04$ & $1.3 \mathrm{E}+02$ \\
\hline $\mathrm{Pu}-239+240$ & $2.0 \mathrm{E}+02$ & $1.3 \mathrm{E}-01$ & $3.2 \mathrm{E}-05$ & $2.0 \mathrm{E}+02$ & 3.8E-01 \\
\hline Pu-238 & $6.6 \mathrm{E}+00$ & 7.3E-02 & $1.9 \mathrm{E}-05$ & $6.6 \mathrm{E}+00$ & $1.3 \mathrm{E}-02$ \\
\hline \multirow[t]{2}{*}{ Anions } & \multicolumn{3}{|c|}{ Liquid Fraction } & \multicolumn{2}{|c|}{ Leached Solids Fraction } \\
\hline & $\mu g / m L$ & [M] & g & $\mu g / g$ & g \\
\hline $\mathbf{F}$ & $4.0 \mathrm{E}+03$ & 2.1E-01 & $1.5 \mathrm{E}+01$ & $2.6 \mathrm{E}+04$ & $1.3 \mathrm{E}+01$ \\
\hline $\mathrm{C}_{2} \mathrm{O}_{4}$ & $1.4 \mathrm{E}+03$ & 1.6E-02 & $5.5 \mathrm{E}+00$ & $<4 . \mathrm{E}+1$ & $<2 . \mathrm{E}-2$ \\
\hline $\mathrm{NO}_{2}$ & $7.8 \mathrm{E}+03$ & $1.7 \mathrm{E}-01$ & $3.0 \mathrm{E}+01$ & $1.2 \mathrm{E}+04$ & $6.0 \mathrm{E}+00$ \\
\hline $\mathrm{NO}_{3}$ & $1.9 \mathrm{E}+05$ & $3.1 \mathrm{E}+00$ & $7.4 \mathrm{E}+02$ & $2.9 \mathrm{E}+05$ & $1.5 \mathrm{E}+02$ \\
\hline $\mathrm{SO}_{4}$ & $1.5 \mathrm{E}+04$ & $1.5 \mathrm{E}-01$ & $5.7 \mathrm{E}+01$ & $2.4 \mathrm{E}+04$ & $1.2 \mathrm{E}+01$ \\
\hline $\mathrm{PO}_{4}$ & $3.1 \mathrm{E}+03$ & 3.3E-02 & $1.2 \mathrm{E}+01$ & $9.2 \mathrm{E}+04$ & $4.8 \mathrm{E}+01$ \\
\hline OH & $1.2 \mathrm{E}+03$ & 6.9E-02 & $4.5 \mathrm{E}+00$ & & \\
\hline \multicolumn{6}{|c|}{$\begin{array}{l}\text { Slurry mass components were calculated from characterization data (Sections } 3 \text { and } 4 \text { ) and the masses of } \\
\text { materials that were added with simulant. Loss of mass from sampling was incorporated. } \\
\text { Liquid fraction mass components were calculated using analytical results from supernate sample TI552-G6-A } \\
\text { (ASO ID 08-01290) and the predicted mass of supernate in the system. } \\
\text { Solids fraction mass components were calculated from the difference between the slurry component mass and } \\
\text { liquid component mass fraction. } \\
\text { Values for sulfur were calculated to be less than zero. }\end{array}$} \\
\hline
\end{tabular}


WTP-RPT-166, Rev. 0

Table 5.3. Group 1/2 Low-Solids Supernate Opportunistic Composition

\begin{tabular}{|c|c|}
\hline \multirow{3}{*}{$\begin{array}{l}\text { Opportunistic } \\
\text { Analytes }\end{array}$} & Supernate \\
\hline & Measured $^{(a)}$ \\
\hline & $\mu \mathrm{g} / \mathrm{mL}$ \\
\hline Ag & $<2.5 \mathrm{E}-1$ \\
\hline As & $<5.2 \mathrm{E}+0$ \\
\hline Ba & {$[0.31]$} \\
\hline $\mathrm{Be}$ & $<6.3 \mathrm{E}-3$ \\
\hline $\mathrm{Ca}$ & {$[2.8]$} \\
\hline Ce & $<1.2 \mathrm{E}+0$ \\
\hline Co & $<2.9 \mathrm{E}-1$ \\
\hline $\mathrm{Cu}$ & $<1.7 \mathrm{E}-1$ \\
\hline Dy & $<3.5 \mathrm{E}-1$ \\
\hline Eu & $<1.3 \mathrm{E}-1$ \\
\hline $\mathbf{L a}$ & $<3.4 \mathrm{E}-1$ \\
\hline $\mathbf{L i}$ & {$[1.0]$} \\
\hline Mg & $<2.8 \mathrm{E}-1$ \\
\hline Mo & 7.11 \\
\hline Nd & $<6.5 \mathrm{E}-1$ \\
\hline $\mathbf{P b}$ & $<3.9 \mathrm{E}+0$ \\
\hline Pd & [1.2] \\
\hline $\mathbf{R h}$ & [2.1] \\
\hline $\mathbf{R u}$ & [1.1] \\
\hline Sb & [4.35] \\
\hline Se & [19] \\
\hline Sn & {$[5.6]$} \\
\hline Ta & $<2.1 \mathrm{E}+0$ \\
\hline Te & [5.15] \\
\hline Th & {$[1.4]$} \\
\hline Ti & {$[0.053]$} \\
\hline Tl & $<4.6 \mathrm{E}+0$ \\
\hline $\mathbf{V}$ & {$[0.092]$} \\
\hline $\mathbf{W}$ & {$[14]$} \\
\hline $\mathbf{Y}$ & $<5.3 \mathrm{E}-2$ \\
\hline
\end{tabular}

(a) Supernatant measured from, ASR 8113, sample TI552-G6-A (RPL ID 08-00218); reference date November 5, 2007.

Analyte uncertainties were typically within $\pm 15 \%$; results in brackets indicate that the analyte concentrations were greater than the method detection limit (MDL) and less than the estimated quantitation limit (EQL), and uncertainties were $>15 \%$.

Opportunistic analytes are reported for information only; quality control (QC) requirements did not apply to these analytes.

The influence of mixing Group 1 and Group 2 waste solids can be evaluated by comparing the PSDs for the source materials (i.e., those for initial characterization samples) to the initial PSD of the low-solids matrix slurry. Some caution must be used when interpreting these results as the initial characterization samples have not been subjected to the same level of shear that the CUF testing sample undergoes during circulation through the filtration loop. 
Figure 5.3 shows the influence of mixing Group 1 and 2 solids in the CUF on the waste sample PSD; the PSD plots shown in the figure were determined after sonication. In overall behavior, the mixed waste PSD most resembles the Group 2 initial characterization sample PSD in that both samples are relatively unimodal. It is clear, however, that the mixed waste PSD is broader than that of the Group 2 source material. Specifically, the mixed Group 1/2 sample contains both particles larger than and smaller than those observed in the Group 2 initial characterization sample. Relative to the Group 1 source material, the mixed Group 1/2 CUF testing sample is composed of smaller sizes of particles/aggregates. Whereas Group 1 solids show particle contributions in the range of 20 to $50 \mu \mathrm{m}$, particles larger than $20 \mu \mathrm{m}$ are absent from the CUF testing sample. It is possible that circulation of the Group 1/2 waste mixture in the CUF sheared apart the 20- to 50- $\mu$ m particles characteristic of Group 1 waste solids. Likewise, this circulation-induced particle disruption could yield the increase in the relative contribution of submicron particles observed in the Group 1/2 CUF testing sample (relative to both Group 1 and Group 2 source material). Overall, the range of sizes observed in the Group 1/2 CUF testing sample is reasonable relative to the source material. However, the PSD for the mixed Group 1/2 solids indicates a shear breakage of particles as a result of circulation of the CUF slurry at a low-solids concentration.

Figure 5.4 shows the distribution of particle/aggregate sizes in the low solids slurry matrix before sonication. The graph indicates a broad distribution of particles ranging from $\sim 0.3$ to $\sim 600 \mu \mathrm{m}$. The majority of particles fall between $\sim 0.3$ and $\sim 200 \mu \mathrm{m}$, with a peak (maximum) population located between 1 and $2 \mu \mathrm{m}$ and a secondary shoulder over the range of 4 to $20 \mu \mathrm{m}$. Distributions at 2000 and $3000 \mathrm{RPM}$ are similar. At $4000 \mathrm{RPM}$, the appearance of a second population peak centered at $\sim 60 \mu \mathrm{m}$ confirms the presence of a larger, difficult-to-suspend, particle or agglomerate species.

Figure 5.5 shows changes that occur in the distribution of particles as a result of applied sonication. Sonication appears to reduce the relative population contribution of particles greater than $10 \mu \mathrm{m}$ while increasing the relative contribution of particles from 3 to $10 \mu \mathrm{m}$. The likely mechanism for this change is sonic disruption of particle agglomerates greater than $10 \mu \mathrm{m}$. The similarity between the during- and after-sonication distributions suggests that the changes that occur during sonication are irreversible over the time frame of the post-sonication particle-size analyses ( 15 minutes). 


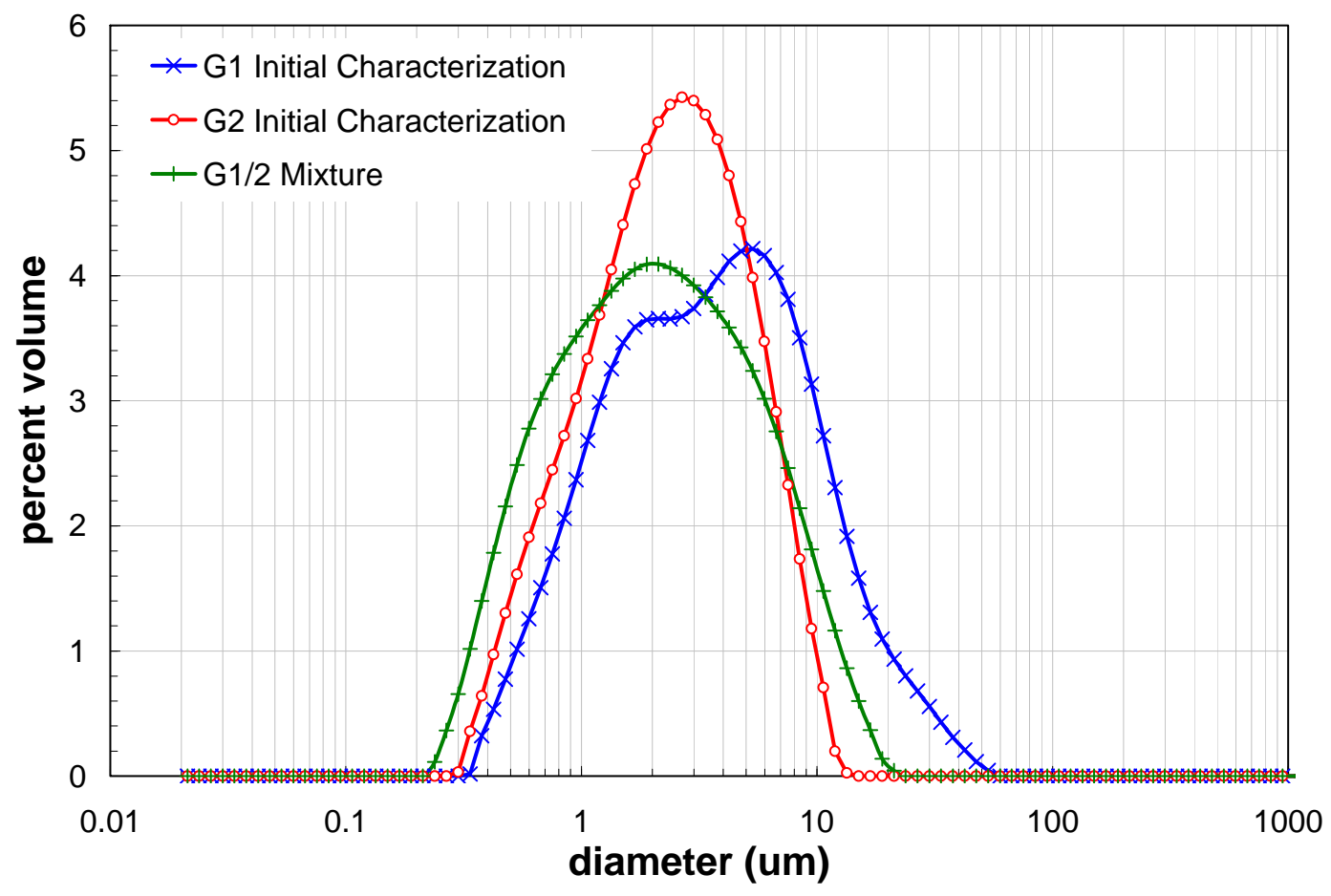

Figure 5.3. PSDs for the Individual Group 1 and 2 Composites and the Mixed Group 1/2 Composite (low solids slurry) After Sonication

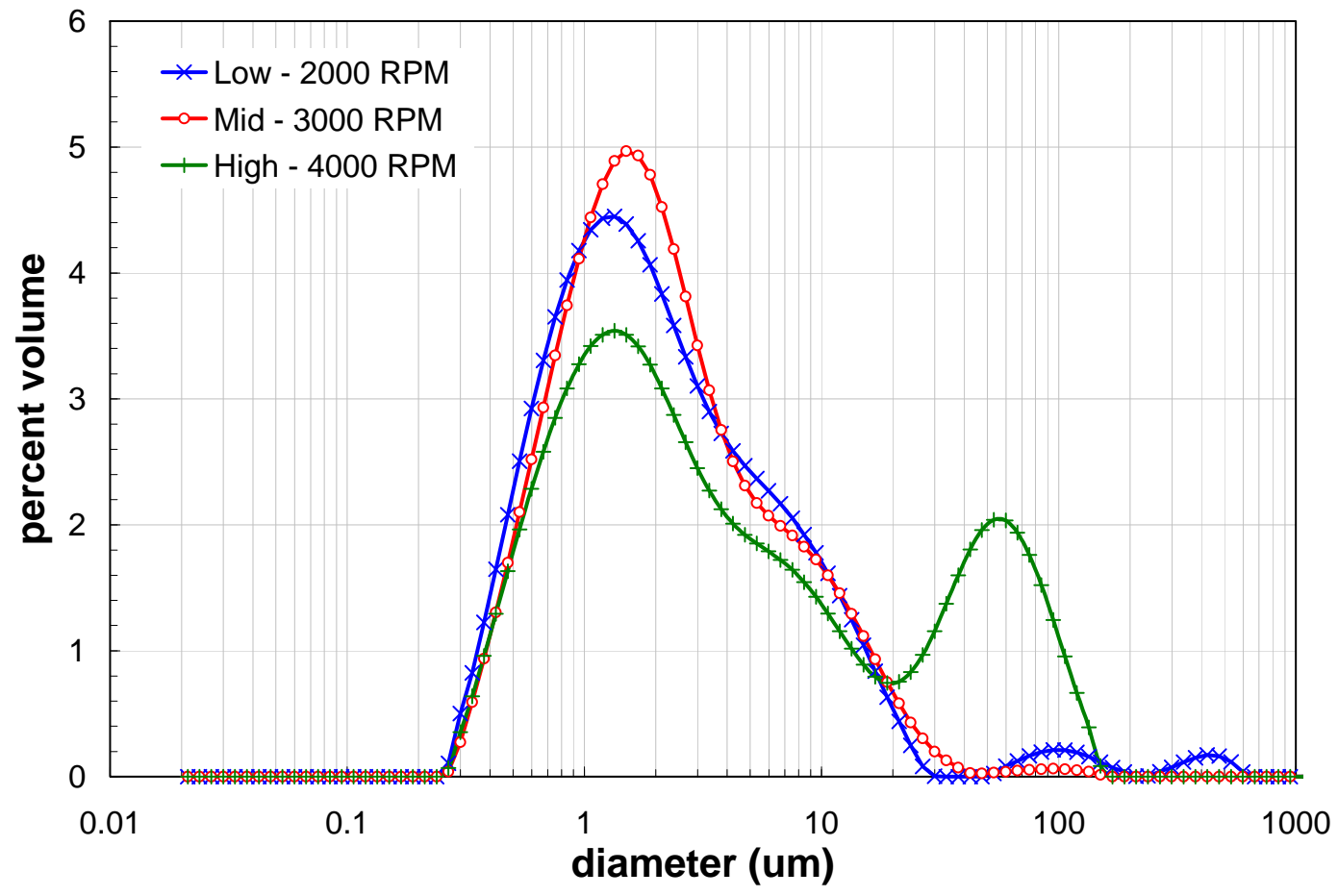

Figure 5.4. Low Solids Matrix Slurry PSD at Varying Pump Speeds Before Sonication 
WTP-RPT-166, Rev. 0

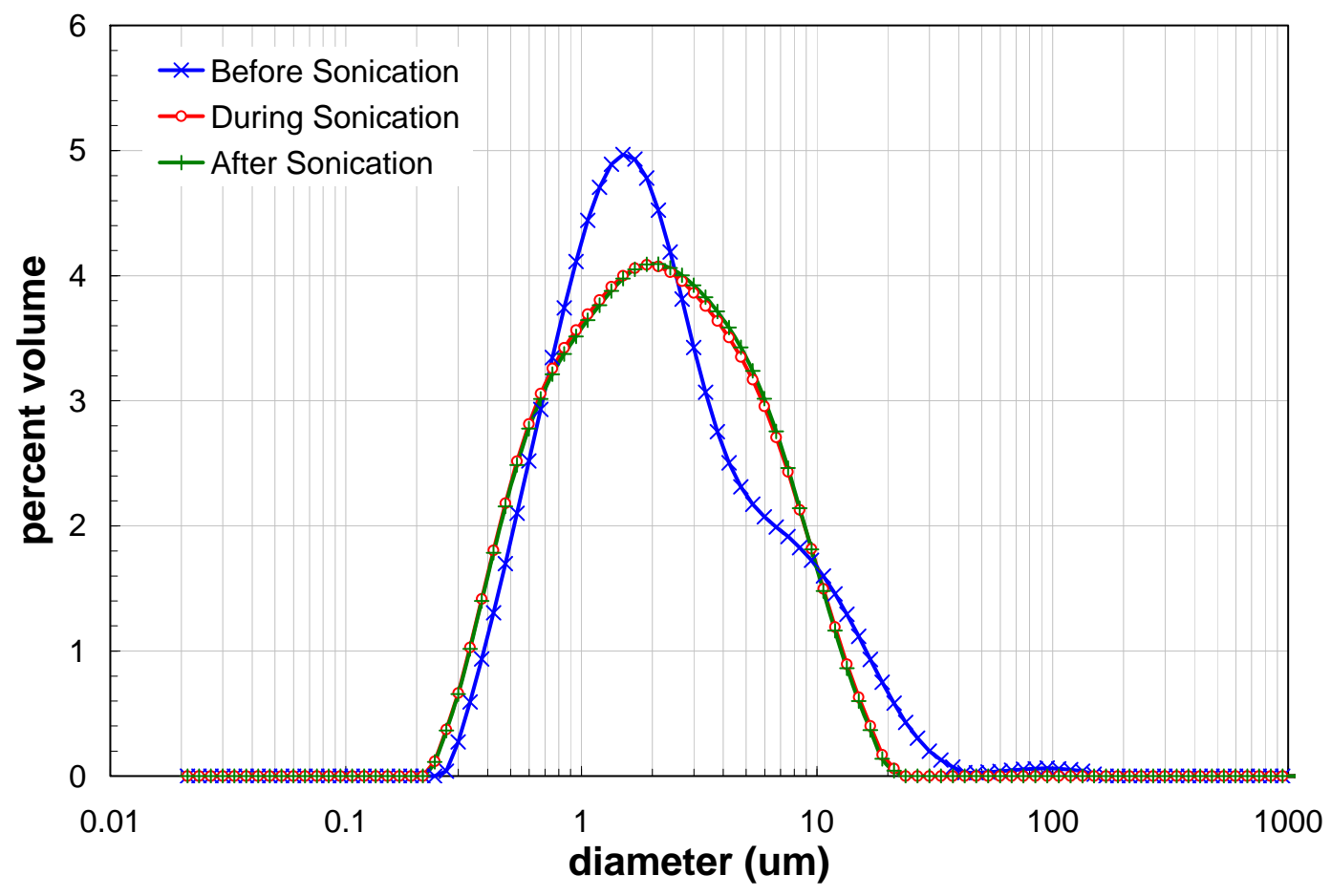

Figure 5.5. Low Solids Matrix Slurry PSD with Sonication

Figure 5.6 shows the results of flow curve testing for the low solids slurry. This slurry shows Newtonian behavior at all temperatures studied. There appears to be a slope transition near $500 \mathrm{~s}^{-1}$, which could be indicative of alignment problems and/or Taylor vortex formation. The flow curves are free of hysteresis, which indicates that suspending phase evaporation is minor and/or does not affect the bulk rheological properties to a significant extent. Increased slurry temperature does not appear to change the rheological behavior between $25^{\circ}$ and $40^{\circ} \mathrm{C}$. A significant reduction in viscosity occurs between $40^{\circ}$ and $60^{\circ} \mathrm{C}$ as evidenced by the decrease in the flow curve linear slope. The decrease in slurry viscosity with increasing temperature is consistent with decreased suspending phase viscosity.

Table 5.4 summarizes the best-fit and averaged Newtonian viscosities for the flow curve and constantrotation data for the low-solids slurry. To avoid the inclusion of data influenced by Taylor Vortex formation, Newtonian model fits were restricted to 0 to $400 \mathrm{~s}^{-1}$. All constant-rotation rate data correspond to $470 \mathrm{~s}^{-1}$. Both constant-rotation and flow curve data measurements indicate a Newtonian viscosity for this slurry between 4.2 and $5.0 \mathrm{mPa} \cdot \mathrm{s}$ at $25^{\circ} \mathrm{C}, 4.2$ and $4.8 \mathrm{mPa} \cdot \mathrm{s}$ at $40^{\circ} \mathrm{C}$, and 3.0 and $3.1 \mathrm{mPa} \cdot \mathrm{s}$ at $60^{\circ} \mathrm{C}$. In general, the fitting results in Table 5.4 confirm the temperature trends discussed in the previous paragraph. 


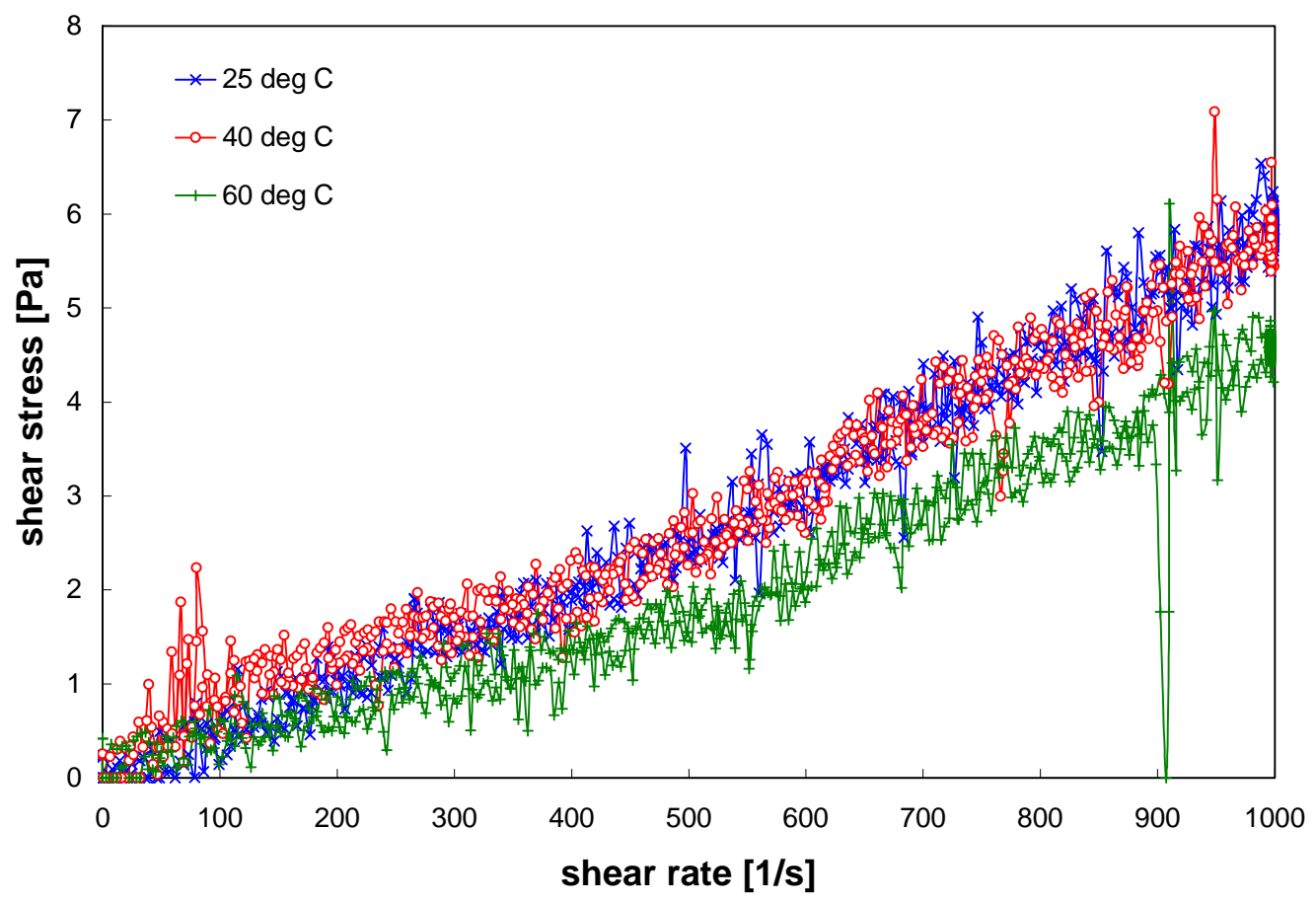

Figure 5.6. Flow Curve for the Group $1 / 2$ CUF Low-Solids Slurry Sample at 25,40 , and $60^{\circ} \mathrm{C}$

Table 5.4. Results of Fitting Analysis for Rheology of the Low-Solids Slurry

\begin{tabular}{||c|c|c|c||}
\hline \multirow{4}{*}{ Model } & $\begin{array}{c}\text { Temperature } \\
{\left[{ }^{\circ} \mathbf{C}\right]}\end{array}$ & $\begin{array}{c}\text { Newtonian } \\
\text { Viscosity } \\
\text { [mPa·s] }\end{array}$ & $\mathbf{R}$ \\
\hline $\begin{array}{c}\text { Flow Curve Fits } \\
\left(0-400 \mathrm{~s}^{-1}\right)\end{array}$ & $25(1$ of 2$)$ & 4.4 & 0.931 \\
\cline { 2 - 4 } & $25(2$ of 2$)$ & 5.0 & 0.945 \\
\cline { 2 - 4 } & 40 & 4.2 & 0.853 \\
\cline { 2 - 4 } & 60 & 3.0 & 0.817 \\
\hline $\begin{array}{c}\text { Constant Rotation } \\
\left(470 \mathrm{~s}^{-1}\right)\end{array}$ & $25(1$ of 2$)$ & $4.2 \pm 0.2$ & $\mathrm{n} / \mathrm{a}$ \\
\cline { 2 - 4 } & $25(2$ of 2$)$ & $4.8 \pm 0.2$ & $\mathrm{n} / \mathrm{a}$ \\
\cline { 2 - 4 } & 40 & $4.8 \pm 0.2$ & $\mathrm{n} / \mathrm{a}$ \\
\cline { 2 - 4 } & 60 & $3.1 \pm 0.1$ & $\mathrm{n} / \mathrm{a}$ \\
\hline
\end{tabular}

\subsection{Filter Flux Testing and Dewatering of Waste Slurry}

This section describes the filtration testing performed using the Group 1/2 composite before leaching, as shown in the left column of Figure 5.1. The following tests were performed.

- Initial clean water flux (CWF) testing to examine filter condition prior to testing.

- Filtration testing of the composite Group 1/2 waste slurry at a low-solids concentration as described in Section 5.2. Testing compares the effects of transmembrane pressure (TMP), axial velocity (AV), and operation time on filter flux. 
- Dewatering of the waste slurry from 8 wt\% UDS to 16\% UDS at a constant TMP and AV to understand the impact of how solid concentration impacts filtration and compare to previous testing of other wastes.

- Filtration testing of the slurry at a high solid concentration. Like before, testing compares the effects of TMP, AV, and operation time on filter flux.

\subsubsection{Initial Clean Water Flux Testing}

Before loading waste into the CUF, a CWF test was performed with $0.01 \mathrm{M} \mathrm{NaOH}$ at three TMP conditions (10, 20, and $30 \mathrm{psid})$ and a constant AV of $11 \mathrm{ft} / \mathrm{s}$. These tests were performed to establish the baseline condition of the filter before and after filtration of a composite waste group. In this case, the Group 1/2 initial CWF test followed the nitric acid cleaning of the filter after the Group 6/5 CUF testing according to TI-RPP-WTP-552, Rev. 0. The measured flux, shown in Figure 5.7, was somewhat less than the initial CWF test of the Group 6/5 waste (Table 5.5), but they were on the same order-of-magnitude. Two values were selected to characterize each TMP condition, one at the start and end of each condition, since a rapid decay of the flux was observed for these tests. The selected values were determined by using condition start and stop times recorded in TI-RPP-WTP-572, Rev. 0.

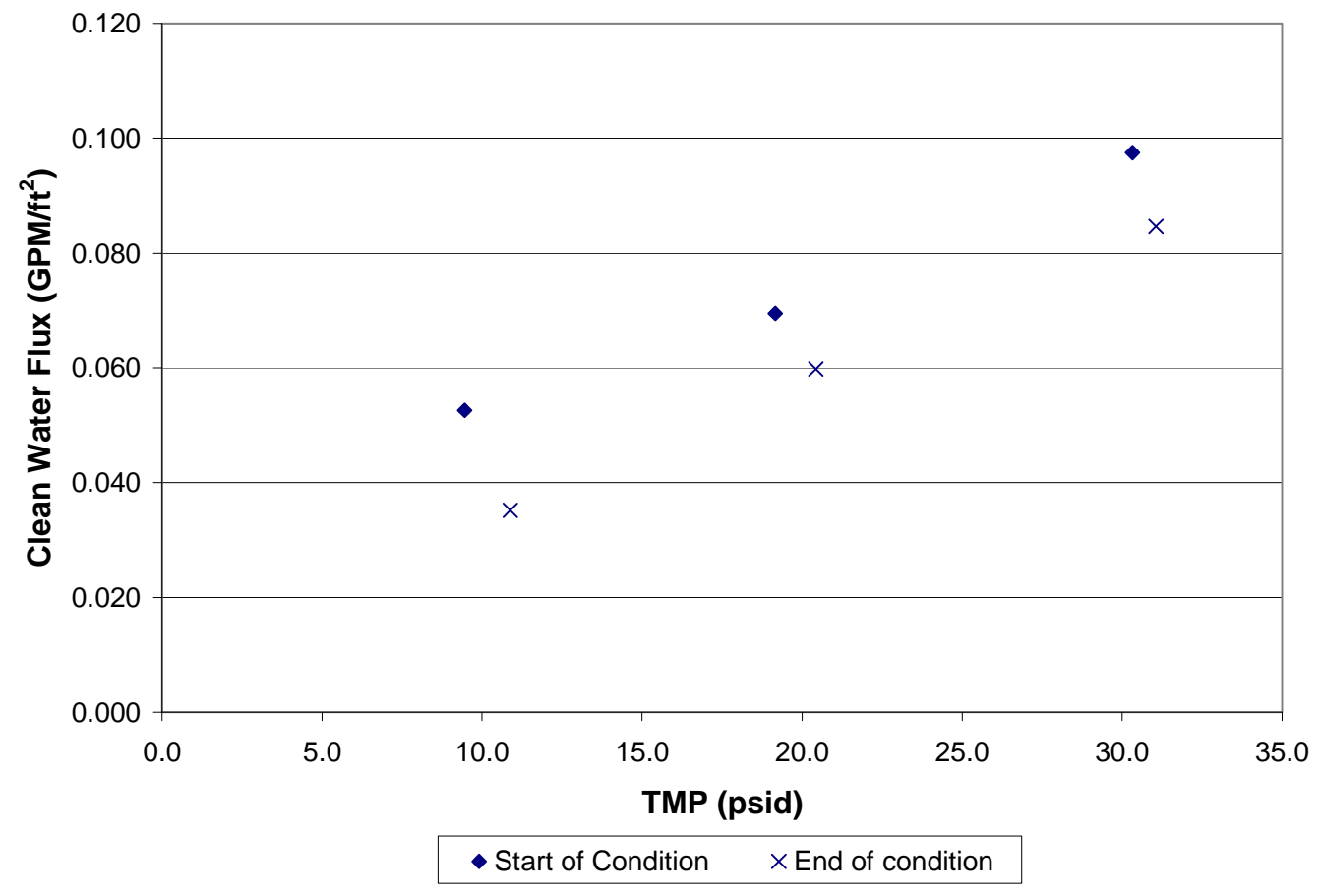

Figure 5.7. Initial CWF After Nitric Acid Cleaning from Group 6/5 Test 
Table 5.5. Comparison of Initial CWF Between Group 1/2 and Group 6/5 Wastes

\begin{tabular}{|c|c|c|c|c|}
\hline TMP & $\begin{array}{l}\text { Group } 1 / 2 \text { Flux, } \\
\text { Start of Condition } \\
\quad\left(G P M / \mathbf{f t}^{2}\right)\end{array}$ & $\begin{array}{l}\text { Group } 1 / 2 \text { Flux, } \\
\text { End of Condition } \\
\quad\left(G P M / \mathbf{f t}^{2}\right)\end{array}$ & $\begin{array}{l}\text { Group 6/5 Flux, } \\
\text { Start of Condition } \\
\left(\mathrm{GPM} / \mathrm{ft}^{2}\right)\end{array}$ & $\begin{array}{l}\text { Group 6/5 Flux, } \\
\text { End of Condition } \\
\quad\left(\mathrm{GPM} / \mathrm{ft}^{2}\right)\end{array}$ \\
\hline 10 & 0.053 & 0.035 & 0.084 & 0.060 \\
\hline 20 & 0.070 & 0.060 & 0.091 & 0.073 \\
\hline 30 & 0.097 & 0.085 & 0.107 & 0.093 \\
\hline \multicolumn{5}{|c|}{$\begin{array}{l}\text { GPM = gallons per minute } \\
\text { Performed at } 25 \pm 2^{\circ} \mathrm{C} \text { and using an } \mathrm{AV} \text { of } 11 \pm 0.2 \mathrm{ft} / \mathrm{s} \text {. Filter flux data are temperature corrected, } \\
\text { as described in Equation K.3 in Appendix K. }\end{array}$} \\
\hline
\end{tabular}

\subsubsection{Low-Solids Filter Matrix Testing (10 wt\%)}

Figure 5.8 shows that after sampling the slurry for physical characterization, the slurry mass inside the circulation loop was $4.96 \mathrm{~kg}$, with $0.24 \mathrm{~kg}$ of supernate present inside the permeate piping and back pulse chamber. As discussed in the previous section, approximately 520 grams of UDS was to be present in the waste samples added. Using that for the UDS mass of the slurry, the UDS concentration of the slurry inside the circulation loop was estimated to be slightly above $10 \mathrm{wt} \%$. This was the starting point for the low-solids filter matrix testing.

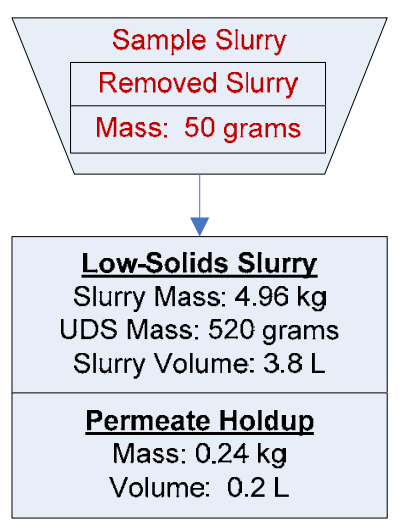

Figure 5.8. Flow Diagram of the Low-Solids Matrix Testing Note: Mass and volume values in figure are rounded to the nearest significant digit of accuracy.

The low-solids filtration tests were performed according to the 11 test conditions described in Table K.1, Appendix K. The test conditions were performed sequentially with a minimum of 1 hour of constant recycle operation at each condition with back-pulsing between conditions. Table 5.6 provides a summary of the average operating conditions and flux for each condition, and Figure 5.10 compares the average $\mathrm{AV}$ and TMP for each test condition to the target value. These values were obtained by calculating the arithmetic mean of each value over the duration of the test condition. Flux data with respect to process time are given in Figure 5.9. As can be seen from the figure, the flux decayed rapidly within each test condition. Back-pulsing between conditions appears to temporarily reverse this effect. However, there appears to be a slight decrease trend in the filter flux over time even with back-pulsing. 
To understand the individual impact of TMP and AV to filter flux, each average value from each test parameter was plotted against the average measured filter flux for each test (Figure 5.11 and Figure 5.12). To evaluate changes in the filter resistance during the test, the median operation time of each test (where $\mathrm{t}=0$ hrs at the start of the test) was also plotted against the filter flux (Figure 5.13). The low-solids slurry exhibited a stronger dependence on TMP than AV over the range of conditions tested. The filter flux was found to be linearly proportional to TMP for the pressures tested (20 to 60 psid) while the AV was found to have no significant impact for the velocities tested ( 9 to $17 \mathrm{ft} / \mathrm{s}$ ) at this slurry concentration. While the linear relationship to TMP implied that the slurry behaved according to the Darcy equation (Equation $\mathrm{K}-6$, Appendix $\mathrm{K}$ ), the $\mathrm{R}^{2}$ correlation factor was only 0.68 , implying that another parameter was impacting the filter flux. Examination of Figure 5.13 demonstrated a general decrease in the filter flux over the course of the test, and that filter resistance for the slurry was not at steady state. The linear correlation coefficient to process time was not very large (0.05).

Figure 5.14 and Figure 5.15 show data that have been further correlated and fitted to two empirical models combining the impact of each test parameter on the filter flux. From the fit equations, a strong dependence of filter flux on TMP was found with no significant impact from AV. As before, the filter flux was found to decrease with operation time, demonstrating that filter resistance was increasing over the course of the test. The linear model showed that 1 hour of operation the filter was equivalent to a decrease of $\sim 1$ psid of the TMP during this test. The exponential model predicted that doubling the operation time was equivalent to decreasing the TMP by $10 \%$ during this test. While both modeling equations have high correlation factors, the use of this model should be limited to understanding how filter flux was influenced by TMP and operation time during this test. Because time was included in both models, offset parameters were developed, which limits the range that they could be applied. Both models do not predict a zero filter flux when the TMP is zero, which demonstrates that the input to these models must be bound by the range of TMP used in this filter test, shown in Table 5.6. The use of these models should also be limited to when the test matrix occurred because the filter resistance was not at steady state, and the parameters developed in these models would be expected to change past the 14-hour period that this model predicts. 
Table 5.6. Average Operating Conditions and Filter Flux for the Low-Solids Matrix Test

\begin{tabular}{|c|c|c|c|c|c|c|c|}
\hline $\begin{array}{c}\text { Design } \\
\text { Test } \\
\text { Condition } \\
\end{array}$ & $\begin{array}{l}\text { Median } \\
\text { Operation } \\
\text { Time of } \\
\text { Test }^{(a)}(h r) \\
\end{array}$ & $\begin{array}{l}\text { Slurry } \\
\text { Temp }^{(b)} \\
\left({ }^{\circ} \mathrm{C}\right)\end{array}$ & $\begin{array}{l}\operatorname{TMP}^{(\mathrm{c})} \\
\text { (psid) }\end{array}$ & $\begin{array}{l}\text { Axial } \\
\text { Velocity } \\
(\mathbf{f t} / \mathrm{s}) \\
\end{array}$ & $\begin{array}{l}\text { Permeate } \\
\text { Flowrate } \\
\text { (mL/min) }\end{array}$ & $\begin{array}{l}\text { Corrected } \\
\text { Permeate } \\
\quad \text { Flux } \\
\left(\text { GPM/ft }{ }^{2}\right) \\
\end{array}$ & $\begin{array}{l}\text { Axial } \\
\text { Pressure } \\
\text { Drop }^{(c)} \\
\text { (psid/ft) }\end{array}$ \\
\hline 1 & 2.1 & 25.4 & 42.2 & 12.9 & 22.5 & 0.022 & 1.5 \\
\hline 2 & 4.9 & 25.1 & 29.1 & 11.1 & 20.1 & 0.020 & 1.1 \\
\hline 3 & 6.0 & 25.2 & 31.1 & 14.9 & 18.4 & 0.018 & 2.0 \\
\hline 4 & 7.0 & 25.4 & 49.7 & 15.1 & 26.2 & 0.026 & 2.2 \\
\hline 5 & 8.1 & 25.5 & 49.4 & 11.0 & 24.8 & 0.025 & 1.2 \\
\hline 6 & 9.1 & 25.5 & 40.9 & 13.0 & 22.4 & 0.022 & 1.5 \\
\hline 7 & 10.2 & 25.3 & 39.2 & 8.8 & 20.4 & 0.020 & 0.5 \\
\hline 8 & 11.3 & 25.4 & 41.4 & 17.2 & 19.4 & 0.019 & 2.8 \\
\hline 9 & 12.4 & 25.2 & 19.5 & 12.9 & 10.4 & 0.010 & 1.4 \\
\hline 10 & 13.4 & 25.4 & 59.7 & 12.8 & 26.1 & 0.026 & 1.7 \\
\hline 11 & 14.4 & 25.3 & 41.0 & 12.9 & 19.6 & 0.020 & 1.3 \\
\hline \multicolumn{8}{|c|}{$\begin{array}{l}\text { (a) Median operation time refers to the midpoint } \\
\text { relative to the start time of the test }(\mathrm{T}=0) \text {. T } \\
\text { (b) Thermocouple accuracy } \pm 2^{\circ} \mathrm{C} \text {. } \\
\text { (c) Pressure transducer accuracy } \pm 1 \text { psig. }\end{array}$} \\
\hline
\end{tabular}




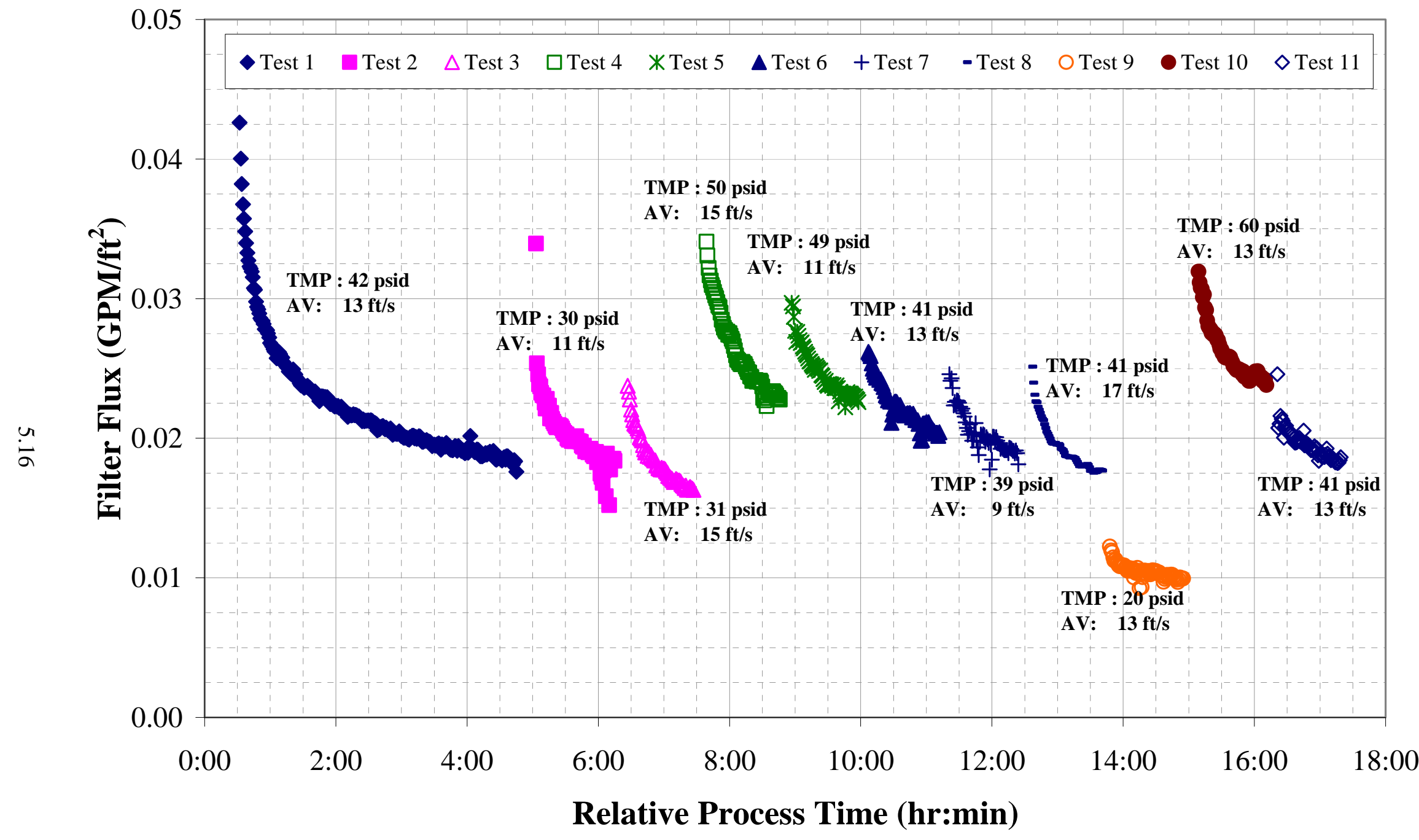

Figure 5.9. Filter Flux Data from Dilute Group 1/2 Matrix Test, 10 wt\% UDS 


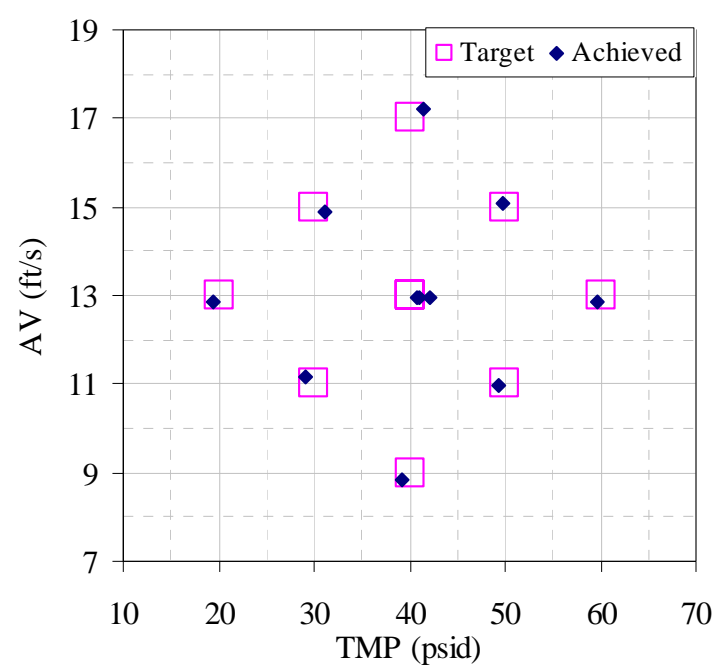

Figure 5.10. Group 1/2 Filter Test Matrix for Lows-Solids

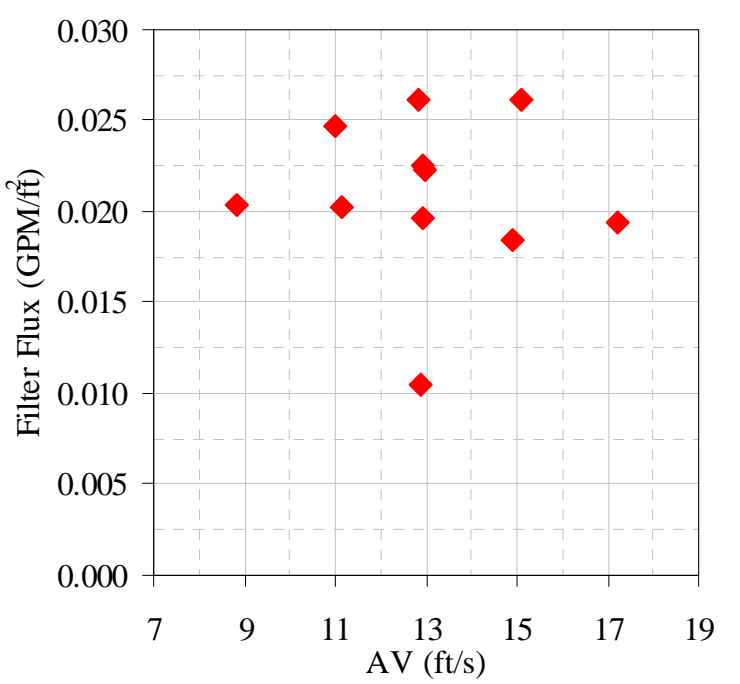

Figure 5.12. Group $1 / 2$ Flux vs. AV for Low-Solids

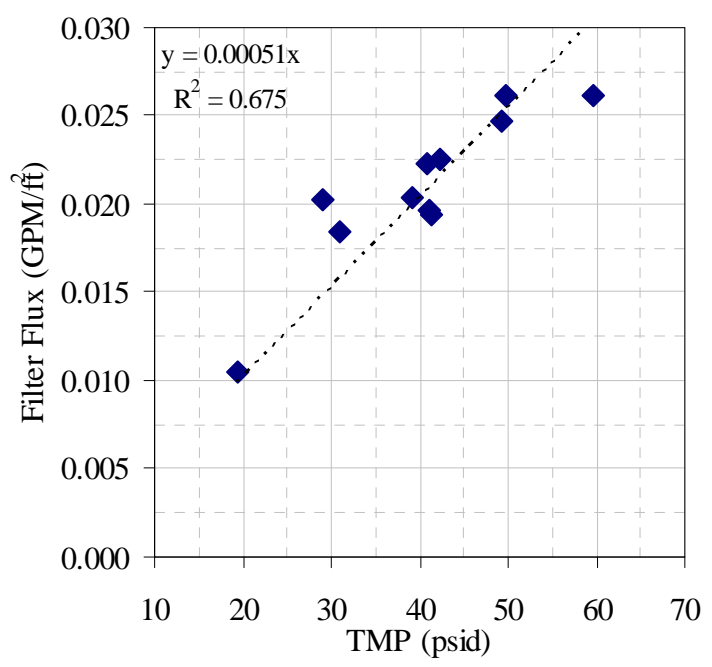

Figure 5.11. Group 1/2 Flux vs. TMP for Low-Solids

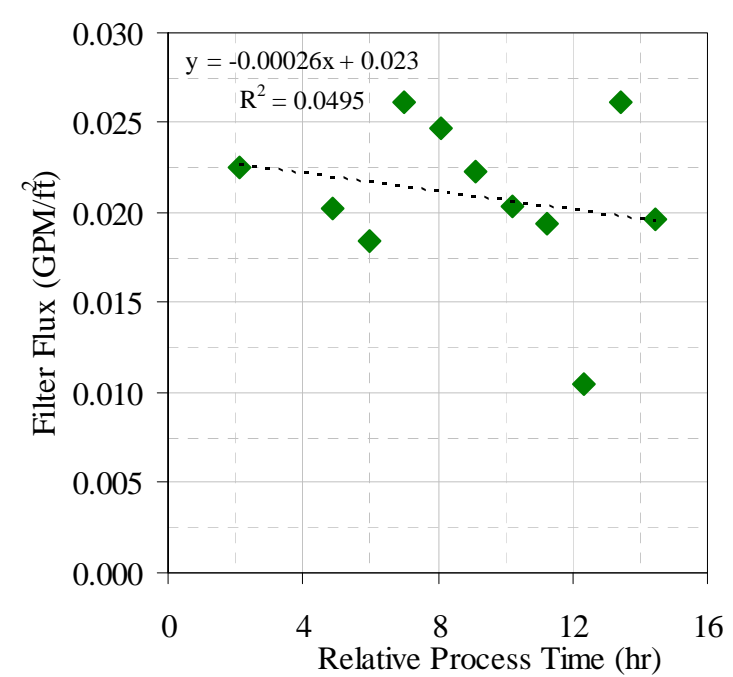

Figure 5.13. Group 1/2 Flux vs. Relative Time for Low-Solids 
WTP-RPT-166, Rev. 0

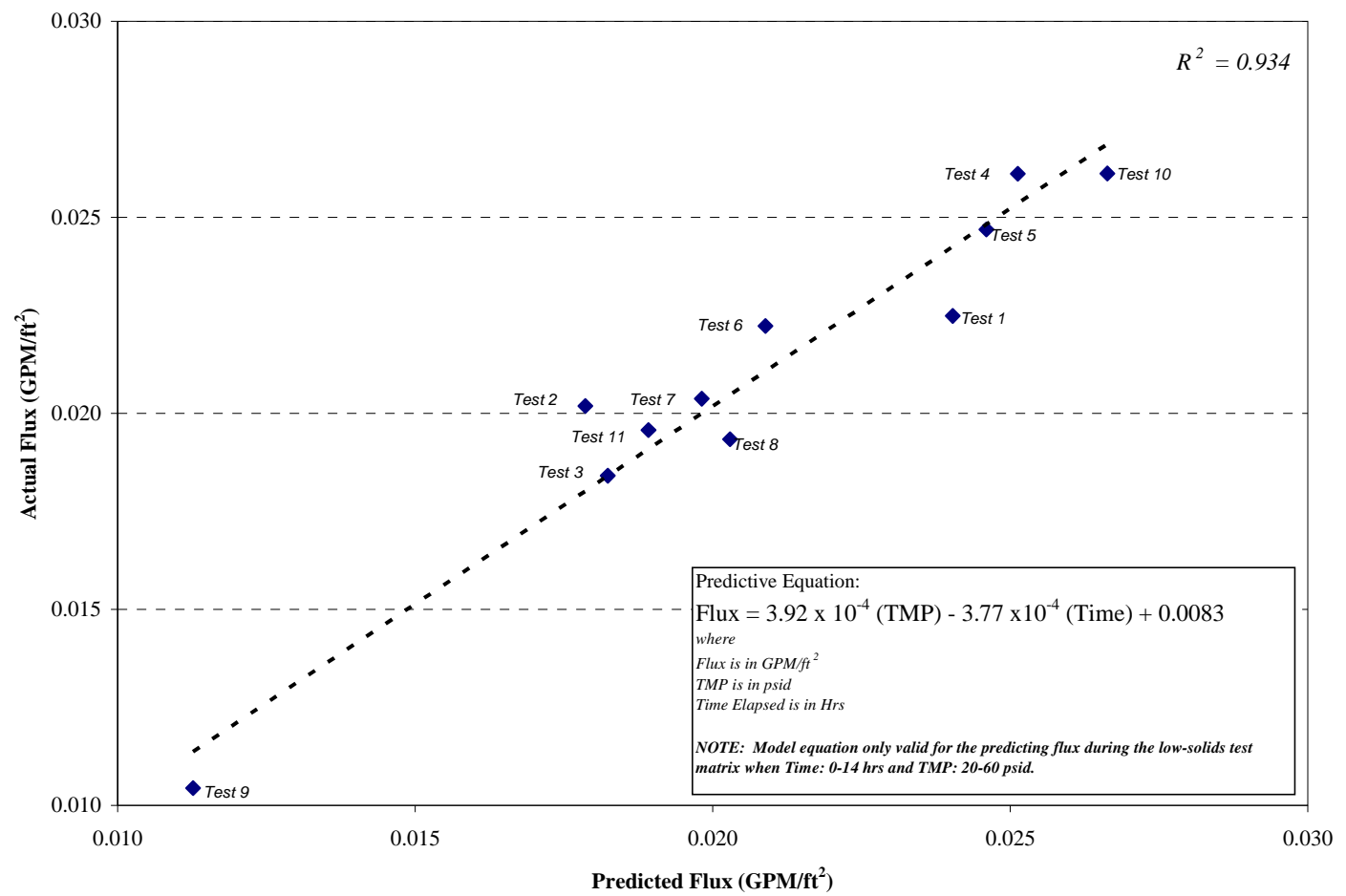

Figure 5.14. Linear Model of Filter Flux of Group 1/2 Slurry at Low-Solids Concentration

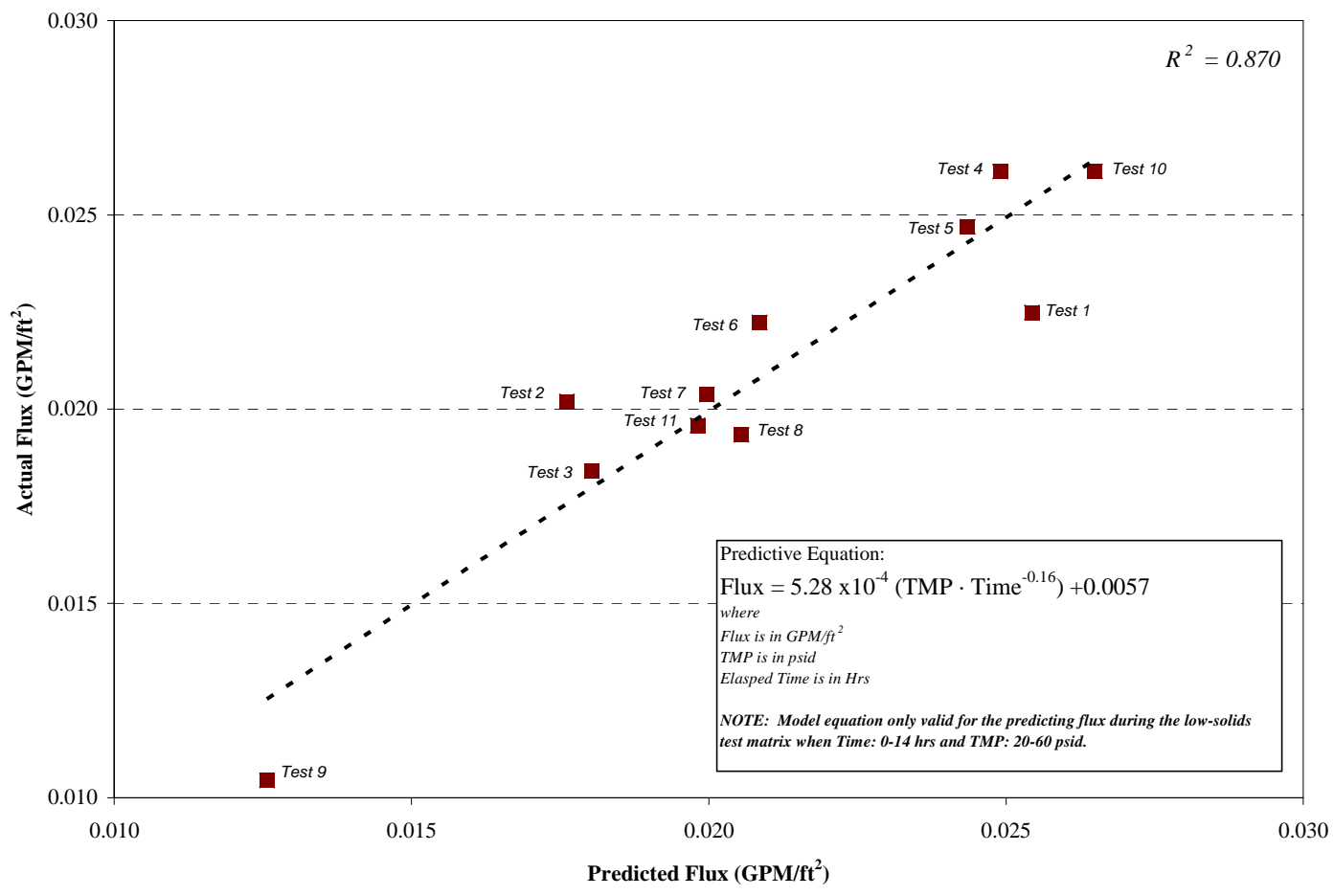

Figure 5.15. Exponential Model of Filter Flux of Group 1/2 Slurry at Low-Solids Concentration 


\subsubsection{Dewatering of Low-Solids Waste Slurry}

Figure 5.16 illustrates the material flow for dewatering of the low-solids slurry. At the conclusion of the low-solids matrix, the tank level was measured by a conductivity level probe and correlated to a table of system volumes on Page 43 of 44 of TI-RPP-WTP-572, Rev. 0. A total of $2395 \mathrm{~g}$ of permeate were removed, corresponding to $1.98 \mathrm{~L}$ at the measured permeate density of $1.21 \mathrm{~g} / \mathrm{mL}$. An overview of the mass balance of the CUF system through the initial dewatering step is given in Table 5.7. Based on the characterization data provided, the slurry UDS concentration was increased from $10 \mathrm{wt} \%$ to $20 \mathrm{wt} \%$.

The measured filter flux for dewatering the slurry is plotted against relative process time in Figure 5.17. The filter flux during the dewatering of the low-solids slurry averaged around $0.017 \mathrm{GPM} / \mathrm{ft}^{2}$. A slight decrease in the filter flux was observed over the course of $\sim 2$ hours that was similar in magnitude to the decrease observed during the low-solids matrix test. The change in the filter flux was believed to be from continued changes in the filter resistance and not due to changes in the slurry UDS concentration.

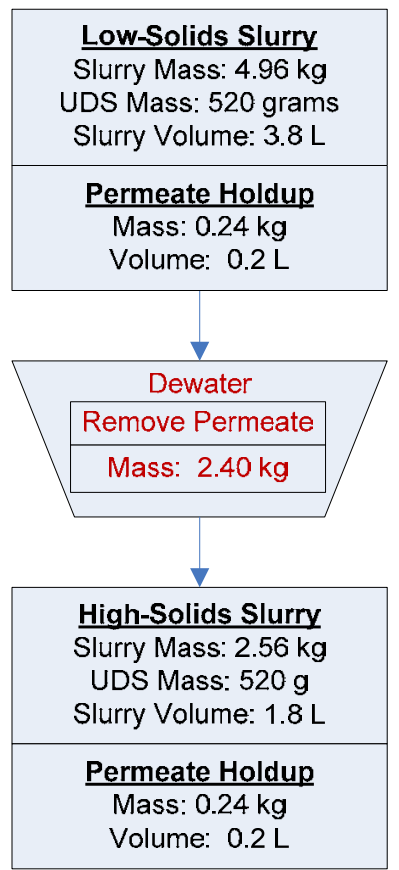

Figure 5.16. Flow Diagram of the Dewatering of the Low-Solids Slurry Note: Mass and volume values in figure are rounded to the nearest significant digit of accuracy. 
WTP-RPT-166, Rev. 0

Table 5.7. Mass Balance Overview for Initial Slurry Dewatering to High-Solids Condition

\begin{tabular}{|l|c|c|c|c|c|c|}
\hline \multicolumn{1}{|c|}{ Step } & $\begin{array}{c}\text { Mass } \\
\text { Added or } \\
\text { Removed } \\
\mathbf{( g )}\end{array}$ & $\begin{array}{c}\text { Total } \\
\text { System } \\
\text { Mass } \\
\mathbf{( g )}\end{array}$ & $\begin{array}{c}\text { Circulation } \\
\text { Slurry } \\
\text { Mass } \\
\mathbf{( g )}\end{array}$ & $\begin{array}{c}\text { (a) } \\
\text { Estimated } \\
\text { UDS Mass } \\
\text { (g) }\end{array}$ & $\begin{array}{c}\text { Estimated } \\
\text { UDS } \\
\text { Conc. } \\
\text { (wt\%) }\end{array}$ & $\begin{array}{c}\text { Measured } \\
\text { UDS } \\
\text { Concen. } \\
\text { (wt\%) }\end{array}$ \\
\hline $\begin{array}{l}\text { Load slurry into } \\
\text { CUF, with added } \\
\text { NaOH pellets }\end{array}$ & +5250 & 5250 & 5010 & 524 & $10.5 \mathrm{wt} \%$ & NA \\
\hline $\begin{array}{l}\text { Slurry sampling } \\
\text { Low-Solids Slurry }\end{array}$ & -50 & 5200 & 4960 & 519 & $10.5 \mathrm{wt} \%$ & $7.4 \mathrm{wt} \%$ \\
\hline $\begin{array}{l}\text { Dewater to } \\
\text { High-Solids Slurry }\end{array}$ & -2400 & 2800 & 2560 & 519 & $20.3 \mathrm{wt} \%$ & $14 \mathrm{wt} \%$ \\
\hline
\end{tabular}




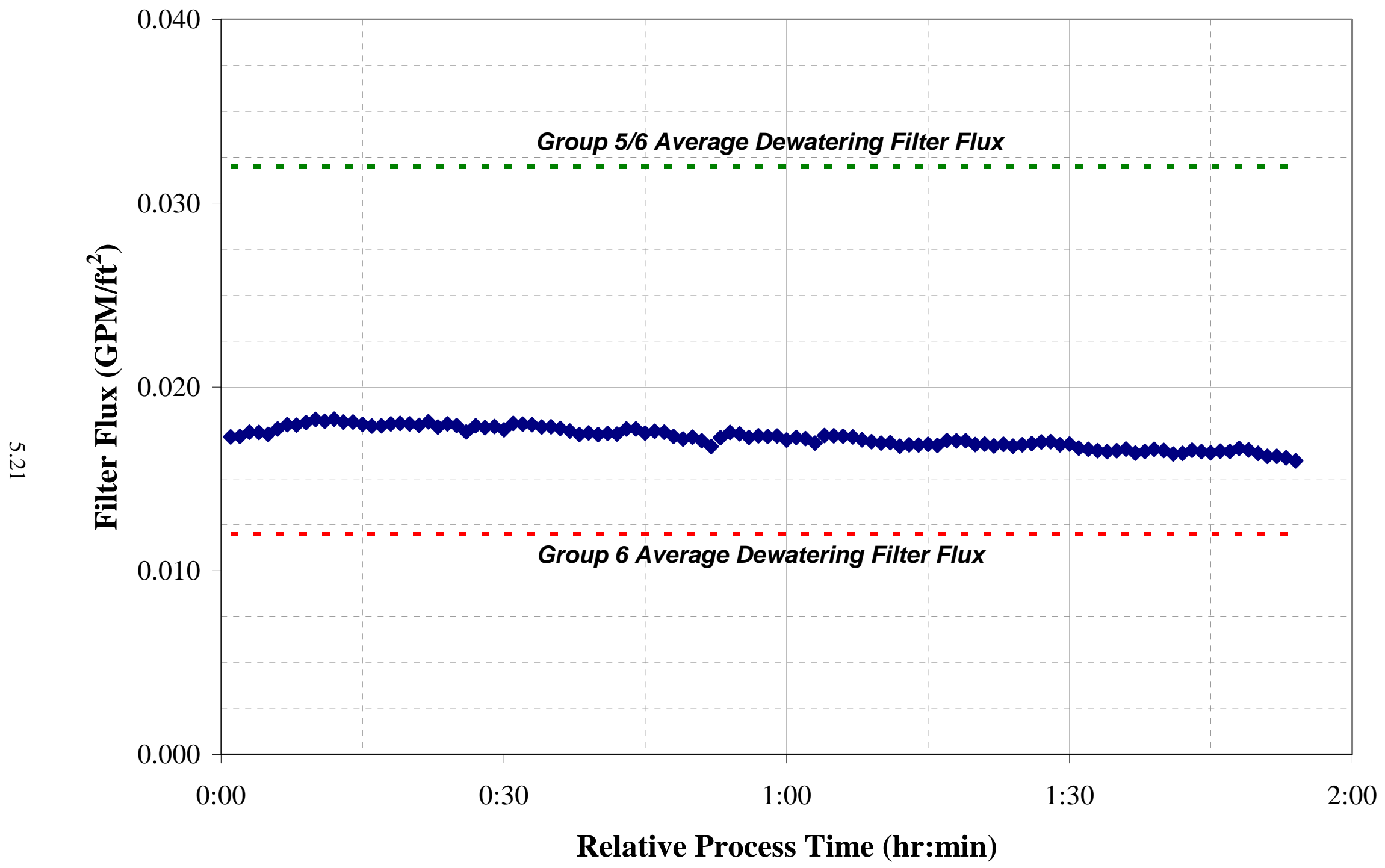

Figure 5.17. Filter Flux During Dewatering of Group 1/2 Blended Waste from 10 wt $\%$ to 20 wt\% UDS 


\subsubsection{High-Solids Filter Matrix Testing}

Figure 5.18 illustrates the material flow during the high-solids matrix testing. After dewatering, the slurry mass inside the circulation loop was estimated to be $2.56 \mathrm{~kg}$ while the permeate piping and back-pulse chamber contained $0.24 \mathrm{~kg}$ of filtered supernate. The wt\% UDS for the matrix of the slurry inside the circulation loop used for the high-solids matrix test was estimated to be $20 \mathrm{wt} \%$.

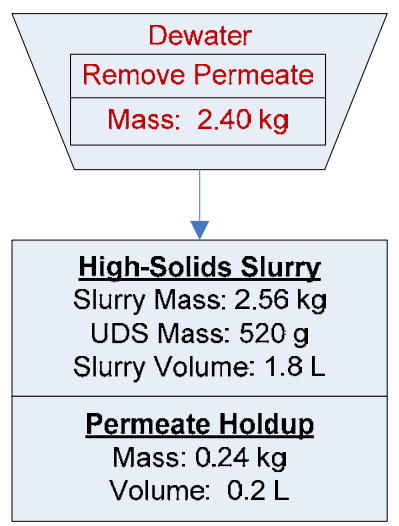

Figure 5.18. Flow Diagram of the High-Solids Matrix Testing Note: Mass and volume values in figure are rounded to the nearest significant digit of accuracy.

The high-solids filtration tests were performed according to the eight test conditions described in Table K.2, Appendix K. The test conditions were performed sequentially with a minimum of 1 hour of constant recycle operation at each condition with back-pulsing between conditions. Table 5.8 provides a summary of the average operating conditions and flux for each condition. These values were obtained by calculating the arithmetic mean of each value over the duration of the test condition. The average TMP and AV of each test condition were plotted against the target values for each test in Figure 5.20.

Flux data with respect to process time are given in Figure 5.19. Compared to the low-solids test, the flux was significantly lower overall, and there was less flux decay within a given test condition. This might have been due the more rapid formation of a cake layer on the membrane at higher solids concentrations with a substantial amount of pore blockage present early at each test condition. The average filter flux measured at the standard conditions for the low-solids matrix tests (tests 1,6 , and 11) was $0.021 \mathrm{GPM} / \mathrm{ft}^{2}$. The filter flux for tests at the standard condition (1, 5, and 8) was $0.016,0.013$, and $0.011 \mathrm{GPM} / \mathrm{ft}^{2}$ in sequence, which is 35 to $50 \%$ lower than the initial filter flux measured. The decrease in the filter flux during the test also indicated a small, irreversible decline in flux with time, although this observation must be tempered by the fact that the average TMP for Test Condition 8 was 2.0 to 2.7 psid lower than Test Conditions 1 and 5. To the extent that flux is TMP dependent, this variation will affect comparisons of the average flux. The flux at test condition 4 at $\mathrm{TMP}=40 \mathrm{psid}$ and $\mathrm{AV}=17 \mathrm{ft} / \mathrm{s}$ was surprising in that it was lower than the value for $A V=9 \mathrm{ft} / \mathrm{s}$ at the same target TMP. Again, this might be attributed to relatively lower TMP (38.9 psid) at this condition compared to other conditions, or it may be further evidence of progressive membrane fouling, or some combination of both.

The average filter flux was plotted against TMP and AV for the eight conditions tested to make a qualitative judgment as to whether the slurry filtered more according to a membrane-resistance, pressuredependent model or a cake-resistance, concentration polarization model. The comparisons are shown in 
Figure 5.21 and Figure 5.22. From these charts, the TMP clearly has a stronger influence on flux, suggesting that the slurry behaves according to a membrane resistance model primarily and can be defined in terms of the Darcy equation. This supports the observation from the initial slurry dewatering that the slurry had not transitioned to cake-resistance-driven flux decay at the ending concentration of $20 \mathrm{wt} \%$ UDS. However, the correlation coefficient $\mathrm{R}^{2}$ was only 0.77 , implying that the filter resistance was changing. Filter flux was plotted against the median operation time of each test condition in Figure 5.23 to access changing in filter resistance over the course of the test. While the linear correlation of the plot was not very high (0.13), the filter flux was found to decrease gradually over the course of the test with time.

To compare these parameters to one another better, the filter matrix data were further correlated and fitted to two empirical models to verify these conclusions. The results of this analysis are shown in Figure 5.24 and Figure 5.25. From the fit equations, a strong dependence of filter flux on TMP was found with no significant impact from AV. Operation time also was found to have a small negative impact on filter flux, demonstrating fouling of the filter occurring that was not reversed by back-pulsing. The results were similar in magnitude to that seen in the low-solids test, where double the operation time was equivalent to $\sim 10 \%$ decrease in the TMP. While both modeling equations have high correlation factors, the use of this model should be limited to understanding how filter flux was influenced by TMP and operation time during this test. Because time was included in both models, offset parameters were developed that limit the range to which they could be applied. Both models do not predict a zero filter flux when the TMP is zero, which demonstrates that the input to these models must be bound by the range of TMP used in this filter test, shown in Table 5.8. The use of these models should also be limited to when the test matrix occurred because the filter resistance was not at steady state, and the parameters developed in these models would be expected to change past the 8-hour period that this model predicts.

Table 5.8. Average Operating Conditions and Filter Flux for the High-Solids Matrix Test

\begin{tabular}{|c|c|c|c|c|c|c|c|}
\hline $\begin{array}{c}\text { Design } \\
\text { Test } \\
\text { Condition } \\
\end{array}$ & $\begin{array}{c}\text { Median } \\
\text { Operation } \\
\text { Time of } \\
\text { Test }^{\text {(a) }} \text { (hr) }\end{array}$ & $\begin{array}{l}\text { Slurry } \\
\text { Temp }^{(b)} \\
\left({ }^{\circ} \mathrm{C}\right)\end{array}$ & $\begin{array}{c}\mathbf{T M P}^{(\mathbf{c})} \\
\text { (psid) }\end{array}$ & $\begin{array}{l}\text { Axial } \\
\text { Velocity } \\
\text { (ft/s) }\end{array}$ & $\begin{array}{l}\text { Permeate } \\
\text { Flowrate } \\
\text { (mL/min) }\end{array}$ & $\begin{array}{l}\text { Corrected } \\
\text { Permeate } \\
\quad \text { Flux } \\
\left(\text { GPM/ft }{ }^{2}\right)\end{array}$ & $\begin{array}{l}\text { Axial } \\
\text { Pressure } \\
\text { Drop }^{(\mathrm{c})} \\
(\mathrm{psid} / \mathrm{ft})\end{array}$ \\
\hline 1 & 1.0 & 25.3 & 41.1 & 12.9 & 15.7 & 0.016 & 1.8 \\
\hline 2 & 2.5 & 25.5 & 40.5 & 14.8 & 13.8 & 0.014 & 2.3 \\
\hline 3 & 3.5 & 25.1 & 41.2 & 8.7 & 14.4 & 0.014 & 0.5 \\
\hline 4 & 4.5 & 25.3 & 38.9 & 17.1 & 11.3 & 0.011 & 3.2 \\
\hline 5 & 5.5 & 25.3 & 41.8 & 12.7 & 13.2 & 0.013 & 1.8 \\
\hline 6 & 6.5 & 25.1 & 19.4 & 13.4 & 6.2 & 0.006 & 1.8 \\
\hline 7 & 7.5 & 25.3 & 60.4 & 13.0 & 16.9 & 0.017 & 2.0 \\
\hline 8 & 8.5 & 25.3 & 39.1 & 13.1 & 10.9 & 0.011 & 1.9 \\
\hline \multicolumn{8}{|c|}{$\begin{array}{l}\text { (a) Median operation time refers to the } \mathrm{m} \\
\text { time of the test }(\mathrm{T}=0) \text {. Time period } \\
\text { (b) Thermocouple accuracy } \pm 2^{\circ} \mathrm{C} \text {. } \\
\text { (c) Pressure transducer accuracy } \pm 1 \mathrm{psig}\end{array}$} \\
\hline
\end{tabular}




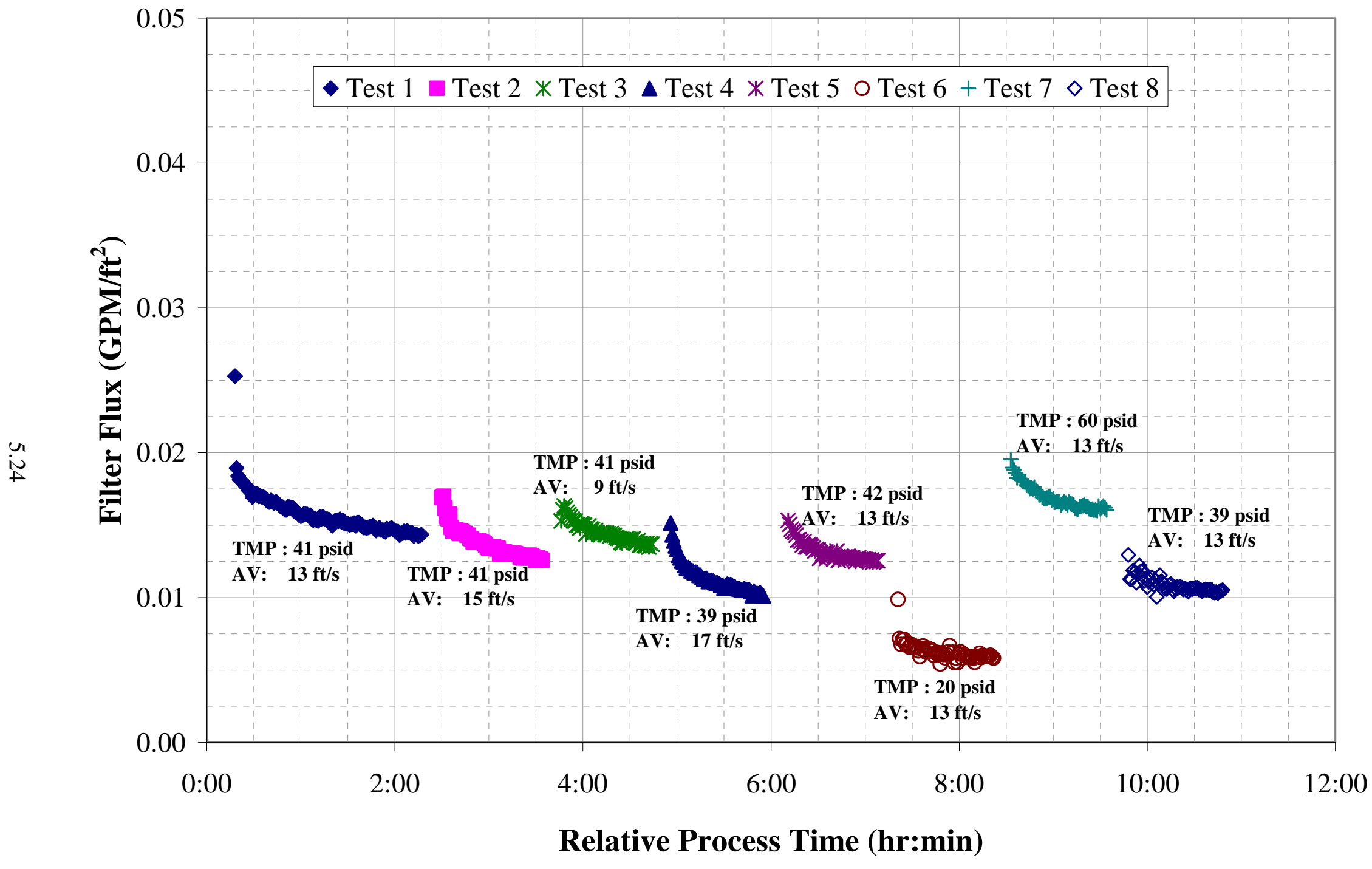

Figure 5.19. Filter Flux Data for Group $1 / 2$ High-Solids Matrix, 20 wt $\%$ UDS 


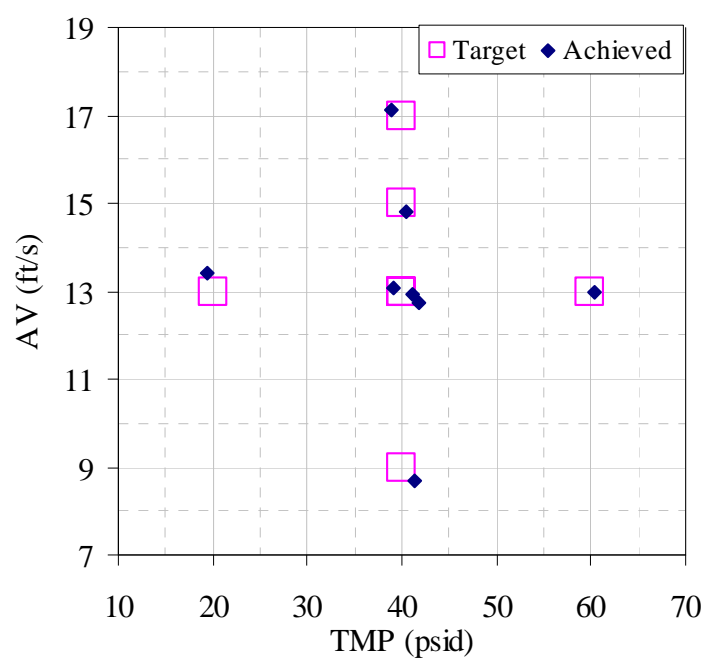

Figure 5.20. Group 1/2 Filter Test Matrix for High-Solids

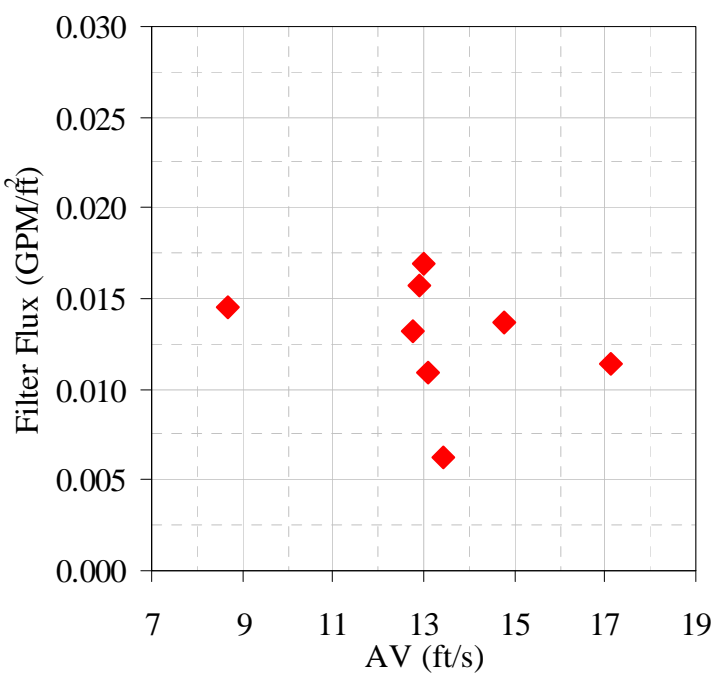

Figure 5.22. Group 1/2 Flux vs. AV for High-Solids

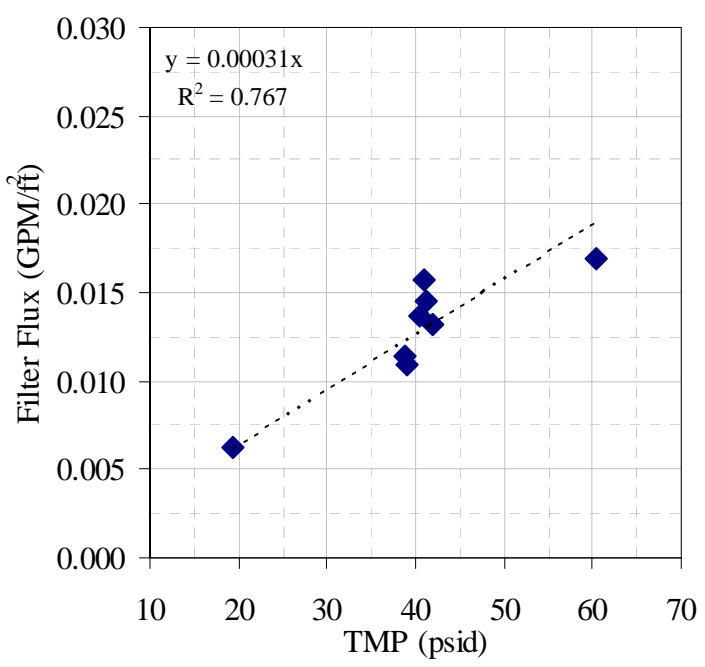

Figure 5.21. Group 1/2 Flux vs. TMP for High-Solids

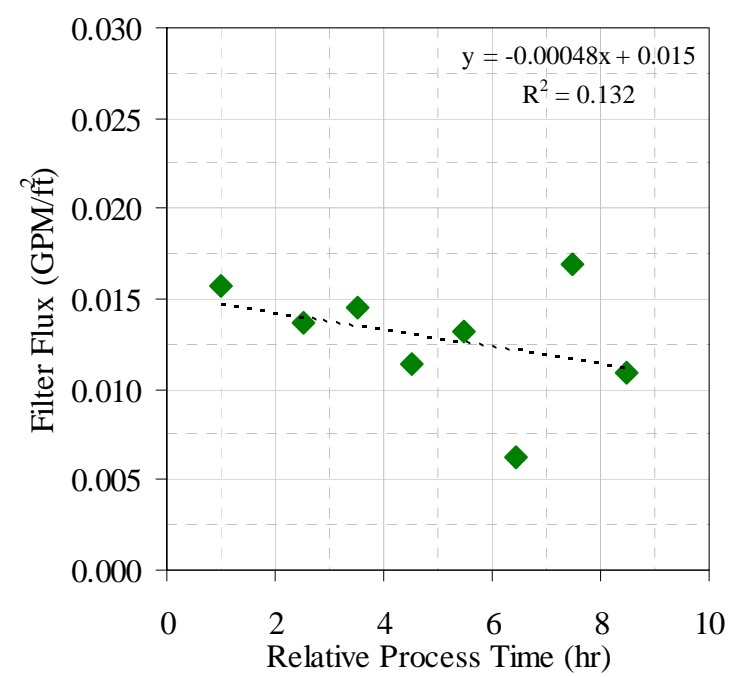

Figure 5.23. Group 1/2 Flux vs. Relative Time for High-Solids 


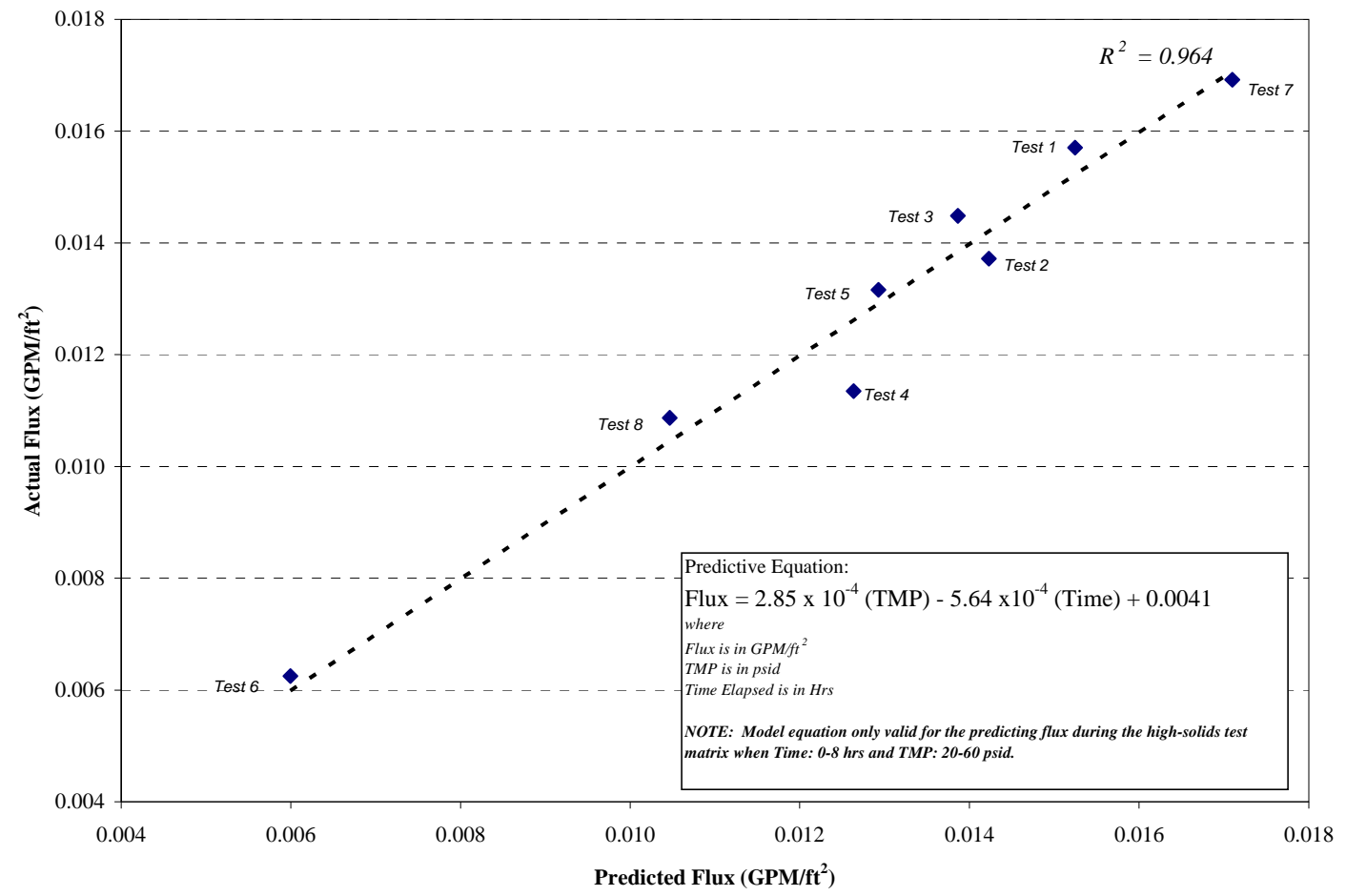

Figure 5.24. Linear Model of Filter Flux of Group 1/2 Slurry at High-Solids Concentration

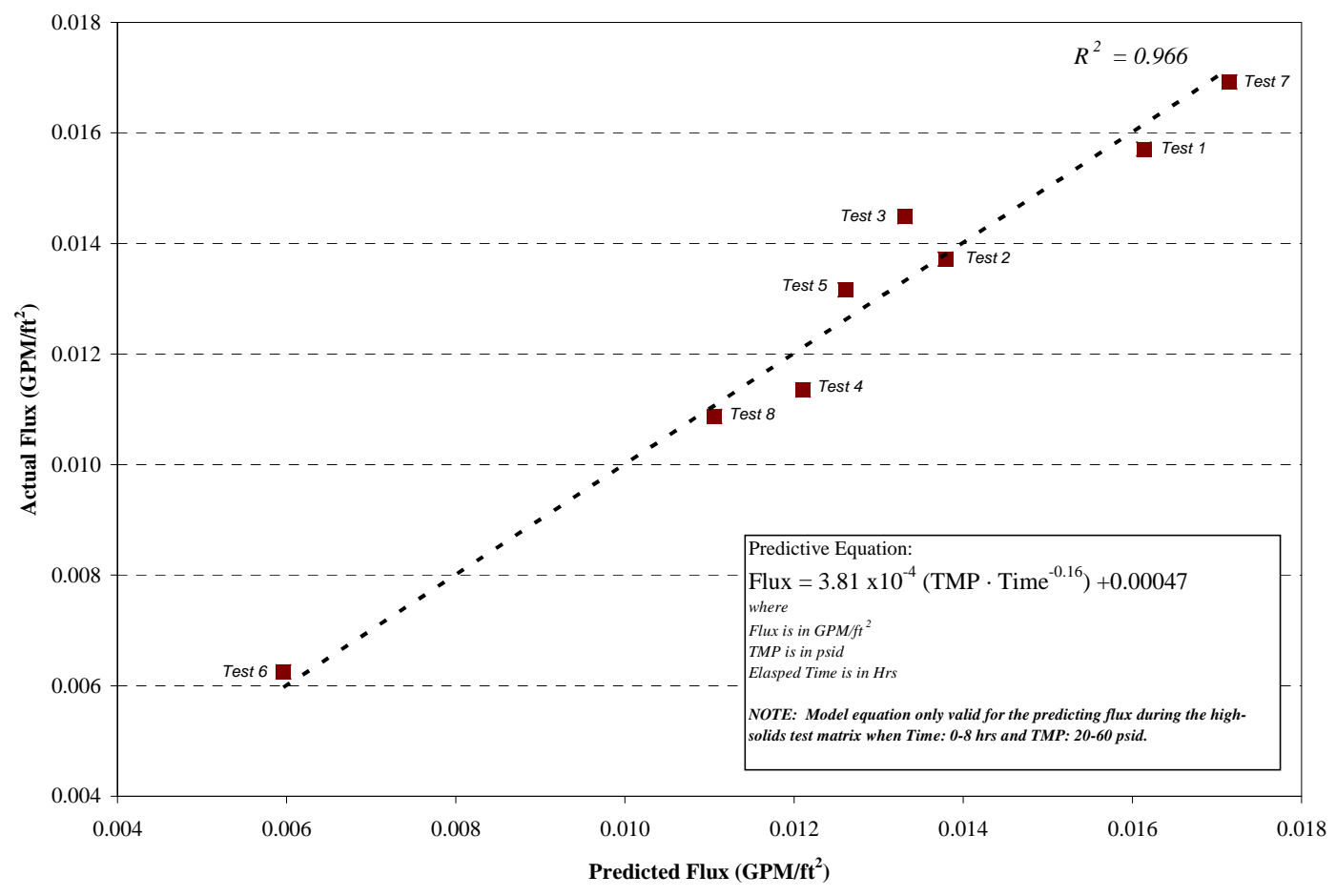

Figure 5.25. Exponential Model of Filter Flux of Group 1/2 Slurry at High-Solids Concentration 


\subsection{High-Solids Slurry Characterization}

After completing the high-solids matrix test, the circulation slurry was sampled for physical and chemical analyses, as shown in Figure 5.26. Overall, 99 grams of the circulating slurry was removed containing an estimated 20 grams of UDS.

The physical properties and composition of this high-solids slurry are shown in Table 5.9 through Table 5.11. As discussed early, the predicted UDS concentration of the slurry (20 wt\%) was significantly higher than the measured UDS concentration (14 wt\%). While it was discussed earlier that problems with the overhead mixer were a likely reason that the slurry sample UDS was not representative of the circulating slurry, there are two other likely possibilities.

- The solids dissolved from mixing the Group 1 and Group 2 slurries.

- Measured UDS values of the Group 1 and Group 2 slurries were not as accurate as thought.

However, there was no evidence supporting either of these two theories. The composition of the Group 1/2 supernate shown in

Table 5.10 and

Table 5.11 correlates well with the supernate compositions reported in Sections 3 and 4, indicating that no significant dissolution of the solids occurred. Also, the solids composition calculated from mass balance data in

Table 5.10 (which assumed 500 grams of UDS was present) only differs by $10 \%$ with solids composition data reported in

Table 5.11, which was based on analytical measurements of the slurry. This difference was considered within the error range of the chemical analyses performed.

Based upon initial dewatering values, $8 \%$ of the aluminum and $30 \%$ of the chromium in the original slurry was present in the supernate in a soluble phase. This would explain the drop from low solids to high solids of the aluminum (8\%) and chromium (20\%) as the soluble portion exited upon dewatering. Sulfur in the slurry is accounted for completely by sulfate, which is highly soluble, its concentration decreasing significantly with each successive dewatering step. There is some soluble phosphate; however, the bulk of the phosphorus appeared to be tied up in insoluble forms. Based on work described elsewhere in this report, the water-insoluble phosphorus was likely in the form of iron(III) phosphate. Soluble anions in the supernatant as well as cesium all were reduced via the dewatering process.

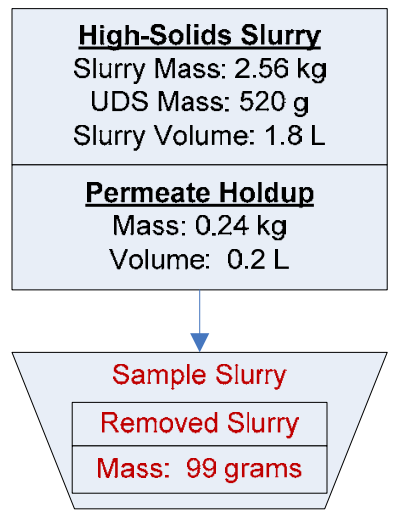

Figure 5.26. Sampling of the High-Solids Slurry

Note: Mass and volume values in figure are rounded to the nearest significant digit of accuracy. 
WTP-RPT-166, Rev. 0

Table 5.9. Physical Property Measurements of the High-Solids Slurry

\begin{tabular}{|r|c|}
\hline Slurry Density (g/mL) & 1.38 \\
\hline Supernate Density (g/mL) & 1.20 \\
\hline Settled Solids (Vol\%) & $95 \%$ \\
\hline Centrifuged UDS (Wt $\%)$ & $26 \%$ \\
\hline Total Solids of the Slurry $(\mathbf{W t} \%)$ & $38 \%$ \\
\hline Dissolved Solids of the Supernate $\mathbf{( W t} \%)$ & $28 \%$ \\
\hline UDS of the Slurry $\mathbf{( W t} \%)$ & $14 \%$ \\
\hline
\end{tabular}


Table 5.10. Group $1 / 2$ High-Solids Slurry Inventory and Composition

\begin{tabular}{|c|c|c|c|c|c|}
\hline & Slurry $^{(a)}$ & \multicolumn{2}{|c|}{ Liquid Fraction $^{(b)}$} & \multicolumn{2}{|c|}{ Solids Fraction $^{(c)}$} \\
\hline Mass (kg) & 2.70 & \multicolumn{2}{|c|}{2.20} & \multicolumn{2}{|c|}{0.50} \\
\hline Wt\% of Slurry & $100 \%$ & \multicolumn{2}{|c|}{$81.5 \%$} & \multicolumn{2}{|c|}{$18.5 \%$} \\
\hline Metal & g & g & $\mu g / m L$ & g & $\mu g / g$ \\
\hline Al & $4.6 \mathrm{E}+01$ & $1.7 \mathrm{E}+00$ & $9.4 \mathrm{E}+02$ & $4.5 \mathrm{E}+01$ & $8.9 \mathrm{E}+04$ \\
\hline $\mathrm{Bi}$ & $2.0 \mathrm{E}+01$ & $<7$. E-3 & $<4 . \mathrm{E}+0$ & $2.0 \mathrm{E}+01$ & $4.1 \mathrm{E}+04$ \\
\hline $\mathrm{Cr}$ & $4.5 \mathrm{E}+00$ & 8.8E-01 & $4.8 \mathrm{E}+02$ & $3.6 \mathrm{E}+00$ & $7.2 \mathrm{E}+03$ \\
\hline $\mathbf{F e}$ & $2.7 \mathrm{E}+01$ & 9.7E-03 & $5.3 \mathrm{E}+00$ & $2.7 \mathrm{E}+01$ & $5.4 \mathrm{E}+04$ \\
\hline Mn & 4.1E-01 & $1.6 \mathrm{E}-04$ & $9.0 \mathrm{E}-02$ & 4.1E-01 & $8.1 \mathrm{E}+02$ \\
\hline $\mathrm{Na}$ & $3.1 \mathrm{E}+02$ & $1.8 \mathrm{E}+02$ & $1.0 \mathrm{E}+05$ & $1.2 \mathrm{E}+02$ & $2.4 \mathrm{E}+05$ \\
\hline $\mathbf{P}$ & $4.1 \mathrm{E}+01$ & $1.9 \mathrm{E}+00$ & $1.0 \mathrm{E}+03$ & $3.9 \mathrm{E}+01$ & $7.9 \mathrm{E}+04$ \\
\hline $\mathbf{S}$ & $7.7 \mathrm{E}+00$ & $9.7 \mathrm{E}+00$ & $5.3 \mathrm{E}+03$ & $\mathrm{~N} / \mathrm{A}^{(\mathrm{d})}$ & $\mathrm{N} / \mathrm{A}^{(\mathrm{d})}$ \\
\hline Si & $1.8 \mathrm{E}+01$ & $1.9 \mathrm{E}-02$ & $1.1 \mathrm{E}+01$ & $1.8 \mathrm{E}+01$ & $3.6 \mathrm{E}+04$ \\
\hline $\mathrm{Sr}$ & $1.6 \mathrm{E}+00$ & 4.2E-04 & 2.3E-01 & $1.6 \mathrm{E}+00$ & $3.2 \mathrm{E}+03$ \\
\hline $\mathbf{U}$ & $6.7 \mathrm{E}+00$ & 2.0E-01 & $1.1 \mathrm{E}+02$ & $6.5 \mathrm{E}+00$ & $1.3 \mathrm{E}+04$ \\
\hline \multirow{2}{*}{$\begin{array}{l}\text { Radiochemical } \\
\text { Isotopes }\end{array}$} & Slurry & \multicolumn{2}{|c|}{ Liquid Fraction } & \multicolumn{2}{|c|}{ Solid Fraction } \\
\hline & mCi & mCi & $\mathbf{m C i} / \mathbf{m L}$ & mCi & $\mathrm{mCi} / \mathrm{g}$ \\
\hline Co-60 & $5.2 \mathrm{E}+00$ & $<7$. E- 2 & $<4$. E-5 & $5.2 \mathrm{E}+00$ & $1.0 \mathrm{E}-02$ \\
\hline Cs-137 & $6.9 \mathrm{E}+04$ & $2.2 \mathrm{E}+04$ & $1.2 \mathrm{E}+01$ & $4.7 \mathrm{E}+04$ & $9.3 \mathrm{E}+01$ \\
\hline Eu-154 & $1.6 \mathrm{E}+01$ & $<4 . \mathrm{E}-1$ & $<2 . \mathrm{E}-4$ & $1.6 \mathrm{E}+01$ & $3.2 \mathrm{E}-02$ \\
\hline Am-241 & $1.4 \mathrm{E}+02$ & $<4 . \mathrm{E}+0$ & $<2 . \mathrm{E}-3$ & $1.4 \mathrm{E}+02$ & 2.9E-01 \\
\hline Gross Alpha & $2.7 \mathrm{E}+02$ & $1.3 \mathrm{E}+00$ & 7.3E-04 & $2.7 \mathrm{E}+02$ & 5.5E-01 \\
\hline Gross Beta & $2.0 \mathrm{E}+05$ & $2.1 \mathrm{E}+04$ & $1.1 \mathrm{E}+01$ & $1.8 \mathrm{E}+05$ & $3.6 \mathrm{E}+02$ \\
\hline Sr-90 & $6.4 \mathrm{E}+04$ & $1.8 \mathrm{E}+01$ & 9.7E-03 & $6.4 \mathrm{E}+04$ & $1.3 \mathrm{E}+02$ \\
\hline Pu-239+240 & $1.9 \mathrm{E}+02$ & $6.0 \mathrm{E}-02$ & $3.2 \mathrm{E}-05$ & $1.9 \mathrm{E}+02$ & $3.8 \mathrm{E}-01$ \\
\hline Pu-238 & $6.5 \mathrm{E}+00$ & 3.5E-02 & $1.9 \mathrm{E}-05$ & $6.5 \mathrm{E}+00$ & $1.3 \mathrm{E}-02$ \\
\hline \multirow[t]{2}{*}{ Anions } & \multicolumn{3}{|c|}{ Liquid Fraction } & \multicolumn{2}{|c|}{ Leached Solids Fractior } \\
\hline & $\mu \mathrm{g} / \mathrm{mL}$ & [M] & g & $\mu \mathrm{g} / \mathrm{g}$ & g \\
\hline $\mathbf{F}$ & $4.0 \mathrm{E}+03$ & 2.1E-01 & $7.3 \mathrm{E}+00$ & $2.6 \mathrm{E}+04$ & $1.3 \mathrm{E}+01$ \\
\hline $\mathrm{C}_{2} \mathrm{O}_{4}$ & $1.4 \mathrm{E}+03$ & $1.6 \mathrm{E}-02$ & $2.6 \mathrm{E}+00$ & $<4 . \mathrm{E}+1$ & $<2$.E-2 \\
\hline $\mathrm{NO}_{2}$ & $7.8 \mathrm{E}+03$ & $1.7 \mathrm{E}-01$ & $1.4 \mathrm{E}+01$ & $1.2 \mathrm{E}+04$ & $5.8 \mathrm{E}+00$ \\
\hline $\mathrm{NO}_{3}$ & $1.9 \mathrm{E}+05$ & $3.1 \mathrm{E}+00$ & $3.5 \mathrm{E}+02$ & $2.9 \mathrm{E}+05$ & $1.4 \mathrm{E}+02$ \\
\hline $\mathrm{SO}_{4}$ & $1.5 \mathrm{E}+04$ & 1.5E-01 & $2.7 \mathrm{E}+01$ & $2.4 \mathrm{E}+04$ & $1.2 \mathrm{E}+01$ \\
\hline $\mathrm{PO}_{4}$ & $3.1 \mathrm{E}+03$ & 3.3E-02 & $5.6 \mathrm{E}+00$ & $9.2 \mathrm{E}+04$ & $4.6 \mathrm{E}+01$ \\
\hline $\mathrm{OH}$ & $1.2 \mathrm{E}+03$ & $6.9 \mathrm{E}-02$ & $2.1 \mathrm{E}+00$ & & \\
\hline \multicolumn{6}{|c|}{$\begin{array}{l}\text { Slurry mass components were calculated from characterization data (Sections } 3 \text { and } 4 \text { ) and the masses of } \\
\text { materials that were added with simulant. Loss of mass from sampling was incorporated. } \\
\text { Liquid fraction mass components were calculated using analytical results from supernate sample TI572-G6-A } \\
\text { (ASO ID 08-01290) and the predicted mass of supernate in the system. } \\
\text { Solids fraction mass components were calculated from the difference between the slurry component mass and } \\
\text { liquid component mass fraction. } \\
\text { Values for sulfur in the solid inventory were calculated to be negative. }\end{array}$} \\
\hline
\end{tabular}


WTP-RPT-166, Rev. 0

Table 5.11. Group 1/2 High-Solids Slurry Composition Based on ICP-OES/Radionuclide Characterization

\begin{tabular}{|c|c|c|c|c|}
\hline $\begin{array}{c}\text { Slurry Prep } \\
\text { Method } \\
\end{array}$ & $\begin{array}{c}\text { ICP-OES } \\
\text { Analytes } \\
\end{array}$ & $\begin{array}{c}\begin{array}{c}\text { Dry Slurry } \\
(\mu \mathrm{g} / \mathrm{g})\end{array} \\
\end{array}$ & $\begin{array}{c}\text { Supernate }^{(\mathrm{b})} \\
(\mu \mathrm{g} / \mathrm{mL})\end{array}$ & $\begin{array}{c}{ }^{D^{2} y} \text { Solids }{ }^{(\mathrm{c})} \\
(\mu \mathrm{g} / \mathrm{g})\end{array}$ \\
\hline \multirow{35}{*}{ 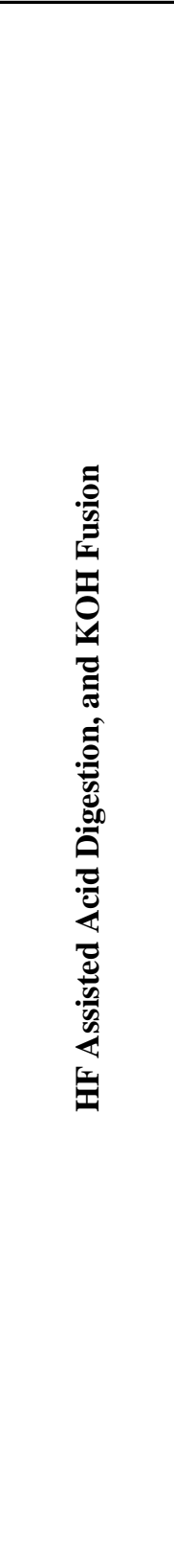 } & Al & 39,075 & 942 & 99,869 \\
\hline & $\mathbf{B i}$ & 19,900 & $<3.7 \mathrm{E}+0$ & 53,232 \\
\hline & Cd & 22.8 & $<4.2 \mathrm{E}-1$ & 58.8 \\
\hline & $\mathrm{Cr}$ & 3,915 & 480 & 8,087 \\
\hline & $\mathbf{F e}$ & 24,375 & [5.3] & 65,198 \\
\hline & $\mathbf{K}$ & 952 & 552 & -203 \\
\hline & Mn & 354 & {$[0.090]$} & 946 \\
\hline & $\mathrm{Na}$ & 263,000 & 100,000 & 205,543 \\
\hline & $\mathbf{N i}$ & 1,455 & $<3.0 \mathrm{E}-1$ & 3,892 \\
\hline & $\mathbf{P}$ & 38,825 & 1,025 & 98,785 \\
\hline & $\mathrm{S}$ & 8,165 & 5,300 & $-4,557$ \\
\hline & Si & 18550.0 & [10.6] & 49584.8 \\
\hline & $\mathrm{Sr}$ & 1,348 & 0.228 & 3,605 \\
\hline & $\mathbf{U}$ & 6,058 & 108 & 15,671 \\
\hline & Zn & 202 & {$[0.54]$} & 539 \\
\hline & $\mathbf{Z r}$ & 76 & $<1.4 \mathrm{E}-1$ & 202 \\
\hline & $A g$ & [4.63] & $<2.6 \mathrm{E}-1$ & [11.1] \\
\hline & $B a$ & 89 & {$[0.31]$} & 235 \\
\hline & $B e$ & 0.455 & $<6.5 \mathrm{E}-3$ & 1.184 \\
\hline & $C a$ & 3,160 & 2.80 & 8,442 \\
\hline & $\mathrm{Ce}$ & 71.9 & $<1.2 \mathrm{E}+0$ & 186.1 \\
\hline & Co & [16] & $<3.0 \mathrm{E}-1$ & {$[42]$} \\
\hline & $\mathrm{Cu}$ & 42.3 & $<1.7 \mathrm{E}-1$ & 112.4 \\
\hline & $L a$ & [14] & $<3.5 \mathrm{E}-1$ & [34] \\
\hline & $\mathrm{Li}$ & 27.6 & {$[1.00]$} & 68.9 \\
\hline & $M g$ & 540 & $<2.9 \mathrm{E}-1$ & 1,444 \\
\hline & Mo & [28] & 7.11 & [40] \\
\hline & $N d$ & [18] & $<6.7 \mathrm{E}-1$ & [44] \\
\hline & $P b$ & 513 & $<4.0 \mathrm{E}+0$ & 1,352 \\
\hline & $R u$ & {$[12.53]$} & {$[2.1]$} & {$[23.08]$} \\
\hline & $T h$ & 9.50 & [5.15] & {$[0.24]$} \\
\hline & $T i$ & 59.0 & 1.40 & 150.9 \\
\hline & $\mathrm{Tl}$ & [74] & {$[0.053]$} & [197] \\
\hline & $V$ & 15.0 & $<4.7 \mathrm{E}+0$ & 16.6 \\
\hline & $Y$ & [2.5] & $<5.5 \mathrm{E}-2$ & {$[6.42]$} \\
\hline
\end{tabular}


WTP-RPT-166, Rev. 0

Table 5.11 (Contd)

\begin{tabular}{|c|c|c|c|c|}
\hline $\begin{array}{c}\text { Slurry Prep } \\
\text { Method }\end{array}$ & Radionuclides & $\begin{array}{c}\begin{array}{c}\text { Dry Slurry } \\
(\mu \mathrm{a})\end{array} \\
(\mathrm{C} / \mathrm{g})\end{array}$ & $\begin{array}{c}\text { Supernate }^{(b)} \\
(\mu \mathrm{Ci} / \mathrm{mL})\end{array}$ & $\begin{array}{c}\text { Dry Solids }^{(c)} \\
(\mu \mathrm{Ci} / \mathrm{g})\end{array}$ \\
\hline \multirow[t]{10}{*}{ KOH Fusion } & Co-60 & $4.42 \mathrm{E}-3$ & $<4 . E-5$ & $1.16 \mathrm{E}-2$ \\
\hline & Cs-137 & $6.28 \mathrm{E}+1$ & $1.21 \mathrm{E}+1$ & $1.08 \mathrm{E}+2$ \\
\hline & Eu-154 & $<7 . \mathrm{E}-3$ & $<2 . E-4$ & $<2 . \mathrm{E}-2$ \\
\hline & Eu-155 & $<3 . \mathrm{E}-2$ & $<2 . E-3$ & $<7 . \mathrm{E}-2$ \\
\hline & Am-241 & $1.19 \mathrm{E}-1$ & $<2 . \mathrm{E}-3$ & $3.10 \mathrm{E}-1$ \\
\hline & Total alpha & $2.53 \mathrm{E}-1$ & $7.32 \mathrm{E}-4$ & $6.73 \mathrm{E}-1$ \\
\hline & Total beta & $1.45 \mathrm{E}+2$ & $1.14 \mathrm{E}+1$ & $3.30 \mathrm{E}+2$ \\
\hline & Sr-90 & $5.61 \mathrm{E}+1$ & $9.69 \mathrm{E}-3$ & $1.50 \mathrm{E}+2$ \\
\hline & Pu-239/240 & $1.34 \mathrm{E}-1$ & $3.24 \mathrm{E}-5$ & $3.60 \mathrm{E}-1$ \\
\hline & Pu-238 & $3.74 \mathrm{E}-3$ & $1.90 \mathrm{E}-5$ & $9.91 \mathrm{E}-3$ \\
\hline \multicolumn{5}{|c|}{$\begin{array}{l}\text { (a) Test sample TI572-G2-A, ASO ID 08-01290 } \\
\text { (b) Test sample TI572-G2-6, ASO ID 08-01317 } \\
\text { (c) Calculated using results from TI572-G2-A and TI572-G2-6 } \\
\text { Note: Analytes in italics were measured opportunistically. Values in brackets [ ] are } \geq \text { MDL } \\
\text { but < EQL, with errors likely to exceed 15\%. }\end{array}$} \\
\hline
\end{tabular}

Figure 5.27 shows the size distribution of particles in the high-solids slurry matrix before sonication. The distribution is broad, ranging from $\sim 0.3$ to $500 \mu \mathrm{m}$, and is characterized by a strong peak with a maximum population between 1 and $2 \mu \mathrm{m}$. At 2000 and 3000 RPM, the distribution shows a broad "shoulder" over the range 4 to $60 \mu \mathrm{m}$. In addition, the distributions at 2000 and 3000 RPM show a small population of large particles, ranging from 60 to $\sim 600 \mu \mathrm{m}$ with a peak population around $400 \mu \mathrm{m}$. This large particle population may represent flocculates that form under weak shear (resulting in the most significant $400 \mu \mathrm{m}$ population at $2000 \mathrm{RPM}$ ). It could also result from poor interpretation of the light scattering signal. Regardless, the contribution of large (60 to $600 \mu \mathrm{m}$ ) particles is minor relative to that of particles making up the primary distribution $(0.2$ to $60 \mu \mathrm{m})$. At $4000 \mathrm{RPM}$, a secondary population peak centered at $50 \mu \mathrm{m}$ appears. The latter is likely associated with difficult-to-suspend particles.

Figure 5.28 shows the effects of sonication on the high-solids slurry matrix at a pump speed of 3000 RPM. Sonication appears to reduce/eliminate the contribution of particles greater than $20 \mu \mathrm{m}$ while increasing the contribution of particles between 2 and $20 \mu \mathrm{m}$. The original (pre-sonication) distribution appears to be preserved in a sub-micrometer shoulder population that spans 0.2 to $1 \mu \mathrm{m}$. The increase in relative contribution of 2- to 20 - $\mu \mathrm{m}$ particles is likely a result of sonic disruption of particle agglomerates greater than $20 \mu \mathrm{m}$. The during- and after-sonication PSDs are relatively similar, indicating that the changes that occur during sonication are mostly irreversible over the time frame of these PSD measurements. On the other hand, a slight decrease in the peak population contribution of particles after sonic power is removed could indicate some reformation of agglomerates, but this decrease is not accompanied by significant changes in the span of the distribution. 


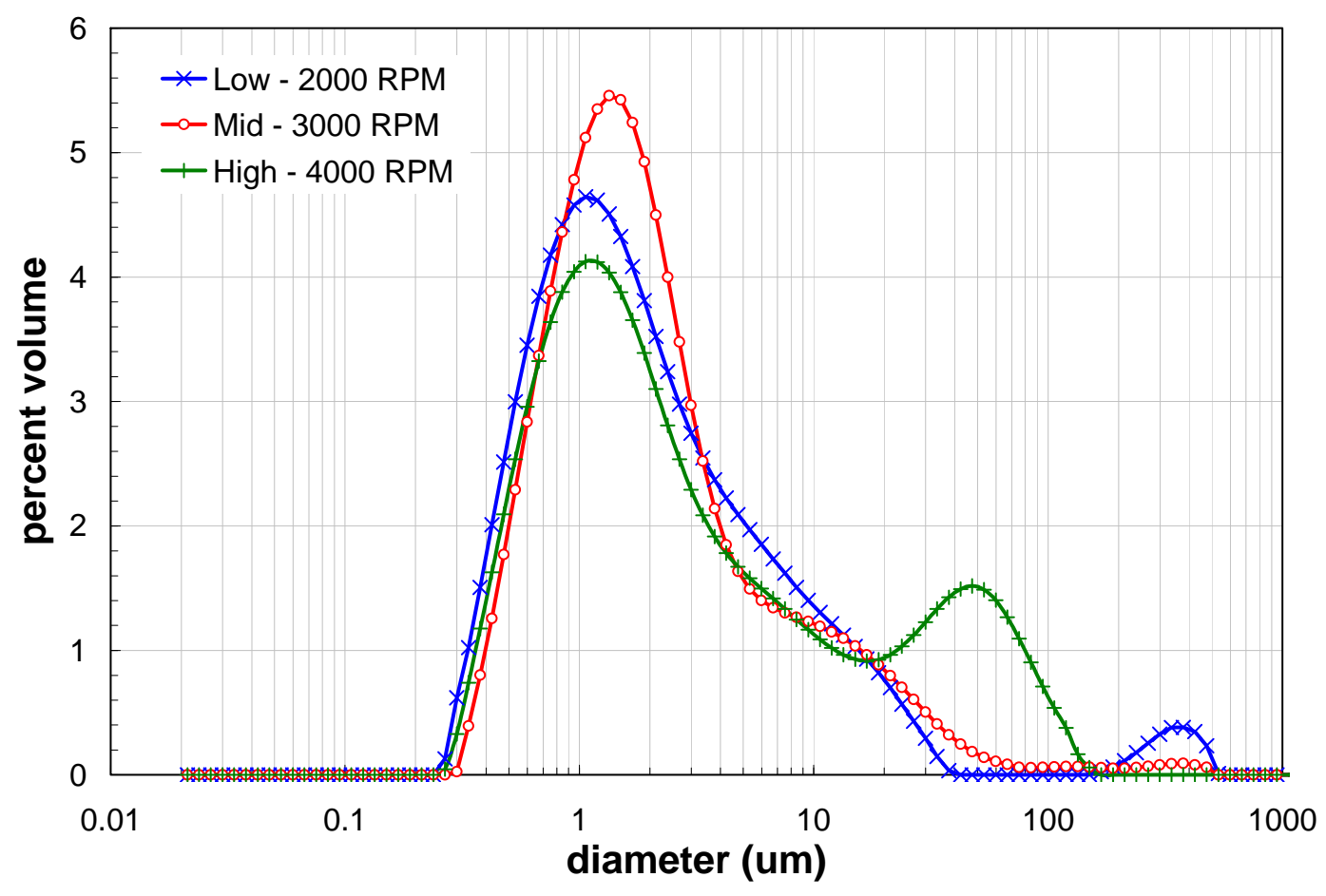

Figure 5.27. High-Solids Slurry Matrix PSD at Varying Pump Speeds

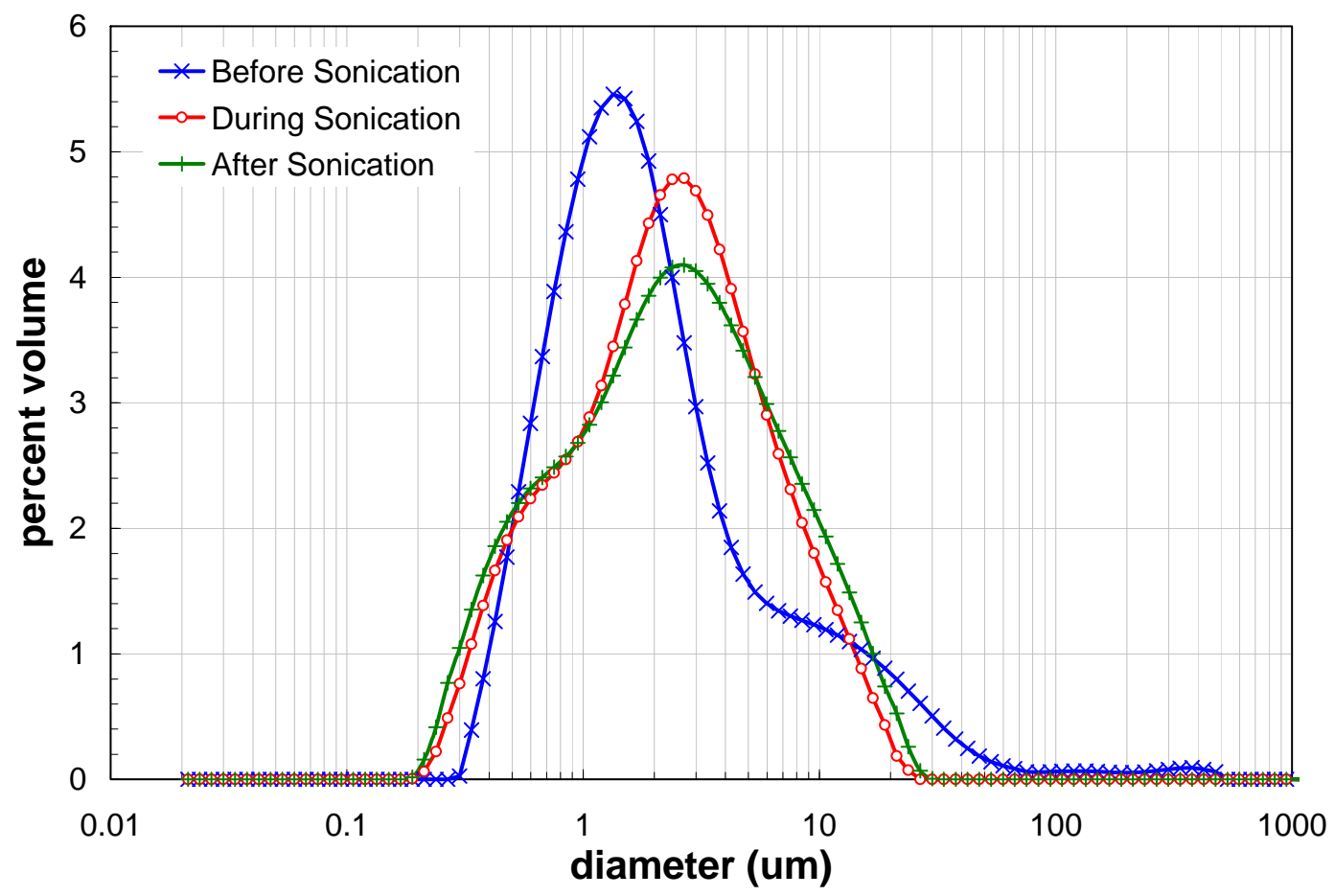

Figure 5.28. High-Solids Slurry Matrix PSD with Sonication at a Pump Speed of 3000 RPM 
Figure 5.29 shows the results of flow curve testing for the high-solids slurry, which shows nonNewtonian behavior at all temperatures studied. All flow curves have a finite yield stress that falls between 2 and $4 \mathrm{~Pa}$. The stress response over 0 to $1000 \mathrm{~s}^{-1}$ shows a slight downward curvature. The flow curves appear to be free of artifacts caused by poor sample rotation, such as significant downward curvature in the 0 to $100 \mathrm{~s}^{-1}$ range. Flow curve hysteresis is present in all flow curves, but appears to influence the $60^{\circ} \mathrm{C}$ measurement data to the greatest extent. Hysteresis at $25^{\circ} \mathrm{C}$ and $40^{\circ} \mathrm{C}$ results from a decrease in the stress required to shear the fluid over time. That is, at these temperatures, the down-ramp data always show a lower stress response than the up-ramp data. One potential cause for this type of hysteresis is continued shear alteration of the sample structure (such as shear breakup of aggregates). The nature of flow curve hysteresis changes at $60^{\circ} \mathrm{C}$. Here, the down-ramp data show a higher stress response relative to the up-ramp data. This type of hysteresis is consistent with increased slurry concentration and rheology as a result of suspending phase evaporation.

Given the noise introduced into the measurement by flow curve hysteresis ( $\sim 1 \mathrm{~Pa})$, the increased slurry temperature does not appear to significantly change the observed yield stress. The slurry consistency appears to decrease as the temperature is increased from $25^{\circ}$ to $60^{\circ} \mathrm{C}$ as evidenced by the decreasing flow curve slope over 0 to $1000 \mathrm{~s}^{-1}$.

Table 5.12 summarizes the best-fit rheological parameters for flow curve data for the high-solids slurry. The fitting parameters show that:

- The Bingham-Plastic and Herschel-Bulkley yield stresses range from 2.7 to $3.2 \mathrm{~Pa}$ and 2.1 to $2.6 \mathrm{~Pa}$ (depending on temperature), respectively. Because the maximum difference between the yield stresses at different temperatures is only $0.5 \mathrm{~Pa}$, it can be concluded that the yield stress does not change significantly with temperature.

- The Bingham-Plastic consistency decreases from $13 \mathrm{mPa} \cdot \mathrm{s}$ at $25^{\circ} \mathrm{C}$ to $9.0 \mathrm{mPa} \cdot \mathrm{s}$ at $60^{\circ} \mathrm{C}$. This decrease is consistent with the temperature-dependence observations made in the preceding paragraph.

- The Herschel-Bulkley flow indices are all near 0.9, confirming that the flow curve data do have a slight downward curvature.

- The two replicate measurements at $25^{\circ} \mathrm{C}$ yield equivalent fitting parameters, given the limit of instrument accuracy ( $\pm 0.5 \mathrm{~Pa}$ for yield stress and $\pm 0.5 \mathrm{mPa} \cdot \mathrm{s}$ for consistency).

For ease of reference, apparent viscosities at 33, 100, 500, and $1000 \mathrm{~s}^{-1}$ are derived from each measurement. For each temperature, the 33, 100, and $500 \mathrm{~s}^{-1}$ reference viscosities are determined from the average of up-ramp and down-ramp flow curve data. The apparent viscosity at $1000 \mathrm{~s}^{-1}$ averages apparent viscosity measurements over the period of constant rotation at $1000 \mathrm{~s}^{-1}$. As a point of comparison, apparent viscosities at $33 \mathrm{~s}^{-1}, 100 \mathrm{~s}^{-1}, 500 \mathrm{~s}^{-1}$, and $1000 \mathrm{~s}^{-1}$ were also calculated using the Bingham-Plastic and Herschel-Bulkley fitting parameters in Table 5.12. The results of these analyses are provided in Table 5.13 and show that apparent viscosities typically range from 76 to $110 \mathrm{mPa} \cdot \mathrm{s}^{2} 33 \mathrm{~s}^{-1}$, 34 to $45 \mathrm{mPa} \cdot \mathrm{s}$ at $100 \mathrm{~s}^{-1}, 14$ to $20 \mathrm{mPa} \cdot \mathrm{s}$ at $500 \mathrm{~s}^{-1}$, and 12 to $16 \mathrm{mPa} \cdot \mathrm{s}$ at $1000 \mathrm{~s}^{-1}$. 


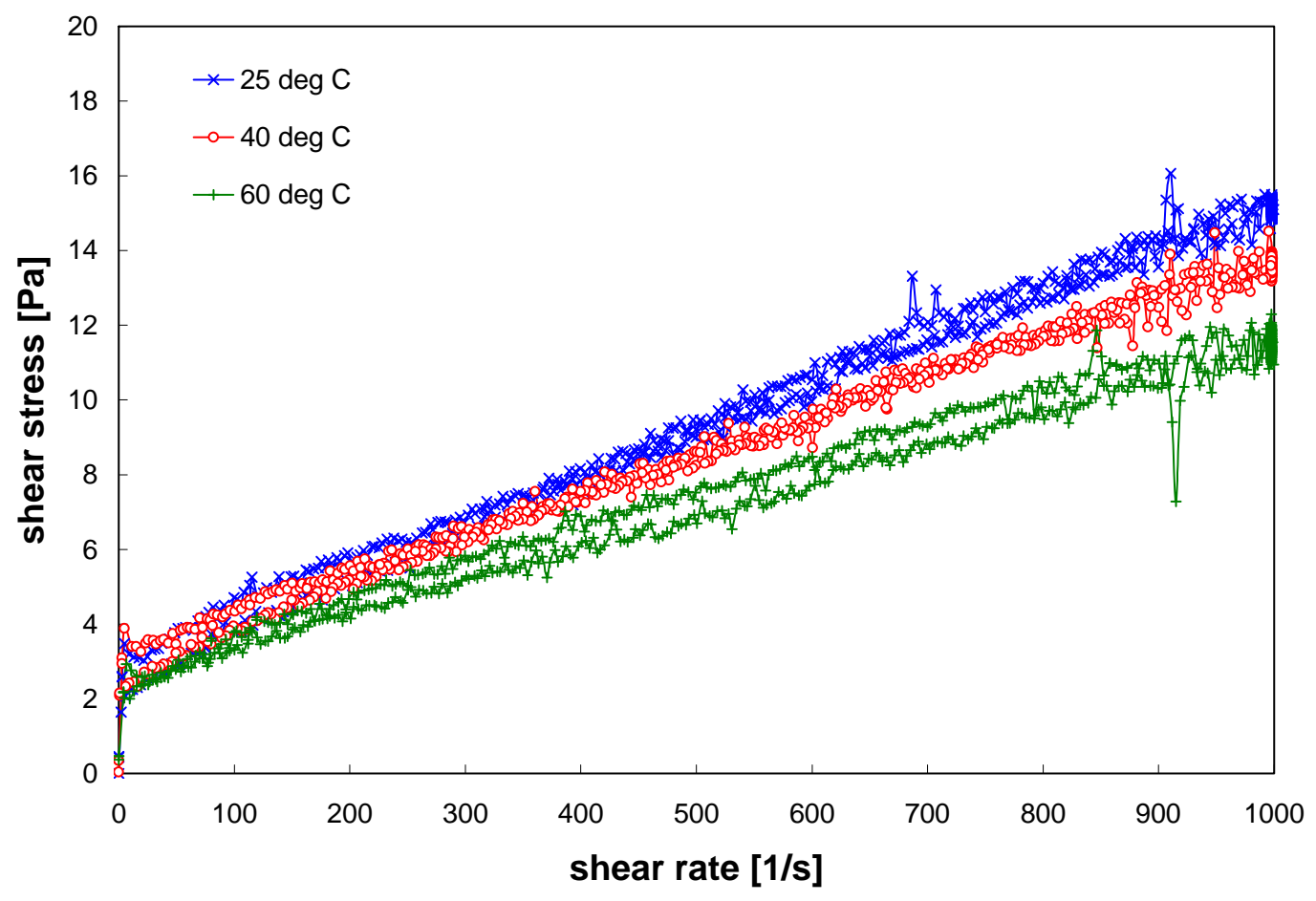

Figure 5.29. Flow Curve for the Group $1 / 2$ CUF High Solids Slurry at 25 , 40, and $60^{\circ} \mathrm{C}$

Table 5.12. Results of Fitting Analysis for the High-Solids Slurry

\begin{tabular}{||c|c|c|c|c|c||}
\hline \hline \multirow{3}{*}{ Model } & $\begin{array}{c}\text { Temperature } \\
{\left[{ }^{\circ} \mathbf{C}\right]}\end{array}$ & $\begin{array}{c}\text { Yield } \\
\text { Stress [Pa] }\end{array}$ & $\begin{array}{c}\text { Consistency } \\
{\left[\mathbf{P a} \cdot \mathbf{s}^{\mathbf{n}}\right]}\end{array}$ & $\begin{array}{c}\text { Flow } \\
\text { Index }\end{array}$ & $\mathbf{R}$ \\
\hline $\begin{array}{c}\text { Bingham-Plastic } \\
\left(0-1000 \mathrm{~s}^{-1}\right)\end{array}$ & $25(1$ of 2$)$ & 3.2 & 0.013 & $\mathrm{n} / \mathrm{a}$ & 0.995 \\
\cline { 2 - 6 } & $25(2$ of 2$)$ & 3.0 & 0.012 & $\mathrm{n} / \mathrm{a}$ & 0.997 \\
\cline { 2 - 6 } & 40 & 3.1 & 0.011 & $\mathrm{n} / \mathrm{a}$ & 0.997 \\
\cline { 2 - 6 } & 60 & 2.7 & 0.0090 & $\mathrm{n} / \mathrm{a}$ & 0.992 \\
\hline $\begin{array}{c}\text { Herschel-Bulkley } \\
\left(0-1000 \mathrm{~s} \mathrm{~s}^{-1}\right)\end{array}$ & $25(1$ of 2$)$ & 2.6 & 0.026 & 0.90 & 0.996 \\
\cline { 2 - 6 } & $25(2$ of 2$)$ & 2.5 & 0.024 & 0.91 & 0.997 \\
\cline { 2 - 7 } & 40 & 2.6 & 0.023 & 0.89 & 0.997 \\
\cline { 2 - 7 } & 60 & 2.1 & 0.023 & 0.87 & 0.993 \\
\hline
\end{tabular}


Table 5.13. Apparent Viscosity of the High-Solids Slurry

\begin{tabular}{|c|c|c|c|c|c|}
\hline \multirow[b]{2}{*}{ Source } & \multirow{2}{*}{$\begin{array}{c}\text { Temperature } \\
{\left[{ }^{\circ} \mathrm{C}\right]}\end{array}$} & \multicolumn{4}{|c|}{ Apparent Viscosity [mPa·s] } \\
\hline & & @ $33 \mathrm{~s}^{-1}$ & $@ 100 \mathrm{~s}^{-1}$ & @ $500 \mathrm{~s}^{-1}$ & @ $1000 \mathrm{~s}^{-1}$ \\
\hline \multirow[t]{4}{*}{ Measured } & 25 (1 of 2$)$ & 96 & 44 & 19 & 16 \\
\hline & $25(2$ of 2$)$ & 93 & 43 & 18 & 15 \\
\hline & 40 & 96 & 41 & 17 & 14 \\
\hline & 60 & 76 & 35 & 14 & 12 \\
\hline \multirow[t]{4}{*}{ Bingham-Plastic } & $25(1$ of 2$)$ & 110 & 45 & 19 & 16 \\
\hline & 25 (2 of 2$)$ & 100 & 42 & 18 & 15 \\
\hline & 40 & 110 & 42 & 17 & 14 \\
\hline & 60 & 89 & 36 & 14 & 12 \\
\hline \multirow{4}{*}{$\begin{array}{l}\text { Herschel- } \\
\text { Bulkley }\end{array}$} & 25 (1 of 2$)$ & 99 & 43 & 20 & 16 \\
\hline & 25 (2 of 2$)$ & 92 & 41 & 19 & 15 \\
\hline & 40 & 96 & 40 & 17 & 14 \\
\hline & 60 & 79 & 34 & 15 & 12 \\
\hline
\end{tabular}

Figure 5.30 and Table 5.14 compare the rheology of the source Group 1 and Group 2 slurries to the lowsolids matrix (dilute) and high-solids matrix (concentrated) Group 1/2 CUF slurries. Both source materials for Group 1 and 2 show slightly non-Newtonian rheological characteristics with yield points near the instrument limit of detection. Of the two source materials, Group 2 shows "stronger" rheology, most likely a result of its much higher solids concentration (37.4-wt\% USD) relative to Group 1 (9.0-wt\% UDS). The dilute Group 1/2 mixture has an UDS concentration of 8.2-wt\%, which is similar to that of Group 1. Based on the similar solids concentration, it is not surprising that the dilute slurry mixture has a consistency (5.0 mPas) that is similar to, but slightly less than, the consistency for source Group 1 (6.7 $\mathrm{mPa} \cdot \mathrm{s})$. From this observation, it could be inferred that the Group 1 slurry rheology is dominant in the mixture; however, this inference is impossible to confirm without Group 2 slurry rheology at a UDS similar to that of the mixture.

Dewatering of the Group 1/2 slurry from the initial 8.2-wt\% UDS to 16.0-wt\% has the expected result of increasing the stress response of the fluid over all rates of shear examined. Concentrating the slurry changes the rheology from Newtonian, with a viscosity of $5.0 \mathrm{mPa} \cdot \mathrm{s}$ to non-Newtonian, with a yield of 3.0 $\mathrm{Pa}$ and a consistency of $12 \mathrm{mPa} \cdot \mathrm{s}$. The concentrated slurry exhibits a higher stress response than either of the source materials. Given that the concentration of the high-solids matrix sample (16.0 wt\%) is still significantly lower than the Group 2 source material (37.4 wt\%), the increased stress response of the concentrated mixture relative to Group 2 suggests that Group 1 rheological properties are dominant. This is consistent with the observation made in the preceding paragraph. 
Table 5.14. Effect of Waste Stream Mixing and Dewatering on Group $1 / 2$ CUF Rheology (at $25^{\circ} \mathrm{C}$ )

\begin{tabular}{||c|c|c|c|c||}
\hline Description & $\begin{array}{c}\text { Solids } \\
\text { Concentration }\end{array}$ & Rheology & $\begin{array}{c}\text { Yield Stress } \\
{[\text { Pa] }}\end{array}$ & $\begin{array}{c}\text { Consistency } \\
{[\mathbf{m P a} \cdot \mathbf{s}]}\end{array}$ \\
\hline $\begin{array}{c}\text { Group 1 Source } \\
\text { (TI508-G1-AR-RH1) }\end{array}$ & $9.0-\mathrm{wt} \%$ & $\begin{array}{c}\text { non- } \\
\text { Newtonian* }\end{array}$ & 0.3 & 6.7 \\
\hline $\begin{array}{c}\text { Group 2 Source } \\
\text { (TI517-G2-AR-RH) }\end{array}$ & $37.4-\mathrm{wt} \%$ & non-Newtonian & 1.1 & 13 \\
\hline $\begin{array}{c}\text { Dilute Group 1/2 Mixture } \\
\text { (TI572-G2-R1) }\end{array}$ & $8.2-\mathrm{wt} \%$ & Newtonian & $\mathrm{n} / \mathrm{a}$ & 5.0 \\
\hline $\begin{array}{c}\text { Concentrated Group 1/2 Mixture } \\
\text { (TI572-G2-R2) }\end{array}$ & $16.0-\mathrm{wt} \%$ & non-Newtonian & 3.0 & 12 \\
\hline *Yield stress is not statistically different than zero. Flow curve is statistically Newtonian. \\
\hline
\end{tabular}

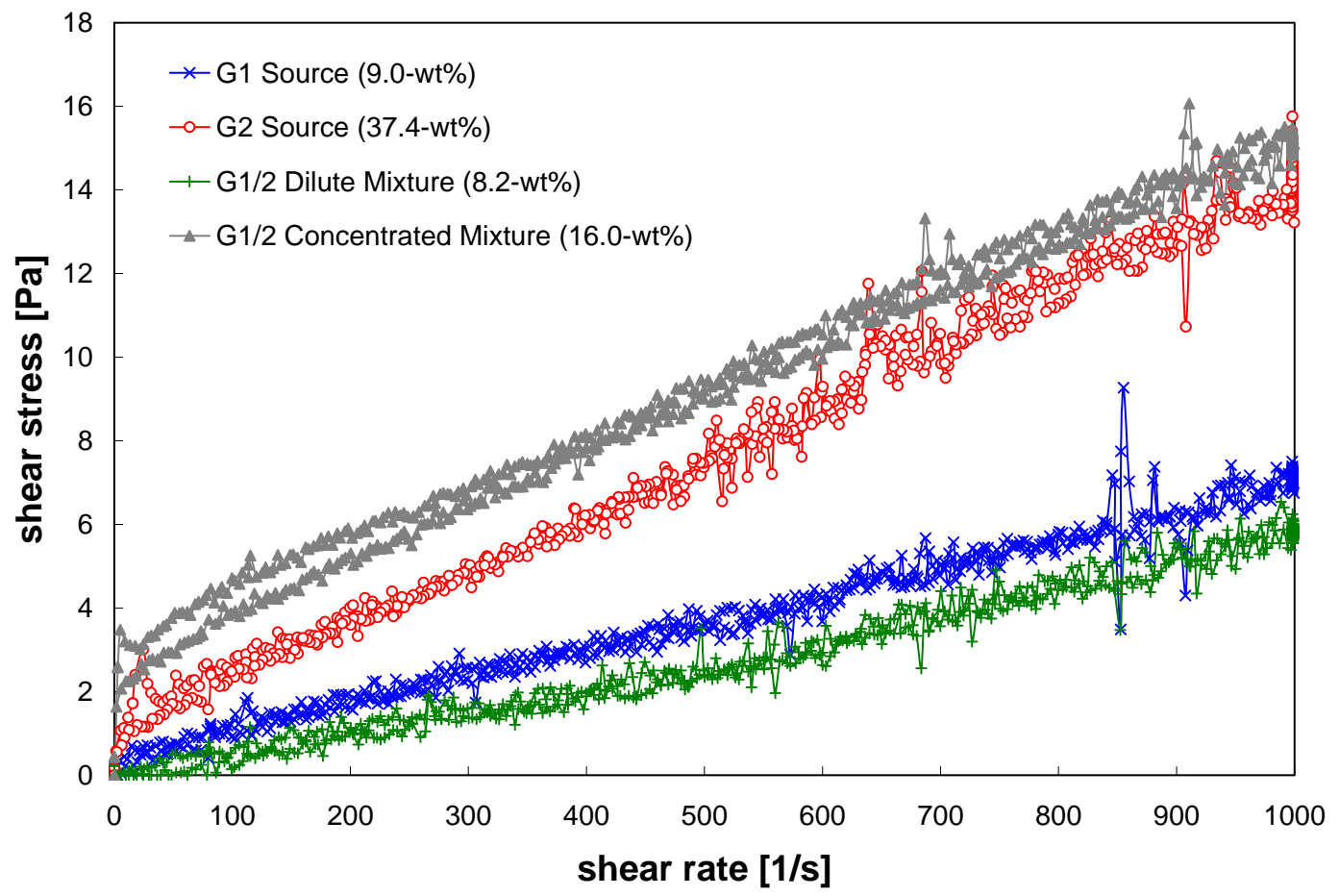

Figure 5.30. A Comparison of Feed Material (Group 1 and Group 2) and CUF 1/2 (high and low solids) Rheologies (measurements are at $25^{\circ} \mathrm{C}$ )

\subsection{Caustic Leaching/Washing}

After completing the filtration and rheological testing of the high-solids slurry, the slurry was drained from the system and prepared for caustic leaching (Figure 5.31). A total of 2,853 grams (approximately $2.3 \mathrm{~L}$ ) of 7.6 M sodium hydroxide $(\mathrm{NaOH})$ was to be added to the Group 1/2 slurry. The slurry loop was rinsed using part of the caustic addition for the leach and additional permeate that was remaining in the back-pulse chamber to flush solids out of the slurry piping. After the slurry and caustic additions were recovered from the system, the slurry reservoir was isolated from the slurry loop. During the transfer of the slurry and leach solution to the slurry reservoir, it was estimated that $5 \mathrm{wt} \%$ of the slurry and caustic solution was lost to hold-up in the containers used to store the slurry and leach solution after it was drained. The mass loss of the combined solution was $0.28 \mathrm{~kg}$, which containing 25 grams of UDS. 
At this point, the caustic leach of the recovered slurry proceeded as outlined in the middle column of Figure 5.1. This entailed:

- Batch caustic leaching of the slurry for removing aluminum and phosphorus

- Dewatering of leaching permeate from the slurry solids

- Batch washing of the caustic-leached slurry and dewatering of the solution afterwards. Five total wash solutions were added to the slurry to remove aluminum and phosphorus from the slurry and lower the free hydroxide level below $0.25 \mathrm{M}$ for subsequent oxidative leaching.

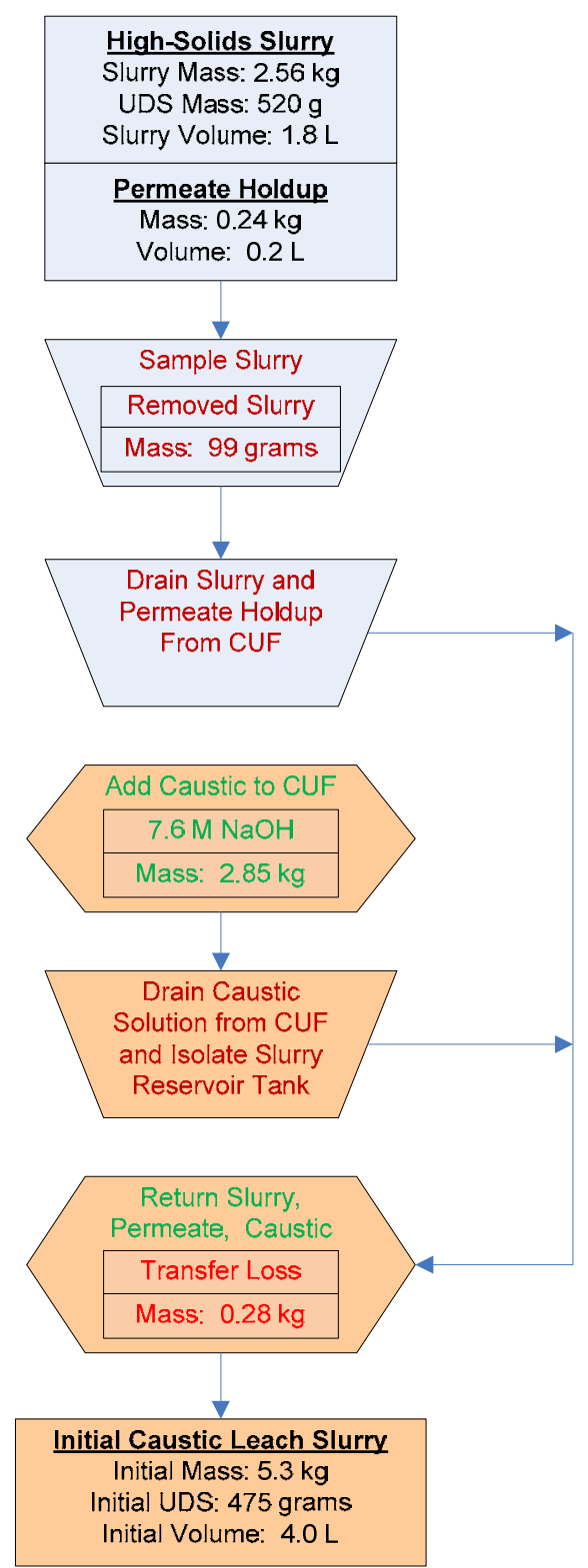

Figure 5.31. Flow Diagram for Batch Caustic Leaching

Note: Mass and volume values in figure are rounded to the nearest significant digit of accuracy. 


\subsubsection{Batch Caustic Leaching Results}

The slurry was heated to $100^{\circ} \mathrm{C}$ over a 5.3 -h period, held at $100^{\circ} \mathrm{C}$ (the control range was $90^{\circ} \mathrm{C}$ to $105^{\circ} \mathrm{C}$ ) for an 8-hour leaching period, and then cooled for 8 hours. Level measurements were taken every half hour during the leaching step, and the slurry was adjusted as necessary with DI water to compensate for evaporation (Figure 5.32). Over the course of the test, $2.1 \mathrm{~L}$ were added to the vessel to maintain the leach volume at $4 \mathrm{~L}$. After the leaching was completed, the volume of the slurry was $3.9 \mathrm{~L}$, so approximately $2.2 \mathrm{~L}$ of water was estimated to have been lost to evaporation. Five slurry samples were collected-two during heat-up and three once the leach temperature was reached. Approximately 26 grams of slurry was sampled during the course of the leach with an estimated loss of 2 grams of UDS.

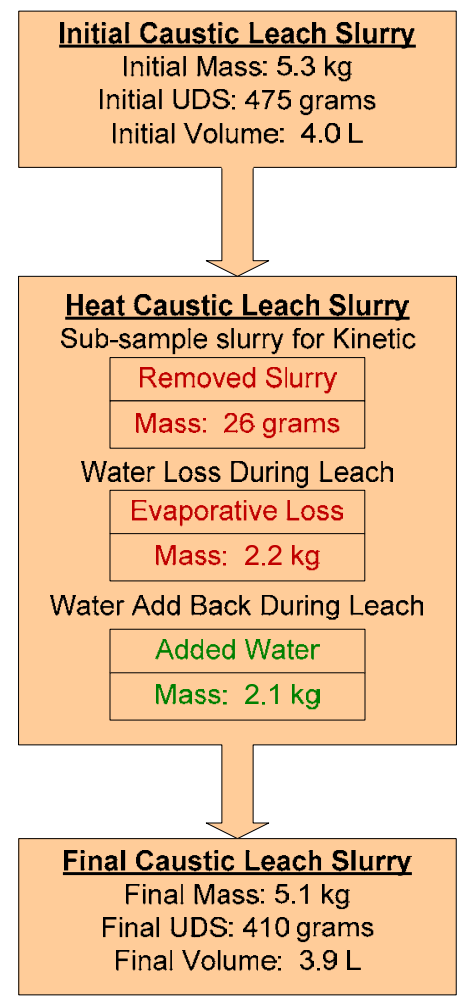

Figure 5.32. Group 1/2 Batch Leach Sampling/Evaporation Loss and Water Additions Note: Mass and volume values in figure are rounded to the nearest significant digit of accuracy.

The slurry supernate was filtered from the samples and analyzed by ICP-OES (elemental analysis) and titration (for free hydroxide ion) to determine the kinetics of aluminum and phosphorus dissolution during the caustic leaching. The results of these analyses are provided in Table 5.15. The results reported are corrected for sample evaporation that occurred between the time the sample was collected and when it was sub-sampled by ASO. Aluminum, chromium, phosphorus, and potassium concentrations provided in Table 5.15 are plotted against each other in Figure 5.33. While the aluminum concentration in the supernate increases during the heat-up, there was little change in the chromium concentration. In the case of phosphorus, the measured concentration of the supernate at $40^{\circ} \mathrm{C}$ was almost 10 times lower than the predicted supernate concentration after the leach solution addition. The phosphorus concentration was observed to increase in the subsequent sample, collected at $76^{\circ} \mathrm{C}$, but remained close to the initial concentration for the remainder of the leaching step. 
The high-solids slurry inventory (

Table 5.10) predicted that 45 grams of insoluble aluminum was present. While preparing the slurry for caustic leaching, the inventory decreased by $5 \mathrm{wt} \%$ from transfer losses. Assuming that 43 grams of aluminum was present in the UDS of the slurry, the supernate concentrations of the slurry supernate samples were used to project the conversion of aluminum during the course of the leach, as shown in Figure 5.34. The one-hour heat-up sample indicated that $7 \mathrm{wt} \%$ of the solid aluminum had leached into solution. By 3 hours into the heat ramp-up, or approximately $75^{\circ} \mathrm{C}$, the aluminum leach factor was 32 $\mathrm{wt} \%$, and by the beginning of the leach period $\left(100^{\circ} \mathrm{C}\right)$, the $\mathrm{Al}$ leaching was essentially done, reaching a maximum leach factor of $45 \mathrm{wt} \%$. It was estimated that 50 grams of the slurry solids was dissolved into the aqueous phase during the caustic leach. 
Table 5.15. Concentration of Major Analyte Components of Filtered Caustic Leach Samples, Corrected for Sample Evaporation

\begin{tabular}{|c|c|c|c|c|c|c|}
\hline & $\begin{array}{c}\text { Start of } \\
\text { Heatup }^{(a)} \\
\left(25^{\circ} \mathrm{C}\right)\end{array}$ & $\begin{array}{c}\text { 1-Hour } \\
\text { Heatup }^{(b)} \\
\left(40^{\circ} \mathrm{C}\right)\end{array}$ & $\begin{array}{c}\text { 3-Hour } \\
\text { Heatup }^{(c)} \\
\left(76^{\circ} \mathrm{C}\right)\end{array}$ & $\begin{array}{l}\text { 0-Hour } \\
\text { Leach }^{(d)} \\
\left(92^{\circ} \mathrm{C}\right)\end{array}$ & $\begin{array}{l}\text { 4-Hour } \\
\text { Leach }^{(e)} \\
\left(97^{\circ} \mathrm{C}\right)\end{array}$ & $\begin{array}{c}\text { 8-Hour Leach } \\
\left(96^{\circ} \mathrm{C}\right)\end{array}$ \\
\hline & $\mu \mathrm{g} / \mathrm{mL}$ & $\mu \mathrm{g} / \mathrm{mL}$ & $\mu \mathrm{g} / \mathrm{mL}$ & $\mu \mathrm{g} / \mathrm{mL}$ & $\mu \mathrm{g} / \mathrm{mL}$ & $\mu \mathrm{g} / \mathrm{mL}$ \\
\hline $\mathrm{Al}$ & $4.1 \mathrm{E}+02$ & $1.1 \mathrm{E}+03$ & $4.0 \mathrm{E}+03$ & $5.7 \mathrm{E}+03$ & $5.5 \mathrm{E}+03$ & $5.5 \mathrm{E}+03$ \\
\hline $\mathrm{Bi}$ & $<2 . \mathrm{E}+0$ & $<1 . \mathrm{E}+1$ & $1.7 \mathrm{E}+02$ & $4.3 \mathrm{E}+02$ & $1.9 \mathrm{E}+02$ & $2.0 \mathrm{E}+02$ \\
\hline $\mathrm{Cr}$ & $2.1 \mathrm{E}+02$ & $1.9 \mathrm{E}+02$ & $1.9 \mathrm{E}+02$ & $2.5 \mathrm{E}+02$ & $2.2 \mathrm{E}+02$ & $2.2 \mathrm{E}+02$ \\
\hline $\mathrm{Fe}$ & $2.3 \mathrm{E}+00$ & $1.3 \mathrm{E}+00$ & $1.9 \mathrm{E}+01$ & $1.8 \mathrm{E}+01$ & $1.2 \mathrm{E}+01$ & $1.3 \mathrm{E}+01$ \\
\hline $\mathrm{K}$ & $2.4 \mathrm{E}+02$ & $2.2 \mathrm{E}+02$ & $2.2 \mathrm{E}+02$ & $2.6 \mathrm{E}+02$ & $3.2 \mathrm{E}+02$ & $2.6 \mathrm{E}+02$ \\
\hline $\mathrm{Mn}$ & $3.9 \mathrm{E}-02$ & $<1 . \mathrm{E}-1$ & $1.9 \mathrm{E}-01$ & $<9$. E-2 & $2.6 \mathrm{E}-01$ & $3.4 \mathrm{E}-01$ \\
\hline $\mathrm{Na}$ & $4.4 \mathrm{E}+04$ & $1.5 \mathrm{E}+05$ & $1.4 \mathrm{E}+05$ & $1.6 \mathrm{E}+05$ & $1.5 \mathrm{E}+05$ & $1.6 \mathrm{E}+05$ \\
\hline $\mathrm{P}$ & $4.5 \mathrm{E}+02$ & $7.0 \mathrm{E}+01$ & $6.6 \mathrm{E}+02$ & $6.0 \mathrm{E}+02$ & $7.2 \mathrm{E}+02$ & $7.0 \mathrm{E}+02$ \\
\hline $\mathrm{S}$ & $2.3 \mathrm{E}+03$ & $4.8 \mathrm{E}+02$ & $1.5 \mathrm{E}+03$ & $5.2 \mathrm{E}+02$ & $1.4 \mathrm{E}+03$ & $1.6 \mathrm{E}+03$ \\
\hline $\mathrm{Si}$ & $4.6 \mathrm{E}+00$ & $3.2 \mathrm{E}+02$ & $4.6 \mathrm{E}+01$ & $1.4 \mathrm{E}+02$ & $2.2 \mathrm{E}+02$ & $2.6 \mathrm{E}+02$ \\
\hline $\mathrm{Sr}$ & $9.9 \mathrm{E}-02$ & $1.1 \mathrm{E}-01$ & $3.2 \mathrm{E}-01$ & $1.0 \mathrm{E}-01$ & $2.3 \mathrm{E}-01$ & $2.9 \mathrm{E}-01$ \\
\hline \multirow[t]{2}{*}{$\mathrm{U}$} & $4.7 \mathrm{E}+01$ & $5.0 \mathrm{E}+01$ & $6.3 \mathrm{E}+01$ & $1.4 \mathrm{E}+01$ & $4.4 \mathrm{E}+01$ & $9.0 \mathrm{E}+00$ \\
\hline & [M] & [M] & [M] & [M] & [M] & [M] \\
\hline $\mathrm{OH}$ & 4.6 & 4.8 & 4.6 & 4.7 & 4.7 & 4.3 \\
\hline
\end{tabular}

Temperature in heading represents the sample temperature taken from the vessel. Accuracy of the thermocouple used was $\pm 2^{\circ} \mathrm{C}$. Samples were later allowed to cool to the hot cell temperature and were later sub-sampled for analyses to be performed outside the hot cell at room temperature.

(a) Predicted concentrations from mixing caustic addition (7.6 M) with slurry supernate. Composition of supernate based on sample TI572-G2-A, ASO ID 08-01290.

(b) Composition based on sample TI572-G2-C1, ASO ID 08-01304. Values divided by 1.41 to account for evaporative loss of sample.

(c) Composition based on sample TI572-G2-C2, ASO ID 08-01305. Values divided by 1.05 to account for evaporative loss of sample.

(d) Composition based on sample TI572-G2-C3, ASO ID 08-01306. Values divided by 1.53 to account for evaporative loss of sample.

(e) Composition based on sample TI572-G2-C4, ASO ID 08-01307. Values divided by 1.01 to account for evaporative loss of sample.

(f) Composition based on sample TI572-G2-C5, ASO ID 08-01308. Values divided by 1.03 to account for evaporative loss of sample. 


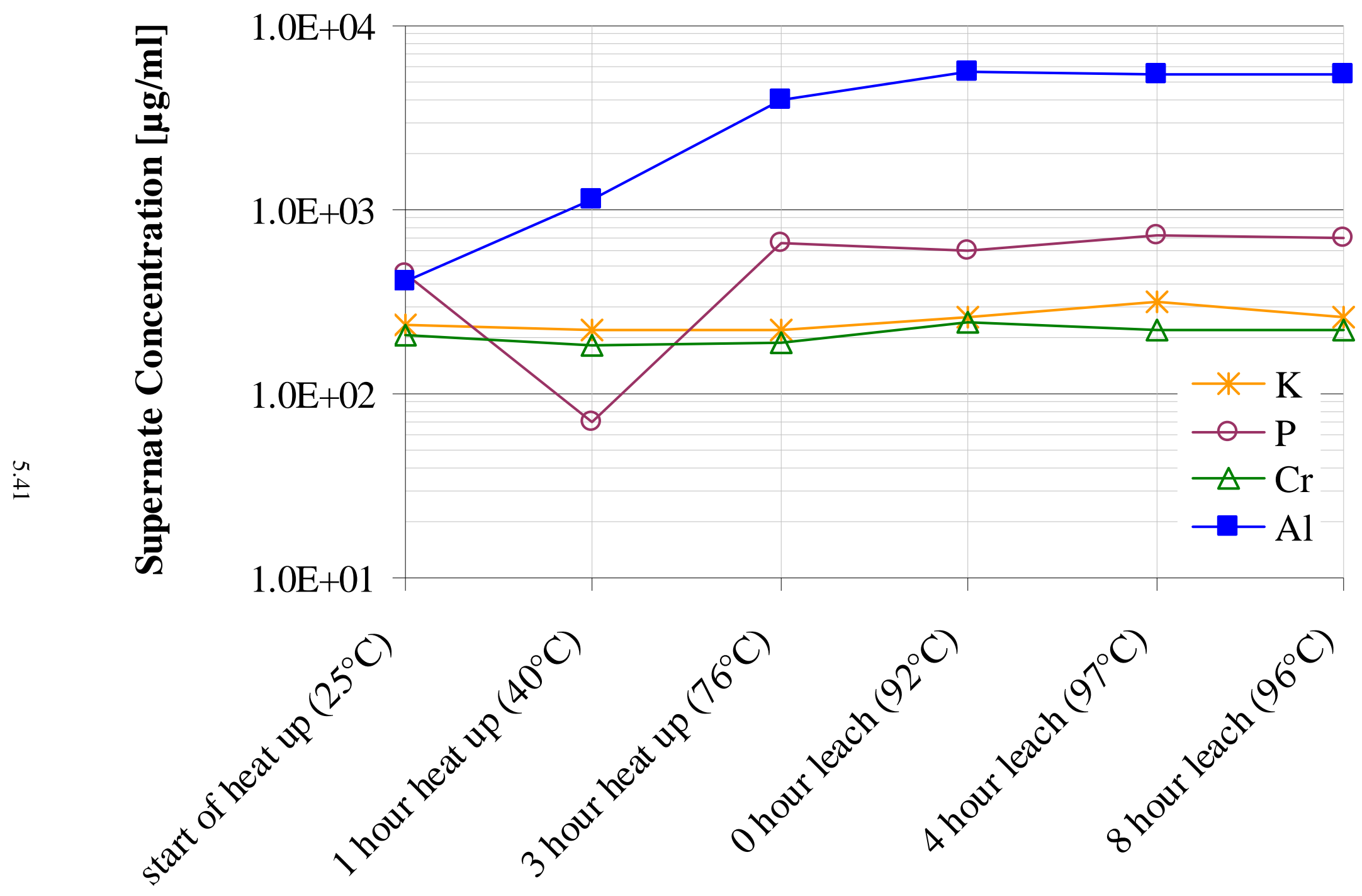

Figure 5.33. Concentration of Al, Cr, P, and K During Caustic Leach of Group 1/2 Slurry 


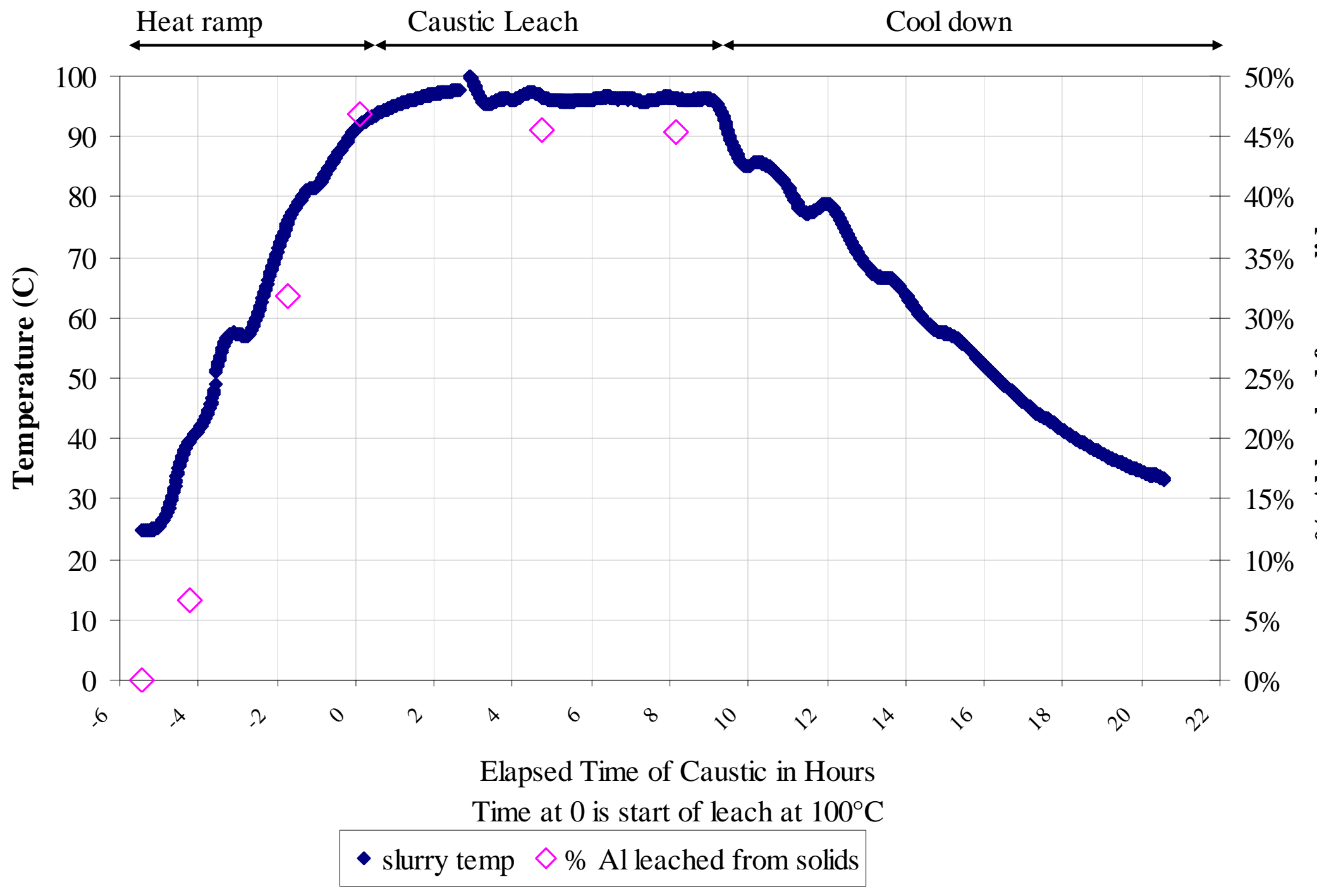

Figure 5.34. Temperature Profile/Aluminum Leach Factors During Caustic Leaching 


\subsubsection{Caustic Leaching Dewatering}

After cooling the leached slurry over a twelve hour period, the valves isolating the tank from the pump and filter were opened in preparation for circulating the slurry and beginning the leach dewatering step when it was discovered that the pump head would not turn. It appeared to be frozen in place. The tank was isolated again, and any slurry that had drained into the flow lines was retrieved and added back to the tank. The sanitary fittings on the pump head were loosened, and a gel was discovered in the pump head that was described to be similar to tapioca pudding. The gel apparently formed in the slurry loop during the caustic leaching step. After several flushes of water, the gel was cleared, and the pump returned to normal operation for the dewatering step. It is hypothesized that this gel consisted of $\mathrm{Na}_{3} \mathrm{PO}_{4} \cdot 12 \mathrm{H}_{2} \mathrm{O}$ that precipitated from the reaction of residual slurry solids with the small amount of caustic solution that was used to flush the slurry loop before the leaching step.

Figure 5.35 summarizes the mass change in the slurry following the dewatering step of the causticleached Group 1/2 composite. The mass of the dewatered permeate collected was $3.28 \mathrm{~kg}(2.6 \mathrm{~L})$. The remaining $1.3 \mathrm{~L}$ of slurry was split between the slurry and supernate circulation piping. It was estimated that $1.6 \mathrm{~kg}$ of the slurry was inside the slurry circulation loop while $0.25 \mathrm{~kg}$ of the slurry supernate were containing in the back pulse chamber and permeate piping.

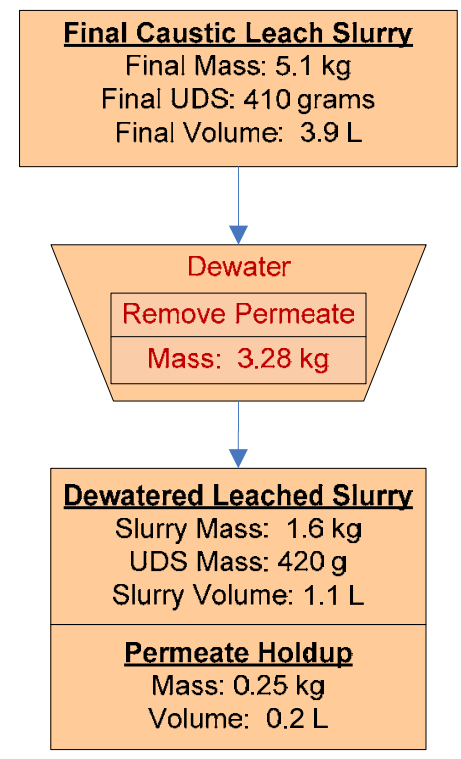

Figure 5.35. Flow Diagram for Caustic-Leach Dewatering Operations Note: Mass and volume values in figure are rounded to the nearest significant digit of accuracy.

The leach dewatering step was conducted at the standard condition of TMP $=40$ psid and $A V=13 \mathrm{ft} / \mathrm{s}$. Dewatering proceeded slowly with an initial flux of $\sim 0.010 \mathrm{GPM} / \mathrm{ft}^{2}$ decreasing to $\sim 0.008 \mathrm{GPM} / \mathrm{ft}^{2}$ by the end of the run (Figure 5.36). The drop in flux relative to the initial dewatering step is due to changes in the suspending phase, namely increased permeate viscosity. It has been noted in previous sections that the filter flux was primarily driven by TMP for low- and high-solids loading, meaning that the flux can be modeled by the Darcy equation: 


$$
J=\frac{\Delta P_{m}}{\mu_{\text {permeate }} R_{m}}
$$

where $\Delta \mathrm{P}_{\mathrm{m}}$ is the pressure drop across the filter membrane, $\mu_{\text {permeate }}$ is the viscosity of the permeate, and $\mathrm{R}_{\mathrm{m}}$ is the overall resistance of the filter membrane. Assuming constant pressure drop and filter resistance, Equation 5.1 may be simplified to give the following relationship where flux at a given condition $\left(\mathrm{J}_{1}\right)$ may be calculated from the flux at a reference condition $\left(\mathrm{J}_{0}\right)$ by the ratio of the viscosities:

$$
J_{1}=J_{0}\left(\frac{\mu_{\text {permeate }, 0}}{\mu_{\text {permeate }, 1}}\right)
$$

Using the above relationship, the average flux for the leach dewatering step was estimated from the initial dewatering average flux. Viscosities and predicted values are summarized in Table 5.16. The predicted flux for the leach dewatering step is low using only viscosity. Since the TMP was the same for both steps, this may indicate a slight decrease in membrane resistance in the leach dewatering step attributable to the dissolution of deeply fouling particles by the caustic-leach solution. It may also indicate that the Darcy equation does not fully characterize the filtration of these slurries and may need to be supplemented by contributions from a gel polarization model for a better fit; however, the simple correlation of permeate viscosity substantially accounts for the difference in filter flux between the two dewatering steps.

Table 5.16. $\quad$ Prediction of Average Flux of Leach Dewatering Step from Initial Dewatering Flux

\begin{tabular}{|c|c|c|c|c|}
\hline Sample & Description & $\begin{array}{c}\text { Viscosity at } \\
25^{\circ} \mathrm{C} \\
(\mathrm{mPa} \cdot \mathrm{s})\end{array}$ & $\begin{array}{l}\text { Predicted Average } \\
\text { Flux }\left(\mathrm{GPM} / \mathrm{ft}^{2}\right)\end{array}$ & $\begin{array}{c}\text { Actual Average Flux } \\
\left(\mathrm{GPM} / \mathrm{ft}^{2}\right)\end{array}$ \\
\hline G2-R2s & $\begin{array}{l}\text { Permeate from } \\
\text { initial dewatering }\end{array}$ & 2.6 & Reference value & 0.017 \\
\hline G2-R3s & $\begin{array}{l}\text { Permeate from } \\
\text { leach dewatering }\end{array}$ & 7.9 & 0.006 & 0.009 \\
\hline
\end{tabular}
Based on Viscosity Differences According to the Darcy Equation 


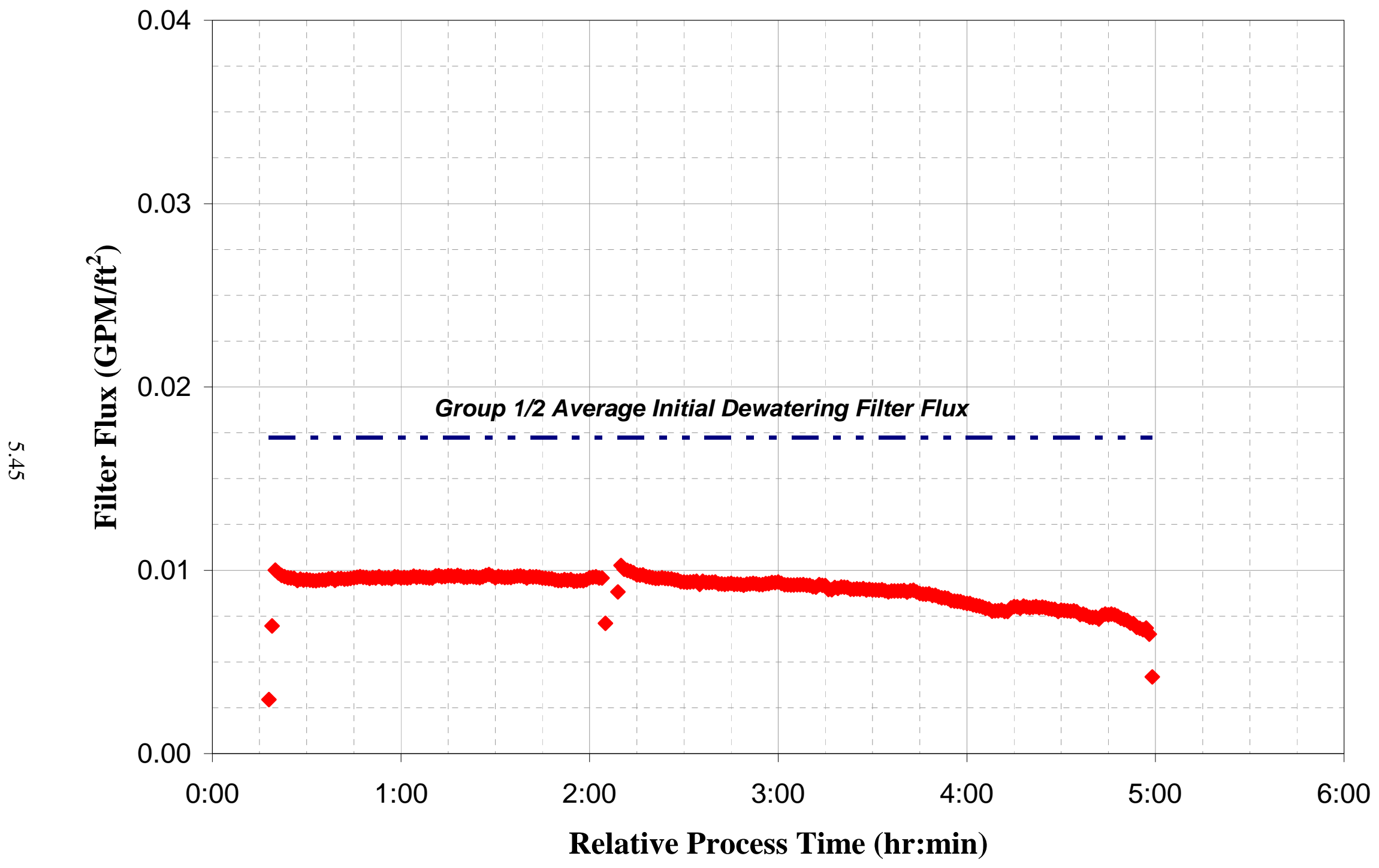

Figure 5.36. Permeate Flux During Leach Dewatering Step 


\subsubsection{Characterization of Dewatered Leached Slurry}

After dewatering the leached slurry, the circulating slurry inside the slurry loop was sampled for physical and chemical characterization (Figure 5.37). The sampled slurry mass was 45 grams, and it was estimated that 10 grams of UDS was removed from the slurry, reducing the inventory to 410 grams.

The physical properties for the caustic-leached and dewatered slurry are shown in Table 5.17, and chemical properties are shown in Table 5.18 and Table 5.19. The measured UDS concentration of the slurry was $18 \mathrm{wt} \%$, while the mass balance predicted the UDS concentration inside the slurry loop to be $26 \mathrm{wt} \%$ (0.42 kg $\div 1.6 \mathrm{~kg} \cong 26 \mathrm{wt} \%)$. The difference between the two results was likely due to the slurry not being homogenous inside the CUF because of problems with the overhead mixer. Comparing the predicted solid concentration based on mass-balance data (Table 5.18) to the calculated solid concentration using the measured composition of the slurry and supernate (Table 5.19) showed the results to be within $10 \%$ for aluminum and phosphorus. However, the slurry-based results were 20 to $25 \%$ higher for elements such as iron, chromium, and uranium.

Leach factors were calculated for analytes measured from the slurry analysis by comparing the composition of the leach slurry in Table 5.19 to the composition of the high-solids slurry in Table 5.11, using uranium and iron as a basis. Overall, only the aluminum fraction in the slurry solids significantly changed, with a calculated 0.58 leach factor. Phosphorus did not appear to have been removed from the solid phase at this point of the test. Because of the increase in the sodium concentration of the supernate from the caustic leach, insoluble phosphorus released as phosphate was believed to have re-precipitated as sodium phosphate. This theory was proven correct later, once the slurry was washed and the sodium concentration of the supernate decreased (Section 5.5.4).

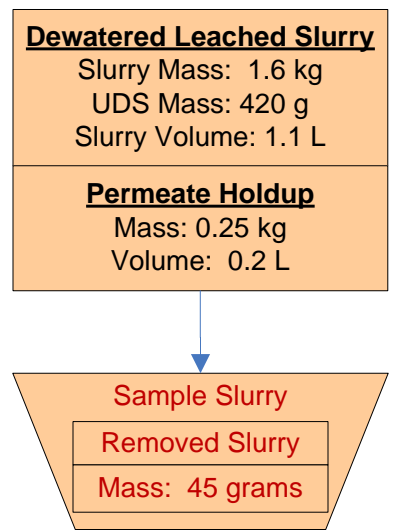

Figure 5.37. Sampling Losses for the Dewatered Leached Group 1/2 Slurry Note: Mass and volume values in figure are rounded to the nearest significant digit of accuracy. 
WTP-RPT-166, Rev. 0

Table 5.17. Physical Property Measurements of the Dewatered Caustic Leached Slurry

\begin{tabular}{|r|c||}
\hline Slurry Density $(\mathbf{g} / \mathbf{m L})$ & 1.37 \\
Supernate Density $\mathbf{( g / m L})$ & 1.18 \\
\hline Settled Solids (Vol\%) & $100 \%$ \\
\hline Centrifuged UDS (Wt $\%)$ & $26 \%$ \\
\hline Total Solids of the Slurry $(\mathbf{W t} \%)$ & $39 \%$ \\
\hline Dissolved Solids of the Supernate $\mathbf{( W t} \%)$ & $26 \%$ \\
\hline UDS of the Slurry $\mathbf{( W t} \%)$ & $18 \%$ \\
\hline
\end{tabular}


Table 5.18. Group 1/2 Caustic leached, Dewatered Slurry Inventory and Composition

\begin{tabular}{|c|c|c|c|c|c|}
\hline & Slurry $^{(\mathbf{a})}$ & \multicolumn{2}{|c|}{ Liquid Fraction $^{(b)}$} & \multicolumn{2}{|c|}{ Solids Fraction ${ }^{(c)}$} \\
\hline Mass (kg) & 1.79 & \multicolumn{2}{|c|}{1.38} & \multicolumn{2}{|c|}{0.41} \\
\hline Wt\% of Slurry & $100 \%$ & \multicolumn{2}{|c|}{$77.0 \%$} & \multicolumn{2}{|c|}{$23.0 \%$} \\
\hline Metal & g & g & $\mu g / m L$ & g & $\mu g / g$ \\
\hline Al & $2.9 \mathrm{E}+01$ & $6.0 \mathrm{E}+00$ & $5.1 \mathrm{E}+03$ & $2.3 \mathrm{E}+01$ & $5.6 \mathrm{E}+04$ \\
\hline $\mathbf{B i}$ & $1.8 \mathrm{E}+01$ & $1.8 \mathrm{E}-01$ & $1.6 \mathrm{E}+02$ & $1.8 \mathrm{E}+01$ & $4.4 \mathrm{E}+04$ \\
\hline $\mathrm{Cr}$ & $3.6 \mathrm{E}+00$ & 2.4E-01 & $2.1 \mathrm{E}+02$ & $3.3 \mathrm{E}+00$ & $8.1 \mathrm{E}+03$ \\
\hline $\mathbf{F e}$ & $2.5 \mathrm{E}+01$ & 9.7E-03 & $8.2 \mathrm{E}+00$ & $2.5 \mathrm{E}+01$ & $6.0 \mathrm{E}+04$ \\
\hline Mn & 3.7E-01 & $1.4 \mathrm{E}-03$ & $1.2 \mathrm{E}+00$ & 3.7E-01 & $9.0 \mathrm{E}+02$ \\
\hline $\mathrm{Na}$ & $2.7 \mathrm{E}+02$ & $1.7 \mathrm{E}+02$ & $1.4 \mathrm{E}+05$ & $1.1 \mathrm{E}+02$ & $2.6 \mathrm{E}+05$ \\
\hline $\mathbf{P}$ & $3.7 \mathrm{E}+01$ & 3.6E-01 & $3.1 \mathrm{E}+02$ & $3.7 \mathrm{E}+01$ & $9.0 \mathrm{E}+04$ \\
\hline $\mathrm{S}$ & $2.2 \mathrm{E}+00$ & $2.1 \mathrm{E}+00$ & $1.8 \mathrm{E}+03$ & $1.1 \mathrm{E}-01$ & $2.7 \mathrm{E}+02$ \\
\hline $\mathrm{Si}$ & $1.6 \mathrm{E}+01$ & 2.5E-01 & $2.2 \mathrm{E}+02$ & $1.6 \mathrm{E}+01$ & $3.8 \mathrm{E}+04$ \\
\hline $\mathrm{Sr}$ & $1.5 \mathrm{E}+00$ & $1.1 \mathrm{E}-04$ & $9.5 \mathrm{E}-02$ & $1.5 \mathrm{E}+00$ & $3.6 \mathrm{E}+03$ \\
\hline $\mathbf{U}$ & $6.2 \mathrm{E}+00$ & 8.9E-03 & $7.6 \mathrm{E}+00$ & $6.2 \mathrm{E}+00$ & $1.5 \mathrm{E}+04$ \\
\hline \multirow{2}{*}{$\begin{array}{l}\text { Radiochemical } \\
\text { Isotopes }\end{array}$} & Slurry & \multicolumn{2}{|c|}{ Liquid Fraction } & \multicolumn{2}{|c|}{ Solid Fraction } \\
\hline & mCi & $\mathbf{m C i}$ & $\mathrm{mCi} / \mathrm{mL}$ & $\mathrm{mCi}$ & $\mathrm{mCi} / \mathrm{g}$ \\
\hline Co-60 & $4.8 \mathrm{E}+00$ & $<4 . \mathrm{E}-2$ & $<3$. E-5 & $4.8 \mathrm{E}+00$ & $1.2 \mathrm{E}-02$ \\
\hline Cs-137 & $4.1 \mathrm{E}+04$ & $9.9 \mathrm{E}+03$ & $8.5 \mathrm{E}+00$ & $3.1 \mathrm{E}+04$ & $7.4 \mathrm{E}+01$ \\
\hline Eu-154 & $1.4 \mathrm{E}+01$ & $<1$.E-1 & $<1$.E-4 & $1.4 \mathrm{E}+01$ & 3.5E-02 \\
\hline Am-241 & $1.3 \mathrm{E}+02$ & $<2 . \mathrm{E}+0$ & $<2$.E-3 & $1.3 \mathrm{E}+02$ & 3.2E-01 \\
\hline Gross Alpha & $2.5 \mathrm{E}+02$ & $<8 . \mathrm{E}-1$ & $<7 . \mathrm{E}-4$ & $2.5 \mathrm{E}+02$ & $6.1 \mathrm{E}-01$ \\
\hline Gross Beta & $1.6 \mathrm{E}+05$ & $9.2 \mathrm{E}+03$ & $7.8 \mathrm{E}+00$ & $1.5 \mathrm{E}+05$ & $3.7 \mathrm{E}+02$ \\
\hline Sr-90 & $5.9 \mathrm{E}+04$ & $4.7 \mathrm{E}+00$ & 4.0E-03 & $5.9 \mathrm{E}+04$ & $1.4 \mathrm{E}+02$ \\
\hline Pu-239+240 & $1.8 \mathrm{E}+02$ & $9.1 \mathrm{E}-03$ & 7.7E-06 & $1.8 \mathrm{E}+02$ & 4.3E-01 \\
\hline Pu-238 & $6.0 \mathrm{E}+00$ & $<$ 1.E-3 & $<$ 1.E-6 & $6.0 \mathrm{E}+00$ & $1.5 \mathrm{E}-02$ \\
\hline \multirow[t]{2}{*}{ Anions } & \multicolumn{3}{|c|}{ Liquid Fraction } & \multicolumn{2}{|c|}{ Leached Solids Fraction } \\
\hline & $\mu g / m L$ & [M] & g & $\mu g / g$ & g \\
\hline $\mathbf{F}$ & $1.5 \mathrm{E}+03$ & 8.0E-02 & $1.8 \mathrm{E}+00$ & $2.9 \mathrm{E}+04$ & $1.2 \mathrm{E}+01$ \\
\hline $\mathrm{C}_{2} \mathrm{O}_{4}$ & $4.3 \mathrm{E}+02$ & 4.9E-03 & 5.1E-01 & $1.2 \mathrm{E}+04$ & $4.7 \mathrm{E}+00$ \\
\hline $\mathrm{NO}_{2}$ & $3.1 \mathrm{E}+03$ & 6.8E-02 & $3.7 \mathrm{E}+00$ & $3.7 \mathrm{E}+03$ & $1.5 \mathrm{E}+00$ \\
\hline $\mathrm{NO}_{3}$ & $7.5 \mathrm{E}+04$ & $1.2 \mathrm{E}+00$ & $8.8 \mathrm{E}+01$ & $9.1 \mathrm{E}+04$ & $3.8 \mathrm{E}+01$ \\
\hline $\mathrm{SO}_{4}$ & $5.1 \mathrm{E}+03$ & 5.3E-02 & $6.0 \mathrm{E}+00$ & $1.1 \mathrm{E}+04$ & $4.5 \mathrm{E}+00$ \\
\hline $\mathrm{PO}_{4}$ & $9.8 \mathrm{E}+02$ & $1.0 \mathrm{E}-02$ & $1.2 \mathrm{E}+00$ & $1.3 \mathrm{E}+05$ & $5.5 \mathrm{E}+01$ \\
\hline OH & $7.1 \mathrm{E}+04$ & $4.2 \mathrm{E}+00$ & $8.3 \mathrm{E}+01$ & & \\
\hline \multicolumn{6}{|c|}{$\begin{array}{l}\text { Slurry mass components were calculated from characterization data (Sections } 3 \text { and } 4 \text { ) and the } \\
\text { masses of materials that were added with simulant. Loss of mass from sampling was incorporated. } \\
\text { Liquid fraction mass components were calculated using analytical results from supernate sample } \\
\text { TI552-G6-D (ASO ID 08-01291) and the predicted mass of supernate in the system. } \\
\text { Solids fraction mass components were calculated from the difference between the slurry component } \\
\text { mass and liquid component mass fraction. }\end{array}$} \\
\hline
\end{tabular}


Table 5.19. Group $1 / 2$ Dewatered Leached Slurry Composition and Calculated Solids Leach Factors

\begin{tabular}{|c|c|c|c|c|c|}
\hline $\begin{array}{c}\text { Slurry Prep } \\
\text { Method }\end{array}$ & $\begin{array}{c}\text { ICP-OES } \\
\text { Analytes }\end{array}$ & $\begin{array}{c}\text { Dry } \\
\text { Slurry }{ }^{(a)} \\
(\mu \mathrm{g} / \mathrm{g})\end{array}$ & $\begin{array}{c}\text { Supernate }^{(b)} \\
(\mu \mathrm{g} / \mathrm{mL})\end{array}$ & $\begin{array}{c}\text { Dry Solids }{ }^{(\mathrm{c})} \\
(\mu \mathrm{g} / \mathrm{g})\end{array}$ & $\begin{array}{c}\text { Solids } \\
\text { Leach }^{(d)} \\
\text { Factor }^{(d)}\end{array}$ \\
\hline \multirow{35}{*}{$\begin{array}{l}\text { HF Assisted } \\
\text { Acid } \\
\text { Digestion, and } \\
\text { KOH Fusion, } \\
\text { Concentration } \\
\text { Factor of } \\
1.18 \text { based on } \\
\mathrm{U} \text { and Fe }\end{array}$} & Al & 31,650 & 5,070 & 49,414 & 0.58 \\
\hline & $\mathbf{B i}$ & 27,200 & 157 & 59,149 & 0.06 \\
\hline & Cd & 31.4 & $<4.2 \mathrm{E}-1$ & 67.2 & 0.03 \\
\hline & $\mathrm{Cr}$ & 5,025 & 206 & 10,224 & -0.07 \\
\hline & $\mathbf{F e}$ & 34,200 & 8.24 & 75,123 & NA \\
\hline & $\mathbf{K}$ & {$[400]$} & 286 & $-[257]$ & -0.07 \\
\hline & Mn & 532 & 1.20 & 1,164 & -0.04 \\
\hline & $\mathbf{N a}$ & 320,500 & 142,000 & 140,289 & 0.42 \\
\hline & $\mathrm{Ni}$ & 2,060 & $<2.9 \mathrm{E}-1$ & 4,526 & 0.01 \\
\hline & $\mathbf{P}$ & 43,950 & 309 & 95,354 & 0.18 \\
\hline & $S$ & 4,075 & 1,800 & 1,805 & 1.34 \\
\hline & Si & 25000.0 & 215 & 54084.2 & 0.08 \\
\hline & Sr & 1,900 & [0.095] & 4,175 & 0.02 \\
\hline & $\mathbf{U}$ & 8,625 & {$[7.6]$} & 18,923 & NA \\
\hline & Zn & 249 & 17.5 & 478 & 0.25 \\
\hline & $\mathbf{Z r}$ & 106 & {$[0.49]$} & 231 & 0.03 \\
\hline & $A g$ & [7.7] & $<2.6 \mathrm{E}-1$ & [15.9] & $-[.21]$ \\
\hline & $B a$ & 123 & {$[0.23]$} & 268 & 0.03 \\
\hline & $B e$ & {$[0.25]$} & {$[0.062]$} & {$[0.30]$} & [.78] \\
\hline & $C a$ & 4,275 & $<7.5 \mathrm{E}-1$ & 9,391 & 0.06 \\
\hline & Ce & 103 & $<1.2 \mathrm{E}+0$ & 220 & 0.00 \\
\hline & Co & 19.8 & $<2.9 \mathrm{E}-1$ & 42.3 & 0.15 \\
\hline & $\mathrm{Cu}$ & 70.5 & 3.32 & 141.6 & -0.07 \\
\hline & $L a$ & [21] & $<3.4 \mathrm{E}-1$ & {$[44]$} & $-[.08]$ \\
\hline & $\mathrm{Li}$ & 36.6 & {$[0.61]$} & 77.9 & 0.04 \\
\hline & $M g$ & 737 & $<2.8 \mathrm{E}-1$ & 1,618 & 0.05 \\
\hline & Mo & [41] & [3.6] & [75] & $-[.6]$ \\
\hline & $N d$ & [27] & $<6.6 \mathrm{E}-1$ & [57] & $-[.09]$ \\
\hline & $P b$ & 618 & [22] & 1,270 & 0.20 \\
\hline & $R u$ & $<2.4 \mathrm{E}+1$ & {$[2.3]$} & $<4.4 \mathrm{E}+1$ & NA \\
\hline & Th & [12] & $<3.2 \mathrm{E}+0$ & [14] & [49.96] \\
\hline & $T i$ & 83.4 & $<1.2 \mathrm{E}+0$ & 178.4 & 0.00 \\
\hline & $T I$ & [110] & $<5.3 \mathrm{E}-2$ & [242] & $-[.04]$ \\
\hline & $V$ & 16.1 & $<4.7 \mathrm{E}+0$ & 16.9 & 0.14 \\
\hline & $Y$ & 3.40 & $<5.4 \mathrm{E}-2$ & 7.26 & 0.04 \\
\hline
\end{tabular}


WTP-RPT-166, Rev. 0

Table 5.19 (Contd)

\begin{tabular}{|c|c|c|c|c|c|}
\hline $\begin{array}{c}\text { Slurry Prep } \\
\text { Method }\end{array}$ & Radionuclides & $\begin{array}{c}\text { Dry } \\
\text { Slurry }{ }^{(a)} \\
(\mu \mathrm{Ci} / \mathbf{g})\end{array}$ & $\begin{array}{c}\text { Supernate } e^{(b)} \\
(\mu \mathrm{Ci} / \mathrm{mL})\end{array}$ & $\begin{array}{c}\text { Dry Solids }{ }^{(\mathrm{c})} \\
(\mu \mathrm{Ci} / \mathrm{g})\end{array}$ & $\begin{array}{c}\text { Solids } \\
\text { Leach } \\
\text { Factor }^{(d)}\end{array}$ \\
\hline \multirow{10}{*}{$\begin{array}{l}\text { KOH Fusion, } \\
\text { Concentration } \\
\text { Factor of } \\
1.18 \text { based on } \\
U \text { and Fe }\end{array}$} & Co-60 & $5.71 \mathrm{E}-3$ & $<3 . \mathrm{E}-5$ & $1.24 \mathrm{E}-2$ & 0.09 \\
\hline & Cs-137 & $4.79 \mathrm{E}+1$ & $8.46 \mathrm{E}+0$ & $7.16 \mathrm{E}+1$ & 0.44 \\
\hline & Eu-154 & $2.52 \mathrm{E}-2$ & $<1$.E-4 & $5.48 \mathrm{E}-2$ & -1.73 \\
\hline & Eu-155 & $<4 . \mathrm{E}-2$ & $<2$.E-3 & $<8 . \mathrm{E}-2$ & NA \\
\hline & Am-241 & $1.71 \mathrm{E}-1$ & $<2$.E-3 & 3.67E-1 & -0.01 \\
\hline & Total alpha & $5.07 \mathrm{E}-1$ & $<7 . E-4$ & $1.11 \mathrm{E}+0$ & -0.40 \\
\hline & Total beta & $2.18 \mathrm{E}+2$ & $7.83 \mathrm{E}+0$ & $4.47 \mathrm{E}+2$ & -0.15 \\
\hline & Sr-90 & $8.28 \mathrm{E}+1$ & $4.03 \mathrm{E}-3$ & $1.82 \mathrm{E}+2$ & -0.03 \\
\hline & Pu-239/240 & $2.01 \mathrm{E}-1$ & $7.75 \mathrm{E}-6$ & 4.43E-1 & -0.04 \\
\hline & Pu-238 & $6.25 \mathrm{E}-3$ & $9.82 \mathrm{E}-7$ & $1.37 \mathrm{E}-2$ & -0.17 \\
\hline \multicolumn{6}{|c|}{$\begin{array}{l}\text { (a) Test sample TI572-G2-D, ASO ID 08-01291 } \\
\text { (b) Test sample TI572-G2-9, ASO ID 08-01318 } \\
\text { (c) Calculated using results from TI572-G2-D and TI572-G2-9. } \\
\text { (d) Calculated using dry solids concentration results listed in } \\
\text { (e) Table 5.11. } \\
\text { Note: Analytes in italics were measured opportunistically. Values in brackets [ ] are } \\
\geq \text { MDL but < EQL, with errors likely to exceed } 15 \% \text {. }\end{array}$} \\
\hline
\end{tabular}

Figure 5.38 shows the size distribution of particles for the caustic-leached, dewatered slurry as a function of pump speed. All distributions show a primary particle population that ranges from 0.3 to $20 \mu \mathrm{m}$. This primary population is characterized by a strong peak population centered between 1 and $2 \mu \mathrm{m}$, which decays rapidly to a shoulder population spanning 5 to $20 \mu \mathrm{m}$. At $4000 \mathrm{RPM}$, a strong secondary peak spanning 20 to $200 \mu \mathrm{m}$ is observed. This secondary population has a maximum at $60 \mu \mathrm{m}$ and is similar to secondary populations observed in previous samples.

Figure 5.39 shows changes that occur in the PSD for the caustic-leached, dewatered slurry as a result of sonication. Applying sonic energy appears to reduce the relative contribution of $\sim 0.6-$ to 3 - $\mu$ m particles while increasing both the relative contributions of submicron $(0.2$ to $0.6 \mu \mathrm{m})$ and 3- to $20-\mu \mathrm{m}$ particles/agglomerates. The increase in submicron particles is likely a result of sonic disruption of larger particles and agglomerates. The origin for the increase in 3- to 20- $\mu \mathrm{m}$ particles is less certain. Potential sources include sonic disruption of agglomerates in the 20- to 200- $\mu$ m range and/or sonication induced aggregation. Of these two possibilities, the former seems more likely. After sonication is removed, a recovery is observed in the 0.6 - to 3 - $\mu$ m population at the expense of particles in both the submicron and the 3- to 20- $\mu \mathrm{m}$ range. This recovery indicates that changes that occur in the PSD are recoverable and correspond to a change in the state of particle aggregation. 


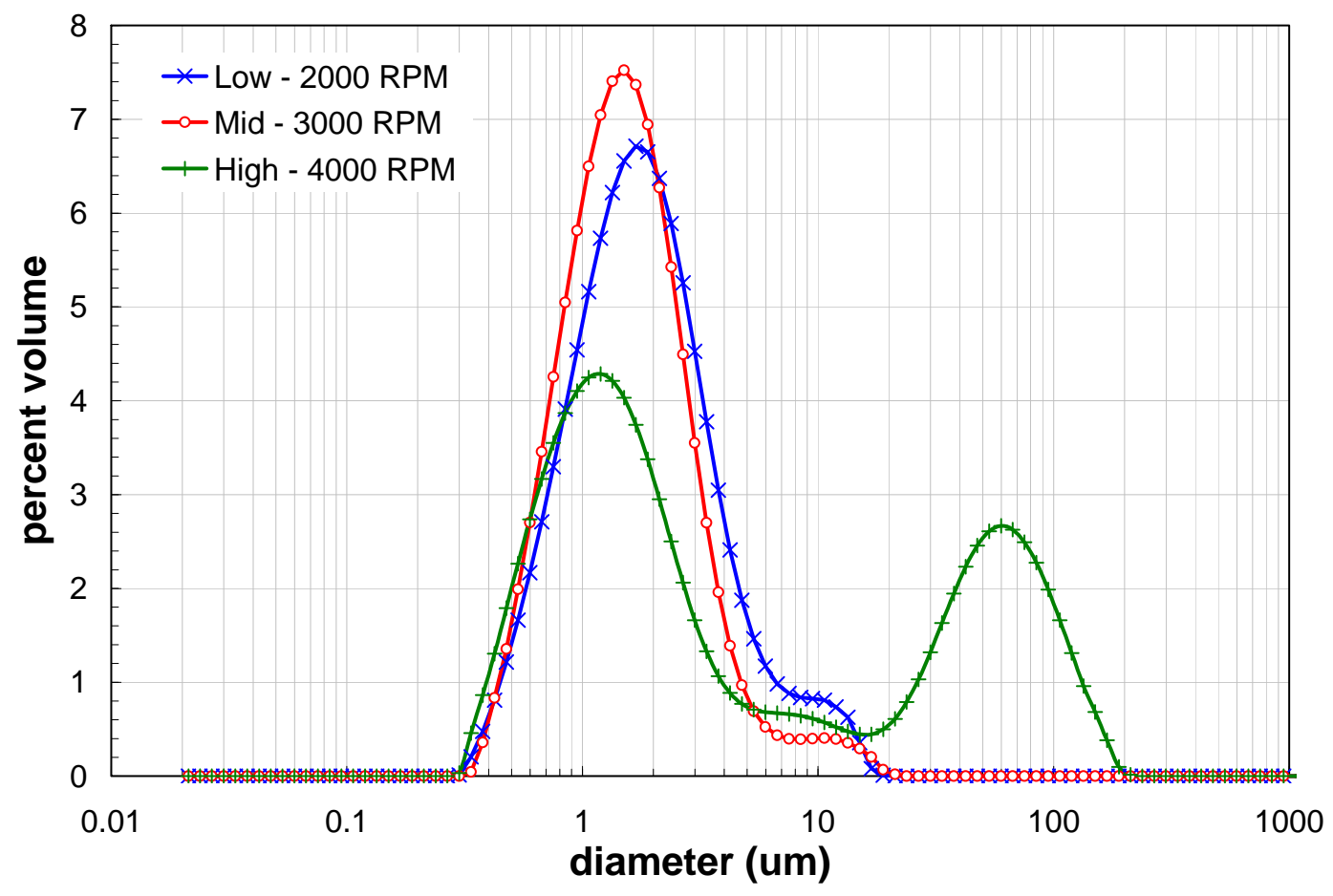

Figure 5.38. Caustic-Leached, Dewatered Slurry PSD as a Function of Pump Speed

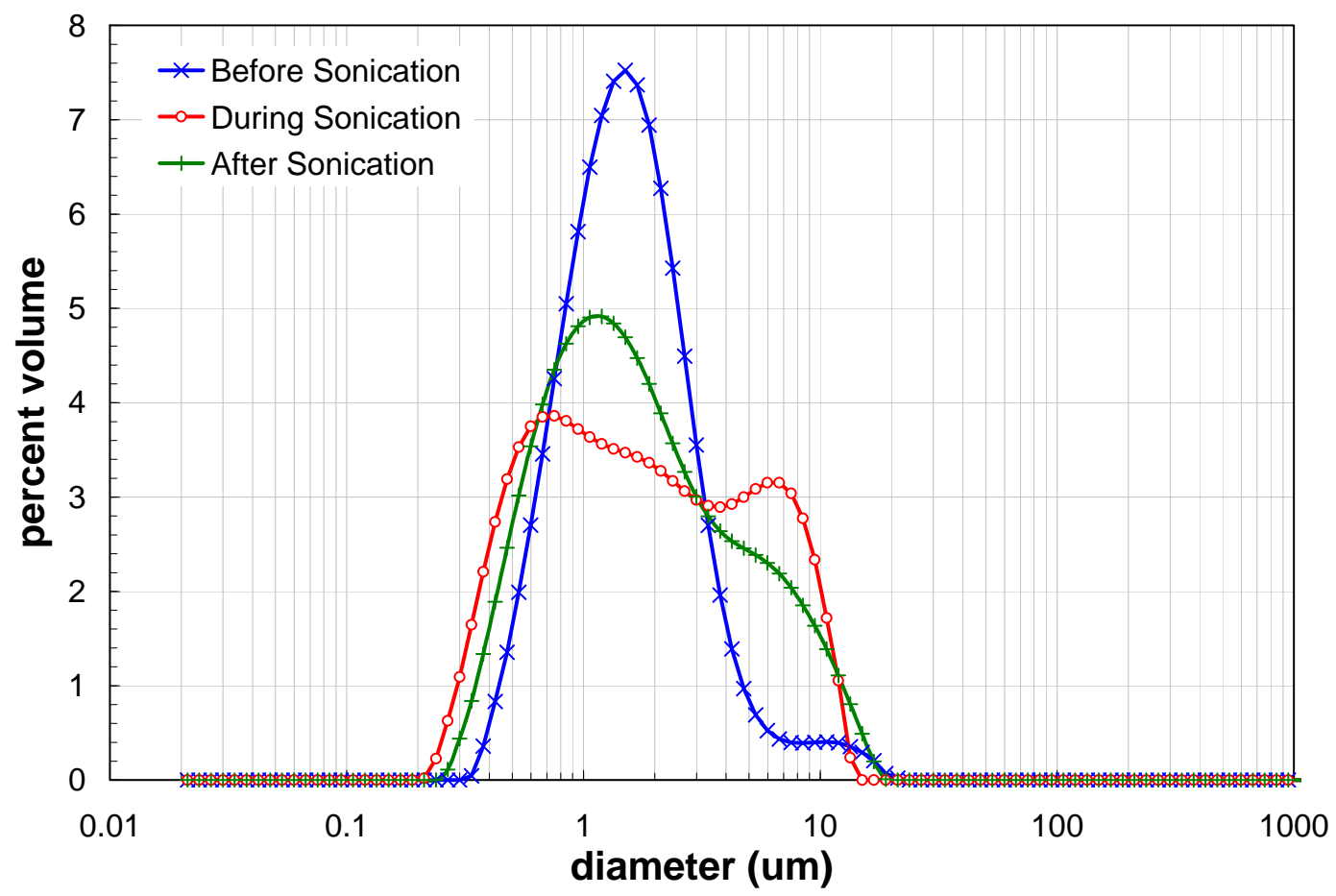

Figure 5.39. Caustic-Leached, Dewatered Slurry PSD as a Function of Sonication at 3000 RPM 
Figure 5.40 shows the results of flow curve testing for the caustic-leached and dewatered slurry, which shows non-Newtonian behavior at all temperatures studied. The flow curves exhibited increasing yield stress with temperature. At $25^{\circ} \mathrm{C}$, the yield stress was approximately $25 \mathrm{~Pa}$, whereas at $60^{\circ} \mathrm{C}$, it was approximately $50 \mathrm{~Pa}$. Below $200 \mathrm{~s}^{-1}$, all data showed strong downward curvature. Given the significant stress response for this sample ( $>20 \mathrm{~Pa}$ ), the curvature at low shear is most likely a result of poor rotational sampling and sample elasticity. Beyond $200 \mathrm{~s}^{-1}$ the stress response was relatively linear, although the $60^{\circ} \mathrm{C}$ did show a slight downward curvature. Overall, the high-shear rate rheology is consistent with a Bingham-Plastic model.

Flow curve hysteresis is present in all flow-curve measurements. At $25^{\circ}$ and $40^{\circ} \mathrm{C}$, the hysteresis primarily occurs in the 100 to $200 \mathrm{~s}^{-1}$ range. Here, hysteresis likely resulted from excess material in the upper rotor recess being forced against the rotor wall by inertia and affecting an increase in the height of sheared material. For the $60^{\circ} \mathrm{C}$ measurement data, hysteresis is consistent with suspending phase evaporation effects.

As stated in the preceding paragraph, increased measurement temperatures observed higher yield stresses. At $25^{\circ}, 40^{\circ}$, and $60^{\circ} \mathrm{C}$, the yield stress for the caustic-leached and dewatered sample was approximately 25,35 , and $50 \mathrm{~Pa}$. This increased yield stress could indicate an increase in the degree of solids structuring (i.e., aggregation) upon sample heating. However, given the significant hysteresis observed in the $60^{\circ} \mathrm{C}$ measurement, part (if not all) of the yield stress increase was likely a result of sample concentration through suspending phase evaporation. On the other hand, increased temperature resulted in a slight decrease in the flow curve slope. This is consistent with the pre-leach Group 1/2 slurry consistency behavior and is speculated to be a result of lowered suspending phase viscosity at higher temperatures.

Table 5.20 summarizes the best-fit rheological parameters for flow curve data for the leached dewatered slurry. The results in Table 5.20 confirm a number of the observations outlined in the preceding paragraphs. To be specific, they show that:

- The Bingham-Plastic and Herschel-Bulkley yield stresses ranged from 32 to $57 \mathrm{~Pa}$ and 13 to $37 \mathrm{~Pa}$, respectively.

- Bingham-Plastic yield stress increased monotonically over the course of measurement. Similar behavior was observed in the Herschel-Bulkley yield stress. Given the current data, it is not possible to de-convolute the degree to which this change is driven by time, shear, and temperature.

- Bingham-Plastic consistency decreased from $29 \mathrm{mPa} \cdot \mathrm{s}$ at $25^{\circ} \mathrm{C}$ to $23 \mathrm{mPa} \cdot \mathrm{s}$ at $60^{\circ} \mathrm{C}$.

Apparent viscosities at $33 \mathrm{~s}^{-1}, 100 \mathrm{~s}^{-1}, 500 \mathrm{~s}^{-1}$, and $1000 \mathrm{~s}^{-1}$ were calculated using the Bingham-Plastic and Herschel-Bulkley fitting parameters in Table 5.20, as previously described. The results (Table 5.21) show that, depending on temperature, apparent viscosities typically range from 680 to $1800 \mathrm{mPa} \cdot \mathrm{s}^{\mathrm{at}} 33 \mathrm{~s}^{-1}, 280$ to $600 \mathrm{mPa} \cdot \mathrm{s}$ at $100 \mathrm{~s}^{-1}, 89$ to $140 \mathrm{mPa} \cdot \mathrm{s}$ at $500 \mathrm{~s}^{-1}$, and 57 to $81 \mathrm{mPa} \cdot \mathrm{s}$ at $1000 \mathrm{~s}^{-1}$. For the caustically leached, dewatered slurry, the apparent viscosity increased significantly (sometimes by a factor of nearly three) with increasing temperature. 


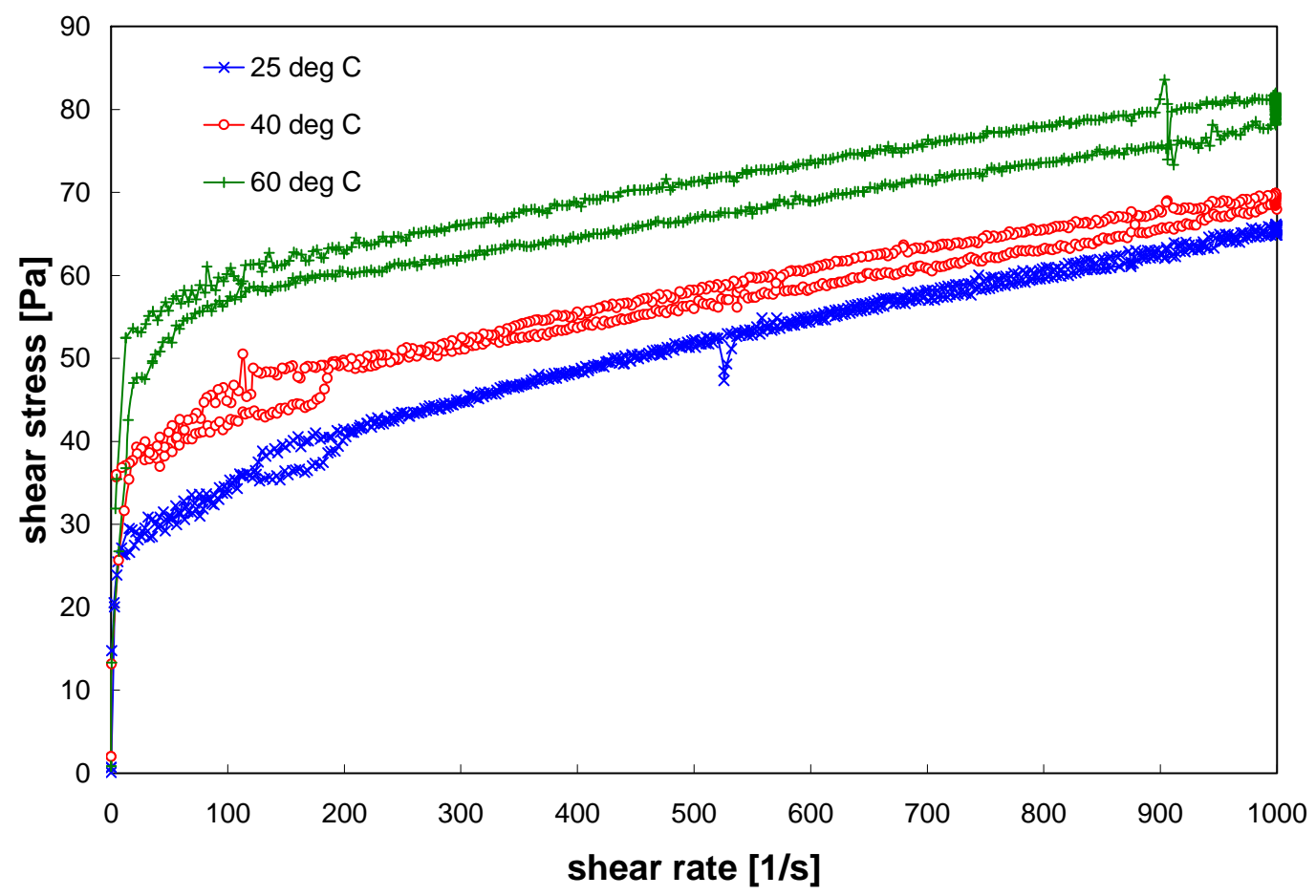

Figure 5.40. Flow Curve for the Group 1/2 CUF Caustic-Leached and Dewatered Slurry at 25, 40, and $60^{\circ} \mathrm{C}$

Table 5.20. Results of Fitting Analysis for the Group 1/2 CUF Caustic-Leached and Dewatered Slurry

\begin{tabular}{||c|c|c|c|c|c||}
\hline \multirow{3}{*}{ Model } & $\begin{array}{c}\text { Temperature } \\
{\left[{ }^{\circ} \mathbf{C}\right]}\end{array}$ & $\begin{array}{c}\text { Yield } \\
\text { Stress [Pa] }\end{array}$ & $\begin{array}{c}\text { Consistency } \\
{\left[\mathbf{P a} \cdot \mathbf{s}^{\mathbf{n}}\right]}\end{array}$ & $\begin{array}{c}\text { Flow } \\
\text { Index }\end{array}$ & $\mathbf{R}$ \\
\hline $\begin{array}{c}\text { Bingham-Plastic } \\
\left(200-1000 \mathrm{~s}^{-1}\right)\end{array}$ & $25(1$ of 2$)$ & 32 & 0.026 & $\mathrm{n} / \mathrm{a}$ & 0.979 \\
\cline { 2 - 6 } & $25(2$ of 2$)$ & 37 & 0.029 & $\mathrm{n} / \mathrm{a}$ & 0.997 \\
\cline { 2 - 6 } & 40 & 44 & 0.025 & $\mathrm{n} / \mathrm{a}$ & 0.992 \\
\cline { 2 - 7 } & 60 & 57 & 0.023 & $\mathrm{n} / \mathrm{a}$ & 0.961 \\
\hline \multirow{3}{*}{$\begin{array}{c}\text { Herschel-Bulkley } \\
\left(0-1000 \mathrm{~s}^{-1}\right)\end{array}$} & $25(1$ of 2$)$ & 13 & 1.8 & 0.46 & 0.991 \\
\cline { 2 - 7 } & $25(2$ of 2$)$ & 19 & 1.6 & 0.49 & 0.996 \\
\cline { 2 - 7 } & 40 & 32 & 0.91 & 0.54 & 0.990 \\
\cline { 2 - 7 } & 60 & 37 & 3.5 & 0.36 & 0.963 \\
\hline
\end{tabular}


Table 5.21. Apparent Viscosity of the Group 1/2 CUF Caustic-Leached and Dewatered Slurry

\begin{tabular}{|c|c|c|c|c|c|}
\hline \multirow[t]{2}{*}{ Source } & \multirow{2}{*}{$\begin{array}{c}\text { Temperature } \\
{\left[{ }^{\circ} \mathrm{C}\right]}\end{array}$} & \multicolumn{4}{|c|}{ Apparent Viscosity [mPa·s] } \\
\hline & & @ $33 \mathrm{~s}^{-1}$ & (a) $100 \mathrm{~s}^{-1}$ & (a) $500 \mathrm{~s}^{-1}$ & @ $1000 \mathrm{~s}^{-1}$ \\
\hline \multirow[t]{4}{*}{ Measured } & 25 (1 of 2$)$ & 700 & 280 & 91 & 57 \\
\hline & 25 (2 of 2$)$ & 900 & 340 & 100 & 66 \\
\hline & 40 & 1200 & 430 & 110 & 70 \\
\hline & 60 & 1600 & 590 & 140 & 81 \\
\hline \multirow[t]{4}{*}{ Bingham-Plastic } & 25 (1 of 2$)$ & 980 & 340 & 89 & 57 \\
\hline & 25 (2 of 2$)$ & 1100 & 400 & 100 & 66 \\
\hline & 40 & 1400 & 470 & 110 & 70 \\
\hline & 60 & 1800 & 600 & 140 & 81 \\
\hline \multirow{4}{*}{$\begin{array}{l}\text { Herschel- } \\
\text { Bulkley }\end{array}$} & 25 (1 of 2$)$ & 680 & 280 & 90 & 57 \\
\hline & $25(2$ of 2$)$ & 850 & 340 & 100 & 65 \\
\hline & 40 & 1200 & 430 & 120 & 69 \\
\hline & 60 & 1500 & 560 & 140 & 80 \\
\hline
\end{tabular}

\subsubsection{Batch Caustic Washing}

Figure 5.41 illustrates the material flow for the caustic washing steps. Following the caustic leach, the slurry was washed five times with decreasing concentrations of sodium hydroxide $(0.56 \mathrm{M}, 0.20 \mathrm{M}$, $0.06 \mathrm{M}, 0.02 \mathrm{M}$, and $0.01 \mathrm{M}$ ). Over the course of the washing, $6.0 \mathrm{~L}$ were added to the CUF, while $5.6 \mathrm{~L}$ were removed. This increased the volume in the CUF by $0.4 \mathrm{~L}$, while the circulating slurry mass stayed relatively the same due to changes in the supernate density. Grab samples of the filtered permeate were collected half-way between each dewatering step to assess the composition of the filtrate. The results were used to predict the slurry inventory and composition at each wash step, shown in Table 5.22 through Table 5.26

Table 5.26. The measured concentration of free hydroxide, radionuclides, and opportunistic ICP-OES analytes for each filtered wash solution is provided in Table 5.27. 
WTP-RPT-166, Rev. 0

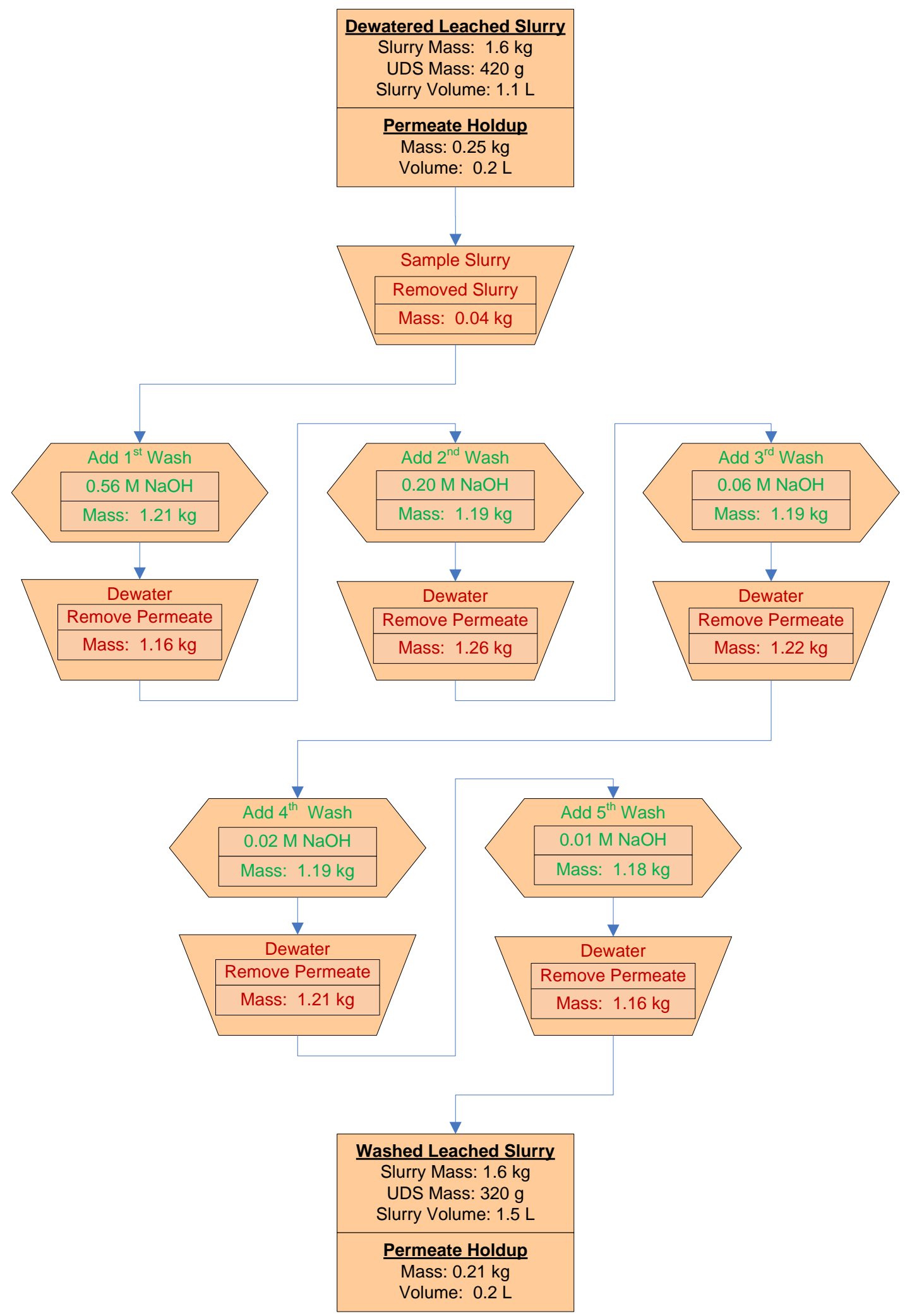

Figure 5.41. Flow Diagram for Batch Caustic Washing

Note: Mass and volume values in figure are rounded to the nearest significant digit of accuracy. 
Table 5.22. Group 1/2 Caustic leached Slurry Inventory and Composition after the First Wash

\begin{tabular}{|c|c|c|c|c|c|c|}
\hline & & Slurry $^{(a)}$ & \multicolumn{2}{|c|}{ Liquid Fraction $^{(b)}$} & \multicolumn{2}{|c|}{ Solids Fraction $^{(c)}$} \\
\hline & Mass (kg) & 1.84 & \multicolumn{2}{|c|}{1.43} & \multicolumn{2}{|c|}{0.41} \\
\hline & Wt\% of Slurry & $100 \%$ & \multicolumn{2}{|c|}{$77.7 \%$} & \multicolumn{2}{|c|}{$22.3 \%$} \\
\hline & Metal & g & g & $\mu g / m L$ & g & $\mu g / g$ \\
\hline & Al & $2.7 \mathrm{E}+01$ & $2.8 \mathrm{E}+00$ & $2.3 \mathrm{E}+03$ & $2.4 \mathrm{E}+01$ & $5.8 \mathrm{E}+04$ \\
\hline & Bi & $1.8 \mathrm{E}+01$ & 5.6E-02 & $4.5 \mathrm{E}+01$ & $1.8 \mathrm{E}+01$ & $4.4 \mathrm{E}+04$ \\
\hline & Cr & $3.4 \mathrm{E}+00$ & $1.5 \mathrm{E}-01$ & $1.2 \mathrm{E}+02$ & $3.3 \mathrm{E}+00$ & $8.0 \mathrm{E}+03$ \\
\hline & $\mathbf{F e}$ & $2.5 \mathrm{E}+01$ & 2.3E-03 & $1.9 \mathrm{E}+00$ & $2.5 \mathrm{E}+01$ & $6.0 \mathrm{E}+04$ \\
\hline & Mn & 3.7E-01 & 5.3E-05 & 4.3E-02 & 3.7E-01 & $9.0 \mathrm{E}+02$ \\
\hline & $\mathrm{Na}$ & $2.1 \mathrm{E}+02$ & $9.3 E+01$ & $7.5 \mathrm{E}+04$ & $1.2 \mathrm{E}+02$ & $3.0 \mathrm{E}+05$ \\
\hline & $\mathbf{P}$ & $3.7 \mathrm{E}+01$ & 7.1E-01 & $5.8 \mathrm{E}+02$ & $3.6 \mathrm{E}+01$ & $8.8 \mathrm{E}+04$ \\
\hline & $\mathrm{S}$ & 9.6E-01 & $1.6 \mathrm{E}+00$ & $1.3 \mathrm{E}+03$ & $-6.1 \mathrm{E}-01$ & $-1.5 \mathrm{E}+03$ \\
\hline & Si & $1.6 \mathrm{E}+01$ & $1.1 \mathrm{E}-01$ & $9.0 \mathrm{E}+01$ & $1.6 \mathrm{E}+01$ & $3.8 \mathrm{E}+04$ \\
\hline & $\mathrm{Sr}$ & $1.5 \mathrm{E}+00$ & 7.3E-05 & 5.9E-02 & $1.5 \mathrm{E}+00$ & $3.6 \mathrm{E}+03$ \\
\hline & $\mathbf{U}$ & $6.2 \mathrm{E}+00$ & $1.3 \mathrm{E}-02$ & $1.1 \mathrm{E}+01$ & $6.2 \mathrm{E}+00$ & $1.5 \mathrm{E}+04$ \\
\hline \multicolumn{5}{|c|}{ Supernate Fraction } & & \\
\hline & Anion & $\mu \mathrm{g} / \mathrm{mL}$ & [M] & g & & \\
\hline & OH & $3.8 \mathrm{E}+04$ & $2.2 \mathrm{E}+00$ & $4.7 \mathrm{E}+01$ & & \\
\hline \multicolumn{7}{|c|}{$\begin{array}{l}\text { (a) Slurry mass components were calculated from characterization data (Sections } 3 \text { and 4) and the } \\
\text { masses of materials that were added with simulant. Loss of mass from sampling was incorporated. } \\
\text { (b) Liquid fraction mass components were calculated using analytical results from supernate sample } \\
\text { TI552-G6-E (ASO ID 08-01309) and the predicted mass of supernate in the system. } \\
\text { (c) Solids fraction mass components were calculated from the difference between the slurry component } \\
\text { mass and liquid component mass fraction. }\end{array}$} \\
\hline
\end{tabular}


Table 5.23. Group 1/2 Caustic Leached Slurry Inventory and Composition after the Second Wash

\begin{tabular}{|c|c|c|c|c|c|c|}
\hline & & Slurry $^{(\mathbf{a})}$ & \multicolumn{2}{|c|}{ Liquid Fraction $^{(b)}$} & \multicolumn{2}{|c|}{ Solids Fraction ${ }^{(c)}$} \\
\hline & Mass (kg) & 1.77 & \multicolumn{2}{|c|}{1.38} & \multicolumn{2}{|c|}{0.39} \\
\hline & Wt\% of Slurry & $100 \%$ & \multicolumn{2}{|c|}{$77.9 \%$} & \multicolumn{2}{|c|}{$22.1 \%$} \\
\hline & Metal & g & g & $\mu \mathrm{g} / \mathrm{mL}$ & g & $\mu \mathrm{g} / \mathrm{g}$ \\
\hline & Al & $2.5 \mathrm{E}+01$ & $1.6 \mathrm{E}+00$ & $1.3 \mathrm{E}+03$ & $2.4 \mathrm{E}+01$ & $6.0 \mathrm{E}+04$ \\
\hline & $\mathbf{B i}$ & $1.8 \mathrm{E}+01$ & 2.3E-02 & $1.8 \mathrm{E}+01$ & $1.8 \mathrm{E}+01$ & $4.6 \mathrm{E}+04$ \\
\hline & $\mathrm{Cr}$ & $3.4 \mathrm{E}+00$ & $9.2 \mathrm{E}-02$ & $7.2 \mathrm{E}+01$ & $3.3 \mathrm{E}+00$ & $8.3 E+03$ \\
\hline & $\mathbf{F e}$ & $2.5 \mathrm{E}+01$ & $9.2 \mathrm{E}-02$ & $7.2 \mathrm{E}+01$ & $2.5 \mathrm{E}+01$ & $6.3 \mathrm{E}+04$ \\
\hline & Mn & 3.7E-01 & $1.5 \mathrm{E}-04$ & $1.2 \mathrm{E}-01$ & 3.7E-01 & $9.5 \mathrm{E}+02$ \\
\hline & $\mathrm{Na}$ & $1.6 \mathrm{E}+02$ & $1.4 \mathrm{E}+02$ & $1.1 \mathrm{E}+05$ & $2.1 \mathrm{E}+01$ & $5.3 \mathrm{E}+04$ \\
\hline & $\mathbf{P}$ & $3.5 E+01$ & $3.2 \mathrm{E}+00$ & $2.5 \mathrm{E}+03$ & $3.2 \mathrm{E}+01$ & $8.1 \mathrm{E}+04$ \\
\hline & $\mathbf{S}$ & 2.2E-01 & $3.0 \mathrm{E}+00$ & $2.3 \mathrm{E}+03$ & $-2.7 \mathrm{E}+00$ & $-7.0 \mathrm{E}+03$ \\
\hline & Si & $1.6 \mathrm{E}+01$ & $6.4 \mathrm{E}-02$ & $5.0 \mathrm{E}+01$ & $1.6 \mathrm{E}+01$ & $4.0 \mathrm{E}+04$ \\
\hline & $\mathrm{Sr}$ & $1.5 \mathrm{E}+00$ & $6.4 \mathrm{E}-02$ & $5.0 \mathrm{E}+01$ & $1.4 \mathrm{E}+00$ & $3.6 \mathrm{E}+03$ \\
\hline & $\mathbf{U}$ & $6.2 \mathrm{E}+00$ & $6.4 \mathrm{E}-02$ & $5.0 \mathrm{E}+01$ & $6.1 \mathrm{E}+00$ & $1.6 \mathrm{E}+04$ \\
\hline \multicolumn{5}{|c|}{ Supernate Fraction } & & \\
\hline & Anion & $\mu g / m L$ & [M] & g & & \\
\hline & $\mathbf{O H}$ & $2.2 \mathrm{E}+04$ & $1.3 \mathrm{E}+00$ & $2.8 \mathrm{E}+01$ & & \\
\hline \multicolumn{7}{|c|}{$\begin{array}{l}\text { (a) Slurry mass components were calculated from characterization data (Sections } 3 \text { and 4) and the } \\
\text { masses of materials that were added with simulant. Loss of mass from sampling was incorporated. } \\
\text { (b) Liquid fraction mass components were calculated using analytical results from supernate sample } \\
\text { TI552-G6-F (ASO ID 08-01310) and the predicted mass of supernate in the system. } \\
\text { (c) Solids fraction mass components were calculated from the difference between the slurry component } \\
\text { mass and liquid component mass fraction. }\end{array}$} \\
\hline
\end{tabular}


Table 5.24. Group 1/2 Caustic Leached Slurry Inventory and Composition after the Third Wash

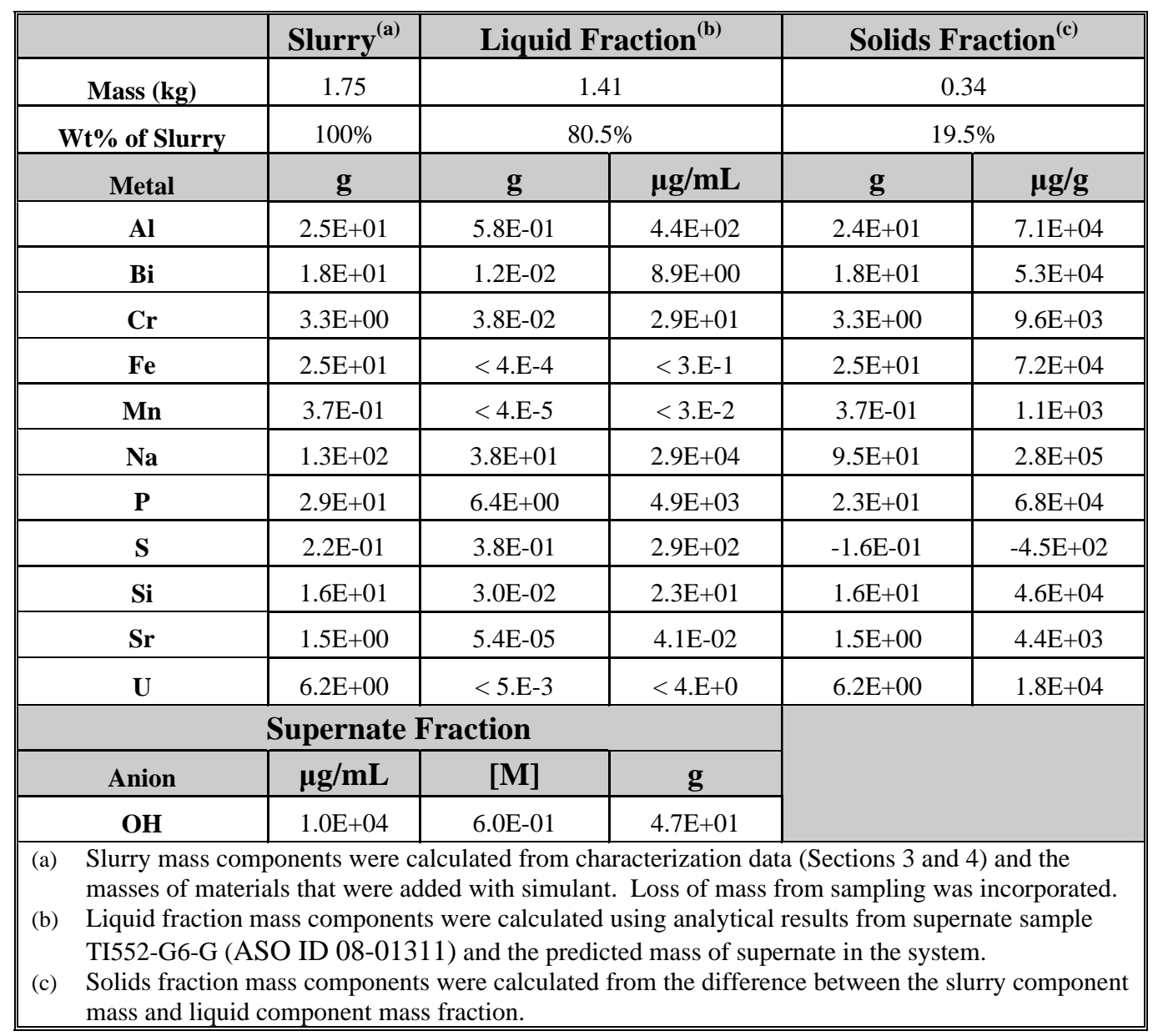


Table 5.25. Group 1/2 Caustic leached Slurry Inventory and Composition after the Fourth Wash

\begin{tabular}{|c|c|c|c|c|c|c|}
\hline & & Slurry $^{(a)}$ & \multicolumn{2}{|c|}{ Liquid Fraction $^{(b)}$} & \multicolumn{2}{|c|}{ Solids Fraction ${ }^{(\mathrm{c})}$} \\
\hline & Mass (kg) & 1.73 & \multicolumn{2}{|c|}{1.41} & \multicolumn{2}{|c|}{0.32} \\
\hline & Wt\% of Slurry & $100 \%$ & \multicolumn{2}{|c|}{$81.4 \%$} & \multicolumn{2}{|c|}{$18.6 \%$} \\
\hline & Metal & g & g & $\mu \mathrm{g} / \mathrm{mL}$ & g & $\mu g / g$ \\
\hline & Al & $2.5 \mathrm{E}+01$ & 2.9E-01 & $2.2 \mathrm{E}+02$ & $2.4 \mathrm{E}+01$ & $7.6 \mathrm{E}+04$ \\
\hline & $\mathbf{B i}$ & $1.8 \mathrm{E}+01$ & 5.3E-03 & $4.0 \mathrm{E}+00$ & $1.8 \mathrm{E}+01$ & $5.7 \mathrm{E}+04$ \\
\hline & $\mathrm{Cr}$ & $3.3 \mathrm{E}+00$ & $1.9 \mathrm{E}-02$ & $1.4 \mathrm{E}+01$ & $3.3 \mathrm{E}+00$ & $1.0 \mathrm{E}+04$ \\
\hline & $\mathbf{F e}$ & $2.5 \mathrm{E}+01$ & $1.2 \mathrm{E}-04$ & 8.7E-02 & $2.5 \mathrm{E}+01$ & $7.7 \mathrm{E}+04$ \\
\hline & Mn & 3.7E-01 & 4.3E-05 & 3.2E-02 & 3.7E-01 & $1.2 \mathrm{E}+03$ \\
\hline & $\mathrm{Na}$ & $1.1 \mathrm{E}+02$ & $2.5 \mathrm{E}+01$ & $1.9 \mathrm{E}+04$ & 8.7E+01 & $2.7 \mathrm{E}+05$ \\
\hline & $\mathbf{P}$ & $2.5 \mathrm{E}+01$ & $5.7 \mathrm{E}+00$ & $4.2 \mathrm{E}+03$ & $1.9 \mathrm{E}+01$ & $5.9 \mathrm{E}+04$ \\
\hline & S & 2.2E-01 & $1.6 \mathrm{E}-01$ & $1.2 \mathrm{E}+02$ & $5.8 \mathrm{E}-02$ & $1.8 \mathrm{E}+02$ \\
\hline & $\mathbf{S i}$ & $1.6 \mathrm{E}+01$ & 6.1E-02 & $4.6 \mathrm{E}+01$ & $1.5 \mathrm{E}+01$ & $4.8 \mathrm{E}+04$ \\
\hline & $\mathrm{Sr}$ & $1.5 \mathrm{E}+00$ & 3.1E-05 & 2.3E-02 & $1.5 \mathrm{E}+00$ & $4.6 \mathrm{E}+03$ \\
\hline & $\mathbf{U}$ & $6.2 \mathrm{E}+00$ & $2.4 \mathrm{E}-03$ & $1.8 \mathrm{E}+00$ & $6.2 \mathrm{E}+00$ & $1.9 \mathrm{E}+04$ \\
\hline \multicolumn{5}{|c|}{ Supernate Fraction } & & \\
\hline & Anion & $\mu \mathrm{g} / \mathrm{mL}$ & [M] & g & & \\
\hline & $\mathbf{O H}$ & $6.3 \mathrm{E}+03$ & 3.7E-01 & $8.5 \mathrm{E}+00$ & & \\
\hline \multicolumn{7}{|c|}{$\begin{array}{l}\text { (a) Slurry mass components were calculated from characterization data (Sections } 3 \text { and 4) and the } \\
\text { masses of materials that were added with simulant. Loss of mass from sampling was incorporated. } \\
\text { (b) Liquid fraction mass components were calculated using analytical results from supernate sample } \\
\text { TI552-G6-H (ASO ID 08-01312) and the predicted mass of supernate in the system. } \\
\text { (c) Solids fraction mass components were calculated from the difference between the slurry component } \\
\text { mass and liquid component mass fraction. }\end{array}$} \\
\hline
\end{tabular}


Table 5.26. Group 1/2 Caustic leached Slurry Inventory and Composition after the Fifth Wash

\begin{tabular}{|c|c|c|c|c|c|}
\hline & Slurry $^{(a)}$ & \multicolumn{2}{|c|}{ Liquid Fraction $^{(b)}$} & \multicolumn{2}{|c|}{ Solids Fraction $^{(c)}$} \\
\hline Mass (kg) & 1.75 & \multicolumn{2}{|c|}{1.43} & \multicolumn{2}{|c|}{0.32} \\
\hline Wt\% of Slurry & $100 \%$ & \multicolumn{2}{|c|}{$81.7 \%$} & \multicolumn{2}{|c|}{$18.3 \%$} \\
\hline Metal & g & g & $\mu \mathrm{g} / \mathrm{mL}$ & $\mathbf{g}$ & $\mu \mathrm{g} / \mathrm{g}$ \\
\hline Al & $2.4 \mathrm{E}+01$ & $1.7 \mathrm{E}-01$ & $1.2 \mathrm{E}+02$ & $2.4 \mathrm{E}+01$ & $7.6 \mathrm{E}+04$ \\
\hline $\mathbf{B i}$ & $1.8 \mathrm{E}+01$ & $<1$.E-3 & $<7 . \mathrm{E}-1$ & $1.8 \mathrm{E}+01$ & $5.7 \mathrm{E}+04$ \\
\hline $\mathrm{Cr}$ & $3.3 \mathrm{E}+00$ & $1.1 \mathrm{E}-02$ & $7.7 \mathrm{E}+00$ & $3.3 \mathrm{E}+00$ & $1.0 \mathrm{E}+04$ \\
\hline $\mathbf{F e}$ & $2.5 \mathrm{E}+01$ & 2.3E-04 & $1.6 \mathrm{E}-01$ & $2.5 \mathrm{E}+01$ & $7.7 \mathrm{E}+04$ \\
\hline Mn & 3.7E-01 & $1.7 \mathrm{E}-05$ & $1.2 \mathrm{E}-02$ & 3.7E-01 & $1.2 \mathrm{E}+03$ \\
\hline $\mathrm{Na}$ & $1.0 \mathrm{E}+02$ & $1.4 \mathrm{E}+01$ & $9.5 \mathrm{E}+03$ & $8.7 \mathrm{E}+01$ & $2.7 \mathrm{E}+05$ \\
\hline $\mathbf{P}$ & $2.2 \mathrm{E}+01$ & $3.1 \mathrm{E}+00$ & $2.1 \mathrm{E}+03$ & $1.9 \mathrm{E}+01$ & $5.9 \mathrm{E}+04$ \\
\hline $\mathrm{S}$ & $1.5 \mathrm{E}-01$ & $9.2 \mathrm{E}-02$ & $6.3 \mathrm{E}+01$ & 5.7E-02 & $1.8 \mathrm{E}+02$ \\
\hline Si & $1.6 \mathrm{E}+01$ & $2.4 \mathrm{E}-02$ & $1.7 \mathrm{E}+01$ & $1.5 \mathrm{E}+01$ & $4.8 \mathrm{E}+04$ \\
\hline Sr & $1.5 \mathrm{E}+00$ & $1.6 \mathrm{E}-05$ & $1.1 \mathrm{E}-02$ & $1.5 \mathrm{E}+00$ & $4.6 \mathrm{E}+03$ \\
\hline $\mathbf{U}$ & $6.2 \mathrm{E}+00$ & < 3.E-6 & $<2$.E-3 & $6.2 \mathrm{E}+00$ & $1.9 \mathrm{E}+04$ \\
\hline \multirow{2}{*}{$\begin{array}{l}\text { Radiochemical } \\
\text { Isotopes }\end{array}$} & Slurry & \multicolumn{2}{|c|}{ Liquid Fraction } & \multicolumn{2}{|c|}{ Solid Fraction } \\
\hline & mCi & mCi & $\mathrm{mCi} / \mathrm{mL}$ & $\mathrm{mCi}$ & $\mathrm{mCi} / \mathrm{g}$ \\
\hline Co-60 & $4.8 \mathrm{E}+00$ & $<3$. E-2 & $<2$.E-5 & $4.8 \mathrm{E}+00$ & $1.5 \mathrm{E}-02$ \\
\hline Cs-137 & $3.3 \mathrm{E}+04$ & $3.2 \mathrm{E}+02$ & $2.2 \mathrm{E}-01$ & $3.2 \mathrm{E}+04$ & $1.0 \mathrm{E}+02$ \\
\hline Eu-154 & $1.4 \mathrm{E}+01$ & $<6 . \mathrm{E}-2$ & $<4 . \mathrm{E}-5$ & $1.4 \mathrm{E}+01$ & 4.5E-02 \\
\hline Am-241 & $1.3 \mathrm{E}+02$ & $<6 . \mathrm{E}-1$ & $<4$.E-4 & $1.3 \mathrm{E}+02$ & 4.1E-01 \\
\hline Gross Alpha & $2.5 \mathrm{E}+02$ & $<9 . \mathrm{E}-1$ & $<6 . \mathrm{E}-4$ & $2.5 \mathrm{E}+02$ & 7.8E-01 \\
\hline Gross Beta & $1.5 \mathrm{E}+05$ & $3.1 \mathrm{E}+02$ & $2.1 \mathrm{E}-01$ & $1.5 \mathrm{E}+05$ & $4.8 \mathrm{E}+02$ \\
\hline Sr-90 & $5.9 \mathrm{E}+04$ & $3.8 \mathrm{E}-01$ & 2.6E-04 & $5.9 \mathrm{E}+04$ & $1.8 \mathrm{E}+02$ \\
\hline $\mathrm{Pu}-239+240$ & $1.8 \mathrm{E}+02$ & $<2$.E-3 & $<1$.E-6 & $1.8 \mathrm{E}+02$ & 5.5E-01 \\
\hline Pu-238 & $6.0 \mathrm{E}+00$ & $<1 . \mathrm{E}-3$ & $<$ 8.E-7 & $6.0 \mathrm{E}+00$ & $1.9 \mathrm{E}-02$ \\
\hline \multirow[t]{2}{*}{ Anions } & \multicolumn{3}{|c|}{ Liquid Fraction } & \multicolumn{2}{|c|}{ Leached Solids Fraction } \\
\hline & $\mu g / m L$ & [M] & $\mathbf{g}$ & $\mu \mathrm{g} / \mathrm{g}$ & g \\
\hline $\mathbf{F}$ & $8.6 \mathrm{E}+02$ & 4.5E-02 & $1.2 \mathrm{E}+00$ & $6.0 \mathrm{E}+03$ & $1.9 \mathrm{E}+00$ \\
\hline $\mathrm{C}_{2} \mathbf{O}_{4}$ & $2.0 \mathrm{E}+02$ & $2.2 \mathrm{E}-03$ & 2.9E-01 & $1.9 \mathrm{E}+03$ & 5.9E-01 \\
\hline $\mathrm{NO}_{2}$ & $5.8 \mathrm{E}+01$ & $1.3 \mathrm{E}-03$ & 8.4E-02 & $5.3 \mathrm{E}+02$ & $1.7 \mathrm{E}-01$ \\
\hline $\mathrm{NO}_{3}$ & $1.5 \mathrm{E}+03$ & $2.4 \mathrm{E}-02$ & $2.2 \mathrm{E}+00$ & $1.6 \mathrm{E}+04$ & $5.3 \mathrm{E}+00$ \\
\hline $\mathrm{SO}_{4}$ & $1.6 \mathrm{E}+02$ & $1.6 \mathrm{E}-03$ & 2.3E-01 & $1.3 \mathrm{E}+03$ & 4.2E-01 \\
\hline $\mathrm{PO}_{4}$ & $6.7 \mathrm{E}+03$ & 7.1E-02 & $9.7 \mathrm{E}+00$ & $3.3 \mathrm{E}+04$ & $1.1 \mathrm{E}+01$ \\
\hline OH & $3.3 \mathrm{E}+03$ & 1.9E-01 & $4.8 \mathrm{E}+00$ & & \\
\hline \multicolumn{6}{|c|}{$\begin{array}{l}\text { Slurry mass components were calculated from characterization data (Sections } 3 \text { and } 4 \text { ) and the } \\
\text { masses of materials that were added with simulant. Loss of mass from sampling was incorporated. } \\
\text { Liquid fraction mass components were calculated using analytical results from supernate sample } \\
\text { TI552-G6-I (ASO ID 08-01292) and the predicted mass of supernate in the system. } \\
\text { Solids fraction mass components were calculated from the difference between the slurry component } \\
\text { mass and liquid component mass fraction. }\end{array}$} \\
\hline
\end{tabular}


Table 5.27. Caustic Wash Solutions Radionuclide and Opportunistic Compositions

\begin{tabular}{|c|c|c|c|c|c|c|}
\hline & Wash 1 & Wash 2 & Wash 3 & Wash 4 & Wash 5 & $\begin{array}{c}\text { Composite } \\
\text { Wash }\end{array}$ \\
\hline $\begin{array}{l}\text { ASO Sample } \\
\text { ID }\end{array}$ & 08-01309 & 08-01310 & 08-01311 & 08-01312 & 08-01292 & 08-01293 \\
\hline $\begin{array}{l}\begin{array}{l}\text { Density } \\
\text { g/mL }>\end{array} \\
\end{array}$ & 1.15 & 1.09 & 1.07 & 1.05 & 1.03 & NA \\
\hline \multicolumn{7}{|l|}{ Analyte } \\
\hline free $\mathrm{OH}, \mathrm{M}$ & $2.21 \mathrm{M}$ & $1.29 \mathrm{M}$ & $0.60 \mathrm{M}$ & $0.37 \mathrm{M}$ & $0.19 \mathrm{M}$ & $0.92 \mathrm{M}$ \\
\hline Analyte & $\mu \mathrm{Ci} / \mathrm{mL}$ & $\mu \mathrm{Ci} / \mathrm{mL}$ & $\mu \mathrm{Ci} / \mathrm{mL}$ & $\mu \mathrm{Ci} / \mathrm{mL}$ & $\mu \mathrm{Ci} / \mathrm{mL}$ & $\mu \mathrm{Ci} / \mathrm{mL}$ \\
\hline${ }^{137} \mathrm{Cs}$ & & & & & $2.17 \mathrm{E}-1$ & $1.42 \mathrm{E}+0$ \\
\hline${ }^{60} \mathrm{Co}$ & & & & & $<2$. E-5 & $<2$.E-5 \\
\hline${ }^{241} \mathrm{Am}$ & & & & & $<4$.E-4 & $<1$.E-3 \\
\hline${ }^{90} \mathrm{Sr}$ & & & & & $2.62 \mathrm{E}-4$ & $1.11 \mathrm{E}-3$ \\
\hline${ }^{238} \mathrm{Pu}$ & & & & & $<8 . \mathrm{E}-7$ & $<1$.E-6 \\
\hline${ }^{239+240} \mathrm{Pu}$ & & & & & $<1$.E-6 & 6.07E-6 \\
\hline Gross alpha & & & & & $<6 . \mathrm{E}-4$ & $<7$. E-4 \\
\hline Gross beta & & & & & $2.10 \mathrm{E}-1$ & $1.27 \mathrm{E}+0$ \\
\hline${ }^{154} \mathrm{Eu}$ & & & & & $<4 . E-5$ & $<8 . E-5$ \\
\hline \multicolumn{7}{|c|}{ Opportunistic Analytes } \\
\hline Analyte & $\mu \mathrm{g} / \mathrm{mL}$ & $\mu \mathrm{g} / \mathrm{mL}$ & $\mu \mathrm{g} / \mathrm{mL}$ & $\mu \mathrm{g} / \mathrm{mL}$ & $\mu \mathrm{g} / \mathrm{mL}$ & $\mu \mathrm{g} / \mathrm{mL}$ \\
\hline $\mathrm{Ag}$ & $<2.6 \mathrm{E}-1$ & $<2.6 \mathrm{E}-1$ & $<2.6 \mathrm{E}-1$ & $<5.1 \mathrm{E}-2$ & $<5.1 \mathrm{E}-2$ & $<5.1 \mathrm{E}-2$ \\
\hline As & $<5.2 \mathrm{E}+0$ & $<5.3 \mathrm{E}+0$ & $<5.4 \mathrm{E}+0$ & $<1.1 \mathrm{E}+0$ & $<1.1 \mathrm{E}+0$ & $<1.0 \mathrm{E}+0$ \\
\hline $\mathrm{Ba}$ & {$[0.22]$} & {$[0.22]$} & {$[0.21]$} & 0.143 & {$[0.12]$} & 0.175 \\
\hline $\mathrm{Be}$ & {$[0.035]$} & {$[0.022]$} & {$[0.0074]$} & [0.0018] & [0.0018] & [0.0071] \\
\hline $\mathrm{Ca}$ & [1.4] & 12.0 & [0.85] & {$[0.24]$} & {$[0.60]$} & $<1.5 \mathrm{E}-1$ \\
\hline $\mathrm{Ce}$ & $<1.2 \mathrm{E}+0$ & $<1.2 \mathrm{E}+0$ & $<1.2 \mathrm{E}+0$ & $<2.5 \mathrm{E}-1$ & $<2.4 \mathrm{E}-1$ & $<2.4 \mathrm{E}-1$ \\
\hline Co & [1.20] & {$[0.53]$} & $<3.0 \mathrm{E}-1$ & $<5.9 \mathrm{E}-2$ & $<5.9 \mathrm{E}-2$ & $<5.8 \mathrm{E}-2$ \\
\hline $\mathrm{Cu}$ & {$[0.66]$} & {$[0.45]$} & {$[0.27]$} & $<3.4 \mathrm{E}-2$ & $<3.4 \mathrm{E}-2$ & {$[0.098]$} \\
\hline Dy & $<3.5 \mathrm{E}-1$ & $<3.6 \mathrm{E}-1$ & $<3.6 \mathrm{E}-1$ & $<7.1 \mathrm{E}-2$ & $<7.1 \mathrm{E}-2$ & $<7.0 \mathrm{E}-2$ \\
\hline $\mathrm{Eu}$ & $<1.3 \mathrm{E}-1$ & $<1.4 \mathrm{E}-1$ & $<1.4 \mathrm{E}-1$ & $<2.7 \mathrm{E}-2$ & $<2.7 \mathrm{E}-2$ & $<2.7 \mathrm{E}-2$ \\
\hline $\mathrm{La}$ & $<3.4 \mathrm{E}-1$ & $<3.4 \mathrm{E}-1$ & $<3.5 \mathrm{E}-1$ & $<6.9 \mathrm{E}-2$ & $<6.9 \mathrm{E}-2$ & $<6.8 \mathrm{E}-2$ \\
\hline $\mathrm{Li}$ & {$[0.77]$} & [0.99] & {$[0.70]$} & {$[0.25]$} & {$[0.21]$} & 0.347 \\
\hline $\mathrm{Mg}$ & $<2.8 \mathrm{E}-1$ & $<2.8 \mathrm{E}-1$ & $<2.9 \mathrm{E}-1$ & $<5.6 \mathrm{E}-2$ & $<5.6 \mathrm{E}-2$ & $<5.6 \mathrm{E}-2$ \\
\hline Mo & [1.2] & $<6.4 \mathrm{E}-1$ & $<6.5 \mathrm{E}-1$ & $<1.3 \mathrm{E}-1$ & {$[0.18]$} & {$[0.72]$} \\
\hline $\mathrm{Nd}$ & $<6.6 \mathrm{E}-1$ & $<6.6 \mathrm{E}-1$ & $<6.7 \mathrm{E}-1$ & $<1.3 \mathrm{E}-1$ & $<1.3 \mathrm{E}-1$ & {$[0.18]$} \\
\hline $\mathrm{Pb}$ & [6.5] & $<3.9 \mathrm{E}+0$ & $<4.0 \mathrm{E}+0$ & $<7.8 \mathrm{E}-1$ & $<7.8 \mathrm{E}-1$ & [2.0] \\
\hline $\mathrm{Pd}$ & [1.3] & $<7.7 \mathrm{E}-1$ & [1.5] & {$[0.38]$} & $<1.5 \mathrm{E}-1$ & {$[0.16]$} \\
\hline $\mathrm{Rh}$ & [2.2] & $<1.5 \mathrm{E}+0$ & $<1.5 \mathrm{E}+0$ & $<2.9 \mathrm{E}-1$ & {$[0.32]$} & {$[0.31]$} \\
\hline $\mathrm{Ru}$ & $<1.0 \mathrm{E}+0$ & $<1.0 \mathrm{E}+0$ & $<1.1 \mathrm{E}+0$ & $<2.1 \mathrm{E}-1$ & $<2.1 \mathrm{E}-1$ & $<2.1 \mathrm{E}-1$ \\
\hline
\end{tabular}


Table 5.27 (Contd)

\begin{tabular}{|c|c|c|c|c|c|c|}
\hline & Wash 1 & Wash 2 & Wash 3 & Wash 4 & Wash 5 & $\begin{array}{c}\text { Composite } \\
\text { Wash }\end{array}$ \\
\hline $\begin{array}{l}\text { ASO Sample } \\
\text { ID }\end{array}$ & 08-01309 & 08-01310 & 08-01311 & 08-01312 & 08-01292 & 08-01293 \\
\hline \multicolumn{7}{|c|}{ Opportunistic Analytes } \\
\hline Analyte & $\mu \mathrm{g} / \mathrm{mL}$ & $\mu \mathrm{g} / \mathrm{mL}$ & $\mu \mathrm{g} / \mathrm{mL}$ & $\mu \mathrm{g} / \mathrm{mL}$ & $\mu \mathrm{g} / \mathrm{mL}$ & $\mu \mathrm{g} / \mathrm{mL}$ \\
\hline $\mathrm{Sb}$ & {$[6.3]$} & $<2.5 \mathrm{E}+0$ & $<2.5 \mathrm{E}+0$ & $<4.9 \mathrm{E}-1$ & {$[0.92]$} & $<4.8 \mathrm{E}-1$ \\
\hline Se & [34.5] & [34] & {$[40]$} & {$[5.9]$} & {$[2.7]$} & $<1.7 \mathrm{E}+0$ \\
\hline Sn & [11.2] & [8.5] & {$[5.6]$} & $<6.6 \mathrm{E}-1$ & $<6.6 \mathrm{E}-1$ & {$[2.1]$} \\
\hline $\mathrm{Ta}$ & $<2.1 \mathrm{E}+0$ & $<2.1 \mathrm{E}+0$ & $<2.1 \mathrm{E}+0$ & $<4.2 \mathrm{E}-1$ & $<4.2 \mathrm{E}-1$ & $<4.1 \mathrm{E}-1$ \\
\hline $\mathrm{Te}$ & $<3.2 \mathrm{E}+0$ & $<3.2 \mathrm{E}+0$ & $<3.2 \mathrm{E}+0$ & $<6.4 \mathrm{E}-1$ & {$[0.90]$} & {$[0.75]$} \\
\hline Th & {$[1.50]$} & [1.9] & [1.4] & $<2.4 \mathrm{E}-1$ & $<2.4 \mathrm{E}-1$ & $<2.4 \mathrm{E}-1$ \\
\hline $\mathrm{Ti}$ & $<5.2 \mathrm{E}-2$ & {$[0.073]$} & $<5.4 \mathrm{E}-2$ & $<1.1 \mathrm{E}-2$ & $<1.1 \mathrm{E}-2$ & {$[0.017]$} \\
\hline $\mathrm{Tl}$ & $<4.6 \mathrm{E}+0$ & $<4.7 \mathrm{E}+0$ & $<4.7 \mathrm{E}+0$ & $<9.3 \mathrm{E}-1$ & $<9.3 \mathrm{E}-1$ & $<9.2 \mathrm{E}-1$ \\
\hline $\mathrm{V}$ & {$[0.40]$} & {$[0.30]$} & {$[0.55]$} & 0.185 & {$[0.058]$} & {$[0.091]$} \\
\hline $\mathrm{W}$ & [3.10] & $<2.3 \mathrm{E}+0$ & $<2.4 \mathrm{E}+0$ & $<4.7 \mathrm{E}-1$ & {$[0.54]$} & [1.5] \\
\hline $\mathrm{Y}$ & $<5.3 \mathrm{E}-2$ & $<5.4 \mathrm{E}-2$ & $<5.5 \mathrm{E}-2$ & $<1.1 \mathrm{E}-2$ & $<1.1 \mathrm{E}-2$ & $<1.1 \mathrm{E}-2$ \\
\hline
\end{tabular}

(a) Density values were obtained from the mass flow meter, which had not been calibrated to NQA-1 standards; they are reported for information only.

ASR 8113 Reference date: November 5, 2007.

Analyte uncertainties were typically within $\pm 15 \%$; results in brackets indicate that the analyte concentrations were greater than the method detection limit (MDL) and less than the estimated quantitation limit (EQL), and uncertainties were $>15 \%$.

Opportunistic analytes are reported for information only; QC requirements did not apply to these analytes.

The leached slurry consisted of 43 grams of insoluble aluminum, which was reduced to 23 to 24 grams of solid aluminum following the caustic leach, or a $45-w t \%$ leach. After dewatering the caustic-leached slurry and performing five volumetric washes afterwards, the total aluminum in the slurry was reduced from an initial (low solids) value of 50 grams to a pre oxidative leach value of 23 total slurry grams (54\%). No aluminum dissolved during oxidative leaching and washing as the total aluminum remained constant throughout the balance of the CUF testing. Over the course of the test, it was estimated that 4.6 grams of aluminum present in the slurry was lost from sampling, which was about $9 \mathrm{wt} \%$ of the original inventory present in the low-solids slurry. Figure 5.42 charts the mass change of the aluminum inventory normalized to the original slurry inventory to project the predicted inventory if no sampling occurred. Without sampling, the projected change in aluminum inventory after the fifth wash would be $45 \mathrm{wt} \%$.

Unlike aluminum, the phosphorus inventory did not change significantly during the caustic leach and dewatering step. After dewatering the slurry, approximately 37 grams of insoluble phosphorus was present with almost none in the liquid phase. As the sodium concentration decreased in the slurry supernate, the mass of isolable phosphorus decreases as the solubility of sodium phosphate increases in the supernate. After the fifth wash, the quantity of insoluble phosphorus in the slurry decreased to 19 grams, which provided an estimated leach/wash factor of $49 \mathrm{wt} \%$. It was estimated that the total mass of insoluble solids in the slurry decreased by 90 grams because the sodium phosphate dissolved. However, this term could be higher if the salt precipitated as a hydrated version of the salt. By this point of the test, $9 \mathrm{wt} \%$ of the original slurry was lost to sampling, decreasing the inventory by 5 grams. 
Figure 5.43 plots the mass change of phosphorus inventory normalized to the original slurry inventory to project the predicted inventory if no sampling occurred. Without sampling, the projected change in phosphorus inventory after the fifth wash was $39 \mathrm{wt} \%$.

The total chromium in the slurry decreased during caustic leaching and washing from 4.3 grams to 3.3 grams (23\%). This is likely due to the oxidation of some $\mathrm{Cr}^{3+}$ to $\mathrm{Cr}^{6+}$ by adventitious oxygen and dewatering it with the existing water-soluble chromium in the slurry (WTP-RPT-173, Lumetta 2008). Taking slurry sampling into account, comparing the caustic-leached and washed-slurry composition (Table 5.26) to that of the high-solids slurry inventory just before caustic leaching ( Table 5.10) revealed no appreciable decrease in any radionuclide aside from an $\sim 40 \%$ drop in cesium and a 9-wt\% loss from the slurry transfer. 

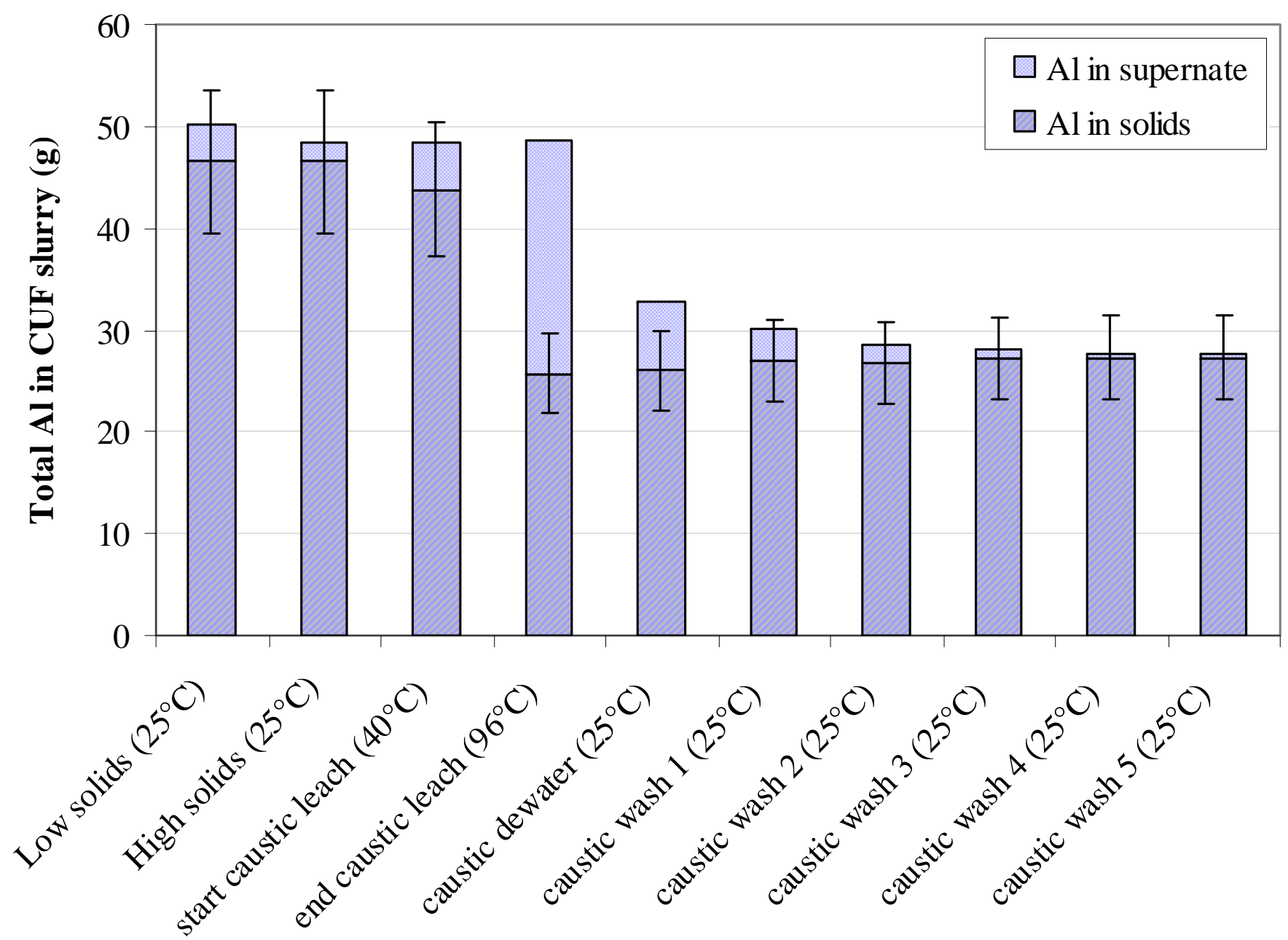

*Temperatures on X-axis represent the slurry temperature when sampled

Figure 5.42. Normalized Aluminum Inventory in Group 1/2 Slurry through Caustic Leach and Washing (Inventory in Figure Normalized to Eliminate Sample Loss Impacts) 

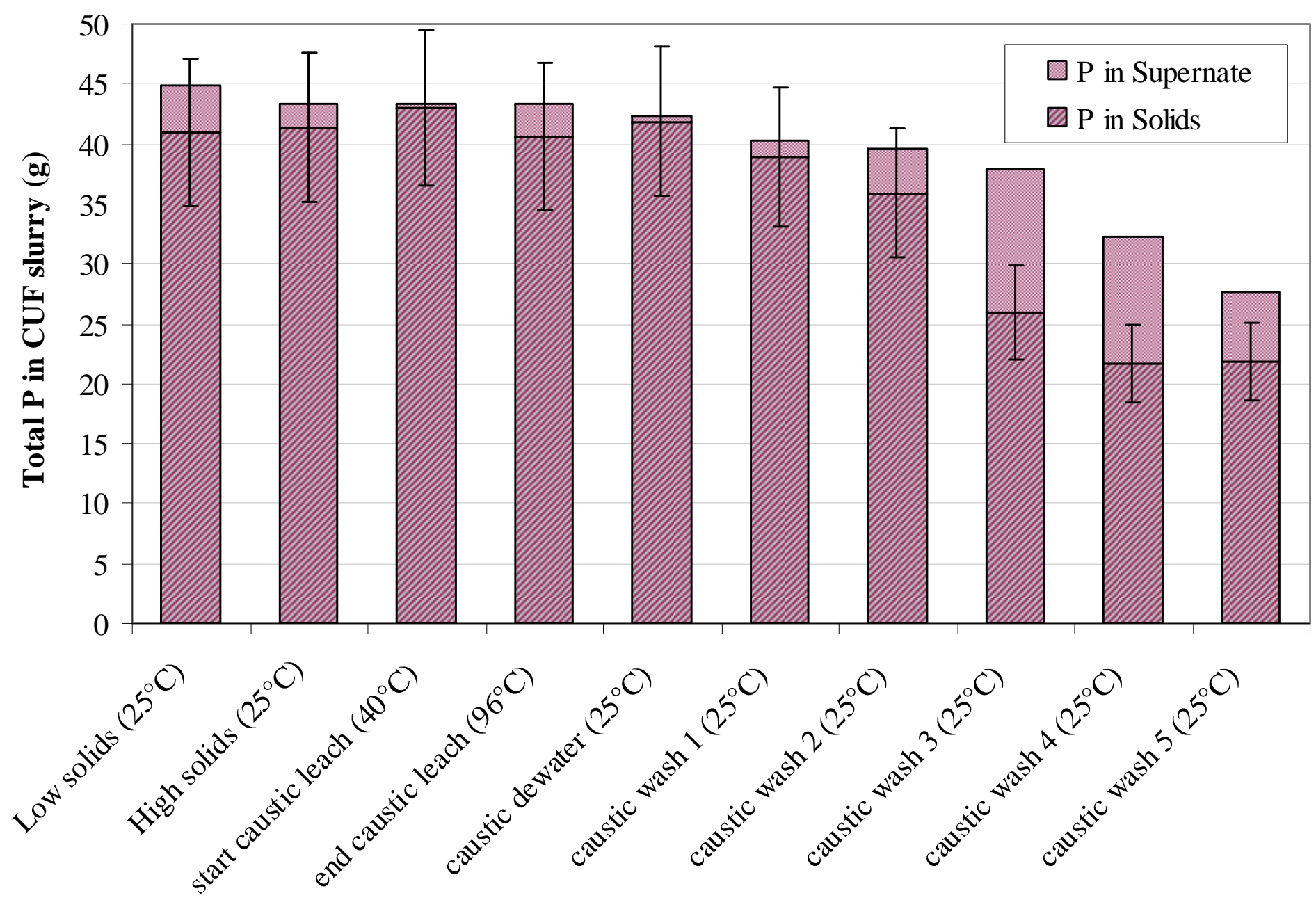

*Temperatures on $X$-axis represent the slurry sample temperature

Figure 5.43. Normalized Phosphorus Inventory in Group 1/2 Slurry through Caustic Leach and Washing (Inventory in Figure Normalized to Eliminate Sample Loss Impacts) 


\subsubsection{Characterization of the Washed Caustic-Leached Slurry}

After completing the fifth wash, the circulation slurry was sampled for physical and chemical analyses, as shown in Figure 5.44. Overall, 110 grams of the circulating slurry was removed containing an estimated 20 grams of UDS.

The physical properties of the washed slurry are detailed in Table 5.28. It should be noted that the solids in the slurry appeared flocculent and did not settle within 24 hours (as can be seen by the $96 \%$ settled solids value). The measured UDS of the slurry was again lower than the predicted UDS of the slurry $(0.32 \mathrm{~kg} \div 1.6 \mathrm{~kg} \cong 20 \mathrm{wt} \%)$. The analytical results for the composition of the washed caustic-leached slurry are provided in Table 5.29. Comparing the solid composition to that developed from mass balance calculations in Table 5.26 shows significant differences. Overall, the slurry analysis predicts the concentration to be higher for almost all the elements, indicating that more of the insoluble solids dissolved during washing. The exception to this was for phosphorus, which was almost six times lower than the mass balance calculation indicated. The leach-factor calculation for phosphorus was 0.94 . The calculated leach factor for phosphorus is almost two times greater than the leach factor calculated from the mass balance results in the previous section, which was only 0.49. Besides phosphorus, the leach factor for ${ }^{238} \mathrm{Pu}$ was calculated to be 0.28 . However, the leach factor is not significantly different from the analytical error for the analyte, which was $24 \%$ for the high solids composition.

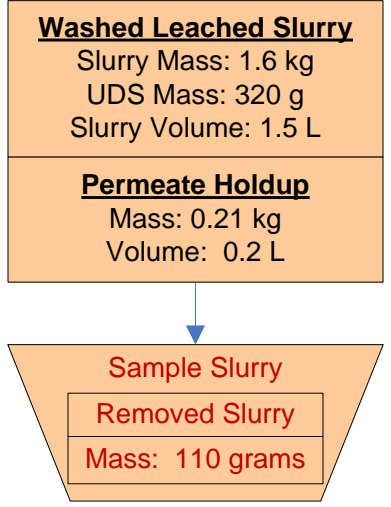

Figure 5.44. Sampling of the Washed Leached Slurry

Note: Mass and volume values in figure are rounded to the nearest significant digit of accuracy.

Table 5.28. Physical-Property Measurements of the Group 1/2 Caustic-Leached and Washed Slurry

\begin{tabular}{|c|c|}
\hline Slurry Density (g/mL) & 1.07 \\
\hline Supernate Density (g/mL) & 0.98 \\
\hline Settled Solids (Vol\%) & $96 \%$ \\
\hline Centrifuged UDS (Wt\%) & $32 \%$ \\
\hline Total Solids of the Slurry (Wt\%) & $14 \%$ \\
\hline Dissolved Solids of the Supernate (Wt\%) & $2.7 \%$ \\
\hline UDS of the Slurry (Wt\%) & $11 \%$ \\
\hline
\end{tabular}


Table 5.29. Group $1 / 2$ Washed Leach Slurry Composition and Caustic Leach Factor Calculations Based on ICP-OES/Radiochemical Characterization

\begin{tabular}{|c|c|c|c|c|c|}
\hline $\begin{array}{l}\text { Slurry Prep } \\
\text { Method }\end{array}$ & $\begin{array}{c}\text { ICP-OES } \\
\text { Analytes }\end{array}$ & $\begin{array}{c}\text { Dry } \\
\text { Slurry }^{(a)} \\
(\mu g / g)\end{array}$ & $\begin{array}{c}\text { Supernate }{ }^{(b)} \\
(\mu g / m L)\end{array}$ & $\begin{array}{c}\text { Dry Solids }{ }^{(\mathrm{c})} \\
(\mu \mathrm{g} / \mathrm{g})\end{array}$ & $\begin{array}{c}\text { Solids } \\
\text { Leach } \\
\text { Factor }^{(d)}\end{array}$ \\
\hline \multirow{35}{*}{$\begin{array}{l}\text { HF Assisted } \\
\text { Acid Digestion, } \\
\text { and KOH } \\
\text { Fusion, } \\
\text { Concentration } \\
\text { Factor of } \\
2.01 \text { based on } \mathrm{U} \\
\text { and Fe }\end{array}$} & Al & 80,250 & 115 & 96,136 & 0.52 \\
\hline & $\mathbf{B i}$ & 80,200 & $<7.3 \mathrm{E}-1$ & 96,970 & 0.09 \\
\hline & Cd & 125 & $<8.3 \mathrm{E}-2$ & 150 & -0.27 \\
\hline & $\mathrm{Cr}$ & 13,300 & 7.65 & 16,022 & 0.02 \\
\hline & $\mathbf{F e}$ & 105,350 & {$[0.16]$} & 127,386 & NA \\
\hline & $\mathbf{K}$ & {$[140]$} & [5.4] & [127] & 1.31 \\
\hline & Mn & 1,625 & {$[0.012]$} & 1,965 & -0.03 \\
\hline & $\mathrm{Na}$ & 165,000 & 9,540 & 124,813 & 0.70 \\
\hline & $\mathbf{N i}$ & 5,690 & $<5.9 \mathrm{E}-2$ & 6,880 & 0.12 \\
\hline & $\mathbf{P}$ & 22,950 & 2,130 & 11,072 & 0.94 \\
\hline & $\mathbf{S}$ & {$[1,650]$} & 63.1 & {$[1,501]$} & 1.16 \\
\hline & Si & 84,700 & 16.5 & 102,288 & -0.02 \\
\hline & Sr & 6,030 & [0.011] & 7,291 & -0.01 \\
\hline & $\mathbf{U}$ & 26,850 & $<7.8 \mathrm{E}-1$ & 32,460 & NA \\
\hline & Zn & 507 & {$[0.50]$} & 609 & 0.44 \\
\hline & $\mathbf{Z r}$ & 580 & $<2.7 \mathrm{E}-2$ & 701 & -0.72 \\
\hline & $A g$ & 20.1 & $<5.1 \mathrm{E}-2$ & 23.9 & -0.07 \\
\hline & $B a$ & 357 & {$[0.12]$} & 431 & 0.09 \\
\hline & $B e$ & 0.839 & {$[0.0018]$} & 1.000 & 0.58 \\
\hline & $\mathrm{Ca}$ & 12,800 & {$[0.60]$} & 15,473 & 0.09 \\
\hline & $\mathrm{Ce}$ & 333 & $<2.4 \mathrm{E}-1$ & 401 & -0.07 \\
\hline & Co & 55.9 & $<5.9 \mathrm{E}-2$ & 67.1 & 0.21 \\
\hline & $\mathrm{Cu}$ & 113 & $<3.4 \mathrm{E}-2$ & 136 & 0.40 \\
\hline & $L a$ & 56.0 & $<6.9 \mathrm{E}-2$ & 67.2 & 0.03 \\
\hline & $L i$ & 91.4 & {$[0.21]$} & 108.8 & 0.22 \\
\hline & $M g$ & 2,250 & $<5.6 \mathrm{E}-2$ & 2,720 & 0.06 \\
\hline & Mo & [45] & {$[0.18]$} & {$[52]$} & {$[0.34]$} \\
\hline & Nd & 73.5 & $<1.3 \mathrm{E}-1$ & 87.8 & 0.01 \\
\hline & $P b$ & 1,970 & $<7.8 \mathrm{E}-1$ & 2,376 & 0.13 \\
\hline & $R u$ & [25] & {$[0.32]$} & {$[28]$} & {$[0.40]$} \\
\hline & $T h$ & [45] & {$[0.90]$} & [47] & [98.97] \\
\hline & $T i$ & 249 & $<2.4 \mathrm{E}-1$ & 299 & 0.01 \\
\hline & $T I$ & $<9.4 \mathrm{E}+1$ & $<1.1 \mathrm{E}-2$ & $<1.1 \mathrm{E}+2$ & NA \\
\hline & $V$ & 39.3 & $<9.3 \mathrm{E}-1$ & 40.2 & -0.21 \\
\hline & $Y$ & 10.9 & $<1.1 \mathrm{E}-2$ & 13.1 & -0.01 \\
\hline
\end{tabular}


Table 5.29 (Contd)

\begin{tabular}{|c|c|c|c|c|c|}
\hline $\begin{array}{c}\text { Slurry Prep } \\
\text { Method }\end{array}$ & Radionuclides & $\begin{array}{c}\text { Dry } \\
\text { Slurry } \\
(\mu \mathrm{C}) / \mathrm{g})\end{array}$ & $\begin{array}{l}\text { Supernate }^{(b)} \\
(\mu \mathrm{Ci} / \mathrm{mL})\end{array}$ & $\begin{array}{c}\text { Dry Solids }{ }^{(\mathrm{c})} \\
(\mu \mathrm{Ci} / \mathrm{g})\end{array}$ & $\begin{array}{c}\text { Solids } \\
\text { Leach }^{(\mathrm{d})} \\
\text { Factor }^{(\mathrm{d})}\end{array}$ \\
\hline \multirow{10}{*}{$\begin{array}{l}\text { KOH Fusion, } \\
\text { Concentration } \\
\text { Factor of } \\
2.01 \text { based on } U \\
\text { and Fe }\end{array}$} & Co-60 & $1.19 \mathrm{E}-1$ & $<2 . E-5$ & $1.4 \mathrm{E}-1$ & -5.16 \\
\hline & Cs-137 & $1.30 \mathrm{E}+2$ & $2.17 \mathrm{E}-1$ & $1.6 \mathrm{E}+2$ & 0.28 \\
\hline & Eu-154 & $9.07 \mathrm{E}-2$ & $<4 . \mathrm{E}-5$ & $1.1 \mathrm{E}-1$ & -2.19 \\
\hline & Eu-155 & $<6 . \mathrm{E}-2$ & $<2$.E-4 & $<7 . \mathrm{E}-2$ & NA \\
\hline & Am-241 & $5.40 \mathrm{E}-1$ & $<4 . \mathrm{E}-4$ & $6.5 \mathrm{E}-1$ & -0.04 \\
\hline & Total alpha & $1.38 \mathrm{E}+0$ & $<6 . \mathrm{E}-4$ & $1.7 \mathrm{E}+0$ & -0.23 \\
\hline & Total beta & $7.23 \mathrm{E}+2$ & $2.10 \mathrm{E}-1$ & $8.7 \mathrm{E}+2$ & -0.31 \\
\hline & Sr-90 & $2.89 \mathrm{E}+2$ & $2.62 \mathrm{E}-4$ & $3.5 \mathrm{E}+2$ & -0.16 \\
\hline & Pu-239/240 & $6.96 \mathrm{E}-1$ & $<1$.E-6 & $8.4 \mathrm{E}-1$ & -0.16 \\
\hline & Pu-238 & $1.17 \mathrm{E}-2$ & $\begin{array}{l}<8 . \mathrm{E}-7 \\
\end{array}$ & $1.4 \mathrm{E}-2$ & 0.29 \\
\hline \multicolumn{6}{|c|}{$\begin{array}{l}\text { (a) Test sample TI572-G2-I, ASO ID 08-01292 } \\
\text { (b) Test sample TI572-G2-12, ASO ID 08-01319 } \\
\text { (c) Calculated using results from TI572-G2-I and TI572-G2-12 } \\
\text { (d) Calculated using results listed in } \\
\text { (e) Table } 5.11 \\
\text { Note: Analytes in italics were measured opportunistically. Values in brackets [ ] are } \geq \\
\text { MDL but < EQL, with errors likely to exceed } 15 \% \text {. }\end{array}$} \\
\hline
\end{tabular}

Figure 5.45 shows the pre-sonication PSD for the caustic-leached, washed slurry as a function of pump speed. The distribution was characterized at all pump speeds by a strong primary peak centered at $\sim 1 \mu \mathrm{m}$ and spanning 0.3 to $3 \mu \mathrm{m}$. In all cases, small population peaks were observed over 5 to $200 \mu \mathrm{m}$. These secondary peaks may correspond to loose particle flocs.

Figure 5.46 shows the effect of sonication on the size distribution of the caustic-leached, washed slurry. A significant drop in the relative contribution of 0.6- to 2- $\mu$ m particles was observed after applying sonic energy. This drop was accompanied by a dramatic increase in the relative volume contribution of 0.1- to 0.6- $\mu \mathrm{m}$ particles and 2- to 10- $\mu \mathrm{m}$ particles. Although the original 1- $\mu \mathrm{m}$ particle population peak appeared to be preserved in a small peak over the range 1 to $2 \mu \mathrm{m}$, a new dominant population formed at $\sim 0.3 \mu \mathrm{m}$. The increased submicron fraction was likely formed by sonic disruption of particles. The origin for the increased 2 to $10 \mu \mathrm{m}$ fractions was likely sonic disruption of the 5- to 200- $\mu \mathrm{m}$ floc populations. The increase in the population of 2 to $10 \mu \mathrm{m}$ particles continued after sonication was removed and may indicate the partial recovery of some flocs. 


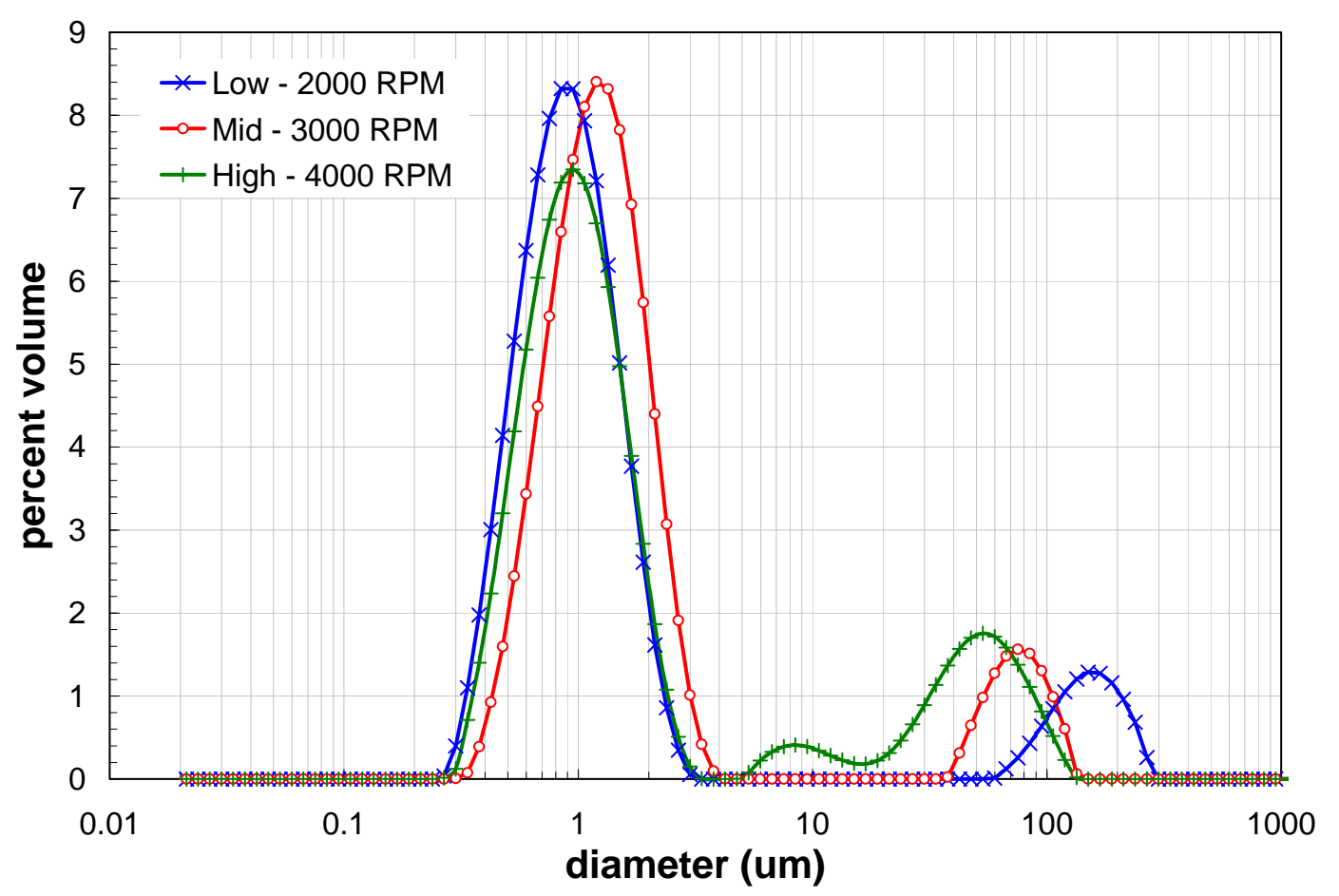

Figure 5.45. Caustic-Leached, Washed Slurry PSD as a Function of Pump Speed

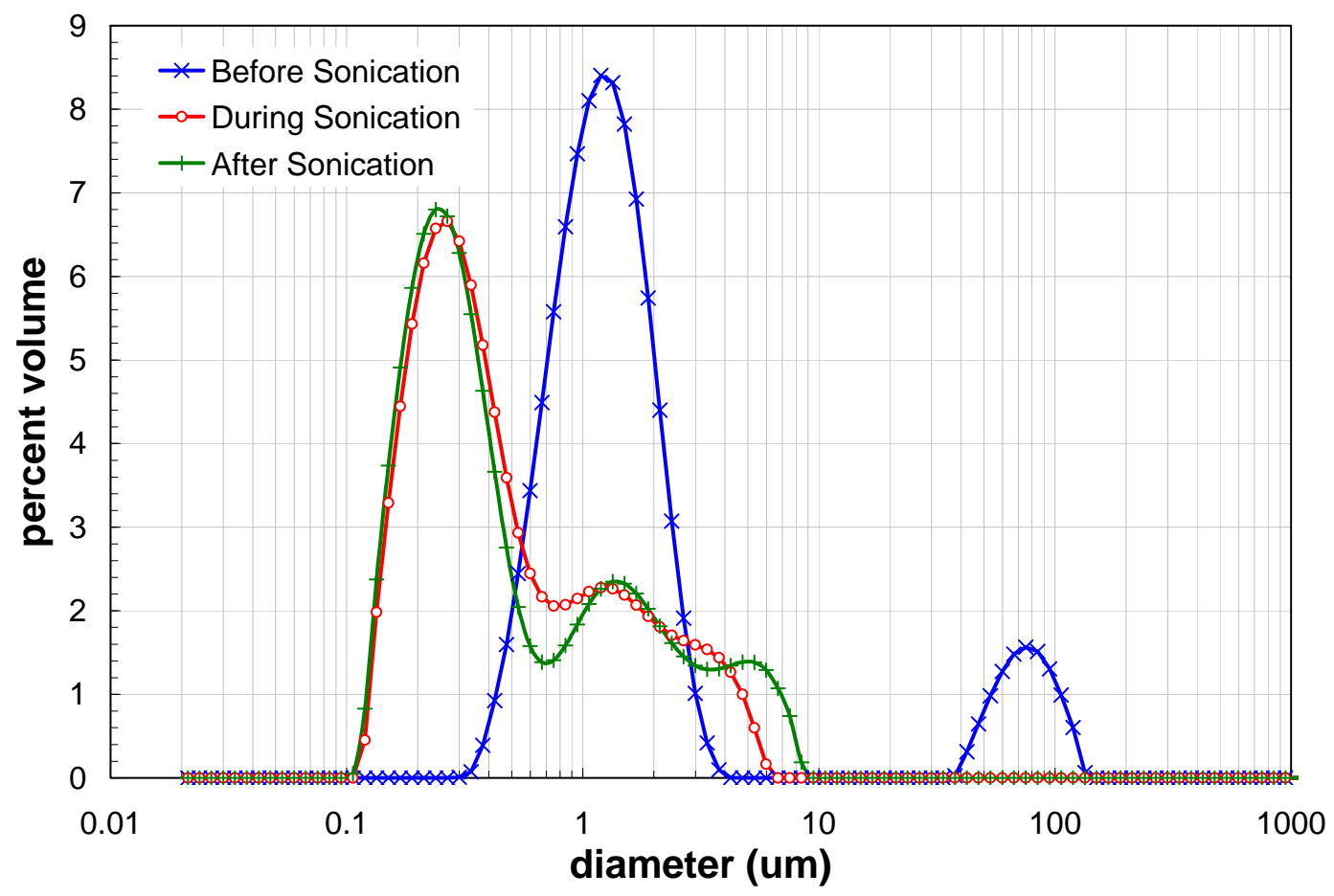

Figure 5.46. Caustic-Leached, Washed Slurry PSD as a Function of Sonication at 3000 RPM 
Figure 5.47 shows the results of flow curve testing for the caustic-leached, dewatered, and washed slurry, which shows non-Newtonian behavior at all temperatures studied. The three flow curves showed finite yield stresses that fall around 4 to $6 \mathrm{~Pa}$. The stress response over 0 to $1000 \mathrm{~s}^{-1}$ is mostly linear; however, the $25^{\circ} \mathrm{C}$ may have a slight downward curvature. The flow curves appear to be relatively free of artifacts caused by poor rotational sampling; strong curvature in the low-shear region is limited to shear rates below $\sim 30 \mathrm{~s}^{-1}$.

Flow curve hysteresis is present in the $25^{\circ}$ and $40^{\circ} \mathrm{C}$ measurement data but is absent in the $60^{\circ} \mathrm{C}$ measurement data. This type of hysteresis is consistent with long-term shear breakup of particle agglomerates within the sample. The absence of shear hysteresis at $60^{\circ} \mathrm{C}$, where evaporation of the suspending phase is usually significant, suggests that evaporation does not effect significant changes in the bulk rheology of this sample.

Flow curve yield stress and slope both decrease monotonically with increasing temperature. Given the noise and hysteresis in the low-shear data, it is difficult to determine if the change in yield stress is significant from qualitative examination of the flow curve data alone. Based on the fact that the data appear to overlap below $100 \mathrm{~s}^{-1}$, the change is likely not significant (although quantitative evaluation may indicate otherwise). There appears to be a statistically significant drop in slurry consistency (i.e., flow curve slope) between $25^{\circ}$ and $40^{\circ} \mathrm{C}$. The decrease in slope continues from 40 and $60^{\circ} \mathrm{C}$ but is much less than observed over the first temperature jump.

Table 5.30 summarizes the best-fit rheological parameters for flow curve data for the leached and washed slurry. The fitting parameters confirm a number of the observations made above. In particular, they show that:

- The Bingham-Plastic and Herschel-Bulkley yield stresses range from 5.0 to $7.9 \mathrm{~Pa}$ and 4.6 to $6.1 \mathrm{~Pa}$ (depending on temperature), respectively. Because the maximum difference between the yield stresses at different temperatures is greater than $0.5 \mathrm{~Pa}$, the variance is most likely significant. On the other hand, the final three regressed values of the Herschel-Bulkley yield stress (i.e., those at 25 [2 of 2], 40, and $60^{\circ} \mathrm{C}$ ) all agree within the experimental limit of accuracy. Given the large degree of flow curve hysteresis, basing the significance solely off of the instrument limit of \pm 0.5 Pa may not be appropriate in this case.

- In terms of temperature dependence, the yield stress shows a monotonic decrease in magnitude as the temperature is increased from $25^{\circ}$ to $60^{\circ} \mathrm{C}$.

- The Bingham-Plastic consistency decreases from $11 \mathrm{mPa} \cdot \mathrm{s}$ at $25^{\circ} \mathrm{C}$ to $5.4 \mathrm{mPa} \cdot \mathrm{s}$ at $60^{\circ} \mathrm{C}$. This decrease is consistent with the temperature-dependence observations made in the preceding paragraph and is likely a result of the suspending phase viscosity decrease.

- The Herschel-Bulkley flow indices are all near 0.7 to 0.9 . This indicates some degree of non-linearity in the flow curve fit. However, based on the fit shown in Table 5.30, the Herschel-Bulkley fit favors the down-ramp and does not appear to be an appropriate average of both up- and down-ramp data. The cause of this fitting deficiency may be the strong downward curvature in the low-shear region (i.e., below $30 \mathrm{~s}^{-1}$ ), resulting from poor rotational sampling. The overall result is that the HerschelBulkley fits show more curvature than appears appropriate, such that the 0.7 to 0.9 flow indexes are overstated and would be closer to unity if the poor rotational-sampling-data artifacts were eliminated.

Apparent viscosities at $33 \mathrm{~s}^{-1}, 100 \mathrm{~s}^{-1}, 500 \mathrm{~s}^{-1}$, and $1000 \mathrm{~s}^{-1}$ were calculated using the Bingham-Plastic and Herschel-Bulkley fitting parameters in Table 5.30, as previously described. The results (Table 5.31) show 
that apparent viscosities typically range from 150 to $300 \mathrm{mPa} \cdot \mathrm{s}_{\text {at }} 33 \mathrm{~s}^{-1}, 54$ to $97 \mathrm{mPa} \cdot \mathrm{s}$ at $100 \mathrm{~s}^{-1}, 15$ to $28 \mathrm{mPa} \cdot \mathrm{s}$ at $500 \mathrm{~s}^{-1}$, and 10 to $19 \mathrm{mPa} \cdot \mathrm{s}$ at $1000 \mathrm{~s}^{-1}$. Both measured apparent viscosities and those calculated from fitting parameters decrease with increasing temperature and shear rate.

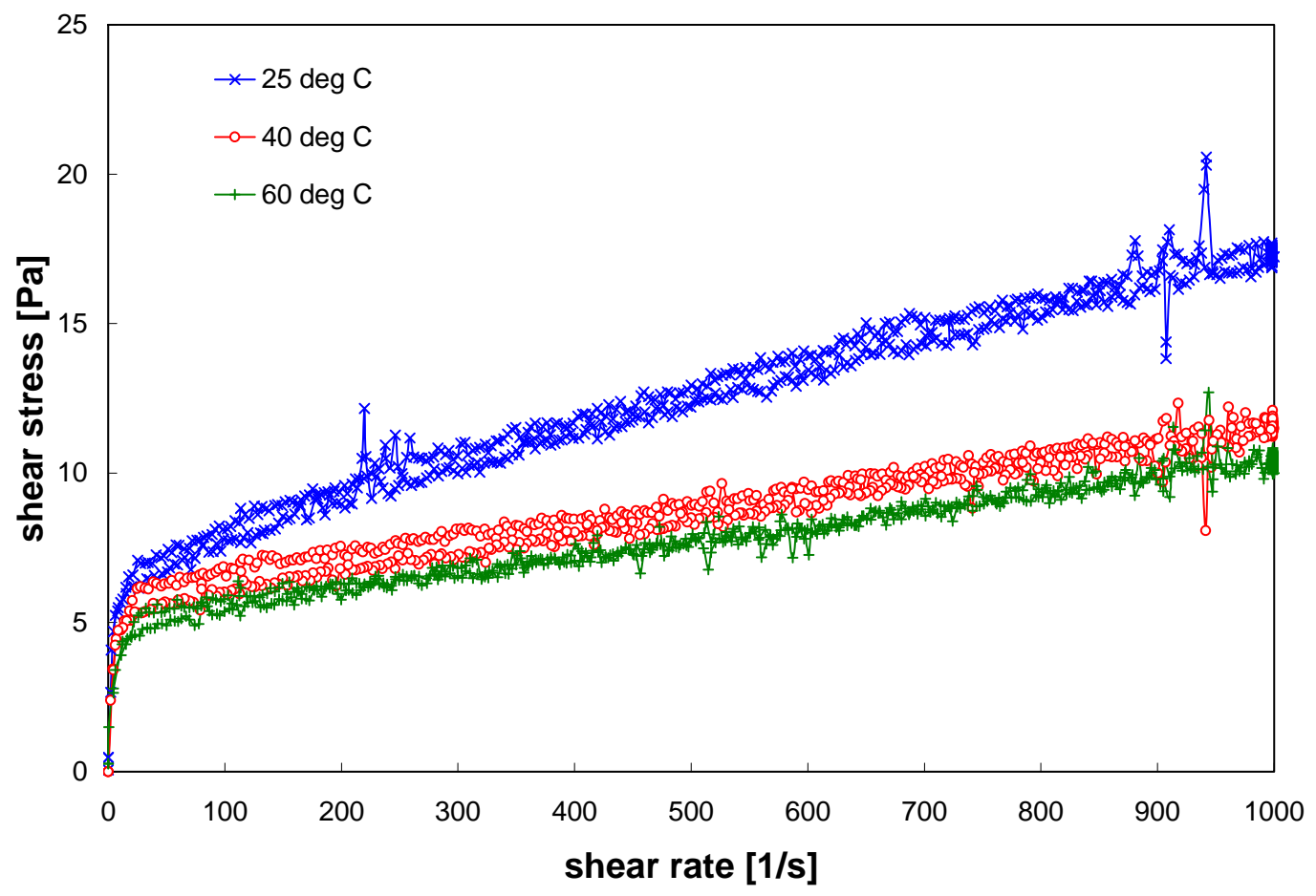

Figure 5.47. Flow Curve for the Group 1/2 CUF Caustic-Leached, Dewatered, and Washed Slurry at 25, 40 , and $60^{\circ} \mathrm{C}$

Table 5.30. Results of Fitting Analysis for Group 1/2 CUF Caustic-Leached, Dewatered, and Washed Slurry

\begin{tabular}{||c|c|c|c|c|c||}
\hline \hline \multirow{3}{*}{ Model } & $\begin{array}{c}\text { Temperature } \\
{\left[{ }^{\circ} \mathbf{C}\right]}\end{array}$ & $\begin{array}{c}\text { Yield } \\
\text { Stress [Pa] }\end{array}$ & $\begin{array}{c}\text { Consistency } \\
{\left[\mathbf{P a} \cdot \mathbf{s}^{\mathbf{n}}\right]}\end{array}$ & $\begin{array}{c}\text { Flow } \\
\text { Index }\end{array}$ & $\mathbf{R}$ \\
\hline $\begin{array}{c}\text { Bingham-Plastic } \\
\left(0-1000 \mathrm{~s}^{-1}\right)\end{array}$ & $25(1$ of 2$)$ & 7.9 & 0.011 & $\mathrm{n} / \mathrm{a}$ & 0.996 \\
\cline { 2 - 6 } & $25(2$ of 2$)$ & 7.7 & 0.0097 & $\mathrm{n} / \mathrm{a}$ & 0.987 \\
\cline { 2 - 6 } & 40 & 5.9 & 0.0057 & $\mathrm{n} / \mathrm{a}$ & 0.980 \\
\cline { 2 - 6 } & 60 & 5.0 & 0.0054 & $\mathrm{n} / \mathrm{a}$ & 0.985 \\
\hline \multirow{3}{*}{$\begin{array}{c}\text { Herschel-Bulkley } \\
\left(0-1000 \text { s }^{-1}\right)\end{array}$} & $25(1$ of 2$)$ & 6.1 & 0.066 & 0.77 & 0.992 \\
\cline { 2 - 6 } & $25(2$ of 2$)$ & 5.2 & 0.11 & 0.68 & 0.992 \\
\cline { 2 - 7 } & 40 & 5.0 & 0.031 & 0.77 & 0.980 \\
\cline { 2 - 6 } & 60 & 4.6 & 0.014 & 0.87 & 0.987 \\
\hline
\end{tabular}


Table 5.31. Apparent Viscosity of Group 1/2 CUF Caustic-Leached, Dewatered, and Washed Slurry

\begin{tabular}{|c|c|c|c|c|c|}
\hline \multirow[t]{2}{*}{ Source } & \multirow{2}{*}{$\begin{array}{c}\text { Temperature } \\
{\left[{ }^{\circ} \mathrm{C}\right]}\end{array}$} & \multicolumn{4}{|c|}{ Apparent Viscosity [mPa·s] } \\
\hline & & @ $33 \mathrm{~s}^{-1}$ & @ $100 \mathrm{~s}^{-1}$ & @ $500 \mathrm{~s}^{-1}$ & @ $1000 \mathrm{~s}^{-1}$ \\
\hline \multirow[t]{4}{*}{ Measured } & $25(1$ of 2$)$ & 300 & 97 & 26 & 19 \\
\hline & 25 (2 of 2$)$ & 200 & 79 & 25 & 17 \\
\hline & 40 & 170 & 64 & 17 & 12 \\
\hline & 60 & 160 & 56 & 16 & 10 \\
\hline \multirow[t]{4}{*}{ Bingham-Plastic } & 25 (1 of 2$)$ & 250 & 90 & 27 & 19 \\
\hline & 25 (2 of 2$)$ & 240 & 87 & 25 & 17 \\
\hline & 40 & 180 & 64 & 17 & 12 \\
\hline & 60 & 160 & 56 & 15 & 10 \\
\hline \multirow{4}{*}{$\begin{array}{l}\text { Herschel- } \\
\text { Bulkley }\end{array}$} & 25 (1 of 2$)$ & 210 & 83 & 28 & 19 \\
\hline & 25 (2 of 2$)$ & 190 & 77 & 25 & 17 \\
\hline & 40 & 170 & 61 & 18 & 12 \\
\hline & 60 & 150 & 54 & 16 & 10 \\
\hline
\end{tabular}

Table 5.32 and Figure 5.48 show the influence of caustic leaching and washing on the Group 1/2 waste rheology. The post-caustic-leach rheology corresponds to the dewatered (but not washed) slurry. Before leaching, the 16-wt\% UDS initial slurry is non-Newtonian with a yield of 3.0 $\mathrm{Pa}$ and a consistency of $12 \mathrm{mPa} \cdot \mathrm{s}$. After caustic leaching and dewatering to 17.8-wt\% UDS, the slurry is highly non-Newtonian (relative to the initial slurry) and has a yield stress of $37 \mathrm{~Pa}$ and a consistency of $29 \mathrm{mPa} \cdot \mathrm{s}$. Thus, for Group 1/2 wastes, caustic leaching is observed to dramatically increase slurry rheology. Specifically, the yield stress is increased by nearly a factor of 10 while consistency more than doubles. The mechanism by which this increase occurs is likely the metathesis of iron(III) phosphate, resulting in the formation of a sodium phosphate $\left(\mathrm{Na}_{3} \mathrm{PO}_{4} \cdot 12 \mathrm{H}_{2} \mathrm{O}\right)$ gel. Increased dissolved solids and $\mathrm{Na}_{3} \mathrm{PO}_{4}$ gelation both serve to increase the viscosity of the slurry suspending phase.

Both fitting results and flow curve data indicate that, although washing does not eliminate non-Newtonian behavior, it does appear to reduce the slurry yield stress and consistency. The caustic-leached and dewatered slurry has a yield stress and consistency of $37 \mathrm{~Pa}$ and $29 \mathrm{mPa} \cdot \mathrm{s}$, respectively. In comparison, the caustic-leached, dewatered, and washed slurry has a yield stress and consistency of 7.7 Pa and 9.7 $\mathrm{mPa} \cdot \mathrm{s}$, respectively. This constitutes a decrease of yield stress by a factor of 4 and consistency by a factor of 3. A decrease in slurry rheology as a result of washing is expected, given that washing reduces the concentration of dissolved species in the suspending phase (sodium phosphate in particular). However, not all of the decrease in rheology can be attributed to the washing process alone. The post-wash samples have a significantly lower UDS relative to the pre-wash sample. Reduced solids concentration will also effect a reduction in both yield stress and consistency. Without the benefit of additional rheology tests after each wash removal, it is impossible to quantify the individual contributions of washing and solids dilution to the overall reduction in rheology during the washing process. 
Table 5.32. Effect of Caustic Leaching/Washing on Group 1/2 CUF Slurry Rheology

\begin{tabular}{||c|c|c|c|c||}
\hline Description & Solids Concentration & Rheology & $\begin{array}{c}\text { Yield Stress } \\
\text { [Pa] }\end{array}$ & $\begin{array}{c}\text { Consistency } \\
\text { [mPa·s] }\end{array}$ \\
\hline $\begin{array}{c}\text { Initial Slurry } \\
\text { (TI572-G2-R2) }\end{array}$ & $16.0-\mathrm{wt} \%$ & $\begin{array}{c}\text { Non- } \\
\text { Newtonian }\end{array}$ & 3.0 & 12 \\
\hline $\begin{array}{c}\text { Caustic-Leached } \\
\text { and Dewatered } \\
\text { (TI572-G2-R3) }\end{array}$ & $17.8-\mathrm{wt} \%$ & $\begin{array}{c}\text { Non- } \\
\text { Newtonian }\end{array}$ & 37 & 29 \\
\hline $\begin{array}{c}\text { Caustic-Leached } \\
\text { and Washed } \\
\text { (TI572-G2-R4) }\end{array}$ & $12.0-\mathrm{wt} \%$ & $\begin{array}{c}\text { non- } \\
\text { Newtonian }\end{array}$ & 7.7 & 9.7 \\
\hline
\end{tabular}


A comparison of Group 1/2 CUF slurries showing the effect of caustic leaching on rheology at $25^{\circ} \mathrm{C}$.

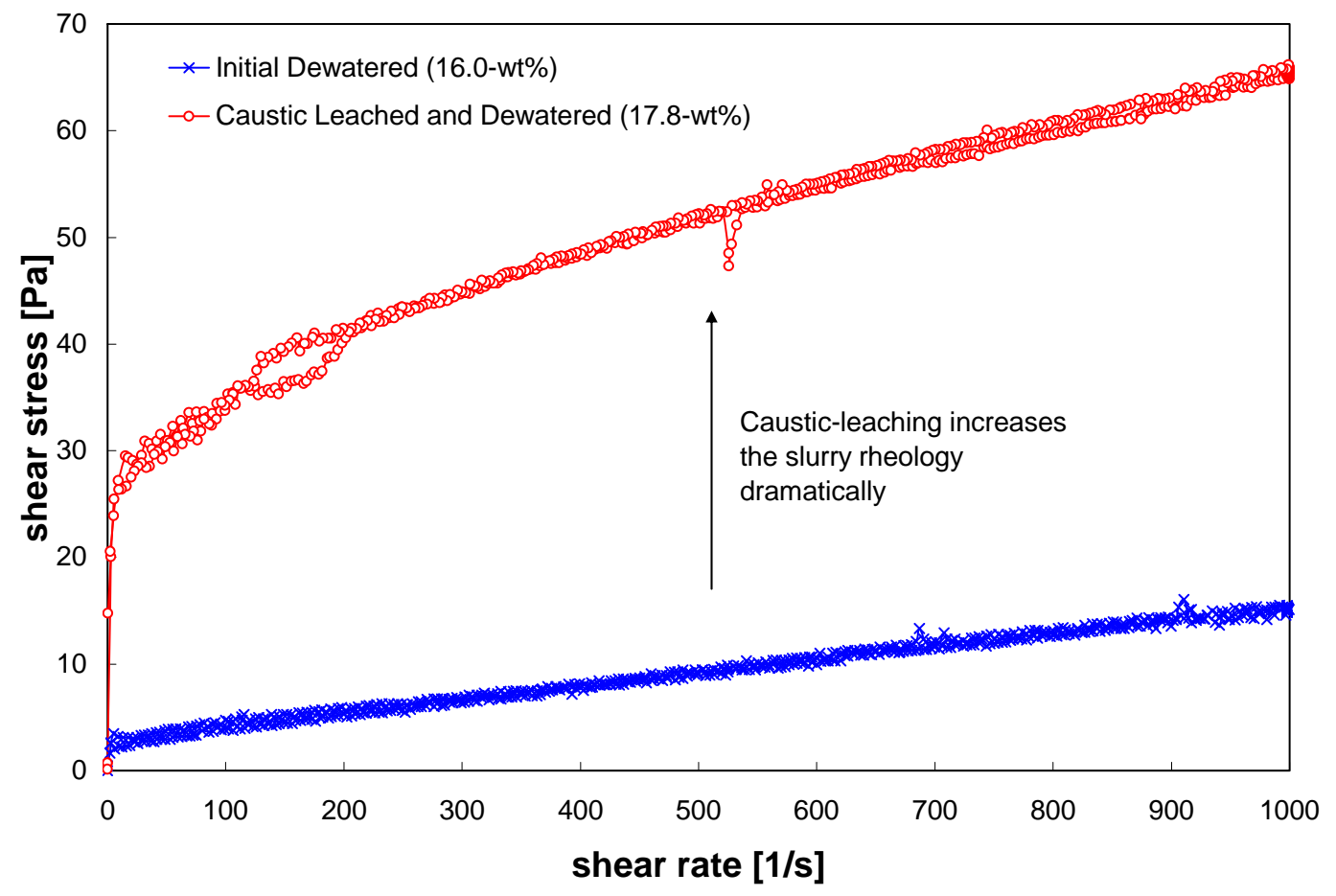

A comparison of Group 1/2 CUF slurries showing the effect of solids washing on rheology at $25^{\circ} \mathrm{C}$.

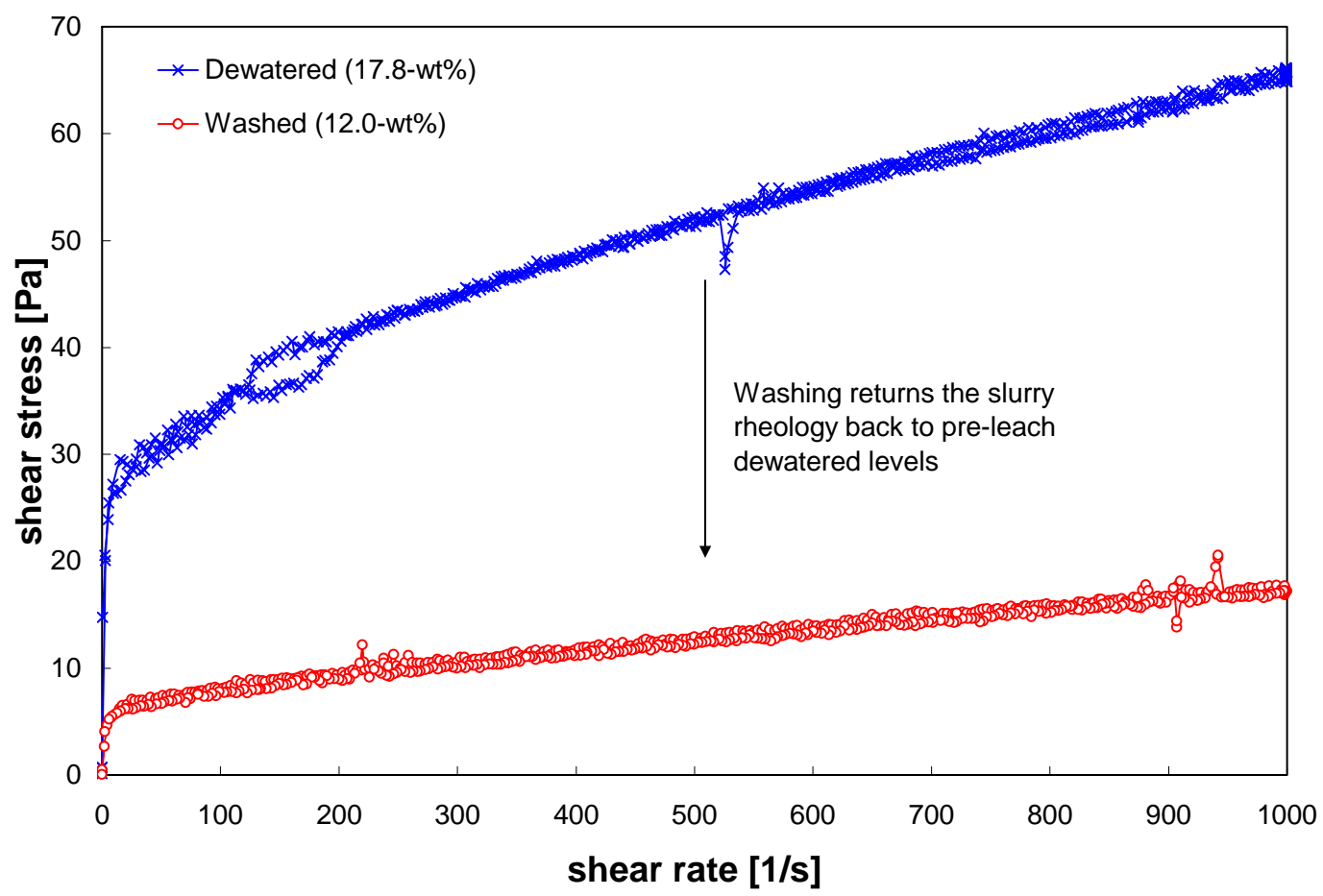

Figure 5.48. A Comparison of Group $1 / 2$ CUF Slurries Showing the Effect of Caustic Leaching/Washing on Rheology at $25^{\circ} \mathrm{C}$ 


\subsubsection{Dewatering of Caustic Washes}

The caustic-leached slurry was washed five successive times with $\mathrm{NaOH}$ solutions (1.2 L each) with decreasing sodium concentration to reduce the sodium concentration of the slurry to $<0.25 \mathrm{M}$. The filter flux increased steadily during washing and reached a maximum average flux near $0.070 \mathrm{GPM} / \mathrm{ft}^{2}$. The results are given in Table 5.33 and Figure 5.49.

The filter-flux data from the second, fourth, and fifth wash demonstrated a significant decrease in the filter flux within ten minutes of the dewatering. The observed decreases appeared similar to that predicted by the gel concentration model. However, without physical property measurements to confirm the UDS and centrifuged solids of the slurry at each step, this is conjecture. This decrease was not observed during dewatering of the third wash. However, the slurry was initially dewatering at a lower TMP. It is not clear how this may have impacted the filter results.

Table 5.33. Average Flux of Caustic Washes

\begin{tabular}{|c|c|c|c|c|}
\hline & $\begin{array}{c}\text { Wash } \\
\text { Volume (L) }\end{array}$ & $\begin{array}{c}\text { [Na] of } \\
\text { Slurry } \\
\text { waOH] of }\end{array}$ & $\begin{array}{c}\text { Supernate } \\
\text { (M) }\end{array}$ & $\begin{array}{c}\text { Average Filter } \\
\text { Flux (GPM/ft }{ }^{2}\end{array}$ \\
\hline Wash 1 & 1.2 & 0.56 & 2.21 & 0.026 \\
\hline Wash 2 & 1.2 & 0.20 & 1.29 & 0.051 \\
\hline Wash 3 & 1.2 & 0.06 & 0.60 & 0.049 \\
\hline Wash 4 & 1.2 & 0.02 & 0.37 & 0.067 \\
\hline Wash 5 & 1.2 & 0.01 & 0.19 & 0.069 \\
\hline
\end{tabular}




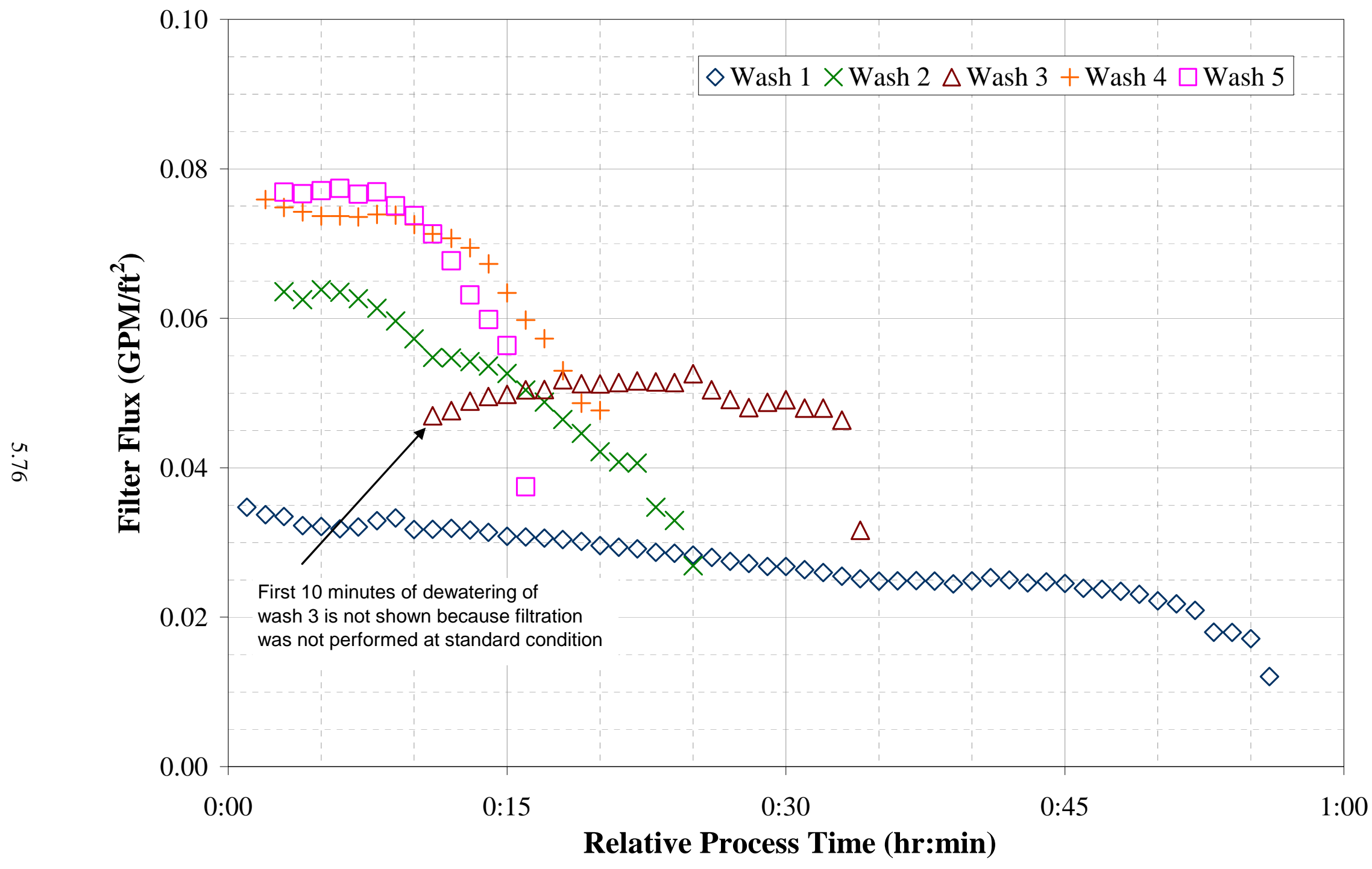

Figure 5.49. Flux Data from Dewatering Caustic Rinses at Standard Conditions (TMP $=40 \pm 5 \mathrm{psid}, \mathrm{AV}=13 \pm 1 \mathrm{ft} / \mathrm{s}$ ) 


\subsection{Oxidative Leaching/Washing}

After completing the filtration and rheological testing of the washed caustic-leached slurry, the slurry was drained from the system and prepared for oxidative leaching (Figure 5.50). The system was rinsed using the additional permeate that was remaining in the back-pulse chamber and some dewatered permeate from the last rinse. After the slurry and permeate additions were recovered from the system, the slurry reservoir was isolated from the CUF. The recovered slurry and permeate were placed into the reservoir for oxidative leaching, as outlined in the right column of Figure 5.1. It was estimated that $5 \%$ of the slurry was lost during transfer operations, decreasing the inventory of the UDS by 15 grams.

The activities involved in this process were:

- Batch oxidative leaching of slurry for removing chromium

- Batch washing of the oxidative leached slurry and dewatering the solution afterwards.

- Three equal volumetric wash solutions (1.2 L each) were added to the slurry to remove dissolved chromium from the slurry.

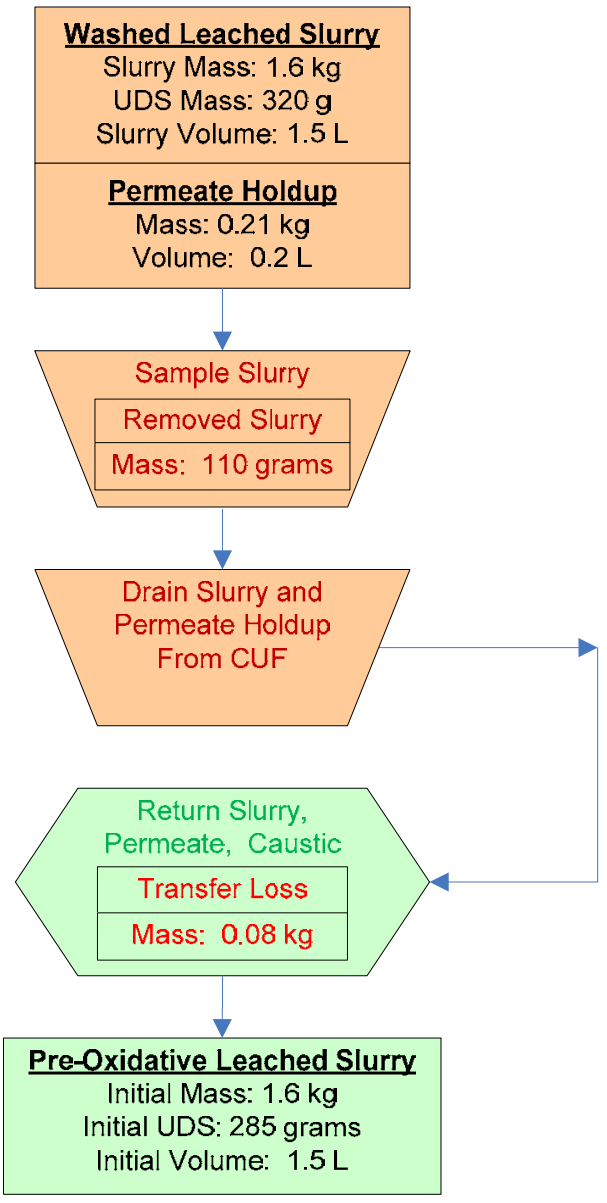

Figure 5.50. Process Flow for Batch Oxidative Leaching and Washing Note: Mass and volume values in figure are rounded to the nearest significant digit of accuracy. 


\subsubsection{Batch Oxidative Leaching Results and Characterization}

Figure 5.51 illustrates the material flow during the oxidative leaching and washing. Twenty three milliliters of $1 \mathrm{M}$ sodium permanganate $\left(\mathrm{NaMnO}_{4}\right)$ was added to the dewatered, caustic-leached and washed slurry and allowed to react at room temperature $\left(25^{\circ} \mathrm{C}\right)$ for 6 hours. The free hydroxide concentration during the oxidative leaching step was $\sim 0.2 \mathrm{M}$. The amount of sodium permanganate added was based on a targeted $\mathrm{Mn} / \mathrm{Cr}$ molar ratio of 1 and the assumption that $70 \%$ of the total Cr would have been removed during caustic leaching and washing. This assumption was conservative, but was based on combined wash/leach factors for Tanks B-104, BY-108, BY-110, BY-104, and BX-110 taken from TWIN data and reported by G. J. Lumetta and R.T. Hallen in Review of Caustic Leaching Testing With Hanford Tank Waste Sludges (WPT-RPT-151). However, only 30\% of the total Cr was actually removed from the slurry during caustic leaching and washing. As a result, the $\mathrm{Mn} / \mathrm{Cr}$ ratio during oxidative leaching was actually only 0.4 , or $60 \%$ less than the targeted value.

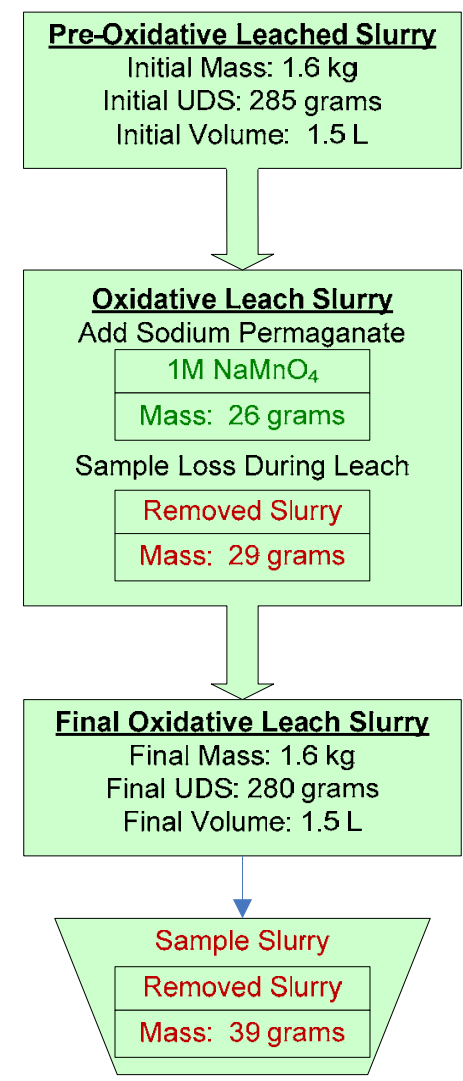

Figure 5.51. Process Flow for Oxidative Leach

Note: Mass and volume values in figure are rounded to the nearest significant digit of accuracy.

Based on samples taken during the oxidative leaching step, $27 \%$ of the water-insoluble chromium was removed by treatment with the sodium permanganate (Figure 5.52). The length of the oxidative leaching seemed to have no bearing on the amount of $\mathrm{Cr}$ removed. Analysis of the filtered supernate during oxidative leach dewatering did not show the presence of manganese at the end of the leach, indicating that all of the permanganate reacted, and Mn was precipitated in solid form. The reason for the low conversion of $\mathrm{Cr}-27 \%$ rather than $40 \%$ based on the reaction stoichiometry-is currently unknown. However, it was likely that the low conversion rate of insoluble Cr was partially due to the overhead 
mixer not functioning properly during the leach and not suspending the insoluble solids off of the bottom of the slurry reservoir.

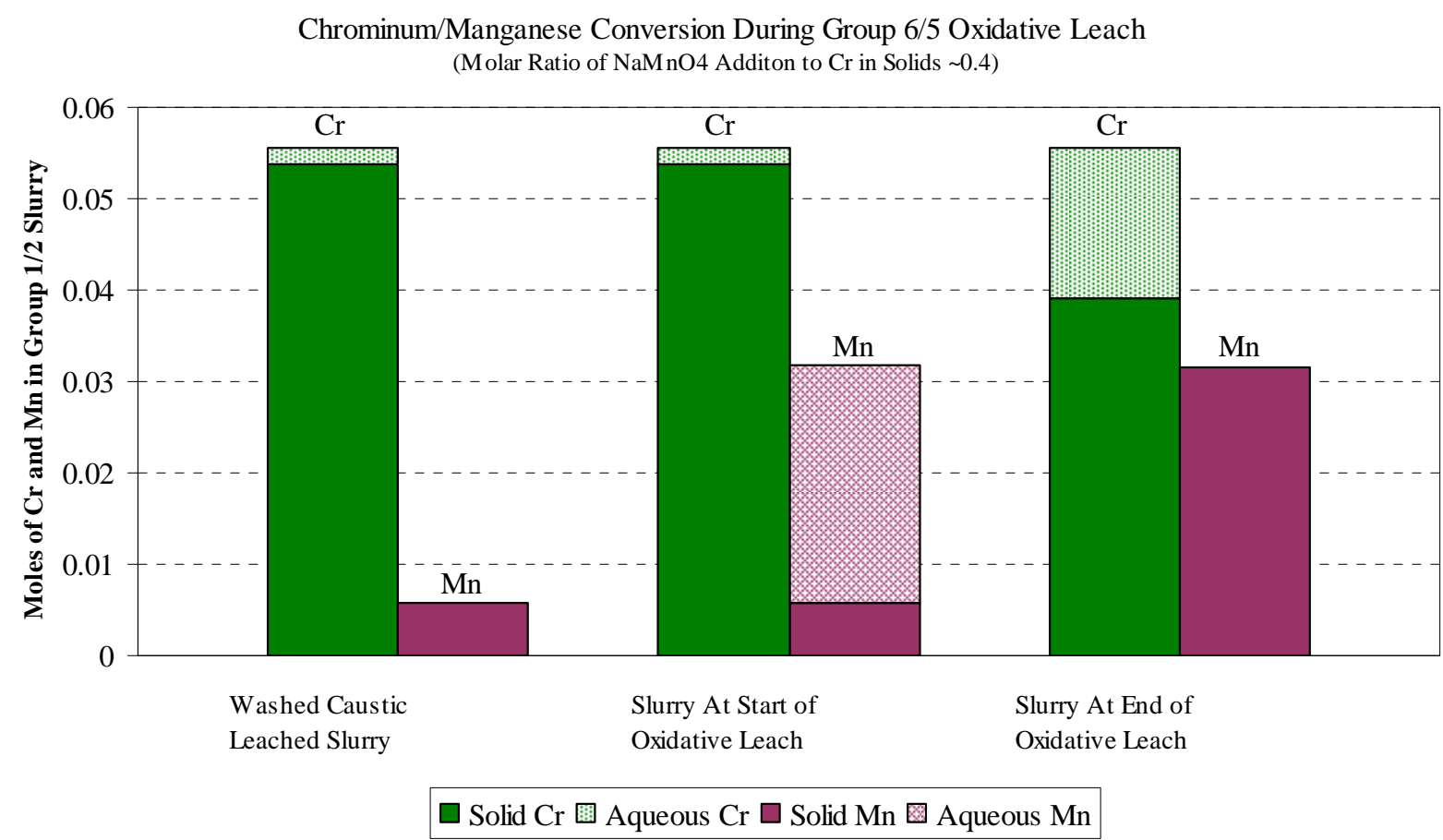

Figure 5.52. Moles of Chromium and Manganese in the Slurry Before and After Oxidative Leaching

After the 6-hour leach was completed, the oxidative leached slurry was sub-sampled inside the slurry reservoir before washing (Figure 5.51). Overall, 29 grams of the slurry was removed from the vessel containing an estimated 6 grams of solids. The physical properties of the oxidative leached, dewatered slurry are shown in Table 5.34 and chemical properties and leach factors in Table 5.35. Because the overhead mixer was not functional, the samples removed from the slurry were likely not representative of the slurry. The measured UDS of the sample was only $4.5 \mathrm{wt} \%$, indicating very little solids were present. Also, the calculated leach factor for $\mathrm{Cr}$ was over 1.0, which is unlikely considered that the supernate concentration did not support this change in mass. It is likely that a majority of dense UDS remained at the bottom of the vessel while it was sub-sampled, skewing the results.

Table 5.34. Physical Property Measurements of the Group 1/2 Oxidative Leached Slurry

\begin{tabular}{|r|c||}
\hline Slurry Density $(\mathbf{g} / \mathbf{m L})$ & 1.05 \\
Supernate Density $\mathbf{( g / m L})$ & 0.99 \\
\hline Settled Solids (Vol\%) & $61 \%$ \\
\hline Centrifuged UDS (Wt $\%)$ & $26 \%$ \\
\hline Total Solids of the Slurry(Wt\%) & $6.9 \%$ \\
\hline Dissolved Solids of the Supernate (Wt $\%)$ & $2.5 \%$ \\
\hline UDS of the Slurry $(\mathbf{W t} \%)$ & $4.5 \%$ \\
\hline
\end{tabular}


Table 5.35. Group 1/2 Oxidative Leached Slurry Composition and Leach Factor Calculations Based on ICP-OES/Radiochemical Characterization

\begin{tabular}{|c|c|c|c|c|c|}
\hline $\begin{array}{l}\text { Slurry Prep } \\
\text { Method }\end{array}$ & $\begin{array}{l}\text { ICP-OES } \\
\text { Analytes }\end{array}$ & $\begin{array}{c}\text { Dry } \\
\text { Slurry }^{(a)} \\
(\mu g / g)\end{array}$ & $\begin{array}{l}\text { Supernate }^{(b)} \\
(\mu \mathrm{g} / \mathrm{mL})\end{array}$ & $\begin{array}{c}\text { Dry Solids }{ }^{(\mathrm{c})} \\
(\mu \mathrm{g} / \mathrm{g})\end{array}$ & $\begin{array}{c}\text { Solids } \\
\text { Leach } \\
\text { Factor }^{(d)}\end{array}$ \\
\hline \multirow{35}{*}{$\begin{array}{l}\text { HF Assisted } \\
\text { Acid Digestion, } \\
\text { and KOH } \\
\text { Fusion, } \\
\text { Concentration } \\
\text { Factor of } \\
1.85 \text { based on } \\
\mathrm{U} \text { and Fe }\end{array}$} & Al & 59,150 & 243 & 84,658 & 0.54 \\
\hline & $\mathbf{B i}$ & 59,900 & {$[0.82]$} & 90,964 & 0.07 \\
\hline & Cd & 90.6 & $<8.5 \mathrm{E}-2$ & 135.8 & -0.25 \\
\hline & $\mathrm{Cr}$ & 12,050 & 1,050 & $-4,101$ & 1.27 \\
\hline & $\mathbf{F e}$ & 74,250 & 1.32 & 112,749 & NA \\
\hline & $\mathbf{K}$ & [330] & 27.5 & $-[86]$ & 0.77 \\
\hline & Mn & 12,000 & {$[0.098]$} & 18,225 & -9.44 \\
\hline & $\mathrm{Na}$ & 197,500 & 15,300 & $-26,466$ & 1.07 \\
\hline & $\mathbf{N i}$ & 4,650 & $<6.0 \mathrm{E}-2$ & 7,062 & 0.02 \\
\hline & $\mathbf{P}$ & 31,850 & 3,180 & $\begin{array}{l}-19,473 \\
\end{array}$ & 1.11 \\
\hline & $\mathrm{S}$ & {$[2,200]$} & 115 & {$[888]$} & 1.11 \\
\hline & Si & 56200 & 28.4 & 84756 & 0.07 \\
\hline & $\mathrm{Sr}$ & 4455 & 0.0596 & 6765 & -0.02 \\
\hline & $\mathbf{U}$ & 20,250 & $<8.0 \mathrm{E}-1$ & 30,740 & NA \\
\hline & Zn & 394 & $<7.0 \mathrm{E}-2$ & 596 & 0.40 \\
\hline & $\mathbf{Z r}$ & 404 & {$[0.076]$} & 611 & -0.64 \\
\hline & $A g$ & [17] & {$[0.063]$} & [24] & $-[0.16]$ \\
\hline & $B a$ & 278 & [0.13] & 419 & 0.04 \\
\hline & $B e$ & 0.593 & {$[0.0080]$} & 0.729 & 0.67 \\
\hline & Ca & 9,750 & {$[0.77]$} & 14,793 & 0.05 \\
\hline & $\mathrm{Ce}$ & 247 & $<2.5 \mathrm{E}-1$ & 370 & -0.08 \\
\hline & Co & 42.8 & $<6.0 \mathrm{E}-2$ & 63.6 & 0.18 \\
\hline & $\mathrm{Cu}$ & 87.9 & $<3.5 \mathrm{E}-2$ & 132.8 & 0.36 \\
\hline & $L a$ & 40.5 & $<7.0 \mathrm{E}-2$ & 59.9 & 0.06 \\
\hline & $\overline{L i}$ & 71.2 & 0.408 & 99.4 & 0.22 \\
\hline & $M g$ & 1,700 & $<5.8 \mathrm{E}-2$ & 2,581 & 0.03 \\
\hline & Mo & {$[40]$} & {$[0.84]$} & [42] & {$[0.42]$} \\
\hline & Nd & 55.0 & $<1.4 \mathrm{E}-1$ & 80.6 & 0.01 \\
\hline & $P b$ & 1,490 & {$[2.2]$} & 2,216 & 0.11 \\
\hline & $R u$ & {$[30]$} & $<3.0 \mathrm{E}-1$ & [39] & {$[0.08]$} \\
\hline & Th & [43] & {$[0.67]$} & [51] & [117.56] \\
\hline & $T i$ & 172 & [1.5] & 228 & 0 \\
\hline & $T I$ & [69] & {$[0.035]$} & [104] & {$[0.71]$} \\
\hline & $V$ & 24.8 & $<9.5 \mathrm{E}-1$ & 17.3 & 0.43 \\
\hline & $\bar{Y}$ & 7.71 & $<1.1 \mathrm{E}-2$ & 11.47 & 0.03 \\
\hline
\end{tabular}


Table 5.35 (Contd)

\begin{tabular}{|c|c|c|c|c|c|}
\hline $\begin{array}{l}\text { Slurry Prep } \\
\text { Method }\end{array}$ & Radionuclides & $\begin{array}{c}\text { Dry } \\
\text { Slurry }^{(a)} \\
(\mu \mathrm{Ci} / \mathrm{g}) \\
\end{array}$ & $\begin{array}{c}\text { Supernate }^{(b)} \\
(\mu \mathrm{Ci} / \mathrm{mL})\end{array}$ & $\begin{array}{c}\text { Dry Solids }^{(c)} \\
(\mu \mathrm{Ci} / \mathrm{g})\end{array}$ & $\begin{array}{c}\text { Solids } \\
\text { Leach }^{\text {(d) }} \\
\text { Factor }^{\text {(d) }}\end{array}$ \\
\hline \multirow{10}{*}{$\begin{array}{c}\text { KOH } \\
\text { Fusion, } \\
\text { Concentrati } \\
\text { on Factor of } \\
1.85 \text { based on } \\
\text { U and Fe }\end{array}$} & Co-60 & $9.06 \mathrm{E}-3$ & $<2 . \mathrm{E}-5$ & 1.3E-2 & 0.38 \\
\hline & Cs-137 & $8.78 \mathrm{E}+1$ & $5.61 \mathrm{E}-1$ & $1.2 \mathrm{E}+2$ & 0.39 \\
\hline & Eu-154 & $5.69 \mathrm{E}-2$ & $<5 . \mathrm{E}-5$ & 8.5E-2 & -1.72 \\
\hline & Eu-155 & $<5 . \mathrm{E}-2$ & $<4 . \mathrm{E}-4$ & $<6 . \mathrm{E}-2$ & NA \\
\hline & Am-241 & $4.14 \mathrm{E}-1$ & $<7 . \mathrm{E}-4$ & $6.1 \mathrm{E}-1$ & -0.07 \\
\hline & Total alpha & $9.57 \mathrm{E}-1$ & $<7 . \mathrm{E}-4$ & $1.4 \mathrm{E}+0$ & -0.16 \\
\hline & Total beta & $5.06 \mathrm{E}+2$ & $5.05 \mathrm{E}-1$ & $7.6 \mathrm{E}+2$ & -0.24 \\
\hline & Sr-90 & $2.00 \mathrm{E}+2$ & $2.38 \mathrm{E}-3$ & $3.0 \mathrm{E}+2$ & -0.10 \\
\hline & Pu-239/240 & $4.83 \mathrm{E}-1$ & $1.46 \mathrm{E}-4$ & 7.3E-1 & -0.10 \\
\hline & Pu-238 & $9.75 \mathrm{E}-3$ & 5.97E-6 & $1.5 \mathrm{E}-2$ & 0.20 \\
\hline \multicolumn{6}{|c|}{$\begin{array}{l}\text { (a) Test sample TI572-G2-L5, ASO ID 08-01292 } \\
\text { (b) Test sample TI572-G2-15, ASO ID 08-01301 } \\
\text { (c) Calculated using results from TI572-G2-L5 and TI572-G2-15 } \\
\text { (d) Calculated using results listed in } \\
\text { (e) Table 5.11 } \\
\text { Note: Analytes in italics were measured opportunistically. Values in brackets [ ] are } \geq \\
\text { MDL but < EQL, with errors likely to exceed 15\%. }\end{array}$} \\
\hline
\end{tabular}

PSD measurements were also performed on the oxidative leached slurry. Figure 5.53 shows the pre-sonic size distribution of solids in the caustic-leached, dewatered slurry as a function of pump speed. All distributions show similar particle populations. A primary peak spanning 0.3 to $6 \mu \mathrm{m}$ with a maximum population from 1 to $2 \mu \mathrm{m}$ dominates the distribution. This peak shifts to smaller diameters at both 2000 and 4000 RPM, which may suggest particle-size reduction because of the lower ionic strength of the suspending phase, and/or shear forces were increased during analysis. Smaller secondary peaks occur from 6 to $200 \mu \mathrm{m}$ and likely correspond to particle flocs. The relative contribution of these secondary peaks is highest at $4000 \mathrm{RPM}$, indicating the presence of difficult-to-suspend particles.

Figure 5.54 shows how sonication affects the PSD for the oxidative leached, dewatered slurry. Sonication causes a significant increase in the contribution of 0.2 - to 1- $\mu$ m particles and a significant decrease in the contribution of 1- to 5- $\mu \mathrm{m}$ particles. Accompanying these changes is an increase in the fraction of 5- to $20-\mu \mathrm{m}$ particles and a complete elimination of particles larger than $20 \mu \mathrm{m}$. These changes are likely a result of sonic disruption of particles and flocs. After sonication is removed, an immediate recovery of 20 - to $200-\mu \mathrm{m}$ particles is observed, which suggests a rapid reformation of flocs. 


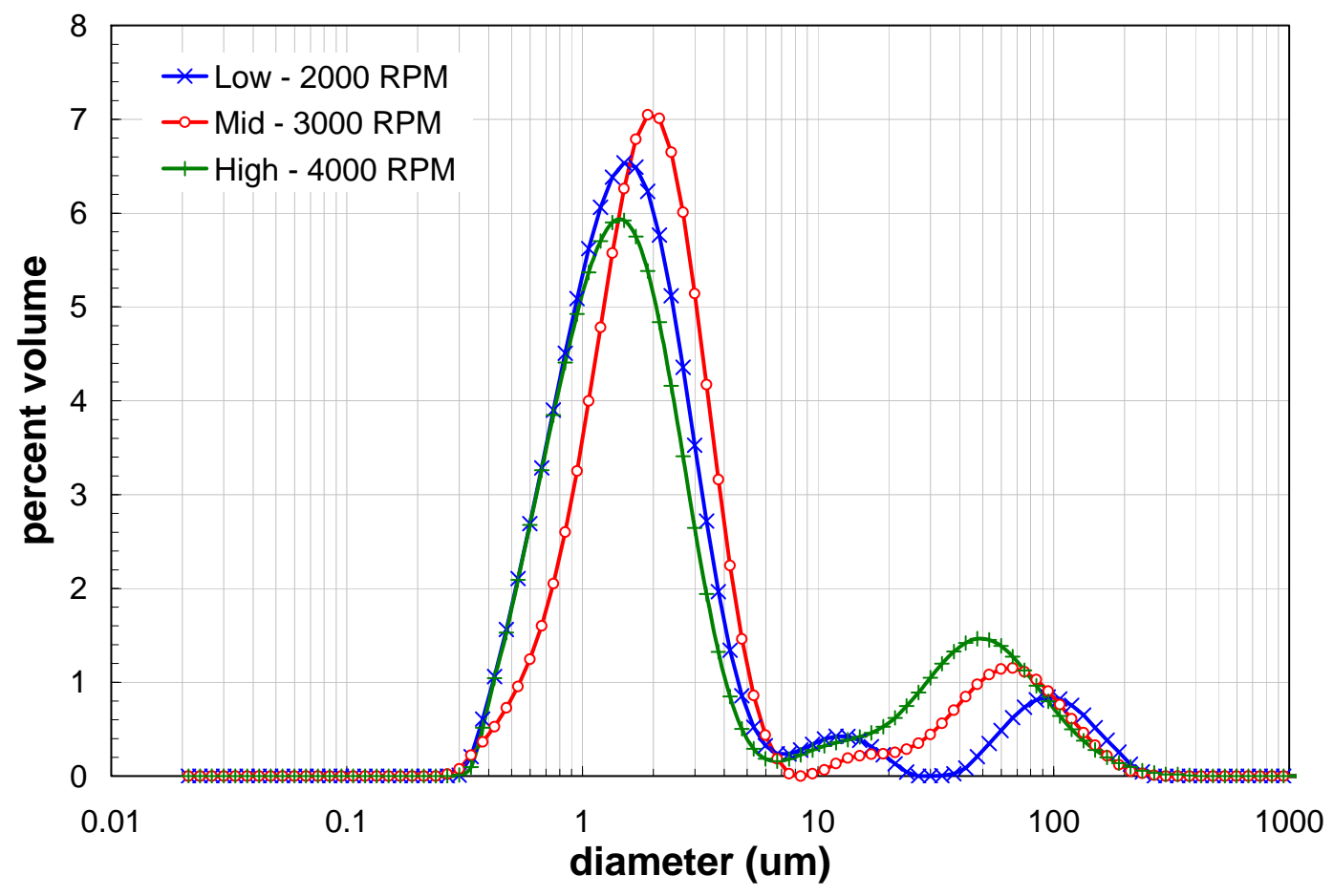

Figure 5.53. Oxidative Leached, Dewatered PSD as a Function of Pump Speed

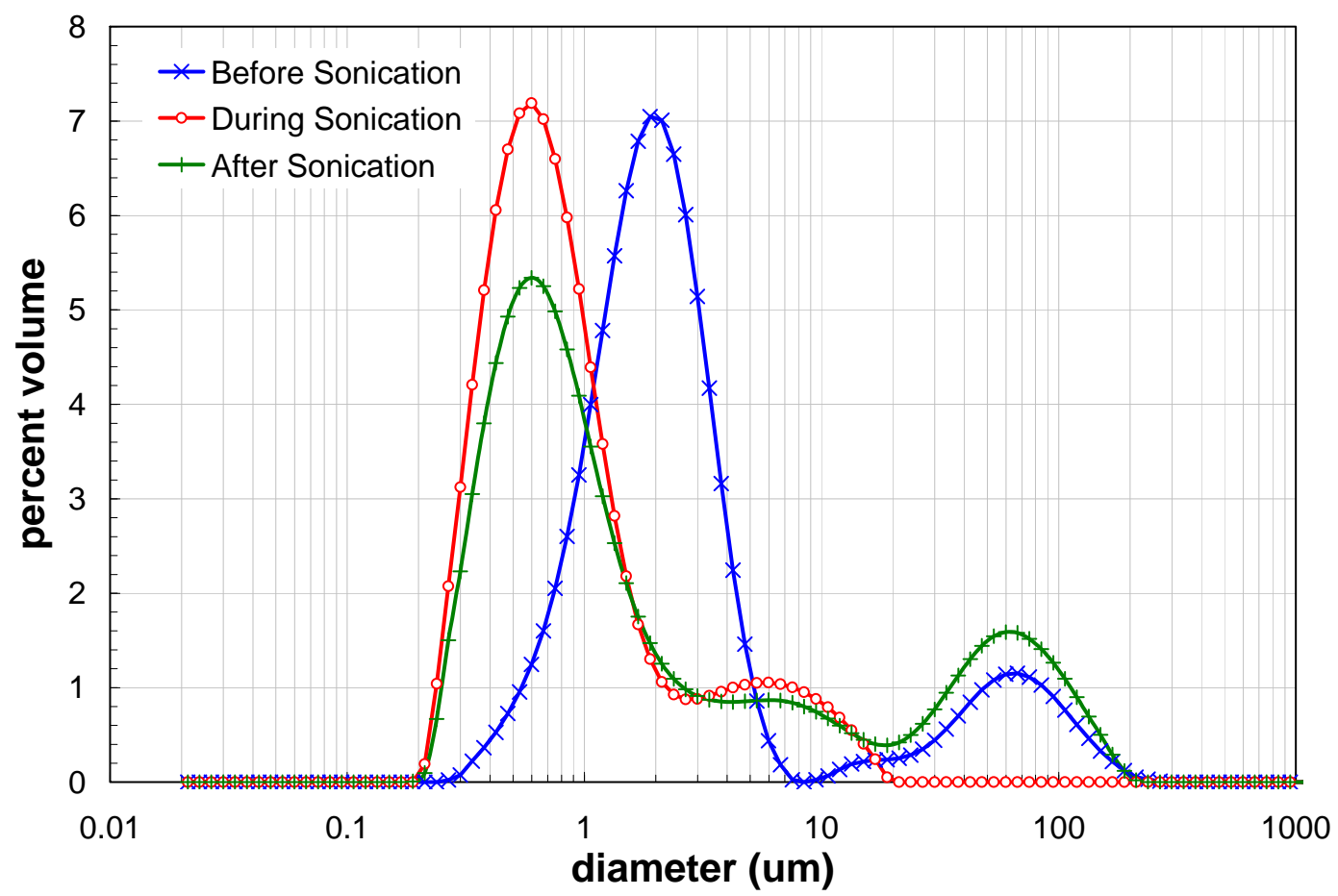

Figure 5.54. Oxidative Leached, Dewatered Slurry PSD as a Function of Sonication at 3000 RPM 


\subsubsection{Batch Oxidative Washing Results}

The leached material was washed three times with $0.01 \mathrm{M} \mathrm{NaOH}$ (Figure 5.55), during which time the leached chromium was largely washed out of the slurry. The metals composition of the oxidative leached slurry following each of the washes is shown in Table 5.36 through Table 5.39.

The total $\mathrm{Cr}$ in the system before the caustic and oxidative leaching (low solids slurry) was $5.66 \mathrm{~g}$. By the start of the oxidative leach test, the actual inventory of Cr had decreased to 2.9 grams. Leaching and washing afterwards decrease the total inventory to 2.0 grams. However, sampling and transfer losses accounted for 1 gram of lost Cr before the start of the leach. Figure 5.56 plots the corrected inventory of $\mathrm{Cr}$ throughout the test. The inventory at each step was normalized to the original slurry inventory and corrected for sample loss. It was projected that the total amount of $\mathrm{Cr}$ removed was $45 \%$ (Figure 5.57), if sampling did not occur. The solid leach factor of the Cr was $23 \%$ where 2.89 of the original 3.77 grams of $\mathrm{Cr}$ solids remained after the leach. Similarly, it was projected that half (50\%) of the P was removed during leaching and dewatering operations if sampling was excluded.

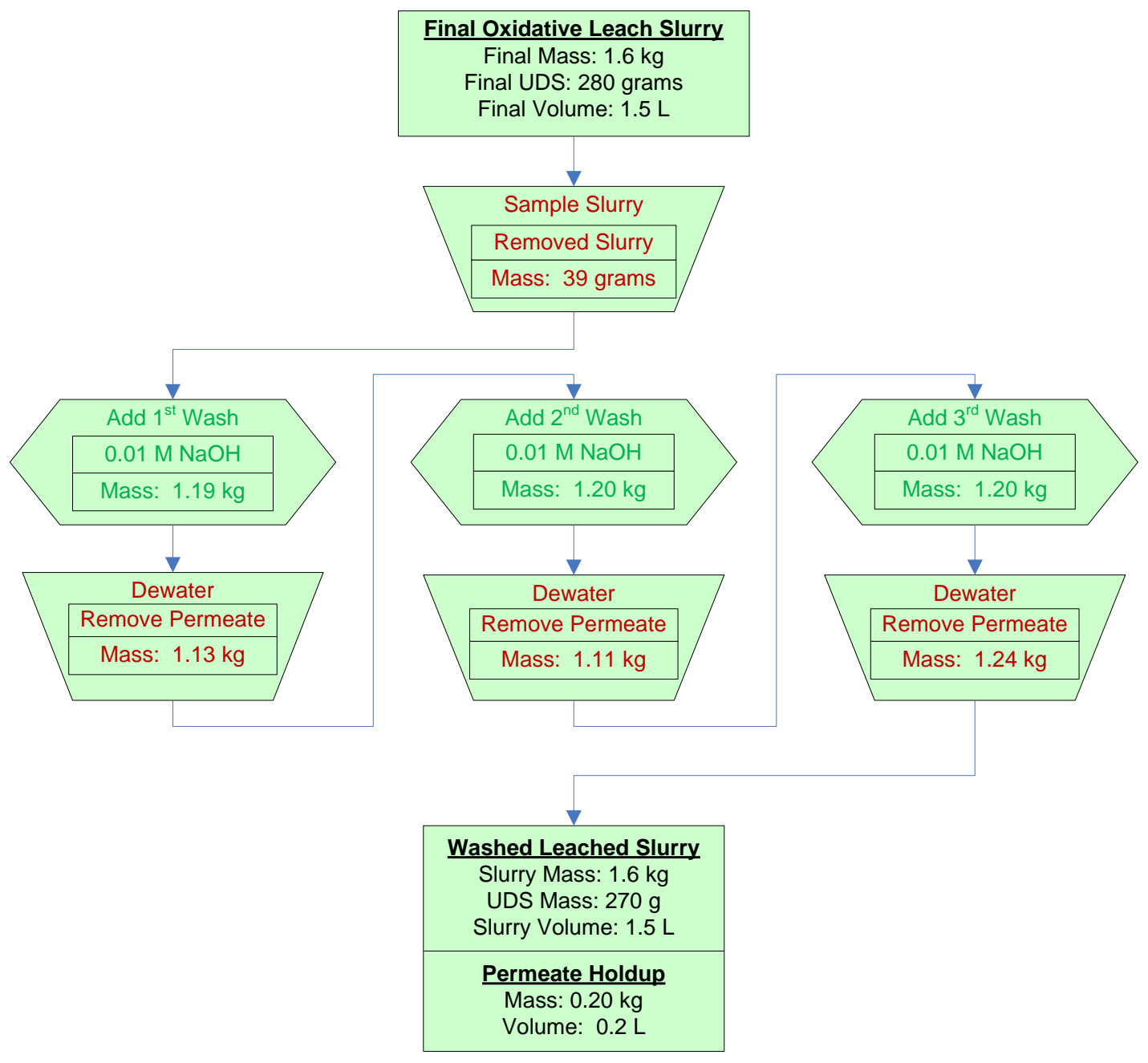

Figure 5.55. Process Flow for Washing after Oxidative Leaching Note: Mass and volume values in figure are rounded to the nearest significant digit of accuracy. 
Table 5.36. Slurry composition after the first wash of the Group 1/2 Oxidative leached Slurry (Including Permeate Hold-up)

\begin{tabular}{|c|c|c|c|c|c|c|}
\hline & & Slurry $^{(a)}$ & \multicolumn{2}{|c|}{ Liquid Fraction $^{(b)}$} & \multicolumn{2}{|c|}{ Solids Fraction $^{(\mathrm{c})}$} \\
\hline & Mass (kg) & 1.55 & \multicolumn{2}{|c|}{1.28} & \multicolumn{2}{|c|}{0.27} \\
\hline & Wt\% of Slurry & $100 \%$ & \multicolumn{2}{|c|}{$82.5 \%$} & \multicolumn{2}{|c|}{$17.5 \%$} \\
\hline & Metal & g & g & $\mu \mathrm{g} / \mathrm{mL}$ & g & $\mu g / g$ \\
\hline & Al & $2.1 \mathrm{E}+01$ & 1.7E-01 & $1.4 \mathrm{E}+02$ & $2.1 \mathrm{E}+01$ & $7.7 \mathrm{E}+04$ \\
\hline & $\mathbf{B i}$ & $1.5 \mathrm{E}+01$ & 3.0E-03 & $2.4 \mathrm{E}+00$ & $1.5 \mathrm{E}+01$ & $5.7 \mathrm{E}+04$ \\
\hline & $\mathrm{Cr}$ & $2.5 \mathrm{E}+00$ & 4.1E-01 & $3.4 \mathrm{E}+02$ & $2.0 \mathrm{E}+00$ & $7.5 \mathrm{E}+03$ \\
\hline & $\mathbf{F e}$ & $2.1 \mathrm{E}+01$ & 5.3E-04 & 4.3E-01 & $2.1 \mathrm{E}+01$ & $7.7 \mathrm{E}+04$ \\
\hline & Mn & $1.7 \mathrm{E}+00$ & $1.1 \mathrm{E}-05$ & 8.8E-03 & $1.7 \mathrm{E}+00$ & $6.1 \mathrm{E}+03$ \\
\hline & $\mathbf{N a}$ & $8.6 \mathrm{E}+01$ & $7.8 \mathrm{E}+00$ & $6.4 \mathrm{E}+03$ & $7.8 \mathrm{E}+01$ & $2.9 \mathrm{E}+05$ \\
\hline & $\mathbf{P}$ & $1.9 \mathrm{E}+01$ & $1.4 \mathrm{E}+00$ & $1.1 \mathrm{E}+03$ & $1.8 \mathrm{E}+01$ & $6.5 \mathrm{E}+04$ \\
\hline & $\mathrm{S}$ & $9.8 \mathrm{E}-02$ & 6.3E-02 & $5.1 \mathrm{E}+01$ & 3.5E-02 & $1.3 \mathrm{E}+02$ \\
\hline & Si & $1.3 \mathrm{E}+01$ & $3.4 \mathrm{E}-02$ & $2.8 \mathrm{E}+01$ & $1.3 \mathrm{E}+01$ & $4.7 \mathrm{E}+04$ \\
\hline & $\mathrm{Sr}$ & $1.3 \mathrm{E}+00$ & $1.5 \mathrm{E}-05$ & $1.2 \mathrm{E}-02$ & $1.3 \mathrm{E}+00$ & $4.7 \mathrm{E}+03$ \\
\hline & $\mathbf{U}$ & $5.2 \mathrm{E}+00$ & $1.0 \mathrm{E}-03$ & 8.1E-01 & $5.2 \mathrm{E}+00$ & $1.9 \mathrm{E}+04$ \\
\hline \multicolumn{5}{|c|}{ Supernate Fraction } & & \\
\hline & Anion & $\mu \mathrm{g} / \mathrm{mL}$ & [M] & g & & \\
\hline & $\mathbf{O H}$ & $2.4 \mathrm{E}+03$ & $1.4 \mathrm{E}-01$ & $2.9 \mathrm{E}+00$ & & \\
\hline \multicolumn{7}{|c|}{$\begin{array}{l}\text { (a) Slurry mass components were calculated from characterization data (Sections } 3 \text { and 4) and the } \\
\text { masses of materials that were added with simulant. Loss of mass from sampling was incorporated. } \\
\text { (b) Liquid fraction mass components were calculated using analytical results from supernate sample } \\
\text { TI552-G6-M (ASO ID 08-01313) and the predicted mass of supernate in the system. } \\
\text { (c) Solids fraction mass components were calculated from the difference between the slurry component } \\
\text { mass and liquid component mass fraction. }\end{array}$} \\
\hline
\end{tabular}


Table 5.37. Slurry Composition After the Second Wash of the Group 1/2 Oxidative Leached Slurry (Including Permeate Hold-up)

\begin{tabular}{|c|c|c|c|c|c|}
\hline & Slurry $^{(\mathbf{a})}$ & \multicolumn{2}{|c|}{ Liquid Fraction $^{(b)}$} & \multicolumn{2}{|c|}{ Solids Fraction $^{(\mathrm{c})}$} \\
\hline Mass (kg) & 1.62 & \multicolumn{2}{|c|}{1.35} & \multicolumn{2}{|c|}{0.27} \\
\hline Wt\% of Slurry & $100 \%$ & \multicolumn{2}{|c|}{$83.2 \%$} & \multicolumn{2}{|c|}{$16.8 \%$} \\
\hline Metal & g & g & $\mu \mathrm{g} / \mathrm{mL}$ & g & $\mu g / g$ \\
\hline Al & $2.1 \mathrm{E}+01$ & 2.3E-01 & $1.7 \mathrm{E}+02$ & $2.1 \mathrm{E}+01$ & $7.6 \mathrm{E}+04$ \\
\hline Bi & $1.5 \mathrm{E}+01$ & $1.4 \mathrm{E}-03$ & $1.1 \mathrm{E}+00$ & $1.5 \mathrm{E}+01$ & $5.7 \mathrm{E}+04$ \\
\hline $\mathrm{Cr}$ & $2.2 \mathrm{E}+00$ & 3.6E-01 & $2.7 \mathrm{E}+02$ & $1.8 \mathrm{E}+00$ & $6.6 \mathrm{E}+03$ \\
\hline $\mathbf{F e}$ & $2.1 \mathrm{E}+01$ & $1.4 \mathrm{E}-03$ & $1.1 \mathrm{E}+00$ & $2.1 \mathrm{E}+01$ & $7.7 \mathrm{E}+04$ \\
\hline Mn & $1.7 \mathrm{E}+00$ & 8.1E-06 & $6.2 \mathrm{E}-03$ & $1.7 \mathrm{E}+00$ & $6.1 \mathrm{E}+03$ \\
\hline $\mathrm{Na}$ & $7.9 \mathrm{E}+01$ & $7.7 \mathrm{E}+00$ & $5.9 \mathrm{E}+03$ & $7.2 \mathrm{E}+01$ & $2.6 \mathrm{E}+05$ \\
\hline $\mathbf{P}$ & $1.8 \mathrm{E}+01$ & $1.3 \mathrm{E}+00$ & $9.7 \mathrm{E}+02$ & $1.7 \mathrm{E}+01$ & $6.2 \mathrm{E}+04$ \\
\hline $\mathrm{S}$ & $9.8 \mathrm{E}-02$ & 7.7E-02 & $5.9 \mathrm{E}+01$ & $2.1 \mathrm{E}-02$ & $7.7 \mathrm{E}+01$ \\
\hline Si & $1.3 \mathrm{E}+01$ & 4.4E-02 & $3.4 \mathrm{E}+01$ & $1.3 \mathrm{E}+01$ & $4.7 \mathrm{E}+04$ \\
\hline $\mathrm{Sr}$ & $1.3 \mathrm{E}+00$ & $2.1 \mathrm{E}-05$ & $1.6 \mathrm{E}-02$ & $1.3 \mathrm{E}+00$ & $4.7 \mathrm{E}+03$ \\
\hline $\mathbf{U}$ & $5.2 \mathrm{E}+00$ & $2.4 \mathrm{E}-03$ & $1.8 \mathrm{E}+00$ & $5.2 \mathrm{E}+00$ & $1.9 \mathrm{E}+04$ \\
\hline \multicolumn{4}{|c|}{ Supernate Fraction } & & \\
\hline Anion & $\mu g / m L$ & [M] & g & & \\
\hline $\mathbf{O H}$ & $7.8 \mathrm{E}+02$ & 4.6E-02 & $1.0 \mathrm{E}+00$ & & \\
\hline \multicolumn{6}{|c|}{$\begin{array}{l}\text { (a) Slurry mass components were calculated from characterization data (Sections } 3 \text { and 4) and the } \\
\text { masses of materials that were added with simulant. Loss of mass from sampling was incorporated. } \\
\text { (b) Liquid fraction mass components were calculated using analytical results from supernate sample } \\
\text { TI552-G6-N (ASO ID 08-01314) and the predicted mass of supernate in the system. } \\
\text { (c) Solids fraction mass components were calculated from the difference between the slurry component } \\
\text { mass and liquid component mass fraction. }\end{array}$} \\
\hline
\end{tabular}


Table 5.38. Slurry Inventory and Composition After the Third Wash of the Group 1/2 Oxidative Leached Slurry (including permeate hold-up)

\begin{tabular}{|c|c|c|c|c|c|}
\hline & Slurry $^{(a)}$ & \multicolumn{2}{|c|}{ Liquid Fraction $^{(\mathbf{b})}$} & \multicolumn{2}{|c|}{ Solids Fraction ${ }^{(c)}$} \\
\hline Mass (kg) & 1.55 & \multicolumn{2}{|c|}{1.28} & \multicolumn{2}{|c|}{0.27} \\
\hline Wt\% of Slurry & $100 \%$ & \multicolumn{2}{|c|}{$82.5 \%$} & \multicolumn{2}{|c|}{$17.5 \%$} \\
\hline Metal & $\mathbf{g}$ & $\mathbf{g}$ & $\mu g / m L$ & $\mathbf{g}$ & $\mu g / g$ \\
\hline Al & $2.1 \mathrm{E}+01$ & $1.2 \mathrm{E}-01$ & $9.0 \mathrm{E}+01$ & $2.1 \mathrm{E}+01$ & $7.6 \mathrm{E}+04$ \\
\hline$\overline{\mathbf{B i}}$ & $1.5 \mathrm{E}+01$ & $3.8 \mathrm{E}-03$ & $2.9 \mathrm{E}+00$ & $1.5 \mathrm{E}+01$ & $5.7 \mathrm{E}+04$ \\
\hline $\mathrm{Cr}$ & $2.0 \mathrm{E}+00$ & $1.6 \mathrm{E}-01$ & $1.2 \mathrm{E}+02$ & $1.8 \mathrm{E}+00$ & $6.7 \mathrm{E}+03$ \\
\hline $\mathbf{F e}$ & $2.1 \mathrm{E}+01$ & $1.2 \mathrm{E}-03$ & $9.5 \mathrm{E}-01$ & $2.1 \mathrm{E}+01$ & $7.7 \mathrm{E}+04$ \\
\hline Mn & $1.7 \mathrm{E}+00$ & $2.0 \mathrm{E}-05$ & $1.5 \mathrm{E}-02$ & $1.7 \mathrm{E}+00$ & $6.1 \mathrm{E}+03$ \\
\hline $\mathbf{N a}$ & $7.6 \mathrm{E}+01$ & $3.8 \mathrm{E}+00$ & $2.9 \mathrm{E}+03$ & $7.2 \mathrm{E}+01$ & $2.6 \mathrm{E}+05$ \\
\hline $\mathbf{P}$ & $1.7 \mathrm{E}+01$ & $5.9 \mathrm{E}-01$ & $4.5 \mathrm{E}+02$ & $1.7 \mathrm{E}+01$ & $6.2 \mathrm{E}+04$ \\
\hline $\mathbf{S}$ & $6.0 \mathrm{E}-02$ & 3.5E-02 & $2.7 \mathrm{E}+01$ & $2.5 \mathrm{E}-02$ & $9.0 \mathrm{E}+01$ \\
\hline Si & $1.3 \mathrm{E}+01$ & $1.5 \mathrm{E}-02$ & $1.2 \mathrm{E}+01$ & $1.3 \mathrm{E}+01$ & $4.7 \mathrm{E}+04$ \\
\hline $\mathrm{Sr}$ & $1.3 \mathrm{E}+00$ & $1.1 \mathrm{E}-05$ & $8.6 \mathrm{E}-03$ & $1.3 \mathrm{E}+00$ & $4.7 \mathrm{E}+03$ \\
\hline $\mathbf{U}$ & $5.2 \mathrm{E}+00$ & $<5$. E-3 & $<4 . \mathrm{E}+0$ & $5.2 \mathrm{E}+00$ & $1.9 \mathrm{E}+04$ \\
\hline \multirow{2}{*}{$\begin{array}{l}\text { Radiochemical } \\
\text { Isotopes }\end{array}$} & Slurry & \multicolumn{2}{|c|}{ Liquid Fraction } & \multicolumn{2}{|c|}{ Solid Fraction } \\
\hline & mCi & $\mathbf{m C i}$ & $\mathrm{mCi} / \mathrm{mL}$ & $\mathrm{mCi}$ & $\mathrm{mCi} / \mathrm{g}$ \\
\hline Co-60 & $2.3 \mathrm{E}+00$ & $<3$. E-2 & $<2$. E-5 & $2.3 \mathrm{E}+00$ & $8.4 \mathrm{E}-03$ \\
\hline Cs-137 & $2.7 \mathrm{E}+04$ & $2.8 \mathrm{E}+02$ & $2.1 \mathrm{E}-01$ & $2.6 \mathrm{E}+04$ & $9.7 \mathrm{E}+01$ \\
\hline Eu-154 & $1.2 \mathrm{E}+01$ & $<8$. E-2 & $<6$. E-5 & $1.2 \mathrm{E}+01$ & 4.3E-02 \\
\hline Am-241 & $1.1 \mathrm{E}+02$ & $<1$.E-1 & $<1$. E-4 & $1.1 \mathrm{E}+02$ & $4.2 \mathrm{E}-01$ \\
\hline Gross Alpha & $2.1 \mathrm{E}+02$ & $<9$. -E-1 & $<7$. -E-4 & $2.1 \mathrm{E}+02$ & 7.6E-01 \\
\hline Gross Beta & $1.3 \mathrm{E}+05$ & $2.4 \mathrm{E}+02$ & $1.8 \mathrm{E}-01$ & $1.3 \mathrm{E}+05$ & $4.8 \mathrm{E}+02$ \\
\hline Sr-90 & $4.9 \mathrm{E}+04$ & $2.5 \mathrm{E}-01$ & $1.9 \mathrm{E}-04$ & $4.9 \mathrm{E}+04$ & $1.8 \mathrm{E}+02$ \\
\hline $\mathrm{Pu}-239+240$ & $1.5 \mathrm{E}+02$ & $<3 . \mathrm{E}-3$ & $<3$. E-6 & $1.5 \mathrm{E}+02$ & $5.6 \mathrm{E}-01$ \\
\hline Pu-238 & $5.4 \mathrm{E}+00$ & $<3$. E-3 & $<3$. E-6 & $5.4 \mathrm{E}+00$ & $2.0 \mathrm{E}-02$ \\
\hline \multirow[t]{2}{*}{ Anions } & \multicolumn{3}{|c|}{ Liquid Fraction } & \multicolumn{2}{|c|}{ Leached Solids Fraction } \\
\hline & $\mu g / m L$ & [M] & g & $\mu g / g$ & g \\
\hline $\mathbf{F}$ & $2.2 \mathrm{E}+02$ & $1.2 \mathrm{E}-02$ & $2.9 \mathrm{E}-01$ & $2.2 \mathrm{E}+03$ & $6.0 \mathrm{E}-01$ \\
\hline $\mathrm{C}_{2} \mathrm{O}_{4}$ & $7.4 \mathrm{E}+01$ & $8.4 \mathrm{E}-04$ & 9.7E-02 & $1.2 \mathrm{E}+03$ & $3.3 \mathrm{E}-01$ \\
\hline $\mathrm{NO}_{2}$ & $2.5 \mathrm{E}+01$ & 5.5E-04 & 3.3E-02 & $3.3 \mathrm{E}+02$ & 8.9E-02 \\
\hline $\mathrm{NO}_{3}$ & $7.1 \mathrm{E}+02$ & $1.1 \mathrm{E}-02$ & 9.3E-01 & $1.2 \mathrm{E}+04$ & $3.3 \mathrm{E}+00$ \\
\hline $\mathrm{SO}_{4}$ & $8.3 \mathrm{E}+01$ & 8.7E-04 & $1.1 \mathrm{E}-01$ & $1.3 \mathrm{E}+03$ & $3.6 \mathrm{E}-01$ \\
\hline $\mathrm{PO}_{4}$ & $1.5 \mathrm{E}+03$ & $1.6 \mathrm{E}-02$ & $2.0 \mathrm{E}+00$ & $1.2 \mathrm{E}+04$ & $3.3 \mathrm{E}+00$ \\
\hline $\mathbf{O H}$ & $5.4 \mathrm{E}+02$ & $3.2 \mathrm{E}-02$ & $7.1 \mathrm{E}-01$ & & \\
\hline \multicolumn{6}{|c|}{$\begin{array}{l}\text { (a) Slurry mass components were calculated from characterization data (Sections } 3 \text { and 4) and the } \\
\text { masses of materials that were added with simulant. Loss of mass from sampling was incorporated. } \\
\text { (b) Liquid fraction mass components were calculated using analytical results from supernate sample } \\
\text { TI552-G6-O (ASO ID 08-01294) and the predicted mass of supernate in the system. } \\
\text { (c) Solids fraction mass components were calculated from the difference between the slurry component } \\
\text { mass and liquid component mass fraction. }\end{array}$} \\
\hline
\end{tabular}


Table 5.39. Oxidative Wash Solutions Radionuclide and Opportunistic Compositions

\begin{tabular}{|c|c|c|c|c|}
\hline & Wash 1 & Wash 2 & Wash 3 & Composite Wash \\
\hline ASO Sample ID & 08-01313 & 08-01314 & 08-01294 & 08-01295 \\
\hline Density $^{(a)}, g / m L>$ & 1.04 & 1.03 & 1.01 & NA \\
\hline \multicolumn{5}{|l|}{ Analyte } \\
\hline free $\mathrm{OH}, \mathrm{M}$ & $0.14 \mathrm{M}$ & $0.05 \mathrm{M}$ & $0.03 \mathrm{M}$ & $0.07 \mathrm{M}$ \\
\hline Analyte & $\mu \mathrm{Ci} / \mathrm{mL}$ & $\mu \mathrm{Ci} / \mathbf{m L}$ & $\mu \mathrm{Ci} / \mathbf{m L}$ & $\mu \mathrm{Ci} / \mathbf{m L}$ \\
\hline${ }^{137} \mathrm{Cs}$ & & & $2.10 \mathrm{E}-1$ & $3.56 \mathrm{E}-1$ \\
\hline${ }^{60} \mathrm{Co}$ & & & $<2$.E-5 & $<1$.E-5 \\
\hline${ }^{241} \mathrm{Am}$ & & & $<1$.E-4 & $<5 . \mathrm{E}-4$ \\
\hline${ }^{90} \mathrm{Sr}$ & & & $1.90 \mathrm{E}-4$ & $2.32 \mathrm{E}-4$ \\
\hline${ }^{238} \mathrm{Pu}$ & & & $<3$. E-6 & $<2$. E-6 \\
\hline${ }^{239+240} \mathrm{Pu}$ & & & $<3$. E-6 & $<3$. E-6 \\
\hline Gross alpha & & & $<7 . \mathrm{E}-4$ & $<5$. E-4 \\
\hline Gross beta & & & $1.81 \mathrm{E}-1$ & $2.94 \mathrm{E}-1$ \\
\hline${ }^{154} \mathrm{Eu}$ & & & $<6$. E-5 & $<4$.E-5 \\
\hline \multicolumn{5}{|c|}{ Opportunistic Analytes } \\
\hline Analyte & $\mu \mathrm{g} / \mathrm{mL}$ & $\mu \mathrm{g} / \mathrm{mL}$ & $\mu \mathrm{g} / \mathrm{mL}$ & $\mu \mathrm{g} / \mathrm{mL}$ \\
\hline Ag & $<5.1 \mathrm{E}-2$ & $<5.1 \mathrm{E}-2$ & $<2.6 \mathrm{E}-1$ & [0.059] \\
\hline As & $<1.0 \mathrm{E}+0$ & $<1.1 \mathrm{E}+0$ & $<5.3 \mathrm{E}+0$ & $<8.5 \mathrm{E}-1$ \\
\hline $\mathrm{Ba}$ & {$[0.088]$} & 0.166 & 0.308 & 0.247 \\
\hline $\mathrm{Be}$ & {$[0.0033]$} & [0.0017] & $<6.4 \mathrm{E}-3$ & {$[0.0012]$} \\
\hline $\mathrm{Ca}$ & {$[0.80]$} & 3.31 & {$[0.64]$} & [0.52] \\
\hline $\mathrm{Ce}$ & $<2.4 \mathrm{E}-1$ & $<2.5 \mathrm{E}-1$ & $<1.2 \mathrm{E}+0$ & $<2.0 \mathrm{E}-1$ \\
\hline Co & {$[0.14]$} & $<5.9 \mathrm{E}-2$ & $<3.0 \mathrm{E}-1$ & $<4.7 \mathrm{E}-2$ \\
\hline $\mathrm{Cu}$ & [0.047] & {$[0.060]$} & $<1.7 \mathrm{E}-1$ & $<2.8 \mathrm{E}-2$ \\
\hline Dy & $<7.1 \mathrm{E}-2$ & $<7.1 \mathrm{E}-2$ & $<3.6 \mathrm{E}-1$ & $<5.7 \mathrm{E}-2$ \\
\hline $\mathrm{Eu}$ & $<2.7 \mathrm{E}-2$ & $<2.7 \mathrm{E}-2$ & $<1.4 \mathrm{E}-1$ & $<2.2 \mathrm{E}-2$ \\
\hline $\mathrm{La}$ & $<6.8 \mathrm{E}-2$ & $<6.9 \mathrm{E}-2$ & $<3.4 \mathrm{E}-1$ & $<5.5 \mathrm{E}-2$ \\
\hline $\mathrm{Li}$ & [0.29] & 0.318 & {$[0.15]$} & 0.239 \\
\hline $\mathrm{Mg}$ & $<5.6 \mathrm{E}-2$ & $<5.6 \mathrm{E}-2$ & $<2.8 \mathrm{E}-1$ & $<4.5 \mathrm{E}-2$ \\
\hline Mo & $<1.3 \mathrm{E}-1$ & $<1.3 \mathrm{E}-1$ & $<6.4 \mathrm{E}-1$ & {$[0.23]$} \\
\hline $\mathrm{Nd}$ & $<1.3 \mathrm{E}-1$ & $<1.3 \mathrm{E}-1$ & $<6.6 \mathrm{E}-1$ & $<1.1 \mathrm{E}-1$ \\
\hline $\mathrm{Pb}$ & $<7.8 \mathrm{E}-1$ & $<7.8 \mathrm{E}-1$ & [1.5] & $<6.3 \mathrm{E}-1$ \\
\hline $\mathrm{Pd}$ & {$[0.20]$} & $<1.5 \mathrm{E}-1$ & $<7.7 \mathrm{E}-1$ & $<1.2 \mathrm{E}-1$ \\
\hline $\mathrm{Rh}$ & $<2.9 \mathrm{E}-1$ & $<2.9 \mathrm{E}-1$ & $<1.5 \mathrm{E}+0$ & {$[0.24]$} \\
\hline $\mathrm{Ru}$ & $<2.1 \mathrm{E}-1$ & $<2.1 \mathrm{E}-1$ & $<1.0 \mathrm{E}+0$ & $<1.7 \mathrm{E}-1$ \\
\hline
\end{tabular}


Table 5.39 (Contd)

\begin{tabular}{||l|c|c|c|c||}
\hline & Wash 1 & Wash 2 & Wash 3 & Composite Wash \\
\hline AsO Sample ID & $\mathbf{0 8 - 0 1 3 1 3}$ & $\mathbf{0 8 - 0 1 3 1 4}$ & $\mathbf{0 8 - 0 1 2 9 4}$ & $\mathbf{0 8 - 0 1 2 9 5}$ \\
\hline \multicolumn{2}{|c|}{ Opportunistic Analytes } & & & \\
\hline Analyte & $\mu \mathbf{g} / \mathbf{m L}$ & $\mu \mathbf{g} / \mathbf{m L}$ & $\mu \mathbf{g} / \mathbf{m L}$ & $\mu \mathbf{g} / \mathbf{m L}$ \\
\hline $\mathrm{Sb}$ & $<4.9 \mathrm{E}-1$ & $<4.9 \mathrm{E}-1$ & $<2.5 \mathrm{E}+0$ & $<3.9 \mathrm{E}-1$ \\
\hline $\mathrm{Se}$ & {$[4.0]$} & {$[8.8]$} & {$[2.0]$} & $<1.4 \mathrm{E}+0$ \\
\hline $\mathrm{Sn}$ & {$[2.4]$} & {$[1.4]$} & $<3.3 \mathrm{E}+0$ & $<5.3 \mathrm{E}-1$ \\
\hline $\mathrm{Ta}$ & $<4.1 \mathrm{E}-1$ & $<4.2 \mathrm{E}-1$ & $<2.1 \mathrm{E}+0$ & $<3.4 \mathrm{E}-1$ \\
\hline $\mathrm{Te}$ & $<6.3 \mathrm{E}-1$ & $<6.4 \mathrm{E}-1$ & $<3.2 \mathrm{E}+0$ & {$[0.59]$} \\
\hline $\mathrm{Th}$ & {$[0.43]$} & {$[0.43]$} & $<1.2 \mathrm{E}+0$ & {$[0.31]$} \\
\hline $\mathrm{Ti}$ & $<1.0 \mathrm{E}-2$ & {$[0.015]$} & $<5.3 \mathrm{E}-2$ & {$[0.012]$} \\
\hline $\mathrm{Tl}$ & $<9.3 \mathrm{E}-1$ & $<9.3 \mathrm{E}-1$ & $<4.7 \mathrm{E}+0$ & $<7.5 \mathrm{E}-1$ \\
\hline $\mathrm{V}$ & 0.244 & 0.208 & {$[0.099]$} & {$[0.14]$} \\
\hline $\mathrm{W}$ & {$[0.47]$} & $<4.7 \mathrm{E}-1$ & $<2.3 \mathrm{E}+0$ & $<3.7 \mathrm{E}-1$ \\
\hline $\mathrm{Y}$ & $<1.1 \mathrm{E}-2$ & $<1.1 \mathrm{E}-2$ & $<5.4 \mathrm{E}-2$ & $<8.7 \mathrm{E}-3$ \\
\hline
\end{tabular}

(a) Density values were obtained from the mass flow meter, which had not been calibrated to NQA-1 standards; they are reported for information only.

ASR 8113 Reference date: November 5, 2007.

Analyte uncertainties were typically within $\pm 15 \%$; results in brackets indicate that the analyte concentrations were greater than the method detection limit (MDL) and less than the estimated quantitation limit (EQL), and uncertainties were $>15 \%$.

Opportunistic analytes are reported for information only; QC requirements did not apply to these analytes. 


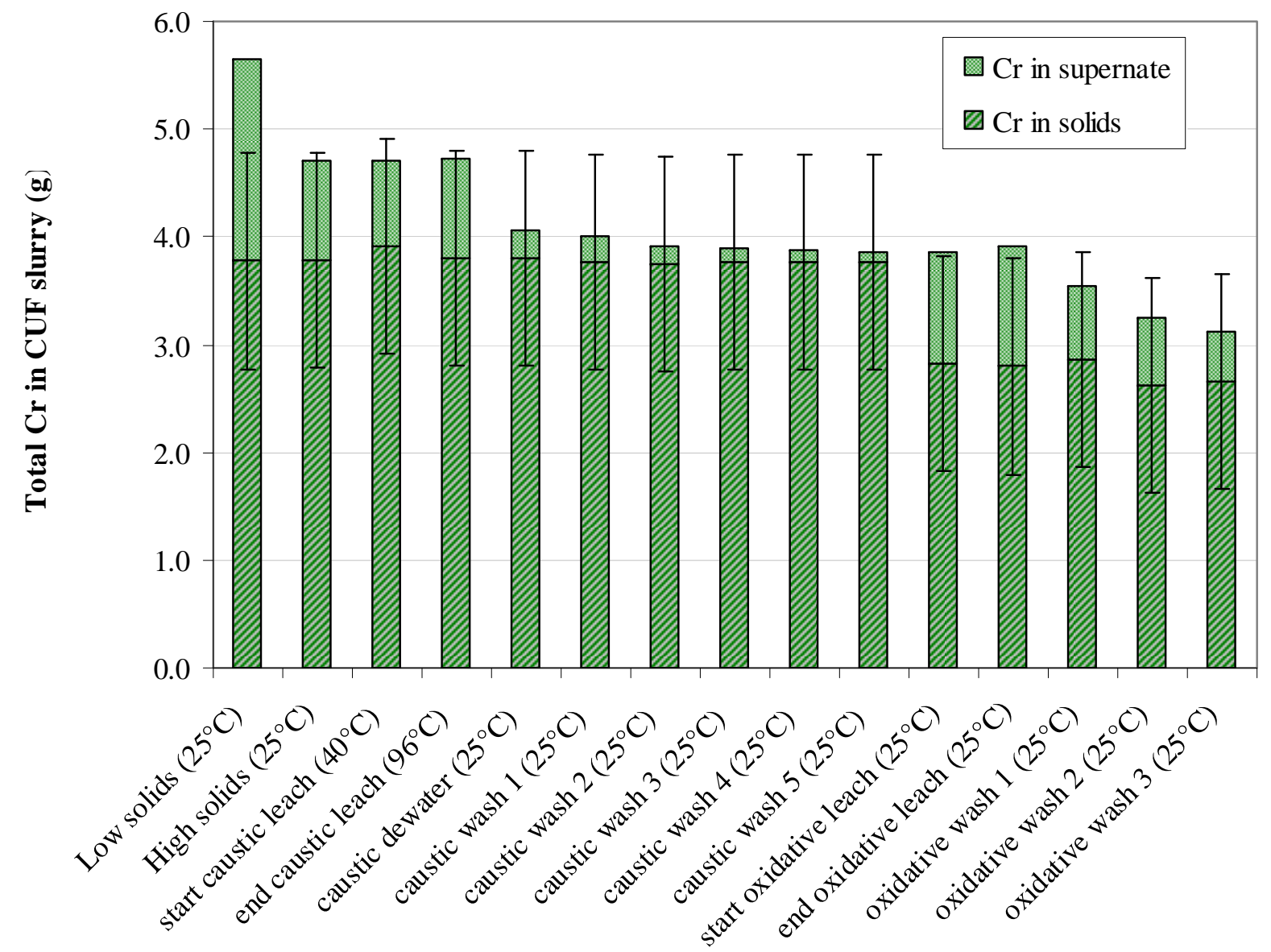

*Temperatures on $X$-axis represent the slurry temperature when sampled

Figure 5.56. Normalized Chromium Inventory in Group 1/2 Slurry through Oxidative Leach and Washing (Inventory in Figure Normalized to Eliminate Sample Loss Impacts.) 

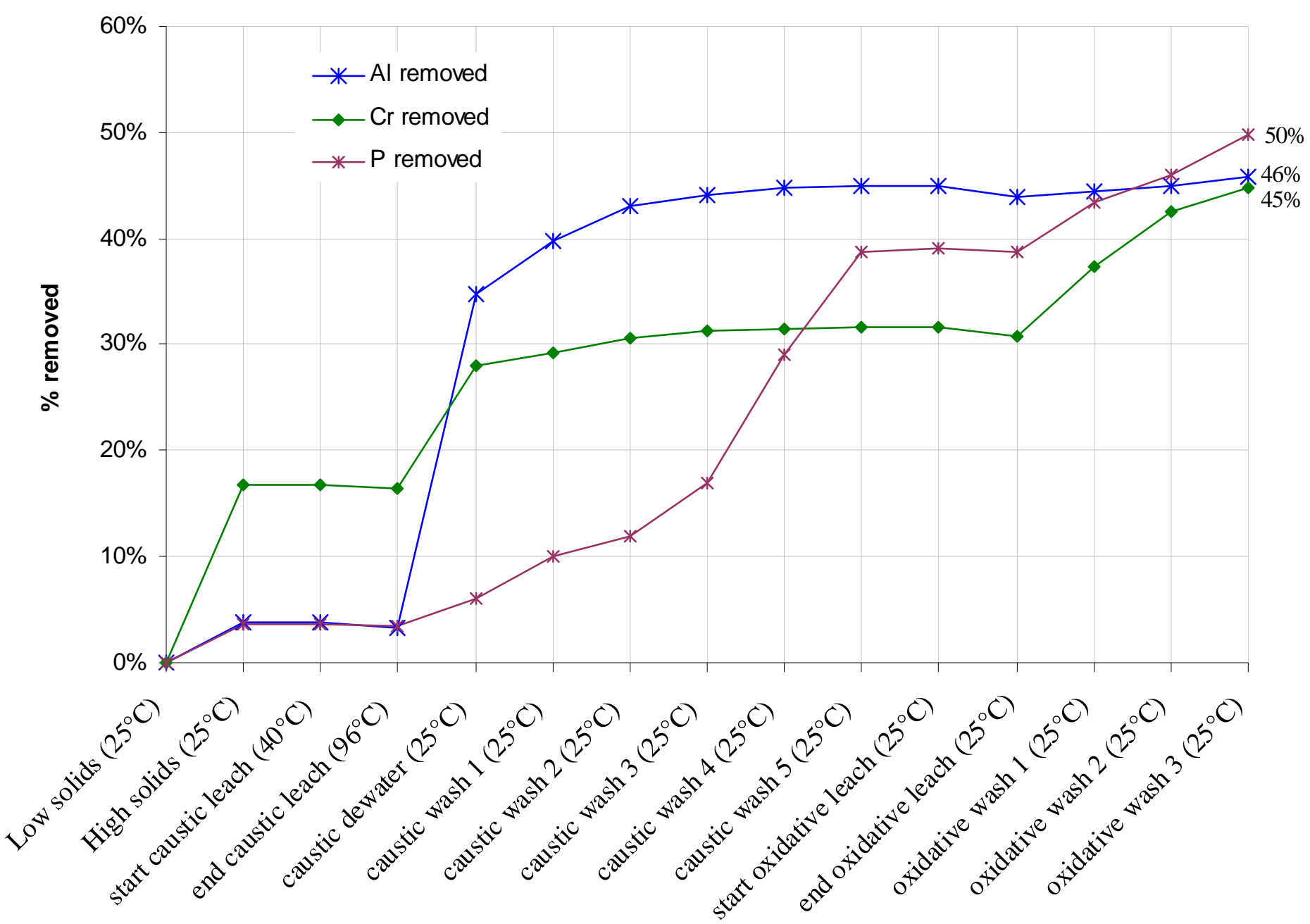

*Temperatures on $X$-axis represent the slurry temperature when sampled.

Figure 5.57. Chromium, Phosphorus, and Aluminum Behavior in the Group 1/2 CUF Slurry (Changes in Inventory in Figure Normalized to Eliminate Sample Loss Impacts.) 


\subsubsection{Dewatering Oxidative Washes Results}

The oxidative leach slurry was washed three times with 1.2-L portions of $0.01 \mathrm{M} \mathrm{NaOH}$. The full volume of each wash solution was mixed and dewatered from the slurry before adding the next wash solution. The filter flux during the oxidative leach washing steps is given in Figure 5.58. The chart contains a second axis for process temperature because the first two washes were conducted above the specified ambient process temperature.

This situation occurred because the chiller was not turned on again after the oxidative leach step. It is typical to put the chiller into stand-by mode during leaching steps and to start it again when filtration starts. In this case, the situation was realized near the beginning of the second wash, and the flux data corresponded to the decrease in temperature in that wash. Both corrected and uncorrected flux data (Equation K.3, Appendix K) are presented in the chart. If the temperature correction can be rightly extended to the range of temperatures in the wash steps, it may be asserted that the flux was essentially constant for the three wash steps $\left(\sim 0.040 \mathrm{GPM} / \mathrm{ft}^{2}\right)$. This is reasonable based on the fact that the permeate would be expected to change little between subsequent washings as only a relatively small amount of dissolved material is being washed away from the slurry. 


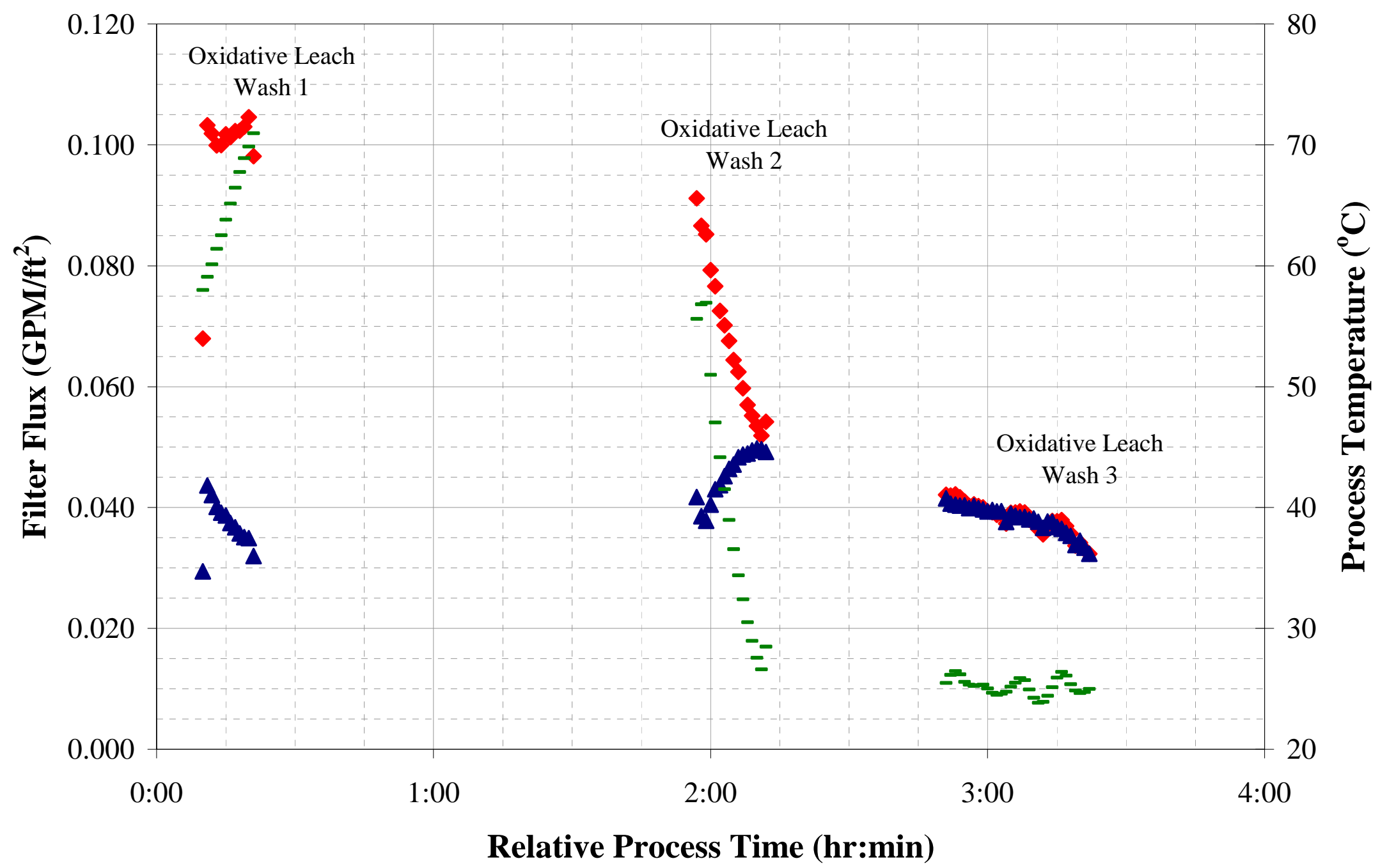

Flux at Process Temperature $\boldsymbol{\Delta}$ Corrected Flux at 25C - Process Temperature

Figure 5.58. Flux Data from Dewatering Oxidative Washes 


\subsection{Final Dewater and Filter Flux Test Matrix}

Figure 5.59 illustrates the material flow during the final filter flux testing matrix. Following the dewatering of the third wash of the oxidative leach slurry, approximately $300 \mathrm{~mL}$ of G2-OxWash3 permeate was added back to the slurry reservoir to aid pumping for the leached-solids filtration test matrix. Tests were performed according to the conditions described in Table K.2, Appendix K, sequentially with a minimum of 1 hour of constant recycle operation at each condition and back-pulsing between test conditions. The AV could not be increased beyond $15 \mathrm{ft} / \mathrm{s}$ at TMP=40 psid without exceeding the maximum operating speed of the pump. The measured UDS concentration of the slurry was $7.0 \%$ according to physical-properties measurements, while mass balance calculations project it to be over 2 times greater. Table 5.40 provides a summary of the average operating conditions and flux for each condition, and Figure 5.61 plots the average TMP and AV measured from each test condition against the target TMP and AV planned for the test. These values were obtained by calculating the arithmetic mean of each value over the duration of the test condition.

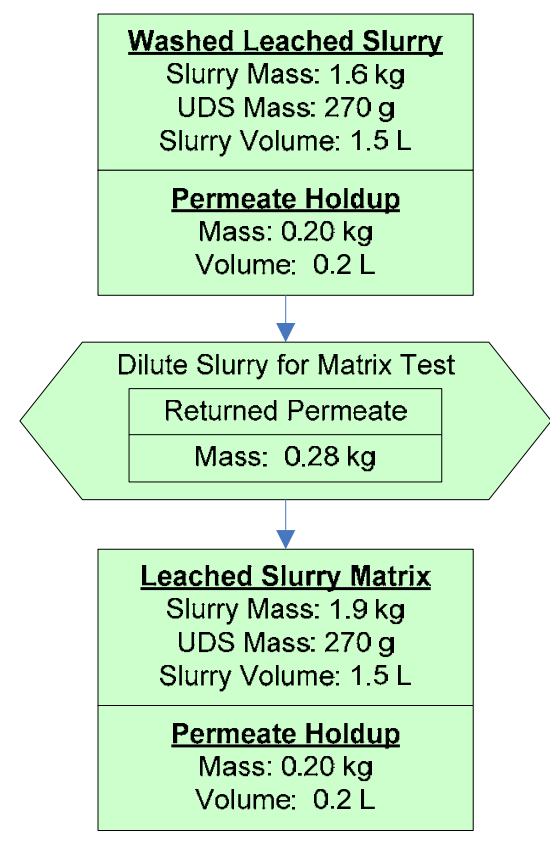

Figure 5.59. Flow Diagram for the Final Filter Flux Test Matrix Note: Mass and volume values in figure are rounded to the nearest significant digit of accuracy.

The average filter flux ranged from $0.015 \mathrm{GPM} / \mathrm{ft}^{2}$ for Test Condition 5 to $0.038 \mathrm{GPM} / \mathrm{ft}^{2}$ for Test Condition 6 . The filter flux was approximately $50 \%$ higher for this test matrix compared to the initial low-solids matrix for similar conditions. There was an observed decrease of permeate flux at the standard condition with time. The three tests at the standard condition (Test Conditions 1, 4, and 7) had average fluxes of $0.034,0.032$, and $0.028 \mathrm{GPM} / \mathrm{ft}^{2}$, respectively, a relative percent decrease of $18 \%$. The flux for Test Condition 4 might be on a slightly higher basis when compared to the other two as the TMP was slightly higher than the TMP for Test Conditions 1 and 7. Filter flux data are shown in Figure 5.60 with blue symbols for $\mathrm{TMP}=40$ psid, pink for TMP=20 psid, and green for TMP=60 psid.

As can be seen by inspecting Figure 5.62 and Figure 5.63, the flux is dependent on both TMP and AV, defying a simple classification of the slurry into a membrane-resistance or cake-resistance model. 
Figure 5.64 also demonstrated a negative trend in the filter flux over the course of the test, which was similar in magnitude to that seen in the previous filter tests, indicating that the filter resistance was still changing after days of testing. The data were further correlated and fitted to validate these conclusions. The results of this analysis are shown in Figure 5.65 and Figure 5.66. From the fit equations, TMP and $\mathrm{AV}$ were shown to have equal impact on filter flux. The operation time was also shown to have the same negative impact on filter flux seen from the previous filter testing. This implies that the agents in the slurry causing the irreversible fouling on the filter were not removed from caustic or oxidative leaching, such as iron. While both modeling equations have high correlation factors, the use of this model should be limited to understanding how filter flux was influenced by TMP, AV, and operation time during this test. Because all three parameters were included in both models, offset parameters were developed, which limits the range that they could be applied. Both models do not predict a zero filter flux when the TMP and AV is zero, which demonstrates that the input to these models must be bound by the range of TMP and AV used in this filter test, shown in Table 5.8. The use of these models should also be limited to when the test matrix occurred because the filter resistance was not at steady state, and the parameters developed in these models would be expected to change past the 8-hour period that this model predicts.

Table 5.40. Average Operating Conditions and Filter Flux for the High-Solids Matrix Test

\begin{tabular}{|c|c|c|c|c|c|c|c|}
\hline $\begin{array}{c}\text { Design } \\
\text { Test } \\
\text { Condition }\end{array}$ & $\begin{array}{c}\text { Median } \\
\text { Operation } \\
\text { Time of } \\
\text { Test }^{\left({ }^{(a)}\right.}(\mathrm{hr})\end{array}$ & $\begin{array}{c}\text { Slurry } \\
\text { Temp }^{(b)} \\
\left({ }^{\circ} \mathrm{C}\right)\end{array}$ & $\begin{array}{c}\mathrm{TMP}^{(\mathrm{c})} \\
\text { (psid) }\end{array}$ & $\begin{array}{c}\text { Axial } \\
\text { Velocity } \\
\text { (ft/s) }\end{array}$ & $\begin{array}{l}\text { Permeate } \\
\text { Flowrate } \\
\text { (mL/min) }\end{array}$ & $\begin{array}{c}\text { Corrected } \\
\text { Permeate } \\
\text { Flux } \\
\left(\mathrm{GPM} / \mathrm{ft}^{2}\right)\end{array}$ & $\begin{array}{c}\text { Axial } \\
\text { Pressure } \\
\text { Drop }^{(\mathrm{c})} \\
\text { (psid/ft) }\end{array}$ \\
\hline 1 & 1.0 & 24.9 & 37.8 & 13.3 & 33.6 & 0.034 & 0.5 \\
\hline 2 & 2.5 & 25.1 & 38.9 & 15.1 & 34.0 & 0.034 & 0.2 \\
\hline 3 & 3.6 & 25.0 & 38.9 & 8.7 & 23.6 & 0.024 & 1.1 \\
\hline 4 & 4.6 & 25.0 & 41.2 & 13.1 & 31.9 & 0.032 & 0.4 \\
\hline 5 & 5.6 & 25.0 & 19.4 & 12.9 & 15.1 & 0.015 & 0.7 \\
\hline 6 & 6.5 & 25.2 & 59.1 & 12.8 & 37.5 & 0.038 & 0.3 \\
\hline 7 & 7.8 & 25.1 & 39.1 & 13.2 & 27.7 & 0.028 & 0.5 \\
\hline \multicolumn{8}{|c|}{$\begin{array}{l}\text { (a) Median operation time refers to the midpoint in processing time of the specific filtration test condition relative to the start } \\
\text { time of the test }(\mathrm{T}=0) \text {. Time periods between test conditions were excluded. } \\
\text { (b) Thermocouple accuracy } \pm 2^{\circ} \mathrm{C} \text {. }\end{array}$} \\
\hline
\end{tabular}




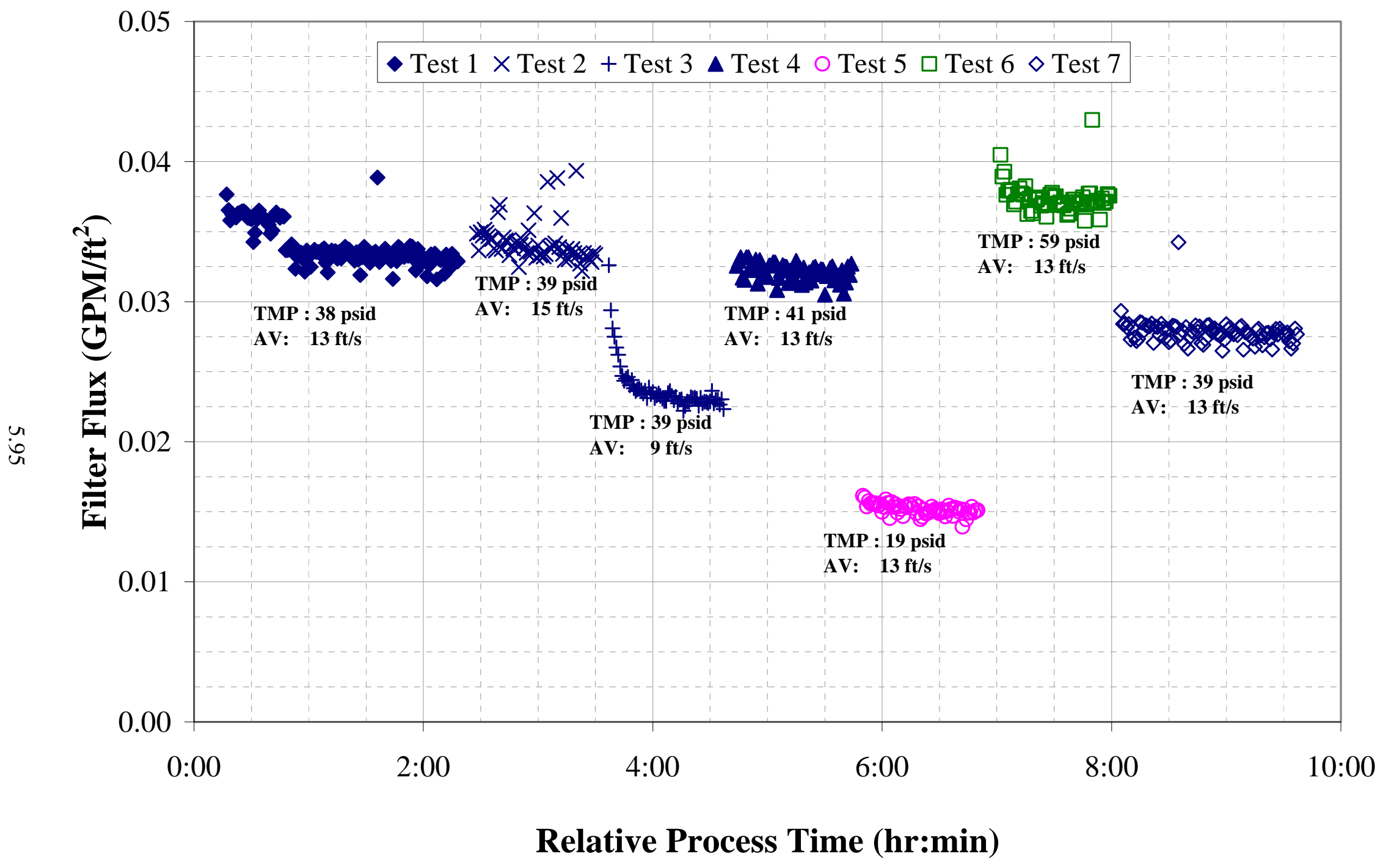

Figure 5.60. Final Filter Flux Testing of Washed Leached Group $1 / 2$ Solids, 7-wt\% UDS 


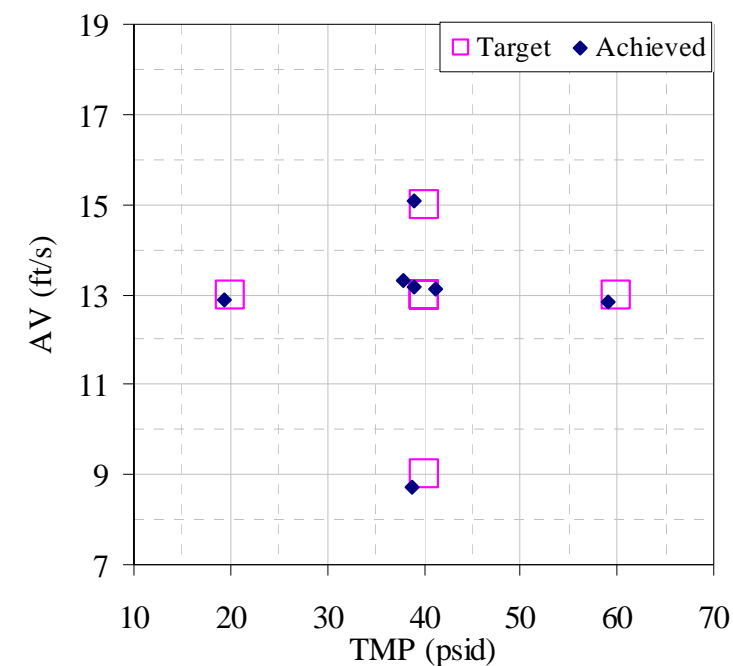

Figure 5.61. Group 1/2 Filter Test Matrix for Leached-Solids

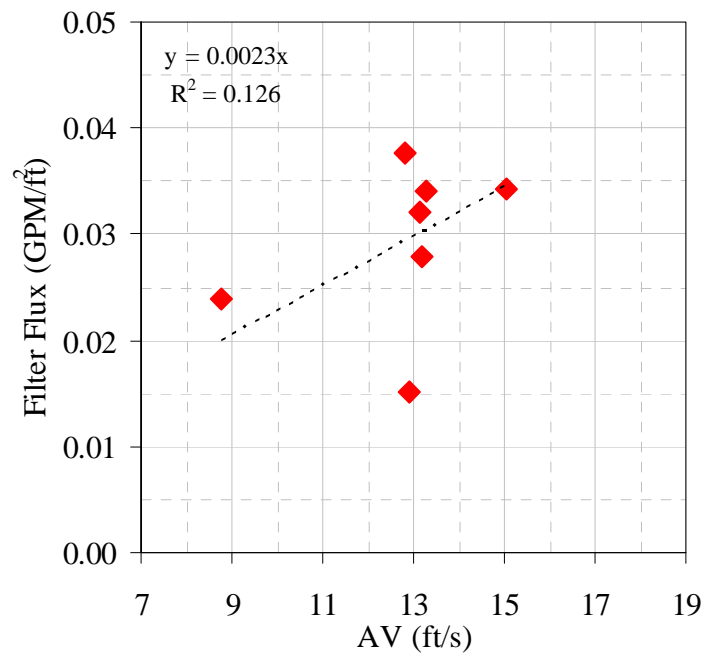

Figure 5.63. Group $1 / 2$ Flux vs. AV for Leached-Solids

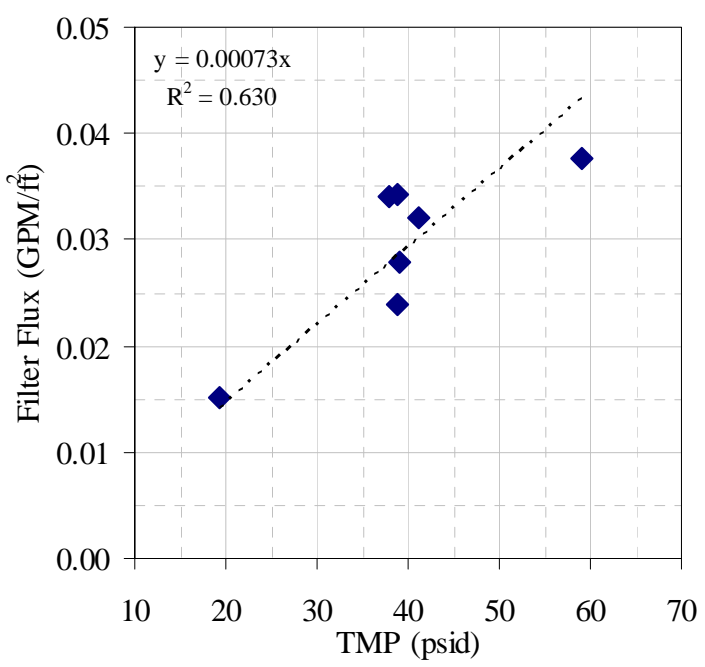

Figure 5.62. Group 1/2 Flux vs. TMP for Leached-Solids

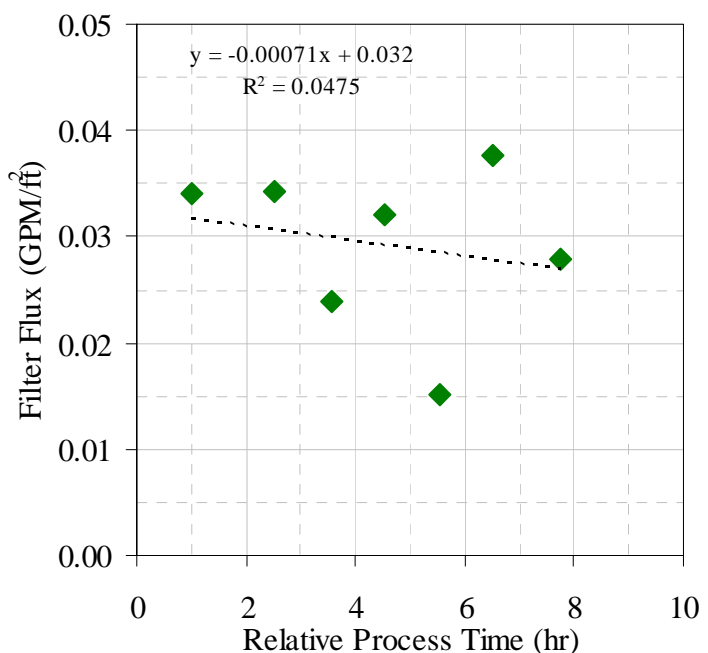

Figure 5.64. Group 1/2 Flux vs. Relative Time for LeachedSolids 


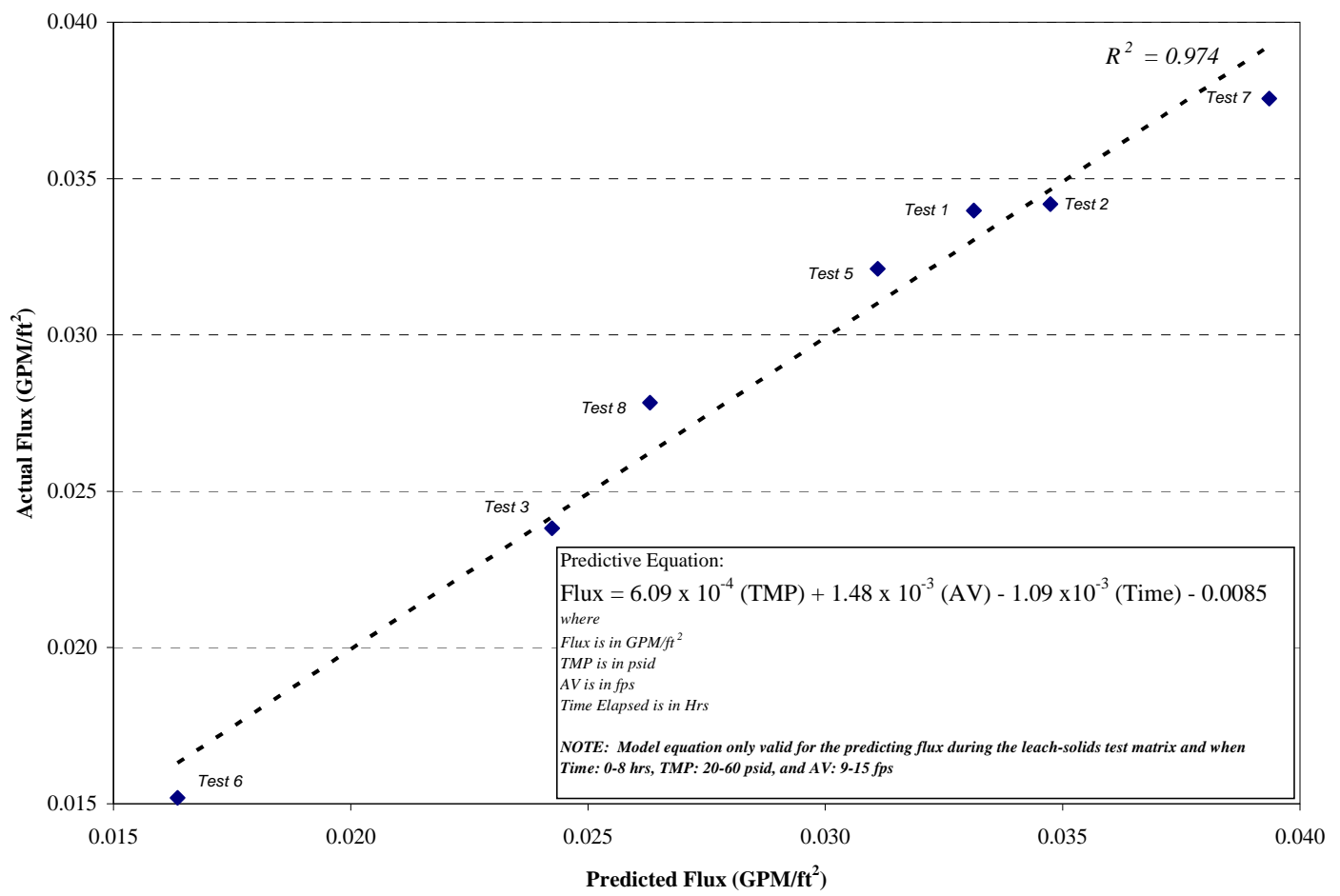

Figure 5.65. Linear Model of Filter Flux for Leached Group 1/2 Slurry

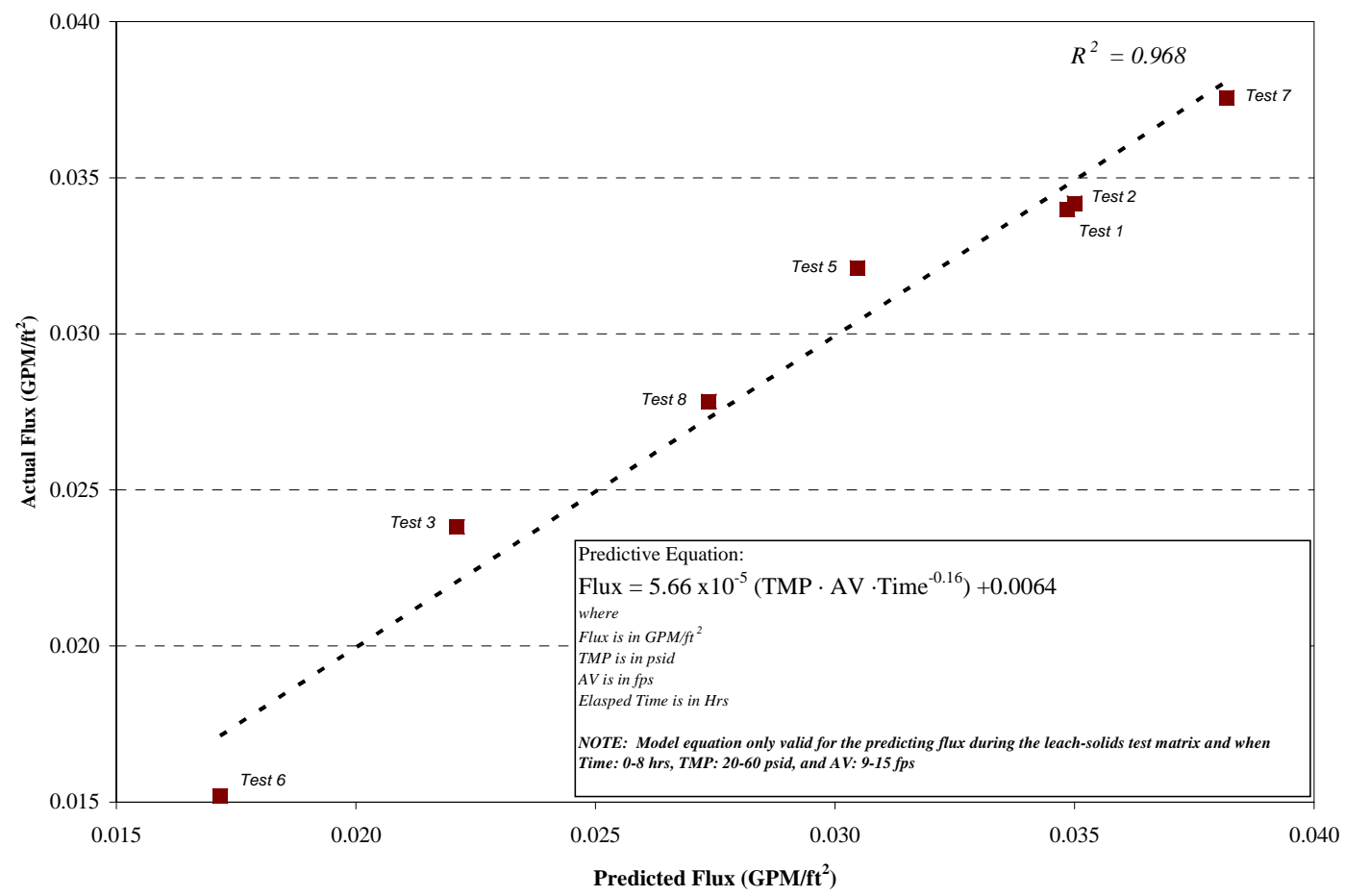

Figure 5.66. Exponential Model of Filter Flux for Leached Group 1/2 Slurry 
After the conclusion of the leached solids matrix, the slurry was sampled and recovered from the system. The CUF was rinsed with $0.01 \mathrm{M} \mathrm{NaOH}$ to flush out residual solids from the tank and circulation loop. After several such rinses were complete, a CWF test was performed at TMP=10, 20, and 30 psid and $A V=11 \mathrm{ft} / \mathrm{s}$. This test captured the condition of the filter before acid cleaning. The system was then drained and cleaned by adding and circulating $1.5 \mathrm{~L}$ of $2 \mathrm{M} \mathrm{HNO}_{3}$. Following this acid cleaning step, the system was rinsed with several liters of $0.01 \mathrm{M} \mathrm{NaOH}$ to dilute and flush the acid from the system, and another CWF test was performed. The results from these two CWF tests are presented in Figure 5.67.

Each TMP condition of a CWF test is characterized by a starting and final value on account of the rapid flux decay observed for these tests. There are several observations to make relative to these CWF tests:

- Overall, the CWF is an order of magnitude less than that recorded for the clean filter (see Figure K.9, Appendix K). This indicates that significant irreversible membrane fouling has occurred since loading the CUF into the hot cell and running two leaching and filtration tests.

- The flux is lower after Group 1/2 waste leaching and filtration compared to measured pre-run values. This supports observations of time-dependent flux decrease in matrix tests.

- The flux actually decreases on average as a result of nitric acid cleaning, suggesting that the nitric acid cleaning accomplishes nothing in terms of membrane resistance and may cause an apparent decrease in CWF by loosening solids on the tank walls and other exposed surfaces that are able to surface-foul the filter during CWF tests. This assertion rests on the observation that the flux can be repeatedly restored to a high initial value during CWF tests by back-pulsing.

There was clearly significant irreversible membrane fouling present at this point in the actual waste CUF testing that seems not to be affected by rinsing with inhibited water or by nitric acid cleaning. Because the iron content of the waste was higher than the previous materials tested (Group 5 and 6), it was suspected that iron particles, which would not be affected by leaching operations or a 2-M nitric clean, were the likely fouling agents. After the test was completed, the system was cleaned using $0.5 \mathrm{M}$ oxalic acid before the next test. This cleaning solution was used because it had been proven to be effective in cleaning the filter system used for simulant development when dealing with iron rich simulants. The CWF testing of the filter before and after cleaning are shown in Figure 5.68. After cleaning, the filter flux improved from $0.036 \mathrm{GPM} / \mathrm{ft}^{2}$ to $0.76 \mathrm{GPM} / \mathrm{ft}^{2}$ at a TMP of $20 \mathrm{psid}$ and an $\mathrm{AV}$ of $11 \mathrm{ft} / \mathrm{s}$ after running at steady state for 15 minutes. The dramatic improvement to the CWF supported the assumption that iron in the waste was likely fouling the filter over the course of the test. 
WTP-RPT-166, Rev. 0

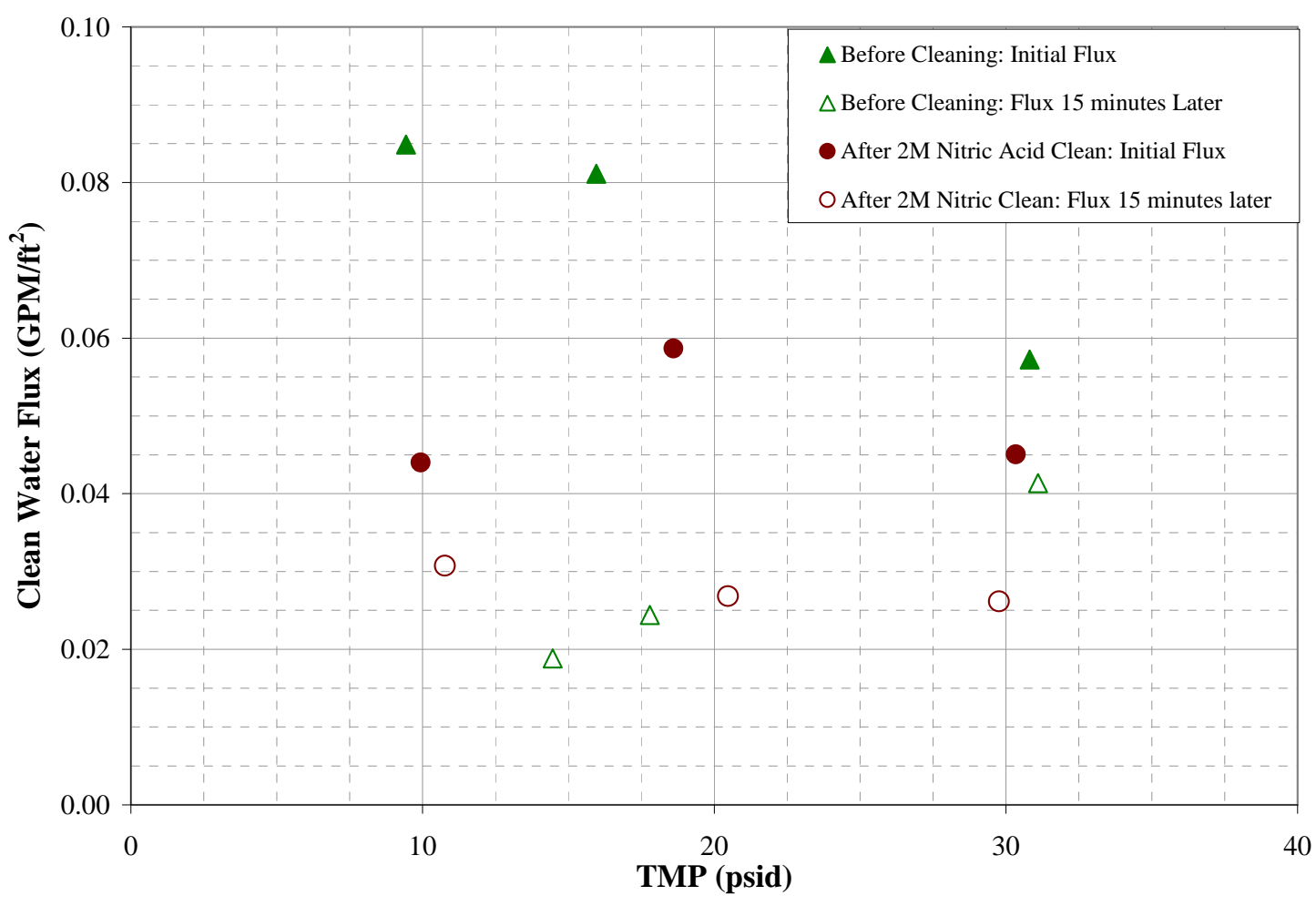

Figure 5.67. CWF Tests Before and After 2-M Nitric Cleaning

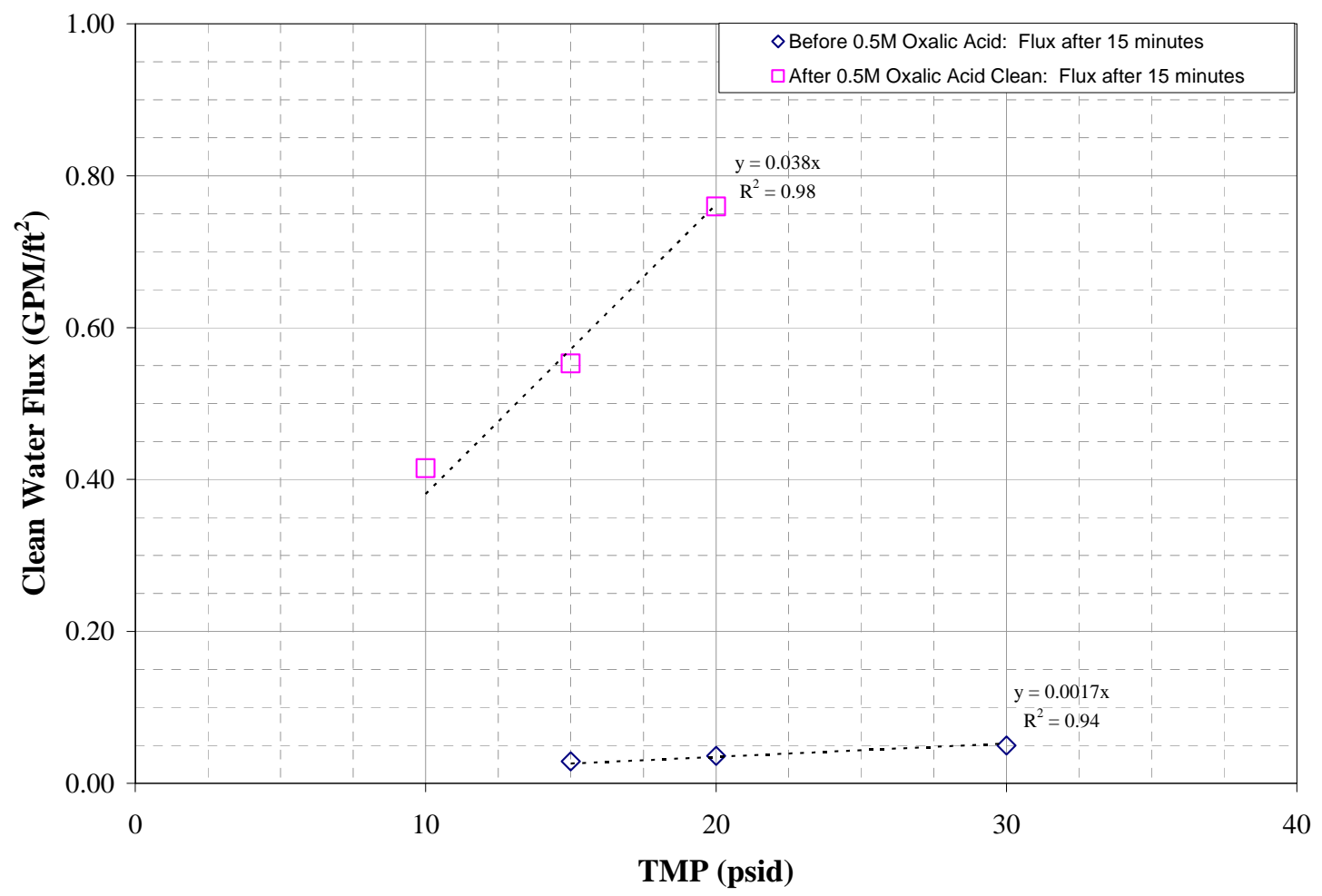

Figure 5.68. CWF Testing Before and After Cleaning with 0.5-M Oxalic Acid Note: Filter flux measurements after oxalic acid cleaning were performed with a user calibrated flow device. 


\subsection{Characterization of the Washed Oxidative Slurry}

To achieve a slurry composition that could meet test conditions for the leached high-solids matrix test, 288 grams of the third oxidative wash was added back to the CUF slurry. After completing the filter test matrix, the slurry was sub-sampled for physical and chemical characterization (Figure 5.69). Physicalproperty measurements of the final slurry are shown in Table 5.41 and the overall composition in Table 5.42 and Table 5.43. However, the results from Table 5.41 and Table 5.43 are likely skewed because the overhead mixer did not work. There are large differences in the reported composition of the UDS when comparing the results of Table 5.42 (based on mass balance calculations) and Table 5.43 (based on the slurry composition sample). With the mixer not operating, the sampled slurry was likely not representative of the slurry in its entirety.

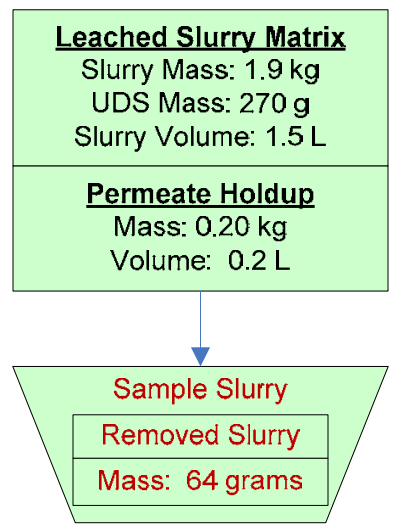

Figure 5.69. Sampling of the Leached Matrix Test Slurry

Note: Mass and volume values in figure are rounded to the nearest significant digit of accuracy.

Table 5.41. Physical Property Measurements of the CUF 1/2 Washed Oxidative Leached Slurry

\begin{tabular}{|r|c||}
\hline Slurry Density (g/mL) & 1.05 \\
\hline Supernate Density (g/mL) & 0.98 \\
\hline Settled Solids (Vol\%) & $52 \%$ \\
\hline Centrifuged UDS (Wt $\%)$ & $33 \%$ \\
\hline Total Solids of the Slurry (Wt\%) & $7.0 \%$ \\
\hline Dissolved Solids of the Supernate (Wt $\%)$ & $0.56 \%$ \\
\hline UDS of the Slurry $(\mathbf{W t} \%)$ & $6.5 \%$ \\
\hline
\end{tabular}


WTP-RPT-166, Rev. 0

Table 5.42. CUF 1/2 Caustic and Oxidative Leached Material (final slurry including permeate hold-up)

\begin{tabular}{|c|c|c|c|c|c|}
\hline & Slurry $^{(a)}$ & \multicolumn{2}{|c|}{ Liquid Fraction $^{(b)}$} & \multicolumn{2}{|c|}{ Solids Fraction ${ }^{(c)}$} \\
\hline Mass (kg) & 1.78 & \multicolumn{2}{|c|}{1.51} & \multicolumn{2}{|c|}{0.26} \\
\hline Wt\% of Slurry & $100 \%$ & \multicolumn{2}{|c|}{$85.2 \%$} & \multicolumn{2}{|c|}{$14.8 \%$} \\
\hline Metal & g & g & $\mu g / m L$ & g & $\mu \mathrm{g} / \mathrm{g}$ \\
\hline Al & $2.1 \mathrm{E}+01$ & $1.3 \mathrm{E}-01$ & $8.7 \mathrm{E}+01$ & $2.0 \mathrm{E}+01$ & $7.8 \mathrm{E}+04$ \\
\hline Bi & $1.5 \mathrm{E}+01$ & 4.3E-03 & $2.8 \mathrm{E}+00$ & $1.5 \mathrm{E}+01$ & $5.7 \mathrm{E}+04$ \\
\hline $\mathrm{Cr}$ & $2.0 \mathrm{E}+00$ & $2.0 \mathrm{E}-01$ & $1.3 \mathrm{E}+02$ & $1.8 \mathrm{E}+00$ & $6.8 \mathrm{E}+03$ \\
\hline $\mathbf{F e}$ & $2.1 \mathrm{E}+01$ & $1.2 \mathrm{E}-03$ & 7.7E-01 & $2.1 \mathrm{E}+01$ & $7.8 \mathrm{E}+04$ \\
\hline Mn & $1.6 \mathrm{E}+00$ & $1.9 \mathrm{E}-05$ & 1.3E-02 & $1.6 \mathrm{E}+00$ & $6.1 \mathrm{E}+03$ \\
\hline $\mathrm{Na}$ & 7.6E+01 & $4.6 \mathrm{E}+00$ & $3.0 \mathrm{E}+03$ & 7.1E+01 & $2.7 \mathrm{E}+05$ \\
\hline $\mathbf{P}$ & $1.8 \mathrm{E}+01$ & 7.3E-01 & $4.7 \mathrm{E}+02$ & $1.7 \mathrm{E}+01$ & $6.4 \mathrm{E}+04$ \\
\hline $\mathbf{S}$ & $6.4 \mathrm{E}-02$ & 4.5E-02 & $2.9 \mathrm{E}+01$ & $1.9 \mathrm{E}-02$ & $7.2 \mathrm{E}+01$ \\
\hline $\mathrm{Si}$ & $1.2 \mathrm{E}+01$ & $1.8 \mathrm{E}-02$ & $1.2 \mathrm{E}+01$ & $1.2 \mathrm{E}+01$ & $4.7 \mathrm{E}+04$ \\
\hline Sr & $1.2 \mathrm{E}+00$ & $1.1 \mathrm{E}-05$ & 6.9E-03 & $1.2 \mathrm{E}+00$ & 4.7E+03 \\
\hline $\mathbf{U}$ & $5.1 \mathrm{E}+00$ & $<6 . \mathrm{E}-3$ & $<4 . \mathrm{E}+0$ & $5.1 \mathrm{E}+00$ & $1.9 \mathrm{E}+04$ \\
\hline \multirow{2}{*}{$\begin{array}{l}\text { Radiochemical } \\
\text { Isotopes }\end{array}$} & Slurry & \multicolumn{2}{|c|}{ Liquid Fraction } & \multicolumn{2}{|c|}{ Solid Fraction } \\
\hline & mCi & mCi & $\mathrm{mCi} / \mathbf{m L}$ & mCi & $\mathrm{mCi} / \mathrm{g}$ \\
\hline Co-60 & $2.2 \mathrm{E}+00$ & $<3 . \mathrm{E}-2$ & $<2$.E-5 & $2.2 \mathrm{E}+00$ & 8.5E-03 \\
\hline Cs-137 & $2.6 \mathrm{E}+04$ & $3.3 \mathrm{E}+02$ & $2.1 \mathrm{E}-01$ & $2.6 \mathrm{E}+04$ & $9.9 \mathrm{E}+01$ \\
\hline Eu-154 & $1.1 \mathrm{E}+01$ & $<9 . \mathrm{E}-2$ & $<6 . \mathrm{E}-5$ & $1.1 \mathrm{E}+01$ & 4.3E-02 \\
\hline Am-241 & $1.1 \mathrm{E}+02$ & $<2$.E-1 & $<1$.E-4 & $1.1 \mathrm{E}+02$ & 4.2E-01 \\
\hline Gross Alpha & $2.0 \mathrm{E}+02$ & $<1 . \mathrm{E}+0$ & $<7 . \mathrm{E}-4$ & $2.0 \mathrm{E}+02$ & 7.6E-01 \\
\hline Gross Beta & $1.3 \mathrm{E}+05$ & $2.8 \mathrm{E}+02$ & $1.8 \mathrm{E}-01$ & $1.3 \mathrm{E}+05$ & $4.8 \mathrm{E}+02$ \\
\hline Sr-90 & $4.8 \mathrm{E}+04$ & 2.9E-01 & $1.9 \mathrm{E}-04$ & $4.8 \mathrm{E}+04$ & $1.8 \mathrm{E}+02$ \\
\hline Pu-239+240 & $1.5 \mathrm{E}+02$ & $<4 . \mathrm{E}-3$ & $<3$. E-6 & $1.5 \mathrm{E}+02$ & $5.6 \mathrm{E}-01$ \\
\hline Pu-238 & $5.4 \mathrm{E}+00$ & $<4$. E-3 & $<3$. E- 6 & $5.4 \mathrm{E}+00$ & $2.0 \mathrm{E}-02$ \\
\hline \multirow[t]{2}{*}{ Anions } & \multicolumn{3}{|c|}{ Liquid Fraction } & \multicolumn{2}{|c|}{ Leached Solids Fraction } \\
\hline & $\mu g / m L$ & [M] & $\mathbf{g}$ & $\mu g / g$ & g \\
\hline $\mathbf{F}$ & $2.2 \mathrm{E}+02$ & $1.2 \mathrm{E}-02$ & 3.5E-01 & $2.2 \mathrm{E}+03$ & 5.8E-01 \\
\hline $\mathrm{C}_{2} \mathbf{O}_{4}$ & $7.4 \mathrm{E}+01$ & 8.4E-04 & $1.1 \mathrm{E}-01$ & $1.2 \mathrm{E}+03$ & 3.2E-01 \\
\hline $\mathrm{NO}_{2}$ & $2.5 \mathrm{E}+01$ & 5.5E-04 & 3.9E-02 & $3.3 \mathrm{E}+02$ & 8.6E-02 \\
\hline $\mathrm{NO}_{3}$ & $7.1 \mathrm{E}+02$ & $1.1 \mathrm{E}-02$ & $1.1 \mathrm{E}+00$ & $1.2 \mathrm{E}+04$ & $3.2 \mathrm{E}+00$ \\
\hline $\mathrm{SO}_{4}$ & $8.3 \mathrm{E}+01$ & 8.7E-04 & 1.3E-01 & $1.3 \mathrm{E}+03$ & 3.5E-01 \\
\hline $\mathrm{PO}_{4}$ & $1.5 \mathrm{E}+03$ & $1.6 \mathrm{E}-02$ & $2.3 E+00$ & $1.2 \mathrm{E}+04$ & $3.2 \mathrm{E}+00$ \\
\hline OH & $5.4 \mathrm{E}+02$ & 3.2E-02 & 8.4E-01 & & \\
\hline \multicolumn{6}{|c|}{$\begin{array}{l}\text { Slurry mass components were calculated from characterization data (Sections } 3 \text { and } 4 \text { ) and the } \\
\text { masses of materials that were added with simulant. Loss of mass from sampling was incorporated. } \\
\text { Liquid fraction mass components were calculated using analytical results from supernate sample } \\
\text { TI552-G6-O (ASO ID 08-01294) and the predicted mass of supernate in the system. } \\
\text { Solids fraction mass components were calculated from the difference between the slurry component } \\
\text { mass and liquid component mass fraction. }\end{array}$} \\
\hline
\end{tabular}


Table 5.43. Group 1/2 Washed Oxidative and Caustic Leach Slurry Composition and Overall Leach Factor Calculations Based on ICP-OES/Radiochemical Characterization

\begin{tabular}{|c|c|c|c|c|c|}
\hline $\begin{array}{c}\text { Slurry Prep } \\
\text { Method }\end{array}$ & $\begin{array}{l}\text { ICP-OES } \\
\text { Analytes }\end{array}$ & $\begin{array}{c}\text { Dry } \\
\text { Slurry }{ }^{(a)} \\
(\mu g / g)\end{array}$ & $\begin{array}{c}\text { Supernate }^{(b)} \\
(\mu \mathrm{g} / \mathrm{mL})\end{array}$ & $\begin{array}{c}\text { Dry Solids }{ }^{(\mathrm{c})} \\
(\mu \mathrm{g} / \mathrm{g})\end{array}$ & $\begin{array}{c}\text { Solids } \\
\text { Leach } \\
\text { Factor }^{(d)}\end{array}$ \\
\hline \multirow{35}{*}{$\begin{array}{l}\text { HF Assisted } \\
\text { Acid Digestion, } \\
\text { and KOH } \\
\text { Fusion, } \\
\text { Concentration } \\
\text { Factor of } \\
1.80 \text { based on } \\
\mathrm{U} \text { and Fe }\end{array}$} & Al & 77,950 & 86.6 & 82,966 & 0.54 \\
\hline & $\mathbf{B i}$ & 81,450 & {$[2.75]$} & 87,983 & 0.08 \\
\hline & Cd & 120 & $\begin{array}{l}{[0.22]} \\
\end{array}$ & 126 & -0.20 \\
\hline & $\mathrm{Cr}$ & 7,635 & 127 & 6,388 & 0.56 \\
\hline & $\mathbf{F e}$ & 104,000 & $\begin{array}{l}{[0.77]} \\
\end{array}$ & 112,382 & NA \\
\hline & $\mathbf{K}$ & {$[170]$} & {$[10.3]$} & [32] & [1.09] \\
\hline & Mn & 10,950 & {$[0.013]$} & 11,834 & -5.95 \\
\hline & $\mathrm{Na}$ & 123,000 & 2,985 & 88,971 & 0.76 \\
\hline & $\mathbf{N i}$ & 6,420 & $<3.0 \mathrm{E}-1$ & 6,934 & 0.01 \\
\hline & $\mathbf{P}$ & 14,400 & 470 & 8,641 & 0.95 \\
\hline & $\mathrm{S}$ & [945] & [29] & [594] & 1.07 \\
\hline & Si & 78600 & 11.7 & 84772 & 0.05 \\
\hline & $\mathrm{Sr}$ & 5740 & {$[0.0069]$} & 6203 & 0.04 \\
\hline & $\mathbf{U}$ & 27,250 & $<3.9 \mathrm{E}+0$ & 29,391 & NA \\
\hline & Zn & 495 & {$[0.56]$} & 527 & 0.46 \\
\hline & $\mathrm{Zr}$ & 517 & $<1.4 \mathrm{E}-1$ & 557 & $\begin{array}{l}-0.53 \\
\end{array}$ \\
\hline & $A g$ & [16] & $<2.6 \mathrm{E}-1$ & [13] & {$[0.32]$} \\
\hline & $B a$ & 361 & {$[0.160]$} & 388 & 0.08 \\
\hline & $B e$ & 0.675 & $<6.4 \mathrm{E}-3$ & 0.635 & 0.70 \\
\hline & Ca & 13,500 & {$[0.79]$} & 14,578 & 0.04 \\
\hline & $\mathrm{Ce}$ & 343 & $<1.2 \mathrm{E}+0$ & 353 & -0.05 \\
\hline & Co & 57.9 & $<3.0 \mathrm{E}-1$ & 58.2 & 0.23 \\
\hline & $\mathrm{Cu}$ & 114 & $<1.7 \mathrm{E}-1$ & 120 & 0.41 \\
\hline & $L a$ & 50.7 & $<3.4 \mathrm{E}-1$ & 49.7 & 0.20 \\
\hline & $\boldsymbol{L i}$ & 86.2 & {$[0.15]$} & 90.9 & 0.27 \\
\hline & $M g$ & 2,280 & $<2.8 \mathrm{E}-1$ & 2,460 & 0.05 \\
\hline & Mo & [41] & $<6.4 \mathrm{E}-1$ & [34] & {$[0.52]$} \\
\hline & $N d$ & 78.4 & $<6.6 \mathrm{E}-1$ & 74.9 & 0.05 \\
\hline & $P b$ & 1,945 & {$[1.5]$} & 2,080 & 0.15 \\
\hline & $R u$ & [16.8] & $<1.5 \mathrm{E}+0$ & -[3.58] & [1.09] \\
\hline & Th & [27] & $<3.2 \mathrm{E}+0$ & $-[18]$ & $-[42.23]$ \\
\hline & $\mathrm{Ti}$ & 248 & $<1.2 \mathrm{E}+0$ & 250 & 0.08 \\
\hline & $T I$ & [110] & $<5.3 \mathrm{E}-2$ & [118] & {$[0.67]$} \\
\hline & $V$ & 34.7 & $<4.7 \mathrm{E}+0$ & -31.3 & 2.05 \\
\hline & $Y$ & 10.9 & $<5.4 \mathrm{E}-2$ & 11.0 & 0.05 \\
\hline
\end{tabular}


Table 5.43. (Contd)

\begin{tabular}{|c|c|c|c|c|c|}
\hline $\begin{array}{l}\text { Slurry Prep } \\
\text { Method }\end{array}$ & Radionuclides & $\begin{array}{c}\text { Dry } \\
\text { Slurry }^{(a)} \\
(\mu \mathrm{Ci} / \mathrm{g})\end{array}$ & $\begin{array}{c}\text { Supernate }^{(b)} \\
(\mu \mathrm{Ci} / \mathrm{mL})\end{array}$ & $\begin{array}{c}\text { Dry Solids }^{(\mathrm{c})} \\
(\mu \mathrm{Ci} / \mathrm{g})\end{array}$ & $\begin{array}{c}\text { Solids } \\
\text { Leach }^{(d)} \\
\text { Factor }^{(d)}\end{array}$ \\
\hline \multirow{10}{*}{$\begin{array}{c}\text { KOH } \\
\text { Fusion, } \\
\text { Concentrati } \\
\text { on Factor of } \\
1.80 \text { based on } \\
U \text { and Fe }\end{array}$} & Co-60 & $8.71 \mathrm{E}-3$ & $<2 . \mathrm{E}-5$ & $9.1 \mathrm{E}-3$ & 0.56 \\
\hline & Cs-137 & $1.14 \mathrm{E}+2$ & $2.10 \mathrm{E}-1$ & $1.2 \mathrm{E}+2$ & 0.38 \\
\hline & Eu-154 & $8.61 \mathrm{E}-2$ & $<6 . \mathrm{E}-5$ & $9.2 \mathrm{E}-2$ & -2.01 \\
\hline & Eu-155 & $<7 . \mathrm{E}-2$ & $<2 . E-4$ & $<7 . E-2$ & NA \\
\hline & Am-241 & $4.92 \mathrm{E}-1$ & $<1 . \mathrm{E}-4$ & $5.3 \mathrm{E}-1$ & 0.05 \\
\hline & Total alpha & $1.00 \mathrm{E}+0$ & $<7$. E-4 & $1.1 \mathrm{E}+0$ & 0.11 \\
\hline & Total beta & $6.27 \mathrm{E}+2$ & $1.81 \mathrm{E}-1$ & $6.8 \mathrm{E}+2$ & -0.14 \\
\hline & Sr-90 & $2.66 \mathrm{E}+2$ & $1.90 \mathrm{E}-4$ & $2.9 \mathrm{E}+2$ & -0.07 \\
\hline & Pu-239/240 & $6.59 \mathrm{E}-1$ & $<3 . \mathrm{E}-6$ & $7.1 \mathrm{E}-1$ & -0.10 \\
\hline & Pu-238 & $1.10 \mathrm{E}-2$ & $<3 . \mathrm{E}-6$ & $1.2 \mathrm{E}-2$ & 0.33 \\
\hline \multicolumn{6}{|c|}{$\begin{array}{l}\text { (a) Test sample TI572-G2-O, ASO ID 08-01294 } \\
\text { (b) Test sample TI572-G2-18, ASO ID 08-01321 } \\
\text { (c) Calculated using results from TI572-G2-O and TI572-G2-18. } \\
\text { (d) Calculated using results listed in } \\
\text { (e) Table 5.11. } \\
\text { Note: Analytes in italics were measured opportunistically. Values in brackets [ ] are } \\
\geq \text { MDL but < EQL, with errors likely to exceed 15\%. }\end{array}$} \\
\hline
\end{tabular}

At the beginning of the test, it was estimated that 524 grams of solid material was present in the slurry; by the end, there was 263 grams, or $51 \mathrm{wt} \%$ of the original solids. Adjusting this value for the sampling that was done gives a total solids value of $70 \%$ of the original. Cesium was the only radionuclide that decreased by a significant factor during the leaches and the washes. As detailed in Figure 5.70, the cesium decreased by $49 \%$ to a value $51 \%$ of the initial feed. By contrast, the rest of the radionuclides decreased by only $\pm 2 \%$, based on mass-balance calculations that use the concentration of removed filtered supernate to projected mass changes. While Table 5.43 projects significant leach factors for ${ }^{238} \mathrm{Pu}$ and ${ }^{60} \mathrm{Co}$, the composition of the supernate throughout the test does not support this sizeable decrease in the inventory. 
WTP-RPT-166, Rev. 0

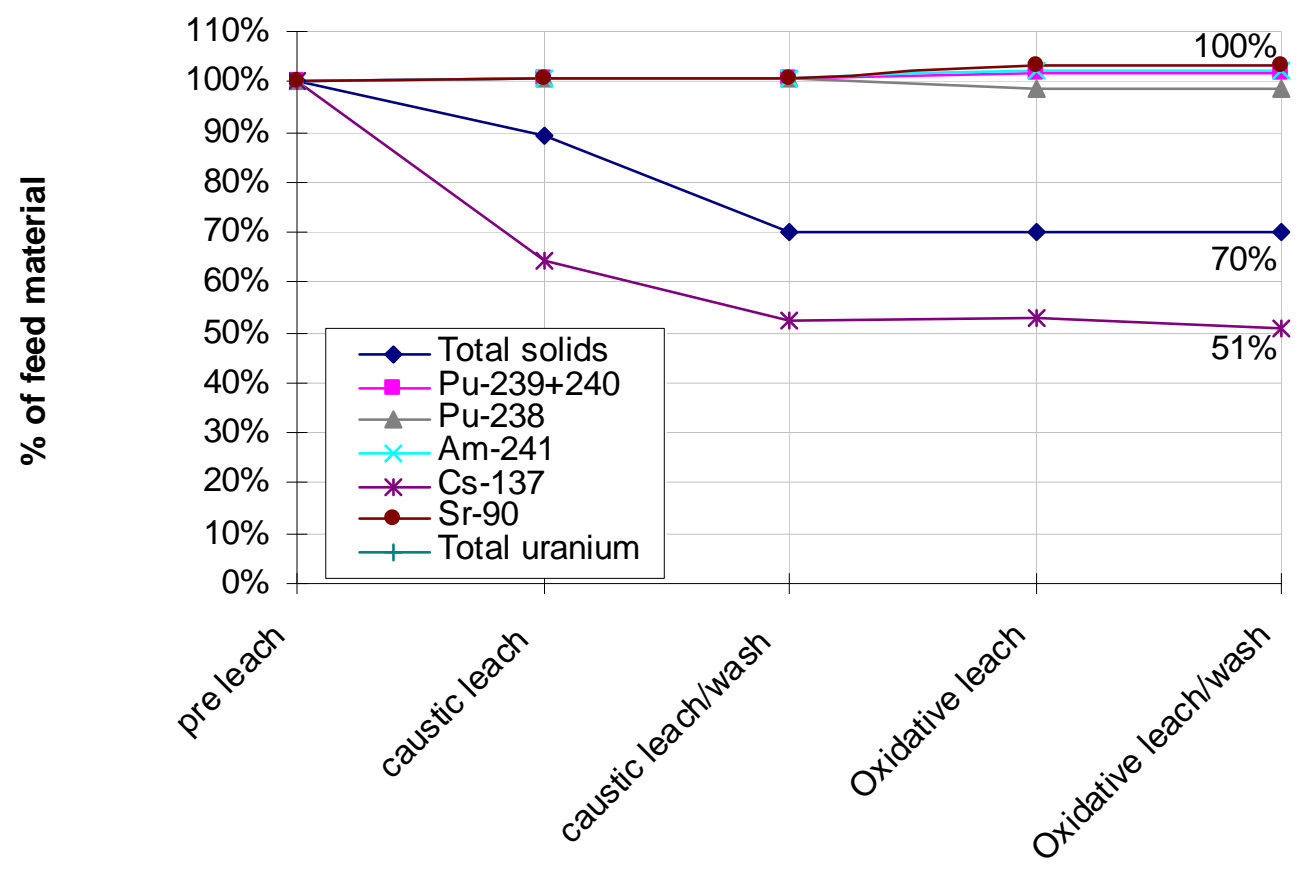

Figure 5.70. Radionuclides/Total Solids in CUF 1/2 Slurry, Adjusted for Sampling

The anions, specifically phosphate, in the permeate exhibit interesting behavior. While the nitrite, nitrate, sulfate, and oxalate follow an expected decrease (nitrite, nitrate, and sulfate decreasing consistently with each other, oxalate at a slower rate due to its relatively low solubility), phosphate increases in concentration after the caustic washes (Figure 5.71). During the same time period, the overall slurry phosphorus decreases (Figure 5.72). This can be explained by the precipitation of phosphate in higher concentrations of sodium (WTP-RPT-173, Lumetta 2008). Immediately after the caustic leach, the sodium concentration in the slurry supernate was $6 \mathrm{M}$. This caused insoluble phosphorus released as a phosphate ion from metathesis to re-precipitate as a sodium salt and still appear insoluble under these specific conditions. As the slurry was washed, the sodium concentration decreased, increasing the solubility of phosphate into the slurry's liquid phase. Repeated rinsing of the slurry afterwards allowed phosphates formed from the caustic leach to become soluble and be washed out of the slurry. This is further demonstrated in Figure 5.72. The caustic leached slurry has almost no phosphorus in the supernate and does not show a significant change in the insoluble fraction of the slurry. However, the fraction of phosphorus in the soluble liquid phase dramatically increases after the third wash, demonstrating that phosphorus was dissolving out of the insoluble phase. This indicates that the insoluble phosphorus was artificially elevated because of a large amount of "gelled" phosphate. All of these observations are consistent with the formation of sodium phosphate through metathesis of other metal phosphate (primarily $\mathrm{FePO}_{4}$ ). 


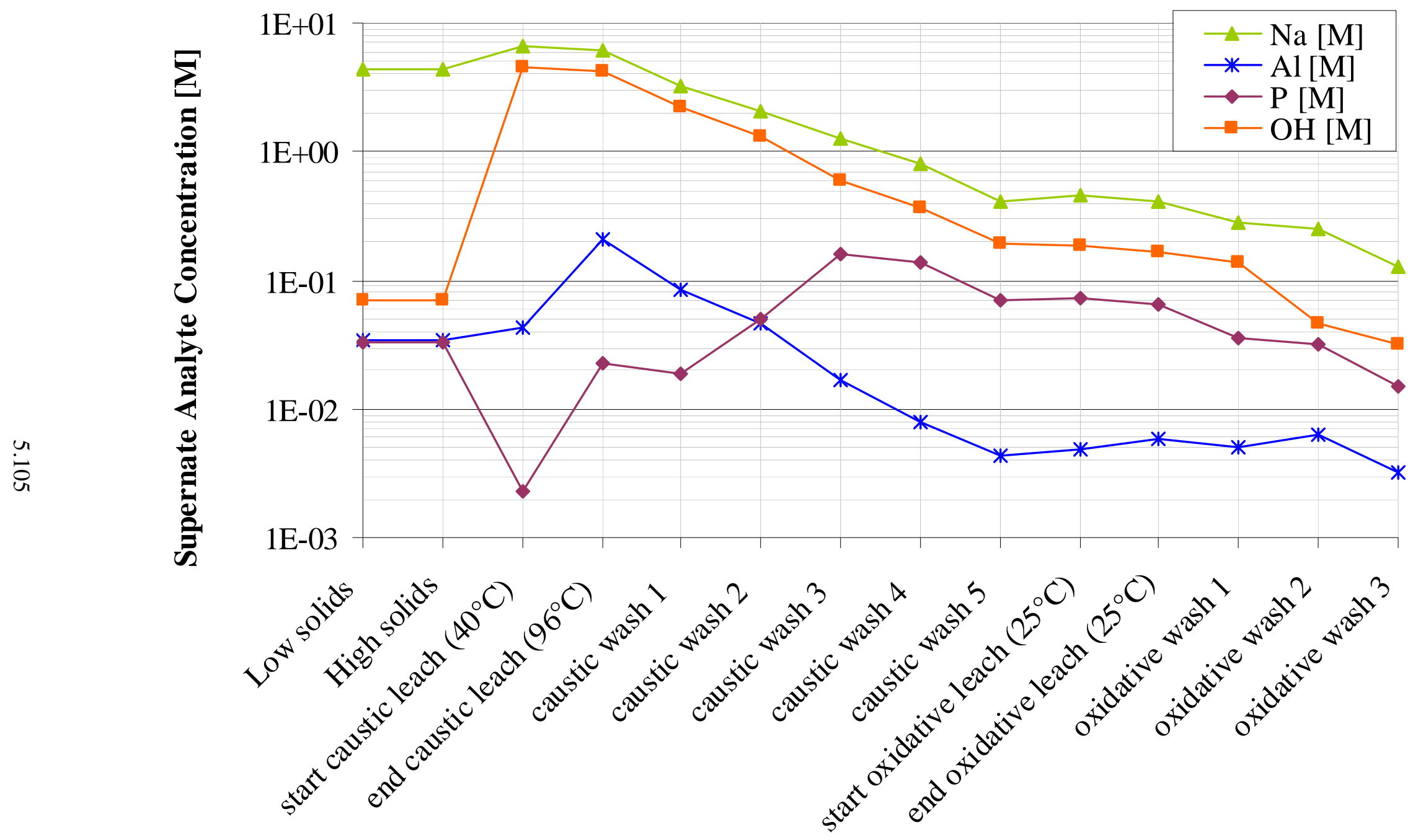

Figure 5.71. Sodium, Free Hydroxide, Al, and P Molarities During CUF Run 


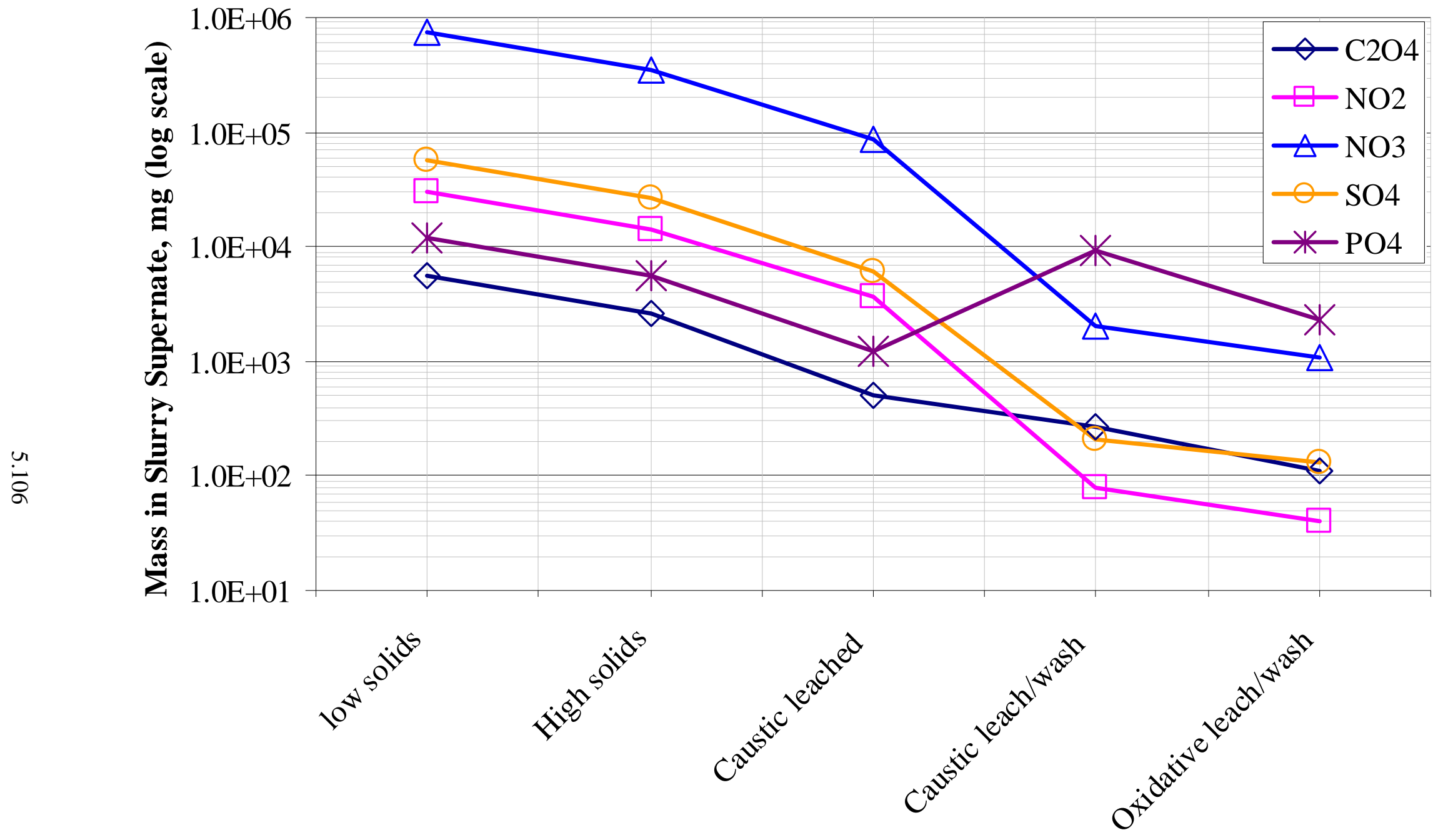

Figure 5.72. Inventory of Selected Anions in the Liquid Phase of the CUF 1/2 Slurry During Test 
The surface area of the leached solids was determined by BET analysis and found to be $96.3 \mathrm{~m} / \mathrm{g}$. Sodium aluminum silicate nitrate hydrate $\left[\mathrm{Na}_{7.92}\left(\mathrm{AlSiO}_{4}\right)_{6}\left(\mathrm{NO}_{3}\right)_{1.74}\left(\mathrm{H}_{2} \mathrm{O}\right)_{2.34}\right]$ was the predominant phase found by XRD analysis (Figure 5.73). Other mineral phases found were clarkeite $\left\{\mathrm{Na}\left[\left(\mathrm{UO}_{2}\right) \mathrm{O}(\mathrm{OH})\right]\right\}$, sodium aluminum carbonate silicate $\left[3 \mathrm{NaAlSiO}_{4} \cdot \mathrm{Na}_{2} \mathrm{CO}_{3}\right]$ and sodium uranium oxide $\left[\mathrm{Na}_{6} \mathrm{U}_{7} \mathrm{O}_{24}\right]$. Phases that are possibly present, but not confirmed, are boehmite [AlOOH] and iron hydrogen phosphate hydrate $\left[\mathrm{FeH}_{2} \mathrm{PO}_{3} \mathrm{O}_{10} \cdot \mathrm{H}_{2} \mathrm{O}\right]$.

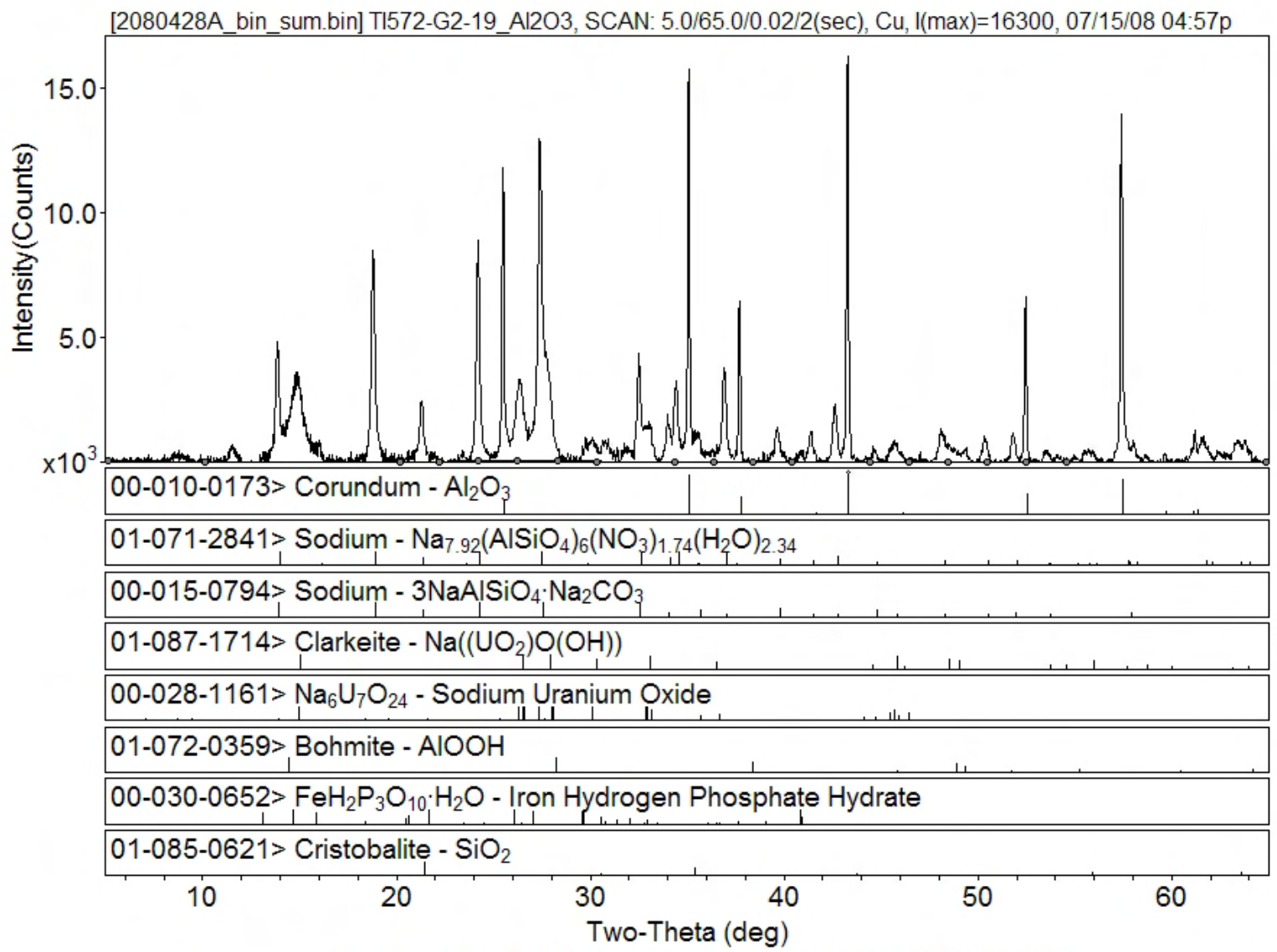

Figure 1.2. Phases identified, sample TI572-G2-19_Al2O3. Background subtracted data.

Figure 5.73. XRD Scan of CUF 1/2 Final Leached and Washed Solids

SEM (Figure 5.74 and Figure 5.75) and TEM (Figure 5.76) imaging as well as EDS analysis add validity to the XRD analysis and the suspected crystal forms present. Furthermore, a bismuth iron phase agglomerated with large particles of cancrinite was identified that would tend to make dissolution more difficult. XRD data suggested the presence of a uranyl oxide hydrate; however, TEM-EDS proves that the phase contains Si and a small amount of Al. Bismuth is present possibly as a mixed Al-P and Fe-Bi phase. EDS compositional analysis of this phase suggests that it is iron rich with aluminum incorporated into it. The uranium phase appears to be a uranium(VI) silicate with a high Si:U ratio. 
WTP-RPT-166, Rev. 0

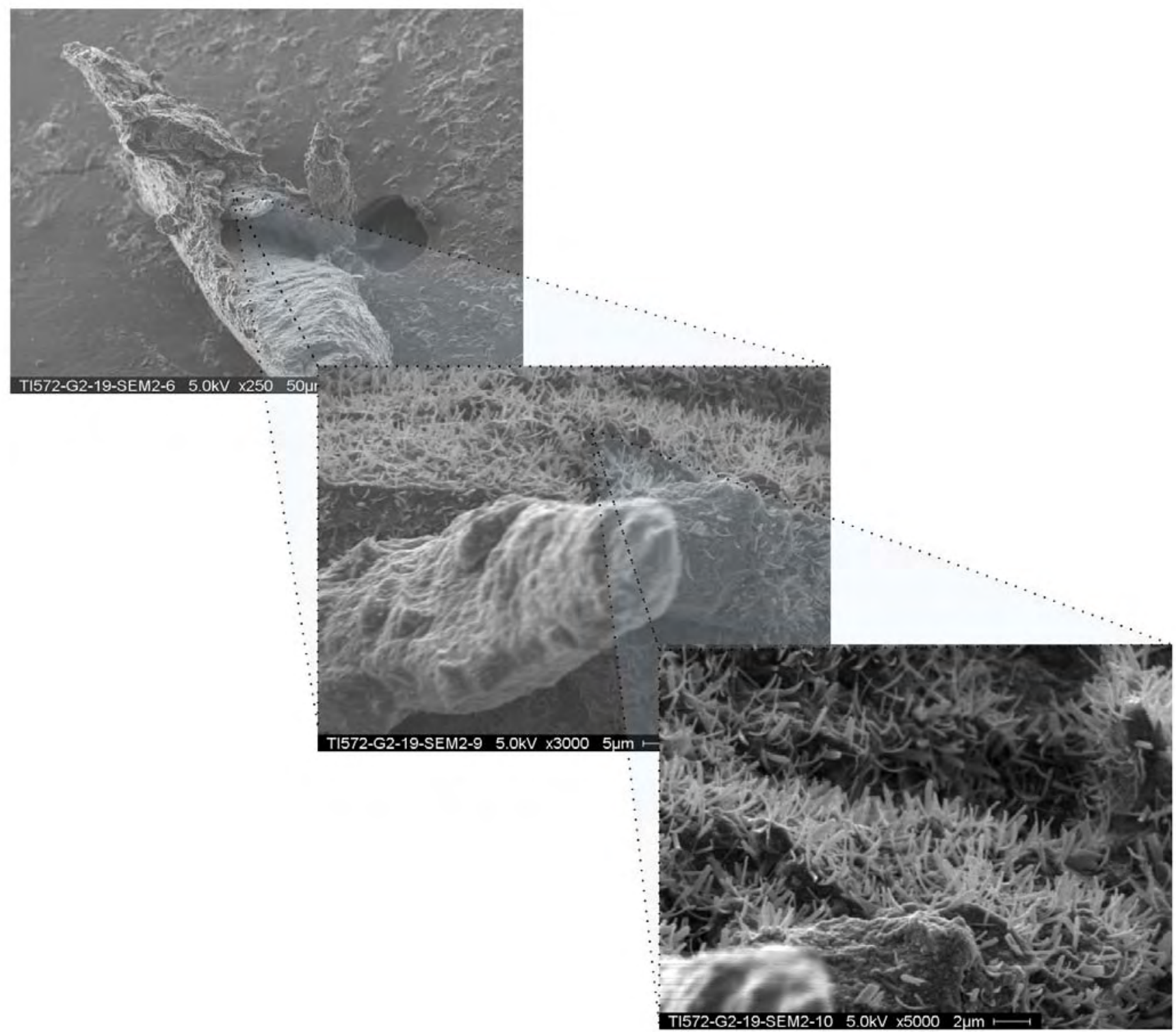

Figure 5.74. SEM Image of Leached/Washed CUF 1/2 Solids 


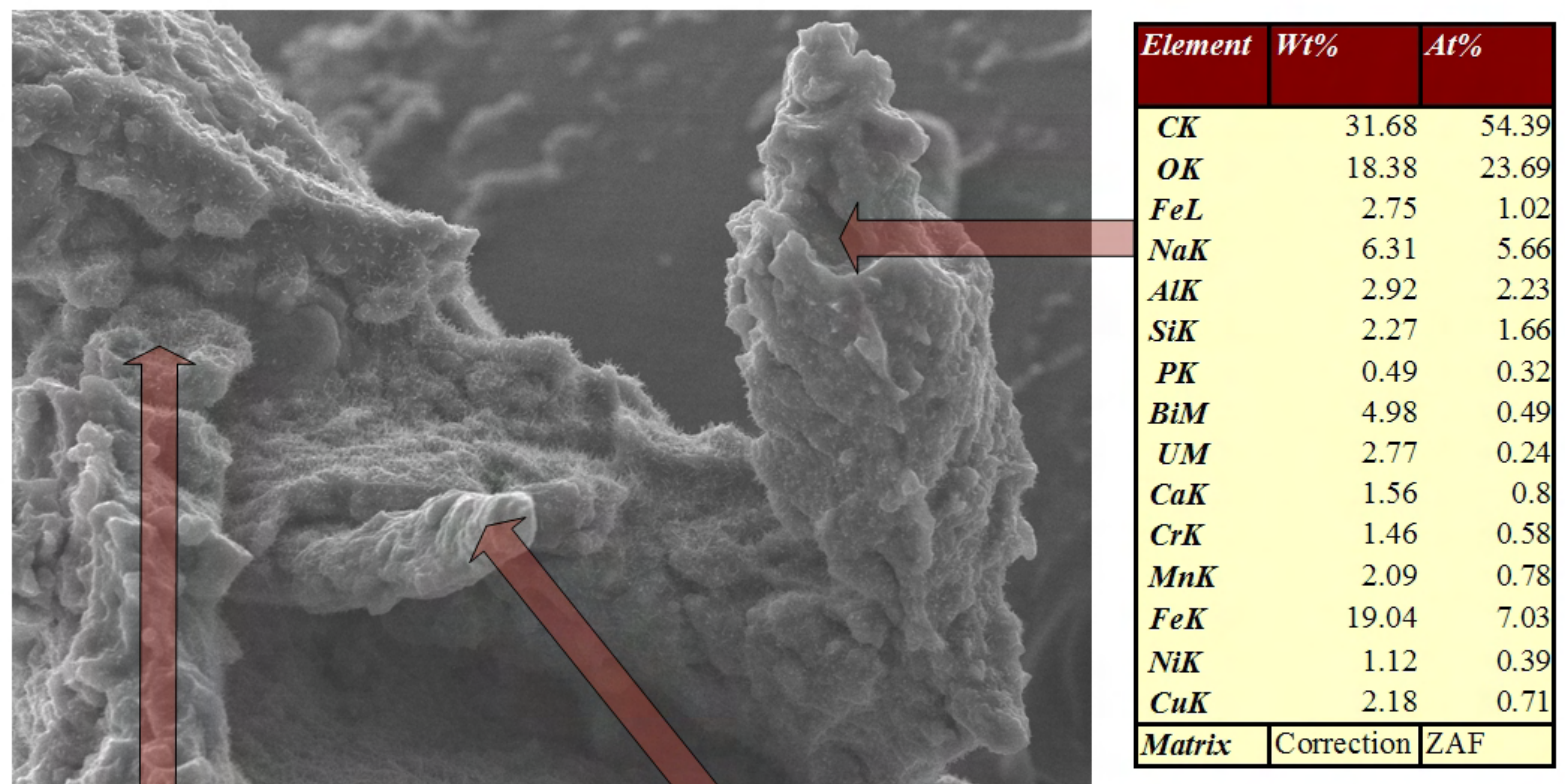

\begin{tabular}{|c|c|c|}
\hline Element & $W t \%$ & $\boldsymbol{A t} \%$ \\
\hline$C K$ & 30.88 & 45.02 \\
\hline$O K$ & 33.68 & 36.86 \\
\hline $\mathrm{NaK}$ & 11.26 & 8.58 \\
\hline$A l K$ & 5.18 & 3.36 \\
\hline SiK & 4.27 & 2.66 \\
\hline$P K$ & 0.93 & 0.53 \\
\hline$B i M$ & 4.66 & 0.39 \\
\hline$U M$ & 1.57 & 0.12 \\
\hline $\mathrm{CaK}$ & 0.74 & 0.32 \\
\hline $\mathrm{CrK}$ & 0.44 & 0.15 \\
\hline$M n K$ & 0.62 & 0.2 \\
\hline $\mathrm{FeK}$ & 5.77 & 1.81 \\
\hline Matrix & Correction & ZAF \\
\hline
\end{tabular}

\begin{tabular}{|l|rr|}
\hline Element & Wt $\%$ & \multicolumn{2}{|l|}{ At\% } \\
\hline CK & 39.48 & 62.77 \\
OK & 15.77 & 18.82 \\
NaK & 4.95 & 4.11 \\
AlK & 1.98 & 1.4 \\
SiK & 1.05 & 0.72 \\
$\boldsymbol{P K}$ & 0.2 & 0.12 \\
BiM & 1.42 & 0.13 \\
CaK & 0.35 & 0.17 \\
MnK & 3.02 & 1.05 \\
FeK & 27.1 & 9.27 \\
NiK & 1.37 & 0.45 \\
CuK & 3.32 & 1 \\
\hline Matrix & Correction & ZAF \\
\hline
\end{tabular}

Figure 5.75. SEM and EDS of Leached Washed CUF 1/2 Solids 


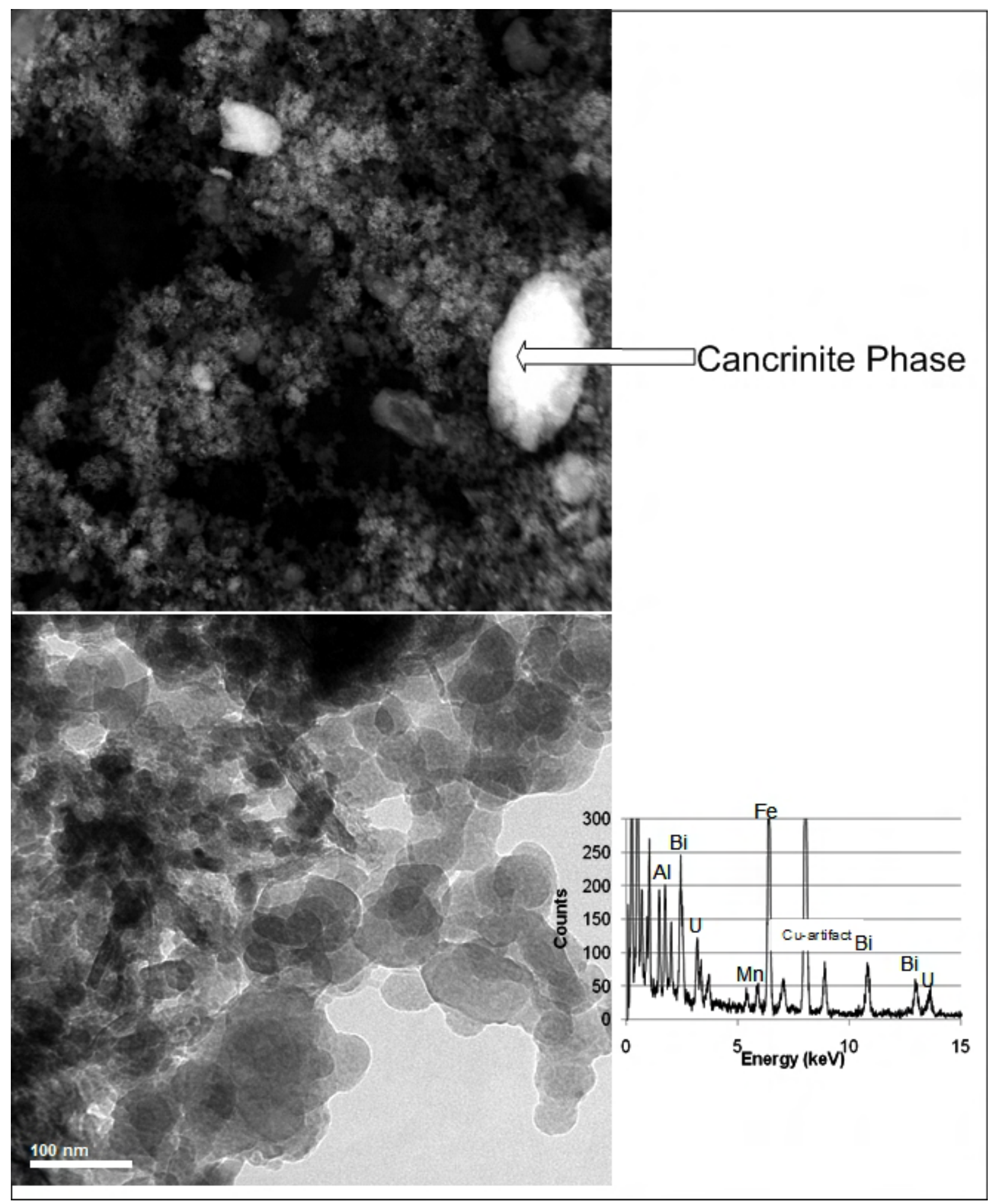

Figure 5.76. TEM Image of Leached Washed CUF Solids 
Figure 5.77 shows the pre-sonication size distribution of solids for the oxidative leached, washed slurry as a function of pump speed. Regardless of pump speed, all distributions show a strong single peak spanning $\sim 0.2$ to $3 \mu \mathrm{m}$ with a maximum population ranging from 0.7 to $0.8 \mu \mathrm{m}$. Secondary peaks appear at sizes larger than $3 \mu \mathrm{m}$. The initial measurement at 3000 RPM exhibits a secondary peak spanning 40 to $200 \mu \mathrm{m}$. At $4000 \mathrm{RPM}$, two adjacent secondary peaks form a continuous distribution of particles from 3 to just below $200 \mu \mathrm{m}$. A portion of the observed particle population at 4000 RPM may correspond to difficult-to-suspend particles observable only at 4000 RPM. Finally, the measurement at 2000 RPM indicates a single secondary peak spanning 3 to $10 \mu \mathrm{m}$. Although this peak is not observed at $3000 \mathrm{RPM}$, it is observed at the 4000 RPM measurement preceding the 2000 RPM set point. As such, it is likely that this peak corresponds to particles either suspended at 4000 RPM (that have yet to settle out) or particles formed by shearing apart particle flocs making up the secondary peaks observed at 3000 and 4000 RPM.

Figure 5.78 shows changes in the PSD for the oxidative leached, washed slurry that occur as a result of applied sonication. Similar to the oxidative leached sample, sonication reduces the relative contribution of intermediate particles $(0.5$ to $2 \mu \mathrm{m})$ while increasing the contributions of both submicron ( 0.1 to $0.5 \mu \mathrm{m}$ ) and 3- to $\sim 10$ - $\mu \mathrm{m}$ particles. Secondary peaks greater than $10 \mu \mathrm{m}$ in size were not observed either during or after sonication. This suggests full disruption of flocs at the end of sonication, either through sonic action or shear. It can be speculated that the submicron particles are the result of breakage (de-agglomeration) of particles in the 0.5 - to 2 - $\mu \mathrm{m}$ range and that 3 - to $10-\mu \mathrm{m}$ particles result from the breakage of flocs in the 10 - to 200 - $\mu \mathrm{m}$ range. Both during and after sonication measurements show similar distributions, indicating that agglomerate reformation does not occur over the time frame of the measurement.

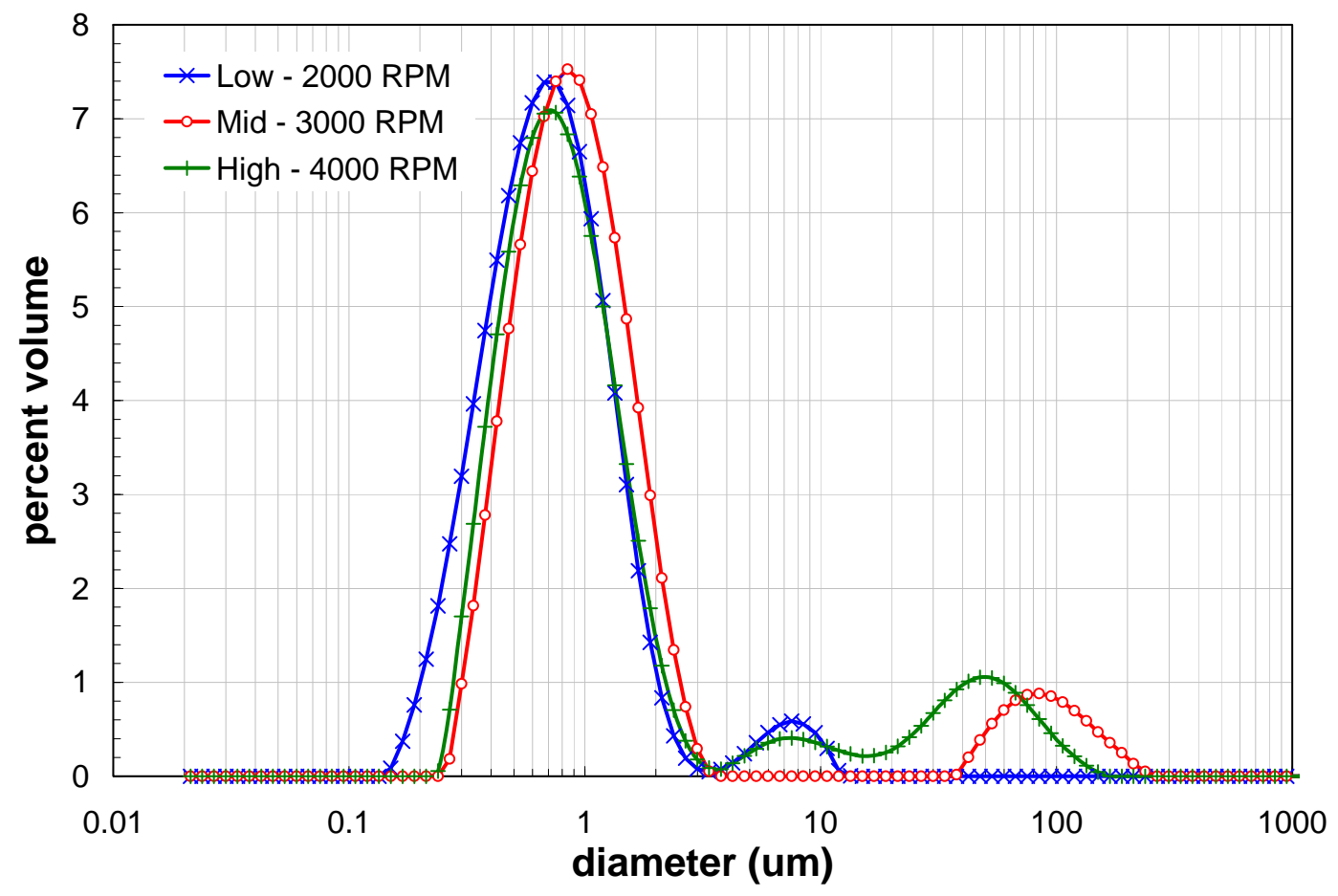

Figure 5.77. Oxidative Leached, Washed Slurry PSD as a Function of Pump Speed 
WTP-RPT-166, Rev. 0

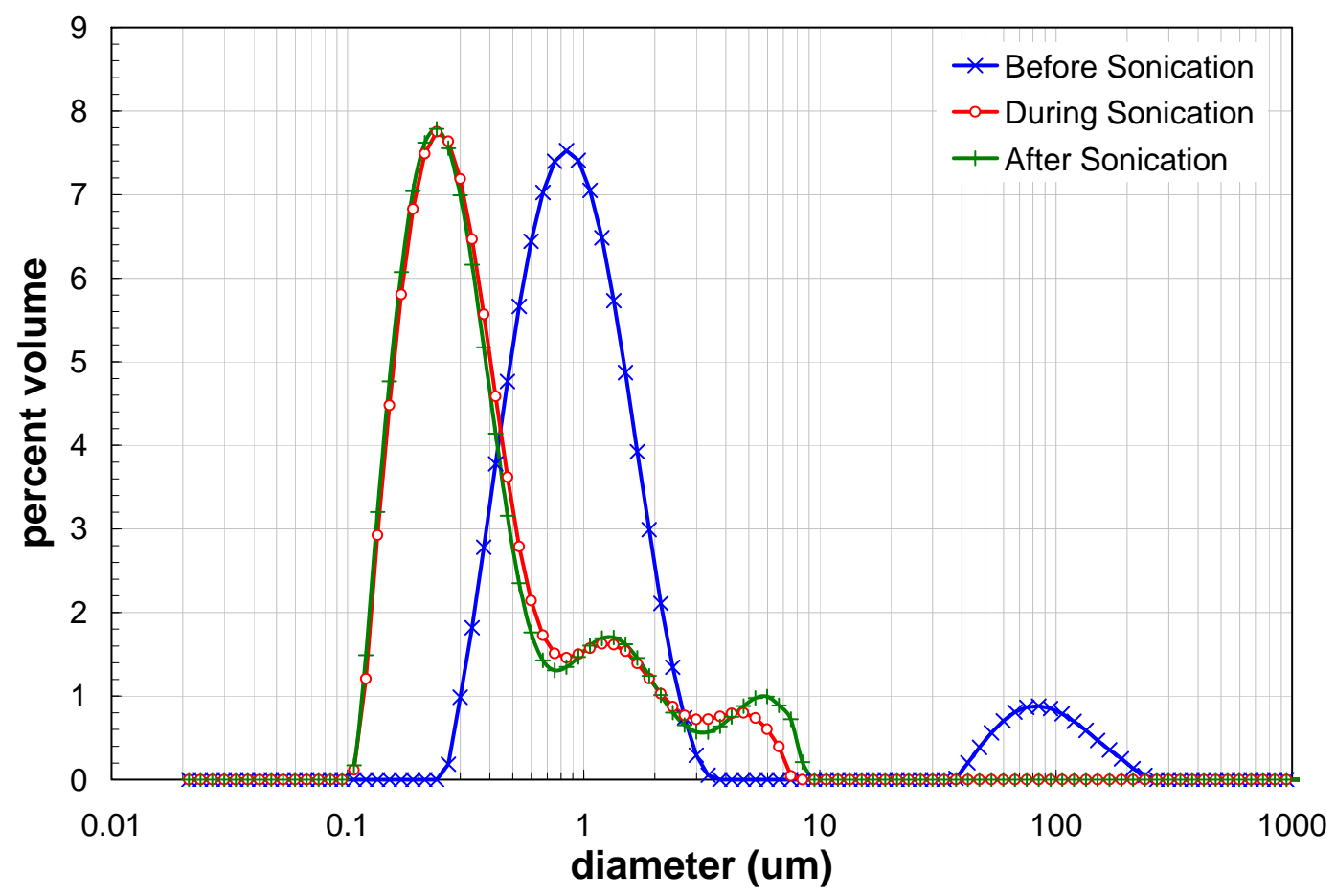

Figure 5.78. Oxidative Leached, Washed Slurry PSD as a Function of Sonication at 3000 RPM

Figure 5.79 shows the results of flow curve testing for the oxidative-leached and washed slurry, which shows Newtonian behavior. The flow curves for 40 and $60^{\circ} \mathrm{C}$ have a stress axis intercept greater than zero but less than the limit of instrument accuracy ( $\pm 0.5 \mathrm{~Pa})$. This may indicate weak non-Newtonian behavior; however, given the measurement noise of the M5 system, it is impossible to statistically distinguish any finite yield stress for this slurry based on the magnitude of its stress response. For this reason, the slurry shall be defined as Newtonian.

The flow curves are free of artifacts caused by poor sample rotation. Over shear rates from 0 to $400 \mathrm{~s}^{-1}$, the stress response is linear. A slope transition is observed at $\sim 500 \mathrm{~s}^{-1}$, indicating the formation of Taylor Vortices. When fitting these flow curves, data for shear rates above $400 \mathrm{~s}^{-1}$ will be avoided to prevent the inclusion of data affected by vortex formation. Although it is difficult to observe because of significant data overlap and noise, flow curve hysteresis occurs in all measurements. Hysteresis manifests as a lower stress response on the down-ramp relative to the up-ramp. Given the relatively weak stress response of the material ( $\sim 1 \mathrm{~Pa}$ at $500 \mathrm{~s}^{-1}$ ), this type of hysteresis is consistent with rotor inertial effects. That is, the additional torque required to accelerate on the up-ramp increases its stress response, whereas the resisting torque of the fluid will help slow the rotor down during the down-ramp portion of testing, which reduces the apparent stress response of the fluid. As such, hysteresis is not associated with any changes to bulk sample rheology.

The noise-to-signal ratio is so significantly large that it is impossible to qualitatively evaluate whether temperature influences the oxidative-leached and washed slurry stress response. Based on Figure 5.79, the flow curves appear to be statistically similar. Table 5.44 summarizes the best-fit "Newtonian" viscosities for the oxidative leached and washed slurry flow-curve data as well as the viscosities 
determined by constant rotation at $470 \mathrm{~s}^{-1}$ (i.e., the shearing step run before every measurement). The analysis results in Table 5.44 show that:

- The Newtonian viscosity appears to decrease slightly with increasing temperature (as expected based on suspending phase viscosity lowering).

- Given the best expected accuracy limit of $\pm 0.5 \mathrm{mPa} \cdot \mathrm{s}$, the viscosities are similar to each other. Statistically, the viscosities determined from the flow curves at 25 (2 of 2), 40 , and $60^{\circ} \mathrm{C}$ are the same.

- The repeat measurements at $25^{\circ} \mathrm{C}$ appear to show reasonable agreement. Although the flow curve fits show a larger-than-expected difference $(0.7 \mathrm{mPa} \cdot \mathrm{s})$, the constant rotation analysis shows a difference that falls on the limit of instrument accuracy $(0.5 \mathrm{mPa} \cdot \mathrm{s})$.

- The constant rotation and flow curve generally agree within $\pm 0.5 \mathrm{mPa} \cdot \mathrm{s}$, with exception of the $40^{\circ} \mathrm{C}$, which shows a 0.7 - $\mathrm{mPa} \cdot \mathrm{s}$ difference.

Because the oxidative leached and washed slurry shows Newtonian behavior, the apparent viscosities should be nominally independent of shear and should be equal to the Newtonian viscosities reported in Table 5.44 .

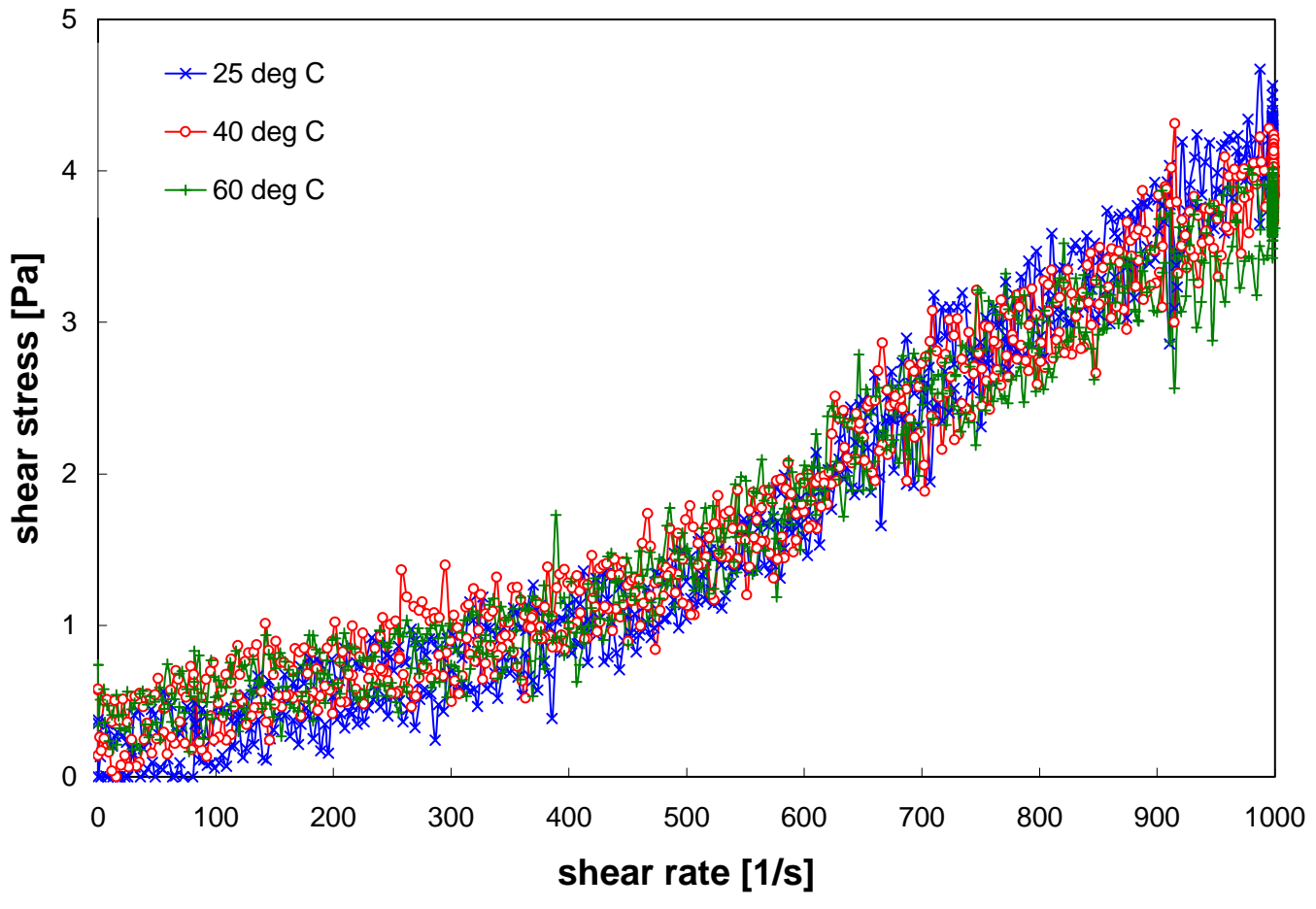

Figure 5.79. Flow Curve for the Group 1/2 CUF Oxidative Leached and Washed Slurry at 25, 40, and $60^{\circ} \mathrm{C}$ 
Table 5.44. Results of Fitting Analysis for the Group 1/2 CUF Oxidative Leached and Washed Slurry

\begin{tabular}{||c|c|c|c||}
\hline \multirow{4}{*}{ Model } & $\begin{array}{c}\text { Temperature } \\
{\left[{ }^{\circ} \mathbf{C}\right]}\end{array}$ & $\begin{array}{c}\text { Newtonian } \\
\text { Viscosity } \\
\text { [mPa·s] }\end{array}$ & $\mathbf{R}$ \\
\hline \multirow{3}{*}{$\begin{array}{c}\text { Flow Curve Fits } \\
\left(0-400 \mathrm{~s}^{-1}\right)\end{array}$} & $25(1$ of 2$)$ & 2.8 & 0.862 \\
\cline { 2 - 4 } & $25(2$ of 2$)$ & 2.1 & 0.799 \\
\cline { 2 - 4 } & 40 & 2.0 & 0.757 \\
\cline { 2 - 4 } & 60 & 1.6 & 0.737 \\
\hline $\begin{array}{c}\text { Constant Rotation } \\
\left(470 \mathrm{~s}^{-1}\right)\end{array}$ & $25(1$ of 2$)$ & $2.8 \pm 0.2$ & $\mathrm{n} / \mathrm{a}$ \\
\cline { 2 - 4 } & $25(2$ of 2$)$ & $2.3 \pm 0.1$ & $\mathrm{n} / \mathrm{a}$ \\
\cline { 2 - 4 } & 40 & $2.7 \pm 0.2$ & $\mathrm{n} / \mathrm{a}$ \\
\cline { 2 - 4 } & 60 & $1.2 \pm 0.2$ & $\mathrm{n} / \mathrm{a}$ \\
\hline
\end{tabular}

Table 5.45 and Figure 5.80 show the influence of oxidative-leaching and washing on the rheology of the caustic-leached, dewatered, and washed Group 1/2 waste slurry. Before oxidative leaching, the 12.0-wt\% slurry showed a 7.7-Pa yield stress and a 9.7- mPa·s consistency. After oxidative leaching and washing, the slurry concentration was reduced to $6.8 \mathrm{wt} \%$, and the slurry behavior was Newtonian with a viscosity of $2.1 \mathrm{mPa} \cdot \mathrm{s}$. The reduction in rheology appears to be a continuation of the reduction observed during washing of the caustic-leached and dewatered slurry. For the current process step, reduction is likely a result of both changes in the suspending phase chemistry and solids concentration. It is speculated that oxidative leaching and washing further reduces the concentration of both dissolved $\mathrm{Na}_{3} \mathrm{PO}_{4}$ and the UDS. A reduction in both would be consistent with a reduction in rheology, as 1) $\mathrm{Na}_{3} \mathrm{PO}_{4}$ lends strength to the suspending phase through gel formation and 2) increased UDS concentrations yield increased particle colloidal and frictional interactions.

Table 5.45. Effect of Oxidative-Leaching and Washing on Group $1 / 2$ CUF Slurry Rheology (at $25^{\circ} \mathrm{C}$ )

\begin{tabular}{||c|c|c|c|c||}
\hline Description & $\begin{array}{c}\text { Solids } \\
\text { Concentration }\end{array}$ & Rheology & $\begin{array}{c}\text { Yield Stress } \\
\text { [Pa] }\end{array}$ & $\begin{array}{c}\text { Consistency } \\
\text { [mPa·s] }\end{array}$ \\
\hline $\begin{array}{c}\text { Caustic-Leached, } \\
\text { Dewatered, Washed } \\
\text { (TI572-G2-R4) }\end{array}$ & $12.0-\mathrm{wt} \%$ & non-Newtonian & 7.7 & 9.7 \\
\hline $\begin{array}{c}\text { Oxidative-Leached and } \\
\text { Washed } \\
\text { (TI572-G2-R5) }\end{array}$ & $6.8-\mathrm{wt} \%$ & Newtonian & $\mathrm{n} / \mathrm{a}$ & 2.1 \\
\hline
\end{tabular}


WTP-RPT-166, Rev. 0

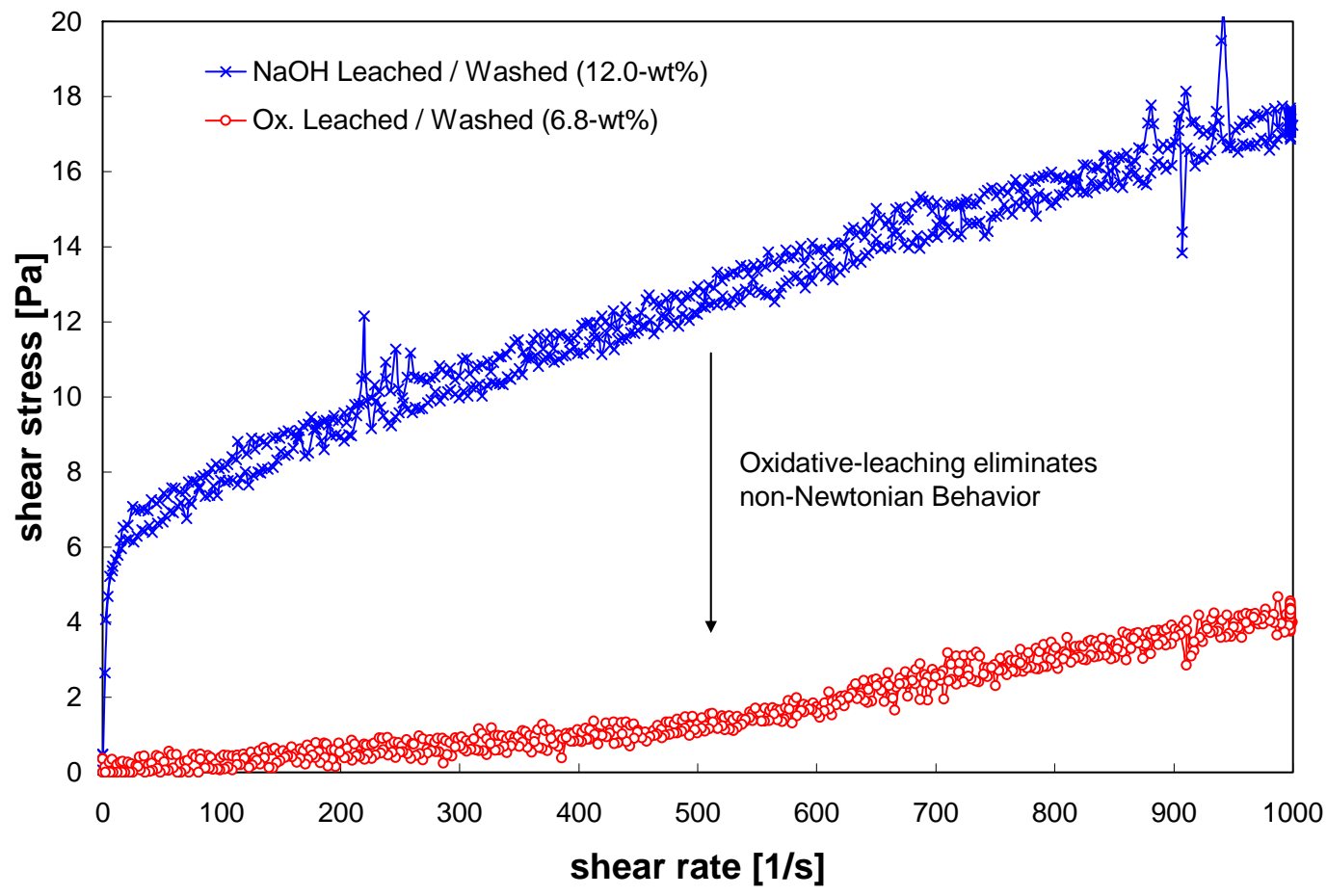

Figure 5.80. A Comparison of Group 1/2 CUF Slurries Showing the Effect of Oxidative-Leaching and Post-Oxidative-Leach Solids Washing on Rheology at $25^{\circ} \mathrm{C}$ 
WTP-RPT-166, Rev. 0

\subsection{Summary and Lessons Learned from the Group 1/2 CUF Run}

Filtration, chemical leaching, and physical characterization results are summarized in

Table 5.46,

Table 5.47, and Figure 5.81. During the course of the test, several problems occurred that impacted the performance of test and have created some uncertainty about the results. However, conducting the test created additional understanding about the process that had added benefits.

\section{Failure of the Mixer Blade Due to Erosion}

During the course of this test, the propeller mixing blade came off the shaft of the overhead mixer used to homogenize the slurry inside the slurry reservoir tank. Examination of the blade showed that erosive wear destroyed a crimp seal that attached the blade to the shaft collar. This was surprising, considering that this was only the third test performed with this mixer. However, the crimp seal holding the mixer blade to the shaft collar was at the base of the blade where agitation was the greatest. While the type of mixing used in this system was not prototypic, it demonstrated the highly erosive nature of the tank waste samples used for this test.

The lack of mixing inside the slurry reservoir likely caused several discrepancies during this test. The biggest issue was that physical properties results did not correlate well with predicted estimates. Typically, measured UDS results of the slurry were significantly lower than that predicted from characterization data. While the circulation of the slurry created some mixing inside the reservoir, it likely acted like a wide spot in the pipe, allowing a fraction of the solids to settle out. This would explain the difference between the measured and predicted UDS concentrations. Leaching and washing results from this test were also questionable. Conversions were not as high as that expected from the parametric studies, and comparison of phosphorus conversion using a mass-balance method (50\%) to that based on slurry samples (100\%) shows a big difference. Because phosphorus was found to be released during washing, it may be that the concentration of phosphorus was changing during dewatering as the slurry volume decreased and agitation improved inside the vessel. Samples of the wash were pulled halfway between the dewatering because it was assumed that the slurry was well mixed and would not change. However, the issues that made sampling for UDS a problem likely impacted sampling of the slurry solids for chemical and radiochemical analysis. Heavier particles likely were held up at the bottom of the slurry reservoir, making assumptions of homogeneity of the slurry not valid.

After this test was completed, a new mixing blade and shaft were installed. The blade was installed onto the shaft in a configuration where the crimp seal was protected from slurry erosion. In future tests, the quality of mixing was to be examined throughout the test. In future testing, using a mixer that measures the torque of the mixer blade is recommended as a method to monitor how mixing is occurring without looking into the tank itself.

\section{Pump Plugging with Leached Slurry}

Another issue that occurred during the test was that the circulation pump was not operational after the caustic leach. While preparing the slurry for leaching, the slurry was drained from the CUF. To flush additional solids out of the circulation lines, a small fraction of the caustic addition for the leach was used to rinse out the system piping and pump. After the leach was completed, it was discovered that the pump was stalled and that the drive shaft could not be rotated. The sanitary fittings connecting the circulation piping to the pump were loosened to examine the inside of the pump chamber. A gel was discovered in 
the pump head that apparently formed in the slurry loop during the caustic leaching step. The pump was located close enough to the slurry reservoir that material inside the pump was heated up from thermal conduction of the attached piping and reacted. The main purpose of the leach was to cause metathesis of isolable phosphorus into a soluble phosphate salt. Because of the high concentration of caustic present in the line, it was hypothesized that this gel consisted of $\mathrm{Na}_{3} \mathrm{PO}_{4} \cdot 12 \mathrm{H}_{2} \mathrm{O}$ that precipitated from the reaction of residual slurry solids with the small amount of caustic solution that was used to flush the slurry loop before the leaching step. This gel was removed from the pump head by back pulsing water into the slurry piping and forcing it into the pump cavity. Eventually, the positive displacement blades of the pump broke free and the test was resumed.

Rheology testing of the dewatered caustic-leached slurry found that the final leached slurry possessed a very high shear strength (38 Pa). Analysis of the slurry composition afterwards showed that very little phosphate was in the aqueous phase of the slurry, indicating that phosphate released from metathesis had re-precipitated as sodium phosphate (likely hydrated) due to the high sodium concentration of the slurry. After the slurry was washed and the sodium concentration of the slurry supernate decreased, the phosphate became soluble and was released into the wash solutions. The shear strength of the slurry afterwards decreased to $8 \mathrm{~Pa}$ after washing and later became Newtonian after oxidative leaching and washing.

How the leached slurry behaved during the test helped explain what occurred in the pump:

- Caustic leaching releases insoluble phosphorus into the slurry supernate as phosphate.

- However, high sodium concentrations present from the addition of sodium hydroxide caused the phosphate to precipitate as sodium phosphate.

- This caused a change in the shear strength of the fluid. Because of the concentration of waste and caustic inside the pump, this effect was amplified and caused a plug to form that stalled the pump.

- Diluting the slurry with water by back pulsing water into the chamber allowed the sodium phosphate to re-dissolve.

- Once the phosphate became soluble, the yield stress of the slurry decreased. In the case of the pump, the back pulsing of water into the pump chamber lowered the shear strength of the "gel” inside the pump enough to allow the pump displacement blades to rotate freely.

To prevent this from occurring in future tests, the slurry lines and pump chamber will be flushed afterwards with water after flushing the lines using caustic. This will wash any waste material that is in contact with a reactant (such as caustic) from the piping to prevent problems with plugging and stalling of the pump. Future designs should incorporate better methods of flushing lines and the pump to recover solids in the lines as well as to dislodge highly concentrated slurries/packed solids that plug lines or the pump.

Predicting Sodium Permanganate Addition for Chromium Dissolution

The goal of the oxidative leach was to operate the leach when the free-hydroxide concentration was equal to or less than $0.25 \mathrm{M}$, and the molar ratio of $\mathrm{Mn}$ to $\mathrm{Cr}=1: 1$. However, this proved difficult to do. This required that: 
- The initial slurry mass be known and the slurry chemically characterized

- Losses of UDS be accounted for throughout the test

- The caustic leach factor of chromium due to caustic leaching be accurately accounted for.

In the previous test (Group 6/5 CUF), the initial slurry mass and composition, as well as the caustic leach factor for chromium, was well understood. However, in that test, the loss of UDS during the test was underestimated. The quantity of insoluble chromium was projected to be too high, and additional sodium permanganate was added. For this test, slurry sampling was considered to be more significant, and characterization data for the Group 1 and Group 2 slurry were known. However, leaching studies of the Group 1 and Group 2 wastes were just completed, and analytical results from this testing were not available in time for guiding the Group 1/2 CUF experiment. Because of this, the predicted causticleaching factors for chromium were derived from previous studies of the tanks present in the two groups. The highest value found for chromium dissolution was used, which was 70\%. However, parametric studies found that chromium dissolution would be much lower (closer to 20 to 30\%). This caused projections of insoluble chromium present in the slurry to be too low, making the sodium permanganate addition too conservative.

For this test, the Mn:Cr ratio during the oxidative leach test was only 0.4 rather than the target of 1.1. On the other hand, the Mn:Cr ratio for the Group 6/5 test was 1.7 (WPT-PRT-172, Shimskey 2009). Assumptions and compounding errors during both tests (e.g., mistakes with the permanganate additions for the Group 6/5 test and mixing issues with this test) caused significant deviation from the planned Mn:Cr molar ratio. These problems demonstrate the need for accurate mass balance, characterization, and leaching data of the waste to achieve a more precise $\mathrm{Mn}: \mathrm{Cr}$ ratio for oxidative leaching.

\section{Cleaning with $2 \mathrm{M}$ Nitric Acid and $0.5 \mathrm{M}$ Oxalic Acid}

The test plan dictated that the filter was to be cleaned with $2 \mathrm{M}$ nitric acid. And while that was done for the Group 5, Group 6/5, and Group 1/2 tests, cleaning did not return the filter to the original condition. Over the course of the three tests, the CWF measured decreased each time with nitric cleaning having little impact. Because the final CWF of the filter was only $0.07 \mathrm{GPM} / \mathrm{ft}^{2}$ at a project TMP of $40 \mathrm{psid}$ after nitric cleaning, it was felt another cleaning method needed to be tried.

Because 0.5 M oxalic acid successfully cleaned the filter being used for simulant development, this solution was used after nitric acid cleaning. The results of cleaning were dramatic, with the final CWF measured of the filter to be $0.7 \mathrm{GPM} / \mathrm{ft}^{2}$ at $20 \mathrm{psid}$ - or $1.4 \mathrm{GPM} / \mathrm{ft}^{2}$ at $40 \mathrm{TMP}$.

Although $2 \mathrm{M}$ nitric acid was proving not to be an effective cleaning agent for the waste tests so far, it was planned to continue to use it for the remaining testing planned. However, it was also planned to use oxalic acid to understand when it was an effective cleaning agent and when it was not. 
Table 5.46. Group 1/2 CUF Filtration, PSD, and Rheology Test Result Summary

\begin{tabular}{|c|c|c|}
\hline Filtration Step & Property & Results \\
\hline \multirow[t]{7}{*}{$\begin{array}{l}\text { Low Solids Filtration Testing } \\
\text { (Section 5.2, 5.3.2) }\end{array}$} & Material Description & $\begin{array}{l}\text { Group 1-2 diluted with } \\
\text { excess supernatant from } \\
\text { homogenization and } \\
\text { circulated in CUF }\end{array}$ \\
\hline & Measured UDS & $7 \mathrm{wt} \%$ \\
\hline & Predicted UDS & $10 w t \%$ \\
\hline & $\begin{array}{l}\text { Slurry Rheology } \\
\text { @ } 25^{\circ} \mathrm{C}-60^{\circ} \mathrm{C} \\
\text { (Sample ID: TI572-G2-R1) }\end{array}$ & $\begin{array}{l}\text { Newtonian } \\
\text { Viscosity: 5-3 mPa·s }\end{array}$ \\
\hline & Particle Size & $\begin{array}{l}\text { d(10): } 0.56 \mu \mathrm{m} \\
\mathrm{d}(50): 2.0 \mu \mathrm{m} \\
\mathrm{d}(90): 7.4 \mu \mathrm{m} \\
\end{array}$ \\
\hline & Permeate Composition & $\begin{array}{l}{[\mathrm{Na}]: 4.4 \mathrm{M}} \\
{[\mathrm{Al}]: 0.035 \mathrm{M}} \\
{[\mathrm{OH}]: 0.07 \mathrm{M}}\end{array}$ \\
\hline & Permeate Viscosity (TI572-G2-R2s) & 2.6 mPa-s@25ㄷ \\
\hline \multirow{5}{*}{$\begin{array}{l}\text { Dewatering of Waste Before } \\
\text { Leaching (Section 5.3.3) } \\
\text { Target Filtration Conditions } \\
T M P: 40 \text { psid } \\
A V: 13 \mathrm{ft} / \mathrm{s}\end{array}$} & Material Description & $\begin{array}{l}\text { Dewatered Group 1-2 } \\
\text { slurry }\end{array}$ \\
\hline & Final Measured UDS & $14 \mathrm{wt} \%$ \\
\hline & Final Predicted UDS & $20 w t \%$ \\
\hline & Permeate Composition & $\begin{array}{l}{[\mathrm{Na}]: 4.4 \mathrm{M}} \\
{[\mathrm{Al}]: 0.035 \mathrm{M}} \\
{[\mathrm{OH}]: 0.07 \mathrm{M}} \\
\end{array}$ \\
\hline & Permeate Viscosity (TI572-G2-R2s) & $2.6 \mathrm{mPa}-\mathrm{s} @ 25^{\circ} \mathrm{C}$ \\
\hline \multirow[t]{6}{*}{$\begin{array}{l}\text { High-Solids Filtration Testing } \\
\text { (Section 5.3.4) }\end{array}$} & Material Description & $\begin{array}{l}\text { Dewatered Group 1-2 } \\
\text { slurry }\end{array}$ \\
\hline & Measured UDS & $14 \mathrm{wt} \%$ \\
\hline & $\begin{array}{l}\text { Slurry Rheology } \\
\text { @ } 25^{\circ} \mathrm{C}-60^{\circ} \mathrm{C} \\
\text { (Sample ID: TI572-G2-R2) }\end{array}$ & $\begin{array}{l}\text { Non-Newtonian } \\
\text { Yield Stress: } 3.2-2.1 \mathrm{~Pa} \\
\text { Consistency: } 10-23 \mathrm{mPa} \cdot \mathrm{s} \\
\end{array}$ \\
\hline & Particle Size & $\begin{array}{l}d(10): 0.52 \mu \mathrm{m} \\
d(50): 2.4 \mu \mathrm{m} \\
d(90): 9.5 \mu \mathrm{m} \\
\end{array}$ \\
\hline & Permeate Composition & $\begin{array}{l}{[\mathrm{Na}]: 4.4 \mathrm{M}} \\
{[\mathrm{Al}]: 0.035 \mathrm{M}} \\
{[\mathrm{OH}]: 0.07 \mathrm{M}}\end{array}$ \\
\hline & Permeate Viscosity (TI572-G2-R3s) & 2.6 mPa-s@25ㄷ \\
\hline
\end{tabular}


Table 5.46 (Contd)

\begin{tabular}{|c|c|c|}
\hline Filtration Step & Property & Results \\
\hline \multirow{5}{*}{$\begin{array}{l}\text { Caustic Leach Dewater } \\
\text { (Section 5.5.2-5.5.3) } \\
\text { Target Filtration Conditions } \\
T M P: 40 \text { psid } \\
A V: 13 \mathrm{ft} / \mathrm{s}\end{array}$} & Measured UDS & $18 \mathrm{wt} \%$ \\
\hline & $\begin{array}{l}\text { Slurry Rheology } \\
\text { @ } 25^{\circ} \mathrm{C}-60^{\circ} \mathrm{C} \\
\text { (Sample ID: TI572-G2-R3) }\end{array}$ & $\begin{array}{l}\text { Non-Newtonian } \\
\text { Yield Stress: 32-57 Pa } \\
\text { Consistency: 26-23 mPa·s }\end{array}$ \\
\hline & Particle Size & $\begin{array}{l}\mathrm{d}(10): 0.56 \mu \mathrm{m} \\
\mathrm{d}(50): 1.6 \mu \mathrm{m} \\
\mathrm{d}(90): 6.9 \mu \mathrm{m}\end{array}$ \\
\hline & Permeate Composition & $\begin{array}{l}{[\mathrm{Na}]: 6.2 \mathrm{M}} \\
{[\mathrm{Al}]: 0.20 \mathrm{M}} \\
{[\mathrm{OH}]: 4.2 \mathrm{M}}\end{array}$ \\
\hline & Permeate Viscosity (TI572-G2-R3s) & 7.9 mPa-s@25C \\
\hline \multirow{3}{*}{$\begin{array}{l}\text { Caustic Wash } 1 \\
\text { (Section 5.5.4-5.5.5) } \\
\text { Target Filtration Conditions } \\
\text { TMP: } 40 \text { psid } \\
A V: 13 \mathrm{ft} / \mathrm{s}\end{array}$} & Wash Solution & $0.56 \mathrm{M} \mathrm{NaOH}$ \\
\hline & Permeate Composition & $\begin{array}{l}\mathrm{Na}]: 3.3 \mathrm{M} \\
{[\mathrm{Al}]: 0.085 \mathrm{M}} \\
{[\mathrm{OH}]: 2.2 \mathrm{M}}\end{array}$ \\
\hline & & \\
\hline \multirow{3}{*}{$\begin{array}{l}\text { Caustic Wash } 2 \\
\text { (Section 5.5.4-5.5.5) } \\
\text { Target Filtration Conditions } \\
T M P: 40 \text { ssid } \\
A V: 13 \mathrm{ft} / \mathrm{s}\end{array}$} & Wash Solution & $0.20 \mathrm{M} \mathrm{NaOH}$ \\
\hline & Permeate Composition & $\begin{array}{l}\mathrm{Na}]: 2.1 \mathrm{M} \\
{[\mathrm{Al}]: 0.047 \mathrm{M}} \\
{[\mathrm{OH}]: 1.3 \mathrm{M}}\end{array}$ \\
\hline & & \\
\hline \multirow{3}{*}{$\begin{array}{l}\text { Caustic Wash } 3 \\
\text { (Section 5.5.4-5.5.5) } \\
\text { Target Filtration Conditions } \\
T M P: 40 \text { psid } \\
A V: 13 \mathrm{ft} / \mathrm{s}\end{array}$} & Wash Solution & $0.06 \mathrm{M} \mathrm{NaOH}$ \\
\hline & Permeate Composition & $\begin{array}{l}\mathrm{Na}]: 1.3 \mathrm{M} \\
{[\mathrm{Al}]: 0.016 \mathrm{M}} \\
{[\mathrm{OH}]: 0.60 \mathrm{M}}\end{array}$ \\
\hline & & \\
\hline \multirow{3}{*}{$\begin{array}{l}\text { Caustic Wash } 4 \\
\text { (Section 5.5.4-5.5.5) } \\
\text { Target Filtration Conditions } \\
T M P: 40 \text { psid } \\
A V: 13 \mathrm{ft} / \mathrm{s}\end{array}$} & Wash Solution & $0.02 \mathrm{M} \mathrm{NaOH}$ \\
\hline & Permeate Composition & $\begin{array}{l}\mathrm{Na}]: 0.81 \mathrm{M} \\
{[\mathrm{Al}]: 0.008 \mathrm{M}} \\
{[\mathrm{OH}]: 0.37 \mathrm{M}}\end{array}$ \\
\hline & & \\
\hline
\end{tabular}


Table 5.46 (Contd)

\begin{tabular}{|c|c|c|}
\hline Filtration Step & Property & Results \\
\hline \multirow{5}{*}{$\begin{array}{l}\text { Caustic Wash } 5 \text { \& Slurry } \\
\text { Condition } \\
\text { (Section 5.5.4-5.5.5) } \\
\text { Target Filtration Conditions } \\
T M P: 40 \mathrm{psid} \\
A V: 13 \mathrm{ft} / \mathrm{s}\end{array}$} & Wash Solution & $0.01 \mathrm{M} \mathrm{NaOH}$ \\
\hline & Permeate Composition & $\begin{array}{l}\text { [Na]: } 0.41 \mathrm{M} \\
{[\mathrm{Al}]: 0.004 \mathrm{M}} \\
{[\mathrm{OH}]: 0.19 \mathrm{M}}\end{array}$ \\
\hline & Measured UDS & $11 \mathrm{wt} \%$ \\
\hline & Particle Size & $\begin{array}{l}\text { d(10): } 0.17 \mu \mathrm{m} \\
d(50): 0.36 \mu \mathrm{m} \\
d(90): 3.2 \mu \mathrm{m}\end{array}$ \\
\hline & $\begin{array}{l}\text { Rheology } \\
\text { @ } 25^{\circ} \mathrm{C}-60^{\circ} \mathrm{C} \\
\text { (Sample ID: TI572-G2-R4) }\end{array}$ & $\begin{array}{l}\text { Non-Newtonian } \\
\text { Yield Stress: 2.8-1.6 Pa } \\
\text { Consistency: 11-5 mPa·s }\end{array}$ \\
\hline \multirow{2}{*}{$\begin{array}{l}\text { Oxidative Leach Slurry } \\
\text { (Section 5.6) }\end{array}$} & Measured UDS & $5 \mathrm{wt} \%$ \\
\hline & Particle Size & $\begin{array}{l}\mathrm{d}(10): 0.38 \mu \mathrm{m} \\
\mathrm{d}(50): 1.0 \mu \mathrm{m} \\
\mathrm{d}(90): 61 \mu \mathrm{m}\end{array}$ \\
\hline \multirow{3}{*}{$\begin{array}{l}\text { Oxidative Wash } 1 \text { (Section 5.6) } \\
\text { Filtration Conditions } \\
T M P: 40 \text { psid } \\
A V: 13 \mathrm{fps}\end{array}$} & Wash Solution & $0.01 \mathrm{M} \mathrm{NaOH}$ \\
\hline & Permeate Composition & $\begin{array}{l}{[\mathrm{Na}]: 0.28 \mathrm{M}} \\
{[\mathrm{OH}]: 0.14 \mathrm{M}}\end{array}$ \\
\hline & & \\
\hline \multirow{3}{*}{$\begin{array}{l}\text { Oxidative Wash } 2 \\
\text { Filtration Conditions } \\
T M P: 40 \text { psid } \\
A V: 13 \mathrm{fps}\end{array}$} & Wash Solution & $0.01 \mathrm{M} \mathrm{NaOH}$ \\
\hline & Permeate Composition & $\begin{array}{l}{[\mathrm{Na}]: 0.26 \mathrm{M}} \\
{[\mathrm{OH}]: 0.05 \mathrm{M}}\end{array}$ \\
\hline & & \\
\hline \multirow{5}{*}{$\begin{array}{l}\text { Oxidative Wash } 3 \text { \& Final Slurry } \\
\text { (Section 5.6) } \\
\text { Filtration Conditions } \\
T M P: 40 \text { psid } \\
\text { AV: } 13 \text { fps } \\
\text { Final Filter Testing (Section 5.7) }\end{array}$} & Wash Solution & $0.01 \mathrm{NaOH}$ \\
\hline & Permeate Composition & $\begin{array}{l}{[\mathrm{Na}]: 0.13 \mathrm{M}} \\
{[\mathrm{OH}]: 0.03 \mathrm{M}}\end{array}$ \\
\hline & Measured UDS & $7 \mathrm{wt} \%$ \\
\hline & Particle Size & $\begin{array}{l}d(10): 0.16 \mu \mathrm{m} \\
d(50): 0.30 \mu \mathrm{m} \\
d(90): 1.9 \mu \mathrm{m}\end{array}$ \\
\hline & $\begin{array}{l}\text { Rheology } \\
\text { @ } 25^{\circ} \mathrm{C}-60^{\circ} \mathrm{C} \\
\text { (Sample ID: TI572-G2-R5) }\end{array}$ & $\begin{array}{l}\text { Newtonian } \\
\text { Viscosity: } 0.7-1.4 \mathrm{~Pa} \\
\text { Consistency: } 5-3 \mathrm{mPa} \cdot \mathrm{s}\end{array}$ \\
\hline
\end{tabular}


Table 5.47. Summary of Overall Solid Leach Factors and Removal from Slurry

\begin{tabular}{|c|c|c|c|}
\hline \multirow[b]{2}{*}{ Element } & \multicolumn{2}{|c|}{ Solid Leach Factors } & \multirow[b]{2}{*}{$\begin{array}{c}\text { Total Removal } \\
\text { from Slurry } \\
\text { wt } \%\end{array}$} \\
\hline & $\begin{array}{c}\text { Applying Total } \\
\text { Mass Balance, } \\
\text { wt \% }\end{array}$ & $\begin{array}{c}\text { Using Slurry } \\
\text { and Supernate } \\
\text { Analysis } \\
\text { wt\% }\end{array}$ & \\
\hline $\mathrm{Al}$ & $45 \mathrm{wt} \%$ & $52-58$ wt $\%$ & $46 \mathrm{wt} \%$ \\
\hline $\mathrm{P}$ & $56 \mathrm{wt} \%$ & $<90 \mathrm{wt} \%$ & $50 \mathrm{wt} \%$ \\
\hline $\mathrm{Cr}$ & $26 \mathrm{wt} \%$ & $<50 \mathrm{wt} \%$ & $45 \mathrm{wt} \%$ \\
\hline
\end{tabular}

(a) Analyte mass percent removal includes the components in the initial supernate phase. Results were corrected to exclude sampling losses from this value.

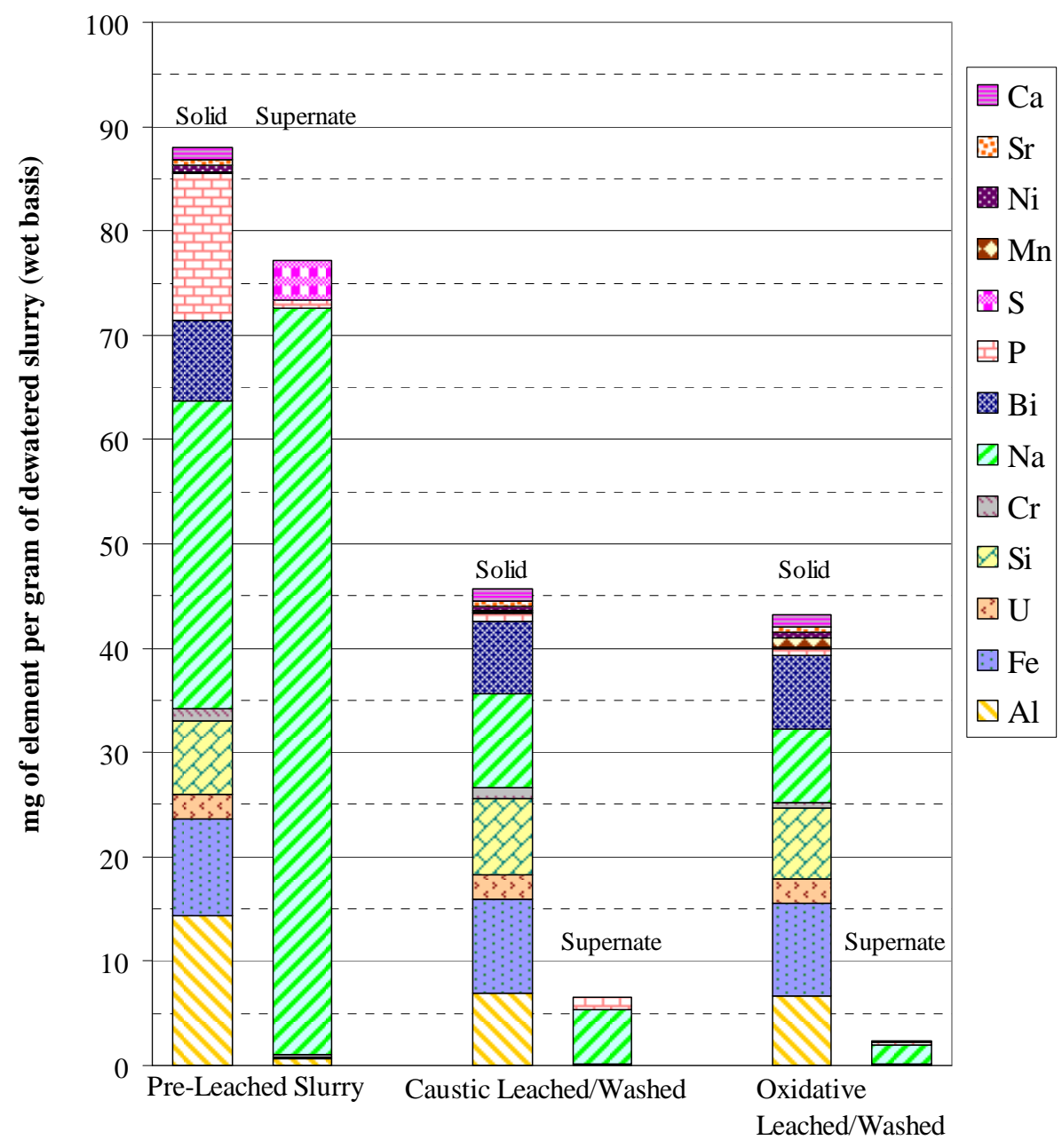

Figure 5.81. Comparison of Slurry Composition Before and After Leaching and Washing (Basis 1 gram of dewatered slurry: results taken from slurry ICP-OES Analysis.) 
WTP-RPT-166, Rev. 0

\subsection{Group 1/2 Post-CUF Batch Parametric Oxidative Leaching}

A portion of the composite Group 1/2 sample that was subjected to caustic leaching and washing in the CUF apparatus was also subjected to a parametric oxidative leaching experiment. This experiment examined the influence of free-hydroxide concentration and the permanganate-to-chromium ratio on the efficacy of $\mathrm{Cr}$ removal and on the behavior of Pu and other criticality-safety-related components. This section reports and discusses the results of the parametric Group 1/2 post-CUF parametric leaching experiment.

\subsection{Group 1/2 Post-CUF Batch Parametric Leaching: Experimental}

Parametric oxidative leaching tests were performed on the blended Group 1 bismuth phosphate sludge sample and Group 2 bismuth phosphate saltcake sample to determine the behavior of chromium during leaching at different conditions. The composite Group 1/2 sample material as received after caustic leaching and washing with $\mathrm{NaOH}$ in the CUF was subdivided and subjected to a parametric test matrix for oxidative leach testing as discussed in the following sections. ${ }^{(a)}$

\subsubsection{Preparation for Oxidative Leaching Tests}

To successfully subdivide the sample, it was necessary to first determine the weight percent waterinsoluble solids. One 9.5-g slurry sample (584-G1/2-CL-Slurry) was removed from the hot cell, and two aliquots from this sample were dried to constant weight. Since the material had been previously washed in the CUF, the dried solids obtained in this way were assumed to represent the UDS. Based on this, it was determined that the slurry contained $14.7 \mathrm{wt} \%$ UDS. To determine the amount of leachable $\mathrm{Cr}$ in the slurry, an initial estimate was made of the Cr content in one 3.6-g portion of the slurry, and an oxidative leach was performed with an excess of $\mathrm{NaMnO}_{4}$. After 6 hours, a sample was removed and submitted for analysis by UV/Vis spectroscopy; the amount of $\mathrm{Cr}$ oxidized under these conditions was taken to be the amount of leachable $\mathrm{Cr}$ in the slurry (5,040 $\mu$ g leachable $\mathrm{Cr}$ in $0.5 \mathrm{~g}$ of solids).

\subsubsection{Division of the Caustic Leached and Washed Group 1/2 Solids}

Seven 3.6-g slurry samples were transferred to 125-mL HDPE bottles with a large disposable polyethylene pipet. Each sample contained $\sim 0.5 \mathrm{~g}$ UDS. The samples were removed from the hot cell for follow-on processing at the fume hood workstation.

\subsubsection{Oxidative Leaching of the Caustic Leached Group 1/2 Solids}

The leaching conditions for each of the seven samples are summarized in Table 6.1. The test matrix was designed to evaluate the effects of the $\mathrm{Mn} / \mathrm{Cr}$ molar ratio $(0.75,1.0,1.25$, and 1.5) at a constant hydroxide concentration $(0.25 \mathrm{M})$ and the effect of hydroxide concentration $(0.25$ and $1.25 \mathrm{M})$ at a high $\mathrm{Mn} / \mathrm{Cr}$ molar ratio (1.25) on the chromium leaching kinetics and efficacy. Sodium hydroxide (19 M) was added to each aliquot of washed solids in the following amounts: $0.66 \mathrm{~mL}$ to yield $0.25 \mathrm{M} \mathrm{NaOH}$, and $3.3 \mathrm{~mL}$ to yield $1.25 \mathrm{M} \mathrm{NaOH}$. The slurry mixtures were then diluted to $50 \mathrm{~mL}$ (with an estimated uncertainty of 2

(a) Testing was conducted according to TI-RPP-WTP-456, Parametric Oxidative Leach Test of Group 1/2 Hanford Tank Waste, Post-CUF Test, L Snow, January, 2008. 
$\mathrm{mL}$ ) with DI water. Contact time with the concentrated $\mathrm{NaOH}$ was brief ( $<5 \mathrm{~min}$ ). The sample bottles were mixed by swirling by hand, the solids were allowed to settle until sufficient clear liquid was available to sample, and then approximately $2.0 \mathrm{~mL}$ of the clarified leachate solution was withdrawn with a transfer pipette and filtered through a $0.45-\mu \mathrm{m}$ pore size nylon syringe filter; the syringe filter and the syringe had been pre-heated in an oven to the sample temperature before filtering in an effort to minimize temperature changes impacting the sample. One $0.5-\mathrm{mL}$ sample of filtered solution was acidified with 15 $\mathrm{mL}$ of $0.3 \mathrm{M} \mathrm{HNO}_{3}$ for analysis by ICP-OES; another 0.5-mL sample of filtered solution was added to 2.5 $\mathrm{mL}$ of $2 \mathrm{M} \mathrm{HNO}_{3}$ for analysis of plutonium, and one $0.5-\mathrm{mL}$ sample of filtered leachate was analyzed directly (or following dilution in $0.096 \mathrm{M} \mathrm{NaOH}$ ) using UV/vis for chromate concentration. The remaining filtered solution was returned to the leaching vessel. This was the time $=0$ sample.

Aliquots of $1 \mathrm{M} \mathrm{NaMnO}_{4}$ (freshly prepared and filtered) were then added to each sample, resulting in the following amounts: $0.073 \mathrm{~mL}$ to yield $0.75 \mathrm{Mn} / \mathrm{Cr}$ mole ratio, $0.097 \mathrm{~mL}$ to yield $1.0 \mathrm{Mn} / \mathrm{Cr}$ mole ratio, $0.121 \mathrm{~mL}$ to yield $1.25 \mathrm{Mn} / \mathrm{Cr}$ mole ratio, and $0.146 \mathrm{~mL}$ to yield a $1.5 \mathrm{Mn} / \mathrm{Cr}$ mole ratio. The sample bottles were weighed after each addition of reagents $\left(\mathrm{NaOH}\right.$, water, and $\left.\mathrm{NaMnO}_{4}\right)$. The time of addition of $\mathrm{NaMnO}_{4}$ was defined as $\mathrm{T}_{0}$. Each leaching vessel was closed with a cap equipped with a tube condenser. The condenser was used to eliminate pressurization and minimize water loss while at the same time minimizing the spread of contamination. The leaching mixtures were shaken for 24 hours at 200 RPM resulting in good suspension of the solids. Samples were withdrawn in the same manner as the time $=0$ sample at $0.5,1,2,4,6$, and 24 hours. At 24 hours, additional samples of the leachate were filtered for analysis to determine the free-hydroxide ion concentration and U by KPA.

After the final samples were taken at temperature, the slurries were removed from the mixing/heating block and cooled to ambient temperature. The slurries were centrifuged, and the leachates were decanted. $^{(\text {a) }}$

The equilibrium concentration values for free hydroxide and sodium are shown in Table 6.1 and were based on results from the samples taken at 24 hours.

(a) The contact dose rates of the leached solids were too high to safely conduct transfer to volume-graduated centrifuge tubes to assess the volume of centrifuged solids. 
Table 6.1. Oxidative Leaching Conditions for Group 1/2 Caustic-Leached Solids

\begin{tabular}{|c|c|c|c|c|c|c|c|}
\hline \multirow{2}{*}{ Bottle ID } & \multicolumn{2}{|c|}{ Free OH, M } & \multicolumn{2}{|c|}{ Na, M } & \multicolumn{2}{|c|}{$\begin{array}{c}\text { Mn/Cr } \\
\text { Mole Ratio }\end{array}$} & \multirow{2}{*}{$\begin{array}{c}\text { Temperature, } \\
{ }^{\circ} \mathrm{C}^{(\mathrm{c})}\end{array}$} \\
\hline & Target & Measured $^{(a)}$ & Target & Measured $^{(a)}$ & Target & Actual $^{(\mathbf{b})}$ & \\
\hline 584-G1/2-OL-0.75 & 0.25 & 0.29 & 0.25 & 0.33 & 0.75 & 0.59 & 45 \\
\hline 584-G1/2-OL-1a & 0.25 & 0.29 & 0.25 & 0.33 & 1.0 & 0.79 & 45 \\
\hline 584-G1/2-OL-1b & 0.25 & 0.28 & 0.25 & 0.33 & 1.0 & 0.79 & 45 \\
\hline 584-G1/2-OL-1c & 0.25 & 0.27 & 0.25 & 0.31 & 1.0 & 0.79 & 45 \\
\hline 584-G1/2-OL-1.25 & 0.25 & 0.29 & 0.25 & 0.33 & 1.25 & 0.98 & 45 \\
\hline 584-G1/2-OL-1.5 & 0.25 & 0.28 & 0.25 & 0.32 & 1.5 & 1.19 & 45 \\
\hline $\begin{array}{l}\text { 584-G1/2-OL-1.25- } \\
1.25\end{array}$ & 1.25 & 1.38 & 1.25 & 1.44 & 1.25 & 0.98 & 45 \\
\hline
\end{tabular}

(a) The measured analyte concentrations represent the equilibrium concentration obtained after a 24-h contact time.

(b) As mentioned in Section 6.1.1, the amount of $\mathrm{NaMnO}_{4}$ added to achieve the desired $\mathrm{Mn} / \mathrm{Cr}$ mole ratio was calculated based on the amount of $\mathrm{Cr}$ leached during a preliminary 6-h contact of a portion of the slurry with excess $\mathrm{MnMnO}_{4}$. However, this method underestimated the amount of $\mathrm{Cr}$ in the slurry because that portion that is unreactive towards permanganate was not accounted for. ICP-OES analysis of the solids indicated the total $\mathrm{Cr}$ concentration was 6,425 $\mu \mathrm{g}$ per $0.5 \mathrm{~g}$ of solids (versus 5,040 $\mu \mathrm{g}$ leachable $\mathrm{Cr}$ in $0.5 \mathrm{~g}$ of solids). The Actual $\mathrm{Mn} / \mathrm{Cr}$ mole ratios listed here were calculated using the total $\mathrm{Cr}$ concentration determined by ICP-OES and the amount of $\mathrm{NaMnO}_{4}$ that was added to each sample.

(c) The temperature uncertainty was $\pm 2.5^{\circ} \mathrm{C}$.

Analytical Service Request (ASR): 8111

\subsubsection{Washing of Oxidative-Leached Group 1/2 Solids for Analysis}

The solids from the triplicate samples (G1/2-OL-1a, $-1 \mathrm{~b},-1 \mathrm{c}$, leached at $40^{\circ} \mathrm{C}$ in $0.25 \mathrm{M} \mathrm{NaOH}$ at a $\mathrm{Mn} / \mathrm{Cr}$ of 1) were prepared for characterization as shown in Figure 6.1. The process followed was essentially the same as that for the leached Group 1 solids (Section 3.3.4). 


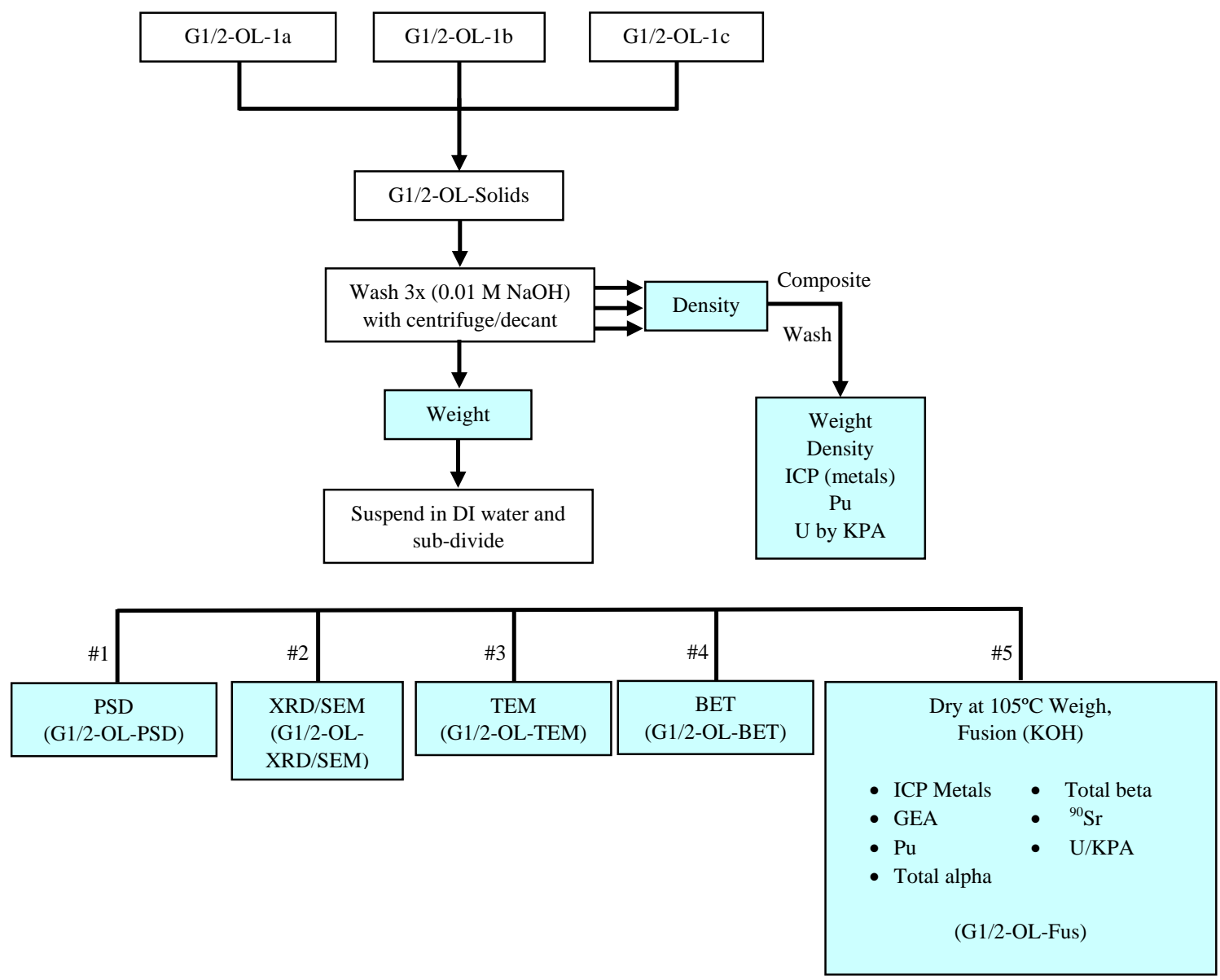

Figure 6.1. Washing, Subdivision, and Analysis Scheme for the Group 1/2 Oxidatively Leached Solids

\subsection{Group 1/2 Bi-Phosphate Sludge/Saltcake Waste Parametric Oxidative Leaching Test Results}

As discussed in Section 4.4, the Cr concentration in the caustic-leached Group 2 solids is sufficiently high that $\mathrm{Cr}$ would be expected to be the component limiting HLW glass waste loading for this material. Thus, oxidative leaching of the caustic-leached Group 2 solids to remove $\mathrm{Cr}$ is of interest. To investigate the oxidative leaching behavior of the caustic-insoluble $\mathrm{Cr}$ component, the combined Group 1/2 sample that was caustic leached in the CUF was subjected to parametric oxidative leaching tests. The objective of this testing was to gain an understanding of the Cr dissolution behavior for the actual tank waste to help guide development of suitable Cr-containing simulants. Another objective was to determine the extent of Pu mobilization during oxidative leaching. The latter issue is of concern for criticality safety within the WTP. The results from the parametric oxidative leach testing and the composition of the residual solids are discussed in the following sections. 
WTP-RPT-166, Rev. 0

\subsubsection{Chromium Behavior During Oxidative Leaching of the Caustic-Leached Group 1/2 Solids}

The oxidation of $\mathrm{Cr}$ as a function of time, free-hydroxide concentration, and $\mathrm{Mn} / \mathrm{Cr}$ molar ratios was evaluated. Based on the total Cr concentration in the initial (caustic-leached) solids material (12.85 mg $\mathrm{Cr} / \mathrm{g}$ ), and the wt\% UDS of the starting slurry (14.66\%), the complete dissolution of Cr would result in a concentration of $0.138 \mathrm{mg} \mathrm{Cr} / \mathrm{mL}$ or $0.003 \mathrm{M}$. The $\mathrm{Cr}$ did not completely dissolve under any of the conditions examined in this experiment. In this discussion, the reported wt\% of $\mathrm{Cr}$ dissolved at each sampling point was calculated based on the final $\mathrm{Cr}$ concentration in the triplicate samples, as discussed in Section 6.2.6.2.

The oxidative leaching data at constant temperature and varying free-hydroxide concentrations and $\mathrm{Mn} / \mathrm{Cr}$ molar ratios are shown in Figure 6.2. A measure of experimental precision is shown by the triplicate tests conducted at $0.25 \mathrm{M}$ free hydroxide at $45^{\circ} \mathrm{C}$ with a $\mathrm{Mn} / \mathrm{Cr}$ mole ratio of 0.79 . The scatter was within the analytical uncertainty of $\pm 15 \%$.

Under all testing conditions, $>50 \%$ of the Cr was removed from the solid phase within the first 30 min of contact time. Most of the Cr oxidation occurred within the first 30 minutes, and equilibrium was achieved within $6 \mathrm{~h}$ for samples having $\mathrm{Mn} / \mathrm{Cr}$ molar ratios of 0.59 and 0.79 . Samples with higher amounts of Mn dissolved an additional 2 to $4 \%$ of $\mathrm{Cr}$ between 6 and $24 \mathrm{~h}$. Increasing the $\mathrm{Mn} / \mathrm{Cr}$ mole ratio from 0.59 to 0.79 directly increased the amount of $\mathrm{Cr}$ in solution (initially and at equilibrium conditions). The test conditions at the sub-stoichiometric Mn/Cr molar ratios of 0.59 and 0.79 mobilized $\sim 56 \%$ and $66 \%$ of the $\mathrm{Cr}$, respectively. The stoichiometric and super-stoichiometric amounts of 0.98 and $1.19 \mathrm{Mn} / \mathrm{Cr}$ mole ratio resulted in $\sim 72 \% \mathrm{Cr}$ dissolution. The amount of $\mathrm{NaOH}(0.25$ or $1.25 \mathrm{M})$ at the $\mathrm{Mn} / \mathrm{Cr}$ molar ratio of 0.98 had no effect on the amount of $\mathrm{Cr}$ dissolved.

Figure 6.3 shows the average of the 2-, 4-, 6-, and 24-hr data points taken under all conditions of $\mathrm{NaOH}$ concentration as a function of the $\mathrm{Mn} / \mathrm{Cr}$ molar ratio. The $\mathrm{y}$-axis error bars define the standard deviation of all results at the given $\mathrm{Mn} / \mathrm{Cr}$ mole ratios. From the 0.59 to $0.79 \mathrm{Mn} / \mathrm{Cr}$ mole ratio, there was a slight impact of time on the dissolution of chromium up to $6 \mathrm{~h}$. There was no significant impact of time on the dissolution of $\mathrm{Cr}$ beyond $6 \mathrm{~h}$. At the high $\mathrm{Mn} / \mathrm{Cr}$ mole ratios of 0.98 and 1.19, there was a slight time dependence from 6 to $24 \mathrm{~h}$. The main factor controlling dissolution was the amount of added permanganate up to an excess of permanganate. There was no added value in adding greater excesses of permanganate (from a $\mathrm{Mn} / \mathrm{Cr}$ mole ratio of 0.98 to 1.19). 
WTP-RPT-166, Rev. 0

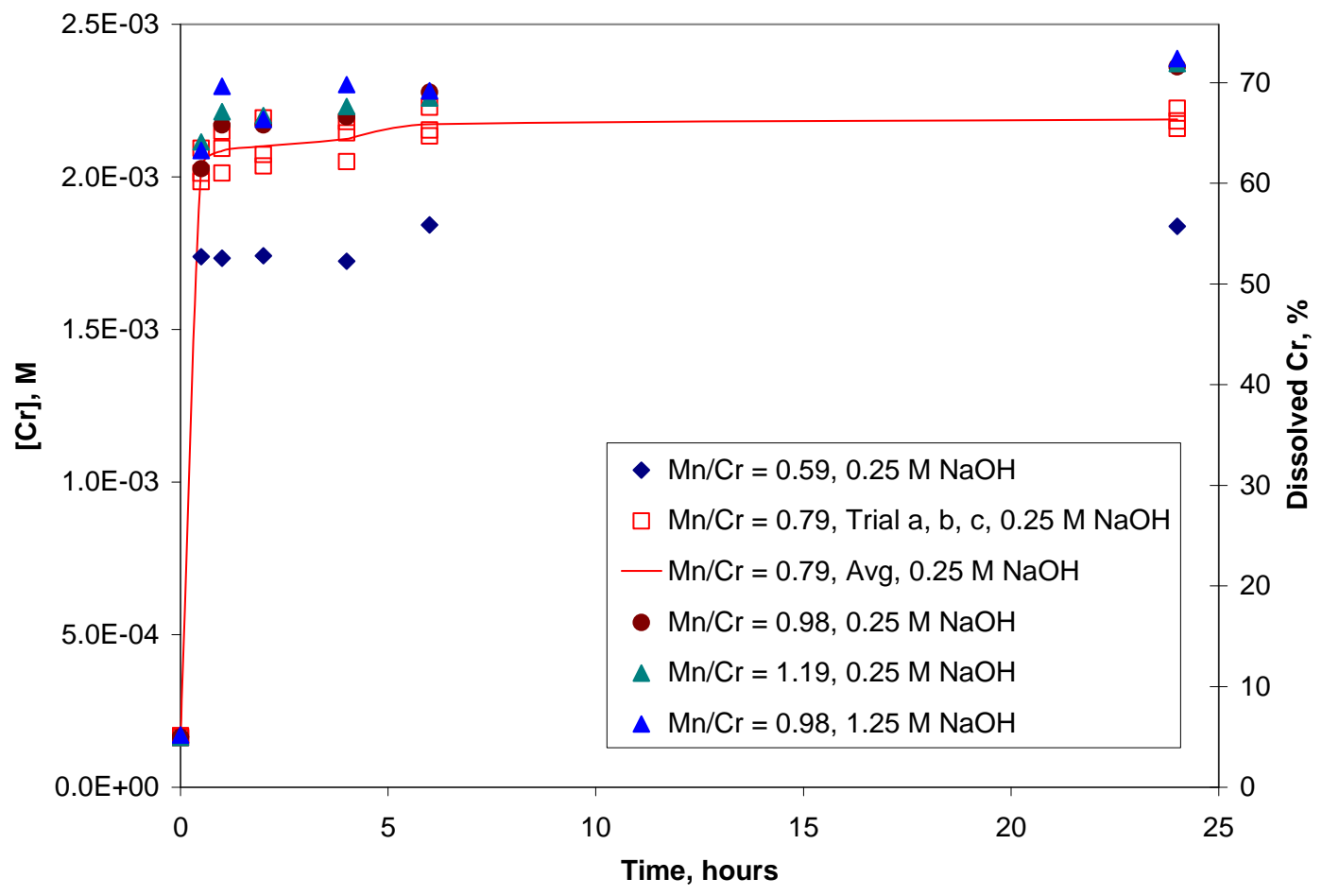

Figure 6.2. Chromium Concentration Versus Time at $45^{\circ} \mathrm{C}$ with $\mathrm{Mn} / \mathrm{Cr}$ Mole Ratios of $0.59,0.79,0.98$, and 1.19 in $0.25 \mathrm{M} \mathrm{NaOH}$, and at a $\mathrm{Mn} / \mathrm{Cr}$ Mole Ratio of 0.98 in 1.25 M NaOH for Group 1/2 Bi-Phosphate Sludge/Saltcake (During Oxidative Leaching)

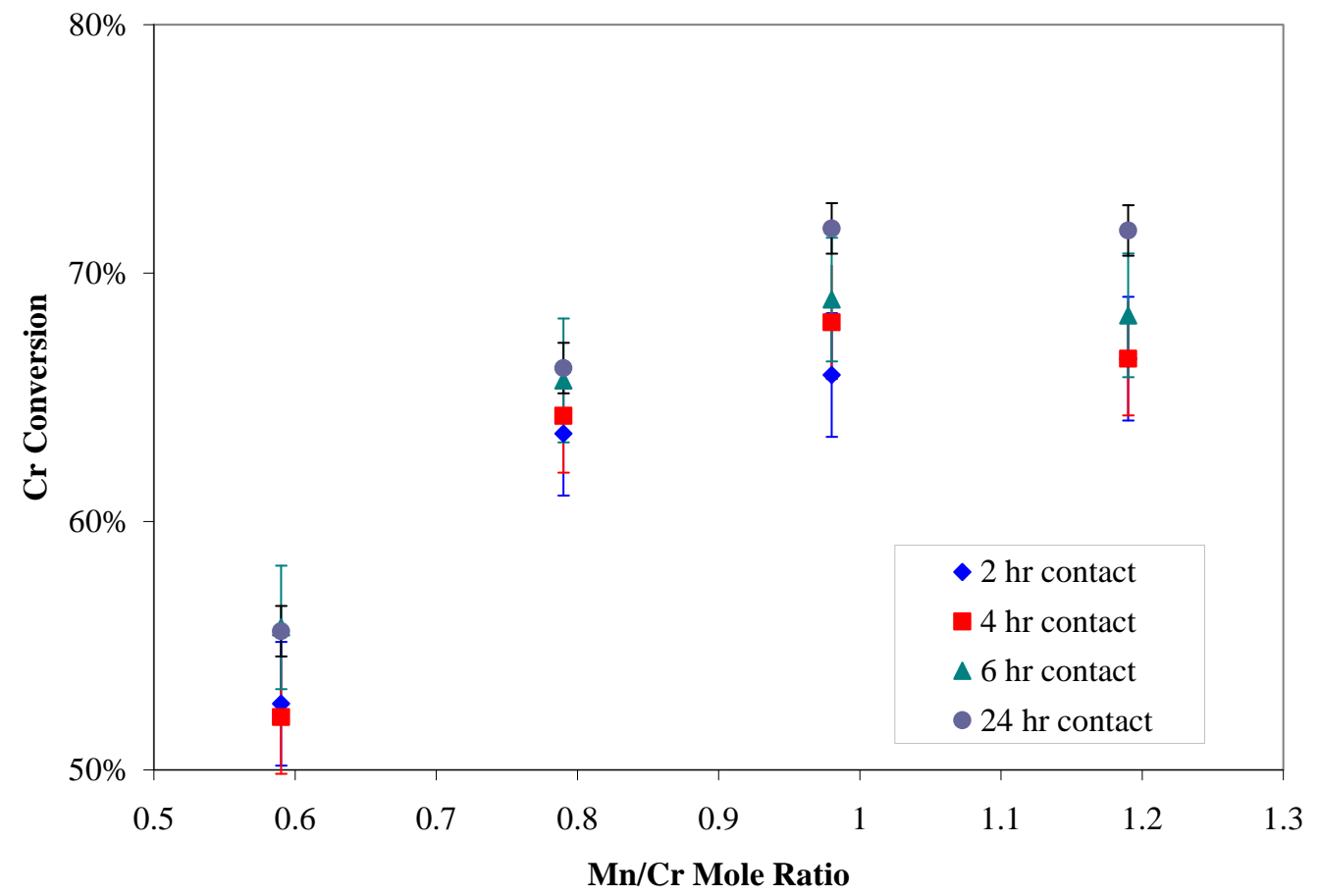

Figure 6.3. Amount of Chromium Removed as a Function of Mn/Cr Mole Ratio and Time for Group 1/2 Bi-Phosphate Sludge/Saltcake (During Oxidative Leaching) 
For each sample, the total Cr concentration was measured by ICP-OES, and the Cr(VI) (as chromate) concentration was measured by UV/Vis spectrophotometry. Results from the two measurement techniques for three test conditions are shown in Figure 6.4. Results for all tests are tabulated in Appendix L along with the percent difference between the two techniques. The agreement between the two techniques was excellent; all were within $14 \%$, and in most cases were well within $10 \%$. The differences in the Cr concentrations determined by ICP-OES and by spectrophotometry were well within the analytical uncertainty.

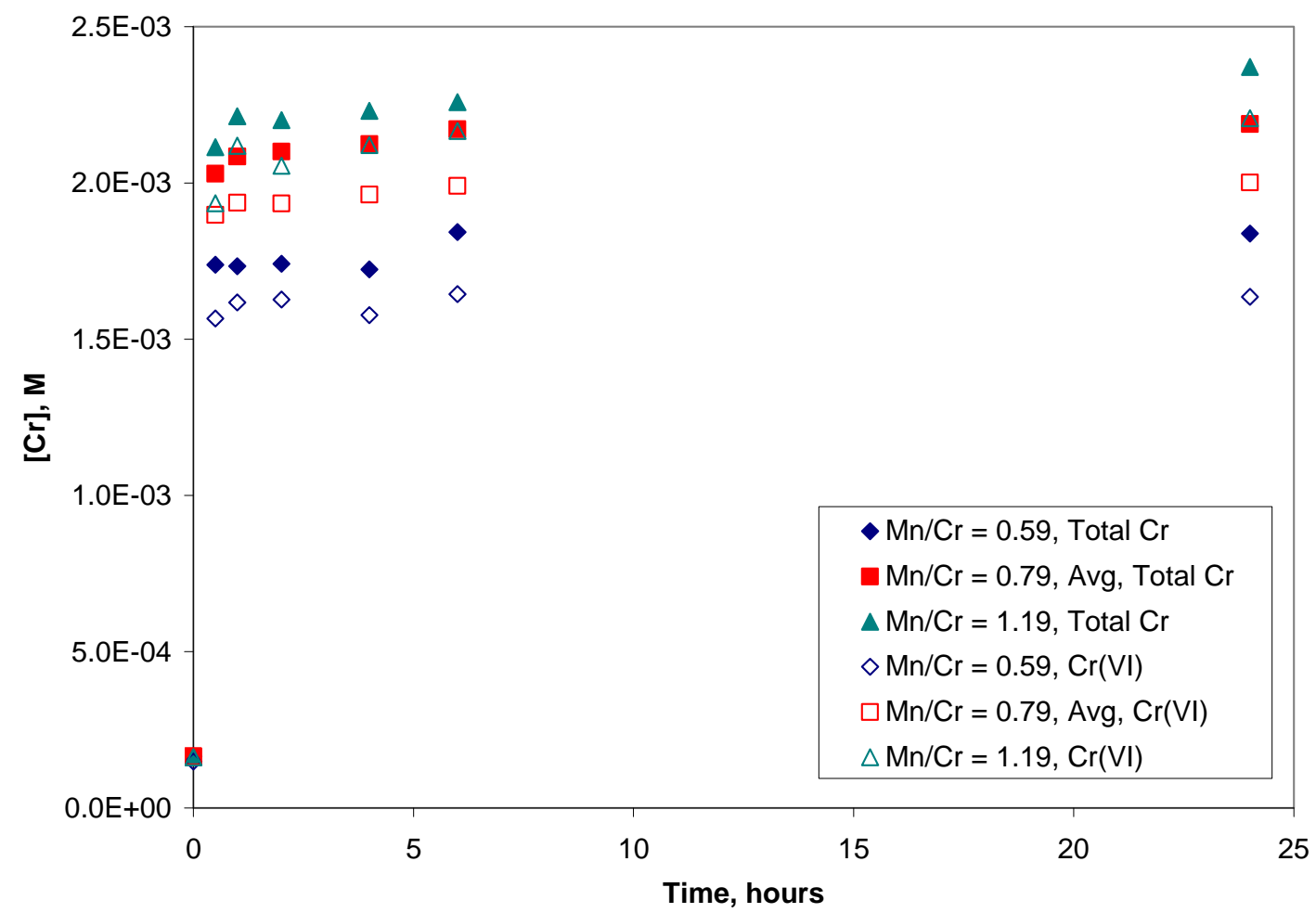

Figure 6.4. Total Chromium and Cr(VI) Concentrations Versus Time for Group 1/2 Bi-Phosphate Sludge/Saltcake (during oxidative leaching). Conditions: $45^{\circ} \mathrm{C}$ leaching temperature in 0.25 $\mathrm{M} \mathrm{NaOH}$ at $\mathrm{Mn} / \mathrm{Cr}$ molar ratios of $0.59,0.79$, and 1.19 .

\subsubsection{Aluminum Behavior During Oxidative Leaching of the Caustic-Leached Group 1/2 Solids}

The Al dissolution behavior during the oxidative leaching tests was evaluated as a function of time, freehydroxide concentration, and the $\mathrm{Mn} / \mathrm{Cr}$ molar ratio. Based on the total Al concentration in the initial (caustic leached) solids material $(77.85 \mathrm{mg} \mathrm{Al} / \mathrm{g}$ ) and the wt\% UDS of the starting slurry (14.66\%), the complete dissolution of $\mathrm{Al}$ would result in a concentration of $0.838 \mathrm{mg} \mathrm{Al} / \mathrm{mL}$ or $0.03 \mathrm{M}$. Complete $\mathrm{Al}$ dissolution was not reached in this experiment. In this discussion, the reported wt\% of Al dissolved at each sampling point was calculated based on the final $\mathrm{Al}$ concentration in the triplicate samples, as discussed in Section 6.2.6.2. 
The leaching data at constant temperature and varying free-hydroxide concentrations and $\mathrm{Mn} / \mathrm{Cr}$ molar ratios are shown in Figure 6.5. A measure of experimental precision is shown by the triplicate tests conducted at $0.25 \mathrm{M}$ free hydroxide at $45^{\circ} \mathrm{C}$ with a $\mathrm{Mn} / \mathrm{Cr}$ mole ratio of 0.79 . The scatter was within the analytical uncertainty of $\pm 15 \%$.

Under all six test conditions in $0.25 \mathrm{M} \mathrm{NaOH}, \sim 21 \%$ of the Al dissolved within $24 \mathrm{~h}$ of contact time. Equilibrium conditions were achieved within $6 \mathrm{~h}$. Increasing the $\mathrm{Mn} / \mathrm{Cr}$ mole ratio from 0.59 to $1.19 \mathrm{had}$ no impact on the amount of $\mathrm{Al}$ in solution (initially and at equilibrium conditions). The amount of $\mathrm{NaOH}$ $(0.25$ or $1.25 \mathrm{M})$ at the $\mathrm{Mn} / \mathrm{Cr}$ molar ratio of 0.98 had an effect on the amount of Al dissolution, increasing it from $21 \%$ to $38 \%$. The latter result suggests that the $\mathrm{Al}$ did not completely dissolve during caustic leaching of the Group 1/2 solids in the CUF apparatus. This might be explained by the relatively low liquid-to-solids ratio (8 mL leachate/g solids per Figure 5.26) during leaching in the CUF compared to that used in the parametric leaching experiments $(100 \mathrm{~mL} / \mathrm{g}$ solids).

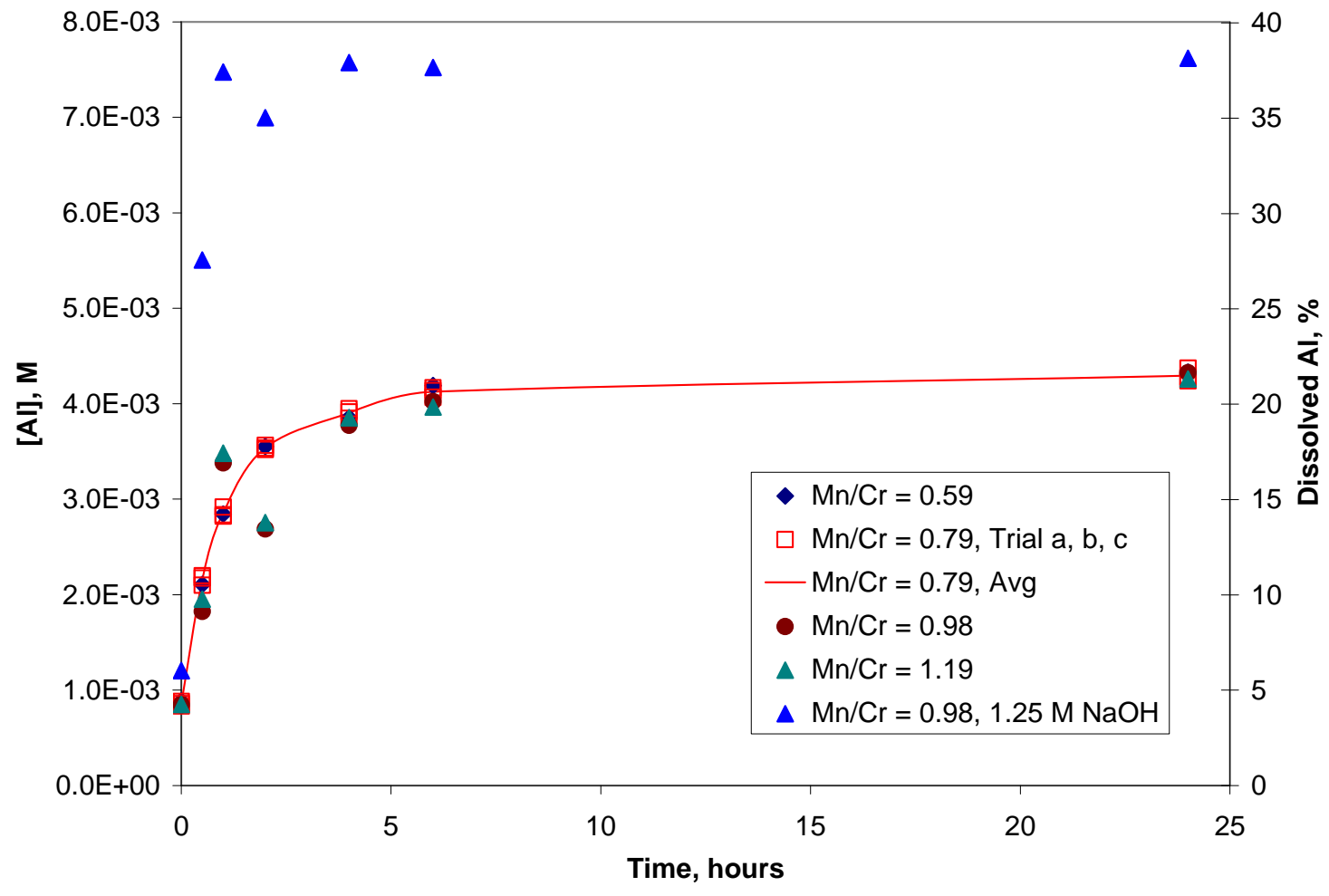

Figure 6.5. Aluminum Concentration Versus Time at $45^{\circ} \mathrm{C}$ Leach Temperature at $\mathrm{Mn} / \mathrm{Cr}$ Mole Ratios of $0.59,0.79,0.98$, and 1.19 in $0.25 \mathrm{M} \mathrm{NaOH}$, and at a $\mathrm{Mn} / \mathrm{Cr}$ Mole Ratio of 0.98 in $1.25 \mathrm{M}$ $\mathrm{NaOH}$ for Group 1/2 Bi-Phosphate Sludge/Saltcake (During Oxidative Leaching)

\subsubsection{Phosphorus Behavior During Oxidative Leaching of the Caustic-Leached Group 1/2 Solids}

The $\mathrm{P}$ dissolution during oxidative leaching was determined as a function of time, temperature, freehydroxide concentration, and the $\mathrm{Mn} / \mathrm{Cr}$ molar ratio. Based on the total $\mathrm{P}$ concentration in the initial (caustic leached) solids material (14.75 mg P/g) and the wt\% UDS of the starting slurry (14.66\%), the complete dissolution of $\mathrm{P}$ would result in a concentration of $0.159 \mathrm{mg} \mathrm{P} / \mathrm{mL}$ or $0.005 \mathrm{M}$. The $\mathrm{P}$ did not 
completely dissolve in this experiment. In this discussion, the reported $\mathrm{wt} \%$ of $\mathrm{P}$ dissolved at each sampling point was calculated based on the final solids concentration in the triplicate samples, as discussed in Section 6.2.6.2.

The leaching data at constant temperature and varying free-hydroxide concentrations and $\mathrm{Mn} / \mathrm{Cr}$ molar ratios are shown in Figure 6.6. A measure of experimental precision is shown by the triplicate tests conducted at $0.25 \mathrm{M}$ free hydroxide at $45^{\circ} \mathrm{C}$ with a $\mathrm{Mn} / \mathrm{Cr}$ mole ratio of 0.79 . The scatter was within the analytical uncertainty of $\pm 15 \%$.

Under all six test conditions in $0.25 \mathrm{M} \mathrm{NaOH}, 58$ to $62 \%$ of the residual $\mathrm{P}$ following caustic leaching was dissolved within $24 \mathrm{~h}$, and equilibrium was achieved within $6 \mathrm{~h}$. Increasing the $\mathrm{Mn} / \mathrm{Cr}$ mole ratio from 0.59 to 1.19 had no impact on the amount of $\mathrm{P}$ in solution (initially and at equilibrium conditions). The amount of $\mathrm{NaOH}(0.25$ or $1.25 \mathrm{M})$ at the $\mathrm{Mn} / \mathrm{Cr}$ molar ratio of 0.98 also had no effect on the amount of $\mathrm{P}$ dissolution.

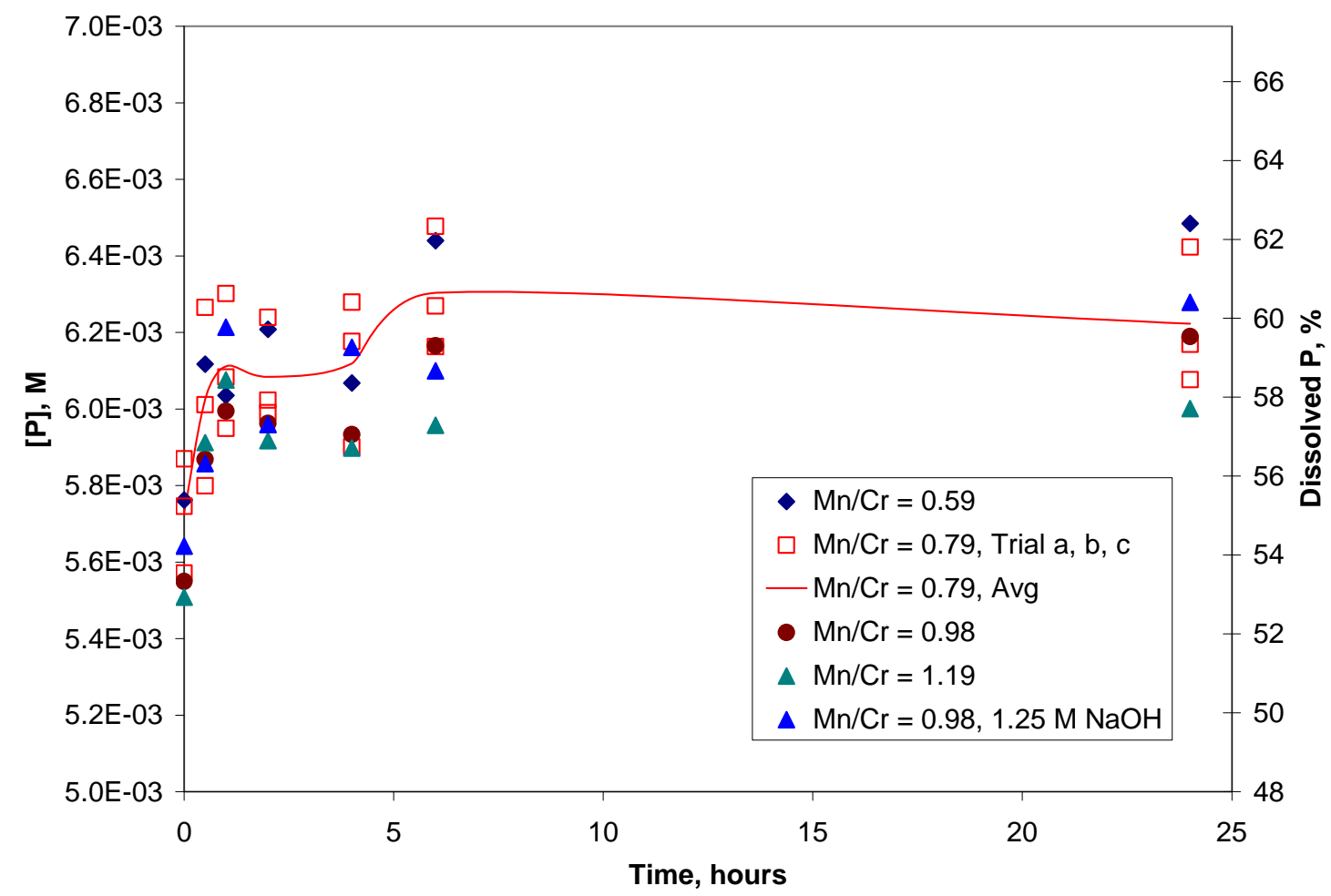

Figure 6.6. Phosphorus Concentration Versus Time at $45^{\circ} \mathrm{C}$ Leach Temperature at $\mathrm{Mn} / \mathrm{Cr}$ Mole Ratios of $0.59,0.79,0.98$, and 1.19 in $0.25 \mathrm{M} \mathrm{NaOH}$, and at a Mn/Cr Mole Ratio of 0.98 in $1.25 \mathrm{M}$ $\mathrm{NaOH}$ for Group 1/2 Bi-Phosphate Sludge/Saltcake (during oxidative leaching) 


\subsubsection{Behavior of Plutonium and Other Safety-Related Components During Oxidative Leaching of the Caustic-Leached Group 1/2 Solids}

The ${ }^{239+240} \mathrm{Pu}$ and ${ }^{238} \mathrm{Pu}$ concentrations were measured for each leaching condition and at each sampling time. The amount of ${ }^{239+240} \mathrm{Pu}$ dissolved, expressed in terms of the percent dissolved, ${ }^{(\mathrm{a})}$ is shown in Figure 6.7; numeric values are provided in Appendix L. The results obtained from the ${ }^{238} \mathrm{Pu}$ measurement were similar to that for ${ }^{239+240} \mathrm{Pu}$. Also shown on in Figure 6.7 as a point of reference are the $\mathrm{Pu}$ concentrations (assuming all the ${ }^{239+240} \mathrm{Pu}$ activity is attributed only to the isotope ${ }^{239} \mathrm{Pu}$ ) in terms of grams $\mathrm{Pu} / \mathrm{L}$ at 10 and 40\% dissolution of the Pu. As previously observed (Fiskum et al. 2008), the Pu dissolution was strongly dependent on the free-hydroxide concentration. There was a large $(\sim 6 \times)$ increase in the Pu concentration when the $\mathrm{NaOH}$ concentration was increased from $0.25 \mathrm{M}$ to $1.25 \mathrm{M}$. For example, after leaching for $6 \mathrm{~h}$ at a $\mathrm{Mn} / \mathrm{Cr}$ ratio of 0.98 , the ${ }^{239+240} \mathrm{Pu}$ concentration was $1.54 \times 10^{-3}$ $\mu \mathrm{Ci} / \mathrm{mL}$ at $1.25 \mathrm{M} \mathrm{NaOH}$ and $2.54 \times 10^{-4} \mu \mathrm{Ci} / \mathrm{mL}$ at $0.25 \mathrm{M} \mathrm{NaOH}$. Clearly, low free-hydroxide concentrations will need to be maintained to minimize Pu mobilization during oxidative leaching of Cr. It is unclear why there is such a large drop in Pu concentration for the 24-h sampling point in $1.25 \mathrm{M} \mathrm{NaOH}$ with a $\mathrm{Mn} / \mathrm{Cr}$ mole ratio of 0.98 . The difference in values for ${ }^{238} \mathrm{Pu}$ is greater than the $15 \%$ uncertainty in the analytical results.

The $U$ concentrations in the oxidative leaching solutions remained low (see Appendix L) under all conditions examined. Typically, the U concentration was $\sim 3 \mu \mathrm{g} / \mathrm{mL}$ after leaching for $24 \mathrm{~h}$. The exception was during leaching in $1.25 \mathrm{M} \mathrm{NaOH}$ at a $\mathrm{Mn} / \mathrm{Cr}$ ratio of 0.98 ; in that case, the U concentration in solution reached a level of $\sim 8 \mu \mathrm{g} / \mathrm{mL}$. The Fe content of the leachates was also very low, generally $<1 \mu \mathrm{g} / \mathrm{mL}$. In some samples (e.g., the 1-h sample for the $0.25 \mathrm{M} \mathrm{NaOH}, \mathrm{Mn} / \mathrm{Cr}=0.98$ case), elevated concentrations of Fe were observed. But this was likely because of Fe-contamination of the sample since the time points before and after displayed much less Fe. At $0.25 \mathrm{M} \mathrm{NaOH}$ and $\mathrm{Mn} / \mathrm{Cr} \leq 0.79$, Mn was below the detection limit. Manganese was observed to be in the leachate solutions at $\mathrm{Mn} / \mathrm{Cr}=0.98$ or higher, but the amount in solution decreased with time and was below the detection limit at $24 \mathrm{~h}$. The concentrations of $\mathrm{Ni}$ and $\mathrm{Cd}$ were below the detection limits in nearly all solutions analyzed. The B concentrations were near the detection limit and always $<1 \mu \mathrm{g} / \mathrm{mL}$.

(a) To obtain the percent Pu removed values plotted in Figure 6.7, the total amount of Pu in the solution was divided by the amount of $\mathrm{Pu}$ in the caustic-leached solids used for each leaching experiment $(\sim 0.38 \mu \mathrm{Ci}$ ${ }^{239+240} \mathrm{Pu}$ ) and then multiplied by 100 to get the percent removed value. 
WTP-RPT-166, Rev. 0

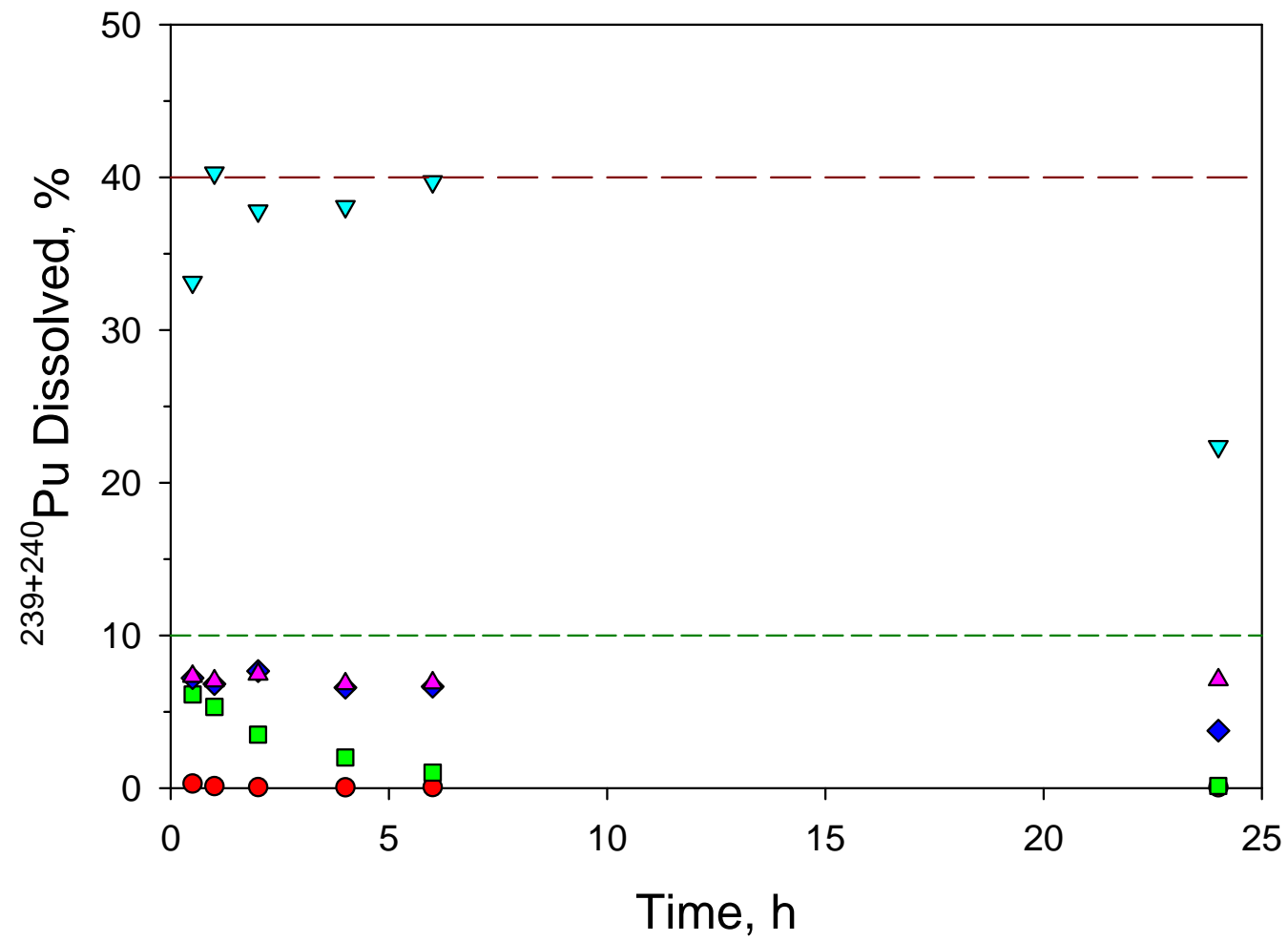

\begin{tabular}{|ll|}
\hline$\circ$ & $0.25 \mathrm{M} \mathrm{NaOH} ; \mathrm{Mn} / \mathrm{Cr}=0.59$ \\
$\square$ & $0.25 \mathrm{M} \mathrm{NaOH} ; \mathrm{Mn} / \mathrm{Cr}=0.79$, Mean Values \\
$\nabla$ & $0.25 \mathrm{M} \mathrm{NaOH} ; \mathrm{Mn} / \mathrm{Cr}=0.98$ \\
$\Delta$ & $0.25 \mathrm{M} \mathrm{NaOH} ; \mathrm{Mn} / \mathrm{Cr}=1.19$ \\
$\nabla$ & $1.25 \mathrm{M} \mathrm{NaOH} ; \mathrm{Mn} / \mathrm{Cr}=0.98$ \\
--- & $1.0 \times 10^{-8} \mathrm{~g} / \mathrm{L}$ (if all $\left.\mathrm{Pu}-239\right)$ \\
------ & $2.5 \times 10^{-9} \mathrm{~g} / \mathrm{L}$ (if all $\left.\mathrm{Pu}-239\right)$
\end{tabular}

Figure 6.7. Effect of Free-Hydroxide Concentration on Pu Mobilization During Oxidative Leaching for Group 1/2 Bi-Phosphate Sludge/Saltcake

\subsubsection{Assessment of Final Leach Conditions}

A summary of the final (24-hr) leach solution chemistry and physical parameters is shown in Table 6.2. The final free-hydroxide and sodium concentrations were at the targeted values, within the uncertainty of the analytical method $( \pm 15 \%)$. The calculated amount of $\mathrm{Cr}$ removed at each leaching condition is also shown in the table. Appendix L summarizes the concentrations of total $\mathrm{Cr}, \mathrm{Cr}(\mathrm{VI}), \mathrm{Al}, \mathrm{B}, \mathrm{Cd}, \mathrm{Fe}, \mathrm{Mn}$, Na, Ni, P, Si, U, U by KPA, ${ }^{239+240} \mathrm{Pu}$, and ${ }^{238} \mathrm{Pu}$ in the leaching solutions. 
Table 6.2. Group $1 / 2$ Bi-Phosphate Sludge/Saltcake Oxidative Leaching Final Aqueous Phase Conditions

\begin{tabular}{||c|c|c|c|c|c|c||}
\hline Temp, ${ }^{\circ} \mathbf{C}$ & Free $\mathbf{O H}, \mathbf{M}$ & $\mathbf{N a}, \mathbf{M}$ & $\begin{array}{c}\mathbf{M n} / \mathbf{C r} \\
\text { Mole Ratio }\end{array}$ & $\begin{array}{c}\text { Density, } \\
\mathbf{g} / \mathbf{m L}\end{array}$ & $\mathbf{C r}, \mathbf{M}$ & $\begin{array}{c}\text { \% Cr } \\
\text { Removed }\end{array}$ \\
\hline 45 & 0.29 & 0.33 & 0.59 & 1.03 & $1.83 \mathrm{E}-03$ & 56 \\
\hline 45 (trial a) & 0.28 & 0.33 & 0.79 & 1.02 & $2.22 \mathrm{E}-03$ & 67 \\
\hline 45 (trial b) & 0.28 & 0.33 & 0.79 & 1.01 & $2.16 \mathrm{E}-03$ & 65 \\
\hline 45 (trial c) & 0.27 & 0.31 & 0.79 & 1.02 & $2.18 \mathrm{E}-03$ & 66 \\
\hline 45 & 0.29 & 0.33 & 0.98 & 1.02 & $2.36 \mathrm{E}-03$ & 71 \\
\hline 45 & 0.28 & 0.32 & 1.19 & 1.02 & $2.37 \mathrm{E}-03$ & 72 \\
\hline 45 & 1.38 & 1.44 & 0.98 & 1.07 & $2.39 \mathrm{E}-03$ & 72 \\
\hline \multicolumn{7}{|l}{ Analytical Service Request: ASR 8111 } \\
\hline
\end{tabular}

\subsubsection{Composition of Group 1/2 Caustic and Oxidatively Leached and Washed Solids}

The Group $1 / 2$ solids that had been oxidatively-leached at $45^{\circ} \mathrm{C}$ in $0.25 \mathrm{M} \mathrm{NaOH}$ with a $\mathrm{Mn} / \mathrm{Cr}$ mole ratio of 0.79 for $24 \mathrm{~h}$ were combined and washed in preparation for analysis. The wash solution composition and the washed solids chemical, radiochemical, particle size, and crystal habit are discussed.

\subsubsection{Leached Solids Washing Solution}

The densities of the three sequential washing solutions were $1.006,1.000$, and $1.005 \mathrm{~g} / \mathrm{mL}$, respectively. The composite washing solution (126.05 mL volume) density, ICP metals, U measured by KPA, and Pu concentration are shown in Table 6.3.

Table 6.3. Solids Wash Solution Composition

\begin{tabular}{|c|c|c|c|}
\hline Analyte & $\mathbf{M}$ & Density $^{(a)}$ & $\mathrm{g} / \mathrm{mL}$ \\
\hline $\mathrm{Al}$ & 2.30E-03 & Composite wash & 1.00 \\
\hline $\mathrm{Bi}$ & 4.45E-06 & Radionuclides & $\mu \mathrm{Ci} / \mathrm{mL}$ \\
\hline $\mathrm{Cr}$ & 1.19E-04 & ${ }^{239+240} \mathrm{Pu}$ & $2.52 \mathrm{E}-06$ \\
\hline $\mathrm{Fe}$ & [2.50E-05] & ${ }^{238} \mathrm{Pu}$ & $<1.3 \mathrm{E}-7$ \\
\hline $\mathrm{Mn}$ & [6.21E-07] & & \\
\hline $\mathrm{Na}$ & $3.25 \mathrm{E}-02$ & & \\
\hline $\mathrm{P}$ & [5.12E-04] & & \\
\hline $\mathrm{Si}$ & $1.98 \mathrm{E}-03$ & & \\
\hline U (ICP) & [1.11E-05] & & \\
\hline $\mathrm{U}(\mathrm{KPA})$ & 1.07E-06 & & \\
\hline \multicolumn{4}{|c|}{$\begin{array}{l}\text { (a) Temperature was } 21.8^{\circ} \mathrm{C} \text {. } \\
\text { ASR } 8111 \\
\text { Analyte uncertainties were typically within } \pm 15 \% \text { (2-s); results in brackets } \\
\text { indicate that the analyte concentrations were greater than the minimum } \\
\text { detection limit (MDL) and less than the estimated quantitation limit (EQL), } \\
\text { and uncertainties were }>15 \% \text {. }\end{array}$} \\
\hline
\end{tabular}


WTP-RPT-166, Rev. 0

\subsubsection{Chemical and Radiochemical Composition of the Oxidatively Leached Group 1/2 Solids}

Table 6.4 presents the composition of the Group $1 / 2$ solids after oxidative leaching at $45^{\circ} \mathrm{C}$ for $24 \mathrm{~h}$ in $0.25 \mathrm{M} \mathrm{NaOH}$ at a $\mathrm{Mn} / \mathrm{Cr}$ molar ratio of 0.79 , and subsequent washing. For comparison, the composition of the starting caustic-leached and washed solids is also provided in the table. The largest mass fraction of the solids was composed of Fe followed by $\mathrm{Na}, \mathrm{Si}, \mathrm{Bi}, \mathrm{Al}, \mathrm{U}, \mathrm{Mn}, \mathrm{P}, \mathrm{Ni}$, and Cr. The fraction of each component removed (as determined by the concentration factor method) as a result of oxidative leaching is also given in Table 6.4. A large amount (66\%) of the $\mathrm{Cr}$ was removed from the solids, as well as $60 \%$ of the P. Approximately $20 \%$ of the $\mathrm{Al}$ and Si were also mobilized to the aqueous phase. Uranium and iron remained in the solids phase.

As was done for the Group 1 and Group 2 solids, the data from the Group 1/2 oxidative leaching experiments were analyzed by the three methods described in Section 3.4.6.2 for determining the percent of each component removed during leaching. In the case of the Group 1/2 solids, the caustic-leached solids were dominated by Fe (10.4 wt\%), Si (8.1 wt\%), Al (7.8 wt\%), Bi (7.3 wt\%), U (2.6 wt\%), P (1.5 wt\%), and $\mathrm{Cr}$ (1.3 wt\%), and the analysis of the leachate solutions showed that Fe, Ni, Sr, U, and Zn had not dissolved. The relative CF of these analytes averaged 1.31 in the final oxidatively leached and washed solids, based on the ratio of analyte concentration after oxidative leaching and washing to analyte concentration after caustic leaching and washing. This term was used to determine the specific analyte leach factors according to Equation 6.1.

$$
L F_{3}=1-\left(\frac{C_{O L}}{C_{C L} \times 1.31}\right)
$$

where $\mathrm{LF}_{3}$ is the caustic-leach factor, $\mathrm{C}_{\mathrm{OL}}$ is the oxidatively leached analyte concentration, and $\mathrm{C}_{\mathrm{CL}}$ is the caustic-leached analyte concentration.

Results from all three methods are given in Table 6.5. For Al, the results from all three methods are slightly different, with method one giving the lowest values and method three giving the highest values. For P, there was a greater difference between results from each method, with method one giving the highest values and method three giving the lowest values. For $\mathrm{Cr}$, the results from all methods are slightly different, with method one giving the highest values and method three giving the lowest values. All values of percent leached plotted in this section and shown in Tables 6.2 and 6.4 were calculated using method three, the "concentration factor" method. 
Table 6.4. Leached Solids Composition and Leach Factors of Group 1/2 Bi-Phosphate Sludge/Saltcake (Water-Insoluble Solids)

\begin{tabular}{|c|c|c|c|}
\hline Analyte & $\begin{array}{c}\text { After Caustic } \\
\text { Leaching, } \\
\mu g / g^{(a)} \\
\text { (ASR 8111) }\end{array}$ & $\begin{array}{c}\text { After Oxidative } \\
\text { Leaching, } \\
\mu g / g^{(a)} \\
\text { (ASR 8111) }\end{array}$ & $\begin{array}{c}\text { Observed } \\
\text { Leach Factor }\end{array}$ \\
\hline $\mathrm{Al}$ & 77,850 & 79,833 & 0.21 \\
\hline $\mathrm{B}$ & [48] & [43] & -- \\
\hline $\mathrm{Bi}$ & 73,050 & 82,967 & 0.13 \\
\hline $\mathrm{Cd}$ & [131] & 160 & -- \\
\hline $\mathrm{Cr}$ & 12,850 & 5,677 & 0.66 \\
\hline $\mathrm{Fe}$ & 103,500 & 135,667 & -- \\
\hline Mn & 1,610 & 14,733 & -- \\
\hline $\mathrm{Na}$ & na & 87,550 & -- \\
\hline $\mathrm{Ni}$ & 5,995 & 7,630 & 0.03 \\
\hline $\mathrm{P}$ & 14,750 & 7,740 & 0.60 \\
\hline $\mathrm{S}$ & $<666.729$ & $<640.608$ & -- \\
\hline $\mathrm{Si}$ & 81,350 & 86,467 & 0.19 \\
\hline $\mathrm{Sr}$ & 5,800 & 7,453 & 0.02 \\
\hline $\mathrm{Zn}$ & 502 & 685 & -- \\
\hline $\mathrm{Zr}$ & na & [211] & -- \\
\hline U (ICP) & 25,800 & 33,500 & -- \\
\hline U (KPA) & 23,152 & 33,870 & -- \\
\hline Radionuclides & $\mu \mathrm{Ci} / \mathbf{g}^{(a)}$ & $\mu \mathrm{Ci} / \mathrm{g}^{(\mathrm{a})}$ & $\begin{array}{c}\text { Observed } \\
\text { Leach Factor }\end{array}$ \\
\hline${ }^{239-240} \mathrm{Pu}$ & 7.12E-01 & 8.73E-01 & 0.06 \\
\hline${ }^{238} \mathrm{Pu}$ & $1.29 \mathrm{E}-02$ & $1.45 \mathrm{E}-02$ & 0.14 \\
\hline${ }^{90} \mathrm{Sr}$ & $2.86 \mathrm{E}+02$ & $3.47 \mathrm{E}+02$ & 0.07 \\
\hline Total alpha & $1.41 \mathrm{E}+00$ & $1.68 \mathrm{E}+00$ & 0.09 \\
\hline Total beta & $7.12 \mathrm{E}+02$ & $8.33 \mathrm{E}+02$ & 0.10 \\
\hline Opportunistic & $\begin{array}{l}\text { After Caustic } \\
\text { Leaching, } \\
\mu \mathrm{g} / \mathrm{g}^{(\mathbf{a})} \\
\text { (ASR 8111) }^{\text {A } 811}\end{array}$ & $\begin{array}{c}\text { After Oxidative } \\
\text { Leaching, } \\
\mu \mathrm{g} / \mathrm{g}^{(\mathbf{a})} \\
\text { (ASR 8111) }\end{array}$ & $\begin{array}{c}\text { Observed } \\
\text { Leach Factor }\end{array}$ \\
\hline $\mathrm{Ag}$ & $<6.251$ & {$[17]$} & -- \\
\hline As & $<162.515$ & $<156.148$ & -- \\
\hline $\mathrm{Ba}$ & 349 & 450 & 0.01 \\
\hline $\mathrm{Be}$ & $<0.200$ & {$[.7]$} & -- \\
\hline $\mathrm{Ca}$ & {$[17,000]$} & {$[17,667]$} & -- \\
\hline $\mathrm{Ce}$ & [344] & 420 & -- \\
\hline Co & [45] & {$[60]$} & -- \\
\hline $\mathrm{Cu}$ & 99.3 & 161 & -0.24 \\
\hline Dy & $<12.084$ & $<11.611$ & -- \\
\hline $\mathrm{Eu}$ & $<1.542$ & [1.7] & -- \\
\hline $\mathrm{K}$ & $<16668.215$ & 16194.33 & -- \\
\hline $\mathrm{La}$ & [49] & [71] & -- \\
\hline $\mathrm{Li}$ & 103 & 113 & 0.16 \\
\hline
\end{tabular}


Table 6.4 (contd)

\begin{tabular}{|c|c|c|c|}
\hline Opportunistic & $\begin{array}{l}\text { After Caustic } \\
\text { Leaching, } \\
\mu \mathrm{g} / \mathrm{g}^{(\mathrm{a})} \\
\text { (ASR 8111) }\end{array}$ & $\begin{array}{l}\text { After Oxidative } \\
\text { Leaching, } \\
\mu \mathrm{g} / \mathrm{g}^{(\mathrm{a})} \\
\text { (ASR 8111) }\end{array}$ & $\begin{array}{c}\text { Observed } \\
\text { Leach Factor }\end{array}$ \\
\hline $\mathrm{Mg}$ & 2,195 & 2,817 & \\
\hline Mo & $<30.003$ & [33] & -- \\
\hline $\mathrm{Nd}$ & {$[42]$} & {$[88]$} & -- \\
\hline $\mathrm{Pb}$ & 1,865 & 2,437 & -- \\
\hline $\mathrm{Pd}$ & $<26.669$ & $<25.624$ & -- \\
\hline $\mathrm{Rh}$ & $<54.172$ & $<52.049$ & -- \\
\hline $\mathrm{Ru}$ & {$[30]$} & {$[30]$} & -- \\
\hline $\mathrm{Sb}$ & $<129.179$ & $<138.949$ & -- \\
\hline $\mathrm{Se}$ & $<458.376$ & [595] & -- \\
\hline Sn & [160] & $<144.407$ & -- \\
\hline Ta & $<<83.341$ & $<80.076$ & -- \\
\hline $\mathrm{Te}$ & $<108.343$ & $<104.099$ & -- \\
\hline Th & {$[255]$} & {$[118]$} & -- \\
\hline $\mathrm{Ti}$ & 245 & 321 & 0.00 \\
\hline $\mathrm{Tl}$ & $<125.012$ & $<120.114$ & -- \\
\hline $\mathrm{V}$ & [39] & [35] & -- \\
\hline W & $<107.945$ & $<84.080$ & -- \\
\hline $\mathrm{Y}$ & [9.75] & 13.9 & -- \\
\hline \multicolumn{4}{|c|}{$\begin{array}{l}\text { (a) Dry mass basis. } \\
\text { ASR 8111, radioisotope reference date: January } 31,2008 \text {. } \\
\text { Analyte uncertainties were typically within } \pm 15 \%(2-s) \text {; results in brackets indicate that } \\
\text { the analyte concentrations were greater than the minimum detection limit (MDL) and less } \\
\text { than the estimated quantitation limit (EQL), and uncertainties were }>15 \% \text {. }\end{array}$} \\
\hline
\end{tabular}

Table 6.5. Group 1/2 Bi-Phosphate Sludge/Saltcake Leach Factors

\begin{tabular}{|c|c|c|c|c|c|c|c|c|c|c|c|}
\hline \multirow{2}{*}{$\begin{array}{c}\text { Temp., } \\
{ }^{\circ} \mathrm{C}\end{array}$} & \multirow{2}{*}{$\begin{array}{c}\text { Free } \\
{[\mathrm{OH}],} \\
\mathbf{M}\end{array}$} & \multirow{2}{*}{$\begin{array}{l}\mathrm{Mn} / \\
\mathrm{Cr}\end{array}$} & \multicolumn{3}{|c|}{$\begin{array}{c}\text { Fraction Removed } \\
\text { Based on Initial } \\
\text { Solids/Leachate } \\
\text { Solution }\end{array}$} & \multicolumn{3}{|c|}{$\begin{array}{c}\text { Fraction Removed } \\
\text { Based on Final } \\
\text { Solids/Leachate } \\
\text { Solution }\end{array}$} & \multicolumn{3}{|c|}{$\begin{array}{c}\text { Fraction Removed } \\
\text { Based on Initial/Final } \\
\text { Solids ("concentration } \\
\text { factor" method) }\end{array}$} \\
\hline & & & Al & $\mathrm{Cr}$ & $\mathbf{P}$ & $\mathbf{A l}$ & $\mathrm{Cr}$ & $\mathbf{P}$ & Al & $\mathbf{C r}$ & $\mathbf{P}$ \\
\hline 45 & 0.29 & 0.75 & 0.14 & 0.68 & 1.25 & 0.17 & 0.62 & 0.81 & 0.22 & 0.56 & 0.62 \\
\hline $\begin{array}{r}45 \\
\text { Trial a }\end{array}$ & 0.28 & 1 & 0.14 & 0.83 & 1.24 & 0.17 & 0.74 & 0.78 & 0.21 & 0.67 & 0.62 \\
\hline $\begin{array}{r}45 \\
\text { Trial b }\end{array}$ & 0.28 & 1 & 0.14 & 0.81 & 1.19 & 0.17 & 0.73 & 0.77 & 0.21 & 0.65 & 0.58 \\
\hline $\begin{array}{r}45 \\
\text { Trial c } \\
\end{array}$ & 0.27 & 1 & 0.14 & 0.82 & 1.20 & 0.17 & 0.73 & 0.77 & 0.22 & 0.66 & 0.59 \\
\hline 45 & 0.29 & 1.25 & 0.14 & 0.90 & 1.23 & 0.17 & 0.79 & 0.77 & 0.22 & 0.71 & 0.60 \\
\hline 45 & 0.28 & 1.5 & 0.14 & 0.90 & 1.19 & 0.17 & 0.80 & 0.75 & 0.21 & 0.72 & 0.58 \\
\hline 45 & 1.38 & 1.25 & 0.24 & 0.89 & 1.21 & 0.30 & 0.80 & 0.78 & 0.38 & 0.72 & 0.60 \\
\hline
\end{tabular}


As shown in Figure 6.8, approximately $12 \mathrm{wt} \%$ of the metal solids (represented primarily by Al, P, Si, and $\mathrm{Cr}$ ) dissolved in the oxidative-leach process. Based on the composition of the residual solids, $\mathrm{Cr}$ would still be expected to be the component limiting the HLW glass loading; although if $70 \%$ rather than $66 \%$ of the $\mathrm{Cr}$ had been dissolved (based on the "concentration factor" method), Fe would become the limiting component.

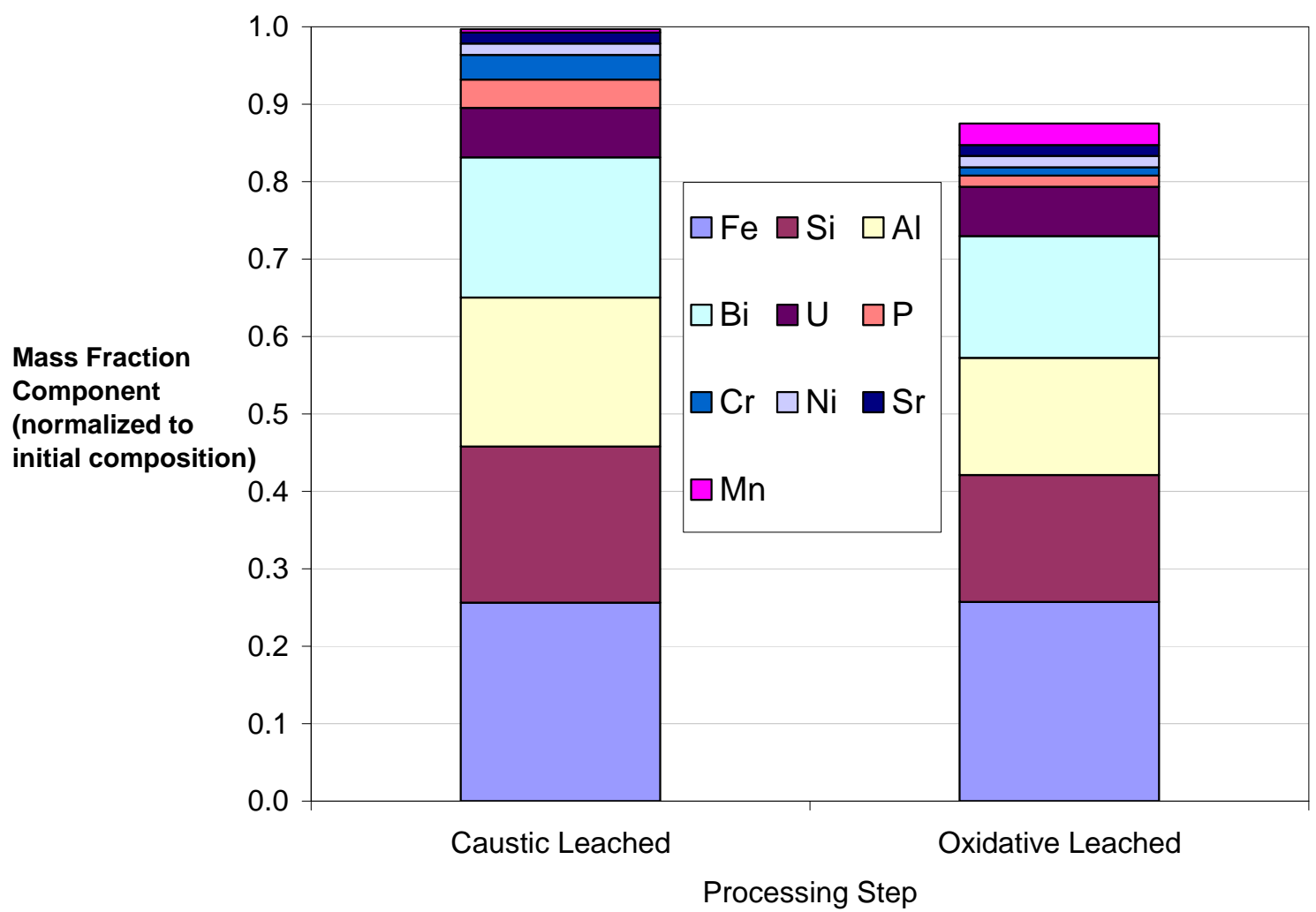

Figure 6.8. Group 1/2 Bi-Phosphate Sludge/Saltcake Reduction in Solid Mass with Oxidative Leaching

Notes: Caustic-leaching conditions: Caustic leached in CUF, $\sim 7 \mathrm{M} \mathrm{NaOH}$, slurry was heated to $100^{\circ} \mathrm{C}$ over a 5.3-h period, held at $100^{\circ} \mathrm{C}$ for an 8-h leach, and then cooled for $8 \mathrm{~h}$. Oxidative-leaching conditions: $\mathrm{Mn}: \mathrm{Cr}$ mole ratio $=0.79,45^{\circ} \mathrm{C}, 1.25 \mathrm{M} \mathrm{NaOH}$ for $24 \mathrm{~h}$.

\subsubsection{Particle-Size Distribution}

The waste solids comprising Sample 584-G1/2-OL-PSD are a mixture of Group 1 ( $\mathrm{BiPO}_{4}$ sludge) and Group $2\left(\mathrm{BiPO}_{4}\right.$ saltcake) solids that have been both caustic- and oxidatively-leached as part of a series of parametric testing studies. Table 6.6 shows select cumulative undersize percentiles derived from particlesize analysis. Here, the $d(10)$ ranges from 0.24 to $0.69 \mu \mathrm{m}$, the $d(50)$ ranges from 0.55 to $1.4 \mu \mathrm{m}$, and the $\mathrm{d}(90)$ ranges from 1.2 to $2.5 \mu \mathrm{m}$.

Pre-sonication percentile results suggest a relatively stable size distribution with respect to pump speed. Both $d(10)$ and $d(50)$ appear to decrease over the course of measurements 1 to 3 , suggesting possible size reduction as a result of shear (or dilution of the suspending phase). Applying sonic energy effects substantial (greater than 10\%) reductions in all reported percentiles. This is suggestive of sonic disruption 
of particle agglomerates. A slight recovery in the $d(90)$ value is observed after the immediate removal of sonic energy, indicating that agglomerate reformation may occur during measurement condition 7. Postsonication percentiles at 3000 and 2000 RPM are statistically similar (i.e., within 10\% of each other), suggesting similar states of particle suspension and agglomeration in both. An increase in the d(50) and d(90) values at 4000 RPM may indicate improved suspension and suggests the presence of difficult-tosuspend particles. On the other hand, the 4000 RPM measurement corresponds to the final test condition and could also suggest continued particle agglomeration over longer periods of time.

Table 6.6. Particle Size Analysis Percentile Results for Sample 584-G1/2-OL-PSD

\begin{tabular}{||c|c|c|c|c|c||}
\hline $\begin{array}{c}\text { Measurement } \\
\text { Condition }\end{array}$ & Pump Speed & Sonication & $\begin{array}{c}\mathbf{d}(\mathbf{1 0}) \\
{[\boldsymbol{\mu} \mathbf{m}]}\end{array}$ & $\begin{array}{c}\mathbf{d}(\mathbf{5 0}) \\
{[\boldsymbol{\mu} \mathbf{m}]}\end{array}$ & $\begin{array}{c}\mathbf{d}(\mathbf{9 0}) \\
{[\boldsymbol{\mu m}]}\end{array}$ \\
\hline 1 & 3000 & pre-sonic & 0.69 & 1.4 & 2.5 \\
\hline 2 & 2000 & pre-sonic & 0.69 & 1.3 & 2.4 \\
\hline 3 & 4000 & pre-sonic & 0.59 & 1.2 & 2.4 \\
\hline 4 & 3000 & $25 \%$ & 0.49 & 0.93 & 1.8 \\
\hline 5 & 3000 & $50 \%$ & 0.34 & 0.69 & 1.3 \\
\hline 6 & 3000 & $75 \%$ & 0.27 & 0.59 & 1.2 \\
\hline 7 & 3000 & post-sonic & 0.24 & 0.55 & 1.4 \\
\hline 8 & 2000 & post-sonic & 0.25 & 0.56 & 1.3 \\
\hline 9 & 4000 & post-sonic & 0.24 & 0.61 & 2.0 \\
\hline
\end{tabular}

Figure 6.9 shows the PSD for Sample 584-G1/2-OL-PSD before sonication as a function of pump speed. All distributions show a strong peak spanning 0.3 to $5 \mu \mathrm{m}$ and having a maximum between 1 and $2 \mu \mathrm{m}$. Distributions at 2000 and 3000 RPM are uni-modal. At 4000 RPM, a small secondary peak spanning 5 to $10 \mu \mathrm{m}$ appears and is probably representative of difficult-to-suspend (i.e., dense) particles or agglomerates.

Figure 6.10 shows the changes that occur in the distribution of particles as a result of applied sonication. Sonication effects a significant reduction in particle size, with the primary population shifting to smaller particle sizes. During sonication, the primary population of particles spans 0.1 to $2 \mu \mathrm{m}$, has a population maximum at $0.7 \mu \mathrm{m}$, and exhibits a small shoulder population over 2 to $5 \mu \mathrm{m}$. Size reduction is likely a result of sonic disruption of particle agglomerates. After sonication is removed, a decrease in the relative contribution of 0.4 - to 1 - $\mu \mathrm{m}$ particles and a corresponding increase in the relative contribution of 2- to 5 - $\mu \mathrm{m}$ particles are observed. This is suggestive of agglomerate reformation and could indicate that changes in the particle size as a result of sonication are reversible. It also confirms the observation of agglomeration in measurement condition 7 based on the percentiles in Table 6.6. 


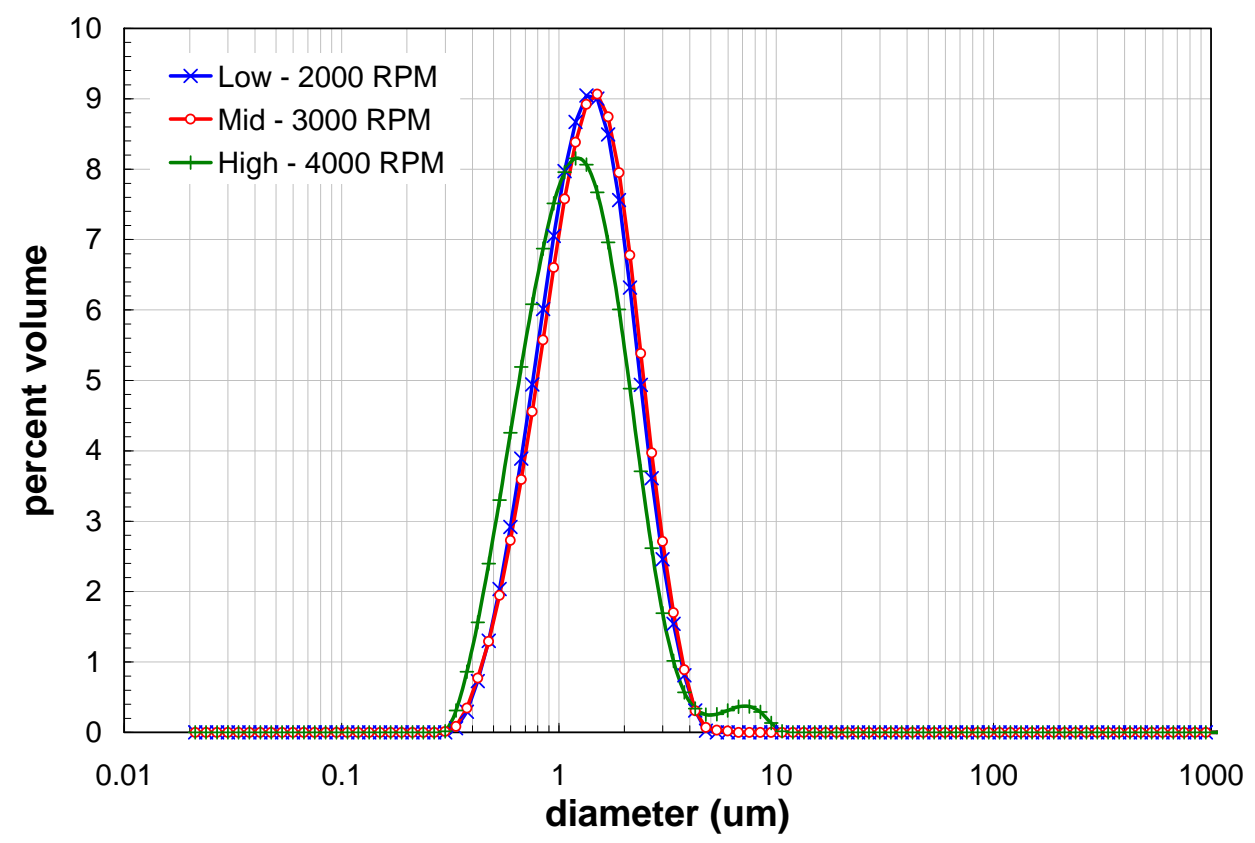

Figure 6.9. Pre-Sonication Volume Distribution Result for Sample 584-G1/2-OL-PSD as a Function of Pump Speed

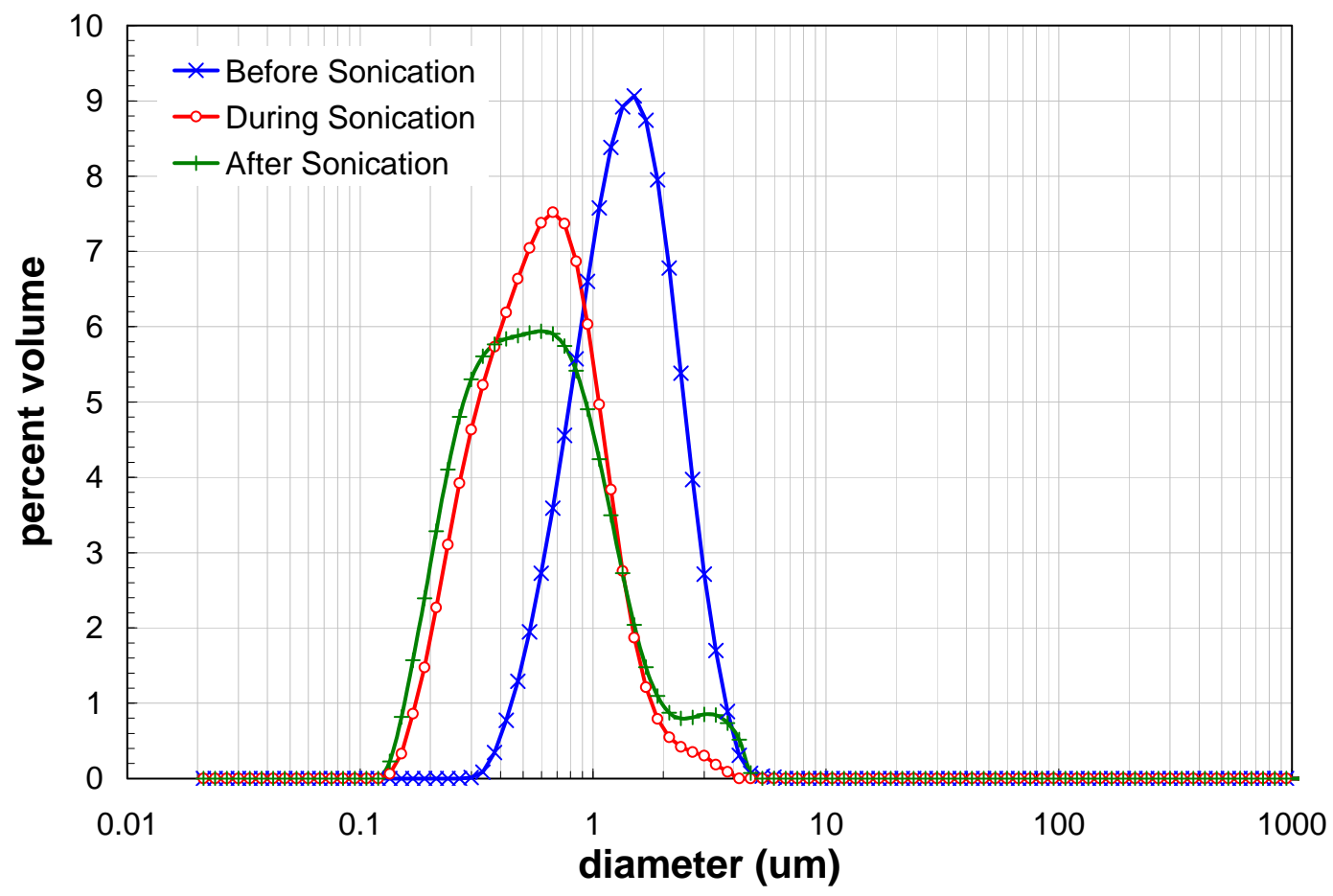

Figure 6.10. Volume Distribution Result for Sample 584-G1/2-OL-PSD Before, During, and After Sonication at 3000 RPM. Note: the during-sonication condition corresponds to measurement condition 6 (see Table 6.6). 
Figure 6.11 shows the post-sonication PSD behavior of Sample 584-G1/2-OL-PSD as a function of analyzer to pump speed. With exception of changes in the secondary population of particles (likely agglomerates) over 2 to $5 \mu \mathrm{m}$, the distributions are relatively insensitive to changes in analyzer pump speed. With regard to the 2- to 5 - $\mu$ m population, the relative volume contribution of particles in this range appears to scale with analyzer pump speed. Specifically, 2000 RPM shows the lowest volume contribution of 2- to 5- $\mu \mathrm{m}$ particles, whereas 4000 RPM shows the highest. This suggests that the 2- to 5 - $\mu \mathrm{m}$ particles are likely "difficult-to-suspend" particles and that the differences in the post-sonication PSDs are likely a result of differences in the state of particle suspension.

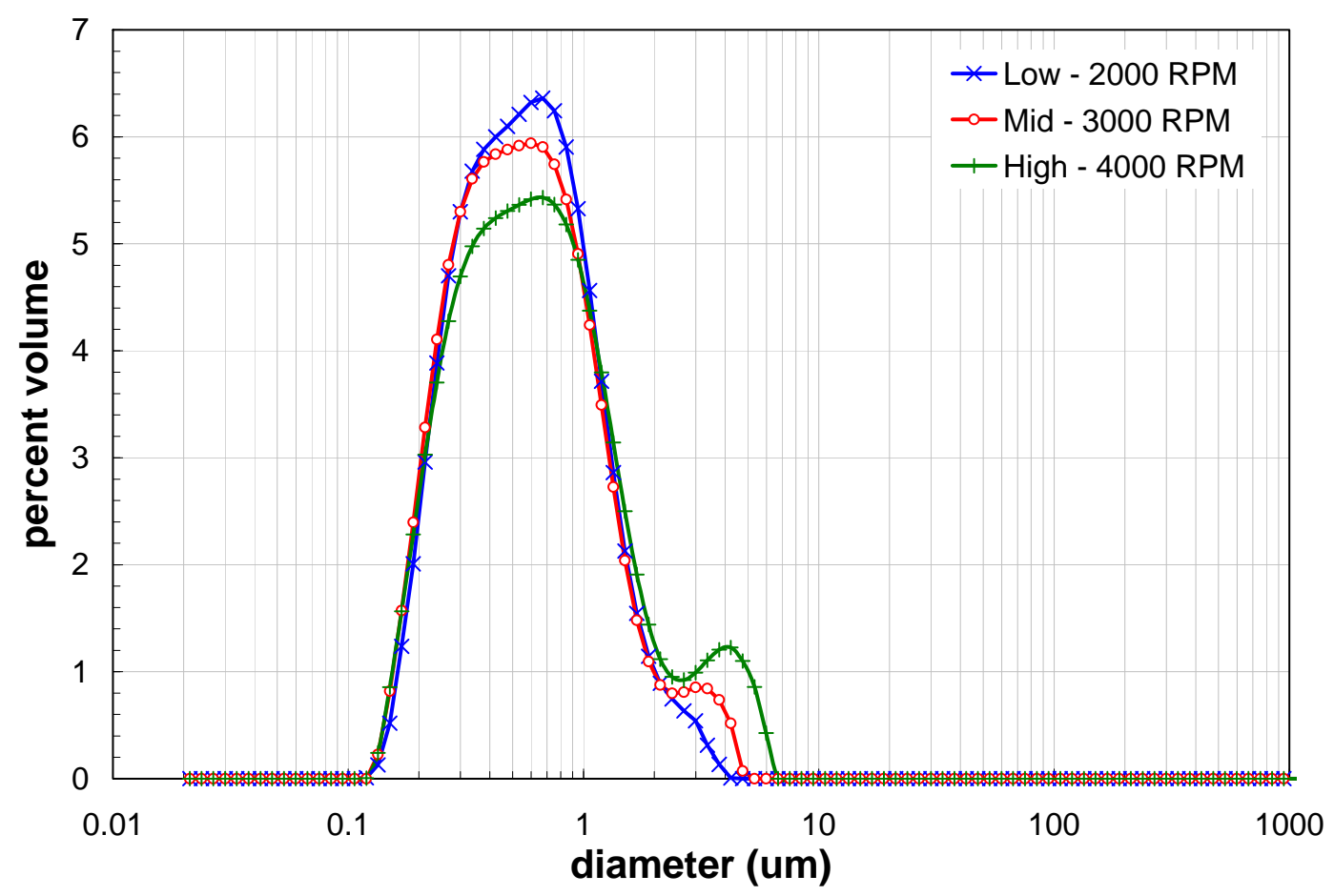

Figure 6.11. Post-Sonication Volume Distribution Result for Sample 584-G1/2-OL-PSD Sample as a Function of Pump Speed

The effect of both caustic and oxidative leaching on Group 1/2 mixed waste solids PSD can be evaluated by comparing to the PSD for the untreated Group 1/2 CUF slurry. Here, the parametric testing sample (584-G1/2-OL-PSD) is compared to the untreated high-solids CUF slurry sample (TI572-G2-6-PSD). In addition, a comparison of the oxidative-leached and washed sample from the CUF studies (Sample TI572-G2-18-PSD) and the parametric testing oxidative-leached sample (584-G1/2-OL-PSD) will be made to highlight any differences or similarities between the leached solids from different studies.

Table 6.7 and Figures 6.12 and 6.13 show changes that occur to the Group 1/2 mixed solids PSD as a result of caustic- and oxidative-leaching and washing. Relative to the unleached material, the size distribution of particles in the caustic- and oxidative- leached and washed waste solids favors smaller particle sizes. Relative to the CUF testing sample, the leached solids derived from parametric testing favor larger particle sizes. However, both samples contain significant fractions of submicron particles and relatively small contributions of 1 - to $10-\mu \mathrm{m}$ particles. As discussed in Section 5 , the small particle 
sizes observed the oxidative-leached samples are likely a result of weakening of particle aggregates during the washing (rather than the leaching) operations.

Table 6.7. Cumulative Undersize Percentiles Showing the Influence of Caustic and Oxidative Leaching and Washing on the PSD of Group 1/2 Mixed Waste Solids at Measurement Condition 73000 RPM, post-sonication (see Table 6.6).

\begin{tabular}{||l|c|c|c||}
\hline \multicolumn{1}{|c|}{ Sample } & $\begin{array}{c}\mathbf{d}(\mathbf{1 0}) \\
{[\boldsymbol{\mu m}]}\end{array}$ & $\begin{array}{c}\mathbf{d}(\mathbf{5 0}) \\
{[\boldsymbol{\mu m}]}\end{array}$ & $\begin{array}{c}\mathbf{d}(\mathbf{9 0}) \\
{[\mu \mathbf{m}]}\end{array}$ \\
\hline Untreated Group 1/2 CUF Slurry (TI572-G2-6-PSD) & 0.52 & 2.4 & 9.5 \\
\hline CL/OL Washed CUF Slurry (TI572-G2-18-PSD) & 0.16 & 0.30 & 1.9 \\
\hline CL/OL Washed Parametric Slurry (584-G1/2-OL-PSD) & 0.24 & 0.55 & 1.4 \\
\hline CL = caustic leaching; OL = oxidative leaching
\end{tabular}

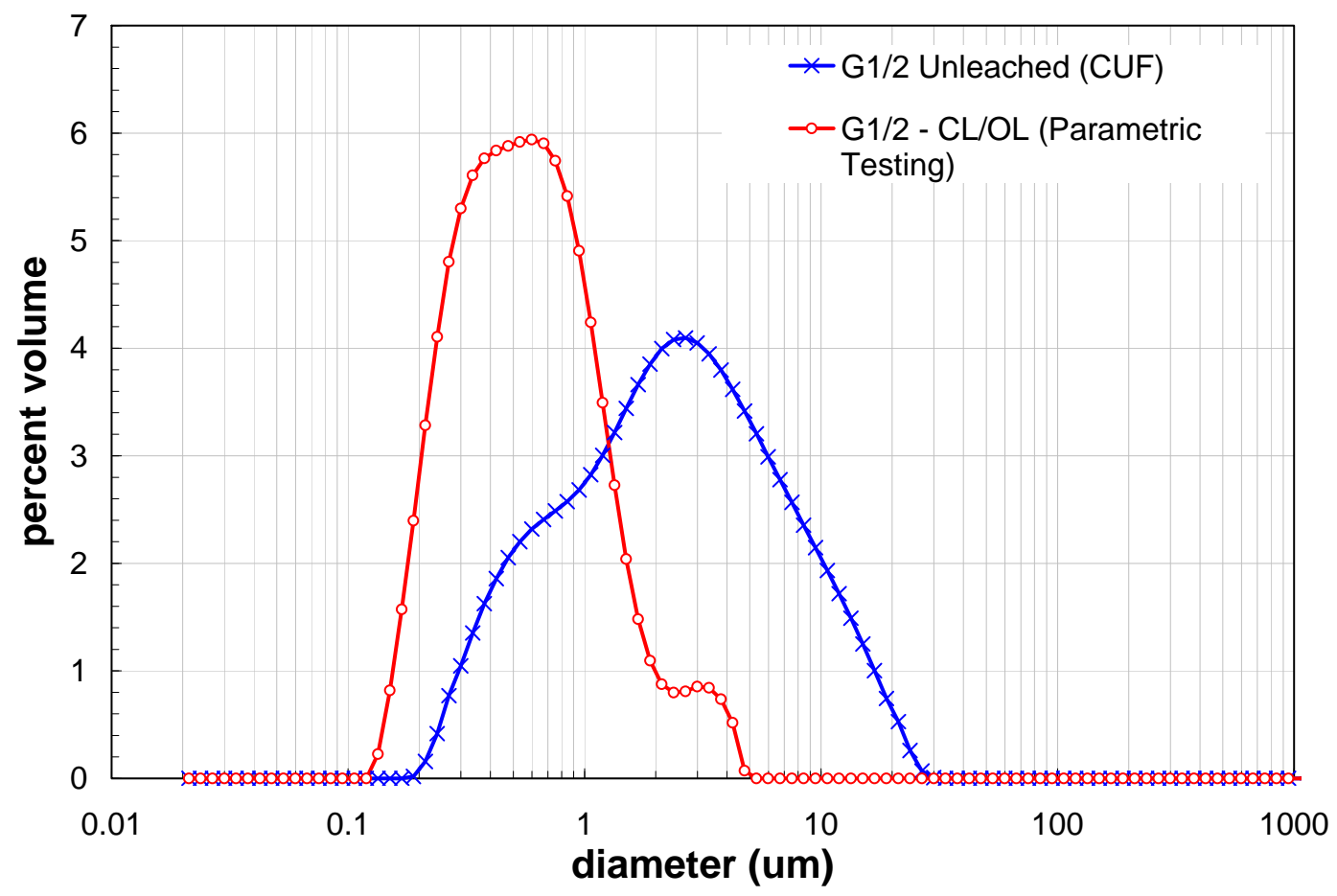

Figure 6.12. Influence of Caustic and Oxidative Leaching and Washing on Group $1 / 2$ Mixed Waste Solids PSD. All PSDs taken at measurement condition 7-3000 RPM, post-sonication (see Table 6.6). 
WTP-RPT-166, Rev. 0

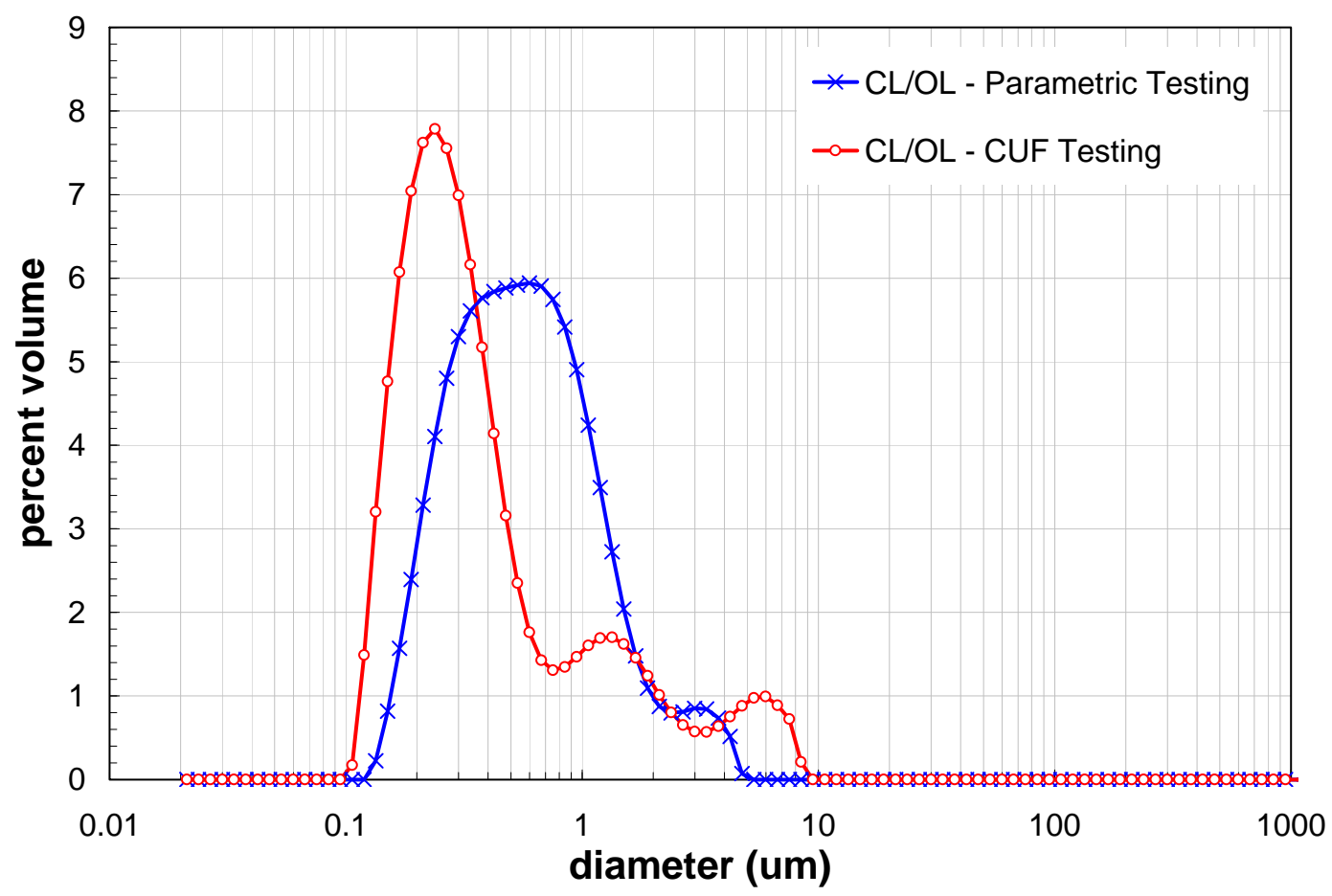

Figure 6.13. Comparison of Caustic- and Oxidatively-Leached and Washed Group 1/2 Mixed Waste Solids PSD from Parametric and CUF Testing. All PSDs taken at measurement condition 7-3000 RPM, post-sonication (see Table 6.6).

To summarize, the PSDs of the leached solids for Group 1/2 were measured and the effects of chemical leaching on the particle size determined. The sample generally showed complex particle-size behavior with respect to both flow rate and sonication. The sample_showed a uni-modal distribution of particles spanning 0.3 to $5 \mu \mathrm{m}$ and having a maximum between 1 and $2 \mu \mathrm{m}$. High pump speeds indicate a relatively small-volume contribution of difficult-to-suspend 4- to $10-\mu \mathrm{m}$ particles. Applying sonic energy effects a significant reduction in particle size, with the majority of particles after sonication having a size smaller than $1 \mu \mathrm{m}$. Post sonication PSD measurements suggest partial recovery of particle structures greater than $1 \mu \mathrm{m}$, which is suggestive of aggregate reformation.

In terms of the effects of chemical leaching, the PSD results indicate that caustic and oxidative leaching decreases the apparent particle size of mixed Group 1/2 solids. The resulting size distribution is populated by a majority of submicron particles. The size distribution derived from parametric testing is similar to that of caustic/oxidative leached $1 / 2$ solids derived from CUF testing. It is speculated that the combination of leaching and washing operations renders the Group 1/2 particle aggregates susceptible to size disruption.

\subsubsection{Crystal Form and Habit}

The following sections summarize the mineral-phase evaluation of the leached and washed solids. 
WTP-RPT-166, Rev. 0

\subsection{XRD}

The XRD pattern of the leached and washed solids is provided in Figure 6.14a; the background-subtracted $\mathrm{XRD}$ pattern with stick-figure phase identification is shown in Figure 6.14b.

Rutile, $\mathrm{TiO}_{2}$, was used as an internal standard for 2-theta calibration. Identification was done on 2-theta calibrated data. Two crystalline phases were positively identified. These included hydroxycancrinite $\left(1.06 \mathrm{Na}_{2} \mathrm{O} \cdot \mathrm{Al}_{2} \mathrm{O}_{3} \cdot 1.60 \mathrm{SiO}_{2} \cdot 1.6 \mathrm{H}_{2} \mathrm{O}\right)$ and clarkeite $\left[\mathrm{Na}\left(\mathrm{UO}_{2}\right) \mathrm{O}(\mathrm{OH})\right]$. The broad clarkeite peak at 14.95 indicates a crystallite size of about $196 \AA$.

Amorphous material accounts for a significant amount of the leached Group 1/2 solids, as indicated by the broad amorphous peak from about 10 to 30 degrees 2-theta in the raw data displayed in Figure 6.14a. This amorphous material cannot be characterized by XRD. 
WTP-RPT-166, Rev. 0

(a)

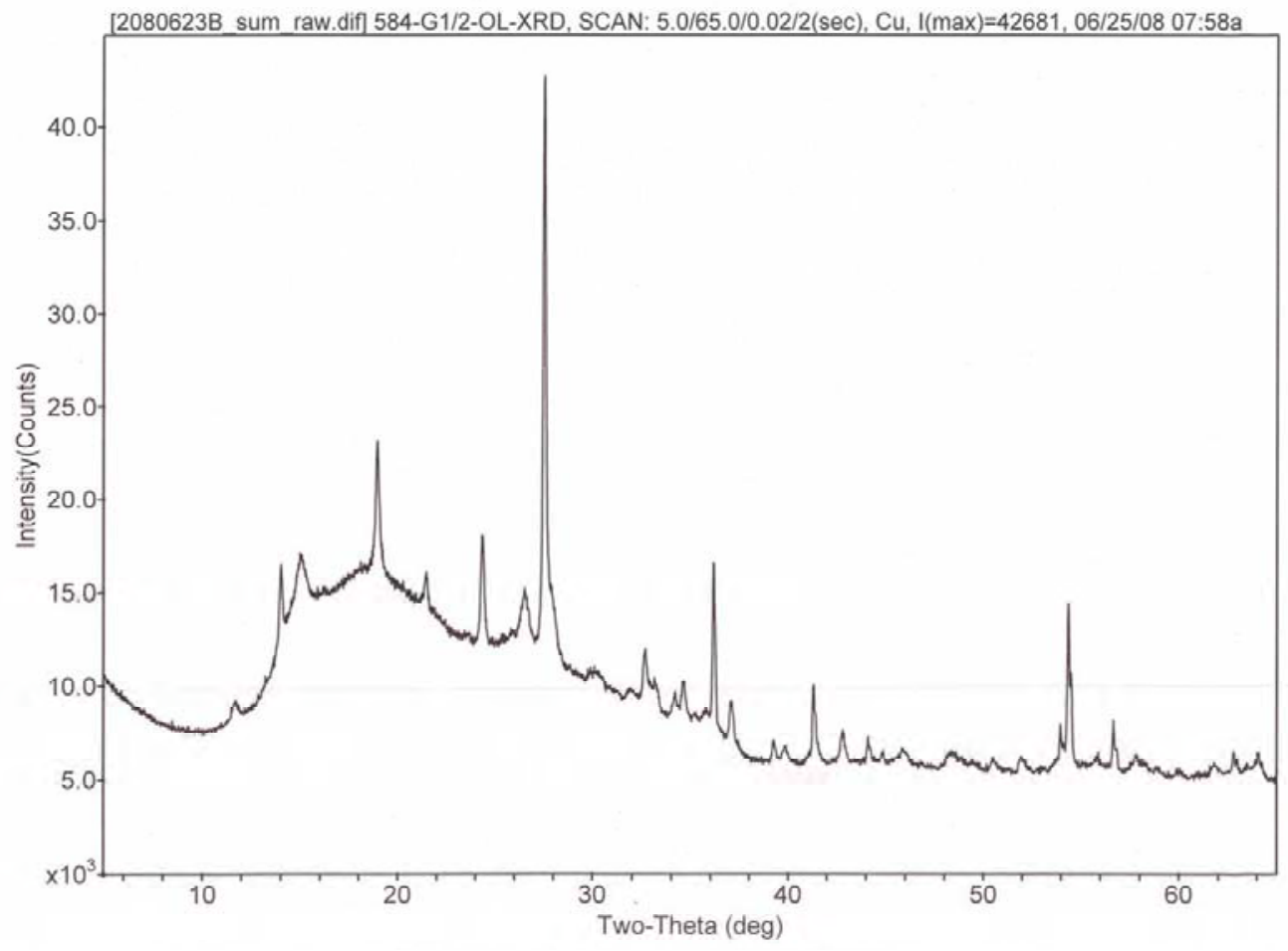

(b)

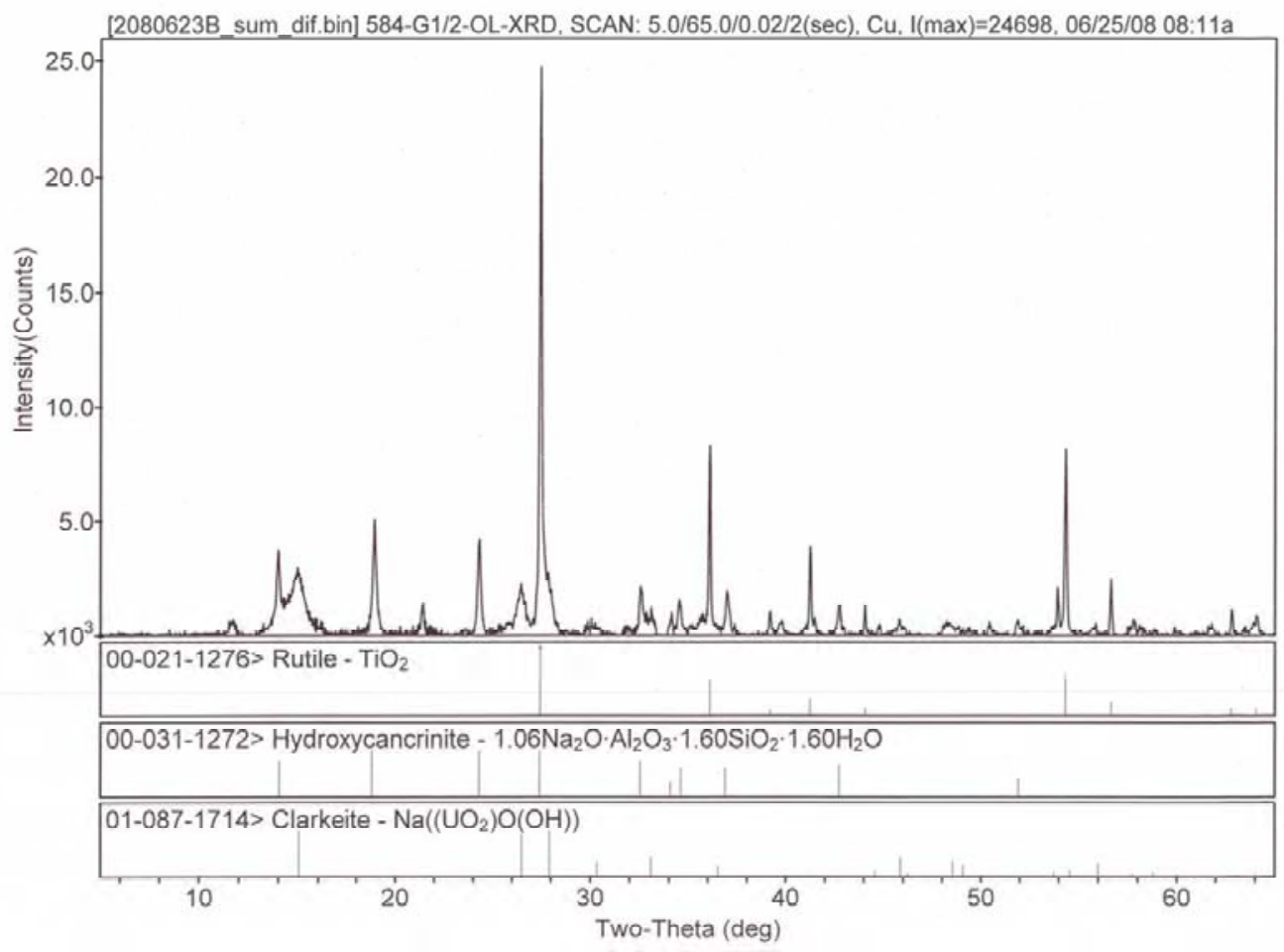

Figure 6.14. XRD Pattern of Oxidatively Leached Group $1 / 2$ Bi-Phosphate Sludge/Saltcake with Rutile $\left(\mathrm{TiO}_{2}\right)$ Internal Standard (a) Raw Data and (b) Background-Subtracted with StickFigure Peak Identification 


\subsection{SEM and TEM}

Several SEM images of the oxidatively leached Group 1/2 solids are shown in Figure 6.15. The particles seen in these images are typically on the order of 5 to $40 \mu \mathrm{m}$, with one particle in Figure 6.13c being $\sim 140 \mu \mathrm{m}$. The smaller particles are consistent with the PSD data reported above. However, no particles larger than $\sim 20 \mu \mathrm{m}$ were seen by PSD.

(a)

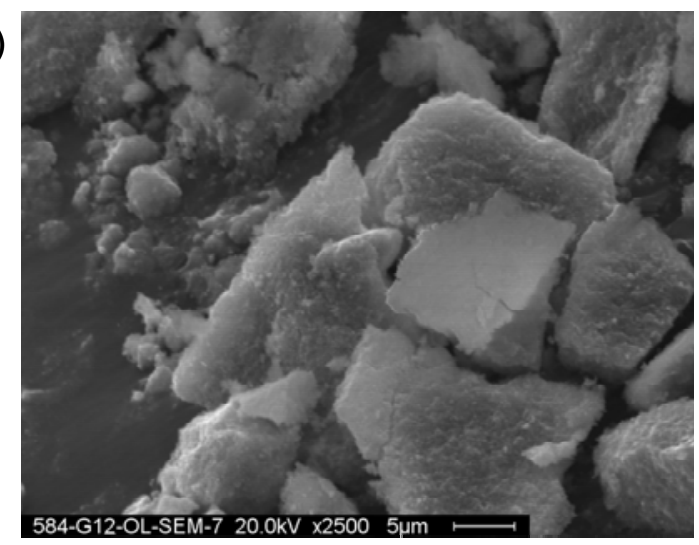

(c)

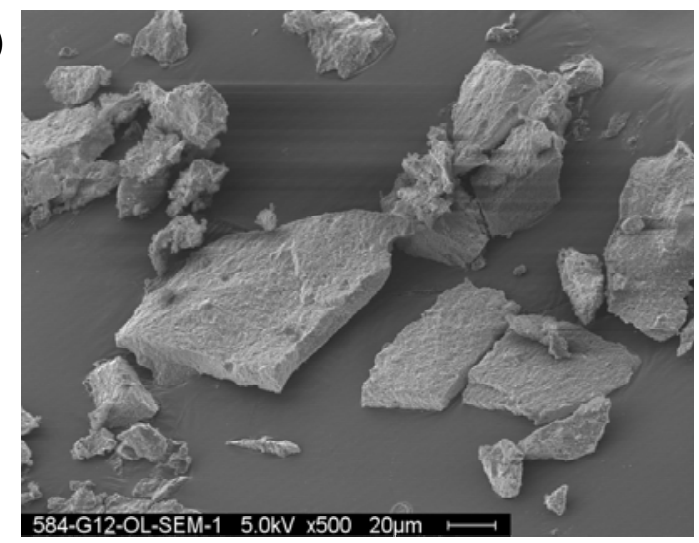

(b)

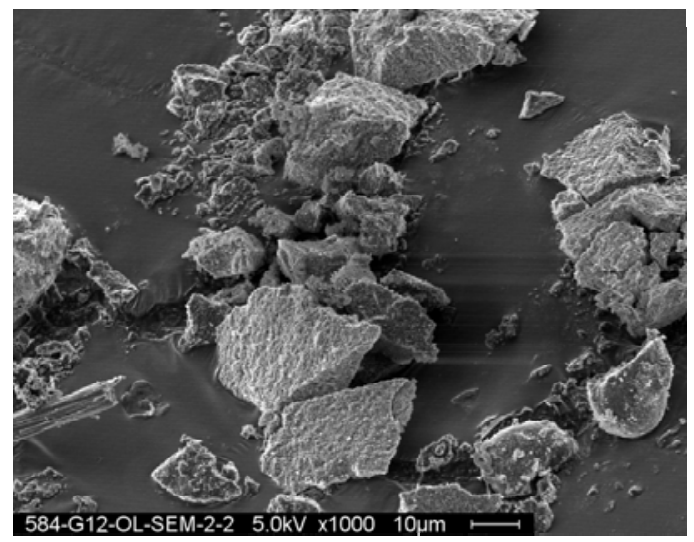

(d)

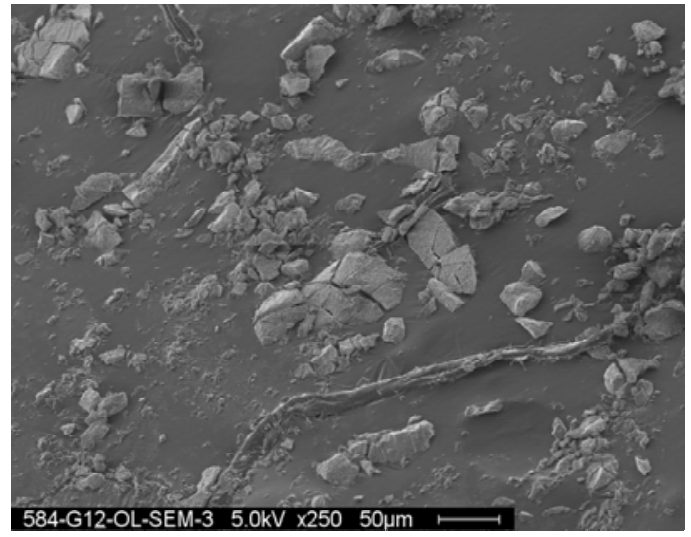

Figure 6.15. SEM images of Group $1 / 2$ Bi-Phosphate Sludge/Saltcake Oxidatively Leached and Washed Solids (a) $20 \mathrm{kV}, 2500 \times$; (b) $5 \mathrm{kV}, 1000 \times$; (c) $5 \mathrm{kV}, 500 \times$; (d) $5 \mathrm{kV}, 250 \times$.

Figures 6.16 through 6.18 each show an SEM image along with EDS spectra of two different particles for each. The elemental analysis shows a large amount of oxygen and carbon, which is an artifact of the sample preparation (carbon is sputtered onto the sample to eliminate problems with charging). If this is removed, and the other constituents normalized, the weight percentages shown in Table 6.8 for each analysis are obtained. As was found for the Group 1 caustic-leached solids, the SEM EDS examination indicated that most of the particles had similar elemental composition. A total of 23 particles were analyzed by SEM EDS. Unlike the Group 2 solids where several particles were found to contain only Na, $\mathrm{Al}$, and $\mathrm{Si}$, in this case, only one particle having only these constituents (as well as a small amount of iron, $2.73 \mathrm{wt} \% \mathrm{Fe}$ ) was found (Figure 6.18 spot 7). The three particles shown in Figure 6.16 spot 5, Figure 6.15 spot 1, and Figure 6.18 spot 3 each consist of the nine elements that were found in the majority of the particles, at concentrations that were within $2 \%$ of the average of all 23 analyses. 
The remaining two particles that were examined by EDS and shown in these three figures were composed of the same elements, just in higher or lower concentrations. The particle in Figure 6.16 spot 1 had much less $\mathrm{Na}$ than the other particles (7.9 wt\% compared to an average of $17.2 \%$ ) as well as slightly higher concentrations of $\mathrm{U}(8.0 \mathrm{wt} \%$ compared to an average of $6.1 \%$ ) and $\mathrm{Ca}$ (3.9 wt\% compared to an average of 2.8\%). The particle in Figure 6.17 spot 4 had less $\mathrm{Al}$ and $\mathrm{P}$ than the other particles (8.4 and $0.7 \mathrm{wt} \%$, respectively, compared to an average of 14.0 and 1.2\%) and much more Fe (39.5 wt\% compared to an average of $25.0 \%$ ). 
(a)

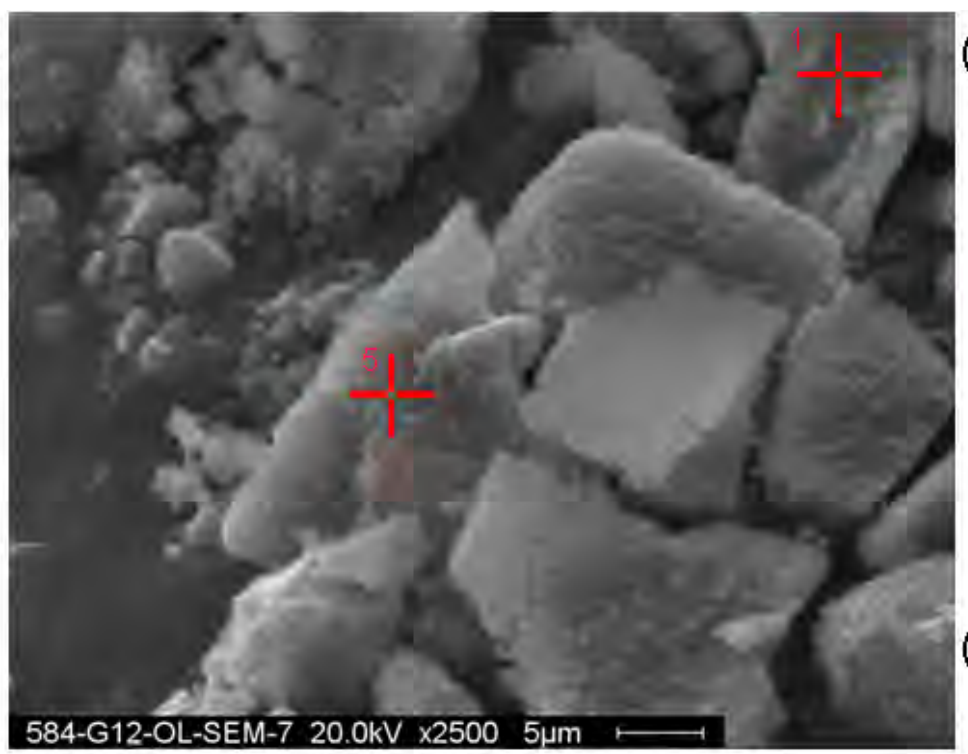

i

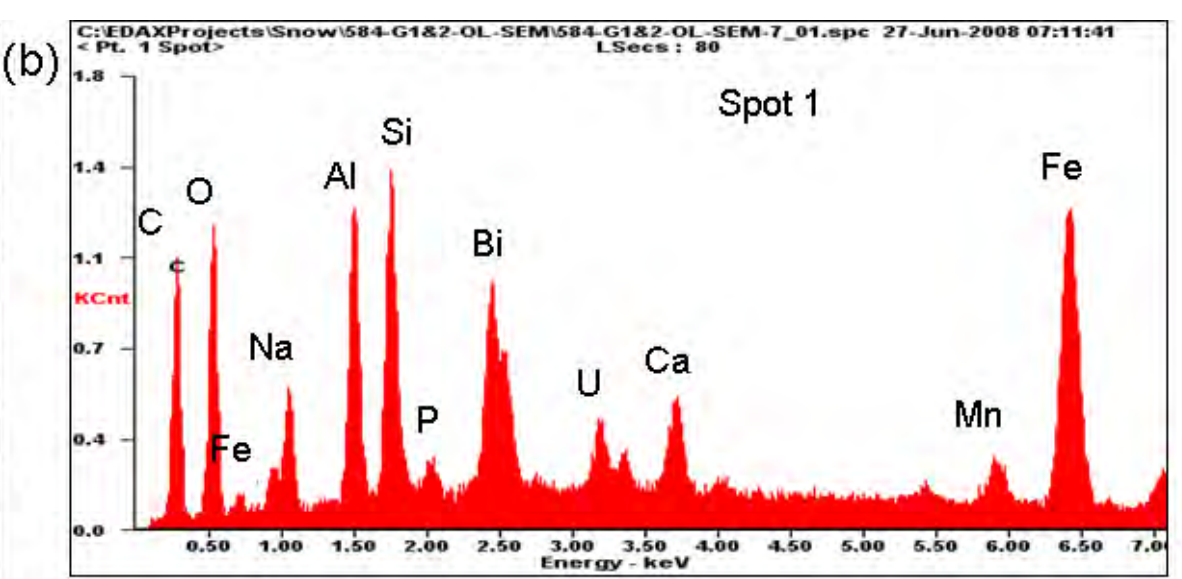

(c)

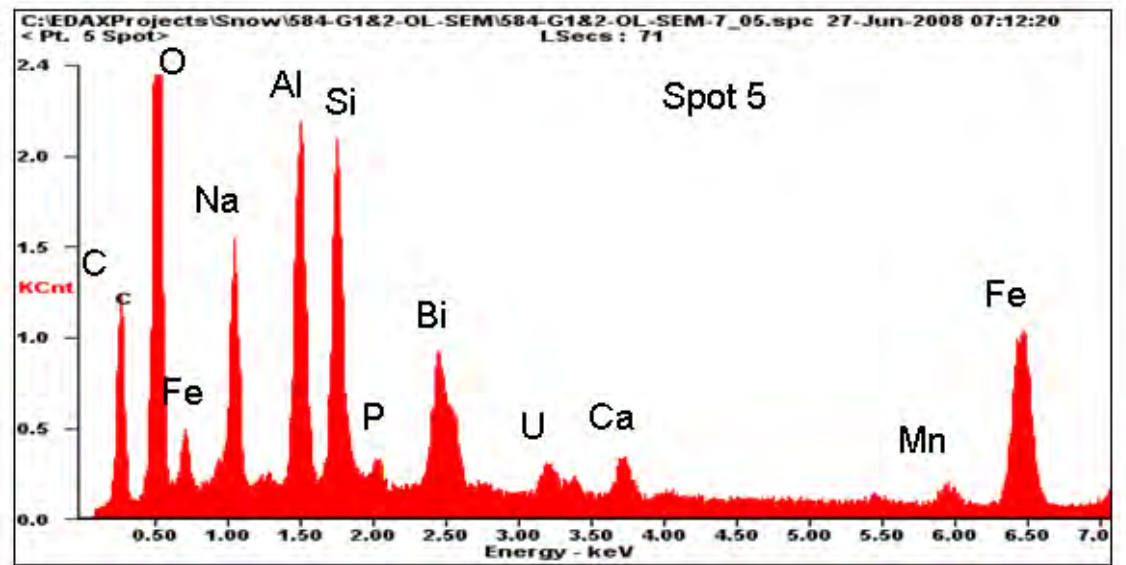

Figure 6.16. SEM Image of Group $1 / 2$ Bi-Phosphate Sludge/Saltcake Oxidatively Leached and Washed Solids with EDS Spectra (a) SEM Image; (b) EDS Spectra of Spot 1; (c) EDS Spectra of Spot 5 
(a)

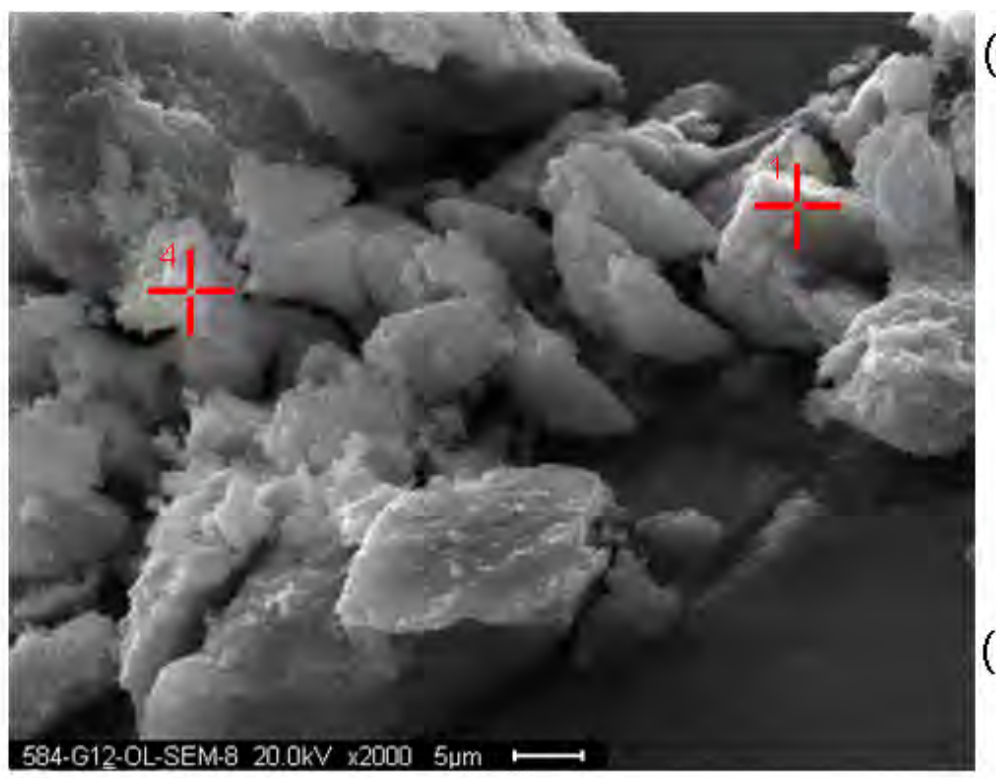

(b)

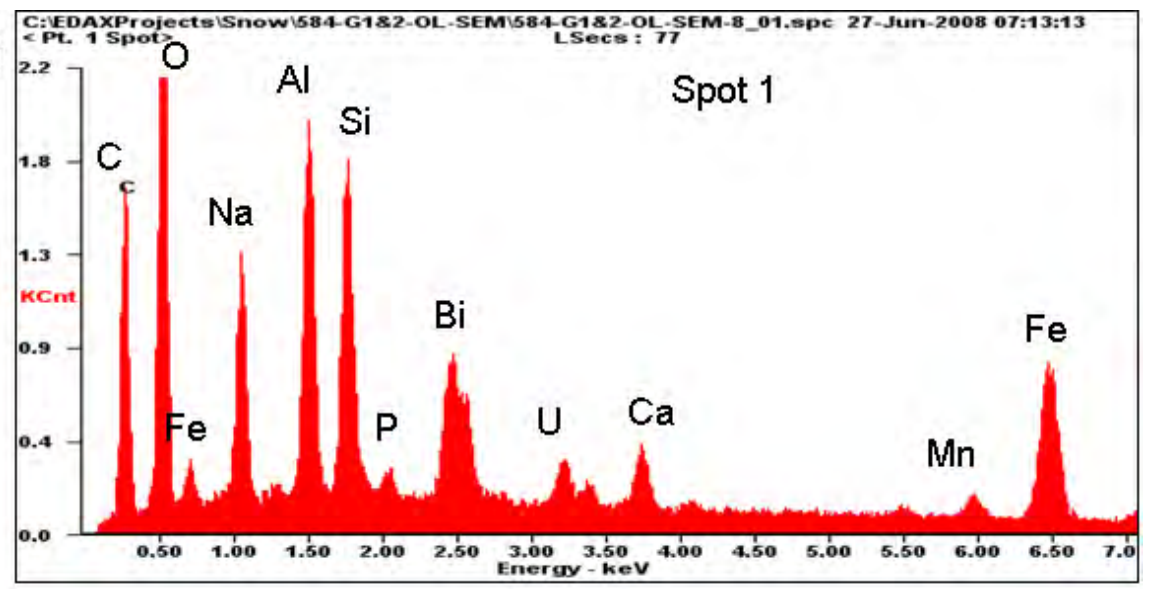

(c)

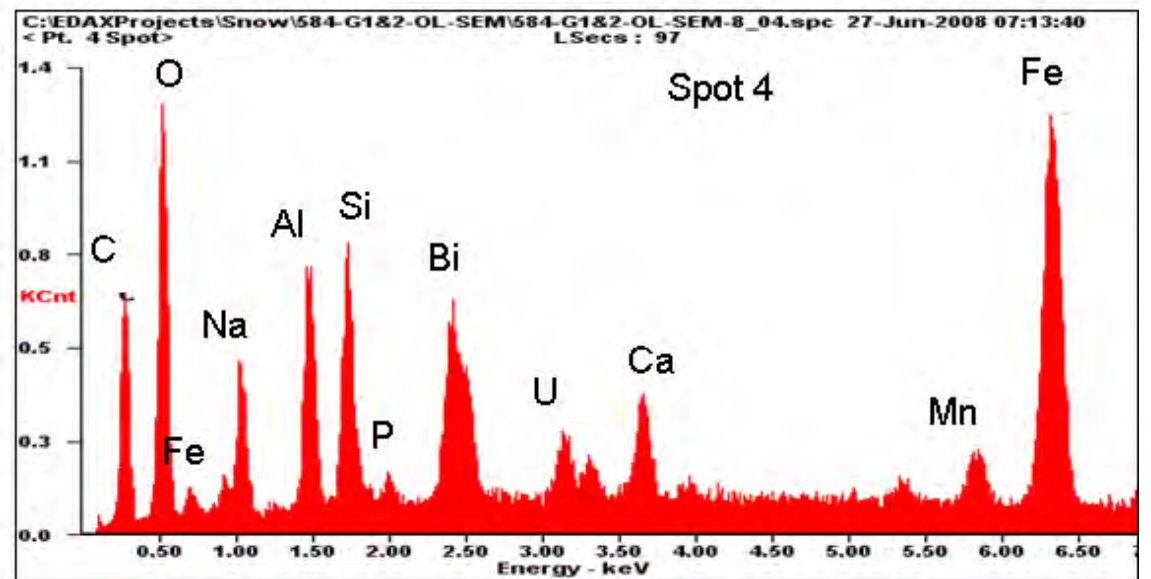

Figure 6.17. SEM Image of Group 1/2 Bi-Phosphate Sludge/Saltcake Oxidatively Leached and Washed Solids with EDS Spectra (a) SEM Image; (b) EDS Spectra of Spot 1; (c) EDS Spectra of Spot 4 

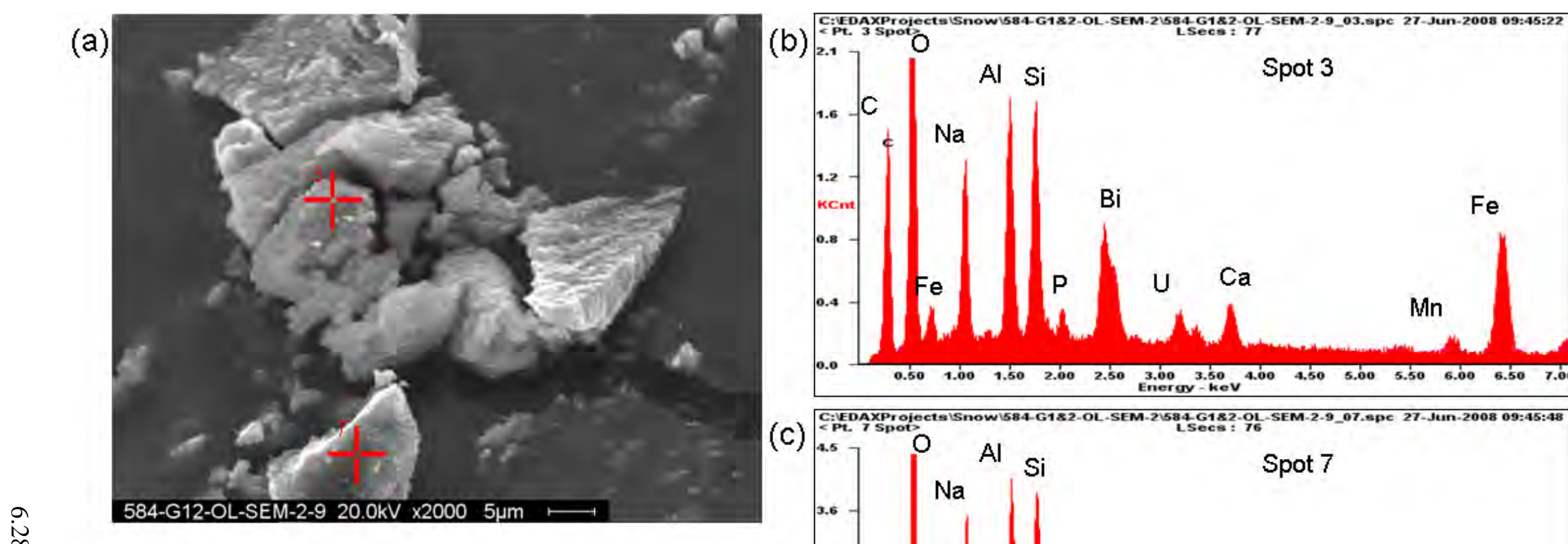

(c)

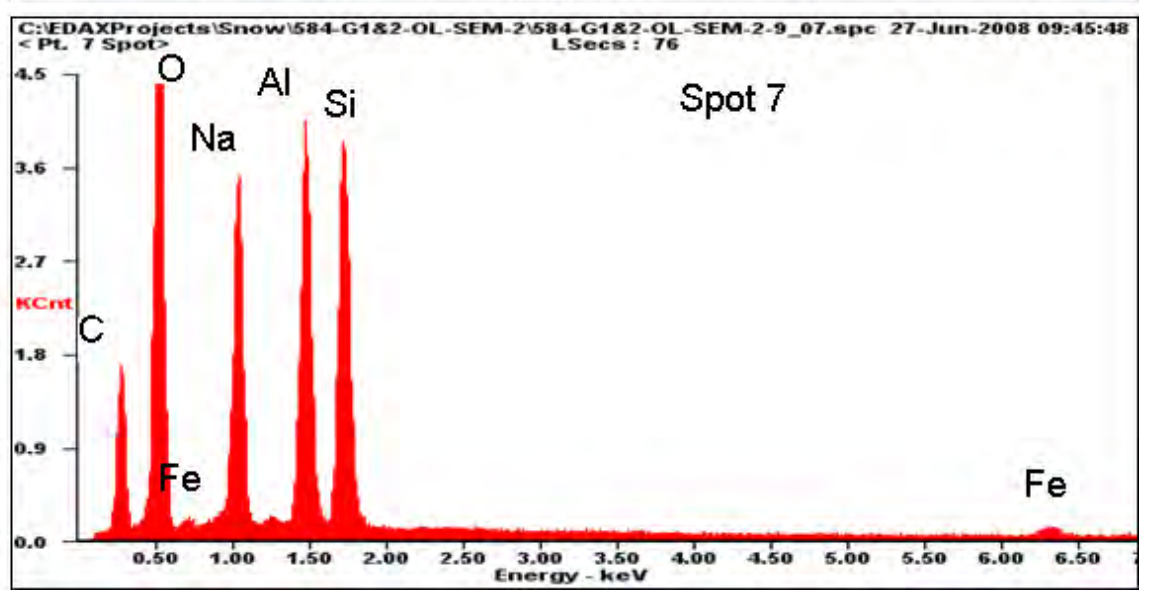

Figure 6.18. SEM Image of Group 1/2 Bi-Phosphate Sludge/Saltcake Oxidatively Leached and Washed Solids with EDS Spectra (a) SEM Image; (b) EDS Spectra of Spot 3; (c) EDS Spectra of Spot 7 
Table 6.8. Normalized Weight Percents for Various Analytes Found by EDS of SEM Images for Figures 6.6, 6.17, and 6.18

\begin{tabular}{|c|c|c|c|c|c|c|c||}
\hline & \multicolumn{7}{|c|}{ Normalized Weight Percent } \\
\cline { 2 - 8 } Element & $\begin{array}{c}\text { Fig 6.14 } \\
\text { Spot 1 }\end{array}$ & $\begin{array}{c}\text { Fig 6.14 } \\
\text { Spot 5 }\end{array}$ & $\begin{array}{c}\text { Fig 6.15 } \\
\text { Spot 1 }\end{array}$ & $\begin{array}{c}\text { Fig 6.15 } \\
\text { Spot 4 }\end{array}$ & $\begin{array}{c}\text { Fig 6.16 } \\
\text { Spot 3 }\end{array}$ & $\begin{array}{c}\text { Fig 6.16 } \\
\text { Spot 7 }\end{array}$ & $\begin{array}{c}\text { Avg of all 23 } \\
\text { Analyses }\end{array}$ \\
\hline $\mathrm{Na}$ & 7.9 & 17.3 & 16.9 & 9.5 & 17.3 & 38.7 & 17.2 \\
\hline $\mathrm{Al}$ & 10.2 & 15.5 & 15.2 & 8.4 & 13.6 & 29.8 & 14.0 \\
\hline $\mathrm{Si}$ & 9.7 & 13.3 & 13.0 & 7.6 & 12.3 & 28.8 & 11.8 \\
\hline $\mathrm{P}$ & 0.9 & 1.2 & 1.1 & 0.7 & 1.4 & 0 & 1.2 \\
\hline $\mathrm{Bi}$ & 19.9 & 17.3 & 19.0 & 17.5 & 19.6 & 0 & 18.5 \\
\hline $\mathrm{U}$ & 8.0 & 5.1 & 6.8 & 7.8 & 6.3 & 0 & 6.1 \\
\hline $\mathrm{Ca}$ & 4.0 & 2.3 & 3.00 & 3.8 & 3.1 & 0 & 2.8 \\
\hline $\mathrm{Mn}$ & 4.0 & 2.3 & 2.7 & 5.2 & 2.8 & 0 & 3.3 \\
\hline $\mathrm{Fe}$ & 31.5 & 25.7 & 22.4 & 39.5 & 23.7 & 2.7 & 24.9 \\
\hline
\end{tabular}

Figure 6.19 provides an SEM-EDS map of selected elements in the leached and washed solids. Iron, bismuth, silica, and sodium are concentrated within the same area, suggesting a complex consisting of these elements. Further evidence of this is seen with TEM, as discussed below, where a likely match to a compound containing $\mathrm{Fe}, \mathrm{Bi}$, and $\mathrm{Si}$ is found. Calcium, manganese, and uranium are fairly evenly distributed throughout the area.

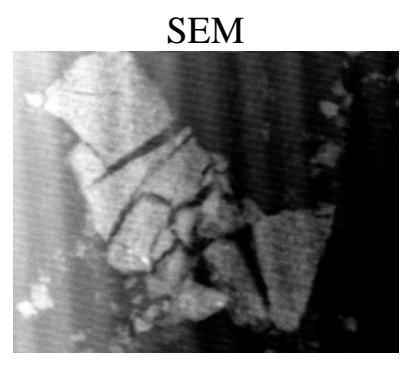

$\mathrm{Ca}$

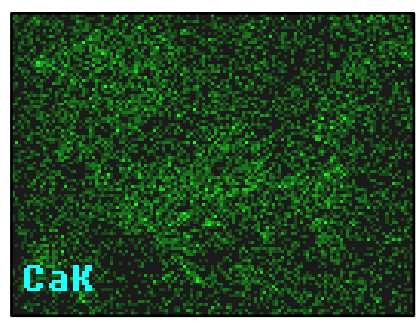

$\mathrm{Fe}$

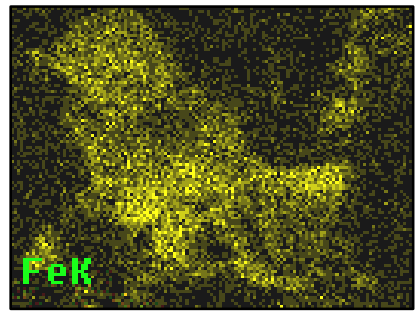

$\mathrm{Mn}$

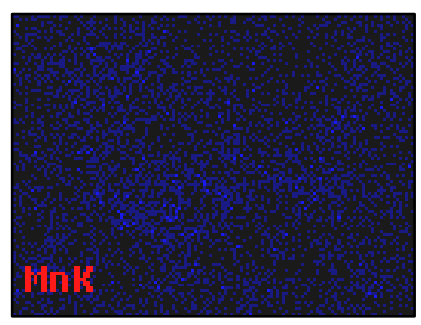

$\mathrm{Si}$

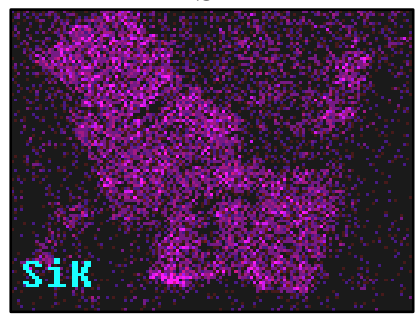

$\mathrm{U}$

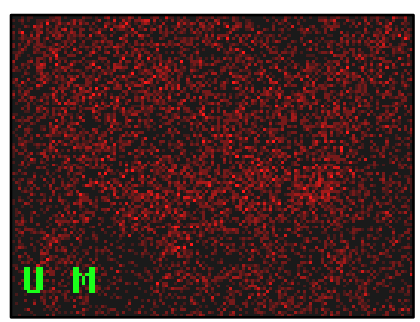

$\mathrm{Bi}$

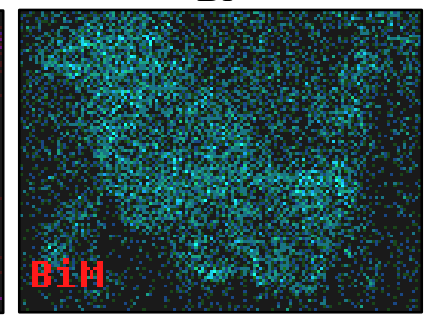

$\mathrm{Na}$

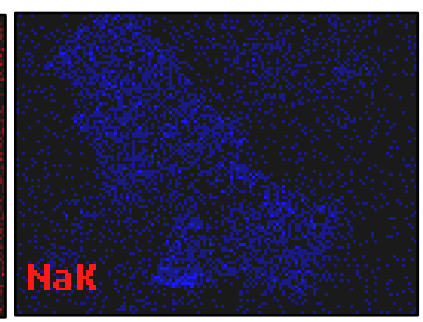

Figure 6.19. SEM-EDS Image of Oxidatively Leached Group 1/2 Bi-Phosphate Sludge/Saltcake with Fe, Si, Bi, Ca, Mn, U, and Na Maps

Figure 6.20 shows four different TEM images of the oxidatively leached solids. The solids are agglomerates of small round particles that consist mainly of iron and bismuth, as well as larger particles of cancrinite. Cancrinite was identified with EDS and electron diffraction as large euhedral particles surrounded by a bismuth phase. Hydroxycancrinite was identified by XRD. Cancrinite and hydroxycancrinite have very similar patterns in XRD and are difficult to distinguish. 

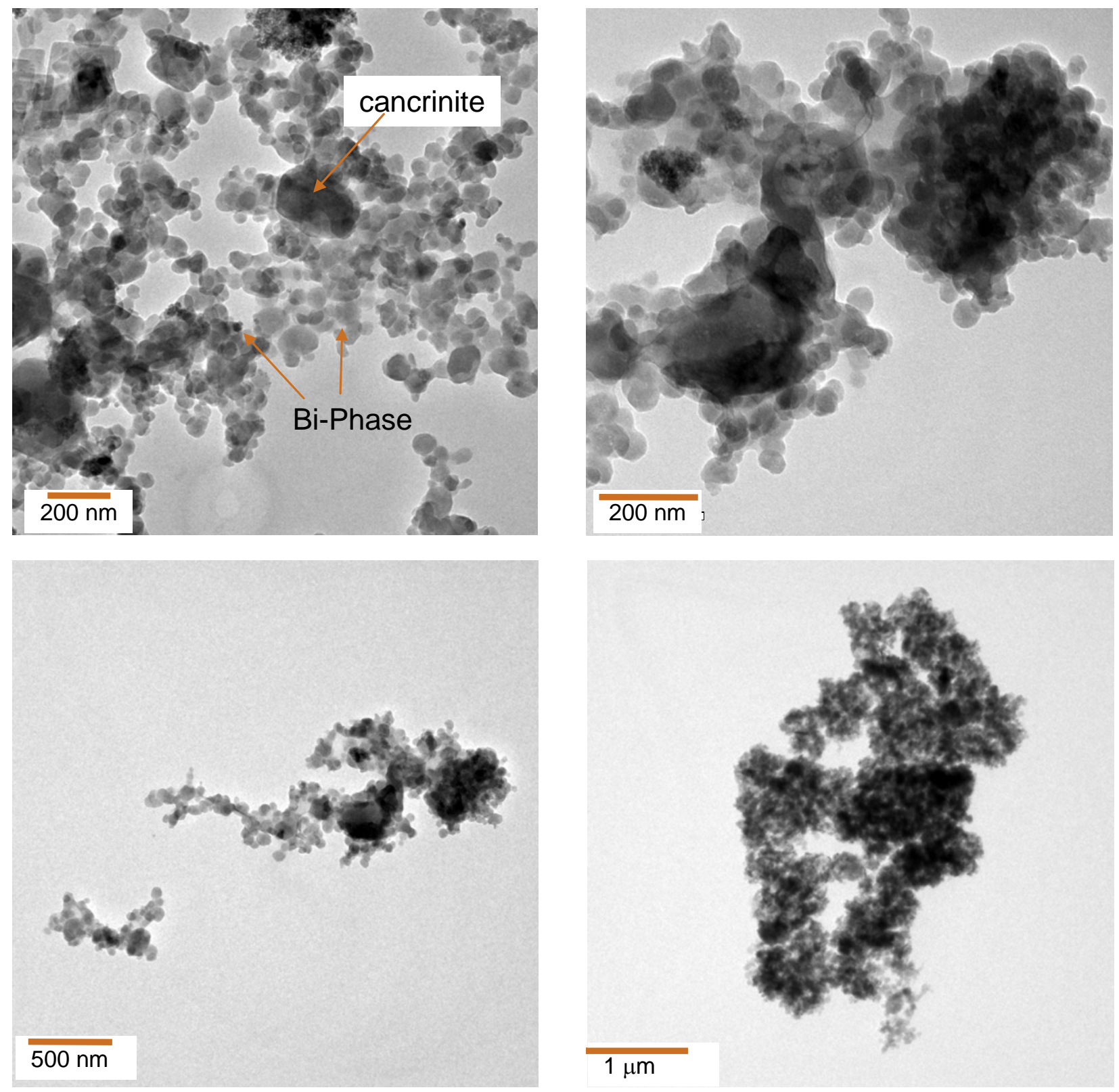

Figure 6.20. TEM Images of Oxidatively-Leached Group 1/2 Bi-Phosphate Sludge/Saltcake

Figure 6.21 shows a typical TEM image with EDS analysis of two regions in the sample. Figure 6.21a shows the STEM-HAADF image and the two areas where EDS spectra were taken. Figure 6.21b is a TEM image of the same agglomerate shown in 6.21a. The smaller particles are Bi-Fe phases, as shown by the EDS spectrum in Figure 6.21c and 6.21d. The larger particle in the upper right of Figure 6.21b is a cancrinite particle. Using various sized nano-probes in TEM mode and STEM, the dominant phase in the sample was determined to be a bismuth iron oxide. The phase composition is consistent with bismuthoferrite. It is present as agglomerates that are variable in size. Based on EDS analysis, the iron content appears to be variable. 

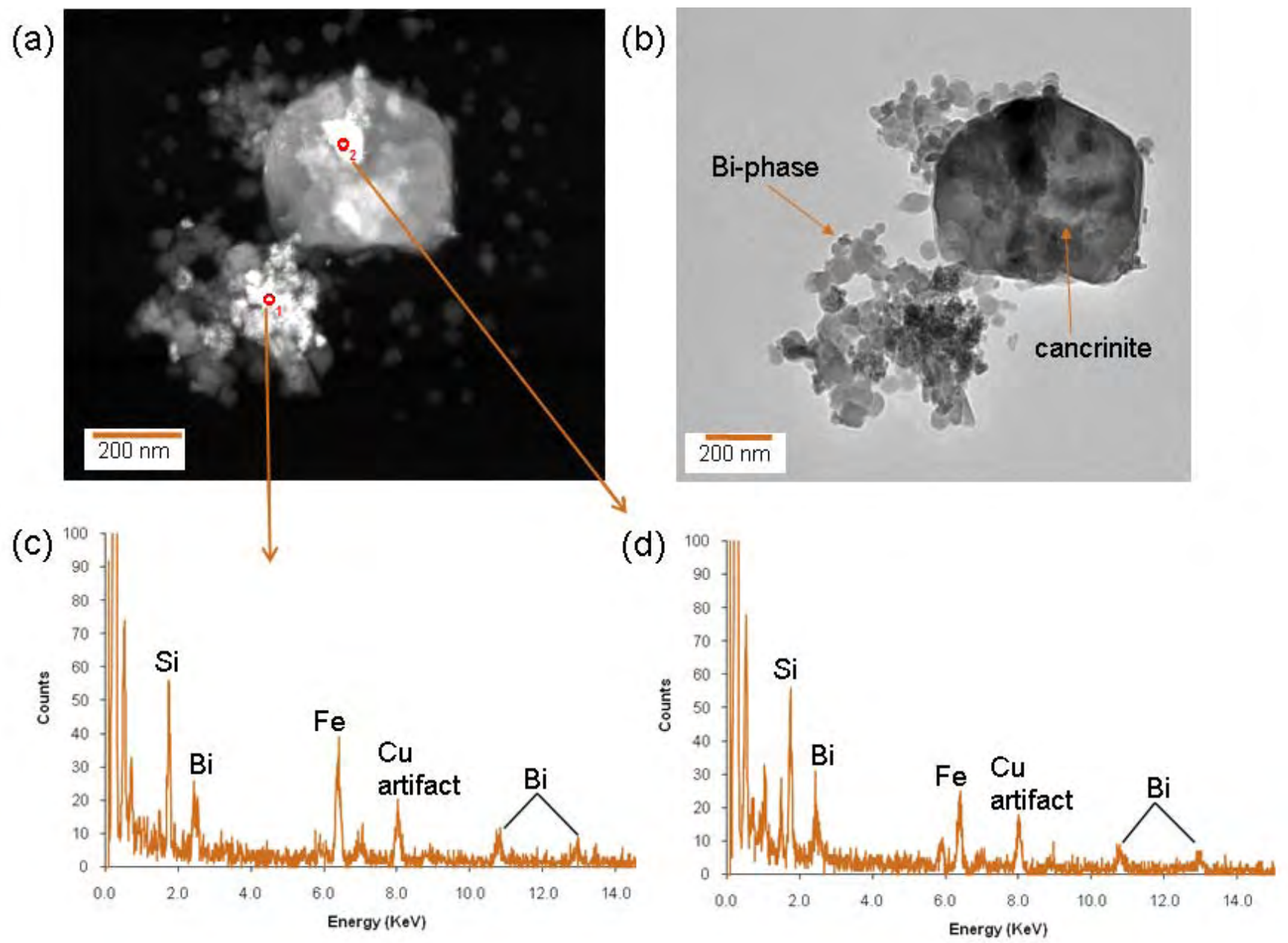

Figure 6.21. TEM Images with EDS Analysis: (a) STEM-HAADF Image; (b) TEM Image Showing Cancrinite Particle and Bi-Fe Phases; (c) EDS Spectrum of Bi-Fe Phase; (d) EDS Spectrum of a $\mathrm{Bi}-\mathrm{Fe}$ Particle that is Under the Cancrinite Particle

Results from electron diffraction analysis of the iron bismuth particles in this sample are compared to literature values for a bismuth iron phase, bismuthoferrite $\left[\mathrm{Fe}_{2} \mathrm{Bi}\left(\mathrm{SiO}_{4}\right)_{2}(\mathrm{OH})\right]$ in Table 6.9 (Zhukhlistov and Zvyagin 1977) The measured D-spacings on these particles are very good matches to those reported in the literature. This is also in agreement with the SEM EDS map shown in Figure 6.19, where Bi, Fe, and Si seem to be at high concentrations in the same area. The bismuthoferrite phase was not identified in the bulk XRD analysis, perhaps because of the very small $(\sim 50 \mathrm{~nm})$ size of the primary crystals. 
Table 6.9. Electron Diffraction Analysis Data for Group 1/2 Bi-Phosphate Sludge/Saltcake Oxidatively Leached Solids

\begin{tabular}{|c|c|c|}
\hline $\begin{array}{c}\text { Measured D- } \\
\text { Spacing (Å) }\end{array}$ & $\begin{array}{c}\text { Literature D- } \\
\text { Spacing ( }(\AA)\end{array}$ & hkl \\
\hline $3.13,3.10$ & 3.1534 & $\begin{array}{lll}-1 & 1 & 2\end{array}$ \\
\hline 1.90 & 1.90 & $\begin{array}{lll}-1 & 3 & 3\end{array}$ \\
\hline 1.605 & 1.607 & $\begin{array}{lll}-1 & 3 & 4\end{array}$ \\
\hline 1.59 & 1.5900 & $\begin{array}{lll}-1 & 5 & 2\end{array}$ \\
\hline 1.42 & 1.4291 & $\begin{array}{lll}-2 & 0 & 5\end{array}$ \\
\hline 1.205 & 1.207 & $\begin{array}{lll}-2 & 4 & 5\end{array}$ \\
\hline 1.131 & 1.12 & \\
\hline 1.117 & 1.11 & \\
\hline
\end{tabular}

Not all of the iron was associated with bismuth. Figure 6.22 shows an EDS spectrum of a particle that is high in iron, but has a low concentration of bismuth. Based on the ICP analysis of the oxidatively leached and washed solids, the molar ratio of iron to bismuth is 6, suggesting that although a portion of the iron is bound to bismuth, there is still an excess of iron that most likely exists as an iron oxide.

(a)

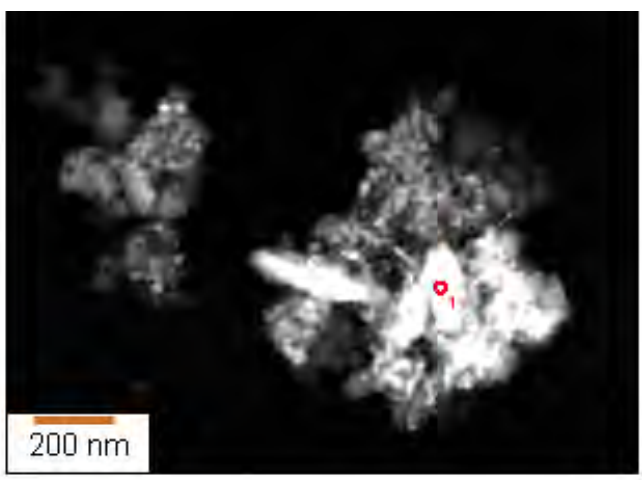

(b)

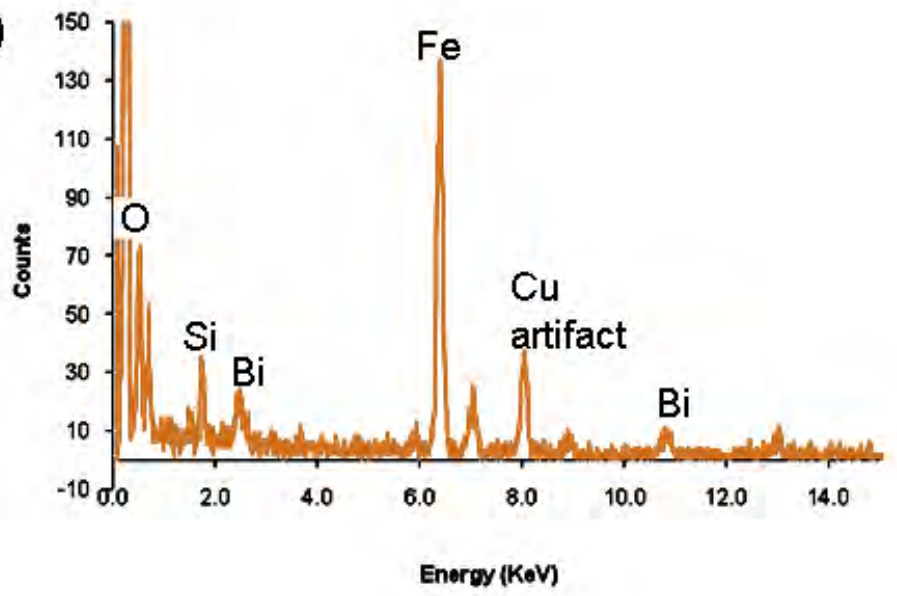

Figure 6.22. Particle High in Iron (a) TEM Image; (b) EDS Analysis Showing High Iron Content as Well as Very Little Bismuth

Figure 6.23 shows the analysis of a cancrinite phase; the EDS spectrum is shown in Figure 6.23b. The [100] direction of the crystal is shown. Figure 6.24 shows the identification of a uranium phase. Three EDS spectra are shown in Figure 6.24b. The top spectrum shows the U phase. The particle that was examined is circled in Figure 6.24a. The middle spectrum shows another analysis of a phase high in Bi and $\mathrm{Fe}$, and the bottom spectrum could possibly be another cancrinite particle. 
WTP-RPT-166, Rev. 0

(a)

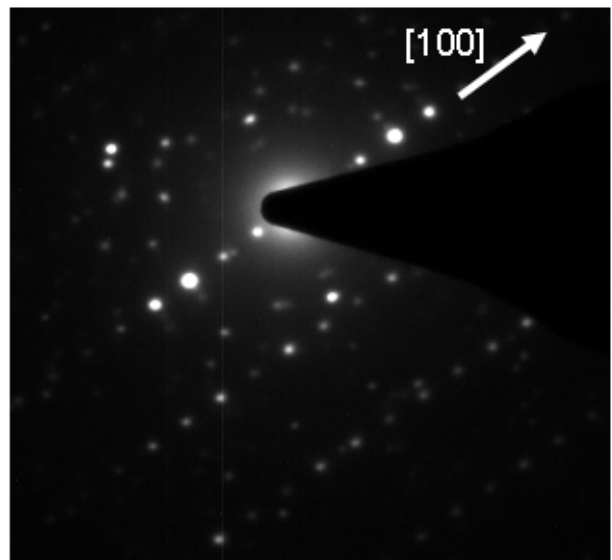

(b)

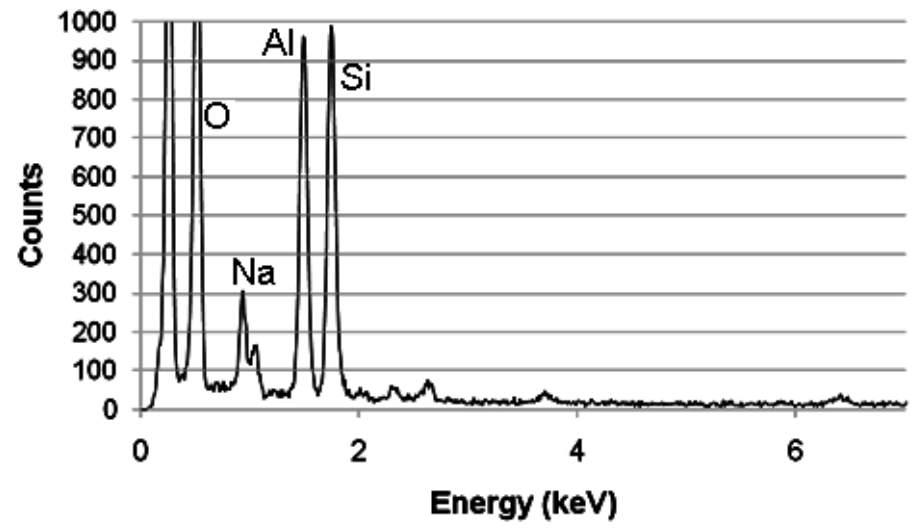

Figure 6.23. TEM Analysis of Cancrinite Phase: (a) SAED Image; (b) EDS Spectrum 


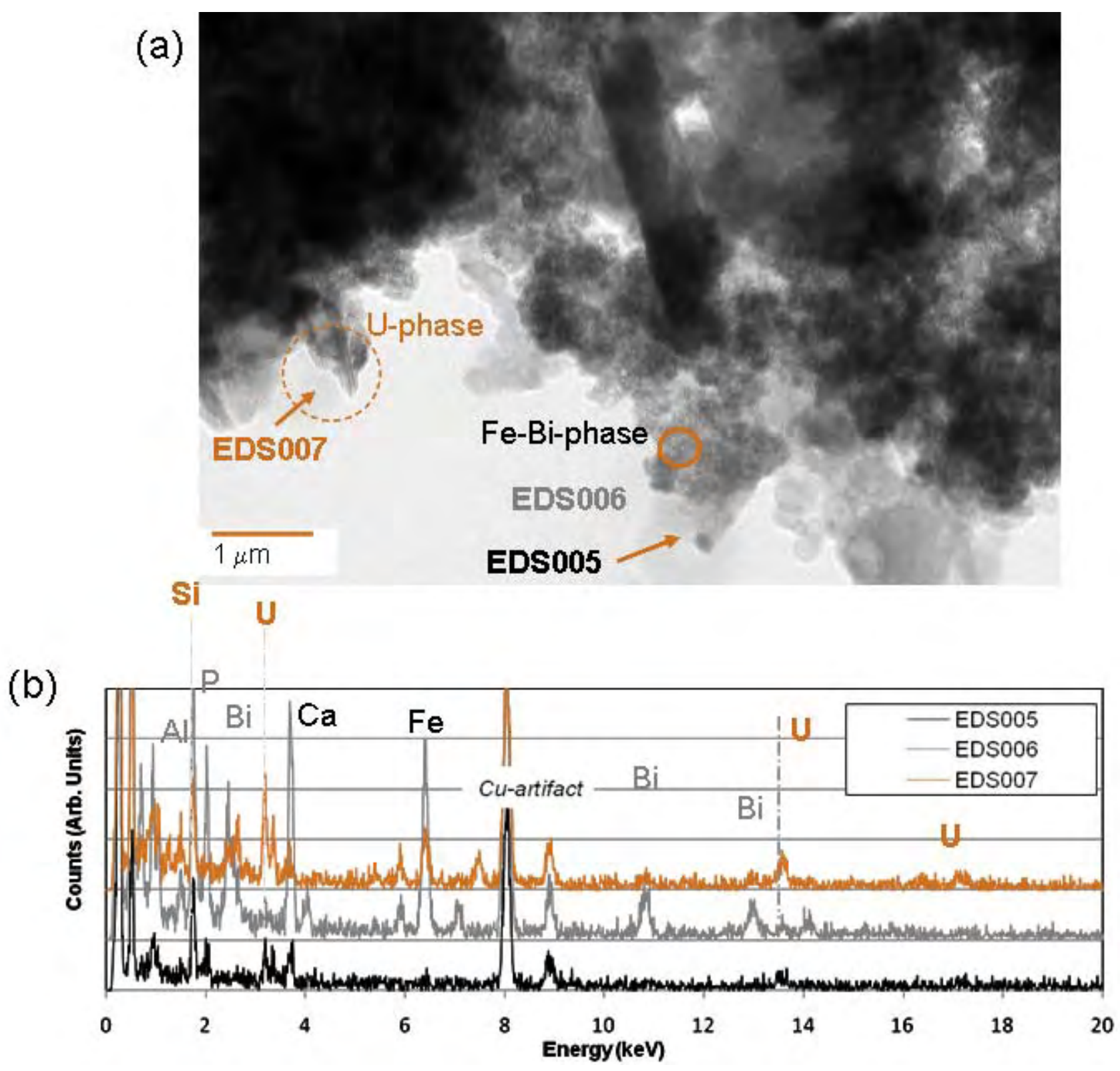

Figure 6.24. (a) TEM Image; (b) EDS Analysis Showing Uranium Phase, Iron Bismuth Phase, and Cancrinite

Figure 6.25 shows a TEM with an EDS spectrum of a metal particle that is high in nickel. The particle is composed of nickel, chromium, iron, and molybdenum. This composition is similar to a corrosionresistant metal such as Hastalloy $\mathrm{X}(47 \mathrm{Ni}-22 \mathrm{Cr}-18 \mathrm{Fe}-9 \mathrm{Mo}-0.6 \mathrm{~W}-1.5 \mathrm{Co})$ that was used as cladding material at the Hanford site in the 1960s. Corrosion in the tank sludge might have removed iron preferentially over time from the metallic particles. 
(a)

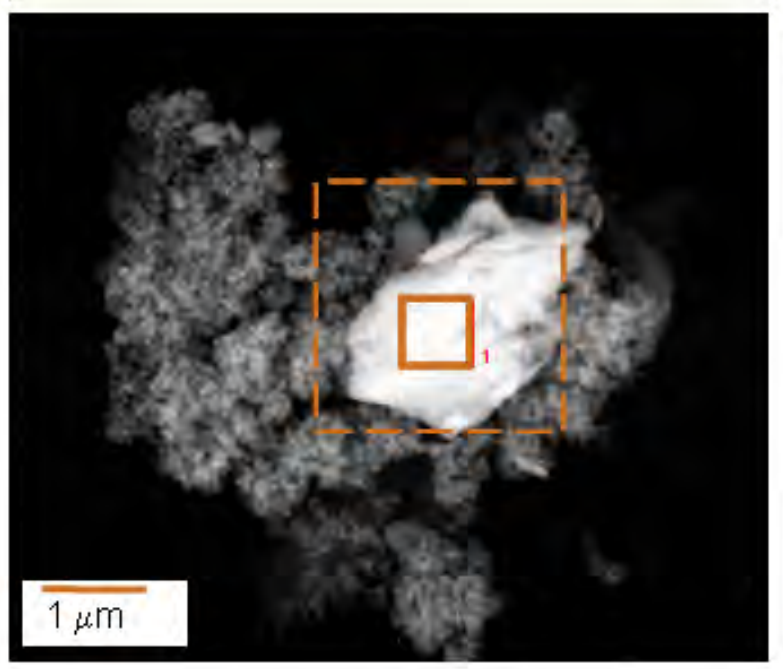

(b)

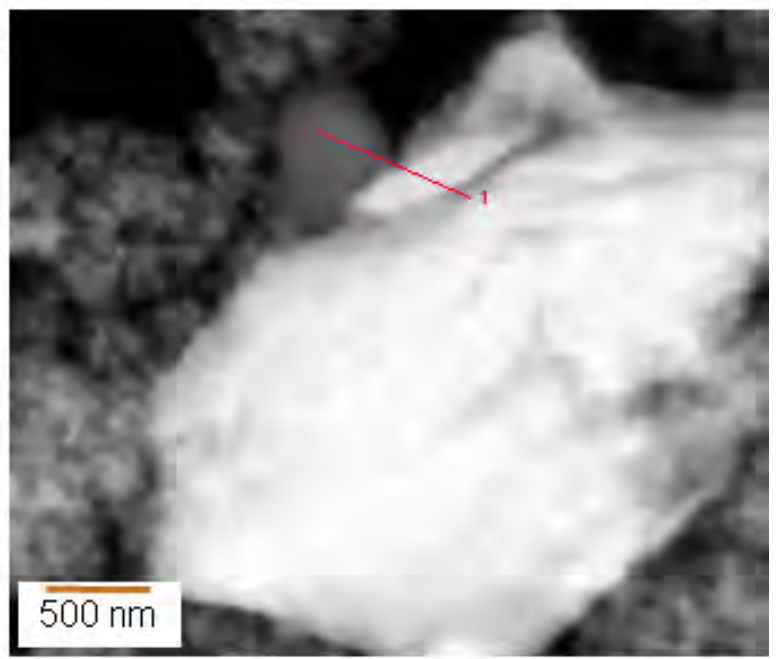

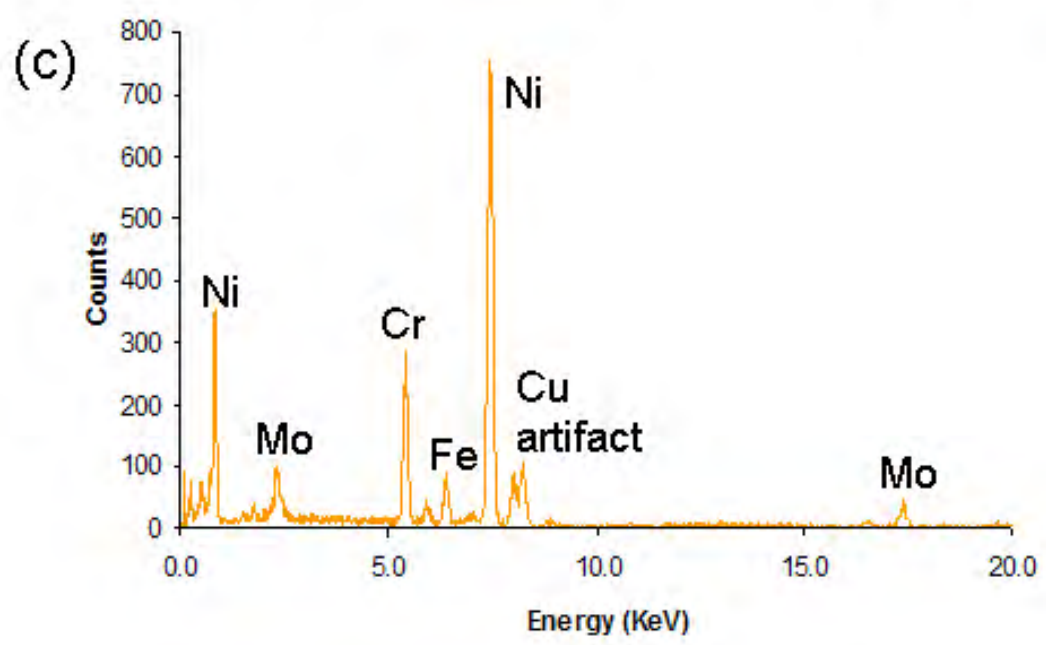

Figure 6.25. TEM image of a Nickel Particle: (a) TEM Image; (b) Close-up of Area in the Dotted Square in (a); (c) EDS Spectrum Taken of the Area 1 Shown in (a)

\subsubsection{Surface Area by BET}

A BET measurement was conducted on the oxidatively leached and washed solids, resulting in a surface area of $125.9 \mathrm{~m}^{2} / \mathrm{g}$. This is higher than the value of $96.3 \mathrm{~m}^{2} / \mathrm{g}$ found for the solids that were oxidatively leached in the CUF. However, this could be due to the difference in amount of $\mathrm{Cr}$ that was leached from the two experiments. In the CUF, only $26 \%$ of the Cr was leached from the solids, while in the parametric tests, $66 \%$ of the Cr was leached. 
WTP-RPT-166, Rev. 0

\subsection{Summary}

Tank waste sludge and saltcake at the Hanford Site have been categorized into eight general groupings representing $\sim 75 \mathrm{wt} \%$ of the total high-level waste mass expected to be processed through the WTP. Two of the eight groups, Group 1 and Group 2, are the subject of this report. Group 1 represents bismuth phosphate sludge waste containing a high fraction of phosphate; Group 2 represents bismuth phosphate saltcake, which contains a large fraction of the tank waste aluminum, chromium, phosphate, and sulfate.

Multiple samples representative of these two waste groups, all of which had been stored for 10 years or more, were identified in the 222S sample archive. Materials representative of Group 1 (and containing high P) were obtained from archived samples from tanks B-104, T104, BX-112, and S-107, although the sample composite used was dominated by the B-104 waste. Materials representative of Group 2 were selected from archived samples from tanks BX-110, BX-111, BY-104, BY-105, BY-107, BY-108, BY-109, BY-110, BY-112, T-108, T-109, TX-104, and TX-113. These materials were combined into their respective composite group using water to suspend solids during mixing and dissolve the watersoluble species.

The tank waste composites were extensively characterized for physical properties, rheological properties, and chemical composition of the solids and liquid phases as well as the crystal habit of the insoluble solids. Table 7.1 summarizes the physical properties for the Group 1 and Group 2 samples, and Table 7.2 summarizes selected elemental analysis information.

\section{Group 1 Parametric Testing}

The Group 1 bismuth phosphate sludge waste was subjected to parametric caustic leach testing to understand phosphorus dissolution characteristics and to support the development of a suitable simulant material for this type of waste (although simulant development was outside the scope of the work reported here). Leaching was conducted in a 1:100 solids-mass to solution-volume ratio under varying hydroxide concentrations (1, 3, and $5 \mathrm{M}$ ) and varying temperature (40, 60, and $80^{\circ} \mathrm{C}$ ). Periodic sampling (1 to $24 \mathrm{~h}$ ) and analysis was conducted to determine the reaction behavior at each reaction condition. Table 7.3 provides the composition of the residual solids from leaching the Group 1 solids in $3 \mathrm{M} \mathrm{NaOH}$ at $40^{\circ} \mathrm{C}$ for $24 \mathrm{~h}$, along with the leach factors for selected waste components. The following are the key conclusions from this work.

- Under all caustic leaching conditions examined, phosphate removal from the Group 1 solids was rapid with essentially complete removal typically being achieved after $2 \mathrm{~h}$.

- Even before heating, adding $1 \mathrm{M} \mathrm{NaOH}$ resulted in $~ 60 \%$ P removal from the Group 1 solids; this was accompanied by a dramatic color change from beige to rusty-red.

- Identifying specific phases present in the Group 1 solids was difficult because of the amorphous nature of the solids. It is hypothesized that the phosphorus in the washed Group 1 solids was primarily in the form of an iron(III) phosphate phase, which rapidly metathesizes to ferric hydroxide (yielding the rusty-red color) and sodium phosphate. FTIR spectroscopy, SEM-EDS examination, and chemical observations support this hypothesis. 
- Seventy-five to $85 \%$ of the $\mathrm{Al}$ present in the washed Group 1 solids readily dissolved in caustic media (1 to $3 \mathrm{M} \mathrm{NaOH})$.

- Chromium was not readily removed from the Group 1 solids. Even under the most rigorous caustic leaching conditions examined ( $3 \mathrm{M} \mathrm{NaOH}$ at $80^{\circ} \mathrm{C}$ ), only $22 \%$ of the $\mathrm{Cr}$ was removed after $24 \mathrm{~h}$ of leaching.

- Chromium would likely be the component constraining waste loading in the HLW glass for the Group 1 solids remaining after leaching in $3 \mathrm{M} \mathrm{NaOH}$ at $40^{\circ} \mathrm{C}$.

- The PSD for the leached Group 1 solids shifted to larger particle sizes compared to the un-leached material. This could be attributed to either dissolution of the smaller particles originally present (with the larger particles being insoluble in caustic) or to the formation of agglomerates in the leached material (or a combination of both). The PSD for the leached Group 1 solids is broad, spanning 0.3 to $300 \mu \mathrm{m}$, and multimodal. At a pump speed of $3000 \mathrm{RPM}$, the distribution is dominated by a peak with a maximum population at 30 to $40 \mu \mathrm{m}$. There is a secondary population of particles spanning from 0.3 to $8 \mu \mathrm{m}$, which decreases when the pump speed is increased. This observation suggests breakage of agglomerates through the shear action of the pump.

Table 7.1. Summary of Major Physical Properties and Mineral Phases of Group 1 Bismuth Phosphate Sludge and Group 2 Bismuth Phosphate Saltcake

\begin{tabular}{|l|c|c||}
\hline \multirow{2}{*}{ Physical } & $\begin{array}{c}\text { Group 1 Bismuth } \\
\text { Phosphate Sludge }\end{array}$ & $\begin{array}{c}\text { Group 2 Bismuth } \\
\text { Phosphate Saltcake }\end{array}$ \\
\cline { 2 - 3 } & Slurry & Slurry \\
\hline Total slurry volume & $2,163 \mathrm{~mL}$ & $814 \mathrm{~mL}$ \\
\hline Total UDS & $9.0 \mathrm{wt} \%$ & $37.4 \mathrm{wt} \%$ \\
\hline Bulk density & $1.31 \mathrm{~g} / \mathrm{mL}$ & $1.66 \mathrm{~g} / \mathrm{mL}$ \\
\hline Centrifuged solids & $36.7 \mathrm{vol} \%$ & $68.6 \mathrm{vol} \%$ \\
\hline Shear strength ${ }^{(a)}$ & $15 \mathrm{~Pa}$ & $21 \mathrm{~Pa}$ \\
\hline Apparent viscosity ${ }^{(\mathrm{b})}$ & 6 to $26 \mathrm{cP}$ & 49 to $144 \mathrm{cP}$ \\
\hline Behavior & Newtonian $(\mathrm{mostly})$ & Non-Newtonian \\
\hline Bingham Yield Stress & $<0.5 \mathrm{~Pa}$ & $1.4 \mathrm{~Pa}$ \\
\hline PSD & $\begin{array}{c}\text { Peak: } 10 \mu \mathrm{m} \\
\text { Range: } 0.3-100 \mu \mathrm{m}\end{array}$ & Peak: $4 \mu \mathrm{m}$ \\
\hline Surface Area & $95 \mathrm{~m}^{2} / \mathrm{g}$ & $46 \mathrm{~m}^{2} / \mathrm{g}$ \\
\hline $\begin{array}{l}\text { (a) Strength of settled solids } 67 \text { hours after mixing. } \\
\text { (b) Apparent viscosity taken at a shear rate of } 33 \mathrm{~s}^{-1} .\end{array}$ \\
\hline
\end{tabular}


Table 7.2. Summary of Elemental Composition of Group 1 Bismuth Phosphate Sludge and Group 2 Bismuth Phosphate Saltcake Slurries

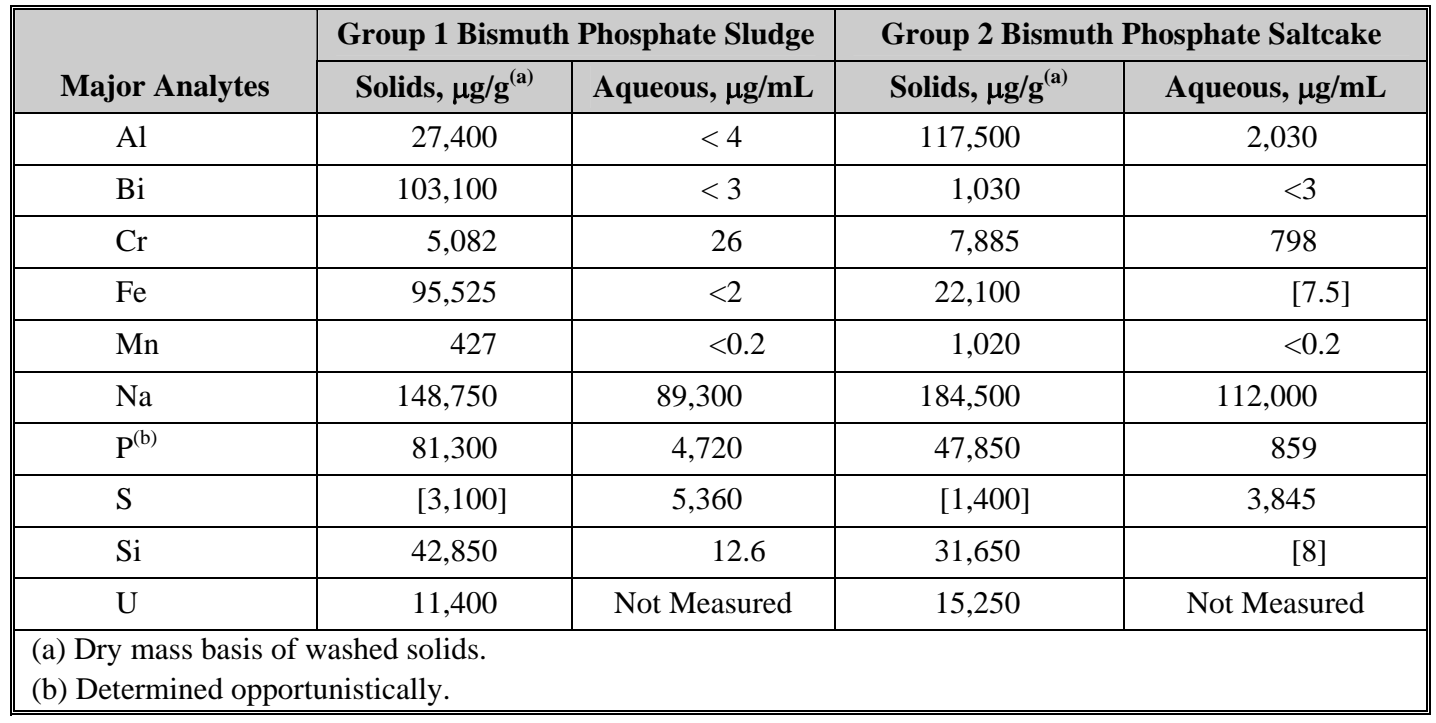

Table 7.3. Composition of Caustic-Leached Group 1 Solids with Leach Factors of Selected Analytes (3 $\mathrm{M} \mathrm{NaOH}, 40^{\circ} \mathrm{C}, 24 \mathrm{~h}$ )

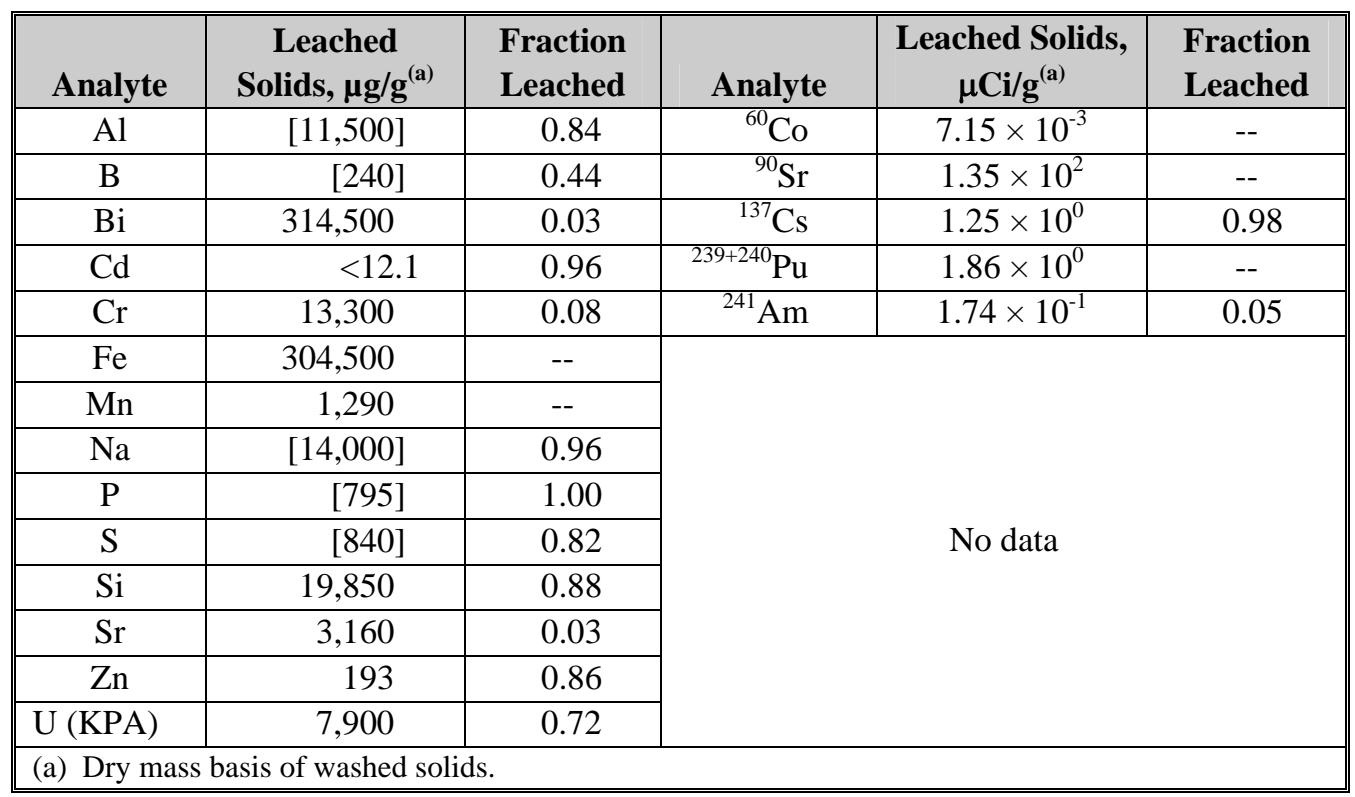

\section{Group 2 Parametric Testing}

The Group 2 bismuth phosphate saltcake solids contained significant concentrations of $\mathrm{Al}, \mathrm{Cr}, \mathrm{P}$, and S after washing with dilute hydroxide. Removing these components is desired to increase waste loading in the HLW glass. Gibbsite and nitrate cancrinite were determined to be in the Group 2 solids through both XRD and FTIR analysis. Other phases suggested by the XRD analysis included urancalcarite $\mathrm{Ca}\left(\mathrm{UO}_{2}\right)_{3} \mathrm{CO}_{3}(\mathrm{OH})\left(\mathrm{H}_{2} \mathrm{O}\right)_{3}$ and dorfmanite $\left(\mathrm{Na}_{2} \mathrm{HPO}_{4}\left(\mathrm{H}_{2} \mathrm{O}\right)_{2}\right)$, although there was no evidence for the latter 
in the FTIR spectrum, and this species would not be expected to survive the initial washing process. The precise mineralogical forms of phosphorus, chromium, and sulfur are not yet well characterized for the Group 2 solids.

The Group 2 waste was subjected to parametric caustic leaching tests to determine the Al, Cr, and $\mathrm{P}$ dissolution characteristics; the P results were determined opportunistically. Leaching was conducted in a 1:100 solids-mass to solution-volume ratio under varying hydroxide concentrations $(1,3$, and $5 \mathrm{M})$ and varying temperature $\left(60,80\right.$, and $\left.100^{\circ} \mathrm{C}\right)$. Periodic sampling (1 to $24 \mathrm{~h}$ ) and analysis was conducted to determine changes in component dissolution at each reaction condition. Table 7.4 provides the composition of the residual solids from leaching the Group 2 solids in $3 \mathrm{M} \mathrm{NaOH}$ at $80^{\circ} \mathrm{C}$ for $24 \mathrm{~h}$, along with the leach factors for selected waste components. The following are the key conclusions from this work.

- Aluminum dissolution from the Group 2 solids was similar under all conditions examined, indicating only a slight dependence on hydroxide concentration and temperature. Steady-state Al concentrations were reached within 4 to $8 \mathrm{~h}$. The steady-state concentrations corresponded to $\sim 60 \% \mathrm{Al}$ dissolved, indicating that $\sim 40 \%$ of the $\mathrm{Al}$ in the Group 2 solids was resistant to caustic leaching. This behavior would reasonably be explained by $\sim 60 \%$ of the $\mathrm{Al}$ present as gibbsite and the remainder as aluminosilicates, such as cancrinite.

- Chromium removal from the Group 2 solids displayed only a slight dependence on the hydroxide concentration. For leaching in 3 and $5 \mathrm{M} \mathrm{NaOH}$ (at $80^{\circ} \mathrm{C}$ ), the $\mathrm{Cr}$ removal gradually increased up to a value of $70 \%$ removed after $24 \mathrm{~h}$ of leaching. In the case of $1 \mathrm{M} \mathrm{NaOH}$, the $\mathrm{Cr}$ removal did appear to stabilize at only $\sim 45 \%$ after $8 \mathrm{~h}$ of leaching.

- Chromium removal from the Group 2 solids was strongly temperature dependent when measured at a constant hydroxide concentration of $3 \mathrm{M}$. In order to not exceed the glass loading limits of $\mathrm{Cr}$ in the HLW form, approximately $85 \%$ of the $\mathrm{Cr}$ needs to be removed from the water-insoluble Group 2 solids. This condition was just met at 24 hours in $3 \mathrm{M} \mathrm{NaOH}$ at $100^{\circ} \mathrm{C}$. Dissolution at $80^{\circ} \mathrm{C}$ reached approximately $70 \%$ dissolved after 24 hours, while only 30\% of the $\mathrm{Cr}$ was dissolved after 24 hours at $60^{\circ} \mathrm{C}$. Oxidative leaching might be required to sufficiently remove $\mathrm{Cr}$ from the Group 2 solids.

- Phosphorus removal from the Group 2 solids was not strongly influenced by NaOH concentration, but did display some temperature dependence. Nevertheless, P removal from the Group 2 solids was much lower than that observed for Group 1. Only about 25\% of the P was removed from the Group 2 solids under the most aggressive conditions examined (i.e., $24 \mathrm{~h}$ leaching with $5 \mathrm{M} \mathrm{NaOH}$ at $80^{\circ} \mathrm{C}$ or $3 \mathrm{M} \mathrm{NaOH}$ at $100^{\circ} \mathrm{C}$ ). This can be attributed to $\mathrm{P}$ being present in the form of hydroxyapatite, $\mathrm{Ca}_{5}(\mathrm{OH})\left(\mathrm{PO}_{4}\right)_{3}$, which is a very stable phase under caustic leaching conditions (Lumetta 2008).

- The PSD (at a pump speed of 3000 RPM) for the leached Group 2 solids displayed particles in the range of $\sim 0.2$ to $20 \mu \mathrm{m}$ with a maximum population between 1 and $2 \mu \mathrm{m}$ and a large shoulder population in the range of 3 to $20 \mu \mathrm{m}$. At a pump speed of 4000 RPM, a large secondary peak spanning 20 to $200 \mu \mathrm{m}$ and with a peak population at $60 \mu \mathrm{m}$ was observed, indicating the presence of particles that are difficult to suspend. Caustic leaching resulted in a decrease in the PSD for the Group 2 solids, which is likely a result of either material dissolving from the particle surfaces or agglomerates breaking. 
Table 7.4. Composition of Caustic-Leached Group 2 Solids with Leach Factors of Selected Analytes (3 $\mathrm{M} \mathrm{NaOH}, 80^{\circ} \mathrm{C}, 24 \mathrm{~h}$ )

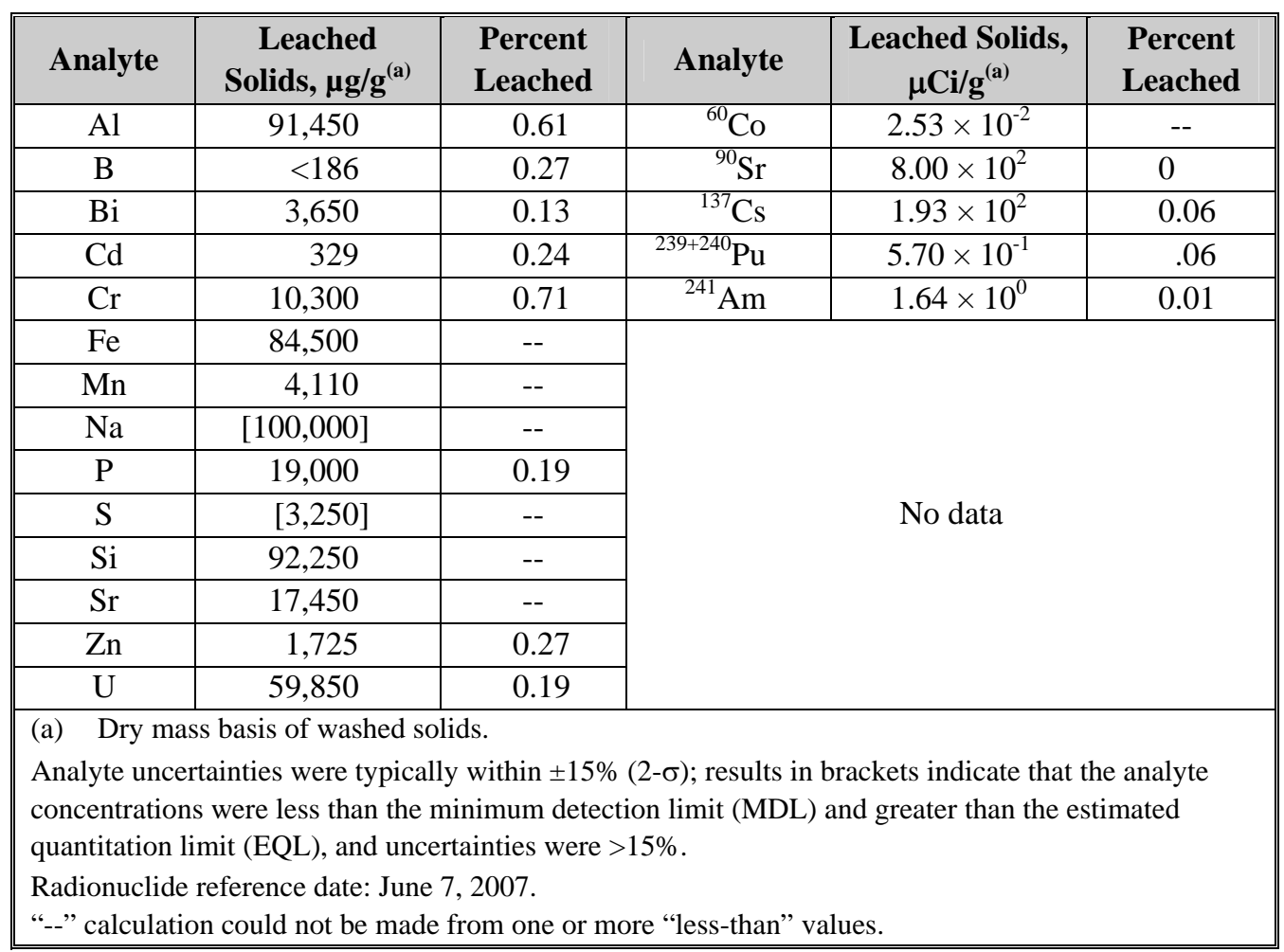

\section{Group 1/2 CUF Testing}

A blend of the Group 1 and Group 2 solids was made at a UDS concentration of $8 \mathrm{wt} \%$ (low-solids slurry) for CUF testing. The filter flux for the low-solids slurry was dependent upon the TMP in the range of TMPs examined (20 to 60 psid), but the axial velocity had no significant influence of the filter flux in the range of 8 to $18 \mathrm{ft} / \mathrm{s}$. Fouling of the membrane was observed while the low-solids slurry was being filtered. Although the flux could be mostly restored by back-pulsing, some irreversible fouling of the membrane occurred during the course of the low-solids slurry tests. The filter fluxes decreased rapidly during filtration of the low-solids slurry. The filter flux was stable at $\sim 0.017 \mathrm{GPM} / \mathrm{ft}^{2} \mathrm{during}$ dewatering of the low-solids Group 1/2 slurry to an UDS concentration of $16 \mathrm{wt} \%$ (resulting in the highsolids slurry).

Although the decline in the filter flux over time was less pronounced for the high-solids slurry compared to the low-solids slurry, the overall filter flux was significantly lower for the high-solids slurry. The average fluxes measured at the standard conditions for the high-solids slurry were sequentially 0.016 , 0.013, and $0.011 \mathrm{GPM} / \mathrm{ft}^{2}$, indicating a small, but apparently irreversible, decline in flux with time. For the high-solids Group 1/2 slurry, the filter flux was dependent upon the TMP, but not the AV.

Caustic leaching of the Group $1 / 2$ slurry in $\mathrm{NaOH}$ (with the free hydroxide concentration $=4.6 \mathrm{M}$ initially and $3.9 \mathrm{M}$ at the conclusion of leaching) at $100^{\circ} \mathrm{C}$ led to $41 \%$ removal of $\mathrm{Al}$ from the solids. Less $\mathrm{Al}$ was removed than during the individual parametric leaching tests for Group 1 and Group 2, which is likely because of the lower caustic-to-solids ratio used during leaching in the CUF apparatus. Approximately 
$41 \%$ of the $\mathrm{P}$ was removed from the Group $1 / 2$ slurry by caustic leaching, but most of this removal actually occurred during the third and fourth washing steps following the caustic leaching. The amount of P removed suggests dominance of the Group 2 solids in the composite because the parametric tests indicated most the $\mathrm{P}$ in the Group 2 solids was resistant to caustic leaching, whereas $\mathrm{P}$ was easily removed from the Group 1 solids. Another contributor to the low P removal might have been the relatively low liquid-to-solids ratio used during washing in the CUF, leading to incomplete dissolution of $\mathrm{Na}_{3} \mathrm{PO}_{4} \cdot 12 \mathrm{H}_{2} \mathrm{O}$. Approximately $23 \%$ of the $\mathrm{Cr}$ was removed during the caustic leaching and subsequent water washing.

At the initiation of the dewatering step following caustic leaching, it was discovered that the pump head was clogged with a gel. This gel is hypothesized to be caused by precipitation of $\mathrm{Na}_{3} \mathrm{PO}_{4} \cdot 12 \mathrm{H}_{2} \mathrm{O}$ from the caustic-leaching solution. Similar gels have been observed in experiments examining phosphate solubility in simulated caustic-leaching solutions. The phosphate concentration in the process solutions will need to be carefully managed with respect to the solubility of $\mathrm{Na}_{3} \mathrm{PO}_{4} \cdot 12 \mathrm{H}_{2} \mathrm{O}$ to avoid gel formation in the WTP. In the case of the clogged pump, the gel could be cleared by flushing with water. The filter flux during dewatering of the caustic leachate was low $\left(<0.01 \mathrm{GPM} / \mathrm{ft}^{2}\right)$ and declined approximately $2 \%$ during the course of the 5-h filtration test. The filter flux increased with successive washing of the caustic-leached slurry.

The caustic leached slurry was washed five times using solutions with progressively decreasing $\mathrm{NaOH}$ concentrations. Dewatering steps were conducted in the CUF after each washing step. The average permeate flux increased steadily with decreasing $\mathrm{NaOH}$ concentration in the washing medium, reaching a maximum average flux of $0.07 \mathrm{GPM} / \mathrm{ft}^{2}$ during the final washing step.

Oxidative leaching of the caustic leached solids with sodium permanganate resulted in only an additional $\sim 25 \%$ removal of $\mathrm{Cr}$ from the solids (for a total of $48 \%$ of the $\mathrm{Cr}$ removed). Based on the reaction stoichiometry, and the amount of permanganate used, $40 \%$ removal of the $\mathrm{Cr}$ was expected to be leached. The reason for the low Cr conversion is currently unknown. During the first two washings of the oxidative-leached slurry, the temperature was above ambient because the chiller was inadvertently not turned on. When corrected for the effects of higher temperature, the data indicated that filter flux was essentially constant at $\sim 0.04 \mathrm{GPM} / \mathrm{ft}^{2}$ during the three washes of the oxidatively-leached solids.

The filter flux was dependent upon the TMP during the final dewatering of the Group 1/2 slurry, but also showed an apparent dependence on the AV. So, simple classification of the final slurry into a membraneresistance or cake-resistance model is not obvious. Comparison with the initial clean water flux measurements suggests an irreversible fouling of the membrane following the leaching and filtration tests.

\section{Group 1/2 Post-CUF Parametric Testing}

A portion of the caustic-leached and washed Group 1/2 sample was subjected to parametric leaching with permanganate. The parameters examined included $\mathrm{NaOH}$ concentration $(0.25$ and $1.25 \mathrm{M})$ and the $\mathrm{Mn} / \mathrm{Cr}$ molar ratio $\left(0.59,0.79,0.98\right.$, and 1.19). In all cases, $\mathrm{Cr}$ reaction with the $\mathrm{MnO}_{4}{ }^{-}$was rapid, with nearsteady state $\mathrm{Cr}$ concentration reached within $1 \mathrm{~h}$ of leaching. As would be expected, the amount of $\mathrm{Cr}$ removed from the Group 1/2 solids was dependent upon the $\mathrm{Mn} / \mathrm{Cr}$ ratio, with the most impact observed in going from $\mathrm{Mn} / \mathrm{Cr}=0.59$ to $\mathrm{Mn} / \mathrm{Cr}=0.79$. Above a $\mathrm{Mn} / \mathrm{Cr}$ ratio of 0.79 , there was only a minor improvement in the amount of $\mathrm{Cr}$ removed, and there was virtually no difference between the results with 
$\mathrm{Mn} / \mathrm{Cr}=0.98$ and $\mathrm{Mn} / \mathrm{Cr}=1.19$. About $65 \%$ of the $\mathrm{Cr}$ from the caustic-leached Group $1 / 2$ solids was removed by treatment with 0.79 molar equivalent of $\mathrm{Mn}(\mathrm{VII})$ in $0.25 \mathrm{M} \mathrm{NaOH}$ at $45^{\circ} \mathrm{C}$.

The reaction of $\mathrm{Cr}(\mathrm{III})$ with permanganate can be represented by the following equation::

$$
\mathrm{Cr}(\mathrm{III})(\mathrm{s})+\mathrm{MnO}_{4}^{-}(\mathrm{aq})+\mathrm{OH}^{-}(\mathrm{aq}) \rightarrow \mathrm{CrO}_{4}{ }^{2-}(\mathrm{aq})+\mathrm{MnO}_{2}(\mathrm{~s})+2 \mathrm{H}_{2} \mathrm{O}
$$

Although this reaction would suggest a dependence of $\mathrm{Cr}$ leaching on the hydroxide concentration, virtually no improvement in $\mathrm{Cr}$ removal was observed when the $\mathrm{NaOH}$ concentration was raised from 0.25 to $1.25 \mathrm{M}$. This suggests that under the conditions examined, there is sufficient excess hydroxide ion at $0.25 \mathrm{M} \mathrm{NaOH}$ so that the reaction is not constrained by this component. On the other hand, the $\mathrm{Al}$ dissolution was $\sim 70 \%$ higher at $1.25 \mathrm{M} \mathrm{NaOH}$ compared to $0.25 \mathrm{M}$ during the oxidative leaching at $45^{\circ} \mathrm{C}$. This result was somewhat surprising in that the solids had been previously leached with caustic. It is possible that the caustic-to-aluminum ratio during the CUF caustic leaching was not sufficiently high to dissolve all the leachable Al.

Under all six test conditions in $0.25 \mathrm{M} \mathrm{NaOH}, 58$ to $62 \%$ of the $\mathrm{P}$ was dissolved within $24 \mathrm{~h}$, and equilibrium was achieved within $6 \mathrm{~h}$. Increasing the $\mathrm{Mn} / \mathrm{Cr}$ mole ratio from 0.75 to 1.5 had no impact on the amount of $\mathrm{P}$ in solution (initially and at equilibrium conditions). The amount of $\mathrm{NaOH}(0.25$ or $1.25 \mathrm{M}$ ) at the $\mathrm{Mn} / \mathrm{Cr}$ molar ratio of 1.25 also had no effect on the amount of P dissolution.

The Pu dissolution during oxidative leaching of the Group 1/2 solids was strongly dependent on the freehydroxide concentration, with the Pu concentration increasing by approximately 6-fold when the $\mathrm{NaOH}$ concentration was increased from $0.25 \mathrm{M}$ to $1.25 \mathrm{M}$. For example, after leaching for $6 \mathrm{~h}$ at a $\mathrm{Mn} / \mathrm{Cr}$ ratio of 0.98 , the ${ }^{239+240} \mathrm{Pu}$ concentration was $1.54 \times 10^{-3} \mu \mathrm{Ci} / \mathrm{mL}$ at $1.25 \mathrm{M} \mathrm{NaOH}$ and $2.54 \times 10^{-4} \mu \mathrm{Ci} / \mathrm{mL}$ at $0.25 \mathrm{M} \mathrm{NaOH}$. Clearly, low free-hydroxide concentrations will need to be maintained to minimize $\mathrm{Pu}$ mobilization during oxidative leaching of $\mathrm{Cr}$.

Under all conditions examined, the $\mathrm{U}$ concentrations in the oxidative leaching solutions remained low, with the $\mathrm{U}$ concentration typically $\sim 3 \mu \mathrm{g} / \mathrm{mL}$ after leaching for $24 \mathrm{~h}$. The exception was during leaching in $1.25 \mathrm{M} \mathrm{NaOH}$ at a $\mathrm{Mn} / \mathrm{Cr}$ ratio of 1.25 ; in that case, the $\mathrm{U}$ concentration in solution reached a level of $\sim 8 \mu \mathrm{g} / \mathrm{mL}$. The Fe, Ni, Cd, and B concentrations in the oxidative leaching solutions were also very low, generally below the detection limit or $<1 \mu \mathrm{g} / \mathrm{mL}$. Manganese was observed to be in the leachate solutions at $\mathrm{Mn} / \mathrm{Cr}=1.25$ or higher, but the amount in solution decreased with time and was below the detection limit at $24 \mathrm{~h}$. The mechanism by which the excess Mn precipitates is not yet understood. 
WTP-RPT-166, Rev. 0

Appendix A

\section{Analytical Methods}




\section{Appendix A}

\section{Analytical Methods}

This section describes the analytical methods used to determine the chemical and radiochemical composition of the Group 1 and Group 2 samples.

\section{A.1 Sample Preparation for Chemical Characterization}

The samples taken for chemical characterization were centrifuged at $1000 \mathrm{G}$ for $1 \mathrm{hr}$, and then the supernatant liquids were decanted. The solids were washed with three successive additions of $0.01 \mathrm{M}$ $\mathrm{NaOH} .{ }^{(a)}$ After adding each washing solution, the sample was agitated for 15 min and centrifuged $30 \mathrm{~min}$ at $1000 \mathrm{G}$, and the liquid phase was removed. The three wash solutions were combined into a composite and passed through a 0.45 -micron pore size nylon filter. The supernatant and wash-solution densities were determined by measuring the masses of $1-\mathrm{mL}$ volume deliveries four times per sample.

More $0.01 \mathrm{M} \mathrm{NaOH}$ was added to the washed solids so that the slurry could be easily mixed with a Teflon-coated stirbar, and the solids were suspended. Aliquots of the suspended-solids slurries were taken for chemical and radiochemical analysis, PSD, BET, SEM, TEM, and XRD analyses. The washed solid slurry sample aliquots taken for chemical analysis were dried to constant mass at $105^{\circ} \mathrm{C}$; the solids chemical analysis was based on the dry sample mass. The supernatant liquid and the filtered solids washing solution were provided directly to the Analytical Services Operation (ASO) for chemical characterization.

\section{A.2 Chemical and Radioisotope Characterization}

The following sections describe the procedures used to support the chemical and radiochemical characterization of the solids and aqueous samples. Aqueous samples were distributed directly to the free hydroxide, ion chromatrography (IC), and total inorganic carbon/total organic carbon (TIC/TOC) analytical workstations. The solids and liquids required a digestion step before distribution to the ICP-OES and radiochemistry workstations.

\section{A.2.1 Free Hydroxide}

The free hydroxide concentration was determined by potentiometric titration with standardized HCl according to procedure RPG-CMC-228, Determination of Hydroxyl $\left(\mathrm{OH}^{-}\right)$and Alkalinity of Aqueous Solutions, Leachates, and Supernates and Operation of Brinkman 636 Auto-Titrator. The free hydroxide was defined as the first inflection point on the titration curve. Quality control (QC) samples were generated at the analytical workstation and included a sample replicate determination, process blank, blank spike (BS), and matrix spike (MS).

(a) Specific wash volumes are provided in the context of the results discussion. 
WTP-RPT-166, Rev. 0

\section{A.2.2 Anions}

Anions were determined by ion chromatography using a Dionix ICS-2500 IC system equipped with a conductivity detector according to procedure RPG-CMC-212, Determination of Common Anions by Ion Chromatography. Additional sample dilutions from $100 \times$ to $25,000 \times$ were required to accurately measure the analytes. QC samples were generated at the analytical workstation and included a sample replicate determination, process blank, BS, and MS.

\section{A.2.3 TIC/TOC}

The TIC was determined by using silver-catalyzed hot persulfate (HP) oxidation according to procedure RPG-CMC-385, Carbon Measured in Solids, Sludge, and Liquid Matrices. The hot persulfate wet oxidation method was used. This method takes advantage of acid decomposition of the carbonate (TIC measure) followed by oxidation of organic carbon (TOC measure) using acidic potassium persulfate at 92 to $95^{\circ} \mathrm{C}$. QC samples were generated at the analytical workstation and included a sample replicate determination, process blank, BS, and MS.

\section{A.2.4 Acid Digestion}

Aqueous samples were digested with acid according to procedure PNL-ALO-128, $\mathrm{HNO}_{3}-\mathrm{HCl}$ Acid Extraction of Liquids for Metals Analysis Using a Dry-Block Heater. The acid-digested solutions were brought to a nominal 25-mL volume (resulting in a nominal $25 \times$ dilution where the initial sample size was 1-mL); absolute volumes were determined based on final solution weights and densities. As part of the analytical preparation batch, the ASO processed a digestion preparation blank (PB), a BS, and an MS. The spike solution contained a broad suite of stable elements; radionuclides were not included in the digestion preparation. Aliquots of the BS, MS, and PB, along with the sample aliquots, were delivered to the ICP-OES workstation for analysis; sample and PB aliquots were delivered to the radiochemical workstations for separations supporting specific radioisotope analysis.

\section{A.2.5 KOH Fusion}

The potassium hydroxide $(\mathrm{KOH})$ fusion was conducted in the shielded analytical facility (hot cells) according to PNL-ALO-115, Solubilization of Metals from Solids using $\mathrm{KOH}-\mathrm{KNO}_{3}$ Fusion. A nominal sample size of 0.1 to $0.2 \mathrm{~g}$ dry solids was combined with a $\mathrm{KOH} / \mathrm{KNO}_{3}$ flux mixture and fused at $550^{\circ} \mathrm{C}$ for 1 hour in a nickel crucible. The fused material was acidified with $\mathrm{HNO}_{3}$, taken to a 100 -mL volume with DI water, and then split for metals and radionuclide analysis. Samples were typically prepared in duplicate along with a fusion blank and a laboratory control sample (LCS) (SRM-2710, Montana Soil, purchased from the National Institute for Science and Technology [NIST]).

\section{A.2.6 $\mathrm{NaOH} / \mathrm{Na}_{2} \mathrm{O}_{2}$ Fusion}

The $\mathrm{NaOH} / \mathrm{Na}_{2} \mathrm{O}_{2}$ fusion was conducted in the shielded analytical facility (hot cells) according to PNLALO-114, Solubilization of Metals from Solids using a $\mathrm{Na}_{2} \mathrm{O}_{2}-\mathrm{NaOH}$ Fusion. A nominal sample size of 0.1 to $0.2 \mathrm{~g}$ dry solids was combined with a $\mathrm{NaOH} / \mathrm{Na}_{2} \mathrm{O}_{2}$ flux mixture and fused at $550^{\circ} \mathrm{C}$ for 1 hour in a zirconium crucible. The fused material was acidified with $\mathrm{HNO}_{3}$, taken to a $100-\mathrm{mL}$ volume with DI water, and then split for metals analysis. The sample was prepared in duplicate along with a fusion blank and an LCS (SRM-2710, Montana Soil). 
WTP-RPT-166, Rev. 0

\section{A.2.7 HF-Assisted Acid Digestion}

The HF-assisted acid digestion was conducted in the Sample Receiving and Preparation Laboratory according to PNL-ALO-138, $\mathrm{HNO}_{3}-\mathrm{HF}-\mathrm{HCl}$ Acid Digestion of Solids for Metals Analyses Using a Dry Block Heater. A nominal sample size of 0.1 to $0.2 \mathrm{~g}$ dry solids was contacted with a mixture of concentrated $\mathrm{HF}$ and $\mathrm{HNO}_{3}$ and evaporated to dryness in a Teflon ${ }^{\circledR}$ reaction tube. Concentrated $\mathrm{HCl}$ was then added, and the sample was evaporated to dryness a second time. Additional concentrated $\mathrm{HNO}_{3}$ and $\mathrm{HCl}$ were added, the reaction tube was capped tightly, and the mixture was heated in a dry-block heater at $95^{\circ} \mathrm{C}$ for $6.5 \mathrm{~h}$. The digestate was cooled, brought to a $50-\mathrm{mL}$ volume, and then split for metals analysis. The sample was prepared in duplicate along with a fusion blank and an LCS (SRM-2710, Montana Soil).

\section{A.2.8 Metals Analysis by ICP-OES}

Metals were measured by ICP-OES according to procedure RPG-CMC-211, Determination of Elemental Composition by Inductively Coupled Argon Plasma Optical Emission Spectrometry (ICPOES). The preparative QC samples (duplicate, PB, BS, MS) were processed along with analytical workstation QC (post digestion spike and serial dilution).

\section{A.2.9 U (KPA)}

Uranium was determined directly from samples prepared by $\mathrm{KOH}$ fusion using a Chem Chek Instruments KPA according to procedure RPG-CMC-4014, Rev. 1, Uranium by Kinetic Phosphorescence Analysis. The LCS did not contain U, so preparative QC was limited to the duplicate and PB. A post-digestion spike was conducted at the analytical workstation.

\section{A.2.10 Gamma Energy Analysis}

Gamma energy analysis was performed with direct or diluted samples that were prepared from acid digestion, fusion, or neat (see Figure 4.1). Sample counting was conducted according to procedure RPG-CMC-450, Gamma Energy Analysis (GEA) and Low-Energy Photon Spectroscopy (LEPS), using high-purity germanium detectors. Extended count times (up to $20 \mathrm{~h}$ ) were employed as needed to achieve low detection limits. In many cases, the Compton background from the high ${ }^{137} \mathrm{Cs}$ activity (661 keV) limited the achievable detection limit of lower-energy gamma emitters (e.g., ${ }^{241} \mathrm{Am}$ at $59 \mathrm{keV}$ ). The QC associated with the GEA analysis was composed of the sample duplicate and PB; because this is a direct analysis, no additional QC samples were required.

\section{A.2.11 Gross Alpha and Gross Beta}

Aqueous samples were prepared for gross alpha and beta determinations by acid-digestion, and the washed-solids samples were prepared by $\mathrm{KOH} / \mathrm{KNO}_{3}$ fusion. Prepared sample aliquots were plated directly onto stainless steel planchets according to procedure RPG-CMC-4001, Source Preparation for Gross Alpha and Gross Beta Analysis. The mounts prepared for gross alpha analysis were counted with Ludlum alpha scintillation counters. The gross alpha analysis tends to be confounded by the dissolved solids in the sample matrix. The solids can absorb the alpha particles, decreasing the intensity relative to the detector, which biases the results low. The sources prepared for gross beta analysis were counted with an LB4100 gas-proportional counter. In both cases, counting operations were conducted according to procedure RPG-CMC-408, Rev.1, Total Alpha and Total Beta Analysis. The preparative QC included the sample duplicates and the preparation blank. The BS and MS were prepared at the analytical workstation on sample dilutions. 


\section{A.2.12 Pu Isotopes: ${ }^{238} \mathrm{Pu}$ and ${ }^{239+240} \mathrm{Pu}$}

The ${ }^{238} \mathrm{Pu}$ and ${ }^{239+240} \mathrm{Pu}$ activities were measured from aqueous samples prepared by acid-digestion and washed solids samples prepared by $\mathrm{KOH} / \mathrm{KNO}_{3}$ fusion. Radiochemical separations were conducted according to procedure RPG-CMC-4017, Analysis of Environmental Water Samples for Actinides and Strontium-90 (analyte purification using ion exchange); source preparation was conducted according to RPG-CMC-496, Coprecipitation Mounting of Actinides for Alpha Spectroscopy (co-precipitation of PuF 3 with $\mathrm{LaF}_{3}$ ); and alpha counting was conducted according to RPG-CMC-422, Rev.1, Solutions Analysis: Alpha Spectrometry. The preparative QC included the sample duplicates and the preparation blank. The BS and MS were prepared at the analytical workstation on sample dilutions.

\section{A.2.13 Strontium-90}

The ${ }^{90} \mathrm{Sr}$ activities were measured from aqueous samples prepared by acid-digestion, and washed-solids samples were prepared by $\mathrm{KOH} / \mathrm{KNO}_{3}$ fusion. Radiochemical separation was conducted according to procedure RPG-CMC-476, Strontium-90 Separation Using Eichrom Strontium Resin; source preparation and beta counting were conducted according RPG-CMC-474, Measurement of Alpha and Beta Activity by Liquid Scintillation Spectrometry.

\section{A.2.14 Chromate}

The $\mathrm{Cr}(\mathrm{VI})$ concentration was determined from the major optical absorbance band of chromate $\left(\mathrm{CrO}_{4}{ }^{2-}\right)$ with a maximum at $372 \mathrm{~nm}$ in selected leachate samples. The determination of chromate concentration in diluted leachates was based on the linear relationship between optical absorbance of the sample at the peak maximum $\left(\mathrm{A}_{372}\right)$ and concentration of $\mathrm{Cr}(\mathrm{VI})$ in the analyzed solution $\left(\mathrm{C}_{\text {chromate }}\right)$ as illustrated below:

$$
\mathrm{A}_{372}=\varepsilon_{372} \cdot \mathrm{C}_{\text {chromate }} \cdot \mathrm{l}
$$

where $\varepsilon_{372}$ is the molar absorptivity of the chromate peak at $372 \mathrm{~nm}$ (expressed in $\mathrm{M}^{-1} \mathrm{~cm}^{-1}$ ), and $\mathrm{l}$ is the optical path length of a spectrophotometric cell (expressed in $\mathrm{cm}$ ) used to contain the analyzed sample.

The linearity of Equation A.1 was verified in a calibration experiment using a series of solutions with a known concentration of chromate in a $0.24-\mathrm{M} \mathrm{NaOH}$ matrix. The calibration curve showed good linearity $\left(\mathrm{R}^{2}=0.9994\right)$ with a slope equal to $5312 \pm 43 \mathrm{M}^{-1}$ in the dynamic range of $0.0069 \mathrm{mM}$ to $0.42 \mathrm{mM}$ of chromate.

The same spectrophotometric cell was used in all subsequent experiments in the determination of sample chromate concentrations. For this reason, it was not necessary to determine the actual optical pathlength of the cell. Therefore, the chromate concentration was calculated simply as the ratio of $A_{372}$ and the slope of the calibration curve

$$
\mathrm{C}_{\text {chromate }}=\mathrm{A}_{372} / \text { slope }
$$

Most of the samples submitted for chromate analysis were too concentrated in chromate to be measured directly. In these cases, the samples were diluted with $0.24 \mathrm{M} \mathrm{NaOH}$ to lower the chromate concentration to less than $0.2 \mathrm{mM}$ so as to have optical readings within the linearity range of the calibration plot. Applying $0.24 \mathrm{M} \mathrm{NaOH}$ instead of water verified that the $\mathrm{Cr}(\mathrm{VI})$ in the diluted solutions was present exclusively as the chromate species.

The UV-visible measurements were made on a 400 Series charge-coupled device array spectrophotometer (Spectral Instruments Inc, Tucson, AZ) with a 200- to 950-nm scanning range. The solutions were held in PLASTIBRAND $^{\circledR} 1$-cm cuvettes. The $0.24 \mathrm{M} \mathrm{NaOH}$ solution (diluent) was used to obtain the baseline 
WTP-RPT-166, Rev. 0

reading before measuring the chromate-containing samples. Because NIST-traceable standards were not used, the calculated chromate concentrations are reported for information only. 
Appendix B

Physical Properties Determination and Rheology Methods 
WTP-RPT-166, Rev. 0

\section{Appendix B}

\section{Physical Properties Determination and Rheology Methods}

This appendix describes the experimental methods used to determine rheological properties and physical properties, including particle size distribution and surface area measurements.

\section{B.1 Physical Properties}

The physical-property characterization was conducted according to procedure RPL-COLLOID-02, Rev. 1, Measurement of Physical and Rheological Properties of Solutions, Slurries and Sludges, which is consistent with the WTP guidelines document. ${ }^{\text {(a) }}$ Samples for physical-properties characterization were taken in triplicate near the beginning (S1), middle (S2), and end (S3) of the aliquoting activity following slurry homogenization. Samples sizes were generally between 10 and $15 \mathrm{~mL}$. The samples were collected in volume-graduated, glass centrifuge tubes.

Settling studies were conducted by thoroughly agitating the samples and then allowing the solids to settle by gravity with periodic measurement of the settled-solids volume. The sample tubes were undisturbed over the 3-day settling period. Following the settling measurements, the samples were centrifuged at $\sim 1000 \mathrm{G}$ for 1 hour. The total sample volume and solids volume were recorded to assess the vol\% wet centrifuged solids (WCS). The centrifuged supernatants were decanted and transferred to tared graduated cylinders; the net solution masses and volumes were determined. The remaining wet centrifuged solids were weighed in the centrifuge tubes to assess gross densities. The supernatant samples were transferred to tared glass vials. Both the supernatant fractions and the residual solids fractions (containing interstitial supernatant) were air-dried and then transferred to a $105^{\circ} \mathrm{C}$ oven for continued drying until constant mass was attained. The data collected were processed as described by Smith and Prindiville ${ }^{(a)}$ to determine the volume and weight percent of wet solids (total, settled, and centrifuged), densities, total undissolved solids, and dissolved solids content.

\section{B.2 Rheology}

Rheological testing was conducted on the solids in contact with the supernatant generated as part of the homogenization process. Testing was conducted according to RPL-COLLOID-02, Measurement of Physical and Rheological Properties of Solutions, Slurries and Sludges. For the current study, two regions of tank waste flow behavior are considered: 1 ) incipient motion in settled tank waste solids (shear strength) and 2) non-elastic flow of tank waste slurries and supernates (flow curve).

\section{B.2.1 Shear-Strength Testing}

For tank waste slurries, a finite stress must be applied before the material will begin to flow. The stress required to transition the material from elastic deformation to viscous flow is referred to as the shear

(') 24590-WTP-GPG-RTD-001, Rev 0, "Guidelines for Performing Chemical, Physical, and Rheological Properties Measurements,” G. L. Smith and K. Prindiville, May 2002. 
strength, and its origin can be attributed to static and kinetic friction between individual particles and/or aggregates, the strength of the matrix supporting the coarse fraction (i.e., the interstitial fluid), and sludge cohesion arising from interparticle adhesive forces such as van der Waals forces.

The shear strength was measured using the vane method. For the vane technique, the stress required to begin motion is determined by slowly rotating a vane immersed in the test sample's settled solids while continuously monitoring the resisting torque as a function of time. A material's static shear strength is then associated with the maximum torque measured during the transition from initial to steady-state vane rotation.

The maximum torque required for incipient motion is dependent on vane geometry. To account for vane geometry affects, shear strength is expressed in terms of the uniform and isotropic stress acting over the surface area of the cylinder of rotation swept out by the vane. The shear strength is related to the maximal torque during incipient motion according to Equation B.1 (Barnes and Dzuy 2001):

$$
\tau_{S S}=\frac{M_{\max }}{4 \pi R^{3}\left(\frac{H}{2 R}+\frac{1}{3}\right)}
$$

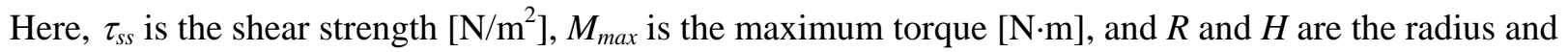
height of the cylinder of rotation swept out by the vane $[\mathrm{m}]$. Because the shear band observed upon slow rotation of the vane does not extend appreciably beyond the vane paddles, $R$ and $H$ are taken to be the dimensions of the vane itself.

\section{B.2.2 Flow Curve Testing}

Non-elastic flow of tank waste slurries and supernates is characterized with rotational viscometry. The typical result of such testing is a set of flow curve data, which shows the stress response of a material to a range of applied rates-of-deformation. Specifically, flow-curve testing allows characterization of a material's shear stress, $\tau$, and response as a function of applied shear rate, $\dot{\gamma}$. Once measured, flow curve data can be interpreted with several constitutive equations for the viscous stress/rate-of-strain relationship. Such analysis allows the flow behavior over a broad range of conditions to be described with just a few rheological descriptors such as viscosity, yield stress, consistency, and flow index.

A concentric cylinder rotational viscometer operated in controlled-rate mode was used for flow-curve testing of tank waste slurries and supernates. Rotational viscometers operate by placing a given volume of test sample into a measurement cup of known geometry. A cylindrical rotor attached to a torque sensor is then lowered into the sample until the slurry is even with, but does not cover, the top of the rotor. A single-point determination of a fluid's flow properties is made by spinning a rotor at a known rotational speed, $\Omega$, and measuring the resisting torque, $M$, acting on the rotor. The torque acting on the rotor can be directly related to the shear stress $(\tau)$ at the rotor using the equation,

$$
\tau=\frac{M}{2 \pi H R_{I}^{2}}
$$


where $R_{I}$ and $H$ are the radius and height of the rotor, respectively (see Figure B.1). Shear stress has units of force per area $\left(\mathrm{N} / \mathrm{m}^{2}\right)$. The rotational rate is related to the shear rate. However, calculating the fluid shear rate at the rotor is complicated by the fact that the shear rate depends on both the measurement system geometry and the fluid rheological properties. For the simplest fluids (i.e., Newtonian fluids), the shear rate $(\dot{\gamma})$ of the fluid at the rotor can be calculated given the geometry of the cup rotor shear by using the equation,

$$
\dot{\gamma}=\left(\frac{2 R_{O}^{2}}{R_{O}^{2}-R_{I}^{2}}\right) \Omega
$$

Here, $R_{I}$ is the inner radius of the cup, such that the gap width between cup and rotor is $\left(R_{O}\right.$ to $\left.R_{I}\right)$. The shear rate has units of inverse seconds $\left[\mathrm{s}^{-1}\right]$. Calculating shear rate for materials showing more complex shear-stress versus shear-rate behavior (i.e., non-Newtonian fluids) requires estimates of yield stress and degree of shear-thinning or shear-thickening. As the goal of rheological testing is to determine and quantify such behavior, these values are typically not known. This requirement can be circumvented by using a cup and rotor system with a small gap $(\sim 1 \mathrm{~mm})$ for fluid shear. For fluid flow in small gap cup and rotor systems, shear-rate effects introduced by fluid properties are minimized such that Equation B.3 provides an accurate determination of shear rate for non-Newtonian materials. Shear rates examined in this study spanned the range from 1 to $1000 \mathrm{~s}^{-1}$.

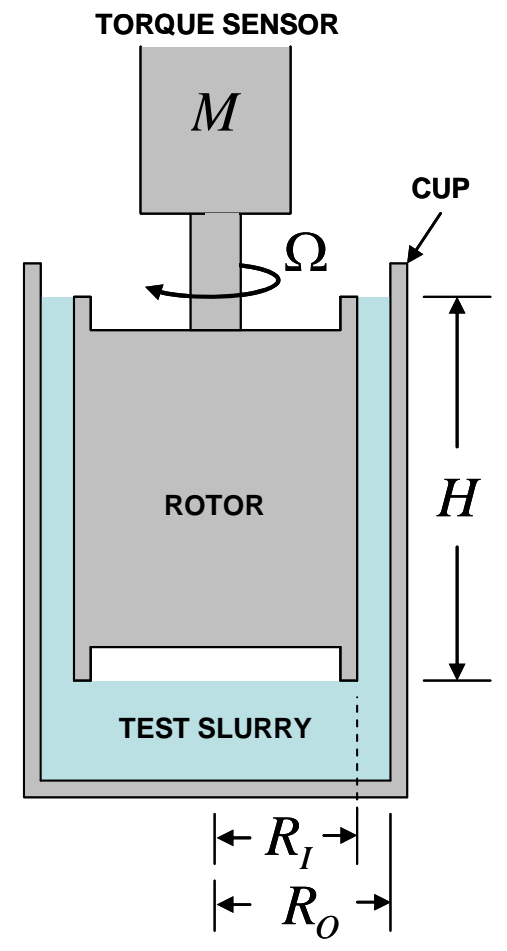

Figure B.1. Rotor and Cup Geometry Used in Rotational Viscometry Testing

The resistance of a fluid to flow is often described in terms of the fluid's apparent viscosity, $\eta_{a p p}$, which is defined as the ratio of the shear stress to shear rate: 


$$
\eta_{a p p}=\frac{\tau}{\dot{\gamma}}
$$

For Newtonian fluids, the apparent viscosity is independent of shear rate. For non-Newtonian fluids, the apparent viscosity will vary as a function of shear rate. The units of apparent viscosity are Pa·s, although it is typically reported in units of centipoise (cP; where $1 \mathrm{cP}=1 \mathrm{mPa} \cdot \mathrm{s})$.

Flow-curve data are usually combined plots of $\tau$ and $\eta_{\text {app }}$ as a function of $\dot{\gamma}$. As stated above, flow-curve data can be interpreted with several constitutive equations (i.e., flow curves), allowing the data to be characterized with just a few rheological descriptors. The behavior of tank waste sludges, slurries, and supernates can be described by four common flow-curve equations:

- Newtonian-Newtonian fluids flow as a result of any applied stress and show constant viscosity over all shear conditions. The flow curve for Newtonian fluids is,

$$
\tau=\eta \dot{\gamma}
$$

where $\eta$ is the Newtonian viscosity.

- Ostwald (Power Law) - Power-law fluids flow as a result of any applied stress and have viscosities that either increase or decrease with increasing shear rate. They are described by,

$$
\tau=m \dot{\gamma}^{n}
$$

where $m$ is the power-law consistency index, and $n$ is the power-law index. Power-law fluids with $n<1$ are referred to as psuedoplastic (shear-thinning), whereas power-law fluids with $n>1$ are referred to as dilatant (shear-thickening).

- Bingham Plastic - Bingham plastics are fluids that show finite yield points. A finite stress (i.e., the yield stress), must be exceeded before these types of materials flow. Once flow is initiated, the stress response of the material is Newtonian over the rest of the shear-rate range. Bingham plastics are described by,

$$
\tau=\tau_{O}^{B}+k_{B} \dot{\gamma}
$$

where $\tau_{O}^{B}$ is the Bingham yield index, and $k_{B}$ is the Bingham consistency index.

- Herschel-Bulkley - Fluids that behave in accordance with a Herschel-Bulkley model show a finite yield followed by power-law behavior over the rest of the shear-rate range. They are described by,

$$
\tau=\tau_{O}^{H}+k_{H} \dot{\gamma}^{b}
$$


where $\tau_{O}^{H}$ is the Herschel-Bulkley yield index, $k_{H}$ is the Herschel-Bulkley consistency index, and b is the Herschel-Bulkley power-law index.

Power-law fluids, Bingham plastics, and Herschel-Bulkley fluids are examples of non-Newtonian fluids. In general, liquids without internal and/or interconnected structures (such as tank waste supernates) are Newtonian. Sludges and slurries are typically non-Newtonian, but their exact behavior depends on the concentration of solids and suspending phase chemistry. Sufficiently dilute slurries may show Newtonian behavior.

\section{B.2.3 Rheology Instrumentation}

Rheological characterization was accomplished using a Rotovisco ${ }^{\circledR}$ RV20 Measuring System M equipped with an M5 measuring head sold by HAAKE Mess-Technik GmbH u. Co. (now the Thermo Electron Corporation, Madison, WI). The M5 measuring head is a "Searle" type viscometer capable of producing rotational speeds up to 500 revolutions per minute (RPM) and measuring torques up to $0.049 \mathrm{~N} \cdot \mathrm{m}$. The minimum rotational speed and torque resolution achievable by this measuring head are $0.05 \mathrm{RPM}$ and $0.49 \mathrm{mN} \cdot \mathrm{m}$, respectively.

Specific measurement tools, such as cup and rotor assemblies and shear vanes, are attached to measure selected rheological properties. Shear-strength measurements employed an 8-mm $\times 16-\mathrm{mm}$ (radius $\times$ height) shear vane tool. Flow-curve measurements employed an MV1 stainless steel measuring cup and rotor. The dimensions of the MV1 and vane measuring systems are listed in Table B.1.

Table B.1. Vane and Cup and Rotor Measuring System Dimensions

\begin{tabular}{||l|c|c|c|c||}
\hline Measuring System & $\begin{array}{c}\text { Vane/Rotor Radius, } \\
\mathbf{m m}\end{array}$ & $\begin{array}{c}\text { Vane/Rotor Height, } \\
\mathbf{m m}\end{array}$ & $\begin{array}{c}\text { Cup Radius, } \\
\mathbf{m m}\end{array}$ & $\begin{array}{c}\text { Gap Width, } \\
\mathbf{m m}\end{array}$ \\
\hline Vane Tool & 8 & 16 & $>16$ & $>8$ \\
\hline MV1 & 20.04 & 60 & 21 & 0.96 \\
\hline \hline
\end{tabular}

The temperature was controlled with a combination of the standard measuring system M temperature jacket and a Cole-Parmer ${ }^{\circledR}$ Polystat ${ }^{\circledR}$ Temperature-Controlled Recirculator, Model Number C-12920-00. The temperature jacket provided a heat-transfer area between the cup and the recirculating fluid. The jacket temperature was monitored using a Type-K thermocouple (Omega Model TJ36-CASS-116-G-6CC). Temperature control was employed only for flow-curve measurements. The shear strengths ( $\left.\tau_{s s}\right)$ were measured at ambient temperature $\left(\sim 30^{\circ} \mathrm{C}\right.$ in the hot cells).

The rheometer was controlled and data were acquired with a remote computer connection using the RheoWin Pro Job Manager Software, Version 2.96 (Thermo Electron Corporation, Copyright ${ }^{\circledR}$ 1997). During measurement, the software automatically collects and converts rotor torque readings into shear stresses based on Equation B.1 (for vane testing) or Equation B.2 (for flow-curve testing). Likewise, the software also automatically converts the rotational rate readings into shear rates based on Equation B.3.

\section{Rheology Materials and Methods}

No sample treatment was performed before analysis with the exception of the mechanical agitation required to mix and sub-sample selected waste jars. 


\section{B.2.4 Shear-Strength Testing}

Before testing, the tank waste slurry samples were mixed thoroughly and subsequently allowed to settle for 48 to $72 \mathrm{~h}$. When possible, the shear strength was measured by immersing the $8-\times 16$-mm vane tool to a depth of $15 \mathrm{~mm}$ into the settled solids. The vane was slowly rotated at $0.3 \mathrm{RPM}$ for $180 \mathrm{~s}$. For the entire duration of rotation, the time, rotational rate, and vane torque were continuously monitored and recorded. At the end of the measurement, shear stress-versus-time data were parsed, and the maximum measured shear stress (i.e., the material's shear strength) was determined.

\section{B.2.4.1 Flow Curve Testing}

Each flow curve was measured over a 15-min period and split into three 5-min intervals. Over the first $5 \mathrm{~min}$, the shear rate was smoothly increased from zero to $1000 \mathrm{~s}^{-1}$. For the second $5 \mathrm{~min}$, the shear rate was held constant at $1000 \mathrm{~s}^{-1}$. For the final $5 \mathrm{~min}$, the shear rate was smoothly reduced back to zero. During this time, the resisting torque and rotational rate were continuously monitored and recorded.

Before each test, the sample was left undisturbed in the measuring system for 5 min to allow temperature equilibration. The sample was then mixed for 3 min using the measuring system rotor to re-disperse any settled solids and to pre-shear slurries before measurement.

Flow-curve tests were run at 25,40 , and $60^{\circ} \mathrm{C}$. Because of limited sample volume, all three temperature tests were performed on the same sample. To combat the effects of sample evaporation, a moisture barrier was installed over the opening at the top of the temperature jacket during testing, and after each test, the cup was raised so that fresh sludge/slurry filled the measurement gap.

\section{B.3 Particle-Size Attributes}

Determination of particle physical attributes, including size distribution and surface area, are discussed in the following sections.

\section{B.3.1 Particle-Size Distribution}

Particle size distributions were characterized according to procedure RPL-COLLOID-01, Rev. 1, Particle Size Analysis Using Malvern MS2000. This procedure uses a Mastersizer 2000 (Malvern Instruments, Inc., Southborough, MA 01772 USA) with a Hydro $\mu$ P wet dispersion accessory. Malvern lists the Mastersizer particle-size measurement range as nominally 0.02 to $2000 \mu \mathrm{m}$. The actual PSD measurement range is dependent on the accessory used as well as the properties of the solids being analyzed. When coupled with the Hydro $\mu \mathrm{P}$ wet dispersion accessory, the nominal listed measuring range is reduced to 0.02 to $150 \mu \mathrm{m}$. The Malvern 2000 uses laser diffraction technology to define PSD.

The Hydro $\mu \mathrm{P}$ wet-dispersion accessory consisted of a 20-mL sample flow cell with a continuous variable and independent pump and ultrasound. Both flow and sonication can be controlled and altered during measurement. PSD measurements were made before, during, and after sonication, allowing determination of the influence of each on the sample PSD. The primary measurement functions of the Malvern analyzer were controlled through Mastersizer 2000 software, Version 5.1 (Malvern Instruments, Ltd. Copyright ${ }^{\circledR}$ 1998-2002). 
The optical properties applied to the test samples are summarized in Table B.2. For initial characterization and parametric testing samples, bismuth oxide $\left(\mathrm{Bi}_{2} \mathrm{O}_{3}\right)$ optical properties were assumed. With regard to CUF testing samples, the optical properties for boehmite were employed for both pre- and post-caustic leach samples. After oxidative-leaching, the optical properties of $\mathrm{Bi}_{2} \mathrm{O}_{3}$ were used. It should be noted that using boehmite and $\mathrm{Bi}_{2} \mathrm{O}_{3}$ properties (as well as a single species refractive index) to represent the optical properties of the mixture of solid species and mineral phases in the tank waste is not exact. However, given the species diversity in the sample and tendency for tank waste particles to aggregate, the measurement analysis still provides an adequate representation of the apparent particle size of the wastes. Correction of assumed refractive indexes to a more accurate value typically does not significantly alter the particle size distribution determined by the original analysis.

The solids were dispersed in $0.01 \mathrm{M} \mathrm{NaOH}$ for the PSD measurements. The sample dispersion was added drop-wise to the instrument (while the pump was active) until an $\sim 10 \%$ obscuration was reached. For all samples, less than $10 \mathrm{mg}$ of solids was required to reach the desired obscuration in the $20-\mathrm{mL}$ flow cell.

Table B.2. Optical Properties Applied To Test Materials

\begin{tabular}{|c|c|c|c|}
\hline Test & $\begin{array}{l}\text { Material Selected for } \\
\text { Optical Properties }^{\text {(a) }}\end{array}$ & $\begin{array}{c}\text { Refractive Index } \\
\text { (RI) }\end{array}$ & Absorption \\
\hline \multicolumn{4}{|l|}{ Initial Characterization } \\
\hline Group 1 & Bismuth Oxide & 1.91 & 1.0 \\
\hline Group 2 & Bismuth Oxide & 1.91 & 1.0 \\
\hline \multicolumn{4}{|l|}{ Parametric Testing } \\
\hline Group 1 & Bismuth Oxide & 1.91 & 1.0 \\
\hline Group 2 & Bismuth Oxide & 1.91 & 1.0 \\
\hline Group 1/2 Mixture & Bismuth Oxide & 1.91 & 1.0 \\
\hline \multicolumn{4}{|l|}{ CUF Testing } \\
\hline All Samples & Bismuth Oxide & 1.91 & 1.0 \\
\hline Pre-Leach Low-Solids & Boehmite & 1.66 & 1.0 \\
\hline Pre-Leach High-Solids & Boehmite & 1.66 & 1.0 \\
\hline Caustic-Leached & Boehmite & 1.66 & 1.0 \\
\hline Caustic-Leached / Washed & Boehmite & 1.66 & 1.0 \\
\hline Oxidative-Leached & Bismuth Oxide & 1.91 & 1.0 \\
\hline Oxidative-Leached / Washed & Bismuth Oxide & 1.91 & 1.0 \\
\hline All/Suspending Phase & Water $^{(\mathrm{a})}$ & 1.33 & $\mathrm{n} / \mathrm{a}$ \\
\hline
\end{tabular}

The size distributions of particles were measured under varying flow conditions before, during, and after sonication. The test matrix employed for analysis is shown in Table B.3. For each condition, three successive 20-second measurements of PSD were taken. An average of these measurements was then generated by the analyzer software. Both individual measurement and average were saved to the analyzer data file. Once measurements were complete, the sonic power for the next condition was set, the sample was given 30 to 60 seconds to equilibrate, and the next set of measurements was taken. 
WTP-RPT-166, Rev. 0

Table B.3. Prototypic Particle-Size Analysis Test Matrix

\begin{tabular}{|c|c|c|c|}
\hline Condition No. & Pump Speed (RPM) & Sonic Power & Comment \\
\hline 1 & 3000 & $0 \%$ & pre-sonic measurement \\
\hline 2 & 2000 & $0 \%$ & pre-sonic measurement \\
\hline 3 & 4000 & $0 \%$ & pre-sonic measurement \\
\hline 4 & 3000 & $25 \%$ & sonicated measurement \\
\hline 5 & 3000 & $50 \%$ & sonicated measurement \\
\hline 6 & 3000 & $75 \%$ & sonicated measurement \\
\hline 7 & 3000 & $0 \%$ & post-sonic measurement \\
\hline 8 & 2000 & $0 \%$ & post-sonic measurement \\
\hline 9 & 4000 & $0 \%$ & post-sonic measurement \\
\hline
\end{tabular}

\section{B.3.2 Surface Area (BET)}

Samples were prepared for surface-area measurements in an effort to minimize solidification into a monolith upon drying. To this end, the solids were rinsed twice with ethanol and twice again with diethyl ether according to procedure TPR-RPP-WTP-486, Procedure for BET Sample Preparation Using Ethanol and Ethyl Ether as Drying Agents. Each rinse was conducted in a centrifuge tube. The solids were well suspended in the rinse solution, and then the phases were separated by centrifuging and decanting. The final ethyl ether rinse was used to transfer the solids slurry to the sample cell. The diethyl ether was then evaporated at room temperature directly from the sample cell.

The sample was further dried and out-gassed using the Quantachrome Instruments Monosorb Model MS-21 (Boynton Beach, FL) outgassing station. This entailed pre-flushing nitrogen through the sample cell for $\sim 10 \mathrm{~min}$ and then heating and flushing for overnight $(>10 \mathrm{~h})$ at $110^{\circ} \mathrm{C}$.

The surface-area measurements were conducted according to OCRWM-BET-01, Surface Area Measurement with a Monosorb Gas Analyzer, which is consistent with ASTM method D5604-96, Test Method B (Single-Point Surface Area by Flowing Gas Apparatus). The flow gas used in the measurement mode was composed of $30 \%$ nitrogen in helium. The system was calibrated per manufacturer instructions. The system performance was assessed using a $29.9 \pm 0.75 \mathrm{~m}^{2} / \mathrm{g}$ carbon surface area standard Lot D-6 obtained from Micromeritics (Norcross, GA). 
WTP-RPT-166, Rev. 0

\section{Appendix C}

\section{Crystal Form and Habit}


WTP-RPT-166, Rev. 0

\section{Appendix C}

\section{Crystal Form and Habit}

This section describes the methods used to determine the crystal forms and habits of the tank solids samples. The solids crystal characteristics were determined on small aliquots of the solids. In all cases, the solids sample fractions were allowed to air dry at room temperature in preparation for analysis. This effort was intended to minimize morphological changes that might occur upon heating. The methods applied for XRD, SEM, and TEM evaluations are discussed in the following sections.

\section{C.1 X-Ray Diffraction}

The sample mounts for XRD examination were prepared from the dried solids according to procedure RPL-PIP-4, Preparing Sealed Radioactive Samples for XRD and Other Purposes. Specimens were pulverized to a powder with a boron carbide mortar and pestle, mixed with an internal standard (rutile, $\mathrm{TiO}_{2}$, or alumina, $\mathrm{Al}_{2} \mathrm{O}_{3}$ ), and mounted on a glass slide. In some cases, the internal standard was omitted to provide better clarity of the sample diffraction pattern free from potential interference from the internal standard diffraction pattern. The XRD examination was conducted according to procedure PNNL-RPG268, Solids Analysis, $X$-Ray Diffraction Using RGD \#34. Process parameters included examining the $\mathrm{X}$-ray 2-theta range from 5 to 65 degrees with a step size of 0.02 degrees and a dwell time of 20 seconds.

Phase identification was performed with JADE, Version 8.0 (Materials Data Inc., Livermore, CA) software search and peak match routines with comparison to the International Centre for Diffraction Data (ICDD) database PDF-2, Version 2.0602 (2006). The ICDD database included the Inorganic Crystal Structure Database (ICSD) maintained by Fachinformationszentrum, Karlsuhe, Germany. Phase identification incorporated chemistry restrictions based on the elements determined from chemical analysis.

\section{C.2 Scanning Electron Microscopy}

A small sample was transferred with a wooden Q-tip stem onto carbon tape supported by an aluminum pedestal mount. The sample was analyzed using the radiation-shielded Amray Model 1610T SEM according to RPL-611A-SEM, Scanning Electron Microscope Examinations. In selected cases, the mount was carbon-coated. Selected sample areas were evaluated by energy dispersive X-ray spectroscopy (EDS) for qualitative elemental composition.

\section{C.3 Transmission Electron Microscopy}

The TEM samples were prepared in a two-step methanol rinsing process. A small amount of the sludge slurry was mixed and transferred into methanol; a drop of the methanol slurry was transferred into a second vial containing methanol; then a drop of this second solution was deposited onto a lacey carbon TEM grid. The particles were air-dried on the lacey grid. Note that the sample drying process may induce changes in the morphology of the particle agglomerates. However, the objective of the TEM 
investigation was to look at the fundamental characteristics and sizes of individual particle crystallites that are not dependent on drying effects.

The TEM examinations were performed on an FEI Tecnai G2-30 (FEI Inc., Hillsboro, OR) with a field emission filament operating at $300 \mathrm{keV}$ equipped with a Scanning Transmission Unit and High Angle Annular Dark-Field Detector (HAADF), energy dispersive X-ray detector, and a Gatan Imaging Filter (GIF), model GIF2000 (Gatan Inc., Pleasanton, CA). Particle or area analysis was performed by identifying the composition with EDS and electron energy-loss spectroscopy (EELS). Images were obtained with either the scanning transmission electron microscopy (STEM) system or normal brightfield imaging. Energy-filtered images were also obtained with the image filter to produce elementspecific area maps.

\section{C.4 Electron Energy-Loss Spectroscopy}

The EELS spectra were obtained using a 0.6-mm entrance aperture and an energy dispersion of $0.1 \mathrm{eV} /$ channel. Low-loss spectra (including the zero loss peak) were acquired with an integration time of $<0.2 \mathrm{~s}$ and core-loss spectra between 2 and $5 \mathrm{~s}$. To reduce potential beam reduction, the acquisition time was kept as small as possible. The spectra were collected in the imaging mode of the transmission electron microscope and were corrected for dark current and channel-to-channel gain variation of the charge coupled device (CCD) detector.

The core-loss regime was energy calibrated, and the energy drift was measured while data were being acquired by collecting zero-loss spectra before or after core-loss spectra were collected. The position of the $\mathrm{C}-\mathrm{K}(1 s)$ peak at $284 \mathrm{eV}$ (arising from transitions to the $\pi^{*}$ molecular orbital) from the TEM lacy carbon support film was used to evaluate the energy calibration and as a means of roughly checking that the energy resolution was sufficient for collecting data.

Two methods were adopted for determining the chemical state of chromium in the sludge samples. In the first method, we obtained the following ratio defined as:

$$
\mathrm{I}-\text { ratio }=\frac{\mathrm{I}\left(\mathrm{L}_{3}\right)}{\mathrm{I}\left(\mathrm{L}_{2}\right)}
$$

$\mathrm{L}_{2}$ and $\mathrm{L}_{3}$ are the intensities of background-corrected Cr-absorption edges. The second method was to look at the O:Cr ratio as an indication of oxygen content. Oxygen detection with EELS is more accurate that with $\mathrm{x}$-rays because the loss in energy of the primary beam is measured instead of an emitted x-ray, as in the case of EDS analyses, which can be subjected to significant attenuation. 
WTP-RPT-166, Rev. 0

Appendix D

\section{Quality Assurance and Quality Control}


WTP-RPT-166, Rev. 0

\section{Appendix D}

\section{Quality Assurance and Quality Control}

This appendix describes the quality assurance (QA) program and QC measures applied to the conduct of work.

\section{D.1 Application of WTPSP Quality Assurance Requirements}

PNNL's QA program is based on requirements defined in DOE Order 414.1C, Quality Assurance, and 10 CFR 830, Energy/Nuclear Safety Management, Subpart A-Quality Assurance Requirements (a.k.a., the Quality Rule). PNNL has chosen to implement the requirements of DOE Order 414.1C and 10 CFR 830, Subpart A by integrating them into the laboratory's management systems and daily operating processes. The procedures necessary to implement the requirements are documented through PNNL’s Standards-Based Management System.

PNNL implemented the RPP-WTP quality requirements by performing work in accordance with the River Protection Project - Waste Treatment Plant Support Program (RPP-WTP) Quality Assurance Plan (RPPWTP-QA-001, QAP). Work was performed to the quality requirements of NQA-1-1989 Part I, Basic and Supplementary Requirements, NQA-2a-1990, Part 2.7, and DOE/RW-0333P, Rev 13, Quality Assurance Requirements and Descriptions (QARD). These quality requirements are implemented through the River Protection Project - Waste Treatment Plant Support Program (RPP-WTP) Quality Assurance Manual (RPP-WTP-QA-003, QAM).

A matrix that cross-references the NQA-1, NQA-2a, and quality assurance requirements and descriptions (QARD) requirements with PNNL's procedures for this work was given in the test plan, TP-RPP-WTP467. ${ }^{\text {(a) }}$ It included justification for those requirements not implemented. The QA requirements of DOE/RW-0333P, Rev 13, QARD and DOE Order 414.1C were not identified as a requirement for this work in the test specification.

\section{D.2 Conduct of Experimental and Analytical Work}

Experiments that were not method-specific were performed in accordance with PNNL's procedures QA-RPP-WTP-1101 "Scientific Investigations" and QA-RPP-WTP-1201 "Calibration and Control of Measuring and Testing Equipment,” verifying that sufficient data were taken with properly calibrated measuring and test equipment (M\&TE) to obtain quality results.

As specified in the supporting Test Specification, 24590-PTF-TSP-RT-06-0001, Rev. 0, BNI's Quality Assurance Project Plan (QAPjP), PL-24590-QA00001, was not applicable because the work was not performed in support of environmental/regulatory testing, and the data will not be used as such.

(a) SK Fiskum, TP-RPP-WTP-467, Rev. 0, 2/2/07 and Rev. 1 7/31/07, Characterization and Small Scale Testing of Hanford Wastes to Support the Development and Demonstration of Leaching and Ultrafiltration Pretreatment Processes, Pacific Northwest National Laboratory, Richland, WA. 
Balances are calibrated annually by a certified contractor, QC Services, Portland, Oregon. A balance performance check was conducted each day the balance was used.

ASO conducted analytical testing according to the Statement of Work RPP-WTP-QA-005, Rev. 2, Analytical Support by the PNNL RPL Analytical Support Operation. The analytical results and raw data are traceable through the project files according to the Analytical Services Request (ASR) number and RPL number.

\section{D.3 Internal Data Verification and Validation}

PNNL addressed internal verification and validation activities by conducting an independent technical review of the final data report in accordance with PNNL's procedure QA-RPP-WTP-604. This review verified that the reported results were traceable, that inferences and conclusions were soundly based, and the reported work satisfied the Test Plan objectives. This review procedure is part of PNNL's RPP-WTP Quality Assurance Manual. 


\section{Appendix E}

\section{Duplicate Sample Differential Particle Size Plots for the Initial Group 1 Sample}




\section{Appendix E}

\section{Duplicate Sample Differential Particle Size Plots for the Initial Group 1 Sample}

Figures E.1, E.2, and E.3 show the differential volume distribution as a function of particle diameter for the duplicate Group 1 initial characterization sample, TI483-G1-S-WL-PSD-2. Specifically, Figure E.1 shows the pre-sonication PSDs as a function of pump speed, Figure E.2 shows the PSDs as a function of sonication, and Figure E.3 shows the post-sonication PSDs as a function of pump speed.

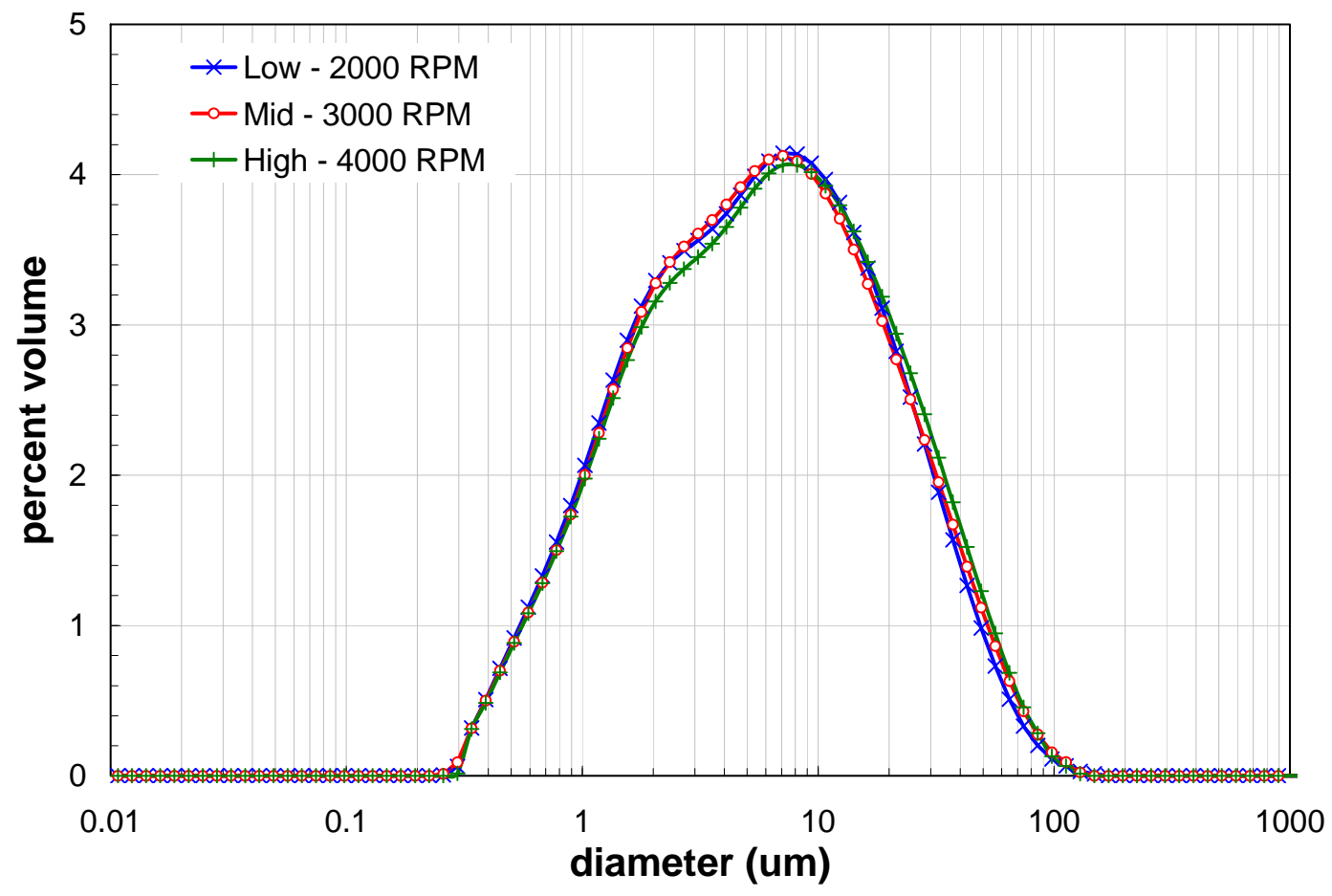

Figure E.1. Pre-Sonication Volume Distribution Result for the Duplicate Group 1 Initial Characterization Sample as a Function of Pump Speed 


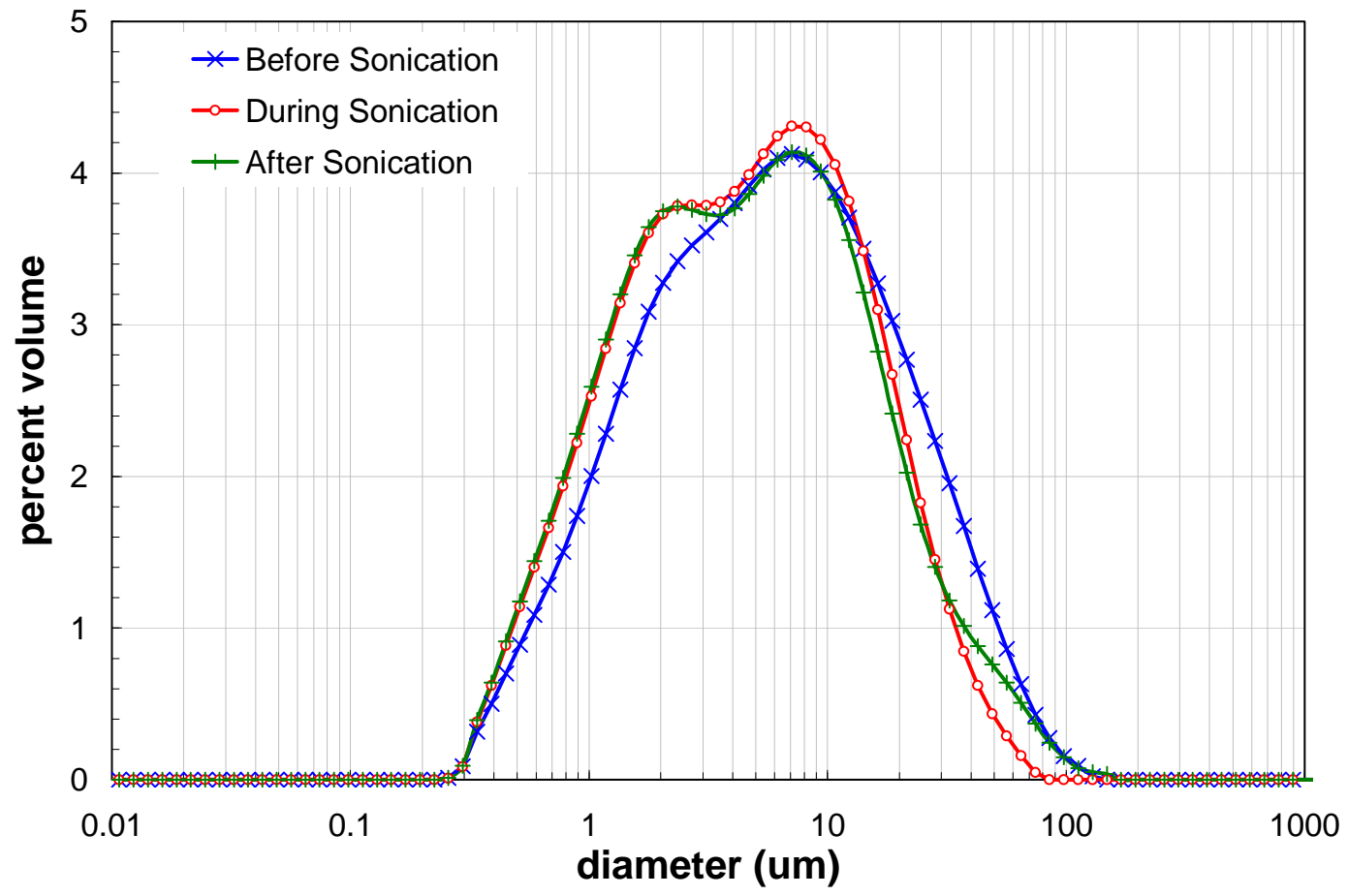

Figure E.2. Volume Distribution Result for the Duplicate Group 1 Initial Characterization Sample as a Function of Sonication (75\% power)

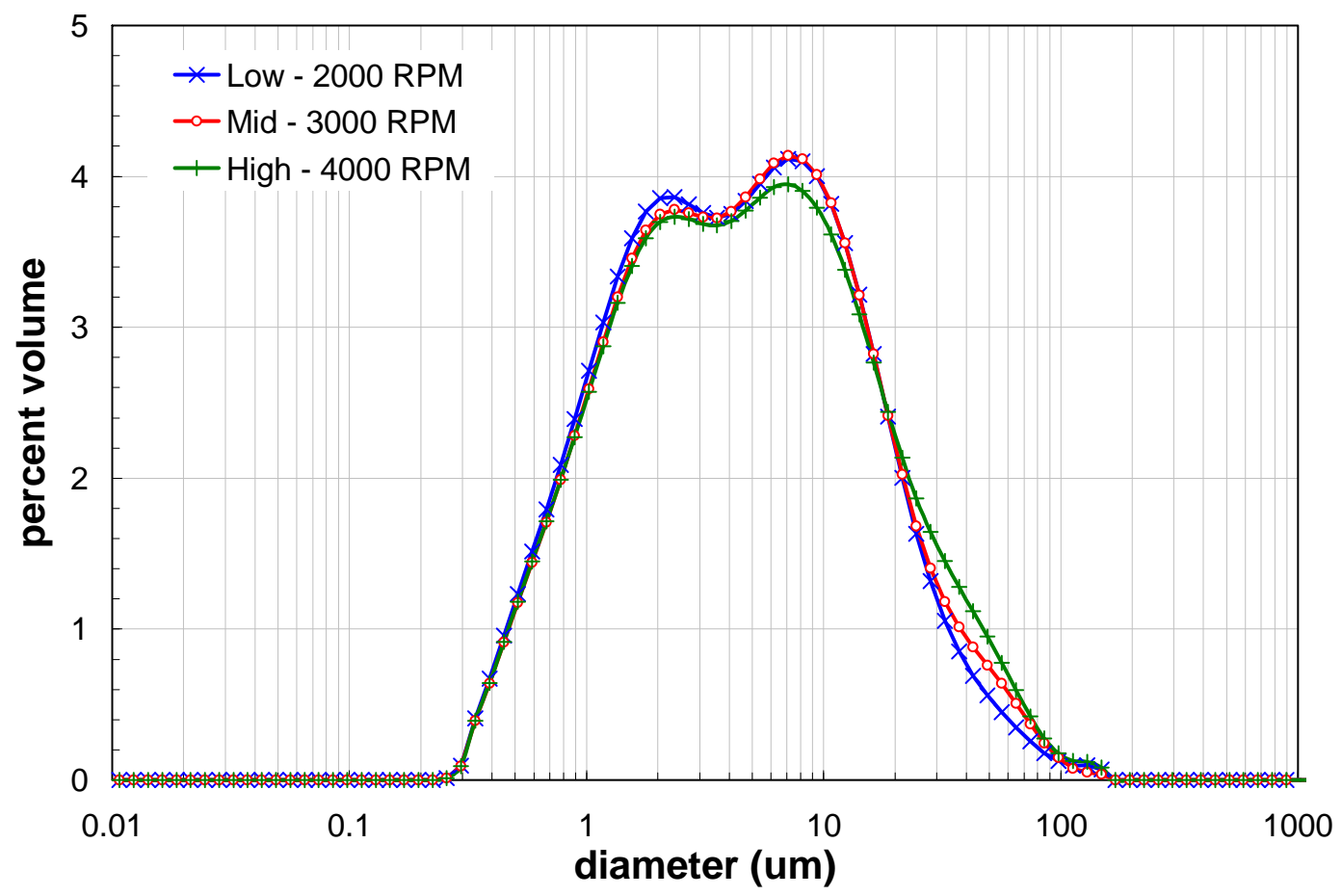

Figure E.3. Post-Sonication Volume Distribution Result for the Duplicate Group 1 Initial Characterization Sample as a Function of Pump Speed 


\section{Appendix F}

\section{Detailed Cumulative PSD for the Initial Group 1 Sample}


WTP-RPT-166, Rev. 0

\section{Appendix F}

\section{Detailed Cumulative PSD for the Initial Group 1 Sample}

Tables F.1 and F.2 present detailed cumulative oversize distributions (by volume/weight) for Group 1 Initial Characterization samples TI483-G1-S-WL-PSD-1 and -2, respectively. The results are reported as a function of test condition. This appendix does not provide a discussion of the detailed distributions; however, a portion of these results (specifically, the $10^{\text {th }}, 50^{\text {th }}$, and $90^{\text {th }}$ diameter percentiles) are presented and discussed in the main body of the report.

Table F.1. Cumulative Oversize Diameter Distributions for the Primary Group 1 Initial Characterization Sample, TI483-G1-S-WL-PSD-1

\begin{tabular}{|c|c|c|c|c|c|c|c|c|c|c|c|c|c|c|c|}
\hline \multirow[b]{2}{*}{ Test Condition } & \multicolumn{15}{|c|}{ Volume / Weight Cumulative Oversize Diameter $(\mu \mathrm{m})$} \\
\hline & $1 \%$ & $5 \%$ & $10 \%$ & $20 \%$ & $25 \%$ & $30 \%$ & $40 \%$ & $50 \%$ & $60 \%$ & $70 \%$ & $75 \%$ & $80 \%$ & $90 \%$ & $95 \%$ & $99 \%$ \\
\hline 1 - 3000/pre-sonic & 0.44 & 0.80 & 1.2 & 2.2 & 2.7 & 3.4 & 4.9 & 6.9 & 9.6 & 14 & \begin{tabular}{|l|}
16 \\
\end{tabular} & 20 & 31 & 43 & 67 \\
\hline $2-2000 / p$ & 45 & 0.81 & 1.2 & 2.1 & 2.7 & 3.3 & 4.9 & 6.9 & 9.6 & 13 & 16 & 19 & 30 & 41 & 64 \\
\hline $3-4000 / 1$ & 45 & 0.81 & & 2. & & & 5. & 7.0 & 9.7 & 14 & 16 & 9 & 30 & 41 & 64 \\
\hline $4-3000 / 25 \%$ & 0.45 & 0.78 & 1.2 & 2.0 & 2.4 & 3.0 & 4.5 & 6.4 & 8.8 & 12 & 14 & 17 & 26 & 35 & 55 \\
\hline$\overline{5-3000 /}$ & .44 & 0.74 & 1. & 1.8 & 2.2 & 2.7 & 4.1 & 5.8 & 8.0 & 11 & 13 & 15 & 24 & 33 & 55 \\
\hline 6 - 3000/75\% & 0.43 & 0.71 & 1.0 & 1.7 & 2.0 & 2.5 & 3.6 & 5.2 & 7.2 & 9.9 & 12 & 14 & 22 & 31 & 61 \\
\hline 7 - 3000/post-so & 0.43 & 0.70 & 1.0 & 1.6 & 2.0 & 2.4 & 3.5 & 5.0 & 7.1 & 9.8 & 12 & 14 & 23 & 35 & 71 \\
\hline $8-2000 / p$ & 0.43 & 0.69 & 0.97 & 1.6 & 1.9 & 2.3 & 3.3 & 4.8 & 6.8 & 9.5 & 11 & 13 & 21 & 31 & 66 \\
\hline 9 - 4000/post-sonic & 0.43 & 0.69 & 0.99 & 1.6 & 2.0 & 2.4 & 3.5 & 5.0 & 7.1 & 10 & 12 & 14 & 24 & 37 & 77 \\
\hline
\end{tabular}

Table F.2. Cumulative Oversize Diameter Distributions for the Duplicate Group 1 Initial Characterization Sample, TI483-G1-S-WL-PSD-2

\begin{tabular}{|c|c|c|c|c|c|c|c|c|c|c|c|c|c|c|c|}
\hline \multirow[b]{2}{*}{ Test Condition } & \multicolumn{15}{|c|}{ Volume / Weight Cumulative Oversize Diameter $(\mu \mathrm{m})$} \\
\hline & $1 \%$ & $5 \%$ & $10 \%$ & $20 \%$ & $25 \%$ & $30 \%$ & $40 \%$ & $50 \%$ & $60 \%$ & $70 \%$ & $75 \%$ & $80 \%$ & $90 \%$ & $95 \%$ & $99 \%$ \\
\hline 1 - 3000/pre-sonic & 0.42 & 0.73 & & 1.8 & 2.3 & 2.8 & 4.0 & 5.7 & 8.0 & 11 & 14 & 17 & 28 & 40 & 69 \\
\hline $2-2000 / p$ & 43 & 0.73 & 1.1 & 1.8 & 2.2 & 2.7 & 4.0 & 5.7 & 7.9 & 11 & 13 & 16 & 26 & 37 & 64 \\
\hline $3-4000 / 1$ & 44 & 0.74 & & & & & & 6.0 & 8.5 & 12 & 15 & 8 & 29 & 41 & 68 \\
\hline $4-3000 /$ & .43 & 0.71 & 1.0 & 1.7 & 2.1 & 2.5 & 3.7 & 5.3 & 7.4 & 10 & 12 & 14 & 22 & 30 & 50 \\
\hline $5-3000$ & .42 & 0.69 & 0.99 & 1.6 & 2.0 & 2. & 3.5 & 5.0 & 7.0 & 9.6 & 11 & 14 & 21 & 29 & 48 \\
\hline 6 - 3000/75\% & 0.41 & 0.66 & 0.94 & 1.5 & 1.8 & 2.2 & 3.2 & 4.6 & 6.4 & 8.8 & 10 & 12 & 19 & 26 & 45 \\
\hline 7 - 3000/post-so & 0.41 & 0.65 & 0.92 & 1.5 & 1.8 & 2.2 & 3.1 & 4.5 & 6.4 & 9.0 & 11 & 13 & 21 & 34 & 68 \\
\hline $8-2000 / p$ & 0.40 & 0.64 & 0.90 & 1.4 & 1.7 & 2.1 & 3.0 & 4.3 & 6.1 & 8.6 & 10 & 12 & 20 & 29 & 64 \\
\hline 9 - 4000/post-sonic & 0.41 & 0.65 & 0.92 & 1.5 & 1.8 & 2.2 & 3.2 & 4.6 & 6.6 & 9.4 & 11 & 14 & 24 & 38 & 73 \\
\hline
\end{tabular}

Table F.3 shows the absolute relative percent difference (RPD) between primary and duplicate results, which is calculated as: 


$$
R P D=\left|\frac{d_{d}(n)-d_{p}(n)}{d_{p}(n)}\right|
$$

where $d_{p}(n)$ and $d_{d}(n)$ are the primary and duplicate cumulative oversize diameters corresponding to the $n^{\text {th }}$ percentile. As before, this appendix does not provide a discussion of the RPD results; however, the RPD for the $10^{\text {th }}, 50^{\text {th }}$, and $90^{\text {th }}$ diameter percentiles are presented and discussed in the main body of this interim report.

Table F.3. Relative Percent Difference Between Primary and Duplicate Group 1 Initial Characterization Samples (TI483-G1-S-WL-PSD-1 and -2, respectively) as a Function of Test Condition

\begin{tabular}{|c|c|c|c|c|c|c|c|c|c|c|c|c|c|c|c|}
\hline \multirow[b]{2}{*}{ Test Condition } & \multicolumn{15}{|c|}{ Absolute RPD (\%) } \\
\hline & $1 \%$ & $5 \%$ & $10 \%$ & $20 \%$ & $25 \%$ & $30 \%$ & $40 \%$ & $50 \%$ & $60 \%$ & $70 \%$ & $75 \%$ & $80 \%$ & $90 \%$ & $95 \%$ & $99 \%$ \\
\hline 1 - 3000/pre-sonic & 3.2 & 8.7 & 12 & 15 & 17 & 18 & 18 & 17 & 17 & 16 & 16 & 15 & 12 & 7.9 & 2.3 \\
\hline 2 - 2000/pre-sonic & 4.5 & 9.8 & 12 & 15 & 17 & 18 & 19 & 18 & 17 & 17 & 16 & 16 & 13 & 8.9 & 0.9 \\
\hline 3 - 4000/pre-sonic & 4.0 & 8.5 & 10 & 13 & 14 & 15 & 15 & 14 & 13 & 11 & 9.7 & 8.2 & 4.1 & 0.6 & 6.7 \\
\hline $4-3000 / 25 \%$ & 4.5 & 8.8 & 11 & 13 & 14 & 15 & 17 & 16 & 15 & 15 & 14 & 14 & 13 & 13 & 10 \\
\hline $5-3000 / 50 \%$ & 4.1 & 7.7 & 9.4 & 11 & 12 & 13 & 14 & 14 & 13 & 13 & 12 & 12 & 12 & 13 & 13 \\
\hline $6-3000 / 75 \%$ & 5.1 & 7.3 & 8.4 & 9.3 & 9.8 & 10 & 12 & 12 & 11 & 11 & 11 & 11 & 13 & 16 & 26 \\
\hline 7 - 3000/post-sonic & 4.9 & 6.9 & 7.9 & 8.4 & 8.7 & 9.3 & 10 & 10 & 9.3 & 8.7 & 8.4 & 8.1 & 6.8 & 5.3 & 5.2 \\
\hline 8 - 2000/post-sonic & 5.2 & 7.0 & 8.0 & 8.7 & 9.1 & 9.7 & 11 & 11 & 10 & 9.6 & 9.3 & 9.0 & 7.9 & 6.4 & 2.0 \\
\hline 9 - 4000/post-sonic & 4.9 & 6.6 & 7.5 & 7.9 & 8.1 & 8.4 & 8.8 & 8.3 & 7.2 & 5.8 & 4.7 & 3.2 & 2.3 & 2.8 & 5.0 \\
\hline
\end{tabular}



Appendix G

Group 1 Analytical Results from Parametric Leaching 
WTP-RPT-166, Rev. 0

\section{Appendix G: Group 1 Analytical Results from Parametric Leaching}

Table G.1 provides information about analyte concentrations during leaching at various time increments at $40^{\circ} \mathrm{C}$, Table G.2 at $60^{\circ} \mathrm{C}$, and Table G3 at $80^{\circ} \mathrm{C}$.

Table G.1. Analyte Concentrations as a Function of Time for Leaching at $40^{\circ} \mathrm{C}$

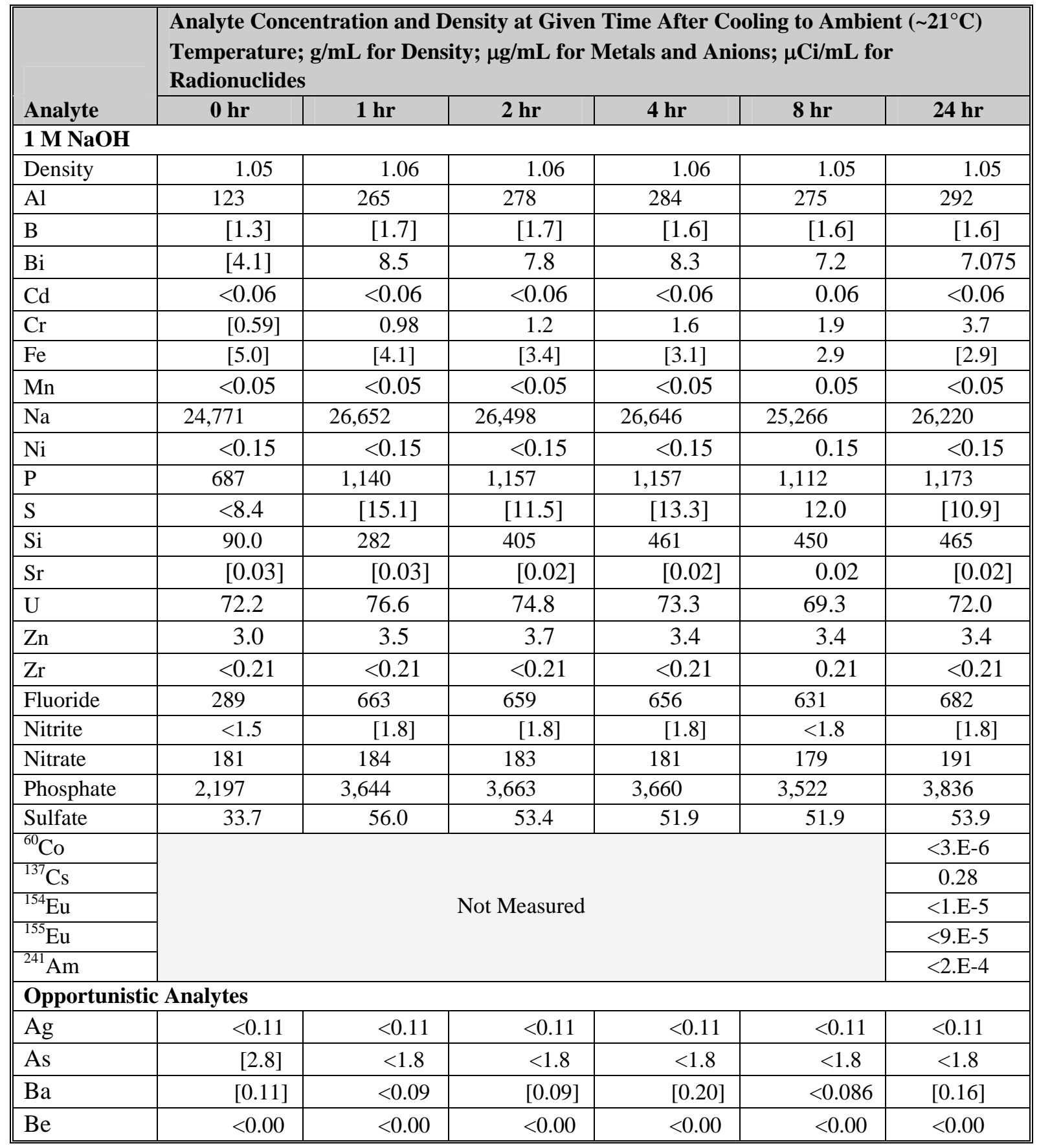


Table G.1 (Contd)

\begin{tabular}{|c|c|c|c|c|c|c|}
\hline \multirow[b]{2}{*}{ Analyte } & \multicolumn{6}{|c|}{$\begin{array}{l}\text { Analyte Concentration and Density at Given Time After Cooling to Ambient }\left(\sim 21^{\circ} \mathrm{C}\right) \\
\text { Temperature; } \mathrm{g} / \mathrm{mL} \text { for Density; } \mu \mathrm{g} / \mathrm{mL} \text { for Metals and Anions; } \mu \mathrm{Ci} / \mathrm{mL} \text { for } \\
\text { Radionuclides }\end{array}$} \\
\hline & $0 \mathrm{hr}$ & $1 \mathrm{hr}$ & $2 \mathrm{hr}$ & $4 \mathrm{hr}$ & $8 \mathrm{hr}$ & $24 \mathrm{hr}$ \\
\hline $\mathrm{Ca}$ & $<0.54$ & $<0.55$ & $<0.54$ & $<0.54$ & $<0.54$ & $<0.54$ \\
\hline $\mathrm{Ce}$ & $<0.31$ & $<0.31$ & $<0.31$ & $<0.31$ & $<0.30$ & $<0.31$ \\
\hline Co & $<0.10$ & $<0.10$ & $<0.10$ & $<0.10$ & $<0.10$ & $<0.10$ \\
\hline $\mathrm{Cu}$ & {$[0.41]$} & {$[0.35]$} & {$[0.34]$} & {$[0.34]$} & {$[0.35]$} & {$[0.34]$} \\
\hline Dy & $<0.09$ & $<0.09$ & $<0.09$ & $<0.09$ & $<0.09$ & $<0.09$ \\
\hline $\mathrm{Eu}$ & $<0.03$ & $<0.03$ & $<0.03$ & $<0.03$ & $<0.03$ & $<0.03$ \\
\hline $\mathrm{K}$ & {$[6.6]$} & [6.3] & [11.8] & [13.9] & {$[8.5]$} & {$[14.0]$} \\
\hline $\mathrm{La}$ & $<0.03$ & $<0.03$ & $<0.03$ & $<0.03$ & $<0.03$ & $<0.03$ \\
\hline $\mathrm{Li}$ & {$[0.20]$} & {$[0.44]$} & {$[0.44]$} & {$[0.40]$} & {$[0.43]$} & {$[0.43]$} \\
\hline $\mathrm{Mg}$ & $<0.18$ & $<0.18$ & $<0.18$ & $<0.18$ & $<0.18$ & $<0.18$ \\
\hline Mo & $<0.17$ & {$[0.20]$} & $<0.17$ & $<0.24$ & {$[0.24]$} & $<0.17$ \\
\hline $\mathrm{Nd}$ & $<0.44$ & $<0.45$ & $<0.44$ & $<0.44$ & $<0.44$ & $<0.44$ \\
\hline $\mathrm{Pb}$ & $<0.96$ & $<0.96$ & $<0.95$ & $<0.95$ & $<0.94$ & $<0.95$ \\
\hline $\mathrm{Pd}$ & $<0.32$ & $<0.33$ & $<0.32$ & $<0.32$ & $<0.32$ & $<0.32$ \\
\hline $\mathrm{Rh}$ & $<0.65$ & $<0.66$ & $<0.65$ & $<0.65$ & $<0.64$ & $<0.65$ \\
\hline $\mathrm{Ru}$ & $<0.21$ & $<0.21$ & $<0.21$ & $<0.21$ & $<0.21$ & $<0.21$ \\
\hline $\mathrm{Sb}$ & $<0.81$ & $<0.82$ & $<0.81$ & $<0.80$ & $<0.80$ & $<0.81$ \\
\hline Se & {$[2.6]$} & $<1.3$ & {$[4.4]$} & [1.3] & {$[2.6]$} & {$[2.8]$} \\
\hline Sn & $<0.52$ & $<0.52$ & [0.94] & [0.51] & $<0.51$ & $<0.52$ \\
\hline $\mathrm{Ta}$ & $<0.34$ & $<0.35$ & $<0.34$ & $<0.34$ & $<0.34$ & $<0.34$ \\
\hline $\mathrm{Te}$ & $<0.82$ & $<0.82$ & $<0.81$ & $<0.81$ & $<0.80$ & $<0.81$ \\
\hline Th & $<0.31$ & $<0.31$ & $<0.31$ & $<0.30$ & $<0.30$ & $<0.30$ \\
\hline $\mathrm{Ti}$ & $<0.02$ & $<0.03$ & $<0.02$ & $<0.02$ & $<0.02$ & $<0.02$ \\
\hline $\mathrm{Tl}$ & $<1.68$ & $<1.69$ & $<1.67$ & $<1.66$ & $<1.65$ & $<1.67$ \\
\hline $\mathrm{V}$ & $<0.08$ & $<0.08$ & $<0.08$ & $<0.08$ & $<0.08$ & $<0.08$ \\
\hline $\mathrm{W}$ & $<0.39$ & $<0.39$ & $<0.39$ & $<0.38$ & $<0.38$ & $<0.38$ \\
\hline $\mathrm{Y}$ & $<0.02$ & $<0.02$ & $<0.02$ & $<0.02$ & $<0.02$ & $<0.02$ \\
\hline \multicolumn{7}{|c|}{$3 \mathrm{M} \mathrm{NaOH}$, Trial a } \\
\hline Density & 1.13 & 1.14 & 1.14 & 1.14 & 1.14 & 1.14 \\
\hline $\mathrm{Al}$ & 222 & 302 & 312 & 313 & 320 & 337 \\
\hline B & $<2.3$ & $<2.4$ & $<2.4$ & $<2.3$ & $<2.3$ & $<2.3$ \\
\hline $\mathrm{Bi}$ & 42 & 53 & 57 & 64 & 60 & 67 \\
\hline $\mathrm{Cd}$ & $<0.31$ & $<0.31$ & $<0.31$ & $<0.31$ & $<0.31$ & $<0.31$ \\
\hline $\mathrm{Cr}$ & {$[2.3]$} & {$[2.2]$} & {$[2.6]$} & {$[3.7]$} & 5.8 & 12.5 \\
\hline $\mathrm{Fe}$ & 27.0 & [19.1] & {$[17.2]$} & [16.1] & [16.5] & [11.9] \\
\hline $\mathrm{Mn}$ & {$[0.27]$} & $<0.27$ & $<0.27$ & $<0.26$ & $<0.26$ & $<0.26$ \\
\hline $\mathrm{Na}$ & 73,322 & 73,817 & 75,191 & 75,397 & 74,306 & 74,988 \\
\hline $\mathrm{Ni}$ & $<0.75$ & $<0.75$ & $<0.75$ & $<0.74$ & $<0.75$ & $<0.73$ \\
\hline $\mathrm{P}$ & 851 & 1,057 & 1,117 & 1,170 & 1,169 & 1,188 \\
\hline$S$ & $<42.0$ & $<42.3$ & $<42.2$ & $<41.9$ & $<42.0$ & [55.1] \\
\hline $\mathrm{Si}$ & 288 & 513 & 530 & 527 & 529 & 536 \\
\hline $\mathrm{Sr}$ & {$[0.06]$} & {$[0.08]$} & {$[0.07]$} & {$[0.06]$} & {$[0.06]$} & {$[0.06]$} \\
\hline
\end{tabular}


Table G.1 (Contd)

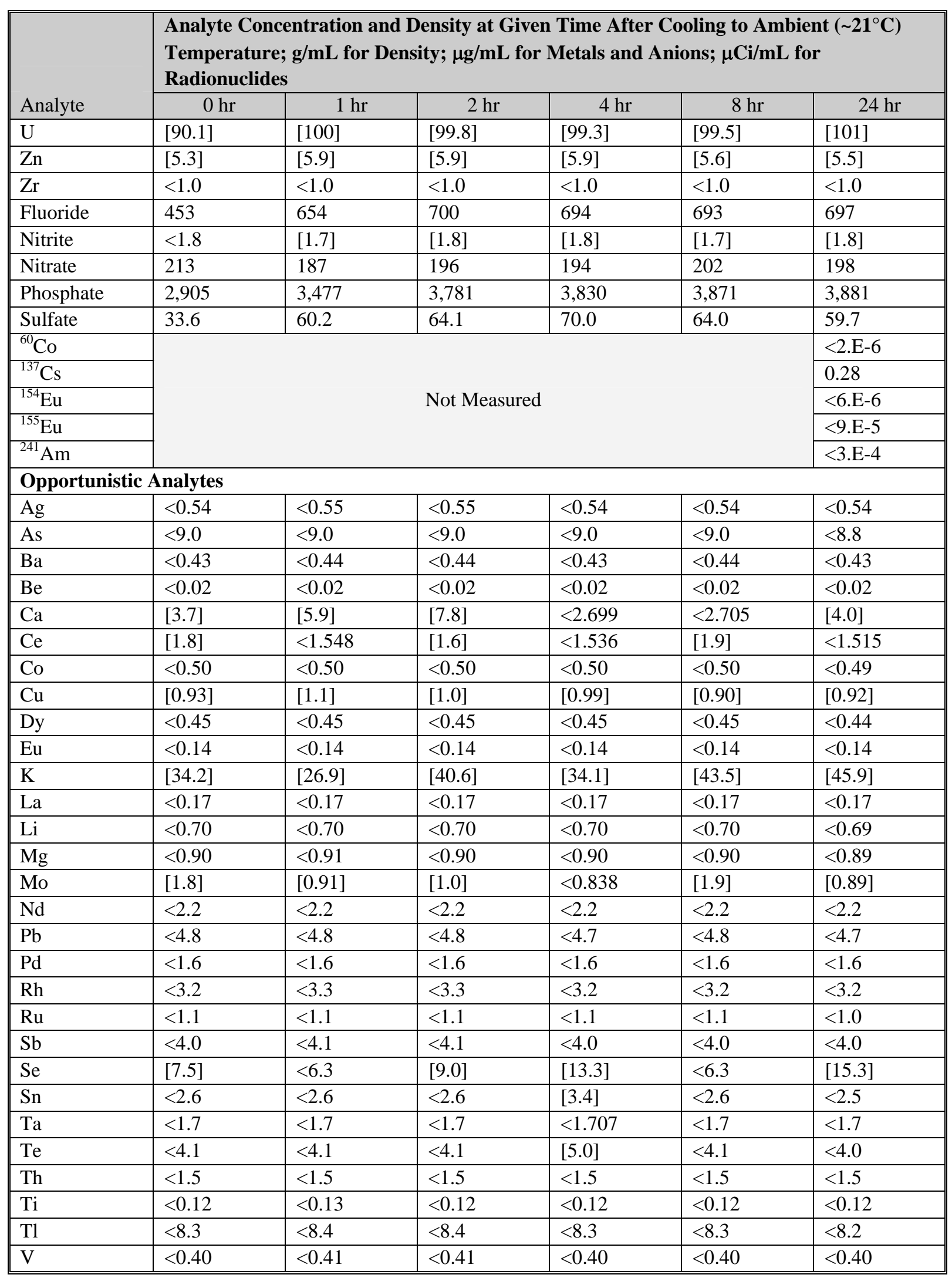


Table G.1 (Contd)

\begin{tabular}{|c|c|c|c|c|c|c|}
\hline \multirow[b]{2}{*}{ Analyte } & \multicolumn{6}{|c|}{$\begin{array}{l}\text { Analyte Concentration and Density at Given Time After Cooling to Ambient }\left(\sim 21^{\circ} \mathrm{C}\right) \\
\text { Temperature; } \mathrm{g} / \mathrm{mL} \text { for Density; } \mu \mathrm{g} / \mathrm{mL} \text { for Metals and Anions; } \mu \mathrm{Ci} / \mathrm{mL} \text { for } \\
\text { Radionuclides }\end{array}$} \\
\hline & $0 \mathrm{hr}$ & $1 \mathrm{hr}$ & $2 \mathrm{hr}$ & $4 \mathrm{hr}$ & \begin{tabular}{|l}
$\mathrm{hr}$ \\
\end{tabular} & $24 \mathrm{hr}$ \\
\hline $\mathrm{W}$ & $<1.9$ & $<1.9$ & $<1.9$ & $<1.9$ & $<1.9$ & $<1.9$ \\
\hline $\mathrm{Y}$ & $<0.11$ & $<0.11$ & $<0.11$ & $<0.11$ & $<0.11$ & $<0.11$ \\
\hline \multicolumn{7}{|c|}{3 M NaOH, Trial b } \\
\hline Density & 1.13 & 1.14 & 1.14 & 1.14 & 1.13 & 1.14 \\
\hline $\mathrm{Al}$ & 151 & 288 & 295 & 308 & 300 & 321 \\
\hline B & $<2.4$ & $<2.4$ & $<2.4$ & $<2.3$ & $<2.3$ & $<2.3$ \\
\hline $\mathrm{Bi}$ & 37.5 & 47.4 & 54.4 & 68.4 & 67.7 & 71.1 \\
\hline $\mathrm{Cd}$ & $<0.31$ & $<0.31$ & $<0.31$ & $<0.31$ & $<0.31$ & $<0.31$ \\
\hline $\mathrm{Cr}$ & {$[2.7]$} & [1.9] & {$[2.7]$} & {$[4.0]$} & 5.1 & 11.5 \\
\hline $\mathrm{Fe}$ & 27.2 & [18.8] & [17.8] & [18.6] & [15.5] & [13.0] \\
\hline $\mathrm{Na}$ & 75,857 & 76,245 & 76,845 & 77,031 & 73,334 & 76,034 \\
\hline $\mathrm{Ni}$ & $<0.75$ & $<0.75$ & $<0.75$ & $<0.74$ & $<0.75$ & $<0.74$ \\
\hline $\mathrm{P}$ & 727 & 875 & 962 & 1,182 & 1,159 & 1,175 \\
\hline$S$ & $<42.2$ & $<42.4$ & $<42.2$ & $<41.8$ & $<42.0$ & [49.5] \\
\hline $\mathrm{Si}$ & 328 & 505 & 519 & 535 & 528 & 532 \\
\hline $\mathrm{Sr}$ & {$[0.06]$} & {$[0.06]$} & {$[0.07]$} & {$[0.06]$} & {$[0.06]$} & {$[0.06]$} \\
\hline $\mathrm{U}$ & {$[81.2]$} & {$[91.0]$} & {$[96.8]$} & {$[99.0]$} & [109] & {$[95.8]$} \\
\hline Zn & [4.7] & [5.6] & [5.3] & [5.9] & [5.9] & [6.2] \\
\hline $\mathrm{Zr}$ & $<1.05$ & $<1.05$ & $<1.05$ & $<1.04$ & $<1.04$ & $<1.04$ \\
\hline Fluoride & 279 & 570 & 602 & 682 & 697 & 678 \\
\hline Nitrite & [1.7] & [1.8] & [1.8] & [1.8] & [2.4] & $<1.8$ \\
\hline Nitrate & 187 & 192 & 192 & 191 & 198 & 198 \\
\hline Phosphate & 2,321 & 2,889 & 3,131 & 3,796 & 3,919 & 3,830 \\
\hline Sulfate & 35.0 & 64.1 & 54.3 & 56.2 & 62.5 & 57.3 \\
\hline${ }^{60} \mathrm{Co}$ & \multirow{5}{*}{\multicolumn{5}{|c|}{ Not Measured }} & $<3$. -E-6 \\
\hline${ }^{137} \mathrm{Cs}$ & & & & & & 0.30 \\
\hline${ }^{154} \mathrm{Eu}$ & & & & & & $<1 . E-5$ \\
\hline${ }^{155} \mathrm{Eu}$ & & & & & & $<8 . \mathrm{E}-5$ \\
\hline${ }^{241} \mathrm{Am}$ & & & & & & $<4 . \mathrm{E}-5$ \\
\hline \multicolumn{7}{|c|}{ Opportunistic Analytes } \\
\hline $\mathrm{Ag}$ & $<0.55$ & $<0.55$ & $<0.55$ & $<0.54$ & $<0.54$ & $<0.54$ \\
\hline As & $<9.006$ & $<9.052$ & $<9.012$ & $<8.925$ & $<8.965$ & $<8.917$ \\
\hline $\mathrm{Ba}$ & $<0.44$ & $<0.44$ & $<0.44$ & $<0.43$ & $<0.44$ & $<0.43$ \\
\hline $\mathrm{Be}$ & $<0.02$ & $<0.02$ & $<0.02$ & $<0.02$ & $<0.02$ & $<0.02$ \\
\hline $\mathrm{Ca}$ & {$[5.6]$} & [3.5] & $<2.718$ & {$[3.1]$} & {$[3.0]$} & $<2.7$ \\
\hline $\mathrm{Ce}$ & $<1.5$ & $<1.6$ & $<1.5$ & $<1.5$ & [1.6] & $<1.5$ \\
\hline Co & $<0.50$ & $<0.50$ & $<0.50$ & $<0.49$ & $<0.50$ & $<0.49$ \\
\hline $\mathrm{Cu}$ & {$[0.91]$} & {$[0.72]$} & {$[0.66]$} & {$[0.77]$} & {$[0.78]$} & {$[0.87]$} \\
\hline Dy & $<0.45$ & $<0.45$ & $<0.45$ & $<0.45$ & $<0.45$ & $<0.45$ \\
\hline $\mathrm{Eu}$ & $<0.14$ & $<0.14$ & $<0.14$ & $<0.14$ & $<0.14$ & $<0.14$ \\
\hline $\mathrm{K}$ & {$[40.6]$} & [20.1] & [26.6] & [25.7] & [30.1] & [37.1] \\
\hline $\mathrm{La}$ & $<0.17$ & $<0.17$ & $<0.17$ & $<0.17$ & $<0.17$ & $<0.17$ \\
\hline
\end{tabular}


Table G.1 (Contd)

\begin{tabular}{|c|c|c|c|c|c|c|}
\hline \multirow[b]{2}{*}{ Analyte } & \multicolumn{6}{|c|}{$\begin{array}{l}\text { Analyte Concentration and Density at Given Time After Cooling to Ambient }\left(\sim 21^{\circ} \mathrm{C}\right) \\
\text { Temperature; } \mathrm{g} / \mathrm{mL} \text { for Density; } \mu \mathrm{g} / \mathrm{mL} \text { for Metals and Anions; } \mu \mathrm{Ci} / \mathrm{mL} \text { for } \\
\text { Radionuclides }\end{array}$} \\
\hline & $0 \mathrm{hr}$ & $1 \mathrm{hr}$ & $2 \mathrm{hr}$ & $4 \mathrm{hr}$ & $8 \mathrm{hr}$ & $24 \mathrm{hr}$ \\
\hline $\mathrm{Li}$ & $<0.70$ & $<0.71$ & $<0.70$ & $<0.70$ & $<0.70$ & $<0.70$ \\
\hline $\mathrm{Mg}$ & $<0.91$ & $<0.91$ & $<0.91$ & $<0.90$ & $<0.90$ & $<0.90$ \\
\hline Mo & $<0.84$ & {$[1.8]$} & [1.3] & {$[1.1]$} & {$[0.87]$} & [1.1] \\
\hline $\mathrm{Nd}$ & $<2.2$ & $<2.2$ & $<2.2$ & $<2.2$ & $<2.2$ & $<2.2$ \\
\hline $\mathrm{Pb}$ & $<4.8$ & $<4.8$ & $<4.8$ & $<4.7$ & $<4.8$ & $<4.7$ \\
\hline $\mathrm{Pd}$ & $<1.6$ & $<1.6$ & $<1.6$ & $<1.6$ & $<1.6$ & $<1.6$ \\
\hline$\overline{\mathrm{Rh}}$ & $<3.3$ & $<3.3$ & $<3.3$ & $<3.2$ & $<3.2$ & $<3.2$ \\
\hline $\mathrm{Ru}$ & $<1.1$ & $<1.1$ & $<1.1$ & $<1.1$ & $<1.1$ & $<1.1$ \\
\hline $\mathrm{Sb}$ & $<4.1$ & $<4.1$ & $<4.1$ & $<4.0$ & $<4.0$ & $<4.0$ \\
\hline Se & [15.0] & [20.7] & [15.3] & $<6.3$ & [16.5] & $<6.3$ \\
\hline Sn & $<2.6$ & $<2.6$ & $<2.6$ & $<2.6$ & $<4.0$ & $<2.6$ \\
\hline $\mathrm{Ta}$ & $<1.7$ & $<1.7$ & $<1.7$ & $<1.7$ & $<1.7$ & $<1.7$ \\
\hline $\mathrm{Te}$ & $<4.1$ & $<4.1$ & $<4.1$ & $<4.0$ & $<4.1$ & $<4.0$ \\
\hline Th & $<1.5$ & $<1.5$ & $<1.5$ & $<1.5$ & $<1.5$ & $<1.5$ \\
\hline $\mathrm{Ti}$ & $<0.12$ & $<0.13$ & $<0.12$ & $<0.12$ & $<0.12$ & $<0.12$ \\
\hline $\mathrm{Tl}$ & $<8.4$ & $<8.4$ & $<8.4$ & $<8.3$ & $<8.3$ & $<8.3$ \\
\hline $\mathrm{V}$ & $<0.41$ & $<0.41$ & $<0.41$ & $<0.40$ & $<0.40$ & $<0.40$ \\
\hline $\mathrm{W}$ & $<1.9$ & $<1.9$ & $<1.9$ & $<1.9$ & $<1.9$ & $<1.9$ \\
\hline $\mathrm{Y}$ & $<0.11$ & $<0.11$ & $<0.11$ & $<0.11$ & $<0.11$ & $<0.11$ \\
\hline \multicolumn{7}{|c|}{$3 \mathrm{M} \mathrm{NaOH}$, Trial c } \\
\hline Density & 1.13 & 1.14 & 1.14 & 1.14 & 1.14 & 1.13 \\
\hline $\mathrm{Al}$ & 132 & 252 & 284 & 300 & 306 & 308 \\
\hline B & $<2.4$ & $<2.3$ & $<2.3$ & $<2.3$ & $<2.3$ & $<2.3$ \\
\hline $\mathrm{Bi}$ & 36.3 & 42.5 & 52.9 & 66.9 & 67.0 & 65.5 \\
\hline $\mathrm{Cd}$ & $<0.31$ & $<0.31$ & $<0.31$ & $<0.31$ & $<0.31$ & $<0.30$ \\
\hline $\mathrm{Cr}$ & {$[2.1]$} & {$[2.0]$} & {$[2.6]$} & [3.4] & 5.2 & 9.9 \\
\hline $\mathrm{Fe}$ & 27.2 & {$[17.7]$} & {$[18.0]$} & [18.1] & [15.4] & {$[12.4]$} \\
\hline $\mathrm{Mn}$ & $<0.27$ & $<0.26$ & $<0.26$ & $<0.26$ & $<0.26$ & $<0.26$ \\
\hline $\mathrm{Na}$ & 73,591 & 73,602 & 73,974 & 75,936 & 74,356 & 73,085 \\
\hline $\mathrm{Ni}$ & $<0.75$ & $<0.75$ & $<0.74$ & $<0.75$ & $<0.74$ & $<0.72$ \\
\hline $\mathrm{P}$ & 733 & 826 & 994 & 1,161 & 1,140 & 1,145 \\
\hline$S$ & $<42.3$ & $<42.0$ & $<41.8$ & $<42.1$ & $<41.5$ & $<40.8$ \\
\hline $\mathrm{Si}$ & 265 & 491 & 517 & 538 & 516 & 525 \\
\hline $\mathrm{Sr}$ & [0.06] & {$[0.07]$} & {$[0.06]$} & {$[0.07]$} & [0.06] & {$[0.05]$} \\
\hline $\mathrm{U}$ & [87.7] & [96.3] & [102] & [103] & [95.2] & [96.6] \\
\hline Zn & [4.7] & [5.3] & [5.3] & [5.9] & [5.8] & [5.1] \\
\hline $\mathrm{Zr}$ & $<1.0$ & $<1.0$ & $<1.0$ & $<1.0$ & $<1.0$ & $<1.0$ \\
\hline Fluoride & 256 & 495 & 589 & 666 & 670 & 681 \\
\hline Nitrite & $<1.8$ & [1.8] & [1.7] & [1.8] & [1.8] & [2.4] \\
\hline Nitrate & 169 & 188 & 186 & 190 & 188 & 194 \\
\hline
\end{tabular}


Table G.1 (Contd)

\begin{tabular}{|c|c|c|c|c|c|c|}
\hline \multirow[b]{2}{*}{ Analyte } & \multicolumn{6}{|c|}{$\begin{array}{l}\text { Analyte Concentration and Density at Given Time After Cooling to Ambient }\left(\sim 21^{\circ} \mathrm{C}\right) \\
\text { Temperature; } \mathrm{g} / \mathrm{mL} \text { for Density; } \mu \mathrm{g} / \mathrm{mL} \text { for Metals and Anions; } \mu \mathrm{Ci} / \mathrm{mL} \text { for } \\
\text { Radionuclides }\end{array}$} \\
\hline & $0 \mathrm{hr}$ & $1 \mathrm{hr}$ & $2 \mathrm{hr}$ & $4 \mathrm{hr}$ & $8 \mathrm{hr}$ & $24 \mathrm{hr}$ \\
\hline Phosphate & 2,367 & 2,639 & 3,188 & 3,731 & 3,744 & 3,812 \\
\hline Sulfate & 44.4 & 54.3 & 59.5 & 61.3 & 52.2 & 66.9 \\
\hline${ }^{60} \mathrm{Co}$ & \multirow{5}{*}{\multicolumn{5}{|c|}{ Not Measured }} & $<3 . \mathrm{E}-6$ \\
\hline${ }^{137} \mathrm{Cs}$ & & & & & & 0.24 \\
\hline${ }^{154} \mathrm{Eu}$ & & & & & & $<1 . \mathrm{E}-5$ \\
\hline${ }^{155} \mathrm{Eu}$ & & & & & & $<8$.E-5 \\
\hline${ }^{241} \mathrm{Am}$ & & & & & & $<2$.E-4 \\
\hline \multicolumn{7}{|c|}{ Opportunistic Analytes } \\
\hline $\mathrm{Ag}$ & $<0.55$ & $<0.54$ & $<0.54$ & $<0.54$ & $<0.54$ & $<0.53$ \\
\hline As & $<9.0$ & $<9.0$ & $<8.9$ & $<9.0$ & $<8.9$ & $<8.7$ \\
\hline $\mathrm{Ba}$ & $<0.44$ & $<0.43$ & $<0.43$ & $<0.44$ & $<0.43$ & $<0.42$ \\
\hline $\mathrm{Be}$ & $<0.02$ & $<0.02$ & $<0.02$ & $<0.02$ & $<0.02$ & $<0.02$ \\
\hline $\mathrm{Ca}$ & {$[3.1]$} & {$[4.0]$} & $<2.693$ & {$[3.4]$} & {$[3.0]$} & $<2.6$ \\
\hline $\mathrm{Ce}$ & $<1.6$ & $<1.5$ & {$[1.6]$} & $<1.5$ & $<1.5$ & $<1.5$ \\
\hline Co & $<0.50$ & $<0.50$ & $<0.50$ & $<0.50$ & $<0.49$ & $<0.48$ \\
\hline $\mathrm{Cu}$ & {$[0.94]$} & {$[0.93]$} & {$[0.84]$} & [1.3] & {$[0.89]$} & {$[0.85]$} \\
\hline Dy & $<0.45$ & $<0.45$ & $<0.45$ & $<0.45$ & $<0.45$ & $<0.44$ \\
\hline $\mathrm{Eu}$ & $<0.14$ & $<0.14$ & $<0.14$ & $<0.14$ & $<0.14$ & $<0.14$ \\
\hline $\mathrm{K}$ & [34.4] & [31.1] & {$[34.0]$} & {$[40.5]$} & {$[43.0]$} & $<15.206$ \\
\hline $\mathrm{La}$ & $<0.17$ & $<0.17$ & $<0.17$ & $<0.17$ & $<0.17$ & $<0.17$ \\
\hline $\mathrm{Li}$ & $<0.70$ & $<0.70$ & $<0.70$ & {$[0.78]$} & $<0.69$ & $<0.68$ \\
\hline $\mathrm{Mg}$ & $<0.91$ & $<0.90$ & $<0.90$ & $<0.90$ & $<0.89$ & $<0.88$ \\
\hline Mo & [1.628] & $<0.84$ & $<0.84$ & $<0.84$ & $<0.83$ & $<0.82$ \\
\hline $\mathrm{Nd}$ & {$[2.2]$} & $<2.2$ & $<2.2$ & $<2.2$ & $<2.2$ & $<2.1$ \\
\hline $\mathrm{Pb}$ & $<4.8$ & $<4.8$ & $<4.7$ & $<4.8$ & $<4.7$ & $<4.6$ \\
\hline $\mathrm{Pd}$ & $<1.6$ & $<1.6$ & $<1.6$ & $<1.6$ & $<1.6$ & $<1.6$ \\
\hline$\overline{\mathrm{Rh}}$ & $<3.3$ & $<3.2$ & $<3.2$ & $<3.3$ & $<3.2$ & $<3.2$ \\
\hline $\mathrm{Ru}$ & $<1.1$ & $<1.1$ & $<1.1$ & $<1.1$ & $<1.0$ & $<1.0$ \\
\hline $\mathrm{Sb}$ & $<4.1$ & $<4.0$ & $<4.0$ & $<4.0$ & $<4.0$ & $<3.9$ \\
\hline Se & {$[8.77]$} & [10.9] & [11.8] & [10.6] & {$[20.6]$} & {$[7.6]$} \\
\hline Sn & $<2.6$ & $<2.6$ & $<2.6$ & $<2.6$ & $<2.6$ & [2.7] \\
\hline Ta & $<1.7$ & $<1.7$ & $<1.7$ & $<1.7$ & $<1.7$ & $<1.7$ \\
\hline $\mathrm{Te}$ & $<4.1$ & $<4.1$ & $<4.0$ & $<4.1$ & $<4.0$ & $<3.9$ \\
\hline Th & $<1.5$ & $<1.5$ & $<1.5$ & $<1.5$ & $<1.5$ & $<1.5$ \\
\hline $\mathrm{Ti}$ & $<0.13$ & $<0.12$ & $<0.12$ & $<0.12$ & $<0.12$ & $<0.12$ \\
\hline $\mathrm{Tl}$ & $<8.4$ & $<8.3$ & $<8.3$ & $<8.4$ & $<8.2$ & $<8.1$ \\
\hline $\mathrm{V}$ & $<0.41$ & $<0.40$ & $<0.40$ & $<0.40$ & $<0.40$ & $<0.39$ \\
\hline $\mathrm{W}$ & $<1.9$ & $<1.9$ & $<1.9$ & $<1.9$ & $<1.9$ & $<1.9$ \\
\hline $\mathrm{Y}$ & $<0.11$ & $<0.11$ & $<0.11$ & $<0.11$ & $<0.11$ & $<0.11$ \\
\hline
\end{tabular}


Table G.2. Analyte Concentrations as a Function of Time for Leaching at $60^{\circ} \mathrm{C}$

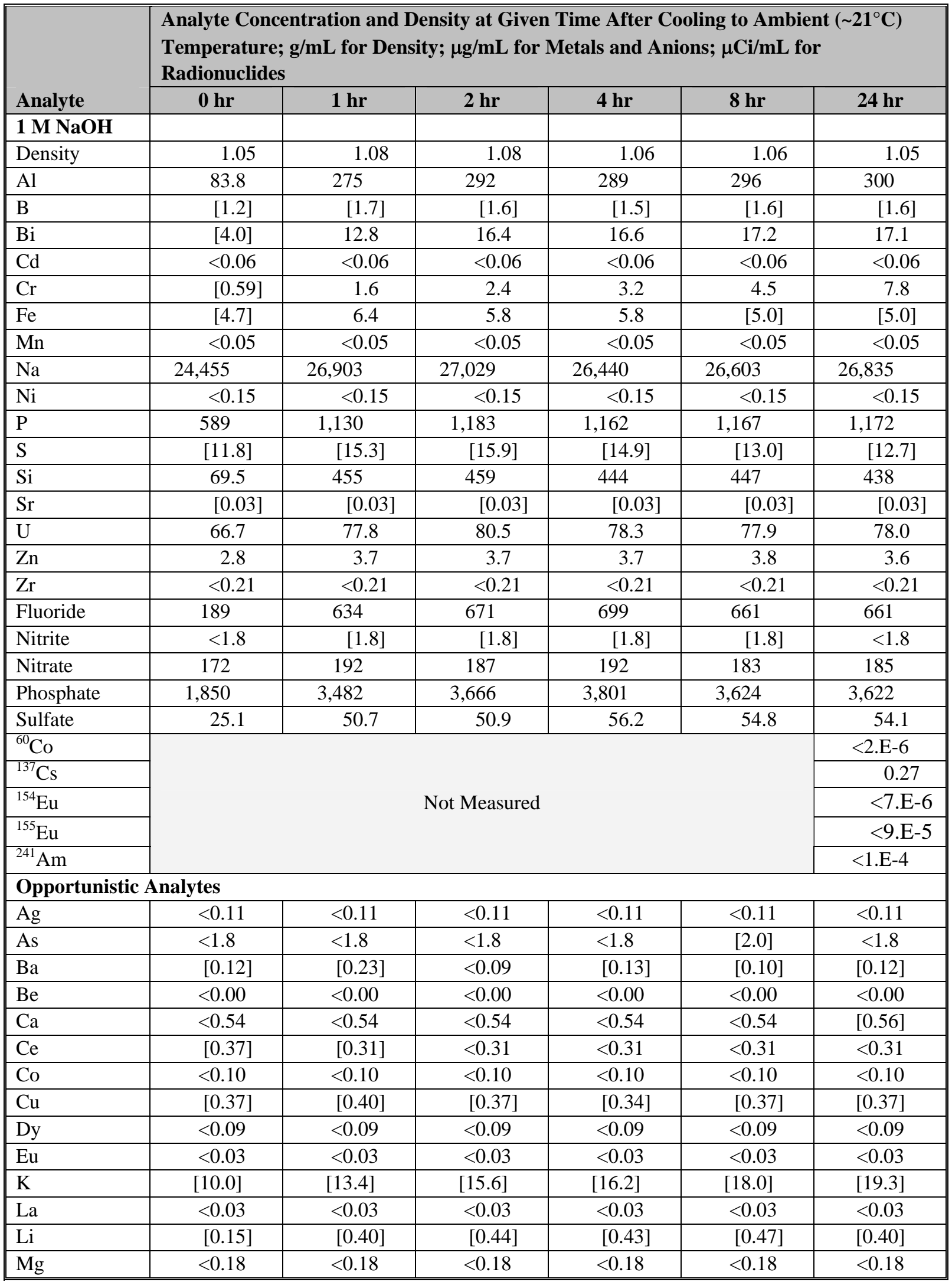


Table G.2 (Contd)

\begin{tabular}{|c|c|c|c|c|c|c|}
\hline \multirow[b]{2}{*}{ Analyte } & \multicolumn{6}{|c|}{$\begin{array}{l}\text { Analyte Concentration and Density at Given Time After Cooling to Ambient }\left(\sim 21^{\circ} \mathrm{C}\right) \\
\text { Temperature; } \mathrm{g} / \mathrm{mL} \text { for Density; } \mu \mathrm{g} / \mathrm{mL} \text { for Metals and Anions; } \mu \mathrm{Ci} / \mathrm{mL} \text { for } \\
\text { Radionuclides }\end{array}$} \\
\hline & $0 \mathrm{hr}$ & $1 \mathrm{hr}$ & $2 \mathrm{hr}$ & $4 \mathrm{hr}$ & \begin{tabular}{|l}
$\mathrm{hr}$ \\
\end{tabular} & $24 \mathrm{hr}$ \\
\hline Mo & {$[0.22]$} & {$[0.30]$} & {$[0.23]$} & $<0.17$ & {$[0.29]$} & {$[0.17]$} \\
\hline $\mathrm{Nd}$ & $<0.44$ & $<0.44$ & $<0.44$ & $<0.44$ & $<0.44$ & $<0.44$ \\
\hline $\mathrm{Pb}$ & $<0.95$ & $<0.95$ & $<0.96$ & $<0.95$ & $<0.95$ & $<0.95$ \\
\hline $\mathrm{Pd}$ & $<0.32$ & $<0.32$ & $<0.32$ & $<0.32$ & $<0.32$ & $<0.32$ \\
\hline $\mathrm{Rh}$ & $<0.65$ & $<0.65$ & $<0.65$ & $<0.65$ & $<0.65$ & $<0.65$ \\
\hline $\mathrm{Ru}$ & $<0.21$ & $<0.21$ & $<0.21$ & $<0.21$ & $<0.21$ & $<0.21$ \\
\hline $\mathrm{Sb}$ & $<0.81$ & $<0.81$ & $<0.81$ & $<0.81$ & $<0.81$ & {$[0.84]$} \\
\hline Se & {$[4.4]$} & [1.4] & [3.0] & [3.1] & [4.7] & {$[1.8]$} \\
\hline Sn & $<0.52$ & {$[0.87]$} & {$[0.91]$} & $<0.52$ & $<0.52$ & $<0.52$ \\
\hline $\mathrm{Ta}$ & $<0.34$ & $<0.34$ & $<0.34$ & $<0.34$ & $<0.34$ & $<0.34$ \\
\hline $\mathrm{Te}$ & $<0.81$ & $<0.81$ & $<0.81$ & $<0.81$ & $<0.81$ & $<0.81$ \\
\hline Th & $<0.31$ & $<0.31$ & $<0.31$ & $<0.30$ & $<0.30$ & $<0.30$ \\
\hline $\mathrm{Ti}$ & $<0.02$ & $<0.02$ & $<0.02$ & $<0.02$ & $<0.02$ & $<0.02$ \\
\hline $\mathrm{Tl}$ & $<1.7$ & $<1.7$ & $<1.7$ & $<1.7$ & $<1.7$ & [1.9] \\
\hline $\mathrm{V}$ & $<0.08$ & $<0.08$ & $<0.08$ & $<0.08$ & $<0.08$ & $<0.08$ \\
\hline $\mathrm{W}$ & $<0.39$ & $<0.39$ & $<0.39$ & $<0.39$ & $<0.38$ & $<0.39$ \\
\hline $\mathrm{Y}$ & $<0.02$ & $<0.02$ & $<0.02$ & $<0.02$ & $<0.02$ & $<0.02$ \\
\hline \multicolumn{7}{|l|}{$3 \mathrm{M} \mathrm{NaOH}$} \\
\hline Density & 1.14 & 1.15 & 1.15 & 1.13 & 1.14 & 1.14 \\
\hline $\mathrm{Al}$ & 131 & 292 & 328 & 331 & 338 & 331 \\
\hline $\mathrm{B}$ & $<2.3$ & $<2.3$ & $<2.4$ & [2.4] & $<2.3$ & $<2.3$ \\
\hline $\mathrm{Bi}$ & 34.6 & 98.7 & 123 & 124 & 129 & 125 \\
\hline $\mathrm{Cd}$ & $<0.31$ & $<0.31$ & $<0.31$ & $<0.31$ & $<0.31$ & $<0.31$ \\
\hline $\mathrm{Cr}$ & {$[3.4]$} & {$[4.0]$} & 6.9 & 9.8 & 13.5 & 21.1 \\
\hline $\mathrm{Fe}$ & 30.4 & [22.9] & [23.1] & {$[20.0]$} & [18.0] & [15.1] \\
\hline $\mathrm{Mn}$ & [0.34] & $<0.26$ & $<0.27$ & $<0.27$ & $<0.26$ & $<0.26$ \\
\hline $\mathrm{Na}$ & 74,194 & 72,111 & 79,096 & 76,185 & 76,206 & 75,131 \\
\hline $\mathrm{Ni}$ & $<0.74$ & $<0.74$ & $<0.75$ & $<0.75$ & $<0.74$ & $<0.74$ \\
\hline $\mathrm{P}$ & 686 & 1,074 & 1,194 & 1,186 & 1,183 & 1,163 \\
\hline$S$ & $<41.8$ & [43.33] & $<42.3$ & $<42.2$ & $<41.9$ & $<41.8$ \\
\hline $\mathrm{Si}$ & 162 & 504 & 541 & 540 & 536 & 532 \\
\hline $\mathrm{Sr}$ & [0.07] & [0.08] & [0.09] & [0.08] & [0.09] & [0.08] \\
\hline $\mathrm{U}$ & [83.5] & [99.0] & 109.73 & 109.28 & [105] & [105] \\
\hline $\mathrm{Zn}$ & [5.6] & [5.9] & {$[5.6]$} & [5.9] & [6.8] & [5.9] \\
\hline $\mathrm{Zr}$ & $<1.0$ & $<1.0$ & $<1.0$ & $<1.0$ & $<1.0$ & $<1.0$ \\
\hline Fluoride & 267 & 696 & 701 & 768 & 235 & 731 \\
\hline Nitrite & [1.8] & [1.8] & [1.8] & [2.4] & [1.8] & [1.8] \\
\hline Nitrate & 184 & 197 & 213 & 233 & 213 & 219 \\
\hline Phosphate & 2,213 & 3,762 & 3,844 & 4,161 & 3,842 & 3,956 \\
\hline Sulfate & 47.4 & 61.7 & 73.7 & 85.3 & 82.3 & 97.1 \\
\hline
\end{tabular}


Table G.2 (Contd)

\begin{tabular}{|c|c|c|c|c|c|c|}
\hline \multirow[b]{2}{*}{ Analyte } & \multicolumn{6}{|c|}{$\begin{array}{l}\text { Analyte Concentration and Density at Given Time After Cooling to Ambient }\left(\sim 21^{\circ} \mathrm{C}\right) \\
\text { Temperature; } \mathrm{g} / \mathrm{mL} \text { for Density; } \mu \mathrm{g} / \mathrm{mL} \text { for Metals and Anions; } \mu \mathrm{Ci} / \mathrm{mL} \text { for } \\
\text { Radionuclides }\end{array}$} \\
\hline & $0 \mathrm{hr}$ & $1 \mathrm{hr}$ & $2 \mathrm{hr}$ & $4 \mathrm{hr}$ & $8 \mathrm{hr}$ & $24 \mathrm{hr}$ \\
\hline${ }^{60} \mathrm{Co}$ & \multirow{5}{*}{\multicolumn{5}{|c|}{ Not Measured }} & $<4 . \mathrm{E}-6$ \\
\hline${ }^{137} \mathrm{Cs}$ & & & & & & 0.29 \\
\hline${ }^{154} \mathrm{Eu}$ & & & & & & $<1$.E-5 \\
\hline${ }^{155} \mathrm{Eu}$ & & & & & & $<1$.E-4 \\
\hline${ }^{241} \mathrm{Am}$ & & & & & & $<1$. E-4 \\
\hline \multicolumn{7}{|c|}{ Opportunistic Analytes } \\
\hline $\mathrm{Ag}$ & $<0.54$ & $<0.54$ & $<0.55$ & $<0.55$ & $<0.54$ & $<0.54$ \\
\hline As & $<8.9$ & $<8.9$ & $<9.0$ & $<9.0$ & {$[10.5]$} & $<8.9$ \\
\hline $\mathrm{Ba}$ & $<0.43$ & $<0.43$ & $<0.44$ & $<0.44$ & $<0.43$ & $<0.43$ \\
\hline $\mathrm{Be}$ & $<0.02$ & $<0.02$ & $<0.02$ & $<0.02$ & $<0.02$ & $<0.02$ \\
\hline $\mathrm{Ca}$ & {$[5.9]$} & {$[4.6]$} & {$[3.1]$} & {$[3.1]$} & {$[3.4]$} & {$[3.7]$} \\
\hline $\mathrm{Ce}$ & $<1.5$ & [1.9] & $<1.5$ & $<1.5$ & $<1.5$ & $<1.5$ \\
\hline Co & $<0.49$ & $<0.50$ & $<0.50$ & $<0.50$ & $<0.50$ & $<0.49$ \\
\hline $\mathrm{Cu}$ & {$[0.897]$} & {$[1.1]$} & {$[1.0]$} & {$[1.0]$} & {$[0.93]$} & {$[0.80]$} \\
\hline Dy & $<0.45$ & $<0.45$ & $<0.45$ & $<0.45$ & $<0.45$ & $<0.45$ \\
\hline $\mathrm{Eu}$ & $<0.14$ & $<0.14$ & $<0.14$ & $<0.14$ & $<0.14$ & $<0.14$ \\
\hline $\mathrm{K}$ & [49.5] & {$[46.4]$} & {$[50.0]$} & [24.7] & {$[31.0]$} & [34.0] \\
\hline $\mathrm{La}$ & $<0.17$ & $<0.17$ & [0.275] & $<0.17$ & $<0.17$ & $<0.17$ \\
\hline $\mathrm{Li}$ & $<0.70$ & {$[0.712]$} & $<0.70$ & $<0.70$ & $<0.70$ & $<0.70$ \\
\hline $\mathrm{Mg}$ & $<0.90$ & $<0.90$ & $<0.91$ & $<0.91$ & $<0.90$ & $<0.90$ \\
\hline Mo & {$[1.1]$} & {$[1.1]$} & {$[0.88]$} & {$[0.87]$} & {$[1.0]$} & $<0.835$ \\
\hline $\mathrm{Nd}$ & $<2.2$ & $<2.2$ & $<2.2$ & $<2.2$ & $<2.2$ & $<2.2$ \\
\hline $\mathrm{Pb}$ & $<4.7$ & $<4.7$ & $<4.8$ & $<4.8$ & $<4.7$ & $<4.7$ \\
\hline $\mathrm{Pd}$ & $<1.6$ & $<1.6$ & $<1.6$ & $<1.6$ & $<1.6$ & $<1.6$ \\
\hline $\mathrm{Rh}$ & $<3.2$ & $<3.2$ & $<3.3$ & $<3.3$ & $<3.2$ & $<3.2$ \\
\hline $\mathrm{Ru}$ & $<1.1$ & $<1.1$ & $<1.1$ & $<1.1$ & $<1.1$ & $<1.1$ \\
\hline $\mathrm{Sb}$ & $<4.0$ & $<4.0$ & $<4.1$ & $<4.1$ & $<4.0$ & $<4.0$ \\
\hline Se & {$[8.0]$} & {$[18.0]$} & {$[16.6]$} & [11.9] & $<6.3$ & [14.2] \\
\hline Sn & $<2.6$ & $<2.6$ & $<2.6$ & $<2.6$ & $<2.6$ & $<2.6$ \\
\hline $\mathrm{Ta}$ & $<1.7$ & $<1.7$ & $<1.7$ & $<1.7$ & $<1.7$ & $<1.7$ \\
\hline $\mathrm{Te}$ & $<4.0$ & $<4.0$ & $<4.1$ & $<4.1$ & $<4.0$ & $<4.0$ \\
\hline Th & $<1.5$ & $<1.5$ & $<1.5$ & $<1.5$ & $<1.5$ & $<1.5$ \\
\hline $\mathrm{Ti}$ & $<0.12$ & $<0.12$ & $<0.13$ & $<0.12$ & $<0.12$ & $<0.12$ \\
\hline $\mathrm{Tl}$ & $<8.3$ & $<8.3$ & $<8.4$ & $<8.4$ & $<8.3$ & $<8.3$ \\
\hline $\mathrm{V}$ & $<0.40$ & $<0.40$ & $<0.41$ & $<0.41$ & $<0.40$ & $<0.40$ \\
\hline $\mathrm{W}$ & $<1.9$ & $<1.9$ & $<1.9$ & $<1.9$ & $<1.9$ & $<1.9$ \\
\hline $\mathrm{Y}$ & $<0.11$ & $<0.11$ & $<0.11$ & $<0.11$ & $<0.11$ & $<0.11$ \\
\hline
\end{tabular}


Table G.3. Analyte Concentrations as a Function of Time for Leaching at $80^{\circ} \mathrm{C}$

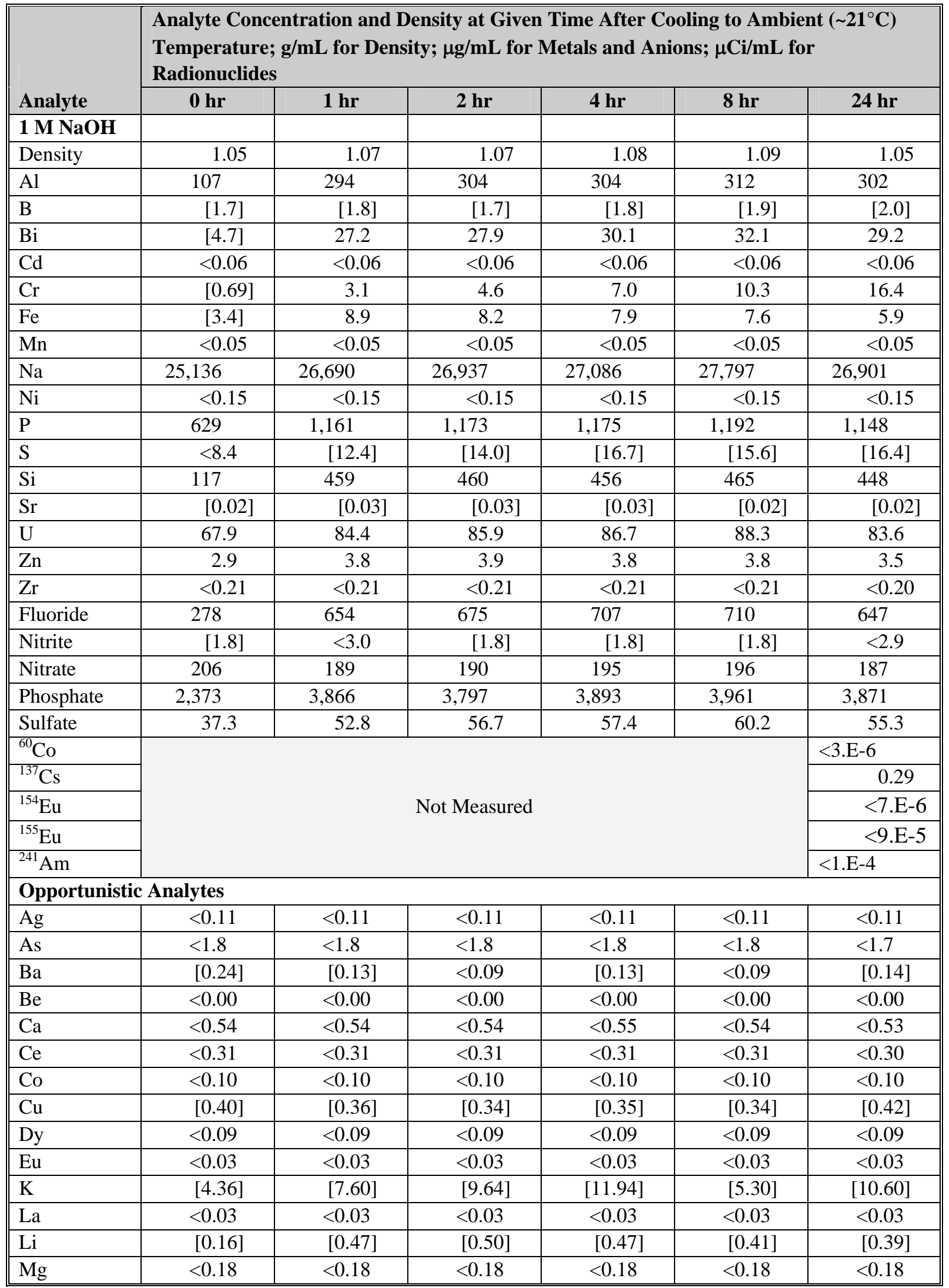


Table G.3 (Contd)

\begin{tabular}{|c|c|c|c|c|c|c|}
\hline \multirow[b]{2}{*}{ Analyte } & \multicolumn{6}{|c|}{$\begin{array}{l}\text { Analyte Concentration and Density at Given Time After Cooling to Ambient }\left(\sim 21^{\circ} \mathrm{C}\right) \\
\text { Temperature; } \mathrm{g} / \mathrm{mL} \text { for Density; } \mu \mathrm{g} / \mathrm{mL} \text { for Metals and Anions; } \mu \mathrm{Ci} / \mathrm{mL} \text { for } \\
\text { Radionuclides }\end{array}$} \\
\hline & $0 \mathrm{hr}$ & $1 \mathrm{hr}$ & $2 \mathrm{hr}$ & $4 \mathrm{hr}$ & $8 \mathrm{hr}$ & $24 \mathrm{hr}$ \\
\hline Mo & $<0.17$ & $<0.17$ & $<0.17$ & $<0.17$ & $<0.17$ & $<0.16$ \\
\hline $\mathrm{Nd}$ & $<0.44$ & $<0.44$ & $<0.44$ & $<0.45$ & $<0.44$ & $<0.43$ \\
\hline $\mathrm{Pb}$ & $<0.95$ & {$[1.1]$} & {$[1.2]$} & {$[1.3]$} & {$[1.1]$} & $<0.93$ \\
\hline $\mathrm{Pd}$ & $<0.32$ & $<0.32$ & $<0.32$ & $<0.33$ & $<0.32$ & $<0.32$ \\
\hline $\mathrm{Rh}$ & $<0.65$ & $<0.65$ & $<0.65$ & $<0.66$ & $<0.65$ & $<0.63$ \\
\hline $\mathrm{Ru}$ & $<0.21$ & $<0.21$ & $<0.21$ & $<0.21$ & $<0.21$ & $<0.21$ \\
\hline $\mathrm{Sb}$ & $<0.81$ & $<0.81$ & $<0.81$ & $<0.82$ & $<0.81$ & $<0.79$ \\
\hline Se & {$[2.0]$} & $<1.3$ & [1.7] & $<1.3$ & $<1.3$ & $<1.2$ \\
\hline Sn & $<0.52$ & $<0.52$ & $<0.52$ & $<0.52$ & $<0.52$ & $<0.50$ \\
\hline $\mathrm{Ta}$ & $<0.34$ & $<0.34$ & $<0.34$ & $<0.35$ & $<0.34$ & $<0.33$ \\
\hline $\mathrm{Te}$ & $<0.81$ & $<0.81$ & $<0.81$ & $<0.82$ & $<0.81$ & $<0.79$ \\
\hline Th & $<0.31$ & $<0.30$ & $<0.30$ & $<0.31$ & $<0.31$ & $<0.30$ \\
\hline $\mathrm{Ti}$ & $<0.02$ & $<0.02$ & $<0.02$ & $<0.03$ & $<0.02$ & $<0.02$ \\
\hline $\mathrm{Tl}$ & $<1.7$ & $<1.7$ & $<1.7$ & $<1.7$ & $<1.7$ & $<1.6$ \\
\hline $\mathrm{V}$ & $<0.08$ & $<0.08$ & $<0.08$ & $<0.08$ & $<0.08$ & $<0.08$ \\
\hline $\mathrm{W}$ & $<0.39$ & {$[0.41]$} & $<0.39$ & $<0.39$ & $<0.39$ & $<0.38$ \\
\hline $\mathrm{Y}$ & $<0.02$ & $<0.02$ & $<0.02$ & $<0.02$ & $<0.02$ & $<0.02$ \\
\hline \multicolumn{7}{|c|}{$3 \mathrm{M} \mathrm{NaOH}$} \\
\hline Density & 1.13 & 1.14 & 1.15 & 1.15 & 1.17 & 1.14 \\
\hline $\mathrm{Al}$ & 123 & 319 & 329 & 331 & 337 & 333 \\
\hline B & $<2.3$ & {$[2.6]$} & [2.3] & $<2.3$ & $<2.4$ & {$[2.4]$} \\
\hline $\mathrm{Bi}$ & 34.0 & 152 & 113 & 96.4 & 81.0 & 82.2 \\
\hline $\mathrm{Cd}$ & $<0.31$ & $<0.31$ & $<0.31$ & $<0.31$ & $<0.31$ & $<0.31$ \\
\hline $\mathrm{Cr}$ & [3.4] & 9.0 & 13.6 & 19.1 & 25.1 & 32.1 \\
\hline $\mathrm{Fe}$ & 26.0 & 28.8 & [25.2] & [23.2] & [21.2] & [16.5] \\
\hline $\mathrm{Mn}$ & [0.31] & $<0.26$ & $<0.26$ & $<0.26$ & $<0.26$ & $<0.26$ \\
\hline $\mathrm{Na}$ & 72,211 & 74,808 & 74,959 & 75,369 & 76,650 & 74,822 \\
\hline $\mathrm{Ni}$ & $<0.73$ & $<0.74$ & $<0.74$ & $<0.74$ & $<0.75$ & $<0.73$ \\
\hline $\mathrm{P}$ & 542 & 1,119 & 1,115 & 1,106 & 1,137 & 1,118 \\
\hline $\mathrm{S}$ & $<41.4$ & $<41.4$ & $<41.5$ & $<41.7$ & $<42.1$ & $<41.3$ \\
\hline $\mathrm{Si}$ & 112 & 518 & 519 & 525 & 542 & 531 \\
\hline $\mathrm{Sr}$ & [0.07] & [0.10] & [0.10] & [0.10] & [0.09] & {$[0.06]$} \\
\hline $\mathrm{U}$ & [61.2] & [104] & [101] & [98.8] & [99.7] & [91.6] \\
\hline $\mathrm{Zn}$ & [4.0] & [5.8] & [5.5] & [5.6] & [5.6] & [5.5] \\
\hline $\mathrm{Zr}$ & $<1.0$ & $<1.0$ & $<1.0$ & $<1.0$ & $<1.0$ & $<1.0$ \\
\hline Fluoride & 282 & 719 & 711 & 687 & 730 & 711 \\
\hline Nitrite & [1.8] & [1.8] & [1.8] & [1.8] & [1.8] & [1.8] \\
\hline Nitrate & 191 & 219 & 213 & 209 & 224 & 219 \\
\hline Phosphate & 1,791 & 3,956 & 3,858 & 3,827 & 4,006 & 3,957 \\
\hline Sulfate & 42.7 & 72.5 & 75.3 & 74.8 & 91.4 & 83.4 \\
\hline
\end{tabular}


Table G.3 (Contd)

\begin{tabular}{|c|c|c|c|c|c|c|}
\hline \multirow[b]{2}{*}{ Analyte } & \multicolumn{6}{|c|}{$\begin{array}{l}\text { Analyte Concentration and Density at Given Time After Cooling to Ambient }\left(\sim 21^{\circ} \mathrm{C}\right) \\
\text { Temperature; } \mathrm{g} / \mathrm{mL} \text { for Density; } \mu \mathrm{g} / \mathrm{mL} \text { for Metals and Anions; } \mu \mathrm{Ci} / \mathrm{mL} \text { for } \\
\text { Radionuclides }\end{array}$} \\
\hline & $0 \mathrm{hr}$ & $1 \mathrm{hr}$ & $2 \mathrm{hr}$ & $4 \mathrm{hr}$ & $8 \mathrm{hr}$ & $24 \mathrm{hr}$ \\
\hline${ }^{60} \mathrm{Co}$ & \multirow{5}{*}{\multicolumn{5}{|c|}{ Not Measured }} & $<3 . \mathrm{E}-6$ \\
\hline${ }^{137} \mathrm{Cs}$ & & & & & & 0.30 \\
\hline${ }^{154} \mathrm{Eu}$ & & & & & & $<1 . \mathrm{E}-5$ \\
\hline${ }^{155} \mathrm{Eu}$ & & & & & & $<8 . \mathrm{E}-5$ \\
\hline${ }^{241} \mathrm{Am}$ & & & & & & $<4 . \mathrm{E}-5$ \\
\hline \multicolumn{7}{|c|}{ Opportunistic Analytes } \\
\hline $\mathrm{Ag}$ & $<0.54$ & $<0.54$ & $<0.54$ & $<0.54$ & $<0.55$ & $<0.53$ \\
\hline As & $<8.8$ & $<8.8$ & $<8.9$ & $<8.9$ & $<9.0$ & $<8.8$ \\
\hline $\mathrm{Ba}$ & $<0.43$ & $<0.43$ & $<0.43$ & $<0.43$ & $<0.44$ & $<0.43$ \\
\hline $\mathrm{Be}$ & $<0.02$ & $<0.02$ & $<0.02$ & $<0.02$ & $<0.02$ & $<0.02$ \\
\hline $\mathrm{Ca}$ & $<2.7$ & $<2.7$ & $<2.7$ & $<2.7$ & $<2.7$ & $<2.7$ \\
\hline $\mathrm{Ce}$ & $<1.5$ & $<1.5$ & $<1.5$ & $<1.5$ & $<1.5$ & $<1.5$ \\
\hline Co & $<0.49$ & $<0.49$ & $<0.49$ & $<0.49$ & $<0.50$ & $<0.49$ \\
\hline $\mathrm{Cu}$ & {$[0.67]$} & {$[0.86]$} & {$[0.80]$} & {$[0.68]$} & {$[0.75]$} & {$[0.76]$} \\
\hline Dy & $<0.44$ & $<0.44$ & $<0.45$ & $<0.45$ & $<0.45$ & $<0.44$ \\
\hline $\mathrm{Eu}$ & $<0.14$ & $<0.14$ & $<0.14$ & $<0.14$ & $<0.14$ & $<0.14$ \\
\hline $\mathrm{K}$ & [22.3] & [26.4] & [29.8] & [25.9] & [34.3] & [30.5] \\
\hline $\mathrm{La}$ & $<0.17$ & $<0.17$ & $<0.17$ & $<0.17$ & $<0.17$ & $<0.17$ \\
\hline $\mathrm{Li}$ & $<0.69$ & {$[0.71]$} & {$[0.77]$} & {$[0.74]$} & {$[0.72]$} & $<0.69$ \\
\hline $\mathrm{Mg}$ & $<0.89$ & $<0.89$ & $<0.89$ & $<0.90$ & $<0.90$ & $<0.89$ \\
\hline Mo & $<0.83$ & $<0.83$ & $<0.83$ & {$[1.1]$} & $<0.84$ & $<0.82$ \\
\hline $\mathrm{Nd}$ & $<2.2$ & $<2.2$ & $<2.2$ & $<2.2$ & $<2.2$ & $<2.2$ \\
\hline $\mathrm{Pb}$ & $<4.7$ & $<4.7$ & $<4.7$ & $<4.7$ & $<4.8$ & $<4.7$ \\
\hline $\mathrm{Pd}$ & $<1.6$ & $<1.6$ & $<1.6$ & $<1.6$ & $<1.6$ & $<1.6$ \\
\hline $\mathrm{Rh}$ & $<3.2$ & $<3.2$ & $<3.2$ & $<3.2$ & $<3.3$ & $<3.2$ \\
\hline $\mathrm{Ru}$ & $<1.0$ & $<1.0$ & $<1.0$ & $<1.1$ & $<1.1$ & $<1.0$ \\
\hline $\mathrm{Sb}$ & $<4.0$ & $<4.0$ & $<4.0$ & $<4.0$ & $<4.1$ & $<4.0$ \\
\hline Se & $<6.2$ & $<6.2$ & [7.7] & $<6.3$ & $<6.3$ & $<6.2$ \\
\hline Sn & $<2.5$ & $<2.5$ & $<2.5$ & $<2.6$ & $<2.6$ & $<2.5$ \\
\hline $\mathrm{Ta}$ & $<1.7$ & $<1.7$ & $<1.7$ & $<1.7$ & $<1.7$ & $<1.7$ \\
\hline $\mathrm{Te}$ & $<4.0$ & $<4.0$ & $<4.0$ & $<4.0$ & $<4.1$ & $<4.0$ \\
\hline Th & $<1.5$ & $<1.5$ & $<1.5$ & $<1.5$ & $<1.5$ & $<1.5$ \\
\hline $\mathrm{Ti}$ & $<0.12$ & $<0.12$ & $<0.12$ & $<0.12$ & $<0.12$ & $<0.12$ \\
\hline $\mathrm{Tl}$ & $<8.2$ & $<8.2$ & $<8.2$ & $<8.3$ & $<8.4$ & $<8.2$ \\
\hline V & $<0.40$ & $<0.40$ & $<0.40$ & $<0.40$ & $<0.41$ & $<0.40$ \\
\hline $\mathrm{W}$ & $<1.9$ & $<1.9$ & $<1.9$ & {$[2.3]$} & $<1.9$ & $<1.9$ \\
\hline $\mathrm{Y}$ & $<0.11$ & $<0.11$ & $<0.11$ & $<0.11$ & $<0.11$ & $<0.11$ \\
\hline
\end{tabular}


WTP-RPT-166, Rev. 0

Table G.4. Analyte Concentrations for Composite Wash Solution for Wash of Samples Leached at $40^{\circ} \mathrm{C}$ in $3 \mathrm{M} \mathrm{NaOH}$

\begin{tabular}{|c|c|c|c|}
\hline Analyte & $\begin{array}{c}\text { Concentration } \\
(\mu \mathrm{g} / \mathrm{mL})\end{array}$ & $\begin{array}{l}\text { Opportunistic } \\
\text { Analytes }\end{array}$ & $\begin{array}{c}\text { Concentration } \\
(\mu \mathrm{g} / \mathrm{mL})\end{array}$ \\
\hline $\mathrm{Al}$ & [4.73] & $\mathrm{Ag}$ & $<0.103$ \\
\hline B & $<0.446$ & As & $<1.70$ \\
\hline $\mathrm{Bi}$ & [1.83] & $\mathrm{Ba}$ & $<0.083$ \\
\hline $\mathrm{Cd}$ & $<0.059$ & $\mathrm{Be}$ & $<0.003$ \\
\hline $\mathrm{Cr}$ & 1.23 & $\mathrm{Ca}$ & $<0.514$ \\
\hline $\mathrm{Fe}$ & [0.561] & $\mathrm{Ce}$ & $<0.292$ \\
\hline $\mathrm{Mn}$ & $<0.050$ & Co & $<0.095$ \\
\hline $\mathrm{Na}$ & 1,542 & $\mathrm{Cu}$ & {$[0.413]$} \\
\hline $\mathrm{Ni}$ & $<0.142$ & Dy & $<0.086$ \\
\hline $\mathrm{P}$ & [5.61] & $\mathrm{Eu}$ & $<0.027$ \\
\hline$S$ & $<7.98$ & $\mathrm{~K}$ & $<2.97$ \\
\hline $\mathrm{Si}$ & 6.32 & $\mathrm{La}$ & $<0.032$ \\
\hline $\mathrm{Sr}$ & {$[0.010]$} & $\mathrm{Li}$ & $<0.133$ \\
\hline $\mathrm{U}$ & $<2.05$ & $\mathrm{Mg}$ & $<0.171$ \\
\hline $\mathrm{Zn}$ & [0.679] & Mo & $<0.159$ \\
\hline $\mathrm{Zr}$ & $<0.198$ & $\mathrm{Nd}$ & $<0.419$ \\
\hline Fluoride & 2.33 & $\mathrm{~Pb}$ & $<0.904$ \\
\hline Nitrite & $<1.49$ & $\mathrm{Pd}$ & $<0.307$ \\
\hline Nitrate & 86.6 & $\mathrm{Rh}$ & $<0.617$ \\
\hline Phosphate & 16.1 & $\mathrm{Ru}$ & $<0.201$ \\
\hline Sulfate & [2.75] & $\mathrm{Sb}$ & $<0.768$ \\
\hline & & Se & {$[2.72]$} \\
\hline & & Sn & $<0.490$ \\
\hline & & Ta & $<0.325$ \\
\hline & & $\mathrm{Te}$ & $<0.771$ \\
\hline & & Th & $<0.289$ \\
\hline & & $\mathrm{Ti}$ & $<0.024$ \\
\hline & & $\mathrm{Tl}$ & $<1.59$ \\
\hline & & $\mathrm{V}$ & $<0.077$ \\
\hline & & $\mathrm{W}$ & $<0.366$ \\
\hline & & $\mathrm{Y}$ & $<0.021$ \\
\hline
\end{tabular}




\section{Appendix $\mathrm{H}$}

\section{Duplicate Sample Differential Particle Size Plots for the Initial Group 2 Sample}




\section{Appendix H: Duplicate Sample Differential Particle Size Plots for the Initial Group 2 Sample}

Figures H.1, H.2, and H.3 show show the differential volume distribution as a function of particle diameter for the duplicate Group 2 initial characterization sample, TI517-G2-S-WL-PSD-2. Specifically, Figure H.1 shows the pre-sonication PSDs as a function of pump speed, Figure H.2 shows the PSDs as a function of sonication, and Figure H.3 shows the post-sonication PSDs as a function of pump speed.

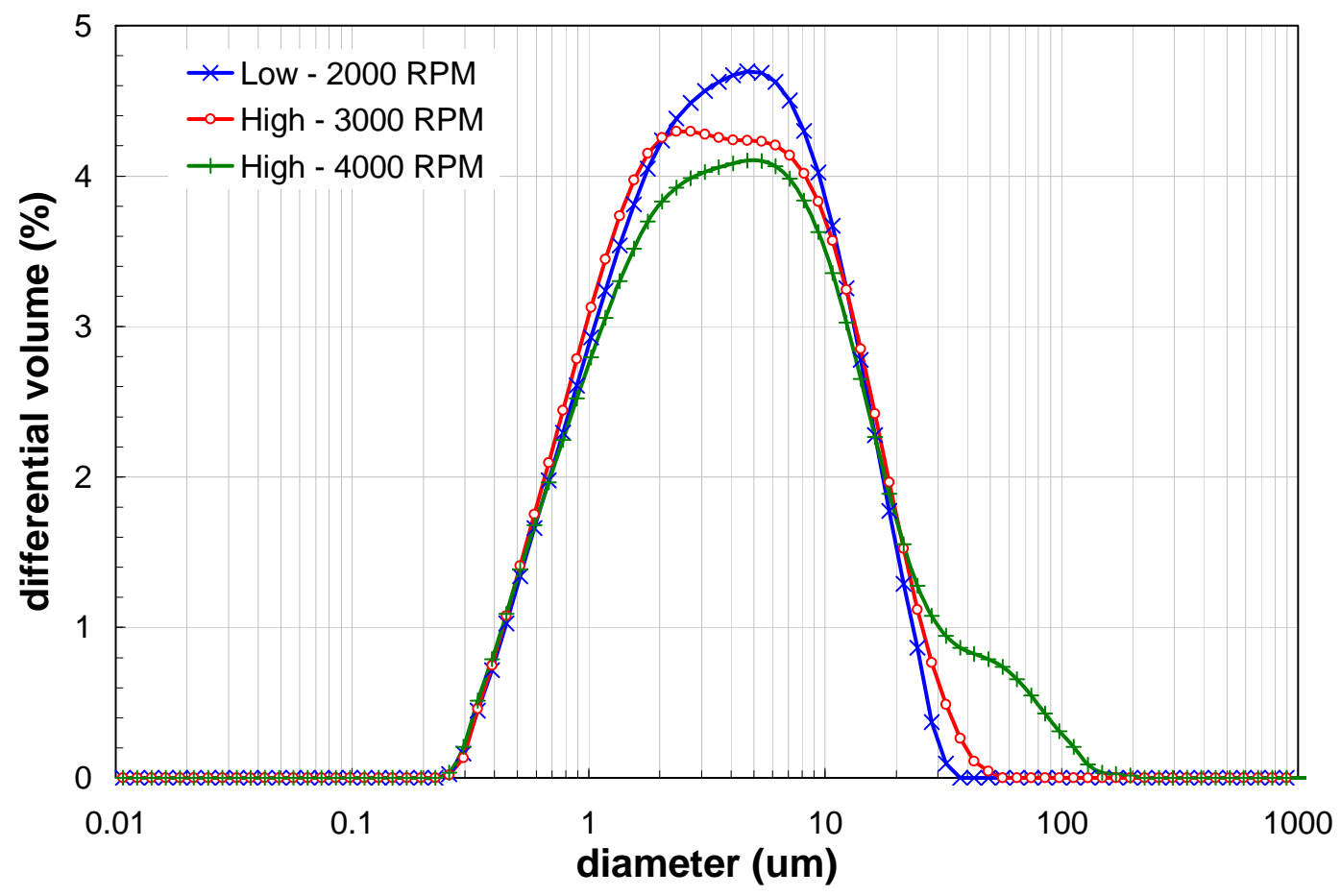

Figure H.1. Pre-Sonication Volume Distribution Result for the Duplicate Group 2 Initial Characterization Sample as a Function of Pump Speed 


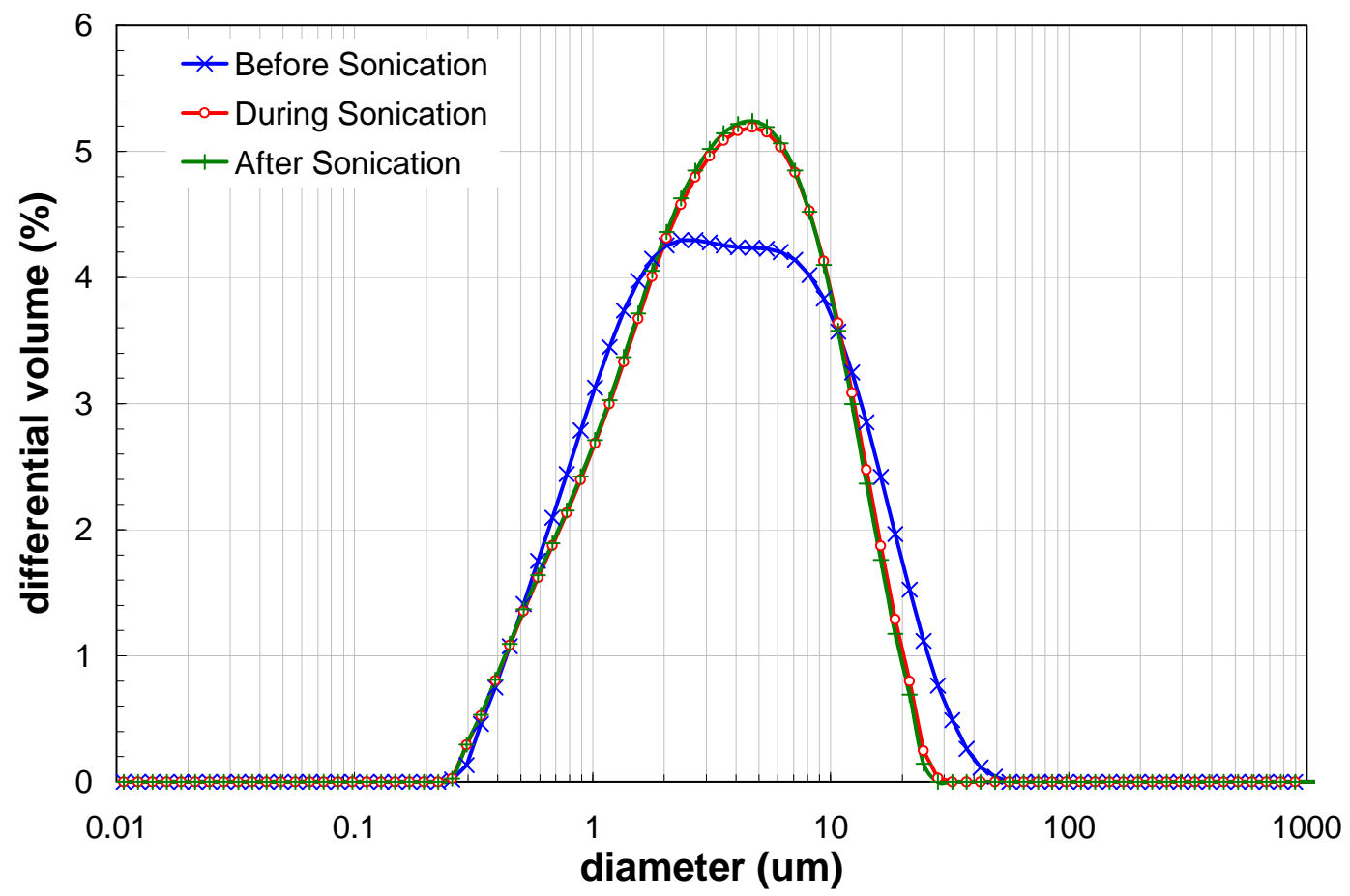

Figure H.2. Volume Distribution Result for the Duplicate Group 2 Initial Characterization Sample as a Function of Sonication (75\% power)

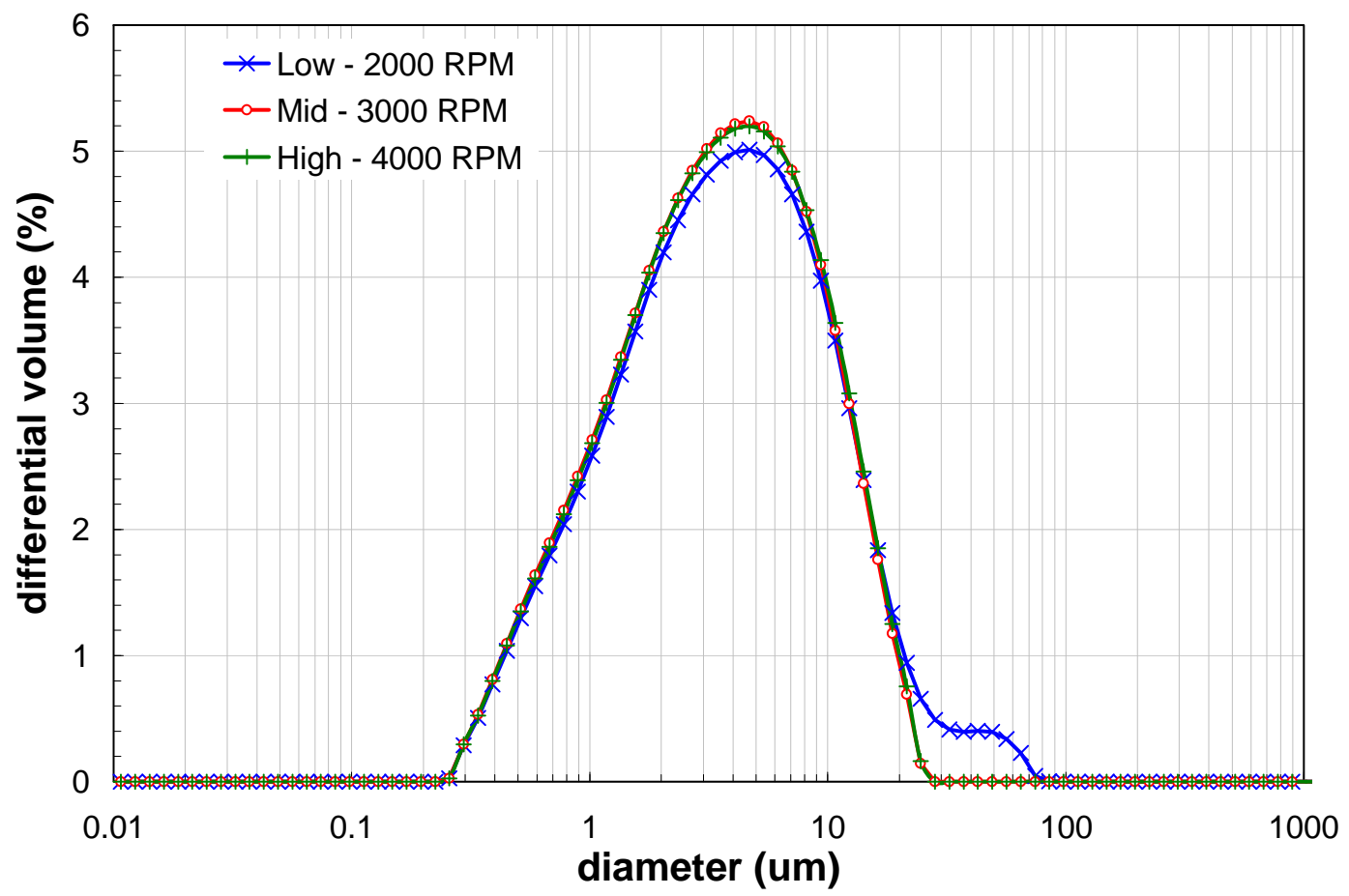

Figure H.3. Post-Sonication Volume Distribution Result for the Duplicate Group 2 Initial Characterization Sample as a Function of Pump Speed 


\section{Appendix I}

\section{Detailed Cumulative PSD for the Initial Group 2 Sample}




\section{Appendix I: Detailed Cumulative PSD for the Initial Group 2 Sample}

Tables I.1 and I.2 present detailed cumulative oversize distributions (by volume/weight) for Group 2 Initial Characterization samples TI517-G2-S-WL-PSD-1 and -2, respectively. The results are reported as a function of test condition. This appendix does not provide discussion of the detailed distributions; however, a portion of these results (specifically, the $10^{\text {th }}, 50^{\text {th }}$, and $90^{\text {th }}$ diameter percentiles) are presented and discussed in the main body of the report.

Table I.1. Cumulative Oversize Diameter Distributions for the Primary Group 2 Initial Characterization Sample, TI517-G2-S-WL-PSD-1

\begin{tabular}{|c|c|c|c|c|c|c|c|c|c|c|c|c|c|c|c|}
\hline \multirow[b]{2}{*}{ Test Condition } & \multicolumn{15}{|c|}{ Volume/Weight Cumulative Oversize Diameter $(\mu \mathrm{m})$} \\
\hline & $1 \%$ & $5 \%$ & $10 \%$ & $20 \%$ & $25 \%$ & $30 \%$ & $40 \%$ & $50 \%$ & $60 \%$ & $70 \%$ & $75 \%$ & $80 \%$ & $90 \%$ & $95 \%$ & $99 \%$ \\
\hline 1 - 3000/pre-sonic & 0.42 & 0.64 & 0.86 & 1.3 & 1.5 & 1.8 & 2.4 & 3.2 & 4.2 & 5.7 & 6.6 & 7.7 & 11 & 14 & 20 \\
\hline 2 - 4000/pre-sonic & 0.41 & 0.64 & 0.87 & 1.4 & 1.6 & 1.9 & 2.6 & 3.5 & 4.6 & 6.2 & 7.2 & 8.5 & 13 & 17 & 190 \\
\hline 3 - 2000/pre-sonic & 0.42 & 0.65 & 0.88 & 1.3 & 1.6 & 1.8 & 2.4 & 3.2 & 4.2 & 5.5 & 6.4 & 7.4 & 10 & 13 & 19 \\
\hline $4-3000 / 25 \%$ & 0.38 & 0.57 & 0.79 & 1.2 & 1.5 & 1.7 & 2.3 & 3.1 & 4.1 & 5.4 & 6.2 & 7.2 & 10 & 13 & 19 \\
\hline $5-3000 / 50 \%$ & 0.36 & 0.56 & 0.77 & 1.2 & 1.5 & 1.8 & 2.4 & 3.1 & 4.0 & 5.3 & 6.1 & 7.1 & 10 & 13 & 18 \\
\hline $6-3000 / 75 \%$ & 0.36 & 0.55 & 0.77 & 1.2 & 1.5 & 1.8 & 2.4 & 3.1 & 4.0 & 5.2 & 5.9 & 6.9 & 9.7 & 12 & 17 \\
\hline 7 - 3000/post-sonic & 0.36 & 0.55 & 0.77 & 1.2 & 1.5 & 1.8 & 2.4 & 3.1 & 4.0 & 5.1 & 5.9 & 6.8 & 9.6 & 12 & 17 \\
\hline 8 - 4000/post-sonic & 0.38 & 0.59 & 0.84 & 1.4 & 1.7 & 1.9 & 2.6 & 3.4 & 4.3 & 5.6 & 6.4 & 7.3 & 10 & 13 & 18 \\
\hline 9 - 2000/post-sonic & 0.36 & 0.56 & 0.78 & 1.3 & 1.5 & 1.8 & 2.4 & 3.1 & 4.0 & 5.2 & 5.9 & 6.8 & 9.6 & 12 & 17 \\
\hline
\end{tabular}

Table I.2. Cumulative Oversize Diameter Distributions for the Duplicate Group 2 Initial Characterization Sample, TI517-G2-S-WL-PSD-2

\begin{tabular}{||l|c|c|c|c|c|c|c|c|c|c|c|c|c|c|c|c||}
\hline \multirow{2}{*}{ Test Condition } & \multicolumn{10}{|c||}{ Volume / Weight Cumulative Oversize Diameter $(\boldsymbol{\mu m})$} \\
\cline { 2 - 21 } & $\mathbf{1 \%}$ & $\mathbf{5 \%}$ & $\mathbf{1 0 \%}$ & $\mathbf{2 0 \%}$ & $\mathbf{2 5 \%}$ & $\mathbf{3 0 \%}$ & $\mathbf{4 0 \%}$ & $\mathbf{5 0 \%}$ & $\mathbf{6 0 \%}$ & $\mathbf{7 0 \%}$ & $\mathbf{7 5 \%}$ & $\mathbf{8 0 \%}$ & $\mathbf{9 0 \%}$ & $\mathbf{9 5 \%}$ & $\mathbf{9 9 \%}$ \\
\hline $\mathbf{1}$ - 3000/pre-sonic & 0.39 & 0.60 & 0.83 & 1.3 & 1.5 & 1.8 & 2.5 & 3.5 & 4.8 & 6.7 & 7.9 & 9.4 & 14 & 19 & 30 \\
\hline $\mathbf{2}$ - 4000/pre-sonic & 0.38 & 0.60 & 0.84 & 1.4 & 1.7 & 2.0 & 2.8 & 4.0 & 5.6 & 7.9 & 9.5 & 12 & 21 & 38 & 82 \\
\hline $\mathbf{3}$ - 2000/pre-sonic & 0.39 & 0.61 & 0.85 & 1.3 & 1.6 & 1.9 & 2.6 & 3.6 & 4.8 & 6.5 & 7.5 & 8.8 & 13 & 17 & 24 \\
\hline $\mathbf{4}$ - 3000/25\% & 0.39 & 0.62 & 0.86 & 1.4 & 1.7 & 2.0 & 2.7 & 3.6 & 4.8 & 6.4 & 7.4 & 8.6 & 12 & 16 & 23 \\
\hline $\mathbf{5}$ - 3000/50\% & 0.38 & 0.60 & 0.86 & 1.4 & 1.7 & 2.0 & 2.7 & 3.6 & 4.8 & 6.3 & 7.3 & 8.4 & 12 & 15 & 22 \\
\hline $\mathbf{6}$ - 3000/75\% & 0.38 & 0.60 & 0.85 & 1.4 & 1.7 & 2.0 & 2.7 & 3.6 & 4.6 & 6.1 & 7.0 & 8.1 & 11 & 14 & 20 \\
\hline $\mathbf{7}$ - 3000/post-sonic & 0.37 & 0.59 & 0.84 & 1.4 & 1.7 & 2.0 & 2.7 & 3.5 & 4.6 & 6.0 & 6.8 & 7.9 & 11 & 14 & 19 \\
\hline $\mathbf{8}$ - 4000/post-sonic & 0.37 & 0.60 & 0.85 & 1.4 & 1.7 & 2.0 & 2.7 & 3.5 & 4.6 & 6.0 & 6.9 & 8.0 & 11 & 14 & 20 \\
\hline $\mathbf{9}$ - 2000/post-sonic & 0.38 & 0.61 & 0.87 & 1.4 & 1.7 & 2.1 & 2.8 & 3.7 & 4.9 & 6.5 & 7.5 & 8.8 & 13 & 18 & 46 \\
\hline
\end{tabular}

Table I.3 shows the absolute relative percent difference (RPD) between primary and duplicate results, which is calculated as:

$$
R P D=\left|\frac{d_{d}(n)-d_{p}(n)}{d_{p}(n)}\right|
$$


where $d_{p}(n)$ and $d_{d}(n)$ are the primary and duplicate cumulative oversize diameters corresponding to the $n^{\text {th }}$ percentile. As before, this appendix does not provide discussion of the RPD results; however, the RPD for the $10^{\text {th }}, 50^{\text {th }}$, and $90^{\text {th }}$ diameter percentiles are presented and discussed in the main body of this interim report.

Table I.3. Relative Percent Difference Between Primary and Duplicate Group 2 Initial Characterization Samples (TI517-G2-S-WL-PSD-1 and -2, respectively) as a Function of Test Condition

\begin{tabular}{|c|c|c|c|c|c|c|c|c|c|c|c|c|c|c|c|}
\hline \multirow[b]{2}{*}{ Test Condition } & \multicolumn{15}{|c|}{ Absolute RPD (\%) } \\
\hline & $1 \%$ & $5 \%$ & $10 \%$ & $20 \%$ & $25 \%$ & $30 \%$ & $40 \%$ & $50 \%$ & $60 \%$ & $70 \%$ & $75 \%$ & $80 \%$ & $90 \%$ & $95 \%$ & $99 \%$ \\
\hline 1 - 3000/pre & 5.5 & 5.6 & 4.4 & 1.2 & 0.33 & 2.0 & 5.7 & \begin{tabular}{|c|}
9.8 \\
\end{tabular} & 14 & 18 & 20 & 22 & 28 & 34 & 50 \\
\hline $2-4000 / p$ & 6.6 & 6.1 & 4.3 & 0.30 & 2.7 & 5.1 & 10 & 15 & 21 & 27 & 31 & 36 & 63 & 120 & 57 \\
\hline $3-2000 / p$ & 6.2 & 5.3 & 3.4 & 0.52 & 2.5 & 4.4 & 8.0 & 11 & 14 & 17 & 18 & 20 & 24 & 26 & 29 \\
\hline $4-3000 / 25 \%$ & 3.5 & 7.3 & 9.8 & 12 & 13 & 14 & 16 & 17 & 18 & 19 & 19 & 19 & 20 & 21 & 22 \\
\hline $5-3000 / 50 \%$ & 3.8 & 7.9 & 11 & 13 & 14 & 14 & 16 & 17 & 18 & 19 & 19 & 19 & 19 & 19 & 19 \\
\hline 6 - 3000/75\% & 3.9 & 7.8 & 10 & 12 & 13 & 13 & 14 & 16 & 17 & 18 & 18 & 18 & 17 & 16 & 15 \\
\hline 7 - 3000/post-sonic & 3.6 & 7.2 & 9.6 & 11 & 11 & 12 & 13 & 14 & 15 & 16 & 16 & 16 & 15 & 14 & 13 \\
\hline 8 - 4000/post-sonic & 0.27 & 0.34 & 0.59 & 0.80 & 1.1 & 1.5 & 2.9 & 4.7 & 6.6 & 8.3 & 9.0 & 9.5 & 10 & 10 & 10 \\
\hline 9 - 2000/post-sonic & 3.6 & 8.4 & 12 & 14 & 15 & 15 & 17 & 20 & 23 & 26 & 27 & 29 & 36 & 51 & 170 \\
\hline
\end{tabular}


Appendix $\mathbf{J}$

Group 2 Analytical Results from Parametric Leaching 
WTP-RPT-166, Rev. 0

\section{Appendix J: Group 2 Analytical Results from Parametric Leaching}

Table J.1 provides information about analyte concentrations during leaching at various hour increments at $60^{\circ} \mathrm{C}$, Table $\mathrm{J} .2$ at $80^{\circ} \mathrm{C}$, and Table $\mathrm{J} .3$ at $100^{\circ} \mathrm{C}$.

Table J.1. Analyte Concentrations as a Function of Time for Leaching at $60^{\circ} \mathrm{C}$

\begin{tabular}{|c|c|c|c|c|c|c|}
\hline \multirow[b]{2}{*}{ Analyte } & \multicolumn{6}{|c|}{$\begin{array}{l}\text { Analyte Concentration and Density at Given Time After Cooling to Ambient }\left(\sim 21^{\circ} \mathrm{C}\right) \\
\text { Temperature; } \mathrm{g} / \mathrm{mL} \text { for Density; } \mu \mathrm{g} / \mathrm{mL} \text { for Metals and Anions; } \mu \mathrm{Ci} / \mathrm{mL} \text { for } \\
\text { Radionuclides }\end{array}$} \\
\hline & $0 \mathrm{hr}$ & $1 \mathrm{hr}$ & $2 \mathrm{hr}$ & $4 \mathrm{hr}$ & $8 \mathrm{hr}$ & $24 \mathrm{hr}$ \\
\hline \multicolumn{7}{|c|}{$3 \mathrm{M} \mathrm{NaOH}$} \\
\hline Density & 1.14 & 1.14 & 1.16 & 1.17 & 1.15 & 1.13 \\
\hline $\mathrm{Al}$ & 188 & 736 & 921 & 1,095 & 1,191 & 1,256 \\
\hline $\mathrm{B}$ & {$[2.6]$} & $<2.4$ & {$[2.6]$} & $<2.4$ & {$[2.4]$} & $<2.3$ \\
\hline $\mathrm{Bi}$ & $<3.0$ & {$[4.1]$} & $<2.931$ & {$[3.8]$} & [3.2] & {$[3.0]$} \\
\hline $\mathrm{Cd}$ & $<0.31$ & $<0.31$ & $<0.31$ & $<0.31$ & $<0.32$ & $<0.30$ \\
\hline $\mathrm{Cr}$ & [1.3] & 6.1 & 8.6 & 12.6 & 18.1 & 36.4 \\
\hline $\mathrm{Fe}$ & $<2.6$ & $<2.6$ & {$[2.7]$} & [2.9] & {$[3.1]$} & [3.3] \\
\hline $\mathrm{Mn}$ & $<0.27$ & $<0.26$ & $<0.26$ & $<0.27$ & $<0.27$ & $<0.26$ \\
\hline $\mathrm{Na}$ & 71,486 & 73,253 & 75,369 & 75,707 & 71,854 & 73,400 \\
\hline $\mathrm{P}$ & [24.8] & [9.7] & $<7.0$ & $<7.1$ & [11.35] & $<6.9$ \\
\hline $\mathrm{S}$ & $<42.4$ & $<42.1$ & {$[43.4]$} & [43.8] & $<42.6$ & $<41.0$ \\
\hline $\mathrm{Si}$ & 64.9 & 186 & 189 & 183 & 170 & 162 \\
\hline $\mathrm{Sr}$ & {$[0.13]$} & {$[0.10]$} & {$[0.11]$} & [0.09] & [0.09] & {$[0.08]$} \\
\hline $\mathrm{U}$ & $<10.9$ & {$[15.0]$} & [12.7] & $<10.8$ & [17.3] & [12.7] \\
\hline $\mathrm{Zn}$ & [1.0] & [1.2] & [1.3] & [1.6] & [1.7] & [1.5] \\
\hline $\mathrm{Zr}$ & $<1.1$ & $<1.0$ & $<1.0$ & $<1.0$ & $<1.1$ & $<1.0$ \\
\hline Fluoride & 10.3 & 12.6 & 13.0 & 12.7 & 12.1 & 12.1 \\
\hline Nitrite & $<1.4$ & $<1.4$ & {$[1.5]$} & [1.7] & [1.7] & [1.7] \\
\hline Nitrate & 501 & 553 & 555 & 551 & 554 & 531 \\
\hline Phosphate & 64.3 & 59.1 & 59.3 & 57.2 & 54.6 & 54.7 \\
\hline Sulfate & [1.1] & {$[0.97]$} & {$[0.98]$} & [1.1] & {$[0.87]$} & {$[0.89]$} \\
\hline${ }^{54} \mathrm{Mn}$ & \multirow{7}{*}{\multicolumn{5}{|c|}{ Not Measured }} & $<1 \mathrm{E}-5$ \\
\hline${ }^{60} \mathrm{Co}$ & & & & & & $<3 \mathrm{E}-6$ \\
\hline${ }^{137} \mathrm{Cs}$ & & & & & & 0.809 \\
\hline${ }^{152} \mathrm{Eu}$ & & & & & & $<1 \mathrm{E}-5$ \\
\hline${ }^{154} \mathrm{Eu}$ & & & & & & $<2 \mathrm{E}-5$ \\
\hline${ }^{155} \mathrm{Eu}$ & & & & & & $<1 \mathrm{E}-4$ \\
\hline${ }^{241} \mathrm{Am}$ & & & & & & $<6 \mathrm{E}-5$ \\
\hline \multicolumn{7}{|c|}{ Opportunistic Analytes } \\
\hline $\mathrm{Ag}$ & $<0.55$ & $<0.55$ & $<0.54$ & $<0.55$ & $<0.55$ & $<0.53$ \\
\hline As & $<9.05$ & $<8.99$ & $<8.95$ & $<9.03$ & $<9.09$ & $<8.75$ \\
\hline $\mathrm{Ba}$ & $<0.44$ & $<0.44$ & $<0.43$ & $<0.44$ & $<0.44$ & $<0.42$ \\
\hline $\mathrm{Be}$ & $<0.02$ & $<0.02$ & $<0.02$ & 0.02 & 0.02 & 0.02 \\
\hline $\mathrm{Ca}$ & 2.9 & 2.7 & 2.7 & 2.7 & 2.7 & 2.6 \\
\hline
\end{tabular}


Table J.1 (Contd)

\begin{tabular}{|c|c|c|c|c|c|c|}
\hline \multirow[b]{2}{*}{ Analyte } & \multicolumn{6}{|c|}{$\begin{array}{l}\text { Analyte Concentration and Density at Given Time After Cooling to Ambient }\left(\sim 21^{\circ} \mathrm{C}\right) \\
\text { Temperature; } \mathrm{g} / \mathrm{mL} \text { for Density; } \mu \mathrm{g} / \mathrm{mL} \text { for Metals and Anions; } \mu \mathrm{Ci} / \mathrm{mL} \text { for } \\
\text { Radionuclides }\end{array}$} \\
\hline & o hr & $1 \mathrm{hr}$ & $2 \mathrm{hr}$ & $4 \mathrm{hr}$ & $8 \mathrm{hr}$ & $24 \mathrm{hr}$ \\
\hline Ce & 1.6 & 2.0 & 2.0 & 1.5 & 1.6 & 1.5 \\
\hline $\mathrm{Co}$ & $<0.50$ & $<0.50$ & $<0.50$ & $<0.50$ & $<0.50$ & $<0.49$ \\
\hline $\mathrm{La}$ & $<0.17$ & $<0.17$ & $<0.17$ & $<0.17$ & 0.2 & $<0.17$ \\
\hline $\mathrm{Li}$ & $<0.71$ & $<0.70$ & $<0.70$ & $<0.70$ & $<0.71$ & $<0.68$ \\
\hline $\mathrm{Mg}$ & $<0.91$ & $<0.90$ & $<0.90$ & $<0.91$ & $<0.91$ & $<0.88$ \\
\hline Mo & $<0.85$ & $<0.84$ & $<0.84$ & $<0.84$ & $<0.85$ & $<0.82$ \\
\hline $\mathrm{Nd}$ & $<2.2$ & $<2.2$ & $<2.2$ & $<2.2$ & $<2.2$ & $<2.2$ \\
\hline $\mathrm{Pb}$ & 5.6 & 8.4 & 8.7 & 5.3 & 7.2 & 7.6 \\
\hline $\mathrm{Pd}$ & $<1.6$ & $<1.6$ & $<1.6$ & $<1.6$ & $<1.6$ & $<1.6$ \\
\hline $\mathrm{Rh}$ & $<3.3$ & $<3.3$ & $<3.2$ & $<3.3$ & $<3.3$ & $<3.2$ \\
\hline $\mathrm{Ru}$ & $<1.1$ & $<1.1$ & $<1.1$ & 1.6 & $<1.1$ & $<1.0$ \\
\hline $\mathrm{Sb}$ & $<4.1$ & $<4.1$ & $<4.0$ & $<4.1$ & $<4.1$ & $<3.9$ \\
\hline Se & $<6.3$ & 14.7 & 9.0 & 16.3 & $<6.4$ & $<6.1$ \\
\hline Sn & 3.8 & 3.1 & 2.6 & 5.6 & 3.0 & 2.5 \\
\hline $\mathrm{Ta}$ & $<1.7$ & $<1.7$ & $<1.7$ & $<1.7$ & 2.0 & $<1.7$ \\
\hline $\mathrm{Te}$ & $<4.1$ & $<4.1$ & $<4.0$ & $<4.1$ & $<4.1$ & $<4.0$ \\
\hline Th & $<1.5$ & 1.7 & 2.6 & $<1.5$ & $<1.5$ & $<1.5$ \\
\hline $\mathrm{Ti}$ & $<0.13$ & $<0.12$ & $<0.12$ & $<0.13$ & $<0.13$ & $<0.12$ \\
\hline $\mathrm{Tl}$ & $<8.4$ & $<8.4$ & $<8.3$ & $<8.4$ & $<8.5$ & $<8.1$ \\
\hline V & $<0.41$ & $<0.41$ & $<0.40$ & $<0.41$ & $<0.41$ & $<0.39$ \\
\hline $\mathrm{W}$ & 2.0 & 1.9 & 1.9 & 1.9 & 2.8 & 1.9 \\
\hline $\mathrm{Y}$ & $<0.11$ & $<0.11$ & $<0.11$ & $<0.11$ & $<0.11$ & $<0.11$ \\
\hline
\end{tabular}


Table J.2. Analyte Concentrations as a Function of Time for Leaching at $80^{\circ} \mathrm{C}$

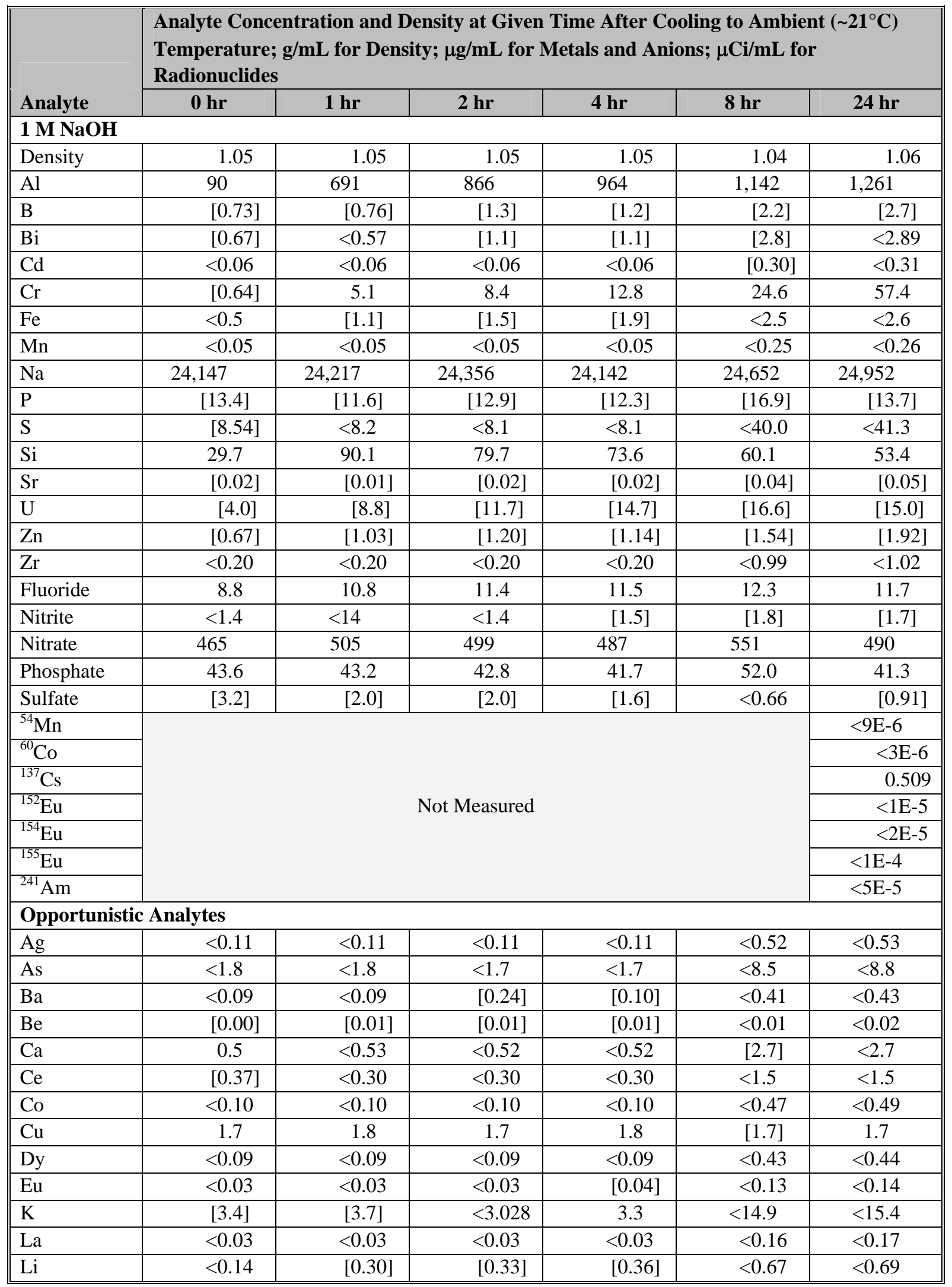


Table J.2 (Contd)

\begin{tabular}{|c|c|c|c|c|c|c|}
\hline \multirow[b]{2}{*}{ Analyte } & \multicolumn{6}{|c|}{$\begin{array}{l}\text { Analyte Concentration and Density at Given Time After Cooling to Ambient }\left(\sim 21^{\circ} \mathrm{C}\right) \\
\text { Temperature; } \mathrm{g} / \mathrm{mL} \text { for Density; } \mu \mathrm{g} / \mathrm{mL} \text { for Metals and Anions; } \mu \mathrm{Ci} / \mathrm{mL} \text { for } \\
\text { Radionuclides }\end{array}$} \\
\hline & o hr & $1 \mathrm{hr}$ & $2 \mathrm{hr}$ & $4 \mathrm{hr}$ & $8 \mathrm{hr}$ & $24 \mathrm{hr}$ \\
\hline $\mathrm{Mg}$ & $<0.18$ & $<0.18$ & $<0.17$ & $<0.17$ & $<0.86$ & $<0.89$ \\
\hline Mo & $<0.16$ & $<0.16$ & $<0.16$ & $<0.16$ & $<0.80$ & $<0.82$ \\
\hline $\mathrm{Nd}$ & $<0.43$ & $<0.43$ & $<0.43$ & $<0.43$ & $<2.10$ & $<2.17$ \\
\hline $\mathrm{Ni}$ & $<0.15$ & $<0.15$ & $<0.14$ & $<0.14$ & $<0.71$ & $<0.73$ \\
\hline $\mathrm{Pb}$ & {$[2.0]$} & [4.3] & [3.9] & [4.5] & {$[5.6]$} & [5.2] \\
\hline $\mathrm{Pd}$ & $<0.32$ & $<0.32$ & $<0.31$ & $<0.31$ & $<1.5$ & $<1.6$ \\
\hline $\mathrm{Rh}$ & $<0.64$ & $<0.64$ & $<0.63$ & $<0.63$ & $<3.1$ & $<3.2$ \\
\hline $\mathrm{Ru}$ & $<0.21$ & $<0.21$ & $<0.20$ & $<0.20$ & $<1.0$ & $<1.0$ \\
\hline $\mathrm{Sb}$ & $<0.79$ & $<0.79$ & $<0.78$ & $<0.78$ & $<3.8$ & $<4.0$ \\
\hline Se & {$[2.2]$} & {$[2.1]$} & {$[1.2]$} & $<1.216$ & $<6.0$ & [11.0] \\
\hline Sn & [1.2] & [1.1] & {$[0.75]$} & {$[0.90]$} & $<2.5$ & $<2.5$ \\
\hline $\mathrm{Ta}$ & $<0.34$ & $<0.33$ & $<0.33$ & {$[0.36]$} & $<1.6$ & $<1.7$ \\
\hline $\mathrm{Te}$ & $<0.80$ & $<0.79$ & $<0.78$ & $<0.78$ & $<3.9$ & $<4.0$ \\
\hline Th & $<0.30$ & $<0.30$ & $<0.29$ & $<0.29$ & $<1.5$ & $<1.5$ \\
\hline $\mathrm{Ti}$ & $<0.02$ & $<0.02$ & $<0.02$ & $<0.02$ & $<0.12$ & $<0.12$ \\
\hline $\mathrm{Tl}$ & $<1.6$ & $<1.6$ & $<1.6$ & $<1.6$ & $<7.9$ & $<8.2$ \\
\hline $\mathrm{V}$ & {$[0.15]$} & {$[0.19]$} & {$[0.15]$} & {$[0.19]$} & $<0.38$ & $<0.40$ \\
\hline $\mathrm{W}$ & $<0.38$ & $<0.38$ & $<0.37$ & $<0.37$ & $<1.8$ & $<1.9$ \\
\hline $\mathrm{Y}$ & $<0.02$ & $<0.02$ & $<0.02$ & $<0.02$ & $<0.10$ & $<0.11$ \\
\hline \multicolumn{7}{|c|}{$3 \mathrm{M}$ NaOH, Trial a } \\
\hline Density & 1.12 & 1.12 & 1.12 & 1.13 & 1.13 & 1.13 \\
\hline $\mathrm{Al}$ & 144 & 969 & 1,120 & 1,246 & 1,272 & 1,331 \\
\hline B & $<2.3$ & $<2.3$ & $<2.2$ & $<2.3$ & $<3.3$ & $<2.3$ \\
\hline $\mathrm{Bi}$ & $<2.9$ & [3.4] & {$[3.0]$} & [3.3] & $<6.0$ & {$[5.2]$} \\
\hline $\mathrm{Cd}$ & $<0.30$ & $<0.30$ & {$[0.36]$} & $<0.30$ & $<0.33$ & {$[0.46]$} \\
\hline $\mathrm{Cr}$ & {$[0.94]$} & 10.0 & 17.8 & 28.2 & 53.4 & 91.6 \\
\hline $\mathrm{Fe}$ & $<2.6$ & {$[3.4]$} & {$[4.8]$} & {$[4.5]$} & {$[5.4]$} & [6.7] \\
\hline $\mathrm{Mn}$ & $<0.26$ & $<0.26$ & {$[0.25]$} & {$[0.28]$} & $<0.25$ & $<0.26$ \\
\hline $\mathrm{Na}$ & 70,740 & 70,729 & 69,514 & 69,801 & 71,995 & 72,653 \\
\hline $\mathrm{P}$ & [17.5] & {$[22.0]$} & [18.7] & [14.1] & [16.8] & [22.6] \\
\hline$S$ & $<40.9$ & $<41.2$ & $<40.1$ & $<40.7$ & $<40.5$ & $<41.3$ \\
\hline $\mathrm{Si}$ & 57.4 & 163 & 153 & 153 & 155 & 158 \\
\hline $\mathrm{Sr}$ & {$[0.11]$} & {$[0.08]$} & {$[0.08]$} & {$[0.09]$} & {$[0.13]$} & {$[0.18]$} \\
\hline $\mathrm{U}$ & $<10.5$ & {$[11.9]$} & {$[11.3]$} & {$[13.8]$} & {$[21.9]$} & [20.8] \\
\hline $\mathrm{Zn}$ & {$[0.85]$} & [1.4] & [1.4] & [2.0] & [1.9] & [2.0] \\
\hline $\mathrm{Zr}$ & $<1.0$ & $<1.0$ & $<1.00$ & $<1.0$ & $<1.0$ & $<1.0$ \\
\hline Fluoride & 9.7 & 10.9 & 11.4 & 12.1 & 11.8 & 12.2 \\
\hline Nitrite & $<1.3$ & $<1.4$ & [1.6] & [1.6] & $<1.3$ & [1.8] \\
\hline Nitrate & 481 & 490 & 522 & 532 & 483 & 534 \\
\hline Phosphate & 49.8 & 47.6 & 50.3 & 51.1 & 42.0 & 49.1 \\
\hline Sulfate & {$[2.8]$} & {$[1.0]$} & {$[1.0]$} & [1.1] & {$[1.6]$} & [0.7] \\
\hline
\end{tabular}


Table J.2 (Contd)

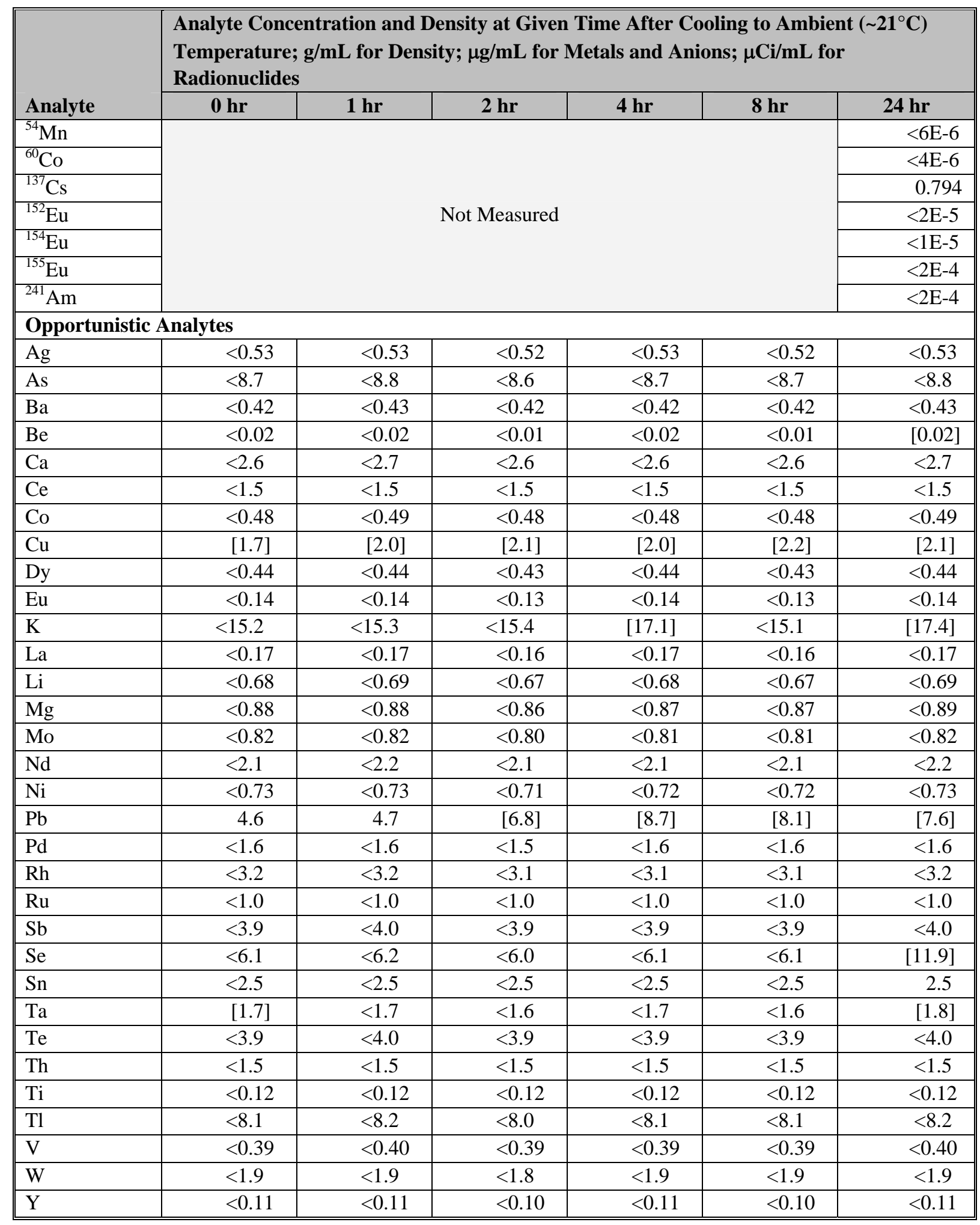


Table J.2 (Contd)

\begin{tabular}{|c|c|c|c|c|c|c|}
\hline \multirow[b]{2}{*}{ Analyte } & \multicolumn{6}{|c|}{$\begin{array}{l}\text { Analyte Concentration and Density at Given Time After Cooling to Ambient }\left(\sim 21^{\circ} \mathrm{C}\right) \\
\text { Temperature; } \mathrm{g} / \mathrm{mL} \text { for Density; } \mu \mathrm{g} / \mathrm{mL} \text { for Metals and Anions; } \mu \mathrm{Ci} / \mathrm{mL} \text { for } \\
\text { Radionuclides }\end{array}$} \\
\hline & o hr & $1 \mathrm{hr}$ & $2 \mathrm{hr}$ & $4 \mathrm{hr}$ & $8 \mathrm{hr}$ & $24 \mathrm{hr}$ \\
\hline \multicolumn{7}{|c|}{$3 \mathrm{M} \mathrm{NaOH}$, Trial b } \\
\hline Density & 1.13 & 1.13 & 1.13 & 1.13 & 1.13 & 1.13 \\
\hline $\mathrm{Al}$ & 138 & 954 & 1,171 & 1,273 & 1,284 & 1,281 \\
\hline $\mathrm{B}$ & $<2.3$ & $<2.3$ & $<2.3$ & $<2.3$ & $<2.3$ & $<2.3$ \\
\hline $\mathrm{Bi}$ & $<2.9$ & {$[4.0]$} & {$[2.9]$} & $<2.9$ & $<2.9$ & $<2.8$ \\
\hline $\mathrm{Cd}$ & $<0.30$ & $<0.31$ & $<0.30$ & $<0.31$ & $<0.30$ & [0.39] \\
\hline $\mathrm{Cr}$ & {$[0.94]$} & 9.6 & 17.7 & 27.1 & 50.5 & 88.1 \\
\hline $\mathrm{Fe}$ & $<2.6$ & {$[3.1]$} & {$[4.3]$} & {$[4.6]$} & {$[5.4]$} & {$[6.3]$} \\
\hline $\mathrm{Mn}$ & $<0.26$ & $<0.26$ & $<0.26$ & {$[0.27]$} & $<0.26$ & $<0.26$ \\
\hline $\mathrm{Na}$ & 70,781 & 72,487 & 72,681 & 72,818 & 72,818 & 71,279 \\
\hline $\mathrm{P}$ & [21.2] & [22.9] & [18.9] & [13.8] & [14.5] & [10.8] \\
\hline $\mathrm{S}$ & $<40.9$ & $<41.9$ & $<41.1$ & $<41.4$ & $<40.8$ & $<40.6$ \\
\hline $\mathrm{Si}$ & 58.1 & 162 & 159 & 156 & 156 & 154 \\
\hline $\mathrm{Sr}$ & [0.11] & [0.09] & [0.09] & [0.10] & [0.12] & {$[0.17]$} \\
\hline $\mathrm{U}$ & $<10.5$ & [13.9] & {$[14.9]$} & {$[18.1]$} & {$[19.6]$} & [18.9] \\
\hline $\mathrm{Zn}$ & [0.91] & [1.6] & [1.4] & [1.7] & [1.8] & [1.7] \\
\hline $\mathrm{Zr}$ & $<1.0$ & $<1.0$ & $<1.0$ & $<1.0$ & $<1.0$ & $<1.0$ \\
\hline Fluoride & 9.3 & 12.3 & 11.8 & 11.9 & 12.6 & 12.3 \\
\hline Nitrite & $<1.4$ & [1.5] & [1.5] & $<1.4$ & $<1.4$ & {$[1.8]$} \\
\hline Nitrate & 484 & 550 & 508 & 577 & 518 & 534 \\
\hline Phosphate & 46.2 & 54.4 & 51.6 & 51.3 & 51.3 & 49.0 \\
\hline Sulfate & {$[0.90]$} & {$[3.4]$} & $<2.0$ & {$[0.89]$} & {$[0.83]$} & {$[0.72]$} \\
\hline${ }^{54} \mathrm{Mn}$ & \multirow{7}{*}{\multicolumn{5}{|c|}{ Not Measured }} & $<6 \mathrm{E}-6$ \\
\hline${ }^{60} \mathrm{Co}$ & & & & & & $<4 \mathrm{E}-6$ \\
\hline${ }^{137} \mathrm{Cs}$ & & & & & & 0.796 \\
\hline${ }^{152} \mathrm{Eu}$ & & & & & & $<2 \mathrm{E}-5$ \\
\hline${ }^{154} \mathrm{Eu}$ & & & & & & $<1 \mathrm{E}-5$ \\
\hline${ }^{155} \mathrm{Eu}$ & & & & & & $<2 \mathrm{E}-4$ \\
\hline${ }^{241} \mathrm{Am}$ & & & & & & $<2 \mathrm{E}-4$ \\
\hline \multicolumn{7}{|c|}{ Opportunistic Analytes } \\
\hline $\mathrm{Ag}$ & $<0.53$ & $<0.54$ & $<0.53$ & $<0.54$ & $<0.53$ & $<0.53$ \\
\hline As & $<8.7$ & $<8.9$ & $<8.8$ & $<8.8$ & $<8.7$ & $<8.7$ \\
\hline $\mathrm{Ba}$ & $<0.42$ & $<0.43$ & $<0.43$ & $<0.43$ & $<0.42$ & $<0.42$ \\
\hline $\mathrm{Be}$ & $<0.02$ & $<0.02$ & $<0.02$ & $<0.02$ & $<0.02$ & {$[0.02]$} \\
\hline $\mathrm{Ca}$ & $<2.6$ & $<2.7$ & $<2.6$ & $<2.7$ & $<2.6$ & $<2.6$ \\
\hline $\mathrm{Ce}$ & $<1.5$ & $<1.5$ & $<1.5$ & $<1.5$ & $<1.5$ & $<1.5$ \\
\hline Co & $<0.48$ & $<0.50$ & $<0.49$ & $<0.49$ & $<0.48$ & $<0.48$ \\
\hline $\mathrm{Cu}$ & {$[1.6]$} & {$[1.9]$} & {$[2.0]$} & {$[2.1]$} & {$[2.1]$} & {$[2.1]$} \\
\hline Dy & $<0.44$ & $<0.45$ & $<0.44$ & $<0.44$ & $<0.44$ & $<0.44$ \\
\hline $\mathrm{Eu}$ & $<0.14$ & $<0.14$ & {$[0.16]$} & $<0.14$ & $<0.14$ & $<0.14$ \\
\hline $\mathrm{K}$ & [17.8] & [23.5] & $<15.3$ & $<15.4$ & $<15.2$ & [19.8] \\
\hline $\mathrm{La}$ & $<0.17$ & $<0.17$ & $<0.17$ & $<0.17$ & $<0.17$ & $<0.17$ \\
\hline $\mathrm{Li}$ & $<0.68$ & $<0.70$ & $<0.68$ & $<0.69$ & $<0.68$ & $<0.68$ \\
\hline
\end{tabular}


Table J.2 (Contd)

\begin{tabular}{|c|c|c|c|c|c|c|}
\hline \multirow[b]{2}{*}{ Analyte } & \multicolumn{6}{|c|}{$\begin{array}{l}\text { Analyte Concentration and Density at Given Time After Cooling to Ambient }\left(\sim 21^{\circ} \mathrm{C}\right) \\
\text { Temperature; } \mathrm{g} / \mathrm{mL} \text { for Density; } \mu \mathrm{g} / \mathrm{mL} \text { for Metals and Anions; } \mu \mathrm{Ci} / \mathrm{mL} \text { for } \\
\text { Radionuclides }\end{array}$} \\
\hline & o hr & $1 \mathrm{hr}$ & $2 \mathrm{hr}$ & $4 \mathrm{hr}$ & $8 \mathrm{hr}$ & $24 \mathrm{hr}$ \\
\hline $\mathrm{Mg}$ & $<0.88$ & $<0.90$ & $<0.88$ & $<0.89$ & $<0.88$ & $<0.87$ \\
\hline Mo & $<0.82$ & $<0.84$ & $<0.82$ & $<0.83$ & $<0.82$ & $<0.81$ \\
\hline $\mathrm{Nd}$ & $<2.1$ & $<2.2$ & $<2.2$ & $<2.2$ & $<2.1$ & $<2.1$ \\
\hline $\mathrm{Ni}$ & $<0.73$ & $<0.74$ & $<0.73$ & $<0.73$ & $<0.73$ & $<0.72$ \\
\hline $\mathrm{Pb}$ & $<4.6$ & {$[5.6]$} & [7.9] & [7.3] & {$[5.1]$} & {$[7.2]$} \\
\hline $\mathrm{Pd}$ & $<1.6$ & $<1.6$ & $<1.6$ & $<1.6$ & $<1.6$ & $<1.6$ \\
\hline $\mathrm{Rh}$ & $<3.2$ & $<3.2$ & $<3.2$ & $<3.2$ & $<3.2$ & $<3.1$ \\
\hline $\mathrm{Ru}$ & $<1.0$ & $<1.1$ & $<1.0$ & $<1.0$ & $<1.0$ & $<1.0$ \\
\hline $\mathrm{Sb}$ & $<3.9$ & $<4.0$ & $<4.0$ & $<4.0$ & $<3.9$ & $<3.9$ \\
\hline Se & $<6.1$ & {$[12.4]$} & {$[9.4]$} & $<6.2$ & $<6.1$ & $<6.1$ \\
\hline Sn & $<2.5$ & [2.7] & $<2.5$ & {$[2.6]$} & $<2.5$ & [2.6] \\
\hline $\mathrm{Ta}$ & $<1.7$ & $<1.7$ & {$[3.0]$} & $<1.7$ & {$[1.8]$} & [2.7] \\
\hline $\mathrm{Te}$ & $<3.9$ & $<4.0$ & $<4.0$ & $<4.0$ & $<3.9$ & $<3.9$ \\
\hline Th & $<1.5$ & $<1.5$ & $<1.5$ & $<1.5$ & $<1.5$ & $<1.5$ \\
\hline $\mathrm{Ti}$ & $<0.12$ & $<0.12$ & $<0.12$ & $<0.12$ & $<0.12$ & $<0.12$ \\
\hline $\mathrm{Tl}$ & $<8.1$ & $<8.3$ & $<8.2$ & $<8.2$ & $<8.1$ & $<<8.1$ \\
\hline $\mathrm{V}$ & $<0.39$ & $<0.40$ & $<0.40$ & $<0.40$ & $<0.39$ & $<0.39$ \\
\hline $\mathrm{W}$ & $<1.9$ & $<1.9$ & $<1.9$ & $<1.9$ & $<1.9$ & $<1.9$ \\
\hline $\mathrm{Y}$ & $<0.11$ & $<0.11$ & $<0.11$ & $<0.11$ & $<0.11$ & $<0.11$ \\
\hline \multicolumn{7}{|c|}{3 M NaOH, Trial c } \\
\hline Density & 1.13 & 1.14 & 1.13 & 1.12 & 1.14 & 1.12 \\
\hline $\mathrm{Al}$ & 132 & 849 & 1,076 & 1,240 & 1,360 & 1,323 \\
\hline B & $<2.3$ & $<2.2$ & $<2.2$ & $<2.3$ & $<2.3$ & $<2.2$ \\
\hline $\mathrm{Bi}$ & {$[4.6]$} & [5.1] & [5.9] & [3.6] & {$[5.8]$} & {$[4.6]$} \\
\hline $\mathrm{Cd}$ & $<0.31$ & $<0.30$ & $<0.30$ & $<0.30$ & {$[0.40]$} & $<0.29$ \\
\hline $\mathrm{Cr}$ & {$[0.61]$} & 8.8 & 15.5 & 24.6 & 47.7 & 83.0 \\
\hline $\mathrm{Fe}$ & $<2.6$ & {$[2.8]$} & [3.9] & {$[4.2]$} & {$[5.2]$} & {$[6.1]$} \\
\hline $\mathrm{Mn}$ & $<0.26$ & $<0.25$ & $<0.25$ & $<0.26$ & $<0.26$ & $<0.25$ \\
\hline $\mathrm{Na}$ & 72,755 & 70,629 & 71,129 & 71,491 & 72,134 & 69,642 \\
\hline $\mathrm{P}$ & [19.6] & [16.1] & [21.3] & [18.1] & [18.3] & [16.2] \\
\hline$S$ & $<41.3$ & $<40.3$ & $<40.1$ & $<40.8$ & $<41.3$ & $<39.2$ \\
\hline $\mathrm{Si}$ & 61.4 & 156 & 152 & 151 & 150 & 142 \\
\hline $\mathrm{Sr}$ & {$[0.10]$} & {$[0.08]$} & {$[0.08]$} & [0.09] & {$[0.13]$} & {$[0.17]$} \\
\hline $\mathrm{U}$ & $<10.6$ & [11.3] & [12.4] & [18.7] & [15.0] & [16.0] \\
\hline $\mathrm{Zn}$ & {$[0.98]$} & {$[2.0]$} & {$[1.6]$} & {$[1.8]$} & {$[1.6]$} & {$[2.1]$} \\
\hline $\mathrm{Zr}$ & $<1.0$ & $<1.00$ & $<0.99$ & $<1.0$ & $<1.0$ & $<1.0$ \\
\hline Fluoride & 9.6 & 12.0 & 12.5 & 12.1 & 10.5 & 12.3 \\
\hline Nitrite & $<1.34$ & [1.4] & [1.6] & $<1.4$ & $<1.4$ & [2.0] \\
\hline Nitrate & 516 & 540 & 547 & 548 & 582 & 545 \\
\hline Phosphate & 47.0 & 51.9 & 51.9 & 50.3 & 55.0 & 50.8 \\
\hline Sulfate & {$[0.85]$} & {$[0.96]$} & {$[1.0]$} & {$[0.96]$} & $<0.68$ & $<0.66$ \\
\hline
\end{tabular}


Table J.2 (Contd)

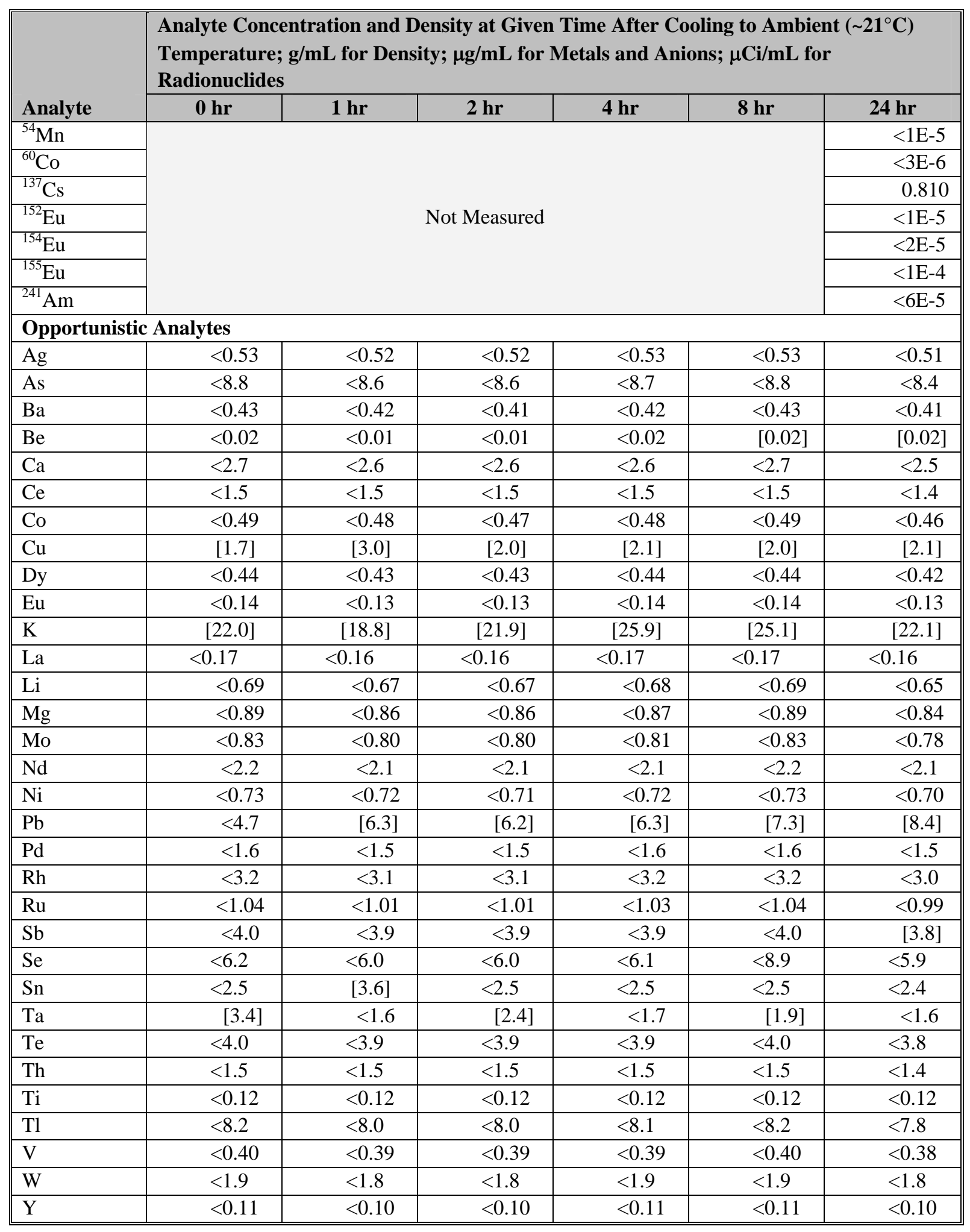


Table J.2 (Contd)

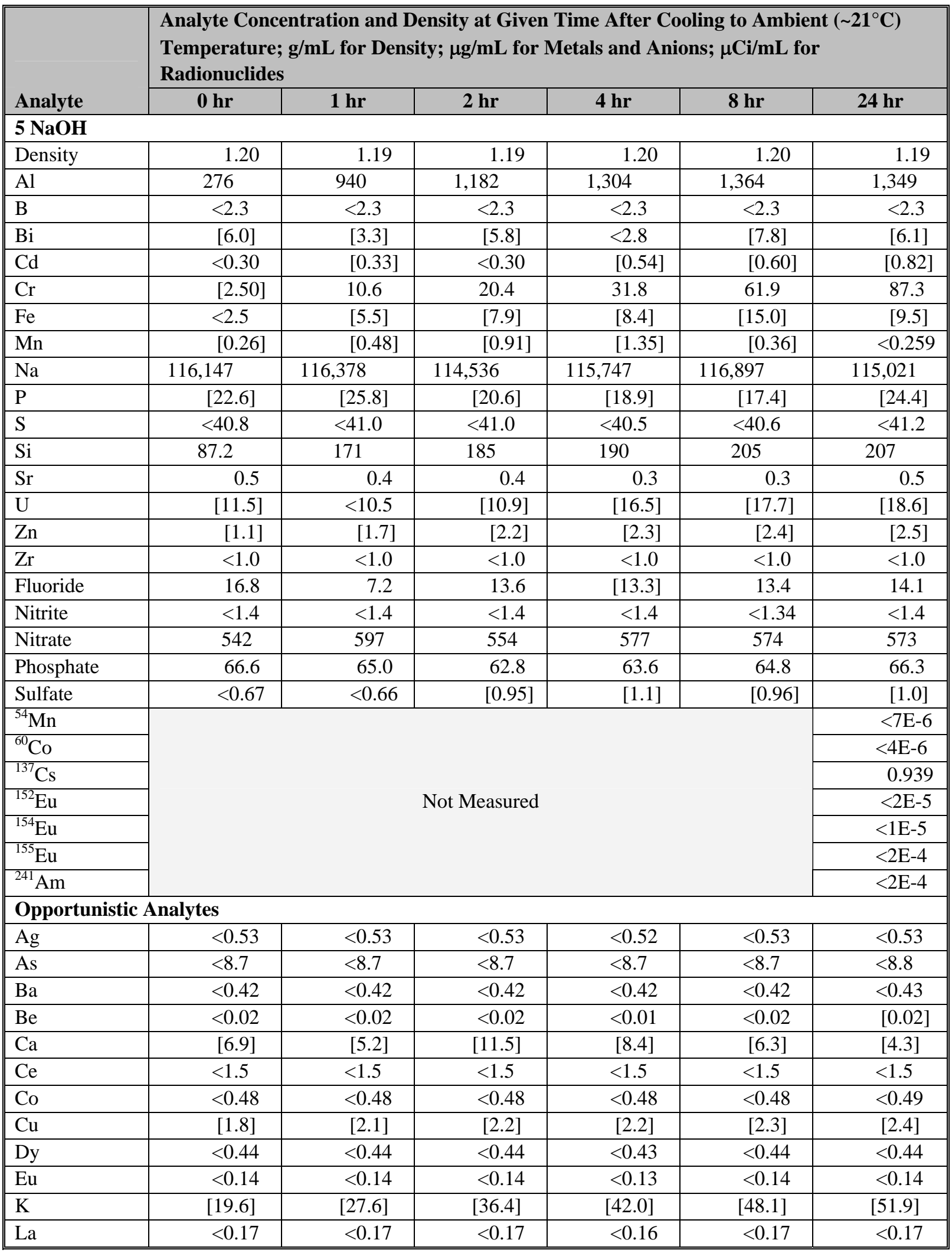


Table J.2 (Contd)

\begin{tabular}{|c|c|c|c|c|c|c|}
\hline \multirow[b]{2}{*}{ Analyte } & \multicolumn{6}{|c|}{$\begin{array}{l}\text { Analyte Concentration and Density at Given Time After Cooling to Ambient }\left(\sim 21^{\circ} \mathrm{C}\right) \\
\text { Temperature; } \mathrm{g} / \mathrm{mL} \text { for Density; } \mu \mathrm{g} / \mathrm{mL} \text { for Metals and Anions; } \mu \mathrm{Ci} / \mathrm{mL} \text { for } \\
\text { Radionuclides }\end{array}$} \\
\hline & o hr & $1 \mathrm{hr}$ & 2 hr & $4 \mathrm{hr}$ & $8 \mathrm{hr}$ & $24 \mathrm{hr}$ \\
\hline $\mathrm{Li}$ & $<0.68$ & $<0.68$ & $<0.68$ & $<0.67$ & $<0.68$ & $<0.69$ \\
\hline $\mathrm{Mg}$ & $<0.87$ & $<0.88$ & $<0.88$ & $<0.87$ & $<0.87$ & $<0.88$ \\
\hline Mo & $<0.81$ & $<0.82$ & $<0.82$ & $<0.81$ & $<0.81$ & $<0.82$ \\
\hline $\mathrm{Nd}$ & $<2.1$ & $<2.2$ & $<2.2$ & $<2.1$ & $<2.1$ & $<2.2$ \\
\hline $\mathrm{Ni}$ & $<0.72$ & $<0.73$ & $<0.73$ & $<0.72$ & $<0.72$ & $<0.73$ \\
\hline $\mathrm{Pb}$ & $<4.6$ & {$[7.0]$} & [7.3] & [5.7] & [8.7] & [8.2] \\
\hline $\mathrm{Pd}$ & $<1.6$ & $<1.6$ & $<1.6$ & $<1.6$ & $<1.6$ & $<1.6$ \\
\hline $\mathrm{Rh}$ & $<3.2$ & $<3.2$ & $<3.2$ & $<3.1$ & $<3.1$ & $<3.2$ \\
\hline $\mathrm{Ru}$ & $<1.0$ & $<1.0$ & $<1.0$ & $<1.0$ & $<1.0$ & $<1.0$ \\
\hline $\mathrm{Sb}$ & $<3.9$ & $<3.9$ & $<3.9$ & [5.7] & $<3.9$ & [4.6] \\
\hline Se & $<6.1$ & [11.8] & $<6.1$ & $<6.1$ & [6.3] & [9.2] \\
\hline Sn & $<2.5$ & 2.5 & {$[3.6]$} & {$[2.5]$} & $<2.5$ & $<2.5$ \\
\hline $\mathrm{Ta}$ & $<1.7$ & $<1.7$ & $<1.7$ & $<1.6$ & $<1.7$ & [2.7] \\
\hline $\mathrm{Te}$ & $<3.9$ & $<4.0$ & $<4.0$ & $<3.9$ & $<3.9$ & $<4.0$ \\
\hline Th & $<1.5$ & $<1.5$ & $<1.5$ & $<1.5$ & $<1.5$ & $<1.5$ \\
\hline $\mathrm{Ti}$ & $<0.12$ & $<0.12$ & $<0.12$ & $<0.12$ & $<0.12$ & $<0.12$ \\
\hline $\mathrm{Tl}$ & $<8.1$ & $<8.1$ & $<8.1$ & $<8.1$ & $<8.1$ & $<8.2$ \\
\hline $\mathrm{V}$ & $<0.39$ & $<0.39$ & $<0.39$ & $<0.39$ & $<0.39$ & $<0.40$ \\
\hline $\mathrm{W}$ & $<1.9$ & $<1.9$ & $<1.9$ & $<1.9$ & $<1.9$ & $<1.9$ \\
\hline $\mathrm{Y}$ & $<0.11$ & $<0.11$ & $<0.11$ & $<0.10$ & $<0.11$ & $<0.11$ \\
\hline
\end{tabular}


Table J.3. Analyte Concentrations as a Function of Time for Leaching at $100^{\circ} \mathrm{C}$

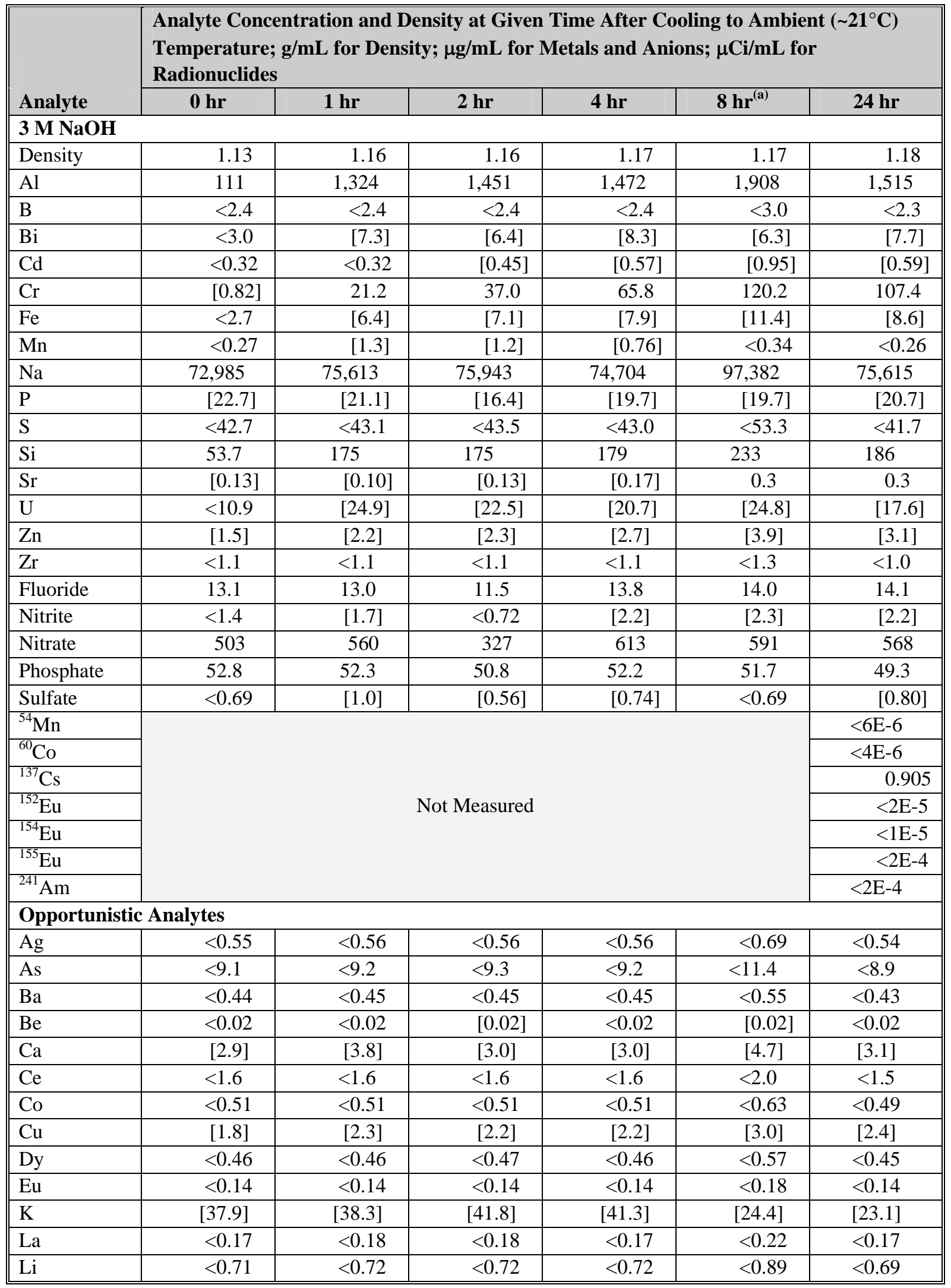


Table J.3 (Contd)

\begin{tabular}{|c|c|c|c|c|c|c|}
\hline \multirow[b]{2}{*}{ Analyte } & \multicolumn{6}{|c|}{$\begin{array}{l}\text { Analyte Concentration and Density at Given Time After Cooling to Ambient }\left(\sim 21^{\circ} \mathrm{C}\right) \\
\text { Temperature; } \mathrm{g} / \mathrm{mL} \text { for Density; } \mu \mathrm{g} / \mathrm{mL} \text { for Metals and Anions; } \mu \mathrm{Ci} / \mathrm{mL} \text { for } \\
\text { Radionuclides }\end{array}$} \\
\hline & $0 \mathrm{hr}$ & $1 \mathrm{hr}$ & $2 \mathrm{hr}$ & $4 \mathrm{hr}$ & $8 h^{(a)}$ & $24 \mathrm{hr}$ \\
\hline $\mathrm{Mg}$ & $<0.92$ & $<0.93$ & $<0.93$ & $<0.92$ & $<1.14$ & $<0.90$ \\
\hline Mo & $<0.85$ & $<0.86$ & $<0.87$ & $<0.86$ & $<1.06$ & $<0.83$ \\
\hline $\mathrm{Nd}$ & $<2.2$ & $<2.3$ & $<2.3$ & $<2.3$ & $<2.8$ & $<2.2$ \\
\hline $\mathrm{Ni}$ & $<0.76$ & $<0.77$ & $<0.77$ & $<0.76$ & $<0.95$ & $<0.74$ \\
\hline $\mathrm{Pb}$ & $<4.8$ & [7.3] & [7.1] & [7.9] & {$[11.0]$} & [9.3] \\
\hline $\mathrm{Pd}$ & $<1.6$ & $<1.7$ & $<1.7$ & $<1.7$ & $<2.1$ & $<1.6$ \\
\hline $\mathrm{Rh}$ & $<3.3$ & $<3.3$ & $<3.4$ & $<3.3$ & $<4.1$ & $<3.2$ \\
\hline $\mathrm{Ru}$ & $<1.1$ & $<1.1$ & $<1.1$ & $<1.1$ & $<1.3$ & $<1.0$ \\
\hline $\mathrm{Sb}$ & $<4.1$ & $<4.1$ & $<4.2$ & $<4.1$ & $<5.1$ & $<4.0$ \\
\hline Se & $<6.4$ & $<6.5$ & $<6.5$ & $<6.4$ & [8.3] & [7.4] \\
\hline Sn & $<2.6$ & $<2.6$ & $<2.7$ & $<2.6$ & [4.3] & 2.6 \\
\hline $\mathrm{Ta}$ & $<1.7$ & $<1.8$ & $<1.8$ & $<1.7$ & $<2.2$ & $<1.7$ \\
\hline $\mathrm{Te}$ & $<4.1$ & $<4.2$ & $<4.2$ & $<4.1$ & $<5.1$ & $<4.0$ \\
\hline Th & $<1.5$ & $<1.6$ & $<1.6$ & $<1.6$ & $<1.9$ & $<1.5$ \\
\hline $\mathrm{Ti}$ & $<0.13$ & $<0.13$ & $<0.13$ & $<0.13$ & $<0.16$ & $<0.12$ \\
\hline $\mathrm{Tl}$ & $<8.5$ & $<8.6$ & $<8.6$ & $<8.5$ & $<10.6$ & $<8.3$ \\
\hline $\mathrm{V}$ & $<0.41$ & $<0.41$ & $<0.42$ & $<0.41$ & $<0.51$ & $<0.40$ \\
\hline $\mathrm{W}$ & $<2.0$ & $<2.0$ & $<2.0$ & $<2.0$ & $<2.4$ & $<1.9$ \\
\hline $\mathrm{Y}$ & $<0.11$ & $<0.11$ & $<0.11$ & $<0.11$ & $<0.14$ & $<0.11$ \\
\hline
\end{tabular}

(a) The accuracy of the 8-h leachate concentrations is suspect because the analyte values appear to be biased high even though the mass of the aliquot added was lower than expected. 
Table J.4. Analyte Concentrations for Composite Wash Solution for Wash of Samples Leached at $80^{\circ} \mathrm{C}$ in $3 \mathrm{M} \mathrm{NaOH}$

\begin{tabular}{|c|c|c|c|}
\hline Analyte & $\begin{array}{c}\text { Concentration } \\
(\mu \mathrm{g} / \mathrm{mL})\end{array}$ & $\begin{array}{c}\text { Opportunistic } \\
\text { Analytes }\end{array}$ & $\begin{array}{c}\text { Concentration } \\
(\mu \mathrm{g} / \mathrm{mL})\end{array}$ \\
\hline $\mathrm{Al}$ & 103 & $\mathrm{Ag}$ & $<0.112$ \\
\hline B & $<0.485$ & As & $<1.85$ \\
\hline $\mathrm{Bi}$ & $<0.607$ & $\mathrm{Ba}$ & {$[0.212]$} \\
\hline $\mathrm{Cd}$ & $<0.064$ & $\mathrm{Be}$ & $<0.003$ \\
\hline $\mathrm{Cr}$ & 7.30 & $\mathrm{Ca}$ & $<0.559$ \\
\hline $\mathrm{Fe}$ & $<0.543$ & $\mathrm{Ce}$ & $<0.318$ \\
\hline $\mathrm{Mn}$ & $<0.055$ & Co & $<0.103$ \\
\hline $\mathrm{Na}$ & 5,399 & $\mathrm{Cu}$ & 1.79 \\
\hline$S$ & $<8.69$ & Dy & $<0.093$ \\
\hline $\mathrm{Si}$ & 13.6 & $\mathrm{Eu}$ & $<0.029$ \\
\hline$\overline{\mathrm{Sr}}$ & {$[0.016]$} & $\mathrm{K}$ & $<3.236$ \\
\hline $\mathrm{U}$ & $<2.23$ & $\mathrm{La}$ & $<0.035$ \\
\hline $\mathrm{Zn}$ & {$[0.836]$} & $\mathrm{Li}$ & $<0.145$ \\
\hline $\mathrm{Zr}$ & $<0.215$ & $\mathrm{Mg}$ & $<0.186$ \\
\hline Fluoride & {$[0.812]$} & Mo & $<0.174$ \\
\hline Nitrite & $<1.56$ & $\mathrm{Nd}$ & $<0.456$ \\
\hline Nitrate & 470 & $\mathrm{Ni}$ & $<0.154$ \\
\hline Phosphate & {$[4.50]$} & $\mathrm{P}$ & [2.09] \\
\hline \multirow[t]{15}{*}{ Sulfate } & {$[0.812]$} & $\mathrm{Pb}$ & $<0.983$ \\
\hline & & $\mathrm{Pd}$ & $<0.334$ \\
\hline & & $\mathrm{Rh}$ & $<0.672$ \\
\hline & & $\mathrm{Ru}$ & $<0.219$ \\
\hline & & $\mathrm{Sb}$ & $<0.836$ \\
\hline & & Se & $<1.30$ \\
\hline & & Sn & {$[0.546]$} \\
\hline & & $\mathrm{Ta}$ & {$[0.354]$} \\
\hline & & $\mathrm{Te}$ & $<0.839$ \\
\hline & & Th & $<0.315$ \\
\hline & & $\mathrm{Ti}$ & $<0.026$ \\
\hline & & $\mathrm{Tl}$ & $<1.73$ \\
\hline & & $\mathrm{V}$ & $<0.084$ \\
\hline & & $\mathrm{W}$ & $<0.399$ \\
\hline & & $\mathrm{Y}$ & $<0.022$ \\
\hline
\end{tabular}





\section{Appendix K}

\section{CUF Filtration/Leaching Experimental Methods and Analyses}




\section{Appendix K: CUF Filtration/Leaching Experimental Methods and Analyses}

This appendix describes the experimental equipment and analyses used to perform the bench top filtration and leaching tests with both the Group 1 and 2 composite waste samples using the CUF filtration skid, described in Section 5 of this report.

\section{K.1 Filtration/Leaching Apparatus}

The testing apparatus is a bench top skid that allows up to 4-liters of a waste solution to be circulated through a tubular filter. The apparatus can simultaneously measure the filter feed flow rates, filtrate flow rates, system pressures, and temperatures. The testing skid uses a heat exchanger on the main flow loop to cool the feed solution during filtration operations, and it has a heater on the main holding tank to perform leaching at elevated temperatures.

\section{K.1.1 Cell Unit Filter}

The WTP Pre-Treatment facility will use cross flow ultrafiltration to separate the LAW liquid streams from the HLW slurry streams. The filter elements to be used are called CUFs and are simply porous sintered metal tubes that the filter feed flows through axially while the permeate passes through the tube walls radially. Filtration occurs when sufficient pressure is applied to the filter feed flowing through the element to drive the slurry permeate through the tubular walls. Because the filter feed is flowing across the filter walls, solid buildup is minimized allowing filtration to occur continuously with minimal downtime for back-pulsing.

The filters used in this testing work were obtained from the Mott Corporation, ${ }^{(a)}$ using the same specifications $^{(\mathrm{b})}$ for the filters being purchased for the WTP-Pretreatment Facility. The dimensions of the filter element used in this test are shown in Figure K.1.
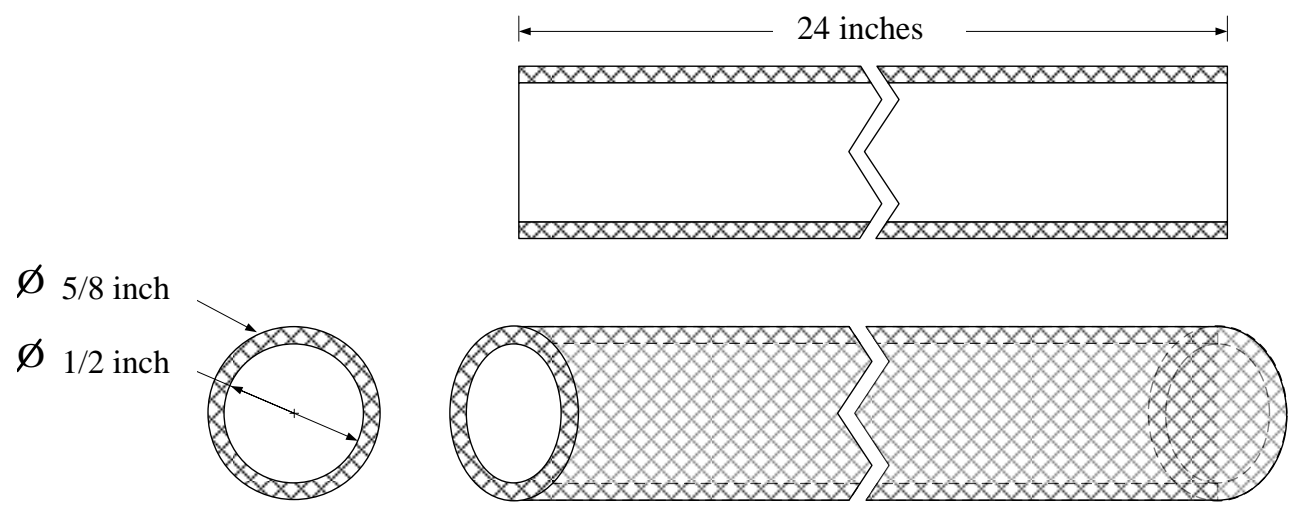

Figure K.1. Illustration of the Filter Element

(a) Mott Corporation, 84 Spring Lane, Farmington, CT 06032.

(b) Specification WTP-070110, written by JGH Geeting, for PNNL Purchase Order 38825, February 2, 2007. 
The as-received filter element was installed in a shell-in-tube configuration with an outer tube surrounding the filter element to capture the filtrate while the inlet and outlet of the filter were welded to steel tubing of the matching outer/inner diameter that extends past the shell, and this provides access to the inside diameter of the filter. The shell side had two $3 / 8$-inch stainless tubes exiting from the filter assembly; one is in the center to collect filtrate from the filter, and the other is near the inlet of the filter to function as a drain. Pressure ports (1/4-inch stainless tubing) were installed on the inlet and outlet connections to the assembly to measure the pressure inside the filter. VCO Swagelok fittings were also placed on the inlet and outlet filter feed tube connections for easy installation to the filtration/leaching skid. Figure K.2 and Figure K.3 show the filter assembly tested.

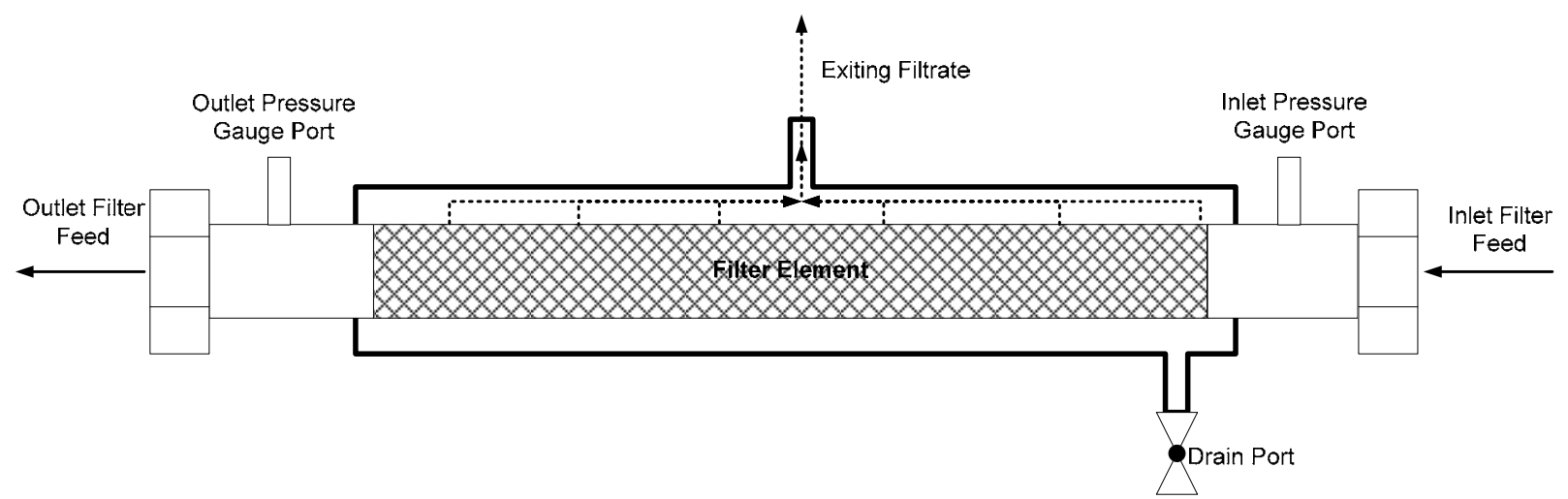

Figure K.2. Illustration of the Filter Assembly Sketch (Not to Scale)

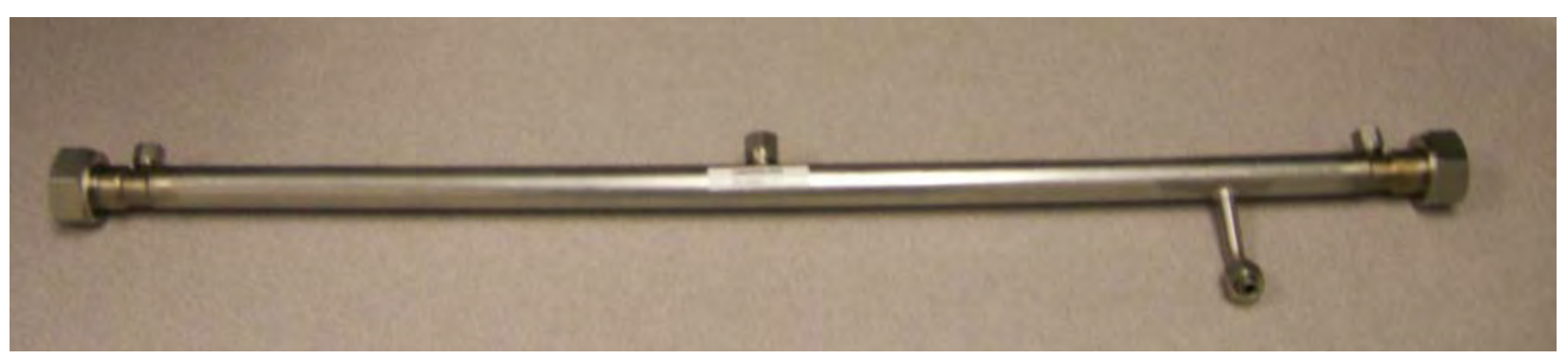

Figure K.3. Photograph of the Filter Assembly

\section{K.1.1.1 Filtration/Leaching Skid}

The filter described in the section above is installed in a bench top skid that circulates the test waste slurries through the inside of the filter and diverts the filter permeate to a collection bottle or recycles it back into the slurry. Figure K.4 shows a piping diagram of the testing skid. Figure K.5 and Figure K.6 are electronic photographs of the assembled system before and after installation into a hot cell in the Shielded Analytical Laboratory where the testing was performed. 
WTP-RPT-166, Rev. 0

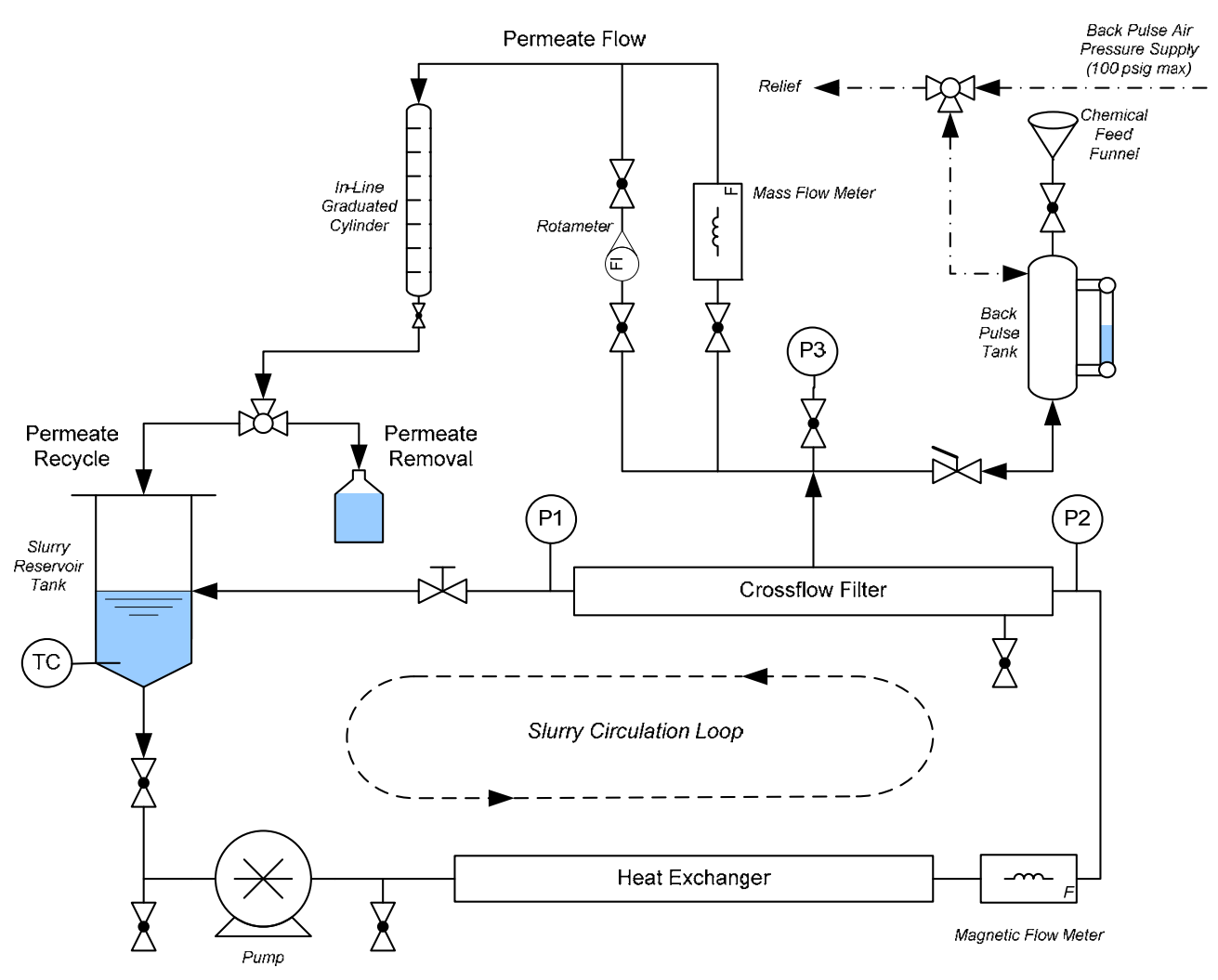

Figure K.4. Piping Diagram of CUF Skid 


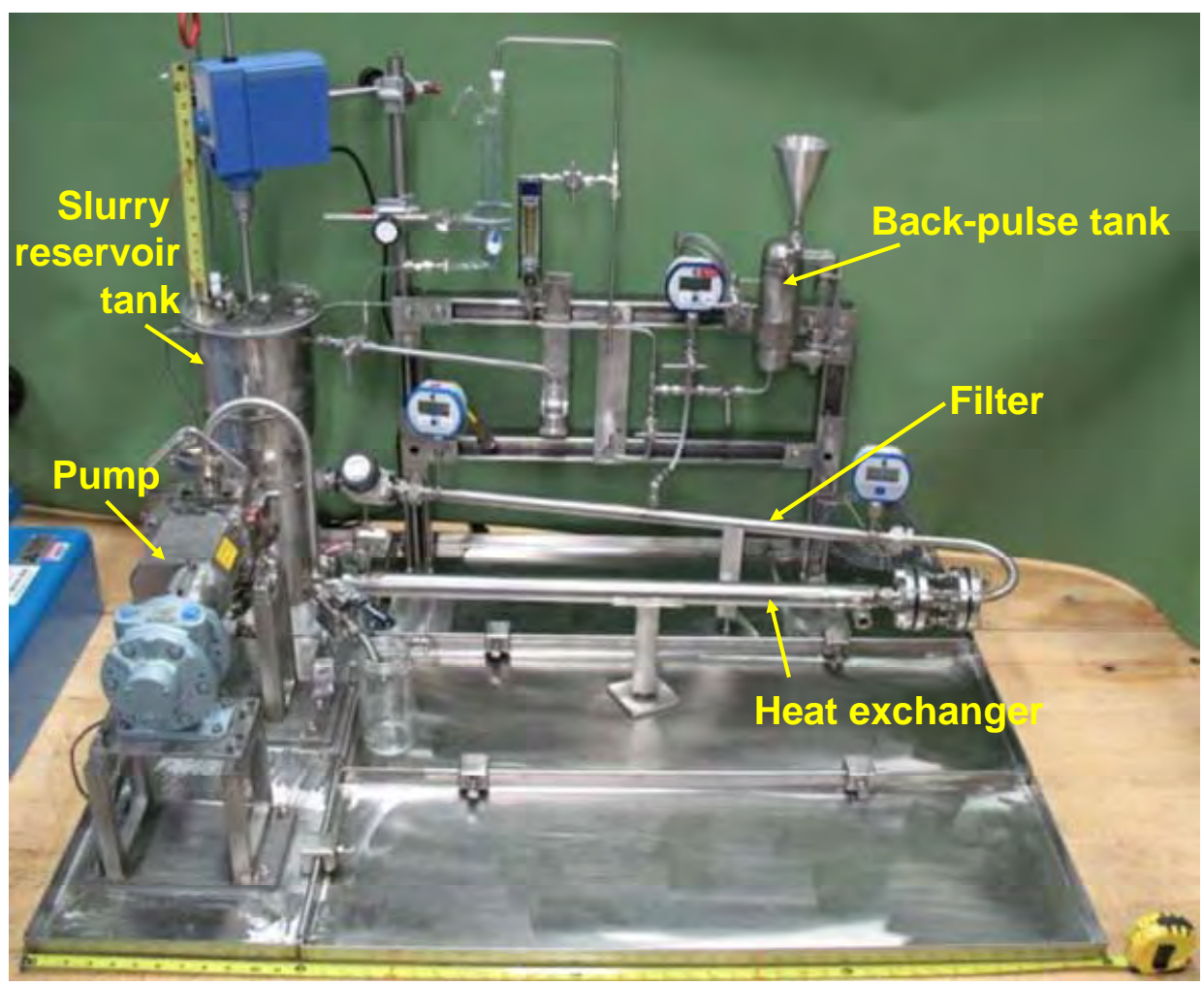

Figure K.5. Photograph of the CUF Testing Skid Prior to Hot Cell Installation 


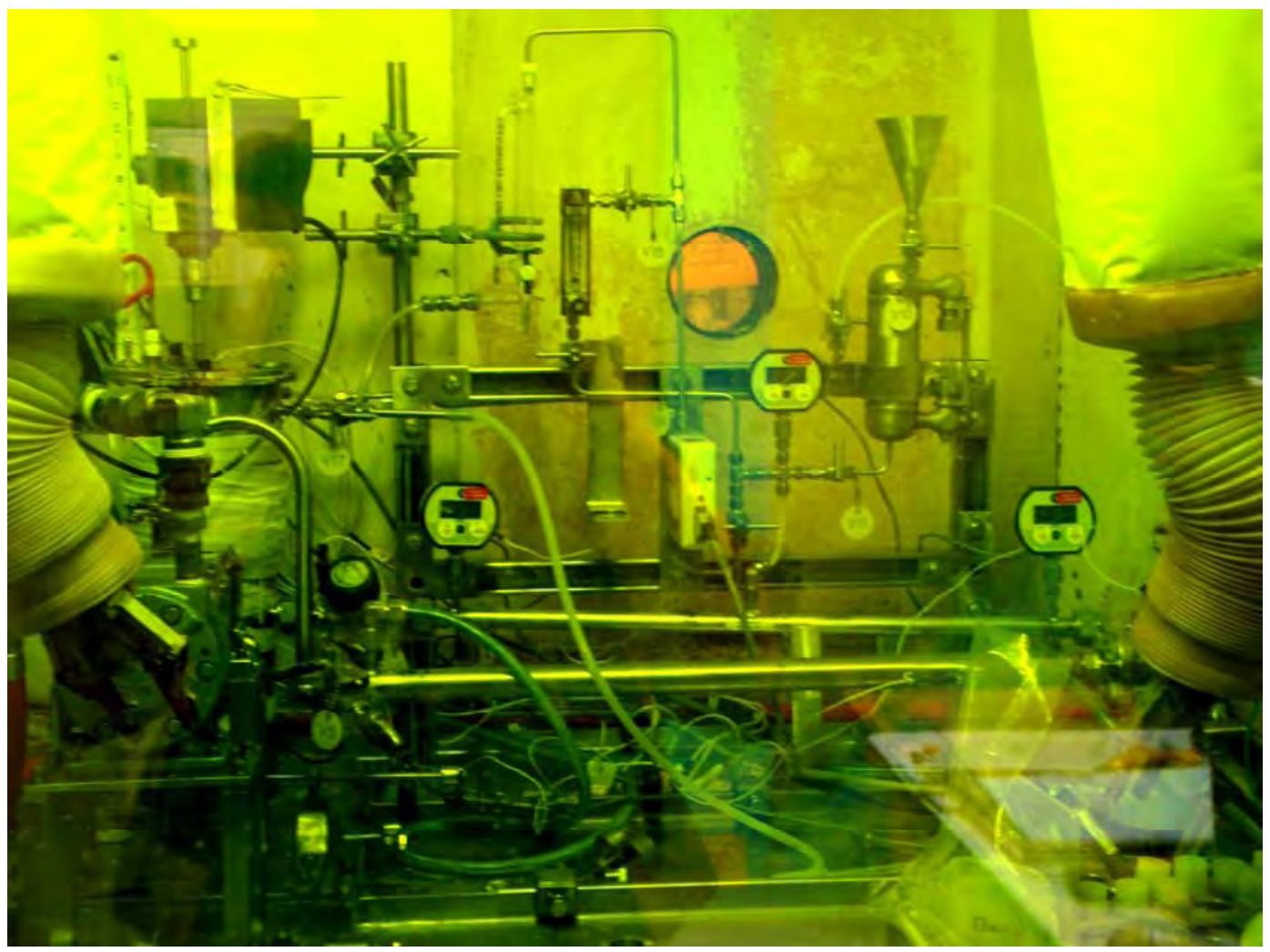

Figure K.6. Picture of Test Skid Installed in Cell 5 of the Shielded Analytical Laboratory

The CUF skid has four main parts:

- $\quad$ Slurry reservoir tank

- Slurry recirculation loop

- Permeate flow loop

- Permeate back pulse chamber.

The slurry reservoir is a cylindrical stainless steel tank with a 4-L capacity. Agitation in the tank is provided from an overhead mixer using a 2-inch diameter 3-blade marine propeller. Baffles are also installed inside the tank wall to make sure that the slurry is mixed homogenously. Heat tape is installed around the walls of the tank for leaching at elevated temperatures. The heat tape is connected to a temperature controller that adjusts the electrical load to the heat tape based on a thermocouple input. A duel Type-K thermocouple is installed inside the reservoir tank (extruding just below the overhead mixing impeller) to measure the temperature of the slurry inside the reservoir. One of the thermocouple elements is connected to the heat tape's temperature controller and the other to a data-collection system. To allow the system to be easily drained, the bottom of the vessel is sloped at a $15^{\circ}$ angle.

The slurry recirculation loop directs slurry flow from the slurry reservoir, through the CUF filter assembly, and back into the reservoir for filtration operations. The bottom of the slurry reservoir feeds into the connection piping for the slurry recirculation pump-a positive displacement rotary lobe pump. The pump is driven with an air motor that is supplied with compressed air from an exterior air 
compressor. The speed of the pump is controlled by an exterior air regulator controlling the pressure of the compressed air feed to the air motor. An optical tachometer measures the speed of the pump by measuring the rotational speed of the connection coupling between the air motor and the pump, which had a piece of reflective tape placed on it. The discharge of the pump flows through a single-pass shell-andtube heat exchanger used to remove excess heat from the system because of frictional flow.

An exterior chiller circulates chilled fluid (water/anti-freeze mixture) through the exterior shell of the heat exchanger to pull heat away from the circulating slurry on the tube side of the heat exchanger. The chiller controllers the chilling fluid temperature by monitor the temperature of the slurry exiting the heat exchanger via a resistance temperature device installed in the discharge line.

The slurry then flows through a magnetic flow sensor that monitors the volumetric flow of the slurry inside the slurry recirculation loop. The sensor's output is displayed on an external panel meter that generates an analog output signal monitored by a data-collection system. The data from this device are used to calculate the axial velocity inside the filter element.

The flowing slurry then enters the filter assembly. Digital pressure gauges are installed on the inlet and outlet port of the filter, which displays the pressure at both locations in pounds per inch squared, gauge (psig). The gauges also transmit analog output signals monitored by a data-collection system. The data from these devices are used to calculate the average pressure inside the filter and the axial pressure drop across the element.

At the discharge of the filter is a manual pinch valve. The valve is used to adjust the pressure inside the filter to drive permeate flow through the filter membrane wall. It is also connected to the slurry reservoir tank and is closed completely when the tank is isolated for leaching.

The permeate flow loop begins at the center of the filter assembly where a poly-line connects the filter to a manifold of $1 / 4$-inch stainless steel piping that directs the filter permeate through a series of measurement devices before either returning to the slurry reservoir tank, or to a sample container to capture dewatered permeate. A digital pressure gauge is installed at this point to measure the pressure on the permeate side of the filter in psig. Like the other two digital gauges, this instrument transmits an analog output to a data-collection system. The pressure drop across the filter is then calculated by subtracting the pressure on the permeate side of the filter from the average pressure of the slurry inside the filter. This term is called the transmembrane pressure.

Flow from the filter is either diverted through a mass flow meter calibrated up to $180 \mathrm{~mL} / \mathrm{min}$ or to a usercalibrated rotometer that can measure flow up to $30 \mathrm{~mL} / \mathrm{s}$. The mass flow meter also can measure the density of the permeate flow and sends two analog output signals to the data-collection system for the volumetric flow rate and the density. The rotometer is a manual read-out device that is user calibrated. To confirm the volumetric flow rate, an in-line glass cylinder was installed on the discharge of both meters to take manual measurements of the permeate flow. Measurements are taken by closing a valve at the bottom of the cylinder and allowing the permeate to fill the vessel. The volume of the glass vessel is marked on the outside, so the change in permeate volume in the cylinder can be quantified over a time interval. 
Flow from the glass cylinder goes through a 3-way valve. This valve directs flow either back to the slurry reservoir tank to be mixed back to the slurry or to a sampling hose that is used to transfer the permeate into a sample container.

The permeate back pulse chamber is to the right of the permeate flow loop and is connected to the filter at the same location as the permeate pressure gauge. The chamber is an approximately $500-\mathrm{mL}$ steel vessel with a sight-glass to track the volume inside the chamber. The vessel has three entry ports, a $1 / 4$-inch port on the bottom from the permeate side of the filter, a $1 / 4$-inch line from a funnel on top, and a $1 / 4$-inch line from a compressed air line on the side of the vessel. The bottom line is used to fill the chamber with permeate from the filter and also to send pressurized permeate backwards to the filter as a back pulse. The funnel on the top of the chamber is used to introduce cleaning and rinse solutions directly to the vessel. The compressed gas line is the source of the pressure for the back pulse. Once the chamber is half full of permeate, compressed gas is introduced to the chamber to pressurize the fluid. The chamber is then isolated, and the slurry pressure drops below the pressure of the compressed gas line. The valve at the bottom of the tank is opened, and the pressurized permeate inside the chamber is allowed to flow backwards through the filter. After the back pulse is completed, the chamber is vented to atmospheric pressure through a 3-way valve that either sends compressed gas to the chamber or to a vent line inside the slurry reservoir tank.

\section{K.1.1.2 Instrumentation and Data-Acquisition System}

Because the system was to be operated in a hot cell, one of the design goals of the skid was to minimize the number of manual measurements during testing and record the data in an electronic format that could be analyzed readily with other approved software. Most of the sensors on the skid transmit analog data to an external data acquisition collection system (DACS), manufactured by National Instruments. This system relayed the analog data to a LabView data-collection program operating on a computer desktop system using Windows XP, service pack 2. The software program scales the analog data and simultaneously records the data electronically and displays it on the computer's monitor. The performance of the software was verified by test plan RPP-WTP-QA-010, and all reportable data are measured on calibrated instrumentation, including the external DACS board. Figure K.7 shows a diagram of the electronic sensors attached to the DACS, and Figure K.8 displays the screen windows from the data-collection program.

\section{K.1.1.3 Operations of CUF Skid and Sampling}

The CUF skid was developed to operate in several different operational modes to simulate the filtration and leaching processes of the WTP Pre-treatment system. The slurry can be filtered with two methodsrecycle and dewatering. During recycling operations, permeate is returned to the slurry reservoir tank to maintain a steady-state UDS. The slurry is operated in this mode to understand how the effects of time, pressure, and axial velocity impact filtration of the slurry while maintaining its physical properties. During dewatering operations, permeate from the filter is diverted to a collection vessel, usually operating the system at a constant pressure and flow rate. Removing permeate from the slurry increases the UDS concentration and can change the rheological and filtration properties. 

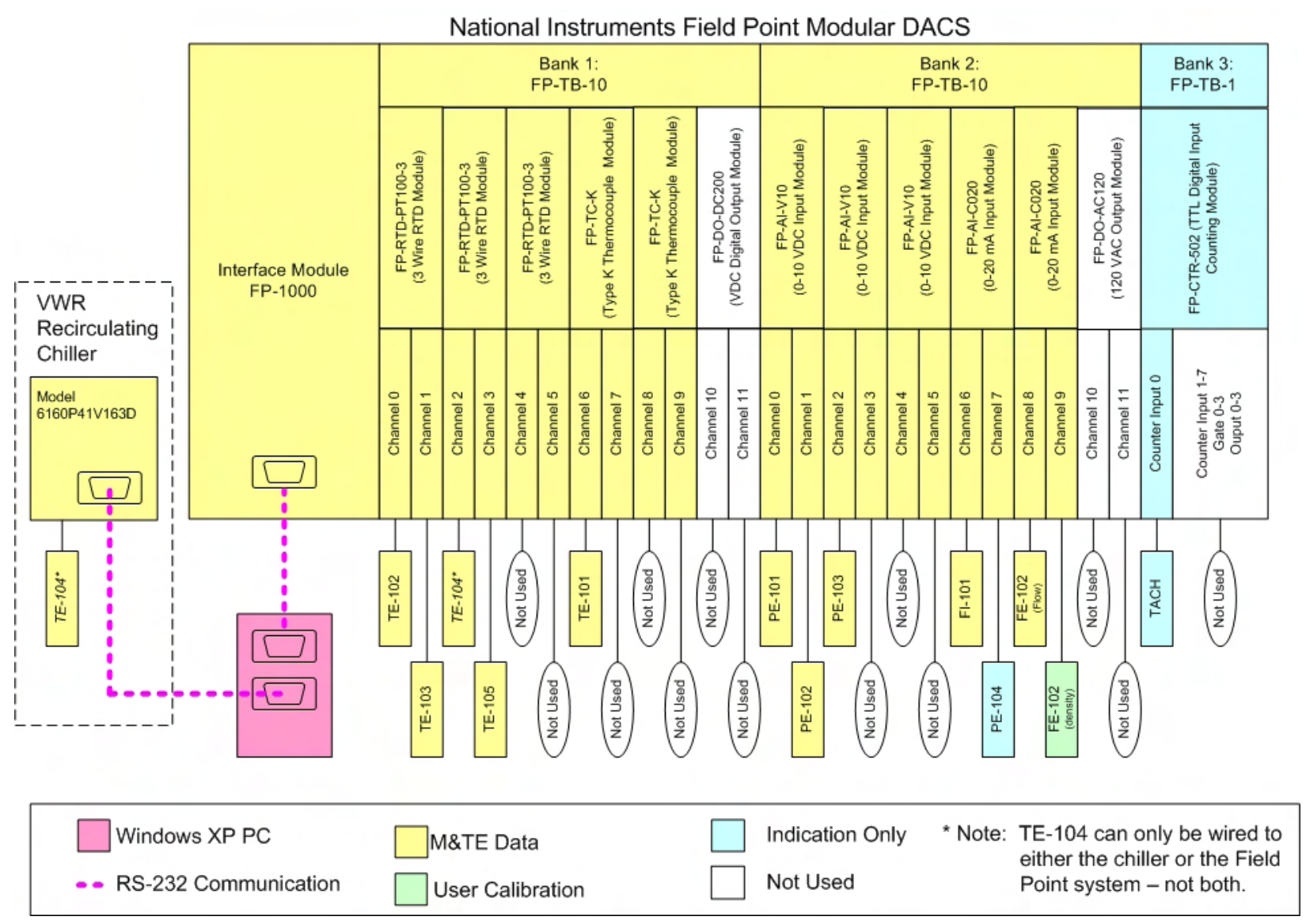

Figure K.7. Diagram of DACS System

Chemical leaching can occur in the slurry reservoir tank when the slurry circulation lines are isolated from the tank. However, to place the slurry in the tank with the valves to the piping closed requires that the slurry and permeate inside the skid be drained first. Once the waste slurry has been removed, the tank is then isolated, and the drained slurry/permeate is returned to the slurry reservoir tank. When the leach is to occur at elevated temperatures, the temperature controller is programmed to create a heating profile to simulate the heat ramp, soak, and cool down of the reaction vessel.

Samples are collected throughout testing to measure the physical and chemical properties of the waste slurry or permeate. Slurry samples are collected from two separate locations on the system. Small slurry samples $(20-\mathrm{mL})$ are collected from the top of the slurry reservoir with the mixer operating using either a polymer or glass pipette 18 inches long, depending on the slurry temperature. The tips of the pipettes are cut at an angle to allow slurry to flow into the pipette to prevent being plugged. Larger samples (100 mL), such as rheology, can be captured using the drain valve on the pump discharge while the pump is running. Permeate samples are collected during dewatering operations directly from the dewatering sample hose. However, permeate collected during leaching operations is more difficult. A slurry sample is initially collected from the slurry reservoir using a pipette described earlier. Next, the sample is filtered through a $0.45-\mu \mathrm{m}$ nylon or polytetraflouroethylene syringe filter. Permeate samples such as these are collected to measure the kinetics during leaching operations, which requires removing the leaching solution from the solids in the slurry. 


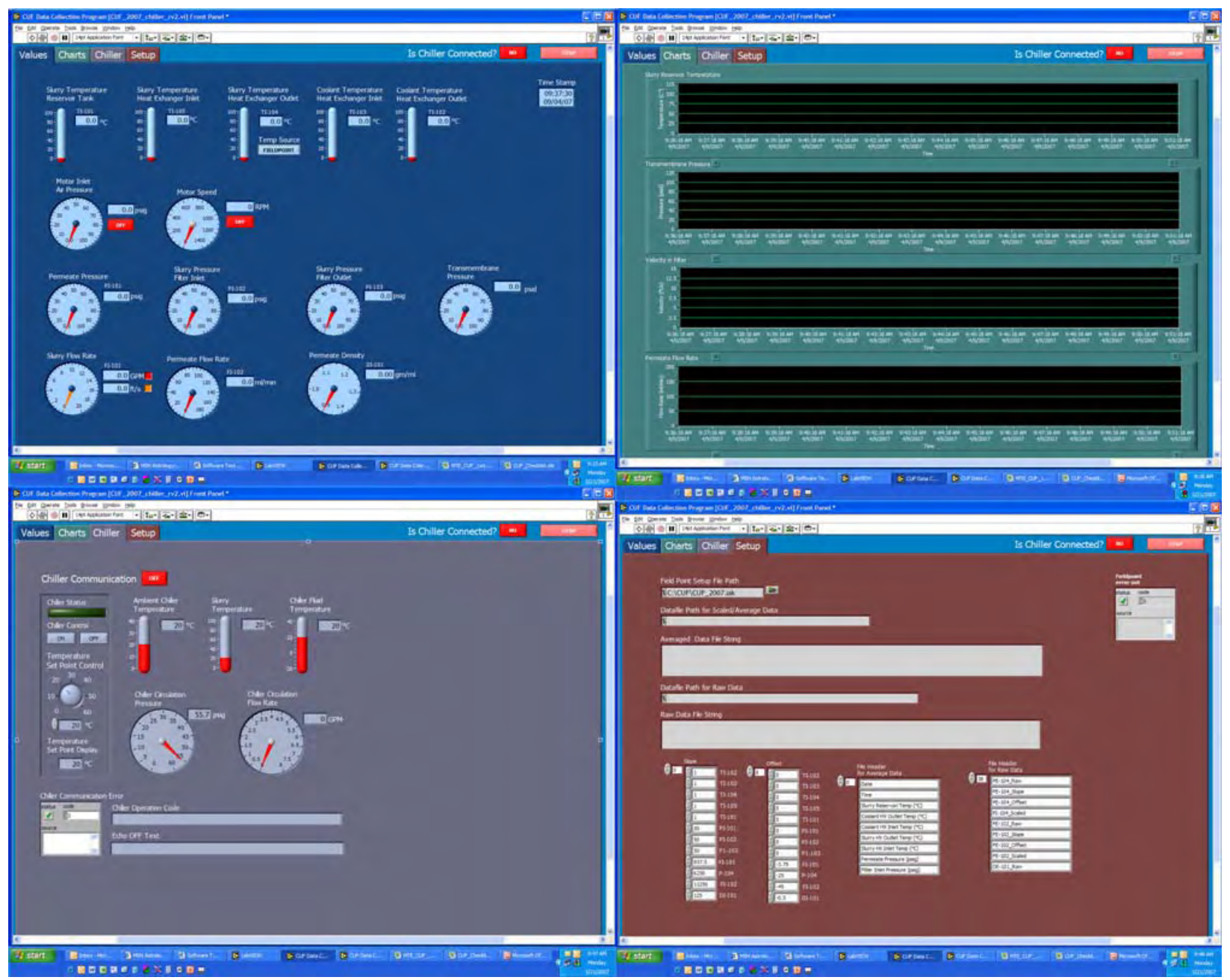

Figure K.8. Digital Images of DACS Display Windows

\section{K.1.1.4 Baseline Testing of Filter}

Before testing with HLW composite waste, the skid and the filter were initially cleaned with a laboratory cleaning solution (Alconox $^{(\mathrm{a})}$ at 1:100 dilution) and rinsed with DI water to remove cutting oils and soils from the skid fabrication process and shipping from the manufacturer. After cleaning, the filter flux was measured with a solution of $0.01 \mathrm{M} \mathrm{NaOH}$ - this is referred to as the clean water flux. Testing was performed at 10, 15, and 20 transmembrane pressure (TMP) at an axial velocity of $11 \mathrm{fps}$. Each pressure condition was held for 20 minutes, with a single back-pulse performed before changing the pressure. Next, a strontium carbonate $\left(\mathrm{SrCO}_{3}\right)$ slurry was prepared to test the filter flux with a slurry solution. As before, the $\mathrm{SrCO}_{3}$ slurry was placed in the filtration skid and was operated with the permeate recycling back into the slurry reservoir. Testing was performed at 10, 20, and $30 \mathrm{TMP}$ at an axial velocity of 11 fps. A single back pulse was performed between each test condition. Afterwards, the slurry was removed

(a) Alconox, Inc., 30 Glenn Street, Suite 309, White Plains, NY 10603 USA. 
and rinsed out with DI water (approximately $10 \mathrm{~L}$ ). The clean water flux was again tested with a solution of $0.01 \mathrm{M} \mathrm{NaOH}$ to verify that the filter was clean before testing with HLW slurries.

The results of the baseline filter flux testing are shown in Figure K.9. Overall, the baseline flux for the filter was demonstrated to be considerably higher than the predicted flux for the waste slurries to be tested (e.g., $0.04 \mathrm{gpm} / \mathrm{ft}^{2}$ for dewatering operations). No solids were evident in the permeate during filtration of the strontium carbonate slurry, and the density of the permeate was measured at $1.12 \mathrm{~g} / \mathrm{mL}$ by the mass flow meter. A sample of the permeate was taken, and its density was measured as $1.11 \mathrm{~g} / \mathrm{mL}$ using a calibrated balance and a 50-mL volumetric flask. While the density could be measured, the volumetric flow of the permeate was beyond the range of the mass flow meter for all three tests. After a density check, permeate flow was diverted through the skid's rotometer. For the $\mathrm{SrCO}_{3}$ flux measurements, the flow was slow enough to verify the flow rate using the in-line volumetric cylinder to measure the permeate flow.

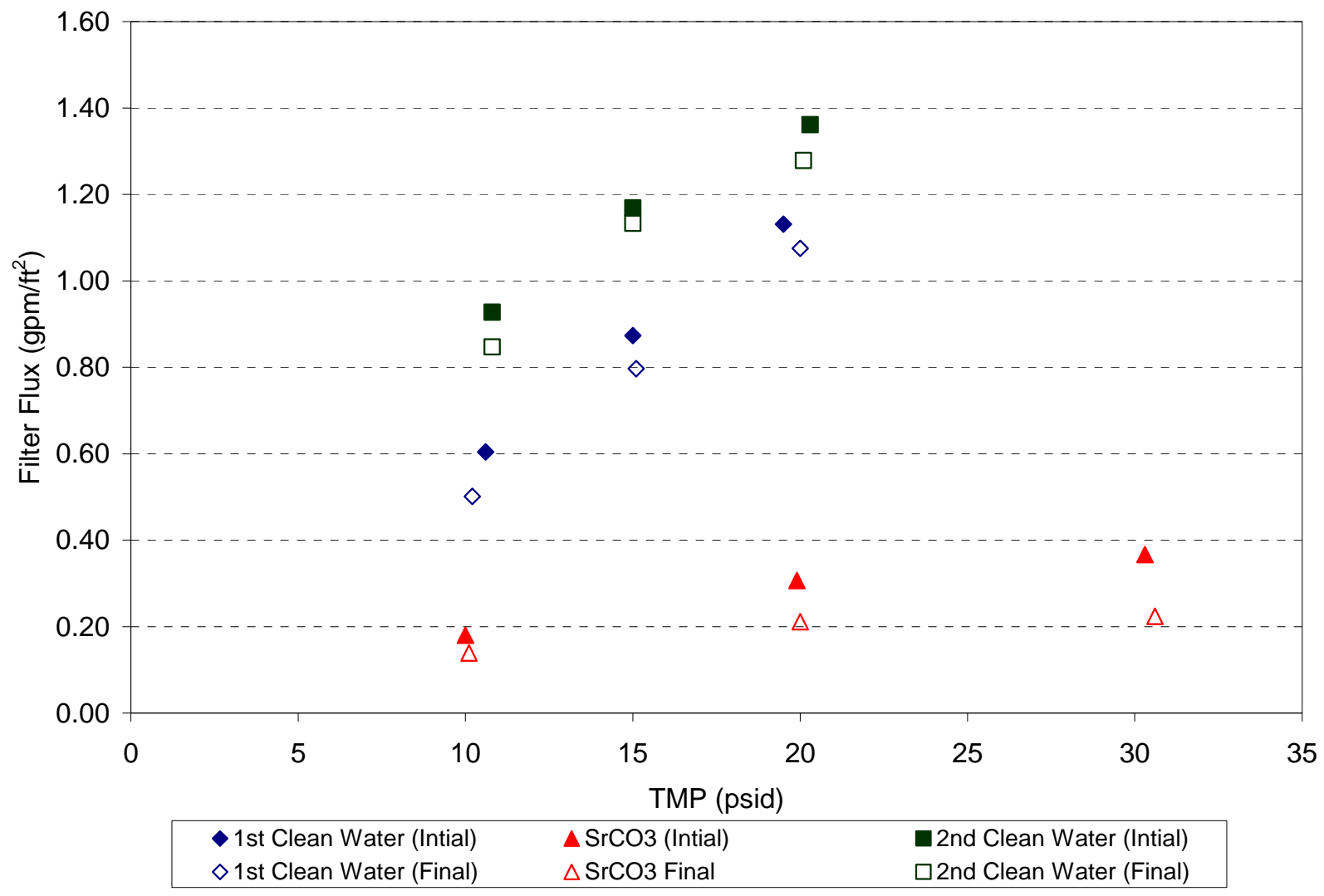

Figure K.9. Initial Clean Water/ $\mathrm{SrCO}_{3}$ Flux Measurements of Filter 


\section{K.1.2 Filtration Data Analysis}

\section{K.1.2.1 Filtration Terms and Equations}

Filtration is examined in this report as a filter flux defined as:

$$
J=\frac{Q_{\text {permeate }}}{A_{\text {filter }}}
$$

where $J$ is the filter flux (gpm/ft ${ }^{2}$ ), $Q_{\text {permeate }}$ is the volumetric permeate flow, and $A_{\text {filter }}$ is the filtration surface area.

In this study, the filter area is assumed as the inside area of the filter element which is defined as:

$$
A_{\text {filter }}=\pi D i_{\text {filter }} L_{\text {filter }}
$$

where $D i_{\text {filter }}$ is the filter element inside diameter, and $L_{\text {filter }}$ is the filter element length.

The permeate volumetric flow rate is also corrected for viscosity and surface tension effects because the permeate temperature deviated from $25^{\circ} \mathrm{C}$. For a temperature $\mathrm{T}$, the corrected permeate flow rate and filter flux are given as:

$$
\begin{aligned}
& Q_{25^{\circ} \mathrm{C}}=Q_{T} e^{2500\left[\frac{1}{T+273}-\frac{1}{298}\right]} \\
& J_{25^{\circ} \mathrm{C}}=J_{T} e^{2500\left[\frac{1}{T+273}-\frac{1}{298}\right]}
\end{aligned}
$$

The pressure drop across the filter (i.e., the TMP) is calculated in this test to be:

$$
T M P=\Delta P_{m}=\frac{\left(P_{\text {inlet }}+P_{\text {outlet }}\right)}{2}-P_{\text {permeate }}
$$

where $P_{\text {inlet }}$ is the pressure at the filter inlet, $P_{\text {outlet }}$ is the pressure at the filter outlet, and $P_{\text {permeate }}$ is the pressure at the permeate side of the filter.

The axial velocity inside the filter is calculated by dividing the volumetric slurry flow of the filter by the cross section area of the inside diameter of filter: 


$$
A V=\frac{Q_{\text {slurry }}}{S_{a}}=\frac{Q_{\text {slurry }}}{\frac{\pi}{4} D i_{\text {filter }}^{2}}
$$

where $S_{a}$ is the cross sectional area of axial flow, and $Q_{\text {slurry }}$ is the volumetric slurry flowrate in the axial direction.

The Darcy equation describes filter flux as:

$$
J=\frac{\Delta P_{m}}{\mu_{\text {permeate }} R_{m}}
$$

where $\Delta P_{m}$ is the pressure drop across the filter membrane, $\mu_{\text {permeate }}$ is the viscosity of the permeate, and $R_{m}$ is the overall resistance of the filter membrane.

The filter resistance term is considered a more complicated term, which is a sum of the resistance of the actual filter, the resistance of the filter cake that forms on the surface of the filter surface, and the resistance due to fouling of the filter. For cross flow filtration, the overall resistance of the filter membrane for low concentrated slurries is usually constant, and turbulent flow conditions exist inside the filter. The transmembrane pressure and permeate viscosity are the controlling operation parameters. During dewatering, the slurry's flow properties change, and the filter resistance becomes more significant. When the slurry's UDS concentration begins to approach a maximum limit, known as the gel concentration, the filter flux can be described as

$$
J=k \cdot \ln \left[\frac{C_{s}}{C_{g}}\right]
$$

where $C_{s}$ is the slurry UDS concentration, and $C_{g}$ is the slurry gel concentration.

When the flux is impacted by the UDS concentration, the impact of axial velocity becomes significant as well. This is due to how the axial velocity affects the thickness of the filter cake inside the filter.

\section{K.1.2.2 Filtration Test Matrix}

To understand the impact of the transmembrane pressure and axial velocity on the filter flux of the waste slurry, a filtration test matrix was developed to understand their individual effects. Like the clean water and $\mathrm{SrCO}_{3}$ slurry flux testing described in section K.1.1.4, the waste slurry is circulated through the filtration skid while the slurry permeate leaving the filter is recycled back to the slurry reservoir. By recycling permeate in this way, the UDS concentration of the slurry stays constant. Using a TMP of 40 psid and an AV of 13 fps as the baseline condition, the testing conditions are varied to demonstrate how the flux varies as TMP and AV change from the center condition. Table K.1 and Figure K.9 outline the conditions for the testing performed. 
Each filtration condition is maintained for at least an hour while permeate is recycled back to the slurry reservoir tank. Before the test condition is changed, a back-pulse on the filter is performed to provide the same starting conditions for each test. The initial test performed at the baseline condition is performed for a minimum of 3 hours to track how the filter flux varies with time to track possible fouling due to the waste. If needed, the test matrix can be reduced in size by starting at Test 6 in Table K.1 and running this test for a 2-hour period.

Table K.1. Filtration Test Matrix Operating Conditions

\begin{tabular}{|c|c|c|c|}
\hline $\begin{array}{c}\text { Test } \\
\text { number }\end{array}$ & $\begin{array}{c}\text { Duration } \\
\text { (hours) }\end{array}$ & $\begin{array}{c}\text { Target TMP } \\
\text { (psid) }\end{array}$ & $\begin{array}{c}\text { Target AV* } \\
\text { (fps) }\end{array}$ \\
\hline 1 & 3 (min) & 40 & 13 \\
\hline 2 & 1 & 30 & 11 \\
\hline 3 & 1 & 30 & 15 \\
\hline 4 & 1 & 50 & 15 \\
\hline 5 & 1 & 50 & 11 \\
\hline 6 & 1 & 40 & 13 \\
\hline 7 & 1 & 40 & 9 \\
\hline 8 & 1 & 40 & 17 \\
\hline 9 & 1 & 20 & 13 \\
\hline 10 & 1 & 60 & 13 \\
\hline 11 & 1 & 40 & 13 \\
\hline
\end{tabular}

(a) Actual conditions may vary based upon slurry volume and rheology. All conditions may not be obtainable.

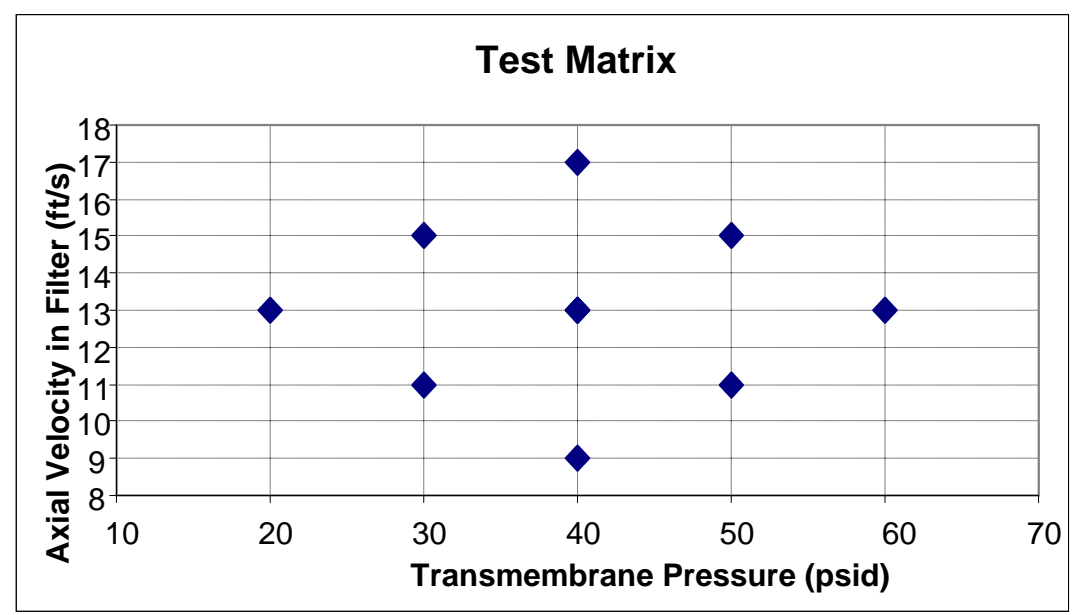

Figure K.9. Filtration Test Matrix Chart 
WTP-RPT-166, Rev. 0

Table K.2. Abridged Filter Test Matrix

\begin{tabular}{||c|c|c|c||}
\hline $\begin{array}{c}\text { Test } \\
\text { number }\end{array}$ & $\begin{array}{c}\text { Duration } \\
\text { (hrs) }\end{array}$ & $\begin{array}{c}\text { Target TMP } \\
\text { (psid) }\end{array}$ & $\begin{array}{c}\text { Target AV } \\
\text { (fps) }\end{array}$ \\
\hline 1 & 2 (min) & 40 & 13 \\
\hline 2 & 1 & 40 & 17 (or max) \\
\hline 3 & 1 & 40 & 9 \\
\hline 4 & 1 & 40 & 13 \\
\hline 5 & 1 & 20 & 13 \\
\hline 6 & 1 & 60 & 13 \\
\hline 7 & 1 & 40 & 13 \\
\hline
\end{tabular}

When the slurry is at low concentrations, the system is expected to be controlled by the transmembrane pressure (Equation K.6), with little impact from the axial velocity. However, once the slurry is concentrated and the flow properties change, it is expected that the axial velocity will have some effect on the filtration of the system.

\section{K.1.2.3 Dewatering Operation Analysis}

During dewatering operations of the waste slurries, the transmembrane pressure and axial velocity are maintained at the baseline condition of 40 psid and 13 fps. By maintaining the operating conditions of the filtration, the only effect on filtration should be the slurry concentration. As the slurry's UDS changes, the filter flux can be monitored and graphically charted, as shown in Figure K.10. As discussed earlier, the filter flux is initially expected to follow Equation K-6 for low-solids concentrations, which will appear as a horizontal line on the chart when the TMP is held constant. But as the slurry begins to concentrate, the filtration behavior of the slurry is expected to change and begin to follow Equation K.7. With graphic analysis, the transition in filtration behavior can be understood. 


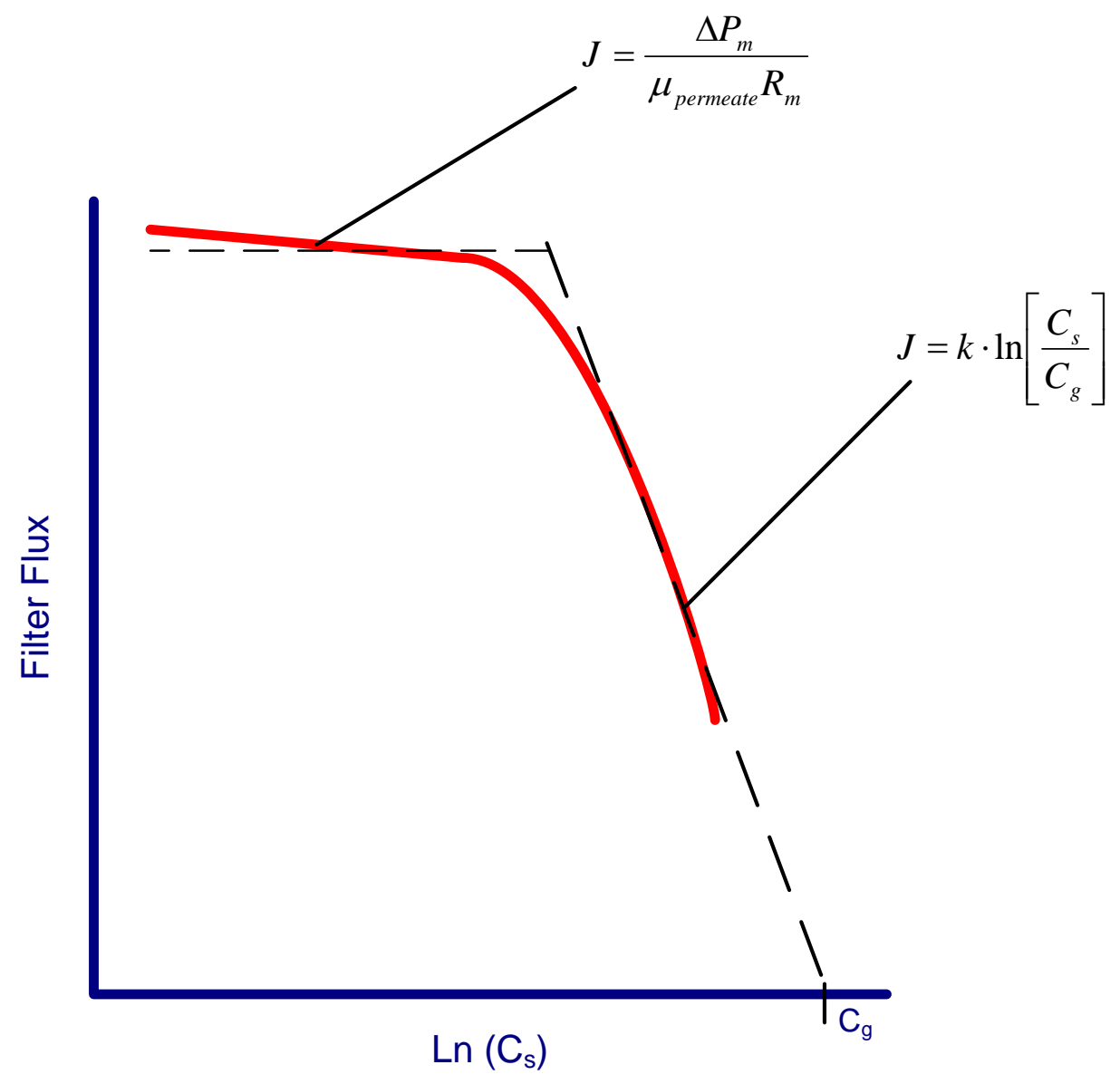

Figure K.10. Example of a Dewatering Curve

\section{K.1.2.4 Effects of Rheology and Particle Size}

During testing operations, rheology and particle-size samples are collected to characterize the solids in the slurry and their impact on flow and filtration behavior. As slurries concentrate, their flow behavior changes and becomes more viscous and less Newtonian. This directly impacts the cross-flow behavior of the filter and the formation of filter cake. Particle size also can have an impact by affecting the gel concentration of the slurry and possibly impact fouling. Because the slurries are sheared during filtration, the particle size of the slurry can change-especially if the initial solids are agglomerated. Chemical leaching has a similar impact as well.

\section{K.1.3 Chemical Data Analysis}

During the test, the mass of material placed inside the skid and removed is constantly measured to perform an overall mass balance of the slurry during the test. Two main goals are to be achieved from this analysis: 1) verification that transuranic (TRU) material stays in the HLW stream and 2) calculation of the chemical leach factors of glass-limiting compounds of interest. 


\section{K.1.3.1 Validation of Filtration Separation of TRU Material}

The main goal of the chemical and physical separation processes tested in this report is to demonstrate the effectiveness of removing load-limiting glass compounds (e.g., phosphorus and chromium) from the HLW stream while not introducing TRU material into the LAW waste stream. This is examined during filtration and leaching processes. During filtration, it is important to verify that TRU materials present in the waste slurry do not pass through the filtration media as a colloid or as a particle $<0.1 \mathrm{~mm}$. During leaching, it is also important to verify that TRU compounds are not chemically dissolved during operations designed only to remove glass-limiting compounds for the LAW stream. This is achieved by performing radiochemical analysis on permeate and slurry samples throughout the test to verify that the permeate streams contain minimal TRU compounds and that a mass balance on the system shows that almost all the TRU stays in the HLW slurry stream.

\section{K.1.3.2 Chemical Leach Factors for Caustic and Oxidative Leaching}

In this report, the chemical leach factor is defined as the percentage difference in mass of a solid component in the waste after chemical leaching.

$$
f_{i}=1-\frac{m_{i}^{\text {final }}}{m_{i}^{\text {initial }}}
$$

where $f_{i}$ is the leach factor for component $\mathrm{i}, m_{i}^{\text {initial }}$ is the initial solid mass of component $\mathrm{i}$, and $m_{i}^{\text {final }}$ is the final solid mass of component $i$.

The following methods are used to derive the initial and final mass of the components:

- Overall mass balance of the system along with physical property measurement of the solids fraction of the slurry

- Mass balance of the slurry before and after leaching using insoluble components, such as uranium, to trace the fractional change in mass

- Mass balance of the liquid permeate before and after leaching to measure the change of mass in the solids.

\section{K.1.3.3 Physical Examination of Final Leach Material}

The chemical characterization and physical morphology are examined after leaching. While most of the analyses used are qualitative, they can show:

- If particles are crystal, agglomerates, or amorphous

- Whether TRU and glass-limiting compounds (like aluminum or chromium) are blends of different phases or single compounds

- What is the crystal phase of the remaining glass-limiting compound (e.g., boehmite for aluminum). 
Appendix L

Group 1/2 Analytical Results from Parametric Leaching 


\section{Appendix L: Group 1/2 Analytical Results from Parametric Leaching}

Table L.1 provides information about analyte concentrations at various time intervals during oxidative leaching of the caustic-leached Group $1 / 2$ solids at $45^{\circ} \mathrm{C}$.

Table L.1. Analyte Concentrations as a Function of Time for Leaching at $45^{\circ} \mathrm{C}$

\begin{tabular}{|c|c|c|c|c|c|c|c|}
\hline \multirow[b]{2}{*}{ Analyte } & \multicolumn{7}{|c|}{$\begin{array}{l}\text { Analyte Concentration and Density at Given Time After Cooling to Ambient }\left(\sim 21^{\circ} \mathrm{C}\right) \\
\text { Temperature; } \mathrm{g} / \mathrm{mL} \text { for Density; } \mu \mathrm{g} / \mathrm{mL} \text { for Metals; } \mu \mathrm{Ci} / \mathrm{mL} \text { for Radionuclides }\end{array}$} \\
\hline & o hr & $0.5 \mathrm{hr}$ & $1 \mathrm{hr}$ & $2 \mathrm{hr}$ & $4 \mathrm{hr}$ & $6 \mathrm{hr}$ & $24 \mathrm{hr}$ \\
\hline \multicolumn{8}{|c|}{$0.25 \mathrm{M} N a \mathrm{OH}, \mathrm{Mn} / \mathrm{Cr}=0.59$} \\
\hline Density & 1.02 & 1.02 & 1.03 & 1.03 & 1.02 & 1.02 & 1.03 \\
\hline Total Cr & 8.57 & 90.4 & 90.1 & 90.6 & 89.6 & 95.8 & 95.6 \\
\hline $\mathrm{Cr}(\mathrm{VI})$ & 7.75 & 81.4 & 84.1 & 84.6 & 82.0 & 85.5 & 85.0 \\
\hline$\%$ Diff & 9.6 & 9.9 & 6.7 & 6.6 & 8.5 & 10.8 & 11.0 \\
\hline $\mathrm{Al}$ & 23.9 & 56.8 & 76.7 & 95.8 & 103.9 & 113.0 & 116.7 \\
\hline B & {$[0.544]$} & [0.652] & [0.609] & {$[0.622]$} & [0.498] & [0.437] & [0.563] \\
\hline $\mathrm{Bi}$ & [1.5] & $<0.93$ & {$[1.0]$} & [1.0] & $<0.93$ & [1.1] & {$[0.94]$} \\
\hline $\mathrm{Cd}$ & $<0.106$ & $<0.106$ & $<0.104$ & $<0.106$ & $<0.106$ & $<0.106$ & $<0.106$ \\
\hline $\mathrm{Fe}$ & [0.777] & [0.932] & [0.792] & [0.840] & [0.902] & [1.155] & [0.938] \\
\hline $\mathrm{Mn}$ & $<0.007$ & $<0.007$ & $<0.007$ & $<0.007$ & $<0.007$ & $<0.007$ & $<0.007$ \\
\hline $\mathrm{Na}$ & 7,183 & 7,361 & 7,429 & 7,561 & 7,343 & 7,741 & 7,663 \\
\hline $\mathrm{Ni}$ & $<0.075$ & $<0.075$ & $<0.073$ & {$[0.087]$} & $<0.075$ & {$[0.078]$} & $<0.075$ \\
\hline $\mathrm{P}$ & 178.5 & 189.5 & 187.0 & 192.3 & 187.9 & 199.5 & 200.5 \\
\hline$S$ & [8.9] & [9.9] & [9.1] & {$[7.8]$} & [6.8] & [13.1] & [5.3] \\
\hline $\mathrm{Si}$ & 8.1 & 31.7 & 45.7 & 59.1 & 61.9 & 66.2 & 62.6 \\
\hline $\mathrm{Sr}$ & {$[0.03]$} & {$[0.02]$} & {$[0.02]$} & {$[0.02]$} & {$[0.02]$} & {$[0.01]$} & {$[0.02]$} \\
\hline $\mathrm{U}$ & [2.705] & {$[4.35]$} & [2.710] & {$[3.42]$} & [2.769] & [3.43] & [2.002] \\
\hline U by KPA & NM & NM & NM & NM & NM & NM & 2.73 \\
\hline $\mathrm{Zn}$ & {$[0.72]$} & {$[0.50]$} & {$[0.58]$} & {$[0.47]$} & {$[0.90]$} & {$[0.66]$} & {$[0.63]$} \\
\hline $\mathrm{Zr}$ & $<0.04$ & $<0.03$ & $<0.03$ & $<0.03$ & $<0.03$ & $<0.03$ & $<0.03$ \\
\hline${ }^{239+240} \mathrm{Pu}$ & $1.54 \mathrm{E}-06$ & 1.11E-05 & $4.70 \mathrm{E}-06$ & 2.69E-06 & 2.02E-06 & 2.42E-06 & 1.93E-06 \\
\hline${ }^{238} \mathrm{Pu}$ & 1.11E-06 & 5.25E-07 & 6.43E-07 & 3.90E-07 & 5.71E-07 & $9.25 \mathrm{E}-07$ & 8.53E-07 \\
\hline \multicolumn{8}{|c|}{ Opportunistic Analytes } \\
\hline Ag & $<0.07$ & $<0.07$ & $<0.06$ & $<0.07$ & $<0.07$ & $<0.07$ & $<0.07$ \\
\hline As & $<1.4$ & $<1.3$ & $<1.3$ & $<1.3$ & $<1.3$ & $<1.3$ & $<1.3$ \\
\hline $\mathrm{Ba}$ & $<0.15$ & {$[0.06]$} & 0.19 & {$[0.11]$} & {$[0.13]$} & {$[0.15]$} & 0.319 \\
\hline $\mathrm{Be}$ & $<0.00$ & [0.002] & [0.002] & $<0.002$ & [0.003] & [0.002] & [0.002] \\
\hline $\mathrm{Ca}$ & $<0.64$ & {$[0.53]$} & {$[0.67]$} & {$[0.59]$} & {$[0.65]$} & {$[1.03]$} & {$[0.75]$} \\
\hline $\mathrm{Ce}$ & $<0.31$ & $<0.31$ & $<0.30$ & $<0.31$ & $<0.31$ & $<0.31$ & $<0.31$ \\
\hline Co & {$[0.09]$} & $<0.07$ & {$[0.09]$} & $<0.07$ & $<0.07$ & $<0.07$ & $<0.08$ \\
\hline $\mathrm{Cu}$ & {$[0.05]$} & $<0.04$ & {$[0.05]$} & {$[0.07]$} & [0.31] & {$[0.07]$} & $<0.04$ \\
\hline Dy & {$[0.10]$} & {$[0.11]$} & $<0.09$ & {$[0.11]$} & $<0.09$ & $<0.09$ & $<0.09$ \\
\hline
\end{tabular}


Table L.1 (contd)

\begin{tabular}{|c|c|c|c|c|c|c|c|}
\hline \multirow[b]{2}{*}{ Analyte } & \multicolumn{7}{|c|}{$\begin{array}{l}\text { Analyte Concentration and Density at Given Time After Cooling to Ambient }\left(\sim 21^{\circ} \mathrm{C}\right) \\
\text { Temperature; } \mathrm{g} / \mathrm{mL} \text { for Density; } \mu \mathrm{g} / \mathrm{mL} \text { for Metals; } \mu \mathrm{Ci} / \mathrm{mL} \text { for Radionuclides }\end{array}$} \\
\hline & $0 \mathrm{hr}$ & $0.5 \mathrm{hr}$ & $1 \mathrm{hr}$ & $2 \mathrm{hr}$ & $4 \mathrm{hr}$ & $6 \mathrm{hr}$ & $24 \mathrm{hr}$ \\
\hline $\mathrm{Eu}$ & {$[0.05]$} & {$[0.04]$} & $<0.03$ & $<0.03$ & $<0.03$ & $<0.03$ & $<0.03$ \\
\hline $\mathrm{K}$ & {$[0.96]$} & {$[2.1]$} & [1.2] & {$[1.6]$} & {$[2.7]$} & [1.4] & [1.5] \\
\hline $\mathrm{La}$ & $<0.09$ & $<0.09$ & $<0.09$ & $<0.09$ & $<0.09$ & $<0.09$ & $<0.09$ \\
\hline $\mathrm{Li}$ & {$[0.20]$} & {$[0.27]$} & [0.21] & {$[0.20]$} & [0.15] & {$[0.18]$} & [0.19] \\
\hline $\mathrm{Mg}$ & {$[0.11]$} & {$[0.16]$} & $<0.07$ & $<0.07$ & $<0.07$ & $<0.07$ & $<0.07$ \\
\hline Mo & {$[0.28]$} & $<0.16$ & $<0.16$ & $<0.16$ & [0.19] & $<0.16$ & {$[0.44]$} \\
\hline $\mathrm{Nd}$ & {$[0.18]$} & $<0.17$ & $<0.16$ & $<0.17$ & $<0.17$ & $<0.17$ & $<0.17$ \\
\hline $\mathrm{Pb}$ & $<1.0$ & $<0.99$ & $<0.97$ & $<1.0$ & $<1.0$ & [1.1] & $<1.0$ \\
\hline $\mathrm{Pd}$ & {$[0.27]$} & $<0.20$ & $<0.19$ & $<0.20$ & $<0.20$ & $<0.20$ & $<0.20$ \\
\hline $\mathrm{Rh}$ & {$[0.42]$} & {$[0.50]$} & $<0.37$ & $<0.37$ & $<0.37$ & $<0.37$ & $<0.38$ \\
\hline $\mathrm{Ru}$ & $<0.26$ & $<0.26$ & $<0.26$ & $<0.26$ & $<0.26$ & $<0.27$ & $<0.27$ \\
\hline $\mathrm{Sb}$ & {$[0.90]$} & {$[1.0]$} & $<0.61$ & [1.7] & $<0.62$ & $<0.62$ & $<0.63$ \\
\hline Se & $<2.2$ & $<2.2$ & $<2.1$ & $<2.2$ & $<2.2$ & $<2.2$ & $<2.2$ \\
\hline Sn & $<0.84$ & $<0.84$ & $<0.82$ & $<0.84$ & $<0.84$ & $<0.84$ & $<0.84$ \\
\hline $\mathrm{Ta}$ & $<0.53$ & $<0.53$ & $<0.52$ & $<0.53$ & $<0.53$ & $<0.53$ & $<0.53$ \\
\hline $\mathrm{Te}$ & {$[0.95]$} & $<0.81$ & {$[0.85]$} & $<0.81$ & $<0.81$ & $<0.81$ & {$[0.91]$} \\
\hline Th & {$[0.43]$} & {$[0.68]$} & {$[0.33]$} & {$[0.37]$} & $<0.30$ & $<0.31$ & $<0.31$ \\
\hline $\mathrm{Ti}$ & {$[0.02]$} & {$[0.02]$} & $<0.01$ & $<0.01$ & $<0.01$ & $<0.01$ & $<0.01$ \\
\hline $\mathrm{Tl}$ & $<1.2$ & $<1.2$ & $<1.2$ & $<1.2$ & $<1.2$ & $<1.2$ & $<1.2$ \\
\hline $\mathrm{V}$ & {$[0.07]$} & {$[0.12]$} & {$[0.16]$} & {$[0.15]$} & {$[0.18]$} & {$[0.17]$} & {$[0.18]$} \\
\hline $\mathrm{W}$ & {$[0.73]$} & {$[0.71]$} & $<0.58$ & {$[0.68]$} & {$[0.75]$} & $<0.59$ & $<0.59$ \\
\hline $\mathrm{Y}$ & $<0.01$ & {$[0.02]$} & $<0.01$ & $<0.01$ & $<0.01$ & $<0.01$ & $<0.01$ \\
\hline \multicolumn{8}{|c|}{$0.25 \mathrm{M} \mathrm{NaOH}, \mathrm{Mn} / \mathrm{Cr}=0.79$, Trial a } \\
\hline Density & 1.02 & 1.02 & 1.02 & 1.02 & 1.02 & 1.02 & 1.02 \\
\hline Total Cr & 8.80 & 108. & 111.8 & 114.1 & 113.4 & 115.9 & 115.7 \\
\hline Cr (VI) & 9.23 & 101.0 & 103.2 & 105.1 & 105.7 & 107.1 & 109.7 \\
\hline \% Diff & -4.9 & 7.2 & 7.7 & 7.8 & 6.7 & 7.6 & 5.1 \\
\hline $\mathrm{Al}$ & 23.8 & 56.6 & 76.1 & 96.2 & 105.6 & 112.4 & 115.3 \\
\hline B & {$[0.340]$} & {$[0.560]$} & {$[0.457]$} & {$[0.462]$} & [0.532] & [0.502] & {$[0.534]$} \\
\hline $\mathrm{Bi}$ & {$[1.6]$} & $<0.93$ & [1.0] & $<0.92$ & $<0.94$ & [1.3] & $<0.94$ \\
\hline $\mathrm{Cd}$ & $<0.105$ & $<0.106$ & $<0.104$ & $<0.105$ & $<0.106$ & $<0.107$ & $<0.107$ \\
\hline $\mathrm{Fe}$ & {$[0.648]$} & 2.27 & {$[0.731]$} & {$[1.140]$} & {$[0.908]$} & {$[0.848]$} & {$[0.943]$} \\
\hline Mn & $<0.007$ & 1.36 & $<0.007$ & $<0.007$ & $<0.007$ & $<0.007$ & $<0.007$ \\
\hline $\mathrm{Na}$ & 7,315 & 7,433 & 7,582 & 7,675 & 7,611 & 7,755 & 7,543 \\
\hline $\mathrm{Ni}$ & $<0.074$ & $<0.075$ & $<0.073$ & {$[0.099]$} & $<0.075$ & {$[0.126]$} & $<0.075$ \\
\hline $\mathrm{P}$ & 181.8 & 194.1 & 195.2 & 193.3 & 194.5 & 200.6 & 198.9 \\
\hline$S$ & [5.9] & [6.5] & [13.7] & [4.3] & [13.2] & {$[16.0]$} & [15.7] \\
\hline $\mathrm{Si}$ & 8.06 & 32.3 & 46.0 & 58.9 & 63.9 & 65.9 & 61.9 \\
\hline $\mathrm{Sr}$ & {$[0.01]$} & {$[0.02]$} & {$[0.02]$} & {$[0.02]$} & {$[0.01]$} & {$[0.01]$} & {$[0.01]$} \\
\hline
\end{tabular}


Table L.1 (contd)

\begin{tabular}{|c|c|c|c|c|c|c|c|}
\hline \multirow[b]{2}{*}{ Analyte } & \multicolumn{7}{|c|}{$\begin{array}{l}\text { Analyte Concentration and Density at Given Time After Cooling to Ambient }\left(\sim 21^{\circ} \mathrm{C}\right) \\
\text { Temperature; } g / \mathrm{mL} \text { for Density; } \mu \mathrm{g} / \mathrm{mL} \text { for Metals; } \mu \mathrm{Ci} / \mathrm{mL} \text { for Radionuclides }\end{array}$} \\
\hline & $0 \mathrm{hr}$ & $0.5 \mathrm{hr}$ & $1 \mathrm{hr}$ & $2 \mathrm{hr}$ & $4 \mathrm{hr}$ & $6 \mathrm{hr}$ & $24 \mathrm{hr}$ \\
\hline $\mathrm{U}$ & [1.57] & [4.98] & [3.35] & [3.02] & {$[2.41]$} & {$[2.86]$} & {$[2.42]$} \\
\hline U by KPA & NM & NM & NM & NM & NM & NM & 2.46 \\
\hline \begin{tabular}{l|l}
$\mathrm{Zn}$ \\
\end{tabular} & [0.59] & {$[0.59]$} & {$[0.52]$} & {$[0.65]$} & {$[0.75]$} & {$[0.44]$} & [0.57] \\
\hline $\mathrm{Zr}$ & $<0.03$ & $<0.03$ & $<0.03$ & $<0.03$ & $<0.03$ & $<0.03$ & $<0.03$ \\
\hline${ }^{239+240} \mathrm{Pu}$ & 6.13E-07 & 4.08E-06 & 3.08E-06 & 2.27E-06 & $1.16 \mathrm{E}-06$ & $4.76 \mathrm{E}-07$ & $3.46 \mathrm{E}-07$ \\
\hline${ }^{238} \mathrm{Pu}$ & $6.90 \mathrm{E}-07$ & $2.48 \mathrm{E}-04$ & 2.12E-04 & $1.44 \mathrm{E}-04$ & 6.65E-05 & 3.54E-05 & 4.85E-06 \\
\hline \multicolumn{8}{|c|}{ Opportunistic Analytes } \\
\hline Ag & $<0.06$ & $<0.06$ & $<0.06$ & $<0.06$ & $<0.06$ & $<0.06$ & $<0.06$ \\
\hline As & $<1.3$ & $<1.3$ & $<1.3$ & $<1.3$ & $<1.3$ & $<1.4$ & $<1.4$ \\
\hline $\mathrm{Ba}$ & {$[0.08]$} & {$[0.11]$} & {$[0.14]$} & {$[0.10]$} & {$[0.06]$} & {$[0.05]$} & {$[0.10]$} \\
\hline $\mathrm{Be}$ & {$[0.00]$} & {$[0.00]$} & $<0.002$ & {$[0.00]$} & {$[0.00]$} & $<0.002$ & {$[0.00]$} \\
\hline $\mathrm{Ca}$ & {$[0.46]$} & {$[0.56]$} & {$[0.64]$} & {$[0.52]$} & {$[0.69]$} & {$[0.91]$} & {$[0.79]$} \\
\hline $\mathrm{Ce}$ & $<0.06$ & $<0.06$ & $<0.06$ & $<0.06$ & $<0.06$ & $<0.06$ & $<0.06$ \\
\hline Co & $<0.06$ & $<0.06$ & $<0.06$ & [0.09] & $<0.06$ & $<0.06$ & $<0.06$ \\
\hline $\mathrm{Cu}$ & $<0.06$ & {$[0.06]$} & $<0.06$ & {$[0.06]$} & $<0.06$ & $<0.06$ & $<0.06$ \\
\hline Dy & $<0.06$ & {$[0.11]$} & $<0.06$ & $<0.06$ & $<0.06$ & $<0.06$ & $<0.06$ \\
\hline $\mathrm{Eu}$ & $<0.06$ & {$[0.04]$} & $<0.06$ & $<0.06$ & $<0.06$ & $<0.06$ & $<0.06$ \\
\hline $\mathrm{K}$ & $<0.06$ & {$[2.6]$} & {$[2.1]$} & {$[1.7]$} & [3.1] & {$[3.0]$} & {$[2.7]$} \\
\hline $\mathrm{La}$ & $<0.06$ & $<0.06$ & $<0.06$ & $<0.06$ & $<0.06$ & $<0.06$ & $<0.06$ \\
\hline $\mathrm{Li}$ & {$[0.16]$} & {$[0.20]$} & {$[0.20]$} & {$[0.21]$} & {$[0.20]$} & {$[0.22]$} & {$[0.17]$} \\
\hline $\mathrm{Mg}$ & $<0.06$ & $<0.06$ & $<0.06$ & $<0.06$ & $<0.06$ & $<0.06$ & $<0.06$ \\
\hline Mo & {$[0.16]$} & $<0.06$ & {$[0.33]$} & {$[0.17]$} & {$[0.44]$} & {$[0.23]$} & {$[0.35]$} \\
\hline $\mathrm{Nd}$ & $<0.06$ & $<0.06$ & $<0.06$ & $<0.06$ & $<0.06$ & $<0.06$ & $<0.06$ \\
\hline $\mathrm{Pb}$ & $<0.06$ & $<0.06$ & $<0.06$ & $<0.06$ & $<1.0$ & $<1.0$ & $<1.0$ \\
\hline $\mathrm{Pd}$ & $<0.06$ & $<0.06$ & $<0.06$ & $<0.06$ & $<0.06$ & $<0.06$ & $<0.06$ \\
\hline $\mathrm{Rh}$ & $<0.06$ & $<0.06$ & $<0.06$ & $<0.06$ & $<0.06$ & $<0.06$ & $<0.06$ \\
\hline $\mathrm{Ru}$ & $<0.06$ & {$[0.31]$} & {$[0.30]$} & $<0.06$ & $<0.06$ & $<0.06$ & $<0.06$ \\
\hline $\mathrm{Sb}$ & {$[0.96]$} & {$[1.2]$} & {$[1.0]$} & {$[1.2]$} & {$[0.91]$} & $<0.628$ & {$[1.4]$} \\
\hline Se & $<2.2$ & 2.2 & $<2.1$ & $<4.6$ & $<2.2$ & $<2.2$ & $<2.2$ \\
\hline Sn & $<0.06$ & $<0.06$ & $<0.06$ & $<0.06$ & $<0.06$ & $<0.06$ & $<0.06$ \\
\hline $\mathrm{Ta}$ & $<0.06$ & $<0.06$ & $<0.06$ & $<0.06$ & $<0.06$ & $<0.06$ & $<0.06$ \\
\hline $\mathrm{Te}$ & $<0.06$ & {$[1.2]$} & $<0.06$ & $<0.06$ & $<0.06$ & $<0.06$ & {$[0.91]$} \\
\hline Th & {$[0.34]$} & {$[0.47]$} & {$[0.43]$} & {$[0.43]$} & {$[0.41]$} & $<0.06$ & $<0.06$ \\
\hline $\mathrm{Ti}$ & $<0.06$ & {$[0.02]$} & $<0.06$ & $<0.06$ & $<0.06$ & $<0.06$ & {$[0.014]$} \\
\hline $\mathrm{Tl}$ & {$[1.5]$} & {$[1.6]$} & $<1.2$ & $<1.2$ & $<1.2$ & $<1.2$ & $<1.2$ \\
\hline $\mathrm{V}$ & {$[0.09]$} & {$[0.16]$} & {$[0.16]$} & {$[0.18]$} & {$[0.21]$} & {$[0.23]$} & {$[0.19]$} \\
\hline $\mathrm{W}$ & $<0.06$ & {$[0.65]$} & $<0.06$ & {$[1.4]$} & {$[0.69]$} & {$[0.91]$} & {$[1.1]$} \\
\hline $\mathrm{Y}$ & $<0.06$ & $<0.06$ & $<0.06$ & $<0.06$ & $<0.06$ & $<0.06$ & $<0.06$ \\
\hline \multicolumn{8}{|c|}{$0.25 \mathrm{M} \mathrm{NaOH}, \mathrm{Mn} / \mathrm{Cr}=0.79$, Trial b } \\
\hline Density & 1.02 & 1.02 & 1.02 & 1.02 & 1.02 & 1.02 & 1.01 \\
\hline
\end{tabular}


Table L.1 (contd)

\begin{tabular}{|c|c|c|c|c|c|c|c|}
\hline \multirow[b]{2}{*}{ Analyte } & \multicolumn{7}{|c|}{$\begin{array}{l}\text { Analyte Concentration and Density at Given Time After Cooling to Ambient }\left(\sim 21^{\circ} \mathrm{C}\right) \\
\text { Temperature; } \mathrm{g} / \mathrm{mL} \text { for Density; } \mu \mathrm{g} / \mathrm{mL} \text { for Metals; } \mu \mathrm{Ci} / \mathrm{mL} \text { for Radionuclides }\end{array}$} \\
\hline & $0 \mathrm{hr}$ & $0.5 \mathrm{hr}$ & $1 \mathrm{hr}$ & $2 \mathrm{hr}$ & $4 \mathrm{hr}$ & $6 \mathrm{hr}$ & $24 \mathrm{hr}$ \\
\hline Total Cr & 8.56 & 104.6 & 108.9 & 107.8 & 111.5 & 111.0 & 112.2 \\
\hline $\mathrm{Cr}(\mathrm{VI})$ & 8.20 & 99.6 & 98.3 & 98.5 & 99.5 & 100.7 & 102.1 \\
\hline \% Diff & 4.2 & 4.8 & 9.7 & 8.6 & 10.7 & 9.2 & 9.0 \\
\hline $\mathrm{Al}$ & 23.2 & 59.3 & 78.6 & 95.4 & 106.5 & 109.7 & 114.3 \\
\hline B & {$[0.372]$} & 0.403 & [0.339] & {$[0.424]$} & [0.621] & [0.527] & [0.490] \\
\hline $\mathrm{Bi}$ & [1.3] & 0.96 & [1.0] & $<0.91$ & [0.99] & $<0.93$ & $<0.92$ \\
\hline $\mathrm{Cd}$ & $<0.105$ & 0.106 & $<0.105$ & $<0.103$ & $<0.106$ & $<0.105$ & $<0.104$ \\
\hline $\mathrm{Fe}$ & [0.651] & 0.714 & [0.709] & [0.697] & {$[0.870]$} & [0.899] & [0.920] \\
\hline $\mathrm{Mn}$ & $<0.007$ & 1.92 & {$[0.046]$} & $<0.007$ & $<0.007$ & $<0.007$ & $<0.007$ \\
\hline $\mathrm{Na}$ & 7,225 & 7,324 & 7,402 & 7,389 & 7,485 & 7,500 & 7,602 \\
\hline $\mathrm{Ni}$ & $<0.074$ & 0.074 & $<0.074$ & $<0.073$ & [0.099] & $<0.074$ & $<0.074$ \\
\hline $\mathrm{P}$ & 178.0 & 186.2 & 188.4 & 186.6 & 191.3 & 190.9 & 188.2 \\
\hline S & [11.2] & 6.207 & [2.2] & [10.6] & [6.8] & [4.0] & [11.0] \\
\hline $\mathrm{Si}$ & 8.06 & 35.4 & 48.7 & 60.0 & 65.2 & 65.7 & 62.2 \\
\hline $\mathrm{Sr}$ & {$[0.02]$} & 0.02 & {$[0.02]$} & {$[0.01]$} & {$[0.02]$} & {$[0.01]$} & {$[0.01]$} \\
\hline $\mathrm{U}$ & [2.108] & 3.72 & [2.621] & [3.03] & [3.42] & [2.417] & [2.146] \\
\hline U by KPA & NM & NM & NM & NM & NM & NM & 2.35 \\
\hline $\mathrm{Zn}$ & {$[0.71]$} & 0.56 & {$[0.52]$} & {$[0.58]$} & {$[0.56]$} & {$[0.65]$} & [0.58] \\
\hline $\mathrm{Zr}$ & $<0.03$ & 0.03 & $<0.03$ & $<0.03$ & $<0.03$ & $<0.03$ & $<0.03$ \\
\hline${ }^{239+240} \mathrm{Pu}$ & $6.78 \mathrm{E}-07$ & 3.61E-06 & 2.03E-06 & $2.14 \mathrm{E}-06$ & $1.36 \mathrm{E}-06$ & $6.08 \mathrm{E}-07$ & 2.89E-07 \\
\hline${ }^{238} \mathrm{Pu}$ & 6.30E-07 & $2.45 \mathrm{E}-04$ & $2.14 \mathrm{E}-04$ & $1.22 \mathrm{E}-04$ & 8.73E-05 & 4.64E-05 & 6.67E-06 \\
\hline \multicolumn{8}{|c|}{ Opportunistic Analytes } \\
\hline \begin{tabular}{l|l}
$\mathrm{Ag}$ &
\end{tabular} & $<0.07$ & $<0.07$ & $<0.06$ & $<0.06$ & $<0.07$ & $<0.07$ & $<0.06$ \\
\hline As & $<1.3$ & $<1.3$ & $<1.3$ & $<1.3$ & $<1.3$ & $<1.3$ & {$[2.3]$} \\
\hline $\mathrm{Ba}$ & 0.180 & {$[0.09]$} & {$[0.08]$} & {$[0.08]$} & {$[0.08]$} & {$[0.11]$} & {$[0.09]$} \\
\hline $\mathrm{Be}$ & $<0.002$ & $<0.002$ & {$[0.00]$} & $<0.002$ & {$[0.00]$} & {$[0.00]$} & {$[0.00]$} \\
\hline $\mathrm{Ca}$ & {$[0.50]$} & {$[0.59]$} & {$[0.52]$} & {$[0.55]$} & {$[0.84]$} & {$[0.90]$} & {$[0.83]$} \\
\hline $\mathrm{Ce}$ & $<0.31$ & $<0.31$ & $<0.31$ & $<0.30$ & $<0.31$ & $<0.31$ & $<0.31$ \\
\hline Co & $<0.07$ & {$[0.11]$} & $<0.07$ & {$[0.08]$} & {$[0.08]$} & {$[0.08]$} & {$[0.10]$} \\
\hline $\mathrm{Cu}$ & {$[0.05]$} & {$[0.14]$} & $<0.04$ & {$[0.04]$} & $<0.04$ & $<0.04$ & {$[0.04]$} \\
\hline Dy & {$[0.10]$} & $<0.09$ & $<0.09$ & {$[0.11]$} & $<0.09$ & $<0.09$ & $<0.09$ \\
\hline $\mathrm{Eu}$ & $<0.03$ & $<0.03$ & $<0.03$ & $<0.03$ & {$[0.06]$} & $<0.03$ & $<0.03$ \\
\hline $\mathrm{K}$ & $<0.62$ & [2.1] & [4.6] & [3.9] & {$[0.6]$} & [1.7] & [1.1] \\
\hline $\mathrm{La}$ & $<0.09$ & $<0.09$ & $<0.09$ & $<0.08$ & $<0.09$ & $<0.09$ & $<0.09$ \\
\hline $\mathrm{Li}$ & {$[0.17]$} & {$[0.16]$} & {$[0.19]$} & {$[0.21]$} & {$[0.22]$} & {$[0.22]$} & {$[0.21]$} \\
\hline Mg & $<0.07$ & $<0.07$ & $<0.07$ & $<0.07$ & {$[0.08]$} & $<0.07$ & $<0.07$ \\
\hline Mo & {$[0.17]$} & $<0.16$ & {$[0.21]$} & {$[0.19]$} & {$[0.21]$} & {$[0.43]$} & {$[0.18]$} \\
\hline $\mathrm{Nd}$ & $<0.17$ & {$[0.18]$} & $<0.17$ & $<0.16$ & $<0.17$ & $<0.17$ & $<0.17$ \\
\hline $\mathrm{Pb}$ & $<0.99$ & $<0.99$ & $<0.99$ & $<0.97$ & $<0.99$ & $<0.99$ & $<0.98$ \\
\hline$\overline{P d}$ & $<0.20$ & $<0.20$ & $<0.19$ & $<0.19$ & $<0.20$ & $<0.20$ & $<0.19$ \\
\hline
\end{tabular}


Table L.1 (contd)

\begin{tabular}{|c|c|c|c|c|c|c|c|}
\hline \multirow[b]{2}{*}{ Analyte } & \multicolumn{7}{|c|}{$\begin{array}{l}\text { Analyte Concentration and Density at Given Time After Cooling to Ambient }\left(\sim 21^{\circ} \mathrm{C}\right) \\
\text { Temperature; } g / \mathrm{mL} \text { for Density; } \mu \mathrm{g} / \mathrm{mL} \text { for Metals; } \mu \mathrm{Ci} / \mathrm{mL} \text { for Radionuclides }\end{array}$} \\
\hline & o hr & 0.5 hr & $1 \mathrm{hr}$ & $2 \mathrm{hr}$ & $4 \mathrm{hr}$ & $6 \mathrm{hr}$ & $24 \mathrm{hr}$ \\
\hline $\mathrm{Rh}$ & $<0.37$ & $<0.37$ & $<0.37$ & $<0.36$ & $<0.37$ & $<0.37$ & $<0.37$ \\
\hline $\mathrm{Ru}$ & $<0.26$ & $<0.26$ & $<0.26$ & $<0.26$ & $<0.26$ & $<0.26$ & $<0.26$ \\
\hline $\mathrm{Sb}$ & [2.3] & $<0.62$ & $<0.62$ & $<0.61$ & $<0.62$ & $<0.62$ & $<0.61$ \\
\hline Se & $<2.2$ & {$[2.3]$} & {$[2.5]$} & $<2.1$ & $<2.2$ & {$[3.1]$} & $<2.1$ \\
\hline Sn & $<0.84$ & $<0.84$ & $<0.83$ & $<0.82$ & $<0.84$ & $<0.84$ & $<0.83$ \\
\hline $\mathrm{Ta}$ & $<0.53$ & {$[0.5]$} & $<0.52$ & $<0.51$ & $<0.53$ & $<0.53$ & $<0.52$ \\
\hline $\mathrm{Te}$ & $<0.81$ & {$[1.6]$} & $<0.80$ & $<0.79$ & [1.3] & {$[2.0]$} & [1.0] \\
\hline Th & $<0.30$ & {$[0.34]$} & $<0.30$ & $<0.30$ & [1.0] & {$[0.53]$} & $<0.30$ \\
\hline $\mathrm{Ti}$ & $<0.01$ & $<0.01$ & {$[0.02]$} & $<0.01$ & {$[0.03]$} & {$[0.02]$} & {$[0.02]$} \\
\hline $\mathrm{Tl}$ & [1.5] & $<1.2$ & $<1.2$ & $<1.2$ & $<1.2$ & $<1.2$ & $<1.2$ \\
\hline V & {$[0.05]$} & {$[0.18]$} & {$[0.18]$} & [0.19] & {$[0.21]$} & {$[0.21]$} & {$[0.22]$} \\
\hline $\mathrm{W}$ & $<0.59$ & {$[0.74]$} & [0.99] & [0.58] & $<0.59$ & [0.93] & $<0.58$ \\
\hline $\mathrm{Y}$ & $<0.01$ & $<0.01$ & $<0.01$ & [0.01] & $<0.01$ & $<0.01$ & $<0.01$ \\
\hline \multicolumn{8}{|c|}{$0.25 \mathrm{M} \mathrm{NaOH}, \mathrm{Mn} / \mathrm{Cr}=0.79$, Trial c } \\
\hline Density & 1.02 & 1.02 & 102 & 1.02 & 1.02 & 1.03 & 1.02 \\
\hline Total Cr & 8.44 & 103.2 & 104.6 & 105.8 & 106.6 & 112.0 & 113.5 \\
\hline $\mathrm{Cr}(\mathrm{VI})$ & 8.25 & 95.5 & 100.7 & 98.2 & 100.8 & 102.7 & 100.4 \\
\hline \% Diff & 2.3 & 7.5 & 3.8 & 7.3 & 5.4 & 8.3 & 11.5 \\
\hline $\mathrm{Al}$ & 22.5 & 58.6 & 76.6 & 95.0 & 103.8 & 111.6 & 117.9 \\
\hline B & [0.403] & [0.338] & {$[0.370]$} & {$[0.374]$} & [0.310] & {$[0.314]$} & {$[0.568]$} \\
\hline $\mathrm{Bi}$ & {$[1.1]$} & {$[1.0]$} & $<0.93$ & $<0.93$ & $<0.93$ & [1.2] & [1.2] \\
\hline $\mathrm{Cd}$ & $<0.106$ & $<0.104$ & $<0.105$ & $<0.106$ & $<0.105$ & $<0.109$ & $<0.107$ \\
\hline $\mathrm{Fe}$ & {$[0.652]$} & {$[0.676]$} & {$[0.741]$} & {$[0.716]$} & {$[0.775]$} & {$[0.832]$} & {$[0.914]$} \\
\hline $\mathrm{Mn}$ & $<0.007$ & 1.20 & $<0.007$ & $<0.007$ & $<0.007$ & $<0.007$ & $<0.007$ \\
\hline $\mathrm{Na}$ & 6,859 & 6,909 & 6,945 & 7,004 & 7,033 & 7,326 & 7,220 \\
\hline $\mathrm{Ni}$ & $<0.074$ & $<0.074$ & $<0.074$ & $<0.075$ & [0.133] & $<0.077$ & [0.082] \\
\hline $\mathrm{P}$ & 172.6 & 179.6 & 184.3 & 185.5 & 182.8 & 194.2 & 191.1 \\
\hline S & [6.5] & [6.8] & [5.2] & [10.0] & [4.6] & [10.9] & [10.1] \\
\hline $\mathrm{Si}$ & 7.67 & 33.8 & 47.54 & 58. & 63.2 & 66.9 & 64.3 \\
\hline $\mathrm{Sr}$ & {$[0.01]$} & {$[0.01]$} & {$[0.02]$} & [0.02] & {$[0.01]$} & {$[0.01]$} & {$[0.01]$} \\
\hline $\mathrm{U}$ & [2.173] & [3.38] & [3.70] & [2.615] & [2.478] & [2.399] & [4.41] \\
\hline U by KPA & NM & NM & NM & NM & NM & NM & 2.45 \\
\hline $\mathrm{Zn}$ & {$[0.78]$} & [0.52] & {$[0.68]$} & [0.53] & {$[0.56]$} & [0.64] & {$[0.79]$} \\
\hline $\mathrm{Zr}$ & $<0.03$ & $<0.03$ & $<0.03$ & $<0.03$ & $<0.03$ & $<0.04$ & $<0.03$ \\
\hline${ }^{239+240} \mathrm{Pu}$ & 3.30E-07 & 3.87E-06 & 3.39E-06 & $1.38 \mathrm{E}-06$ & $1.59 \mathrm{E}-06$ & $4.46 \mathrm{E}-07$ & $1.15 \mathrm{E}-06$ \\
\hline${ }^{238} \mathrm{Pu}$ & 5.13E-07 & 2.13E-04 & $1.88 \mathrm{E}-04$ & $1.38 \mathrm{E}-04$ & 7.72E-05 & 3.68E-05 & 5.73E-06 \\
\hline \multicolumn{8}{|c|}{ Opportunistic Analytes } \\
\hline $\mathrm{Ag}$ & $<0.07$ & $<0.06$ & $<0.06$ & $<0.07$ & $<0.07$ & $<0.07$ & $<0.07$ \\
\hline As & $<1.3$ & {$[2.7]$} & $<1.3$ & $<1.3$ & $<1.3$ & $<1.4$ & $<1.4$ \\
\hline $\mathrm{Ba}$ & 0.214 & {$[0.05]$} & {$[0.10]$} & {$[0.10]$} & {$[0.11]$} & {$[0.11]$} & {$[0.09]$} \\
\hline
\end{tabular}


Table L.1 (contd)

\begin{tabular}{|c|c|c|c|c|c|c|c|}
\hline \multirow[b]{2}{*}{ Analyte } & \multicolumn{7}{|c|}{$\begin{array}{l}\text { Analyte Concentration and Density at Given Time After Cooling to Ambient }\left(\sim 21^{\circ} \mathrm{C}\right) \\
\text { Temperature; } \mathrm{g} / \mathrm{mL} \text { for Density; } \mu \mathrm{g} / \mathrm{mL} \text { for Metals; } \mu \mathrm{Ci} / \mathrm{mL} \text { for Radionuclides }\end{array}$} \\
\hline & $0 \mathrm{hr}$ & $0.5 \mathrm{hr}$ & $1 \mathrm{hr}$ & $2 \mathrm{hr}$ & $4 \mathrm{hr}$ & $6 \mathrm{hr}$ & $24 \mathrm{hr}$ \\
\hline $\mathrm{Be}$ & {$[0.00]$} & {$[0.00]$} & {$[0.00]$} & {$[0.00]$} & {$[0.00]$} & {$[0.00]$} & {$[0.00]$} \\
\hline $\mathrm{Ca}$ & {$[0.37]$} & {$[0.58]$} & {$[0.40]$} & {$[0.47]$} & {$[0.81]$} & {$[0.93]$} & [1.3] \\
\hline $\mathrm{Ce}$ & $<0.31$ & $<0.31$ & $<0.31$ & $<0.31$ & $<0.31$ & $<0.32$ & $<0.32$ \\
\hline Co & $<0.07$ & {$[0.12]$} & {$[0.10]$} & {$[0.11]$} & $<0.07$ & $<0.08$ & $<0.08$ \\
\hline $\mathrm{Cu}$ & $<0.04$ & $<0.04$ & $<0.04$ & $<0.04$ & $<0.04$ & $<0.04$ & {$[0.08]$} \\
\hline Dy & $<0.09$ & $<0.09$ & $<0.09$ & $<0.09$ & $<0.09$ & $<0.09$ & {$[0.11]$} \\
\hline $\mathrm{Eu}$ & $<0.03$ & $<0.03$ & $<0.03$ & $<0.03$ & $<0.03$ & $<0.04$ & $<0.03$ \\
\hline $\mathrm{K}$ & {$[2.0]$} & [1.7] & [3.0] & {$[2.8]$} & [3.1] & [3.8] & [3.2] \\
\hline $\mathrm{La}$ & $<0.09$ & $<0.09$ & $<0.09$ & $<0.09$ & $<0.09$ & $<0.09$ & $<0.09$ \\
\hline $\mathrm{Li}$ & [0.15] & {$[0.18]$} & {$[0.18]$} & {$[0.21]$} & {$[0.20]$} & {$[0.20]$} & {$[0.22]$} \\
\hline $\mathrm{Mg}$ & $<0.07$ & $<0.07$ & $<0.07$ & $<0.07$ & $<0.07$ & $<0.07$ & $<0.07$ \\
\hline Mo & $<0.16$ & $<0.16$ & $<0.16$ & $<0.16$ & {$[0.28]$} & [0.29] & {$[0.22]$} \\
\hline $\mathrm{Nd}$ & $<0.17$ & $<0.17$ & $<0.17$ & $<0.17$ & $<0.17$ & $<0.17$ & $<0.17$ \\
\hline $\mathrm{Pb}$ & $<0.99$ & $<0.98$ & $<0.99$ & $<1.00$ & $<0.99$ & $<1.02$ & $<1.01$ \\
\hline $\mathrm{Pd}$ & $<0.20$ & $<0.19$ & $<0.19$ & $<0.20$ & $<0.20$ & $<0.20$ & $<0.20$ \\
\hline $\mathrm{Rh}$ & $<0.37$ & $<0.37$ & $<0.37$ & $<0.37$ & $<0.37$ & $<0.38$ & $<0.38$ \\
\hline $\mathrm{Ru}$ & $<0.26$ & {$[0.28]$} & $<0.26$ & $<0.26$ & $<0.26$ & $<0.27$ & $<0.27$ \\
\hline $\mathrm{Sb}$ & [0.93] & {$[0.89]$} & $<0.62$ & $<0.62$ & $<0.62$ & $<0.64$ & $<0.63$ \\
\hline Se & $<2.2$ & $<2.1$ & $<2.2$ & $<2.2$ & $<2.2$ & $<2.2$ & $<2.2$ \\
\hline Sn & $<0.84$ & $<0.83$ & [0.83] & $<0.84$ & $<0.84$ & $<0.86$ & $<0.85$ \\
\hline $\mathrm{Ta}$ & $<0.53$ & $<0.52$ & $<0.52$ & $<0.53$ & $<0.53$ & $<0.54$ & $<0.54$ \\
\hline $\mathrm{Te}$ & $<0.81$ & $<0.80$ & {$[0.96]$} & $<0.81$ & {$[0.84]$} & $<0.83$ & {$[1.0]$} \\
\hline Th & $<0.30$ & $<0.30$ & $<0.30$ & $<0.31$ & $<0.30$ & $<0.31$ & {$[0.69]$} \\
\hline $\mathrm{Ti}$ & $<0.01$ & {$[0.01]$} & $<0.01$ & {$[0.01]$} & {$[0.02]$} & $<0.01$ & $<0.01$ \\
\hline $\mathrm{Tl}$ & $<1.2$ & $<1.2$ & $<1.2$ & $<1.2$ & $<1.2$ & $<1.2$ & $<1.2$ \\
\hline $\mathrm{V}$ & {$[0.10]$} & {$[0.17]$} & [0.21] & {$[0.20]$} & {$[0.21]$} & {$[0.22]$} & {$[0.22]$} \\
\hline $\mathrm{W}$ & $<0.59$ & {$[0.61]$} & {$[0.80]$} & $<0.59$ & {$[0.68]$} & [0.99] & {$[0.73]$} \\
\hline $\mathrm{Y}$ & $<0.01$ & $<0.01$ & $<0.01$ & $<0.01$ & $<0.01$ & $<0.01$ & $<0.01$ \\
\hline \multicolumn{8}{|c|}{$0.25 \mathrm{M} \mathrm{NaOH}, \mathrm{Mn} / \mathrm{Cr}=0.98$} \\
\hline Density & 1.02 & 1.02 & 1.01 & 1.02 & 1.02 & 1.02 & 1.02 \\
\hline Total Cr & 8.56 & 105.4 & 112.8 & 112.8 & 114.2 & 118.4 & 122.8 \\
\hline $\mathrm{Cr}(\mathrm{VI})$ & 8.61 & 93.4 & 99.4 & 98.9 & 101.3 & 107.2 & 108.2 \\
\hline \% Diff & -0.6 & 11.4 & 11.9 & 12.3 & 11.3 & 9.5 & 11.9 \\
\hline $\mathrm{Al}$ & 22.8 & 49.2 & 91.2 & 72.5 & 101.8 & 108.5 & 116.7 \\
\hline B & {$[0.740]$} & {$[0.815]$} & [0.563] & {$[0.531]$} & {$[0.572]$} & [0.540] & {$[0.577]$} \\
\hline $\mathrm{Bi}$ & $<0.91$ & $<0.91$ & $<0.89$ & $<0.94$ & $<0.90$ & $<0.90$ & $<0.91$ \\
\hline $\mathrm{Cd}$ & $<0.103$ & $<0.103$ & $<0.101$ & $<0.106$ & $<0.102$ & $<0.102$ & $<0.103$ \\
\hline $\mathrm{Fe}$ & {$[0.740]$} & {$[0.755]$} & 27.036 & {$[0.750]$} & {$[0.723]$} & [0.779] & [1.398] \\
\hline $\mathrm{Mn}$ & $<0.007$ & 31.7 & 12.79 & 22.010 & 4.37 & 0.995 & $<0.007$ \\
\hline $\mathrm{Na}$ & 7,199 & 7,367 & 7,462 & 7,438 & 7,441 & 7,615 & 7,626 \\
\hline
\end{tabular}


Table L.1 (contd)

\begin{tabular}{|c|c|c|c|c|c|c|c|}
\hline \multirow[b]{2}{*}{ Analyte } & \multicolumn{7}{|c|}{$\begin{array}{l}\text { Analyte Concentration and Density at Given Time After Cooling to Ambient }\left(\sim 21^{\circ} \mathrm{C}\right) \\
\text { Temperature; } \mathrm{g} / \mathrm{mL} \text { for Density; } \mu \mathrm{g} / \mathrm{mL} \text { for Metals; } \mu \mathrm{Ci} / \mathrm{mL} \text { for Radionuclides }\end{array}$} \\
\hline & o hr & 0.5 hr & $1 \mathrm{hr}$ & $2 \mathrm{hr}$ & $4 \mathrm{hr}$ & $6 \mathrm{hr}$ & $24 \mathrm{hr}$ \\
\hline $\mathrm{Ni}$ & $<0.072$ & $<0.072$ & $<0.071$ & $<0.075$ & $<0.072$ & $<0.072$ & $<0.073$ \\
\hline $\mathrm{P}$ & 171.9 & 181.8 & 185.7 & 184.7 & 183.8 & 191.0 & 191.7 \\
\hline$S$ & [8.6] & [9.1] & [7.7] & [5.3] & $<2.2$ & $<2.2$ & [7.3] \\
\hline $\mathrm{Si}$ & 7.5 & 27.1 & 56.6 & 42.8 & 61.8 & 64.8 & 62.6 \\
\hline $\mathrm{Sr}$ & {$[0.01]$} & {$[0.02]$} & {$[0.01]$} & {$[0.01]$} & {$[0.01]$} & {$[0.01]$} & {$[0.01]$} \\
\hline $\mathrm{U}$ & [3.17] & [4.53] & [3.26] & {$[4.06]$} & [4.22] & [3.30] & [3.34] \\
\hline U by KPA & NM & NM & NM & NM & NM & NM & 2.73 \\
\hline $\mathrm{Zn}$ & {$[0.88]$} & {$[0.63]$} & {$[0.56]$} & {$[0.47]$} & {$[0.36]$} & {$[0.45]$} & {$[0.46]$} \\
\hline $\mathrm{Zr}$ & {$[0.05]$} & {$[0.04]$} & {$[0.04]$} & {$[0.04]$} & {$[0.05]$} & $<0.03$ & $<0.03$ \\
\hline${ }^{239+240} \mathrm{Pu}$ & 5.47E-07 & $4.29 \mathrm{E}-06$ & $4.24 \mathrm{E}-06$ & 4.03E-06 & $4.11 \mathrm{E}-06$ & $4.22 \mathrm{E}-06$ & $1.97 \mathrm{E}-06$ \\
\hline${ }^{238} \mathrm{Pu}$ & $1.15 \mathrm{E}-06$ & $2.72 \mathrm{E}-04$ & 2.57E-04 & 2.74E-04 & 2.47E-04 & $2.54 \mathrm{E}-04$ & $1.42 \mathrm{E}-04$ \\
\hline \multicolumn{8}{|c|}{ Opportunistic Analytes } \\
\hline $\mathrm{Ag}$ & $<0.06$ & $<0.06$ & $<0.06$ & $<0.07$ & $<0.06$ & $<0.06$ & $<0.06$ \\
\hline As & [1.3] & [1.5] & $<1.273$ & $<1.344$ & $<1.295$ & $<1.289$ & $<1.306$ \\
\hline $\mathrm{Ba}$ & 0.200 & 0.234 & {$[0.09]$} & 0.184 & {$[0.11]$} & 0.174 & {$[0.09]$} \\
\hline $\mathrm{Be}$ & $<0.002$ & $<0.002$ & $<0.002$ & $<0.002$ & $<0.002$ & $<0.002$ & $<0.002$ \\
\hline $\mathrm{Ca}$ & {$[0.95]$} & {$[1.2]$} & {$[0.255]$} & {$[0.406]$} & [0.283] & {$[0.282]$} & {$[0.486]$} \\
\hline $\mathrm{Ce}$ & $<0.30$ & $<0.30$ & $<0.30$ & $<0.31$ & $<0.30$ & $<0.30$ & $<0.30$ \\
\hline Co & $<0.07$ & {$[0.07]$} & $<0.07$ & $<0.08$ & $<0.07$ & $<0.07$ & {$[0.09]$} \\
\hline $\mathrm{Cu}$ & $<0.04$ & $<0.04$ & $<0.04$ & $<0.04$ & $<0.04$ & $<0.04$ & $<0.04$ \\
\hline Dy & $<0.09$ & $<0.09$ & $<0.09$ & $<0.09$ & $<0.09$ & $<0.09$ & $<0.09$ \\
\hline $\mathrm{Eu}$ & $<0.033$ & $<0.03$ & $<0.03$ & $<0.03$ & $<0.03$ & $<0.03$ & $<0.03$ \\
\hline $\mathrm{K}$ & {$[1.1]$} & [3.6] & [4.1] & [2.2] & [3.6] & [3.3] & {$[2.6]$} \\
\hline $\mathrm{La}$ & $<0.08$ & $<0.08$ & $<0.08$ & $<0.09$ & $<0.08$ & $<0.08$ & $<0.09$ \\
\hline $\mathrm{Li}$ & {$[0.08]$} & {$[0.11]$} & {$[0.17]$} & {$[0.12]$} & {$[0.14]$} & {$[0.11]$} & {$[0.14]$} \\
\hline Mg & $<0.07$ & $<0.07$ & $<0.07$ & $<0.07$ & $<0.07$ & $<0.07$ & $<0.07$ \\
\hline Mo & {$[0.23]$} & {$[0.22]$} & {$[0.36]$} & {$[0.38]$} & $<0.16$ & $<0.16$ & $<0.16$ \\
\hline $\mathrm{Nd}$ & $<0.16$ & $<0.16$ & $<0.16$ & $<0.17$ & $<0.16$ & $<0.16$ & $<0.16$ \\
\hline $\mathrm{Pb}$ & $<0.97$ & $<0.97$ & $<0.95$ & $<1.00$ & $<0.96$ & $<0.96$ & $<0.97$ \\
\hline $\mathrm{Pd}$ & $<0.19$ & $<0.19$ & $<0.19$ & $<0.20$ & [0.292] & $<0.19$ & [0.207] \\
\hline $\mathrm{Rh}$ & $<0.36$ & $<0.36$ & $<0.36$ & $<0.38$ & $<0.36$ & $<0.36$ & $<0.36$ \\
\hline $\mathrm{Ru}$ & $<0.26$ & $<0.26$ & $<0.25$ & $<0.27$ & $<0.26$ & $<0.25$ & $<0.26$ \\
\hline $\mathrm{Sb}$ & [1.1] & [1.4] & {$[0.6]$} & [2.7] & [1.1] & [1.1] & [1.2] \\
\hline Se & [3.6] & $<2.1$ & $<2.1$ & $<2.2$ & $<2.1$ & $<2.1$ & $<2.1$ \\
\hline Sn & $<0.81$ & $<0.82$ & $<0.80$ & $<0.84$ & $<0.81$ & $<0.81$ & $<0.82$ \\
\hline $\mathrm{Ta}$ & $<0.51$ & $<0.51$ & $<0.50$ & $<0.53$ & $<0.51$ & $<0.51$ & $<0.52$ \\
\hline $\mathrm{Te}$ & $<0.78$ & $<0.79$ & $<0.77$ & $<0.81$ & $<0.78$ & $<0.78$ & $<0.79$ \\
\hline Th & $<0.30$ & $<0.30$ & $<0.29$ & $<0.31$ & $<0.30$ & $<0.29$ & $<0.30$ \\
\hline $\mathrm{Ti}$ & $<0.01$ & $<0.01$ & $<0.01$ & $<0.01$ & $<0.01$ & $<0.01$ & $<0.01$ \\
\hline $\mathrm{Tl}$ & [1.3] & $<1.1$ & [2.9] & $<1.2$ & {$[2.0]$} & {$[2.3]$} & {$[1.2]$} \\
\hline
\end{tabular}


Table L.1 (contd)

\begin{tabular}{|c|c|c|c|c|c|c|c|}
\hline \multirow[b]{2}{*}{ Analyte } & \multicolumn{7}{|c|}{$\begin{array}{l}\text { Analyte Concentration and Density at Given Time After Cooling to Ambient }\left(\sim 21^{\circ} \mathrm{C}\right) \\
\text { Temperature; } \mathrm{g} / \mathrm{mL} \text { for Density; } \mu \mathrm{g} / \mathrm{mL} \text { for Metals; } \mu \mathrm{Ci} / \mathrm{mL} \text { for Radionuclides }\end{array}$} \\
\hline & o hr & $0.5 \mathrm{hr}$ & $1 \mathrm{hr}$ & $2 \mathrm{hr}$ & $4 \mathrm{hr}$ & $6 \mathrm{hr}$ & $24 \mathrm{hr}$ \\
\hline $\mathrm{V}$ & {$[0.04]$} & {$[0.14]$} & {$[0.15]$} & {$[0.14]$} & {$[0.17]$} & {$[0.20]$} & 0.230 \\
\hline $\mathrm{W}$ & {$[0.60]$} & $<0.57$ & $<0.56$ & $<0.59$ & {$[0.57]$} & $<0.57$ & $<0.58$ \\
\hline $\mathrm{Y}$ & $<0.01$ & $<0.01$ & $<0.01$ & $<0.01$ & $<0.01$ & $<0.01$ & $<0.01$ \\
\hline \multicolumn{8}{|c|}{$0.25 \mathrm{M} \mathrm{NaOH}, \mathrm{Mn} / \mathrm{Cr}=1.19$} \\
\hline \begin{tabular}{l|l} 
Density \\
\end{tabular} & 1.02 & 1.02 & 1.02 & 1.02 & 1.02 & 1.02 & 1.02 \\
\hline Total Cr & 8.47 & 109.9 & 115.1 & 114.4 & 116.0 & 117.4 & 123.3 \\
\hline $\mathrm{Cr}(\mathrm{VI})$ & 8.44 & 100.6 & 110. & 106.9 & 110.3 & 112.7 & 114.8 \\
\hline \% Diff & 0.3 & 8.5 & 4.3 & 6.6 & 4.9 & 4.1 & 6.9 \\
\hline $\mathrm{Al}$ & 22.90 & 52.7 & 94.0 & 74.3 & 104.0 & 107.0 & 114.9 \\
\hline $\mathrm{B}$ & [0.359] & [0.521] & [0.483] & [0.362] & [0.361] & [0.509] & [0.541] \\
\hline $\mathrm{Bi}$ & $<0.90$ & $<0.92$ & $<0.91$ & $<0.91$ & $<0.90$ & $<0.90$ & $<0.90$ \\
\hline $\mathrm{Cd}$ & $<0.102$ & $<0.104$ & $<0.103$ & $<0.103$ & $<0.102$ & $<0.102$ & $<0.102$ \\
\hline $\mathrm{Fe}$ & [0.659] & [0.735] & [0.755] & [0.755] & {$[0.721]$} & [0.749] & [1.113] \\
\hline $\mathrm{Mn}$ & $<0.007$ & 60.3 & 36.3 & 48.6 & 23.5 & 16.57 & $<0.007$ \\
\hline $\mathrm{Na}$ & 6,975 & 7,349 & 7,341 & 7,247 & 7,271 & 7,339 & 7,339 \\
\hline $\mathrm{Ni}$ & $<0.072$ & $<0.073$ & $<0.073$ & $<0.072$ & $<0.072$ & $<0.072$ & $<0.072$ \\
\hline $\mathrm{P}$ & 170.6 & 183.1 & 188.2 & 183.3 & 182.7 & 184.5 & 185.9 \\
\hline$S$ & [5.7] & [7.3] & [9.7] & [13.6] & [9.9] & [4.2] & $<2.2$ \\
\hline $\mathrm{Si}$ & 7.69 & 28.3 & 58.6 & 43.8 & 62.8 & 63.8 & 62.0 \\
\hline $\mathrm{Sr}$ & {$[0.01]$} & {$[0.01]$} & {$[0.01]$} & {$[0.01]$} & {$[0.01]$} & {$[0.01]$} & {$[0.01]$} \\
\hline $\mathrm{U}$ & [1.98] & [3.67] & [4.23] & [3.62] & [3.91] & [3.59] & [4.51] \\
\hline $\mathrm{U}$ by KPA & NM & NM & NM & NM & NM & NM & 3.23 \\
\hline $\mathrm{Zn}$ & {$[0.66]$} & {$[0.49]$} & [0.69] & {$[0.42]$} & [0.39] & {$[0.51]$} & {$[0.54]$} \\
\hline $\mathrm{Zr}$ & $<0.03$ & {$[0.05]$} & {$[0.04]$} & [0.04] & [0.04] & [0.04] & [0.05] \\
\hline${ }^{239+240} \mathrm{Pu}$ & 2.91E-07 & $5.10 \mathrm{E}-06$ & $4.71 \mathrm{E}-06$ & $4.77 \mathrm{E}-06$ & $4.89 \mathrm{E}-06$ & $4.45 \mathrm{E}-06$ & $4.22 \mathrm{E}-06$ \\
\hline${ }^{238} \mathrm{Pu}$ & 5.41E-07 & $2.78 \mathrm{E}-04$ & 2.63E-04 & 2.81E-04 & $2.58 \mathrm{E}-04$ & $2.62 \mathrm{E}-04$ & $2.68 \mathrm{E}-04$ \\
\hline \multicolumn{8}{|c|}{ Opportunistic Analytes } \\
\hline $\mathrm{Ag}$ & $<0.06$ & $<0.06$ & $<0.06$ & $<0.06$ & $<0.06$ & $<0.06$ & $<0.06$ \\
\hline As & {$[1.4]$} & {$[3.0]$} & $<1.30$ & $<1.30$ & $<1.29$ & $<1.29$ & {$[2.3]$} \\
\hline $\mathrm{Ba}$ & {$[0.10]$} & 0.195 & 0.207 & {$[0.08]$} & {$[0.07]$} & {$[0.10]$} & {$[0.16]$} \\
\hline $\mathrm{Be}$ & $<0.002$ & $<0.002$ & {$[0.00]$} & $<0.002$ & $<0.002$ & $<0.002$ & $<0.002$ \\
\hline $\mathrm{Ca}$ & {$[0.28]$} & {$[0.25]$} & {$[0.36]$} & {$[0.28]$} & {$[0.20]$} & {$[0.30]$} & {$[0.45]$} \\
\hline $\mathrm{Ce}$ & $<0.30$ & $<0.31$ & $<0.30$ & $<0.30$ & $<0.30$ & $<0.30$ & $<0.30$ \\
\hline Co & $<0.07$ & $<0.07$ & $<0.07$ & $<0.07$ & [0.078] & $<0.07$ & $<0.07$ \\
\hline $\mathrm{Cu}$ & $<0.04$ & $<0.04$ & $<0.04$ & $<0.04$ & $<0.04$ & $<0.04$ & $<0.04$ \\
\hline Dy & $<0.09$ & $<0.09$ & $<0.09$ & $<0.09$ & $<0.09$ & $<0.09$ & $<0.09$ \\
\hline $\mathrm{Eu}$ & $<0.03$ & $<0.03$ & $<0.03$ & $<0.03$ & $<0.03$ & $<0.03$ & $<0.03$ \\
\hline $\mathrm{K}$ & {$[0.78]$} & [3.67] & [3.32] & {$[2.446]$} & [3.61] & {$[2.187]$} & [3.31] \\
\hline $\mathrm{La}$ & $<0.08$ & $<0.09$ & $<0.08$ & $<0.08$ & $<0.08$ & $<0.08$ & $<0.08$ \\
\hline $\mathrm{Li}$ & {$[0.07]$} & {$[0.14]$} & {$[0.16]$} & {$[0.12]$} & {$[0.12]$} & {$[0.16]$} & {$[0.19]$} \\
\hline
\end{tabular}


Table L.1 (contd)

\begin{tabular}{|c|c|c|c|c|c|c|c|}
\hline \multirow[b]{2}{*}{ Analyte } & \multicolumn{7}{|c|}{$\begin{array}{l}\text { Analyte Concentration and Density at Given Time After Cooling to Ambient }\left(\sim 21^{\circ} \mathrm{C}\right) \\
\text { Temperature; } \mathrm{g} / \mathrm{mL} \text { for Density; } \mu \mathrm{g} / \mathrm{mL} \text { for Metals; } \mu \mathrm{Ci} / \mathrm{mL} \text { for Radionuclides }\end{array}$} \\
\hline & $0 \mathrm{hr}$ & $0.5 \mathrm{hr}$ & $1 \mathrm{hr}$ & $2 \mathrm{hr}$ & $4 \mathrm{hr}$ & $6 \mathrm{hr}$ & $24 \mathrm{hr}$ \\
\hline $\mathrm{Mg}$ & $<0.07$ & $<0.07$ & $<0.07$ & $<0.07$ & $<0.07$ & $<0.07$ & $<0.07$ \\
\hline Mo & $<0.16$ & {$[0.31]$} & {$[0.19]$} & {$[0.20]$} & {$[0.51]$} & {$[0.23]$} & {$[0.18]$} \\
\hline $\mathrm{Nd}$ & $<0.16$ & $<0.17$ & $<0.16$ & $<0.16$ & $<0.16$ & $<0.16$ & $<0.16$ \\
\hline $\mathrm{Pb}$ & $<0.96$ & $<0.98$ & $<0.97$ & $<0.97$ & $<0.96$ & [0.99] & $<0.96$ \\
\hline $\mathrm{Pd}$ & $<0.19$ & $<0.19$ & $<0.19$ & $<0.19$ & {$[0.28]$} & $<0.19$ & {$[0.19]$} \\
\hline $\mathrm{Rh}$ & $<0.36$ & $<0.37$ & $<0.36$ & $<0.36$ & $<0.36$ & $<0.36$ & $<0.36$ \\
\hline $\mathrm{Ru}$ & $<0.25$ & $<0.26$ & $<0.26$ & $<0.26$ & $<0.26$ & $<0.25$ & $<0.26$ \\
\hline $\mathrm{Sb}$ & {$[0.63]$} & $<0.61$ & [1.4] & [1.8] & [1.9] & {$[0.9]$} & $<0.60$ \\
\hline Se & $<2.10$ & $<2.14$ & $<2.11$ & $<2.11$ & [4.2] & $<2.10$ & $<2.11$ \\
\hline Sn & $<0.81$ & $<0.83$ & {$[1.2]$} & $<0.82$ & $<0.81$ & $<0.81$ & $<0.81$ \\
\hline $\mathrm{Ta}$ & $<0.51$ & $<0.52$ & $<0.51$ & $<0.51$ & $<0.51$ & $<0.51$ & $<0.51$ \\
\hline $\mathrm{Te}$ & $<0.78$ & $<0.80$ & $<0.79$ & $<0.79$ & $<0.78$ & $<0.78$ & $<0.78$ \\
\hline Th & $<0.29$ & $<0.30$ & $<0.30$ & $<0.30$ & $<0.29$ & $<0.29$ & $<0.29$ \\
\hline $\mathrm{Ti}$ & $<0.01$ & $<0.01$ & $<0.01$ & $<0.01$ & $<0.01$ & $<0.01$ & $<0.01$ \\
\hline $\mathrm{Tl}$ & $<1.14$ & [3.4] & [3.3] & [1.5] & [1.7] & {$[2.6]$} & [2.3] \\
\hline $\mathrm{V}$ & {$[0.04]$} & {$[0.13]$} & {$[0.17]$} & {$[0.15]$} & {$[0.18]$} & {$[0.16]$} & {$[0.20]$} \\
\hline $\mathrm{W}$ & $<0.57$ & $<0.58$ & {$[0.97]$} & $<0.57$ & $<0.57$ & $<0.57$ & $<0.57$ \\
\hline $\mathrm{Y}$ & $<0.01$ & $<0.01$ & $<0.01$ & $<0.01$ & $<0.01$ & $<0.01$ & $<0.01$ \\
\hline \multicolumn{8}{|c|}{$1.25 \mathrm{M} \mathrm{NaOH}, \mathrm{Mn} / \mathrm{Cr}=0.98$} \\
\hline Density & 1.06 & 1.07 & 1.06 & 1.07 & 1.06 & 1.06 & 1.07 \\
\hline Total Cr & 8.93 & 108.5 & 119.4 & 113.8 & 119.7 & 118.7 & 124.2 \\
\hline $\mathrm{Cr}(\mathrm{VI})$ & 8.01 & 96.7 & 103.4 & 99.3 & 105.1 & 105.4 & 107.3 \\
\hline \% Diff & 10.2 & 10.9 & 13.4 & 12.8 & 12.3 & 11.2 & 13.6 \\
\hline $\mathrm{Al}$ & 32.5 & 148.5 & 201.7 & 188.8 & 204.3 & 202.9 & 205.5 \\
\hline B & {$[0.439]$} & [0.563] & [0.522] & [0.508] & [0.390] & [0.639] & {$[0.449]$} \\
\hline $\mathrm{Bi}$ & {$[12.9]$} & {$[3.3]$} & {$[4.6]$} & {$[3.6]$} & {$[4.2]$} & {$[4.6]$} & {$[6.3]$} \\
\hline $\mathrm{Cd}$ & $<0.199$ & $<0.202$ & $<0.209$ & $<0.203$ & $<0.204$ & $<0.207$ & $<0.203$ \\
\hline $\mathrm{Fe}$ & {$[0.966]$} & {$[0.978]$} & [1.044] & [1.016] & [1.050] & [1.095] & [1.257] \\
\hline Mn & $<0.013$ & 26.15 & 7.86 & 15.98 & 1.48 & {$[0.076]$} & $<0.014$ \\
\hline $\mathrm{Na}$ & 31,321 & 31,424 & 32,232 & 32,258 & 32,707 & 32,552 & 33,209 \\
\hline $\mathrm{Ni}$ & $<0.141$ & $<0.142$ & $<0.147$ & $<0.143$ & $<0.144$ & $<0.146$ & $<0.144$ \\
\hline $\mathrm{P}$ & 174.8 & 181.4 & 192.5 & 184.6 & 190.8 & 188.9 & 194.5 \\
\hline $\mathrm{S}$ & {$[27.8]$} & {$[27.6]$} & [11.7] & [16.1] & [5.7] & $<4.381$ & [19.4] \\
\hline $\mathrm{Si}$ & 14.93 & 123.6 & 165.8 & 155.9 & 162.9 & 159.1 & 155.9 \\
\hline $\mathrm{Sr}$ & {$[0.02]$} & [0.01] & [0.01] & [0.01] & [0.01] & [0.02] & [0.02] \\
\hline $\mathrm{U}$ & [5.27] & [10.67] & {$[7.06]$} & {$[8.96]$} & {$[8.10]$} & [7.91] & {$[8.08]$} \\
\hline U by KPA & NM & NM & NM & NM & NM & NM & 7.46 \\
\hline \begin{tabular}{l|l}
$\mathrm{Zn}$ \\
\end{tabular} & {$[1.0]$} & [1.1] & [1.1] & [1.5] & [1.3] & [1.5] & {$[1.4]$} \\
\hline $\mathrm{Zr}$ & {$[0.08]$} & [0.12] & [0.12] & [0.12] & $<0.07$ & {$[0.10]$} & $<0.07$ \\
\hline${ }^{239+240} \mathrm{Pu}$ & $3.30 \mathrm{E}-07$ & $2.05 \mathrm{E}-05$ & $2.24 \mathrm{E}-05$ & $2.23 \mathrm{E}-05$ & $2.38 \mathrm{E}-05$ & $2.29 \mathrm{E}-05$ & $1.34 \mathrm{E}-05$ \\
\hline
\end{tabular}


Table L.1 (contd)

\begin{tabular}{|c|c|c|c|c|c|c|c|}
\hline \multirow[b]{2}{*}{ Analyte } & \multicolumn{7}{|c|}{$\begin{array}{l}\text { Analyte Concentration and Density at Given Time After Cooling to Ambient }\left(\sim 21^{\circ} \mathrm{C}\right) \\
\text { Temperature; } \mathrm{g} / \mathrm{mL} \text { for Density; } \mu \mathrm{g} / \mathrm{mL} \text { for Metals; } \mu \mathrm{Ci} / \mathrm{mL} \text { for Radionuclides }\end{array}$} \\
\hline & o hr & $0.5 \mathrm{hr}$ & $1 \mathrm{hr}$ & $2 \mathrm{hr}$ & $4 \mathrm{hr}$ & $6 \mathrm{hr}$ & $24 \mathrm{hr}$ \\
\hline${ }^{238} \mathrm{Pu}$ & $6.24 \mathrm{E}-06$ & $1.29 \mathrm{E}-03$ & $1.55 \mathrm{E}-03$ & $1.45 \mathrm{E}-03$ & $1.48 \mathrm{E}-03$ & $1.54 \mathrm{E}-03$ & $8.14 \mathrm{E}-04$ \\
\hline \multicolumn{8}{|c|}{ Opportunistic Analytes } \\
\hline $\mathrm{Ag}$ & $<0.12$ & $<0.12$ & $<0.13$ & $<0.13$ & $<0.13$ & $<0.13$ & $<0.13$ \\
\hline As & $<2.5$ & $<2.5$ & [4.9] & $<2.6$ & $<2.6$ & $<2.6$ & $<2.6$ \\
\hline $\mathrm{Ba}$ & {$[0.26]$} & {$[0.11]$} & {$[0.11]$} & {$[0.12]$} & {$[0.10]$} & {$[0.18]$} & {$[0.14]$} \\
\hline $\mathrm{Be}$ & [0.003] & $<0.003$ & {$[0.004]$} & $<0.003$ & {$[0.004]$} & $<0.003$ & {$[0.004]$} \\
\hline $\mathrm{Ca}$ & {$[1.7]$} & {$[2.2]$} & {$[0.52]$} & {$[0.96]$} & {$[0.66]$} & {$[0.55]$} & {$[1.3]$} \\
\hline $\mathrm{Ce}$ & $<0.59$ & $<0.59$ & $<0.61$ & $<0.60$ & $<0.60$ & $<0.61$ & $<0.60$ \\
\hline Co & $<0.14$ & {$[0.26]$} & $<0.15$ & $<0.14$ & $<0.14$ & $<0.15$ & $<0.14$ \\
\hline $\mathrm{Cu}$ & $<0.08$ & $<0.08$ & $<0.09$ & {$[0.10]$} & $<0.08$ & $<0.09$ & $<0.08$ \\
\hline Dy & $<0.17$ & $<0.17$ & $<0.18$ & $<0.17$ & $<0.17$ & $<0.18$ & $<0.17$ \\
\hline $\mathrm{Eu}$ & $<0.06$ & $<0.07$ & $<0.07$ & $<0.07$ & $<0.07$ & $<0.07$ & $<0.07$ \\
\hline $\mathrm{K}$ & $<1.17$ & {$[5.0]$} & [8.0] & {$[6.0]$} & [8.4] & [7.3] & [7.2] \\
\hline $\mathrm{La}$ & $<0.16$ & $<0.17$ & $<0.17$ & $<0.17$ & $<0.17$ & $<0.17$ & $<0.17$ \\
\hline $\mathrm{Li}$ & {$[0.12]$} & {$[0.21]$} & {$[0.24]$} & {$[0.18]$} & {$[0.22]$} & {$[0.21]$} & {$[0.23]$} \\
\hline $\mathrm{Mg}$ & $<0.13$ & $<0.14$ & $<0.14$ & $<0.14$ & $<0.14$ & $<0.14$ & $<0.14$ \\
\hline Mo & $<0.30$ & {$[0.53]$} & {$[0.49]$} & {$[0.42]$} & $<0.31$ & $<0.32$ & $<0.31$ \\
\hline $\mathrm{Nd}$ & $<0.32$ & $<0.32$ & $<0.33$ & $<0.32$ & $<0.32$ & $<0.33$ & $<0.32$ \\
\hline $\mathrm{Pb}$ & $<1.9$ & {$[3.3]$} & {$[4.3]$} & {$[3.3]$} & {$[4.2]$} & {$[3.3]$} & {$[2.4]$} \\
\hline $\mathrm{Pd}$ & $<0.37$ & $<0.37$ & $<0.39$ & $<0.38$ & $<0.38$ & $<0.38$ & $<0.38$ \\
\hline $\mathrm{Rh}$ & $<0.70$ & $<0.71$ & $<0.74$ & $<0.72$ & $<0.72$ & $<0.73$ & $<0.72$ \\
\hline $\mathrm{Ru}$ & $<0.50$ & $<0.50$ & $<0.52$ & $<0.51$ & $<0.51$ & $<0.52$ & $<0.51$ \\
\hline $\mathrm{Sb}$ & [2.9] & {$[3.0]$} & {$[4.0]$} & {$[2.8]$} & [1.5] & {$[2.3]$} & {$[2.1]$} \\
\hline Se & $<4.1$ & $<4.2$ & $<4.3$ & $<4.182$ & [6.9] & $<4.3$ & $<4.2$ \\
\hline Sn & $<1.6$ & $<1.6$ & $<1.7$ & {$[2.2]$} & [1.7] & $<1.6$ & $<1.6$ \\
\hline $\mathrm{Ta}$ & $<1.0$ & $<1.0$ & $<1.0$ & $<1.0$ & $<1.0$ & $<1.0$ & $<1.0$ \\
\hline $\mathrm{Te}$ & $<1.5$ & $<1.5$ & $<1.6$ & $<1.6$ & $<1.6$ & $<1.6$ & $<1.6$ \\
\hline Th & $<0.57$ & $<0.58$ & $<0.60$ & $<0.59$ & $<0.59$ & $<0.60$ & $<0.59$ \\
\hline $\mathrm{Ti}$ & $<0.03$ & $<0.03$ & $<0.03$ & $<0.03$ & $<0.03$ & $<0.03$ & $<0.03$ \\
\hline $\mathrm{Tl}$ & {$[3.8]$} & {$[2.8]$} & [3.1] & [3.9] & {$[4.5]$} & [3.7] & {$[4.2]$} \\
\hline $\mathrm{V}$ & {$[0.10]$} & {$[0.28]$} & {$[0.26]$} & {$[0.22]$} & {$[0.27]$} & [0.29] & {$[0.26]$} \\
\hline $\mathrm{W}$ & $<1.1$ & $<1.1$ & $<1.2$ & $<1.1$ & $<1.1$ & $<1.2$ & $<1.1$ \\
\hline $\mathrm{Y}$ & $<0.03$ & $<0.03$ & $<0.03$ & $<0.03$ & $<0.03$ & $<0.03$ & $<0.03$ \\
\hline
\end{tabular}


Table L.2. Analyte Concentrations for Composite Wash Solution for Wash of Samples OxidativelyLeached in $0.25 \mathrm{M} \mathrm{NaOH}$ with a $\mathrm{Mn} / \mathrm{Cr}$ ratio of 0.79

\begin{tabular}{|c|c|c|c|}
\hline Analyte & $\begin{array}{c}\text { Concentration } \\
(\mu \mathrm{g} / \mathrm{mL})\end{array}$ & $\begin{array}{c}\text { Opportunistic } \\
\text { Analytes }\end{array}$ & $\begin{array}{c}\text { Concentration } \\
(\mu \mathrm{g} / \mathrm{mL})\end{array}$ \\
\hline $\mathrm{Al}$ & 62.0 & $\mathrm{Ag}$ & $<0.065$ \\
\hline B & {$[0.496]$} & As & $<1.33$ \\
\hline $\mathrm{Bi}$ & $<0.930$ & $\mathrm{Ba}$ & 0.171 \\
\hline $\mathrm{Cd}$ & $<0.105$ & $\mathrm{Be}$ & $<0.002$ \\
\hline $\mathrm{Cr}$ & 6.17 & $\mathrm{Ca}$ & 2.73 \\
\hline $\mathrm{Fe}$ & [1.40] & $\mathrm{Ce}$ & $<0.310$ \\
\hline $\mathrm{Mn}$ & [0.034] & Co & $<0.074$ \\
\hline $\mathrm{Na}$ & 747 & $\mathrm{Cu}$ & $<0.043$ \\
\hline $\mathrm{Ni}$ & {$[0.118]$} & Dy & $<0.090$ \\
\hline $\mathrm{P}$ & 15.8 & $\mathrm{Eu}$ & {$[0.037]$} \\
\hline$S$ & $<2.23$ & $\mathrm{~K}$ & {$[1.18]$} \\
\hline $\mathrm{Si}$ & 55.5 & $\mathrm{La}$ & $<0.087$ \\
\hline $\mathrm{Sr}$ & 0.574 & $\mathrm{Li}$ & {$[0.071]$} \\
\hline $\mathrm{U}$ & [2.64] & $\mathrm{Mg}$ & {$[0.146]$} \\
\hline $\mathrm{Zn}$ & {$[0.744]$} & Mo & {$[0.372]$} \\
\hline $\mathrm{Zr}$ & [0.093] & $\mathrm{Nd}$ & [0.183] \\
\hline & & $\mathrm{Pb}$ & $<0.992$ \\
\hline & & $\mathrm{Pd}$ & $<0.195$ \\
\hline & & $\mathrm{Rh}$ & $<0.372$ \\
\hline & & $\mathrm{Ru}$ & $<0.264$ \\
\hline & & $\mathrm{Sb}$ & {$[1.40]$} \\
\hline & & Se & $<2.17$ \\
\hline & & Sn & $<0.837$ \\
\hline & & $\mathrm{Ta}$ & $<0.527$ \\
\hline & & $\mathrm{Te}$ & $<0.806$ \\
\hline & & Th & {$[0.434]$} \\
\hline & & $\mathrm{Ti}$ & [0.015] \\
\hline & & $\mathrm{Tl}$ & {$[1.55]$} \\
\hline & & $\mathrm{V}$ & {$[0.084]$} \\
\hline & & $\mathrm{W}$ & {$[0.930]$} \\
\hline & & $\mathrm{Y}$ & $<0.014$ \\
\hline
\end{tabular}


WTP-RPT-166, Rev. 0

Appendix M

\section{Group 1/2 CUF Analytical Results}


WTP-RPT-166, Rev. 0

\title{
Appendix M: Group 1/2 CUF Analytical Results
}

\author{
Special Instructions for the \\ CUF Group 1/2 Bismuth Phosphate Sludge/Saltcake and \\ CUF Group 5/6 Redox Sludge/Saltcake Treatablility Studies \\ Analysis Requirements
}

\begin{abstract}
A blend of two composite materials containing liquid and sludge from Hanford waste tanks was subjected to CUF process as per TI-RPP-WTP-572. The first composite blend was from tanks B104, BX-112, and T-104, representing waste described as Bismuth Phosphate Sludge (Group 1). The second composite blend was comprised of material from tanks BX-110, BX-111, BY-104, BY-105, BY-107, BY-108, BY-109, BY-110, BY-112, T-108, T-109, TX-104 and SX-103, representing tank waste described as Bismuth Phosphate Saltcake (Group 2). The start date for this treatability study is January 7 th, 2008. Color code: Fluorescent Pink.
\end{abstract}

In addition to these samples, additional samples are to be analyzed from the CUF Group 5/6 CUF treatability study started on November 5th, 2007 as per TI-RPP-WTP-552 and ASR 8055. In this case, two archive slurry samples are to be analyzed as a verification of result provided from ASR 8055. Along with those samples, an archive permeate sample from the run will be analyzed along with a filtered sample of a $2 \mathrm{M}$ nitric solution used to clean the system. The color code for these samples is: Brilliant Lime.

The processing and analysis schematic is shown by Figure 1, Figure 2, and Table 1 . The aqueous samples are ready to directly sub-sample for analysis and acid digestion. The solid slurry samples have yet to be split into aliquots and prepped for fusion or HF-assisted acid digestion.

\section{SAL Preparation/Analysis}

Please record observations associated with the dissolution preparations. If any residual solids remain after any of the fusion and acid digestions, note on the bench sheet (include estimated quantity, color, texture, etc.) and contact RW Shimskey or MK Edwards for further instruction prior to distribution.

\section{Archive of SAL Fusion Preparation Samples}

The fusion preparations will result in a $100-\mathrm{mL}$ volume. This solution will be apportioned to the laboratory as needed to conduct work-station-specific analyses. Please prepare a $15-\mathrm{mL}$ aliquot from each preparation as an archive sample. The vials need to be labeled with the following: date, ASO-ID, matrix, treatablility study, hazard, fusion prep (if applicable) and their tare, gross masses, and IDs provided to RW Shimskey or MK Edwards. The vials may be removed from the hot cells for storage. The remaining portions of the fusion preparations may be disposed of.

\section{Quality Control}

All work is to be conducted according to RPP-WTP-QA-005, Rev. 2. 
Preparative or sample analysis QC includes a preparation blank, sample, sample duplicate, matrix spike, and a LCS or BS. The samples submitted for fusion are sub-aliquoted into fusion vessels in duplicate (sample, sample duplicate). If possible, the matrix spike and LCS/BS need to include all the analytes of interest to be reported for the specific analysis.

The duplicate, LCS/BS, and MS QC acceptance criteria for the aqueous phases and solid phases are provided in Table 4 . The preparation blank (PB) analyte concentration shall be less than the estimated quantitation limit (EQL) or the minimum detectable activity (MDA) of the associated sample. When the PB concentration is equal to or exceeds the EQL, then the PB concentration shall not exceed $5 \%$ of the measured concentration present in the sample. Failure of the PB, and/or duplicates, and/or LCS/BS to meet the acceptance criteria requires that affected samples in the processing batch be re-prepared and re-analyzed for the failed analytes, availability of samples permitting, at ASO expense.

In the case of multi-elemental methods (IC and ICP-OES), isolated QC failure(s) may be communicated to RW Shimskey or MK Edwards for an assessment of the impact on data interpretation. If the data are acceptable, RW Shimskey or MK Edwards will indicate, in writing, that the data may be reported, and the resulting limitations on the data from the QC sample failure(s) shall be included in the final report.

When the MS fails to meet the acceptance criteria, the results shall be investigated for potential sources of error. When the sources of error cannot be identified, the failure of the MS and any resulting limitations on the data shall be included in the report.

Note that in some cases BS and MS are requested for U/KPA as well as ICP metals in solution analysis. Because the broad suite of ICP BS metals will interfere with the U KPA analysis, two MS and BS samples (one supporting each technique) will need to be prepared as part of the acid digestion.

\section{Reporting Units}

Report aqueous sample results in units of $\mathrm{ug} / \mathrm{mL}$ or $\mathrm{uCi} / \mathrm{mL}$. Report solids sample results as $\mathrm{ug} / \mathrm{g}$ or $\mathrm{uCi} / \mathrm{g}$; the initial dry mass of solids (as measured in each fusion crucible) will be provided. For radiochemistry, the reference date shall be November 5, 2007 for samples from TI-RPP-WTP552 and January 7 th, 2008 for samples from TI-RPP-WTP-572. Report the hydroxide concentration in units of molarity and $\mathrm{ug} / \mathrm{mL}$.

\section{Reporting}

Please prepare the analytical data report in accordance with PNL-ASO-058, Rev. 0, Section 5.3, Comprehensive Data Report. Please be sure to include action taken with respect to any identified unexpected results and discrepancies.

The following elements may be included in the final report or be traceable to the test results (usually by entry in the LRB, Test Instruction, or data sheet) and be maintained as lifetime records:

- identification of standards used

- identification of M\&TE used

- reference to the Test Plan (identified on page 1 of the ASR)

- signature and date of person who performed the test and recorded the data 
- hand calculation review documentation.

Analytical results shall be reported both in hard copy and electronically. Preliminary data reports and electronic files shall be provided as soon as practical after completion of analysis. The final ASR data report shall be provided no later than the commitment date on the ASR.

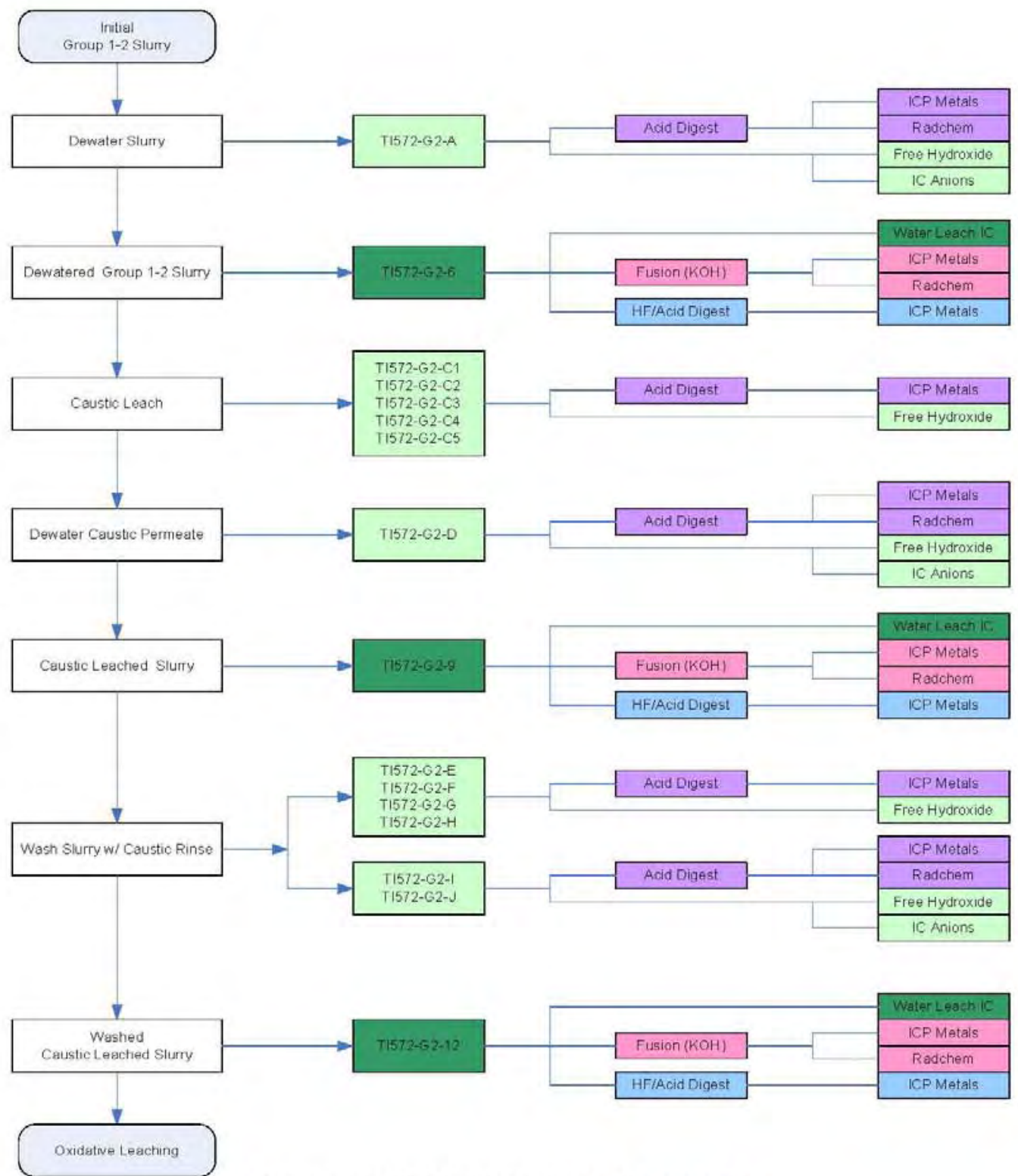

Figure 1: TI-RPP-WTP-572 Process Sampling Plan 


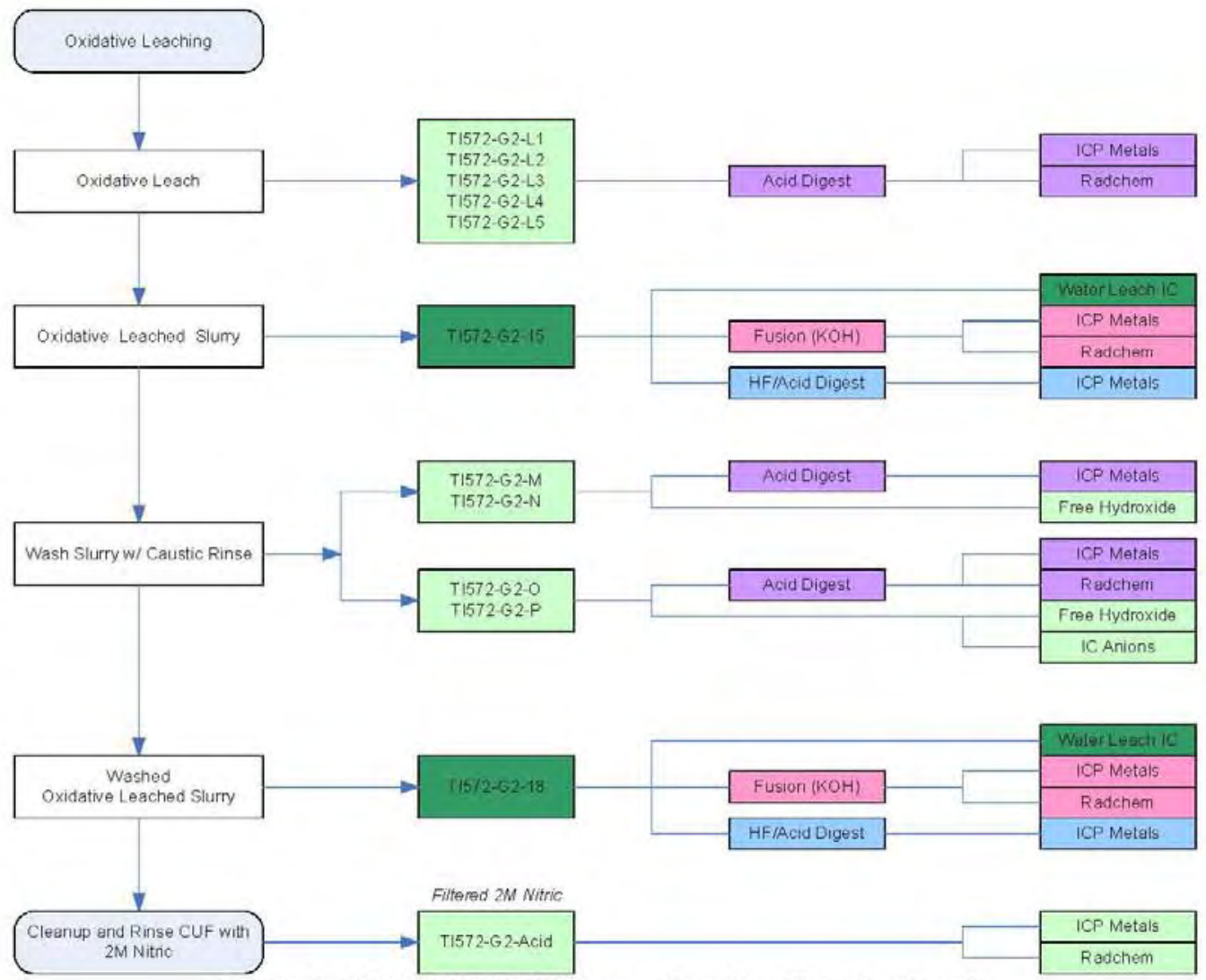

Figure 1: TI-RPP-WTP-572 Process Sampling Plan (Continued)

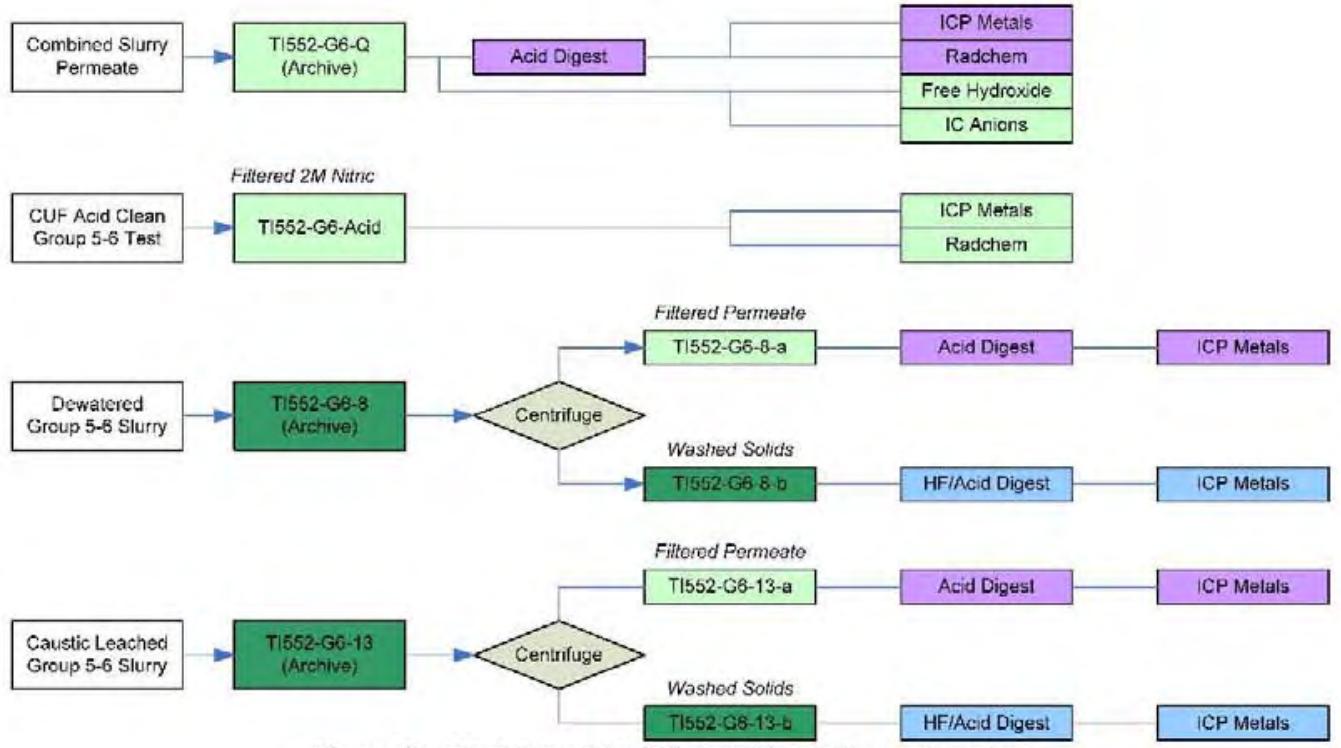

Figure 2: TI-RPP-WTP-552 Additional Sampling Plan 
WTP-RPT-166, Rev. 0

Table 1. Cross-Reference of Process component, Sample W, and RPL ID

\begin{tabular}{|c|c|c|}
\hline Component & Sample ID & ASO ID \\
\hline \multicolumn{3}{|c|}{ TI-RPP-WTP-572: Group 1/2 CUF Test and TI-RPP-WTP-552: Group 5/6 CUF Tes } \\
\hline Dewater filtrate & TI572-G2-A & $08-01290$ \\
\hline Leach permeate & TI572-G2-D & 08-01291 \\
\hline wash 5 permeate & TI572-G2-I & 08-01292 \\
\hline Combined permeate & TI572-G2-J & $08-01293$ \\
\hline Oxidative wash 3 permeate & TI572-G2-O & $08-01294$ \\
\hline Combined wash & TI572-G2-P & 08-01295 \\
\hline Final Slurry Permeate from TI552 & TI552-G6-Q & $08-01296$ \\
\hline $0.5 \mathrm{hr}$ oxidative leach & TI572-G2-L1 & $08-01297$ \\
\hline $1 \mathrm{hr}$ oxidative leach & TI572-G2-L2 & $08-01298$ \\
\hline 2 hr oxidative leach & TI572-G2-L3 & 08-01299 \\
\hline 4 hr oxidative leach & TI572-G2-L4 & $08-01300$ \\
\hline $6 \mathrm{hr}$ oxidative leach & TI572-G2-L5 & 08-01301 \\
\hline 2M Nitric Acid Wash Solution & TI572-G2-Acid & $08-01302$ \\
\hline 2M Nitric Acid Wash Solution & TI552-G6-Acid & $08-01303$ \\
\hline Caustic leach filtrate, 1 hour heat up & TI572-G2-Cl & 08-01304 \\
\hline Caustic leach filtrate, 3 hour heat up & TI572-G2-C2 & $08-01305$ \\
\hline Caustic leach filtrate, 0 hour leach & TI572-G2-C3 & 08-01306 \\
\hline Caustic leach filtrate, 4 hour leach & TI572-G2-C4 & $08-01307$ \\
\hline Caustic leach filtrate, 8 hour leach & TI572-G2-C5 & $08-01308$ \\
\hline wash 1 permeate & TI572-G2-E & $08-01309$ \\
\hline wash 2 permeate & TI572-G2-F & $08-01310$ \\
\hline wash 3 permeate & TI572-G2-G & $08-01311$ \\
\hline wash 4 permeate & TI572-G2-H & $08-01312$ \\
\hline Oxidative wash 1 permeate & TI572-G2-M & $08-01313$ \\
\hline Oxidative wash 2 permeate & TI572-G2-N & $08-01314$ \\
\hline Group 5/6 Slurry Permeate & TI552-G6-8-a & 08-01315 \\
\hline Leached 5/6 Slurry Permeate & T1552-G6-13-a & $08-01316$ \\
\hline $20 \mathrm{wt} \%$ slurry & TI572-G2-6 & 08-01317 \\
\hline Leach slurry & TI572-G2-9 & 08-01318 \\
\hline Leached and washed slurry & TI572-G2-12 & $08-01319$ \\
\hline Leached and washed slurry & TI572-G2-15 & $08-01320$ \\
\hline Leached and washed slurry & TI572-G2-18 & $08-01321$ \\
\hline Group 5/6 Slurry Washed Solids & TI552-G6-8-b & $08-01322$ \\
\hline Leached $5 / 6$ Slurry Washed Solids & TI552-G6-13-b & $08-01323$ \\
\hline
\end{tabular}




\section{Laboratory Analysis}

The required sample analyses are shown in Table 2. Filtration and Leach Testing Characterization Plan.

Table 2. Filtration and Leach Testing Characterization Plan

\begin{tabular}{|c|c|}
\hline Process Step & Analyte \\
\hline \multicolumn{2}{|c|}{ TI-RPP-WTP-572 } \\
\hline \multirow[t]{3}{*}{$\begin{array}{l}\text { Dewatered slurry } \\
\text { (TI572-G2-6) }\end{array}$} & $\begin{array}{r}\text { HF assisted Acid digestion } \\
\text { - ICP metals (Table } 3 \text { ) } \\
\end{array}$ \\
\hline & $\begin{array}{l}\mathrm{KOH} \text { fusion } \\
\text { - ICP metals (Table 3) } \\
\text { - GEA } \\
\text { - Total alpha } \\
\text { - }{ }^{238} \mathrm{Pu},{ }^{239+240} \mathrm{Pu} \\
\text { - } \mathrm{U} / \mathrm{KPA} \\
\text { - }{ }^{90} \mathrm{Sr} \\
\text { - Total beta }\end{array}$ \\
\hline & $\begin{array}{l}\text { Water Leach } \\
\text { - Anions (Table 3) }\end{array}$ \\
\hline \multirow[t]{2}{*}{$\begin{array}{l}\text { Dewater filtrate } \\
\text { (TI572-G2-A) }\end{array}$} & $\begin{array}{l}\text { Direct distribution } \\
\text { - Anions (Table 3) } \\
\text { - Free hydroxide } \\
\end{array}$ \\
\hline & $\begin{array}{l}\text { Acid digestion } \\
\text { - ICP metals (Table 3) } \\
\text { - GEA } \\
\text { - Total alpha } \\
\text { - }{ }^{238} \mathrm{Pu},{ }^{239+240} \mathrm{Pu} \\
\text { - U/KPA } \\
\text { - }{ }^{90} \mathrm{Sr} \\
\text { - Total beta }\end{array}$ \\
\hline \multirow{2}{*}{$\begin{array}{l}\text { Time interval Caustic Leach filtrates } \\
\text { (TI572-G2-C1, TI572-G2-C2, TI572-G2-C3, } \\
\text { TI572-G2-C4, TI572-G2-C5) }\end{array}$} & $\begin{array}{l}\text { Direct distribution } \\
\text { - Free hydroxide }\end{array}$ \\
\hline & $\begin{array}{l}\text { Acid digestion } \\
\text { - ICP metals (Table 3) }\end{array}$ \\
\hline \multirow[t]{2}{*}{$\begin{array}{l}\text { Caustic-leached permeate } \\
\text { (TI572-G2-D) }\end{array}$} & $\begin{array}{l}\text { Direct distribution } \\
\text { - Anions (Table 3) } \\
\text { - Free hydroxide } \\
\end{array}$ \\
\hline & $\begin{array}{l}\text { Acid digestion } \\
\text { - ICP metals (Table 3) } \\
\text { - GEA } \\
\text { - Total alpha } \\
\text { - }{ }^{238} \mathrm{Pu},{ }^{239+240} \mathrm{Pu} \\
\text { - U/KPA } \\
\text { - }{ }^{90} \mathrm{Sr} \\
\text { - Total beta }\end{array}$ \\
\hline
\end{tabular}




\begin{tabular}{|c|c|}
\hline Process Step & Analyte \\
\hline \multirow[t]{3}{*}{$\begin{array}{l}\text { Caustic-leached slurry } \\
\text { (TI572-G2-9) }\end{array}$} & $\begin{array}{l}\text { HF assisted Acid digestion } \\
\text { - ICP metals (Table 3) }\end{array}$ \\
\hline & $\begin{array}{l}\text { KOH fusion } \\
\text { - ICP metals (Table 3) } \\
\text { - GEA } \\
\text { - Total alpha } \\
\text { - }{ }^{238} \mathrm{Pu},{ }^{239+240} \mathrm{Pu} \\
\text { - U/KPA } \\
\text { - }{ }^{90} \mathrm{Sr} \\
\text { - Total beta }\end{array}$ \\
\hline & $\begin{array}{l}\text { Water Leach } \\
\text { - Anions (Table 3) }\end{array}$ \\
\hline \multirow{2}{*}{$\begin{array}{c}\text { First through fourth washes } \\
\text { following caustic leach } \\
\text { (TI572-G2-E, TI572-G2-F, TI572-G2-G, } \\
\text { TI572-G2-H) }\end{array}$} & $\begin{array}{l}\text { Direct distribution } \\
\text { - Free hydroxide } \\
\end{array}$ \\
\hline & $\begin{array}{l}\text { Acid digestion } \\
\text { - ICP metals (Table 3) }\end{array}$ \\
\hline \multirow[t]{2}{*}{$\begin{array}{l}\text { Fifth wash and combined washes } \\
\text { following caustic leach } \\
\text { (TI572-G2-I, TI572-G2-J) }\end{array}$} & $\begin{array}{l}\text { Direct distribution } \\
\text { - Anions (Table 3) } \\
\text { - Free hydroxide } \\
\end{array}$ \\
\hline & $\begin{array}{l}\text { Acid digestion } \\
\text { - ICP metals (Table } 3 \text { ) } \\
\text { - GEA } \\
\text { - Total alpha } \\
\text { - }{ }^{238} \mathrm{Pu},{ }^{239+240} \mathrm{Pu} \\
\text { - U/KPA } \\
\text { - }{ }^{90} \mathrm{Sr} \\
\text { - Total beta }\end{array}$ \\
\hline \multirow[t]{3}{*}{$\begin{array}{l}\text { Caustic-leached and washed slurry } \\
\text { (TI572-G2-12) }\end{array}$} & $\begin{array}{l}\mathrm{HF} \text { assisted Acid digestion } \\
\text { - ICP metals (Table 3) }\end{array}$ \\
\hline & $\begin{array}{l}\text { KOH fusion } \\
\text { - ICP metals (Table 3) } \\
\text { - GEA } \\
\text { - Total alpha } \\
\text { - }{ }^{238} \mathrm{Pu},{ }^{239+240} \mathrm{Pu} \\
\text { - U/KPA } \\
\text { - }{ }^{90} \mathrm{Sr} \\
\text { - Total beta }\end{array}$ \\
\hline & $\begin{array}{l}\text { Water Leach } \\
\text { - Anions (Table 3) }\end{array}$ \\
\hline $\begin{array}{c}\text { Time interval Oxidative Leach filtrates } \\
\text { (TI572-G2-L1, TI572-G2-L2, TI572-G2-L3, } \\
\text { TI572-G2-L4, TI572-G2-L5) }\end{array}$ & $\begin{array}{l}\text { Acid digestion } \\
\text { - ICP metals (Table 3) } \\
\text { - GEA } \\
\text { - Total alpha } \\
\text { - }{ }^{238} \mathrm{Pu},{ }^{239+240} \mathrm{Pu} \\
\text { - } \mathrm{U} / \mathrm{KPA} \\
\text { - }{ }^{90} \mathrm{Sr} \\
\text { - Total beta }\end{array}$ \\
\hline
\end{tabular}




\begin{tabular}{|c|c|}
\hline Process Step & Analyte \\
\hline \multirow[t]{3}{*}{$\begin{array}{l}\text { Oxidative leach slurry } \\
\text { (TI572-G2-15) }\end{array}$} & $\begin{array}{r}\mathrm{HF} \text { assisted Acid digestion } \\
\text { - ICP metals (Table } 3 \text { ) }\end{array}$ \\
\hline & $\begin{array}{l}\text { KOH fusion } \\
\text { - ICP metals (Table 3) } \\
\text { - GEA } \\
\text { - Total alpha } \\
\text { - }{ }^{238} \mathrm{Pu},{ }^{239+240} \mathrm{Pu} \\
\text { - U/KPA } \\
\text { - }{ }^{90} \mathrm{Sr} \\
\text { - Total beta }\end{array}$ \\
\hline & $\begin{array}{l}\text { Water Leach } \\
\text { - Anions (Table 3) }\end{array}$ \\
\hline \multirow{2}{*}{$\begin{array}{l}\text { First and second washes } \\
\text { following oxidative leach } \\
\text { (TI572-G2-M, TI572-G2-N) }\end{array}$} & $\begin{array}{l}\text { Direct distribution } \\
\text { - Free hydroxide }\end{array}$ \\
\hline & $\begin{array}{l}\text { Acid digestion } \\
\text { - ICP metals (Table } 3 \text { ) }\end{array}$ \\
\hline \multirow[t]{2}{*}{$\begin{array}{l}\text { Third wash and combined washes } \\
\text { following oxidative leach } \\
\text { (TI572-G2-O, TI572-G2-P) }\end{array}$} & $\begin{array}{l}\text { Direct distribution } \\
\text { - Anions (Table 3) } \\
\text { - Free hydroxide } \\
\end{array}$ \\
\hline & $\begin{array}{l}\text { Acid digestion } \\
\text { - ICP metals (Table 3) } \\
\text { - GEA } \\
\text { - Total alpha } \\
\text { - }{ }^{238} \mathrm{Pu},{ }^{239+240} \mathrm{Pu} \\
\text { - U/KPA } \\
\text { - }{ }^{90} \mathrm{Sr} \\
\text { - Total beta }\end{array}$ \\
\hline \multirow[t]{3}{*}{$\begin{array}{l}\text { Oxidative leached and washed slurry } \\
\text { (TI572-G2-18) }\end{array}$} & $\begin{array}{l}\text { HF assisted Acid digestion } \\
\text { - ICP metals (Table 3) }\end{array}$ \\
\hline & $\begin{array}{l}\mathrm{KOH} \text { fusion } \\
\text { - ICP metals (Table 3) } \\
\text { - GEA } \\
\text { - Total alpha } \\
\text { - }{ }^{238} \mathrm{Pu},{ }^{239+240} \mathrm{Pu} \\
\text { - U/KPA } \\
\text { - }{ }^{90} \mathrm{Sr} \\
\text { - Total beta }\end{array}$ \\
\hline & $\begin{array}{l}\text { Water Leach } \\
\text { - Anions (Table 3) }\end{array}$ \\
\hline $\begin{array}{l}\text { Nitric Acid Wash Sample } \\
\text { (TI572-G2-Acid) }\end{array}$ & $\begin{array}{l}\text { Direct distribution } \\
\text { - ICP metals (Table 3) } \\
\text { - GEA } \\
\text { - Total alpha } \\
\text { - }{ }^{238} \mathrm{Pu},{ }^{239+240} \mathrm{Pu} \\
\text { - } \mathrm{U} / \mathrm{KPA} \\
\text { - }{ }^{90} \mathrm{Sr} \\
\text { - Total beta }\end{array}$ \\
\hline
\end{tabular}




\begin{tabular}{|c|c|}
\hline Process Step & Analyte \\
\hline \multicolumn{2}{|c|}{ TI-RPP-WTP-552 } \\
\hline \multirow[t]{2}{*}{$\begin{array}{l}\text { Combined Slurry Permeate } \\
\text { (TI552-G6-Q) }\end{array}$} & $\begin{array}{l}\text { Direct distribution } \\
\text { - Anions (Table 3) } \\
\text { - Free Hydroxide }\end{array}$ \\
\hline & $\begin{array}{l}\text { Acid digestion } \\
\text { - ICP metals (Table 3) } \\
\text { - GEA } \\
\text { - Total alpha } \\
\text { - }{ }^{238} \mathrm{Pu},{ }^{239+240} \mathrm{Pu} \\
\text { - U/KPA } \\
\text { - }{ }^{90} \mathrm{Sr} \\
\text { - Total beta }\end{array}$ \\
\hline $\begin{array}{l}\text { Nitric Acid Wash Sample } \\
\text { (TI552-G6-Acid) }\end{array}$ & $\begin{array}{l}\text { Direct distribution } \\
\text { - ICP metals (Table } 3 \text { ) } \\
\text { - GEA } \\
\text { - Total alpha } \\
\text { - }{ }^{238} \mathrm{Pu},{ }^{239+240} \mathrm{Pu} \\
\text { - U/KPA } \\
\text { - }{ }^{90} \mathrm{Sr} \\
\text { - Total beta }\end{array}$ \\
\hline $\begin{array}{c}\text { Permeate } \\
\text { from Dewatered Slurry Archive } \\
\text { (TI552-G6-8-a) }\end{array}$ & $\begin{array}{l}\text { Acid digestion } \\
\text { - ICP metals (Table } 3 \text { ) }\end{array}$ \\
\hline $\begin{array}{c}\text { Washed Solids } \\
\text { from Dewatered Slurry Archive } \\
\text { (TI552-G6-8-b) }\end{array}$ & $\begin{array}{l}\mathrm{HF} \text { assisted Acid digestion } \\
\text { - ICP metals (Table } 3 \text { ) }\end{array}$ \\
\hline $\begin{array}{c}\text { Permeate } \\
\text { from Leached Slurry Archive } \\
\text { (TI552-G6-13-a) }\end{array}$ & $\begin{array}{l}\text { Acid digestion } \\
\text { - ICP metals (Table 3) }\end{array}$ \\
\hline $\begin{array}{l}\text { Washed Solids } \\
\text { from Leached Slurry Archive } \\
\text { (TI552-G6-13-b) }\end{array}$ & $\begin{array}{l}\text { HF assisted Acid digestion } \\
\text { - ICP metals (Table 3) }\end{array}$ \\
\hline
\end{tabular}

All analyses are to be conducted per approved PNNL procedures or test plans with the QC defined in the QC information Section. Table 3 defines the analytes of interest, the required detection limits, and analysis methods. 
Table 3. Method Detection Lim its for Solids and Supernatants

\begin{tabular}{|c|c|c|c|}
\hline Analyte & Solids & Solutions & Analysis Method \\
\hline & $\mu \mathrm{Ci} / \mathrm{g}^{(\mathrm{a})}$ & $\mu \mathrm{Ci} / \mathrm{ml}$ & \\
\hline${ }^{137} \mathrm{Cs}$ & $6.0 \mathrm{E}-02$ & $1.0 \mathrm{E}-02$ & \multirow{5}{*}{ GEA } \\
\hline${ }^{60} \mathrm{Co}$ & $3.0 \mathrm{E}-02$ & $1.0 \mathrm{E}-02$ & \\
\hline${ }^{154} \mathrm{Eu}$ & $5.0 \mathrm{E}-03$ & 4.0E-04 & \\
\hline${ }^{155} \mathrm{Eu}$ & $8.0 \mathrm{E}-03$ & 4.0E-04 & \\
\hline${ }^{241} \mathrm{Am}$ & $3.0 \mathrm{E}-03$ & $2.0 \mathrm{E}-03$ & \\
\hline $\mathrm{Pu}$ & $1.0 \mathrm{E}-03$ & $1.0 \mathrm{E}-04$ & ${ }^{239+240} \mathrm{Pu}$ and ${ }^{238} \mathrm{Pu}$ by AEA \\
\hline Total alpha & $1.0 \mathrm{E}-02$ & $4.0 \mathrm{E}-03$ & Proportional counting \\
\hline Total beta & $1.0 \mathrm{E}-02$ & $1.0 \mathrm{E}-03$ & Proportional counting \\
\hline \multirow[t]{2}{*}{${ }^{90} \mathrm{Sr}$} & $1.0 \mathrm{E}-02$ & $1.0 \mathrm{E}-03$ & Separation and proportional counting \\
\hline & $\mu \mathrm{g} / \mathrm{g}$ & $\mu \mathrm{g} / \mathrm{ml}$ & \\
\hline $\mathrm{Al}$ & $3.0 \mathrm{E}+02$ & $7.5 \mathrm{E}+01$ & \multirow{17}{*}{ ICP-OES } \\
\hline B & $2.0 \mathrm{E}+02$ & $7.5 \mathrm{E}+01$ & \\
\hline $\mathrm{Bi}$ & $4.0 \mathrm{E}+02$ & $3.0 \mathrm{E}+01$ & \\
\hline $\mathrm{Cd}$ & $7.5 \mathrm{E}+01$ & $7.5 \mathrm{E}+01$ & \\
\hline $\mathrm{Cr}$ & $1.2 \mathrm{E}+02$ & $1.5 \mathrm{E}+01$ & \\
\hline $\mathrm{Fe}$ & $3.0 \mathrm{E}+02$ & $7.5 \mathrm{E}+01$ & \\
\hline $\mathrm{K}$ & $1.0 \mathrm{E}+03^{(\mathrm{b})}$ & $5.0 \mathrm{E}+01$ & \\
\hline $\mathrm{Mn}$ & $3.0 \mathrm{E}+02$ & $1.5 \mathrm{E}+01$ & \\
\hline $\mathrm{Na}$ & $3.0 \mathrm{E}+03$ & $7.5 \mathrm{E}+01$ & \\
\hline $\mathrm{Ni}$ & $1.6 \mathrm{E}+02^{(\mathrm{b})}$ & $3.0 \mathrm{E}+01$ & \\
\hline $\mathrm{P}$ & $2.0 \mathrm{E}+02$ & $1.0 \mathrm{E}+01$ & \\
\hline $\mathrm{S}$ & $1.5 \mathrm{E}+03$ & $2.0 \mathrm{E}+2$ & \\
\hline $\mathrm{Si}$ & $3.0 \mathrm{E}+03$ & $7.5 \mathrm{E}+01$ & \\
\hline $\mathrm{Sr}$ & $3.0 \mathrm{E}+02$ & $7.5 \mathrm{E}+01$ & \\
\hline $\mathrm{Zn}$ & $3.0 \mathrm{E}+02$ & $7.5 \mathrm{E}+01$ & \\
\hline $\mathrm{Zr}$ & $3.0 \mathrm{E}+02$ & $7.5 \mathrm{E}+01$ & \\
\hline $\mathrm{U}$ & $2.5 \mathrm{E}+03$ & $7.5 \mathrm{E}+01$ & \\
\hline $\mathrm{U}$ & $6.0 \mathrm{E}+01$ & $6.0 \mathrm{E}+01$ & Kinetic Phosphorescence \\
\hline Fluoride & $2.5 \mathrm{E}+02$ & $1.2 \mathrm{E}+02$ & \multirow{6}{*}{$\begin{array}{l}\text { Ion Chromatography } \\
\text { (water-soluble species) }\end{array}$} \\
\hline Nitrite & $2.5 \mathrm{E}+02$ & $1.2 \mathrm{E}+02$ & \\
\hline Nitrate & $2.5 \mathrm{E}+02$ & $1.2 \mathrm{E}+02$ & \\
\hline Phosphate & $2.5 \mathrm{E}+02$ & $1.2 \mathrm{E}+02$ & \\
\hline Sulfate & $2.5 \mathrm{E}+02$ & $1.2 \mathrm{E}+02$ & \\
\hline Oxalate & $8.0 \mathrm{E}+02$ & $4.0 \mathrm{E}+02$ & \\
\hline Hydroxide & NA & $1 \mathrm{E}-01 \mathrm{M}$ & Titration \\
\hline Total organic carbon & NA & $4.0 \mathrm{E}+02$ (as $\mathrm{C}$ ) & \multirow{2}{*}{ Hot persulfate method } \\
\hline Total inorganic carbon & $\mathrm{NA}$ & $2.0 \mathrm{E}+02($ as $\mathrm{C})$ & \\
\hline $\begin{array}{l}\text { (a) } \mathrm{KOH} \text { fusion for solic } \\
\text { (b) The } \mathrm{Ni} \text { and } \mathrm{K} \text { canno } \\
\text { assessed from a separate }\end{array}$ & samples. & $\begin{array}{l}\mathrm{KOH} \text { fusion whic } \\
\text { tion. }\end{array}$ & es a Ni crucible. The $\mathrm{Ni}$ and $\mathrm{K}$ will be \\
\hline
\end{tabular}




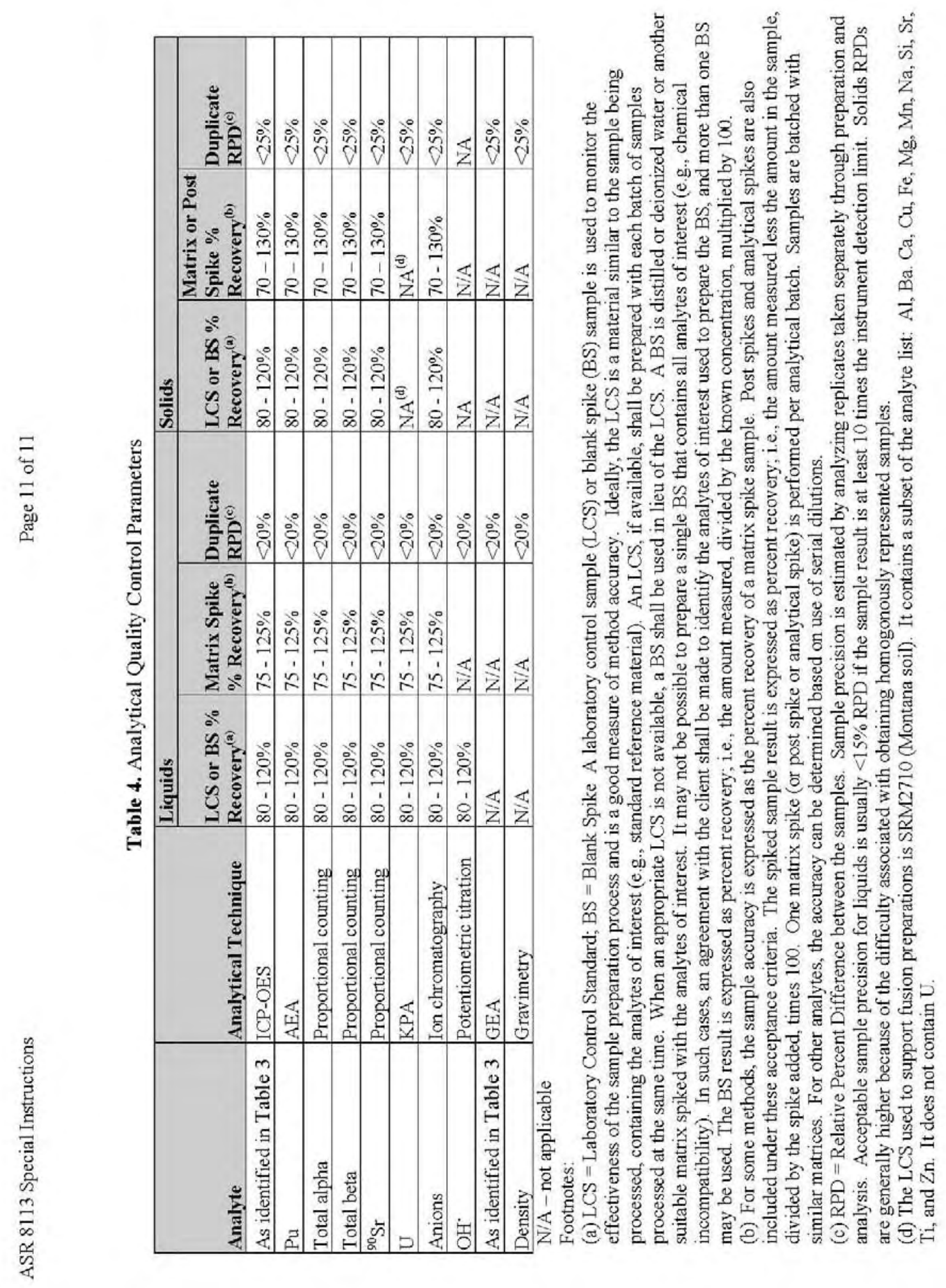


Requestor --- Complete all fields on this COVER PAGE, unless specified as optional or ASR is a revision

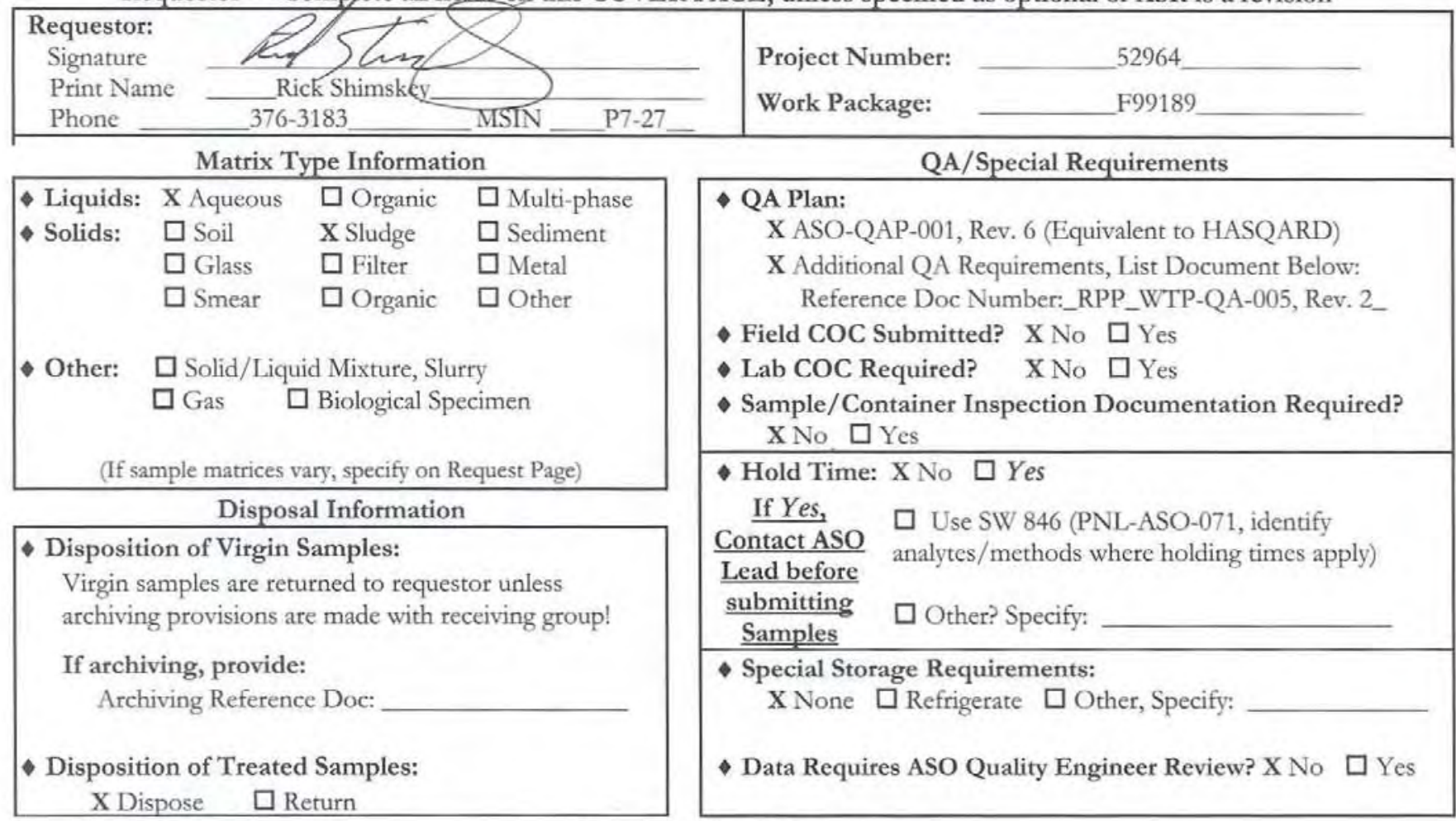

Data Reporting Information

Is Work Associated with a Fee-Based
Milestone? X No $\square$ Yes
If yes, milestone due date:
Preliminary Results Requested, As
Available? $\square$ No X Yes

Data Reporting Level
X ASO-QAP-001 (Equivalent to
HASQARD).
$\square$ Minimum data report.
$\square$ Project Specific Requirements:
Contact ASO Lead or List Reference
Document:

Waste Designation Information

Sample Information Check List Attached? X No $\square$ Yes
If no, Reference Doc Attached:
or, Previous ASR Number:
or, Previous RPL Number:

$$
\begin{aligned}
& \text { Sample Information Check List } \\
& \text { If no, Reference Doc Attached: } \\
& \text { or, Previous ASR Number: } \\
& \text { or, Previous RPL Number: }
\end{aligned}
$$

Send Report To:

$$
\text { Rick Shimskey }
$$$$
\text { Matt Edwards }
$$$$
\text { MSIN }
$$$$
\text { MSIN }
$$

\author{
- Requested Analytical Work Completion Date: \\ (Note: Priority rate charge for $<10$ business day turn-around time)
}

- Negotiated Commitment Date: $5 / 26 / 08$ (To be completed by ASO Lead) KNP LRG $7 S$ LPD KJC $B M O$ PKB, IEB, RGG MTS Does the Waste Designation Documentation Indicate Presence of PCBs? $\mathrm{X}$ No $\square$ Yes

Additional or Special Instructions_The requirements of Statement of Work, RPP-WTP-QA-005, Rev. 2, apply to this work. Task-specific Quality Control criteria are attached. Reference Document (i.e., TP-RPP-W'TP-__ ):

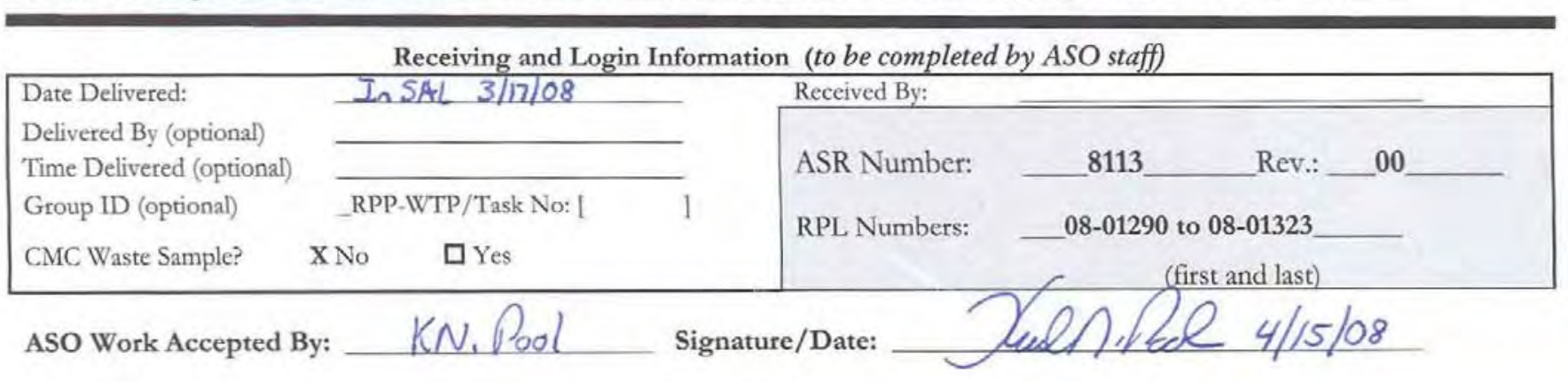




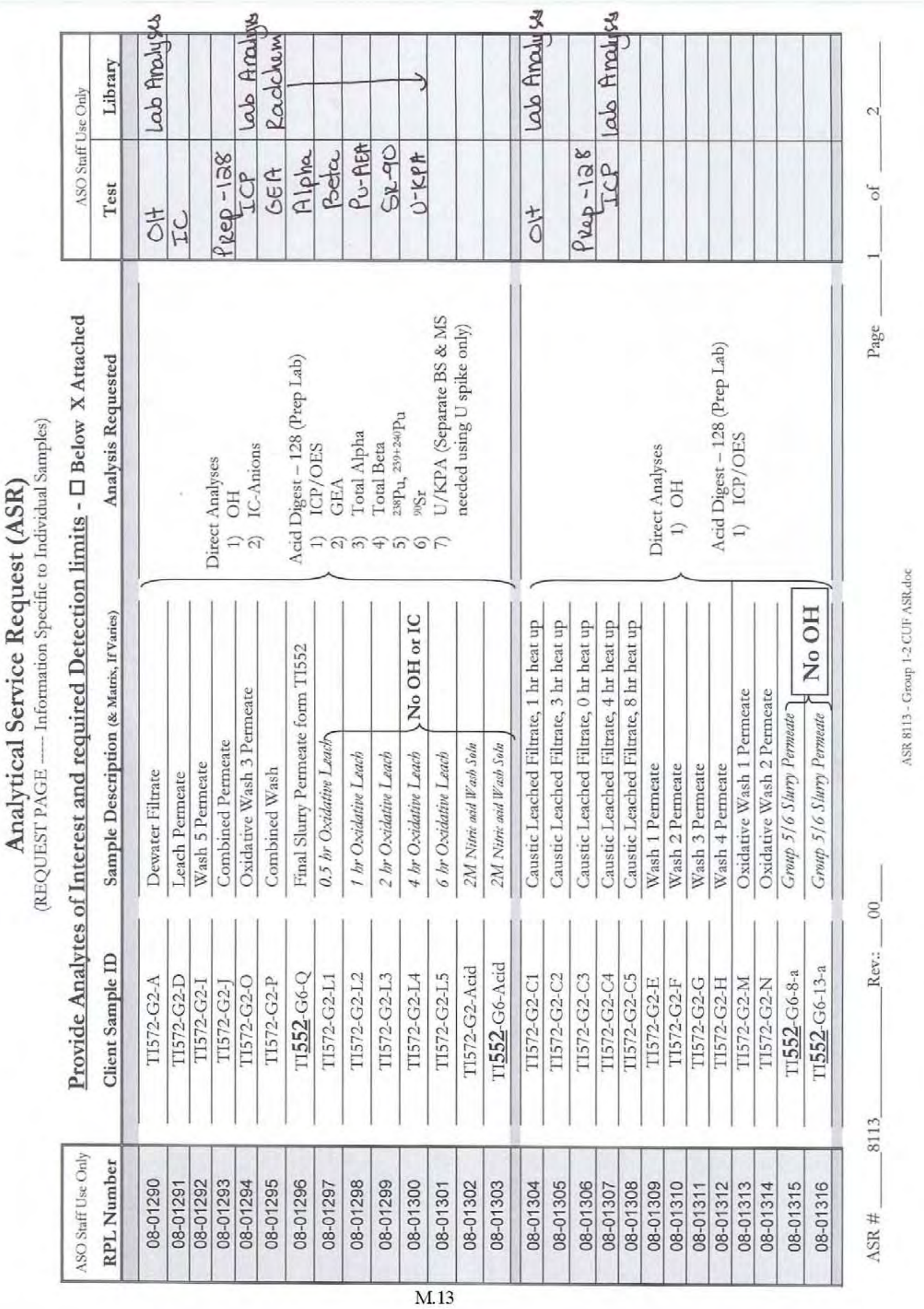


WTP-RPT-166, Rev. 0
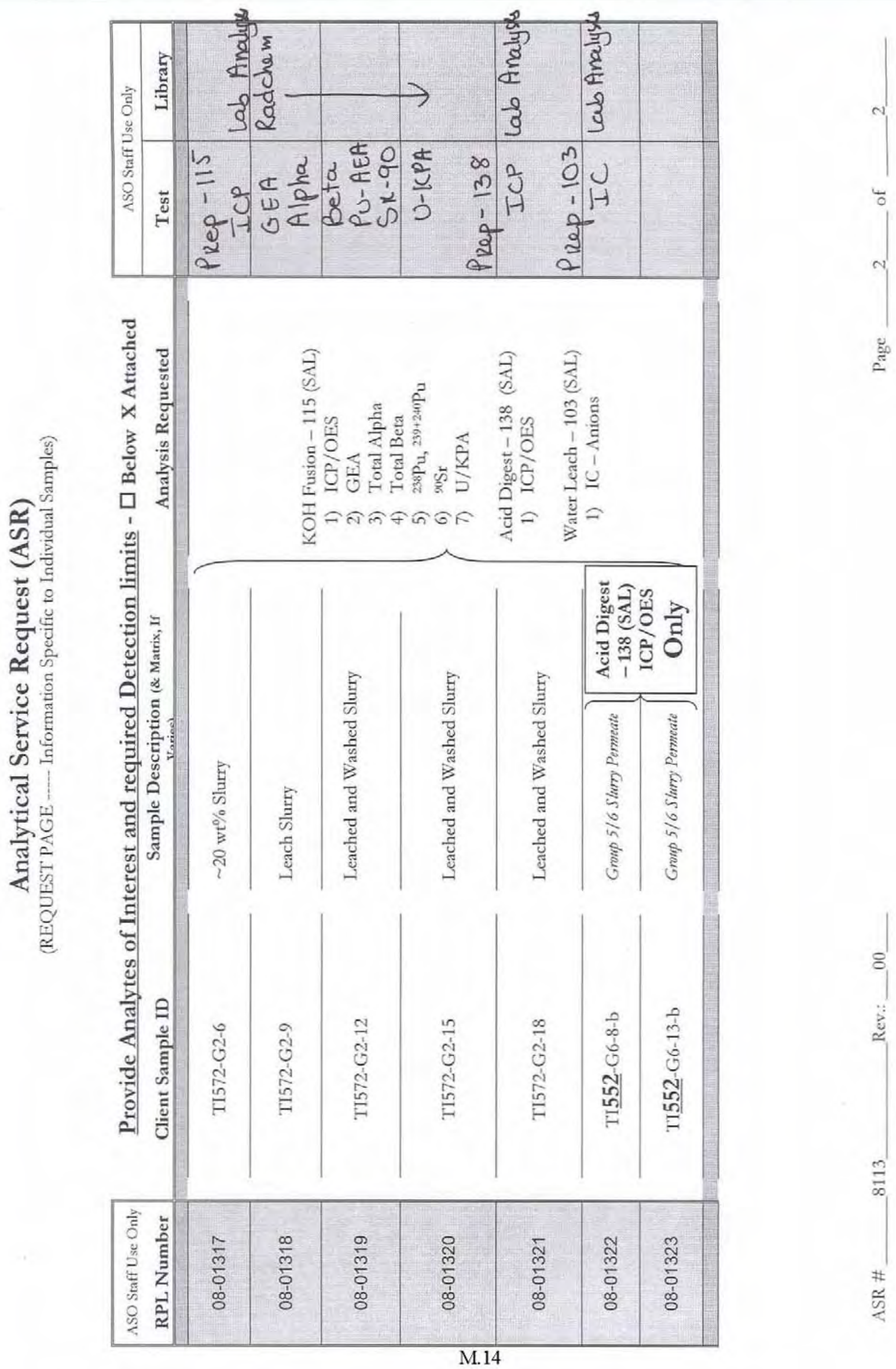
WTP-RPT-166, Rev. 0

Battelle PNNL/RPG/Inorganic Analysis: ICP-OES Data Report for KOH Fusions

\begin{tabular}{|c|c|c|c|c|c|c|c|c|c|}
\hline & & Run Date > & $4 / 23 / 2008$ & $4 / 23 / 2008$ & $4 / 23 / 2008$ & $4 / 23 / 2008$ & $4 / 23 / 2008$ & $4 / 23 / 2008$ & $4 / 23 / 2008$ \\
\hline & & Multiplier > & 2967.1 & 2598.8 & 2655.3 & 3617.9 & 3138.7 & 2997.6 & 3010.2 \\
\hline & & RPLLAB > & $\begin{array}{l}08-01317- \\
115-B \text { @5 }\end{array}$ & $\begin{array}{l}08-01317- \\
115-5 \text { @5 }\end{array}$ & $\begin{array}{l}\text { 08-01317- } \\
\text { 115-D @5 }\end{array}$ & $\begin{array}{l}08-01318- \\
115-5 @ 5\end{array}$ & $\begin{array}{l}08-01319- \\
115-5 \text { @ } 5\end{array}$ & $\begin{array}{l}08-01320- \\
115-5 \text { @5 }\end{array}$ & $\begin{array}{l}08-01321- \\
115-5 \text { @5 }\end{array}$ \\
\hline $\begin{array}{l}\text { Instr. Det. } \\
\text { Limit (IDL) }\end{array}$ & $\begin{array}{l}\text { Est. Quant. } \\
\text { Limit (EQL) }\end{array}$ & Client ID > & Prep Blank & \multicolumn{2}{|c|}{ M1572-G2-6 } & T1572-G2-9 & T1572-G2-12 & T1572-G2-15 & n572-G2-18 \\
\hline$(\mu \mathrm{g} / \mathrm{mL})$ & $(\mu \mathrm{g} / \mathrm{mL})$ & (Analyte) & $(\mu g / g)$ & $(\mu g / g)$ & $(\mu g / g)$ & $(\mu g / g)$ & $(\mu g / g)$ & \begin{tabular}{|c|}
$(\mu \mathrm{g} / \mathrm{g})$ \\
\end{tabular} & $(\mu g / g)$ \\
\hline 0.2900 & 2.900 & Al & - & 37,300 & 37,600 & 30,500 & 83,900 & 56,500 & 75,100 \\
\hline 0.0077 & 0.077 & $\mathrm{~B}$ & - & {$[97]$} & [92] & - & - & - & - \\
\hline 0.0240 & 0.240 & $\mathrm{Bi}$ & - & 19,100 & 19,200 & 26,500 & 84,500 & 57,800 & 78,300 \\
\hline 0.0029 & 0.029 & $\mathrm{Cd}$ & - & {$[18]$} & [13] & {$[20]$} & 128 & [82] & 108 \\
\hline 0.0024 & 0.024 & $\mathrm{Cr}$ & [17] & 3,790 & 3,750 & 4,930 & 13,900 & 11,400 & 7,250 \\
\hline 0.1800 & 1.800 & $\mathrm{Fe}$ & - & 23,600 & 23,400 & 33,100 & 111,000 & 71,200 & 101,000 \\
\hline 4.0000 & 40.000 & $K$ & na & na & na & na & na & na & na \\
\hline 0.0011 & 0.011 & $\mathrm{Mn}$ & [8.1] & 347 & 348 & 529 & 1,730 & 11,600 & 10,700 \\
\hline 1.9000 & 19.000 & $\mathrm{Na}$ & - & 260,000 & 258,000 & 314,000 & 177,000 & 194,000 & 121,000 \\
\hline 0.0400 & 0.400 & $\mathrm{Ni}$ & na & na & na & na & na & na & na \\
\hline 0.0540 & 0.540 & $\mathbf{P}$ & [280] & 37,700 & 37,100 & 42,200 & 24,300 & 30,900 & 14,100 \\
\hline 0.1600 & 1.600 & $\mathbf{s}$ & - & 8,120 & 7,650 & {$[3,900]$} & {$[2,000]$} & {$[2,800]$} & [590] \\
\hline 0.2300 & 2.300 & $\mathrm{SI}$ & - & 18,500 & 18,600 & 25,000 & 84,700 & 56,200 & 78,600 \\
\hline 0.0003 & 0.005 & $\mathrm{sr}$ & [1.5] & 1,300 & 1,290 & 1,820 & 6,280 & 4,280 & 5,700 \\
\hline 0.0410 & 0.820 & $U$ & $*$ & 5,820 & 5,760 & 8,290 & 28,100 & 19,200 & 25,900 \\
\hline 0.0032 & 0.064 & $\mathrm{Zn}$ & [53] & 202 & 199 & 290 & 546 & 391 & 470 \\
\hline 0.0035 & 0.035 & $\mathrm{Zr}$ & - & [49] & [42] & [65] & 751 & 468 & 570 \\
\hline \multicolumn{10}{|c|}{ Other Analytes } \\
\hline 0.0015 & \begin{tabular}{|l|}
0.015 \\
\end{tabular} & $\mathrm{Ag}$ & - & - & [4.5] & - & [21] & [16] & [13] \\
\hline 0.0390 & 0.390 & As & -- & -- & - & - & -- & - & - \\
\hline 0.0005 & 0.010 & $\mathrm{Ba}$ & [5.4] & 77.6 & 77.6 & 113 & 374 & 253 & 344 \\
\hline 0.0000 & 0.000 & $\mathrm{Be}$ & - & {$[0.46]$} & {$[0.53]$} & {$[0.25]$} & [0.82] & {$[0.53]$} & {$[0.69]$} \\
\hline 1.1000 & 11.000 & $\mathrm{Ca}$ & - & - & - & {$[4,100]$} & {$[13,000]$} & {$[9,200]$} & {$[13,000]$} \\
\hline 0.0083 & 0.083 & $\mathrm{Ce}$ & - & {$[72]$} & [48] & {$[86]$} & 331 & [220] & 321 \\
\hline 0.0027 & 0.027 & $\mathrm{Co}$ & - & {$[18]$} & {$[20]$} & [20] & [58] & {$[44]$} & [58] \\
\hline 0.0020 & 0.020 & $\mathrm{Cu}$ & - & [43] & {$[47]$} & 97.7 & 125 & 93.5 & 113 \\
\hline 0.0029 & 0.029 & Dy & - & $*$ & - & - & -- & - & - \\
\hline 0.0004 & 0.004 & $\mathrm{Eu}$ & 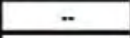 & -- & - & - & - & - & - \\
\hline 0.0027 & 0.027 & La & - & [11] & [12] & [21] & [58] & [39] & [44] \\
\hline 0.0019 & 0.019 & Li & [6.4] & [29] & [28] & [39] & 98.7 & 72.3 & 83.9 \\
\hline 0.0052 & 0.052 & $\mathrm{Mg}$ & 423 & 492 & 578 & 716 & 2,390 & 1,690 & 2,210 \\
\hline 0.0072 & 0.072 & Mo & [45] & [32] & [38] & [65] & [53] & [63] & [53] \\
\hline 0.0062 & 0.062 & Nd & $*$ & $*$ & [19] & - & [75] & {$[52]$} & {$[77]$} \\
\hline 0.0320 & 0.320 & $\mathrm{~Pb}$ & - & [460] & {$[480]$} & [590] & 2,050 & 1,470 & 1,870 \\
\hline 0.0064 & 0.064 & $\mathbf{P d}$ & $*$ & - & [21] & - & -- & - & - \\
\hline 0.0130 & 0.130 & Rh & - & - & - & - & - & - & - \\
\hline 0.0067 & 0.067 & $\mathrm{Ru}$ & - & - & [24] & - & [38] & [42] & [25] \\
\hline 0.0310 & 0.310 & $\mathrm{Sb}$ & [120] & - & [150] & - & -- & - & - \\
\hline 0.1100 & 1.100 & $\mathrm{Se}$ & - & $\ldots$ & - & - & - & - & - \\
\hline 0.0250 & 0.250 & Sn & - & - & - & - & - & - & - \\
\hline 0.0200 & 0.200 & $\mathrm{Ta}$ & - & - & - & - & -- & - & - \\
\hline 0.0260 & 0.260 & $\mathrm{Te}$ & - & - & - & - & [88] & - & - \\
\hline 0.0084 & 0.084 & Th & - & - & - & - & {$[47]$} & {$[60]$} & [31] \\
\hline 0.0005 & 0.005 & $\mathrm{Ti}$ & - & 56.1 & 52.9 & 82.5 & 259 & 165 & 236 \\
\hline 0.0300 & 0.300 & $\mathrm{TI}$ & - & [84] & - & - & - & - & - \\
\hline 0.0032 & 0.032 & V & $*$ & [14] & [12] & [14] & [38] & [21] & [28] \\
\hline 0.0210 & 0.210 & $w$ & - & - & - & - & - & - & - \\
\hline 0.0003 & \begin{tabular}{|l|}
0.003 \\
\end{tabular} & $\mathrm{Y}$ & . & [2.6] & [2.2] & [3.2] & 11.3 & [7.1] & 10.5 \\
\hline \multirow{2}{*}{\multicolumn{10}{|c|}{ 1) "--" indicates the value is $\angle M D L$. The method detection limit $(M D L)=I D L$ times the "muthiplier" }} \\
\hline \multicolumn{7}{|c|}{ near the top of each column. The estimated sample quantǐation limi $=E Q L$ (in Column 2) } & & & \\
\hline \multicolumn{10}{|c|}{ times the "muttiplier". Overall error for values $\geq E Q L$ is estimated to be within $\pm 15 \%$. } \\
\hline \multicolumn{10}{|c|}{ 2) Values in brackets [] are $\geq M D L$ but < EQL, with errors likely to exceed $15 \%$} \\
\hline$m-n$ & 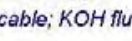 & & & lux and $\mathrm{Zr} \mathrm{cr}$ & & & & & \\
\hline
\end{tabular}


WTP-RPT-166, Rev. 0

Battelle PNNL/RPG/Inorganic Analysis:

Page 1 of 6 ICP-OES Data Report for Acid Digestions

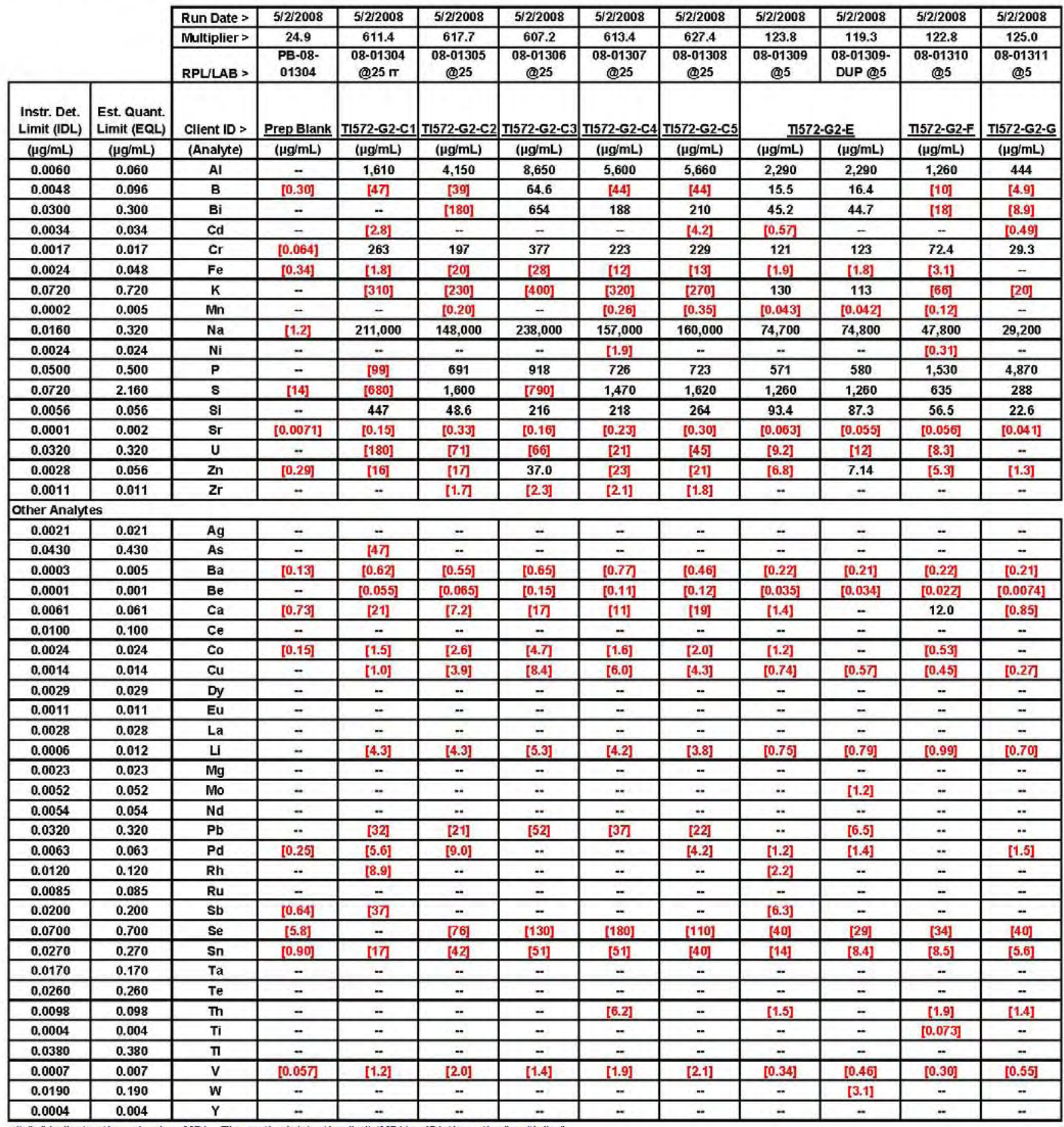

1) "-." indicates the value is $<M D L$. The method detection limit $(M D L)=I D L$ times the "muttiplier"

near the top of each column. The estimated sample quanthation limk $=E Q L$ (in Column 2)

times the "multiplier". Overall error for values $\geq E Q L$ is estimated to be within $\pm 15 \%$.

2) Values in brackets [] are $\geq M D L$ but < EQL, with errors likely to exceed $15 \%$. 
WTP-RPT-166, Rev. 0

Battelle PNNL/RPG/Inorganic Analysis:

Page 2 of 6 ICP-OES Data Report for Acid Digestions

\begin{tabular}{|c|c|c|c|c|c|}
\hline $5 / 2 / 2008$ & $5 / 2 / 2008$ & $5 / 2 / 2008$ & $5 / 2 / 2008$ & $5 / 2 / 2008$ & $5 / 2 / 2008$ \\
\hline 24.5 & 24.4 & 24.5 & 122.6 & 122.7 & 613.7 \\
\hline $08-01312$ & $08-01313$ & $08-01314$ & $\begin{array}{c}\begin{array}{c}08-01315 \\
@ 5\end{array} \\
\end{array}$ & $\begin{array}{c}08-01316 \\
\text { @ } 5\end{array}$ & $\begin{array}{c}08-01316 \\
\text { (@) } 25 \mathrm{rr}\end{array}$ \\
\hline TI572-G2-H & T1572-G2-M & TI572-G2-N & $\frac{\text { TI552-G6-8- }}{\underline{a}}$ & \multicolumn{2}{|c|}{ ד1552-G6-13-a } \\
\hline$(\mu \mathrm{g} / \mathrm{mL})$ & $(\mu \mathrm{g} / \mathrm{mL})$ & $(\mu \mathrm{g} / \mathrm{mL})$ & $(\mu \mathrm{g} / \mathrm{mL})$ & $(\mu \mathrm{g} / \mathrm{mL})$ & $(\mu \mathrm{g} / \mathrm{mL})$ \\
\hline 215 & 138 & 172 & 3,530 & 15,600 & \\
\hline [1.5] & [1.0] & [1.1] & 46.1 & 30.6 & \\
\hline$[4.0]$ & {$[2.4]$} & {$[1,1]$} & - &.- & \\
\hline- & {$[0,10]$} & {$[0.11]$} & {$[0,43]$} & {$[0.67]$} & \\
\hline 14.3 & 337 & 271 & 1,260 & 1,660 & \\
\hline$[0.087]$ & {$[0,43]$} & {$[1,1]$} & {$[1.4]$} & 14.9 & \\
\hline$[12]$ & {$[13]$} & [10] & 1,030 & 576 & \\
\hline$[0.032]$ & {$[0.0088]$} & {$[0.0062]$} & {$[0,11]$} & 0.645 & \\
\hline 18,700 & 6,380 & 5,880 & 113,000 & over-range & 214,000 \\
\hline- & - &.- & {$[2.6]$} & {$[0.31]$} & \\
\hline 4,240 & 1,120 & 971 & 2,490 & 678 & \\
\hline 123 & [51] & 58.5 & 2,330 & 1,180 & \\
\hline 45.6 & 27.9 & 33.8 & 50.1 & 49.9 & \\
\hline$[0.023]$ & [0.012] & {$[0.016]$} & {$[0.057]$} & [0.11] & \\
\hline$[1.8]$ & {$[0.81]$} & {$[1.8]$} & - & {$[8.0]$} & \\
\hline$[0.42]$ & - & {$[0.22]$} & - & [6.6] & \\
\hline- & [0.042] & - & {$[0.24]$} & {$[0.68]$} & \\
\hline
\end{tabular}

\begin{tabular}{|c|c|c|c|c|c|}
\hline- & - & - & - & - & \\
\hline- & -- & - & - & - & \\
\hline 0.143 & {$[0.088]$} & 0.166 & {$[0.27]$} & [0.34] & \\
\hline$[0.0018]$ & {$[0.0033]$} & {$[0.0017]$} & {$[0.014]$} & 0.0800 & \\
\hline$[0.24]$ & {$[0.80]$} & 3.31 & 21.1 & [2.9] & \\
\hline- & - & - & - & - & \\
\hline- & {$[0.14]$} & - & {$[0.54]$} & - & \\
\hline- & {$[0.047]$} & {$[0.060]$} & {$[0.28]$} & 2.74 & \\
\hline- & - & - & - & - & \\
\hline- & - & - & - & - & \\
\hline- & - & - & - & -- & \\
\hline [0.25] & {$[0.29]$} & 0.318 & {$[0.60]$} & 3.19 & \\
\hline- & - & - & - & - & \\
\hline- & - & - & 30.1 & 16.2 & \\
\hline- & 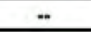 & - & - & - & \\
\hline- & $-\cdot$ & 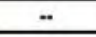 & - & [36] & \\
\hline$[0.38]$ & {$[0.20]$} & $-\cdot$ & [3.1] & {$[2.7]$} & \\
\hline- & - & - & {$[3.6]$} & {$[2.7]$} & \\
\hline- & - & - & {$[4.7]$} & {$[2.7]$} & \\
\hline- & - & - & - & -- & \\
\hline [5.9] & [4.0] & {$[8.8]$} & {$[27]$} & [29] & \\
\hline- & {$[2.4]$} & {$[1.4]$} & [15] & [14] & \\
\hline- & -- & - & - & - & \\
\hline- & - & - & - & - & \\
\hline- & {$[0.43]$} & {$[0,43]$} & {$[2 \pi]$} & [1.9] & \\
\hline- & - & {$[0.015]$} & - & - & \\
\hline- & - & - & - & - & \\
\hline 0.185 & 0.244 & 0.208 & 1.74 & {$[0.80]$} & \\
\hline- & {$[0.47]$} & - & 56.5 & 30.6 & \\
\hline- & - & $=$ & - & 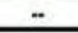 & \\
\hline
\end{tabular}


WTP-RPT-166, Rev. 0

Battelle PNNL/RPG/Inorganic Analysis:

Page 3 of 6 ICP-OES Data Report for Acid Digestions

\begin{tabular}{|c|c|c|c|c|c|c|}
\hline Criteria > & $\leq \mathbf{2 0} \%$ & $80 \%-120 \%$ & $75 \%-125 \%$ & $75 \%-125 \%$ & $75 \%-125 \%$ & $\leq 10 \%$ \\
\hline$Q C I D>$ & $\begin{array}{c}\text { 08-01309 } \\
\text { Dup }\end{array}$ & LCS/BS & $\begin{array}{c}08-01309 \\
\text { MS }\end{array}$ & $\begin{array}{c}08-1309+ \\
\text { PS-A }\end{array}$ & $\begin{array}{c}08-1309+ \\
\text { PS-B }\end{array}$ & $\begin{array}{c}\text { 08-01304 } \\
5 \text {-fold } \\
\text { Serial Dil }\end{array}$ \\
\hline Analytes & RPD $(\%)$ & $\%$ Rec & $\%$ Rec & \%Rec & $\%$ Rec & $\%$ Diff \\
\hline Al & 0.0 & 98 & 102 & 104 & & 3.2 \\
\hline $\mathrm{B}$ & 5.6 & 104 & 103 & 103 & & \\
\hline $\mathrm{Bi}$ & 1.3 & 96 & 91 & 96 & & \\
\hline Cd & & 98 & 99 & 97 & & \\
\hline $\mathrm{Cr}$ & 1.0 & 98 & 102 & 104 & & 0.9 \\
\hline $\mathrm{Fe}$ & & 97 & 101 & 100 & & \\
\hline $\mathrm{K}$ & 13.9 & 99 & 102 & 101 & & \\
\hline $\mathrm{Mn}$ & & 99 & 98 & 101 & & \\
\hline $\mathrm{Na}$ & 0.2 & 97 & $\mathrm{nr}$ & $\mathrm{nr}$ & & 2.0 \\
\hline $\mathrm{Ni}$ & & 97 & 99 & 102 & & \\
\hline $\mathbf{P}$ & 1.6 & 100 & 99 & 101 & & \\
\hline$s$ & 0.0 & 97 & 101 & & 101 & \\
\hline SI & 6.7 & 96 & 97 & 107 & & 9.2 \\
\hline $\mathrm{Sr}$ & & 100 & 100 & 103 & & \\
\hline $\mathbf{U}$ & & 95 & 96 & & 97 & \\
\hline $\mathrm{Zn}$ & & 99 & 111 & 105 & & \\
\hline $\mathrm{Zr}$ & & 89 & 87 & 100 & & \\
\hline
\end{tabular}

\begin{tabular}{|c|c|c|c|c|c|}
\hline $\mathrm{Ag}$ & & & 96 & & \\
\hline As & & & 103 & & \\
\hline $\mathrm{Ba}$ & 97 & 99 & 99 & & \\
\hline $\mathrm{Be}$ & 95 & 98 & 100 & & \\
\hline $\mathrm{Ca}$ & 98 & 98 & 101 & & \\
\hline $\mathrm{Ce}$ & 92 & 91 & & 95 & \\
\hline Co & & & 102 & & \\
\hline $\mathrm{Cu}$ & 96 & 98 & 101 & & \\
\hline Dy & & & & 97 & \\
\hline Eu & & & & 97 & \\
\hline La & 93 & 92 & & 94 & \\
\hline LI & 99 & 100 & 101 & & \\
\hline $\mathrm{Mg}$ & 98 & 98 & 100 & & \\
\hline Mo & 100 & 102 & 102 & & \\
\hline Nd & 94 & 93 & & 95 & \\
\hline $\mathrm{Pb}$ & 100 & 101 & 102 & & \\
\hline $\mathrm{Pd}$ & & & & 92 & \\
\hline $\mathbf{R h}$ & & & & 98 & \\
\hline$R \mathbf{R u}$ & & & & 97 & \\
\hline $\mathrm{Sb}$ & & & 98 & & \\
\hline $\mathrm{Se}$ & & & 107 & & \\
\hline Sn & & & 97 & & \\
\hline $\mathrm{Ta}$ & & & 103 & & \\
\hline $\mathrm{Te}$ & & & & 97 & \\
\hline Th & 61 & 74 & & 95 & \\
\hline $\mathrm{Ti}$ & 100 & 98 & 98 & & \\
\hline $\mathrm{TI}$ & & & 96 & & \\
\hline $\mathrm{v}$ & 91 & 92 & 96 & & \\
\hline$w$ & 96 & 102 & 97 & & \\
\hline $\mathrm{Y}$ & & & 96 & & \\
\hline
\end{tabular}

Shaded results are outside the acceptance criteria.

$n r=n \alpha$ recovered; spike concentration less than $25 \%$ of sample concentration. 
WTP-RPT-166, Rev. 0

Battelle PNNL/RPG/Inorganic Analysis:

Page 4 of 6 ICP-OES Data Report for Acid Digestions

\begin{tabular}{|c|c|c|c|c|c|c|c|c|c|c|c|c|}
\hline & Run Date> & $5 / 5 / 2008$ & $5 / 5 / 2008$ & $5 / 5 / 2008$ & $5 / 5 / 2008$ & $5 / 5 / 2008$ & $5 / 5 / 2008$ & $5 / 5 / 2008$ & $5 / 5 / 2008$ & $5 / 5 / 2008$ & $5 / 5 / 2008$ \\
\hline & & Multiplier > & 19.9 & 118.2 & 124.1 & 122.7 & 613.4 & 24.5 & 24.2 & 121.1 & 123.0 & 19.7 \\
\hline & & RPLLAB > & $\begin{array}{l}\text { PB-08- } \\
01290\end{array}$ & $\begin{array}{l}\text { 08-01290- } \\
128 @ 5 \mathrm{r}\end{array}$ & $\begin{array}{c}\text { 08-01290- } \\
\text { DUP-128 @5 }\end{array}$ & $\begin{array}{c}\text { 08-01291- } \\
128 \text { @ }\end{array}$ & $\begin{array}{l}08-01291- \\
128 @ 25\end{array}$ & $\begin{array}{c}08-01292- \\
128\end{array}$ & $\begin{array}{c}08-01293- \\
128\end{array}$ & $\begin{array}{c}08-01293- \\
128 @ 5\end{array}$ & $\begin{array}{c}08-01294- \\
128 @ 5\end{array}$ & $\begin{array}{c}08-01295- \\
128\end{array}$ \\
\hline $\begin{array}{l}\text { Instr. Det. } \\
\text { Limit (IDL) }\end{array}$ & $\begin{array}{l}\text { Est. Quant. } \\
\text { Limit (EQL) }\end{array}$ & Client ID > & Prep Blank & \multicolumn{2}{|c|}{ T1572-G2-A } & \multicolumn{2}{|c|}{ T1572-G2-D } & T1572-G2-1 & \multicolumn{2}{|c|}{ I1572-G2 J } & T1572-G2-O & T1572-G2-P \\
\hline$(\mu \mathrm{g} / \mathrm{mL})$ & $(\mu \mathrm{g} / \mathrm{mL})$ & (Analyte) & $(\mu \mathrm{g} / \mathrm{mL})$ & $(\mu g / m L)$ & $(\mu g / m L)$ & $(\mu \mathrm{g} / \mathrm{mL})$ & $(\mu g / m L)$ & $(\mu g / m L)$ & $(\mu \mathrm{g} / \mathrm{mL})$ & $(\mu g / m L)$ & $\left(\mu g^{\prime} / \mathrm{mL}\right)$ & $(\mu \mathrm{g} / \mathrm{mL})$ \\
\hline 0.0060 & 0.060 & Al & - & 952 & 931 & 5,070 & & 115 & 802 & & 841 & 123 \\
\hline 0.0048 & 0.096 & B & {$[1.0]$} & 63.2 & 65.4 & 33.9 & & [1.1] & 5.38 & & [7.5] & [0.73] \\
\hline 0.0300 & 0.300 & $\mathrm{Bi}$ & - & - & $-\cdot$ & 157 & & -- & 13.1 & & [9.1] & - \\
\hline 0.0034 & 0.034 & $\mathrm{Cd}$ & - & -- & -- & -- & & $-\cdot$ & - & & $-\cdot$ & - \\
\hline 0.0017 & 0.017 & $\mathrm{Cr}$ & [0.063] & 486 & 473 & 206 & & 7.65 & 45.1 & & 47.2 & 231 \\
\hline 0.0024 & 0.048 & $\mathrm{Fe}$ & {$[0.075]$} & [5.6] & {$[5.0]$} & 8.24 & & [0.16] & {$[0.77]$} & & {$[0,75]$} & {$[0.74]$} \\
\hline 0.0720 & 0.720 & $\mathrm{~K}$ & - & 557 & 547 & 286 & & {$[5.4]$} & 46.1 & & [42] & {$[7.8]$} \\
\hline 0.0002 & 0.005 & $\mathrm{Mn}$ & - & [0.093] & [0.086] & 1.20 & & {$[0.012]$} & {$[0.053]$} & & $*$ & {$[0.011]$} \\
\hline 0.0160 & 0.320 & $\mathrm{Na}$ & - & 100,000 & 100,000 & over-range & 142,000 & 9,540 & over-range & 36,300 & 36,500 & 4,840 \\
\hline 0.0024 & 0.024 & $\mathrm{Ni}$ & - & - & - & - & & - & - & & - & - \\
\hline 0.0500 & 0.500 & $\mathbf{P}$ & - & 1,010 & 1,040 & 309 & & 2,130 & 2,890 & & 3,000 & 819 \\
\hline 0.0720 & 2.160 & $s$ & - & 5,360 & 5,240 & 1,800 & & 63.1 & 448 & & 446 & 42.6 \\
\hline 0.0056 & 0.056 & Si & - & [5.9] & 15.3 & 215 & & 16.5 & 80.2 & & 20.0 & 24.6 \\
\hline 0.0001 & 0.002 & $\mathrm{sr}$ & {$[0.0034]$} & 0.226 & 0.230 & {$[0.095]$} & & {$[0.011]$} & {$[0.022]$} & & [0.042] & {$[0.0096]$} \\
\hline 0.0320 & 0.320 & $\mathbf{U}$ & - & 107 & 109 & {$[7.6]$} & & - & {$[1.8]$} & & - & - \\
\hline 0.0028 & 0.056 & $\mathrm{Zn}$ & {$[0.68]$} & {$[0.54]$} & {$[0.53]$} & 17.5 & & {$[0,50]$} & 2.24 & & {$[2.9]$} & {$[0,61]$} \\
\hline 0.0011 & 0.011 & $\mathrm{Zr}$ & - & - & - & {$[0.49]$} & & - & - & & - & - \\
\hline \multicolumn{13}{|c|}{ Other Analytes } \\
\hline 0.0021 & 0.021 & $\mathrm{Ag}$ & - & - & - & - & & - & - & & 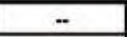 & [0.059] \\
\hline 0.0430 & 0.430 & As & - & - & - & - & & - & - & & 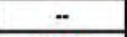 & - \\
\hline 0.0003 & 0.005 & $\mathrm{Ba}$ & {$[0.031]$} & [0.31] & {$[0.30]$} & [0.23] & & {$[0.12]$} & 0.175 & & {$[0.22]$} & 0.247 \\
\hline 0.0001 & 0.001 & $\mathrm{Be}$ & - & - & - & {$[0.062]$} & & {$[0.0018]$} & {$[0.0071]$} & & {$[0.0078]$} & {$[0.0012]$} \\
\hline 0.0061 & 0.061 & $\mathrm{Ca}$ & [0.82] & - & {$[28]$} & - & & [0.60] & - & & [2.5] & [0.52] \\
\hline 0.0100 & 0.100 & $\mathrm{Ce}$ & - & - & -- & - & & -- & - & & - & - \\
\hline 0.0024 & 0.024 & Co & - & - & 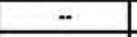 & - & & - & - & & $\cdots$ & - \\
\hline 0.0014 & 0.014 & $\mathrm{Cu}$ & - & - & $*$ & 3.32 & & - & {$[0.098]$} & & {$[0.20]$} & - \\
\hline 0.0029 & 0.029 & Dy & - & - & - & - & & - & - & & .. & 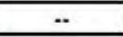 \\
\hline 0.0011 & 0.011 & Eu & - & - & $*$ & $*$ & & $\cdots$ & $*$ & & *. & $*$ \\
\hline 0.0028 & 0.028 & La & $*$ & 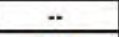 & -. & 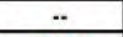 & & .. & -. & & -. & 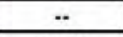 \\
\hline 0.0006 & 0.012 & Li & -. & {$[0.89]$} & [1.1] & {$[0.61]$} & & {$[0.21]$} & 0.347 & & {$[0.64]$} & 0.239 \\
\hline 0.0023 & 0.023 & $\mathrm{Mg}$ & $\ddot{*}$ & 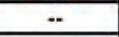 & .. & $=$ & & 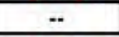 & 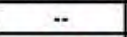 & & 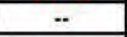 & 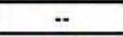 \\
\hline 0.0052 & 0.052 & Mo & 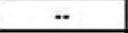 & 7.02 & 7.19 & [3.6] & & {$[0.18]$} & {$[0.72]$} & & - & {$[0.23]$} \\
\hline 0.0054 & 0.054 & $\mathrm{Nd}$ & $\because$ & 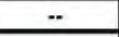 & .. & $\cdots$ & & .. & {$[0.18]$} & & .. & - \\
\hline 0.0320 & 0.320 & $\mathrm{~Pb}$ & $-\cdot$ & $\ddot{*}$ & $*$ & [22] & & - & {$[2.0]$} & & [5.5] & $*$ \\
\hline 0.0063 & 0.063 & $P d$ & $-\cdot$ & $\cdots$ & [1.2] & $*$ & & $-\cdot$ & {$[0.16]$} & & 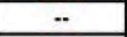 & $*$ \\
\hline 0.0120 & 0.120 & Rh & 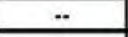 & [2.1] & - & {$[2.3]$} & & {$[0.32]$} & {$[0.31]$} & & {$[2.6]$} & {$[0.24]$} \\
\hline 0.0085 & 0.085 & $\mathbf{R u}$ & 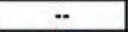 & .. & [1.1] & $*$ & & - & -. & & 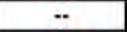 & -. \\
\hline 0.0200 & 0.200 & Sb & [1.2] & [5.5] & [3.2] & $\cdots$ & & {$[0.92]$} & $*$ & & [7.7] & - \\
\hline 0.0700 & 0.700 & Se & - & [16] & [21] & [10] & & {$[2.7]$} & - & & - & - \\
\hline 0.0270 & 0.270 & $\mathrm{Sn}$ & - & $*$ & [5.6] & [11] & & -- & [2.1] & & - &.- \\
\hline 0.0170 & 0.170 & $\mathrm{Ta}$ & - & $*$ & $=$ & - & & - & - & & $*$ & - \\
\hline 0.0260 & 0.260 & $\mathrm{Te}$ & {$[0.58]$} & {$[3.5]$} & {$[6.8]$} & - & & {$[0.90]$} & {$[0.75]$} & & [5.2] & {$[0.59]$} \\
\hline 0.0098 & 0.098 & Th & - & - & [1.4] & - & & - & - & & - & {$[0.31]$} \\
\hline 0.0004 & 0.004 & $\mathrm{TI}$ & - & {$[0.053]$} & - & - & & - & {$[0.017]$} & & - & {$[0.012]$} \\
\hline 0.0380 & 0.380 & $\mathrm{TI}$ & - & - & - & - & & $=$ & - & & - & - \\
\hline 0.0007 & 0.007 & $v$ & - & {$[0.092]$} & -- & - & & {$[0.058]$} & {$[0.091]$} & & {$[0.21]$} & {$[0.14]$} \\
\hline 0.0190 & 0.190 & $w$ & - & [14] & [13] & {$[7.0]$} & & {$[0.54]$} & {$[1.5]$} & & - & - \\
\hline 0.0004 & 0.004 & $\mathrm{Y}$ & - & - & - & - & & -- & - & & - & - \\
\hline
\end{tabular}

1) "--" indicates the value is $<M D L$. The method detection limit (MDL) $=I D L$ times the "mutiplier" near the top of each column. The estimated sample quant tiation limit $=E Q L$ (in Column 2)

times the "mutiplier". Overall error for values $\geq E Q L$ is estimated to be within $\pm 15 \%$.

2) Values in brackets [] are $\geq M D L$ but $<E Q L$, with errors likely to exceed $15 \%$. 
WTP-RPT-166, Rev. 0

Battelle PNNL/RPG/Inorganic Analysis:

Page 5 of 6 ICP-OES Data Report for Acid Digestions

\begin{tabular}{|c|c|c|c|c|c|c|c|}
\hline $5 / 5 / 2008$ & $5 / 5 / 2008$ & $5 / 5 / 2008$ & $5 / 5 / 2008$ & $5 / 5 / 2008$ & $5 / 5 / 2008$ & $5 / 5 / 2008$ & $5 / 5 / 2008$ \\
\hline 24.9 & 126.2 & 24.9 & 24.1 & 24.6 & 25.1 & 23.9 & 24.8 \\
\hline $\begin{array}{c}08-01296- \\
128\end{array}$ & $\begin{array}{c}08-01297- \\
128 @ 5\end{array}$ & $\begin{array}{c}08-01298- \\
128\end{array}$ & $\begin{array}{c}08-01299- \\
128\end{array}$ & $\begin{array}{c}08-01300= \\
128\end{array}$ & $\begin{array}{c}08-01301 . \\
128\end{array}$ & $\begin{array}{c}08-01302- \\
128\end{array}$ & $\begin{array}{c}08-01303- \\
128\end{array}$ \\
\hline T1552-G6-Q & T1572-G2-L1 & T1572-G2-L2 & П1572-G2-L3 & П1572-G2-L4 & T1572-G2-L5 & $\frac{\text { n572-G2- }}{\text { Acid }}$ & $\frac{\text { m552-G6- }}{\text { Acid }}$ \\
\hline$(\mu \mathrm{g} / \mathrm{mL})$ & $(\mu \mathrm{g} / \mathrm{mL})$ & $(\mu \mathrm{g} / \mathrm{mL})$ & $(\mu \mathrm{g} / \mathrm{mL})$ & $(\mu \mathrm{g} / \mathrm{mL})$ & $(\mu \mathrm{g} / \mathrm{mL})$ & $(\mu \mathrm{g} / \mathrm{mL})$ & $(\mu \mathrm{g} / \mathrm{mL})$ \\
\hline 1,170 & 316 & 111 & 170 & 158 & 243 & 40.3 & 111 \\
\hline$[1.7]$ & {$[3.7]$} & {$[0.89]$} & {$[1.4]$} & [1.2] & [1.8] & {$[0,16]$} & {$[0.26]$} \\
\hline- & - & - & - & - & [0.82] & - & 149 \\
\hline .. & - & .. & 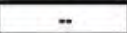 & - & -. & .- & {$[0.16]$} \\
\hline 284 & 1,500 & 329 & 710 & 713 & 1,050 & 4.08 & 14.3 \\
\hline$[0.082]$ & {$[0.42]$} & {$[0.17]$} & {$[0.25]$} & {$[0.26]$} & 1.32 & 31.2 & 142 \\
\hline 32.0 & [46] & [11] & 29.7 & 17.9 & 27.5 & {$[2.8]$} & {$[2.0]$} \\
\hline 3.98 & 340 & 112 & 850 & 39.7 & {$[0.098]$} & 9.02 & 7.59 \\
\hline 10,300 & 25,400 & 7,350 & 11,600 & 10,300 & 15,300 & 187 & 383 \\
\hline- & - & - & - & - & - & 2.97 & 8.29 \\
\hline 28.0 & 5,250 & 1,550 & 2,300 & 2,100 & 3,180 & - & 59.3 \\
\hline [12] & [220] & 56.9 & 99.6 & 72.9 & 115 & [5.6] & [3.9] \\
\hline 5.86 & 15.5 & 9.31 & 21.1 & 15.8 & 28.4 & 21.5 & 59.6 \\
\hline$[0.0043]$ & {$[0.029]$} & [0.0059] & - & {$[0.0054]$} & 0.0596 & 9.42 & 8.56 \\
\hline- & - & -- & - & - & - & 48.7 & 38.0 \\
\hline$[0.62]$ & - & {$[0,49]$} & {$[0.64]$} & - & - & 1.45 & 1.66 \\
\hline$[0.047]$ & - & - & - & {$[0.066]$} & {$[0.076]$} & {$[0.26]$} & 0.632 \\
\hline
\end{tabular}

\begin{tabular}{|c|c|c|c|c|c|c|c|}
\hline- & - & - & - & [0.071] & [0.063] & {$[0.060]$} & - \\
\hline- & - & [1.5] & - & - & - & - & - \\
\hline$[0.13]$ & {$[0.16]$} & [0.099] & [0.098] & [0.13] & [0.13] & 0.647 & 0.721 \\
\hline [0.0016] & - & - & {$[0.0037]$} & [0.0059] & {$[0.0080]$} & [0.0015] & [0.0021] \\
\hline$[0.74]$ & {$[0.94]$} & [0.72] & - & {$[0.62]$} & {$[0.77]$} & 6.52 & 20.5 \\
\hline -. & - & -. & - & - & -. &.- & {$[0.62]$} \\
\hline$=$ & - & $=$ & $=$ & - & - & 4.67 & 1.08 \\
\hline- & - & - & - & - & $=$ & 0.399 & {$[0,18]$} \\
\hline- & - & - & - & - & - & - & - \\
\hline- & - & - & $*$ & - & $=$ & - & - \\
\hline- & - & - & - & - & - & {$[0.071]$} & - \\
\hline$[0.078]$ & [0.79] & {$[0.18]$} & {$[0.23]$} & {$[0.28]$} & 0.408 & {$[0.063]$} & {$[0.12]$} \\
\hline- & - & -- & - & - & $=$ & 1.24 & 3.05 \\
\hline$[0.63]$ & [1.1] & [0.53] & {$[0.42]$} & {$[0.42]$} & {$[0.84]$} & -- & {$[0.31]$} \\
\hline- & [1.0] & {$[0.17]$} & - & {$[0,16]$} & - & [0.39] & {$[0.18]$} \\
\hline [1.5] & [4.8] & [1.2] & [2.1] & [1.3] & [2.2] & [0.93] & [2.9] \\
\hline- & - & - & - & - & - & - & - \\
\hline- & - & - & - & {$[0,40]$} & - & {$[0.36]$} & - \\
\hline [0.31] & - & - & - & - & - & - & - \\
\hline- & [3.5] & [1.4] & - & - & -- & - & [1.4] \\
\hline- & [19] & [5.1] & [3.0] & [4.2] & {$[5.0]$} & -. & - \\
\hline- & - & -- & -- & - & -- & - & - \\
\hline . & - & $=$ & $=$ & - & $=$ & - & - \\
\hline$[0.83]$ & {$[5.8]$} & -- & [1.1] & - & {$[0.67]$} & {$[1.0]$} & - \\
\hline$[0.41]$ & {$[1.7]$} & [0.61] & {$[1.2]$} & {$[0.97]$} & [1.5] & {$[0.26]$} & - \\
\hline$[0.013]$ & - & -. & {$[0.019]$} & {$[0.018]$} & {$[0.035]$} & 0.120 & 0.259 \\
\hline- & - & $\cdots$ & - & - & $\cdots$ & - & - \\
\hline$[0.15]$ & {$[0.52]$} & {$[0.13]$} & 0.180 & {$[0.18]$} & {$[0.18]$} & {$[0.032]$} & 0.207 \\
\hline- & - & - & {$[0.52]$} & - & {$[0.48]$} & - & - \\
\hline- & - & - & - & - & - & {$[0.040]$} & {$[0.018]$} \\
\hline
\end{tabular}

e-report_(17).xls

Worksheet: ASR 8113 Batch 2 Final 
WTP-RPT-166, Rev. 0

Battelle PNNL/RPG/Inorganic Analysis:

Page 6 of 6

\section{ICP-OES Data Report for Acid Digestions}

\begin{tabular}{|c|c|c|c|c|c|c|}
\hline Criteria > & $\leq 20 \%$ & $80 \%-120 \%$ & $75 \%-125 \%$ & $75 \%-125 \%$ & $75 \%-125 \%$ & $\leq 10 \%$ \\
\hline$Q C I D>$ & $\begin{array}{c}\text { 08-01290 } \\
\text { Dup }\end{array}$ & LCS/BS & $\begin{array}{c}08-01290 \\
\text { MS }\end{array}$ & $\begin{array}{c}08-01290+ \\
\text { PS-A }\end{array}$ & $\begin{array}{c}08-01290+ \\
\text { PS-B }\end{array}$ & $\begin{array}{c}08-01290 \\
5-f o l d \\
\text { Serial Dil }\end{array}$ \\
\hline Analytes & RPD (\%) & $\%$ Rec & $\% \operatorname{Rec}$ & \%Rec & $\%$ Rec & $\%$ Diff \\
\hline Al & 2.2 & 96 & 98 & 102 & & 1.8 \\
\hline B & 3.3 & 101 & 105 & 103 & & 2.5 \\
\hline $\mathrm{Bi}$ & & 95 & 90 & 97 & & \\
\hline $\mathrm{Cd}$ & & 97 & 98 & 97 & & \\
\hline $\mathrm{Cr}$ & 2.8 & 97 & $\mathrm{nr}$ & 101 & & 3.5 \\
\hline $\mathrm{Fe}$ & & 97 & 104 & 104 & & \\
\hline $\mathrm{K}$ & 1.8 & 98 & 103 & 101 & & 6.2 \\
\hline $\mathrm{Mn}$ & & 97 & 99 & 101 & & \\
\hline $\mathrm{Na}$ & 0.3 & 97 & $\mathrm{nr}$ & $\mathrm{nr}$ & & 2.6 \\
\hline $\mathrm{Ni}$ & & 97 & 101 & 104 & & \\
\hline $\mathbf{P}$ & 2.9 & 99 & 98 & 100 & & 0.7 \\
\hline$s$ & 2.2 & 88 & 92 & & 100 & 1.1 \\
\hline $\mathrm{Si}$ & & 96 & 102 & 102 & & \\
\hline $\mathrm{Sr}$ & 1.8 & 99 & 101 & 102 & & \\
\hline $\mathbf{U}$ & 1.6 & 95 & 98 & & 96 & \\
\hline $\mathrm{Zn}$ & & 97 & 101 & 104 & & \\
\hline $\mathrm{Zr}$ & & 89 & 93 & 102 & & \\
\hline \multicolumn{7}{|c|}{ Other Analytes } \\
\hline $\mathrm{Ag}$ & & & & 94 & & \\
\hline As & & & & 100 & & \\
\hline $\mathrm{Ba}$ & & 98 & 100 & 102 & & \\
\hline $\mathrm{Be}$ & & 94 & 99 & 100 & & \\
\hline $\mathrm{Ca}$ & & 96 & 99 & 100 & & \\
\hline $\mathrm{Ce}$ & & 92 & 93 & & 95 & \\
\hline $\mathrm{Co}$ & & & & 101 & & \\
\hline $\mathrm{Cu}$ & & 96 & 101 & 104 & & \\
\hline Dy & & & & & 98 & \\
\hline Eu & & & & & 98 & \\
\hline La & & 93 & 95 & & 95 & \\
\hline Li & & 97 & 101 & 101 & & \\
\hline $\mathrm{Mg}$ & & 99 & 101 & 102 & & \\
\hline Mo & 2.4 & 98 & 98 & 101 & & \\
\hline $\mathrm{Nd}$ & & 94 & 97 & & 95 & \\
\hline $\mathrm{Pb}$ & & 98 & 100 & 101 & & \\
\hline $\mathbf{P d}$ & & & & & 94 & \\
\hline $\mathbf{R h}$ & & & & & 99 & \\
\hline $\mathbf{R u}$ & & & & & 98 & \\
\hline Sb & & & & 99 & & \\
\hline Se & & & & 107 & & \\
\hline $\mathrm{Sn}$ & & & & 99 & & \\
\hline $\mathrm{Ta}$ & & & & 100 & & \\
\hline $\mathrm{Te}$ & & & & & 99 & \\
\hline Th & & 63 & 20 & & 98 & \\
\hline $\mathrm{TI}$ & & 100 & 102 & 102 & & \\
\hline $\mathrm{TI}$ & & & & 95 & & \\
\hline $\mathrm{v}$ & & 92 & 95 & 98 & & \\
\hline$w$ & & 96 & 117 & 102 & & \\
\hline$Y$ & & & & 99 & & \\
\hline
\end{tabular}

Shaded results are outside the acceptance criteria.

$n r=n o t$ recovered; spike concentration less than $25 \%$ of sample concentration. 
WTP-RPT-166, Rev. 0

Battelle PNNL/RPG/Inorganic Analysis:

\section{ICP-OES Data Report for HF-Assisted Acid Digestions}

\begin{tabular}{|c|c|c|c|c|c|c|c|c|}
\hline & & Run Date > & $4 / 24 / 2008$ & $4 / 24 / 2008$ & $4 / 24 / 2008$ & 4/24/2008 & $4 / 24 / 2008$ & $4 / 24 / 2008$ \\
\hline & & Multipller > & 784.5 & 716.8 & 711.2 & 749.6 & 874.1 & 4370.6 \\
\hline & & RPLLAB > & $\begin{array}{c}08-01317- \\
138-\mathrm{B}\end{array}$ & $\begin{array}{c}08-01317- \\
138-5\end{array}$ & $\begin{array}{c}08-01317- \\
138-D\end{array}$ & $\begin{array}{c}08-01318- \\
138-\mathrm{S}\end{array}$ & $\begin{array}{c}08-01319- \\
138-5\end{array}$ & $\begin{array}{l}\text { 08-01319. } \\
138-5 @ 5\end{array}$ \\
\hline $\begin{array}{l}\text { Instr. Det. } \\
\text { Limit (IDL) }\end{array}$ & $\begin{array}{l}\text { Est. Quant. } \\
\text { Limit (EQL) }\end{array}$ & Client ID > & Prep Blank & \multicolumn{2}{|c|}{$\underline{7572-\mathrm{G} 2-6}$} & T1572-G2-9 & 11572-G2-12 & П1572-G2-12 \\
\hline$(\mu \mathrm{g} / \mathrm{mL})$ & $(\mu \mathrm{g} / \mathrm{mL})$ & (Analyte) & $(\mu g / g)$ & $(\mu g / g)$ & $(\mu g / g)$ & $(\mu g / g)$ & \begin{tabular}{l|l}
$(\mu g / g)$ \\
\end{tabular} & $(\mu \mathrm{g} / \mathrm{g})$ \\
\hline 0.0060 & 0.060 & Al & [30] & 40,900 & 40,500 & 32,800 & 76,600 & \\
\hline 0.0048 & 0.096 & $\mathbf{B}$ & - & {$[54]$} & [53] & - & - & \\
\hline 0.0300 & 0.300 & $\mathrm{Bi}$ & - & 20,700 & 20,600 & 27,900 & 75,900 & \\
\hline 0.0034 & 0.034 & Cd & - & 30.3 & 29.7 & 42.7 & 121 & \\
\hline 0.0017 & 0.017 & $\mathrm{Cr}$ & -- & 4,080 & 4,040 & 5,120 & 12,700 & \\
\hline 0.0024 & 0.048 & $\mathrm{Fe}$ & [24] & 25,400 & 25,100 & 35,300 & 99,700 & \\
\hline 0.0720 & 0.720 & $\mathbf{K}$ & [25] & 934 & 970 & [400] & {$[140]$} & \\
\hline 0.0002 & 0.005 & Mn & {$[0.93]$} & 362 & 358 & 535 & 1,520 & \\
\hline 0.0160 & 0.320 & $\mathrm{Na}$ & [50] & 268,000 & 266,000 & 327,000 & 153,000 & \\
\hline 0.0024 & 0.024 & $\mathrm{Ni}$ & - & 1,460 & 1,450 & 2,060 & 5,690 & \\
\hline 0.0500 & 0.500 & $\mathbf{P}$ & [62] & 40,300 & 40,200 & 45,700 & 21,600 & \\
\hline 0.0720 & 2.160 & $s$ & {$[100]$} & 8,450 & 8,440 & 4,250 & {$[1,300]$} & \\
\hline 0.0056 & 0.056 & SI & na & na & na & na & na & \\
\hline 0.0001 & 0.002 & $\mathrm{Sr}$ & {$[0.58]$} & 1,410 & 1,390 & 1,980 & over-range & 5,780 \\
\hline 0.0320 & 0.320 & $\mathbf{U}$ & $\cdots$ & 6,360 & 6,290 & 8,960 & 25,600 & \\
\hline 0.0028 & 0.056 & $\mathrm{Zn}$ & 54.9 & 207 & 201 & 208 & 468 & \\
\hline 0.0011 & 0.011 & $\mathbf{z r}$ & {$[2.0]$} & 106 & 106 & 147 & 408 & \\
\hline \multicolumn{9}{|c|}{ Other Analytes } \\
\hline 0.0021 & 0.021 & Ag & - & {$[4.4]$} & [5.0] & {$[7.7]$} & 19.2 & \\
\hline 0.0430 & 0.430 & As & - & - & - & - & - & \\
\hline 0.0003 & 0.005 & $\mathrm{Ba}$ & 8.19 & 109 & 90.0 & 132 & 340 & \\
\hline 0.0001 & 0.001 & $\mathrm{Be}$ & {$[0.051]$} & 0.431 & 0.397 & {$[0.25]$} & 0.858 & \\
\hline 0.0061 & 0.061 & $\mathrm{Ca}$ & 110 & 3,190 & 3,130 & 4,450 & 12,600 & \\
\hline 0.0100 & 0.100 & $\mathrm{Ce}$ & - & 84.1 & 83.3 & 119 & 335 & \\
\hline 0.0024 & 0.024 & Co & - & [15] & [12] & 19.6 & 53.7 & \\
\hline 0.0014 & 0.014 & $\mathrm{Cu}$ & [3.2] & 39.7 & 39.6 & 43.2 & 101 & \\
\hline 0.0029 & 0.029 & Dy & $\cdot-$ & - & - & - & - & \\
\hline 0.0011 & 0.011 & Eu & - & - & - & - & {$[1.0]$} & \\
\hline 0.0028 & 0.028 & La & [2.2] & [15] & [16] & {$[20]$} & 54.0 & \\
\hline 0.0006 & 0.012 & Li & 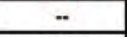 & 27.2 & 26.2 & 34.1 & 84.0 & \\
\hline 0.0023 & 0.023 & $\mathrm{Mg}$ & 22.1 & 546 & 544 & 758 & 2,110 & \\
\hline 0.0052 & 0.052 & Mo & 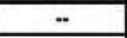 & [18] & [24] & [16] & [36] & \\
\hline 0.0054 & 0.054 & Nd & $*$ & {$[17]$} & [17] & [27] & 72.0 & \\
\hline 0.0320 & 0.320 & $\mathrm{~Pb}$ & - & 578 & 533 & 645 & 1,890 & \\
\hline 0.0063 & 0.063 & Pd & - & 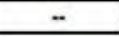 & - & -- & 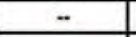 & \\
\hline 0.0120 & 0.120 & $\mathbf{R h}$ & - & - & - & - & - & \\
\hline 0.0085 & 0.085 & $\mathbf{R u}$ & - & [7.5] & [6.1] & - & [12] & \\
\hline 0.0200 & 0.200 & Sb & - & - & [33] & - & - & \\
\hline 0.0700 & 0.700 & $\mathrm{Se}$ & - & - & - & - & - & \\
\hline 0.0270 & 0.270 & Sn & $=$ & {$[47]$} & [21] & $=$ & - & \\
\hline 0.0170 & 0.170 & $\mathrm{Ta}$ & - & - & - & - & - & \\
\hline 0.0260 & 0.260 & $\mathrm{Te}$ & - & - & - & - & - & \\
\hline 0.0098 & 0.098 & Th & - & - & [9.5] & [12] & [42] & \\
\hline 0.0004 & 0.004 & $\mathrm{Ti}$ & {$[0.74]$} & 63.6 & 63.4 & 84.2 & 239 & \\
\hline 0.0380 & 0.380 & $\mathrm{TI}$ & [51] & [55] & [82] & [110] & - & \\
\hline 0.0007 & 0.007 & $\mathrm{~V}$ & [1.1] & 16.9 & 17.0 & 18.2 & 40.6 & \\
\hline 0.0190 & 0.190 & $w$ & 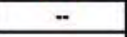 & {$[27]$} & [31] & - & - & \\
\hline 0.0004 & 0.004 & $Y$ & $=$ & [2.6] & {$[2.6]$} & 3.60 & 10.5 & \\
\hline
\end{tabular}

1) "-" indicates the value is $\angle M D L$. The method detection limit $(M D L)=I D L$ times the "multiplier"

near the top of each column. The estimated sample quantitation limit $=E Q L$ (in Column 2)

times the "multiplier". Overall error for values $\geq E Q L$ is estimated to be within $\pm 15 \%$.

2) Values in brackets [] are $\geq M D L$ but < EQL, with errors likely to exceed $15 \%$.

na indicates that the analyte is not recovered for the preparation procedure. 
WTP-RPT-166, Rev. 0

Battelle PNNL/RPG/Inorganic Analysis:

Page 2 of 3

\section{ICP-OES Data Report for HF-Assisted Acid Digestions}

\begin{tabular}{|c|c|c|c|c|c|}
\hline $4 / 24 / 2008$ & $4 / 24 / 2008$ & $4 / 24 / 2008$ & $4 / 24 / 2008$ & $4 / 24 / 2008$ & $4 / 24 / 2008$ \\
\hline 1014.2 & 988.1 & 4940.7 & 763.9 & 620.7 & 3103.7 \\
\hline $\begin{array}{c}08-01320- \\
138-\mathrm{s}\end{array}$ & $\begin{array}{c}08-01321- \\
\text { 138-s }\end{array}$ & $\begin{array}{l}08-01321 . \\
138-s @ 5\end{array}$ & $\begin{array}{c}08-01322-138- \\
\mathrm{s}\end{array}$ & $\begin{array}{c}08-01323-138- \\
\mathrm{s}\end{array}$ & $\begin{array}{c}08-01323-138 \\
\text { s @5 }\end{array}$ \\
\hline TI572-G2-15 & m572-G2-18 & -1572-G2-18 & 7552-G6-8-b & TIS52-G6-13-b & TIS52-G6-13-b \\
\hline$(\mu \mathrm{g} / \mathrm{g})$ & $(\mu \mathrm{g} / \mathrm{g})$ & \begin{tabular}{|c|}
$(\mu \mathrm{g} / \mathrm{g})$ \\
\end{tabular} & \begin{tabular}{|l|}
$(\mu g / g)$ \\
\end{tabular} & $(\mu g / g)$ & $(\mu g / g)$ \\
\hline 61,800 & 80,800 & & 357,000 & over-range & 368,000 \\
\hline- & -- & & 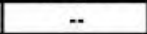 & .. & \\
\hline 62,000 & 84,600 & & 308 & 334 & \\
\hline 99.2 & 132 & & 56.0 & 67.8 & \\
\hline 12,700 & 8,020 & & 31,200 & 33,500 & \\
\hline 77,300 & 107,000 & & 10,800 & 14,300 & \\
\hline [330] & {$[170]$} & & {$[99]$} &.- & \\
\hline 12,400 & 11,200 & & 6,360 & 7,870 & \\
\hline 201,000 & 125,000 & & 21,200 & 17,400 & \\
\hline 4,650 & 6,420 & & 735 & 1,050 & \\
\hline 32,800 & 14,700 & & 1,300 & 403 & \\
\hline$[1,600]$ & {$[1,300]$} & & -. & {$[210]$} & \\
\hline na & na & & na & na & \\
\hline 4,630 & over-range & 6,250 & 1,200 & 1,790 & \\
\hline 21,300 & 28,600 & & 24,000 & 35,400 & \\
\hline 396 & 520 & & 146 & 125 & \\
\hline 339 & 464 & & 340 & 430 & \\
\hline
\end{tabular}

\begin{tabular}{|c|c|c|c|}
\hline [17] & [19] & [14] & 17.2 \\
\hline- & - & .. & 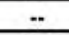 \\
\hline 302 & 378 & 146 & 207 \\
\hline 0.655 & 0.660 & 0.964 & 0.392 \\
\hline 10,300 & 14,000 & 3,100 & 4,170 \\
\hline 274 & 365 & 146 & 204 \\
\hline 41.5 & 57.8 & {$[8.3]$} & 15.0 \\
\hline 82.3 & 114 & 69.3 & 49.5 \\
\hline- & - & 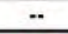 & {$[1.9]$} \\
\hline- & - & {$[3.8]$} & {$[5.4]$} \\
\hline 41.9 & 57.4 & 124 & 158 \\
\hline 70.0 & 88.4 & 78.2 & 42.9 \\
\hline 1,710 & 2,350 & 501 & 709 \\
\hline [16] & {$[28]$} & [12] & [11] \\
\hline 57.9 & 79.7 & 271 & 370 \\
\hline 1,510 & 2,020 & 1,100 & 898 \\
\hline- & 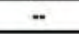 & .. & .. \\
\hline- & - &.- &.- \\
\hline [18] & [8.6] & 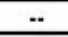 & {$[7.3]$} \\
\hline- & - & $*$ & 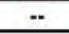 \\
\hline- & - & .. & 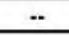 \\
\hline- & 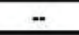 & 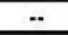 & 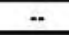 \\
\hline- & - & .. & .. \\
\hline- & 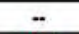 & 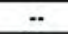 & - \\
\hline [26] & {$[22]$} & 133 & 149 \\
\hline 178 & 260 & 51.4 & 67.3 \\
\hline [69] & [110] & [37] & -. \\
\hline 28.6 & 41.4 & 8.57 & 6.15 \\
\hline- & - & [55] & [15] \\
\hline 8.31 & 11.3 & 37.5 & 52.0 \\
\hline
\end{tabular}

Group1-2_Slurry_ICP.xIs

Worksheet: ASR 8113138 Final 
WTP-RPT-166, Rev. 0

Battelle PNNL/RPG/Inorganic Analysis:

Page 3 of 3 ICP-OES Data Report for HF-Assisted Acid Digestions

\begin{tabular}{|c|c|c|c|c|c|c|}
\hline Criteria > & $\leq 25 \%$ & $80 \%-120 \%$ & $70 \%-130 \%$ & $70 \%-130 \%$ & $70 \%-130 \%$ & $\leq 10 \%$ \\
\hline$Q C I D>$ & $\begin{array}{c}\text { 08-01317 } \\
\text { Dup }\end{array}$ & LCSIBS & MS (none) & $\begin{array}{c}08-01317+ \\
\text { AS-A }\end{array}$ & $\begin{array}{c}08-01317+ \\
\text { AS-B }\end{array}$ & $\begin{array}{c}08-01317 \\
5 \text {-fold } \\
\text { Serial Dil }\end{array}$ \\
\hline Analytes & RPD (\%) & $\%$ Rec & $\%$ Rec & $\%$ Rec & $\%$ Rec & $\%$ Diff \\
\hline Al & 0.9 & 102 & & 100 & & 0.5 \\
\hline B & & & & 102 & & \\
\hline $\mathrm{Bi}$ & 0.1 & & & 96 & & 1.7 \\
\hline $\mathrm{Cd}$ & 2.0 & 94 & & 99 & & \\
\hline $\mathrm{Cr}$ & 1.1 & & & 99 & & 3.0 \\
\hline $\mathrm{Fe}$ & 1.2 & 101 & & 99 & & 1.7 \\
\hline$K$ & 3.9 & & & 101 & & \\
\hline $\mathrm{Mn}$ & 1.2 & 102 & & 99 & & 3.1 \\
\hline $\mathrm{Na}$ & 0.8 & 100 & & 97 & & 0.2 \\
\hline $\mathrm{Ni}$ & 0.6 & $\mathrm{nr}$ & & 100 & & 2.6 \\
\hline $\mathbf{P}$ & 0.1 & 91 & & $\mathrm{nr}$ & & 1.1 \\
\hline $\mathbf{s}$ & 0.1 & 104 & & & 96 & 5.6 \\
\hline $\mathrm{si}$ & na & na & na & na & na & na \\
\hline $\mathrm{Sr}$ & 1.0 & & & 100 & & 1.0 \\
\hline $\mathbf{U}$ & 1.2 & & & & 99 & 0.2 \\
\hline $\mathrm{Zn}$ & 3.0 & 102 & & 104 & & 4.0 \\
\hline $\mathrm{zr}$ & 0.0 & & & 100 & & 2.2 \\
\hline \multicolumn{7}{|c|}{ Other Analytes } \\
\hline $\mathrm{Ag}$ & & 103 & & 96 & & \\
\hline As & & 99 & & 101 & & \\
\hline $\mathrm{Ba}$ & 19.1 & 101 & & 100 & & 1.0 \\
\hline $\mathrm{Be}$ & 8.3 & & & 99 & & \\
\hline $\mathrm{Ca}$ & 1.8 & 103 & & 102 & & 3.8 \\
\hline $\mathrm{Ce}$ & 0.9 & & & & 97 & \\
\hline $\mathrm{Co}$ & & & & 102 & & \\
\hline $\mathrm{Cu}$ & 0.3 & 99 & & 100 & & \\
\hline Dy & & & & & 99 & \\
\hline Eu & & & & & 97 & \\
\hline La & & & & & 99 & \\
\hline Li & 3.8 & & & 101 & & \\
\hline $\mathrm{Mg}$ & 0.5 & 97 & & 101 & & 0.4 \\
\hline Mo & & & & 103 & & \\
\hline Nd & & & & & 99 & \\
\hline $\mathrm{Pb}$ & 8.2 & 103 & & 103 & & \\
\hline Pd & & & & & 94 & \\
\hline Rh & & & & & 97 & \\
\hline Ru & & & & & 96 & \\
\hline $\mathrm{Sb}$ & & & & 100 & & \\
\hline $\mathrm{Se}$ & & & & 100 & & \\
\hline $\mathrm{Sn}$ & & & & 98 & & \\
\hline $\mathrm{Ta}$ & & & & 103 & & \\
\hline $\mathrm{Te}$ & & & & & 97 & \\
\hline Th & & & & & 97 & \\
\hline $\mathrm{Ti}$ & 0.2 & 97 & & 99 & & 4.7 \\
\hline $\mathrm{TI}$ & & & & 96 & & \\
\hline $\mathrm{v}$ & 1.0 & 96 & & 97 & & \\
\hline $\bar{w}$ & & & & 100 & & \\
\hline $\mathrm{Y}$ & & & & 98 & & \\
\hline
\end{tabular}

Group1-2_Slurry_ICP.xIs

Worksheet: ASR 8113138 Final 


\section{Direct Liquid Sample Results ASR 8113}

\begin{tabular}{|c|c|c|c|c|c|c|c|c|c|c|}
\hline RPL Number & $\begin{array}{l}\text { Client } \\
\text { Sample ID } \\
\end{array}$ & $\begin{array}{c}\mathrm{F} \\
\mathrm{MDL} \\
\mu \mathrm{g} / \mathrm{mL} \\
\end{array}$ & $\begin{array}{c}\text { F } \\
\text { Result } \\
\mu \mathrm{g} / \mathrm{mL} \\
\end{array}$ & DF & $\begin{array}{c}\mathrm{NO}_{2} \\
\mathrm{MDL} \\
\mu \mathrm{g} / \mathrm{mL}\end{array}$ & $\begin{array}{c}\mathrm{NO}_{2} \\
\text { Result } \\
\mu \mathrm{g} / \mathrm{mL} \\
\end{array}$ & DF & $\begin{array}{c}\mathrm{SO}_{4} \\
\mathrm{MDL} \\
\mu \mathrm{g} / \mathrm{mL} \\
\end{array}$ & $\begin{array}{c}\mathrm{SO}_{4} \\
\text { Result } \\
\mu \mathrm{gg} / \mathrm{mL} \\
\end{array}$ & DF \\
\hline $08-01290$ & TI572-G2-A & 82 & 3,970 & & 130 & 7,800 & & 200 & 14,700 & \\
\hline $08-01291$ & TI572-G2-D & 16 & 1,520 & & 26 & 3,130 & & 40 & 5,090 & \\
\hline 08-01292 & TI572-G2-I & 16 & 860 & & 5.3 & 57.5 & & 7.9 & 156 & \\
\hline $08-01293$ & TI572-G2-J & 16 & 2,330 & & 5.3 & 493 & & 7.9 & 1,280 & \\
\hline $08-01294$ & TI572-G2-O & 3.3 & 224 & & 1.1 & 25.2 & & 1.6 & 83.1 & \\
\hline 08-01295 & TI572-G2-P & 3.3 & 378 & & 1.1 & 42.9 & & 1.6 & 111 & \\
\hline $08-01296$ & TI552-G6-Q & 0.66 & 1.50 & $\mathrm{~J}$ & 5.3 & 1,070 & & 1.6 & 37.8 & \\
\hline Dilution Blank & DB 5/12/08 & 0.031 & 0.031 & $\mathrm{U}$ & 0.050 & 0.050 & $\mathrm{U}$ & 0.076 & 0.076 & $\mathrm{U}$ \\
\hline RPL Number & $\begin{array}{l}\text { Client } \\
\text { Sample ID }\end{array}$ & $\begin{array}{c}\mathrm{C}_{2} \mathrm{O}_{2} \\
\mathrm{MDL} \\
\mu \mathrm{g} / \mathrm{mL}\end{array}$ & $\begin{array}{c}\mathrm{C}_{2} \mathrm{O}_{2} \\
\text { Result } \\
\mu \mathrm{g} / \mathrm{mL}\end{array}$ & DF & $\begin{array}{c}\mathrm{NO}_{3} \\
\mathrm{MDL} \\
\mu \mathrm{g} / \mathrm{mL}\end{array}$ & \begin{tabular}{|c|}
$\mathrm{NO}_{3}$ \\
Result \\
Mg/m L
\end{tabular} & DF & $\begin{array}{c}\mathrm{PO}_{4} \\
\mathrm{MDL} \\
\mu \mathrm{g} / \mathrm{mL}\end{array}$ & $\begin{array}{c}\mathrm{PO}_{4} \\
\text { Result } \\
\mu \mathrm{g} / \mathrm{mL}\end{array}$ & DF \\
\hline $08-01290$ & TI572-G2-A & 26 & 1,430 & & 1,300 & 191,000 & & 31 & 3,070 & \\
\hline $08-01291$ & TI572-G2-D & 26 & 432 & & 1,300 & 74,900 & & 31 & 982 & \\
\hline $08-01292$ & TI572-G2-I & 5.2 & 197 & & 11 & 1,490 & & 31 & 6,690 & \\
\hline 08-01293 & \begin{tabular}{|l} 
TI572-G2-J \\
\end{tabular} & 5.2 & 957 & & 53 & 12,100 & & 160 & 9,110 & \\
\hline $08-01294$ & TI572-G2-O & 1.0 & 73.7 & & 11 & 709 & & 6.3 & 1,510 & \\
\hline $08-01295$ & T1572-G2-P & 1.0 & 1.0 & $\mathrm{U}$ & 11 & 1,150 & & 31 & 2,570 & \\
\hline $08-01296$ & TI552-G6-Q & 1.0 & 98.4 & & 53 & 4,310 & & 1.3 & 85.4 & \\
\hline Dilution Blank & DB 5/12/08 & 0.050 & 0.050 & $\overline{\mathrm{U}}$ & 0.10 & 0.100 & $\mathrm{U}$ & 0.060 & 0.060 & $\mathrm{U}$ \\
\hline
\end{tabular}

\section{Direct Liquid Sample QC Results ASR 8113}

Sample/Replicate Precision Results ${ }^{(a)}$

\begin{tabular}{|c|c|c|c|c|c|c|c|c|c|c|c|c|c|}
\hline \multirow[b]{2}{*}{ RPL Number } & \multirow[b]{2}{*}{ Sample ID } & \multicolumn{2}{|l|}{ F } & \multicolumn{2}{|c|}{$\mathrm{NO}_{2}$} & \multicolumn{2}{|l|}{$\mathrm{SO}_{4}$} & \multicolumn{2}{|c|}{$\mathrm{C}_{2} \mathrm{O}_{4}$} & \multicolumn{2}{|l|}{$\mathrm{NO}_{3}$} & \multicolumn{2}{|l|}{$\mathrm{PO}_{4}$} \\
\hline & & $\mu \mathrm{g} / \mathrm{mL}$ & $\%$ RSD & $\mu \mathrm{g} / \mathrm{mL}$ & $\%$ RSD & $\mu \mathrm{g} / \mathrm{mL}$ & $\%$ RSD & $\mu \mathrm{g} / \mathrm{mL}$ & \%RSD & $\mu \mathrm{g} / \mathrm{mL}$ & $\%$ RSD & $\mu \mathrm{g} / \mathrm{mL}$ & $\%$ RSD \\
\hline \multirow[t]{2}{*}{ 08-01296 } & Sample & $\mathrm{J}$ & -- & 1070 & -- & 37.8 & -- & 98.4 & -- & 4310 & -- & 85.4 & -- \\
\hline & $\begin{array}{l}\text { Duplicate | RPD } \\
\end{array}$ & $\bar{J}$ & N/A & 1070 & 0 & 37.9 & 0 & 95.9 & 3 & 4320 & 0 & 84.5 & 1 \\
\hline
\end{tabular}

Sample Spike Results - At IC Workstation

\begin{tabular}{|c|c|c|c|c|c|c|c|c|c|c|c|c|c|}
\hline \multirow[b]{2}{*}{ RPL Number } & \multirow[b]{2}{*}{ Sample ID } & \multicolumn{2}{|l|}{ F } & \multicolumn{2}{|l|}{$\mathrm{NO}_{2}$} & \multicolumn{2}{|l|}{$\mathrm{SO}_{4}$} & \multicolumn{2}{|c|}{$\mathrm{C}_{2} \mathrm{O}_{4}$} & \multicolumn{2}{|l|}{$\mathrm{NO}_{3}$} & \multicolumn{2}{|l|}{$\mathrm{PO}_{4}$} \\
\hline & & $\mu \mathrm{g} / \mathrm{mL}$ & $\%$ Rec & $\mu \mathrm{g} / \mathrm{mL}$ & $\% \operatorname{Rec}$ & $\mu \mathrm{g} / \mathrm{mL}$ & $\% \operatorname{Rec}$ & $\mu \mathrm{g} / \mathrm{mL}$ & $\%$ Rec & $\mu \mathrm{g} / \mathrm{mL}$ & $\% \operatorname{Rec}$ & $\mu \mathrm{g} / \mathrm{mL}$ & $\% \operatorname{Rec}$ \\
\hline \multirow[t]{2}{*}{$08-01290$} & Sample & 3970 & -- & 7800 & -- & 14700 & -- & 1430 & -- & 191000 & -- & 3070 & -- \\
\hline & AS Sample & 1.75 & 99 & 3.97 & 100 & 6.57 & 100 & U & N/A & 40.9 & 103 & 6 & 99 \\
\hline
\end{tabular}

LCS Results - IC System

\begin{tabular}{|l|c|c|c|c|c|c|c|}
\hline RPL Number & Run ID & $\begin{array}{c}\mathrm{F} \\
\% \text { Rec }\end{array}$ & $\begin{array}{c}\mathrm{NO}_{2} \\
\% \text { Rec }\end{array}$ & $\begin{array}{c}\mathrm{SO}_{4} \\
\% \text { Rec }\end{array}$ & $\begin{array}{c}\mathrm{C}_{2} \mathbf{O}_{2} \\
\% \text { Rec }\end{array}$ & $\begin{array}{c}\mathrm{NO}_{3} \\
\% \text { Rec }\end{array}$ & $\begin{array}{c}\mathbf{P O}_{4} \\
\% \text { Rec }\end{array}$ \\
\hline LCS & $5 / 13 / 200810: 15$ & 101 & 101 & 101 & 105 & 103 & 102 \\
\hline
\end{tabular}

AS = Analytical Spike: Spike performed at IC Workstation on liquid Sample.

LCS - Laboratory Control Sample (Standard analyzed at IC Workstation)

RPD $=$ Relative Percent Difference

$\%$ Rec $=$ Percent Recovery

$\mathrm{U}=$ Not Detected Above Method Detection Limit

$\mathrm{I}=$ Detected, Result are Qualitative: Result $>\mathrm{MDL}$ but $<\mathrm{EQL}$ (estimated quantitation limit)

-- - Value Not Calculated, place holder for blank cell

$\mathrm{a}=\% \mathrm{RPD}$ is not calculated for results which are below the EQL 


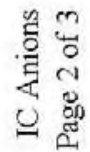

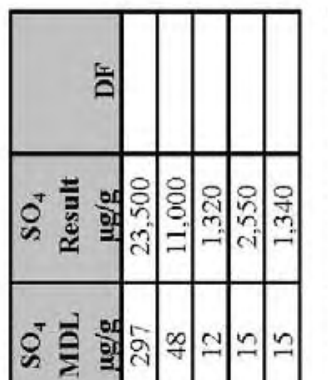

뜸

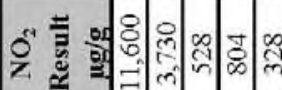

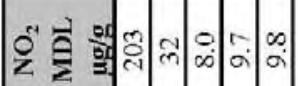

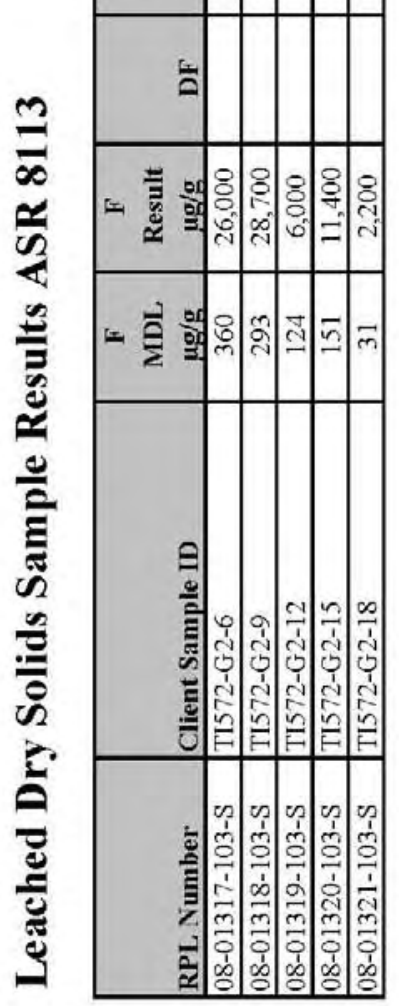

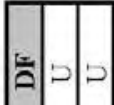

光

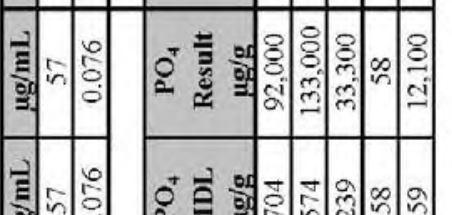

힙 in

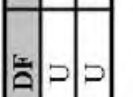

\begin{tabular}{|l|l|}
\hline & $P$ \\
\hline
\end{tabular}

혁융ㅇㅇ

혁 $\infty$

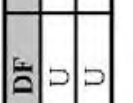

त्रात क्ष

혁

형 ले के

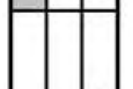

啚

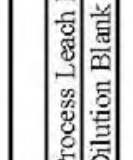

茝兽

농

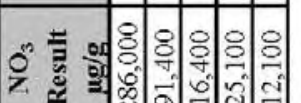

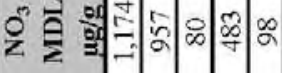

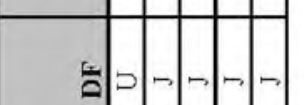

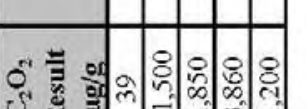

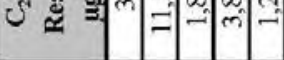

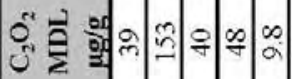

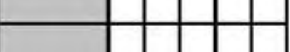

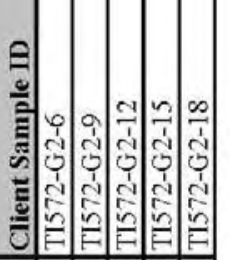

-

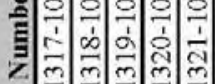

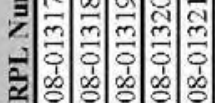

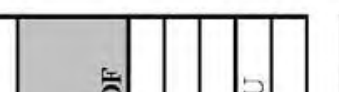

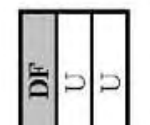

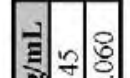

히의

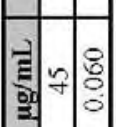

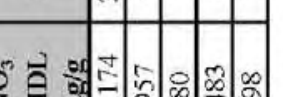

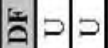

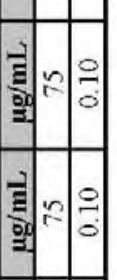

$\circ \Rightarrow$

항

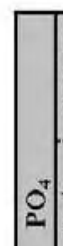

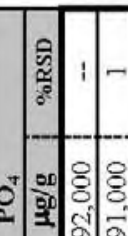

잉

10

.

의 $\frac{\sin }{30} 8$

1

象 1,5

की

ڤ्ञे।
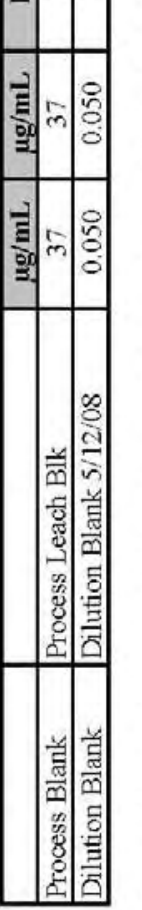

윰에을

चे ले ले

क्ष्: 10

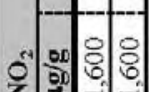

क्रे

: $:-$

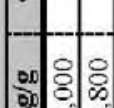

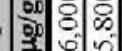

$\simeq$

$\frac{0}{2}$

छ

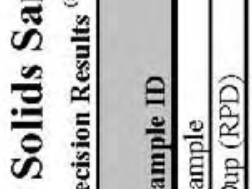

-. 究

คे

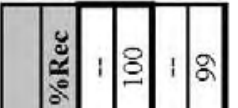

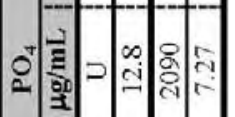

$1,1,8$

ㅇํㅇ 110

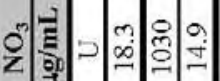

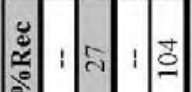

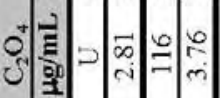

$\div 1: 12$

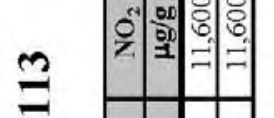

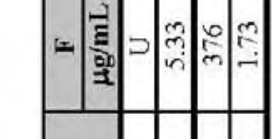

ही हो

: $: 1: \div$

잉

$121: 8$

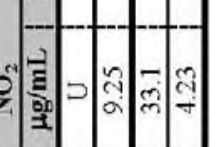

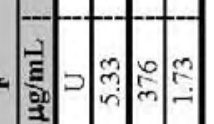

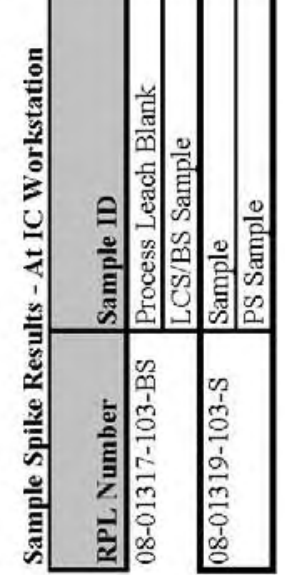

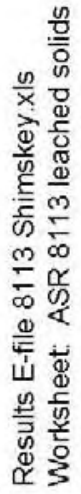


WTP-RPT-166, Rev. 0

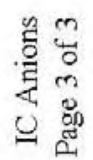
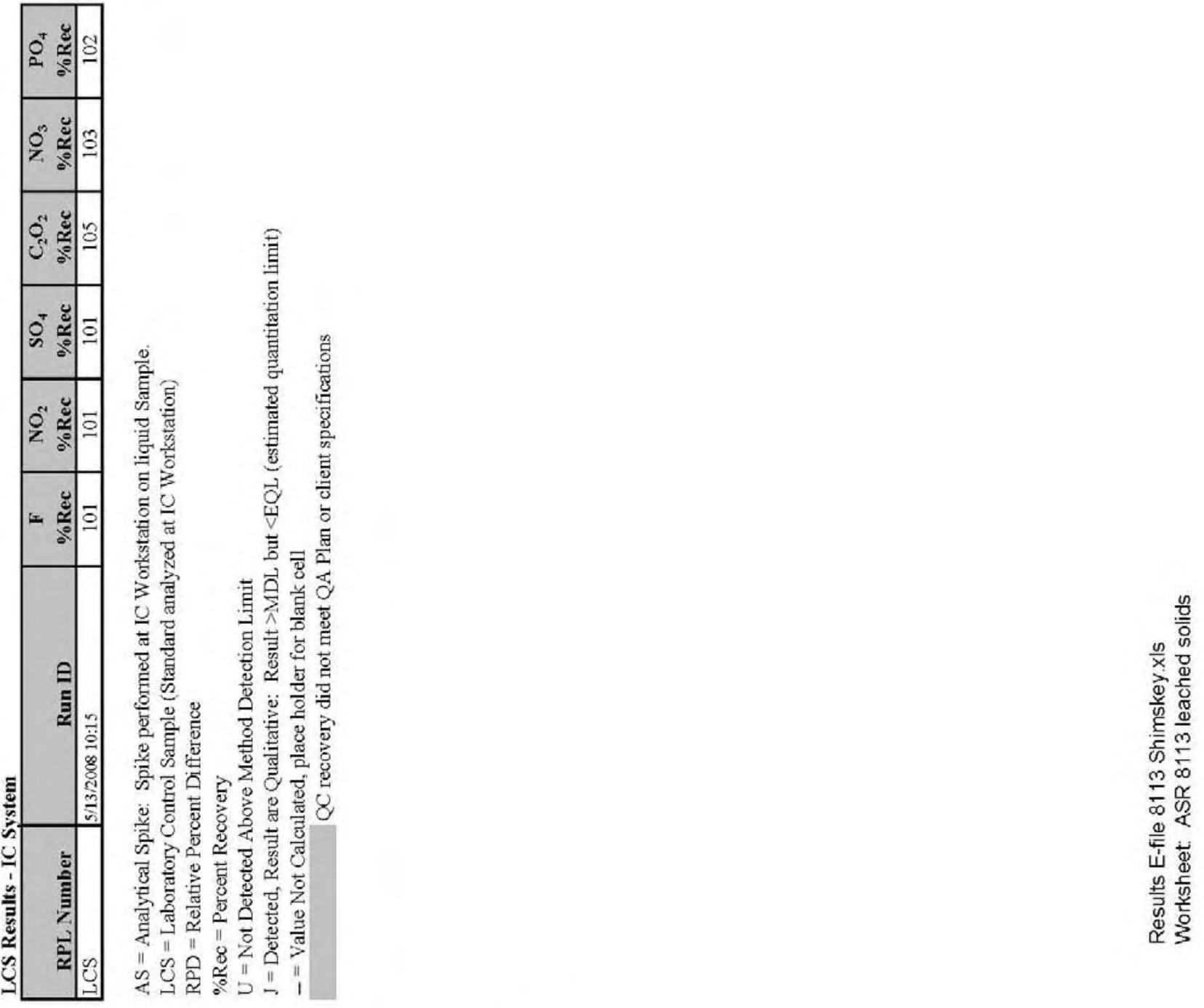
WTP-RPT-166, Rev. 0

\section{วิศ \\ ... Putting Technology To Work}

Client: Rick Shimskey

Report Date: $5 / 5 / 2008$

Analysis Date: $5 / 2 / 2008$

Subject: Hydroxide Analyses for:

CUF Group 1/2 Bi-Phosphate Sludge and

Group 5/6 Redox Sludge/Saltcake Treatability

$\begin{array}{llll}\text { ASR: } & 8113 & \text { Rev-0 } & \\ \text { Sample ID. } \quad 08-01290 & \text { thru } & 08-01296 \\ & \text { and } 08-01304 & \text { thru } & 08-01314\end{array}$

Procedure: RPG-CMC-228-Rev 1

and 08-01304 thru 08-01314

Direct sample aliquots of CUF Group 1/2 Bi-Phosphate Sludge/Saltcake, and CUF Group 5/6 REDOX Sludge Treatability samples (see above assigned RPL Sample \#'s), 18 samples total were analyzed in duplicate for the base constituents content following procedure RPG-CMC-228, and using a Brinkman 636 Auto-Titrator. The titrant used was $0.1016 \mathrm{M} \mathrm{HCl}$ and the base standard, $0.1118 \mathrm{M} \mathrm{NaOH}$ was used for QC verification standards and matrix spike. - See Chemrec_139 pdf imbedded in the result report.

The hydroxide Standard recovery was $100 \%$, well within the allowed $\pm 20 \%$ recovery range. Although not required in this ASR, three matrix spikes were analyzed with recoveries of $96 \%, 99 \%$, and $97 \%$. No hydroxide was detected in the reagent blank.

The initial $\mathrm{pH}$ is reported on attached Report Summary along with the free hydroxide molarities (generally the 1 st inflection point whenever the initial $\mathrm{pH}$ is 12 or more). In such cases, generally the 2nd inflection point around $\mathrm{pH} 7-8$, indicates the total hydroxide molarity. Generally, the analysis used very small volumes $(0.05 \mathrm{ml})$ due to high caustic, yet surprisingly these results showed excellent Relative Percent Deviation (RPD) for the first inflection point, well within $\pm 20 \%$ allowed range. Many of the samples also indicated a third inflection point around $\mathrm{pH} 4-5$, and most RPD's for 2 nd and third points were within $\pm 20 \%$ allowed range even though this is not a requirement. Again this data is very acceptable considering the small sample size, undissolved species in some samples, and the fact that other base constituent molarities were very miminal compared to the hydroxide.

The best estimate of the MDL for this method is obtained from the reagent blank which did not show any inflection points and is consistent with a value of 0 within our measurement sensitivity. All samples molarities were well above the MDL $(0.1 \mathrm{M})$ for this analysis. The results are accepted based on the $\mathrm{QC}$ data meeting the acceptance criteria as specified in the ASR.

Following is the report summary, the sample results calculated from the raw data, and the record file for the standardized acid and base used. The entire sample fractions supplied for hydroxide analysis were consumed in the analysis.

Copies of the titration curves are available upon request.

OH ASR81 13-rs-rev-0.xls

Worksheet: Narrative

Page 1 of 10 
Battelle Pacific Northwest Laboratory

Radiochemical Processing Group-325 Building

Chemical Measurements Center

Hydroxide and Alkalinity Determination

Procedure: RPG-CMC-228-Rev 1

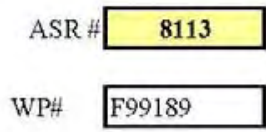

Equip \# WB76843

$$
\begin{array}{rl|l|}
\text { Report Summary for ASR \#- } & \mathbf{8 1 1 3} \\
\text { Revision } & \text { Rev-0 } & \begin{array}{r}
\text { Report Date: } \\
\text { Analysis Date: }
\end{array} 5 / 2008 \\
\hline 5 / 2 / 2008 \\
\hline
\end{array}
$$

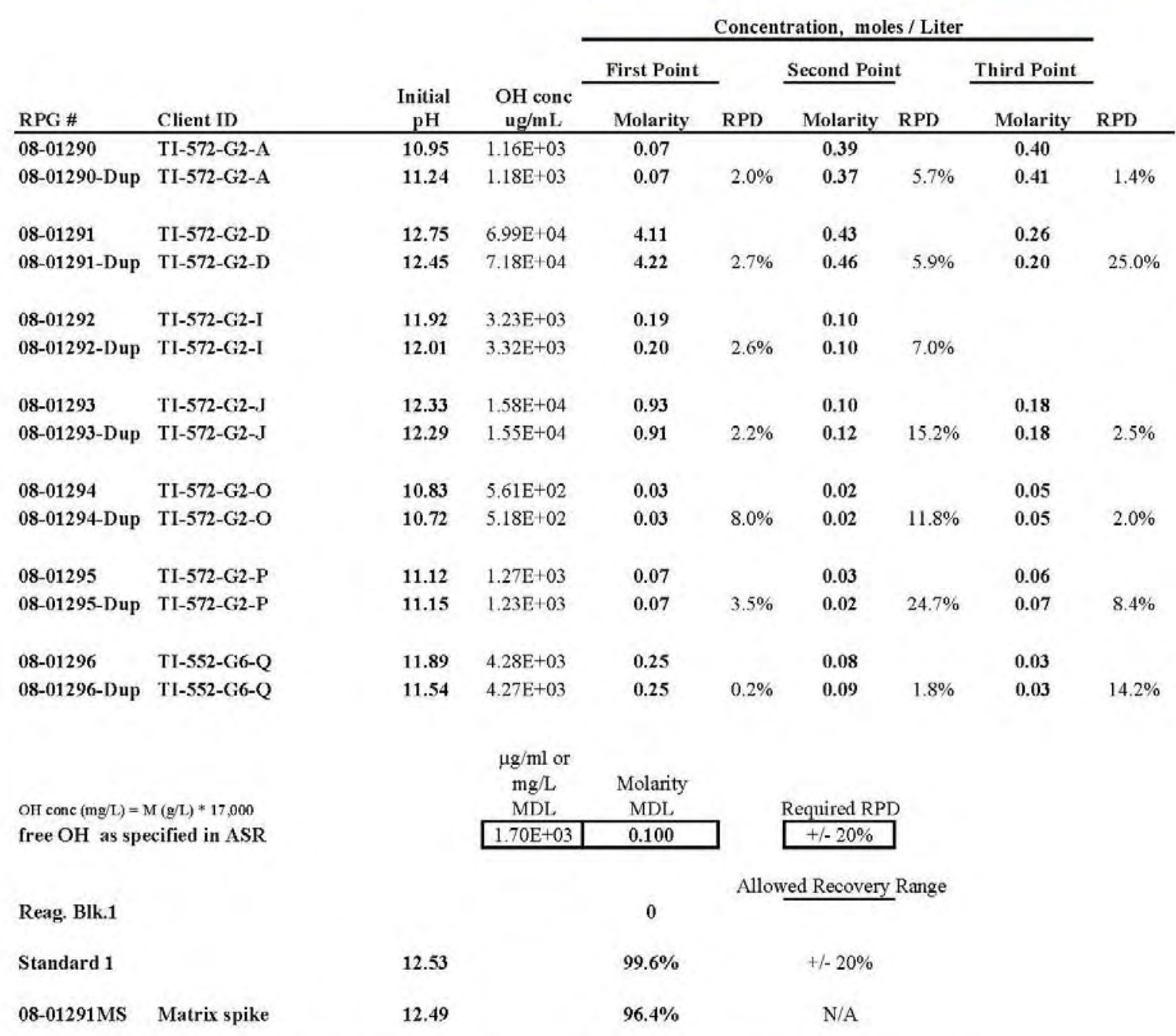

Note: Results are presented for the first, second, and third inflection points on the titration curves, as applicable. The first inflection point is generally associated with the free hydroxide concentration. The second inflection point generally represents total hydroxide, or carbonate or a combination of aluminate and carbonate. The third inflection point is usually indicative of bicarbonate or other weak acids or possibly the continued protonation of alumina. 
Battelle Pacific Northwest Laboratory

Radiochemical Processing Group-325 Building

Chemical Measurements Center

Hydroxide and Alkalinity Determination

Procedure: RPG-CMC-228-Rev 1

\section{ASR \# 8113}

WP\# F99189

Equip \# WB76843

\section{Report Sum mary for ASR \# -- 8113}

Revision \# $\operatorname{Rev}-0$

\begin{tabular}{r|r|}
$r$ Report Date: & $5 / 5 / 2008$ \\
Analysis Date: & $5 / 2 / 2008$ \\
\hline
\end{tabular}

\begin{tabular}{|c|c|c|c|c|c|c|c|c|c|}
\hline \multirow[b]{2}{*}{ RPG \# } & \multirow[b]{2}{*}{ Client ID } & \multirow[b]{2}{*}{$\begin{array}{c}\text { Initial } \\
\mathrm{pH}\end{array}$} & \multirow[b]{2}{*}{$\begin{array}{c}\text { OH conc } \\
\mathbf{u g} / \mathrm{mL}\end{array}$} & \multirow{2}{*}{$\begin{array}{l}\text { First Point } \\
\text { Molarity }\end{array}$} & \multirow[b]{2}{*}{ RPD } & \multicolumn{2}{|c|}{ Second Point } & \multirow{2}{*}{$\begin{array}{r}\text { Third Point } \\
\text { Molarity }\end{array}$} & \multirow[b]{2}{*}{ RPD } \\
\hline & & & & & & Molarity & RPD & & \\
\hline 08-01304 & TI-572-G2-C1 & 12.60 & $1.14 \mathrm{E}+05$ & 6.73 & & 0.50 & & - & \\
\hline 08-01304-Dup & $\mathrm{TI}-572-\mathrm{G} 2-\mathrm{Cl}$ & 12.55 & 1.17E+05 & 6.88 & $2.1 \%$ & 0.48 & $4.6 \%$ & 0.73 & $\cdots$ \\
\hline 08-01305 & $\mathrm{TI}-572-\mathrm{G} 2-\mathrm{C} 2$ & 12.71 & $8.20 \mathrm{E}+04$ & 4.83 & & 0.36 & & 0.26 & \\
\hline 08-01305-Dup & $\mathrm{TI}-572-\mathrm{G} 2-\mathrm{C} 2$ & 12.56 & $8.18 \mathrm{E}+04$ & 4.81 & $0.3 \%$ & 0.39 & $7.0 \%$ & 0.24 & $4.9 \%$ \\
\hline $08-01306$ & TI-572-G2-C3 & 12.61 & $1.26 \mathrm{E}+05$ & 7.40 & & 0.63 & & 0.24 & \\
\hline 08-01306-Dup & $\mathrm{TI}-572-\mathrm{G} 2-\mathrm{C} 3$ & 12.60 & $1.19 \mathrm{E}+05$ & 6.98 & $5.9 \%$ & 0.68 & $8.0 \%$ & 0.30 & $23.6 \%$ \\
\hline 08.01307 & TI $572 \mathrm{G} 2 \mathrm{C} 4$ & 12.50 & $8.07 \mathrm{E}+04$ & 4.75 & & 0.55 & & 0.25 & \\
\hline 08-01307-Dup & $\mathrm{TI}-572-\mathrm{G} 2-\mathrm{C} 4$ & 12.52 & $7.99 \mathrm{E}+04$ & 4.70 & $1.1 \%$ & 0.62 & $12.1 \%$ & 0.32 & $25.9 \%$ \\
\hline 0801308 & TI-572-G2-C5 & 12.50 & $7.88 \mathrm{E}+04$ & 4.63 & & 0.48 & & 0.18 & \\
\hline 08-01308-Dup & TI-572-G2-C5 & 12.33 & $7.16 \mathrm{E}+04$ & 4.21 & $9.5 \%$ & 0.44 & $7.9 \%$ & 0.16 & $10.8 \%$ \\
\hline 0801309 & TI-572-G2-E & 12.08 & $3.78 \mathrm{E}+04$ & 2.22 & & 0.23 & & 0.18 & \\
\hline 08-01309-Dup & TI-572-G2-E & 12.28 & $3.72 \mathrm{E}+04$ & 2.19 & $1.5 \%$ & 0.26 & $12.2 \%$ & 0.30 & $49.0 \%$ \\
\hline $08-01310$ & TI-572-G2-F & 12.29 & $2.20 \mathrm{E}+04$ & 1.29 & & 0.15 & & 0.24 & \\
\hline 08-01310-Dup & TI-572-G2-F & 12.25 & $2.20 \mathrm{E}+04$ & 1.29 & $0.1 \%$ & 0.16 & $5.8 \%$ & 0.25 & $4.1 \%$ \\
\hline
\end{tabular}

OH conc $(\mathrm{mg} / \mathrm{L})=\mathrm{M}(\mathrm{g} / \mathrm{L}) \cdot 17,000$

free $\mathrm{OH}$ as specifled in ASR

\begin{tabular}{|c|c|c|}
\hline $\begin{array}{c}\mu \mathrm{g} / \mathrm{ml} \text { or } \\
\mathrm{mg} / \mathrm{L}\end{array}$ & Molarity & \\
\hline MDL & MDL & Required RPD \\
\hline $1.70 \mathrm{E}+03$ & 0.100 & \begin{tabular}{|l|}
$+/-20 \%$ \\
\end{tabular} \\
\hline
\end{tabular}

Reag. Blk.1

Allowed Recovery Range

Standard 1

12.53

$99.6 \%$

$98.8 \%$
$+/-20 \%$

N/A

Note: Results are presented for the first, second, and third inflection points on the titration curves, as applicable. The first inflection point is generally associated with the free hydroxide concentration. The second inflection point generally represents total hydroxide, or carbonate or a combination of aluminate and carbonate. The third inflection point is usually indicative of bicarbonate or other weak acids or possibly the continued protonation of alumina. 
Battelle Pacific Northwest Laboratory

Radiochemical Processing Group-325 Building

Chemical Measurements Center

Hydroxide and Alkalinity Determination

Procedure: RPG-CMC-228-Rev 1

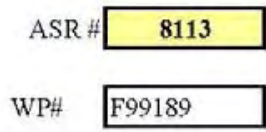

Equip \# WB76843

\section{Report Summary for ASR \# - 8113 \\ Revision Hev-0}

\begin{tabular}{r|r|} 
Report Date: & $5 / 5 / 2008$ \\
Analysis Date: & $5 / 2 / 2008$ \\
\hline
\end{tabular}

Concentration, moles/Liter

\begin{tabular}{|c|c|c|c|c|c|c|c|c|c|}
\hline \multirow[b]{3}{*}{ RPG \# } & \multirow[b]{3}{*}{ Client ID } & \multirow[b]{3}{*}{$\begin{array}{c}\text { Initial } \\
\mathrm{pH}\end{array}$} & \multirow[b]{3}{*}{$\begin{array}{c}\text { OH conc } \\
\mathrm{ug} / \mathrm{mL}\end{array}$} & \multicolumn{5}{|c|}{ Concentration, moles/Liter } & \multirow[b]{3}{*}{ RPD } \\
\hline & & & & \multirow{2}{*}{$\begin{array}{l}\text { First Point } \\
\text { Molarity }\end{array}$} & \multirow[b]{2}{*}{ RPD } & \multicolumn{2}{|c|}{ Second Point } & \multirow{2}{*}{$\begin{array}{c}\text { Third Point } \\
\text { Molarity } \\
\end{array}$} & \\
\hline & & & & & & Molarity & RPD & & \\
\hline $08-01311$ & TI-572-G2-G & 12.00 & $1.01 \mathrm{E}+04$ & 0.59 & & 0.06 & & 0.04 & \\
\hline 08-01311-Dup & TI-572-G2-G & 12.24 & $1.04 \mathrm{E}+04$ & 0.61 & $3.2 \%$ & 0.08 & $26.2 \%$ & 0.04 & $18.1 \%$ \\
\hline 08-01312 & TI-572-G2-H & 12.03 & $6.37 \mathrm{E}+03$ & 0.37 & & 0.19 & & & \\
\hline 08-01312-Dup & TI-572-G2-H & 11.99 & $6.30 \mathrm{E}+03$ & 0.37 & $1.2 \%$ & 0.20 & $1.3 \%$ & & \\
\hline 08-01313 & TI-572-G2-M & 11.75 & $2.34 \mathrm{E}+03$ & 0.14 & & 0.07 & & & \\
\hline 08-01313-Dup & TI-572-G2-M & 11.70 & $2.37 \mathrm{E}+03$ & 0.14 & $1.1 \%$ & 0.07 & $0.0 \%$ & & \\
\hline 08-01314 & TI-572-G2-N & 10.25 & $8.12 \mathrm{E}+02$ & 0.05 & & 0.14 & & & \\
\hline 08-01314-Dup & TI-572-G2-N & 10.29 & $7.51 \mathrm{E}+02$ & 0.04 & $7.7 \%$ & 0.14 & $4.3 \%$ & & \\
\hline
\end{tabular}

$\mathrm{OH} \operatorname{conc}(\mathrm{mg} / \mathrm{L})=\mathrm{M}(\mathrm{g} / \mathrm{L}) * 17,000$ free $\mathrm{OH}$ as specified in ASR

Reag. Blk.1

Standard 1

08-01311MS Matrix spike
12.53

12.10

\begin{tabular}{|c|c|}
\multicolumn{1}{c}{$\mu \mathrm{g} / \mathrm{ml}$ or } \\
$\mathrm{mg} / \mathrm{L}$ & Molarity \\
$\mathrm{MDL}$ & MDL \\
\hline $1.70 \mathrm{E}+03$ & $\mathbf{0 . 1 0 0}$ \\
\hline
\end{tabular}

Required RPD

Allowed Recovery Range

0

$99.6 \%$

$+/-20 \%$

$96.7 \%$

N/A

Note: Results are presented for the first, second, and third inflection points on the titration curves, as applicable. The first inflection point is generally associated with the free hydroxide concentration. The second inflection point generally represents total hydroxide, or carbonate or a combination of aluminate and carbonate. The third inflection point is usually indicative of bicarbonate or other weak acids or possibly the continued protonation of alumina.

OH ASR8113-rs-rev-0.xls

Worksheet: Report (3)

Page 4 of 10 
WTP-RPT-166, Rev. 0

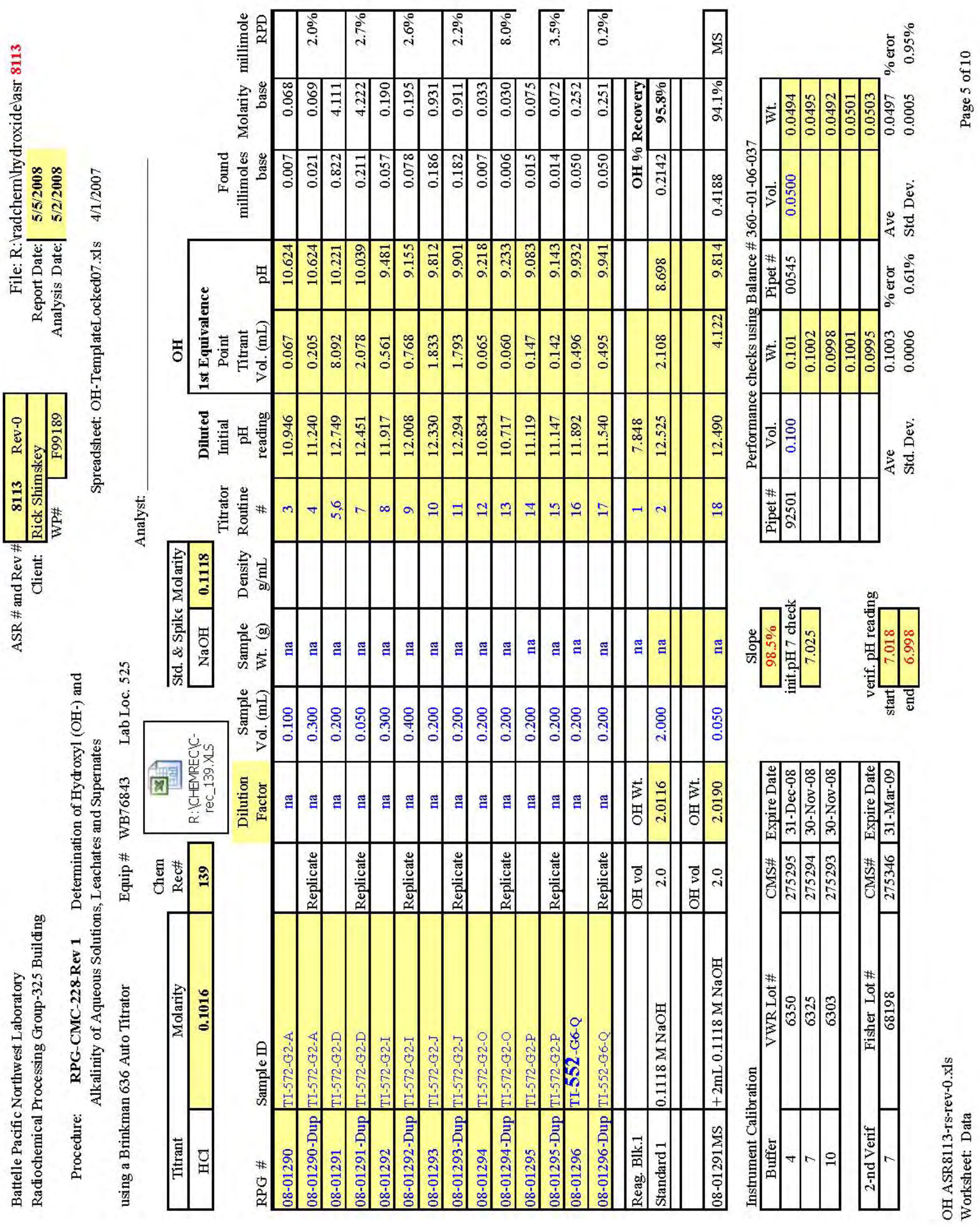


WTP-RPT-166, Rev. 0
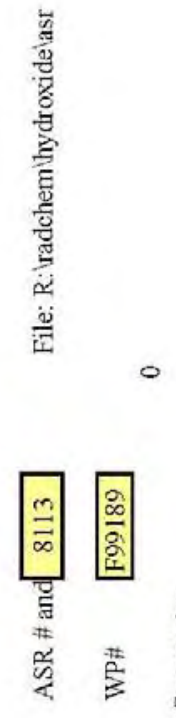

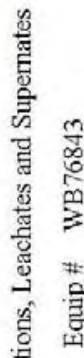

응

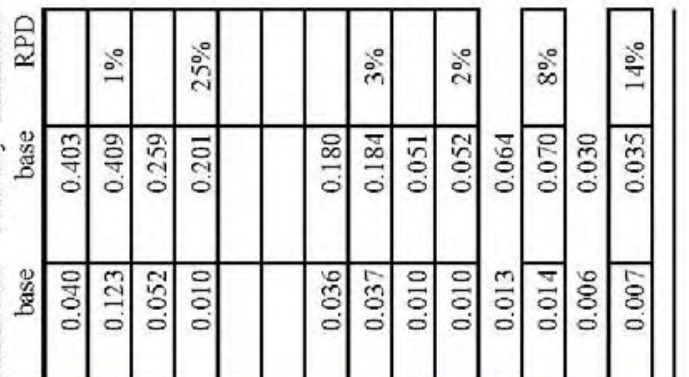

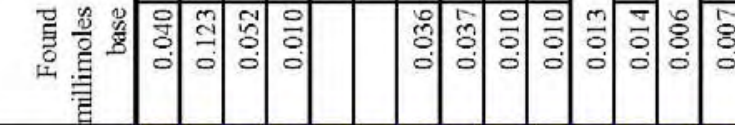
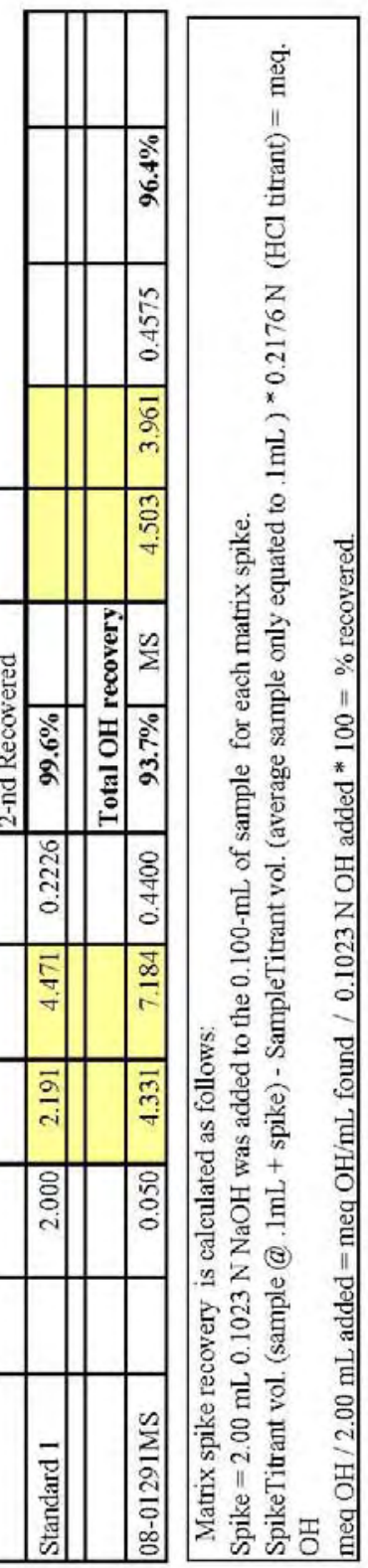
WTP-RPT-166, Rev. 0

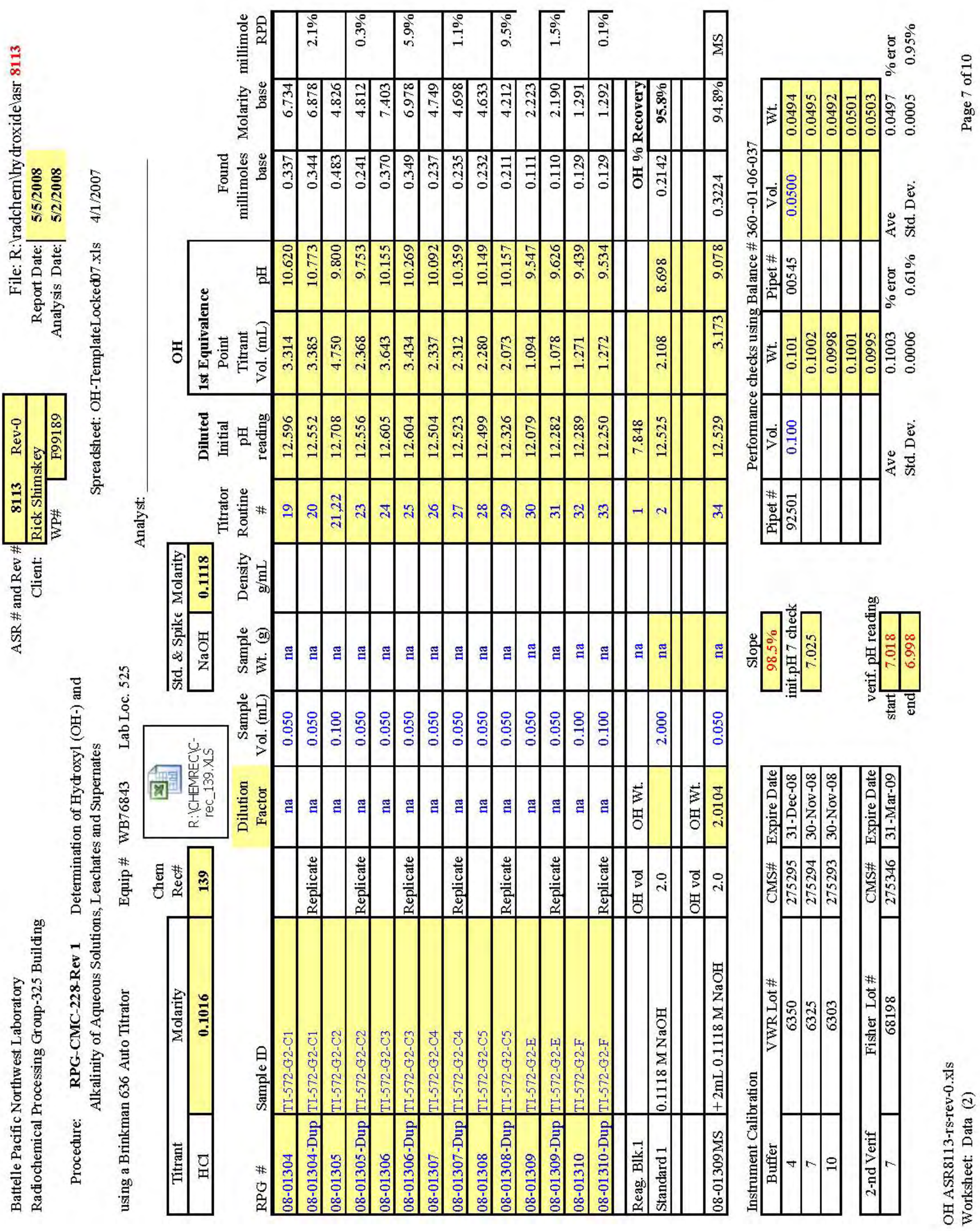


WTP-RPT-166, Rev. 0<smiles>C1CC(C2CCC2)C1</smiles>

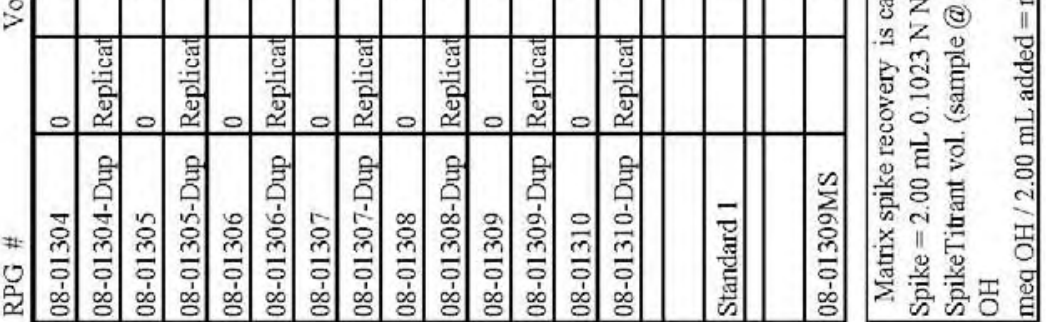


WTP-RPT-166, Rev. 0

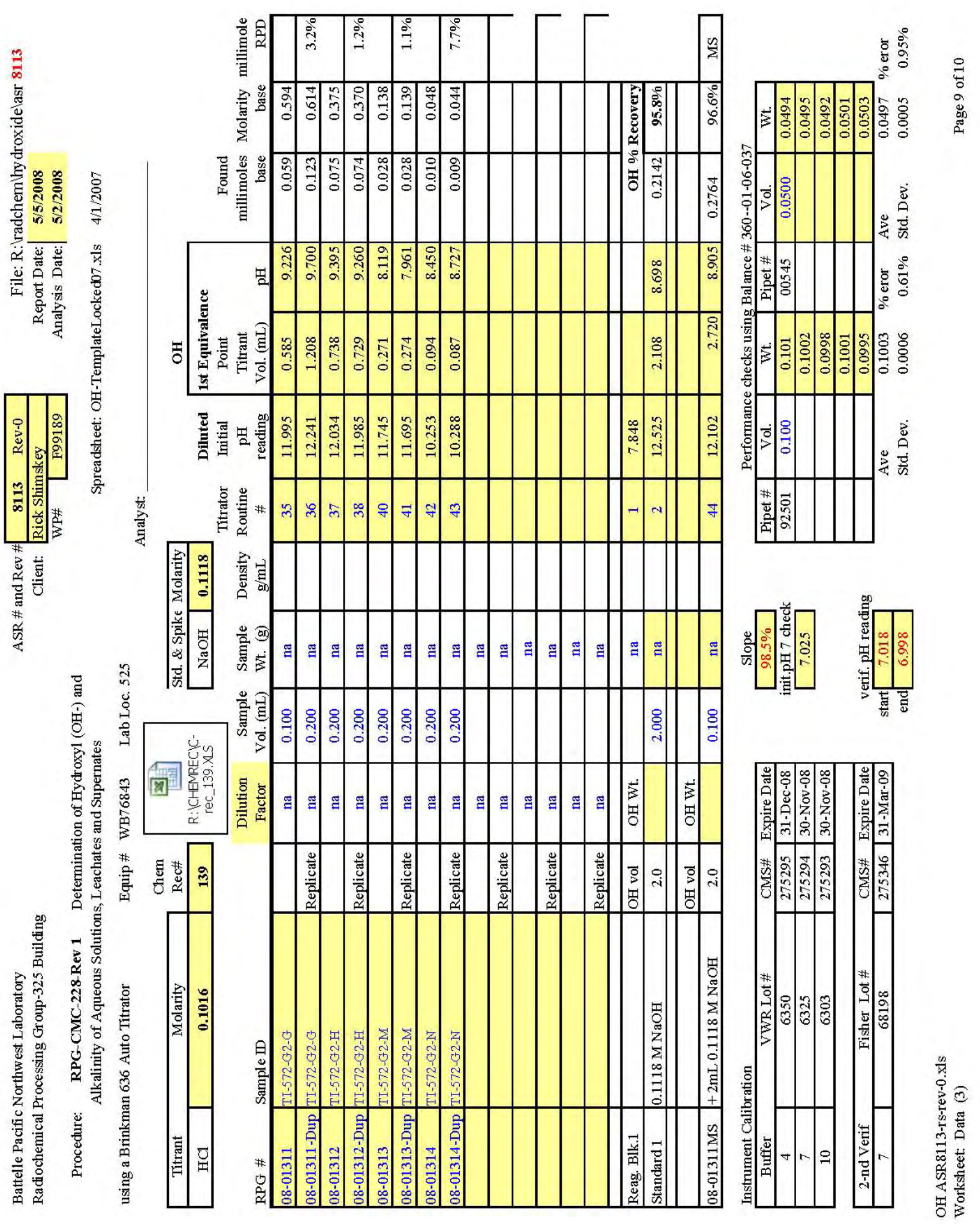


WTP-RPT-166, Rev. 0

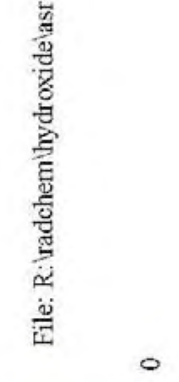

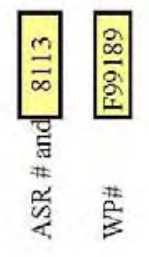

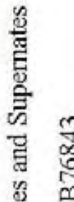

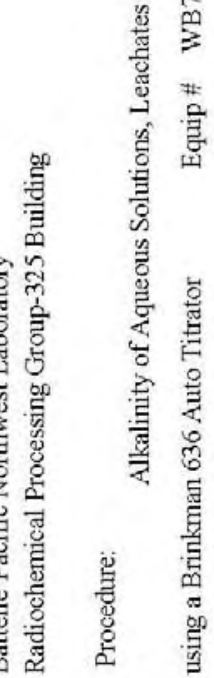

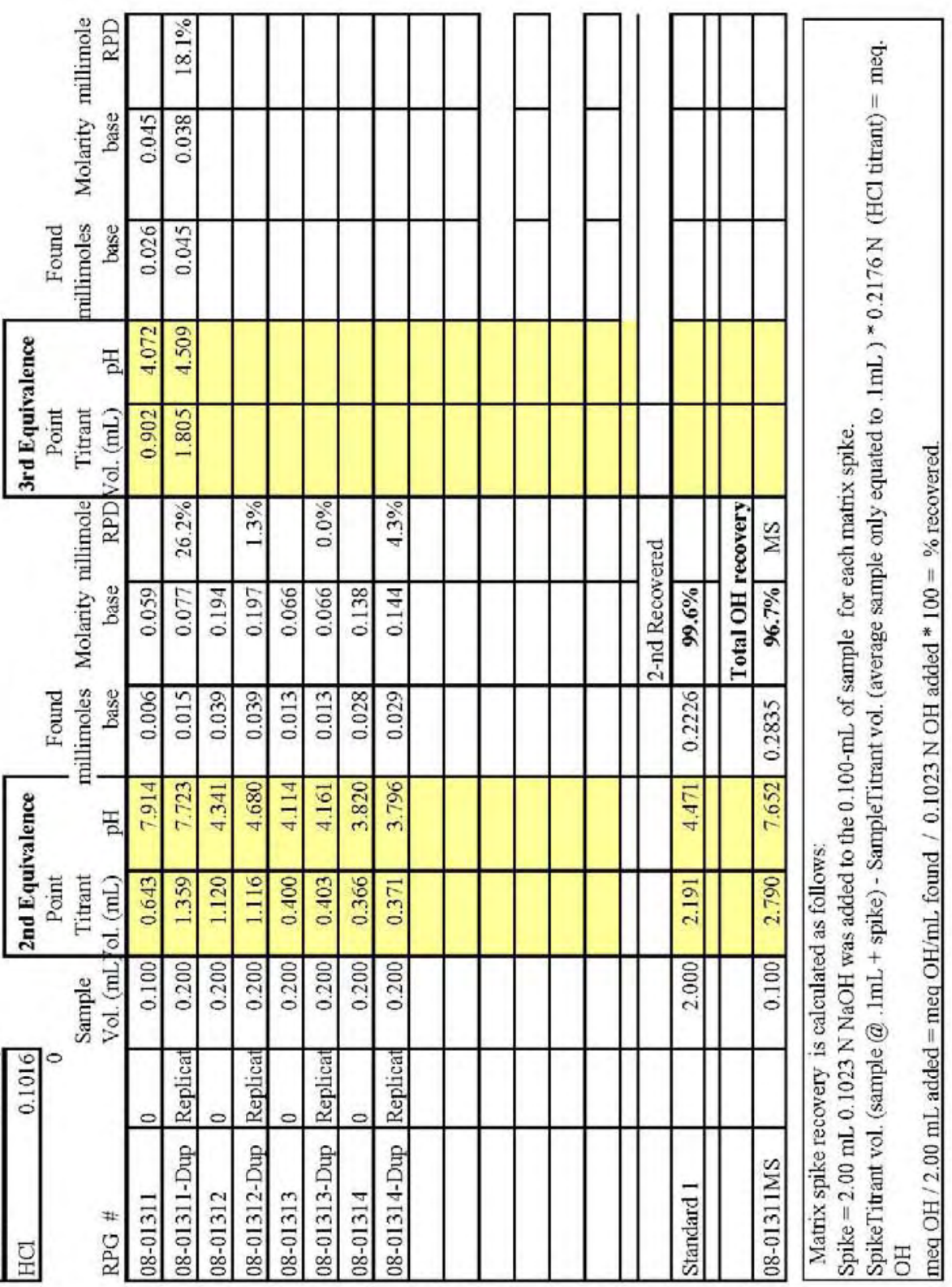


WTP-RPT-166, Rev. 0
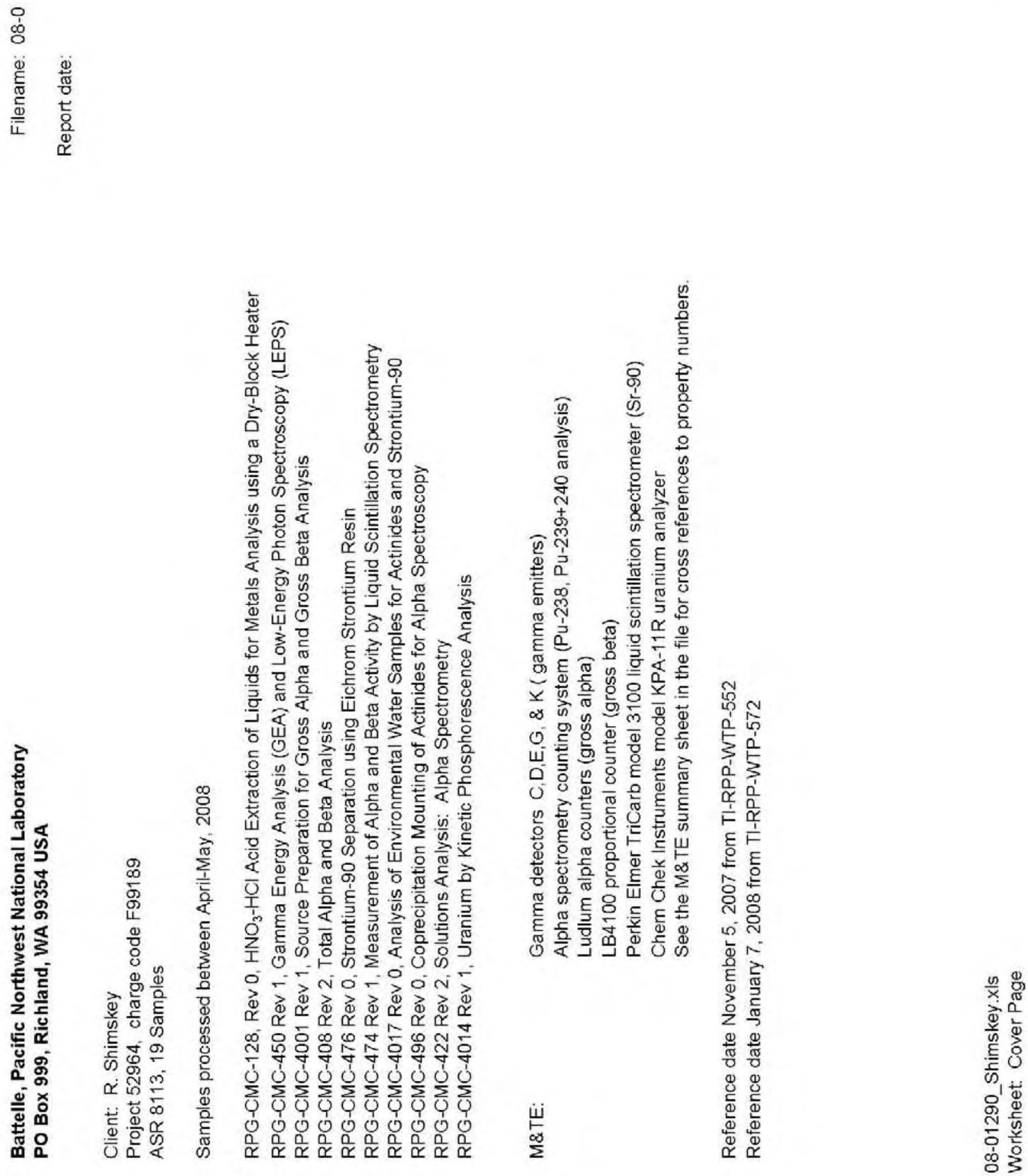
WTP-RPT-166, Rev. 0
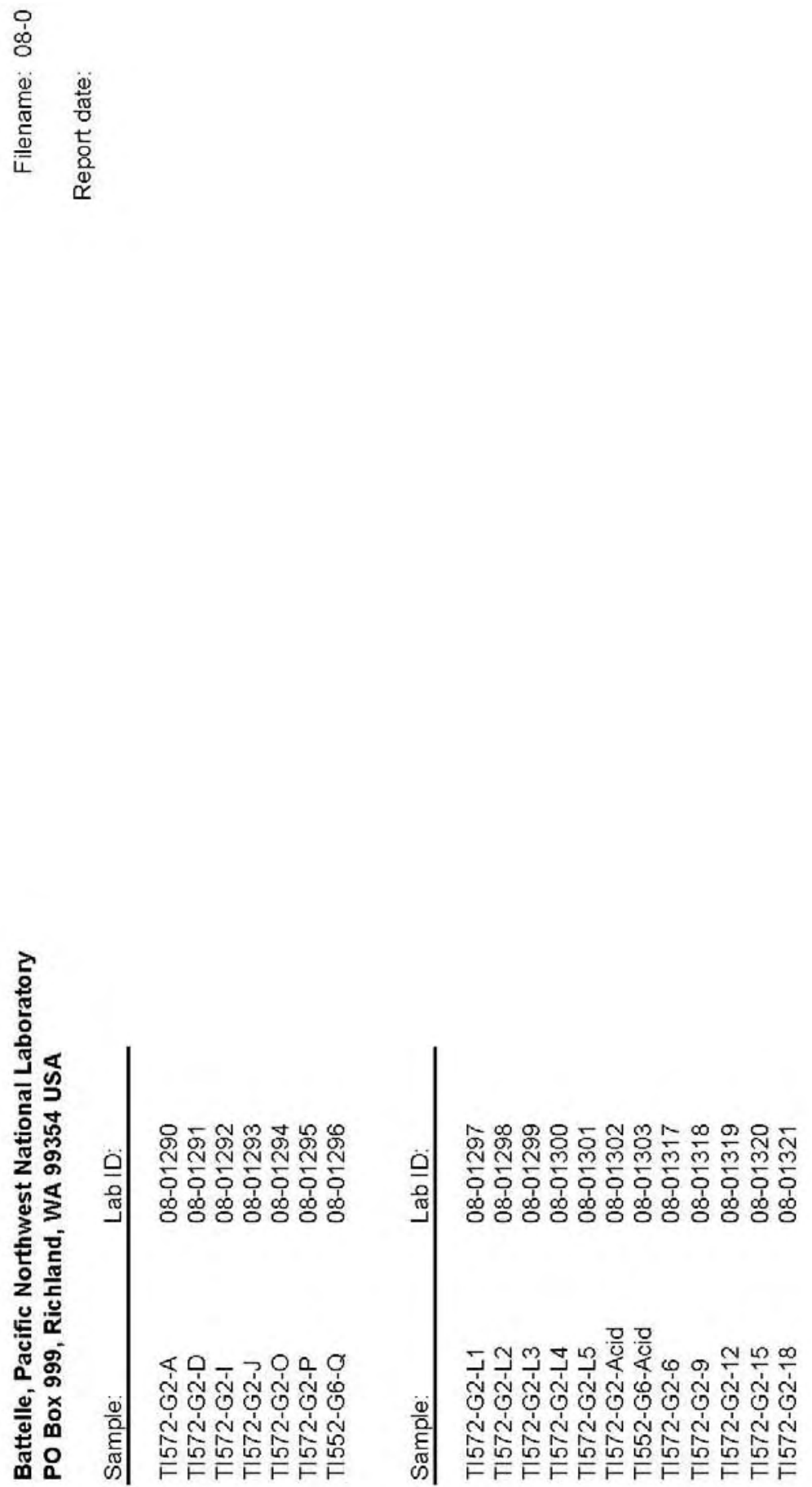
Battelle, Pacific Northwest National Laboratory
Richland, WA

Radiochemical Sciences and Engineering Group filename 08-01290_Shimskey

$5 / 20 / 2008$

Client: R. Shimskey

ASR 8113

\section{The Samples}

These samples were delivered to the analytical lab in late March 2008. The samples required analysis of metals by ICPOES, hydroxide, anions, and several radionuclides. Only the radiochemistry data is reported here; the inorganic analytes are reported separately.

\section{Sample Preparation}

The aqueous samples were digested in dilute nitric acid (procedure RPG-CMC-128), and the digestions were used for all the subsequent radiochemistry. The solid samples were fused with potassium hydroxide (procedure PNL-ALO-115). The fusion solutions were used for radiochemical analysis.

\section{Quality Control Results}

All of the quality control results fell well within the limits prescribed by the project, with the exception of detection limits for some of the gamma emitters. The high Compton background from Cs-137 made it impossible to reach the detection limits requested for EU-154 and Eu-155 on some of the samples. All of the blanks were negligible compared to the samples.

All pairs of duplicates agree closely, within two standard deviations in every case. All of the spike recoveries fell within the limits prescribed by the project, and within expected uncertainty.

\section{Gamma Emitters (procedure RPG-CMC-450)}

Gamma emitters were measured by counting 2-mL aliquots of the acid digestions and potassium hydroxide fusions. All gamma emitters that were detected were reported, except for potassium- 40 . Because no sample preparation or separation is done for gamma counting, no spikes are prepared.

The Compton background from the high Cs-137 in the solid samples made it impossible to reach the requested detection limit for Eu-155.

Gross Alpha and Gross Beta (procedures RPG-CMC-4001 and -408)

To measure gross alpha, a small volume of each sample solution (the acid digestion or fusion solution) was dried onto a steel disk and counted on a Ludlum solid scintillation alpha counter.

To measure gross beta, a small volume of each sample solution was evaporated onto a planchet and counted on a gas proportional counter. Nearly all the activity is beta, not alpha, and crosstalk corrections were not necessary. Solids loading on the counting planchets was too small to affect the data. 
Battelle, Pacific Northwest National Laboratory Richland, WA

Radiochemical Sciences and Engineering Group filename 08-01290_Shimskey

$5 / 20 / 2008$

Client: R. Shimskey

ASR 8113

The aqueous samples have too little alpha to measure accurately by gross alpha counting. The sum of Pu-239+240, Pu-238, and Am-241 is a more accurate and sensitive estimate of the gross alpha activity of these samples. (Uranium contributes only a small part of the alpha activity.) The solid samples have enough alpha activity to measure by gross alpha count, but the uncertainty is high. Only a small amount of the fusion solution can be evaporated onto a counting disk without compromising the accuracy from mass loading.

The gross beta activity agrees reasonably well with the sum of Cs-137, Sr-90, and Y-90.

Strontium-90 (procedures RPG-CMC-476 and -474)

Strontium was chemically separated from the acid digestion preparations, then measured by liquid scintillation. Some of the aqueous samples have little Sr-90. The solid samples have very high $\mathrm{Sr}$ 90 activity.

Plutonium (procedures RPG-CMC-4017, -496, and -422)

Plutonium was separated from the sample solutions by anion exchange in hydrochloric acid, then mounted for alpha spectroscopy by coprecipitation, then measured using alpha spectrometry.

Uranium (procedures RPG-CMC-4017 and -4014)

Uranium was chemically separated from the samples by anion exchange in hydrochloric acid, then measured by kinetic phosphorescence. All of the samples have easily measurable uranium, well above the blanks.

08-01290_Shimskey.xls

Worksheet: Narrative 


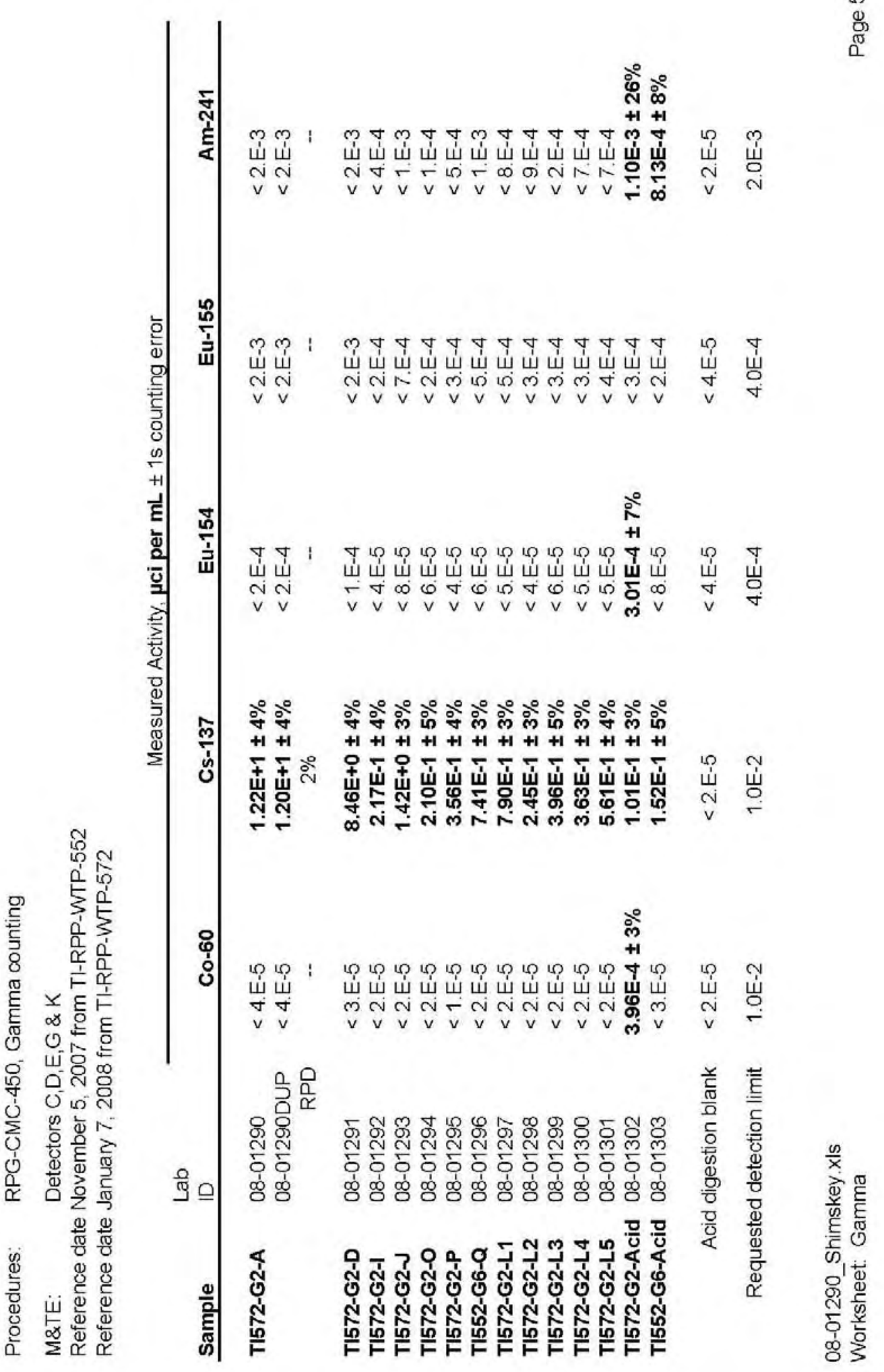


WTP-RPT-166, Rev. 0
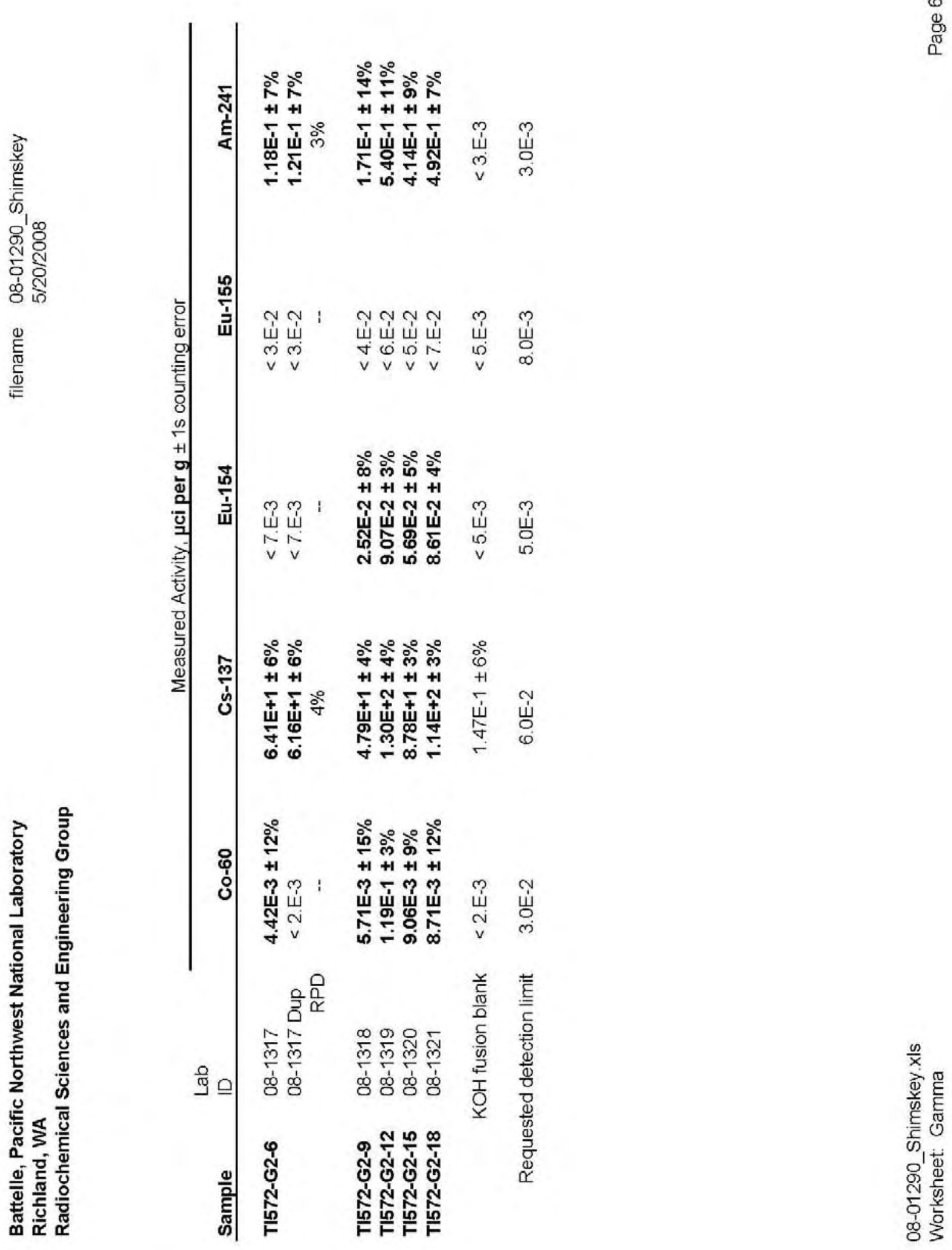
WTP-RPT-166, Rev. 0
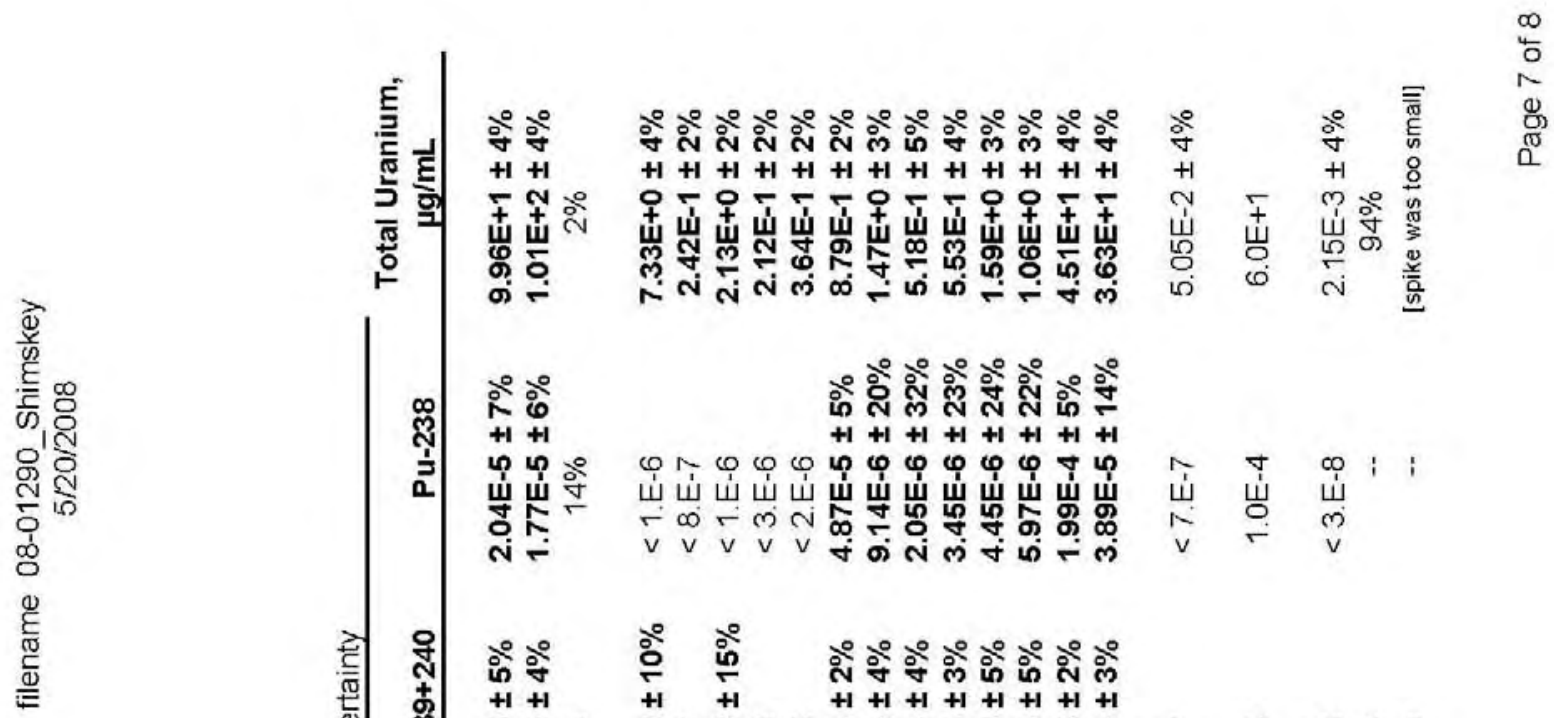

ஓ゚ஷ

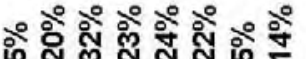

$+1+1+1+1+1+1+1+1$

$\begin{array}{lll}+1+1 & +1 \\ 0 & 0 & 0\end{array}$

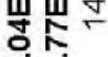

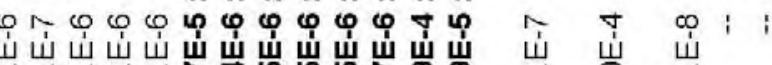

i

v v v v v

崩 岁

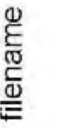

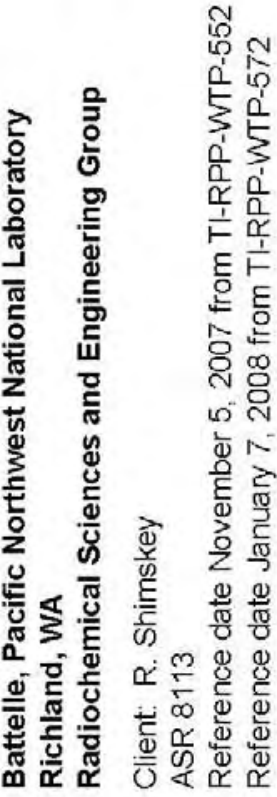

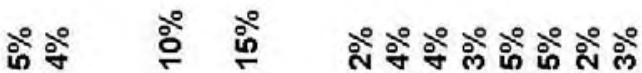
$+1+1+1+1+1+1+1+1+1$

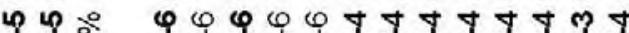

แั แั

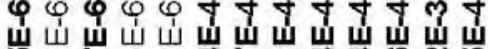

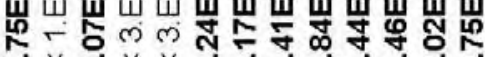

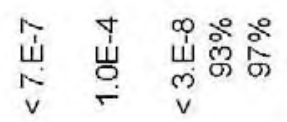

iा का

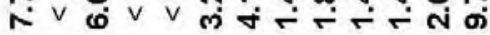

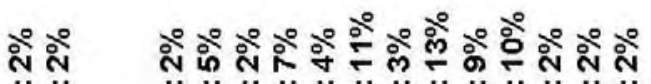

$+1+1 \quad+1+1+1+1+1+1+1+1+1+1+1+1+1$

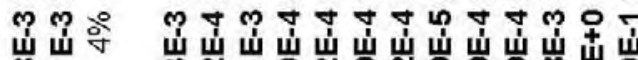

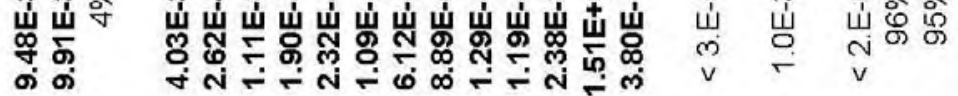

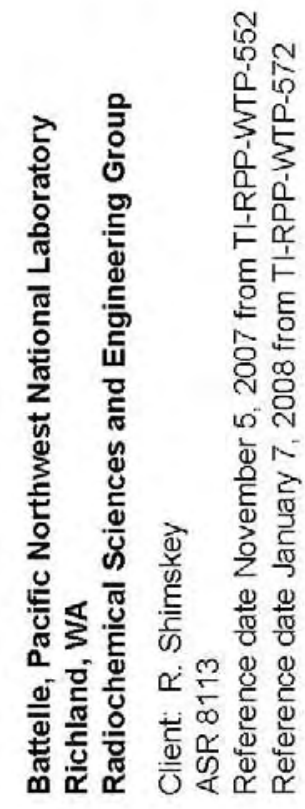

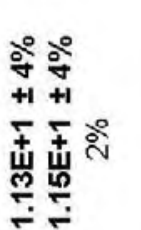

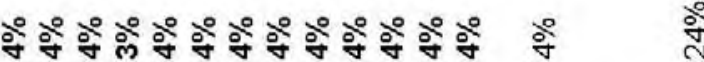

$+1+1+1+1+1+1+1+1+1+1+1+1+1$

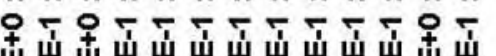

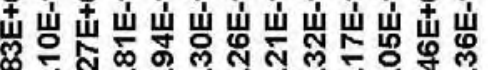

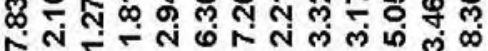

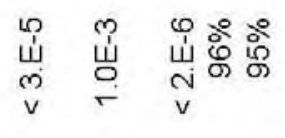

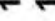

ฉे

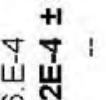

ㅇํํ

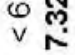

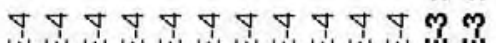

யய山ய山ய山ய山ய山ய山

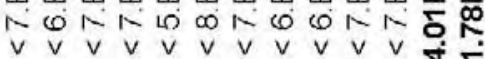

음음

윰

ํㅗำ

둥ำ

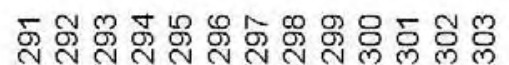

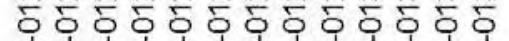

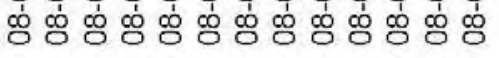

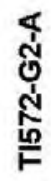

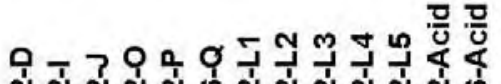

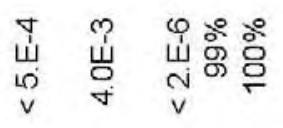

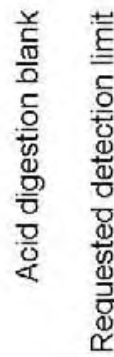

రิ

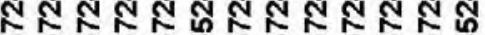

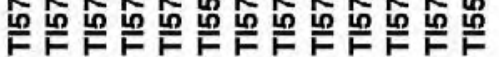

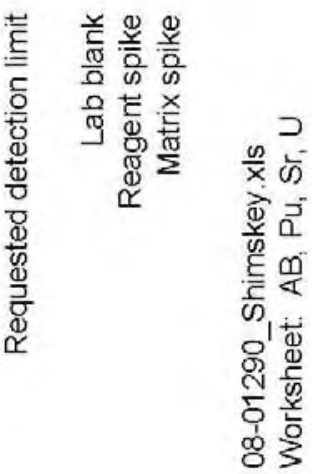




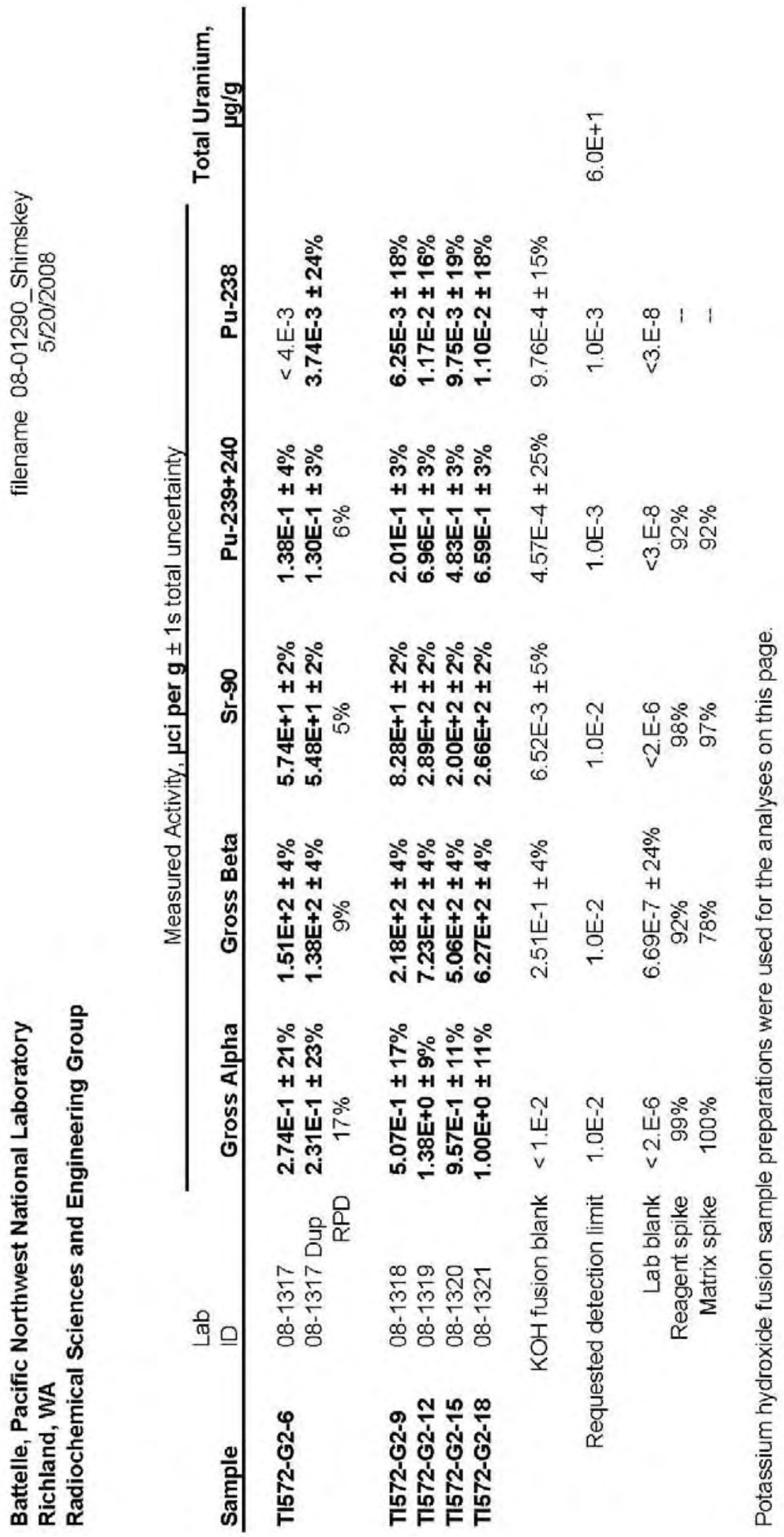


PNNL-17992

WTP-RPT-166, Rev 0

\section{Distribution}

No. of

\section{Copies}

\section{ONSITE}

4 Bechtel National, Inc.

WTP R\&T Docs (2) H4-02

P. S. Sundar H4-02

S. Barnes H4-02

16 Pacific Northwest National Laboratory

EC Buck

P7-27

RC Daniel

P7-22

K. Draper

K6-75

MK Edwards

P7-25

SK Fiskum

P7-25

RT Hallen

P8-60

LK Jagoda

K6-24

AE Kozelisky

P7-25

DE Kurath

K3-52

GJ Lumetta

P7-25

RA Peterson

P7-22

RW Shimskey

P7-27

SI Sinkov

P7-25

LA Snow

P7-25

Information Release

P8-55

Project File

K3-52 